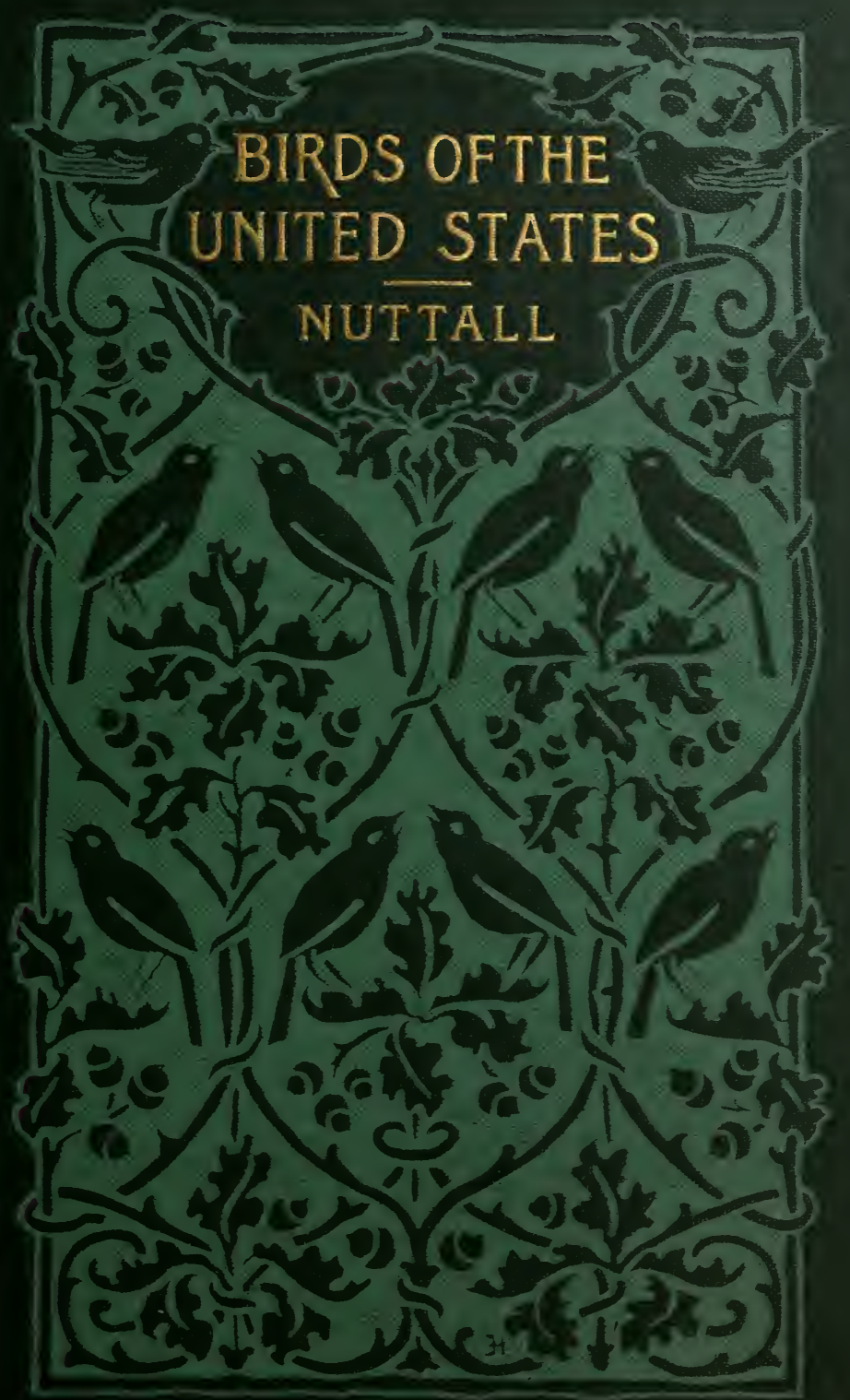




\section{Frank M. Chapman}

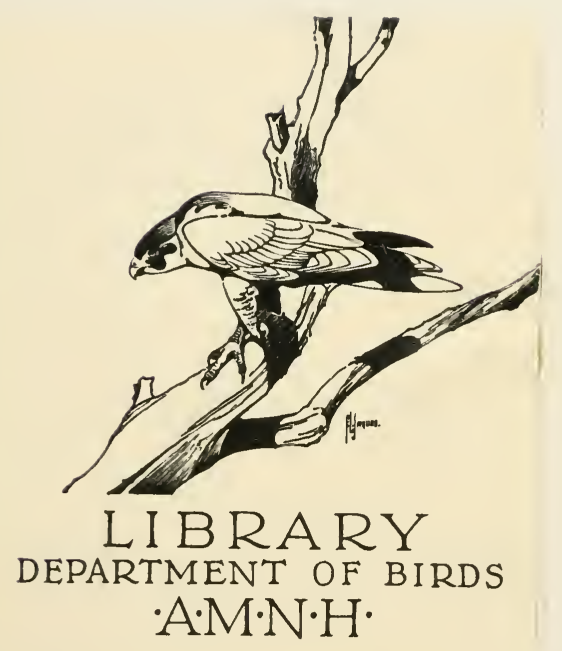




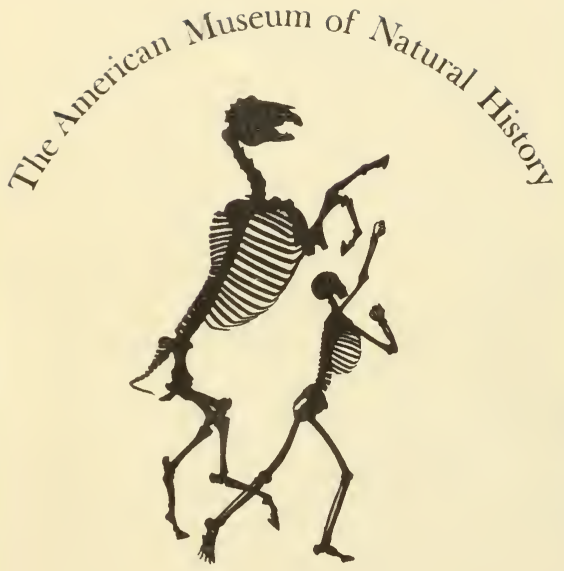

1869

THE LIBRARY 



Pl.
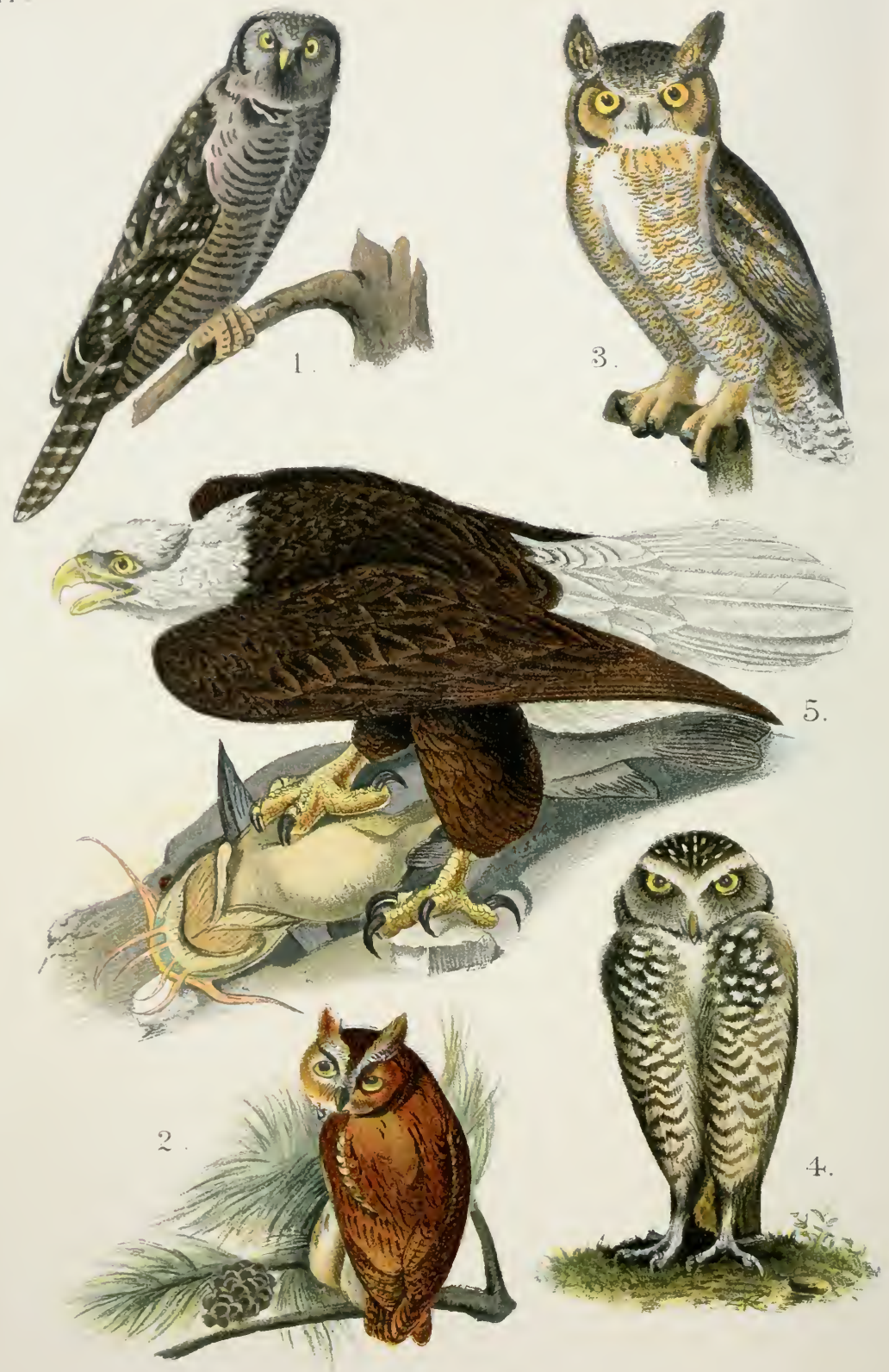

1. Hawk Owl.

3. Great Horned Owl.

5. Bald Eagle.

2. Screech Ow.

4. Florida Burrowing Owl. 


\title{
A Popular Handbook
} of the

\section{Birds of the United States and Canada}

\author{
By Thomas, Nuttall
}

New Revised and Annotated Edition

By Montague Chamberlain

With Additions, and One Hundred and Ten

Illustrations in Color

Boston

Little, Brown, and Company

I 903 
Copyright, 1891, 1896, 1903,

By Little, Brown, and Company.

$45-160382$ - May 22

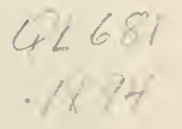

UNIVERSITY PRESS - JOHN WILSON

AND SON - CAMBRIDGE, U. S. A. 


\section{PART I. - LAND BIRDS.}

\section{CONTENTS.}

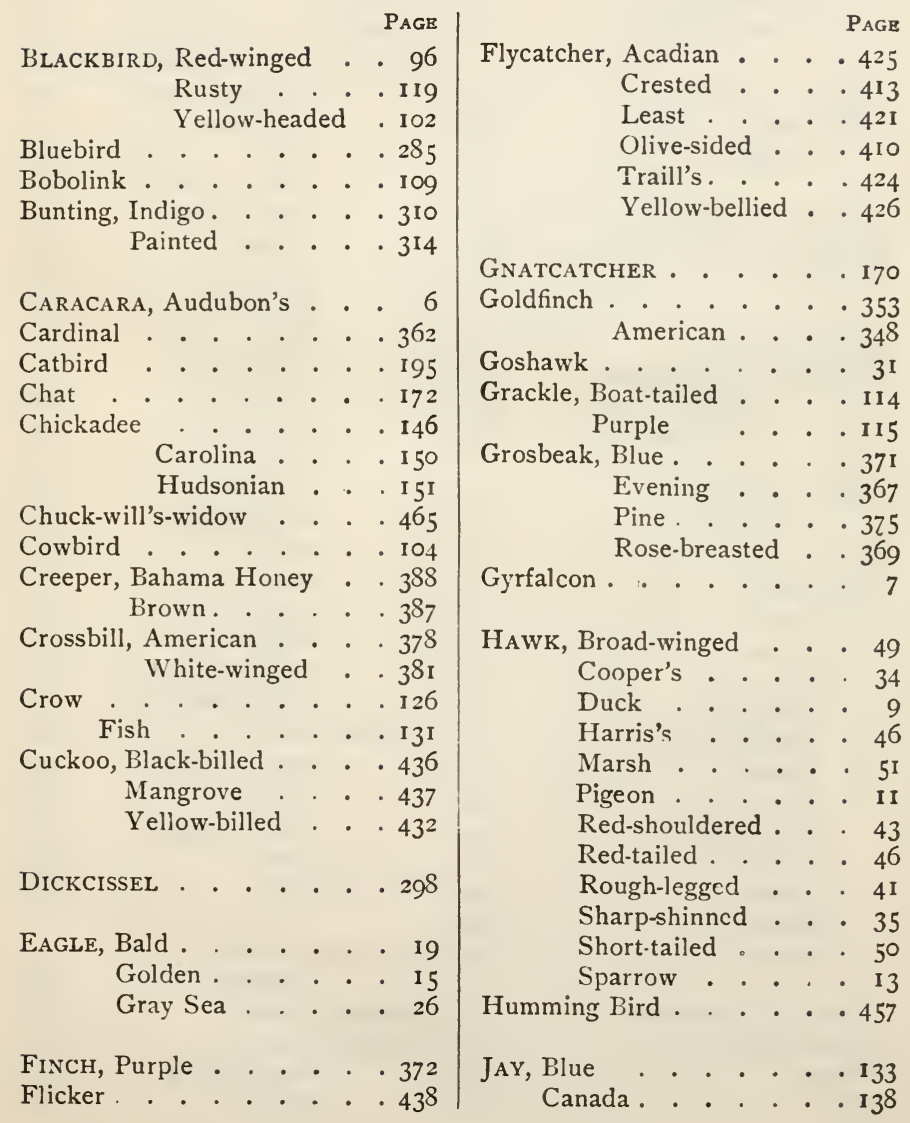




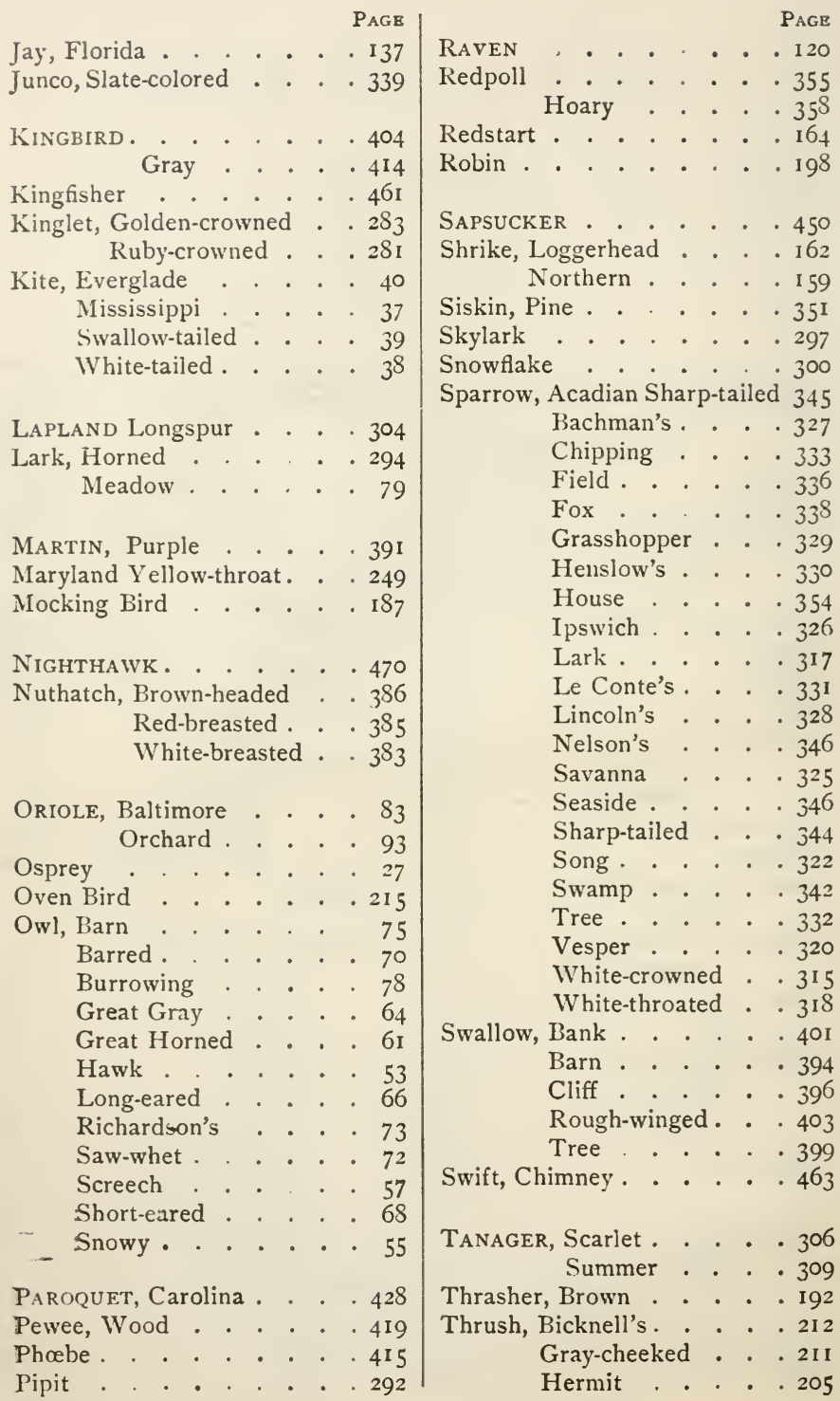




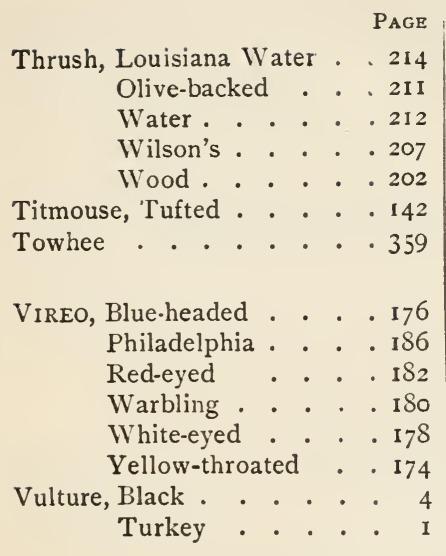

WARBLER, Bachman's . . 26I

Bay-breasted . . 237

Black and white $\cdot 389$

Blackburnian . 232

Black-poll . . 238

Black-throated Blue 245

Black-throated

Green . . . 230

Blue-winged . . $.25 \mathrm{~S}$

Canadian . . . 227

Cape May . . 226

Cerulean . . . 247

Chestnut-sided . . 235

Connecticut . . 253

Golden-winged . 260

Hooded . . . I67

Kentucky . . . 246

Kirtland's . . 265
PAGE

Warbler, Magnolia . . . 224

Mourning . . 251

Myrtle. . . . 217

Nashville. . . 263

Orange-crowned . 264

Parula . . . . 244

Pine . . . 239

Prairie . . . 242

Prothonotary . . 257

Swainson's . . . 256

Tennessee . . .26I

Wilson's . . . I68

Worm-eating . . 255

Yellow . . . 230

Yellow Palm . . 219

Yellow-throated . 228

Waxwing, Bohemian . . 152

Cedar . . . . 154

Wheatear . . . . . 290

Whip-poor-will . . . . . . 467

Woodpecker, American threetoed . . 456

Arctic three-toed 455

Downy . . . 452

Hairy . . . 45 I

Ivory-billed . . 44I

Pileated . . 444

Red-bellied • 448

Red-cockaded . 454

Red-headed . 446

Wren, Bewick's . . . . 276

Carolina . . . . 272

House . . . . . 266

Long-billed Marsh . . 279

Short-billed Marsh . . 277

Winter . . . . 270 



\section{ILLUSTRATIONS IN PART I.}

\section{COLORED PLATES.}

Plate I. . . . Frontispiece

I. Hawk OWL.

2. SCREECH OWL.

3. Great Horned Owl.

4. Florida Burrowing OWl.

5. Bald Eagle.

Plate II. . . . . Page 80

I. Baltimore Oriole.

2. MEADOWLARK.

3. Red-Winged Blackbird.

4. Bobolink.

5. American Osprey.

Plate III. . . . Page 146

I. Chickadee.

2. Catbird.

3. Cedar Waxwing.

4. Red-Eyed Vireo.

5. Robin.

Plate IV. . . . P Page 202

I. American Redstart.

2. Blue Jay.

3. WOOD Thrush.

4. Water Thrush.

5. Duck Hawk.

Plate V. . . Page 220

I. Cerulean Warbler.

2. Prairie IVarbler.
Plate V. - continued.

3. Yellow Warbler.

4. Parula Warbler.

5. Blackburnian Warbler.

6. Black-Throated Green IVARBLER.

Plate Vi. . . . . Page 262

I. Maryland Yellow Throat.

2. BLUE BIRD.

3. Winter Wren.

4. Nashville IVARbler.

5. Black-Throated Blue WARBLER.

6. Ruby-Crowned Kinglet.

Plate VII. . . Page 298

I. SNowflake.

2. White-Throated Sparrow.

3. Black-Throated Bunting.

4. Indigo Bunting.

5. Scarlet Tanager.

Plate Vili... . Page 360

I. SNOW BIRD.

2. SoNg Sparrow.

3. PhÆbe.

4. American Goldfinch.

5. Vesper Sparrow.

6. TOWHEE. 
Plate IX. . . . Page 382

I. Pine Grosbeak (Male).

2. Pine Grosbeak (Female).

3. Purple Finch (Male).

4. Purple Finch (Female).

5. Rose-Breasted Grosbeak.

6. White-Winged Crossbill (Male).

7. White-Winged Crossbill (Female).

\section{ILLUSTRATIONS IN THE TEXT.}

No.

I. TURKey Vulture • . I

2. White Gyrfalcon . • 7

3. AMErican Sparrow

HAWK . . . . . 13

4. Golden Eagle •. . 15

5. Bald Eagle . • • . 19

6. AMERICAN OSPREY - . 27

7. AMerican Goshawk . 3 I

8. CoOper's HAWK • • . 34

9. Mississippi Kite • • • 37

IO. AMERican Rough-Legged

HAWK . . . . : $4 \mathrm{I}$

II. RED-Shouldered HAwk 43

12. Broad-Winged Hawk 49

13. HAwK OWL. • . . 53

I4. SNowy OwL . . . 55

15. SCREech OWL . . . 57

I6. Great Horned Owl . 6I

17. LONG-EARED OWL . . 66

I8. SHORT-Eared OwL • . 68

19. BARRED OWL . . . 70

20. Richardson's Owl . . 73

21. BARN OWL . . . . 75

22. Florida Burrowing OWL 78

23. MEAdowlark • • • 79

24. Baltimore Oriole . . 83

25. Red-Winged Blackbird 96

26. Yellow-Headed BlackBIRD . . . . . 102
Plate X. - . . Page 438

I. Ruby-Throated Humming BIRD.

2. Barn Swallow.

3. FlickER.

4. WHIP-POOR-WILL.

5. Crested Red Bird.

6. RED-HEADED WOODPECKER.
No.

27. ВовоLink

28. Blue Jay . • • • I I33

29. Canada Jay • • . 138

30. Tufted Titmouse - . 142

31. Northern Shrike . I 159

32. REDSTART . . . . . 164

33. IVILSON'S WARBLER . . I68

34. Blue-Gray Gnatcatcher 170

35. Yellow-Breasted Chat 172

36. White-Eyed Vireo • I I78

37. Mocking BIRD . . . 187

38. Brown Thrasher • . 192

39. Wilson's Thrush • . 207

40. Oven-Bird • . . 215

41. Black-Throated Green

Warbler . . . 230

42. Parula IVARbler • 244

43. Maryland Yellow.

Throat . . . . 249

44. WORM-EATING WARBLER 255

45. House Wren • . . 266

46. Carolina Wren . . 272

47. Golden-Crowned King-

LET . . . . . 283

48. Bluebird . • . . 285

49. Wheatear • . . . 290

50. American Pipit . . 292

5I. HoRned LARK . • . 294

52. SKYLARK . . . . 297 
No.

53. SNOWfLAKe . . . . 300

54. LAPLAND LONGSPUR . . 304

55. Scarlet TANager * . 306

56. Lark Sparrow . . 317

57. Vesper SPARrow. . 320

59. Song Sparrow . . 322

59. Tree Sparrow . . 332

60. Fox Sparrow . . . $33^{8}$

6i. Sharp-Tailed Sparrow 344

62. American Goldfinch . $34 \mathrm{~S}$

63. Goldfinch . . . . 353

64. REDPOLL . . . . . 355

65. Hoary Redpoll . . 358

66. Caḱdinal . . . . 362

67. Rose-Breasted GrosBEAK . . . . 369

68. Pine Grosbeak . . 375

69. AMerican Crossbill • 378

70. White-Breasted NutHATCH . . . . 383
No.

Page

7I. BLack AND White WaR-

BLER . . . . . 389

72. Barn SWallow . . 394

73. Tree Swallow . . 399

74. Bank Swallow . . 40I

75. KingBird . . . . 404

76. Olive-Sided Flycatcher 4 IO

77. Traill's Flycatcher - 424

78. Carolina Paroquet - 428

79. Yellow-Billed Cuckoo 432

80. IVory-Billed Wood-

PECKER . . . . . 44I

8I. Pileated Woodpecker 444

82. Yellow-Bellied SAP-

SUCKER . . . . . . 450

83. Ruby-Throated Hum-

MING BIRD . . . . 457

84. Belted Kingfisher • 46r

85. Chimney Swift . . 463

86. Nighthawk . . . 470 



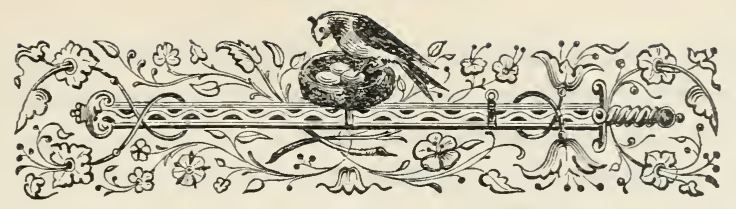

INTRODUCTION.

OF all the classes of animals by which we are surrounded in the ample field of Nature, there are none more remarkable in their appearance and habits than the feathered inhabitants of the air. They play around us like fairy spirits, elude approach in an element which defies our pursuit, soar out of sight in the yielding sky, journey over our heads in marshalled ranks, dart like meteors in the sunshine of summer, or, seeking the solitary recesses of the forest and the waters, they glide before us like beings of fancy. They diversify the still landscape with the most lively motion and beautiful association; they come and go with the change of the season; and as their actions are directed by an uncontrollable instinct of provident Nature, they may be considered as concomitant with the beauty of the surrounding scene. With what grateful sensations do we involuntarily hail the arrival of these faithful messengers of spring and summer, after the lapse of the dreary winter, which compelled them to forsake us for more favored climes. Their songs, now heard from the leafy groves and shadowy forests, inspire delight, or recollections of the pleasing past, in every breast. How volatile, how playfully capricious, how musical and happy, are these roving sylphs of Nature, to whom the air, the earth, and the waters are alike habitable! Their lives are spent in boundless action; and Nature, with an omniscient benevolence, has assisted and formed them for this wonderful display of perpetual life and vigor, in an element almost their own. 
If we draw a comparison between these inhabitants of the air and the earth, we shall perceive that, instead of the large head, formidable jaws armed with teeth, the capacious chest, wide shoulders, and muscular legs of the quadrupeds, they have bills, or pointed jaws destitute of teeth; a long and pliant neck, gently swelling shoulders, immovable vertebræ; the forearm attenuated to a point and clothed with feathers, forming the expansive wing, and thus fitted for a different species of motion; likewise the wide extended tail, to assist the general provision for buoyancy throughout the whole anatomical frame. For the same general purpose of lightness, exists the contrast of slender bony legs and feet. So that, in short, we perceive in the whole conformation of this interesting tribe, a structure wisely and curiously adapted for their destined motion through the air. Lightness and buoyancy appear in every part of the structure of birds : to this end nothing contributes more than the soft and delicate plumage with which they are so warmly clad; and though the wings (or great organs of aërial motion by which they swim, as it were, in the atmosphere) are formed of such light materials, yet the force with which they strike the air is so great as to impel their bodies with a rapidity unknown to the swiftest quadruped. The same grand intention of forming a class of animals to move in the ambient desert they occupy above the earth, is likewise visible in their internal structure. Their bones are light and thin, and all the muscles diminutive but those appropriated for moving the wings. The lungs are placed near to the back-bone and ribs; and the air is not, as in other animals, merely confined to the pulmonary organs, but passes through, and is then conveyed into a number of membranous cells on either side the external region of the heart, communicating with others situated beneath the chest. In some birds these cells are continued down the wings, extending even to the pinions, bones of the thighs, and other parts of the body, which can be distended with air at the pleasure or necessity of the animal. This diffusion of air is not only intended to assist in lightening and elevating the body, but also appears necessary to prevent the stoppage or 
interruption of respiration, which would otherwise follow the rapidity of their motion through the resisting atmosphere; and thus the Ostrich, though deprived of the power of flight, runs almost with the swiftness of the wind, and requires, as he possesses, the usual resources of air conferred on other birds. Were it possible for man to move with the rapidity of a Swallow, the resistance of the air, without some such peculiar provision as in birds, would quickly bring on suffocation. The superior vital heat of this class of beings is likewise probably due to this greater aëration of the vital fluid.

Birds, as well as quadrupeds, may be generally distinguished into two great classes from the food on which they are destined to subsist ; and may, consequently, be termed carnivorous and granivorous. Some also hold a middle nature, or partake of both. The granivorous and herbivorous birds are provided with larger and longer intestines than those of the carnivorous kinds. Their food, consisting chiefly of grain of various sorts, is conveyed whole into the craw or first stomach, where it is softened and acted upon by a peculiar glandular secretion thrown out upon its surface; it is then again conveyed into a second preparatory digestive organ; and finally transmitted into the true stomach, or gizzard, formed of two strong muscles connected externally with a tendinous substance, and lined internally with a thick membrane of great power and strength; and in this place the unmasticated food is at length completely triturated, and prepared for the operation of the gastric juice. The extraordinary powers of the gizzard in comminuting food, to prepare it for digestion, almost exceeds the bounds of credibility. Turkeys and common fowls have been made to swallow sharp angular fragments of glass, metallic tubes, and balls armed with needles, and even lancets, which were found broken and compressed, without producing any apparent pain or wounds in the stomach. The gravel pebbles swallowed by this class of birds with so much avidity, thus appear useful in bruising and comminuting the grain they feed on, and preparing it for the solvent action of the digestive organs.

Those birds which live chiefly on grain and vegetable sub- 
stances partake in a degree of the nature and disposition of herbivorous quadrupeds. In both, the food and the provision for its digestion are very similar. Alike distinguished for sedentary habits and gentleness of manners, their lives are harmlessly and usefully passed in collecting seeds and fruits, and ridding the earth of noxious and destructive insects; they live wholly on the defensive with all the feathered race, and are content to rear and defend their offspring from the attacks of their enemies. It is from this tractable and gentle race, as well as from the amphibious or aquatic tribes, that man has long succeeded in obtaining useful and domestic species, which, from their prolificacy and hardihood, afford a vast supply of wholesome and nutritious food. Of these, the Hen, originally from India; the Goose, Duck, and Pigeon of Europe; the Turkey of America ; and the Pintado, or Guineahen of Africa, are the principal: to which may also be added, as less useful, or more recently naturalized, the Peacock of India, the Pheasant of the same country, the Chinese and Canada Goose, the Muscovy Duck, and the European Swan.

Carnivorous birds by many striking traits evince the destiny for which they have been created; they are provided with wings of great length, supported by powerful muscles, which enable them to fly with energy and soar with ease at the loftiest elevations. They are armed with strong hooked bills and with the sharp and formidable claws of the tiger; they are also further distinguished by their large heads, short necks, strong muscular thighs in aid of their retractile talons, and a sight so piercing as to enable them, while soaring at the greatest height, to perceive their prey, upon which they sometimes descend, like an arrow, with undeviating aim. In these birds the stomach is smaller than in the granivorous kinds, and their intestines are shorter. Like beasts of prey, they are of a fierce and unsociable nature; and so far from herding together like the inoffensive tribes, they drive even their offspring from the eyry, and seek habitually the shelter of desert rocks, neglected ruins, or the solitude of the darkest forest, from whence 
they utter loud, terrific, or piercing cries, in accordance with the gloomy rage and inquietude of their insatiable desires.

Besides these grand divisions of the winged nations, there are others, which, in their habits and manners, might be compared to the amphibious animals, as they live chiefly on the water, and feed on its productions. To enable them to swim and dive in quest of their aquatic food, their toes are connected by broad membranes or webs, with which, like oars, they strike the water, and are impelled with force. In this way even the seas, lakes, and rivers, abounding with fish, insects, and seeds, swarm with birds of various kinds, which all obtain an abundant supply. There are other aquatic birds, frequenting marshes and the margins of lakes, rivers, and the sea, which seem to partake of an intermediate nature between the land and water tribes. Some of these feed on fishes and reptiles; others, with long and sensible bills and extended necks, seek their food in wet and muddy marshes. These birds are not made for swimming; but, familiar with water, they wade, and many follow the edge of the retiring waves of the sea, gleaning their insect prey at the recession of the tides: for this kind of life Nature has provided them with long legs, bare of feathers even above the knees; their toes, unconnected by webs, are only partially furnished with membranous appendages, just sufficient to support them on the soft and boggy grounds they frequent. To this tribe belong the Cranes, Snipes, Sandpipers, Woodcocks, and many others.

In comparing the senses of animals in connection with their instinct, we find that of sight to be more extended, more acute, and more distinct in birds, in general, than in quadrupeds. I say "in general," for there are some birds, such as the Owls, whose vision is less clear than that of quadrupeds; but this rather results from the extreme sensibility of the eye, which, though dazzled with the glare of full day, nicely distinguishes even small objects by the aid of twilight. In all birds the organ of sight is furnished with two membranes, - an external and internal, - additional to those which occur in the human subject. The former, membrana nictitans, or external mem- 
brane, is situated in the larger angle of the eye, and is, in fact, a second and more transparent eyelid, whose motions are directed at pleasure, and its use, besides occasionally cleaning and polishing the cornea, is to temper the excess of light and adjust the quantity admitted to the extreme delicacy of the organ. The other membrane, situated at the bottom of the eye, appears to be an expansion of the optic nerve, which, receiving more immediately the impressions of the light, must be much more sensible than in other animals; and consequently the sight is in birds far more perfect, and embraces a wider range. Facts and observations bear out this conclusion; for a Sparrow-hawk, while hovering in the air, perceives a Lark or other small bird, sitting on the ground, at twenty times the distance that such an object would be visible to a man or dog. A Kite, which soars beyond the reach of human vision, yet distinguishes a lizard, field-mouse, or bird, and from this lofty station selects the tiny object of his prey, descending upon it in nearly a perpendicular line. But it may also be added that this prodigious extent of vision is likewise accompanied with equal accuracy and clearness; for the eye can dilate or contract, be shaded or exposed, depressed or made protuberant, so as readily to assume the precise form suited to the degree of light and the distance of the object; the organ thus answering, as it were, the purpose of a self-adjusting telescope, with a shade for examining the most luminous and dazzling objects: and hence the Eagle is often seen to ascend to the higher regions of the atmosphere, gazing on the unclouded sun as on an ordinary and familiar object.

The rapid motions executed by birds have also a reference to the perfection of their vision; for if Nature, while she endowed them with great agility and vast muscular strength, had left them as short-sighted as ourselves, their latent powers would have availed them nothing, and the dangers of a perpetually impeded progress would have repressed or extinguished their ardor. We may then, in general, consider the celerity with which an animal moves, as a just indication of the perfection of its vision. A bird, therefore, shooting swiftlv 
through the air, must undoubtedly see better than one which slowly describes a waving tract. The weak-sighted bat, flying carefully through bars of willow, even when the eyes were extinguished, may seem to suggest an exception to this rule of relative velocity and vision; but in this case, as in that of some blind individuals of the human species, the exquisite auditory apparatus seems capable of supplying the defect of sight. Nor are the flickerings of the bat, constantly performed in a narrow circuit, at all to be compared to the distant and lofty soarings of the Eagle, or the wide wanderings of the smaller birds, who often annually pass and repass from the arctic circle to the equator.

The idea of motion, and all the other ideas connected with it, such as those of relative velocities, extent of country, the proportional height of eminences, and of the various inequalities that prevail on the surface, are therefore more precise in birds, and occupy a larger share of their conceptions, than in the grovelling quadrupeds. Nature would seem to have pointed out this superiority of vision, by the more conspicuous and elaborate structure of its organ; for in birds the eye is larger in proportion to the bulk of the head than in quadrupeds; it is also more delicate and finely fashioned, and the impressions it receives must consequently excite more vivid ideas.

Another cause of difference in the instincts of birds and quadrupeds is the nature of the element in which they live. Birds know better than man the degrees of resistance in the air, its temperature at different heights, its relative density, and many other particulars, probably, of which we can form no adequate conception. They foresee more than we, and indicate better than our weather-glasses, the changes which happen in that voluble fluid; for often have they contended with the violence of the wind, and still oftener have they borrowed the advantage of its aid. The Eagle, soaring above the clouds, can at will escape the scene of the storm, and in the lofty region of calm, far within the aërial boundary of eternal frost, ${ }^{1}$ enjoy a

1 The mean heights of eternal frost under the equator and at the latitude of $30^{\circ}$ and $60^{\circ}$ are, respectively, $15,207,11,4{ }^{8} 4$, and 3,818 feet.

TOL. I. $-b$ 
serene sky and a bright sun, while the terrestrial animals re. main involved in darkness and exposed to all the fury of the tempest. In twenty-four hours it can change its climate, and sailing over different countries, it will form a picture exceeding the powers of the pencil or the imagination. The quadruped knows only the spot where it feeds, - its valley, mountain, or plain; it has no conception of the expanse of surface or of remote distances, and generally no desire to push forward its excursions beyond the bounds of its immediate wants. Hence remote journeys and extensive migrations are as rare among quadrupeds as they are frequent among birds. It is this desire, founded on their acquaintance with foreign countries, on the consciousness of their expeditious course, and on their foresight of the changes that will happen in the atmosphere, and the revolutions of seasons, that prompts them to retire together at the powerful suggestions of an unerring instinct. When their food begins to fail, or the cold and heat to incommode them, their innate feelings and latent powers urge them to seek the necessary remedy for the evils that threaten their being. The inquietude of the old is communicated to the young; and collecting in troops by common consent, influenced by the same general wants, impressed with the approaching changes in the circumstances of their existence, they give way to the strong reveries of instinct, and wing their way over land and sea to some distant and better country.

Comparing animals with each other, we soon perceive that smell, in general, is much more acute among the quadrupeds than the birds. Even the pretended scent of the Vulture is imaginary, as he does not perceive the tainted carrion, on which he feeds, through a wicker basket, though its odor is as potent as in the open air. This choice also of decaying flesh is probably regulated by his necessities and the deficiency of his muscular powers to attack a living, or even tear in pieces a recent, prey. The structure of the olfactory organ in birds is obviously inferior to that of quadrupeds; the external nostrils are wanting, and those odors which might excite sensation have access only to the duct leading from the palate; and even 
in those, where the organ is disclosed, the nerves, which take their origin from it, are far from being so numerous, so large, or so expanded as in the quadrupeds. We may therefore regard touch in man, smell in the quadruped, and sight in birds, as respectively the three most perfect senses which exercise a general influence on the character.

After sight, the most perfect of the senses in birds appears to be hearing, which is even superior to that of the quadrupeds, and scarcely exceeded in the human species. We perceive with what facility they retain and repeat tones, successions of notes, and even words; we delight to listen to their unwearied songs, to the incessant warbling of their tuneful affection. Their ear and throat are more ductile and powerful than in other animals, and their voice more capacious and generally agreeable. A Crow, which is scarcely more than the thousandth part the size of an ox, may be heard as far, or farther; the Nightingale can fill a wider space with its music than the human voice. This prodigious extent and power of sound depend entirely on the structure of their organs; but the support and continuance of their song result solely from their internal emotions.

The windpipe is wider and stronger in birds than in any other class of animals, and usually terminates below in a large cavity that augments the sound. The lungs too have greater extent, and communicate with internal cavities which are capable of being expanded with air, and, besides lightening the body, give additional strength to the voice. Indeed, the formation of the thorax, the lungs, and all the organs connected with these, seems expressly calculated to give force and duration to their utterance.

Another circumstance, showing the great power of voice in birds, is the distance at which they are audible in the higher regions of the atmosphere. An Eagle may rise at least to the height of seventeen thousand feet, for it is there just visible. Flocks of Storks and Geese may mount still higher, since, notwithstanding the space they occupy, they soar almost out of sight; their cry will therefore be heard from an altitude of 
more than three miles, and is at least four times as powerful as the voice of men and quadrupeds.

Sweetness of voice and melody of song are qualities which in birds are partly natural and partly acquired. The facility with which they catch and repeat sounds, enables them not only to borrow from each other, but often even to copy the more difficult inflections and tones of the human voice, as well as of musical instruments. It is remarkable that in the tropical regions, where the birds are arrayed in the most glowing colors, their voices are hoarse, grating, singular, or terrific. Our sylvan Orpheus (the Mocking-bird), the Brown Thrush, the Warbling Flycatcher, as well as the Linnet, the Thrush, the Blackbird, and the Nightingale of Europe, pre-eminent for song, are all of the plainest colors and weakest tints.

The natural tones of birds, setting aside those derived from education, express the various modifications of their wants and passions; they change even according to different times and circumstances. The females are much more silent than the males ; they have cries of pain or fear, murmurs of inquietude or solicitude, especially for their young; but of song they are generally deprived. The song of the male is inspired by tender emotion, he chants his affectionate lay with a sonorous voice, and the female replies in feeble accents. The Nightingale, when he first arrives in the spring, without his mate, is silent; he begins his lay in low, faltering, and unfrequent airs; and it is not until his consort sits on her eggs that his enchanting melody is complete: he then tries to relieve and amuse her tedious hours of incubation, and warbles more pathetically and variably his amorous and soothing lay. In a state of nature this propensity for song only continues through the breeding season, for after that period it either entirely ceases, becomes enfeebled, or loses its sweetness.

Conjugal fidelity and parental affection are among the most conspicuous traits of the feathered tribes. The pair unite their labors in preparing for the accommodation of their expected progeny; and during the time of incubation their participation of the same cares and solicitudes continually augments 
their mutual attachment. When the young appear, a new source of care and pleasure opens to them, still strengthening the ties of affection; and the tender charge of rearing and defending their infant brood requires the joint attention of both parents. The warmth of first affection is thus succeeded by calm and steady attachment, which by degrees extends, without suffering any diminution, to the rising branches of the family.

This conjugal union, in the rapacious tribe of birds, the Eagles and Hawks, as well as with the Ravens and Crows, continues commonly through life. Among many other kinds it is also of long endurance, as we may perceive in our common Pewee and the Blue-bird, who year after year continue to frequent and build in the same cave, box, or hole in the decayed orchard tree. But, in general, this association of the sexes expires with the season, after it has completed the intentions of reproduction, in the preservation and rearing of the offspring. The appearance even of sexual distinction often vanishes in the autumn, when both the parents and their young are then seen in the same humble and oblivious dress. When they arrive again amongst us in the spring, the males in flocks, often by themselves, are clad anew in their nuptial livery; and with vigorous songs, after the cheerless silence in which they have passed the winter, they now seek out their mates, and warmly contest the right to their exclusive favor.

With regard to food, birds have a more ample latitude than quadrupeds ; flesh, fish, amphibia, reptiles, insects, fruits, grain, seeds, roots, herbs, - in a word, whatever lives or vegetates. Nor are they very select in their choice, but often catch indifferently at what they can most easily obtain. Their sense of taste appears indeed much less acute than in quadrupeds; for if we except such as are carnivorous, their tongue and palate are, in general, hard, and almost cartilaginous. Sight and scent can only direct them, though they possess the latter in an inferior degree. The greater number swallow without tasting; and mastication, which constitutes the chief pleasure in eating, is entirely wanting to them. As their horny jaws are unprovided 
with teeth, the food undergoes no preparation in the mouth, but is swallowed in unbruised and untasted morsels. Yet there is reason to believe that the first action of the stomach, or its preparatory ventriculus, affords in some degree the ruminating gratification of taste, as after swallowing food, in some insectivorous and carnivorous birds, the motion of the mandibles, exactly like that of ordinary tasting, can hardly be conceived to exist without conveying some degree of gratifying sensation.

The clothing of birds varies with the habits and climates they inhabit. The aquatic tribes, and those which live in northern regions, are provided with an abundance of plumage and fine down, - from which circumstance often we may form a correct judgment of their natal regions. In all climates, aquatic birds are almost equally feathered, and are provided with posterior glands containing an oily substance for anointing their feathers, which, aided by their thickness, prevents the admission of moisture to their bodies. These glands are less conspicuous in land birds, - unless, like the fishing Eagles, their habits be to plunge in the water in pursuit of their prey.

The general structure of feathers seems purposely adapted both for warmth of clothing and security of flight. In the wings of all birds which fly, the webs composing the vanes, or plumy sides of the feather, mutually interlock by means of regular rows of slender, hair-like teeth, so that the feather, except at and towards its base, serves as a complete and close screen from the weather on the one hand, and as an impermeable oar on the other, when situated in the wing, and required to catch and retain the impulse of the air. In the birds which do not fly, and inhabit warm climates, the feathers are few and thin, and their lateral webs are usually separate, as in the Ostrich, Cassowary, Emu, and extinct Dodo. In some cases feathers seem to pass into the hairs, which ordinarily clothe the quadrupeds, as in the Cassowary, and others; and the base of the bill in many birds is usually surrounded with these capillary plumes.

The greater number of birds cast their feathers annually, and appear to suffer much more from it than the quadrupeds do 
from a similar change. The best-fed fowl ceases at this time to lay. The season of moulting is generally the end of summer or autumn, and their feathers are not completely restored till the spring. The male sometimes undergoes, as we have already remarked, an additional moult towards the close of summer; and among many of the waders and web-footed tribes, as Sandpipers, Plovers, and Gulls, both sexes experience a moult twice in the year, so that their summer and winter livery appears wholly different.

The stratagems and contrivances instinctively employed by birds for their support and protection are peculiarly remarkable; in this way those which are weak are enabled to elude the pursuit of the strong and rapacious. Some are even screened from the attacks of their enemies by an arrangement of colors assimilated to the places which they most frequent for subsistence and repose : thus the Wryneck is scarcely to be distinguished from the tree on which it seeks its food; or the Snipe from the soft and springy ground which it frequents. The Great Plover finds its chief security in stony places, to which its colors are so nicely adapted that the most exact observer may be deceived. The same resort is taken advantage of by the Night Hawk, Partridge, Plover, and the American Quail, the young brood of which squat on the ground, instinctively conscious of being nearly invisible, from their close resemblance to the broken ground on which they lie, and trust to this natural concealment. The same kind of deceptive and protecting artifice is often employed by birds to conceal or render the appearance of their nests ambiguous. Thus the European Wren forms its nest externally of hay, if against a hayrick; covered with lichens, if the tree chosen is so clad; or made of green moss, when the decayed trunk in which it is built, is thus covered; and then, wholly closing it above, leaves only a concealed entry in the side. Our Hummingbird, by external patches of lichen, gives her nest the appearance of a moss-grown knot. A similar artifice is employed by our Yellow-breasted Flycatcher, or Vireo, and others. The 
Golden-crowned Thrush (Seiurus aurocapillus) makes a nest like an oven, erecting an arch over it so perfectly resembling the tussuck in which it is concealed that it is only discoverable by the emotion of the female when startled from its covert.

The Butcher-bird is said to draw around him his feathered victims by treacherously imitating their notes. The Kingfisher of Europe is believed to allure his prey by displaying the brilliancy of his colors as he sits near some sequestered place on the margin of a rivulet; the fish, attracted by the splendor of his fluttering and expanded wings, are detained while the wily fisher takes an unerring aim. ${ }^{1}$ The Erne, and our Bald Eagle, gain a great part of their subsistence by watching the success of the Fish Hawk, and robbing him of his finny prey as soon as it is caught. In the same way also the rapacious Burgomaster, or Glaucous Gull (Larus glaucus), of the North levies his tribute of food from all the smaller species of his race, who, knowing his strength and ferocity, are seldom inclined to dispute his piratical claims. Several species of Cuckoo, and the Cow Troopial of America, habitually deposit their eggs in the nests of other small birds, to whose deceived affection are committed the preservation and rearing of the parasitic and vagrant brood. The instinctive arts of birds are numerous; but treachery, like that which obtains in these parasitic species, is among the rarest expedients of nature in the feathered tribes, though not uncommon among some insect families.

The art displayed by birds in the construction of their temporary habitations, or nests, is also deserving of passing attention. Among the Gallinaceous tribe, including our land domestic species, as well as the aquatic and wading kinds, scarcely any attempt at a nest is made. The birds which swarm along the sea-coast often deposit their eggs on the bare ground, sand, or slight depressions in shelving rocks; governed alone by grosser wants, their mutual attachment is feeble or nugatory, and neither art nor instinct prompts attention to the construc-

1 The bright feathers of this bird enter often successfully, with others, into the composition of the most attractive artificial fies employed by anglers. 
tion of a nest, - the less necessary, indeed, as the young run or take to the water as soon as hatched, and early release themselves from parental dependence. The habits of the other aquatic birds are not very dissimilar to these; yet it is singular to remark that while our common Geese and Ducks, like domestic Fowls, have no permanent selective attachment for their mates, the Canadian Wild Goose, the Eider Duck, and some others, are constantly and faithfully paired through the season; so that this neglect of accommodation for the young in the fabrication of an artificial nest, common to these with the rest of their tribe, has less connection with the requisition of mutual aid than with the hardy and precocious habits of these unmusical, coarse, and retiring birds. It is true that some of them show considerable address, if little of art, in providing security for their young; in this way some of the Razor-bills (including the Common Puffin) do not trust the exposure of their eggs, like the Gulls, who rather rely on the solitude of their retreat, than art in its defence; but with considerable labor some of the Alcas form a deep burrow for the security of their brood.

Birds of the same genus differ much in their modes of nidification. Thus the Martin makes a nest within a rough-cast rampart of mud, and enters by a flat opening in the upper edge. The Cliff Swallow of Bonaparte conceals its warm and feathered nest in a receptacle of agglutinated mud resembling a narrow-necked purse or retort. Another species, in the Indian seas, forms a small receptacle for its young entirely of interlaced gelatinous fibres, provided by the mouth and stomach; these nests, stuck in clusters against the rocks, are collected by the Chinese, and boiled and eaten in soups as the rarest delicacy. The Bank Martin, like the Kingfisher, burrows deep into the friable banks of rivers to secure a depository for its scantily feathered nest. The Chimney Swallow, originally an inhabitant of hollow trees, builds in empty chimneys a bare nest of agglutinated twigs. The Woodpecker, Nuthatch, Titmouse, and our rural Bluebird, secure their young in hollow trees; and the first often gouge and dig through the solid wood with the success and industry of car- 
penters, and without the aid of any other chisel than their wedged bills.

But the most consummate ingenuity of ornithal architecture is displayed by the smaller and more social tribes of birds, who, in proportion to their natural enemies, foreseen by Nature, are provided with the means of instinctive defence. In this labor both sexes generally unite, and are sometimes occupied a week or more in completing this temporary habitation for their young. We can only glance at a few examples, chiefly domestic; since to give anything like a general view of this subject of the architecture employed by birds would far exceed the narrow limits we prescribe. And here we may remark that, after migration, there is no more certain display of the reveries of instinct than what presides over this interesting and necessary labor of the species. And yet so nice are the gradations betwixt this innate propensity and the dawnings of reason that it is not always easy to decide upon the characteristics of one as distinct from the other. Pure and undeviating instincts are perhaps wholly confined to the invertebral class of animals.

In respect to the habits of birds, we well know that, like quadrupeds, they possess, though in a lower degree, the capacity for a certain measure of what may be termed education, or the power of adding to their stock of invariable habits the additional traits of an inferior degree of reason. Thus in those birds who have discovered (like the faithful dog, that humble companion of man) the advantages to be derived from associating round his premises, the regularity of their instinctive habits gives way, in a measure, to improvable conceptions. In this manner our Golden Robin (Icterus baltimore), or Fiery Hang Bird, originally only a native of the wilderness and the forest, is now a constant summer resident in the vicinity of villages and dwellings. From the depending boughs of our towering elms, and other spreading trees, like the Oriole of Europe, and the Cassican of tropical America, he weaves his pendulous and purse-like nest of the most tenacious and durable materials he can collect. These naturally consist of the 
Indian hemp, flax of the silk-weed (Asclepias species), and other tough and fibrous substances; but with a ready ingenuity he discovers that real flax and hemp, as well as thread, cotton, yarn, and even hanks of silk, or small strings, and horse and cow hair, are excellent substitutes for his original domestic materials; and in order to be convenient to these accidental resources, - a matter of some importance in so tedious a labor, - he has left the wild woods of his ancestry, and conscious of the security of his lofty and nearly inaccessible mansion, has taken up his welcome abode in the precincts of our habitations. The same motives of convenience and comfort have had their apparent influence on many more of our almost domestic feathered tribes; the Bluebirds, Wrens, and Swallows, original inhabitants of the woods, are now no less familiar than our Pigeons. The Catbird often leaves his native solitary thickets for the convenience and refuge of the garden, and watching, occasionally, the motions of the tenant, answers to his whistle with complacent mimicry, or in petulant anger scolds at his intrusion. The Common Robin, who never varies his simple and coarse architecture, tormented by the parasitic Cuckoo or the noisy Jay, who seek at times to rob him of his progeny, for protection has been known fearlessly to build his nest within a few yards of the blacksmith's anvil, or on the stern timbers of an unfinished vessel, where the carpenters were still employed in their noisy labors. That sagacity obtains its influence over unvarying instinct in these and many other familiar birds, may readily be conceived when we observe that this venturous association with man vanishes with the occasion which required it; for no sooner have the Oriole and Robin reared their young than their natural suspicion and shyness again return.

Deserts and solitudes are avoided by most kinds of birds. In an extensive country of unvarying surface, or possessing but little variety of natural productions, and particularly where streams and waters are scarce, few of the feathered tribes are to be found. The extensive prairies of the West, and the gloomy and almost interminable forests of the North, as well as 
the umbrageous, wild, and unpeopled banks of the Mississippi, and other of the larger rivers, no less than the vast pine-barrens of the Southern States, are nearly without birds as permanent residents. In crossing the desolate piny glades of the South, with the exception of Creepers, Nuthatches, Woodpeckers, Pine Warblers, and flocks of flitting Larks (Sturnella), scarcely any birds are to be seen till we approach the meanders of some stream, or the precincts of a plantation. The food of birds being extremely various, they consequently congregate only where sustenance is to be obtained; watery situations and a diversified vegetation are necessary for their support, and convenient for their residence; the fruits of the garden and orchard, the swarms of insects which follow the progress of agriculture, the grain which we cultivate, - in short, everything which contributes to our luxuries and wants, in the way of subsistence, no less than the recondite and tiny enemies which lessen or attack these various resources, all conduce to the support of the feathered race, which consequently seek out and frequent our settlements as humble and useful dependents.

The most ingenious and labored nest of all the North American birds is that of the Orchard Oriole, or Troopial. It is suspended, or pensile, like that of the Baltimore Bird, but, with the exception of hair, constantly constructed of native materials, the principal of which is a kind of tough grass. The blades are formed into a sort of platted purse but little inferior to a coarse straw bonnet; the artificial labor bestowed is so apparent that Wilson humorously adds, on his showing it to a matron of his acquaintance, betwixt joke and earnest, she asked " if he thought it could not be taught to darn stockings." Every one has heard of the Tailor Bird of India (Sylvia sutoria); this little architect, by way of saving labor and gaining security for its tiny fabric, sometimes actually, as a seamstress, sews together the edges of two leaves of a tree, in which her nest, at the extremity of the branch, is then secured for the period of incubation. Among the Sylvias, or Warblers, there is a species, inhabiting Florida and the West Indies, the Sylvia pensilis, which forms its woven, covered nest to rock in 
the air at the end of two suspending strings, rather than trust it to the wily enemies by which it is surrounded; the entrance, for security, is also from below, and through a winding vestibule.

Our little cheerful and almost domestic Wren (Troglodytes fulvus), which so often disputes with the Martin and the Bluebird the possession of the box set up for their accommodation in the garden or near the house, in his native resort of a hollow tree, or the shed of some neglected out-house, begins his fabric by forming a barricade of crooked interlacing twigs, - a kind of chevaux-de-frise, - for the defence of his internal habitation, leaving merely a very small entrance at the upper edge. The industry of this little bird, and his affection for his mate, are somewhat remarkable, as he frequently completes his habitation without aid, and then searches out a female on whom to bestow it; but not being always successful, or the premises not satisfactory to his mistress, his labor remains sometimes without reward, and he continues to warble out his lay in solitude. The same gallant habit prevails also with our recluse Wren of the marshes. Wilson's Marsh Wren (Troglodytes palustris), instead of courting the advantages of a proximity to our dwellings, lives wholly among the reed-fens, suspending his mudplastered and circularly covered nest usually to the stalks of the plant he so much affects. Another marsh species inhabits the low and swampy meadows of our vicinity (Troglodytes brevirostris), and with ready address constructs its globular nest wholly of the intertwined sedge-grass of the tussock on which it is built; these two species never leave their subaquatic retreats but for the purpose of distant migration, and avoid and deprecate in angry twitterings every sort of society but their own.

Among the most extraordinary habitations of birds, illustrative of their instinctive invention, may be mentioned that of the Bengal Grosbeak, whose pensile nest, suspended from the lofty boughs of the Indian fig-tree, is fabricated of grass, like cloth, in the form of a large bottle, with the entrance downwards; it consists also of two or three chambers, supposed to be occasionally illuminated by the fire-flies, which, however, 
only constitute a part of the food it probably conveys for the support of its young. But the most extraordinary instinct of this kind known, is exhibited by the Sociable, or Republican Grosbeak (Ploceus socius, Cuvier), of the Cape of Good Hope. In one tree, according to Mr. Paterson, there could not be fewer than from eight hundred to one thousand of these nests, covered by one general roof, resembling that of a thatched house, and projecting over the entrance of the nest. Their common industry almost resembles that of bees. Beneath this roof there are many entrances, each of which forms, as it were, a regular street, with nests on either side, about two inches distant from each other. The material which they employ in this building is a kind of fine grass, whose seed, also, at the same time serves them for food.

That birds, besides their predilection for the resorts of men, are also capable of appreciating consequences to themselves and young, scarcely admits the shadow of a doubt; they are capable of communicating their fears and nicely calculating the probability of danger or the immunities of favor. We talk of the cunning of the Fox and the watchfulness of the Weasel; but the Eagle, Hawk, Raven, Crow, Pye, and Blackbird possess those traits of shrewdness and caution which would seem to arise from reflection and prudence. They well know the powerful weapons and wiles of civilized man. Without being able to smell powder, - a vulgar idea, - the Crow and Blackbird at. once suspect the character of the fatal gun ; they will alight on the backs of cattle without any show of apprehension, and the Pye even hops upon them with insulting and garrulous playfulness; but he flies instantly from his human enemy, and seems, by his deprecating airs, aware of the proscription that affects his existence. A man on horseback or in a carriage is much less an object of suspicion to those wily birds than when alone; and I have been frequently both amused and surprised, in the Southern States, by the sagacity of the Common Blackbirds in starting from the ploughing field, with looks of alarm, at the sight of a white man, as distinct from and more dangerous than the black slave, whose furrow they closely and familiarly fol- 
lowed, for the insect food it afforded them, without betraying any appearance of distrust. Need we any further proof of the capacity for change of disposition than that which has so long operated upon our domestic poultry? - "those victims," as Buffon slightingly remarks, "which are multiplied without trouble, and sacrificed without regret." How different the habits of our Goose and Duck in their wild and tame condition! Instead of that excessive and timid cautiousness, so peculiar to their savage nature, they keep company with the domestic cattle, and hardly shuffle out of our path. Nay, the Gander is a very ban-dog, - noisy, gabbling, and vociferous, he gives notice of the stranger's approach, is often the terror of the meddling school-boy, in defence of his fostered brood; and it is reported of antiquity, that by their usual garrulity and watchfulness they once saved the Roman capitol. Not only is the disposition of these birds changed by domestication, but even their strong instinct to migration, or wandering longings, are wholly annihilated. Instead of joining the airy phalanx which wing their way to distant regions, they grovel contented in the perpetual abundance attendant on their willing slavery. If instinct can thus be destroyed or merged in artificial circumstances, need we wonder that this protecting and innate intelligence is capable also of another change by improvement, adapted to new habits and unnatural restraints? Even without undergoing the slavery of domestication, many birds become fully sensible of immunities and protection; and in the same aquatic and rude family of birds already mentioned we may quote the tame habits of the Eider Ducks. In Iceland and other countries, where they breed in such numbers as to render their valuable down an object of commerce, they are forbidden to be killed under legal penalty; and as if aware of this legislative security, they sit on their eggs undisturbed at the approach of man, and are entirely as familiar, during this season of breeding, as our tamed Ducks. Nor are they apparently aware of the cheat habitually practised upon them of abstracting the down with which they line their nests, though it is usually repeated until they make the third attempt at incubation. If, 
however, the last nest, with its eggs and down, to the lining of which the male is now obliged to contribute, be taken away, they sagaciously leave the premises, without return. The pious Storks, in Holland, protected by law for their usefulness, build their nests on the tops of houses and churches, often in the midst of cities, in boxes prepared for them, like those for our Martins; and, walking about the streets and gardens without apprehension of danger, perform the usual office of domestic scavengers.

That birds, like our more sedentary and domestic quadrupeds, are capable of exhibiting attachment to those who feed and attend them, is undeniable. Deprived of other society, some of our more intelligent species, particularly the Thrushes, soon learn to seek out the company of their friends or protectors of the human species. The Brown Thrush and Mocking Bird become in this way extremely familiar, cheerful, and capriciously playful; the former, in particular, courts the attention of his master, follows his steps, complains when neglected, flies to him when suffered to be at large, and sings and reposes gratefully perched on his hand, - in short, by all his actions he appears capable of real and affectionate attachment, and is jealous of every rival, particularly any other bird, which he persecutes from his presence with unceasing hatred. His petulant dislike to particular objects of less moment is also displayed by various tones and gestures, which soon become sufficiently intelligible to those who are near him, as well as his notes of gratulation and satisfaction. His language of fear and surprise could never be mistaken, and an imitation of his gutturat low tsherr, tsherr, on these occasions, answers as a premonitory warning when any danger awaits him from the sly approach of cat or squirrel. As I have now descended, as I may say, to the actual biography of one of these birds, which I raised and kept uncaged for some time, I may also add, that besides a playful turn for mischief and interruption, in which he would sometimes snatch off the paper on which I was writing, he had a good degree of curiosity, and was much surprised one day by a large springing beetle or Elater (E. ocellatus), 
which I had caught and placed in a tumbler. On all such occasions his looks of capricious surprise were very amusing; he cautiously approached the glass with fanning and closing wings, and in an under-tone confessed his surprise at the address and jumping motion of the huge insect. At length he became bolder, and perceiving it had a relation to his ordinary prey of beetles, he, with some hesitation, ventured to snatch at the prisoner between temerity and playfulness. But when really alarmed or offended, he instantly flew to his loftiest perch, forbid all friendly approaches, and for some time kept up his low and angry tsherr. My late friend, the venerable William Bartram, was also much amused by the intelligence displayed by this bird, and relates that one which he kept, being fond of hard bread-crumbs, found, when they grated his throat, a very rational remedy in softening them, by soaking in his vessel of water; he likewise, by experience, discovered that the painful prick of the wasps on which he fed, could be obviated by extracting their stings. But it would be too tedious and minute to follow out these glimmerings of intelligence, which exist as well in birds as in our most sagacious quadrupeds. The remarkable talent of the Parrot for imitating the tones of the human voice has long been familiar. The most extraordinary and well-authenticated account of the actions of one of the common ash-colored species is that of a bird which Colonel O'Kelly bought for a hundred guineas at Bristol. This individual not only repeated a great number of sentences, but answered many questions, and was able to whistle a variety of tunes. While thus engaged it beat time with all the appearance of science, and possessed a judgment, or ear so accurate, that if by chance it mistook a note, it would revert to the bar where the mistake was made, correct itself, and still beating regular time, go again through the whole with perfect exactness. So celebrated was this surprising bird that an obituary notice of its death appeared in the "General Evening Post" for the 9 th of October, 1802 . In this account it is added, that besides her great musical faculties, she could express her wants articulately, and give her orders in a manner approaching to

roL. I. $-c$ 
rationality. She was, at the time of her decease, supposed to be more than thirty years of age. The colonel was repeatedly offered five hundred guineas a year for the bird, by persons who wished to make a public exhibition of her; but out of tenderness to his favorite he constantly refused the offer.

The story related by Goldsmith of a parrot belonging to King Henry the Seventh, is very amusing, and possibly true. It was kept in a room in the Palace of Westminster, overlooking the Thames, and had naturally enough learned a store of boatmen's phrases; one day, sporting somewhat incautiously, Poll fell into the river, but had rationality enough, it appears, to make a profitable use of the words she had learned, and accordingly vociferated, "A boat! twenty pounds for a boat!" This welcome sound reaching the ears of a waterman, soon brought assistance to the Parrot, who delivered it to the king, with a request to be paid the round sum so readily promised by the bird; but his Majesty, dissatisfied with the exorbitant demand, agreed, at any rate, to give him what the bird should now award; in answer to which reference, Poll shrewdly cried, "Give the knave a groat!"

The story given by Locke, in his "Essay on the Human Understanding," though approaching closely to rationality, and apparently improbable, may not be a greater effort than could have been accomplished by Colonel O'Kelly's bird. This Parrot had attracted the attention of Prince Maurice, then governor of Brazil, who had a curiosity to witness its powers. The bird was introduced into the room, where sat the prince in company with several Dutchmen. On viewing them, the Parrot exclaimed, in Portuguese, "What a company of white men are here!" Pointing to the prince, they asked, "Who is that man?" to which the Parrot replies, "Some general or other." The prince now asked, "From what place do you come?" The answer was, "From Marignan." "To whom do you belong?" It answered, "To a Portuguese." "What do you do there?" To which the Parrot replied, "I look after chickens!" The prince, now laughing, exclaimed, "You look 
after chickens!" To which Poll pertinently answered, "Yes, $I$, - and I know well enough how to do it; " clucking at the same instant in the manner of a calling brood-hen.

The docility of birds in catching and expressing sounds depends, of course, upon the perfection of their voice and hearing, - assisted also by no inconsiderable power of memory. The imitative actions and passiveness of some small birds, such as Goldfinches, Linnets, and Canaries, are, however, quite as curious as their expression of sounds. A Sieur Roman exhibited in England some of these birds, one of which simulated death, and was held up by the tail or claw without showing any active signs of life. A second balanced itself on the head, with its claws in the air. A third imitated a milkmaid going to market, with pails on its shoulders. A fourth mimicked a Venetian girl looking out at a window. A fifth acted the soldier, and mounted guard as a sentinel. The sixth was a cannonier, with a cap on its head, a firelock on its shoulder, and with a match in its claw discharged a small cannon. The same bird also acted as if wounded, was wheeled in a little barrow, as it were to the hospital; after which it flew away before the company. The seventh turned a kind of windmill ; and the last bird stood amidst a discharge of small fireworks, without showing any sign of fear.

A similar exhibition, in which twenty-four Canary birds were the actors, was also shown in London in 1820 , by a Frenchman named Dujon; one of these suffered itself to be shot at, and falling down, as if dead, was put into a little wheelbarrow and conveyed away by one of its comrades.

The docility of the Canary and Goldfinch is thus, by dint of severe education, put in fair competition with that of the dog; and we cannot deny to the feathered creation a share of that kind of rational intelligence exhibited by some of our sagacious quadrupeds, - an incipient knowledge of cause and effect far removed from the unimprovable and unchangeable destinies of instinct. Nature probably delights less in producing such animated machines than we are apt to suppose; and amidst the mutability of circumstances by which almost every animated 
being is surrounded, there seems to be a frequent demand for that relieving invention denied to those animals which are solely governed by inflexible instinct.

The velocity with which birds are able to travel in their aërial element has no parallel among terrestrial animals; and this powerful capacity for progressive motion is bestowed in aid of their peculiar wants and instinctive habits. The swiftest horse may perhaps proceed a mile in something less than two minutes; but such exertion is unnatural, and quickly fatal. An Eagle, whose stretch of wing exceeds seven feet, with ease and majesty, and without any extraordinary effort, rises out of sight in less than three minutes, and therefore must fly more than three thousand five hundred yards in a minute, or at the rate of sixty miles in an hour. At this speed a bird would easily perform a journey of six hundred miles in a day, since ten hours only would be required, which would allow frequent halts, and the whole of the night for repose. Swallows and other migratory birds might therefore pass from northern Europe to the equator in seven or eight days. In fact, Adanson saw, on the coast of Senegal, Swallows that had arrived there on the 9 th of October, or eight or nine days after their departure from the colder continent. A Canary Falcon, sent to the Duke of Lerma, returned in sixteen hours from Andalusia to the island of Teneriffe, - a distance of seven hundred and fifty miles. The Gulls of Barbadoes, according to Sir Hans Sloane, make excursions in flocks to the distance of more than two hundred miles after their food, and then return the same day to their rocky roosts.

If we allow that any natural powers come in aid of the instinct to migration, so powerful and uniform in birds, besides their vast capacity for motion, it must be in the perfection and delicacy of their vision, of which we have such striking examples in the rapacious tribes. It is possible that at times they may be directed principally by atmospheric phenomena alone; and hence we find that their appearance is frequently a concomitant of the approaching season, and the wild Petrel of the ocean is not the only harbinger of storm and coming change. The currents of the air, in those which make exten- 
sive voyages, are sedulously employed; and hence, at certain seasons, when they are usually in motion, we find their arrival or departure accelerated by a favorable direction of the winds. That birds also should be able to derive advantage in their journeys from the acuteness of their vision, is not more wonderful than the capacity of a dog to discover the path of his master, for many miles in succession, by the mere scent of his steps. It is said, indeed, in corroboration of this conjecture, that the Passenger, or Carrying Pigeon, is not certain to return to the place from whence it is brought, unless it be conveyed in an open wicker basket admitting a view of the passing scenery. Many of our birds, however, follow instinctively the great valleys and river-courses, which tend towards their southern or warmer destination; thus the great valleys of the Connecticut, the Hudson, the Delaware, the Susquehanna, the Santee, and more particularly the vast Mississippi, are often, in part, the leading routes of our migrating birds. But, in fact, mysterious as is the voyage and departure of our birds, like those of all other countries where they remove at all, the destination of many is rendered certain, as soon as we visit the southern parts of the Union, or the adjoining countries of Mexico, to which they have retired for the winter; for now, where they were nearly or wholly unknown in summer, they throng by thousands, and flit before our path like the showering leaves of autumn. It is curious to observe the pertinacity of this adventurous instinct in those more truly and exclusively insectivorous species which wholly leave us for the mild and genial regions of the tropics. Many penetrate to their destination through Mexico overland; to these the whole journey is merely an amusing and varied feast. But to a much smaller number, who keep too far toward the sea-coast, and enter the ocean-bound peninsula of Florida, a more arduous aerial voyage is presented; the wide ocean must be crossed, by the young and inexperienced as well as the old and venturous, before they arrive either at the tropical continent or its scattered islands. When the wind proves propitious, however, our little voyagers wing their unerring way like prosperous 
fairies; but baffled by storms and contrary gales, they often suffer from want, and at times, like the Quails, become victims to the devouring waves. On such unfortunate occasions (as Mr. Bullock ${ }^{1}$ witnessed in a voyage near to Vera Cruz late in autumn), the famished travellers familiarly crowd the decks of the vessel, in the hope of obtaining rest and a scanty meal preparatory to the conclusion of their unpropitious flight.

Superficial observers, substituting their own ideas for facts, are ready to conclude, and frequently assert, that the old and young, before leaving, assemble together for mutual departure ; this may be true in many instances, but in as many more a different arrangement obtains. The young, often instinctively vagrant, herd together in separate flocks previous to their departure, and guided alone by the innate monition of Nature, seek neither the aid nor the company of the old; consequently in some countries flocks of young of particular species are alone observed, and in others, far distant, we recognize the old. From parental aid the juvenile company have obtained all that Nature intended to bestow, - existence and education; and they are now thrown upon the world among their numerous companions, with no other necessary guide than self-preserving instinct. In Europe it appears that these bands of the young always affect even a warmer climate than the old; the aëration of their blood not being yet complete, they are more sensible to the rigors of cold. The season of the year has also its effect on the movements of birds; thus certain species proceed to their northern destination more to the eastward in the spring, and return from it to the south-westward in autumn.

The habitudes and extent of the migrations of birds admit of considerable variety. Some only fly before the inundating storms of winter, and return with the first dawn of spring; these do not leave the continent, and only migrate in quest of food when it actually begins to fail. Among these may be named our common Song Sparrow, Chipping Sparrow, Bluebird, Robin, Pewee, Cedar Bird, Blackbird, Meadow Lark, and many more. Others pass into warmer climates in the autumn, 
after rearing their young. Some are so given to wandering that their choice of a country is only regulated by the resources which it offers for subsistence; such are the Pigeons, Herons of several kinds, Snipes, wild Geese and Ducks, the wandering Albatros, and Waxen Chatterer.

The greater number of birds travel in the night; some species, however, proceed only by day, as the diurnal birds of prey, - Crows, Pies, Wrens, Creepers, Cross-bills, Larks, Bluebirds, Swallows, and some others. Those which travel wholly in the night are the Owls, Butcher Birds, Kingfishers, Thrushes, Flycatchers, Night Hawks, Whip-poor-wills, and also a great number of aquatic birds, whose motions are also principally nocturnal, except in the cold and desolate northern regions, where they usually retire to breed. Other birds are so powerfully impelled by this governing motive to migration that they stop neither day nor night; such are the Herons, Motacillas, Plovers, Swans, Cranes, Wild Geese, Storks, etc. When untoward circumstances render haste necessary, certain kinds of birds, which ordinarily travel only in the night, continue their route during the day, and scarcely allow themselves time to eat; yet the singing-birds, properly so called, never migrate by day, whatever may happen to them. And it may here be inquired, with astonishment, how these feeble but enthusiastic animals are able to pass the time, thus engaged, without the aid of recruiting sleep? But so powerful is this necessity for travel that its incentive breaks out equally in those which are detained in captivity, - so much so that although during the day they are no more alert than usual, and only occupied in taking nourishment, at the approach of night, far from seeking repose, as usual, they manifest great agitation, sing without ceasing in the cage, whether the apartment is lighted or not : and when the moon shines, they appear still more restless, as it is their custom, at liberty, to seek the advantage of its light for facilitating their route. Some birds, while engaged in their journey, still find means to live without halting, - the Swallow, while traversing the sea, pursues its insect prey; those who can subsist on fish without any serious effort, feed as they pass 
or graze the surface of the deep. If the Wren, the Creeper, and the Titmouse rest for an instant on a tree to snatch a hasty morsel, in the next they are on the wing, to fulfil their destination. However abundant may be the nourishment which presents itself to supply their wants, in general, birds of passage rarely remain more than two days together in a place.

The cries of many birds, while engaged in their aërial voyage, are such as are only heard on this important occasion, and appear necessary for the direction of those which fly in assembled ranks.

During these migrations it has been observed that birds fly ordinarily in the higher regions of the air, except when fogs force them to seek a lower elevation. This habit is particularly prevalent with Wild Geese, Storks, Cranes, and Herons, which often pass at such a height as to be scarcely distinguishable.

We shall not here enter into any detailed description of the manner in which each species conducts its migration, but shall content ourselves with citing the single remarkable example of the motions of the Cranes. Of all migrating birds, these appear to be endowed with the greatest share of foresight. They never undertake the journey alone; throughout a circle of several miles they appear to communicate the intention of commencing their route. Several days previous to their departure they call upon each other by a peculiar cry, as if giving warning to assemble at a central point; the favorable moment being at length arrived, they betake themselves to flight, and, in military style, fall into two lines, which, uniting at the summit, form an extended angle with two equal sides. At the central point of the phalanx, the chief takes his station, to whom the whole troop, by their subordination, appear to have pledged their obedience. The commander has not only the painful task of breaking the path through the air, but he has also the charge of watching for the common safety; to avoid the attacks of birds of prey; to range the two lines in a circie at the approach of a tempest, in order to resist with more effect the squalls which menace the dispersion of the 
linear ranks; and, lastly, it is to their leader that the fatigued company look up to appoint the most convenient places for nourishment and repose. Still, important as is the station and function of the aerrial director, its existence is but momentary. As soon as he feels sensible of fatigue, he cedes his place to the next in the file, and retires himself to its extremity. During the night their flight is attended with considerable noise; the loud cries which we hear, seem to be the marching orders of the chief, answered by the ranks who follow his commands. Wild Geese and several kinds of Ducks also make their aërial voyage nearly in the same manner as the Cranes. The loud. call of the passing Geese, as they soar securely through the higher regions of the air, is familiar to all ; but as an additionas proof of their sagacity and caution, we may remark that when fogs in the atmosphere render their flight necessarily low, they steal along in silence, as if aware of the danger to which their lower path now exposes them.

The direction of the winds is of great importance to the migration of birds, not only as an assistance when favorable, but to be avoided when contrary, as the most disastrous of accidents, when they are traversing the ocean. If the breeze suddenly change, the aerial voyagers tack to meet it, and diverging from their original course, seek the asylum of some land or island, as is the case very frequently with the Quails, who consequently, in their passage across the Mediterranean, at variable times, make a descent in immense numbers on the islands of the Archipelago, where they wait, sometimes for weeks, the arrival of a propitious gale to terminate their journey. And hence we perceive the object of migrating birds, when they alight upon a vessel at sea: it has fallen in their course while seeking refuge from a baffling breeze or overwhelming storm, and after a few hours of rest they wing their way to their previous destination. That Nature has provided ample means to fulfil the wonderful instinct of these feeble but cautious wanderers, appears in every part of their economy. As the period approaches for their general departure, and the chills of autumn are felt, their bodies begin to be loaded with 
cellular matter, and at no season of the year are the true birds of passage so fat as at the approach of their migration. The Gulls, Cranes, and Herons, almost proverbially macilent, are at this season loaded with this reservoir of nutriment, which is intended to administer to their support through their arduous and hazardous voyage. With this natural provision, dormant animals also commence their long and dreary sleep through the winter, - a nutritious resource no less necessary in birds while engaged in fulfilling the powerful and waking reveries of instinct.

But if the act of migration surprise us when performed by birds of active power of wing, it is still more remarkable when undertaken by those of short and laborious flight, like the Coots and Rails, who, in fact, perform a part of their route on foot. The Great Penguin (Alca impennis), the Guillemot, and the Divers, even make their voyage chiefly by dint of swimming. The young Loons (Colymbus glacialis), bred in inland ponds, though proverbially lame (and hence the name of Lom, or Loon), without recourse to their wings, which are at this time inefficient, continue their route from pond to pond, floundering over the intervening land by night, until at length they gain some creek of the sea, and finally complete their necessary migration by water.

Birds of passage, both in the old and new continents, are observed generally to migrate southwest in autumn, and to pass to the northeast in spring. Parry, however, it seems, observed the birds of Greenland proceed to the southeast. This apparent aberration from the usual course may be accounted for by considering the habits of these aquatic birds. Intent on food and shelter, a part, bending their course over the cold regions of Norway and Russia, seek the shores of Europe; while another division, equally considerable, proceeding southwest, spread themselves over the interior of the United States and the coast and kingdom of Mexico.

This propensity to change their climate, induced by whatever cause, is not confined to the birds of temperate regions; it likewise exists among many of those who inhabit the tropics. 
Aquatic birds of several kinds, according to Humboldt, cross the line on either side about the time of the periodical rise of the rivers. Waterton, likewise, who spent much time in Demerara and the neighboring countries, observed that the visits of many of the tropical birds were periodical. Thus the wonderful Campanero, whose solemn voice is heard at intervals tolling like the convent-bell, was rare to Waterton, but frequent in Brazil, where it most probably retires to breed. The failure of particular food at any season, in the mildest climate, would be a sufficient incentive to a partial and overland migration with any species of the feathered race.

The longevity of birds is various, and, different from the case of man and quadrupeds, seems to bear but little proportion to the age at which they acquire maturity of character. A few months seems sufficient to bring the bird into full possession of all its native powers; and there are some, as our Marsh Titmouse or Chickadee, which, in fact, as soon as fledged, are no longer to be distinguished from their parents. Land animals generally live six or seven times as long as the period required to attain maturity; but in birds the rate is ten times greater. In proportion to their size, they are also far more vivacious and long-lived than other animals of the superior class. Our knowledge of the longevity of birds is, however, necessarily limited to the few examples of domesticated species which we have been able to support through life: the result of these examples is, that our domestic Fowls have lived twenty years; Pigeons have exceeded that period; Parrots have attained more than thirty years. Geese live probably more than half a century; a Pelican has lived to eighty years ; and Swans, Ravens, and Eagles have exceeded a century. Even Linnets, in the unnatural restraints of the cage, have survived for fourteen or fifteen years, and Canaries twenty-five. To account for this remarkable tenacity of life, nothing very satisfactory has been offered; though Buffon is of opinion that the soft and porous nature of their bones contributes to this end, as the general ossification and rigidity of the system perpetually tends to abridge the boundaries of life. 
In a general way it may be considered as essential for the bird to fly as it is for the fish to swim or the quadruped to walk; yet in all these tribes there are exceptions to the general habits. Thus among quadrupeds the bats fly, the seals swim, and the beaver and otter swim better than they can walk. So also among birds, the Ostrich, Cassowary, and some others, incapable of flying, are obliged to walk ; others, as the Dippers, fly and swim but never walk. Some, like the Swallows and Humming Birds, pass their time chiefly on the wing. A far greater number of birds live on the water than of quadrupeds, for of the latter there are not more than five or six kinds furnished with webbed or oar-like feet, whereas of birds with this structure there are several hundred. The lightness of their feathers and bones, as well as the boat-like form of their bodies, contributes greatly to facilitate their buoyancy and progress in the water, and their feet serve as oars to propel them.

Thus in whatever way we view the feathered tribes which surround us, we shall find much both to amuse and instruct. We hearken to their songs with renewed delight, as the harbingers and associates of the season they accompany. Their return, after a long absence, is hailed with gratitude to the Author of all existence; and the cheerless solitude of inanimate Nature is, by their presence, attuned to life and harmony. Nor do they alone administer to the amusement and luxury of life; faithful aids as well as messengers of the seasons, they associate round our tenements, and defend the various productions of the earth, on which we so much rely for subsistence, from the destructive depredations of myriads of insects, which, but for timely riddance by unnumbered birds, would be followed by a general failure and famine. Public economy and utility, then, no less than humanity, plead for the protection of the feathered race; and the wanton destruction of birds, so useful, beautiful, and amusing, if not treated as such by law, ought to be considered as a crime by every moral, feeling, and reflecting mind. 


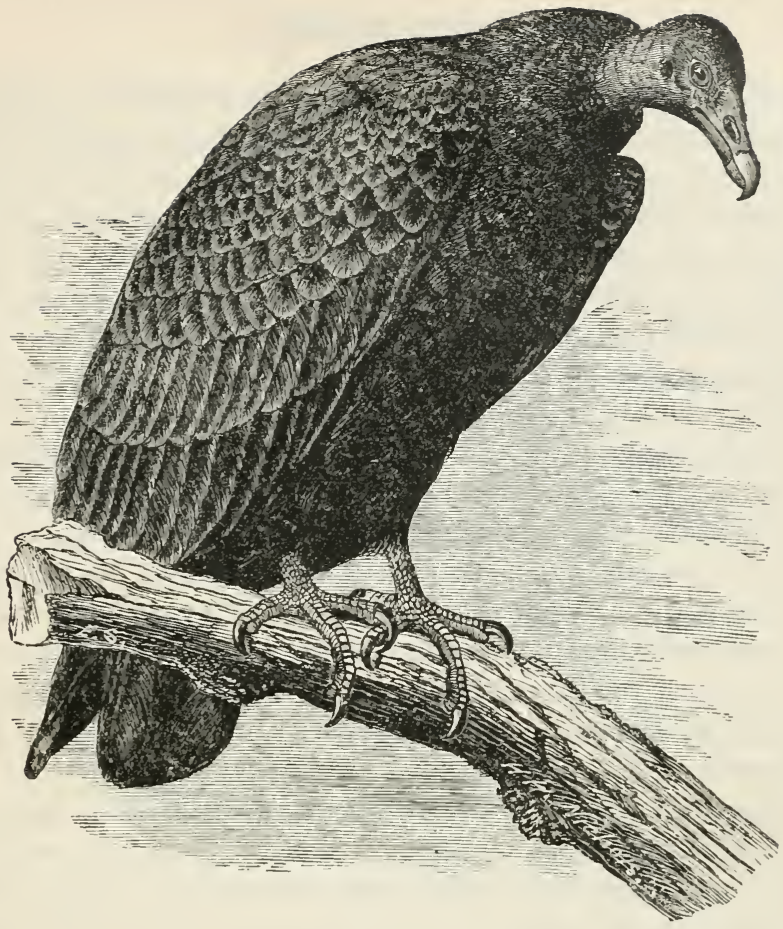

TURKEY VULTURE.

TURKEY BUZZARD.

\section{Cathartes aUR..}

CHAR. Brownish black; head bare of feathers and bright red; bill white; length about 2 feet.

Nest. In a stump, or cavity among rocks, without additional material.

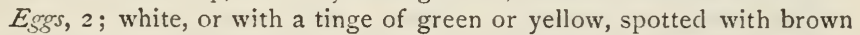
and purple; $2.75 \times 1.90$.

This common Turkey-like Vulture is found abundantly in both North and South America, but seems wholly to avoid the Northeastern or New England States, a straggler being seldom seen as far as the latitude of $4 \mathrm{I}^{\circ}$. Whether this limit arises from some local antipathy, their dislike of the cold eastern storms which prevail in the spring till the time they usually VOL. I. - I 
breed, or some other cause, it is not easily assignable; and the fact is still more remarkable, as they have been observed in the interior by Mr. Say as far as Pembino, in the 49th degree of north latitude, by Lewis and Clarke near the Falls of the Oregon, and they are not uncommon throughout that territory. They are, however, much more abundant in the warmer than in the colder regions, and are found beyond the equator, even as far or farther than the La Plata. All the West India islands are inhabited by them, as well as the tropical continent, where; as in the Southern States of the Union, they are commonly protected for their services as scavengers of carrion, which would prove highly deleterious in those warm and humid climates. In the winter they generally seek out warmth and shelter, hovering often like grim and boding spectres in the suburbs, and on the roofs and chimneys of the houses, around the cities of the Southern States. A few brave the winters of Maryland, Delaware, and New Jersey, but the greater part migrate south at the approach of cold weather.

The Turkey Buzzard has not been known to breed north of New Jersey in any of the Atlantic States. Here they seek out the swampy solitudes, and, without forming any nest, deposit two eggs in the stump of a hollow tree or log, on the mere fragments of rotten wood with which it is ordinarily strewed. Occasionally, in the Southern States, they have been known to make choice of the ruined chimney of a deserted house for this purpose. The eggs are larger than those of a Turkey, of a yellowish white, irregularly blotched with dark brown and blackish spots, chiefly at the larger end. The male often attends while the female is sitting; and if not materially disturbed, they will continue to occupy the same place for several years in succession.

The young are covered with a whitish down, and, in common with the habit of the old birds, will often eject, upon those who happen to molest them, the filthy contents of their stomachs.

In the cities of the South they appear to be somewhat gregarious, and as if aware of the protection afforded them, present themselves often in the streets, and particularly near the 
shambles. They also watch the emptying of the scavengers' carts in the suburbs, where, in company with the still more domestic Black Vultures, they search out their favorite morsels amidst dust, filth, and rubbish of all descriptions. Bits of cheese, of meat, fish, or anything sufficiently fœtid, and easy of digestion, is greedily sought after, and eagerly eyed. When the opportunity offers they eat with gluttonous voracity, and fill themselves in such a manner as to be sometimes incapable of rising from the ground. They are accused at times of attacking young pigs and lambs, beginning their assault by picking out the eyes. Mr. Waterton, however, while at Demerara watched them for hours together amidst reptiles of all descriptions, but they never made any attack upon them. He even killed lizards and frogs and put them in their way, but they did not appear to notice them until they attained the putrid scent. So that a more harmless animal, living at all upon flesh, is not in existence, than the Turkey Vulture.

At night they roost in the neighboring trees, but, I believe, seldom in flocks like the Black kind. In winter they sometimes pass the night in numbers on the roofs of the houses in the suburbs of the Southern cities, and appear particularly desirous of taking advantage of the warmth which they discover to issue from the chimneys. Here, when the sun shines, they and their black relatives, though no wise social, may be observed perched in these conspicuous places basking in the feeble rays, and stretching out their dark wings to admit the warmth directly to their chilled bodies. And when not engaged in acts of necessity, they amuse themselves on fine clear days, even at the coolest season of the year, by soaring, in companies, slowly and majestically into the higher regions of the atmosphere ; rising gently, but rapidly, in vast spiral circles, they sometimes disappear beyond the thinnest clouds. They practise this lofty flight particularly before the commencement of thunder-storms, when, elevated above the war of elements, they float at ease in the ethereal space with outstretched wings, making no other apparent effort than the light balloon, only now and then steadying their sailing pinions as they spread 
them to the fanning breeze, and become abandoned to its accidental sports. In South America, according to Humboldt, they soar even in company with the Condor in his highest flights, rising above the summits of the tropical Andes.

Examples of this species still wander occasionally to New England and to Grand Menan, and in 1887 Mr. Philip Cox reported the capture of two near the mouth of the Miramichi River, on the Gulf of St. Lawrence, in latitude $47^{\circ}$. It occurs regularly on the St. Clair Flats, in Ontario.

The Vultures are not classed as the first of birds by the systematists of the present day. Now the singing-birds - the Oscines ar $\sim$ considered the most highly developed, and of these the Thrush family is given highest rank. The Vultures are classed as the lowest of the birds of prey; and this entire order has been moved down below the Swifts and the Woodpeckers.

\section{BLACK VULTURE.}

\section{CARRION CROW.}

\section{Catharista atrata.}

CHAR. Dull black; head dusky and partially covered above with feathers. Length about 2 feet.

Nest. On the ground screened by bushes, or in a stump. (No attempt is made to build a nest or even to lay a cushion for the eggs.)

Egos. I-3 (usually 2); bluish white, marked with several shades of brown; $3.10 \times 2.05$.

This smaller, black, and truly gregarious species of Vulture in the United States appears to be generally confined to the Southern States, and seems to be most numerous and familiar in the large maritime towns of North and South Carolina, Georgia, and Florida. They are also met with in several of the Western States, and as far up the Ohio as Cincinnati. In the tropical regions of America they are also very common, and extend at least as far as Chili. Like the former species, with which they associate only at meal-times, they are tacitly allowed a public protection for the service they render in ridding the earth of carrion and other kinds of filth. They are 
much more familiar in the towns than the preceding, delighting, during winter, to remain on the roofs of houses, catching the feeble rays of the sun, and stretching out their wings to admit the warm air over their fotid bodies. When the weather becomes unusually chilly, or in the mornings, they may be seen basking upon the chimneys in the warm smoke, which, as well as the soot itself, can add no additional darkness or impurity to such filthy and melancholy spectres. Here, or on the limbs of some of the larger trees, they remain in listless indolence till aroused by the calls of hunger.

Their flight is neither so easy nor so graceful as that of the Turkey Buzzard. They flap their wings and then soar horizontally, renewing the motion of their pinions at short intervals. At times, however, they rise to considerable elevations. In the cities of Charleston and Savannah they are to be seen in numbers walking the streets with all the familiarity of domestic Fowls, examining the channels and accumulations of filth in order to glean up the offal or animal matter of any kind which may happen to be thrown out. They appeared to be very regular in their attendance around the shambles, and some of them become known by sight. This was particularly the case with an old veteran who hopped upon one foot (having by some accident lost the other), and had regularly appeared round the shambles to claim the bounty of the butchers for about twenty years. In the country, where I have surprised them feeding in the woods, they appeared rather shy and timorous, watching my movements alertly like Hawks; and every now and then one or two of them, as they sat in the high boughs of a neighboring oak, communicated to the rest, as I slowly approached, a low bark of alarm, or waugh, something like the suppressed growl of a puppy, at which the whole flock by degrees deserted the dead hog upon which they happened to be feeding. Sometimes they will collect together about one carcase to the number of two hundred and upwards; and the object, whatever it may be, is soon robed in living mourning, scarcely anything being visible but a dense mass of these sable scavengers, who may often be 
seen jealously contending with each other, both in and out of the carcase, defiled with blood and filth, holding on with their feet, hissing and clawing each other, or tearing off morsels so as to fill their throats nearly to choking, and occasionally joined by growling dogs, - the whole presenting one of the most savage and disgusting scenes in nature, and truly worthy the infernal bird of Prometheus.

This species is very rarely seen north of the Carolinas, though a few examples have been taken in New England and at Grand Menan.

\title{
AUDUBON'S CARACARA.
}

\author{
CARACARA EAGLE. KING BUZZARD.
}

\section{POLYBORUS CHERIWAY.}

CHAR. General color brownish black; fore part of back and breast barred with white; tail white, with bars of black. Length $20 \frac{1}{2}$ to 25 inches.

$N^{\top}$ est. On a low tree or bush; made of sticks and leaves.

Eggs. 2-4 (usually 2); brownish white or pale brown, blotched with deeper brown; $2.30 \times 1.75$.

This very remarkable and fine bird was first met with by Mr. Audubon near St. Augustine, in East Florida. He afterwards also found it on Galveston Island, in Texas. From its general habits and graceful, sweeping flight, it was for some time mistaken for a Hawk. Though common in many parts of South America, it is within the limits of the United States merely an accidental visitor. It is said, however, to breed in Florida, in the highest branches of tall trees in the pine-barrens, making a rough nest of sticks like a Hawk. In Texas it breeds, according to Audubon, in the tops of bushes.

Since Nuttall wrote, the Caracara has been found in numbers in parts of Florida, and it is not uncommon in Texas, southern Arizona, and Lower California. 


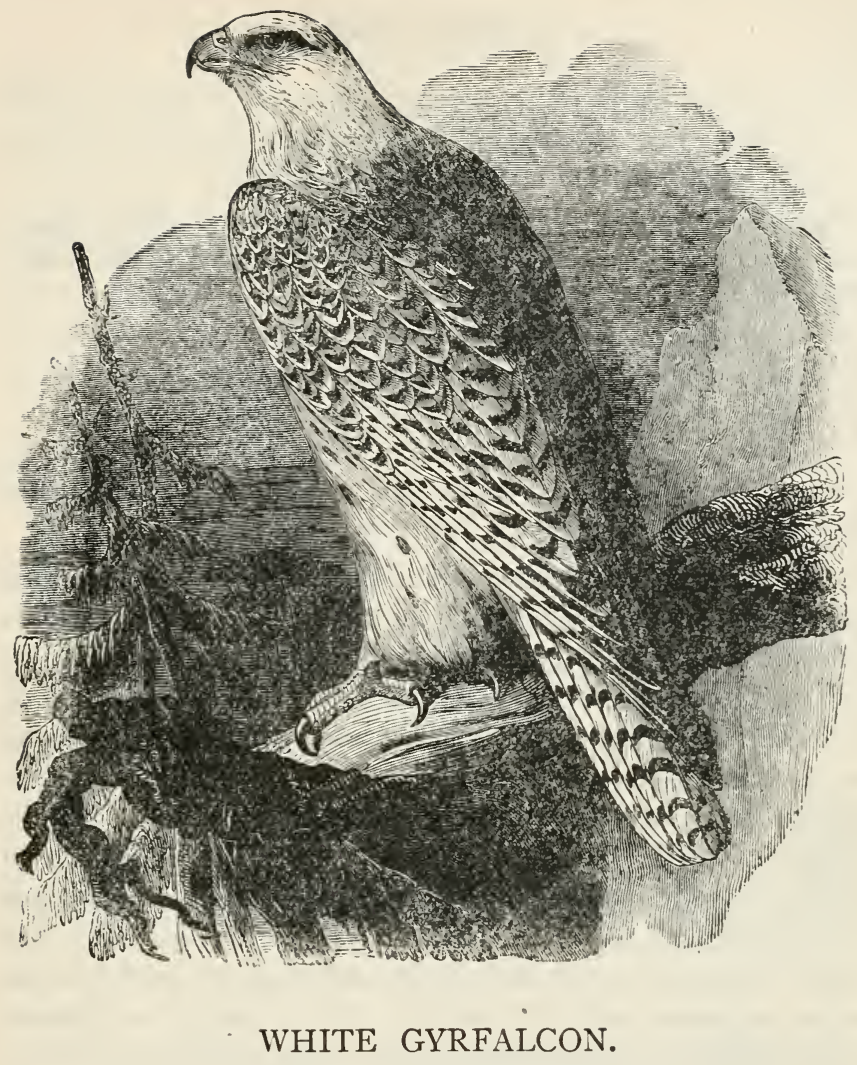

FALCO ISLANDUS.

CHAR. Prevailing color white, often immaculate, but usually with dark markings. Legs partially feathered. A sharp tooth near point of upper mandible; the end of under mandible notched. Length $2 \mathrm{I}$ to 24 inches.

Nest. Usually on a cliff ; roughly made of sticks, - large dry twigs.

Eggs. 3-4; buff or brownish, marked with reddish brown; 2.25 $\times 1.25$.

\section{GRAY GYRFALCON.}

\section{Falco RUSTICOLUS.}

CHAR. Prevailing color dull gray, with whitish and slaty-blue bands and spots; sometimes white prevails; thighs usually barred. 


\section{GYRFALCON. \\ Falco Rusticolus grrfalco.}

CHAR. Upper parts dull brownish (dusky), with bars of bluish gray; lower parts white, or mostly white marked with dusky; thighs heavily barred.

\section{BLACK GYRFALCON.}

\section{Falco Rusticolus obsoletus.}

CHAR. Prevailing color brownish black; usually barred with lighter tints, but sometimes the bars are indistinct.

This elegant and celebrated Falcon is about two feet in length; the female two or three inches longer. They particularly abound in Iceland, and are found also throughout Siberia, and the North of Europe as far as Greenland; Mr. Hutchins, according to Pennant, saw them commonly about Fort Albany, at Hudson's Bay. Occasionally a pair is also seen in this vicinity in the depth of winter. They brave the coldest climates, for which they have such a predilection as seldom to leave the Arctic regions; the younger birds are commonly seen in the North of Germany, but very rarely the old, which are readily distinguished by the superior whiteness of their plumage, which augments with age, and by the increasing narrowness of the transverse stripes that ornament the upper parts of the body. The finest of these Falcons were caught in Iceland by means of baited nets. The bait was commonly a Ptarmigan, Pigeon, or common Fowl; and such was the velocity and power of his pounce that he commonly severed the head from the baited bird as nicely as if it had been done by a razor. These birds were reserved for the kings of Denmark, and from thence they were formerly transported into Germany, and even Turkey and Persia. The taste for the amusement of falconry was once very prevalent throughout Europe, and continued for several centuries; but at this time it has almost wholly subsided. The Tartars, and Asiatics generally, were also equally addicted to this amusement. A Sir 
Thomas Monson, no later than the reign of James the First, is said to have given a thousand pounds for a cast of Hawks.

Next to the Eagle, this bird is the most formidable, active, and intrepid, and was held in the highest esteem for falconry. It boldly attacks the largest of birds; the Swan, Goose, Stork, Heron, and Crane are to it easy victims. In its native regions it lives much on the hare and Ptarmigan; upon these it darts with astonishing velocity, and often seizes its prey by pouncing upon it almost perpendicularly. It breeds in the cold and desert regions where it usually dwells, fixing its nests amidst the most lofty and inaccessible rocks.

Nuttall treated the four forms as one, while I follow the A. O. U. in separating them; though I do not think that the present classification will be retained. The accessible material is very limited, but it appears to indicate that there is but one species with two, or possibly three, geographical races. The nests and eggs 'and the habits are similar, the difference being entirely that of plumage, - the prevalence of the dark or white color.

The White breeds chiefly in North Greenland and along the borders of the Arctic Ocean; the Gray breeds in South Greenland ; the Black is restricted to Labrador; and the habitat of gyrfalco is given as "interior of Arctic America from Hudson's Bay to Alaska." Specimens of all four have been taken south of iatitude $45^{\circ}$, and a few of the Black have been taken, in winter, as far south as southern New England and New York.

Note. - A few examples of the Pratrie Falcon (Falco mexicanus) have accidentally wandered to the prairie districts of Illinois.

\section{DUCK HAWK.}

\section{PEREGRINE FALCON. GREAT-FOOTED HAWK.}

\section{Falco peregrinus anatum.}

CHAR. Above, bluish ash or brownish black, the edges of the feathers paler; below, ashy'or dull tawny, with bars or streaks of brownish; a black patch on the cheeks. Bill of bluish color, and toothed and notched, as in all true Falcons; cere yellow. Wing long, thin, and pointed. Length 17 to 19 inches. 
Nest. On tree or cliff; a loosely arranged platform of dry sticks, sometimes partially lined with grass, leaves, or moss.

Eggs. 2-4; reddish brown - sometimes of bright tint - marked with dull red and rich brown; $2.10 \times 1.60$.

The celebrated, powerful, and princely Falcon is common both to the continent of Europe and America. In the former they are chiefly found in mountainous regions, and make their nests in the most inaccessible clefts of rocks, and very rarely in trees, laying 3 or 4 eggs of a reddish-yellow, with brown spots. In Europe they seldom descend to the plains, and avoid marshy countries. The period of incubation lasts but a short time, and commences in winter, or very early in the spring, so that the young acquire their full growth by the middle of May. They are supposed to breed in the tall trees of the desolate cedar swamps in New Jersey. Audubon, however, found them nesting on shelving rocks on the shores of Labrador and Newfoundland, laying from 2 to 5 eggs of a rusty yellowish brown, spotted and blotched with darker tints of the same color. They also breed on shelving rocks in the Rocky Mountains, where Mr. Townsend obtained a specimen on Big Sandy River of the Colorado of the West in the month of July. When the young have attained their growth, the parents drive them from their haunts, with incessant and piercing screams and complaints, - an unnatural propensity which nothing but dire necessity, the difficulty of acquiring sustenance, can palliate.

In strength and temerity the Falcon is not exceeded by any bird of its size. He soars with easy and graceful motions amidst the clouds or clear azure of the sky; from this lofty elevation he selects his victim from among the larger birds, Grouse, Pheasants, Pigeons, Ducks, or Geese. Without being perceived, he swiftly descends, as if falling from the clouds in a perpendicular line, and carries terror and destruction into the timid ranks of his prey. Instead of flying before their relentless enemy, the Partridge and Pheasant run and closely hide in the grass, the Pigeons glance aside to avoid the fatal blow which is but too sure in its aim, and the Water Fowls seek 
a more certain refuge in diving beneath their yielding element. If the prey be not too large, the Falcon mounts into the air, bearing it off in his talons, and then alights to gorge himself with his booty at leisure. Sometimes he attacks the Kite, another fellow-plunderer, either in wanton insult, or more probably to rob him of his quarry.

The Peregrine is very generally distributed throughout America, but excepting on the Atlantic coast of Labrador, and possibly on Newfoundland, it is nowhere common in this faunal province. It is a winter visitor chiefly in Ohio and southern Ontario, but it is known to breed on isolated cliffs in the Maritime Provinces and the New England States, and it is said that nests have been found in Pennsylvania and Maryland. The report of its building in a swamp in New Jersey has not been confirmed.

\section{PIGEON HAWK.}

\section{Falco columbarius.}

CHAR. Generally the prevailing color, above, is blackish brown, though the older birds assume a dull tint approaching bluish gray; wings, back, and tail streaked and barred with buffy or reddish brown. Tail tipped with white ; the middle tail-feathers in male with four bands of blackish, and in female about six pale bands. Below, dull, pale reddish brown, lighter on breast and throat. Length I I to I 3 inches.

Nest. Usually on branches of trees, though found sometimes in cavities of dead trees and on cliffs; loosely built of twigs, and lined with grass and leaves.

Eggs. 3-6; buffy or pale reddish-brown ground color, blotched with dull red and brown; I. $30 \times \mathbf{1} .55$.

This species is a little larger than the following, bu: by no means so abundant; though met with in latitude forty-eight degrees by Long's Northwestern Expedition, and occasionally extending its migrations from Texas to Hudson's Bay, and rearing its young in the interior of Canada. Its nest was also observed by Audubon in Labrador in the low fir-trees, and contained five eggs, laid about the ist of June. It is shy, skulking, and watchful, seldom venturing beyond the unreclaimed forest, and flies rapidly, but, I believe, seldom soars or hovers. 
Small birds and mice constitute its principal food; and according to Wilson, it follows often in the rear of the gregarious birds, such as the Blackbirds and Reedbirds, as well as after the flitting flocks of Pigeons and Robins, picking up the stragglers, the weak and unguarded, as its legitimate prey. Sometimes, when shot at without effect, it will fly in circles around the gunner and utter impatient shrieks, - probably in apprehension for the safety of the mate, or to communicate a cry of alarm.

The Pigeon Hawk is a common migrant through New England, Ohio, and southern Ontario. It is always late in migrating, and a few examples have been seen in Massachusetts in midwinter. It breeds sparingly in the northern portions of New England, and the Maritime Provinces of Canada. Its breeding area extends north to the lower fur countries, and in winter it ranges to the Southern States and South America.

Note. - One example of the European MERLIN (Falco regulus) has been captured off the coast of Greenland. 


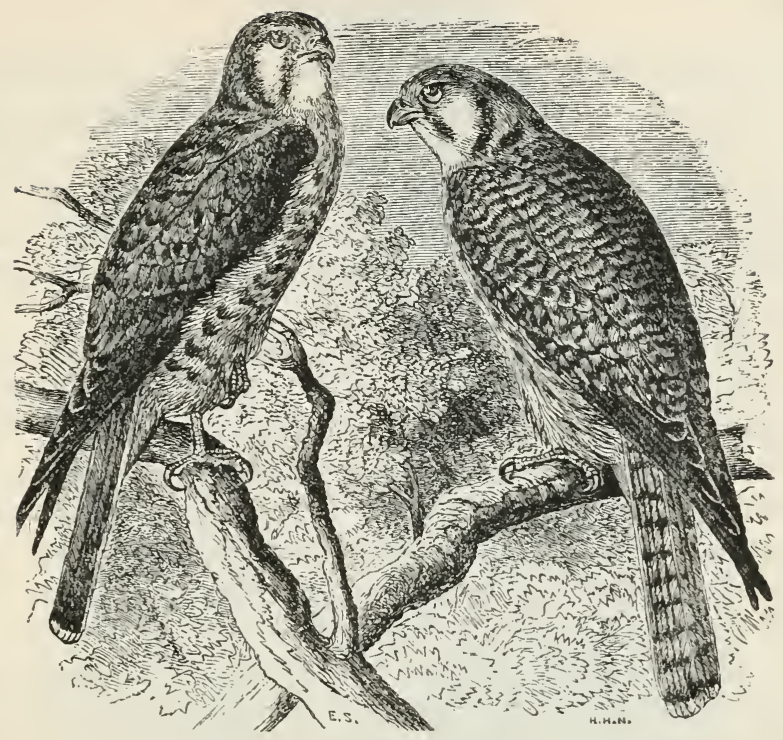

\section{AMERICAN SPARROW HAWK.}

\section{FALCO SPARVERIUS.}

CHAR. Adult male : head bluish ash, with reddish patch on crown, and black patch on sides and nape; back rufous; wings bluish and black in bars; tail tawny, with black band, and tipped with white; below, buffish or tawny. Female: rufous barred with black; underparts buffy streaked with tawny; tail tawny, with blackish lars. Length ro inches.

Nest. Usually in cavities of trees, often in Woodpecker's holes, sometimes in deserted nest of a Crow.

Eggs. 5-7; buffish, occasionally white, blotched with dull red and brown; 1.33 X I.12.

This beautiful and singularly marked bird appears to reside principally in the warmer parts of the United States. They are particularly abundant in the winter throughout South Carolina, Georgia, Alabama, and Florida, whither they assemble from the remote interior of the Northern States, wandering in summer as far as the Rocky Mountains, and were even seen by Dr. Richardson in the remote latitude of $53^{\circ}$; these appear, however, to be only stragglers, nor do they seem at all to visit 
the maritime districts of New England. As they were seen in St. Domingo, by Veillot, abundantly in April and May, the breeding-season, we may naturally conclude that this species has a much greater predilection for the warm than the cold climates. On the south side of the equator, even in Cayenne and Paraguay, they are still found, in all of which countries they probably breed.

According to the habits of this tribe of rapacious birds it appears that the nest is built in a hollow, shattered, or decayed tree at a considerable elevation.

Its motions appear somewhat capricious; it occasionally hovers with beating wings, reconnoitring for prey, and soon impatiently darts off to a distance to renew the same manœuvre. In the winter, however, it is most commonly seen perched on some dead branch, or on a pole or stalk in the fields, often at a little distance from the ground, keeping up a frequent jerking of the tail, and attentively watching for some such humble game as mice, grasshoppers, or lizards. At this time it is likewise so familiar as to enter the garden, orchard, or premises near to the house, and shows but little alarm on being approached. It is, however, by no means deficient in courage, and, like the larger Falcons, often makes a fatal and rapid sweep upon Sparrows or those small birds which are its accustomed prey.

Instead of being a mere straggler outside the warmer portions of the United States, as Nuttall appears to have considered this Falcon, it is quite common throughout most of the continent, and not only breeds in New England, but occasionally winters there. It breeds also throughout Canada, north to the lower fur countries, and during the cold weather ranges from New Jersey to the Southern States.

Note. - The Cuban Sparrow Hawk (Falco dominicensis) has been found in Florida; and two examples of the Kestrel (Falco tinnunculus) have been captured on this side of the Atlantic, - one off the coast of Greenland, and the other at Nantasket, Mass., in 1887. 


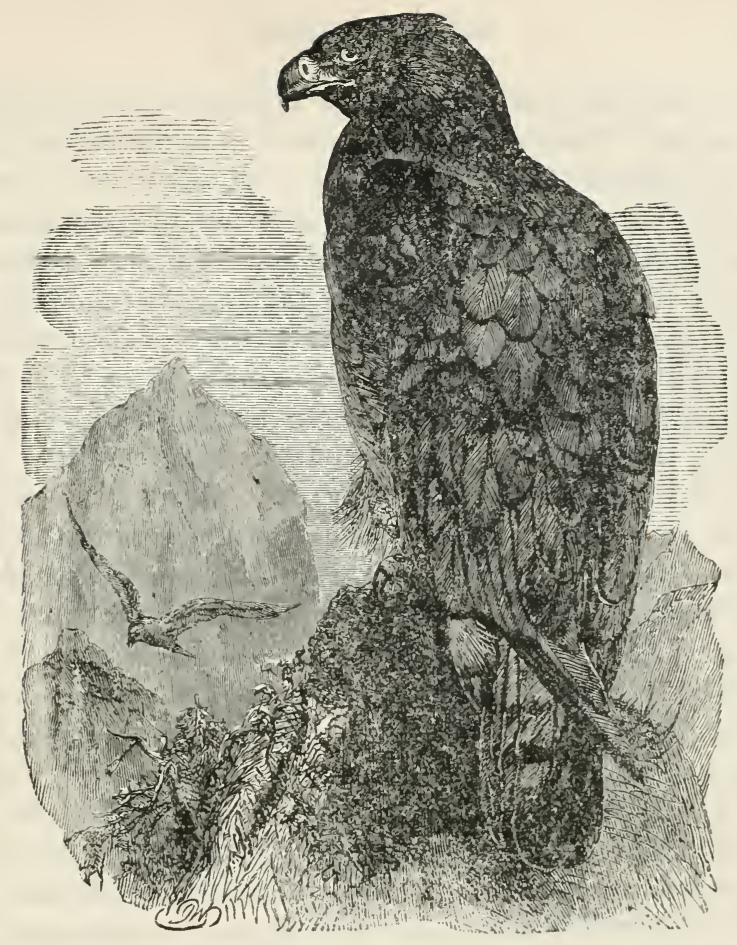

GOLDEN EAGLE.

Aquila CHRYsä̈tos.

CHAR. Dark brown, head and neck tawny brown; legs feathered to the toes; in the young, tail whitish, with broad terminal band of black.

Nest. On a tree, sometimes on a high cliff; loosely built of dry sticks, lined with twigs, grass, moss, leaves, and feathers.

Eggs. 2-3 (usually 2); dull white or pale buff, spotted and blotched more or less thickly with reddish brown and lavender; $3.00 \times 2.30$.

This ancient monarch of the birds is found in all the cold and temperate regions of the northern hemisphere, taking up his abode by choice in the great forests and plains, and in wild, desert, and mountainous regions. His eyry, commonly formed of an extensive set of layers of large sticks, is iıearly horizontal, and occasionally extended between some rock and adjoining 
tree, as was the one described by Willughby in the Peak of Derbyshire. About thirty miles inland from the Mandan Fort on the Missouri I once had occasion to observe the eyry of this noble bird, which here consisted of but a slender lining of sticks conveyed into a rocky chasm on the face of a lofty hill rising out of the grassy, open plain. It contained one young bird, nearly fledged, and almost of the color of the Gyrfalcon. Near their rocky nests they are seen usually in pairs, at times majestically soaring to a vast height and gazing on the sun, towards which they ascend until they disappear from view. From this sublime elevation they often select their devoted prey, - sometimes a kid or a lamb from the sporting flock, or the timid rabbit or hare crouched in the furrow or sheltered in some bush. The largest birds are also frequently their victims; and in extreme want they will not refuse to join with the alarmed Vulture in his cadaverous repast. After this gorging meal the Eagle can, if necessary, fast for several days. The precarious nature of his subsistence and the violence by which it is constantly obtained seem to produce a moral effect on the disposition of this rapacious bird : though in pairs, they are never seen associated with their young; their offspring are driven forth to lead the same unsocial, wandering life as their unfeeling progenitors. This harsh and tyrannical disposition is strongly displayed even when they lead a life of restraint and confinement. The weaker bird is never willingly suffered to eat a single morsel; and though he may cower and quail under the blow with the most abject submission, the same savage deportment continues towards him as long as he exists. Those which I have seen in confinement frequently uttered hoarse and stridulous cries, sometimes almost barkings, accompanied by vaporous breathings, strongly expressive of their ardent, unquenchable, and savage appetites. Their fire-darting eyes, lowering brows, flat foreheads, restless disposition, and terrific plaints, together with their powerful natural weapons, seem to assimilate them to the tiger rather than the timorous bird. Yet it would appear that they may be rendered docile, as the Tartars (according to Marco Polo in I269) were said to train 
this species to the chase of hares, foxes, wolves, antelopes, and other kinds of large game, in which it displayed all the docility of the Falcon. The longevity of the Eagle is as remarkable as its strength; it is believed to subsist for a century, and is about three years in gaining its complete growth and fixed plumage. This bird was held in high estimation by the ancients on account of its extraordinary magnitude, courage, and sanguinary habits. The Romans chose it as an emblem for their imperial standard; and from its aspiring flight and majestic soaring it was fabled to hold communication with heaven and to be the favorite messenger of Jove. The Tartars have a particular esteem for the feathers of the tail, with which they superstitiously think to plume invincible arrows. It is no less the venerated War-Eagle of our Northern and Western aborigines; and the caudal feathers are extremely valued for talismanic head-dresses and as sacred decorations for the Pipe of Peace.

The Eagle appears to be more abundant around Hudson's Bay than in the United States; but they are not unfrequent in the great plains of the Mississippi and Missouri, as appears from the frequent use of the feathers by the natives. The wilderness seems their favorite resort, and they neither crave nor obtain any advantage from the society of man. Attached to the mountains in which they are bred, it is a rare occurrence to see the Eagle in this vicinity; and, as with some other birds, it would appear that the young only are found in the United States, while the old remain in Labrador and the northern regions. The lofty mountains of New Hampshire afford suitable situations for the eyry of the Eagle, over whose snow-clad summits he is seen majestically soaring in solitude and grandeur. A young bird from this region, which $I$ have seen in a state of domestication, showed considerable docility. He had, however, been brought up from the nest, in which he was found in the month of August; he appeared even playful, turning his head about in a very antic manner, as if desirous to attract attention, - still, his glance was quick and fiery. When birds were given to him, he plumed them very clean before he began his meal, and picked the subject to a perfect skeleton.

VOL. I. -2 
The ferocious and savage nature of the Eagle, in an unreclaimed state, is sometimes displayed in a remarkable manner. A peasant attempted to rob an eyry of this bird situated at the Lake of Killarney: for this purpose he stripped and swam over to the spot in the absence of the old birds; but on his return, while yet up to the chin in water, the parents arrived, and missing their young, instantly fell on the unfortunate plunderer and killed him on the spot.

There are several well-authenticated instances of their carrying off children to their nests. In 1737 , in the parish of Norderhougs, in Norway, a boy over two years old, on his way from the cottage to his parents, at work in the fields at no great distance, fell into the pounce of an Eagle, who flew off with the child in their sight, and was seen no more. Anderson, in his history of Iceland, says that in that island children of four or five years of age have occasionally been borne away by Eagles; and Ray relates that in one of the Orkneys a child of a year old was seized in the talons of this ferocious bird and carried about four miles to its nest, but the mother, knowing the place of the eyry, followed the bird, and recovered her child yet unhurt.

The Common, or Ring-tailed Eagle, is now found to be the young of the Golden Eagle. These progressive changes have been observed by Temminck on two living subjects which he kept for several years.

The Golden Eagle is generally considered to be a rare bird in New England and Canada, and, indeed, throughout the settled districts everywhere; though examples have been taken the continent over, from Greenland to Mexico, and west to the Pacific. 


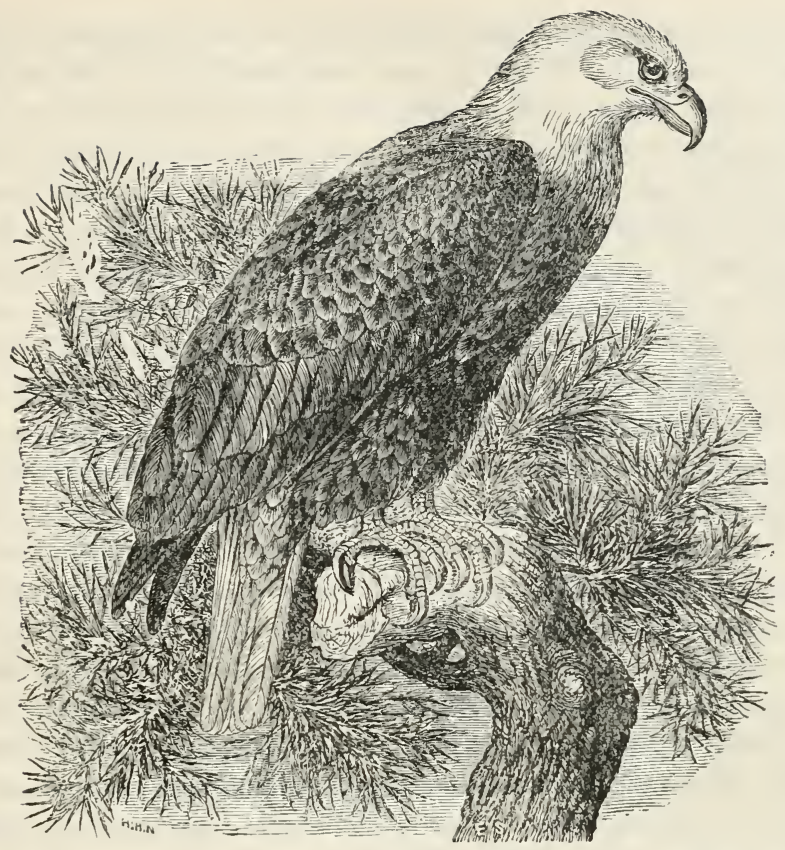

BALD EAGLE.

\section{WASHINGTON EAGLE.}

\section{Haliketus leucocephalus.}

CHAR. Adult : blackish brown, paler on margin of feathers; head and tail white after third year; bill and feet yellow; legs bare of feathers. Young: darker than the adult; no white on head or tail (or concealed by contour feathers); bill and feet brownish.

Length 30 to 40 inches. (The young are larger than the adult birds, and are very similar to the young of the Golden Eagle, though the latter are easily distinguished by their feathered legs.)

Nest. On a high tree, usually in a crotch, seldom on a dead tree, sometimes on a cliff; made of dry sticks loosely arranged, and occasionally weed-stems and coarse grass are added; but there is rarely any attempt at a lining.

Eggs. 2-3; white or pale buff ; $2.90 \times 2.25$. 
The Washington Eagle. - It is to the indefatigable Audubon that we owe the distinct note and description of this noble Eagle, which first drew his attention while voyaging far up the Mississippi, in the month of February, 18 r 4 . At length he had the satisfaction of discovering its eyry, in the high cliffs of Green River, in Kentucky, near to its junction with the Ohio: two young were discovered loudly hissing from a fissure in the rocks, on the approach of the male, from whom they received a fish. The female now also came, and with solicitous alarm for the safety of her young, gave a loud scream, dropped the food she had brought, and hovering over the molesting party, kept up a growling and threatening cry by way of intimidation; and in fact, as our disappointed naturalist soon discovered, she from this time forsook the spot, and found means to convey away her young. The discoverer considers the species as rare, - indeed, its principal residence appears to be in the northern parts of the continent, particularly the rocky solitudes around the Great Northwestern Lakes, where it can at all times collect its finny prey and rear its young without the dread of man. In the winter season, about January and February, as well as at a later period of the spring, these birds are occasionally seen in this vicinity (Cambridge, Mass.),-rendered perhaps bolder and more familiar by want, as the prevalence of the ice and cold at this season drives them to the necessity of wandering farther than usual in search of food. At this early period Audubon observed indications of the approach of the breeding-season. They are sometimes seen contending in the air, so that one of the antagonists will suddenly drop many feet downwards, as if wounded or alarmed. My friend Dr. Hayward, of Boston, had in his possession one of these fine, docile Eagles for a considerable time; but desirous of devoting it to the then Linnæan Museum, he attempted to poison it by corrosive sublimate of mercury: several times, however, doses even of two drams were given to it, concealed in fish, without producing any injurious effect on its health.

The Washington Eagle, bold and vigorous, disdains the piratical habits of the Bald Eagle, and invariably obtains his 
own sustenance without molesting the Osprey. 'The circles he describes in his flight are wider than those of the Whiteheaded Eagle; he also flies nearer to the land or the surface of the water; and when about to dive for his prey, he descends in circuitous, spiral rounds, as if to check the retreat of the fish, on which he darts only when within the distance of a few yards. When his prey is obtained, he flies out at a low elevation to a considerable distance to enjoy his repast at leisure. The quantity of food consumed by this enormous bird is very great, according to the account of those who have had them in confinement. Mr. Audubon's male bird weighed fourteen and one half pounds avoirdupois. One in a small museum in Philadelphia (according to the account of my friend Mr. C. Pickering), also a male, weighed much more, - by which difference it would appear that they are capable of becoming exceedingly fat; for the length of this bird was about the same as that of Audubon, - three feet six or seven inches. The width, however, was only about seven feet, - agreeing pretty nearly with a specimen now in the New England Museum. The male of the Golden Eagle, the largest hitherto known, is seldom more than three feet long.

That this bird is not the White-tailed Eagle (Falco albicilla), or its young, the Sea Eagle ( $F$. ossifragus), is obvious from the difference in size alone, the male of that bird being little over two feet four inches in length, or a little less even than the Bald Eagle. The female of the Washington Eagle must, of course, be six or eight inches longer, which will give a bird of unparalleled magnitude amongst the whole Eagle race. This measurement of the Sea Eagle is obtained from Temminck's "Manual of Ornithology," who has examined more than fifty individuals. At the same time I have a suspicion that the Washington Eagle, notwithstanding this, exists also in Europe; as the great Sea Eagle of Brisson is described by this author as being three feet six inches in length from the point of the bill to the end of the tail, and the stretch of the wings about seven feet! These measurements also are adopted by Buffon; but the individuals were evidently in young 
plumage, in which state, as described by Brisson, they again approach the present species. Nor need it be considered as surprising if two different species be confounded in the Sea Eagle of Europe, as the recently established Imperial Eagle had ever been confounded with the Golden. Another distinguishing trait of the Washington Eagle is in the length of the tail, which is one and one half inches longer than the folded wings. In the White-tailed species this part never extends beyond the wings.

The White-headed or Bald Eagle. - This noble and daring Eagle is found along the sea-coasts, lakes, and rivers throughout the northern regions, being met with in Asia, Europe, and America, where they extend to the shores of the Pacific, and as far as the confines of California. In Behring's Isle, Mackenzie's River, and Greenland, they are not uncommon. But while they are confined in the Old World to this cheerless region so constantly that only two instances are known of their appearance in the centre of Europe, in the United States they are most abundant in the milder latitudes, residing, breeding, and rearing their young in all the intermediate space from Nova Scotia or Labrador to the shores of the Gulf of Mexico. The rocky coast of this part of New England (Massachusetts) is, however, seldom tenanted by this species, though they are occasionally seen in the spring and about the commencement of winter. In the United States it is certain that they show a decided predilection for the milder climates. It is probable that in Europe they are deterred in their migrations by the tyrannical persecution of the White-tailed Eagle ( $F$. albicilla), which abounds in that country, living also principally on fish, and therefore selecting the same maritime situations as our Eagle. In the United States he sways almost without control the whole coast of the Atlantic, and has rendered the rival Osprey his humble tributary, proscribing, in his turn, the appearance of the Sea Eagle, which, if it exist at all with us, is equally as rare as the present species appears to be in Europe. Though on Behring's Isle the Bald Eagle is said to nest on 
cliffs, as the only secure situation that probably offers, in the United States he usually selects, near the sea-coast, some lofty pine or cypress tree for his eyry; this is built of large sticks, several feet in length, forming a floor, within and over which are laid sods of earth, hay, moss, dry reeds, sedge-grass, pinetops, and other coarse materials, piled after several incubations to the height of 5 or 6 . feet, and 4 or 5 feet in breadth. On this almost level bed the female early in February deposits two dull white eggs, one of which is said sometimes to be laid after an interval so considerable that the young are hatched at different periods. Lawson, however, says that they breed so often as to commence laying again under their callow young, whose warmth assists the hatching of the eggs. This eyry or breeding-place continues to be perpetually occupied and repaired as long as the tree endures, - indeed their attachment to particular places is so strong that after their habitation has been demolished, by the destruction of the tree that supported it, they have very contentedly taken possession of an adjoining one. Nor is the period of incubation the only time spent in the nest by this species; it is a shelter and common habitation at all times and seasons, being a home like the hut to the savage, or the cottage to the peasant.

The helpless young, as might be supposed, are fed with great attention, and supplied with such a superfluity of fish and other matters that they often lie scattered around the tree, producing the most putrid and noisome effluvia. The young are at first clothed with a whitish down; they gradually become gray, and continue of a brownish gray until the third year, when the characteristic white of the head and tail becomes perfectly developed. As their food is abundant, the young are not forcibly driven from the nest, but fed for some time after they have left it. They are by no means shy or timorous, will often permit a near approach, and sometimes even bristle up their feathers in an attitude of daring defence. Their cry is sonorous and lamentable, like that of the Great Eagle, and when asleep they are said to make a very audible snoring sound. 
The principal food of the Bald Eagle is fish; and though he possesses every requisite of alertness and keenness of vision for securing his prey, it is seldom that he obtains it by any other means than stratagem and rapine. For this habitual daring purpose he is often seen perching upon the naked limb of some lofty tree which commands an extensive view of the ocean. In this attitude of expectation he heedlessly surveys the active employment of the feathered throng, which course along the wavy strand, or explore the watery deep with beating wing, until from afar he attentively scans the motions of his provider, the ample-winged and hovering Osprey. At length the watery prey is espied, and the feathered fisher descends like a falling rock; cleaving the wave, he now bears his struggling victim from the deep, and mounting in the air, utters an exulting scream. At this signal the Eagle pirate gives chase to the fortunate fisher, and soaring above him, by threatening attitudes obliges him to relinquish his prey; the Eagle, now poising for a surer aim, descends like an arrow, and snatching his booty before it arrives at the water, retires to the woods to consume it at leisure. These perpetual depredations on the industrious Osprey sometimes arouse him to seek for vengeance, and several occasionally unite to banish their tyrannical invader. When greatly pressed by hunger, the Bald Eagle has sometimes been observed to attack the Vulture in the air, obliging him to disgorge the carrion in his craw, which he snatches up before it reaches the ground. $\mathrm{He}$ is sometimes seen also to drive away the Vultures, and feed voraciously on their carrion. Besides fish, he preys upon Ducks, Geese, Gulls, and other sea-fowl ; and when the resources of the ocean diminish, or fail from any cause, particularly on the southern migration of the Osprey, his inland depredations are soon notorious, young lambs, pigs, fawns, and even deer often becoming his prey. So indiscriminate indeed is the fierce appetite of this bold bird that instances are credibly related of their carrying away infants. An attempt of this kind, according to Wilson, was made upon a child lying by its mother as she was weeding a garden at Great Egg. 
Harbor, in New Jersey; but the garment seized upon by the Eagle giving way at the instant of the attempt, the life of the child was spared. I have heard of another instance, said to have happened at Petersburgh, in Georgia, near the Savannah River, where an infant, sleeping in the shade near the house, was seized and carried to the eyry near the edge of a swamp five miles distant, and when found, almost immediately, the child was dead. The story of the Eagle and child, in "The History of the House of Stanley," the origin of the crest of that family, shows the credibility of the exploit, as supposed to have been effected by the White-tailed Eagle, so nearly related to the present. Indeed, about the year I 745 some Scotch reapers, accompanied by the wife of one of them with an infant, repaired to an island in Loch Lomond; the mother laid down her child in the shade at no great distance from her, and while she was busily engaged in labor, an Eagle of this kind suddenly darted upon the infant and immediately bore it away to its rocky eyry on the summit of Ben Lomond. The alarm of this shocking event was soon spread; and a considerable party, hurrying to the rescue, fortunately succeeded in recovering the child alive.

The Bald Eagle, like most of the large species, takes wide circuits in its flight, and soars at great heights. In these sublime attitudes he may often be seen hovering over waterfalls and lofty cataracts, particularly that of the famous Niagara, where he watches for the fate of those unfortunate fish and other animals that are destroyed in the descent of the tumultuous waters.

All ornithologists of the present day agree in the opinion that Audubon's "Bird of Washington" was an immature Bald Eagle, - the difference in size and coloration accounting for the error.

Nuttall, following Audubon, wrote of the two phases as of distinct species; for it was not until about 1870 that washingtoni was dropped from the lists. I have given the two biographies as they appeared in the original work, for together they form a good history of the bird's distinctive habits. The difference in habits noted is not due to difference of age, as might be supposed, but to the different conditions under which the birds chanced to be observed. 
I will take this opportunity of protesting against the perpetuation of an idea, still current, which originated with the older writers, concerning the "nobility" of the Falconida, under which family name are grouped the Eagles, Falcons, Kites, and Hawks. They were until quite recently classed among the first of the feathered race; but the systematists now place them below the Woodpeckers, and next above the Grouse and Pigeons.

The majority of the Falconidce have an attractive physique and superior strength, as well as a haughty bearing. They are handsome, stalwart ruffians, but they are nothing more. They are neither the most intelligent nor most enterprising of birds, nor the bravest. They are not even the swiftest, or most dexterous on the wing; and in bearing, proudly as they carry themselves, are not supreme.

It is now considered probable that the tales of Eagles carrying off children are myths.

\section{GRAY SEA EAGLE.}

\section{WHITE-TAILED EAGLE.}

\section{Halieetus albicilla.}

CHAR. General color, grayish-brown (paler on margin of feathers); head and neck gray, - paler in old birds; tail white; legs bare.

Length : male, 33 inches; female, $3^{8}$ inches.

Nest. In a tree or on a rock, sometimes on the ground; made of dry sticks loosely arranged and often piled to considerable height.

Eggs. I-3 (usually 2); dull white; $2.85 \times 2.25$.

Mr. Hagerup reports that this European bird breeds in southern Greenland and is quite common there. It feeds principally on fish, but will eat any kind of meat or carrion, being particularly partial to water fowl, and is much more enterprising than is its congener, the Bald Eagle. 


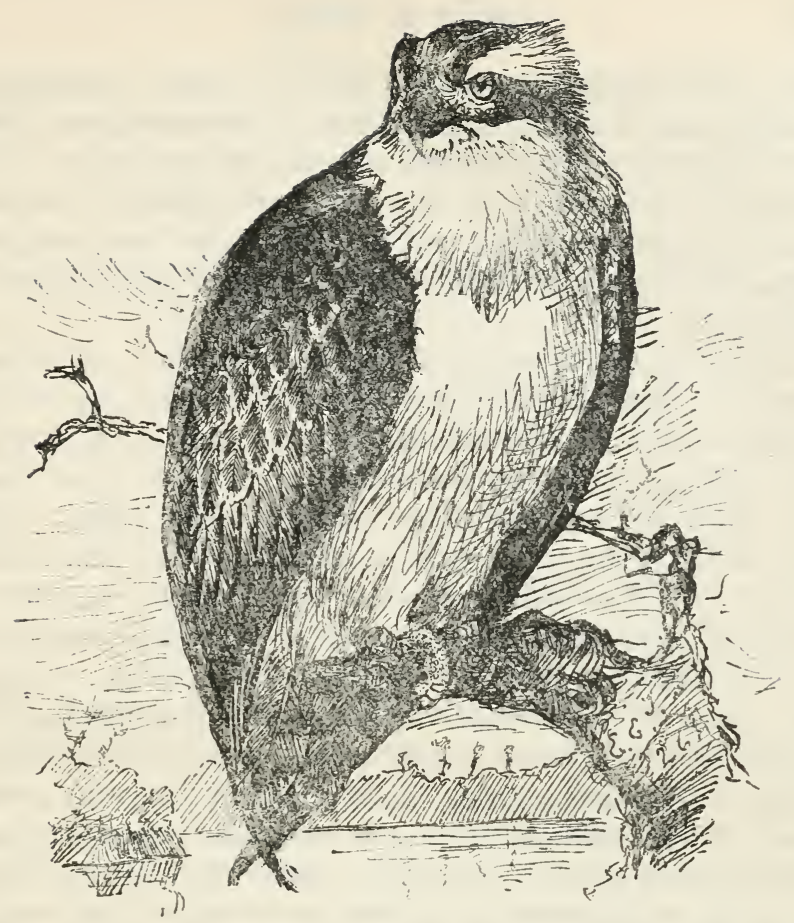

\section{AMERICAN OSPREY.}

\section{FISH HAWK.}

\section{PANDION HALIAËTUS CAROLINENSIS.}

Char. Above, dark brown; head and neck white, with dark stripe on side of the head; tail grayish, with several narrow dark bars, and tipped with white; under-parts white or buffish, sometimes (in female) streaked with brown. Feet and claws large and strong. Hook of the bill long. Length 21 to 25 inches.

Nest. Of loosely arranged sticks on top of high tree, - generally a dead tree is selected; usually near water.

Eggs. 2 to 4 ; variable in shape, color, size, and markings; ground color generally whitish, with yellow or red tint, blotched with reddish brown of various shades. Size about $2.50 \times 1.75$.

This large and well-known species, allied to the Eagles, is found near fresh and salt water in almost every country in the 
world. In summer it wanders into the Arctic regions of Europe, Asia, and America; it is also equally prevalent in the milder parts of both continents, as in Greece and Egypt. In America it is found in the summer from Labrador, and the interior around Hudso:s's Bay, to Florida; and according to Buffon, it extends its residence to the tropical regions of Cayenne.

Its food being almost uniformly fish, it readily acquires subsistence as long as the waters remain unfrozen; but at the commencement of cool weather, even as early as the close of September, or at farthest the middle of October, these birds leave New York and New Jersey and go farther south. This early period of departure is, in all probability, like their arrival towards the close of March, wholly regulated by the coming and going of the shoals of fish on which they are accustomed to feed. Towards the close of March or beginning of April they arrive in the vicinity of Boston with the first shoal of alewives or herrings; but yet are seldom known to breed along the coast of Massachusetts. Their arrival in the spring is welcomed by the fisherman as the sure indication of the approach of those shoals of shad, herring, and other kinds of fish which now begin to throng the bays, inlets, and rivers near the ocean; and the abundance with which the waters teem affords ample sustenance for both the aërial and terrestrial fishers, as each pursues in peace his favorite and necessary employment. In short, the harmless industry of the Osprey, the familiarity with which he rears his young around the farm, his unexpected neutrality towards all the domestic animals near him, his sublimely picturesque flight and remarkable employment, with the strong affection displayed towards his constant mate and long helpless young, and the wrongs he hourly suffers from the pirate Eagle, are circumstances sufficiently calculated, without the aid of ready superstition, to ensure the public favor and tolerance towards this welcome visitor. Driven to no harsh necessities, like his superiors the Eagles, he leads a comparatively harmless life; and though unjustly doomed to servitude, his address and industry raise him greatly above his oppressor, so that he supplies himself and his young with a plentiful 
sustenance. His docility and adroitness in catching fish have also sometimes been employed by man for his advantage.

Intent on exploring the sea for his food, he leaves the nest and proceeds directly to the scene of action, sailing round in easy and wide circles, and turning at times as on a pivot, apparently without exertion, while his long and curving wings seem scarcely in motion. At the height of from one hundred to two hundred feet he continues to survey the bosom of the deep. Suddenly he checks his course and hovers in the air with beating pinions; he then descends with rapidity, but the wily victim has escaped. Now he courses near the surface, and by a dodging descent, scarcely wetting his feet, he seizes a fish, which he sometimes drops, or yields to the greedy Eagle; but, not discouraged, he again ascends in spiral sweeps to regain the higher regions of the air and renew his survey of the watery expanse. His prey again espied, he descends perpendicularly like a falling plummet, plunging into the sea with a loud, rushing noise and with an unerring aim. In an instant he emerges with the struggling prey in his talons, shakes off the water from his feathers, and now directs his laborious course to land, beating in the wind with all the skill of a practised seaman. The fish which he thus carries may be sometimes from six to eight pounds; and so firm sometimes is the penetrating grasp of his talons that when by mistake he engages with one which is too large, he is dragged beneath the waves, and at length both fish and bird perish.

From the nature of its food, the flesh, and even the eggs, are rendered exceedingly rank and nauseous. Though its prey is generally taken in the bold and spirited manner described, an Osprey sometimes sits on a tree over a pond for an hour at a time, quietly waiting its expected approach.

Unlike other rapacious birds, these may be almost considered gregarious, breeding so near each other that, according to Mr. Gardiner, there were on the small island on which he resided, near to the eastern extremity of Long Island (New York), no less than three hundred nests with young. Wilson observed twenty of their nests within half a mile. I have seen them nearly as thick about Rehoboth Bay in Dela- 
ware. Here they live together at least as peaceably as rooks; and so harmless are they considered by other birds that, according to Wilson, the Crow Blackbirds, or Grakles, are sometimes allowed refuge by the Ospreys, and construct their nests in the very interstices of their eyry. It would appear sometimes that, as with Swallows, a general assistance is given in the constructing of a new nest; for previous to this event, a flock have been seen to assemble in the same tree, squealing as is their custom when anything materially agitates them. At times they are also seen engaged in social gambols high in the air, making loud vociferations, suddenly darting down, and then sailing in circles; and these innocent recreations, like many other unmeaning things, are construed into prognostications of stormy or changing weather. Their common friendly call is a kind of shrill whistle, 'phew, 'phew, 'phew, repeated five or six times, and somewhat similar to the tone of a fife. Though social, they are sometimes seen to combat in the air, instigated probably more by jealousy than a love of rapine, as their food is always obtained from an unfailing source.

Early in May the Osprey commences laying, and has from two to four eggs. They are a little larger than those of the Common Fowl, and are from a reddish or yellowish cream-color to nearly white, marked with large blotches and points of reddish brown. During the period of incubation the male frequently supplies his mate with food, and she leaves her eggs for very short intervals.

The young appear about the last of June, and are most assiduously attended and supplied. On the approach of any person towards the nest, the parent utters a peculiar plaintive, whistling note, which increases as it takes to wing, sailing round, and at times making a quick descent, as if aiming at the intruder, but sweeping past at a short distance. On the nest being invaded, either while containing eggs or young, the male displays great courage and makes a violent and dangerous opposition. The young remain a long time in the nest, so that the old are sometimes obliged to thrust them out and encourage them to fly; but they still, for a period, continue to feed them in the air. 


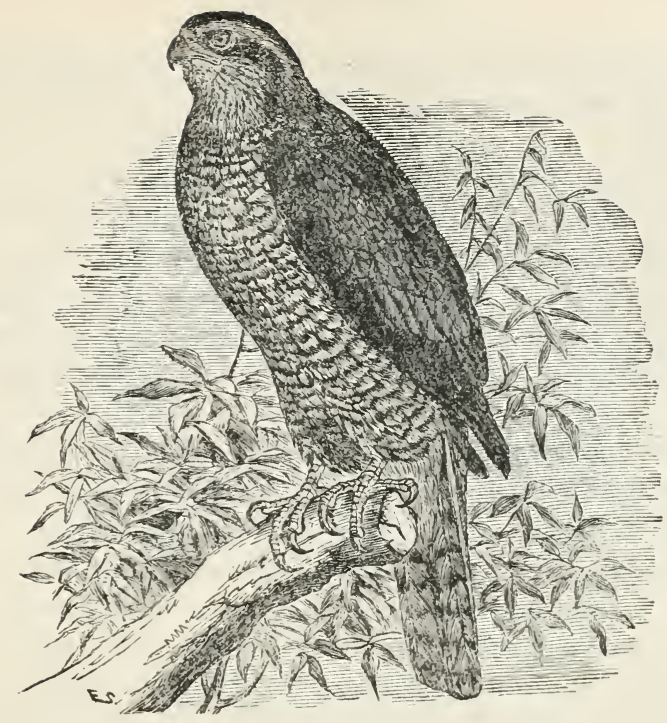

AMERICAN GOSHAWK.

BLUE HEN HAWK.

ACCIPITER ATRICAPILLUS.

ChAR. Above, dark bluish gray; top of head black, the feathers beneath the surface white; white stripe over the eye; tail with four dark bands; below, white barred and streaked with narrow dark lines. Young very different ; above, brown, edges of feathers buffish ; tail lighter, tipped with white and crossed by four or five dark bands; below, buffish, streaked with brown. Length 22 to 24 inches.

Nest. In a tree; made of twigs.

Eggs. 3-4; bluish white, with buff or reddish brown markings; 2.30 $\times 1.75$.

The foreign representative of this elegant and spirited species of Hawk appears to be common in France, Germany, the northern parts of Great Britain, Russia, and Siberia, and extends into Chinese Tartary. Our species, so nearly related to the European bird, is very rare, migrating to the South apparently at the approach of winter. On the 26 th of October, I 830 , I received one of these birds from the proprietor of 
Fresh Pond Hotel, in the moult, having the stomach crammed with moles and mice, and it was shot in the act of devouring a Pigeon.

The Goshawk was held in considerable esteem for falconry, and, according to Bell, was employed for this amusement by the emperor of China, who moved sometimes to these excursions in great state, often bearing a Hawk on his hand, to let fly at any game that might be raised, which was usually Pheasants, Partridges, Quails, or Cranes. In 1269 Marco Polo witnessed this diversion of the emperor, which probably had existed for many ages previous. The falconers distinguished these birds of sport into two classes, - namely, those of falconry properly so called, and those of hawking; and in this second and inferior class were included the Goshawk, the Sparrow Hawk, Buzzard, and Harpy. This species does not soar so high as the longer-winged Hawks, and darts upon its quarry by a side glance, not by a direct descent, like the true Falcon. These birds were caught in nets baited with live Pigeons, and reduced to obedience by the same system of privation and discipline as the Falcon.

A pair of Goshawks were kept for a long time in a cage by Buffon; he remarks that the female was at least a third larger than the male, and the wings, when closed, did not reach within six inches of the end of the tail. The male, though smaller, was much more fierce and untamable. They often fought with their claws, but seidom used the bill for any other purpose than tearing their food. If this consisted of birds, they were plucked as neatly as by the hand of the poulterer; but mice were swallowed whole, and the hair and skin, and other indigestible parts, after the manner of the genus, were discharged from the mouth rolled up in little balls. Its cry was raucous, and terminated by sharp, reiterated, piercing notes, the more disagreeable the oftener they were repeated; and the cage could never be approached without exciting violent gestures and screams. Though of different sexes, and confined to the same cage, they contracted no friendship for each other which might soothe their imprisonment, and finally, 
to end the dismal picture, the female, in a fit of indiscriminate rage and violence, murdered her mate in the silence of the night, when all the other feathered race were wrapped in repose. Indeed, their dispositions are so furious that a Goshawk, left with any other Falcons, soon effects the destruction of the whole. Their ordinary food is young rabbits, squirrels, mice, moles, young Geese, Pigeons, and small birds, and, with a cannibal appetite, they sometimes even prey upon the young of their own species.

The Goshawk is not so rare in America as the older naturalists supposed; indeed, it is quite a common bird in the maritime Provinces of Canada and in northern New England, where it is found during the entire year. It occurs also west to Manitoba (though apparently rare in the Lake Superior region), and ranges, in winter, south to Maryland, Kentucky, and Ohio.

Its usual breeding area is from about latitude $45^{\circ}$ to the fur countries; though a few pairs probably build every year in southern New England. So few, comparatively, of the older and full-plumaged birds are seen that the species is not well known, the younger brown birds being almost indistinguishable from the young of several other Hawks.

There are several species that receive the name of "Hen Hawk" from the farmer ; but none is so much dreaded as the "Blue Hawk," - and for good reason. With a boldness, strength, and dexterity of flight that is rivalled only by the Peregrine, the Goshawk combines a spirit of enterprise worthy of the Osprey, and a ferocity and cunning that are unmatched by any of the tribe. I have seen one swoop into a farmyard while the fowls were being fed, and carry off a half-grown chick without any perceptible pause in the flight.

$$
\text { VOL. I. }-3
$$




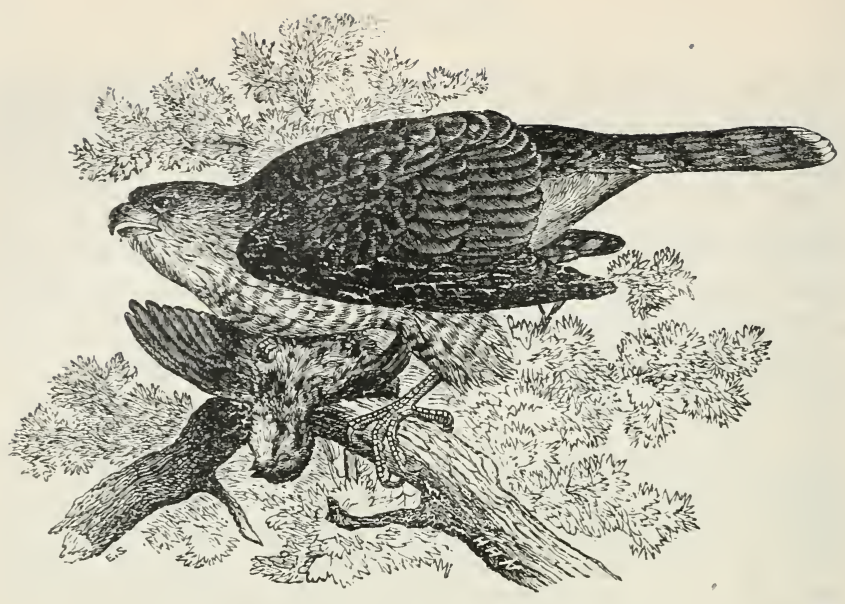

COOPER'S HAWK.

ACCIPITER COOPERII.

Char. Adult bluish gray or almost bluish ash, head darker; below, whitish, breast and belly thickly streaked with reddish brown, sides with a bluish tinge; wings and tail barred with dark brown, tail tipped with white. Length about 16 inches (female 2 to 3 inches longer).

Nest. In a tree, near the trunk; made of twigs, lined with grass.

Egos. 3-4; bluish white spotted with reddish brown (sometimes immaculate); $1.90 \times 1.50$.

This fine species of Hawk is found in considerable numbers in the Middle States, particularly New York and New Jersey, in the autumn and at the approach of winter. It is also seen in the Oregon territory to the shores of the Pacific. Its food appears principally to be birds of various kinds; from the Sparrow to the Ruffed Grouse, all contribute to its rapacious appetite. I have also seen this species as far south as the capital of Alabama, and, in common with the preceding, its depredations among the domestic fowls are very destructive. Mr. Cooper informs me that the plumage of the adult male bears the same analogy to the adult of $F$. fuscus as the young of that species does to the present, excepting that the rufous 
tints are paler. The difference in size between the two is as 2 , or even 3 , to $\mathrm{I}$.

Cooper's Hawk is generally distributed throughout North America from the fur countries to Mexico (in winter), though most abundant in the southern portions of New England and in the Middle States, where it is fairly common at all seasons.

It is called "Chicken Hawk" by the Northern farmers.

\section{SHARP-SHINNED HAWK.}

\section{ACCIPITER vELOX.}

CHAR. The adult may be best described as a small edition of Cooper's Hawk, which it resembles in almost everything but size. The top of the head is bluish, and the cheeks have a reddish tinge. Length of male about $1 \mathrm{I}$ inches; female some 2 inches longer.

Nest. In a tree: made of twigs, and lined with leaves and grass.

Eggs. 3-5; bluish white or greenish white blotched with brown; $1.45 \times 1.15$.

This bold and daring species possesses all the courageous habits and temerity of the true Falcon; and if the princely amusement to which these birds were devoted was now in fashion, few species of the genus would be found more sanguinary and pugnacious than the present. The young bird is described by Pennant under the name of the Dubious Falcon, and he remarks its affinity to the European Sparrow Hawk. It is, however, somewhat less, differently marked on the head, and much more broadly and faintly barred below. The nest of our species, according to Audubon, is made in a tree, and the eggs are four or five, grayish white, blotched with dark brown; they lay about the beginning to the middle of March. The true Sparrow Hawk shows considerable docility, is easily trained to hunt Partridges and Quails, and makes great destruction among Pigeons, young poultry, and small birds of all kinds. In the winter they migrate from Europe into Barbary and Greece, and are seen in great numbers out at sea, making such havoc among the birds of passage they happen to meet in their way that the sailors in the Mediterranean call them Corsairs. Wilson observed the female of our species descend 
upon its prey with great velocity in a sort of zig-zag pounce, after the manner of the Goshawk. Descending furiously and blindly upon its quarry, a young Hawk of this species broke through the glass of the greenhouse at the Cambridge Botanic Garden, and fearlessly passing through a second glass partition, he was only brought up by the third, and caught, though little stunned by the effort. His wing-feathers were much torn by the glass, and nis flignt in this way so impeded as to allow of his being approached. This species feeds principally upon mice, lizards, small birds, and sometimes even squirrels. In the thinly settled States of Georgia and Alabama this Hawk seems to abound, and proves extremely destructive to young chickens, a single bird having been known regularly to come every day until he had carried away between twenty and thirty. At noon-day, while I was conversing with a planter, one of these Hawks came down, and without any ceremony, or heeding the loud cries of the housewife, who most reluctantly witnessed the robbery, snatched away a chicken directly before us. At another time, near Tuscaloosa, in Alabama, I observed a pair of these birds furiously attack the large Red-tailed Hawk, squalling very loudly, and striking him on the head until they had entirely chased him out of sight. This enmity appeared to arise from a suspicion that the Buzzard was prowling round the farm-house for the poultry, which these Hawks seemed to claim as their exclusive perquisite. As this was, however, the I $3^{\text {th }}$ of February, these insulting marauders might possibly be already preparing to breed, and thus be incited to drive away every suspicious intruder approaching their nest. In fine weather I have observed this species soar to a great elevation, and ascend above the clouds. In this exercise, as usual, the wings seem but little exercised, the ascent being made in a sort of swimming gyration; though while near the surface of the earth the motion of the wings in this bird is rapid and continuous.

The Sharp-shinned is the commonest Hawk throughout New England and the settled portions of Canada, and breeds southward to the Southern States. In winter it ranges south to Panama. 


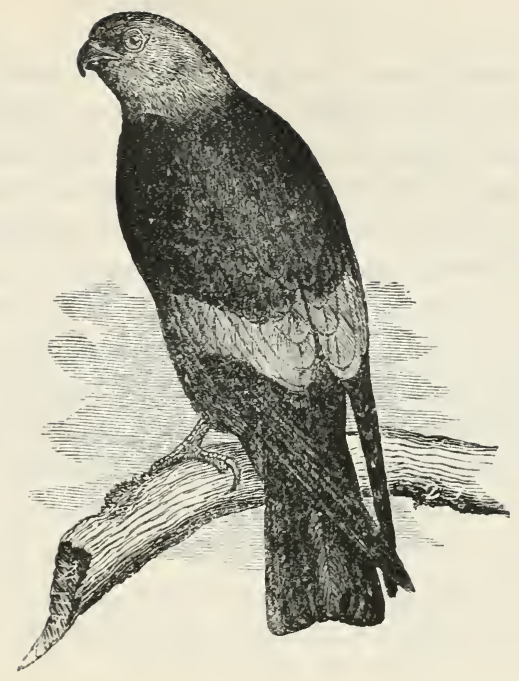

\section{MISSISSIPPI KITE.}

BLUE KITE.

\section{ICTINA MISSISSIPPIENSIS.}

CHAR. General color bluish-gray, lighter on the head and seconda. ries, darker on primaries and tail. Length, 13 to $15 \%$ inches.

Nest. On a tree; of small sticks, lined with moss and leaves.

Eggs. 2-3; bluish white; size variable, averaging $1.65 \times 1.35$.

This remarkably long-winged and beautiful Hawk does not appear to extend its migrations far within the United States. Wilson observed it rather plentiful about and below Natchez in the summer season, sailing in easy circles, sometimes at a great elevation, so as to keep company with the Turkey Buzzards in the most elevated regions of the air ; at other times they were seen among the lofty forest trees, like Swallows sweeping along, and collecting the locusts (Cicadce) which swarmed at this season. My friend Mr. Say observed this species pretty far up the Mississippi, at one of Major Long's cantonments. But except on the banks of this great river, it is rarely seen even in the most southern States. Its food, 
no doubt, abounds more along the immense valley of the Mississippi than in the interior regions, and, besides large insects, probably often consists of small birds, lizards, snakes, and other reptiles, which swarm in these their favorite resorts. On the failure of food these birds migrate by degrees into the Mexican and South American provinces, and were observed by D'Azara in Guiana, about the latitude of $7^{\circ}$. According to Audubon, this Kite breeds in the Southern States as well as in Texas, selecting the tall magnolias and white-oaks. From the narrow limits within which this bird inhabits in the United States, it is more than probable that the principal part of the species are constant residents in the warmer parts of the American continent. They begin to migrate early in August.

The range of this species is given as "southern United States southward from South Carolina, and Wisconsin and Iowa to Mexico."

\section{WHITE-TAILED KITE.}

\section{BLACK-SHOULDERED KITE.}

\section{ElaNUS LEUCURUS.}

CHAR. General color bluish gray fading to white on head and tail ; a large patch of black on shoulder; lower parts white. Length 15 to $163 / 4$ inches.

Nest. In a tree, loosely built of sticks and leaves.

Eggs. 2-4; dull white, heavily blotched with brown, 1.60 × 1.25.

This beautiful Hawk, scarcely distinguishable from a second African species of this section, chiefly inhabits the continent of South America as far as Paraguay. In the United States it is only seen occasionally in the peninsula of East Florida, confining its visits almost to the southern extremity of the Union. It appears to be very shy and difficult of approach; flying in easy circles at a moderate elevation, or at times seated on the deadened branches of the majestic live-oak, it attentively watches the borders of the salt-marshes and watery situations 
for the field-mice of that country, or unwary Sparrows, that approach its perch. The bird of Africa and India is said to utter a sharp and piercing cry, which is often repeated while the bird moves in the air. It builds, in the forks of trees, a broad and shallow nest, lined internally with moss and feathers. A pair have been known to breed on the Santee River in the month of March, according to Audubon.

This Kite occurs regularly in the Southern States, north to South Carolina, and Mr. Ridgway has met with it in southern Illinois. It extends its range westward to California.

\section{SIVALLOW-TAILED KITE.}

FORK-TAILED KITE.

\section{ELANOIDES FORFICATUS.}

CHAR. Head, neck, rump, and lower parts white, other parts black; tail deeply forked. Length $19 \mathrm{~T} / 2$ to $25 \mathrm{~T} / 2$ inches.

Nest. In a tree ; of sticks and moss, lined with grass and leaves.

Eggs. 2-3; white, with buff or green tinge, spotted with various shades of brown; $1.85 \times 1.50$.

This beautiful Kite breeds and passes the summer in the warmer parts of the United States, and is also probably resident in all tropical and temperate America, migrating into the southern as well as the northern hemisphere. In the former, according to Viellot, it is found in Peru and as far as Buenos Ayres; and though it is extremely rare to meet with this species as far as the latitude of $40^{\circ}$ in the Atlantic States, yet, tempted by the abundance of the fruitful valley of the Mississippi, individuals have been seen along that river as far as the Falls of St. Anthony, in the 44th degree of north latitude. Indeed, according to Fleming two stragglers have even found their devious way to the strange climate of Great Britain.

These Kites appear in the United States about the close of April or beginning of May, and are very numerous in the Mis- 
sissippi territory, twenty or thirty being sometimes visible at the same time; often collecting locusts and other large insects, which they are said to feed on from their claws while flying, at times also seizing upon the nests of locusts and wasps, and, like the Honey Buzzard, devouring both the insects and their larvæ. Snakes and lizards are their common food in all parts of America. In the month of October they begin to retire to the South, at which season Mr. Bartram observed them in great numbers assembled in Florida, soaring steadily at great elevations for several days in succession, and slowly passing towards their winter quarters along the Gulf of Mexico. From the other States they migrate early in September.

This species is most abundant in the western division of the Gulf States, but is irregularly distributed over the Southern, Western, and Middle States. It has occasionally visited New England, and examples have been seen in Manitoba and near London and Ottawa in Ontario.

\section{EVERGLADE KITE.}

BLACK KITE. HOOK-BILL KITE. SNAIL HAIV.

\section{ROSTRHANIUS SOCIABILIS.}

CHAR. Prevailing color dull bluish ash, darker on tail, wings, and anterior portion of head; rump white, with terminal bar of light brown; bill black; feet orange. Length i 6 to i 8 inches.

Nest. A platform with a slight depression, composed of sticks or dried grass, built in a low bush or amid tall grass.

Eggs. 2-3; brownish white blotched with various shades of brown; $1.70 \times 1.45$.

This is a tropical species that occurs in Florida. Mr. IV. E. D. Scott reports finding it abundant at Panasofkee Lake, and says: "Their food at this point apparently consists of a kind of large fresh-water snail which is very abundant. . . . They fish over the shallow water, reminding one of gulls in their motions; and having secured a snail by diving, they immediately carry it to the nearest available perch, when the animal is dexterously taken from the shell, without injury to the latter." 


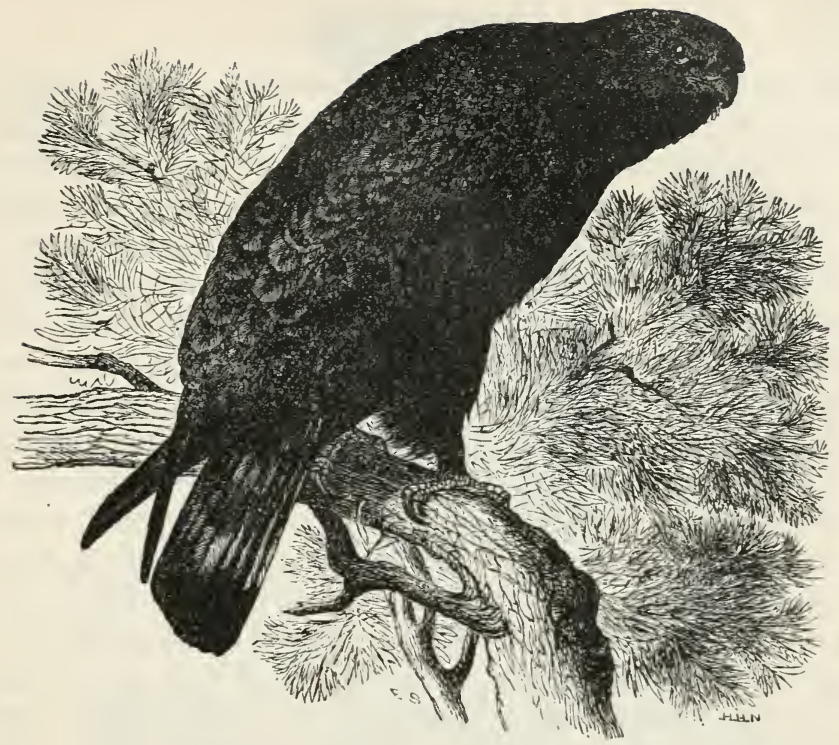

\section{AMERICAN ROUGH-LEGGED HAIVK.}

BLACK HAWK.

\section{ARCHIBUTEO LAGOPUS SANCTI-JOHANNIS.}

CHAR. General color variable, - dark or light brown, or brownish gray, sometimes black; all the feathers edged with lighter color, producing an appearance of streaks. The absence of these streaks on the belly forms a dark band. Tail with dark and light bars, and whitish at its base. Easily distinguished from any other Hawk by the feathered shank. Length $191 / 2$ to 22 inches.

Nest. In a large tree, or on rocks; of sticks lined with grass, dry moss, and feathers.

Eggs. 2-3; white or creamy, more or less spotted with brown; 1.90 $\times \mathbf{1 . 5 5}$.

This remarkable species of Buzzard appears to take up its residence chiefly in the northern and western wilds of America. My friend Mr. Townsend found its nest on the banks of Bear River, west of the Rocky Mountains. The nest, formed of large sticks, was in a thick willow bush about ten feet from the ground, and contained two young almost fledged. It is 
said to lay four eggs, clouded with reddish. It is common also to the north of Europe, if not to Africa. The usual station of these birds is on the outskirts of woods, in the neighborhood of marshes, - situations suited for supplying them with their usual humble prey of frogs, mice, reptiles, and straggling birds, for which they patiently watch for hours together, from daybreak to late twilight. When prey is perceived, the bird takes a cautious, slow, circuitous course near the surface, and sweeping over the spot where the object of pursuit is lurking, he instantly grapples it, and flies off to consume it at leisure. Occasionally they feed on crabs and shell-fish. The inclement winters of the high northern regions, where they are usually bred, failing to afford them food, they are under the necessity of making a slow migration towards those countries which are less severe. According to Wilson, no less than from twenty to thirty young individuals of this species continued regularly to take up their winter quarters in the low meadows below Philadelphia. They are never observed to soar, and when disturbed, utter a loud, squealing note, and only pass from one neighboring tree to another.

The great variation in the plumage of this Hawk has been the cause of considerable controversy. Wilson wrote of the black and the brown phases as of two species, giving them distinct habits. Nuttall, following Audubon, considered the changes from light to dark due only to age. Spencer Baird (in I858), Cassin, and Dr. Brewer agreed with Wilson. Later authorities, however, with more material to aid them, have pronounced both views incorrect, and have decided that there is but one species, - that the black is but a melanistic phase. Our systematists now separate the American from the European form, giving to the former varietal rank, as its "trinomial appellation" denotes.

Nuttall does not mention the occurrence of this bird in Massachusetts, though Dr. Brewer states that at one time it was abundant near Boston, and within more recent years numbers have been captured by Mr. E. O. Damon on the Holyoke Hills, near Springfield. It occurs within the United States principally as a winter visitor when it ranges south to Virginia, its chief breeding-ground lying in the Labrador and Hudson Bay district. 


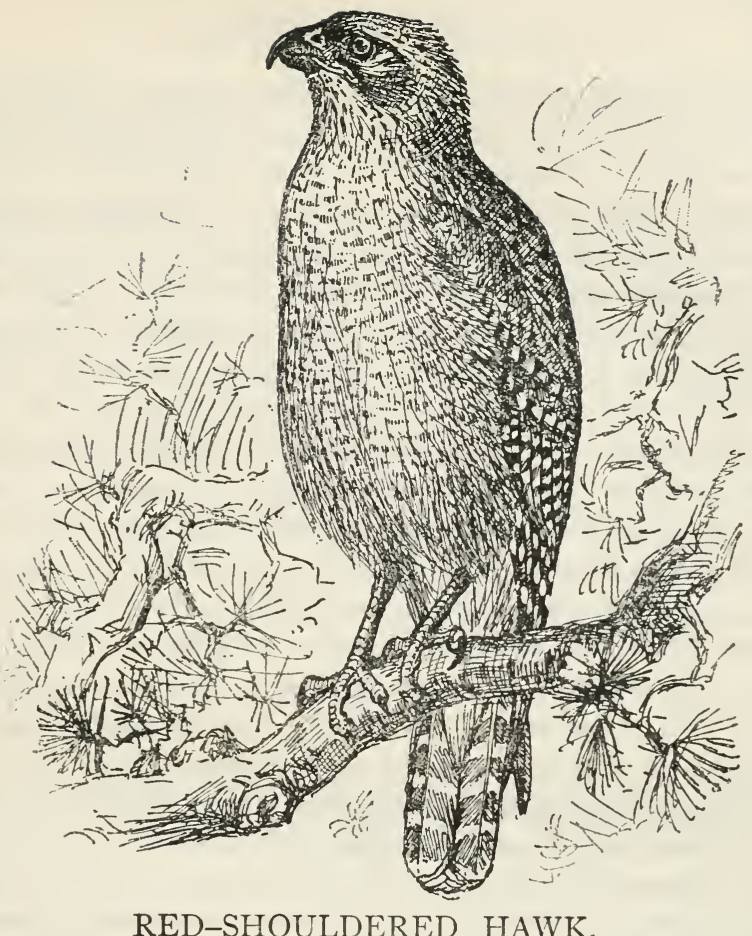

IVINTER HAWK.

Buteo lineatus.

CHAR. Adult : general color dark reddish brown; head and neck rufous : below, lighter, with dark streaks and light bars; wings and tail black with white bars; lesser wing-coverts chestnut. Young, with little of the rufous tinge; below, buffy with dark streaks. Length I9 to 22 inches.

Nest. In a tree; of loosely arranged twigs, lined with grass and feathers.

Eggs. 2-4; bluish white or buffy blotched with brown; $2.20 \times 1.70$.

This very elegant Hawk does not migrate or inhabit very far to the north. It is never seen in Massachusetts, nor perhaps much farther than the State of Pennsylvania. In the Southern States, during winter, these birds are very common in swampy situations, where their quailing cry of mutual recognition may be heard from the depths of the dark forest almost 
every morning of the season. This plaintive echoing note resembles somewhat the garrulous complaint of the Jay, keé-ó, $k e \dot{e}-o \dot{0}, k e \dot{e}-o \dot{o}$, continued with but little intermission sometimes for near twenty minutes. At length it becomes loud and impatient; but on being distantly answered by the mate, the sound softens and becomes plaintive like $k \bar{e} e ́-o o$. This morning call is uttered most loudly and incessantly by the male: inquiring for his adventurous mate, wnom the uncertain result of the chase has perhaps separated from him for the night. As this species is noways shy, and very easily approached, I have had the opportunity of studying it closely. At length, but in no haste, I observed the female approach and take her station on the same lofty, decayed limb with her companion, who, grateful for this attention, plumed the feathers of his mate with all the assiduous fondness of a Dove. Intent upon her meal, however, she soon flew off to a distance, while the male still remained on his perch, dressing up his beautiful feathers for near half an hour, often shaking his tail, like some of the lesser birds, and occasionally taking an indifferent survey of the hosts of small chirping birds which surrounded him, who followed without alarm their occupation of gleaning seeds and berries for subsistence. I have occasionally observed them perched on low bushes and stakes in the rice-fields, remaining thus for half an hour at a time, and then darting after their prey as it comes in sight. I saw one descend upon a Plover, as I thought, and Wilson remarks their living on these birds, Larks, and Sandpipers. The same pair that I watched also hung on the rear of a flock of cow-buntings which were feeding and scratching around them. They sometimes attack squirrels, as I have been informed, and Wilson charges them with preying also upon Ducks.

I never observed them to soar, at least in winter, their time being passed very much in indolence and in watching for their game. Their flight is almost as easy and noiseless as that of the Owl. In the early part of the month of March they were breeding in West Florida, and seemed to choose the densest thickets and not to build at any great height from 
the ground. On approaching these places, the keé-oo became very loud and angry.

Winter Hawk. - This large American Buzzard is not uncommon in this vicinity, as well as in the neighborhood of Philadelphia, where Wilson met with it along the marshes and meadows, feeding almost wholly upon frogs. It is abundant toward winter. It appears to have very much the manners of the European Buzzard, remaining inactive for hours together on the edges of wet meadows, perched upon the larger limbs of trees, and at times keeping up a regular quailing and rather hoarse keigh-oo, keigh-oo, which at intervals is answered by the mate. When approached, it commonly steals off to some other tree at no great distance from the first; but if the pursuit be continued, it flies out and hovers at a considerable height. It is also an inhabitant of Hudson's Bay and Newfoundland.

Nuttall regarded the old and young as distinct species, giving to them not only distinctive names, but a different distribution. Taken together, his two biographies tell about all that is yet known of the habits and range of the species. It is found throughout this faunal province, from the Gulf States to the southern border of the fur countries, has been taken at York Factory on Hudson's Bay, and is common in Manitoba.

Note. - The Florida Red-Shouldered Hawk (Buteolineatus alleni) is a Southern form found in Florida, and ranging on the Atlantic shore north to South Carolina and along the Gulf coast to Texas. It differs from true lineatus in having the rufous tinge on the head and neck replaced by brownish gray. 


\section{HARRIS'S HAWK.}

\section{PARABUteo Unicinctus haRrisi.}

CHAR. Prevailing color black, sometimes chocolate brown, tinged with chestnut on the rump; shoulders and lining of wings chestnut ; tail-coverts, base of tail, and terminal band, white. Length about 20 inches.

Nest. On a cliff or in a tree, - usually the latter; a mere platform of twigs and roots, lined with grass.

Eggs. 2-5 (usually 3); white, tinged with yellow, sometimes marked with brown or lavender, or both; $2.15 \times 1.65$.

Harris's Hawk is abundant in parts of Texas and in Mexico, and occurs in small numbers in the southern part of Mississippi. It is usually represented as a rather sluggish bird, associating with the Vultures and joining in their feasts of carrion, but sometimes preying upon the small reptiles that infest the banks of streams and pools. Mr. Sennett, however, describes those he saw along the lower Rio Grande as more active, feeding chiefly on birds, mice, and gophers.

\section{RED-TAILED HAWK.}

\section{BUTEO BOREALIS.}

CHAR. Above, dull brown streaked with rufous and grayish; below, whitish or tawny streaked with brown; tail chestnut above and gray beneath, with a band of black near the end and tipped with white. In the young the tail is grayish brown crossed by some nine dark bars, and the underparts are white with brown streaks. Length $191 / 2$ to 23 inches.

Nest. In a high tree; of sticks, lined with grass, sometimes with feathers.

Eggs. 2-4; whitish or bluish white, usually heavily spotted or blotched with reddish brown; $2.30 \times 1.80$.

This beautiful Buzzard inhabits most parts of the United States, being observed from Canada to Florida; also, far westward up the Missouri, and even on the coasts of the northern Pacific Ocean, by Lewis and Clarke. Wilson found the young to be fully grown in the month of May, about latitude $3 \mathrm{I}^{\circ}$ on the banks of the Mississippi; at this period they were very noisy and clamorous, keeping up an incessant squealing. It also occasionally nests and breeds in large 
trees in the secluded forests of this part of Massachusetts. The young birds soon become very submissive, and allow themselves to be handled with impunity by those who feed them. The older birds sometimes contest with each other in the air about their prey, and nearly or wholly descend to the earth grappled in each other's talons. Though this species has the general aspect of the Buzzard, its manners are very similar to those of the Goshawk; it is equally fierce and predatory, prowling around the farm often when straitened for food, and seizing, now and then, a hen or chicken, which it snatches by making a lateral approach: it sweeps along near the surface of the ground, and grasping its prey in its talons, bears it away to devour in some place of security. These depredations on the farm-yard happen, however, only in the winter; at all other seasons this is one of the shyest and most difficult birds to approach. It will at times pounce upon rabbits and considerable-sized birds, particularly Larks, and has been observed in the Southern States perseveringly to pursue squirrels from bough to bough until they are overtaken and seized in the talons. It is frequently seen near wet meadows where mice, moles, and frogs are prevalent, and also feeds upon lizards, - appearing, indeed, often content with the most humble game.

They usually associate in pairs, and seem much attached to each other; yet they often find it convenient and profitable to separate in hunting their prey, about which they would readily quarrel if brought into contact. Though a good deal of their time passes in indolence, while perched in some tall and deadened tree, yet at others they may be seen beating the ground as they fly over it in all directions in quest of game. On some occasions they amuse themselves by ascending to a vast elevation, like the aspiring Eagle. On a fine evening, about the middle of January, in South Carolina, I observed one of these birds leave its withered perch, and soaring aloft over the wild landscape, in a mood of contemplation, begin to ascend towards the thin skirting of elevated clouds above him. At length he passed this sublime boundary, and was now per- 
ceived and soon followed by his ambitious mate, and in a little time, by circular ascending gyrations, they both disappeared in the clear azure of the heavens; and though I waited for their re-appearance half an hour, they still continued to be wholly invisible. This amusement, or predilection for the cooler regions of the atmosphere, seems more or less common to all the rapacious birds. In numerous instances this exercise must be wholly independent of the inclination for surveying their prey, as few of them besides the Falcon descend direct upon their quarry. Many, as well as the present species, when on the prowl fly near to the surface of the ground, and often wait and watch so as to steal upon their victims before they can take the alarm. Indeed the Condor frequents and nests upon the summit of the Andes, above which they are seen to soar in the boundless ocean of space, enjoying the invigorating and rarefied atmosphere, and only descending to the plains when impelled by the cravings of hunger.

The Eastern variety of the Red-tail is a common bird throughout eastern North America north to about latitude $49^{\circ}$, and was taken by Dr. Bell at Fort Churchill, on Hudson's Bay. It ranges westward to the Great Plains, where it is replaced by the subspecies krideri. From the Rocky Mountains to the Pacific it is represented by calurus, and examples of this latter variety have been taken, occasionally, as far east as Illinois. The Red-tail is a summer resident only of the Maritime Provinces, but a few are found in winter in southern Ontario and New England.

Note. - Mr. Ridgway now considers Harlan's Hawk to be a variety of the Red-tail, and he proposes to name it Buteo borealis harlani. I ts usual habitat is along the lower Mississippi ; but examples have been taken in Illinois, Iowa, Pennsylvania, and Georgia.

Capt. Bendine reports that KRIDER's Hawk (b.b. Krideri) occurs in Iowa and northern Illinois. (Life Histories of North American Birds.)

Two examples of Swainson's Hawk (Buteo swainsoni), a Western species, have been taken in Massachusetts, - one at Wayland in 1876 , and the other near Salem in 1878 . 


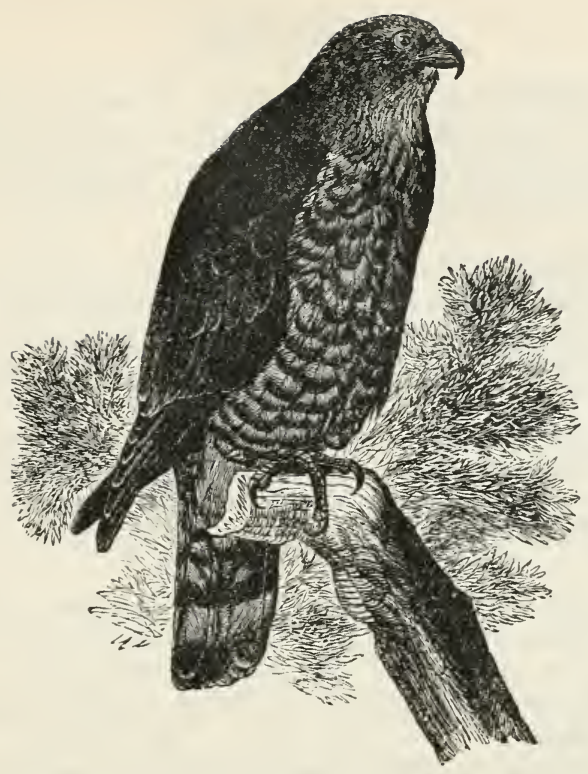

BROAD-WINGED HAWK.

\section{Buteo latissimus.}

CHAR. Above, dull brown, the feathers with paler edges; tail dusky with four light bars and tipped with white; below, buffish or tawny, barred and streaked with rufous. Length 16 inches. Young : similar, but tail brownish, with several dusky bars; below buffy streaked with dusky.

Nest. In a tree; loosely built of twigs, and lined with leaves and feathers.

Eggs. 2-4; buffish, blotched with reddish brown of various shades; $1.90 \times 1.55$.

This species was obtained by Wilson, in the vicinity of Philadelphia, in the act of feeding on a meadow-mouse. On being approached, it uttered a whining whistle and flew to another tree, where it was shot. Its great breadth of wing, as well as of the head and body, compared with its length, appears remarkably characteristic. The following day the mate was observed sailing in wide circles, the wings scarcely moving, and presenting almost a semi-circular outline. These two individuals appear to be all that were known to Wilson of this

VOL. I. -4 
species. Audubon considers it by no means a rare species in Virginia, Maryland, and all the States to the eastward of these. Its usual prey is small birds, very young poultry, small quadrupeds, and insects.

The Broad-wing occurs throughout this eastern faunal province, but is somewhat local in distribution. In portions of the Maritime Provinces it is abundant, though in general it is rather uncommon. Mr. John Neilson considers it common near the city of Quebec, but Mr. Ernest Wintle reports it rare at Montreal, while Mr. William L. Scott thinks it the commonest Hawk in the Ottawa valley. $\mathrm{Mr}$. Thomas McIlwraith gives it as a "casual visitor" to the southern portions of Ontario, and Mr. Ernest Thompson found it abundant in the Muskoka district. Thompson also reports it common in Manitoba.

In the more northern portions of New England it is a fairly common summer visitor, while it is found in Massachusetts and Connecticut throughout the year, but is rather rare. It occurs also in more or less abundance in all the Middle, Western, and Southern States.

My observations in New Brunswick have led me to form a different opinion of the characteristics of this Hawk from those expressed by several writers. The examples I met with were not peculiarly void of either boldness or vigor in pursuit of their prey, nor peculiarly spiritless when wounded. They did, of course, like others of the tribe, pursue weak prey, and displayed little true bravery; but bravery is not a characteristic of the Hawks. A wounded Broad-wing, however, acts just as does the boldest of them, - he turns on his back and hits out with claws, beak, and wings; and the gunner who thinks he has a meek or spiritless bird to handle may regret the thought.

\section{SHORT-TAILED HAWK.}

\section{BUTEO BRACHYURUS.}

CHAR. Above, brownish black or blackish brown; forehead and cheeks white; tail brownish gray barred with black and tipped with white; beneath, pure white, a patch of rufous on side of chest. Length 16 inches.

Nest. In a tall tree; made of dry twigs, lined with fresh twigs of cypress.

Eggs. I-3; dull white, spotted on large end with reddish brown. 
The black and brown phases of plumage worn by this bird have caused the scientific ornithologists no little perplexity, and been the subject of some controversy; so a brief summary of the various opinions held may serve as an illustration of the evolution of many scientific names.

The species was first described from a specimen in brown plumage and given the name it now bears; then a young bird came into the hands of another systematist, and supposing it to be a new species, he named it $B$. oxypterus; and afterwards an example in black was taken by still another, who supposed it to be something new, so he wrote it down $B$. fuliginosus. These two last-mentioned were disposed of by other writers as synonyms of swainsoni, oxypterus being considered the young plumage, and fuliginosus a melanistic phase, while in several more recent works the latter, as the Little Black Hawk, was restored to specific rank. These opinions have recently been abandoned for that which has been held for a long time by the few, - that both fuliginosus and oxypterus are synonyms of the present species.

It cannot, however, be said that the matter is finally adjusted, for the black color still presents this problem: Is it individual or sexual, - a melanistic phase, or the normal color of the adult male?

The bird is entirely tropical in its range, and is found within the United States only in the tropical portions of Florida. It was supposed formerly to occur there merely as a casual or accidental straggler; but recent observations have proved it to be a regular though uncommon visitor, and breeding there.

\section{MARSH HAWK.}

\section{MARSH HARRIER. BLUE HAWK.}

\section{Circus hudsonius.}

Char. Adult male: above, bluish gray; tail with dark bands; rump white; beneath white. Adult female and young: above, dark brown streaked with rufous; tail with dark bands; rump white; beneath, tawny with dark streaks. Length 19 to 24 inches.

Nest. On the ground, in damp meadow or cedar swamp; a loosely arranged platform of dried grass some four to six inches high, with little depression, occasionally lined with softer material.

Eggs. 3-8; bluish white, sometimes spotted with buffish or brown; $1.80 \times 1.40$. 
This species is common to the northern and temperate, as well as the warmer parts of the old and new continents, being met with in Europe, Africa, South America, and the West Indies. In the winter season it extends its peregrinations from Hudson's Bay to the Oregon territory and the southern parts of the United States, frequenting chiefly open, low, and marshy situations, over which it sweeps or skims along, at a little distance usually from the ground, in quest of mice, small birds, frogs, lizards, and other reptiles, which it often selects by twilight as well as in the open day; and at times, pressed by hunger, it is said to join the Owls and seek out its prey even by moonlight. Instances have been known in England in which this bird has carried its temerity so far as to pursue the same game with the armed fowler, and even snatch it from his grasp after calmly waiting for it to be shot, and without even betraying timidity at the report of the gun. The nest of this species is made on the ground, in swampy woods or among rushes, occasionally also under the protection of rocky precipices, and is said to be formed of sticks, reeds, leaves, straw, and similar materials heaped together, and finished with a lining of feathers, hair, or other soft substances. In the $F$. cineraceus, so nearly related to this species, the eggs are of a pure white. When their young are approached, the parents, hovering round the intruder and uttering a sort of uncouth syllable, like geg geg gag, or ge ge ne ge ge, seem full of afright and anxiety. The Crows, however, are their greatest enemies, and they often succeed in demolishing the nests. The young are easily tamed, and feed almost immediately without exhibiting any signs of fear.

Nuttall has told about all that more modern observers have to tell of this species. The authorities differ chiefly in descriptions of the structure of the nest and the markings on the eggs. The nests that I have examined have been composed entirely of coarse grass, without lining, though the softest of the grass was laid on top. The eggs were unspotted. 


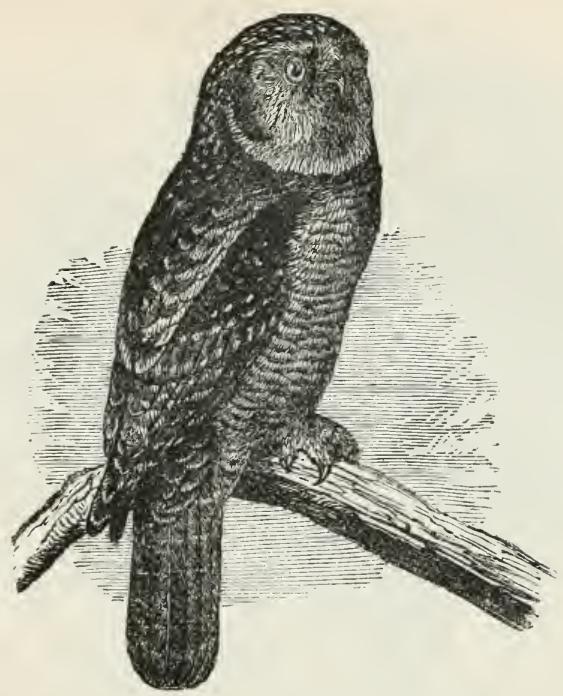

HAWK OWL.

\section{SURNia Ulula CAPAROCH.}

CHAR. Above, dull blackish brown, spotted with white; crown without spots; dark patch on the cheeks; face white, the feathers with dark margins; tail and wing with white bars; below, white with dark bars. Length $14 \frac{3}{4}$ to $17 \frac{1}{2}$ inches.

Nest. On a tree; of twigs lined with feathers.

Eggs. 2-7; dull white; $1.55 \times 1.25$.

This remarkable species, forming a connecting link with the preceding genus of the Hawks, is nearly confined to the Arctic wilds of both continents, being frequent in Siberia and the fur countries from Hudson's Bay to the Pacific. A few stragglers, now and then, at distant intervals and in the depths of winter, penetrate on the one side into the northern parts of the United States, and on the other they occasionally appear in Germany, and more rarely in France. At Hudson's Bay they are observed by day flying high and preying on the White Grouse and other birds, sometimes even attending the hunter like a Falcon, and boldly taking up the wounded game as it 
flutters on the ground. They are also said to feed on mice and insects, and (according to Meyer) they nest upon trees, laying two white eggs. They are said to be constant attendants on the Ptarmigans in their spring migrations towards the North, and are observed to hover round the camp-fires of the natives, in quest probably of any offal or rejected game.

In Massachusetts and the more southern portions of New England the Hawk Owl is only an occasional winter visitor; but in northern New England and the Maritime Provinces it occurs regularly, though of varying abundance, in some seasons being quite rare. It is fairly common near Montreal, and rare in Ontario and in Ohio. Thompson reports it abundant in Manitoba, but only one example has been taken in Illinois (Ridgway). It breeds in Newfoundland, the Magdalen Islands, and northern Manitoba, and north to sub-arctic regions. 


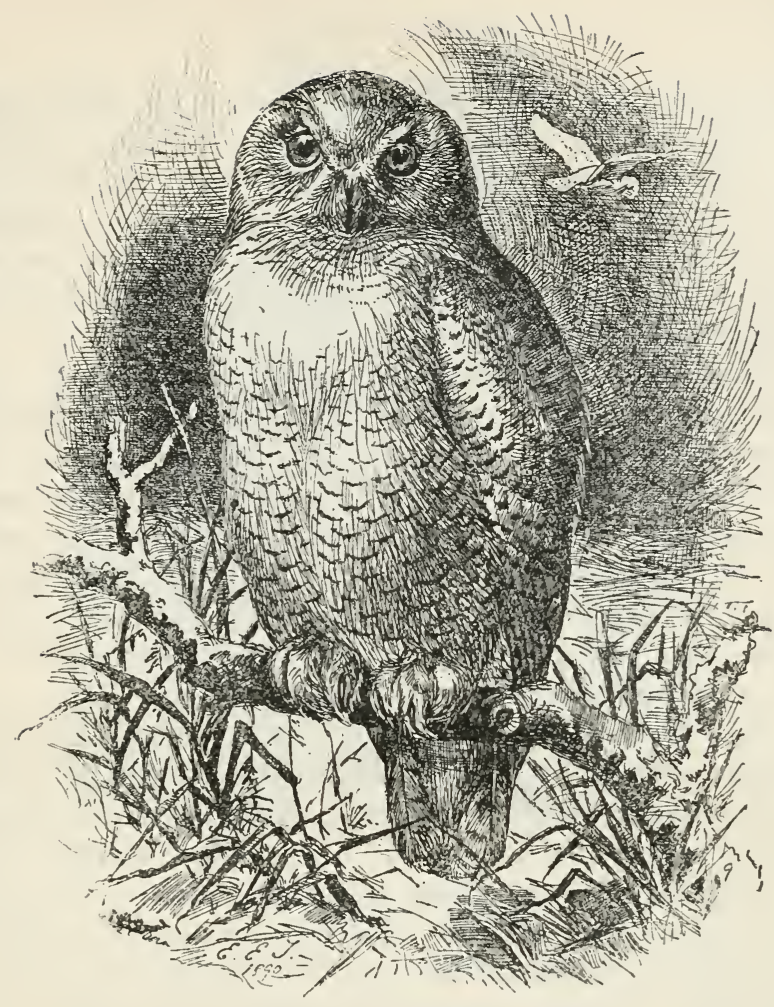

\section{SNOWY OWL.}

\section{NyCTEA NYCTEA.}

CHAR. General color pure white, with markings of dull brown or brownish black, the abundance and shade of the spots varying with age. A large, stout bird. Length 23 to 27 inches.

Nest. On the ground, of twigs and grass, lined with feathers.

Eggs. 5 to I0; white; $2.55 \times 1.90$.

This very large and often snow-white species of Owl is almost an exclusive inhabitant of the Arctic regions of both continents, being common in Iceland, the Shetland Islands, Kamtschatka, Lapland, and Hudson's Bay. In these dreary wilds, surrounded by an almost perpetual winter, he dwells, breeds, and obtains his subsistence. His white robe renders 
him scarcely discernible from the overwhelming snows, where he reigns, like the boreal spirit of the storm. His loud, hollow, barking growl, 'whowh, 'whowh, 'whowh hăh, hăh, hăh,

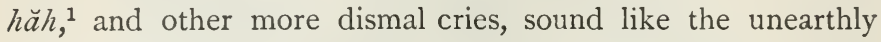
ban of Cerberus ; and heard amidst a region of cheerless solitude, his lonely and terrific voice augments rather than relieves the horrors of the scene.

Clothed with a dense coating of feathers, which hide even the nostrils, and leave only the talons exposed, he ventures abroad boldly at all seasons, and, like the Hawks, seeks his prey by daylight as well as dark, skimming aloft and reconnoitring his prey, which is commonly the White Grouse or some other birds of the same genus, as well as hares. On these he darts from above, and rapidly seizes them in his resistless talons. At times he watches for fish, and condescends also to prey upon rats, mice, and even carrion.

These birds appear to have a natural aversion to settled countries; for which reason, perhaps, and the severity of the climate of Arctic America, they are frequently known to wander in the winter south through the thinly settled interior of the United States. They migrate probably by pairs; and according to Wilson, two of these birds were so stupid, or dazzled, as to alight on the roof of the court-house in the large town of Cincinnati. In South Carolina Dr. Garden saw them occasionally, and they were, in this mild region, observed to hide themselves during the day in the palmetto-groves of the seacoast, and only sallied out towards night in quest of their prey. Their habits, therefore, seem to vary considerably, according to circumstances and climate.

This species is a regular winter visitor to the Northern and Middle States, and during some seasons has been quite abundant. A few pairs have been seen in summer in northern Maine, New Brunswick, and Nova Scotia: but the usual breeding-ground is from about latitude $50^{\circ}$ to the Arctic regions.

While in their more southern resorts they are rarely found far from the forest districts.

1 These latter syllables with the usual quivering sound of the Owl. 


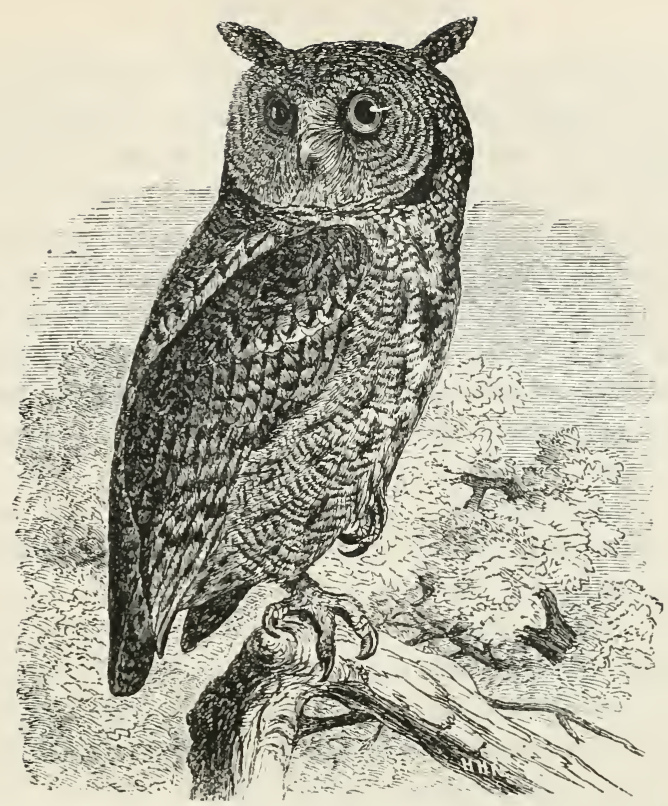

SCREECH OWL.

MOTTLED OWL. RED OWL.

MEgascops asio.

CHAR. Of two phases, brownish gray and brownish red. Above, mottled with darker shades of the prevailing color and with blackish; below, dull whitish or with a rufous tint and heavily marked with dull brown or blackish. In highly colored red examples the spots are less frequent. Large ear tufts; wings and tail barred with the light and dark colors; legs feathered and toes bristled. Length 7 to ro inches.

Nest. In a hollow tree or stump; the bottom of the hole slightly lined with leaves or feathers.

$E_{S g S .} 4-8$; white, nearly round; $1.35 \times 1.20$.

Mottled Owol. - This common, small, and handsome species, known as the Little Screech Owl, is probably resident in every part of the United States, and, in fact, inhabits from Greenland to Florida, and westward to the Oregon. It appears more abundant in autumn and winter, as at those seasons, food fail- 
ing, it is obliged to approach habitations and barns, in which the mice it chiefly preys on now assemble; it also lies in wait for small birds, and feeds on beetles, crickets, and other insects. The nest is usually in the hollow of an old orchard tree, about the months of May or June; it is lined carelessly with a little hay, leaves, and feathers, and the eggs are commonly four to six, white, and nearly round. Aldrovandus remarks that the Great Horned Owl provides so plentifully for its young that a person might obtain some dainties from the nest, and yet leave a sufficiency for the Owlets besides. The same remark may also apply to this species, as in the hollow stump of an apple-tree, which contained a brood of these young Owls, were found several Bluebirds, Blackbirds, and Song Sparrows, intended as a supply of food.

During the day these birds retire into hollow trees and unfrequented barns, or hide in the thickest evergreens. At times they are seen abroad by day, and in cloudy weather they wake up from their diurnal slumbers a considerable time before dark. In the day they are always drowsy, or, as if dozing, closing, or scarcely half opening their heavy eyes, presenting the very picture of sloth and nightly dissipation. When perceived by the smaller birds, they are at once recognized as their insidious enemies; and the rareness of their appearance, before the usual roosting-time of other birds, augments the suspicion they entertain of these feline hunters. From complaints and cries of alarm, the Thrush sometimes threatens blows; and though evening has perhaps set in, the smaller birds and cackling Robins re-echo their shrill chirpings and complaints throughout an extensive wood, until the nocturnal monster has to seek safety in a distant flight. Their notes are most frequent in the latter end of summer and autumn, crying in a sort of wailing quiver, not very unlike the whining of a puppy dog, hō, hò hŏ hŏ hŏ hŏ hŏ, proceeding from high and clear to a low guttural shake or trill. These notes, at little intervals, are answered by some companion, and appear to be chiefly a call of recognition from young of the same brood, or pairs who wish to discover each other after having been sepa- 
rated while dozing in the day. On moonlight evenings this slender wailing is kept up nearly until midnight.

Red Owl. - From the very satisfactory and careful observations of Dr. Ezra Michener, of New Garden, Chester County, Pennsylvania, published in the eighth volume of the Journal of the Academy of Natural Sciences of Philadelphia, it appears certain that the Red and Gray "Screech Owls" of the United States are specifically distinct; he has observed that the Red Owls rear young of the same color, and that the Gray Owls of the preceding species have also young which are gray and mottled from the very nest. Still different as they are in plumage, the habits of the species are nearly alike. The present inhabits and breeds in most parts of the United States. In Pennsylvania they are hatched by the latter end of May, breeding in hollow trees. The eggs are about four.

I have had an opportunity of verifying all that Wilson relates of the manners of this species in a Red or young Owl, taken out of a hollow apple-tree, which I kept for some months. A dark closet was his favorite retreat during the day. In the evening he became very lively and restless, gliding across the room in which he was confined, with a sidelong, noiseless flight, as if wafted by the air alone. At times he clung to the wainscot, and, unable to turn, he brought his head round to his back, so as to present, by the aid of his brilliant eyes, a most spectral and unearthly appearance. As the eyes of all the Owls, according to Wilson, are fixed immovably in the socket by means of a many cleft capsular ligament, this provision for the free versatile motion of the head appears necessary. When approached towards evening, he appeared strongly engaged in reconnoitring the object, blowing with a hissing noise (shay, shay, shay), common to other species, and stretching out his neck with a waving, lateral motion, in a threatening attitude, and, on a nearer approach, made a snapping with the bill, produced by striking together both mandibles, as they are equally movable. He was a very expert mouse-catcher, swallowed his prey whole, and then, after some time, ejected from the bill the bones, skin, and 
hair, in pellets. He also devoured large flies, which at this time came into the room in great numbers; and even the dry parts of these were also ejected from the stomach without digestion. A pet of this species, which Dr. Michener had, drank frequently, and was accustomed to wash every day in a basin of cold water during the heat of summer.

Nuttall, following Wilson and Audubon, treated the gray and red phases of this bird as two distinct species, and wrote separate biographies, which I insert in full. Some ornithologists have supposed that the gray specimens were the young birds; but it has been proved beyond question that the two phases are simply individual variations of the same species. Gray and red birds have been found in one nest, with both parents gray, or both red, or with one of each color.

The Screech Owl is a resident of southern New England and quite common. It breeds northward to the Maritime Provinces, westward to Minnesota and southward to the Gulf States. Probably southern New England is the northern limit of the bird's distribution in winter.

Note. - A smaller and darker race is found in South Carolina, Georgia, and Florida. It is named Florida SCREECH OWL (M. asio floridanus). In this race the reddish feathers wear a richer rufous tint, and the gray are more deeply tinged with brown. 


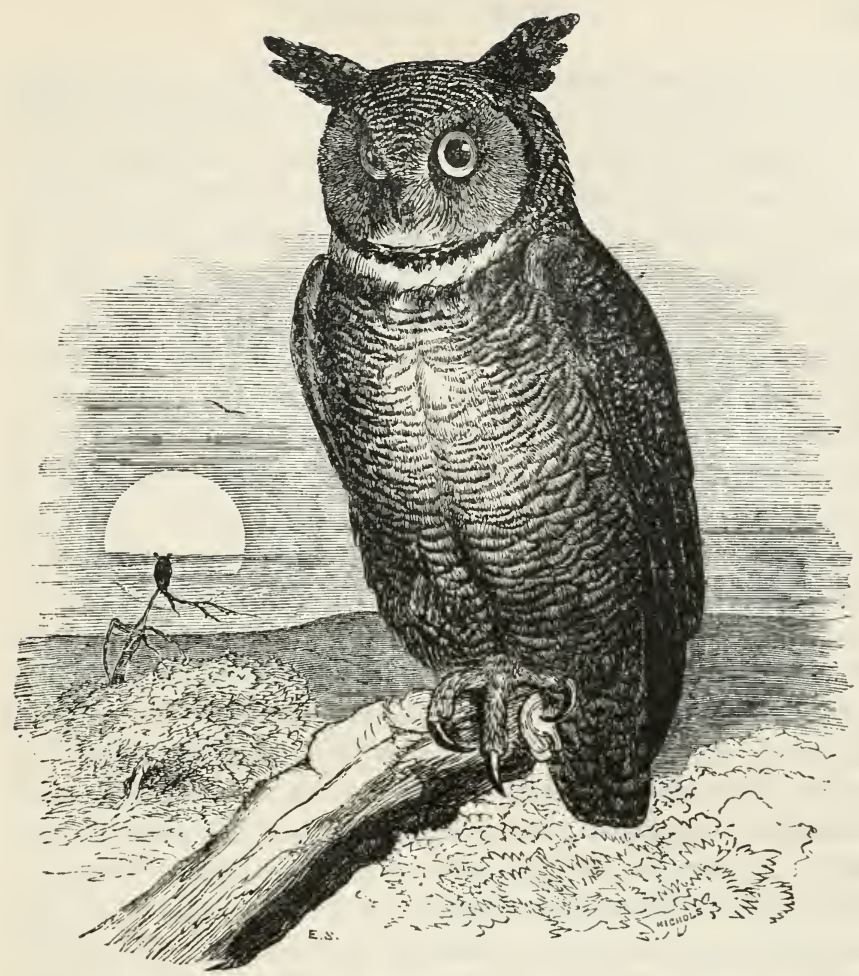

\section{GREAT HORNED OWL.}

\section{CAT OWL.}

\section{Bubo virginianus.}

CHAR. Plumage very variable, of mottled black, light and dark brown, buff, and tawny. A white band on the throat, and a white stripe down the breast, - the latter sometimes obscure. Ear-tufts large and conspicuous; legs and toes feathered. Length $\mathrm{I} 8$ to 25 inches.

Nest. Sometimes within a hollow tree, but usually on an upper limb. A deserted nest of Crow or Hawk is often used, and then it is a clumsy, bulky affair of sticks, lined with feathers.

Eggs. 2-3; white and nearly spherical; $2.20 \times 1.80$.

This species, so nearly related to the Great Eared Owl of Europe, is met with occasionally from Hudson's Bay to 
Florida, and in Oregon; it exists even beyond the tropics, being very probably the same bird described by Marcgrave as inhabiting the forests of Brazil. All climates are alike to this Eagle of the night, the king of the nocturnal tribe of American birds. The aboriginal inhabitants of the country dread his boding howl, dedicating his effigies to their solemnities, and, as if he were their sacred bird of Minerva, forbid the mockery of his ominous, dismal, and almost supernatural cries. His favorite resort, in the dark and impenetrable swampy forests, where he dwells in chosen solitude secure from the approach of every enemy, agrees with the melancholy and sinister traits of his character. To the surrounding feathered race he is the Pluto of the gloomy wilderness, and would scarcely be known out of the dismal shades where he hides, but to his victims, were he as silent as he is solitary. Among the choking, loud, guttural sounds which he sometimes utters in the dead of night, and with a suddenness which always alarms, because of his noiseless approach, is the 'waugh ho! 'waugh ho! which, Wilson remarks, was often uttered at the instant of sweeping down around his camp-fire. Many kinds of Owls are similarly dazzled and attracted by fire-lights, and occasionally finding, no doubt, some offal or flesh thrown out by those who encamp in the wilderness, they come round the nocturnal blaze with other motives than barely those of curiosity. The solitary travellers in these wilds, apparently scanning the sinister motive of his visits, pretend to interpret his address into "'Who 'cooks for you all!" and with a strong guttural pronunciation of the final syllable, to all those who have heard this his common cry, the resemblance of sound is well hit, and instantly recalls the ghastly serenade of his nocturnal majesty in a manner which is not easily forgotten. The shorter cry which we have mentioned makes no inconsiderable approach to that uttered by the European brother of our species, as given by Buffon, namely, 'he-hoo, 'hoo-hoo,boo-hoo, etc. The Greeks called this transatlantic species Byas, either from its note or from the resemblance this bore to the bellowing of the ox. The Latin name $B u b o$ has also reference to the same note of this noc- 
turnal bird. According to Frisch, who kept one of these birds alive, its cries varied according to circumstances; when hungry it had a muling cry like Pühu. I have remarked the young, probably, of our species utter the same low, quailing cry, while yet daylight, as it sat on the low branch of a tree; the sound of both is, at times, also not unlike that made by the Hawks or diurnal birds of prey. Indeed, in gloomy weather I have seen our species on the alert, flying about many hours before dark, and uttering his call of ' $k o k o$, ko kŏ ho. Their usual prey is young rabbits, squirrels, rats, mice, Quails, and small birds of various kinds; and when these resources fail or diminish, they occasionally prowl pretty boldly around the farm-yard in quest of Chickens, which they seize on the roost. Indeed the European Horned Owl frequently contends with the Buzzard for its prey, and generally comes off conqueror; blind and infuriate with hunger, one of these has been known to dart even upon a man, as if for conflict, and was killed in the encounter. My friend Dr. Boykin, of Milledgeville, in Georgia, assured me that one of our own daring nocturnal adventurers, prowling round his premises, saw a cat dozing on the roof of a smoke-house, and supposing grimalkin a more harmless, rabbit-like animal than appeared in the sequel, blindly snatched her up in his talons; but finding he had caught a Tartar, it was not long before he allowed puss once more to tread the ground. In England the same error was committed by an Eagle, who, after a severe conflict with a cat he had carried into the air, was at length brought to the ground before he could disengage himself from the feline grasp.

An Owl of this species, which I have observed in a cage, appeared very brisk late in the morning, hissed and blew when approached with a stick, and dashed at it very heedlessly with his bill; he now and then uttered a 'ko-koh, and was pretty loud in his call at an earlier hour. When approached, he circularly contracted the iris of the eyes to obtain a clearer view of the threatened object; he also listened with great quickness to any sound which occurred near his prison, and eyed the flying Pigeons, which passed by at some distance, with a scruti- 
nizing and eager glance. When fed he often had the habit of hiding away his superfluous provision.

As far as I have been able to observe the retiring manners of this recluse, he slumbers out the day chiefly in the dark tops of lofty trees. In these, according to Wilson, he generally begins to build in the month of May, though probably earlier in the Southern States. The nest is usually placed in the fork of a tree, made of a considerable pile of sticks, and lined with dry leaves and some feathers; and, as a saving of labor, sometimes they select a hollow tree for the purpose.

This Owl is usually found in woods of rather large growth; but Nuttall slightly exaggerated in naming the "dark and impenetrable swampy forest" as its "favorite resort." Throughout the Maritime Provinces it is found on the outskirts of settlements, as well as in the wilderness.

An interesting account of the habits of this species in captivity, from the note-book of Mr. James W. Banks, of St. John, N. B., appeared in "The Auk" for April, I884.

Note. - There are two geographical races of this species that should be named here. The Dusky HoRned OwL ( $B$. virginianus saturatus), an extremely dark form, occurs in Labrador, and is found also on the coast of the Northwest. The WEstern HoRned OWL ( $B$. virginianus subarcticus), a light-gray form, is usually restricted to the middle faunal province, but has been taken in Illinois and Wisconsin.

\section{GREAT GRAY OWL.}

\section{SCOTIAPTEX CINEREA.}

CHAR. Above, sooty brown mottled with irregular bars of dull gray; below, paler tints of same colors in wavy stripes. No ear-tufts. The largest of the Owls. Length. 23 to 30 inches.

Nest. In a tree.

Eggs. 2-3; white; $2.15 \times 1.70$.

This is the largest American species known, and if the $S$. lapponica, common also to the Arctic circle, and seldom leaving it, being only accidental about Lake Superior, and occa- 
sionally seen in Massachusetts in the depth of severe winters. One was caught perched on a wood-pile, in a state of listless inactivity, in the morning after daylight, at Marblehead, in February, I 831. This individual survived for several months, and showed a great partiality for fish and birds. At times he uttered a tremulous cry or hŏ hŏ hŏ hŏ hoo, not very dissimilar to that of the Mottled Owl. At Hudson's Bay and Labrador these Owls reside the whole year, and were found in the Oregon territory by Mr. Townsend. They associate in pairs, fly very low, and feed on mice and hares, which they seize with such muscular vigor as sometimes to sink into the snow after them a foot deep. With ease they are able to carry off the alpine hare alive in their talons. In Europe the species appears wholly confined to the desert regions of Lapland, two or three stragglers being all that have been obtained out of that country by naturalists.

Dr. Richardson says that it is by no means a rare bird in the fur countries, being an inhabitant of all the woody districts lying between Lake Superior and latitudes $67^{\circ}$ or $68^{\circ}$ and between Hudson's Bay and the Pacific. It is common on the borders of Great Bear Lake; and there, and in the higher parallels of latitude, it must pursue its prey, during the summer months, by daylight. It keeps, however, within the woods, and does not frequent the barren grounds, like the Snowy Owl, nor is it so often met with in broad daylight as the Hawk Owl, but hunts principally when the sun is low, - indeed, it is only at such times, when the recesses of the woods are deeply shadowed, that the American hare and the marine animals on which the Cinereous Owl chiefly preys, come forth to feed. On the $23 \mathrm{~d}$ of May I discovered a nest of this Owl, built on the top of a lofty balsam poplar, of sticks, and lined with feathers. It contained three young, which were covered with a whitish down.

The capture in New England of several examples of this species has been recorded. During the winter of $1889-90$, a number were seen along the northern border of these States and in the southern portions of Canada. Mr. McIlwraith reported that a large number had been taken near Hamilton.

.VOL. I. -5 


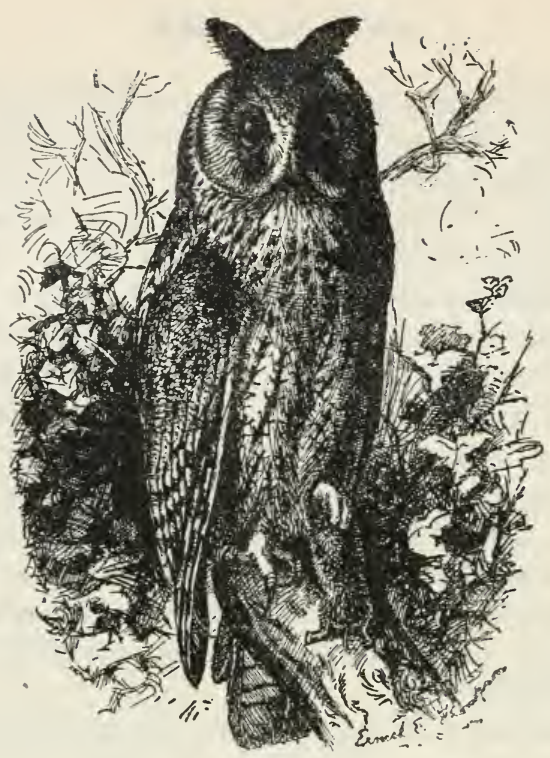

\section{LONG-EARED OWL.}

ASIO WILSONIANUS.

CHAR. Above, finely mottled with dark brown, dull buff, and gray ; breast similar, but of reddish tint; belly paler, with dark markings. Eartufts large; toes feathered. Length 15 inches.

Nest. Usually in a tree; of twigs, lined with grass and feathers. Sometimes a deserted Crow's or Hawk's nest is used.

Eggs. 3-6; white and oval; $1.65 \times 1.30$.

This species, like several others of the genus, appears to be almost a denizen of the world, being found from Hudson's Bay to the West Indies and Brazil, throughout Europe, in Africa, northern Asia, and probably China, in all which countries it appears to be resident, but seems more abundant in certain places in winter, following rats and mice to their retreats in or near houses and barns. It also preys upon small birds, and in summer destroys beetles. It commonly lodges in ruined buildings, the caverns of rocks, or in hollow trees. It defends 
itself with great spirit from the attacks of larger birds, making a ready use of its bill and talons, and when wounded is dangerous and resolute.

The Long-Eared Owl seldom, if ever, takes the trouble to construct a nest of its own; it seeks shelter amidst ruins and in the accidental hollows of trees, and rests content with the dilapidated nursery of the Crow, the Magpie, that of the Wild Pigeon, of the Buzzard, or even the tufted retreat of the squirrel. True to these habits, Wilson found one of these Owls sitting on her eggs in the deserted nest of the Qua Bird, on the $25^{\text {th }}$ of April, six or seven miles below Philadelphia, in the midst of the gloomy enswamped forest which formed the usual resort of these solitary Herons. So well satisfied was she in fact with her company, and so peaceable, that one of the Quas had a nest in the same tree with the Owl. The young, until nearly fully grown, are grayish white, and roost close together on a large branch during the day, sheltered and hid amidst the thickest foliage ; they acquire their natural color in about fifteen days. Besides mice and rats, this species also preys on fieldmice, moles, and beetles. The plaintive cry or hollow moaning made by this bird, "clöw cloud," incessantly repeated during the night, so as to be troublesome where they frequent, is very attractive to the larger birds, who out of curiosity and for persecution assemble around this species when employed as a decoy, and are thus shot or caught by limed twigs.

This Owl occurs throughout temperate North America, and is a common resident everywhere excepting along the northern limit of its range, where it is less abundant, and appears in summer only. 


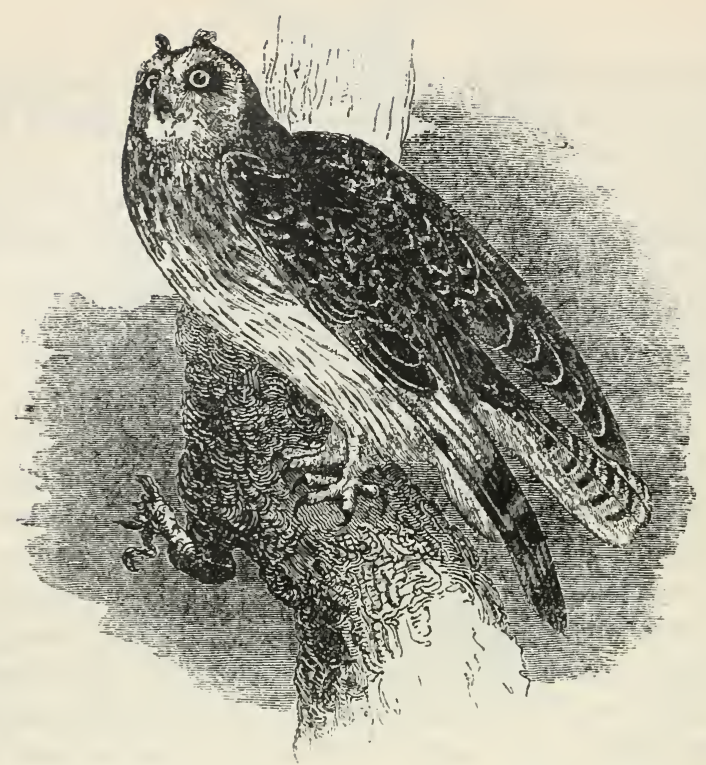

\section{SHORT-EARED OWL.}

\section{Asio ACCIPITRINUS.}

CHAR. Above, mottled with dark brown, tawny, and buffish white; below, paler; feet feathered; ear-tufts inconspicuous. Some examples are much paler, as if the colors had faded. Length about 15 inches.

Nest. On the ground amid tall grass, and composed of a few twigs and a few feathers.

Eggs. 3-6; white and oval ; $1.60 \times 1.20$.

This is another of those nocturnal wanderers which now and then arrive amongst us from the northern regions, where they usually breed. It comes to Hudson's Bay from the South about May, where it makes a nest of dry grass on the ground, and, as usual, has white eggs. After rearing its brood it departs for the South in September, and in its migrations has been met with as far as New Jersey, near Philadelphia, where, according to Wilson, it arrives in November and departs in April. Pennant remarks that it has been met with in the 
southern continent of America at the Faikland Islands. It is likewise spread through every part of Europe, and is common in all the forests of Siberia; it also visits the Orkney Islands and Iceland, and we have observed it at Atooi, one of the Sandwich Islands, in the Pacific, as well as in the territory of Oregon. In England it appears and disappears with the migrations of the Woodcock. Its food is almost exclusively mice, for which it watches, seated on a stump, with all the vigilance of a cat, listening attentively to the low squeak of its prey, to which it is so much alive as to be sometimes brought in sight by imitating the sound. It is readily attracted by the blaze of nocturnal fires, and on such occasions has sometimes had the blind temerity to attack men, and come so close to combat as to be knocked down with sticks. When wounded it also displays the same courageous ferocity, so as to be dangerous to approach. In dark and cloudy weather it sometimes ventures abroad by daylight, takes short flights, and when sitting and looking sharply round, it erects the short, earlike tufts of feathers on the head which are at other times scarcely visible. Like all other migrating birds, roving indifferently over the country in quest of food alone, these Owls have sometimes been seen in considerable numbers together; Bewick even remarks that 28 of them had been counted at once in a turnip-field in England. They are also numerous in Holland in the months of September and October, and in all countries are serviceable for the destruction they make among house and field mice, their principal food. Although they usually breed in high ground, they have also been observed in Europe to nest in marshes, in the middle of the high herbage, - a situation chosen both for safety and solitude.

This is one of the commonest of the New England Owls, and has been supposed to breed in all the suitable marsh land along the coast, but Mr. William Brewster states that he knows "of no authentic record of its breeding in any part of New England within the past ten years." It ranges north to the fur countries, south to the Gulf States and beyond, and west to the Pacific. 


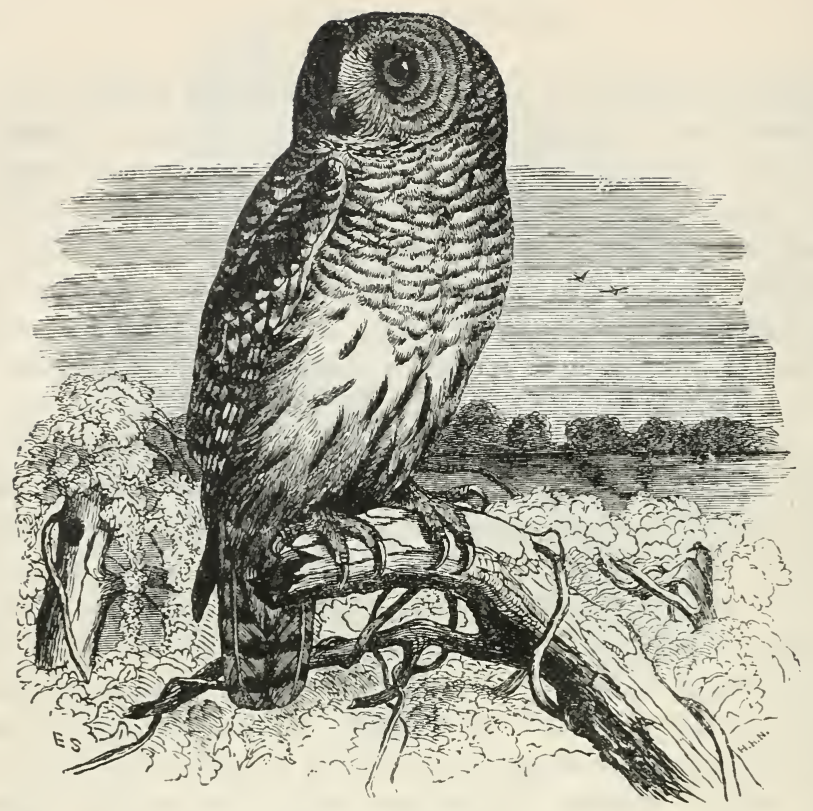

\section{BARRED OWL.}

\section{HOOT OWL.}

\section{SYRNIUM NEBULOSUM.}

Char. Above, brown barred, spotted, and striped with dull gray or tawny; below, similar colors of paler tints; face, gray stripes; tail barred; iris brownish black; bill yellow. Length $193 / 4$ to 24 inches.

Easily distinguished from all other species by its dark eyes.

Nest. Usually in a hollow tree, but often a deserted nest of Crow or Hawk is re-lined and used.

Eggs. 2-4; white and nearly spherical; $1.95 \times 1.65$.

This species inhabits the northern regions of both the old and new continent, but with this difference, as in the Bald Eagle, that in the ancient continent it seldom wanders beyond the Arctic circle, being found no farther to the south than Sweden and Norway; while in America it dwells and breeds at least in all the intermediate region from Hudson's Bay to Florida, being considerably more numerous even than other species throughout the swamps and dark forests of the South- 
ern States. Its food is principally rabbits, squirrels, Grouse, Quails, rats, mice, and frogs. From necessity, as well as choice, these birds not unfrequently appear around the farm-house and garden in quest of the poultry, particularly young chickens. At these times they prowl abroad towards evening, and fly low and steadily about, as if beating for their prey. In Alabama, Georgia, West Florida, and Louisiana, where they abound, they are often to be seen abroad by day, particularly in cloudy weather, and at times even soar and fly with all the address of diurnal birds of prey. Their loud guttural call of ' $k o h$ ' $k o h$ ' $k o$ $k o$, ho', or 'whah 'whah 'whah 'whah-aa, may be heard occasionally both by day and night, and as a note of recognition, is readily answered when mimicked, so as to decoy the original towards the sound. One which I received, in the month of December (1830), was hovering over a covey of Quails in the day-time; and though the sportsman had the same aim, the Owl also joined the chase, and was alone deterred from his sinister purpose by receiving the contents of the gun intended only for the more favorite game. When the young leave the nest they still keep together for mutual warmth and safety in the high, shaded branches of the trees where they have probably been hatched. On being approached by the parents, they utter a hissing call audible for some distance. According to Audubon, when kept in captivity they prove very useful in catching mice. Their flesh is also eaten by the creoles of Louisiana, and considered as palatable.

An interesting article, containing the most valuable information regarding the habits of this Owl that has yet been published, appeared in "The Auk" for April, I890. The writer, Mr. Frank Bolles, kept a pair for several years ; and one of these, having broken its wing, was reduced to such subjection that Mr. Bolles was enabled to make use of it in hunting for other birds, and thus gained an insight into the bird's methods that no other naturalist has equalled.

Note. - The Florida Barred Owl (S. nebulosum alleni), a somewhat darker variety, is restricted to the Gulf States and Florida. 


\title{
SAW-WHET OWL.
}

\author{
ACADIAN OWL.
}

\section{Nyctala aCADica.}

CHAR. Above, dark grayish brown spotted with white; below, white, spotted with reddish brown; tail short, with three narrow bands of white spots. Young almost solid brown of reddish tint, and face with white markings. Length $7 \frac{1}{4}$ to $81 / 2$ inches.

Nest. A hole in a tree (often in a hole that has been deserted by Woodpeckers), lined with feathers.

Eggs. 3-6 (usually 4); white; 1.20 $\times$ 1.00.

This very small species is believed to be an inhabitant of the northern regions of both continents, from which in Europe it seldom wanders, being even very rare in the North of Germany. In the United States it is not uncommon as far to the south as Pennsylvania and New Jersey, where it is resident, having apparently a predilection for the sea-coast, living and nesting in the pine-trees or in the clefts of rocks, and laying 4 or 5 white eggs. It is generally nocturnal; and if accidentally abroad by day, it flies quickly to some shelter from the light. It is very solitary in its habits, living wholly in the evergreen forests, and coming out only towards night or early in the morning in search of mice, beetles, moths, and grasshoppers.

The note of this species is very different from that of the Strix passerina, or Little Owl, to which it is nearly related. This latter kind has a reiterated cry, when flying, like poópoŏ pоŏpoŏ. Another note, which it utters sitting, appears so much like the human voice calling out $a \bar{\imath} m \breve{e}, h \bar{e} m \breve{e}, \bar{e} d m \breve{e}$, that according to Buffon, it deceived one of his servants, who lodged in one of the old turrets of the castle of Montbard; and waking him up at three o'clock in the morning, with this singular cry, he opened the window and called out, "Who's there below? My name is not Edme, but Peter!"

The Saw-whet - called so from its note, which resembles the filing of a saw - breeds from the Middle States northward to about latitude $50^{\circ}$, but is not an abundant bird anywhere. 


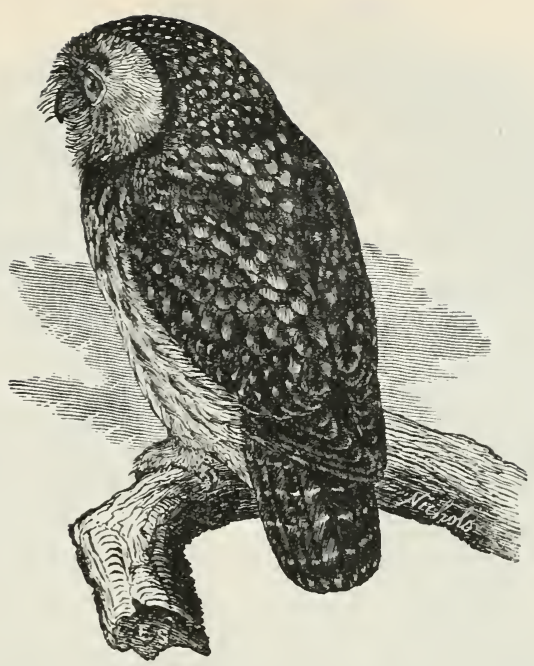

\section{RICHARDSON'S OWL.}

SPARROW OWL.

NyCTALA TENGMALMI RICHARDSONI.

CHAR. Above, dark brown spotted with white; beneath, white streaked with brown; legs and feet buffy, sometimes spotted. Similar to the Sawwhet, but with more white on head and neck. Length 9 to 12 inches.

Nest. In a tree; of grass and leaves.

Eggs. 2-4; white; I. $35 \times$ I.I 5 .

This is a small and nocturnal species, and so much so that when it accidentally wanders abroad by day it is so much dazzled by the light as to be rendered unable to make its escape when surprised, and may then be readily caught by the hand. Its nocturnal cry consists of a single melancholy note repeated at the long intervals of a minute or two: and it is one of the superstitious practices of the Indians to whistle when they hear it ; and if the bird remains silent after this interrogatory challenge, the speedy death of the inquirer is augured; and hence among the Crees it has acquired the omnious appellation of the Bird of Death (Cheepomesēes). According to M. Hutchins, it builds a nest of grass half way up a pine-tree, and lays 
2 eggs in the month of May. It feeds on mice and beetles. It probably inhabits all the forests of the fur countries from Great Slave Lake to the United States. On the banks of the Saskatchewan it is so common that its voice is heard almost every night by the traveller wherever he may select his camp. It inhabits the woods along the streams of the Rocky Mountains down to the Oregon, and betrays but little suspicion when approached.

Richardson's Owl is usually a rare winter visitor to the Maritime Provinces; but Mr. C. B. Cory found it common and breeding on the Magdalene Islands, and a few examples have been taken in New Brunswick in summer.

It is common on the north shore of the Gulf of St. Lawrence, though rare near the city of Quebec; it occurs sparingly in winter along the northern border of New England and in southern Ontario, and occasionally straggles to Massachusetts and Connecticut. Thompson reports it common in Manitoba, and it is found throughout the fur country. Mr. Nelson reports these birds breeding in northern Alaska, where they occupy the deserted nests of other birds - usually on bushes.

Dr. Merriam, on the authority of Mr. Comeau, of Point de Monts, describes the cry of this Owl as "a low liquid note that resembles the sound produced by water slowly dropping from a height." 


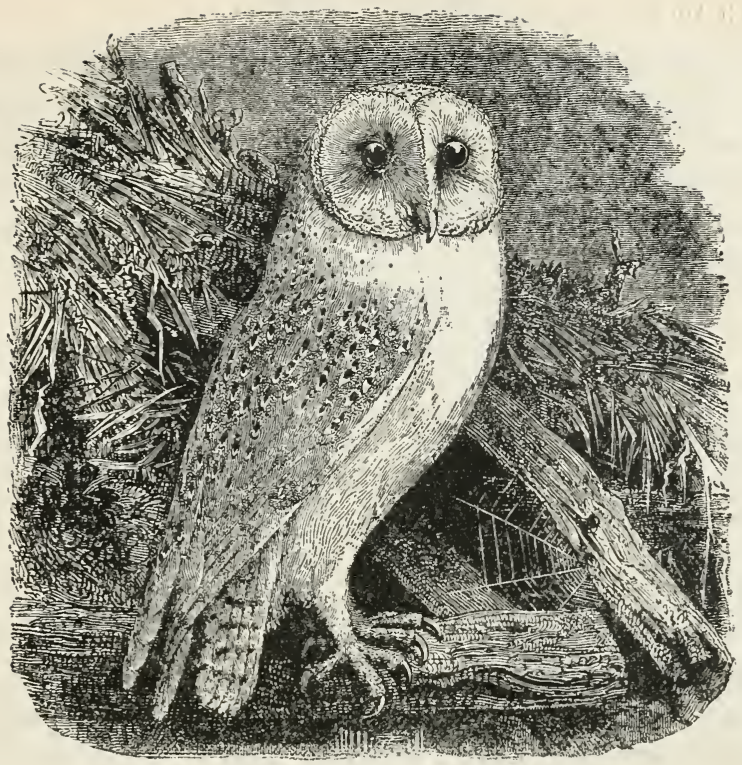

\section{BARN OWL.}

\section{STRIX PRATINCOLA.}

Char. Colors extremely variable. Above, usually yellowish tawny or orange brown, clouded with darker tints and spotted with white; beneath, buffish with dark spots; face white, tinged with tawny; bill whitish. Some examples have but little marking on the back, and the face and lower parts are pure white. Easily distinguished from other Owls by peculiar facial disc. Length 15 to $2 \mathrm{I}$ inches.

Nest. In barn or church tower or hollow tree, - usually the last. The eggs are laid upon a mat of loosely laid twigs and weed-stems or grass.

Eggs. 3-II; white ; 1.75 $\times$ I.30.

There is scarcely any part of the world in which this common species is not found; extending even to both sides of the equator, it is met with in New Holland, India, and Brazil. It is perhaps nowhere more rare than in this part of the United States, and is only met with in Pennsylvania and New Jersey in cold and severe winters. Nor is it ever so familiar as in Europe, frequenting almost uniformly the hollows of trees. 
In the old continent it is almost domestic, inhabiting even populous towns, and is particularly attached to towers, belfries, the roofs of churches, and other lofty buildings, which afford it a retreat during the day. The elegant, graphic lines of Gray, describing its romantic haunt, are in the recollection of every one, -

\section{"From yonder ivy-mantled tower}

The moping Owl does to the moon complain Of such as, wandering near her secret bower, Molest her ancient solitary reign."

Superstition laid aside, these Owls render essential service to the farmer by destroying mice, rats, and shrews, which infest houses and barns; they also catch bats and beetles. They likewise clear churches of such vermin, and now and then, pressed by hunger, they have been known to sip, or rather eat, the oil from the lamps when congealed by cold. A still more extraordinary appetite, attributed to them, is that of catching fish, on which they fed their voracious young. In autumn also they have been known to pay a nightly visit to the places where springes were laid for Woodcocks and Thrushes. The former they killed and ate on the spot; but sometimes carried off the Thrushes and smaller birds, which, like mice, they either swallowed entire, rejecting the indigestible parts by the bill, or if too large, they plucked off the feathers and then bolted them whole, or only took them down piecemeal.

In fine weather they venture out into the neighboring woods at night, returning to their usual retreat at the approach of morning. When they first sally from their holes, their eyes hardly well opened, they fly tumbling along almost to the ground, and usually proceed side-ways in their course. In severe seasons, 5 or 6 , probably a family brood, are discovered in the same retreat, or concealed in the fodder of the barn, where they find. shelter, warmth, and food. The Barn Owl drops her eggs in the bare holes of walls, in the joists of houses, or in the hollows of decayed trees, and spreads no lining to receive them; they are 3 to 5 in number, of a whitish color, and rather long than round. 
When out abroad by day, like most of the other species, they are numerously attended by the little gossiping and insulting birds of the neighborhood; and to add to their distraction, it is not an uncommon practice, in the North of England, for boys to set up a shout and follow the Owl, who becomes so deafened and stunned as at times nearly to fall down, and thus become an easy prey to his persecutors. And the probability of such an effect will not be surprising when we consider the delicacy and magnitude of the auditory apparatus of this bird, the use of which is probably necessary to discover the otherwise silent retreats of their tiny prey. When taken captive, according to Buffon, they do not long survive the loss of liberty, and pertinaciously refuse to eat, - a habit very different from that of the young Red Owl, who allowed himself to feed from my hand, and tugged greedily and tamely at the morsel held out to him until he got it in his possession; small birds also he would instantly grasp in his talons, and hiss and shaie, shaie, when any attempt was made to deprive him of his booty.

The young of this species, when they have just attained their growth, are, in France, considered good food, as they are then fat and plump. When first hatched they are so white and downy as almost entirely to resemble a powder puff. At Hudson's Bay a large Owl, resembling the cinereous, is likewise eaten, and esteemed a delicacy, according to Pennant.

The Barn Owl occurs regularly from the Middle States southward, though it is not abundant north of South Carolina. A few examples have been taken in Connecticut and Massachusetts, and Mr. McIlwraith reports that four have been taken in Ontario. 


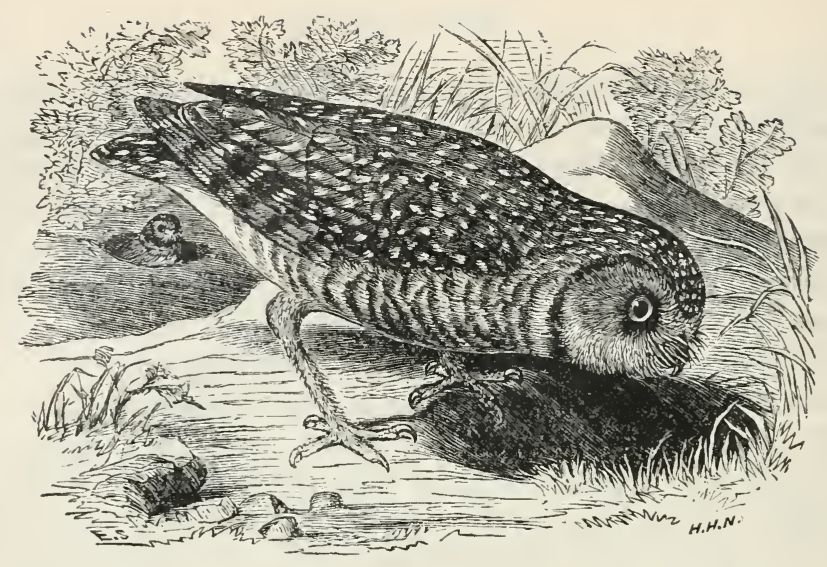

\section{FLORIDA BURROWING OWL.}

\section{SPEOTYTO CUNICULARIA FLORIDANA.}

CHAR. Above, grayish brown spotted and barred with white; below, pale buffish barred with brown; a patch of white on the breast; legs long and slender, and covered with buffish bristles. Length about io inches.

Nest. At the end of a burrow in the ground, lined with grass and feathers.

Eggs. 4-10; white, varying in shape, usually nearly round; I.25 $\times 1.00$.

This variety, which is found in Florida only, is smaller and lightercolored than is the well-known bird of the prairies. In habits the two differ little, the Florida birds living in communities, - sometimes several pairs in one burrow, - and feeding on mice and small birds. The tales related of Burrowing Owls and rattlesnakes occupying the same burrow are "hunter's tales," and lack confirmation.

Note. - The Western form of the Burrowing OwL (S. cunicularia hypogaa, has been taken in Massachusetts; but its occurrence to the eastward of the Great Plains is accidental. 


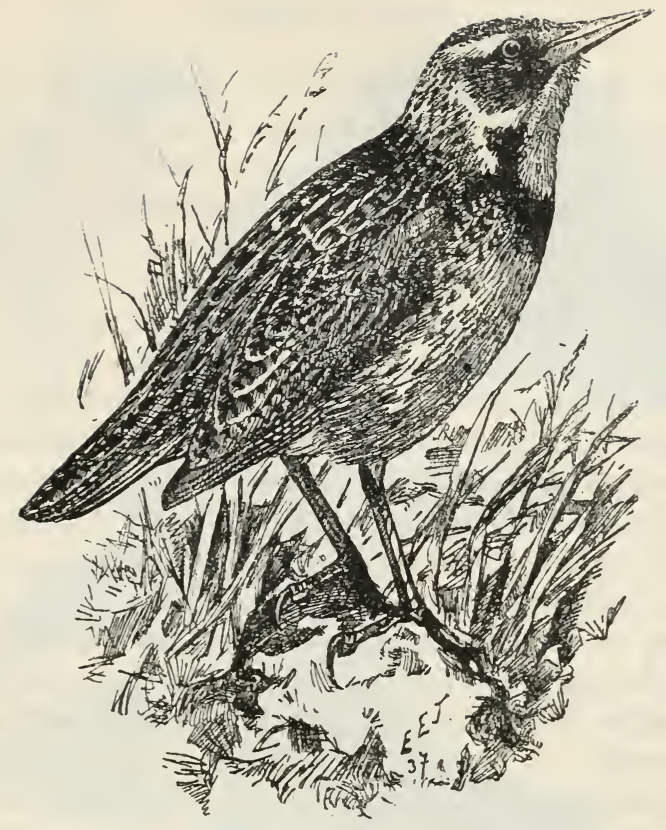

\section{MEADOIVLARK.}

FIELD LARK.

\section{STURNELla MAGNA.}

CHAR. Above, grayish brown barred with black; crown with medial stripe of buff; lateral tail-feathers white; below yellow, sides darker and spotted with brown; black crescent on the breast. Length about Io inches.

Nest. Made of dry grass and placed amid a tuft of long grass in a meadow; often covered, and the opening placed at the side.

Eggs. 4-6; white, thickly spotted with reddish brown and lilac; I.I $5 \times .80$.

This well-known harmless inhabitant of meadows and old fields is not only found in every part of the United States, but appears to be a resident in all the intermediate region, from the frigid latitude of $53^{\circ}$ and the territory of Oregon, to the mild table-land of Mexico and the savannahs of Guiana. In the winter these birds abound in Alabama and Western 
Florida; so that in some degree, like the Jays and the legitimate Starlings, they partially migrate in quest of food during the severity of the weather in the colder States. It is not, however, improbable but that most of the migrating families of these birds, which we find at this season, have merely travelled eastward from the cold Western plains that are annually covered with snow. They are now seen in considerable numbers in and round the salt-marshes, roving about in flocks of ten to thirty or more, seeking the shelter of the sea-coast, though not in such dense flocks as the true Starlings; these, in the manner of our common Blackbirds, assemble in winter like dark clouds, moving as one body, and when about to descend, perform progressive circular evolutions in the air like a phalanx in the order of battle; and when settled, blacken the earth with their numbers, as well as stun the ears with their chatter. Like Crows also, they seek the shelter of reed-marshes to pass the night, and in the day take the benefit of every sunny and sheltered covert.

Our Starling, like the American Quail, is sociable, and somewhat gregarious; and though many, no doubt, wander some distance after food, yet a few, in Pennsylvania as well as in this rigorous climate, may be seen in the market after the ground is covered with snow. Wilson even observed them in the month of February, during a deep snow, among the heights of the Alleghanies, gleaning their scanty pittance on the road, in company with the small Snow Birds.

The flesh of our bird is white, and for size and delicacy it is considered little inferior to the Partridge ; but that of the European species is black and bitter.

The flight of these Larks is laborious and steady, like that of the Quail, with the action of the wings renewed at short intervals. They often alight on trees, and select usually the main branches or topmost twigs on which to perch, though their food is commonly collected from the ground. At various times of the day, and nearly through the winter, in the milder States, their very peculiar lisping, long, and rather melancholy note is heard at short intervals; and without the variations, which are 

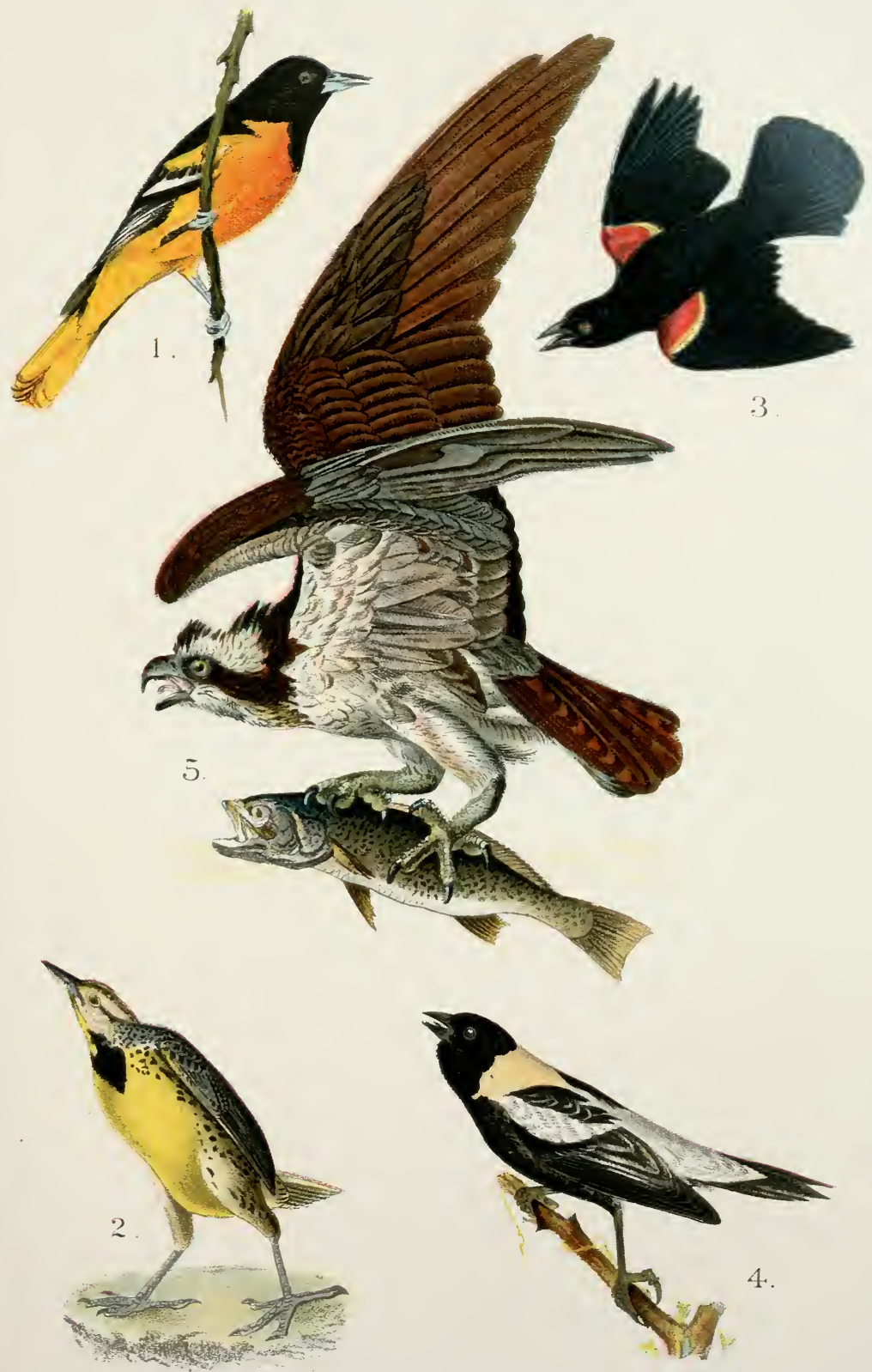

1. Baltimore Oriole.

3. Red-winged Blackbird. 5. American 0sprey.

2. Meadowlark.

4. Bobolink. 

not inconsiderable, bears some resemblance to the slender singing and affected pronunciation of èt sě dée àh, and psédee etsītìo, or tai sedízo in a slow, wiry, shrill tone, and sometimes differently varied and shortened. The same simple ditty is repeated in the spring, when they associate in pairs; the female also, as she rises or descends, at this time frequently gives a reiterated guttural chirp, or hurried twitter, like that of the female Redwinged Blackbird. I have likewise at times heard them utter notes much more musical and vigorous, not very unlike the fine tones of the Sky Lark; but I can by no means compare our lisping songster with that blithe "harbinger of day." There is a monotonous affectation in the song of our Lark which appears indeed somewhat allied to the jingling, though not unpleasant, tune of the Starling. The Stare, moreover, had the faculty of imitating human speech (which ours has not, as far as we yet know), and could indifferently speak even French, English, German, Latin, and Greek, or any other language within his hearing, and repeat short phrases; so that " 'I can't get out, I can't get out,' says the Starling," which accidentally afforded Sterne such a beautiful and pathetic subject for his graphic pen, was probably no fiction.

At the time of pairing, our Lark exhibits a little of the jealous disposition of his tribe; and having settled the dispute which decides his future condition, he retires from his fraternity, and, assisted by his mate, selects a thick tuft for the reception of his nest, which is pretty compact, made of dry, wiry grass, and lined with finer blades of the same. It is usually formed with a covered entrance in the surrounding withered grass, through which a hidden and almost winding path is made, and generally so well concealed that the nest is only to be found when the bird is flushed.

The eggs are four or five, white, with a very faint tint of blue, almost round, and rather large, for the size of the bird, marked with numerous small reddish-brown spots, more numerous at the greater end, blended with other lighter and darker points and small spots of the same. They probably often raise two broods in the season. About the time of

VOL. I. -6 
pairing, in the latter end of the month of April, they have a call, like 'tship, twee, the latter syllable in a fine and slender tone, - something again allied to the occasional notes of the Red-winged Blackbird, to which genus (Icterus) our Sturnella is not very remotely allied. Towards the close of June little else is heard from the species but the noisy twitter of the female, preceded by a hoarse and sonorous 'j'imp or ' $j$ ' $i p$, accompanied by an impatient raising and lowering of the wings, and, in short, all the unpleasant and petulant actions of a brood-hen, as she is now assiduously engaged in fostering and supporting her helpless and dependent offspring.

Their food consists of the larvæ of various insects, as well as worms, beetles, and grass-seeds, to assist the digestion of which they swallow a considerable portion of gravel. It does not appear that these birds add berries or fruits of any kind to their fare, like the Starling, but usually remain the whole summer in moist meadows, and in winter retire to the open grassy woods, having no inclination to rob the orchard or garden, and, except in winter, are of a shy, timid, and retiring disposition.

In the East the Meadowlark seldom ranges north of latitude $45^{\circ}$. I met with but one example in New Brunswick, and learn that it is rare near Montreal. It is common around Ottawa and throughout southern Ontario. In winter these birds are found occasionally as far north as southern New England and Illinois.

Note. - A larger and paler form, named the Western MeadOWLARK (S. magna neglecta), occurs in Wisconsin, Illinois, and Iowa; and Mr. W. E. D. Scott has lately announced that the birds found in southwestern Florida should be referred to mexicana, the Mexican MEadowlark, which is the smallest of the three.

A stray StARLing (Sturnus vulgaris) is said to have wandered from Europe to Greenland; and some sixty were imported and released in Central Park, New York, in 1890. They are thriving and increasing, giving evidence of ability to withstand the winter storm.

A Troupial (Icterus icterus), a South American bird, was taken by Audubon near Charleston, S. C. 


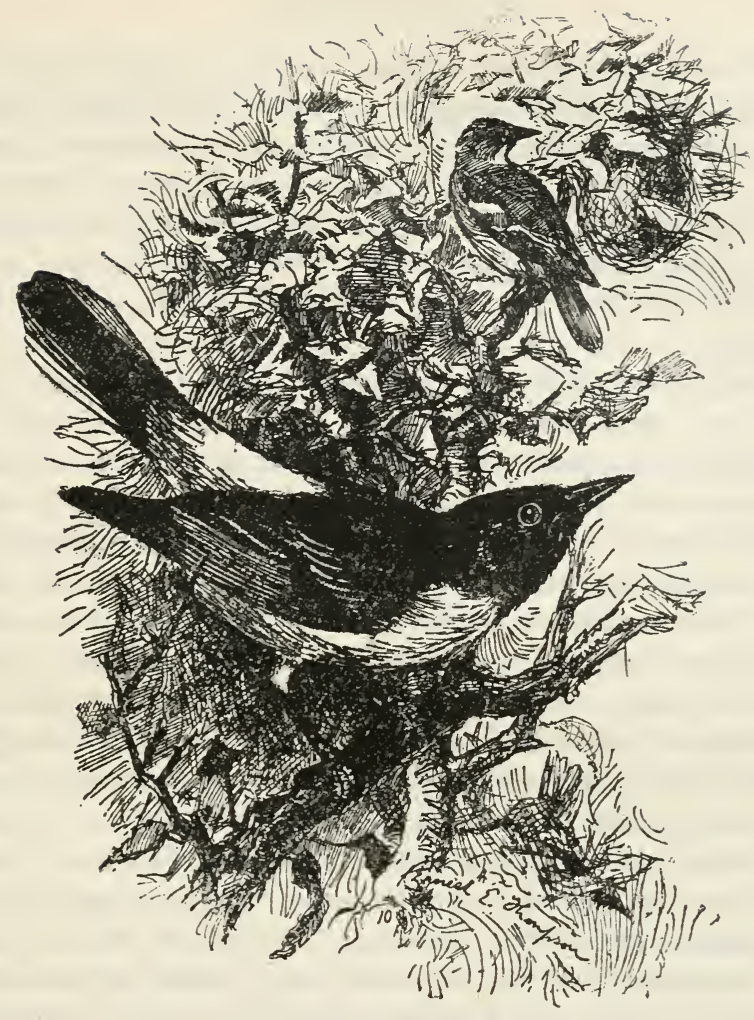

BALTIMORE ORIOLE.

GOLDEN ROBIN. HANG-NEST. FIRE BIRD.

ICTERUS GALBULA.

CHAR. Male : head, neck, throat, back, wings, and greater part of tail black; wing-coverts and secondaries tipped with white; other parts orange. Bill and feet blue black. Female : smaller and paler, sometimes the black replaced by olive brown or grayish orange. Young similar to female. Length 7 to 8 inches.

Nest. Pensile and purse-shaped, 6 to 8 inches deep, suspended from extremity of branch 10 to 50 feet from the ground, composeci of yarn, string, horsehair, grass, etc., woven into a compact texture.

Eggs. 4-6; dull white, blotched irregularly with dark brown; .90 X.60. 
These gay, lively, and brilliant strangers, leaving their hibernal retreat in South America, appear in New England about the first week in May, and more than a month earlier in Louisiana, according to the observations of Audubon. They were not seen, however, in West Florida by the middle of March, although vegetation had then so far advanced that the oaks were in leaf, and the white flowering cornel was in full blossom.

It is here that they pass the most interesting period of their lives; and their arrival is hailed as the sure harbinger of approaching summer. Full of life and activity, these fiery sylphs are now seen vaulting and darting incessantly through the lofty boughs of our tallest trees; appearing and vanishing with restless inquietude, and flashing at quick intervals into sight from amidst the tender waving foliage, they seem like living gems intended to decorate the verdant garment of the new-clad forest. But the gay Baltimore is neither idle nor capricious; the beautiful small beetles and other active-winged insects on which he now principally feeds are in constant motion, and require perpetual address in their capture. At first the males only arrive, but without appearing in flocks; their mates are yet behind, and their social delight is incomplete. They appear to feel this temporary bereavement, and in shrill and loud notes they fife out their tender plaints in quick succession, as they pry and spring through the shady boughs for their tiny and eluding prey. They also now spend much time in the apple-trees, often sipping honey from the white blossoms, over which they wander with peculiar delight, continually roving amidst the sweet and flowery profusion. The mellow whistled notes which they are heard to trumpet from the high branches of our tallest trees and gigantic elms resemble, at times, 'tshippe-tshayia too too, and sometimes 'tshippee 'tshippee (lispingly), too too (with the two last syllables loud and full). These notes are also varied by some birds so as to resemble 'tsh 'tsh 'tsheetshoo tshoo tshoo, 'also 'tsh 'tsheefä' tsheefă 'tsheefă

1 The first three of these notes are derived from the Summer Yellow Bird, though not its most usual tones. 
tshoo and 'k'túf ă túf ă túf a téa kĕrry $;^{1}$ another bird I have occasionally heard to call for hours, with some little variation, tú těo tĕo těo teo too, in a loud, querulous, and yet almost ludicrously merry strain. At other intervals the sensations of solitude seem to stimulate sometimes a loud and interrogatory note, echoed forth at intervals, as k'rry kerry? and terminating plaintively k'rry k'rry k'rry, tū; the voice falling off very slenderly in the last long syllable, which is apparently an imitation from the Cardinal Grosbeak, and the rest is derived from the Crested Titmouse, whom they have already heard in concert as they passed through the warmer States. Another interrogatory strain which I heard here in the spring of I 830 was precisely, 'yip k'rry, 'yip, 'yip k'rry, very loud and oft repeated. Another male went in his ordinary key, tsherry tshèrry, tshipee tsh'rry, - notes copied from the exhaustless stock of the Carolina Wren (also heard on his passage), but modulated to suit the fancy of our vocalist. The female likewise sings, but less agreeably than the male. One which I had abundant opportunity of observing, while busied in the toil of weaving her complicated nest, every now and then, as a relief from the drudgery in which she was solely engaged, sung, in a sort of querulous and rather plaintive strain, the strange, uncouth syllables, 'kà 'keà kŏwà, keka keka, the final tones loud and vaulting, which I have little doubt were an imitation of the discordant notes of some South American bird. For many days she continued this tune at intervals without any variation. The male, also while seeking his food in the same tree with his mate, or while they are both attending on their unfledged brood, calls frequently in a low, friendly whisper, 'twait, tw'it. Indeed, all the individuals of either sex appear pertinaciously to adhere for weeks to the same quaint syllables which they have accidentally collected.

This bird then, like the Starling, appears to have a taste for mimicry, or rather for sober imitation. A Cardinal Grosbeak happening, very unusually, to pay us a visit, his harmonious

I The last phrase loud and ascending, the tea plaintive, and the last syllable tender and echoing. 
and bold whistle struck upon the ear of a Baltimore with great delight; and from that moment his ordinary notes were laid aside for 'woit, 'woit, teú, and other phrases previously foreign to him for that season. I have likewise heard another individual exactly imitating the soft and somewhat plaintive vit $y u$, vit yiu of the same bird, and in the next breath the peít, or call of Wilson's Thrush; also at times the earnest song of the Robin. Indeed his variations and imitations have sometimes led me to believe that I heard several new and melodious birds, and I was only undeceived when I beheld his brilliant livery. So various, in fact, are the individual phrases chanted by this restless and lively bird that it is scarcely possible to fix on any characteristic notes by which he may be recognized; his singular, loud, and almost plaintive tone, and a fondness for harping long on the same string, are perhaps more peculiar than any particular syllables which he may be heard to utter. When alarmed or offended at being too closely watched or approached, both male and female utter an angry, rattling tsher tsh'r, or hiss, tsh' tsh' tsh' 'tsh.

The beautiful Baltimore bird is only one of the tribe of true Icteri, which, except the present and two following species, remain within the tropical regions, or only migrate to short distances in the rainy season. Ours wing their way even into Canada as far as the $55^{\text {th }}$ degree, and breed in every intermediate region to the table-land of Mexico. A yellow Brazilian species of the section of this genus, called cassicus, according to Waterton inhabits also Demerara, where, like our bird, he familiarly weaves his pendulous nest near the planter's house, suspending it from the drooping branches of trees, and so low that it may be readily looked into even by the incurious. Omnivorous like the Starling, he feeds equally on insects, fruits, and seeds. He is called the Mocking Bird, and for hours together, in gratitude as it were for protection, he serenades the inhabitants with his imitative notes. His own song, though short, is sweet and melodious. But hearing perhaps the yelping of the Toucan, he drops his native strain to imitate it, or place it in ridicule by contrast. Again, he gives the cackling 
cries of the Woodpecker, the bleating of the sheep; an interval of his own melody, then probably a puppy dog or a Guineafowl receives his usual attention: and the whole of this mimicry is accompanied by antic gestures indicative of the sport and company which these vagaries afford him. Hence we see that the mimicking talent of the Stare is inherent in this branch of the gregarious family, and our own Baltimore, in a humbler style, is no less delighted with the notes of his feathered neighbors.

There is nothing more remarkable in the whole instinct of our Golden Robin than the ingenuity displayed in the fabrication of its nest, which is, in fact, a pendulous cylindric pouch of five to seven inches in depth, usually suspended from near the extremities of the high, drooping branches of trees (such as the elm, the pear or apple tree, wild-cherry, weeping-willow, tulip-tree, or buttonwood). It is begun by firmly fastening natural strings of the flax of the silk-weed, or swamp-holyhock, or stout artificial threads, round two or more forked twigs, corresponding to the intended width and depth of the nest. With the same materials, willow down, or any accidental ravellings, strings, thread, sewing-silk, tow, or wool, that may be lying near the neighboring houses, or round the grafts of trees, it interweaves and fabricates a sort of coarse cloth into the form intended, towards the bottom of which is placed the real nest, made chiefly of lint, wiry grass, horse and cow hair, sometimes, in defect of hair, lining the interior with a mixture of slender strips of smooth vine-bark, and rarely with a few feathers, the whole being of a considerable thickness, and more or less attached to the external pouch. Over the top, the leaves, as they grow out, form a verdant and agreeable canopy, defending the young from the sun and rain. There is sometimes a considerable difference in the manufacture of these nests, as well as in the materials which enter into their composition. Both sexes seem to be equally adepts at this sort of labor, and I have seen the female alone perform the whole without any assistance, and the male also complete this laborious task nearly without the aid of his consort, - who, how- 
ever, in general, is the principal worker. I have observed a nest made almost wholly of tow, which was laid out for the convenience of a male bird, who with this aid completed his labor in a very short time, and frequently sang in a very ludicrous manner while his mouth was loaded with a mass larger than his head. So eager are these birds to obtain fibrous materials that they will readily tug at and even untie hard knots made of tow. In Audubon's magnificent plates a nest is represented as formed outwardly of the long-moss; where this abounds, of course, the labor of obtaining materials must be greatly abridged. The author likewise remarks that the whole fabric consists almost entirely of this material, loosely interwoven, without any warm lining, - a labor which our ingenious artist seems aware would be superfluous in the warm forests of the lower Mississippi. A female, which I observed attentively, carried off to her nest a piece of lamp-wick ten or twelve feet long. This long string, and many other shorter ones, were left hanging out for about a week before both the ends were wat-

- tled into the sides of the nest. Some other little birds, making use of similar materials, at times twitched these flowing ends, and generally brought out the busy Baltimore from her occupation in great anger.

The haste and eagerness of one of these airy architects, which I accidentally observed on the banks of the Susquehanna, appeared likely to prove fatal to a busy female who, in weaving, got a loop round her neck; and no sooner was she disengaged from this snare than it was slipped round her feet, and thus held her fast beyond the power of escape! The male came frequently to the scene, now changed from that of joy and hope into despair, but seemed wholly incapable of comprehending or relieving the distress of his mate. In a second instance I have been told that a female has been observed dead in the like predicament.

The eggs of this species are usually four or five, white, with a faint, indistinct tint of bluish, and marked, chiefly at the greater end, though sometimes scatteringly, with straggling, serpentine, dark-brown lines and spots, and fainter hair streaks, 
looking sometimes almost like real hair, and occasionally lined only, and without the spots. The period of incubation is fourteen days. In Louisiana, according to Audubon, they frequently raise two broods in the season, arriving in that country with the opening of the early spring. Here they raise but a single brood, whose long and tedious support in their lofty cradle absorbs their whole attention; and at this interesting period they seem, as it were, to live only to protect, cherish, and educate their young. The first and general cry which the infant brood utter while yet in the nest, and nearly able to take wing, as well as for some days after, is a kind of té-did té-

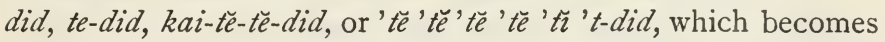
clamorous as the parents approach them with food. They soon also acquire the scolding rattle and short notes which they probably hear around them, such as peet-weet, the cry of the spotted Sandpiper, and others, and long continue to be assiduously fed and guarded by their very affectionate and devoted parents. Unfortunately, this contrivance of instinct to secure the airy nest from the depredations of rapacious monkeys, and other animals which frequent trees in warm or mild climates, is also occasionally attended with serious accidents, when the young escape before obtaining the perfect use of their wings. They cling, however, with great tenacity either to the nest or neighboring twigs; yet sometimes they fall to the ground, and, if not killed on the spot, soon become a prey to numerous enemies. On such occasions it is painful to hear the plaints and wailing cries of the parents. And when real danger offers, the generous and brilliant male, though much the less querulous of the two, steps in to save his brood at every hazard; and I have known one so bold in this hopeless defence as to suffer himself to be killed, by a near approach with a stick, rather than desert his offspring. Sometimes, after this misfortune, or when the fell cat has devoured the helpless brood, day after day the disconsolate parents continue to bewail their loss. They almost forget to eat amidst their distress, and after leaving the unhappy neighborhood of their bereavement, they still come, at intervals, to visit and lament over the fatal spot, as if 
spell-bound by despair. If the season be not too far advanced, the loss of their eggs is generally soon repaired by constructing a second nest, in which, however, the eggs are fewer.

The true Oriole (O. galbula), which migrates into Africa, and passes the breeding season in the centre of Europe, also makes a pendulous nest, and displays great courage in the defence of its young, being so attached to its progeny that the female has been taken and conveyed to a cage on her eggs, on which, with resolute and fatal instinct, she remained faithfully sitting until she expired.

The Baltimore bird, though naturally shy and suspicious, probably for greater security from more dangerous enemies, generally chooses for the nest the largest and tallest spreading trees near farm-houses, and along frequented lanes and roads; and trusting to the inaccessibleness of its ingenious mansion, it works fearlessly and scarcely studies concealment. But as soon as the young are hatched, here, towards the close of June, the whole family begin to leave the immediate neighborhood of their cares, flit through the woods, - a shy, roving, and nearly silent train; and when ready for the distant journey before them, about the end of August or beginning of September, the whole at once disappear, and probably arrive, as with us, amidst the forests of South America in a scattered flock, and continue, like Starlings, to pass the winter in celibacy, wholly engaged in gleaning a quiet subsistence until the return of spring. Then, incited by instinct to prepare for a more powerful passion, they again wing their way to the regions of the north, where, but for this wonderful instinct of migration, the whole race would perish in a single season. As the sexes usually arrive in different flocks, it is evident that the conjugal tie ceases at the period of migration, and the choice of mates is renewed with the season; during which the males, and sometimes also the females, carry on their jealous disputes with much obstinacy.

That our Oriole is not familiar with us, independent of the all-powerful natural impulse which he obeys, is sufficiently obvious when he nests in the woods. Two of these solitary 
and retiring pairs had this summer, contrary to their usual habits, taken up their abode in the lofty branches of a gigantic Buttonwood in the forest. As soon as we appeared they took the alarm, and remained uneasy and irritable until we were wholly out of sight. Others, again, visit the heart of the populous city, and pour forth their wild and plaintive songs from the trees which decorate the streets and gardens, amid the din of the passing crowd and the tumult of incessant and noisy occupations. Audubon remarks that their migrations are performed singly and during the day, and that they proceed high, and fly straight and continuous.

The food of the Baltimore appears to be small caterpillars, sometimes those of the apple-trees, - some uncommon kinds of beetles, cimices, and small flies, like a species of cynips. Occasionally I have seen an individual collecting Cicindeli by the sides of sandy and gravelly roads. They feed their young usually with soft caterpillars, which they swallow, and disgorge on arriving at the nest; and in this necessary toil both sexes assiduously unite. They seldom molest any of the fruits of our gardens, except a few cherries and mulberries, and are the most harmless, useful, beautiful, and common birds of the country. They are, however, accused of sometimes accompanying their young to the garden peas, which they devour while small and green; and being now partly gregarious, the damage they commit is at times rendered visible. Occasionally they are seen in cages, being chiefly fed on soaked bread, or meal and water; they appear also fond of cherries, strawberries, currants, raisins, and figs, so that we may justly consider them, like the Cassicans and Starlings, as omnivorous, though in a less degree. They sing and appear lively in confinement or domestication, and become very docile, playful, and friendly, even going in and out of the house, and sometimes alighting at a whistle on the hand of their protector. The young for a while require to be fed on animal food alone, and the most suitable appears to be fresh minced meat, soaked in new milk. In this way they may be easily raised almost from the first hatching; but at this time vegetable substances 
appear to afford them no kind of nutrition, and at all times they will thrive better if indulged with a little animal food or insects, as well as hard-boiled eggs.

The summer range of this beautiful bird in the fur countries extends to the $55^{\text {th }}$ degree of latitude, arriving on the plains of the Saskatchewan, according to Richardson, about the Ioth of May, or nearly as early as their arrival in Massachusetts. Those which thus visit the wilds of Canada in all probability proceed at once from Mexico, or ascend the great valley of the Mississippi and Missouri.

I have had a male bird in a state of domestication raised from the nest very readily on fresh minced meat soaked in milk. When established, his principal food was scalded Indian cornmeal, on which he fed contentedly, but was also fond of sweet cakes, insects of all descriptions, and nearly every kind of fruit. In short, he ate everything he would in a state of nature, and did not refuse to taste and eat of everything but the condiments which enter into the multifarious diet of the human species: he was literally omnivorous.

No bird could become more tame, allowing himself to be handled with patient indifference, and sometimes with playfulness. The singular mechanical application of his bill was remarkable, and explains at once the ingenious art employed by the species in weaving their nest. If the folded hand was presented to our familiar Oriole, he endeavored to open it by inserting his pointed and straight bill betwixt the closed fingers, and then by pressing open the bill with great muscular force, in the manner of an opening pair of compasses, he contrived, if the force was not great, to open the hand and examine its contents. If brought to the face he did the same with the mouth, and would try hard to open the closed teeth. In this way, by pressing open any yielding interstice, he could readily insert the threads of his nest, and pass them through an infinity of openings, so as to form the ingenious net-work or basis of his suspensory and procreant cradle.

This is a familiar bird throughout the greater part of this faunal province north to the southern portions of Ontario and Quebec, 
and it occurs sparingly in New Brunswick and Nova Scotia. It winters southward to Panama.

Note. - A single example of Bullock's ORIOLE (Icterus bullocki), which was shot near Bangor, Maine, in I889, gives this species a right to be mentioned here. The usual habitat of this species is between the eastern base of the Rockies and the Pacific coast.

\section{ORCHARD ORIOLE.}

\section{ICTERUS SPURIUS.}

CHAR. Male : head, neck, back, wings, and tail black; other parts chestnut, deepest on breast. Female : yellowish olive inclining to brown; wings dusky brown with 2 white bands; beneath, olive yellow. Young similar to female. Length 6 to $7 \frac{1}{4} /$ inches.

Nest. A handsome basket-like structure, about 4 inches in depth, composed of grasses woven into a smooth firm fabric, and lined with feathers or other soft material. It is sometimes partly supported in the forks of small twigs, and often entirely pendent. Usually about io feet from the ground and near the end of the branch.

Eggs. 3-6 (generally 4); white with blue or green tint, irregularly marked with lilac and brown; $.80 \times .60$.

This smaller and plainer species has many of the habits of the Baltimore bird, and arrives in Pennsylvania about a week later. They enter the southern boundary of the United States early in March, and remain there until October. They do not however, I believe, often migrate farther north and east than the State of Connecticut. I have never seen or heard of them in Massachusetts, any more than my scientific friend, and close observer, Mr. C. Pickering. Their stay in the United States, it appears from Wilson, is little more than four months, as they retire to South America early in September, or at least do not winter in the Southern States. According to my friend Mr. Ware, they breed at Augusta, in Georgia; and Mr. Say observed the Orchard Oriole at Major Long's winter quarters on the banks of the Missouri. Audubon has also observed the species towards the sources of the Mississippi, as well as in the State of Maine. The same author likewise remarks that their 
northern migrations, like those of the Baltimore bird, are performed by day, and that the males arrive a week or ten days sooner than their mates. They appear to affect the elevated and airy regions of the Alleghany mountains, where they are much more numerous than the Baltimore.

The Orchard Oriole is an exceedingly active, sprightly, and restless bird; in the same instant almost, he is on the ground after some fallen insect, fluttering amidst the foliage of the trees, prying and springing after his lurking prey, or flying and tuning his lively notes in a manner so hurried, rapid, and seemingly confused that the ear is scarce able to thread out the shrill and lively tones of his agitated ditty. Between these hurried attempts he also gives others, which are distinct and agreeable, and not unlike the sweet warble of the Red-Breasted Grosbeak, though more brief and less varied. In choosing the situation of his nest he is equally familiar with the Baltimore Oriole, and seems to enjoy the general society of his species, suspending his most ingenious and pensile fabric from the bending twig of the apple-tree, which, like the nest of the other, is constructed in the form of a pouch from three to five inches in depth, according to the strength or flexibility of the tree on which he labors; so that in a weeping-willow, according to Wilson, the nest is one or two inches deeper than if in an apple-tree, to obviate the danger of throwing out the eggs and young by the sweep of the long, pendulous branches. It is likewise slighter, as the crowding leaves of that tree afford a natural shelter of considerable thickness. That economy of this kind should be studied by the Orchard Oriole will scarcely surprise so much as the laborious ingenuity and beautiful tissue of its nest. It is made exteriorly of a fine woven mat of long, tough, and flexible grass, as if darned with a needle. The form is hemispherical, and the inside is lined with downy substances, - sometimes the wool of the seeds of the Buttonwood, - forming thus a commodious and soft bed for the young. This precaution of a warm lining, as in the preceding species, is, according to Audubon, dispensed with in the warm climate of Louisiana. The eggs are 4 or 5 , of a very pale bluish 
tint, with a few points of brown, and spots of dark purple, chiefly disposed at the greater end. The female sits about I4 days, and the young continue in the nest ro days before they become qualified to flit along with their parents; but they are generally seen abroad about the middle of June. Previously to their departure, the young, leaving the care of their parents, become gregarious, and assemble sometimes in flocks of separate sexes, from 30 to 40 or upwards, - in the South frequenting the savannahs, feeding much on crickets, grasshoppers, and spiders ; and at this season their flesh is much esteemed by the inhabitants. Wilson found them easy to raise from the nest, but does not say on what they were fed, though they probably require the same treatment as the Baltimore Oriole. According to Audubon, they sing with great liveliness in cages, being fed on rice and dry fruits when fresh cannot be procured. Their ordinary diet, it appears, is caterpillars and insects, of which they destroy great quantities. In the course of the season they likewise feed on various kinds of juicy fruits and berries; but their depredations on the fruits of the orchard are very unimportant.

This is a summer visitor throughout the Eastern States, though not common north of the Connecticut valley. It occurs regularly but sparingly in Massachusetts and southern Ontario, and has been taken in Maine and New Brunswick. It breeds southward to the Gulf States, and in winter ranges into Central America.

Mr. Chapman describes the voice of this Oriole as "unusually rich and flexible," and adds, "he uses it with rare skill and expression." 


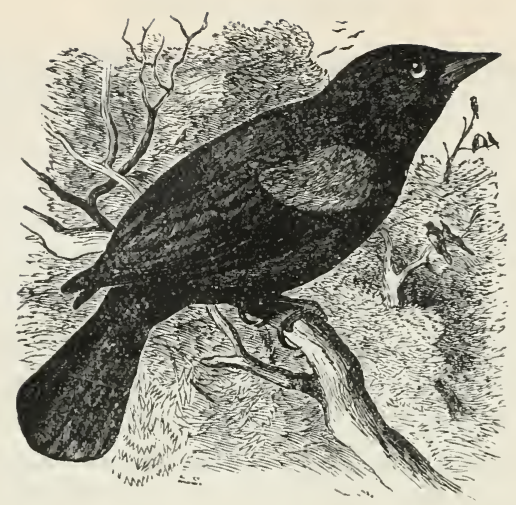

\section{RED-WINGED BLACKBIRD.}

\section{Agelaius PheEniceus.}

CHAR. Male: black; lesser wing-coverts vermilion, bordered with buff. Female : above, blackish brown streaked with paler and grayish; lower parts dusky white streaked with reddish brown; sometimes wing. coverts have a reddish tinge. Young like female, but colors deeper. Length $7 \frac{1}{2}$ to 10 inches.

Nest. In a tuft of grass or on a bush; composed of grass, leaves, and mud, lined with soft grass.

Eggs. 3-5; color varies from bluish white to greenish blue, blotched, streaked, and spotted with lilac and dark brown; size variable, average about $1.00 \times .90$.

The Red-Winged Troopial in summer inhabits the whole of North America from Nova Scotia to Mexico, and is found in the interior from the $53 \mathrm{~d}$ degree across the whole continent to the shores of the Pacific and along the coast as far as California. They are migratory north of Maryland, but pass the winter and summer in great numbers in all the Southern States, frequenting chiefly the settlements and rice and corn fields; towards the sea-coast, where they move about like blackening clouds, rising suddenly at times with a noise like thunder, and exhibiting amidst the broad shadows of their funereal plumage the bright flashing of the vermilion with which their wings are so singularly decorated. After whirling and waving a little distance like the Starling, they descend as a torrent, and, dark- 
ening the branches of the trees by their numbers, they commence a general concert that may be heard for more than two miles. This music seems to be something betwixt chattering and warbling, - jingling liquid notes like those of the Bobolink, with their peculiar kong-quér-ree and $b o b \breve{a} l e, o-b o b \quad \breve{a}$ le $\bar{e}$; then complaining chirps, jars, and sounds like saw-filing, or the motion of a sign-board on its rusty hinge ; the whole constitutıng a novel and sometimes grand chorus of discord and harmony, in which the performers seem in good earnest, and bristle up their feathers as if inclined at least to make up in quantity what their show of music may lack in quality.

When their food begins to fail in the fields, they assemble with the Purple Grakles very familiarly around the corn-cribs and in the barn-yards, greedily and dexterously gleaning up everything within their reach. In the month of March Mr. Bullock found them very numerous and bold near the city of Mexico, where they followed the mules to steal a tithe of their barley.

From the beginning of March to April, according to the nature of the season, they begin to visit the Northern States in scattered parties, flying chiefly in the morning. As they wing their way they seem to relieve their mutual toil by friendly chatter, and being the harbingers of spring, their faults are forgot in the instant, and we cannot help greeting them as old acquaintances in spite of their predatory propensities. Selecting their accustomed resort, they make the low meadows resound again with their notes, particularly in the morning and evening before retiring to or leaving the roost; previous to settling themselves for the night, and before parting in the day, they seem all to join in a general chorus of liquid warbling tones, which would be very agreeable but for the interruption of the plaints and jarring sounds with which it is blended. They continue to feed in small parties in swamps and by slow streams and ponds till the middle or close of April, when they begin to separate in pairs. Sometimes, however, they appear to be partly polygamous, like their cousins the Cow Troopials; as amidst a number of females engaged in

VOL. I. -7 
incubation, but few of the other sex appear associated with them; and as among the Bobolinks, sometimes two or three of the males may be seen in chase of an individual of the other sex, but without making any contest or show of jealous feud with each other, as a concubinage rather than any regular mating seems to prevail among the species.

Assembled again in their native marshes, the male perched, upon the summit of some bush surrounded by water, in company with his mates, now sings out, at short intervals, his guttural kong-quěr-ree, sharply calls $t$ 'tshéah, or when disturbed, plaintively utters 'ttshāy; to which his companions, not insensible to these odd attentions, now and then return a gratulatory cackle or reiterated chirp, like that of the native Meadow Lark. As a pleasant and novel, though not unusual, accompaniment, perhaps the great bull-frog elevates his green head and brassy eyes from the stagnant pool, and calls out in a loud and echoing bellow, 'w' rroo, 'warroo, 'worrörroo, 'boăroo, which is again answered, or, as it were, merely varied by the creaking or cackling voice of his feathered neighbors. This curious concert, uttered as it were from the still and sable waters of the Styx, is at once both ludicrous and solemn.

About the end of April or early in May, in the middle and northern parts of the Union, the Red-Winged Blackbirds commence constructing their nests. The situation made choice of is generally in some marsh, swamp, or wet meadow, abounding with alder (Alnus) or button-bushes (Cephalanthus) ; in these, commonly at the height of five to seven feet from the ground, or sometimes in a detached bush or tussock of rank grass in the meadow, the nest is formed. Outwardly it is composed of a considerable quantity of the long dry leaves of sedge-grass (Carex), or other kinds collected in wet situations, and occasionally the slender leaves of the flag (Iris) carried round all the adjoining twigs of the bush by way of support or suspension, and sometimes blended with strips of the lint of the swamp Asclepias, or silk-weed (Asclepias incarnata). The whole of this exterior structure is also twisted in and out, and carried in loops from one side of the nest to the other, pretty 
much in the manner of the Orioles, but made of less flexible and handsome materials. The large interstices that remain, as well as the bottom, are then filled in with rotten wood, marshgrass roots, fibrous peat, or mud, so as to form, when dry, a stout and substantial, though concealed shell, the whole very well lined with fine dry stalks of grass or with slender rushes (Scirpi). When the nest is in a tussock, it is also tied to the adjoining stalks of herbage; but when on the ground this precaution of fixity is laid aside. The eggs are from 3 to 5, white, tinged with blue, marked with faint streaks of light purple, and long, straggling, serpentine lines and dashes of very dark brown; the markings not very numerous, and disposed almost wholly at the greater end. They raise two broods commonly in the season. If the nest is approached while the female is sitting, or when the young are hatched, loud cries of alarm are made by both parties, but more particularly by the restless male, who flies to meet the intruder, and generally brings together the whole sympathizing company of his fellows, whose nests sometimes are within a few yards of each other. The female cries 'queàh, 'pueàh, and at length, when the mischief they dreaded is accomplished, the louder notes give way to others which are more still, slow, and mournful; one of which resembles $t^{\prime} a \dot{i}, t^{\prime} a \dot{i}$, or téa and $t$ tsheàh. When the young are taken or destroyed, the pair continue restless and dejected for several days; but from the force of their gregarious habit they again commence building, usually soon after, in the same meadow or swamp with their neighbors. In the latter part of July and August the young birds, now resembling the female, begin to fly in flocks and release themselves partly from dependence on their parents, whose cares up to this time are faithful and unremitting; a few males only seem inclined to stay and direct their motions.

About the beginning of September these flocks, by their formidable numbers, do great damage to the unripe corn, which is now a favorite repast; and they are sometimes seen whirling and driving over the devoted cornfields and meadows so as to darken the air with their numbers. The destruction 
at this time made among them by the gun and the Hawks produces but little effect upon the remainder, who continue fearlessly, and in spite of all opposition, from morning to night to ravage the cornfields while anything almost remains to be eaten. The farms near the sea-coast, or alluvial situations, however, are their favorite haunts; and towards the close of September, the corn becoming hard, it is at length rejected for the seeds of the wild rice (Zizania aquatica) and other aquatic plants, which now begin to ripen, and afford a more harmless and cheap repast to these dauntless marauders. At this time, also, they begin to roost in the reeds, whither they repair in large flocks every evening from all the neighboring quarters of the country; upon these they perch or cling, so as to obtain a support above the surrounding waters of the marsh. When the reeds become dry, advantage is taken of the circumstance to destroy these unfortunate gormandizers by fire; and those who might escape the flames are shot down in vast numbers as they hover and scream around the spreading conflagration. Early in November they generally leave the Northern and colder States, with the exception of straggling parties, who still continue to glean subsistence, in the shelter of the seacoast, in Delaware, Maryland, and even in the cold climate of the State of Massachusetts. ${ }^{1}$

To those who seem inclined to extirpate these erratic depredators, Wilson justly remarks, as a balance against the damage they commit, the service they perform in the spring season, by the immense number of insects and their larvæ which they destroy, as their principal food, and which are of kinds most injurious to the husbandman. Indeed, Kalm remarked that after a great destruction made among these and the common Blackbirds for the legal reward of 3 pence a dozen, the Northern States, in I 749, experienced a complete loss of the grass and grain crops, which were now devoured by insects.

Like the Troopial (Oriolus icterus, LATH.), the Redwing shows attachment and docility in confinement, becoming, like

1 My friend Mr. S. Green, of Boston, assures me that he has seen these birds near Newton, in a cedar-swamp, in January. 
the Starling, familiar with those who feed him, and repaying the attention he receives, by singing his monotonous ditty pretty freely, consisting, as we have already remarked, of various odd, grating, shrill, guttural, and sometimes warbling tones, which become at length somewhat agreeable to the ear; and instances are said to have occurred of their acquiring the power of articulating several words pretty distinctly.

The flesh of this bird is but little esteemed except when young, being dark and tough like that of the Starling; yet in some of the markets of the United States they are at times exposed for sale.

The Red-wing is a common summer visitor to the Eastern States and Canada, breeding as far north as latitude $50^{\circ}$. In the West it ranges through the Saskatchewan valley to Great Slave Lake. It winters south to Mexico; but a few individuals have been known to brave a New England winter. During the winter of 1889-90, a male was seen about the Fresh Pond marshes by several members of the Nuttall Club of Cambridge, and since that time several of these birds have been found there every winter.

Note. - The Bahaman Red-wing ( $A$. phonicus bryanti), a smaller, darker race, is found on the Bahama Islands and in southern Florida. 


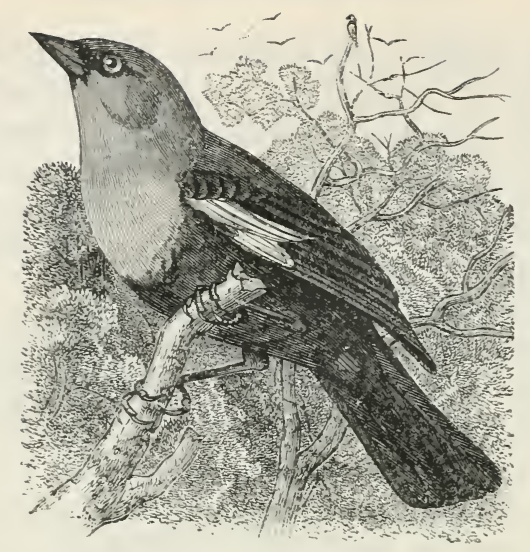

\section{YELLOW-HEADED BLACKBIRD.}

\section{XaNTHOCEPHALUS XaNTHOCEPHALUS.}

CHAR. Male: head, neck, and breast yellow; large patch on wing white; other parts black. Female and young: general color blackish brown; wings without the white spot; throat and breast dull yellow. Length 9 to II inches.

Nest. - Of dried grass, firmly woven and fastened to twigs of a bush or stalks of rushes, in a marsh or swampy meadow.

Eggs. - 2-6; grayish white, sometimes with a green tint, irregularly marked with brown; $1.05 \times 0.70$.

The Yellow-headed Troopial, though long known as an inhabitant of South America, was only recently added to the fauna of the United States by Major Long's expedition. It was seen in great numbers near the banks of the River Platte, around the villages of the Pawnees, about the middle of May; and the different sexes were sometimes observed associated in separate flocks, as the breeding season had not yet probably commenced. The range of this fine species is, apparently, from Cayenne, in tropical America, to the banks of the River Missouri, where Mr. Townsend and myself observed examples not far from the settled line of Missouri State. It has been seen by Dr. Richardson, in summer, as far as the 58th parallel. Its visits in the United States are yet wholly confined to 
the west side of the Mississippi, beyond which, not even a straggler has been seen. These birds assemble in flocks, and in all their movements, aërial evolutions, and predatory character, appear as the counterpart of their Red-winged relatives. They are also seen to frequent the ground in search of food, in the manner of the Cow-Bunting, or Troopial. In the spring season they wage war upon the insect tribes and their larvæ, like the Red-wings, but in autumn they principally depend on the seeds of vegetables. At Demerara, Waterton observed them in flocks, and, as might have been suspected from their habits, they were very greedy after Indian corn.

On the $2 \mathrm{~d}$ of May, in our western tour across the continent, around the Kansa Indian Agency, we now saw abundance of the Yellow-headed Troopial, associated with the Cowbird. They kept wholly on the ground in companies, the males, at this time, by themselves. In loose soil they dig into the earth with their bills in quest of insects and larvæ, are very active, straddle about with a quaint gait, and now and then, in the manner of the Cowbird, whistle out with great effort a chuckling note sounding like ko-kukkle-'ăit, often varying into a straining squeak, as if using their utmost endeavor to make some kind of noise in token of sociability. Their music is, however, even inferior to the harsh note of the Cowbird. In the month of June, by the edge of a grassy marsh, in the open plain of the Platte, several hundred miles inland, Mr. Townsend found the nest of this species built under a tussock formed of fine grasses and canopied over like that of the Sturnella, or Meadow Lark.

While essentially a bird of the prairie, this species occurs regularly and in abundance in Wisconsin and Illinois. It has been observed occasionally in southern Ontario, and examples have been taken at Point des Monts, on the Gulf of St. Lawrence, and in Massachusetts, Pennsylvania, South Carolina, and Florida. 


\section{COWBIRD.}

\section{COW BLACKBIRD.}

\section{MOLOTHRUS ATER.}

CHAR. Male: head and neck dull brown; other parts glossy black. Female and young: brownish gray, paler below, with dark streaks. Length 7 to 8 inches.

Nest. Does not build any, but lays its eggs in nests of other species, usually of smaller birds, such as the Yellow Warbler, Chipping Sparrow, or one of the Vireos.

Eggs. — ? (number unknown, probably 4) ; dull white, sometimes with green or buff tint, irregularly marked with various shades of brown; $085 \times 0.65$.

The Cow-pen Bird, perpetually gregarious and flitting, is observed to enter the Middle and Northern States in the latter end of March or the beginning of April. They make their migration now chiefly under cover of the night, or early dawn; and as the season becomes milder they pass on to Canada, and perhaps follow the Warblers and other small birds into the farthest regions of the north, for they are seen no more after the middle of June until the return of autumn, when, with the colds of October, they again reappear in numerous and augmented flocks, usually associated with their kindred Red-wings, to whom they bear a sensible likeness, as well as a similarity in notes and manners. They pass the winter in the warmer parts of America as well as in the Southern States, where I have observed them in the ploughed fields, gleaning along with the Red-wings and the common Blackbirds. They are also very familiar around the cattle, picking up insects which they happen to disturb, or that exist in their ordure. When on the ground, they scratch up the soil and appear very intent after their food. Sometimes even, infringing on the rights of the Plover, individuals, in the winter, frequent the margins of ponds in quest of aquatic insects and small shell-fish; and they may be seen industriously occupied in turning over the leaves of the water-plants to which they adhere. They also frequent 
occasionally the rice and corn fields, as well as their more notorious associates, but are more inclined to native food and insects at all times, so that they are more independent and less injurious to the farmer. As they exist in Mexico and California, it is probable that they are also bred in the higher table-lands, as well as in the regions of the north. In Louisiana, however, according to Audubon, they are rare visitors at any season, seeming more inclined to follow their route through the maritime districts. Over these countries, high in the air, in the month of October, they are seen by day winging their way to the remoter regions of the south.

We have observed that the Red-wings separate in parties, and pass a considerable part of the summer in the necessary duties of incubation. But the Cow-pen Birds release themselves from all hindrance to their wanderings. The volatile disposition and instinct which prompt birds to migrate, as the seasons change and as their food begins to fail, have only a periodical influence; and for a while they remain domestic, passing a portion of their time in the cares and enjoyments of the conjugal state. But with our bird, like the European Cuckoo, this season never arrives; the flocks live together without ever pairing. A general concubinage prevaíls among them, scarcely exciting any jealousy, and unaccompanied by any durable affection. From the commencement of their race they have been bred as foundlings in the nests of other birds, and fed by foster-parents under the perpetual influence of delusion and deception, and by the sacrifice of the concurrent progeny of the nursing birds. Amongst all the feathered tribes hitherto known, this and the European Cuckoo, with a few other species indigenous to the old continent, are the only kinds who never make a nest or hatch their young. That this character is not a vice of habit, but a perpetual instinct of nature, appears from various circumstances, and from none more evidently than from this, that the eggs of the Cow Troopial are earlier hatched than those of the foster-parent, - a singular and critical provision, on which perhaps the existence of the species depends; for did the natural brood of the deceived parent come first into exis- 
tence, the strange egg on which they sat would generally be destroyed.

When the female is disposed to lay, she appears restless and dejected, and separates from the unregarding flock. Stealing through the woods and thickets, she pries into the bushes and brambles for the nest that suits her, into which she darts in the absence of its owner, and in a few minutes is seen to rise on the wing, cheerful, and relieved from the anxiety that oppressed her, and proceeds back to the flock she had so reluctantly forsaken. If the egg be deposited in the nest alone, it is uniformly forsaken; but if the nursing parent have any of her own, she immediately begins to sit. The Red-eyed Flycatcher, in whose beautiful basket-like nests I have observed these eggs, proves a very affectionate and assiduous nurse to the uncouth foundling. In one of these I found an egg of each bird, and the hen already sitting. I took her own egg and left the strange one; she soon returned, and as if sensible of what had happened, looked with steadfast attention, and shifted the egg about, then sat upon it, but soon moved off, again renewed her observation, and it was a considerable time before she seemed willing to take her seat; but at length I left her on the nest. Two or three days after, I found that she had relinquished her attention to the strange egg and forsaken the nest. Another of these birds, however, forsook the nest on taking out the Cowbird's egg, although she had still two of her own left. The only example, perhaps, to the contrary of deserting the nest when solely occupied by the stray egg, is in the Bluebird, who, attached strongly to the breeding-places in which it often continues for several years, has been known to lay, though with apparent reluctance, after the deposition of the Cowbird's egg. My friend Mr. C. Pickering found two nests of the Summer-yellow Bird, in which had been deposited an egg of the Cowbird previously to any of their own; and unable to eject it, they had buried it in the bottom of the nest and built over it an additional story! I also saw, in the summer of 1830 , a similar circumstance with the same bird, in which the Cowbird's egg, though incarcerated, was still visible 
on the upper edge, but could never have been hatched. At times I think it probable that they lay in the nests of larger birds, who throw out the egg, or that they drop their eggs on the ground without obtaining a deposit, as I have found an egg of this kind thus exposed and broken. On placing an egg of this bird in the Catbird's nest it was almost instantly ejected; and this would probably be the usual fate of the strange egg if the diminutive nurses, thus wisely chosen, were capable of removing it.

The most usual nurse of this bird appears to be the Redeyed Vireo, who commences sitting as soon as the Cowbird's egg is deposited. On these occasions I have known the Vireo to begin her incubation with only an egg of each kind, and in other nests I have observed as many as 3 of her own, with that of the intruder. From the largeness of the strange egg, probably the nest immediately feels filled, so as to induce the nurse directly to sit. This larger egg, brought nearer to the body than her own, is consequently better warmed and sooner hatched; and the young of the Cowbird, I believe, appears about the 12 th or $13^{\text {th }}$ day of sitting. The foundling is very faithfully nursed by the affectionate Vireo, along with her own brood, who make their appearance about a day later than the Troopial. From the great size of the parasite, the legitimate young are soon stifled, and, when dead, are conveyed, as usual, by the duped parent to a distance before being dropped; but they are never found immediately beneath the nest, as would invariably happen if they were ejected by the young Troopial. In the summer of I839 I actually saw a Chipping Sparrow carrying out to a distance one of its dead young thus stifled; and a second nest of the same species in which 3 of its own brood were hatched soon after the Cow Troopial : these survived 2 or 3 days, and as they perished were carried away by the parent bird. As far as I have had opportunity of observing, the foundling shows no hostility to the natural brood of his nurses, but he nearly absorbs their whole attention, and early displays his characteristic cunning and self-possession. When fully fledged, they quickly desert their foster-parent, and skulk 
about in the woods until, at length, they instinctively join company with those of the same feather, and now becoming more bold, are seen in parties of 5 or 6 , in the fields and lanes, gleaning their accustomed subsistence. They still, however, appear shy and watchful, and seem too selfish to study anything more than their own security and advantage.

The song of the Cowbird is guttural and unmusical, utterea with an air of affectation, and accompanied by a bristling of the feathers and a swelling of the body in the manner of the Turkey. These are also all the notes of the species in the season of their attachment; so that their musical talent rates lower than that of any other bird perhaps in the genus. Sometimes the tones of the male resemble the liquid clinking of the Bobolink and Red-winged Blackbird. Sitting on the summit of a lofty branch, he amuses himself perhaps for an hour with an occasional 'kluck'tseé, the latter syllable uttered in a drawling hiss like that of the Red-wing. Accompanied by his mates, he also endeavors to amuse them by his complaisant chatter; and watching attentively for their safety, they flit together at the instant he utters the loud tone of alarm; and they are always shy and suspicious of the designs of every observer. On a fine spring morning, however, perched towards the summit of some tree in the forest where they seek rest after their twilight wanderings, small and select parties may be seen gratefully basking in the mild beams of the sunshine. The male on such occasions seems as proud of his uncouth jargon, and as eager to please his favorite companions, as the tuneful Nightingale with his pathetic and varied lay.

The Cowbird is a common summer resident of New England, though of rather local distribution. Dr. Wheaton reported it as abundant in Ohio during the summer months, and Mr. McIlwraith made a similar report for Ontario. It is rather uncommon in the Maritime Provinces, but ranges as far northward as the 5oth parallel. In January, 1883, two specimens were taken near Cambridge, Mass., by Mr. William Brewster and Mr. Henry M. Spellman, and other evidences of occasional wintering in New England have been reported. 


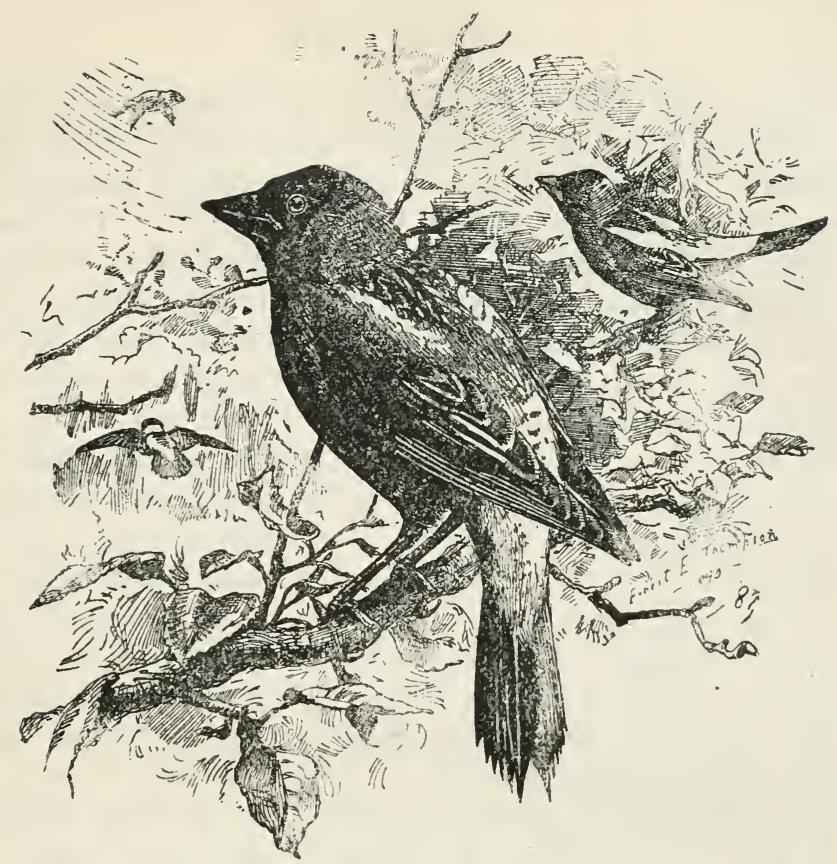

BOBOLINK.

RICE BIRD. SKUNK BLACKBIRD. MEADOW-WINK.

DOLICHONYX ORYZIVORUS.

CHAR. Male in summer : black; back of head and hind-neck buff; scapulars, rump, and upper tail-coverts ashy white. Male in winter, female, and young : above, yellowish brown, beneath paler, more buffy; light stripe on crown. Length $61 / 2$ to $71 / 2$ inches.

Nest. In a meadow; made of dried grass.

Eggs. 4-6; white with green or buff tint, irregularly marked with lilac and brown; $0.85 \times 0.60$.

The whole continent of America, from Labrador to Mexico, and the Great Antilles, are the occasional residence of this truly migratory species. About the middle of March or beginning of April the cheerful Bobolink makes his appearance in the southern extremity of the United States, becoming gradually arrayed in his nuptial livery, and accompanied by troops of his companions, who often precede the arrival of their more tardy 
mates. According to Richardson it is the beginning of June when they arrive at their farthest boreal station in the $54^{\text {th }}$ degree. We observed them in the great western plains to the base of the Rocky Mountains, but not in Oregon. Their wintering resort appears to be rather the West Indies than the tropical continent, as their migrations are observed to take place generally to the east of Louisiana, where their visits are rare and irregular. At this season also they make their approaches chiefly by night, obeying, as it were, more distinctly, the mandates of an overruling instinct, which prompts them to seek out their natal regions; while in autumn, their progress, by day only, is alone instigated by the natural quest of food. About the Ist of May the meadows of Massachusetts begin to re-echo their lively ditty. At this season, in wet places, and by newly ploughed fields, they destroy many insects and their larvæ. According to their success in obtaining food, parties often delay their final northern movement as late as the middle of May, so that they appear to be in no haste to arrive at their destination at any exact period. The principal business of their lives, however, the rearing of their young, does not take place until they have left the parallel of the 4 oth degree. In the savannahs of Ohio and Michigan, and the cool grassy meadows of New York, Canada, and New England, they fix their abode, and obtain a sufficiency of food throughout the summer without molesting the harvest of the farmer, until the ripening of the latest crops of oats and barley, when, in their autumnal and changed dress, hardly now known as the same species, they sometimes show their taste for plunder, and flock together like the greedy and predatory Blackbirds. Although they devour various kinds of insects and worms on their first arrival, I have found that their frequent visits among the grassy meadows were often also for the seeds they contain; and they are particularly fond of those of the dock and dandelion, the latter of which is sweet and oily. Later in the season, and previously to leaving their native regions, they feed principally on various kinds of grass-seeds, particularly those of the Panicums, which are allied to millet. They also devour crickets and grasshoppers, as well as beetles and'spiders. Their nest is fixed on 
the ground in a slight depression, usually in a field of meadow grass, either in a dry or moist situation, and consists merely of a loose bedding of withered grass, so inartificial as scarcely to be distinguishable from the rest of the ground around it. The eggs are 5 or 6 , of a dull white, inclining to olive, scattered all over with small spots and touches of lilac brown, with some irregular blotches of dark rufous brown, chiefly disposed towards the larger end.

The males, arriving a little earlier than the other sex, now appear very vigorous, lively, and familiar. Many quarrels occur before the mating is settled; and the females seem at first very coy and retiring. Emulation fires the Bobolink at this period, and rival songsters pour out their incessant strains of enlivening music from every fence and orchard tree. The quiet females keep much on the ground; but as soon as they appear, they are pursued by the ardent candidates for their affection, and if either seems to be favored, the rejected suitor is chased off the ground, as soon as he appears, by his more fortunate rival. The song of the male continues with little interruption as long as the female is sitting, and his chant, at all times very similar, is both singular and pleasant. Often, like the Skylark, mounted, and hovering on the wing, at a small height above the field, as he passes along from one tree-top or weed to another, he utters such a jingling medley of short, variable notes, so confused, rapid, and continuous, that it appears almost like the blending song of several different birds. Many of these tones are very agreeable; but they are delivered with such rapidity that the ear can scarcely separate them. The general effect, however, like all the simple efforts of Nature, is good, and when several are chanting forth in the same meadow, the concert is very cheerful, though monotonous, and somewhat quaint. Among the few phrases that can be distinguished, the liquid sound of bob-ö-lee bob-o-link bob-o-linké, is very distinct. To give an idea of the variable extent of song, and even an imitation, in some measure, of the chromatic period and air of this familiar and rather favorite resident, the boys of this part of New England make him spout, among others, the following 
ludicrous dunning phrase, as he rises and hovers on the wing near his mate, "'Bŏb-ŏ-link, 'Bŏb-ö-link, 'Tŏm Dĕnny' Tŏm Dënny. - 'Come păy me the twŏ and six pence you've owed

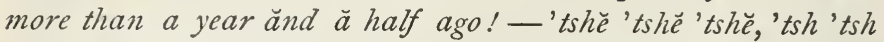
'tshe'," modestly diving at the same instant down into the grass as if to avoid altercation. However puerile this odd phrase may appear, it is quite amusing to find how near it approaches to the time and expression of the notes, when pronounced in a hurried manner. It would be unwise in the naturalist to hold in contempt anything, however trifling, which might tend to elucidate the simple truth of nature; I therefore give the thing as I find it. This relish for song and merriment, confined wholly to the male, diminishes as the period of incubation advances; and when the brood begin to flutter around their parents and protectors, the song becomes less frequent, the cares of the parents more urgent, and any approach to the secret recess of their helpless family is deplored with urgent and incessant cries as they hover fearfully around the intentional or accidental intruder. They appear sometimes inclined to have a second brood, for which preparation is made while they are yet engaged in rearing the first; but the male generally loses his musical talent about the end of the first week in July, from which time his nuptial or pied dress begins gradually to be laid aside for the humble garb of the female. The whole, both young and old, then appear nearly in the same songless livery, uttering only a chink of alarm when surprised in feeding on the grass seeds, or the crops of grain which still remain abroad. When the voice of the Bobolink begins to fail, with the progress of the exhausting moult, he flits over the fields in a restless manner, and merely utters a broken 'bŏb'lee, 'bŏb'lee, or with his songless mate, at length, a 'weet 'weet, b'leet b'leet, and a noisy and disagreeable cackling chirp. At the early dawn of day, while the tuneful talent of the species is yet unabated, the effect of their awakening and faltering voices from a wide expanse of meadows, is singular and grand. The sounds mingle like the noise of a distant torrent, which alternately subsides and rises on the breeze as 
the performers awake or relapse into rest; it finally becomes more distinct and tumultuous, till with the opening day it assumes the intelligible character of their ordinary song. The young males, towards the close of July, having nearly acquired their perfect character, utter also in the morning, from the trees which border their favorite marshy meadows, a very agreeable and continuous low warble, more like that of the Yellow Bird than the usual song of the species; in fact, they appear now in every respect as Finches, and only become jingling musicians when robed in their pied dress as Icteri.

About the middle of August, in congregating numbers, divested already of all selective attachment, vast foraging parties enter New York and Pennsylvania, on their way to the South. Here, along the shores of the large rivers, lined with floating fields of the wild rice, they find an abundant means of subsistence during their short stay; and as their flesh, now fat, is little inferior to that of the European Ortolan, the Reed or Rice Birds, as they are then called in their Sparrow-dress, form a favorite sport for gunners of all descriptions, who turn out on the occasion and commit prodigious havoc among the almost silent and greedy roosting throng. The markets are then filled with this delicious game, and the pursuit, both for success and amusement, along the picturesque and reedy shores of the Delaware and other rivers is second to none but that of Railshooting. As soon as the cool nights of October commence, and as the wild rice crops begin to fail, the Reed Birds take their departure from Pennsylvania and New Jersey, and in their farther progress through the Southern States they swarm in the rice fields; and before the crop is gathered they have already made their appearance in the islands of Cuba and Jamaica, where they also feed on the seeds of the Guinea grass, become so fat as to deserve the name of "Butter-birds," and are in high esteem for the table.

Near the Atlantic coast the Bobolink is not common north of the $45^{\text {th }}$ parallel ; but in the West it ranges to much higher latitudes. A few examples have been observed on the New Brunswick shore of the Gulf of St. Lawrence.

VOL. I. -8 


\title{
BOAT-TAILED GRACKLE.
}

\author{
JACKDAW.
}

\section{Quiscalus Major.}

Char. Extremely long, wedge-shaped tail, less conspicuous in female. Male : black, with metallic tints of green, blue, and purple. Length ${ }_{5}$ to $171 / 2$ inches. Female : above, brown; beneath, grayish brown, changing to reddish and buffy on breast and throat. Length, II $1 / 2$ to 13 inches.

Nest. A bulky structure of dried grass and strips of bark, cemented with mud and lined with fine grass; placed in a tree in swamp or near a marsh, sometimes fastened to rushes.

Eggs. 3-5; grayish drab with tints of green or blue, marked with black and brown blotches and lines; $1.25 \times 0.90$.

This large and Crow-like species, sometimes called the Jackdaw, inhabits the southern maritime parts of the Union only, particularly the States of Georgia and Florida, where they are seen as early as the close of January or beginning of February, but do not begin to pair before March, previously to which season the sexes are seen in separate flocks. But about the latter end of November they quit even the mild climate of Florida, generally, and seek winter-quarters probably in the West Indies, where they are known to be numerous, as well as in Mexico, Louisiana, and Texas ; but they do not ever extend their northern migrations as far as the Middle States. Previous to their departure, at the approach of winter, they are seen to assemble in large flocks, and every morning flights of them, at a great height, are seen moving away to the south.

Like most gregarious birds, they are of a very sociable disposition, and are frequently observed to mingle with the common Crow Blackbirds. They assemble in great numbers among the sea islands, and neighboring marshes on the mainland, where they feed at low water on the oyster-beds and sandflats. Like Crows, they are omnivorous, their food consisting of insects, small shell-fish, corn, and small grain, so that by turns they may be viewed as the friend or plunderer of the planter. 
The note of this species is louder than that of the common kind, according to Audubon resembling a loud, shrill whistle, often accompanied by a cry like crick crick cree, and in the breeding-season changing almost into a warble. They are only heard to sing in the spring, and their concert, though inclining to sadness, is not altogether disagreeable. Their nests are built in company, on reeds and bushes, in the neighborhood of salt-marshes and ponds. They begin to lay about the beginning of April; soon after which the males leave their mates, not only with the care of incubation, but with the rearing of the young, moving about in separate flocks like the Cowbirds, without taking any interest in the fate of their progeny.

This species is rarely found north of Virginia. Several instances of its occurrence in New England have been reported; but the correctness of these reports has been challenged, and Mr. Allen omitted the species from his list of Massachusetts birds issued in I 886.

\section{PURPLE GRACKLE.}

\section{CROW BLACKBIRD.}

\section{Quiscalus Quiscula.}

CHAR. Black, with rich metallic tints of steel blue and purple, the female somewhat duller. Length, I I to $13^{1 / 2}$ inches.

Nest. On the branch of a tree or in a hollow stub; large and roughly made of coarse grass and twigs, and lined with finer grass, sometimes cemented with mud.

Eggs. 4-6; extremely variable in shape, color, and size ; ground color greenish white to reddish brown, with irregular markings of dark brown; I. $25 \times 0.90$.

This very common bird is an occasional or constant resident in every part of America, from Hudson's Bay and the northern interior to the Great Antilles, within the tropic. In most parts of this wide region they also breed, at least from Nova Scotia to Louisiana, and probably farther south. Into the States north of Virginia they begin to migrate from the beginning of March 
to May, leaving those countries again in numerous troops about the middle of November. Thus assembled from the North and West in increasing numbers, they wholly overrun, at times, the warmer maritime regions, where they assemble to pass the winter in the company of their well-known cousins the Redwinged Troopials or Blackbirds; for both, impelled by the same predatory appetite, and love of comfortable winter quarters, are often thus accidentally associated in the plundering and gleaning of the plantations. The amazing numbers in which the present species associate are almost incredible. Wilson relates that on the 2oth of January, a few miles from the banks of the Roanoke in Virginia, he met with one of those prodigious armies of Blackbirds, which, as he approached, rose from the surrounding fields with a noise like thunder, and descending on the stretch of road before him, covered it and the fences completely with black; rising again, after a few evolutions, they descended on the skirt of a leafless wood, so thick as to give the whole forest, for a considerable extent, the appearance of being shrouded in mourning, the numbers amounting probably to many hundreds of thousands. Their notes and screams resembled the distant sound of a mighty cataract, but strangely attuned into a musical cadence, which rose and fell with the fluctuation of the breeze, like the magic harp of Eolus.

Their depredations on the maize crop or Indian corn commence almost with the planting. The infant blades no sooner appear than they are hailed by the greedy Blackbird as the signal for a feast; and without hesitation, they descend on the fields, and regale themselves with the sweet and sprouted seed, rejecting and scattering the blades around as an evidence of their mischief and audacity. Again, about the beginning of August, while the grain is in the milky state, their attacks are renewed with the most destructive effect, as they now assemble as it were in clouds, and pillage the fields to such a degree that in some low and sheltered situations, in the vicinity of rivers, where they delight to roam, one fourth of the crop is devoured by these vexatious visitors. The gun, also, notwith- 
standing the havoc it produces, has little more effect than to chase them from one part of the field to the other. In the Southern States, in winter, they hover round the corn-cribs in swarms, and boldly peck the hard grain from the cob through the air openings of the magazine. In consequence of these reiterated depredations, they are detested by the farmer as a pest to his industry; though on their arrival their food for a long time consists wholly of those insects which are calculated to do the most essential injury to the crops. They at this season frequent swamps and meadows, and familiarly following the furrows of the plough, sweep up all the grub-worms and other noxious animals as soon as they appear, even scratching up the loose soil, that nothing of this kind may escape them. Up to the time of harvest I have uniformly, on dissection, found their food to consist of these larvæ, caterpillars, moths, and beetles, of which they devour such numbers that but for this providential economy the whole crop of grain, in many places, would probably be destroyed by the time it began to germinate. In winter they collect the mast of the beech and oak for food, and may be seen assembled in large bodies in the woods for this purpose. In the spring season the Blackbirds roost in the cedars and pine-trees, to which in the evening they retire with friendly and mutual chatter. On the tallest of these trees, as well as in bushes, they generally build their nests, - which work, like all their movements, is commonly performed in society, so that Io or 15 of them are often seen in the same tree; and sometimes they have been known to thrust their nests into the interstices of the Fish Hawk's eyry, as if for safety and protection. Occasionally they breed in tall poplars near to habitations, and if not molested, continue to resort to the same place for several years in succession. The nest is composed of mud, mixed with stalks and knotty roots of grass, and lined with fine dry grass and horse-hair. According to Audubon, the same species in the Southern States nests in the hollows of decayed trees, after the manner of the Woodpecker, lining the cavity with grass and mud. They seldom produce more than a single brood in the season. In the autumn, and at the approach 
of winter, numerous flocks, after foraging through the day, return from considerable distances to their general roosts among the reeds. On approaching their station, each detachment, as it arrives, in straggling groups like crows, sweeps round the marsh in waving flight, forming circles; amidst these bodies, the note of the old reconnoitring leader may be heard, and no sooner has he fixed upon the intended spot than they all descend and take their stations in an instant. At this time they are also frequently accompanied by the Ferruginous species, with which they associate in a friendly manner.

The Blackbird is easily tamed, sings in confinement, and may be taught to articulate some few words pretty distinctly. Among the variety of its natural notes, the peculiarly affected sibilation of the Starling is heard in the wottitshee, wottitshee, and whistle, which often accompanies this note.

In Nuttall's day variety making had not come in fashion, and the systematists were content to treat the Crow Blackbirds of eastern North America as of one form. Now we have three forms, with three "distinctive scientific appellations." It is somewhat difficult to distinguish these forms, except in extreme phases of plumage, for many specimens of the Northern variety have the diagnostic characters of the Southern birds. The present race is said to occur on the Atlantic coast of the United States, north to Massachusetts, and in the lower valley of the Mississippi.

The Bronze Grackle ( $Q$. quiscula aneus) lacks the purple metallic tint on the body, that being replaced by a tint of bronze; the purple and blue tints are restricted to the head and neck. The wings and tail are purple. This form is abundant throughout the New England States and Canada, and ranges north to Hudson's Bay and west to the Great Plains. I have seen nests of these birds placed on the beams of barns in New Brunswick. The farmers along the St. John and Kenebecasis rivers erect barns on the marshy islands and "intervales" to store their hay until it can be carried to the mainland on the ice; and these barns, being unused during the breeding season, offer excellent building sites for colonies of Crow Blackbirds and Swallows. The nests are fastened to the beams with mud in much the same method as that adopted by Robins.

A smaller race with a larger tail is restricted to Florida and the adjacent country and westward to the Mississippi. It is named the FLORIDA GRACKLE (Q. quiscula algaus) 


\section{RUSTY BLACKBIRD.}

\section{SCOLECOPHAGUS CAROLINUS.}

CHAR. Male in summer: glossy black, generally more or less feathers edged with reddish brown. Male in winter: the brown more conspicuous, the lower parts marked with buffy. Female and young: dull rusty brown above, rusty and ashy beneath. Length $81 / 4$ to $93 / 4$ inches.

Nest. In a tree or on the ground; a large but solid structure of twigs and vines, sometimes cemented with mud, lined with grass and leaves.

Eggs. 4-7; grayish green to pale green, thickly blotched with light and dark brown and purple; $1.00 \times 0.76$.

This species, less frequent than the preceding, is often associated with it or with the Red-winged Troopial or the Cowpen Bird; and according to the season, they are found throughout America, from Hudson's Bay to Florida, and westward to the Pacific Ocean. Early in April, according to Wilson, they pass hastily through Pennsylvania, on their return to the North to breed. In the month of March he observed them on the banks of the Ohio, near Kentucky River, during a snow-storm. They arrive in the vicinity of Hudson's Bay about the beginning of May, and feed much in the manner of the common Crow Blackbird on insects which they find on or near the ground. Dr. Richardson saw them in the winter as far as the latitude of $53^{\circ}$, and in summer they range to the 68th parallel or to the extremity of the wooded region. They sing in the pairing season, but become nearly silent while rearing their young; though when their brood release them from care, they again resume their lay, and may occasionally be heard until the approach of winter. Their song is quite as agreeable and musical as that of the Starling, and greatly surpasses that of any of the other species. I have heard them singing until the middle of October.

They are said to build in trees and bushes at no great distance from the ground, making a nest similar to the other species, and lay five eggs, of a pale blue spotted with black. The young and old, now assembling in large troops, retire from the northern regions in September. From the beginning of 
October to the middle of November, they are seen in flocks through the Eastern States. During their stay in this vicinity they assemble towards night to roost in or round the reedmarshes of Fresh Pond, near Cambridge. Sometimes they select the willows by the water for their lodging, in preference to the reeds, which they give up to their companions the Crow Blackbirds. Early in October they feed chiefly on grasshoppers and berries, and at a later period pay a transient visit to the corn-fields. They pass the winter in the Southern States, and, like their darker relatives, make familiar visits to the barn-yard and corn-cribs. Wilson remarks that they are easily domesticated, and in a few days become quite familiar, being reconciled to any quarters while supplied with plenty of food.

The Rusty Blackbird breeds from about the 45th parallel to the lower fur countries. It is fairly common near the Atlantic, but is more abundant in the interior, and Mr. Thompson reports it commonly abundant in Manitoba. In this region it does not always select an alder swamp for a nesting site, as some authors have stated. A nest discovered by my friend Banks was amid the upper branches of a good sized spruce on a dry hillside in Mr. William Jack's park, near St. John.

\section{NORTHERN RAVEN.}

\section{CORVUS CORAX PRINCIPALIS.}

CHAR. Black with bluish purple gloss. Length 22 to $26 \mathrm{r} / 2$ inches.

Nest. On a cliff or in a tree; made of sticks carefully and compactly arranged, lined with grass or wool, - repaired year after year, and thus increased to considerable bulk.

Eggs. 2-7; pale olive, marked with olive-brown blotches and streaks; $2.00 \times \mathrm{I} .40$.

The sable Raven has been observed and described from the earliest times, and is a resident of almost every country in the world; but is more particularly abundant in the western than the eastern parts of the United States, where it extends along the Oregon to the shores of the Pacific. This ominous bird 
has been generally despised and feared by the superstitious even more than the nocturnal Owl, though he prowls abroad in open day. He may be considered as holding a relation to the birds of prey, feeding not only on carrion, but occasionally seizing on weakly lambs, young hares or rabbits, and seems indeed to give a preference to animal food; but at the same time, he is able to live on all kinds of fruits and grain, as well as insects, earth-worms, even dead fish, and in addition to all, is particularly fond of eggs, so that no animal seems more truly omnivorous than the Raven.

If we take into consideration his indiscriminating voracity, sombre livery, discordant, croaking cry, with his ignoble, wild, and funereal aspect, we need not be surprised that in times of ignorance and error he should have been so generally regarded as an object of disgust and fear. He stood pre-eminent in the list of sinister birds, or those whose only premonition was the announcing of misfortunes ; and, strange to tell, there are many people yet in Europe, even in this enlightened age, who tremble and become uneasy at the sound of his harmless croaking. According to Adair, the Southern aborigines also invoke the Raven for those who are sick, mimicking his voice; and the natives of the Missouri, assuming black as their emblem of war, decorate themselves on those occasions with the plumes. of this dark bird. But all the knowledge of the future, or interest in destiny, possessed by the Raven, like that of other inhabitants of the air, is bounded by an instinctive feeling of the changes which are about to happen in the atmosphere, and which he has the faculty of announcing by certain cries and actions produced by these external impressions. In the southern provinces of Sweden, as Linnæus remarks, when the sky is serene the Raven flies very high and utters a hollow sound, like the word clong, which is heard to a great distance. Sometimes he has been seen in the midst of a thunder-storm with the electric fire streaming from the extremity of his bill, - a natural though extraordinary phenomenon, sufficient to terrify the superstitious and to stamp the harmless subject of it with the imaginary traits and attributes of a demon. 
In ancient times, when divination made a part of religion, the Raven, though a bad prophet, was yet a very interesting bird; for the passion for prying into future events, even the most dark and sorrowful, is an original propensity of human nature. Accordingly, all the actions of this sombre bird, all the circumstances of its flight, and all the different intonations of its discordant voice, of which no less than sixty-four were remarked, had each of them an appropriate signification; and there were never wanting impostors to procure this pretended intelligence, nor people simple enough to credit it. Some even went so far as to impose upon themselves, by devouring the heart and entrails of the disgusting Raven, in the strange hope of thus appropriating its supposed gift of prophecy.

The Raven indeed not only possesses a great many natural inflections of voice corresponding to its various feelings, but it has also a talent for imitating the cries of other animals, and even mimicking language. According to Buffon, colas is a word which he pronounces with peculiar facility. Connecting circumstances with his wants, Scaliger heard one, which when hungry, learnt very distinctly to call upon Conrad the cook. The first of these words bears a great resemblance to one of the ordinary cries of this species, kówallah, kówallah. Besides possessing in some measure the faculty of imitating human speech, they are at times capable of manifesting a durable attachment to their keeper, and become familiar about the house.

The sense of smell, or rather that of sight, is very acute in the Raven, so that he discerns the carrion, on which he often feeds, at a great distance. Thucydides even attributes to him the sagacity of avoiding to feed on animals which had died of the plague. Pliny relates a singular piece of ingenuity employed by this bird to quench his thirst: he had observed water near the bottom of a narrow-necked vase, to obtain which, he is said to have thrown in pebbles, one at a time, until the pile elevated the water within his reach. Nor does this trait, singular as it is, appear to be much more sagacious than that of carrying up nuts and shell-fish into the air, and 
dropping them on rocks, for the purpose of breaking them to obtain their contents, otherwise beyond his reach, - facts observed by men of credit, and recorded as an instinct of the Raven by Pennant and Latham. It is, however, seldom that these birds, any more than the rapacious kinds, feel an inclination for drinking, as their thirst is usually quenched by the blood and juices of their prey. The Ravens are also more social than the birds of prey, - which arises from the promiscuous nature and consequent abundance of their food, which allows a greater number to subsist together in the same place, without being urged to the stern necessity of solitude or famine, - a condition to which the true rapacious birds are always driven. The habits of these birds are much more generally harmless than is usually imagined; they are useful to the farmer in the destruction they make of moles and mice, and are often very well contented with insects and earth-worms.

Though spread over the whole world, they are rarely ever birds of passage, enduring the winters even of the Arctic circle, or the warmth of Mexico, St. Domingo, and Madagascar. They are particularly attached to the rocky eyries where they have been bred and paired. Throughout the year they are observed together in nearly equal numbers, and they never entirely abandon this adopted home. If they descend into the plain, it is to collect subsistence; but they resort to the low grounds more in winter than summer, as they avoid the heat and dislike to wander from their cool retreats. They never roost in the woods, like Crows, and have sufficient sagacity to choose in their rocky retreats a situation defended from the winds of the north, - commonly under the natural vault formed by an extending ledge or cavity of the rock. Here they retire during the night in companies of $\mathrm{I}_{5}$ to 20 . They perch upon the bushes which grow straggling in the clefts of the rocks; but they form their nests in the rocky crevices, or in the holes of the mouldering walls, at the summits of ruined towers; and sometimes upon the high branches of large and solitary trees. After they have paired, their fidelity appears to continue through life. The male expresses his attachment by a particu- 
lar strain of croaking, and both sexes are observed caressing, by approaching their bills, with as much semblance of affection as the truest turtle-doves. In temperate climates the Raven begins to lay in the months of February or March. The eggs are 5 or 6 , of a pale, muddy bluish green, marked with numerous spots and lines of dark olive brown. She sits about 20 days, and during this time the male takes care to provide her with abundance of nourishment. Indeed, from the quantity of grain, nuts, and fruits which have been found at this time in the environs of the nest, this supply would appear to be a store laid up for future occasions. Whatever may be their forethought regarding food, they have a well-known propensity to hide things which come within their reach, though useless to themselves, and appear to give a preference to pieces of metal, or anything which has a brilliant appearance. At Erfurt, one of these birds had the patience to carry and hide, one by one, under a stone in the garden, a quantity of small pieces of money, which amounted, when discovered, to 5 or 6 florins; and there are few countries which cannot afford similar instances of their domestic thefts.

Of the perseverance of the Raven in the act of incubation, Mr. White has related the following remarkable anecdote: In the centre of a grove near Selborne there stood a tall and shapeless oak which bulged out into a large excrescence near the middle of the stem. On this tree a pair of Ravens had fixed their residence for such a series of years that the oak was distinguished by the title of "The Raven Tree." Many were the attempts of the neighboring youths to get at this nest. The difficulty whetted their inclinations, and each was ambitious of accomplishing the arduous task ; but when they arrived at the swelling, it jutted out so in their way, and was so far beyond their grasp, that the boldest lads were deterred, and acknowledged the undertaking to be too hazardous. Thus the Ravens continued to build, and rear their young in security, until the fatal day on which the wood was to be levelled. This was in the month of February, when these birds usually begin to sit. The saw was applied to the trunk, the wedges 
were driven, the woods echoed to the heavy blows of the beetle or mallet, and the tree nodded to its fall ; but still the devoted Raven sat on. At last, when it gave way, she was flung from her ancient eyry; and a victim to parental affection, was whipped down by the twigs, and brought lifeless to the ground.

The young, at first more white than black, are fed by food previously prepared in the craw of the mother and then disgorged by the bill, nearly in the manner of pigeons. The male at this time, doubly vigilant and industrious, not only provides for, but defends his family vigorously from every hostile attack, and shows a particular enmity to the Kite when he appears in his neighborhood, pouncing upon him and striking with his bill until sometimes both antagonists descend to the ground. The young are long and affectionately fed by the parents; and though they soon leave the nest, they remain perching on the neighboring rocks, yet unable to make any extensive flight, and pass the time in continual complaining cries till the approach of the parent with food, when their note changes into craw, craw, craw. Now and then as they gain strength they make efforts to fly, and then return to their rocky roost. About I 5 days after leaving the nest, they become so well prepared for flight as to accompany the parents out on their excursions from morning to night; and it is amusing to watch the progress of this affectionate association, the young continuing the whole summer to go out with the old in the morning, and as regularly return with them again in the evening, so that however we may despise the appetite of the Raven, we cannot but admire the instinctive morality of his nature.

Like birds of prey, the Ravens reject from the stomach, by the bill, the hard and indigestible parts of their food, as the stones of fruit and the bones of small fish which they sometimes eat.

The Northern Raven has been separated lately from the "Mexican" race (for which latter the name of sinuatus has been retained); and the distribution of the Mexican bird is given as from the Rocky Mountains westward. The northern form 
occurs throughout Canada north to the Arctic Ocean and west to the Pacific.

Of late years the Raven has almost forsaken the New England shores, though it is still numerous around the Bay of Fundy, and occurs locally in small numbers along the coast of the Atlantic to North Carolina. In the west it ranges south to northern Michigan and British Columbia. It is more abundant to the westward of the Mississippi than in the Eastern States.

\section{CROIV.}

\section{CORvUs AMERICANUS.}

CHAR. Black, with gloss of purple tinge. Length 17 to $2 \mathrm{I}$ inches.

Nest. In a tree; made of sticks and twigs, lined with grass and leaves. Eggrs. 4-6; sea-green to dull olive, blotched with brown; $1.70 \times 1.20$.

The Crow, like the Raven, which it greatly resembles, is a denizen of nearly the whole world. It is found even in New Holland and the Philippine Islands, but is rare in Sweden, where the Raven abounds. It is also common in Siberia, and plentiful in the Arctic deserts beyond the Lena.

The native Crow is a constant and troublesomely abundant resident in most of the settled districts of North America, as well as an inhabitant of the Western wilds throughout the Rocky Mountains, to the banks of the Oregon and the shores of the Pacific. These birds only retire into the forests in the breeding season, which lasts from March to May. At this time they are dispersed through the woods in pairs, and roost in the neighborhood of the spot which they have selected for their nest ; and the conjugal union, once formed, continues for life. They are now very noisy, and vigilant against any intrusion on their purpose, and at times appear influenced by mutual jealousy, but never proceed to any violence. The tree they select is generally lofty, and preference seems often given to some dark and concealing evergreen. The nest is formed externally of small twigs coarsely interlaced together, plastered and matted with earth, moss, and long horse-hair, 
and thickly and carefully lined with large quantities of the last material, wool, or the finest fibres of roots, so as to form a very comfortable bed for the helpless and naked young.

The male at this season is extremely watchful, reconnoitring the neighborhood, and giving an alarm as any person happens to approach towards their nest, when both retire to a distance till the intruder disappears; and in order the better to conceal their brood, they remain uncommonly silent until these are in a situation to follow them on the wing. The male also carries food to his mate while confined to her eggs, and at times relieves her by sitting in her absence. In Europe, when the Raven, the Buzzard, or the Kestrel makes his appearance, the pair join instantly in the attack, and sometimes, by dint of furious blows, destroy their enemy; yet the Butcher Bird, more alert and courageous, not only resists, but often vanquishes the Crows and carries off their young. Like the Ravens, endued with an unrestrained and natural affection, they continue the whole succeeding summer to succor and accompany their offspring in all their undertakings and excursions.

The Crow is equally omnivorous with the Raven; insects, worms, carrion, fish, grain, fruits, and in short everything digestible by any or all the birds in existence, being alike acceptable to this gormandizing animal. Its destruction of bird-eggs is also very considerable. In Europe Crows are often detected feeding their voracious young with the precious eggs of the Partridge, which they very sagaciously convey by carefully piercing and sticking them expertly on the bill. They also know how to break nuts and shell-fish by dropping them from a great height upon the rocks below. They visit even the snares and devour the birds which they find caught, attacking the weak and wounded game. They also sometimes seize on young chickens and Ducks, and have even been observed to pounce upon Pigeons in the manner of Hawks, and with almost equal success. So familiar and audacious are they in some parts of the Levant that they will frequent the courts of houses, and, like Harpies, alight boldly on the dishes, as the servants are conveying in the dinner, and carry off the meat, if not driven 
away by blows. In turn, however, the Crow finds enemies too powerful for him to conquer, such as the Kite and Eagle Owl, who occasionally make a meal of this carrion bird, - a voracious propensity which the Virginian Owl also sometimes exhibits towards the same species. Wherever the Crow appears, the smaller birds take the alarm, and vent upon him their just suspicions and reproaches. But it is only the redoubtable King Bird who has courage for the attack, beginning the onset by pursuing and diving on his back from above, and harassing the plunderer with such violence that he is generally glad to get out of the way and forego his piratical visit; in short, a single pair of these courageous and quarrelsome birds are sufficient to clear the Crows from an extensive cornfield.

The most serious mischief of which the Crow is guilty is that of pillaging the maize-field. He commences at the planting-time by picking up and rooting out the sprouting grain, and in the autumn, when it becomes ripe, whole flocks, now assembled at their roosting-places, blacken the neighboring fields as soon as they get into motion, and do extensive damage at every visit, from the excessive numbers who now rush to the inviting feast.

Their rendezvous or roosting-places are the resort in autumn of all the Crows and their families for many miles round. The blackening silent train continues to arrive for more than an hour before sunset, and some still straggle on until dark. They never arrive in dense flocks, but always in long lines, each falling into the file as he sees opportunity. This gregarious inclination is common to many birds in the autumn which associate only in pairs in the summer. The forests and groves, stripped of their agreeable and protecting verdure, seem no longer safe and pleasant to the feathered nations. Exposed to the birds of prey, which daily augment in numbers; penetrated by the chilling blasts, which sweep without control through the naked branches, - the birds, now impelled by an overruling instinct, seek in congregated numbers some general, safer, and more commodious retreat. Islands of reeds, dark and solitary thickets, and neglected swamps, are the situations chosen for 
their general diurnal retreats and roosts. Swallows, Blackbirds, Rice Birds, and Crows seem always to prefer the low shelter of reed-flats. On the River Delaware, in Pennsylvania, there are two of these remarkable Crow-roosts. The one mentioned by Wilson is an island near Newcastle called the Pea-Patch, - a low, flat, alluvial spot, just elevated above high-water mark, and thickly covered with reeds, on which the Crows alight and take shelter for the night. Whether this roost be now occupied by these birds or not, I cannot pretend to say; but in December, I829, I had occasion to observe their arrival on Reedy Island, just above the commencement of the bay of that river, in vast numbers; and as the wind wafted any beating vessel towards the shore, they rose in a cloud and filled the air with clamor. Indeed, their vigilant and restless cazving continued till after dark.

Creatures of mere instinct, they foresee no perils beyond their actual vision; and thus, when they least expect it, are sometimes swept away by an unexpected destruction. Some years ago, during the prevalence of a sudden and violent northeast storm accompanied by heavy rains, the Pea-Patch Island was wholly inundated in the night; and the unfortunate Crows, dormant and bewildered, made no attempts to escape, and were drowned by thousands, so that their bodies blackened the shores the following day for several miles in extent.

The Crows, like many other birds, become injurious and formidable only in the gregarious season. At other times they live so scattered, and are so shy and cautious, that they are but seldom seen. But their armies, like all other great and terrific assemblies, have the power, in limited districts, of doing very sensible mischief to the agricultural interests of the community; and in consequence, the poor Crows, notwithstanding their obvious services in the destruction of a vast host of insects and their larvæ, are proscribed as felons in all civilized countries, and, with the wolves, panthers, and foxes, a price is put upon their heads. In consequence, various means of ensnaring the outlaws have been had recourse to. Of the gun they are very cautious, and suspect its appearance at the VOL. I. -9 
first glance, perceiving with ready sagacity the wily manner of the fowler. So fearful and suspicious are they of human arti. fices that a mere line stretched round a field is often found sufficient to deter these wily birds from a visit to the cornfield. Against poison they are not so guarded, and sometimes corn steeped in hellebore is given them, which creates giddinesa and death.

Another curious method is that of pinning a live Crow to the ground by the wings, stretched out on his back, and retained in this posture by two sharp, forked sticks. In this situation, his loud cries attract other Crows, who come sweeping down to the prostrate prisoner, and are grappled in his claws. In this way each successive prisoner may be made the innocent means of capturing his companion. The reeds in which they roost, when dry enough, are sometimes set on fire also to procure their destruction; and to add to the fatality produced by the flames, gunners are also stationed round to destroy those that attempt to escape by flight. In severe winters they suffer occasionally from famine and cold, and fall sometimes dead in the fields. According to Wilson, in one of these severe seasons, more than 600 Crows were shot on the carcase of a dead horse, which was placed at a proper shooting distance from a stable. The premiums obtained for these, and the price procured for the quills, produced to the farmer nearly the value. of the horse when living, besides affording feathers sufficient to fill a bed.

The Crow is easily raised and domesticated, and soon learns to distinguish the different members of the family with which he is associated. He screams at the approach of a stranger; learns to open the door by alighting on the latch; attends regularly at meal times; is very noisy and loquacious; imitates the sounds of various words which he hears; is very thievish, given to hiding curiosities in holes and crevices, and is very fond of carrying off pieces of metal, corn, bread, and food of all kinds; he is also particularly attached to the society of his master, and recollects him sometimes after a long absence.

It is commonly believed and asserted in some parts of this 
country that the Crows engage at times in general combat; but it has never been ascertained whether this hostility arises from civil discord, or the opposition of two different species contesting for some exclusive privilege of subsisting ground. It is well known that Rooks often contend with each other, and drive away by every persecuting means individuals who arrive among them from any other rookery.

NOTE. - The FLORIDA CROw (C. americanus floridanus) differs from true americanus in having the wings and tail shorter, and the bill and feet larger. It is restricted to southern Florida.

\section{FISH CROW.}

\section{CORVUS OSSIFRAGUS.}

CHAR. Black glossed with steel-blue. Length 15 to $17 \frac{1}{2}$ inches.

Nest. On a tree; of sticks and twigs firmly laid, lined with leaves.

Eggs. 5-7; sea-green or olive, blotched and spotted with brown; I. $50 \times 1.05$

Wilson was the first to observe the distinctive traits of this smaller and peculiar American species of Crow along the seacoast of Georgia. It is met with as far north as the coast of New Jersey; and although we did not see it in the western interior of the continent, it is common on the banks of the Oregon, where it was nesting in the month of April. It keeps apart from the common species, and instead of assembling to roost among the reeds at night, retires, towards evening, from the shores which afford it a subsistence, and perches in the neighboring woods. Its notes, probably various, are at times hoarse and guttural, at others weaker and higher. These Crows pass most of their time near rivers, hovering over the stream to catch up dead and perhaps living fish, or other animal matters which float within their reach; at these they dive with considerable celerity, and seizing them in their claws, convey them to an adjoining tree, and devour the fruits of their predatory industry at leisure. They also snatch up water- 
lizards in the same manner, and feed upon small crabs; at times they are seen even contending with the Gulls for their prey. It is amusing to see with what steady watchfulness they hover over the water in search of their precarious food, having, in fact, all the traits of the Gull; but they subsist more on accidental supplies than by any regular system of fishing. On land they have sometimes all the familiarity of the Magpie, hopping upon the backs of cattle, in whose company they no doubt occasionally meet with a supply of insects when other sources fail. They are also regular in their attendance on the fishermen of New Jersey for the purpose of gleaning up the refuse of the fish. They are less shy and suspicious than the common Crow, and showing no inclination for plundering the cornfields, are rather friends than enemies to the farmer. They appear near Philadelphia from the middle of March to the beginning of June, during the season of the shad and herring fishery.

The habitat now accorded to this species is "the Atlantic and Gulf States north to Long Island and west to Louisiana." It probably occurs occasionally along the Connecticut shore, and may straggle into Massachusetts; though Mr. Allen has omitted it from his list.

On the Pacific coast it is replaced by $C$. caurinus.

All Crows are more or less fish-eaters, and in some localities fish forms their staple diet. On the shores of Cape Breton, near the coal districts, the fish-eating Crows are separated by the natives from the common sort. It is said that the flight and voice of these birds can be readily distinguished. Some miners working at Lepreaux, in New Brunswick, who were familiar with the fisheating Crows of Cape Breton, drew my attention to a flock of apparently small and peculiar-voiced Crows gleaning along the shores; but though easily trapped by a fish bait, they proved to be nothing more than rather small common Crows.

Note. - The American Magpie (Pica pica hudsonica) is a Western and Northwestern bird, and occurs as a straggler only east of the Mississippi. It has been taken in Michigan, northern Illinois, and western Ontario ; also at Chambly, near Montreal. 


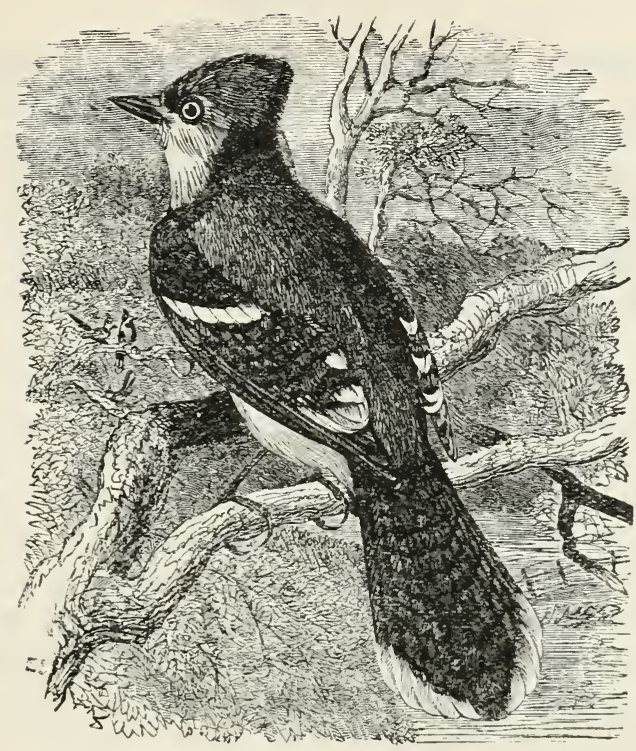

BLUE JAY.

\section{CyanocitTa CRISTATA.}

Char. Above, purplish blue; below, pale purplish gray, lighter on throat and tail-coverts; wings and tail bright blue barred with black ; wingcoverts, secondaries, and most of tail-feathers broadly tipped with white. Head conspicuously crested; tail wedge-shaped. Length II to I $21 / 2$ inches.

Nest. In a small conifer, about 20 feet from the ground, situated in deep forest or near a settlement; roughly but firmly constructed of twigs and roots, and lined with fine roots.

Eggs. 4-5; pale olive or buff, spotted with yellowish brown; I.IO $\times 0.85$.

This elegant and common species is met with in the interior, from the remote northwestern regions near Peace River, in the $54^{\text {th }}$ to the 56 th degree, Lake Winnipeg in the $49^{\text {th }}$ degree, the eastern steppes of the Rocky Mountains, and southwestward to the banks of the Arkansas; also along the Atlantic regions from the confines of Newfoundland to the peninsula of Florida and the shores of the Gulf of Mexico. 
The Blue Jay is a constant inhabitant both of the wooded wilderness and the vicinity of the settled farm, though more familiar at the approach of winter and early in spring than at any other season. These wanderings or limited migrations are induced by necessity alone; his hoards of grain, nuts, and acorns either have failed or are forgotten: for, like other misers, he is more assiduous to amass than to expend or enjoy his stores, and the fruits of his labors very frequently either devolve to the rats or squirrels, or accidentally assist in the replanting of the forest. His visits at this time are not unfrequent in the garden and orchard, and his usual petulant address of djay, jayy, jáy, and other harsh and trumpeting articulations, soon make his retreat known to all in his neighborhood. So habitual is this sentinel cry of alarm, and so expressive, that all the birds within call, as well as other wild animals, are instantly on the alert, so that the fowler and hunter become generally disappointed of their game by this his garrulous and noisy propensity; he is therefore, for his petulance, frequently killed without pity or profit, as his flesh, though eaten, has but little to recommend it. His more complaisant notes, when undisturbed, though guttural and echoing, are by no means unpleasant, and fall in harmoniously with the cadence of the feathered choristers around him, so as to form a finishing part to the general music of the grove. His accents of blandishment, when influenced by the softer passions, are low and musical, so as to be scarcely heard beyond the thick branches where he sits concealed; but as soon as discovered he bursts out into notes of rage and reproach, accompanying his voice by jerks and actions of temerity and defiance. Indeed the Jay of Europe, with whom our beau agrees entirely in habits, is so irascible and violent in his movements as sometimes to strangle himself in the narrow fork of a branch from which he has been found suspended. Like the European species, he also exhibits a great antipathy to the Owl, and by his loud and savage vociferation soon brings together a noisy troop of all the busy birds in the neighborhood. To this garrulous attack the night wanderer has no reply but a threatening stare 
of indifference; and as soon as opportunity offers, he quietly slips from his slandering company. Advantage in some countries is taken of this dislike for the purpose of catching birds; thus the Owl, being let out of a box, sometimes makes a hoot, which instantly assembles a motley group, who are then caught by liming the neighboring twigs on which they perch. In this gossip the Jay and Crow are always sure to take part if within sight or hearing of the call, and are thus caught or destroyed at will. The common Jay is even fond of imitating the harsh voice of the Owl and the noisy Kestrel. I have also heard the Blue Jay mock with a taunting accent the ké oo, ke oo, or quailing, of the Red-shouldered Hawk. Wilson likewise heard him take singular satisfaction in teasing and mocking the little American Sparrow Hawk, and imposing upon him by the pretended plaints of a wounded bird; in which frolic several would appear to join, until their sport sometimes ended in sudden consternation, by the Hawk, justly enough, pouncing on one of them as his legitimate and devoted prey.

His talent for mimicry when domesticated is likewise so far capable of improvement as to enable him to imitate human speech, articulating words with some distinctness; and on hearing voices, like a Parrot, he would endeavor to contribute his important share to the tumult. Bewick remarks of the common Jay of Europe that he heard one so exactly counterfeit the action of a saw that, though on a Sunday, he could scarcely be persuaded but that some carpenter was at work. Another, unfortunately, rendered himself a serious nuisance by learning to hound a cur dog upon the domestic cattle, whistling and calling him by name, so that at length a serious accident occurring in consequence, the poor Jay was proscribed.

One which I have seen in a state of domestication behaved with all the quietness and modest humility of Wilson's caged bird with a petulant companion. He seldom used his voice, came in to lodge in the house at night in any corner where he was little observed, but unfortunately perished by an accident before the completion of his education.

'The favorite food of this species is chestnuts, acorns, and 
Indian corn or maize, the latter of which he breaks before swallowing. He also feeds occasionally on the larger insects and caterpillars, as well as orchard fruits, particularly cherries, and does not even refuse the humble fare of potatoes. In times of scarcity he falls upon carrion, and has been known to venture into the barn, through accidental openings; when, as if sensible of the danger of purloining, he is active and silent, and if surprised, postponing his garrulity, he retreats with noiseless precipitation and with all the cowardice of a thief. The worst trait of his appetite, however, is his relish for the eggs of other birds, in quest of which he may frequently be seen prowling; and with a savage cruelty he sometimes also devours the callow young, spreading the plaint of sorrow and alarm wherever he flits. The whole neighboring community of little birds, assembled at the cry of distress, sometimes, however, succeed in driving off the ruthless plunderer, who, not always content with the young, has been seen to attack the old, though with dubious success; but to the gallant and quarrelsome King Bird he submits like a coward, and driven to seek shelter, even on the ground, from the repeated blows of his antagonist, sneaks off well contented to save his life.

Although a few of these birds are seen with us nearly through the winter, numbers, no doubt, make predatory excursions to milder regions, so that they appear somewhat abundant at this season in the Southern States; yet they are known to rear their young from Canada to South Carolina, so that their migrations may be nothing more than journeys from the highlands towards the warmer and more productive sea-coast, or eastern frontier.

East of the Mississippi the Blue Jay has been rarely seen north of the 5 oth parallel.

Note. - A smaller race, which differs also from true cristata in having less white on the tips of the secondaries and tail-feathers, has been named the Florida Blue JAy (C. cristata florincola). It is found in Florida and along the Gulf coast. 


\section{FLORIDA JAY.}

\section{APHELOCOMA FLORIDANA.}

CHAR. Above, dull azure blue; back with patch of brownish gray; throat and chest grayish white streaked with ashy; belly, brownish gray. No crest ; tail longer than wing. Length $10 \frac{1}{2}$ to $12 \frac{1}{2}$ inches.

Nest. In low tree or thicket of bushes; made of twigs and roots, lined with fine roots and moss.

Eggs. 4-5; pale green or bluish gray, spotted with rufous and black; I. $10 \times 080$.

This elegant species is, as far as yet known, almost wholly confined to the interior of the mild peninsula of East Florida. In a tour through the lower parts of Georgia and West Florida, protracted to the middle of March, I saw none of these birds; and at the approach of winter they even retire to the south of St. Augustine, as Mr. Ord did not meet with them until about the middle of February; from that time, however, they were seen daily, flying low and hopping through the luxuriant thickets, or peeping from the dark branches of the live-oaks which adorn the outlet of the St. Juan. These birds appear to possess the usual propensities of their tribe, being quarrelsome, active, and garrulous. Their voice is less harsh than that of the common Blue Jay, and they have a variety of notes, some of which, probably imitations, are said to have a resemblance to the song of the Thrush and the call of the common Jay.

Only a single brood is raised in the season. Its food is very similar to that of the other species; namely, berries, fruits, mast, and insects. It likewise collects snails from the marshy grounds, feeds largely on the seeds of the sword-palmetto; and, in the manner of the Titmouse, it secures its food between its feet, and breaks it into pieces previous to swallowing. Like other species of the genus, it destroys the eggs and young of small birds, despatching the latter by repeated blows on the head. It is also easily reconciled to the cage, and feeds on fresh or dried fruits and various kinds of nuts. Its attempts at mimicry in this state are very imperfect. 


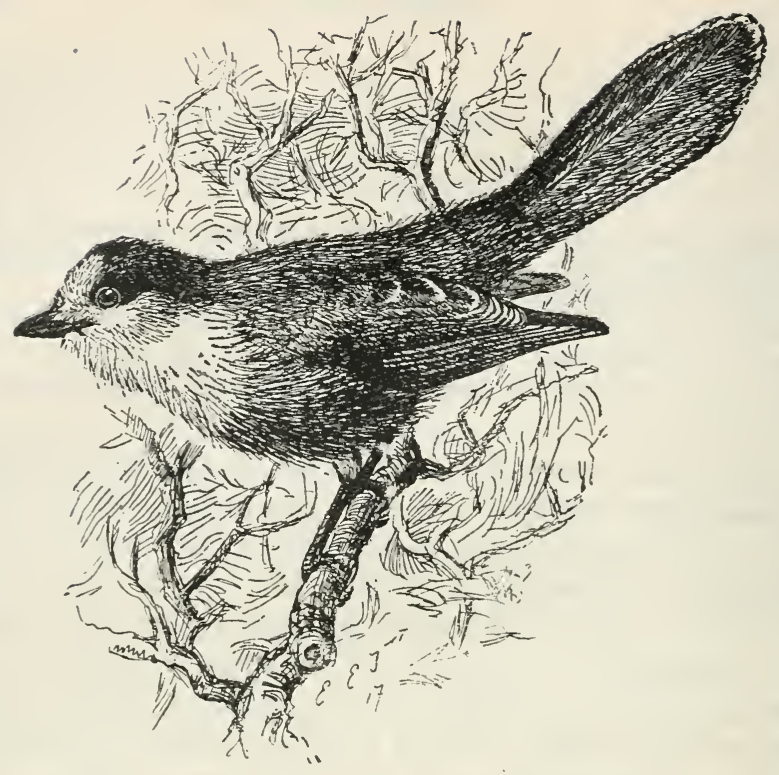

CANADA JAY.

WHISKEY JACK. MOOSE BIRD.

PERISOREUS CANADENSIS.

CHAR. Above, ashy gray; head and nape smoky black; forehead and lower parts whitish gray; breast brownish gray; wings and tail dark ashy, tipped obscurely with white. Young: uniform dull smoky black, paler beneath. Length, II to I 2 inches.

Nest. In a coniferous tree; a bulky but compact structure of dried twigs, shreds of bark and moss thickly lined with feathers.

Eggs. 4-5; of light gray or buffish, spotted with dark gray, lilac gray, and pale brown; $1.15 \times 0.80$.

This species, with the intrusive habits and plain plumage of the Pie, is almost confined to the northern regions of America, being met with around Hudson's Bay, but becoming rare near the St. Lawrence, and in winter only straggling along the coast as far as Nova Scotia. Westward, occasionally driven by the severity of the weather and failure of food, they make their appearance in small parties in the interior of Maine and north- 
ern parts of Vermont, where, according to Audubon, they are frequently known to breed. They also descend into the State of New York as far as the town of Hudson and the banks of the Mohawk. In the month of May I observed a wandering brood of these birds, old and young, on the shady borders of the Wahlamet, in the Oregon territory, where they had probably been bred. They descended to the ground near a spring in quest of insects and small shells.

According to Mr. Hutchins, like the Pie, when near the habitations and tents of the inhabitants and natives, it is given to pilfering everything within reach, and is sometimes so bold as to venture into the tents and snatch the meat from the dishes even, whether fresh or salt. It has also the mischievous sagacity of watching the hunters set their traps for the Martin, from which it purloins the bait. Its appetite, like that of the Crow, appears omnivorous. It feeds on worms, various insects, and their larvæ, and on flesh of different kinds; lays up stores of berries in hollow trees for winter; and at times, with the reindeer, is driven to the necessity of feeding on lichens. The severe winters of the wilds it inhabits, urges it to seek support in the vicinity of habitations. Like the common Jay, at this season it leaves the woods to make excursions after food, trying every means for subsistence; and tamed by hunger, it seeks boldly the society of men and animals. These birds are such praters as to be considered Mocking Birds, and are superstitiously dreaded by the aborigines. They commonly fly in pairs or rove in small families, are no way difficult to approach, and keep up a kind of friendly chattering, sometimes repeating their notes for a quarter of an hour at a time, immediately before snow or falling weather. When caught, they seldom long survive, though they never neglect their food. Like most of their genus, they breed early in the spring, building their nests, which are formed of twigs and grass in the pinetrees. They lay 4 to 6 light-grayish eggs, faintly marked with brown spots. The young brood, at first, are perfect Crows, or nearly quite black, and continue so for some time.

According to Richardson, this inelegant but familiar bird 
inhabits all the woody districts of the remote fur countries from

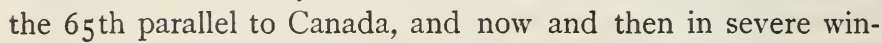
ters extends his desultory migrations within the northern limits of the United States. Scarcely has the winter traveller in those cold regions chosen a suitable place of repose in the forest, cleared away the snow, lighted his fire, and prepared his tent, when Whiskey Jack insidiously pays him a visit, and boldly descends into the social circle to pick up any crumbs of frozen fish or morsels of dry meat that may have escaped the mouths of the weary and hungry sledge-dogs. This confidence is almost the only recommendation of our familiar intruder. There is nothing pleasing in his voice, plumage, or attitudes. But this dark, sinister dwarf of the North is now the only inhabitant of those silent and trackless forests, and trusting from necessity in the forbearance of man, he fearlessly approaches, and craves his allowed pittance from the wandering stranger who visits his dreary domain. At the fur posts and fishing stations he is also a steady attendant, becoming so tamed in the winter by the terrible inclemency of the climate as to eat tamely from the offered hand; yet at the same time, wild and indomitable under this garb of humility, he seldom survives long in confinement, and pines away with the loss of his accustomed liberty. He hops with activity from branch to branch, but when at rest, sits with his head drawn in, and with his plumage loose. The voice of this inelegant bird is plaintive and squeaking, though he occasionally makes a low chattering, especially when his food appears in view. Like our Blue Jay, he has the habit of hoarding berries, morsels of meat, etc., in the hollows of trees or beneath their bark. These magazines prove useful in winter, and enable him to rear his hardy brood even before the disappearance of the snow from the ground, and long before any other bird indigenous to those climates. The nest is concealed with such care that but few of the natives have seen it.

Whiskey Jack has evidently moved somewhat southward since Nuttall made his observations, for the species is now a fairly common resident of the Maritime Provinces of Canada, as well as of the northern portions of Maine, New Hampshire, Vermont, New 
York, and Michigan. Near Ottawa, and in the Muskoka district of Ontario, it occurs regularly, though it is not abundant. In October, I889, one example was taken at Arlington Heights, near Boston, and several have been reported from other localities in Massachusetts.

I examined a nest taken near Edmundston, New Brunswick, on April 7, I883, at which date the country there was covered with snow and ice. The nest was placed on a small tree near the main highway, and not many hundred yards from the railroad station. As the cold in that region is intense, the temperature often being at $-30^{\circ}$ to $-40^{\circ} \mathrm{F}$. in midwinter, it is surprising that the eggs are ever hatched. But the nest is made very warm, and the birds sit close, and when one parent steps off the other at once steps on.

By the first of June the young are in full feather and taking care of themselves.

Nuttall's opinion that these birds appear bold and familiar only when pressed by the hunger of winter, has not found support in my experience. Frequently when camping in the New Brunswick woods during the summer vacation I have seen numbers of these birds gather about my camp-fire within a few minutes after it has been lighted; and they did not hesitate to pick up a piece of meat thrown toward them. Mr. Thompson reports a similar experience in Manitoba. He describes these birds coming to his camp-fireside and helping themselves to scraps lying but a few feet from where he was sitting. Several other observers, however, have recorded a similar opinion to Nuttall's; and it may be that the fearless birds are restricted to localities where they are not disturbed.

The Canadian hunters and lumbermen have a superstitious respect for these birds, fearing the ill-luck that is said to result from killing one, and Whiskey Jack may have discovered that.

Note. - The Labrador JAY ( $P$. canadensis nigricapilus) differs from true canadensis in being darker in general coloration. It is restricted to the coast region of Labrador. 


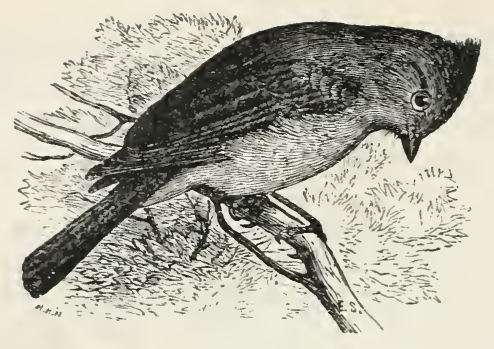

TUFTED TITMOUSE.

PARUS BICOLOR.

CHAR. Above, bluish ash; beneath, dull white; flanks tinged with yellowish brown; forehead black; head conspicuously crested. Length $5 \frac{3}{4}$ to $6 \frac{1}{2}$ inches.

Nest. In a cavity of a tree or stump; composed of leaves, moss, or woollen material, lined with feathers.

Eggs. 5-8; white or pale cream, spotted with reddish brown; 0.75 $\times 0.55$.

From the geographic limits of this species, as it occurs to me, I am inclined to believe that the bird seen in Greenland may be different from the present, as it scarcely appears to exist north beyond the States of Pennsylvania or New York. They are seldom, if ever, seen or heard in this part of Massachusetts, and instead of being more abundant to the north, as believed by Wilson, they are probably not known there at all. In the Southern States, at least in winter and spring, they are very common, and present all the usual habits and notes of the genus. The numbers which I saw in the Southern States from January to March would seem to indicate a migratory habit; but whether they had arrived from the Northeast, or from the great forests of the West, could not be conjectured.

The Peto, as I may call this bird from one of his characteristic notes, and the Carolina Wren, were my constant and amusing companions during the winter as I passed through the dreary solitudes of the Southern States. The sprightliness, caprice, and varied musical talent of this species are quite interesting, and more peculiarly so when nearly all the other vocal tenants of the forest are either absent or silent. To 
hear in the middle of January, when at least the leafless trees and dark cloudy skies remind us of the coldest season, the lively, cheering, varied pipe of this active and hardy bird, is particularly gratifying; and though his voice on paper may appear to present only a list of quaint articulations, yet the delicacy, energy, pathos, and variety of his simple song, like many other things in Nature, are far beyond the feeble power of description; and if in these rude graphic outlines of the inimitable music of birds I am able to draw a caricature sufficient to indicate the individual performer, I shall have attained all the object to be hoped for in an attempt at natural delineation.

The notes of the Peto generally partake of the high, echoing, clear tone of the Baltimore Bird. Among his more extraordinary expressions I was struck with the call of 'whip-tomkilly killy, and now and then 'whip tom killy, with occasionally some variation in the tone and expression, which was very lively and agreeable. The middle syllable (tôm) was pronounced in a hollow reverberating tone. In a few minutes after the subject and its variations were finished, in the estimation of the musical performer, he suddenly twisted himself round the branch on which he had sat, with a variety of odd and fantastic motions; and then, in a lower, hoarser, harsh voice, and in a peevish tone, exactly like that of the Jay and the Chickadee, went $d \bar{a} y-d \bar{a} y-d \bar{a} y$-dáy, and day-dăy-dăy-daydait; sometimes this loud note changed into one which became low and querulous. On some of these occasions he also called 'tshica dee-dee. The jarring call would then change occasionally into kai-tee-did did-dit-did. These peevish notes would often be uttered in anger at being approached; and then again would perhaps be answered by some neighboring rival, against whom they appeared levelled in taunt and ridicule, being accompanied by extravagant gestures.

Later in the season, in February, when in the lower part of Alabama the mild influence of spring began already to be felt, our favorite, as he gayly pursued the busy tribe of insects, now his principal food, called, as he vaulted restlessly from branch to branch, in an echoing rapid voice, at short intervals, petŏ- 
petŏ-peto-petŏ. This tender call of recognition was at length answered, and continued at intervals for a minute or two; they then changed their quick call into a slower péto pétó pétó; and now the natural note passed into the plaintive key, sounding like que-āh que- $\bar{a} h$; then in the same breath a jarring note like that of the Catbird, and in part like the sound made by putting the lower lip to the upper teeth, and calling ' $t s h$ ' $v a h$, ' $t s h$ ' vah. After this the call of kerry-kerry-kerry-kerry struck up with an echoing sound, heightened by the hollow bank of the river whence it proceeded. At length, more delicately than at first, in an under tone, you hear anew, and in a tender accent, peto peto peto. In the caprice and humor of our performer, tied by no rules but those of momentary feeling, the expression will perhaps change into a slow and full peet-peet-a-peet-a-peet, then a low and very rapid ker-ker-ker-ker-ker-kerry, sometimes so quick as almost to resemble the rattle of a watchman. At another time his morning song commences like the gentle whispers of an aërial spirit, and then becoming high and clear like the voice of the nightingale, he cries keeva keeva kéeva keeva; but soon falling into the querulous, the day-day-day-dayday-dait of the Chickadee terminates his performance Imitative, as well as inventive, I have heard the Peto also sing something like the lively chatter of the Swallow, leta-leta-letaletalit, and then vary into pèto-pěto-pěto-pèto-peto extremely quick. Unlike the warblers, our cheerful Peto has no trill, or any other notes than these simple, playful, or pathetic calls; yet the compass of voice and the tone in which they are uttered, their capricious variety and their general effect, at the season of the year when they are heard, are quite as pleasing to the contemplative observer as the more exquisite notes of the summer songsters of the verdant forest.

The sound of 'whip-tom-kelly, which I heard this bird utter, on the I 7 th of January, I 830, near Barnwell, in South Carolina, is very remarkable, and leads me to suppose that the species is also an inhabitant of the West India Islands, where Sloane attributes this note to the Red-eyed Flycatcher; but it is now known to be the note of a tropical species, the vireo longiros- 
tris, and which our bird had probably heard and mimicked in its distant clime.

The Peto, besides insects, like the Jay, to which he is allied, chops up acorns, cracks nuts and hard and shelly seeds to get at their contents, holding them meanwhile in his feet. $\mathrm{He}$ also searches and pecks decayed trees and their bark with considerable energy and industry in quest of larvæ; he often also enters into hollow trunks, prying after the same objects. In these holes they commonly roost in winter, and occupy the same secure situations, or the holes of the small Woodpecker, for depositing and hatching their eggs, which takes place early in April or in May, according to the different parts of the Union they happen to inhabit. Sometimes they dig out a cavity for themselves with much labor, and always line the hollow with a variety of warm materials. Their eggs, about six to eight, are white with a few small specks of brownish red near the larger end. The whole family, young and old, may be seen hunting together throughout the summer and winter, and keeping up a continued mutual chatter.

According to the observations of Wilson it soon becomes familiar in confinement, and readily makes its way out of a wicker cage by repeated blows at the twigs. It may be fed on hemp-seed, cherry-stones, apple-pippins, and hickory nuts, broken and thrown in to it. In its natural state, like the rest of its vicious congeners, it sometimes destroys small birds by blows on the skull.

This species belongs to the Carolinian faunal area, and occurs regularly only from about the 4oth parallel southward; north of that it is but an accidental straggler. A few examples have been taken in New England, mostly in Connecticut. 


\section{CHICKADEE.}

\section{PARUS ATRICAPILlUS.}

CHAR. Above, ashy gray; below, grayish white; flanks buffy; crown and throat black; cheek white. Length $4 \frac{3 / 4}{4}$ to $5 \frac{3 / 4}{4}$ inches.

Nest. In a cavity made in a decayed stump, entering from the top or side; composed of wool or inner fur of small mammals firmly and compactly felted. Sometimes moss and hair are used, and a lining of feathers.

Eggs. 5-8; white speckled with reddish brown, $0.60 \times 0.50$.

This familiar, hardy, and restless little bird chiefly inhabits the Northern and Middle States as well as Canada, in which it is even resident in winter around Hudson's Bay, and has been met with at $62^{\circ}$ on the northwest coast. In all the Northern and Middle States, during autumn and winter, families of these birds are seen chattering and roving through the woods, busily engaged in gleaning their multifarious food, along with Nuthatches and Creepers, the whole forming a busy, active, and noisy group, whose manners, food, and habits bring them together in a common pursuit. Their diet varies with the season; for besides insects, their larvæ and eggs, of which they are more particularly fond, in the month of September they leave the woods and assemble familiarly in our orchards and gardens, and even enter the thronging cities in quest of that support which their native forests now deny them. Large seeds of many kinds, particularly those which are oily, as the sunflower and pine and spruce kernels, are now sought after. These seeds, in the usual manner of the genus, are seized in the claws and held against the branch until picked open by the bill to obtain their contents. Fat of various kinds is also greedily eaten, and they regularly watch the retreat of the hogkillers in the country, to glean up the fragments of meat which adhere to the places where the carcases have been suspended. At times they feed upon the wax of the candle-berry myrtle (Myrica cerifera) ; they likewise pick up crumbs near the houses, and search the weather-boards, and even the window-sills, 

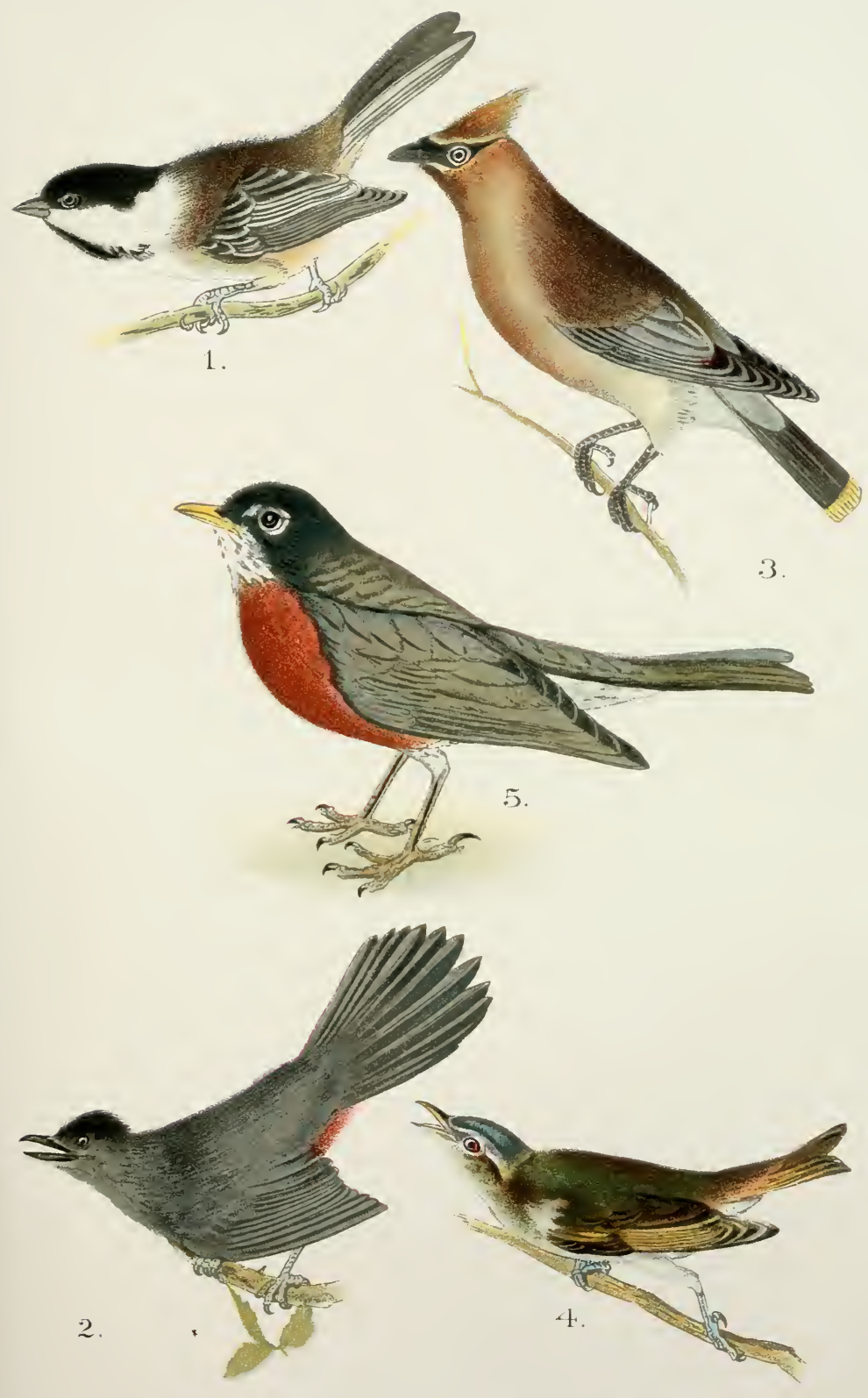

1. Chickadee.

3. Cedar Waxwing .

5. Robin.

2. Catbird. 4. Red-Eyed Vireo. 

familiarly for their lurking prey, and are particularly fond of spiders and the eggs of destructive moths, especially those of the canker-worm, which they greedily destroy in all its stages of existence. It is said that they sometimes attack their own species when the individual is sickly, and aim their blows at the skull with a view to eat the brain; but this barbarity I have never witnessed. In winter, when satisfied, they will descend to the snow-bank beneath and quench their thirst by swallowing small pieces; in this way their various and frugal meal is always easily supplied; and hardy, and warmly clad in light and very downy feathers, they suffer little inconvenience from the inclemency of the seasons. Indeed in the winter, or about the close of October, they at times appear so enlivened as already to show their amorous attachment, like our domestic cock, the male approaching his mate with fluttering and vibrating wings; and in the spring season, the males have obstinate engagements, darting after each other with great velocity and anger. Their roost is in the hollows of decayed trees, where they also breed, making a soft nest of moss, hair, and feathers, and laying from six to twelve eggs, which are white, with specks of brown-red. They begin to lay about the middle or close of April ; and though they commonly make use of natural or deserted holes of the Woodpecker, yet at times they are said to excavate a cavity for themselves with much labor. The first brood take wing about the 7 th or roth of June, and they have sometimes a second towards the end of July. The young, as soon as fledged, have all the external marks of the adult, the head is equally black, and they chatter and skip about with all the agility and self-possession of their parents, who appear nevertheless very solicitous for their safety. From this time the whole family continue to associate together through the autumn and winter. They seem to move by concert from tree to tree, keeping up a continued 'tshe-de-de-de-de, and 'tshede-de-de-dait, preceded by a shrill whistle, all the while busily engaged picking round the buds and branches hanging from their extremities and proceeding often in reversed postures, head downwards, like so many tumblers, prying into every 
crevice of the bark, and searching around the roots and in every possible retreat of their insect prey or its larvæ. If the object chance to fall, they industriously descend to the ground and glean it up with the utmost economy.

On seeing a cat or other object of natural antipathy, the Chickadee, like the peevish Jay, scolds in a loud, angry, and hoarse note, like 'tshe dáigh dáigh dáigh. Among the other notes of this species I have heard a call like tshe-de-jay, tshede-jay, the two first syllables being a slender chirp, with the jay strongly pronounced. Almost the only note of this bird which may be called a song is one which is frequently heard at intervals in the depth of the forest, at times of the day usually when all other birds are silent. We then may sometimes hear in the midst of this solitude two feeble, drawling, clearly whistled, and rather melancholy notes, like 'te-děrry, and sometimes 'yeperrit, and occasionally, but much more rarely, in the same wiry, whistling, solemn tone, 'péhbé. The young, in winter, also sometimes drawl out these contemplative strains. In all cases the first syllable is very high and clear, the second word drops low and ends like a feeble plaint. This is nearly all the quaint song ever attempted by the Chickadee, and is perhaps the two notes sounding like the whetting of a saw, remarked of the Marsh Titmouse in England by Mr. White, in his "Natural History of Selborne." On fine days, about the commencement of October, I have heard the Chickadee sometimes for half an hour at a time attempt a lively, petulant warble very different from his ordinary notes. On these occasions he appears to flit about, still hunting for his prey, but almost in an ecstasy of delight and vigor. But after a while the usual drawling note again occurs. These birds, like many others, are very subject to the attacks of vermin, and they accumulate in great numbers around that part of the head and front which is least accessible to their feet.

The European bird, so very similar to ours, is partial to marshy situations. Ours has no such predilection, nor do the American ones, that I can learn, ever lay up or hide any store of seeds for provision, - a habit reported of the foreign family. 
In this fact, with so many others, we have an additional evidence of affinity between the Titmouse and Jay, particularly that short-billed section which includes the Garrulus canadensis and $G$. infaustus. Even the blue color, so common with the latter, is possessed by several species of this genus. Indeed, from their aggregate relation and omnivorous habit we see no better place of arrangement for these birds than succinctly after the Garruli, or Jays.

Following the authority of Temminck and Montagu, I considered this bird the same as the European Marsh Titmouse. I have since seen the bird of Europe in its native country, and have good reason to believe it wholly different from our lively and familiar Chickadee. Unlike our bird, it is rather shy, seldom seen but in pairs or solitary, never in domestic premises, usually and almost constantly near streams or watercourses, on the willows, alders, or other small trees impending over streams, and utters now and then a feeble complaining or querulous call, and rarely if ever the chicka dee-dee. It also makes a noise in the spring, as it is said, like the whetting of a saw, which ours never does. The Chickadee is seldom seen near waters; often, even in summer, in dry, shady, and secluded woods; but when the weather becomes cold, and as early as October, roving families, pressed by necessity and the failure of their ordinary insect fare, now begin to frequent orchards and gardens, appearing extremely familiar, hungry, indigent, but industrious, prying with restless anxiety into every cranny of the bark or holes in decayed trees after dormant insects, spiders, and larvæ, descending with the strictest economy to the ground in quest of every stray morsel of provision which happens to fall from their grasp. Their quaint notes and jingling warble are heard even in winter on fine days when the weather relaxes in its severity; and, in short, instead of being the river hermit of its European analogue, it adds by its presence, indomitable action and chatter, an air of cheerfulness to the silent and dreary winters of the coldest parts of America. 


\section{CAROLINA CHICKADEE.}

\section{Parus Carolinensis.}

CHAR. Above, ashy gray tinged with dull brown; head and throat black; cheek white; beneath, brownish white; flanks buffish. Length $4 \frac{1}{4}$ to $43 / 4$ inches.

Vest. In a cavity of decayed stump, composed of grass or shreds of bark, and lined with feathers. Sometimes composed entirely of fur or fine wool felted compactly.

Eggs. 5-8; white often spotted with reddish brown; $0.60 \times 0.50$.

This species, detected by Mr. Audubon, is a constant inhabitant of the Southern and Middle States from the borders of New Jersey to East Florida. It has a predilection for the borders of ponds, marshes, and swamps, and less gregarious than the preceding, seldom more than a pair or family are seen together. It is also shy and retiring; inhabiting at all times a mild and genial clime, it never seeks out domestic premises, nor even the waysides, but, like the European Marsh Titmouse, it remains throughout the year in the tangled woods and swamps which gave it birth. In the wilds of Oregon late in autumn we frequently saw small roving restless flocks of these birds associated often with the Chestnut-Backed species. At such times both parties were querulous and noisy; but the tshe te de de is comparatively feeble, uttered in a slender, wiry tone. At such times intently gleaning for insects, they show very little fear, but a good deal of sympathy for their wounded companions, remaining round them and scolding in a petulant and plaintive tone. At the approach of winter those in the Atlantic region retire farther to the south, and on the Pacific border they are to be seen in winter in the woods of Upper California; but in no instance did we see them approach the vicinity of the trading posts or the gardens.

A nest of this species discovered by Dr. Bachman was in a hollow stump about four feet from the ground; it was rather shallow, composed of fine wool, cotton, and some fibres of plants, the whole fitted together so as to be of an uniform thickness throughout, and contained pure white eggs. 


\section{HUDSONIAN CHICKADEE.}

\section{PARUS HUDSONICUS.}

Char. Above, pale dull brown, darker on crown; cheeks white; below, grayish white; flanks rusty; throat brownish black. Length 5 to $5 \frac{3}{4}$.

Nest. In an excavation in a decayed stump, usually entering from the top. On the bottom of the cavity is placed a platform of dried moss, and on this another of felted fur, and upon this latter is set the graceful pouchshaped nest of firm felt, made of the inner fur of small mammals.

Eggs. 6-ro; creamy white with brown spots in a circle around the larger end; $0.5^{8} \times 0.5^{8}$.

This more than usually hardy species continues the whole year about Severn River, braving the inclemency of the winters, and frequents the juniper-bushes on the buds of which it feeds. In winter, like the common species, it is seen roving about in small flocks, busily foraging from tree to tree. It is said to lay five eggs. Mr. Audubon met with it on the coast of Labrador, where it was breeding, about the middle of July. $\mathrm{He}$ describes the nest as being placed at the height of not more than three feet from the ground, in the hollow of a decayed low stump scarcely thicker than a man's leg, the whole so rotten that it crumbled to pieces on being touched. It was shaped like a purse, eight inches in depth, two in diameter inside, its sides about a half an inch thick. It was composed of the finest fur of different quadrupeds, so thickly matted throughout that it looked as if it had been felted by the hand of man. On the nest being assailed, the male flew at the intruder, uttering an angry te-te-te-tee.

The Hudson Bay Chickadee is fairly common in the Maritime Provinces, though more abundant in winter than in summer. It has been found breeding, also, in the northern parts of Maine, New Hampshire, New York, and Michigan, and in the Muskoka districts of Ontario. Mr. Walter Faxon considers it a rare though regular migrant to the eastern part of Massachusetts, but thinks it occurs in numbers in winter amid the Berkshire hills.

A few examples have been taken in Connecticut and in Rhode Island. 


\section{BOHEMIAN IVAXWING.}

\section{AMPELIS GARRULUS.}

CHAR. Prevailing color cinnamon brown or fawn color, darker on front head and cheeks, changing to ashy on rump; chin and line across forehead and through the eyes, rich black; wings and tail slaty; tail tipped with yellow; primaries tipped with white, secondaries with appen. dages like red sealing-wax. Head with long pointed crest. Length $71 / 2$ to $83 / 4$ inches. Easily distinguished from the Cedar Bird by its larger size and darker color.

Nest. In a tree, a bulky structure of twigs and roots, lined with feathers.

Eggs. 3-5; bluish white spotted with lilac and brown; $1.00 \times 0.70$.

The Waxwing, of which stragglers are occasionally seen in Nova Scotia, Massachusetts, Long Island, and the vicinity of Philadelphia, first observed in America in the vicinity of the Athabasca River, near the region of the Rocky Mountains, in the month of March, is of common occurrence as a passenger throughout the colder regions of the whole northern hemisphere. Like our Cedar Birds, they associate in numerous flocks, pairing only for the breeding season; after which the young and old give way to their gregarious habits, and collecting in numerous companies, they perform extensive journeys, and are extremely remarkable for their great and irregular wanderings. The circumstances of incubation in this species are wholly unknown. It is supposed that they retire to the remote regions to breed; yet in Norway they are only birds of passage, and it has been conjectured that they pass the summer in the elevated table-land of Central Asia. Wherever they dwell at this season, it is certain that in spring and late autumn they visit northern Asia or Siberia and eastern Europe in vast numbers, but are elsewhere only uncertain stragglers, whose appearance, at different times, has been looked upon as ominous of some disaster by the credulous and ignorant.

The Waxen Chatterers, like our common Cedar Birds, appear destitute of song, and only lisp to each other their usual low, reiterated call of zé zé re, which becomes more audible 
when they are disturbed and as they take to wing. They are also very sociable and affectionate to their whole fraternity, and sit in rows often on the same branch, when not employed in collecting their food, which is said to consist of juicy fruits of various kinds, particularly grapes; they will also eat juniper and laurel berries, as well as apples, currants, and figs, and are often seen to drink.

Dr. Richardson informs us that this bird appears in flocks at Great Bear Lake about the 24th of May, when they feed on the berries of the alpine arbutus, marsh vaccinium, and other kinds exposed again to the surface after the spring thaw. Another flock of three or four hundred individuals was seen on the banks of the Saskatchewan, at Carlton House, early in the same month. In their usual manner they all settled together on one or two trees, and remained together about the same place for an hour in the morning, making a loud twittering noise, and were too shy to be approached within gunshot. Their stay at most did not exceed a few days, and none of the Indians knew of their nests; though the doctor had reason to believe that they retired in the breeding season to the broken and desolate mountain-limestone districts in the 67 th or 68th parallels, where they find means to feed on the fruit of the common juniper, so abundant in that quarter. Neither Mr. Townsend nor myself observed this bird either in the Columbia River district or on the Rocky Mountains.

The Bohemian is still a rover of uncertain and irregular habits, occasionally in winter appearing along the northern border of the United States and through the settled portions of Canada in large flocks, but sometimes absent for several seasons. The statement has been made that there is no record of its occurrence in New England within the past fifteen years. Colonel Goss found a nest in Labrador, and several have been taken in the Northwest. 


\title{
CEDAR WAXIVING.
}

\author{
CEDAR BIRD. CHERRY BIRD.
}

AMPELIS CEDRORUM.

CHAR. Prevailing color cinnamon brown or fawn color, changing to ashy on rump and yellowish on the belly; chin and line across forehead and through eyes, rich black; wings and tail slaty; tail tipped with yellow; secondaries sometimes with red, wax-like appendages. Head with long, pointed crest. Length $61 / 2$ to $71 / 2$ inches.

Nest. In a tree; large and loosely made of twigs and grass, lined with grass, hair, or feathers.

Eggs. 3-5; bluish white spotted with lilac and brown; $0.85 \times 0.60$.

This common native wanderer, which in summer extends its migrations to the remotest unpeopled regions of Canada, is also found throughout the American continent to Mexico, and parties even roam to the tropical forests of Cayenne. In all this extensive geographical range, where great elevation or latitude tempers the climate so as to be favorable to the production of juicy fruits, the Cedar Bird will probably be found either almost wholly to reside, or to pass the season of reproduction. Like its European representative (the Waxen Chatterer), it is capable of braving a considerable degree of cold ; for in Pennsylvania and New Jersey some of these birds are seen throughout the winter, where, as well as in the early part of the summer and fall, they are killed and brought to market, generally fat, and much esteemed as food. Silky softness of plumage, gentleness of disposition, innocence of character, extreme sociability, and an innate, inextinguishable love of freedom, accompanied by a constant desire of wandering, are characteristic traits in the physical and moral portrait of the second as well as the preceding species of this peculiar and extraordinary genus.

Leaving the northern part of the continent, situated beyond the 4 oth degree, at the approach of winter, they assemble in companies of twenty to a hundred, and wander through the Southern States and Mexico to the confines of the equator, in 
all of which countries they are now either common or abundant. As observed by Audubon, their flight is easy, continued, and often performed at a considerable height; and they move in flocks or companies, making several turns before they alight. As the mildness of spring returns, and with it their favorite food, they reappear in the Northern and Eastern States about the beginning of April, before the ripening of their favorite fruits, the cherries and mulberries. But at this season, to repay the gardener for the tithe of his crop, their natural due, they fail not to assist in ridding his trees of more deadly enemies which infest them, and the small caterpillars, beetles, and various insects now constitute their only food; and for hours at a time they may be seen feeding on the all-despoiling cankerworms which infest our apple-trees and elms. On these occasions, silent and sedate, after plentifully feeding, they sit dressing their feathers in near contact on the same branch to the number of 5 or 6 ; and as the season of selective attachment approaches, they may be observed pluming each other, and caressing with the most gentle fondness, - a playfulness in which, however, they are even surpassed by the contemned Raven, to which social and friendly family our Cedar Bird, different as he looks, has many traits of alliance. But these demonstrations of attachment, which in a more vigorous kind would kindle the feud of jealousy, apparently produce in this bird scarcely any diminution of the general social tie; and as they are gregarious to so late a period of the inviting season of incubation, this affection has been supposed to be independent of sexual distinction. This friendly trait is carried so far that an eye-witness assures me he has seen one among a row of these birds seated upon a branch dart after an insect, and offer it to his associate when caught, who very disinterestedly passed it to the next, and each delicately declining the offer, the morsel has proceeded backwards and forwards before it was appropriated. Whatever may be the fact, as it regards this peculiar sociability, it frequently facilitates the means of their destruction with the thoughtless and rapacious sportsman, who, because many of these unfortunate birds can be killed in an 
instant, sitting in the same range, thinks the exercise of the gun must be credited only by the havoc which it produces against a friendly, useful, and innocent visitor.

Towards the close of May or beginning of June the Cherry Birds, now paired, commence forming the cradle of their young; yet still so sociable are they that several nests may be observed in the same vicinity. The materials and trees chosen for their labors are various, as well as the general markings of their eggs. Two nests, in the Botanic Garden at Cambridge, were formed in small hemlock-trees, at the distance of 16 or 18 feet from the ground, in the forks of the main branches. One of these was composed of dry, coarse grass, interwoven roughly with a considerable quantity of dead hemlock sprigs, further connected by a small quantity of silk-weed lint, and lined with a few strips of thin grape-vine bark, and dry leaves of the silver fir. In the second nest the lining was merely fine rootfibres. On the $4^{\text {th }}$ of June this nest contained 2 eggs, - the whole number is generally about 4 or 5 ; these are of the usual form (not remarkable for any disproportion of the two ends), of a pale clay white, inclining to olive, with a few well-defined black or deep umber spots at the great end, and with others seen, as it were, beneath the surface of the shell. Two or three other nests were made in the apple-trees of an adjoining orchard, one in a place of difficult access, the other on a depending branch easily reached by the hand. These were securely fixed horizontally among the ascending twigs, and were formed externally of a mass of dry, wiry weeds, the materials being firmly held together by a large quantity of cudweed down, in some places softened with glutinous saliva so as to be formed into coarse, connecting shreds. The round edge of the nest was made of coils of the wiry stolons of a common Cinquefoil then lined with exceedingly fine root-fibres; over the whole, to give elasticity, were laid fine stalks of a slender juncus, or minute rush. In these nests the eggs were, as described by Wilson (except as to form), marked with smaller and more numerous spots than the preceding. From the lateness of the autumn, at which period incubation is still going 
on, it would appear that this species is very prolific, and must have at least two hatches in the season; for as late as the $7^{\text {th }}$ of September a brood, in this vicinity, were yet in the nest. The period of sitting is about $\mathrm{I}_{5}$ or 16 days; and while the young are still helpless, it is surprising to witness the silence of the parents, uttering no cries, nor making any approaches to those who may endanger or jeopard the safety of their brood; still, they are flying round, and silently watching the dreaded result, and approach the nest the moment the intruder disappears. They feed the young, at first, with insects and smooth caterpillars; but at the end of the $3 \mathrm{~d}$ or $4^{\text {th }}$ day they are fed, like the old ones, almost exclusively on sweet and juicy fruits, such as whortle and service berries, wild and cultivated cherries, etc. A young bird from one of the nests described, in the hemlock, was thrown upon my protection, having been by some means ejected from his cradle. In this critical situation, however, he had been well fed, or rather gorged, with berries, and was merely scratched by the fall he had received. Fed on cherries and mulberries, he was soon well fledged, while his mate in the nest was suffered to perish by the forgetfulness of his natural protectors. Coeval with the growth of his wingfeathers were already seen the remarkable red waxen appendages, showing that their appearance indicates no particular age or sex; many birds, in fact, being without these ornaments during their whole lives. I soon found my interesting protégé impatient of the cage and extremely voracious, gorging himself to the very mouth with the soft fruits on which he was often fed. The throat, in fact, like a craw, admits of distention, and the contents are only gradually passed off into the stomach. I now suffered the bird to fly at large, and for several days he descended from the trees, in which he perched, to my arm for food; but the moment he was satisfied, he avoided the cage, and appeared unable to survive the loss of liberty. He now came seldomer to me, and finally joined the lisping muster-cry of tze tze tzé, and was enticed away by more attractive associates. When young, nature provided him with a loud, impatient voice, and té-did, té-did, kaí-téd $\tilde{\imath} d$ (often also the clamorous cry of 
the young Baltimore), was his deafening and almost incessant call for food. Another young bird of the first brood, probably neglected, cried so loud and plaintively to a male Baltimore Bird in the same tree that he commenced feeding it. Mr. Winship, of Brighton, informs me that one of the young Cedar Birds, who frequented the front of his house in quest of honeysuckle berries, at length, on receiving food (probably also abandoned by his roving parents), threw himself wholly on his protection. At large day and night, he still regularly attended the dessert of the dinner-table for his portion of fruit, and remained steadfast in his attachment to Mr. W. till killed by an accident, being unfortunately trodden under foot.

Though harmless, exceedingly gentle and artless, they make some show of defence when attacked; as a second bird which I brought up, destitute of the red appendages on the wings, when threatened elevated his crest, looked angry, and repeatedly snapped with his bill.

Almost all kinds of sweet berries are sought for food by the American Waxen-wing. In search of whortle-berries, they retire in Pennsylvania to the western mountain-chains of the Alleghany range ; and in autumn, until the approach of winter, they are equally attached to the berries of the Virginia juniper, as well as those of the sour-gum tree and the wax-myrtle. They also feed late in the season on ripe persimmons, small winter-grapes, bird-cherries, the fruit of the pride of China, and other fruits. The kernels and seeds of these, uninjured by the action of the stomach, are strewed about, and thus accidentally planted in abundance wherever these birds frequent. Like their prototype, the preceding species, the migrations, and time and place of breeding, are influenced by their supply of food. In the spring of $183 \mathrm{I}$ they arrived in this vicinity as usual; but in consequence of the failure of cherries, scarcely any were bred, and very few were either to be heard or seen in the vicinity. In parts of New England this bird is known by the name of the Canada Robin; and by the French Canadians it is fancifully called Recollet, from the color of its crest resembling that of the hood of this religious order. 


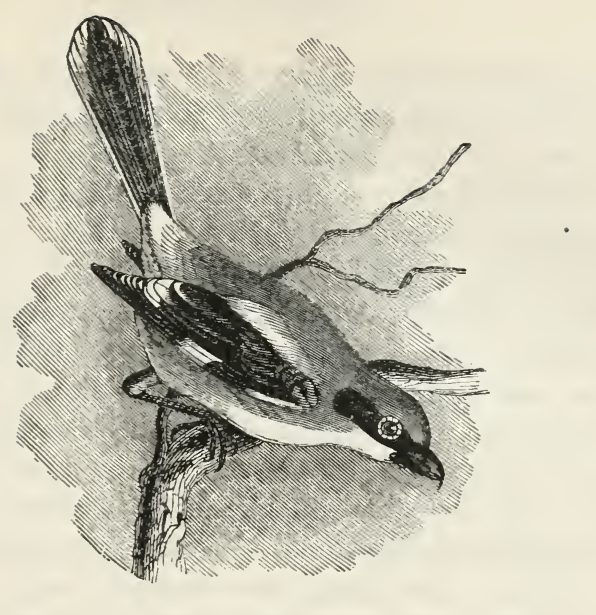

\section{NORTHERN SHRIKE.}

BUTCHER BIRD.

LANIUS BOREALIS.

CHAR. Above, bluish ash, paler on rump; under parts dull white, with fine wavy lines of brownish gray; bar on side of head black; wings and tail black tipped with white; white patch on wing; outer tail feathers white. Length $9 \frac{1}{4}$ to $103 / 4$ inches.

Nest. In a tree or low bush; large and roughly made of sticks and grass, lined with leaves or feathers.

Eggs. 4-6; dull gray with green tint, spotted with lilac and brown; I.05 $\times 0.75$.

This little wary Northern hunter is most commonly seen in this part of the continent at the commencement of winter, a few remaining with us throughout that season. They extend their wanderings, according to Audubon, as far as Natchez, and are not uncommon in Kentucky in severe winters. In March they retire to the North, though some take up their summer abode in the thickest forests in Pennsylvania and New England. The nest is said to be large and compact, in the fork of a small tree, and sometimes in an apple-tree, composed externally of dried grass, with whitish moss, and well lined with feathers. The eggs are about 6 , of a pale cinereous white, 
thickly marked at the greater end with spots and streaks of rufous. The period of sitting is about 15 days. The young appear early in June or the latter end of May.

The principal food of this species is large insects, such as grasshoppers, crickets, and spiders. With the surplus of the former, as well as small birds, he disposes in a very singular manner, by impaling them upon thorns, as if thus providing securely for a future supply of provision. In the abundance, however, which surrounds him in the ample store-house of Nature, he soon loses sight of this needless and sportive economy, and, like the thievish Pie and Jay, he suffers his forgotten store to remain drying and bleaching in the elements till no longer palatable or digestible. As this little Butcher, like his more common European representative, preys upon birds, these impaled grasshoppers were imagined to be lures to attract his victims; but his courage and rapacity render such snares both useless and improbable, as he has been known, with the temerity of a Falcon, to follow a bird into an open cage sooner than lose his quarry. Mr. J. Brown, of Cambridge, informs me that one of these birds had the boldness to attack two Canaries in a cage, suspended one fine winter's day at the window. The poor songsters in their fears fluttered to the side of the cage, and one of them thrust his head through the bars of his prison; at this instant the wily Butcher tore off his head, and left the body dead in the cage. The cause of the accident seemed wholly mysterious, till on the following day the bold hunter was found to have entered the room, through the open window, with a view to despatch the remaining victim; and but for timely interference it would have instantly shared the fate of its companion. On another occasion, while a Mr. Lock in this vicinity was engaged in fowling, he wounded a Robin, who flew to a little distance and descended to the ground; he soon heard the disabled bird uttering unusual cries, and on approaching found him in the grasp of the Shrike. He snatched up the bird from its devourer; but having tasted blood, it still followed, as if determined not to relinquish its proposed prey, and only desisted from the quest on receiving a mortal wound. 
The propensity for thus singularly securing its prey is also practised on birds, which it impales in the same manner, and afterwards tears them to pieces at leisure.

From his attempts to imitate the notes of other small birds, in Canada and some parts of New England he is sometimes called a Mocking Bird. His usual note, like that of the following species, resembles the discordant creaking of a sign-board hinge; and my friend Mr. Brown has heard one mimicking the quacking of his Ducks, so that they answered to him as to a decoy fowl. They also imitate other birds, and I have been informed that they sing pretty well themselves at times, or rather chatter, and mimic the songs of other birds, as if with a view to entice them into sight, for the purpose of making them their prey. This fondness for imitation, as in the Pies, may however be merely the result of caprice.

So complete at times is the resemblance between the Mocking Bird (Mimus pollyglottus) and this species of Lanius, that it is difficult to distinguish them apart. I have lately heard one (November roth, I 833), employed in a low and soft warble resembling that of the Song Sparrow at the present season, and immediately after his note changed to that of the Catbird. Like that pre-eminent minstrel, the Orpheus, he also mounts to the topmost spray of some lofty tree to display his deceptive talent and mislead the small birds so as to bring them within his reach. His attitudes are also light and airy, and his graceful, flowing tail is kept in fantastic motion.

The parents and their brood move in company in quest of their subsistence, and remain together the whole season. The male boldly attacks even the Hawk or the Eagle in their defence, and with such fury that they generally decline the onset.

The Butcher Bird breeds from about latitude $50^{\circ}$ northward, migrating in winter south to the Potomac and Ohio valleys.

Dr. Arthur Chadbourne, of Cambridge, reports that he has heard a female sing, and describes her as "an unusually fine singer and quite a mimic." 


\section{LOGGERHEAD SHRIKE.}

\section{LANIUS LUDOVICIANUS.}

CHAR. Above, bluish ash, generally not much paler on rump; underparts pure white, rarely any lines of gray; flanks tinged with gray; forehead and side of head black; wings and tail black tipped with white; white patch on wings; outer tail feathers white. Length $81 / 2$ to $91 / 2$ inches.

Distinguished from borealis by smaller size and by the black forehead and white under-parts.

Nest. In a tree; roughly made of twigs and grass, lined with leaves and feathers.

Eggs. 4-6; dull gray with green tint spotted with lilac and brown; $0.95 \times 0.70$.

This species principally inhabits the warmer parts of the United States, residing and breeding from North Carolina to Florida, where I have observed it likewise in winter. It was also seen in the table-land of Mexico by that enterprising naturalist and collector, Mr. Bullock, and my friend Mr. T. Townsend found it in the Rocky Mountain range and in the territory of Oregon. According to Audubon it affects the low countries, being seldom met with in the mountainous districts.

Its habits are shy and retiring, and it renders itself useful, and claims protection by destroying mice around the plantation, for which it sits and watches near the rice-stacks for hours together, seldom failing of its prey as soon as it appears. Like most of the genus, it is also well satisfied with large insects, crickets, and grasshoppers, which like the preceding species it often impales. In the breeding-season, according to Dr. Bachman, it has a song which bears some resemblance to that of the young Brown Thrush; and though very irregular, the notes are not unpleasing. At other times its discordant call may almost be compared to the creaking of a sign-board in windy weather; it probably has also the usual talent for mimicry. The pairs mate about March, at which time the male frequently feeds the female, and shows great courage in defending his nest from the intrusion of other birds. The nest 
is, according to Dr. Bachman, usually made in the outer limbs of a tree such as the live-oak or sweet-gum, and often on a cedar $\mathrm{I}_{5}$ to 30 feet from the ground. It is coarsely made of dry crooked twigs, and lined with root-fibres and slender grass. The eggs, 3 to 5, are greenish white. Incubation is performed by both sexes in turn, but each bird procures its own food in the intervals. They rear two broods in the season. Its manners resemble those of a Hawk; it sits silent and watchful until it espies its prey on the ground, when it pounces upon it, and strikes first with the bill, in the manner of small birds, seizing the object immediately after in its claws; but it seldom attacks birds except when previously wounded.

The Loggerhead is now said to be restricted to the southern portion of the Eastern States north to Virginia, Ohio, southern Illinois, and the Great Lakes; and through New York to northern New England and New Brunswick.

Note. - The White-Rumped Shrike (L. ludovicianus excubitorides) is a pale form restricted to the Western plains, and which in habits as in appearance differs but little from the Loggerhead. 


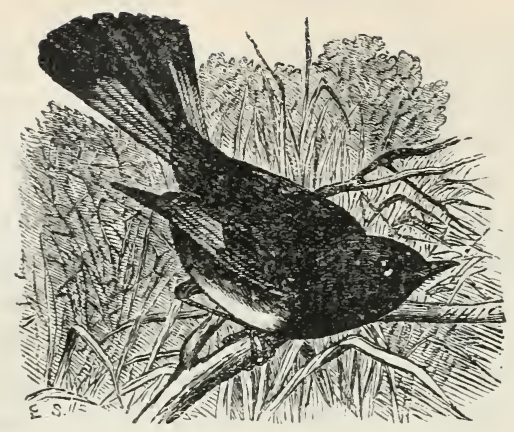

\section{REDSTART.}

\section{SETOPHAGA RUTICILLA.}

CHAR. Male: lustrous blue-black; belly white; patch on sides of breast, basal half of wing-quills and of tail, orange red. Female: the black of the male replaced by olive brown, the red replaced by dull yellow. Young males like female, but gradually changing to full plumage. Bill and feet black. Length 5 to $5 \frac{1}{2}$ inches.

Nest. An exceedingly graceful and compact structure saddled on a branch, or supported by forked twigs of a sapling, from 5 to 20 feet from the ground. It is composed of a variety of materials, in this region most commonly of grass and vegetable fibres lined with fine grass or horse-hair.

Eggs. 4-5; dull white, spotted chiefly around the larger end with brown and lilac; $0.65 \times 0.50$.

This beautiful and curious bird takes up its summer residence in almost every part of the North American continent, being found in Canada, in the remote interior near Red River in the latitude of 49 degrees, throughout Louisiana, Arkansas, and the maritime parts of Mexico; in all of which vast countries it familiarly breeds and resides during the mild season, withdrawing early in September to tropical America, where, in the perpetual spring and summer of the larger West India islands, the species again find means of support. At length, instigated by more powerful feelings than those of ordinary want, the male, now clad in his beautiful nuptial livery, and accompanied by his mate, seeks anew the friendly but far distant natal regions of his race. In no haste, the playful 
Redstart does not appear in Pennsylvania until late in April. The month of May, about the close of the first week, ushers his arrival into the States of New England; but in Louisiana he is seen as early as the beginning of March. He is no pensioner upon the bounty of man. Though sometimes seen, on his first arrival, in the darkest part of the orchard or garden, or by the meandering brook, he seeks to elude observation, and now, the great object of his migrations having arrived, he retires with his mate to the thickest of the sylvan shade. Like his relative Sylvias, he is full of life and in perpetual motion. He does not, like the loitering Pewee, wait the accidental approach of his insect prey, but carrying the war amongst them, he is seen flitting from bough to bough, or at times pursuing the flying troop of winged insects from the top of the tallest tree in a zig-zag, hawk-like, descending flight, to the ground, while the clicking of the bill declares distinctly both his object and success. Then alighting on some adjoining branch, intently watching with his head extended, he runs along upon it for an instant or two, flirting like a fan his expanded, brilliant tail from side to side, and again suddenly shoots off like an arrow in a new direction, after the fresh game he has discovered in the distance, and for which he appeared to be reconnoitring. At first the males are seen engaged in active strife, pursuing each other in wide circles through the forest. The female seeks out her prey with less action and flirting, and in her manners resembles the ordinary Sylvias.

The notes of the male, though not possessed of great compass, are highly musical, and at times sweet and agreeably varied like those of the IVarblers. Many of these tones, as they are mere trills of harmony, cannot be recalled by any words. Their song on their first arrival is however nearly uniform, and greatly resembles the 'tsh' $t$ sh $t$ sh $t$ shee, tshè, tshe, tshe tshea, or 'tsh 'tsh'tsh'tshitshee of the summer Yellow Bird (Sylvia astiva), uttered in a piercing and rather slender tone; now and then also agreeably varied with a somewhat plaintive flowing 'tshé tshé tshé, or a more agreeable 'tshit' tshit a 'tshee, given almost in the tones of the common Yellow Bird (Fringilla tristis). I 
have likewise heard individuals warble out a variety of sweet and tender, trilling, rather loud and shrill notes, so superior to the ordinary lay of incubation that the performer would scarcely be supposed the same bird. On some occasions the male also, when angry or alarmed, utters a loud and snapping chirp.

The nest of this elegant Sylvan Flycatcher is very neat and substantial, fixed occasionally near the forks of a slender - hickory or beech sapling, but more generally fastened or agglutinated to the depending branches or twigs of the former; sometimes securely seated amidst the stout footstalks of the waving foliage in the more usual manner of the delicate cradle of the Indian Tailor Bird, but in the deep and cool shade of the forest, instead of the blooming bower. Both parents, but particularly the male, exhibit great concern for the safety of their nest, whether containing eggs only or young, and on its being approached, the male will flit about within a few feet of the invader, regardless of his personal safety, and exhibiting unequivocal marks of distress. The parents also, in their solicitude and fear, keep up an incessant 'tship when their infant brood are even distantly approached.

Nuttall classed the Redstart with the Flycatchers, as some of its habits - such as darting from a perch, and capturing insects while on the wing - are typical of that family; but the more modern systematists class it with the Wood Warblers. It is an abundant summer resident of this eastern province, breeding from about the valley of the Potomac to southern Labrador. 


\section{HOODED WARBLER.}

\section{SylvaNia MITRATA.}

Char. Male: above, yellow olive; beneath, rich yellow; sides shaded with pale olive; head and neck black, enclosing a wide band of yellow across forehead and through eyes; tail with patch of white on two or three outer tail-feathers. Bill black, feet flesh-color. Female: similar to male, but sometimes lacking the black, in which specimens the crown is olive and the throat yellow.

Nest. In a low bush; made of leaves and vegetable fibre, lined with grass or horse-hair.

Eggs. 4-5; creamy white, spotted chiefly around the larger end with brown and lilac; $0.70 \times 0.53$.

This beautiful and singularly marked summer species, common in the South, is rarely seen to the north of the State of Maryland. It retires to Mexico or the West Indies probably to pass the winter. At Savannah, in Georgia, it arrives from the South about the 2oth of March, according to Wilson. It is partial to low and shady situations darkened with underwood, is frequent among the cane-brakes of Tennessee and Mississippi, and is exceedingly active, and almost perpetually engaged in the pursuit of winged insects. While thus employed, it now and then utters three loud, and not unmusical, very lively notes, resembling the words, twee twee 'twinttshe. In its simple song and general habits it therefore much resembles the summer Yellow Bird. Its neat and compact nest is generally fixed in the fork of a small bush, formed outwardly of moss and flax, lined with hair, and sometimes feathers; the eggs, about 5, are grayish white, with reddish spots towards the great end.

The Hooded Warbler is a Southern species, but is a regular summer resident of the Connecticut valley, and has been found breeding near Cleveland, Ohio, and in southern Michigan. It is said to be more abundant in South Carolina than elsewhere. 


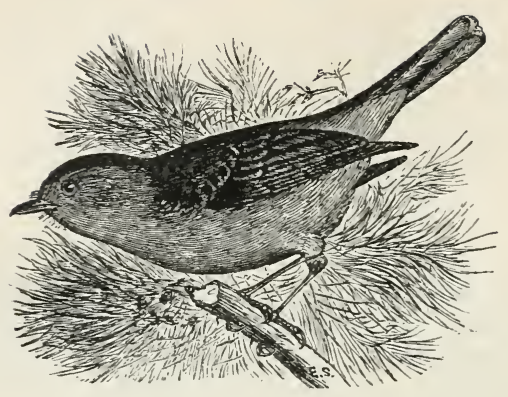

IVILSON'S WARBLER.

\author{
WILSON'S BLACK CAP.
}

SylVANIA PUSILla.

CHAR. Above, olive; crown black; forehead, cheeks, and entire under parts yellow. Female and young duller, and black cap often obscure, sometimes lacking. Length, $4 \frac{1}{4}$ to 5 inches.

Nest. On the ground, in a bushy swamp, or on branch of low bush; of twigs and vegetable fibre lined with moss or fine grass.

Eggs. 4-6; white spotted with brown and lavender; $0.60 \times 0.50$.

This remarkable species of sylvan Flycatcher was first observed by Wilson in New Jersey and Delaware as a transitory bird of passage. Audubon has noticed it in Labrador and Newfoundland, where it was breeding, and it is not uncommon in the State of Maine. $\mathrm{He}$ also saw it in his way to Texas early in April. It begins to migrate from Newfoundland about the middle of August, and is seen in Maine in October. Mr. Townsend and myself had the pleasure of observing the arrival of the little cheerful songsters in the wilds of Oregon about the first week of May, where these birds commonly take up their summer residence, and seem almost the counterpart of our brilliant and cheerful Yellow Birds (Sylvia astiva), tuning their lay to the same brief and lively ditty, like 'tsh 'tsh 'tsh tshea, or something similar; their call, however, is more brief 
and less loud. They were rather familiar and unsuspicious, kept in bushes more than trees, particularly in the thickets which bordered the Columbia, busily engaged collecting their insect fare, and only varying their employment by an occasional and earnest warble. By the I 2 th of May they were already feeding their full-fledged young, though I also found a nest on the I 6 th of the same month, containing 4 eggs, and just commencing incubation. The nest was in the branch of a small service bush, laid very adroitly as to concealment upon an accidental mass of old moss (Usnea) that had fallen from a tree above. It was made chiefly of ground moss (Hypnum), with a thick lining of dry, wiry, slender grass. The female, when approached, went off slyly, running along the ground like a mouse. The eggs are very similar to those of the summer Yellow Bird, sprinkled with spots of pale olive brown, inclined to be disposed in a ring at the greater end, as observed by Mr. Audubon in a nest which he found in Labrador made in a dwarf fir, also made of moss and slender fir-twigs.

Wilson's Black Cap is a regular, though not common, summer resident of northern New England, breeding chiefly north of the United States. It is not uncommon in the Maritime Provinces, and fairly common as a migrant about Montreal, but is rarely seen in Ontario, though abundant in Ohio, and reported as breeding in Minnesota.

Note. - The Sirall-headed Flycatcher (Wilsonia minuta and Sylvia minuta of Wilson and Audubon) was given a place in the "Manual" by Nuttall, who alleged to have seen the species. Not having been found by any of the more modern observers, it has been omitted from many recent works. It was placed on the "hypothetical list" by the A. O. U. committee, but has been again brought forward by Ridgeway, in his "Manual." Wilson stated that he saw it in New Jersey; Audubon said he shot one in Kentucky; and Nuttall's examples were in Massachusetts. As the birds were seen by Nuttall only "at the app"oach of winter," it is probable they were the young of the year of some of the more northern breeding species. 


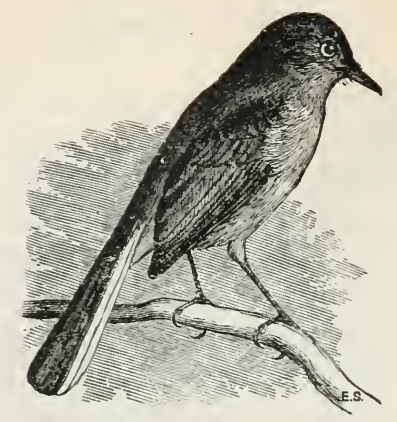

\section{BLUE-GRAY GNATCATCHER.}

\section{POLIOPTILA CERULEA.}

CHAR. Male : above, bluish gray, darker on head, paler on rump; forehead and line over the eye black; beneath, pale bluish white; wings dusky; tail longer than the body, the outer feathers partly white. Female : similar to the male, but lacking the black on head. Length $4^{1 / 2}$ to 5 inches.

Nest. A graceful, cup-shaped structure, saddled on limb of a tree 15 or 20 feet from the ground; composed of felted plant fibre ornamented externally with lichens and lined with feathers.

Eggs. 3-5; bluish white, speckled with bright brown; $0.55 \times 0.45$.

But for the length of the tail, this would rank among the most diminutive of birds. It is a very dexterous, lively insecthunter, and keeps commonly in the tops of tall trees; its motions are rapid and incessant, appearing always in quest of its prey, darting from bough to bough with hanging wings and elevated tail, uttering only at times a feeble song of tsee tsee tsee, scarcely louder than the squeak of a mouse. It arrives in the State of Pennsylvania from the South about the middle of April, and seldom passes to the north of the States of New York and Ohio, though others, following the course of the large rivers, penetrate into Kentucky, Indiana, and Arkansas. Its first visits are paid to the blooming willows along the borders of watercourses, and besides other small insects it now preys on the troublesome mosquitoes. About the beginning of May it forms its nest, which is usually fixed among twigs, at the height of Io, or sometimes even 50 , feet from the ground, near the summit 
of a forest tree. It is formed of slight materials, such as the scales of buds, stems and parts of fallen leaves, withered blossoms, fern down, and the silky fibres of various plants, lined with a few horsehairs, and coated externally with lichens. In this frail nest the Cow Troopial sometimes deposits her egg, and leaves her offspring to the care of these affectionate and pigmy nurses. In this case, as with the Cuckoo in the nest of the Yellow Wren and that of the Red-tailed Warbler, the egg is probably conveyed by the parent, and placed in this small and slender cradle, which would not be able to sustain the weight or receive the body of the intruder.

Though classed with the Flycatchers by Nuttall and other writers of his day, this species is now ranked as one of the highest types of the Oscines, or Singing Birds, and a sub-family has been made for this and the two Western forms. Mr. William Saunders finds the present species fairly common near London, Ontario, but it is only casual in New England, and is rarely seen north of latitude $42^{\circ}$. It winters in the Gulf States and southward.

Mr. Chapman tells us that this bird has "an exquisitely finished song," but the voice is "possessed of so little volume as to be inaudible unless one is quite near the singer." 


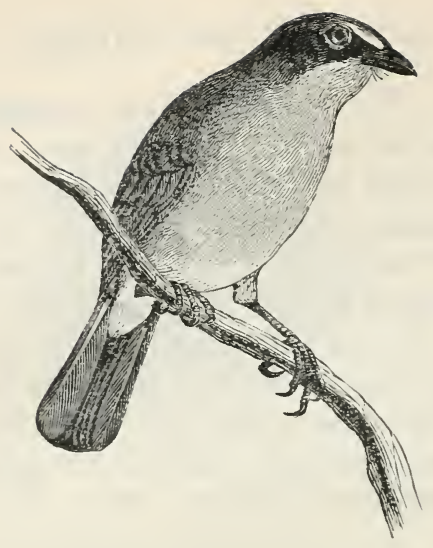

\section{YELLOW-BREASTED CHAT.}

ICTERIA VIRENS.

CHAR. Above, olive; lores black; throat and breast rich yellow; belly white. Length 7 to 8 inches.

Nest. In a thicket 2 or 3 feet from the ground; of dried leaves, strips of bark, or grass lined with fine grass or fibres.

Eggs. 3-4; white, with pink tint, spotted with brown and lilac; 0.90 $\times 0.70$.

This remarkable bird is another summer resident of the United States which passes the winter in tropical America, being found in Guiana and Brazil, so that its migrations probably extend indifferently into the milder regions of both hemispheres. Even the birds essentially tropical are still known to migrate to different distances on either side the equator, so essential and necessary is this wandering habit to almost all the feathered race.

The Icteria arrives in Pennsylvania about the first week in May, and does not usually appear to proceed farther north and east than the States of New York or Connecticut. To the west it is found in Kentucky, and ascends the Ohio to the borders of Lake Erie. In the distant interior, however, near the Rocky Mountains, towards the sources of the Arkansas, this bird was observed by Mr. Say, and Mr. Townsend saw it 
at Walla-Walla, on the Columbia, breeding in the month of June. It retires to the south about the middle of August, or as soon as the only brood it raises are fitted to undertake their distant journey.

The males, as in many other migrating birds, who are not continually paired, arrive several days before the females. As soon as our bird has chosen his retreat, which is commonly in some thorny or viny thicket where he can obtain concealment, he becomes jealous of his assumed rights and resents the least intrusion, scolding all who approach in a variety of odd and uncouth tones very difficult to describe or imitate, except by a whistling, in which case the bird may be made to approach, but seldom within sight. His responses on such occasions are constant and rapid, expressive of anger and anxiety; and still unseen, his voice shifts from place to place amidst the thicket. Some of these notes resemble the whistling of the wings of a flying duck, at first loud and rapid, then sinking till they seem to end in single notes. A succession of other tones are now heard, some like the barking of young puppies, with a variety of hollow, guttural, uncommon sounds frequently repeated, and terminated occasionally by something like the mewing of a cat, but hoarser, - a tone to which all our Vireos, particularly the young, have frequent recurrence. All these notes are uttered with vehemence, and with such strange and various modulations as to appear near or distant, like the manœuvres of ventriloquism. In mild weather also, when the moon shines, this exuberant gabbling is heard nearly throughout the night, as if the performer was disputing with the echoes of his own voice.

Soon after their arrival, or about the middle of May, the Icterias begin to build, fixing the nest commonly in a bramblebush, in an interlaced thicket, a vine, or small cedar, 4 or 5 feet from the ground. The young are hatched in the short period of 12 days, and leave the nest about the second week in June. While the female is sitting, the cries of the male are still more loud and incessant. He now braves concealment, and at times mounts into the air almost perpendicularly 30 
or 40 feet, with his legs hanging down, and descending as he rose, by repeated jerks, he seems to be in a paroxysm of fear and anger. The usual mode of flying is not, however, different from that of other birds.

The food of the Icteria consists of beetles and other shelly insects; and as the summer advances, they feed on various kinds of berries, like the Flycatchers, and seem particularly fond of whortleberries. They are frequent through the Middle States, in hedges, thickets, and near rivulets and watery situations.

This Chat is now found regularly in Connecticut and northern Ohio, and sparingly in Massachusetts. A few examples have been taken in New Hampshire and southern Ontario.

\section{YELLOW-THROATED VIREO.}

\section{VIREO FLAVIFRONS.}

CHAR. Above, rich olive, shading to ashy gray on the rump; line across the forehead and around the eyes yellow; throat and breast rich yellow; belly white, sides shaded with pale olive; wings dusky with two white bars; tail dusky, the feathers edged with white. Length 5 to 6 inches.

Nest. In woods or orchard; suspended from fork of branch 5 to 30 feet from the ground (usually about ro feet); a graceful and compact structure of grass and strips of bark covered with lichens and lined with grass or pine needles.

Eggs. 3-5; white with roseate tint, thickly spotted around the large end with shades of brown; $0.80 \times 0.60$.

This species of Vireo, or Warbling Flycatcher, visits the Middle and Northern States of the Union about the beginning of May or as soon as his insect food allows him a means of subsistence. He resides chiefly in the forests, where he hunts his tiny prey among the high branches; and as he shifts from twig to twig in restless pursuit, he often relieves his toil with a somewhat sad and indolent note, which he repeats, with some variation, at short intervals. This song appears like 'preea 'preeá, etc., and it sometimes finishes with a complaining call 
of recognition, 'prréaigh 'prréaigh. These syllables rise and fall in different tones as they are repeated, but though usually sweet and impressive, are delivered too slow and solemn to be generally pleasing. In other respects they considerably resemble the song of the Red-Eyed Warbling Flycatcher, in whose company it is often heard, blending its deep but languid warble with the loud, energetic notes of the latter; and their united music, uttered during summer, even at noonday, is rendered peculiarly agreeable, as nearly all the songsters of the grove are now seeking a silent shelter from the sultry heat. In the warmest weather the lay of this bird is indeed peculiarly strong and lively; and his usually long-drawn, almost plaintive notes, are now delivered in fine succession, with a peculiar echoing and impressive musical cadence, appearing like a romantic and tender revery of delight. The song, now almost incessant, heard from this roving sylvan minstrel is varied in bars nearly as follows : preă preá preoi, preait preoit p'rrǐweet preeai, pewai praiou, preeai preeo praoŭt, preeo prēăwit preeoo. When irritated, he utters a very loud and hoarse mewing praigh praigh. As soon, however, as the warm weather begins to decline, and the business of incubation is finished, about the beginning of August, this sad and slow but interesting musician nearly ceases his song, a few feeble farewell notes only being heard to the first week in September.

This species, like the rest of the genus, constructs a very beautiful pendulous nest about 3 inches deep and $2 \frac{1}{2}$ in diameter. One, which I now more particularly describe, is suspended from the forked twig of an oak in the near neighborhood of a dwelling-house in the country. It is attached firmly all round the curving twigs by which it is supported; the stoutest external materials or skeleton of the fabric is formed of interlaced folds of thin strips of red cedar bark, connected very intimately by coarse threads and small masses of the silk of spiders' nests and of the cocoons of large moths. These threads are moistened by the glutinous saliva of the bird. Among these external materials are also blended fine blades of dry grass. The inside is thickly bedded with this 
last material and fine root-fibres; but the finishing layer, as if to preserve elasticity, is of rather coarse grass-stalks. Externally the nest is coated over with green lichen, attached very artfully by slender strings of caterpillars' silk, and the whole afterwards tied over by almost invisible threads of the same, so as to appear as if glued on; and the entire fabric now resembles an accidental knot of the tree grown over with moss.

The food of this species during the summer is insects, but towards autumn they and their young feed also on various small berries. About the middle of September the whole move off and leave the United States, probably to winter in tropical America.

Nuttall followed the older authors in naming the forest as the favorite haunt of this species. Later observers consider that it frequents orchards and fields quite as much as the woods, and it is reported as common in the gardens near Boston.

It occurs in southern New England and the Middle States as far west as Iowa, and in Manitoba, where it is common. It has not been found in the Maritime Provinces, but is common near Montreal and in Ontario.

\section{BLUE-HEADED VIREO.}

\section{SOLITARY VIREO.}

\section{VIREO SOLITARIUS.}

CHAR. Above, bright olive; line from nostril to and around the eyes whitish; crown and sides of head bluish ash; beneath, white, sides and flanks shaded with olive and yellow; wings dusky with two bars of yellowish white; tail dusky, feathers edged with white. Length 5 to 6 inches.

Nest. Suspended from fork of branch of low tree or bush; composed of grass or vegetable fibre, ornamented with moss or lichens, lined with grass and plant down.

Eggs. Creamy white, spotted, in wreath around larger end, with bright brown; $0.80 \times 0.50$.

This is one of the rarest species of the genus, and from Georgia to Pennsylvania seems only as a straggler or accidental visitor. 
It possesses all the unsuspicious habits of the genus, allowing a near approach without alarm. It seldom rises beyond the tops of the canes or low bushes amidst which it is commonly seen hopping in quest of its subsistence, which consists of insects and berries. Its flight is generally tremulous and agitated. According to Dr. Bachman, "it is every year becoming more abundant in South Carolina, where it remains from about the middle of February to that of March, keeping to the woods. It has a sweet and loud song of half a dozen notes, heard at a considerable distance."

About the beginning of May, in the oaks already almost wholly in leaf, on the banks of the Columbia, we heard around us the plaintive deliberate warble of this species, first noticed by Wilson. Its song seems to be intermediate between that of the Red-eyed and Yellow-breasted species, having the preai, preai, etc., of the latter, and the fine variety of the former in its tones. It darted about in the tops of the trees, incessantly engaged in quest of food, now and then disputing with some rival. The nest of this bird is made much in the same manner as that of the Vireo olivaceus. One which I examined was suspended from the forked twig of the wild crab-tree, at about ten feet from the ground. The chief materials were dead and whitened grass leaves, with some cobwebs agglutinated together, externally scattered with a few shreds of moss (Hypnum), to resemble the branch on which it was hung; here and there were also a few of the white paper-like capsules of the spider's nest, and it was lined with fine blades of grass and slender root-fibres. The situation, as usual, was open but shady.

This is a fairly common summer resident of northern New England, and it breeds sparingly south to the Middle States, and north to Hudson's Bay. It is a rare bird in the Maritime Provinces and in Quebec, though common in parts of Ontario.

Note. - The Mountain Solitary Vireo ( $V$. solitarius alticola), lately discovered by Mr. William Brewster in western North Carolina, is described as "nearly uniform blackish plumbeous, with only a faint tinge of green on the back."

VOL. I. - 12 


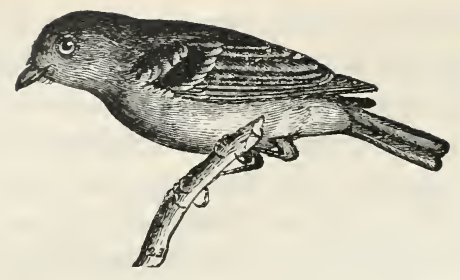

\section{WHITE-EYED VIREO.}

\section{VIREO NOVEBORACENSIS.}

CHAR. Above, olive, shading to ash on hind neck and rump; line from nostril to and around eyes, yellow ; beneath, white, duller on throat and breast; sides shaded with yellow; wings and tail dusky; wing-bars yellow; iris white in the adult. Length about 5 inches.

Nest. Suspended from forked twig of low bush in a thicket, sometimes on edge of swamp; composed of various materials, - grass, twigs, etc., - ornamented with moss and lichens, and lined with grass, etc.

Eggs. 3-5; white, spotted around larger end with brown; $0.75 \times 0.55$.

This interesting little bird appears to be a constant resident within the limits of the United States; as, on the I 2 th of January, I saw them in great numbers near Charleston, S. C., feeding on the wax-myrtle berries, in company with the YellowRumped Sylvias. At this season they were silent, but very familiar, descending from the bushes when whistled too, and peeping cautiously, came down close to me, looking about with complacent curiosity, as if unconscious of any danger. In the last week of February, Wilson already heard them singing in the southern parts of Georgia, and throughout that month to March, I saw them in the swampy thickets nearly every day, so that they undoubtedly reside and pass the winter in the maritime parts of the Southern States. The arrival of this little unsuspicious warbler in Pennsylvania and New England is usually about the middle of April or earlier. On the I 2 th of March I first heard his voice in the low thickets of West Florida. His ditty was now simply ss't (with a whistle) wá witte witte we-ruá (the first part very quick). As late as in the first week in May I observed a few stragglers in this vicinity 
peeping through the bushes; and in the latter end of the month a pair had taken up their abode in the thickets of Fresh Pond, so that those which first arrive leave us and proceed farther to the north. On the $22 \mathrm{~d}$ of June I heard the male in full song, near his nest in our neighborhood, where incubation was going on. His warble was very pleasing, though somewhat monotonous and whimsical. This affectionate note, often repeated near to his faithful mate while confined to her nest, was like 'tshïppewee-wá-say, tshïppewee-wée-was-say', sweetly whistled, and with a greater compass of voice and loudness than might have been expected from the size of the little vocalist. The song is sometimes changed two or three times in the course of twenty minutes; and I have heard the following phrases: 'att tshippewat'wurr, tshippewat'wurr; at another time, 'tshipeway 'tshe ŏ et 'tsherr. On another visit the little performer had changed his song to 'pip té waigh $\breve{a}$ tshewa, with a guttural trill, as usual, at the last syllable. $\mathrm{He}$ soon, however, varied his lay to 'whip te woi wee, the last syllable but one considerably lengthened and clearly whistled. Such were the captious variations of this little quaint and peculiarly earnest musician, whose notes are probably almost cortinually varied. On the 6th of October I still heard one of these wandering little minstrels, who at intervals had for several weeks visited the garden, probably in quest of berries. His short, quaint, and more guttural song was now atshěe-vaŭt (probably the attempt of a young bird). As late as the 3 oth of October the White-Eyed Vireo still lingered around Cambridge, and on the margin of a pond, surrounded by weeds and willows, he was actively employed in gleaning up insects and their larvæ; and now, with a feebler tone of voice, warbled with uncommon sweetness wholly different from his usual strain, sounding something like the sweet whisperings of the Song Sparrow at the present season, and was perhaps an attempt at mimickry. Occasionally, also, he blended in his harsher, scolding, or querulous mewing call.

This species, like the rest, build commonly a pensile nest suspended by the upper edge of the two sides on the circular 
bend, often of the smilax or green briar vine. In the Middle States they often raise 2 broods in the season, generally make choice of thorny thickets for their nest, and show much concern when it is approached, descending within a few feet of the intruder, looking down and hoarsely mewing and scolding with great earnestness. This petulant display of irritability is also continued when the brood are approached, though as large and as active as their vigilant and vociferous parents. In the Middle States this is a common species, but in Massachusetts rather rare. Its food, like the rest of the Vireos, is insects and various kinds of berries, for the former of which it hunts with great agility, attention, and industry.

"Eastern United States, west to the Rockies, south in winter to Guatemala," is usually given as the habitat of this species. It has been seen rarely north of southern New England, and only one example has been taken in New Brunswick, though Mr. J. M. Jones considers it fairly common in portions of Nova Scotia. There is no authentic report of its occurrence in Ontario, but Mr. McIlwraith thinks it may yet be found there.

Note. - Mr. William Brewster has lately described the Key WEST VIREo ( $V$. noveboracensis maynardi) as a larger bird than the type and of duller color, the yellow paler.

Bell's Vireo (Vireo bellii), a bird of much the same appearance and habits as the White-eyed, is found in the prairie districts of Illinois and Iowa. It ranges thence to the eastern base of the Rockies.

\section{WARBLING VIREO.}

VIREO GILVUS.

Char. Above, grayish olive brighter on the rump, shading to ashy on the head; beneath, buffy white, flanks and sides tinged with olive yellow. Length 5 to $5^{1 / 2}$ inches.

Nest. In open pasture or shaded street, suspended from fork of a high branch; composed of grass and vegetable fibre, and lined with fine grass.

Eggs. 3-4; white, spotted, chiefly about the larger end, with brown; $0.75 \times 0.55$. 
This sweetest and most constant warbler of the forest, extending his northern migrations to the confines of Canada and along the coast of the Pacific to the Oregon, arrives from tropical America in Pennsylvania about the middle of April, and reaches this part of New England early in May. His livery, like that of the Nightingale, is plain and unadorned; but the sweet melody of his voice, - surpassing, as far as Nature usually surpasses art, the tenderest airs of the flute, - poured out often from the rising dawn of day to the approach of evening, and vigorous even during the sultry heat of noon, when most other birds are still, gives additional interest to this little vocalist. While chanting forth his easy, flowing, tender airs, apparently without effort, so contrasted with the interrupted emphatical song of the Red-Eye, he is gliding along the thick and leafy branches of our majestic elms and tallest trees busied in quest of his restless insect prey. With us, as in Pennsylvania, the species is almost wholly confined to our villages, and even cities. It is rarely ever observed in the woods; but from the tall trees which decorate the streets and lanes, the almost invisible musician, secured from the enemies of the forest, is heard to cheer the house and cottage with his untiring song. As late as the $2 \mathrm{~d}$ of October I still distinguished his tuneful voice from amidst the yellow fading leaves of the linden, near which he had passed away the summer. The approaching dissolution of those delightful connections which had been cemented by affection and the cheerless stillness of autumn, still called up a feeble and plaintive revery. Some days after this late period, warmed by the mild rays of the morning sun, I heard, as it were, faintly warbled, a parting whisper; and about the middle of this month our vocal woods and fields were once more left in dreary silence.

When offended or irritated, our bird utters an angry 'tshay 'tshay, like the Catbird and the other Vireos, and sometimes makes a loud snapping with his bill. The nest of the Warbling Vireo is generally pendulous, and ambitiously and securely suspended at great elevations. In our elms I have seen one of these airy cradles at the very summit of one of the most gigan- 
tic, more than 100 feet from the ground. At other times they are not more than 50 to 70 feet high. The only nest I have been able to examine was made externally of flat and dry sedge-grass blades, for which, as I have observed, are occasionally substituted strings of bass. These dry blades and strips are confined and tied into the usual circular form by caterpillars' silk, blended with bits of wool, silk-weed lint, and an accidental and sparing mixture of vernal grass tops and old apple-blossoms. It was then very neatly lined with the small flat blades of the meadow grass called Poa compressa.

This species is rather uncommon in the Maritime Provinces excepting near the Maine border in New Brunswick, and in the more southern portions of Nova Scotia. It is fairly common in southern Quebec, and abundant in Ontario. In parts of New England and the Middle States it is a common summer resident. At the West it ranges north to the fur countries.

\section{RED-EYED VIREO.}

\section{Vireo Olivaceus.}

CHAR. Above, bright olive, crown ashy; white line over eyes; iris ruby red; beneath, white faintly tinged with dull olive on sides; wings and tail dusky. Length $51 / 2$ to $61 / 2$ inches.

Nest. In an open pasture or along margin of field; suspended from fork of an upper branch; composed of grass and vegetable fibre, and lined with fine grass, etc.

Eggs. 3-5; white (sometimes with a faint pink tint) spotted sparingly, around larger end, with dull brown; $0.80 \times 0.55$.

These common and indefatigable songsters appear to inhabit every part of the American continent, from Labrador to the large tropical islands of Jamaica and St. Domingo; they are likewise resident in the mild tableland of Mexico. Those individuals who pass the summer with us, however, migrate to the warmer regions at the commencement of winter, as none are found at that season within the limits of the United States. The Red-Eyed Vireo arrives in Pennsylvania late in April, and in New England about the beginning of May. It inhabits the 
shady forests or tall trees near gardens and the suburbs of villages, where its loud, lively, and energetic song is often continued, with little intermission, for several hours at a time, as it darts and pries among the thick foliage in quest of insects and small caterpillars. From its first arrival until August it is the most distinguished warbler of the forest, and when almost all the other birds have become mute, its notes are yet heard with unabated vigor. Even to the 5 th of October, still enlivened by the feeble rays of the sun, the male faintly recalls his song, and plaintively tunes a farewell to his native woods. His summer notes are uttered in short, emphatical bars of 2 or 3 syllables, and have something in them like the simple lay of the Thrush or American Robin when he first earnestly and slowly commences his song. He often makes use, in fact, of the same expressions; but his tones are more monotonous as well as mellow and melodious, like the rest of the Vireos. In moist and dark summer weather his voice seems to be one continued, untiring warble of exquisite sweetness; and in the most populous and noisy streets of Boston his shrill and tender lay is commonly heard from the tall elms; and as the bustle of carts and carriages attempts to drown his voice, he elevates his pipe with more vigor and earnestness, as if determined to be heard in spite of every discord. The call of "Whip-Tomkelly," attributed to this species by Sloane and even Wilson, I have never heard; and common as the species is throughout the Union, the most lively or accidental fit of imagination never yet in this country conceived of such an association of sounds. I have already remarked, indeed, that this singular call is, in fact, sometimes uttered by the Tufted Titmouse. When our Vireo sings slow enough to be distinctly heard, the following sweetly warbled phrases, variously transposed and tuned, may often be caught by the attentive listener: 'tshoǒe peweӗ peeaì mŭsik 'du 'dŭ 'du, 'tshoŏve 'hĕre 'hère, hear hère, 'k'ing 'ritshard, 'p'shĕgru 'tshevŭ, 'tsheevoo 'tshüvee peeaŭt 'pèrŏ, - the whole delivered almost without any sensible interval, with earnest animation, in a pathetic, tender, and pleasing strain, well calculated to produce calm and thoughtful reflection in 
the sensitive mind. Yet while this heavenly revery strikes on the human ear with such peculiar effect, the humble musician himself seems but little concerned; for all the while, perhaps, that this flowing chorus enchants the hearer, he is casually hopping from spray to spray in quest of his active or crawling prey, and if a cessation occurs in his almost untiring lay, it is occasioned by the caterpillar or fly he has just fortunately captured. So unaffected are these delightful efforts of instinct, and so unconscious is the performer, apparently, of this pleasing faculty bestowed upon him by Nature, that he may truly be considered as a messenger of harmony to man alone. Wantonly to destroy these delightful aids to sentimental happiness ought therefore to be viewed, not only as an act of barbarity, but almost as a sacrilege.

The Red-Eyed Vireo is one of the most favorite of all the adopted nurses of the Cowbird; and the remarkable gentleness of its disposition and watchful affection for the safety of its young, or of the foundling confided to its care, amply justifies this selection of a foster-parent. The male, indeed, defends his nest while his mate is sitting, with as much spirit as the King Bird, driving away every intruder and complaining in a hoarse mewing tone when approached by any inquisitive observer. By accident the eggs were destroyed in a nest of this species in the Botanic Garden, in a sugar-maple about 20 feet from the ground. At this time no complaints were heard, and the male sang all day as cheerful as before. In a few days, unwilling to leave the neighborhood, they had made a second nest in a beech at the opposite side of the same premises; but now the male drove away every intruder with the greatest temerity. The young of this species are often hatched in about I 3 days, or 24 hours later than the parasitic Troopial; but for want of room the smaller young are usually stifled or neglected. I have, however, seen in one nest a surviving bird of each kind in a fair way for being reared; yet by a singular infatuation the supposititious bird appeared by far the most assiduously attended, and in this case the real young of the species seemed to be treated as puny foundlings. 
In the month of August the young fed greedily on the small berries of the bitter cornel and astringent Viburnum dentatum, as well as other kinds. One of these inexperienced birds hopped close round me in an adjoining bush, without any fearful apprehension; and as late as the 26 th of October two young birds of the Red-Eye were still lingering in this vicinity, and busily engaged in gleaning subsistence. Eager after flies, about the $25^{\text {th }}$ of August a young bird with hazel instead of red eyes entered a chamber in the neighborhood and became my inmate. I clipped his wing and left him at large in a room; he soon became very gentle, took grasshoppers and flics out of my hand, eat Viburnum berries with a good appetite, and in short seemed pleased with his quarters. A fly could not stir but it was instantly caught; his only difficulty was with a lame King Bird who occupied the same apartment. The King appeared very jealous of this little harmless companion; snapped his bill at him when he approached, and begrudged him subsistence when he perceived that he fed on the same food with himself. At length he would come to me for provision and for protection from his tyrannical associate. But the career of my interesting and lively companion was soon terminated by death, occasioned, in all probability, by a diarrhœa produced in consequence of swallowing a small lock of hair with his food, which was found in his stomach. This bird, very different from a Sylvia autumnalis which I afterwards had in my possession, regurgitated by the bill, like the King Bird, pellets of the indigestible parts of his food, such as the legs and wings of grasshoppers and flies, and the skins and seeds of berries. Unlike the King Bird in one particular, however, he folded his head under his wing when at rest, and reposed with great soundness; whereas for eight months I was never able to detect the former asleep.

The Red-eyed Vireo breeds from the Southern States to Labrador and Manitoba, and in winter ranges from Florida to Central America. 


\section{PHILADELPHIA VIREO.}

\section{VIREO PHILADELPHICUS.}

ChAR. Above, grayish olive, brighter on rump, shading to ashy on crown; white line over eyes; beneath, greenish yellow, paler on throat and belly. Length about $43 / 4$ inches.

Nest. In a grove ; suspended from forked twigs of low branch ; composed of grass and birch bark.

Eggs. 4-?; white, spotted with brown; - ?

This species was first described by Mr. Cassin, in I85I, from a specimen shot by him near Philadelphia in I842. Of the bird's habits we have learned but little. The only nest yet discovered was found by Mr. Ernest E. Thompson in Manitoba in 1884 .

Of the bird's range we have still much to learn. It is a migrant only in southern New England, but is known to spend the summer in Maine, and has been taken at that season in New Hampshire. In I 882 our party secured several at Edmundston, in New Brunswick, near the Quebec border. Dr. Wheaton considered it a regular spring and fall migrant through Ohio, but very few have been observed in Ontario.

- The song of this species is so much like that of the Red-eye, that they are not easily distinguished.

Note. - Mr. Comeau has taken at Godbout, on the north shore of the Gulf of St. Lawrence, one example of the YelLow-GREEN VIREo ( $V$. flavoviridis), a bird of Mexico and Central America. 


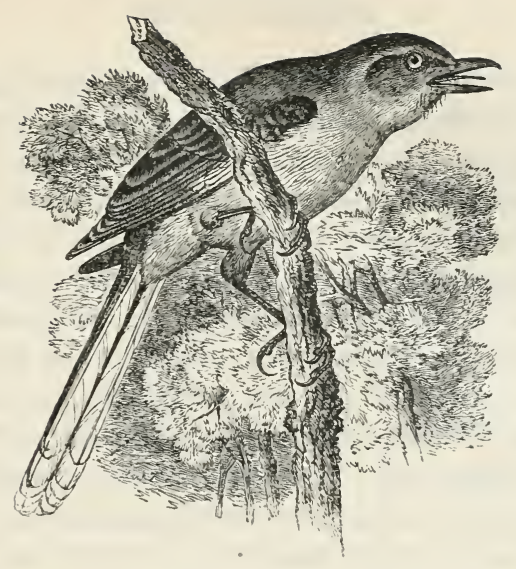

MOCKINGBIRD.

\section{Minus polyglottos.}

CHAR. Above, ashy gray, darker on wings and tail; wings with two white bars; outer tail-feathers white; beneath, white, tinged with gray on the breast; bill and feet black. Length 9 to I I inches.

Nest. In a thicket or bunch of low bushes; composed of twigs, roots, grass, etc.

Eggs. 4-6; greenish blue to pale buff, marked with reddish brown; $0.95 \times 0.70$.

This unrivalled Orpheus of the forest and natural wonder of America inhabits the whole continent, from the State of Rhode Island to the larger isles of the West Indies; and continuing through the equatorial regions, is found in the southern hemisphere as far as Brazil. Nor is it at all confined to the Eastern or Atlantic States. It also exists in the wild territory of Arkansas more than a thousand miles from the mouth of Red River; and I have since seen it in the scanty forests of Upper California. It breeds at the distant western sources of the Platte, near the base of the Rocky Mountains, as well as in Texas; and Mr. Bullock saw it in the table-land of Mexico. The Mocking Bird rears its young, and consequently displays its wonderful powers, in all the intermediate regions of its residence in the United States to the peninsula of Florida. It appears, in short, permanently to inhabit the milder regions of 
the western world in either hemisphere; and the individuals bred north of the Delaware, on this side the equator, are all that ever migrate from their summer residence. A still more partial migration takes place also, probably, from west to east, in quest of the food and shelter which the maritime districts afford. Though now so uncommon in that vicinity, 50 or 60 years ago, according to Bartram, it even wintered near Philadelphia, and made a temporary abode in the mantling ivy of his venerable mansion. In summer a few proceed as far as Rhode Island, following the mild temperature of the sea-coast; but farther north these birds are, I believe, nearly unknown, except rarely and occasionally in Massachusetts near the sea. With the advance of the season, also, in the country which it inhabits, varies the time of incubation. Early in April the nests are begun in the maritime parts of Georgia, but not before the middle of May in Pennsylvania.

In the winter these birds chiefly subsist on berries, particularly those of the Virginia juniper (called red cedar), waxmyrtle, holly, smilax, sumach, sour-gum, and a variety of others, which furnish them and many other birds with a plentiful repast. Insects, worms, grasshoppers; and larvæ are the food on which they principally subsist when so eminently vocal and engaged in the task of rearing their young. In the Southern States, where they are seldom molested, with ready sagacity they seem to court the society of man and fearlessly hop around the roof of the house or fly before the planter's door. When a dwelling is first settled in the wilderness, this bird is not seen sometimes in the vicinity for the first year; but at length he pays his welcome visit to the new-comer, gratified with the little advantages he discovers around him, and seeking out also the favor and fortuitous protection of human society. He becomes henceforth familiar, and only quarrels with the cat and dog, whose approach he instinctively dreads near his nest, and never ceases his complaints and attacks until they retreat from his sight.

None of the domestic animals, or man himself, but particularly the cat and dog, can approach during the period of incubation, without receiving an attack from these affectionate 
guardians of their brood. Their most insidious and deadly enemies, however, are reptiles, particularly the black snake, who spares neither the eggs nor young. As soon as his fatal approach is discovered by the male, he darts upon him without hesitation, eludes his bite, and striking him about the head, and particularly the eyes, where most vulnerable, he soon succeeds in causing him to retreat, and by redoubling his blows, in spite of all pretended fascination, the wily monster often falls a victim to his temerity; and the heroic bird, leaving his enemy dead on the field he provoked, mounts on the bush above his affectionate mate and brood, and in token of victory celebrates with his loudest song.

The Mocking Bird, like the Nightingale, is destitute of brilliant plumage ; but his form is beautiful, delicate, and symmetrical in its proportions. His motions are easy, rapid, and graceful, perpetually animated with a playful caprice and a look that appears full of shrewdness and intelligence. $\mathrm{He}$ listens with silent attention to each passing sound, treasures up lessons from everything vocal, and is capable of imitating with exactness, both in measure and accent, the notes of all the feathered race. And however wild and discordant the tones and calls may be, he contrives, with an Orphean talent peculiarly his own, to infuse into them that sweetness of expression and harmonious modulation which characterize this inimitable and wonderful composer. With the dawn of morning, while yet the sun lingers below the blushing horizon, our sublime songster, in his native wilds, mounted on the topmost branch of a tall bush or tree in the forest, pours out his admirable song, which, amidst the multitude of notes from all the warbling host, still rises pre-eminent, so that his solo is heard alone, and all the rest of the musical choir appear employed in mere accompaniments to this grand actor in the sublime opera of Nature. Nor is his talent confined to imitation; his native notes are also bold, full, and perpetually varied, consisting of short expressions of a few variable syllables, interspersed with imitations and uttered with great emphasis and volubility, sometimes for half an hour at a time, with undiminished ardor. These native strains bear a considerable resemblance to those 
of the Brown Thrush, to whom he is so nearly related in form, habits, and manners; but, like rude from cultivated genius, his notes are distinguished by the rapidity of their delivery, their variety, sweetness, and energy. As if conscious of his unrivalled powers of song, and animated by the harmony of his own voice, his music is, as it were, accompanied by chromatic dancing and expressive gestures; he spreads and closes his light and fanning wings, expands his silvered tail, and with buoyant gayety and enthusiastic ecstasy he sweeps around, and mounts and descends into the air from his lofty spray as his song swells to loudness or dies away in sinking whispers. While thus engaged, so various is his talent that it might be supposed a trial of skill from all the assembled birds of the country; and so perfect are his imitations that even the sportsman is at times deceived, and sent in quest of birds that have no existence around him. The feathered tribes themselves are decoyed by the fancied call of their mates, or dive with fear into the close thicket at the well-feigned scream of the Hawk.

Soon reconciled to the usurping fancy of man, the Mocking Bird often becomes familiar with his master; playfully attacks him through the bars of his cage, or at large in a room; restless and capricious, he seems to try every expedient of a lively imagination that may conduce to his amusement. Nothing escapes his discerning and intelligent eye or faithful ear. He whistles perhaps for the dog, who, deceived, runs to meet his master; the cries of the chicken in distress bring out the clucking mother to the protection of her brood. The barking of the dog, the piteous wailing of the puppy, the mewing of the cat, the action of a saw, or the creaking of a wheelbarrow, quickly follow with exactness. He repeats a tune of considerable length; imitates the warbling of the Canary, the lisping of the Indigo Bird, and the mellow whistle of the Cardinal, in a manner so superior to the originals that, mortified and astonished, they withdraw from his presence, or listen in silence as he continues to triumph by renewing his efforts.

In the cage also, nearly as in the woods, he is full of life and action while engaged in song, throwing himself round with in- 
spiring animation, and, as it were, moving in time to the melody of his own accents. Even the hours of night, which consign nearly all other birds to rest and silence, like the Nightingale he oft employs in song, serenading the houseless hunter and silent cottager to repose, as the rising moon illumines the darkness of the shadowy scene. His capricious fondness for contrast and perpetual variety appears to deteriorate his powers. His imitations of the Brown Thrush are perhaps interrupted by the crowing of the cock or the barking of the dog; the plaintive warblings of the Bluebird are then blended with the chatter of the Swallow or the cackling of the hen; amid the simple lay of the native Robin we are surprised with the vociferations of the Whip-poor-will; while the notes of the garrulous Jay, Wren, and many others succeed with such an appearance of reality that we almost imagine ourselves in the presence of the originals, and can scarcely realize the fact that the whole of this singular concert is the effort of a single bird. Indeed, it is impossible to listen to these Orphean strains, when delivered by a superior songster in his native woods, without being deeply affected and almost riveted to the spot by the complicated feelings of wonder and delight in which, from the graceful and sympathetic action, as well as enchanting voice of the performer, the eye is no less gratified than the ear. It is, however, painful to reflect that these extraordinary powers of nature, exercised with so much generous freedom in a state of confinement, are not calculated for long endurance, and after this most wonderful and interesting prisoner has survived for 6 or 7 years, blindness often terminates his gay career; and thus shut out from the cheering light, the solace of his lonely but active existence, he now after a time droops in silent sadness and dies.

The Mockingbird is a rare but regular summer visitor to Rhode Island, Connecticut, and southern Massachusetts, and examples have been taken in Maine. Mr. McIlwraith reports that a pair spent the summer of 1883 near Hamilton, Ontario, and C. A. McLennan records in the O. \& O. the capture of one near Truro, N. S. The species is chiefly restricted to the Southern States. 


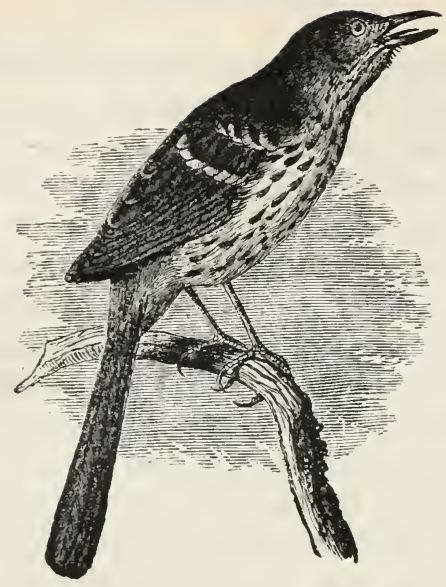

\section{BROWN THRASHER.}

BROWN THRUSH.

HARPORHYNCHUS RUFUS.

CHAR. Above, bright reddish brown or rufous; beneath, white, tinged with rufous or buff; breast and side spotted with brown; bill about as long as the head. Length $101 / 2$ to 12 inches.

Nest. In a thicket or low bush, and sometimes on the ground; bulky, and loosely constructed of twigs, roots, and dried grass, sometimes lined with horse-hair or feathers.

Eggs. 3-6 (usually 4); dull white with buff or green tint, marked with minute spots of reddish brown; $1.00 \times 0.80$.

This large and well-known songster, inferior to none but the Mocking Bird in musical talent, is found in every part of this continent, from Hudson's Bay to the shores of the Mexican Gulf, breeding in all the intermediate space, though more abundantly towards the North. It retires to the South early in October, in the States north of the Carolinas, and probably extends its migrations at this season through the warmer regions towards the borders of the tropics.

From the $5^{\text {th }}$ of April to early in May these birds begin to revisit the Middle and Northern States, keeping pace in some measure with the progress of vegetation and the comparative 
advancement of the season. They appear always to come in pairs, so that their mutual attachment is probably more durable than the season of incubation. Stationed on the top of some tall orchard or forest tree, the male, gay and animated, salutes the morn of his arrival with his loud and charming song. His voice, somewhat resembling that of the Thrush of Europe, but far more varied and powerful, rises pre-eminent amidst all the vocal choir of the forest. His music has the full charm of innate originality; he takes no delight in mimickry, and has therefore no title to the name of Mocking Bird. On his first appearance he falters in his song, like the Nightingale; but when his mate commences her cares and labors, his notes attain all their vigor and variety. The young birds, even of the first season, in a state of solitary domestication, without the aid of the parent's voice, already whisper forth in harmonious revery the pathetic and sweet warble instinctive to the species. In the month of May, while the blooming orchards perfume and decorate the landscape, the enchanting voice of the Thrasher in his affectionate lay seems to give grateful utterance for the bounty and teeming profusion of Nature, and falls in pleasing unison with the harmony and beauty of the season.

From the beginning to the middle of May the Thrashers are engaged in building their nest, selecting for this purpose usually a low, thick bush, in some retired thicket or swamp a few feet from the earth, and sometimes even on the ground in some sheltered tussuck, or near the root of a bush. They display the most ardent affection for their young, attacking snakes, dogs, and cats in their defence. One of the parents, usually the male, seems almost continually occupied in guarding against any dangerous intruder. The cat is attacked commonly at a considerable distance from the young, and the woods echo with his plaintive $y e$-ōer, yé-öw, and the low, guttural, angry 'tsh 'tsh 'tsh 'tsh. The enemy is thus pursued off the field, commonly with success, as guilty grimalkin appears to understand the threatening gestures and complaints with which she is so incessantly assailed. Towards their more VOL. I. -13 
insidious enemies of the human species, when approaching the helpless or unfledged young, every art is displayed; threats, entreaties, and reproaches the most pathetic and powerful, are tried in no equivocal strain; they dart at the ravisher in wild despair, and lament, in the most touching strains of sorrow, the bereavement they suffer. I know of nothing equal to the burst of grief manifested by these affectionate parents excepting the afflicting accents of suffering humanity.

Their food consists of worms and insects generally; also caterpillars, beetles, and other coleopterous tribes, as well as various kinds of berries. In the month of January I observed this Thrush and the Mocking Bird feed on the berries of the sumach. Sometimes they raise up a few grains of planted corn, but this is more the effect of caprice than appetite, as the search for grubworms is what commonly induces this resort to scratching up the soil. The Thrasher is an active, watchful, shy, and vigorous species, generally flying low, dwelling among thickets, and skipping from bush to bush with his long tail sometimes spread out like a fan. About the first week in October, after moulting, they disappear for the season and pass the winter in the Southern States. By the middle of February, or early in March, they already display their vocal powers in the warmer parts of Georgia and West Florida. They are easily reared, and become very familiar and amusing companions, showing a strong attachment to the hand that feeds and protects them. In their manners, intelligence, song, and sagacity, they nearly approach to the Mocking Bird, being equally playful, capricious, petulant, and affectionate.

The Thrasher is abundant in Massachusetts, and is found in Vermont and New Hampshire, but near the Atlantic seaboard does not go farther north than southern Maine. It occurs regularly in the vicinity of Montreal, and is common in Ontario and Manitoba. It winters from about $37^{\circ}$ southward. 


\section{CATBIRD.}

\section{GaLeoscoptes CAROLINENSIS.}

CHAR. General color dark slate, paler beneath; top of head and tail black; under tail-coverts chestnut. Length 8 to $9 \frac{1}{4}$ inches.

Nest. In thicket or orchard; bulky, and rudely constructed of twigs, leaves, and grass, lined with grass or fine roots.

Eggs. 4-6; deep bluish green; $0.95 \times 0.70$.

This quaint and familiar songster passes the winter in the southern extremities of the United States and along the coast of Mexico, whence as early as February it arrives in Georgia. About the middle of April it is first seen in Pennsylvania, and at length leisurely approaches this part of New England by the close of the first or beginning of the second week in May. These birds continue their migration also to Canada, where they proceed into the fur-countries as far as

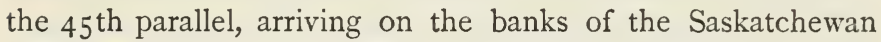
about the close of May. Throughout this extent and to the territory of the Mississippi they likewise pass the period of incubation and rearing their young. They remain in New England till about the middle of October, at which time the young feed principally upon wild berries.

The Catbird often tunes his cheerful song before the break of day, hopping from bush to bush with great agility after his insect prey, while yet scarcely distinguishable amidst the dusky shadows of the dawn. The notes of different individuals vary considerably, so that sometimes his song in sweetness and compass is scarcely at all inferior to that of the Ferruginous Thrush. A quaintness, however, prevails in all his efforts, and his song is frequently made up of short and blended imitations of other birds, - given, however, with great emphasis, melody, and variety of tone, and, like the Nightingale, invading the hours of repose. In the late twilight of a summer's evening, when scarce another note is heard but the hum of the drowsy beetle, his music attains its full effect, and often rises and falls with all the swell and studied cadence of finished harmony. 
During the heat of the day, or late in the morning, the variety of his song declines, or he pursues his employment in silence and retirement.

About the $25^{\text {th }}$ of May one of these familiar birds came into the Botanic Garden and took up his summer abode with us. Soon after his arrival he called up in low whisperings the notes of the Whip-poor-will, the Redbird, the peto peto of the Tufted Titmouse, and other imitations of Southern birds which he had collected on his leisurely route from the South. He also soon mocked the 'tshe-yàh 'tshe-yàh of the little Acadian Flycatchers, with which the neighborhood now abounded. He frequently answered to my whistle in the garden, was very silent during the period of incubation, and expressed great anxiety and complaint on my approaching the young after their leaving the nest.

One of the most remarkable propensities of the Catbird, and to which it owes its name, is the unpleasant, loud, and grating cat-like mew ('pāy, 'pāy, 'pāy) which it often utters on being approached or offended. As the irritation increases, this note becomes more hoarse, reiterated, and vehement; and sometimes this petulance and anger are carried so far as to persecute every intruder who approaches the premises. This temper often prevails after the young are fledged; and though originating no doubt in parental anxiety, it sometimes appears to outlive that season, and occasionally becomes such an annoyance that a revengeful and fatal blow from a stick or stone is but too often, with the thoughtless and prejudiced, the reward of this harmless and capricious provocation. At such times, with little apparent cause, the agitation of the bird is excessive; she hurries backward and forward with hanging wings and open mouth, mewing and screaming in a paroxysm of scolding anger, and alighting almost to peck the very hand that offers the insult. To touch a twig or branch in any part of the garden or wood is often amply sufficient to call down the amusing termagant. This harmless excess, and simulation of grimalkin's tone, - that wizard animal so much disliked by many, - are unfortunate associations in the cry of the Catbird; 
and thus, coupled with an ill name, this delightful and familiar songster, who seeks out the very society of man and reposes an unmerited confidence in his protection, is treated with undeserved obloquy and contempt. The flight of the Catbird is laborious, and usually continued only from bush to bush; his progress, however, is very wily, and his attitudes and jerks amusingly capricious. He appears to have very little fear of enemies, often descends to the ground in quest of insects, and though almost familiar, is very quick in his retreat from real danger.

The food of the Catbird is similar to that of the preceding species, being insects and worms, particularly beetles, and various garden fruits; feeding his young often on cherries and various kinds of berries. Sometimes these birds are observed to attack snakes when they approach the vicinity of the nest, and commonly succeed in driving off the enemy; when bitten, however, by the poisonous kinds, it is probable, as related, that they may act in such a manner as to appear laboring under the influence of fascination. The Catbird, when raised from the nest, is easily domesticated, becomes a very amusing inmate, and seems attached to his cage, as to a dwelling or place of security. About dawn of day, if at large, he flirts about with affected wildness, repeatedly jerks his tail and wings with the noise almost of a whip, and stretching forth his head, opens his mouth and mews. Sometimes this curious cry is so guttural as to be uttered without opening the bill. $\mathrm{He}$ often also gives a squeal as he flies from one place to another, and is very tame, though pugnacious to all other birds which approach him for injury. When wanting food, he stirs round with great uneasiness, jerks everything about within his reach, and utters the feeble cry of the caged Mocking Bird. A very amusing individual, which I now describe, began his vocal powers by imitating the sweet and low warble of the Song Sparrow, as given in the autumn; and from his love of imitation on other occasions, I am inclined to believe that he possesses no original note of his own, but acquires and modulates the songs of other birds. Like the Robin, he is exceedingly 
fond of washing, and dashes about in the water till every feather appears drenched; he also, at times, basks in the gravel in fine weather. His food, in confinement, is almost everything vegetable except unbruised seeds, - as bread, fine pastry, cakes, scalded cornmeal, fruits, particularly those which are juicy, and now and then insects and minced flesh.

The Catbird occurs regularly along the Annapolis valley in Nova Scotia, and in New Brunswick between the Maine border and the valley of the St. John, but it is rarely seen elsewhere in the Maritime Provinces. It is fairly common near the city of Quebec, and abundant about Montreal and in Ontario.

\section{ROBIN.}

\section{MERULA Migratoria.}

Char. Above, olive gray; head and neck darker, sometimes black; wings and tail dusky; outer tail-feathers broadly tipped with white; beneath, brownish red; throat white with dark streaks; under tail-coverts white; bill yellow. Length 9 to 10 inches.

Nest. Usually in a tree, but often on fence-rail or window-ledge of house or barn; a bulky but compact structure of grass, twigs, etc., cemented with mud.

Eggs. 4-5; greenish blue (occasionally speckled); I.I $5 \times 0.80$.

The familiär and welcome Robins are found in summer throughout the North American continent from the desolate regions of Hudson's Bay, in the 53d degree, to the tableland of Mexico. In all this vast space the American Fieldfares rear their young, avoiding only the warmer maritime districts, to which, however, they flock for support during the inclemency of winter. The Robins have no fixed time for migration, nor any particular rendezvous; they retire from the higher latitudes only as their food begins to fail, and so leisurely and desultory are their movements that they make their appearance in straggling parties even in Massachusetts, feeding on winter berries till driven to the South by deep and inundating snows. At this season they swarm in the Southern States, though they never move in large bodies. The holly, prinos, 
sumach, smilax, candle-berry myrtle, and the Virginian juniper now afford them an ample repast in the winter, in the absence of the more juicy berries of autumn, and the insects and worms of the milder season. Even in the vicinity of Boston flocks of Robins are seen, in certain seasons, assembling round open springs in the depth of winter, having arrived probably from the colder interior of the State ; and in those situations they are consequently often trapped and killed in great numbers.

Towards the close of January in South Carolina the Robin at intervals still tuned his song; and about the second week of March, in the Middle States, before the snows of winter have wholly disappeared, a few desultory notes are already given. As soon as the roth of this month they may at times also be heard in this part of New England. Early in April, however, at the close of the jealous contests, which are waged with obstinacy, they are only seen in pairs; and now from the orchard or the edge of the forest, deliver their simple, thrilling lays in all the artless energy of true affection. This earnest song recalls to mind the mellow whistle of the Thrush, which in the charming month of May so sweetly rises in warbling echoes from the low copse and shady glen. Our American bird has not, however, the compass and variety of that familiar and much-loved songster; but his freedom and willingness to please, render him an universal favorite, and he now comes, as it were, with the welcome prelude to the general concert about to burst upon us from all the green woods and blooming orchards. With this pleasing association with the opening season, amidst the fragrance of flowers and the improving verdure of the fields, we listen with peculiar pleasure to the simple song of the Robin. The confidence he reposes in us by making his abode in our gardens and orchards, the frankness and innocence of his manners, besides his vocal powers to please, inspire respect and attachment even in the truant school-boy, and his exposed nest is but rarely molested. $\mathrm{He}$ owes, however, this immunity in no small degree to the fortunate name which he bears; as the favorite Robin Redbreast, said to have covered with a leafy shroud the lost and wander- 
ing " babes in the woods," is held in universal respect in every part of Europe, where he is known by endearing names, and so familiar in winter that he sometimes taps at the window or enters the house in search of crumbs, and like the domestic fowls, claims his welcome pittance at the farmer's door.

The nest of this species is often on the horizontal branch of an apple-tree, or in a bush or tree in the woods, and so large as to be scarcely ever wholly concealed. The parents show great affection, courage, and anxiety for the safety of their young, keeping up a noisy cackling chirp when the place is approached, sometimes even boldly pecking at the hand or flying in the face of the intruder; and they have often serious contests with the piratical Cuckoo, who slyly watches the absence of the parents to devour their eggs. To avoid these visits and the attacks of other enemies, the Robin has been known to build his nest within a few yards of the blacksmith's anvil; and in Portsmouth (New Hampshire) one was seen to employ for the same purpose the stern timbers of an unfinished vessel, in which the carpenters were constantly at work, the bird appearing by this adventurous association as if conscious of the protection of so singular and bold a situation. I have also seen a nest of the Robin bottomed with a mass of pine shavings taken without alarm from the bench of the carpenter. From the petulant and reiterated chirp so commonly uttered by the Robin when surprised or irritated, the Indians of Hudson's Bay call him, from this note, Pee-pee-tshu. They often also utter a loud echoing ' $k h$ ' $k h$ ' $k h$, and sometimes chirp in a high or slender tone when alarmed, and with an affectation of anger sharply flirt the tail and ends of the wings. They raise several broods in a season, and considerable numbers flock together in the latter end of summer and autumn. When feeding on cherries, poke, sassafras, and sour-gum berries, they are so intent as to be easily approached and shot down in numbers; and when fat are justly esteemed for food and often brought to market. In the spring they frequently descend to the ground in quest of worms and insects, which then constitute their principal support. 
They are commonly brought up in the cage, and seem very docile and content. They sing well, readily learn to imitate lively parts of tunes, and some have been taught to pipe forth psalms even to so dull and solemn a measure as that of "Old Hundred" ! They acquire also a considerable taste for mimickry, imitating the notes of most of the birds around them, such as the Bluebird, Pewee, Whip-poor-will, and others. On being approached with the finger, they usually make some show of anger by cracking and snapping the bill. At times. they become very tame, and will go in and out of the house with domestic confidence, feel uneasy when left alone, and on such occasions have sometimes the sagacity of calling attention by articulating endearing words, as pretty, pretty, etc., connecting, apparently with these expressions, their general import of attentive blandishment. They become almost naked in the moulting season, in which they appear to suffer considerably, yet have been known to survive for I 7 years or upwards. The rufous color of the breast becomes deeper in those birds which thus live in confinement. Their principal song is in the morning, and commences before sunrise, at which time it is very loud, full, and emphatic.

The eastern form of this species is not found westward of the Great Plains excepting in the far North, where it has been traced to the Yukon district of Alaska. From the eastern base of the Rockies to the Pacific it is replaced by propinqua, a larger, grayer variety.

I have seen large flocks of Robins in New Brunswick during some winters, and every year they are more or less common during the cold months. These winter birds have much more white on their under parts than is seen on specimens taken in the summer, and their entire plumage is hoary. They doubtless spend the summer much farther north, - probably on the barren lands which border the Arctic Ocean, - and are but the northernmost edge of that cloud of Robins which every autumn rises from their breedinggrounds and sails away southward until, when it has finally settled, its eastern margin is found stretched from the Gulf of St. Lawrence to the West Indies. Throughout this range, embracing as it does many variations of climate, Robins may be found in suitable localities during every winter, - rather rare, sometimes, at the north, but increasing in abundance towards the South. 
The habit of this species of assembling in large communities to roost at night, during the summer months, was unknown to naturalists until a few years ago, and no mention of this habit appeared in print until October, 1890 , when detailed accounts of several "roosts" that had been discovered in the vicinity of Boston were published in the "Atlantic Monthly" and "The Auk." They were written by Mr. Bradford Torrey and Mr. William Brewster respectively. The "roosts" are situated in Norton's Woods, on Beaver Brook, Belmont, in Longwood, and in Melrose.

The Robins assembling in these places are numbered by thousands.

Note. - A few examples of the Varied Thrush (Hesperocichla navia) have wandered from the Pacific coast to the Eastern States; and the ReD-winged Thrush (Turdus iliacus) occasionally wanders from Europe to Greenland.

\section{WOOD THRUSH.}

\section{TURDUS MUSTELINUS.}

CHAR. Above, tawny, brightest on head, shading to olive on rump and tail; beneath, white; breast and sides marked with round spots of dusky. Length $7 \frac{1}{2}$ to $81 / 4$ inches.

Nest. In a thicket or on low branch of small tree, usually in a moist place; of grass and leaves cemented with mud, lined with fine roots.

Eggs. 3-5; pale greenish blue; $1.05 \times 0.75$.

This solitary and retiring songster during summer inhabits the whole continent from Hudson's Bay to Florida; and according to my friend Mr. Ware, breeds as far south as the vicinity of Natchez, in the territory of Mississippi. Whether it leaves the boundaries of the United States in the winter is not satisfactorily ascertained; as the species is then silent, and always difficult of access, its residence is rendered peculiarly doubtful. The lateness of the season in which it still lingers renders it probable that it may winter in the Southern States, as a young bird, gleaning insects and berries, has been caught in a garden in Boston on the 26 th of October.

From the southern parts of the Union, or wherever he may winter, the Wood Thrush arrives in the Middle States from the 

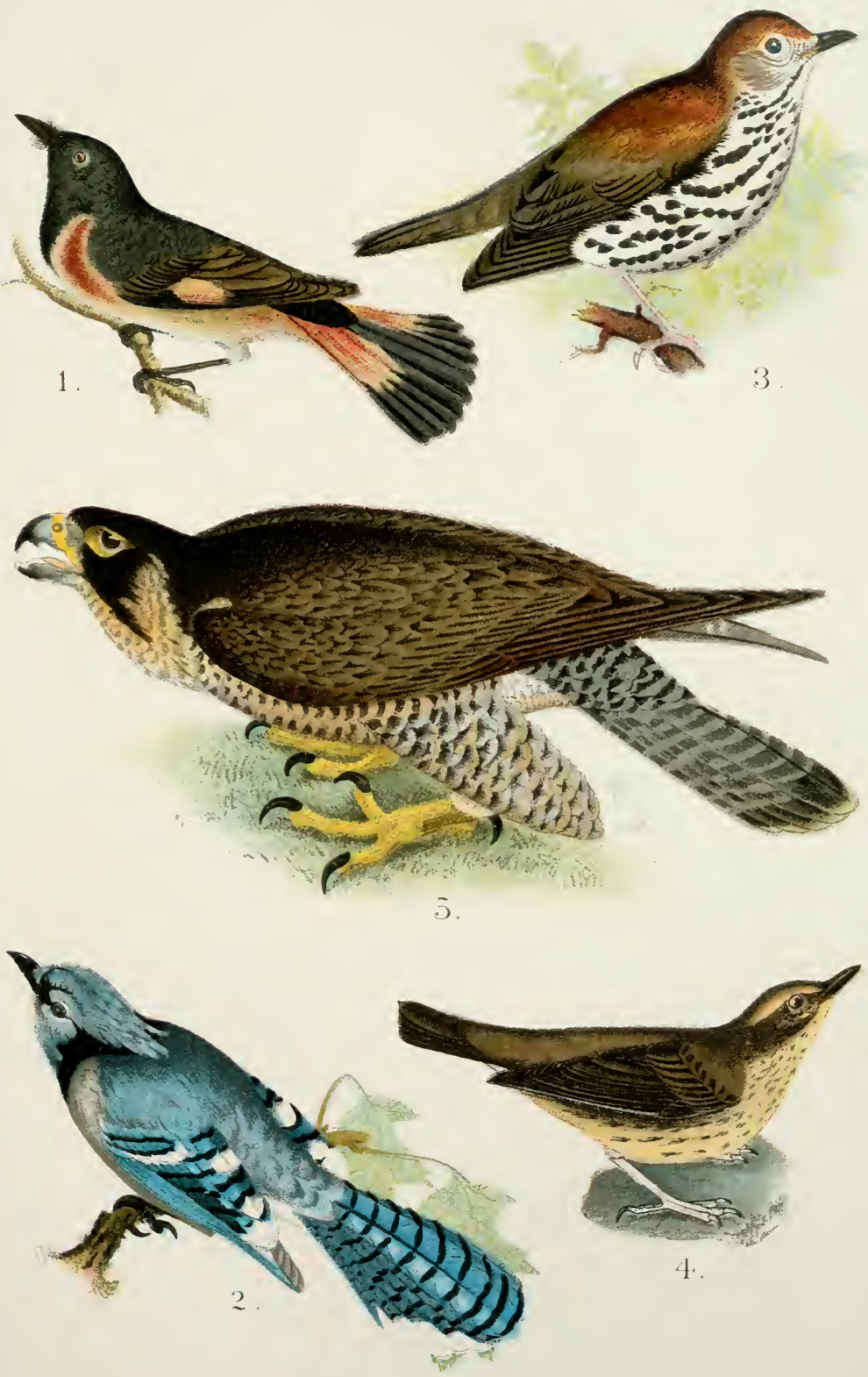

1. Redstart.

3. Wood Thrush.

5. Duck Hawk. 

Ist to the I $5^{\text {th }}$ of April; though his appearance here, where the species is scarce, does not take place earlier than the beginning of May. At the dawn of morning he now announces his presence in the woods, and from the top of some tall tree, rising through the dark and shady forest, he pours out his few, clear, and harmonious notes in a pleasing revery, as if inspired by the enthusiasm of renovated Nature. The prelude to this song resembles almost the double tonguing of the flute, blended with a tinkling, shrill, and solemn warble which re-echoes from his solitary retreat like the dirge of some sad recluse who shuns the busy haunts of life. The whole air consists usually of 4 parts or bars, which succeed, in deliberate time, and finally blend together in impressive and soothing harmony, becoming more mellow and sweet at every repetition. Rival performers seem to challenge each other from various parts of the wood, vying for the favor of their mates with sympathetic responses and softer tones; and some, waging a jealous strife, terminate the warm dispute by an appeal to combat and violence. Like the Robin and the Thrasher, in dark and gloomy weather, when other birds are sheltered and silent, the clear notes of the Wood Thrush are heard through the dropping woods from dawn to dusk, so that the sadder the day, the sweeter and more constant is his song. His clear and interrupted whistle is likewise often nearly the only voice of melody heard by the traveller, to mid-day, in the heat of summer, as he traverses the silent, dark, and wooded wilderness, remote from the haunts of men. It is nearly impossible by words to convey any idea of the peculiar warble of this vocal hermit; but amongst his phrases the sound of 'airŏee, peculiarly liquid, and followed by a trill repeated in two interrupted bars, is readily recognizable. At times the notes bear a considerable resemblance to those of Wilson's Thrush; such as eh rhehu 'vrhehu, then varied to 'eh villia villia, 'eh villia vrhehu, then 'eh velu villiu, high and shrill.

The Wood Thrush is always of a shy and retiring disposition, appearing alone or only in single pairs, and while he willingly charms us with his song, he is content and even soli- 
citous to remain concealed. His favorite haunts are low, shady glens by watercourses, often rendered dark with alder-bushes, mantled with the trailing grape-vine. In quest of his insect prey, he delights to follow the meanders of the rivulet, through whose leafy shades the sunbeams steal only in a few interrupted rays over the sparkling surface of the running brook. So partial is this bird to solitude that I have known one to sing almost uniformly in the same place, though nearly half a mile from his mate and nest. At times indeed he would venture a few faltering, low notes in an oak near his consort, but his mellowest morning and evening warble was always delivered from a tall hickory, overtopping a grove of hemlock firs, in which the dimness of twilight prevailed even at noon. The Wood Thrush, like the Nightingale, therefore feels inspired in darkness ; but instead of waiting for the setting sun, he chooses a retreat where the beams of day can seldom enter. These shady retreats have also an additional attraction to our Thrush; it is here that the most interesting scene of his instinctive labor begins and ends; here he first saw the light and breathed into existence; and here he now bestows his nest in a sapling oak, or in the next thick laurel or blooming alder, whose berries afford him ample repast in the coming autumn. Beetles, caterpillars, various insects, and in autumn, berries, constitute the principal food of the Wood Thrush. The young remain for weeks around gardens in quest of berries, and are particularly fond of those of the various species of cornel and viburnum. At this season they occasionally leave their favorite glens, and in their devious wanderings, previous to their departure, sometimes venture to visit the rural suburbs of the city. The young are easily raised, and sing nearly as well in the cage as in their native wilds.

Nuttall made a mistake in giving to the Wood Thrush so extended a range, and must have confused this species with the Olive-backed, of which he makes no mention. In New England the Wood Thrush is rarely found north of Massachusetts excepting in western Vermont. It occurs in the southern parts of Ontario and Michigan, and has been taken in Minnesota. It has been found in winter in Cuba and Guatemala. 


\title{
HERMIT THRUSH.
}

\author{
SWAMP ROBIN. \\ TURDUS AONALASCHKÆ PALLASII.
}

CHAR. Above, olive brown or russet, shading to rufous on rump and tail; beneath buffish, shaded with olive on sides; throat and breast marked with olive wedge-shaped spots. Length $6 \frac{1}{2}$ to $7 \frac{1}{2}$ inches.

Nest. On the ground, loosely made of leaves, grass, and moss.

Eggs. $3-5$; greenish blue ; $0.85 \times 0.65$.

This species, so much like the Nightingale in color, is scarce inferior to that celebrated bird in its powers of song, and greatly exceeds the Wood Thrush in the melody and sweetness of its lay. It inhabits the United States from the lofty alpine mountains of New Hampshire to Florida. It is also met with on the tableland of Mexico and in the warmer climate of the Antilles. In Pennsylvania, New Jersey, and New England, at the close of autumn, it appears to migrate eastward to the seacoast in quest of the winter berries on which it now feeds; in spring and summer it lives chiefly on insects and their larvæ, and also collects the surviving berries of the Mitchella repens.

Like the preceding species, it appears to court solitude, and lives wholly in the woods. In the Southern States, where it inhabits the whole year, it frequents the dark and desolate shades of the cane swamps. In these almost Stygian regions, which, besides being cool, abound probably with its favorite insect food, we are nearly sure to meet our sweetly vocal hermit flitting through the settled gloom, which the brightest rays of noon scarcely illumine with more than twilight. In one of such swamps, in the Choctaw nation, Wilson examined a nest of this species which was fixed on the horizontal branch of a tree, formed with great neatness and without using any plastering of mud. The outside was made of a layer of coarse grass, having the roots attached, and intermixed with horsehair ; the lining consisted of green filiform blades of dry grass very neatly wound about the interior.

In the Middle States these birds are only seen for a few 
weeks in the spring and fall. They arrive in this part of New England about the Ioth of April, and disperse to pass the summer in the seclusion of the forest. They are often seen on the ground in quest of their food, and frequent low and thick copses, into which they commonly fly for concealment when too attentively observed; though when in small companies, in the spring season, they do not appear very shy, but restless from the unsettled state of their circumstances. When dispersed, they utter a low, chirping call, and for some time continue to frequent the same secluded part of the forest in society. At times, like the Wagtail, they keep this part of their body in a slow, vertical motion. In manners they strongly resemble the following species, but their song seems to be unusually lively and varied.

The Hermit is a common bird in the Maritime Provinces and Quebec, and nests from about latitude $44^{\circ}$ northward. It is common on Anticosti and along the north shore of the Gulf of St. Lawrence, and has been taken at Lake Mistassini. In Ontario it occurs chiefly as a migrant, though breeding in the Muskoka district. In New England also it is principally known as a migrant, breeding in numbers only along the northern border and on the higher hills of Connecticut and Massachusetts. The nest has been taken in Ohio and in southern Michigan.

The opinions expressed by Nuttall that the Hermit Thrush is a peculiarly shy and solitary bird, and that its favorite resorts are amid the deep forests, are, I think, somewhat misleading; at least my observations in New Brunswick led me to form quite different opinions. I did find these birds courting retirement and apparently destitute of either vanity or curiosity; but they always displayed a calm self-possession that is inconsistent with shyness. Nor were they peculiarly solitary, for though it was unusual to see a number of them in close companionship, it was not unusual to meet with half a dozen in as many minutes, or to find as many nests within a small area.

Like all woodland birds, they prefer the groves to the open fields, and they enjoy a cool shade in a moist valley; but they build their nests near the settlements, and rarely go into the denser forests. This is their habit in New Brunswick, though of course when farther north they must resort to the timber districts; there are few settlements to attract them. 


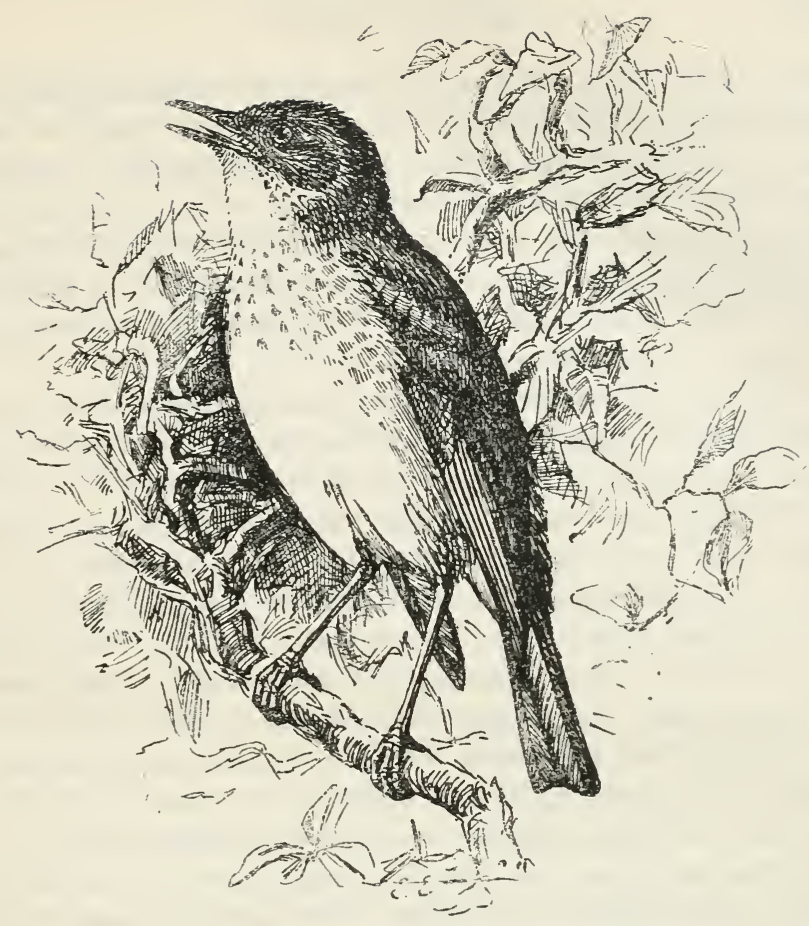

\section{WILSON'S THRUSH.}

TAWNY THRUSH. VEERY.

\section{Turdus fuscescens.}

Char. Above, light tawny or rufous; beneath, white, shaded with creamy buff on breast, and with olive on sides; breast spotted with tawny. Length $6 \frac{1}{2}$ to $73 \frac{1}{4}$ inches.

Nest. On the ground or near it, usually at the base of small tree or in tuft of old grass; of leaves and grass, lined with fine roots.

Eggs. $3-5$; pale greenish blue; $0.85 \times 0.65$.

This common Northern species arrives in Pennsylvania and New England about the beginning of May, and its northern range extends as far as Labrador. It appears to retire to the South early in October, and is more decidedly insectivorous than any other native species. According to Wilson, many of 
these birds winter in the myrtle-swamps of South Carolina. I have not, however, seen them in the Southern States at that season, and most part of the species pass on probably as far as the coast of the Mexican Gulf. They do not, according to Wilson, breed in the lower parts of Pennsylvania, though undoubtedly they do in the mountainous districts, where they are seen as late as the 2 oth of May. They propagate and are very common in Massachusetts.

In its retiring habits and love of concealment this Thrush resembles the preceding. It frequents the dark and shady borders of small brooks and woods, and sometimes the bushy and retired parts of the garden; from whence, without being often seen, in the morning and particularly the evening to the very approach of night, we often hear the singular, quaint, and musical note of this querulous species at short intervals, as one perches upon some low branch of a tree or bush. This curious whistling note sounds like 'vehu 'v'rehu 'v'rehu 'v'rehu, and sometimes 'veă veă 'vrehă 'vrehă vehu', running up the notes till they become shrill and quick at the close, in the first phrase, but from high to low, and terminating slender and slow, in the latter; another expression seems to be, 've 'veá vehurr, ascending like a whistle. The song of another individuăl was expressed in the following manner: 've 'villill'villill 'tullüll'tullül. It was then repeated with variation, 've villillil villill villill; then villillill villillill, tultilill tullilill; the whole agreeably and singularly delivered in a shrill, hollow voice, almost like the sound of liquor passing through a tunnel into a bottle. I have also heard several of these sounds, sometimes occasionally prefaced by a mewing or chirping warble. These sounds, though monotonous, are possessed of greater variety than is at first imagined, the terminating tone or key changing through several repetitions, so as to constitute a harmony and melody in some degree approaching the song of the more musical Wood Thrush. From this habit of serenading into the night, the species is sometimes here dignified with the nickname of the Nightingale. Occasionally he utters an angry, rather plaintive mew, like the Catbird, or a quivering bleat 
almost similar to that of a lamb; and when approached, watches and follows the intruder with an angry or petulant queàh queàh; at other times a sort of mewing, melancholy, or complaining y'eow' 'y'eow is heard, and then, perhaps, a hasty and impatient péŭt péŭt follows. The food of this species, at least during the early part of summer, appears to be shelly insects of various kinds, particularly Chrysomelas, or lady-bugs, and those many legged hard worms of the genus Iulus.

A good while after the commencement of the period of incubation I have observed the males engaged in obstinate quarrels. On the $4^{\text {th }}$ of June, I830, I observed two of these petulant Thrushes thus fiercely and jealously contending; one of them used a plaintive and angry tone as he chased his antagonist up and down the tree. At length, however, a cousin Catbird, to which this species has some affinity, stepped in betwixt the combatants, and they soon parted. One of these birds had a nest and mate in the gooseberry bush of a neighboring garden; the second bird was thus a dissatisfied hermit, and spent many weeks in the Botanic Garden, where, though at times sad and solitary, yet he constantly amused us with his forlorn song, and seemed at last, as it were, acquainted with those who whistled for him, peeping out of the bushes with a sort of complaisant curiosity, and from his almost nocturnal habits became a great persecutor of the assassin Owl whenever he dared to make his appearance.

The nest of Wilson's Thrush (commenced about the close of the first week in May) is usually in a low and thorny bush in the darkest part of the forest, at no great distance from the ground ( $\mathrm{I}$ to 3 feet), sometimes indeed on the earth, but raised by a bed of leaves, and greatly resembles that of the Catbird. This species seems, indeed, for security artfully to depend on the resemblance of itself and its leafy nest with the bosom of the forest on which it rests, and when approached it sits so close as nearly to admit of being taken up by the hand. The nest sometimes appears without any shelter but shade and association of colors with the place on which it rests. I have seen one placed on a mass of prostrated dead brambles, on a VOL. I. - I4 
fallen heap of lilac twigs in a ravine, and also in a smail withered branch of red oak which had fallen into a bush; below it was also bedded with exactly similar leaves, so as easily to deceive the eye. But with all these precautions they appear to lose many eggs and young by squirrels and other animals. The nest is usually bottomed with dry oak or beech leaves, coarse stalks of grass and weeds, and lined very generally with naturally dissected foliage, its stalks, some fine grass, and at other times a mixture of root-fibres; but no earth is employed in the fabric. The eggs, 4 or 5 , are of an emerald green without spots, and differ from those of the Catbird only in being a little smaller and more inclined to blue. So shy is the species that though I feigned a violent chirping near the nest containing their young, which brought Sparrows and a neighboring Baltimore to the rescue, the parents, peeping at a distance, did not venture to approach or even express any marked concern, though they prove very watchful guardians when their brood are fledged and with them in the woods. They have commonly two broods in the season; the second being raised about the middle of July, after which their musical notes are but seldom heard. I afterwards by an accident obtained a young fledged bird, which retained in the cage the unsocial and silent timidity peculiar to the species.

Wilson's Thrush breeds farther to the southward than the Hermit, but does not range quite so far north. It is common in the Maritime Provinces and near the city of Quebec, but has not been taken recently on the north shore of the Gulf of St. Lawrence. Though it is abundant in Manitoba, and Chapman reports its occurrence in Newfoundland, it breeds abundantly in Ontario and in northern Ohio.

In New Brunswick I have found the nest as frequently in an open pasture as in more obscure places.

Note. - The Willow Thrush ( $T$. fuscescens salicicola), a Rocky Mountain form, occurs occasionally in Illinois and casually in South Carolina. 


\section{OLIVE-BACKED THRUSH.}

\section{TURDUS USTUlatus SWAINSONII.}

CHAR. Above, olive; beneath, white, shaded with olive on the sides; sides of head, neck, and breast tinged with buff; throat and breast spotted with olive; yellowish ring around the eye. Length $61 / 2$ to $71 / 2$ inches.

Nest. In a low tree or bush; of twigs, leaves, grass, etc.

Eggs. 3-4; greenish blue speckled with brown; $0.90 \times 0.65$.

This species was omitted by Nuttall, though given by Wilson. It has much the same range and similar habits as the Hermit, though differing in its song and the location of its nest. The tone of its voice is richer and rounder - more flute-like and less metallic than that of any other of the small Thrushes; but the song lacks that spiritual quality so conspicuous in the hymn-like melody of the Hermit.

The Olive-backed is found throughout the temperate region of eastern North America, and westward to the eastern base of the Rockies. It breeds in northern New England and northward, and in the elevated portions of Massachusetts and Connecticut, as well as in northern New York and Michigan, and winters in the Gulf States and southward to Panama.

It is common in the Maritime Provinces, but is reported rather rare between Montreal and Lake Huron, though it being an abundant migrant through Ohio, I should expect to find it plentiful in portions of Ontario.

\section{GRAY-CHEEKED THRUSH.}

\section{ALICE'S THRUSH.}

\section{TURdUS ALICLE.}

CHAR. Above, olive; cheeks grayish, a whitish ring round the eyes; beneath, white; sides tinged with olive; throat and breast tinged with buff and marked with large dark spots. Length 7 to $73 / 4$ inches.

Nest. In a low bush or on the ground; of grass and leaves, etc., lined with fine grass.

Eggs. 3-4; greenish blue spotted with brown; $0.90 \times 0.70$.

After much contention as to the validity of Alice's Thrush as a variety of the Olive-backed, the systematists have decided to give it 
specific rank. In appearance it differs from swainsonii chiefly in lacking the yellow around the eye, and in having gray instead of buff cheeks. Alicice is also a trifle the larger of the two.

The distribution of the present species has not yet been thoroughly worked out, for only a few years have passed since its discovery; but it is known to occur in the United States and the settled portions of Canada as a migrant only, breeding north to the Arctic, and wintering south to Costa Rica.

\title{
BICKNELL'S THRUSH.
}

\section{TURDUS ALICIÆ BICKNELLI.}

CHAR. Above, olive, varying from a grayish to a russet tint; wings and tail slightly browner than back; distinct ring of pale buff around the eyes; cheeks buffish; beneath, white, tinged with olive on the sides; throat and breast tinged with buff and marked with large dark spots. Length 7 to $7^{1 / 2}$ inches.

Nest. On the ground, in a thicket; composed of twigs, grass, and moss, lined with grass.

Eggs. 3-4; pale blueish green speckled with brown; $0.85 \times 0.65$.

This variety of the Gray-cheeked Thrush was discovered by Mr. Eugene P. Bicknell amid the Catskill Mountains in I885. It has been found on all the higher ranges of Eastern America and in Illinois, and Mr. Langille claims to have discovered the nest on an island off the southern coast of Nova Scotia.

\section{WATER THRUSH.}

\author{
WATER IVAGTAIL.
}

\section{SeIURUS NOVEBORACENSIS.}

CHAR. Above, deep olive brown; line over the eye whitish; beneath, white tinged with bright yellow, and spotted with olive. Length $5^{1 / 2}$ to 6 inches.

Nest. On the ground, in border of swamp or stream; bulky, and loosely made of moss, leaves, and grass, lined with roots. Sometimes deeply imbedded in moss, or covered with it.

Eggs. 4-6; white, spotted, most heavily near the larger end, with brown and lilac; $0.75 \times 0.55$. 
This shy and retiring sylvan species extends its summer migrations throughout the United States, breeding rarely in Pennsylvania, proceeding principally to the western and northern regions at the period of incubation. Mr. Townsend and myself observed this bird in Oregon, as well as in Missouri, where it was, no doubt, breeding, and sung in a very lively manner, keeping in a shady wood which bordered a small stream, often descending to the ground after aquatic insects or larvæ, and with the tail in a constant balancing motion, reminding us strongly of the Wagtail or Motacilla of Europe.

The Aquatic Thrush has, indeed, a particular partiality for the vicinity of waters, wading in the shallow streams in search of insects, moving its tail as it leisurely follows its pursuit, and chattering as it flies. During its transient migrating visits it is very timid, and darts into the thickets as soon as approached, uttering a sharp and rather plaintive tship' of alarm. About the beginning of May, these birds appear in Pennsylvania from the South, and stay around dark and solitary streams for ten or twelve days, and then disappear until about the middle of August, when, on their way to their tropical winter quarters, they leave the swamps and mountains of their summer retreat, and, after again gleaning a transient subsistence for a few days towards the sea-coast, depart for the season. In Massachusetts they are scarcely ever seen except in the autumn, and continue in shady gardens, probably feeding on small wild berries till nearly the close of September.

It appears, according to Wilson, that the favorite resort of this species is in the cane-brakes, swamps, river shores, and watery solitudes of Louisiana, Tennessee, and Mississippi. Here it is abundant, and is eminently distinguished by the loudness, sweetness, and expressive vivacity of its notes, which, beginning high and clear, flow and descend in a cadence so delicate as to terminate in sounds that are scarcely audible. At such times the singer sits perched on some branch which stretches impending over the flowing stream, and pours out his charming melody with such effect as to be heard at the distance of nearly half a mile, giving a peculiar charm to the dark 
and solitary wilds he inhabits. The silence of night is also, at times, relieved by the incessant warble of this Western Philomel, whose voice, breaking upon the ear of the lonely traveller in the wilderness, seems like the dulcet lay of something supernatural. His song is also heard in the winter when the weather proves mild. In this habit he appears considerably allied to the Reed Thrush or River Nightingale of Europe, which night and day almost ceaselessly sings, and soothes his sitting mate, among the reeds and marshes of his favorite resorts.

Since Nuttall's day the Water Thrush has been separated from the true Thrushes and classed with the Warblers. The birds seen by Wilson and Audubon in Louisiana, Tennessee, and Mississippi were doubtless referable to :notacilla, for though the present species is found throughout this Eastern Province, west to Illinois and Manitoba, it seldom has been discovered breeding south of $45^{\circ}$. It is a rather common spring and autumn visitor to Massachusetts, and may breed in small numbers on the Berkshire hills.

On the plains the type is replaced by the variety named notabilis, - Grinnell's Water-Thrush, - which is larger and darker. Notabilis occurs occasionally in Illinois and Indiana.

\section{LOUISIANA WATER THRUSH.}

\section{SEIURUS motacilla.}

CHAR. Similar to noveboracensis, but larger, and bill longer and stouter. Under parts tinged with buff, but never with bright yellow; throat free from spots. Length $5 \frac{3}{4}$ to $6 \frac{1}{2}$ inches.

Nest. On the ground, hidden amid roots of fallen tree, or on a mossy bank ; composed of leaves, grass, and moss, lined with grass and hair.

Eggs. 4-6; white, sometimes with creamy tint, speckled with brown and lilac; $0.75 \times 0.60$.

The range of this species extends from southern New England, the Great Lakes, and Minnesota (in summer) to the Gulf States and Central America (in winter). A few pairs are seen every season in southern Ontario. Its habits do not differ from those of its congener. 


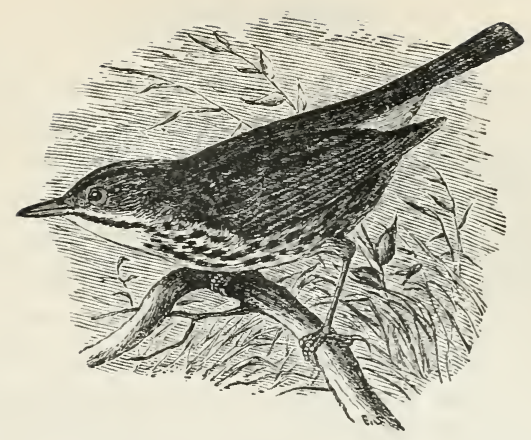

OVEN-BIRD.

GOLDEN-CROWNED THRUSH.

\section{SEIURUS AUROCAPILLUS.}

CHAR. Above, olive ; crown orange-brown, bordered with black stripes, white ring around the eyes; beneath, white, spotted with olive. Length $5^{1 / 2}$ to $61 / 2$ inches.

Nest. On the ground, at the foot of a tree or in the moss on a decayed $\log$; rather loosely made of twigs, grass, leaves, and moss, lined with fine grass and hair. The top is often completely roofed, sometimes arched or domed; the entrance on the side.

Eggs. 4-6; creamy white, spotted with brown and lilac; $0.80 \times 0.55$.

This rather common bird, so nearly allied to the true Thrushes, is found throughout the forests of the United States, Canada, and in the territory of Oregon during the summer, arriving in the Middle and Northern States about the beginning of May or close of April, and departing for tropical America, Mexico, and the larger West India islands early in September.

The Golden-crowned Thrush, shy and retiring, is never seen out of the shade of the woods, and sits and runs along the ground often like the Lark; it also frequents the branches of trees, and sometimes moves its tail in the manner of the Wagtails. It has few pretensions to song, and while perched in the deep and shady part of the forest, it utters, at intervals, a simple, long, reiterated note of 'tsh'e tshe tshe tshe tshe, rising from low to high and shrill, so as to give but little idea of the distance or place from whence the sound proceeds, and often appearing, from the loudness of the closing cadence, to be much 
nearer than it really is. As soon as discovered, like the Wood Thrush, it darts at once timidly into the depths of its sylvan retreat. During the period of incubation, the deliberate lay of the male, from some horizontal branch of the forest tree, where it often sits usually still, is a 'tshe te tshe tĕ tshe tĕ tshee, gradually rising and growing louder. Towards dusk in the evening, however, it now and then utters a sudden burst of notes with a short, agreeable warble, which terminates commonly in the usual 'tshe te tshe. Its curious oven-shaped nest is known to all the sportsmen who traverse the solitary wilds which it inhabits. This ingenious fabric is sunk a little into the ground, and generally situated on some dry and mossy bank contiguous to bushes, or on an uncleared surface ; it is formed, with great neatness, of dry blades of grass, and lined with the same; it is then surmounted by a thick inclined roof of similar materials, the surface scattered with leaves and twigs so as to match the rest of the ground, and an entrance is left at the side. Near Milton hills, in this vicinity, the situation chosen was among low whortleberry bushes, in a stunted cedar and oak grove. When surprised, the bird escapes, or runs from the nest with the silence and celerity of a mouse. If an attempt be made to discover the nest from which she is flushed, she stops, flutters, and pretends lameness, and watching the success of the manœuvre, at length, when the decoy seems complete, she takes to wing and disappears. The Oven Bird is another of the foster-parents sometimes chosen by the Cow Troopial; and she rears the foundling with her accustomed care and affection, and keeps up an incessant tship when her unfledged brood are even distantly approached. These birds have often two broods in a season in the Middle States. Their food is wholly insects and their larvæ, particularly small coleopterous kinds and ants, chiefly collected on the ground.

The Oven-bird, like the Water-Thrush, has been removed by modern authorities from classification with the Thrush family and placed with the Warblers. It is now known to breed from Virginia and Kansas to Labrador and Manitoba. It is abundant in Massachusetts and the Maritime Provinces, and common over its entire range. It winters in Florida and as far south as Central America. 


\section{MYRTLE WARBLER.}

YELLOW-RUMP WARBLER. YELLOIV-CROWNED WARBLER.

\section{DENDROICA CORONATA.}

CHAR. Male: above, bluish gray streaked with black; sides of head black; breast and sides mostly black; patches of yellow on crown and rump and sides of breast ; throat and belly white ; wing-bars and patches on tail white. Female, young, and male in winter: similar, but the back with a tint of brown in place of blue, and all colors duller, and markings less distinct. Length 5 to 6 inches.

Nest. In a coniferous tree 5 to 10 feet from the ground, in a pasture or open grove of woodland; composed of twigs and grass, lined with fine grass, sometimes with feathers.

Eggs. 4-5; dull white or creamy white, spotted chiefly around the larger end with brown and lilac; $0.70 \times 0.50$.

The history of this rather common Warbler remains very imperfect. In the Middle and Northern States it is a bird of passage, arriving from the South about the close of April or beginning of May, and proceeding north as far as Canada and Labrador to pass the summer season in the cares of breeding and rearing the young. As early as the 3 oth of August, or after an absence of little more than three months, these birds again appear; and being hardy, passing parties continue with us in gardens and woods till about the close of November, feeding now almost exclusively on the myrtle-wax berries (My'rica cerifera), or on those of the Virginian juniper. These, other late and persisting berries, and occasional insects, constitute their winter food in the Southern States, where, in considerable numbers, in the swamps and sheltered groves of the sea-coast, they pass the cold season. In fine weather, in the early part of October, they may be seen, at times, collecting grasshoppers and moths from the meadows and pastures, and, like the Blue Bird, they often watch for the appearance of their prey from a neighboring stake, low bough, or fence-rail; and at this time are so familiar and unsuspicious, particularly the young, as fearlessly to approach almost within the reach of the silent spectator. At 
the period of migration, they appear in an altered and less brilliant dress. The bright yellow spot on the crown is now edged with brownish olive, so that the prevailing color of this beautiful mark is only seen on shedding the feathers with the hand; a brownish tint is also added to the whole plumage. But Wilson's figure of this supposed autumnal change only represents the young bird. The old is, in fact, but little less brilliant than in summer, and I have a well-founded suspicion that the wearing of the edges of the feathers, or some other secondary cause, alone produces this change in the livery of spring, particularly as it is not any sexual distinction.

While feeding they are very active, in the manner of Flycatchers, hovering among the cedars and myrtles with hanging wings, and only rest when satisfied with gleaning food. In spring they are still more timid, busy, and restless. According to Audubon, the nest and eggs are scarcely to be distinguished from those of Sylvia astiva; one which he examined from Nova Scotia was made in the extremity of the branch of a low fir-tree, about five feet from the ground. When approached, or while feeding, they only utter a feeble, plaintive tship of alarm. This beautiful species arrives here about the $7^{\text {th }}$ or 8th of May, and now chiefly frequents the orchards, uttering at short intervals, in the morning, a sweet and varied, rather plaintive warble, resembling in part the song of the Summer Yellow Bird, but much more the farewell, solitary autumnal notes of the Robin Redbreast of Europe. The tones at times are also so ventriloquial and variable in elevation that it is not always easy to ascertain the spot whence they proceed. While thus engaged in quest of small caterpillars, the Myrtle seems almost insensible to obtrusion, and familiarly searches for its prey, however near we may approach.

The "Yellow-rump" - by which name this species is best known - breeds regularly from northern New England northward and west to Manitoba; also on the Berkshire hills in Massachusetts. It is an abundant summer resident of the Maritime Provinces, but elsewhere, in the settled portions of Canada, occurs as a migrant only. It winters regularly in Massachusetts and central Ohio, and thence southward as far as Central America. 


\title{
YELLOW PALM WARBLER.
}

\author{
YELLOW RED-POLL WARBLER. \\ DENDROICA PALMARUM HYPOCHRYSEA.
}

Char. Above, brownish olive ; rump yellowish, dusky streaks on the back; crown chestnut; line over eye and under parts rich yellow; breast and sides streaked with brown; no white wing bars; square patches of white on outer tail-feathers. Adult in winter and young; similar but colors duller, and markings less distinct; underparts grayish yellow. Length 5 to $5 \frac{3}{4}$ inches.

Nest. On the ground on border of swamp; loosely made of grass, weeds, and moss fastened with caterpillar's silk, lined with roots, hair, pine-needles, or feathers.

Eggs. 4-5; creamy white, sometimes with roseate tinge, marked on larger end with fine spots of brown and lilac; $0.65 \times 0.50$.

The Yellow Red-polls in small numbers arrive in the Middle and Northern States in the month of April; many proceed as far as Labrador, where they were seen in summer by Audubon, and in the month of August the young were generally fledged. In the Southern States they are abundant in winter. While here, like many other transient passengers of the family, they appear extremely busy in quest of their restless insect prey. They frequent low, swampy thickets, are rare, and their few feeble notes are said scarcely to deserve the name of a song. These stragglers remain all summer in Pennsylvania, but the nest is unknown. They depart in September or early in October, and some probably winter in the southernmost States, as they were met with in February, by Wilson, near Savannah. This is a different species from the Palm Warbler, which probably does not exist in the United States.

This bird appears yet to be very little known. Pennant has most strangely blended up its description with that of the Ruby-crowned Wren! his supposed female being precisely that bird.

The Eastern form of the Palm Warbler is a common bird from the Atlantic to the Mississippi valley, where it is replaced by true palmarum, and is abundant in summer in northern Maine and New Brunswick. 
Mr. Neilson thinks it uncommon near Dornald, Quebec, and says he never sees a specimen later than June ist. Dr. Wheaton has reported it as a common migrant through Ohio, but it is reported rare in Ontario. Nuttall's statement, borrowed from Wilson, that some remained in Pennsylvania during the breeding season, has not been confirmed by more recent observations.

In habits this species stands peculiar. Unlike other Dendroica, it nests on the ground, and unlike most other Warblers, shows a strong preference for fields and road-sides, where it may be found hopping along with the Sparrows, and flirting its tail like a Titlark.

The song is a very simple affair, - a few sweet notes.

Note. - The Palm Warbler (Dendrozca palmarum) differs from hypochrysea in being smaller and much duller colored. It breeds in Manitoba and northward, and winters in the Southern States. A few examples have been seen in the Eastern States.

Audubon's Warbler (Dendroica auduboni), though a bird of the Western Plains, has a right to mention here through examples having been taken in Massachusetts and Pennsylvania.

\section{YELLOW WARBLER.}

\section{SUMMER YELLOW BIRD. SUMMER WARBLER.}

DENDROICA ESTIVA.

CHAR. Male: general color golden yellow, upper parts tinged with olive; breast and sides streaked with orange brown. Female: similar, but upper parts with deeper tinge of olive, and under parts with less streaks. Length $4 \frac{1}{2}$ to $5 \frac{1}{4} /$ inches.

Nest. On a bush or low tree, in a garden or open pasture; gracefully formed and compactly woven, of various vegetable fibres, - grass, stems, etc., - usually lined with hair or plant down, sometimes with feathers.

Eggs. 3-5; dull white or greenish white, marked chiefly around the larger end with brown and lilac; $0.65 \times 0.45$.

This very common and brilliant summer species is found in all parts of the American continent, from the confines of the Arctic circle to Florida and Texas, as well as Oregon and the Rocky Mountains, where it spends the mild season. About the middle of March I already heard the song amidst the 


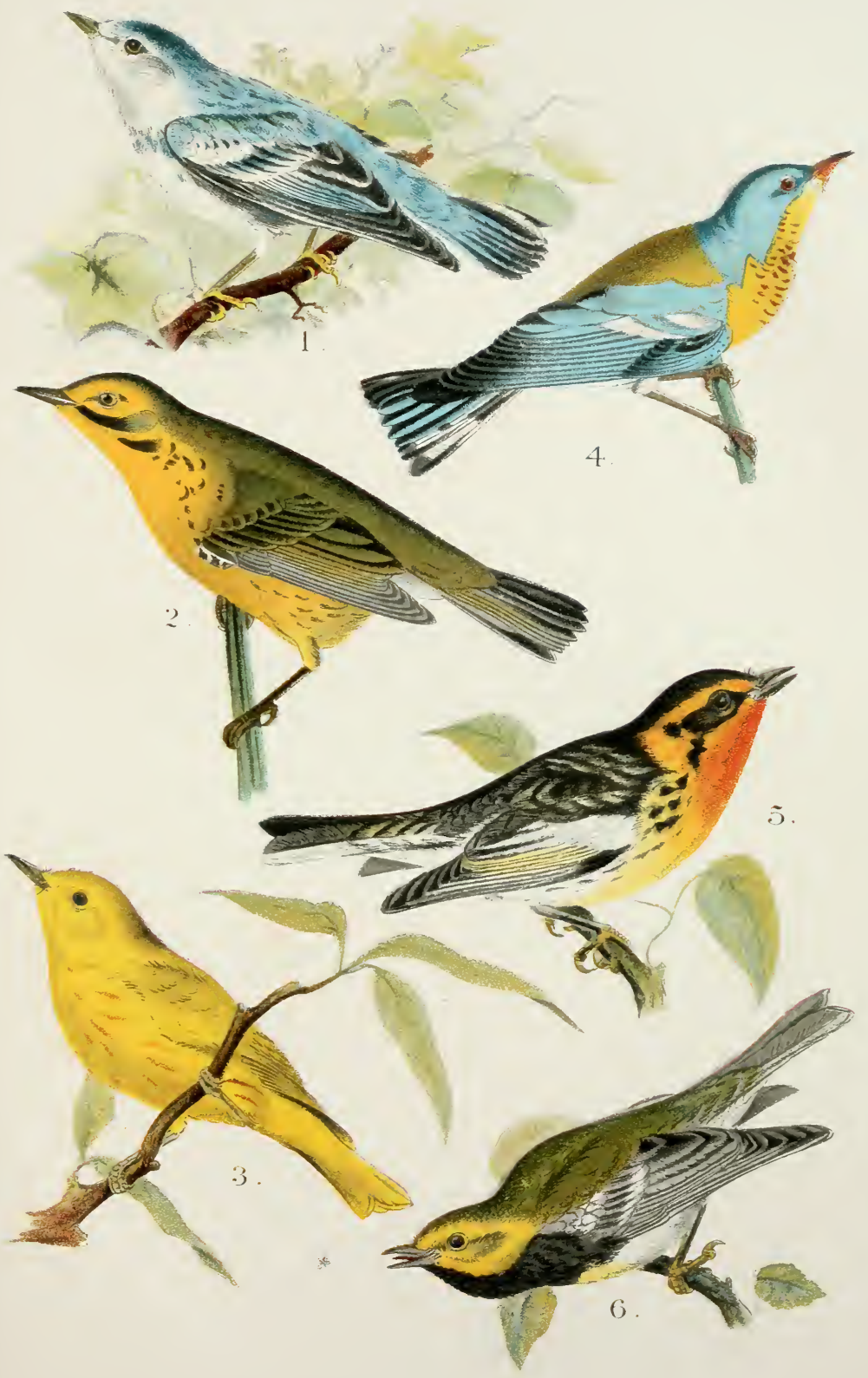

1. Cerulean Warbler.

2. Prairie Warbler.

4. Parula Warbler.

3. Yellow Warbler.

5. Blackburnian Warbler.

6. Black-Throated Green Warbler. 

early blooming thickets and leafy woods of the Altamaha; but the birds do not arrive in Pennsylvania and this part of New England before the Ist of May. About the close of August in the Northern, and by the middle of September in the Central States of the Union, or as soon as their second brood are capable of joining the migrating host, they disappear, probably in the twilight, and wing their way by easy stages to their tropical destination, passing through Louisiana in October and appearing at length about Vera Cruz, whence they spread their numerous host through tropical America to Guiana, Cayenne, St. Domingo, and other of the larger contiguous islands of the West Indies.

This is a very lively, unsuspicious, and almost familiar little bird, and its bright golden color renders it very conspicuous, as in pursuit of flitting insects it pries and darts among the blooming shrubs and orchards. It is particularly attached to willow-trees and other kinds in moist and shady situations, that afford this and other species a variety of small larvæ and caterpillars, on which they delight to feed. While incessantly and busily employed it occasionally mounts the twig, and with a loud, shrill, and almost piercing voice it earnestly utters, at short and irregular intervals, - 'tsh' 'tsh' ' $t$ sh' 'tsh' 'tshaïa, or tshe tshe tsh tshayia tshe tshe; this last phrase rather plaintive and interrogatory, as if expecting the recognition of its mate. Sometimes, but particularly after the commencement of incubation, a more extended and pleasingly modulated song is heard, as se te te tshitshoo, or tsh' tsh' tsh' tsheetshoo, 'tshe 'tshe 'tshe 'tshoo 'peetshee, and 'tshe 'tshe 'tshe'tshe 'tshaïa 'tship ŏ wāy ; the termination tender, plaintive, and solicitous. I have heard this note also sometimes varied to 'soit 'soit' soit'soit 'tship ă wee. The female sometimes sings nearly as well as the male, particularly about the time she is engaged in fabricating her nest. Although the song of these birds may be heard, less vigorously, to the month of August, yet they do not here appear to raise more than a single brood.

The nest, in Massachusetts, is commonly fixed in the forks of a barberry bush, close shrub, or sapling, a few feet from the 
ground; at oiher times, I have known the nest placed upon the horizontal branch of a hornbeam, more than $\mathrm{I}_{5}$ feet from the ground, or even 50 feet high in the forks of a thick sugarmaple or orchard tree. These lofty situations are, however, extraordinary; and the little architects, in instances of this kind, sometimes fail of giving the usual security to their habitation. The nest is extremely neat and durable; the exterior is formed of layers of Asclepias, or silk-weed lint, glutinously though slightly attached to the supporting twigs, mixed with some slender strips of fine bark and pine leaves, and thickly bedded with the down of willows, the nankeen-wool of the Virginian cotton-grass, the down of fern-stalks, the hair from the downy seeds of the buttonwood (Platanus), or the pappus of compound flowers; and then lined either with fine-bent grass (Agrostis), or down, and horse-hair, and rarely with a few accidental feathers. Circumstances sometimes require a variation from the usual habits of the species. In a garden in Roxbury, in the vicinity of Boston, I saw a nest built in a currant-bush, in a small garden very near to the house; and as the branch did not present the proper site of security, a large floor of dry grass and weeds was first made betwixt it and a contiguous board fence; in the midst of this mass of extraneous materials, the small nest was excavated, then lined with a considerable quantity of white horse-hair, and finished with an interior bed of soft cow-hair. The season proving wet and stormy, the nest in this novel situation fell over, but was carried, with the young to a safe situation near the piazza of the house, where the parents now fed and reared their brood. The labor of forming the nest seems often wholly to devolve on the female. On the roth of May I observed one of these industrious matrons busily engaged with her fabric in a low barberry bush, and by the evening of the second day the whole was completed, to the lining, which was made, at length, of hair and willow down, of which she collected and carried mouthfuls so large that she often appeared almost like a mass of flying cotton, and far exceeded in industry her active neighbor, the Baltimore, who was also engaged in collecting the same materials. Notwith- 
standing this industry, the completion of the nest, with this and other small birds, is sometimes strangely protracted or not immediately required. Yet occasionally I have found the eggs of this species improvidently laid on the ground. It is amusing to observe the sagacity of this little bird in disposing of the eggs of the vagrant and parasitic Cow Troopial. The egg, deposited before the laying of the rightful tenant, too large for ejectment, is ingeniously incarcerated in the bottom of the nest, and a new lining placed above it, so that it is never hatched to prove the dragon of the brood. Two instances of this kind occurred to the observation of my friend Mr. Charles Pickering; and in 1833 I obtained a nest with the adventitious egg about two thirds buried, the upper edge only being visible, so that in many instances it is probable that this species escapes from the unpleasant imposition of becoming a nurse to the sable orphan of the Cow Bird. She however acts faithfully the part of a foster-parent when the egg is laid after her own.

I have heard of two instances in which three of the Yellow Bird's own eggs were covered along with that of the Cow Blackbird. In a third, after a Blackbird's egg had been thus concealed, a second was laid, which was similarly treated, thus finally giving rise to a three-storied nest.

The Summer Yellow Bird, to attract attention from its nest, when sitting, or when the nest contains young, sometimes feigns lameness, hanging its tail and head, and fluttering feebly along, in the path of the spectator; at other times, when certain that the intrusion had proved harmless, the bird would only go off a few feet, utter a feeble complaint, or remain wholly silent, and almost instantly resume her seat. The male, as in many other species of the genus, precedes a little the arrival of his mate. Towards the latter end of summer the young and old feed much on juicy fruits, as mulberries, cornel berries, and other kinds. 


\section{MAGNOLIA WARBLER.}

\section{BLACK AND YELLOW WARBLER.}

\section{DENDROICA MACULOSA.}

CHAR. Male : upper parts'black, the feathers edged with olive; rump yellow; crown ash, bordered by black and white; beneath, rich yellow, thickly spotted on breast and sides with black; white patch on wings and on all but middle tail feathers. Female: similar, but colors duller, and back sometimes entirely olive. Length $5 \frac{1}{4}$ inches.

Nest. On a horizontal branch of spruce or fir, usually 3 to 6 feet from the ground, but sometimes higher; made of twigs and grass, lined with fine black roots.

Eggs. 4-5; creamy white, spotted with lilac and several shades of brown; $0.60 \times 0.50$.

This rare and beautiful species is occasionally seen in very small numbers in the Southern, Middle, and Northern States, in the spring season, on its way to its Northern breeding-places. In Massachusetts I have seen it in this vicinity about the middle of May. Its return to the South is probably made through the western interior, - a route so generally travelled by most of our birds of passage at this season; in consequence of which they are not met with, or but very rarely, in the Atlantic States in autumn. In this season they have been seen at sea off the island of Jamaica, and have been met with also in Hispaniola, whither they retire to pass the winter. Like all the rest of the genus, stimulated by the unquiet propensity to migrate, they pass only a few days with us, and appear perpetually employed in pursuing or searching out their active insect prey or larvæ; and while thus engaged, utter only a few chirping notes. The Magnolia has a shrill song, more than usually protracted on the approach of wet weather, so that the Indians bestow upon it the name of Rain Bird. According to Audubon, many of these birds breed in Maine and the British Provinces, as well as in Labrador, and extend their summer residence to the banks of the Saskatchewan. They have also a clear and sweetly modulated song.

Although rare in the United States, it appears, according to Richardson, that this elegant species is a common bird on the 
banks of the Saskatchewan, where it is as familiar as the common Summer Yellow Bird ( $S$. astiva), which it also resembles closely in its manners and in its breeding station, but is gifted with a more varied and agreeable song. It frequents the thickets of young spruce-trees and willows, flitting from branch to branch, at no great distance from the ground, actively engaged in the capture of winged insects, which now constitute its principal fare.

The Magnolia is not so rare a bird as Nuttall supposed, - indeed, it is common everywhere between the Atlantic and the eastern base of the Rockies, breeding in northern New England and in the northern portions of New York, Ohio, and Michigan, and thence to Labrador and Great Slave Lake. It also breeds "southward along the crests of the Alleghanies to Pennsylvania" (Chapman).

It winters in Central America, Cuba, and the Bahamas.

In its habits this bird combines the Creeper and the Flycatcher in true Warbler fashion, picking insects and larvæ from the crannies of the bark and from the leaves, and capturing on the wing the flying mites. The favorite nesting site is the border of a wood or an open pasture, though I have found nests in the deep forest, usually on the margin of an open glade.

The song is Warbler-like in its simplicity, yet is an attractive melody, the tones sweet and musical.

Nuttall's idea that the autumn route of migration taken by more northern breeding birds lies somewhere to the westward of New England, is not consistent with more recent observation; for while it is true that large numbers follow the valley of the Mississippi, some of them crossing to the Atlantic when south of the Alleghanies, - it has also been ascertained that immense flights of birds that breed in the interior go southward along the coast-line. Many species that are not seen in New England during the spring migration are abundant in the autumn. 


\section{CAPE MAY WARBLER.}

\section{DENDROICA TIGRINA.}

CHAR. Male: back yellowish olive, with darker spots; crown blackish; ear-patch chestnut; line from bill around the eyes black; rump yellow, wing-bars white and fused into one large patch; white blotches on three pairs of tail-feathers; beneath, yellow tinged with orange on chin and throat, spotted with black on breast and sides. Female : similar, but back grayish, and lacking distinctive marking on head; under parts paler ; spots on wings and tail smaller or obscure. Length about 5 inches.

Nest. In a pasture or open woodland, on low branch of small tree; a neat, cup-shaped structure, partially pensile, composed of twigs and grass fastened with spider's webbing, lined with horse-hair.

Eggs. 3-4; dull white or buffy, slightly specked, and wreathed around larger end with spots of brown and lilac; $0.70 \times 0.50$.

This very rare Warbler has only been seen near the swamps of Cape May by Edward Harris, Esq. ; near Moorestown, in New Jersey; and in the vicinity of Philadelphia, about the middle of May, - probably as a straggler on its way to some Northern breeding-place. Its notes and further history are yet unknown.

Since Nuttall wrote, we have learned a little more of the life history of this feathered beauty, though our knowledge of the bird's habits is still very limited. So rare is the bird that examples adorn but few collections; yet it has been seen occasionally throughout the Eastern States, and is reported by Thompson as "plentiful " along the Red River, in Manitoba. It has been traced north to Hudson Bay, and south (in winter) to the West Indies. The southern limit of its breeding area is probably about the $45^{\text {th }}$ parallel. The nest has been found by Mr. H. B. Bailey at Umbagog Lake, in Maine, and by Mr. James W. Banks near St. John, N. B.

Banks's nest, which I had the privilege of examining, was completely hidden amid the dense foliage of a clump of cedars, growing on an open hill-side, and quite close to a much-used thoroughfare. When first discovered it was unfinished, and the female was at work upon it. The male never appeared, nor was he heard in the vicinity, though the spot was visited frequently. After four eggs had been laid, female, nest, and eggs were "gathered."

The species had not been observed before near St. John, though Mr. Boardman had reported taking examples at St. Stephen's, and I had seen several at Edmundston, near the Quebec border. 
The Edmundston birds were seen in early June, and those secured proved to be males. As they sang with great frequency, they were easily discovered, and were invariably found amid the top branches of high spruce and fir trees on the crest of a hill. We were anxious to obtain a nest, and of course hunted through these high branches, little thinking that this coterie of Benedicts were making holiday while their industrious but neglected spouses were attending to housekeeping affairs down yonder in the valley. We learned the song, however, and discovered that its theme resembled somewhat the simple lay of the Nashville, though the voice is neither so full nor so sweet, recalling rather the thin, wiry tones of the Black and White Creeper.

\section{CANADIAN WARBLER.}

\section{Sylvania CANAdENSIS.}

CHAR. Male : above, bluish ash; crown marked with black; line from bill around the eyes, yellow; line from beneath the eyes to sides of breast black; under parts yellow spotted with black, the spots forming a line or crescent across the breast; throat unspotted. Female and young: similar but lacking black on head; crescent on breast less distinct. Length 5 to $5 \frac{3}{4}$ inches.

Nest. On the ground, sometimes near border of a stream or by a moist meadow, placed on side of mound or among upturned roots of a tree; composed of grass and stems, lined with hair.

Eggs. 4-5; white or creamy, spotted, chiefly around the larger end, with brown and lilac; $0.70 \times 0.50$.

This is a rare summer species in the Atlantic States, appearing singly, and for a few days only, on the passage north or south in the spring or autumn. These birds breed in Canada and Labrador, and are more abundant in mountainous interior, - the route by which they principally migrate. They winter in the tropical regions, are then silent, and, like the rest of their tribe, very active in darting through the branches after insects.

Audubon found this species breeding in the Great Pine Forest of the Pokono in Pennsylvania, as well as in Maine, the British Provinces, and Labrador. They have a short, unattractive note in the spring, and in the mountains where they dwell they have a predilection for the shady borders of streams where laurels grow. 
The Canadian Warbler is common during the migrations, from the Atlantic to the Mississippi, and though breeding chiefly north of $43^{\circ}$, some pairs nest in Massachusetts, New York, southern Ontario, and Illinois. It has been taken in Labrador and is common in Manitoba. It winters in Central America.

\section{YELLOW-THROATED WARBLER.}

\section{DENDROICA DOMINICA.}

CHAR. Above, grayish ash; forehead and sides of head, black; line from nostril to hind neck, yellow; patch on side of neck, white; wingbars white; outer tail feathers with white patches; beneath, yellowish white; chin and throat rich yellow; sides streaked with black. Length $4 \frac{3}{4}$ to $5 \frac{3}{4}$ inches.

Nest. In an open grove or the edge of heavy woods, on top of horizontal branch or at the forks of a limb, or "concealed in pendant moss," 20 to 90 feet from the ground; made of grass-weed stems, strips of bark, and moss, lined with vegetable fibre, horse-hair, or feathers.

Eggs. 3-5; white, tinged with green, spotted around the larger end with brown and lilac; $0.70 \times 0.50$.

These elegant and remarkable birds reside in the West Indies, and also migrate in considerable numbers into the southern parts of the United States, particularly Louisiana and Georgia, whence indeed they only absent themselves in the two inclement months of December and January. They are seen in February in Georgia. but very rarely venture as far north as Pennsylvania. The song is pretty loud and agreeable, according to Latham and Wilson, resembling somewhat the notes of the Indigo Bird. In the tropical countries they inhabit, this delicate music is continued nearly throughout the year, and participated also by the female, though possessed of inferior vocal powers. The bird appears to have many of the habits of the Creeping Warbler ( $S$. varia), running spirally around the trunks of the pine-trees, on which it alights, and ascending or descending in the active search of its insect fare.

The sagacity displayed by this bird in the construction and situation of its nest is very remarkable. This curious fabric is 
suspended to a kind of rope which hangs from tree to tree, usually depending from branches that bend over rivers or ravines. The nest itself is made of dry blades of grass, the ribs of leaves, and slender root-fibres, the whole interwoven together with great art ; it is also fastened to, or rather worked into, the pendant strings made of the tough silky fibres of some species of Echites, or other plant of that family. It is, in fact, a small circular bed, so thick and compact as to exclude the rain, left to rock in the wind without sustaining or being accessible to any injury. The more securely to defend this precious habitation from the attacks of numerous enemies, the opening, or entrance, is neither made on the top nor the side, but at the bottom; nor is the access direct, for after passing the vestibule, it is necessary to go over a kind of partition, and through another aperture, before it descends into the guarded abode of its eggs and young. This interior lodgment is round and soft, being lined with a kind of lichen, or the silky down of plants.

This species is confined chiefly to the South Atlantic States, though occasionally a few wander to New York, Connecticut, and Massachusetts. It winters in Florida and Central America.

Note. - The Sycamore WARbler (D. dominica albilora) differs from the type in being smaller (length $4 \frac{1}{2}$ to $51 / 2$ inches) and in having the line over the eyes white, instead of yellow. It occurs along the Mississippi valley north to southern Illinois and eastward to Ohio, where it is common, and has been taken also in South Carolina and Florida.

It winters in Central America. 


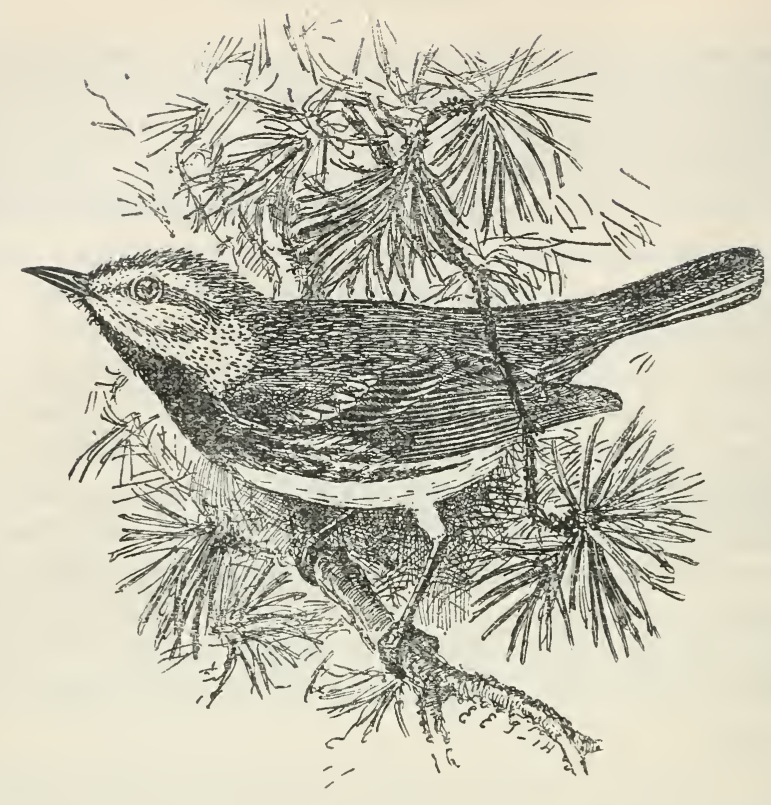

\section{BLACK-THROATED GREEN WARBLER.}

\section{DENDROICA VIRENS.}

Char. Male in spring : above, bright olive; line on sides of head rich yellow; wings and tail dusky; wing-bars and outer tail-feathers white; beneath, white tinged with yellow; throat and chest rich black. Male in autumn, female, and young: similar, but black of throat mixed with yellow, sometimes obscured. Length 5 to $5^{\mathrm{I} / 4}$ inches.

Nest. On the border of heavy woods, in fork of coniferous tree 30 to 50 feet from the ground; of twigs, grass, etc., lined with hair and down.

Eggs. 3-4; white or creamy white wreathed around larger end with spots of brown and lilac; $0.65 \times 0.50$.

This rather rare species arrives from its tropical winterquarters in Pennsylvania towards the close of April or beginning of May. About the $\mathrm{I} 2$ th of the latter month it is seen in this part of Massachusetts; but never more than a single pair are seen together. At this season a silent individual may be occasionally observed, for an hour at a time, carefully and ac- 
tively searching for small caterpillars and winged insects amidst the white blossoms of the shady apple-tree; and so inoffensive and unsuspicious is the little warbler that he pursues without alarm his busy occupation, as the spectator within a few feet of him watches at the foot of the tree. Early in October these birds are seen in small numbers roving restlessly through the forest, preparatory to their departure for the South.

Though the greater part of the species probably proceed farther north to rear their young, a few spend the summer in the Middle and Northern States; but from their timorous and retiring habits it is not easy to trace out their retreats at the period of breeding. In the summer of 1830 , however, on the 8 th of June, I was so fortunate as to find a nest of this species in a perfectly solitary situation on the Blue Hills of Milton. The female was now sitting, and about to hatch. The nest was in a low, thick, and stunted Virginia juniper. When I approached near to the nest the female stood motionless on its edge and peeped down in such a manner that I imagined her to be a young bird. She then darted directly to the earth and ran; but when, deceived, I sought her on the ground, she had very expertly disappeared, and I now found the nest to contain 4 roundish eggs, white, inclining to flesh-color, variegated, more particularly at the great end, with pale, purplish points of various sizes, interspersed with other large spots of brown and blackish. The nest was formed of circularly entwined fine strips of the inner bark of the juniper and the tough white fibrous bark of some other plant, then bedded with soft feathers of the Robin, and lined with a few horse-hairs and some slender tops of bent-grass (Agrostis). The male was singing his simple chant at the distance of a quarter of a mile from the nest, and was now nearly in the same dark wood of tall oaks and white pines in which I had first heard him a fortnight before. This simple, rather drawling, and somewhat plaintive song, uttered at short intervals, resembled the syllables 'te dé teritscá, sometimes te derisca, pronounced pretty loud and slow, and the tones proceeded from high to low. In the intervals he was perpetually busied in catching small cynips and 
other kinds of flies, keeping up a smart snapping of his bill, almost similar to the noise made by knocking pebbles together. This quaint and indolent ditty I have often heard before in the dark and solitary woods of west Pennsylvania; and here, as there, it affords an agreeable relief in the dreary silence and gloom of the thick forest. This note is very much like the call of the Chicadee, and at times both are heard amidst the reigning silence of the summer noon. In the whole district of this extensive hill or mountain, in Milton, there appeared to exist no other pair of these lonely Warblers but the present. Another pair, however, had probably a nest in the vicinity of the woods of Mount Auburn in Cambridge, and in the spring of the present year (I83I) several pairs of these birds were seen for a transient period.

Nuttall was not the only one of the older writers who expressed the opinion that this and other species of the family were less abundant than more modern observers have found them. Wilson and Audubon made similar statements.

This Warbler is now known to be a common bird throughout these Eastern States, and may be found, in summer, in any coniferous forest in Massachusetts, and thence northward to the furcountries and westward to the plains. It breeds also, sparingly, in southern New England, northern Ohio, Illinois, etc., and "along the Alleghanies to South Carolina," and winters in the West Indies and Central America.

\section{BLACKBURNIAN WARBLER.}

\section{DENDROICA BLACKBURNIE.}

CHAR. Male : above, black, back streaked with whitish; sides of head black; crown patch, line over eye, and entire throat and breast rich orange or flame color; belly yellowish white; sides streaked with black; large white patches on wings; outer tail-feathers nearly all white. Female : similar, but black replaced by grayish brown, and orange by dull yellow; white patches on wings and tail less conspicuous. Length $51 / 4$ to $5 \frac{1}{2}$ inches.

Nest. Usually in coniferous woods, saddled on horizontal limb of pine or hemlock, 20 to 40 feet from the ground; composed of twigs, roots, and shreds of bark mixed with vegetable down, lined with feathers and hair.

Eggs. 4; white, often tinged with green, spotted, chiefly around larger end, with brown and lilac; $0.70 \times 0.50$. 
The Blackburnian Warbler is one of the rarest and most beautiful species of the genus, which from the Ist to the I $5^{\text {th }}$ of May, or sometimes later, pays a transient visit to the Middle and Northern States, on its way to its remote boreal place of retirement for the breeding season. It is still more rarely seen in the autumn, about the month of September, in its passage to tropical America, where it winters, as may be presumed, from its occurrence late in autumn about Vera Cruz, according to Mr. Bullock. It is an exceedingly nimble insect-hunter, keeping towards the tops of trees, scarcely uttering even an audible chirp, and at this season no song as far as is yet known.

On the Magdalene Islands in the Gulf of St. Lawrence, in June, Audubon remarks that he heard the song of this beautiful warbler, consisting of five or six loud notes, which it uttered from the branches of a fir-tree while engaged in quest of its prey. The nest found in Nova Scotia was made externally of coarse materials and lined with silky fibres and delicate strips of bark, over which lay a thick bed of feathers and horse-hair. It was found in a small fork of a tree, 5 or 6 feet from the ground, near a brook. Dr. Brewer also found a nest of this species in Massachusetts.

The very rare adult of the Hemlock Warbler was found by Wilson in the Great Pine Swamp in Pennsylvania, and appeared to take up its residence in the dark hemlock-trees of that desolate region. It was very lively and active, climbing among the branches and hanging from the twigs like a Titmouse. It darted after flies to a considerable distance, and beginning with the lower branches, hunted with regularity upwards to the summit of the tree, and in this way it proceeded very industriously to forage through the forest till satisfied. At intervals it stopped an instant to warble out a few low and sweet notes, probably for the recognition or company of its mate, which the discoverer, however, did not see.

The nest of this species, according to Audubon, who discovered it in the Great Pine Swamp, was made in a hemlock or 
spruce tree at a considerable elevation. Lichens, dry leaves of the hemlock, and slender twigs formed the exterior; it was then lined with hair or fur and the feathers of the Ruffed Grouse. He afterwards met with this species in Maine and Newfoundland.

Nothing is more remarkable in the history of this species than the rarity of the adult and the abundance of the young birds; these last, which we have long known as the Autumnal Warbler, appear in gregarious flocks in the larger solitary forests of Massachusetts as early as the 2 oth of July, assembled from the neighboring districts probably, in which they have been reared. They remain there usually until the middle of October, at which time they are also seen in the Middle States. They feed on small insects and berries. Late in the season, on a fine autumnal morning, troops of them may be seen in the fields and lanes, sometimes descending to the ground, and busily employed in turning over the new fallen leaves, or perambulating and searching the chinks of the bark of the trees, or the holes in the posts of the fence, in quest of lurking moths and spiders; and while thus eagerly engaged, they are occasionally molested or driven away by the more legitimate Creepers or Nuthatches, whose jealousy they thus arouse by their invasion. Earlier in the season they prey on cynips, flies, and more active game, in pursuit of which they may be seen fluttering and darting through the verdant boughs of the forest trees. One of these little visitors, which I obtained by its flying inadvertently into an open chamber, soon became reconciled to confinement, flew vigorously after houseflies, and fed greedily on grasshoppers and ivy berries (Cissus hederacea); at length it became so sociable as to court my acquaintance and eat from my hand. Before I restored it to liberty, its occasional tweet attracted several of its companions to the windows of its prison. At this time the bird is destitute of song, and only utters a plaintive call of recognition.

Nuttall followed Wilson and Audubon in considering the young Blackburnians a different species, naming it the "Hemlock War. bler." I have given above Nuttall's account of the two. 
The Blackburnian is rather common in the Atlantic States and westward to the Plains, breeding chiefly north of $45^{\circ}$, and sparingly in Massachusetts and Connecticut, and southward along the crests of the Alleghanies. It winters from the Bahamas and eastern Mexico southward.

Many Canadian observers have considered this Warbler rather rare, but the opinion has probably arisen from the secluded habits of the bird while in its summer home. It shows a preference for the higher branches, and its favorite haunts are amid the deeper forests where the pine and hemlock flourish.

\section{CHESTNUT-SIDED WARBLER.}

\section{DENDROICA PENNSYLVANICA.}

CHAR. Male : back black, streaked with olive of grayish or yellowish tint; crown yellow; sides of head white, enclosing a patch of black ; sides of neck and entire under parts white; sides streaked with chestnut, which extends from neck to flanks; wing-bars and blotches on tail white. Female : similar, but colors duller. Young: upper parts bright olive; wing-bars yellowish ; under parts white. Length $43 / 4$ to $5 \frac{1}{4}$ inches.

Nest. On the edge of an open woodland or the margin of a moist meadow, in low tree or bush; composed of grass and strips of bark fastened with insect silk, and lined with grass or leaves or hair.

Eggs. 4-5; white or creamy, spotted, chiefly around the larger end, which is sometimes wreathed, with reddish brown and lilac; $0.68 \times 0.50$.

This rare and beautiful Sylvia, which probably winters in tropical America, appears in the Middle and Northern States early in May on its way north to breed; it is also seen in the spring in Canada and around Hudson's Bay. A few pairs remain, no doubt, to rear their young in secluded mountainous situations in the Northern States, as on the $22 \mathrm{~d}$ of May, 1830, a pair appeared to have fixed their summer abode near the summit of the Blue Hills of Milton. The note of the male was very similar to that of the Summer Yellow Bird, being only a little louder, and less whistling; it resembles 'tsh 'tsh 'tsh 'tshyza, given at about an interval of half a minute, and answered by his mate at some distance, near which, it is probable, there was a nest. He appeared to be no way suspicious of our approach; his restlessness was sublued, and he quietly sat near the same low bushes, amusing himself and his consort, for an hour at a time, with the display of his lively and simple 
ditty. On their first arrival, previous to pairing, these birds are like the rest of the genus, restless, and intently engaged in the chase of insects amidst the blossoms and tender leaves; they likewise pursue common and green bottle flies with avidity and success. On the $27_{\text {th }}$ of June, I 83 I, I observed a pair selecting food for their young, with their usual address and activity, by the margin of a bushy and secluded swamp on the west side of Fresh Pond, in this vicinity; but I had not the good fortune to discover the nest. I have, however, since, I believe, discovered the nest of this bird, in a hazel copse in a wood in Acton, in this State. It is fixed in the forked twigs of a hazel about breast high. The fabric is rather light and airy, being made externally of a few coarse blades and stalks of dead grass, then filled in with finer blades of the same, the whole matted and tied with caterpillar's silk, and lined with very slender strips of brown bark and similar white-pine leaves. It appeared to have been forsaken before its completion, and the eggs I have never seen.

In the woods around Farranville, on the Susquehanna, within the range of the Alleghany chain, in the month of May, I 830, I saw and heard several males in full song, in the shady forest trees by a small stream, and have no doubt of their breeding in that situation, though I was not fortunate enough to find a nest.

This species is now a common summer resident of New England and the settled portions of Canada, and occurs westward to the Plains. It breeds in numbers as far south as the fortieth parallel, and regularly, though sparingly, on the elevated lands southward to Georgia; is not an uncommon summer visitor to the Maritime Provinces, and is quite common in Manitoba. It winters southward to the Bahamas and Central America. 


\section{BAY-BREASTED WARBLER.}

\section{Dendroica Castanea.}

CHAR. Male : back grayish olive, streaked with black; forehead and cheeks black ; sides of neck buffy ; crown, throat, breast, and sides chestnut; remainder of under parts buffish; wing-bars and patches on tail white. Female : above, olive streaked with black; beneath, buffy, sides and breast tinged with dull rufous. Length $5^{\mathrm{T}} / 2$ to 6 inches.

Vest. In an open woodland, on horizontal branch of coniferous tree Io to 20 feet from the ground; of twigs, shreds of bark, grass roots, and moss, lined with fine roots, moss, or pine-needles.

Eggs. 3-6 (usually 4); white, with blue tint, or bluish green, spotted with reddish brown; $0.70 \times 0.50$.

This is a still rarer and more transient visitor than the last. It arrives in Pennsylvania from the South some time in April or about the beginning of May, and towards the $\mathrm{I} 2$ th or $\mathrm{I}_{5}$ th of the same month it visits Massachusetts, but seldom stays more than a week or ten days, and is very rarely seen on its return in the autumn. Audubon once observed several in Louisiana late in June, so that it probably sometimes breeds in very secluded places without regularly proceeding to the northern regions. It is an active insect-hunter, and keeps much towards the tops of the highest trees, where it darts about with great activity, and hangs from the twigs with fluttering wings. One of these birds, which was wounded in the wing, soon became reconciled to confinement, and greedily caught and devoured the flies which I offered him; but from the extent of the injury, he did not long survive. In habits and manners, as well as markings, this species greatly resembles the preceding.

This Warbler is exceptional in being more abundant in New England in spring than in autumn. Mr. McIlwraith reports that the same rule obtains in Ontario, but Dr. Wheaton considered that in Ohio the birds were more numerous during the autumn; and these apparently conflicting statements suggest an interesting phase in the question of migration routes.

The bird is common as a summer resident in the northern portions of New England, New York, and Michigan, though rather rare 
in New Brunswick, Quebec, and Ontario. The most southern point at which it has been found breeding is Chicarua, N. H., in latitude $44^{\circ}$, where Mr. Frank Bolles obtained a nest in 1890 . The species ranges north to Hudson Bay, and south to Central America.

\section{BLACK-POLL WARBLER.}

\section{DENDROICA STRIATA.}

CHAR. Above, grayish olive thickly streaked with black; top of head black; cheeks and entire under parts white; sides streaked with black; wing-bars and tail-patches white. Length $5^{1 / 2}$ to $5 \frac{3}{4}$ inches.

Nest. In an evergreen forest on low branch (sometimes on the ground) ; of grass, roots, twigs, and lichens; lined with grass covered with white feathers.

Eggs. 4-5; white, with various tints (usually pale pink or creamy), more or less spotted with reddish brown and lilac, - often dark brown and olive gray; $0.75 \times 0.55$.

This rather common and well-marked species is observed to arrive in Pennsylvania from the South about the 2 oth of April, but in Massachusetts hardly before the middle of May; it returns early in September, and appears to feed wholly on insects. In the Middle States it is confined chiefly to the woods, where, in the summits of the tallest trees, it is seen in busy pursuit of its favorite prey. On its first arrival it keeps usually in the tops of the maples, darting about amidst the blossoms. As the woods become clothed with leaves, it may be found pretty generally as a summer resident; it often also seeks the banks of creeks and swamps, in which situations it probably passes the breeding season. In this vicinity the Black-poll is a familiar visitor in the lowest orchard-trees, where it feeds on cankerworms and other small caterpillars, as well as flies of different kinds, etc. At this time, towards the month of June, it is no longer a restless wanderer, but having fixed upon its station for the summer, it now begins, in a humble way, to display its musical talents in the cherished and constant company of its faithful mate. This note, uttered at intervals of half a minute, is like the sound of $t s h$ ' tsh tsh tshé tshé, from low to high, but 
altogether so shrill and slender as to sound almost like the faint filing of a saw. This species extends its migrations to Newfoundland, according to Pennant. In the month of June, Audubon found the nest in Labrador placed about 3 feet from the ground, in the fork of a small branch, close to the main stem of a fir-tree. It was formed of green and white moss and lichens, intermixed with coarse dried grass; within this was a layer of bent-grass, the lining, of dark-colored dry moss, looked like horse-hair, and was arranged in a circular direction with great care; lastly was a thick bed of large soft feathers, - some of them were from Ducks, but most of them from the Willow Grouse. It contained 4 eggs.

The Black-poll breeds sparingly in northern New England, New Brunswick, and northern Michigan, building chiefly beyond the Laurentian hills, in Quebec and Ontario ; though Dr. L. B. Bishop found it breeding in numbers on the Magdalen Islands, and Mr. J. P. Norris took a number of nests on Grand Menan. It ranges northward to the Barren Grounds and to Alaska, and winters in northern South America.

\section{PINE WARBLER.}

\section{DENDROICA VIGORSII.}

CHAR. Above, olive ; beneath, yellow, paler (or white) on belly ; wing. bars and blotches on outer tail-feathers, white. Length $5^{1 / 4}$ to $5 \frac{314}{4}$ inches.

Nest. Usually in evergreen wonds, on horizontal bough of pine or cedar 30 or 40 feet from the ground; of weed stems, shreds of bark, and leaves fastened with insect silk, lined with hair and feathers.

Eggs. 4-5; dull white or gray, spotted with brown and lilac; 0.70 $\times 0.50$.

This common species, to the commencement of winter, inhabits all parts of the United-States, and probably extends its northern migrations to the forests of Newfoundland. It arrives in Pennsylvania at the close of March and beginning of April, and soon after is seen in all parts of New England, amidst the pine and juniper forests, in which it principally 
resides. Both the old and young remain with us till nearly the close of October; stragglers have even been seen in mid-winter in the latitude of $43^{\circ}$. In winter they rove through the pine forests and barrens of the Southern States in companies of 20 to 50 or more, alighting at times on the trunks of the trees, and attentively searching them for lurking larvæ, but are most frequently employed in capturing the small insects which infest the opening buds of the pine, around which they may be seen perpetually hovering, springing, or creeping, with restless activity ; in this way they proceed, from time to time, foraging through the forest; occasionally, also, they alight on the ground in quest of worms and grubs of various kinds, or dart irregularly after hovering flies, almost in the manner of the Flycatchers. In these states they are by far the most numerous of all the Warblers. In the month of March they already began to show indications for pairing, and jealous contests ensued perpetually among the males. The principal body of the species probably remain the year round in the Southern forests, where I saw them throughout the winter; great numbers are also bred in the Northern States. In summer their food is the eggs and larvæ of various insects, as well as flies or cynips, caterpillars, coleoptera, and ants. In autumn, the young frequent the gardens, groves, and orchards, feeding likewise on berries of various kinds, as on those of the cornel, wild grape, and five-leaved ivy; at this season they are very fat, and fly and forage in families. They now only utter a shrill and plaintive chip. I have had a male Pine Warbler, domesticated for a short time; he fed gratefully, from the instant he was caught, upon flies, small earthworms, and minced flesh, and was so tame and artless as to sit contented on every hand, and scarcely shift himself securely from my feet. On offering him drink he walked directly into the vessel, without using the slightest precaution or exhibiting any trace of fear. His tship and manner in all respects were those of the Autumnal Warbler.

The song of the Pine Warbler, though agreeable, amidst the dreary solitude of the boundless forests which he frequents, has 
but little compass or variety; sometimes it approaches the simplest trill of the Canary, but it is commonly a reverberating, gently rising, or murmuring sound, like $e r^{\prime} r{ }^{\prime} r{ }^{\prime} r r^{\prime} r r^{\prime} r a ́ h$; or, in the spring, 'twe 'twe 'tw 'tw' tw' tw' 'tw, and sometimes like 'tsh'tsh'tsh'tw'tw'tw'tw'tw; when harkened to some time, there is a variation in the cadence, which, though rather feeble at a distance, is not unpleasant, as the little minstrel tunes his pipe during the heat of the summer day, while he flits gently and innocently fearless through the shady boughs of the pine or cedar in perpetual quest of his untiring prey. This song is commonly heard at a considerable distance from his mate and nest, from whom he often widely strays, according to the success of his precarious pursuit. As the sound of the warble varies from slender to high or low, it is often difficult to discover the retreat of the little busy musician, which appears far or near with the modulation of his almost ventriloquous note. The female likewise tunes, at times, her more slender lay in a wiry tone, almost like that of the S. varia, in early spring.

About the 7 th of June, I830, I discovered a nest of this species in a Virginian juniper, near Mount Auburn, in this vicinity, at the height of about 40 feet from the ground. It was firmly fixed in the upright twigs of a close branch. The nest was thin, but very neat; the principal material was the wiry old stems of the slender knot-weed (Polygonum tenue), circularly interlaced, and connected externally with rough linty fibres of some species of Asclepias, and blended with caterpillar's webs. The lining was made of a few hog's bristles, slender root-fibres, a mat of the down of fern-stalks, and one or two feathers of the Robin's breast, - a curious medley, but all answering the pose of warmth and shelter for the expected brood. I saw several of these nests, which had at different times been thrown to the ground, and in all, the wiry grass and general material were the same as in the one now described; and this, of course, is entirely different from that given by Wilson on the authority of Mr. Abbot. The nest there mentioned is nothing more than the usual pendulous fabric of the Red-eyed Warbling Flycatcher. The eggs in ours were 4, and, advanced towards vOL. I. - 16 
hatching, they were white, with a slight tinge of green, very full of small pale brown spots, somewhat more numerous towards the larger end, where they appear connected or aggregated around a purplish ground. The female made some little complaint, but almost immediately resumed her seat, though 2 of the eggs were taken away; the male made off immediately, and was but seldom seen near the place.

The Pine Warbler is a common summer resident of New England, but I seldom saw it in New Brunswick, and can find no evi. dence of its occurrence in Nova Scotia. Mr. Neilson thinks it uncommon in the vicinity of Quebec city, and Mr. McIlwraith makes a similar report for Ontario, while Mr. Thompson reports it common in Manitoba. It winters in the Southern States.

\section{PRAIRIE WARBLER.}

\section{DENDROICA DISCOLOR.}

CHAR. Above, olive; back with patch of red spots; forehead, line over the eyes, wing-bars, and entire under parts rich yellow ; black streak on sides of head; sides spotted with black; 3 outer tail-feathers with broad patches of white. Length $4 \frac{1}{2}$ to 5 inches.

Nest. In open woodland or old meadow, on small tree or bush; neatly and compactly made of grass and vegetable fibre lined with hair or feathers. 0.47 .

Eggs. 4-5; white, spotted around larger end with brown; $0.63 \times$

These birds, rare in the Atlantic States, appear to be somewhat more common in the solitary barrens of Kentucky and the open woods of the Choctaw country. Here they prefer the open plains thinly covered with trees; and without betraying alarm at the visits of a spectator, leisurely pursue their search for caterpillars and small flies, examining among the leaves or hopping among the branches, and at times descending pretty near, and familiarly examining the observer, with a confidence and curiosity seldom witnessed in these shy and retiring species. Such was the conduct of a male bird in this vicinity, on the $4^{\text {th }}$ of June, whom I discovered by his slender filing notes, which were uttered every half minute, and like those of 
the Black-poll Warbler resembled the suppressed syllables 'tsh 'tsh 'tsh 'tshéa', beginning low, and gradually growing louder, having nearly the same slender whistle as that species, though somewhat stronger. The pair were busily engaged collecting flies and larvæ from a clump of young locust-trees in the woods of Mount Auburn, and occasionally they flitted among the Virginian junipers; the familiar visit of the male appeared for the purpose of discovering my intentions near the nest, about which he was naturally solicitous, though he made his approaches with the appearance of accident. The female was more timid; yet while I was still engaged in viewing this little interesting and secluded pair, she, without any precaution or concealment, went directly to the nest in the forks of a low barberry bush near by, and when there, she sat and looked at me some time before she removed. She made, however, no pretences to draw me away from the spot, where she was sitting on 4 eggs, of which I took away 2 ; her approaches to the nest were now more cautious, and she came escorted and encouraged by the presence of her mate. Two eggs were again soon added, and the young brood, I believe, reared without any accident.

The nest was scarcely distinguishable from that of the Summer Yellow Bird, and quite different from the nests described by Wilson and Audubon. My opportunity for examination, so long continued, seemed to preclude the possibility of error in the investigation; neither can I compare the slender note of this species to any whirring sound, which would more nearly approach to the song of the Pine Warbler. The Prairie Warbler visits Cambridge about the first or second week in May, and according to the observations of my friend Mr. Cooper, is seen probably about the same time in the vicinity of New York in small numbers and in pairs, and retires to winter in the West Indies about the middle of September.

This species is now considered common in Massachusetts, though it has not been taken farther northward. It occurs in Michigan, but not in Ontario, and breeds southward to Florida. It winters in southern Florida and the West Indies. 


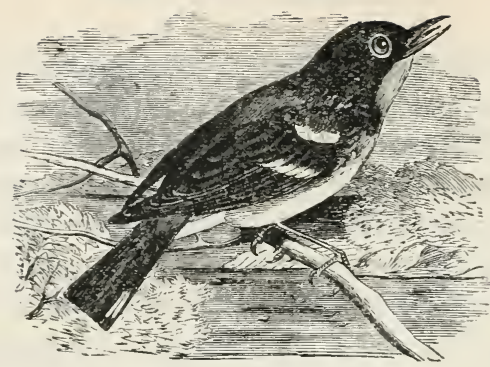

PARULA WARBLER.

BLUE YELLOIV-BACKED WARBLER.

\section{COMPSOTHLYPIS AMERICANA.}

CHAR. Male: above, bright ashy blue, an olive patch on the back; throat and breast yellow, a patch of rich brown on the breast; belly white; wings with 2 broad white bars; white patches on inner web of outer tail-feathers. Female : similar, but colors duller and the patches on back and breast obscure or absent. Length $4^{1 / 2}$ to $4 \frac{3 / 4}{4}$ inches.

Nest. In moist woodland or on border of swamp; usually in a bunch of "beard-moss" (usnea) hanging from the trunk or branch of a tree Io to 40 feet from the ground, and composed of threads of the moss and fine grass or hair compactly woven; sometimes lined with pine-needles or hair.

Eggs. 3-7 (usually 4); white or creamy, thickly spotted with several shades of reddish brown; $0.65 \times 0.45$.

This remarkable species visits the Middle and Northern States about the Ist to the $15^{\text {th }}$ of May, and is seen again early in October on its way to the West Indies (St. Domingo and Porto Rico), whither it retires at the approach of winter. A few, according to Catesby, pass the whole year in South Carolina. It is very abundant in the summer in the woods of Kentucky, is active and restless on its first arrival, and frequents the summits of the highest trees, being particularly fond of the small caterpillars and flies of various kinds which are, in the early part of spring, attracted to the open blossoms and tender shoots. It also possesses in some degree the creeping and prying habits of the Titmouse, to which genus it it was referred by Linnæus and Pennant. Entering the south- 
ern extremity of the Union by the first approach of spring, it is now seen searching for its insect food on shrubs and plants in moist places, by the borders of lakes and streams. In this vicinity it is not common; but as it was singing as late as the $22 \mathrm{~d}$ of May in the woody solitude of the Blue Hills of Milton, it must undoubtedly breed there.

The notes of this species resemble those of the Prairie Warbler in some respects, though sufficiently different; the tones, rising from low to high, are rather weak and insignificant.

In Nuttall's day this dainty bird was named "Party-colored Warbler" and "Finch Creeper." It is a rather common summer resident in Massachusetts, Connecticut, and Rhode Island, and breeds northward to the Gulf of St. Lawrence. The nests have been found also in northern Ohio and southern Illinois, and in winter the birds range through southern Florida and among the more northern West Indies.

The Parula is associated in my mind with secluded woods on cool and shaded hill-sides bordering a stream, and the song comes to me from amid the top branches of tall trees, - birch and poplar. It is an attractive song, though it has little theme, - merely a rapid trill of some twenty sibilant notes delivered with a rising inflection; but the tones are sweet, and the effect is pleasing. The song is clearly an outburst of joyous emotion.

\section{BLACK-THROATED BLUE WARBLER.}

\section{DENDROICA ĊRULESCENS.}

CHAR. Male : above, dull blue, back sometimes streaked with black; sides of head, throat, and chest rich black; remainder of under parts white; white spot on wing; tail with large white blotches. Female: above, dull olive; beneath, dull greenish yellow; white spot on wing. Length 5 to $5^{\mathrm{T} / 2}$ inches.

Nest. In deep woods amid thick underbrush or on high branch; of grass, twigs, vines, and lichens, fastened with insect silk, lined with roots and hair.

Eggs. 3-5; white, with green or buff tint, often, when fresh, tinged with rosy, marked with large spots of reddish brown; $0.70 \times 0.50$.

Of this uncommon species we know very little. It appears only as a transient visitor in the month of April, in the Middle 
States, and after staying to feed for a week or ten days, it proceeds to its northern breeding-place in the wilds of Canada, of which we are wholly ignorant. In November I have observed a few on their return to the South, and according to Vieillot, they winter in St. Domingo and other of the larger West India islands.

Near Farranville, on the Susquehanna, within the range of the Alleghany Mountains, in the month of May, I saw and heard several pairs of this rare species in the shady hemlocktrees. The males were uttering their slender, wiry, and very peculiar notes, while busily engaged in foraging for insects, and seemed, by being paired, to prepare for incubation.

The Pine Swamp Warbler (Sylvia sphagnosa) is now considered only as the young of this species, of which, however, I think there yet remains some doubt.

The history of this species need no longer remain a mystery, for while not abundant, its nesting habits may be studied in any suitable locality in northern New England or northern New York, and westward to the Plains, or along the higher altitudes of the Alleghanies as far down as Georgia; though the major portion of the flocks pass on to the Canadian faunal area before stopping to build.

I did not meet with many examples in New Brunswick, and $\mathrm{Mr}$. Neilson thinks it rare near Quebec city; but Mr. Wintle calls it common near Montreal, and the Ontario observers also regard it as common. It winters in Florida as well as in the West Indies.

\section{KENTUCKY WARBLER.}

\section{GEOTHLYPIS FORMOSA.}

Char. Above, olive; crown and sides of head and neck, black; line from nostril to and around the eye yellow; beneath, yellow, the sides shaded with olive. Length $5^{1 / 2}$ to $5 \frac{3 / 4}{4}$ inches.

Nest. On the ground, in rather thick woods; a bulky affair of loosely laid leaves and grass, lined with vegetable down, roots, or hair.

Eggs. 4-6; white or creamy, spotted with lilac and several shades of brown; $0.73 \times 0.56$

This beautiful species, first described by Wilson, frequents the dark forests of the southwestern parts of the Union, being 
particularly abundant in Louisiana, and not uncommon in Kentucky and Tennessee, and from thence inhabiting throughout the country to the estuaries of the Mississippi. It frequents low, damp woods and the desolate borders of the lagoons, cane-brakes, and swamps near the banks of the great rivers. It arrives in Kentucky about the middle of April, but enters the southern extremity of the Union from Mexico by the same time in March, and by the middle of September retires south of the United States. The males are very pugnacious in the pairing season of spring, and utter some loud notes, in threes, resembling the sound of 'tweedle tweedle tweedle. The nest is often attached to stems of stout weeds, or placed in a tuft of grass. It is made of the dry bark of herbaceous plants, mixed with downy substances, and lined with the cotton of the seed of the wild poplar. The species is scarcely known to the east of North Carolina.

In the A. O. U. check-list the habitat of this species is given as "Eastern United States, west to the Plains, and north to southern New England and southern Michigan. In winter, West Indies and Central America." It is most abundant along the Mississippi valley, and has been seen but rarely east of the Alleghanies. There is only one record of its occurrence in New England, - a pair taken in 1876 , at Suffield, Conn. Mr. John Neilson reports that a pair were frequently seen by him near the city of Quebec during the early part of July, i879.

Those who have heard the song pronounce it an attractive melody, the tones being loud and clear and the theme pleasing. Mr. Wm. Brewster ranks it among the best of the Sylvicoline performances.

\section{CERULEAN WARBLER.}

BLUE IWARBLER.

\section{DENDROICA CæRULEA.}

CHAR. Male: above, bright azure blue; sides of head and back streaked with black; line of dusky blue through the eyes; wings with two white bars; all tail-feathers but inner pair patched with white; beneath, white; breast and sides streaked with dusky blue. Female: similar but upper parts tinged with olive, and under parts tinged with yellow. Length $4 \% / 4$ to 5 inches.

Nest. In open woodland, on horizontal bough 30 to 50 feet from the 
ground; of grass and lichens fastened with insect silk, lined with fine grass.

Eggs. 4; white with green or blue tint, spotted chiefly around the larger end with reddish brown and lilac; $0.70 \times 0.53$.

This very delicately colored species is among the rarest summer residents of the Atlantic States, and does not probably migrate or rather stray farther north than the State of New York. In the Southwestern States, particularly Tennessee and West Florida, it is one of the most abundant species; it is also found in the western wilderness beyond the Mississippi. It is only in the summer that it ventures into the Middle States, from which it retires almost before the first chills of autumn, or by the middle of August. It frequents the borders of streams and marshes, and possesses many of the habits of the Flycatchers, warbling also at times in a lively manner, and though its song be short, it is at the same time sweet and mellow.

The principal range of this daintily dressed songster is through the southwestern division of this Eastern Province, between the valley of the Mississippi and the Alleghanian hills, north to Ohio (where it is abundant), southern Ontario, Indiana, and Illinois. It occasionally wanders eastward to central New York, Rhode Island, and Connecticut.

Nuttall copied Audubon when characterizing the song of this species as "sweet and mellow."

Wilson, who discovered the bird and named it the Blue-green Warbler, described the note as "a feeble chirp." Between the opposed opinions of these fathers of American ornithology comes the report of a recent observer, Mr. William Brewster, who found the species abundant in West Virginia. "At best it is a modest little strain, and far from deserving the encomium passed upon it by Audubon;" and again, "The song is a guttral trill much like that of the Blue Yellow-backed Warbler." 


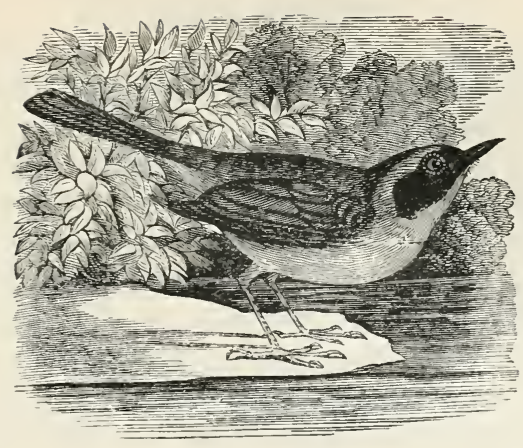

\section{MARYLAND YELLOW-THROAT.}

\section{GEOTHLYPIS TRICHAS.}

Char. Above, olive, duller on the head, brighter on rump; forehead and broad band on side of head black, with whitish border; beneatl rich yellow, paler on the belly. Length $4 \frac{3}{4}$ to $5 \frac{1}{2}$ inches.

Nest. Hidden by tuft of grass, or amid thicket of briers, usually in a moist woodland or on border of swamp; composed exteriorly of loosely laid grass, twigs, etc., lined with fine grass compactly woven.

Eggs. 4-6; white, sometimes creamy, spotted around larger end with brown and lilac; often a few black spots and lines; $0.70 \times 0.5^{2}$.

This common and familiar species extends its summer migrations from Florida to Nova Scotia, arriving in Pennsylvania towards the middle of April, and in this part of New England about the first week in May. The majority return to the South in September; a few stragglers of the young, however, may be seen to the first week in October, and though some may remain and winter in the Southern States, it is more probable that the main body retire at this season into the interior of tropical America, as they were seen late in autumn around Vera Cruz by the naturalist and traveller Mr. Bullock. Early in the month of March, however, I heard this species singing in the forests of West Florida.

The Maryland Yellow-Throat, with cheerful devotedness to the great object of his summer migration, - the attachments and cares of his species, - passes his time near some shady rill of water, amidst briers, brambles, alders, and such other shrubbery as grows in low and watery situations. Unambitious to be seen, 
he seldom ascends above the tops of the underwood, where he dwells, busily employed in collecting the insects on which he feeds. After these, like the Wren, he darts into the deepest thicket, and threads his devious way through every opening; he searches around the stems, examines beneath the leaves, and raising himself on his peculiarly pale and slender legs, peeps into each crevice in order to seize by surprise his tiny lurking prey. While thus engaged, his affection to his neighboring mate is not forgotten, and with a simplicity, agreeable and characteristic, he twitters forth at short intervals his 'whitittetee 'whititetee 'whititetee, but his more common song is 'whittitshee'whitittshee, or 'wetítshee wetítshee wee; and sometimes I have heard his note like, 'wetitshee wetitshee, 'wit'yu we. On this last syllable a plaintive sinking of the voice renders the lively, earnest ditty of the active minstrel peculiarly agreeable. Copying apparently from the Cardinal Bird, the song was, in one instance, which came to my notice, 'vitiyu 'vitiyu 'vitiyu. The whole is likewise often varied and lowered into a slender whisper, or tender revery of vocal instinct. Sometimes he calls out, teetshoo, teetshoo, and sewaidĕdit sewaidêdit sewaidîtsewee, or sewaidüdit sewaiditsiwee, as he busily darts through the blooming and odor-breathing shrubs of the grove or garden, which he examines with minute attention, and sometimes springs perpendicularly after his retreating and discovered prey. He appears by no means shy or suspicious, as long as his nest is unapproached; but for the safety of that precious treasure he scolds, laments, and entreats with great anxiety.

The species generally nest in the recluse thickets of the forest, or the low bushy meadow; but sometimes they take up their abode in the garden, or the field contiguous to the house, and if undisturbed, show a predilection for the place which has afforded security to themselves and their young. They commence their labor of building about the middle of May, fixing the nest on or near the ground, among dry leaves, withered grass, or brush, and choose often for security the most intricate thicket of briers, so that the nest is often sheltered 
and concealed by projecting weeds and grass. Sometimes a mere tussuck of grass or accidental pile of brush is chosen. It is made of dry sedge-grass (Carex), and a few leaves loosely wound together and supported by the weeds or twigs where it rests; the lining consists entirely of fine bent-grass (Agrostis). The young leave the nest, here, about the middle of June, and a second brood is sometimes raised in the course of the season. The parents and young now rove about in restless prying troops, and take to the most secluded bushy marshes, where they pass their time in comparative security till the arrival of that period of scarcity which warns them to depart. As early as the close of July, the lively song of the male ceases to be heard, and the whole party now forage in silence.

This species "breeds from the Gulf States to Manitoba and Labrador; winters from the Gulf States southward." (Chapman.)

Note. - The Western form has lately been separated from true trichas and given varietal rank with the name $G$. trichas occidentalis. Its habitat is from the Mississippi valley to the Pacific. It is somewhat larger and more brightly colored than is the eastern race. Another geographical race, the Florida Yellow-throat ( $G$. trichas ignota), differs from typical trichas in having the yellow of under parts of deeper shade and greater extent; the facial mask is wider also.

\section{MOURNING WARBLER.}

\section{Geothlypis PHILADELPHIA.}

CHAR. Above, olive; head, neck, and breast ashy ; breast mottled with black; remainder of under parts yellow. Length $5 \frac{1}{4}$ to $5 \frac{1}{2}$ inches.

Nest. In open woodland or pasture, on the ground or in low tree or bush; of vegetable fibre, lined with hair.

Eggs. 3-5; white or creamy, with brown and lilac spots wreathed around the larger end; $0.70 \times 0.54$.

Wilson, the discoverer of this curious species, never met with more than a single individual, which in its habits of frequent- 
ing marshy ground, and flitting through low bushes in quest of insects, appears very similar tô the Maryland Yellow-throat. The discoverer, however, also distinguished it more importantly by the novelty of its sprightly and pleasant warble; we may therefore perhaps consider it as a solitary straggler from the main body in the western regions of this vast continent. It was shot in the early part of June near Philadelphia.

On the 20 th of May, I83I, I saw, as I believe, the male of this species in the dark shrubbery of the Botanic Garden (Cambridge). It possessed all the manners of the common species, was equally busy in search of insects in the low bushes, and at little intervals warbled out some very pleasant notes, which though they resembled the lively chant of the Maryland Yellow-throat, even to the wetitshee, yet they were more agreeably varied, so as to approach in some degree the song of the Summer Yellow Bird (Sylvia astiva). This remarkable note, indeed, set me in quest of the bird, which I followed for some time; but at last, perceiving himself watched, he left the garden. As far as I was able to observe this individual, he was above of a dark olive-green, very cinereous on the fore part of the head, with a band of black through the eyes, which descended from the side of the neck, where at length it joined with a crescent of dusky or black spots upon the breast; the throat was yellow and the under parts paler.

Mr. Townsend saw a specimen on the shady borders of the Schuylkill in the month of May last, and a second individual has been obtained by Mr. De Rham in the vicinity of New York. Two or three other specimens have also been obtained in the vicinity of Philadelphia and in New Jersey. It is, however, still a very rare species, and its proper habitation is yet to be discovered.

This is still a rare bird in many localities, and it is among the desiderata of most collectors; yet within the limits of its favorite breeding areas, - at the higher altitudes of the Alleghanies; on the Berkshire Hills; along the northern borders of Vermont and New Hampshire; in portions of New York; and elsewhere between the Atlantic coast and the Plains where suitable conditions of environ- 
ment are obtainable, - the Mourning Warbler is not at all rare, and in the West - in Minnesota, Dakota, and Manitoba - it is decidedly abundant. Evidently it has no special liking for the Maritime Provinces nor for any portion of Canada east of Lake Winnipeg, fôr Canadian observers in general report it rare or uncommon. Yet one of the few nests that have been discovered was secured by Mr. Kells, near Listowel, in Ontario. This nest was in a cedar swamp and placed on the horizontal branch of a small tree quite close to the ground.

The examples I saw in New Brunswick were in small flocks, and were a very busy and very merry company, - busy in searching for their food, moving in most sprightly and vivacious manner, and making merry with sweet voices. The song consists of a few simple notes, but the birds frequently ascend to a high perch to deliver it and sing on as if much pleased with the performance. Merriam reports them singing thus for half an hour at a time.

\section{CONNECTICUT WARBLER.}

\section{GRAY-HEADED WARBLER.}

\section{GeothlyPis AGILIS.}

Char. Male : above, olive; head, neck, and breast ashy, darkest on breast and crown, lightest on the throat; white ring around the eyes; chest and belly yellow, sides shaded with olive. Female : similar, but without ashy tint on the head; throat tinged with brown; belly paler. Length $5^{1 / 2}$ to 6 inches.

Nest. Hidden on a tuft of weeds, or sunk in mossy mound, in swampy woods ; composed of dried grass.

Eggs. 4- ?; creamy, spotted, chiefly around the larger end, with black, brown, and lilac; $0.75+0.55$.

This rare species, discovered by Wilson in Connecticut and afterwards in the neighborhood of Philadelphia, appears to frequent low thickets, and is exceedingly active in pursuit of its prey, scarcely remaining a moment in the same place. IVilson afterwards shot two specimens of a bird which in every particular agreed with the above, except in having the throat dull buff instead of pale ash. These were both females, as he supposed, of the present species.

The history of this bird is still interestingly obscure, so much has yet to be learned; but gleaning from records made by observers in various parts of the country, I am enabled to add a little to Nuttall's account. 
The bird has been taken throughout the greater part of this Eastern Province; but its distribution appears, from the evidence so far gathered, to be somewhat peculiar. It winters in Mexico and southward, and in the spring migrates wholly along the Mississippi valley, where it is more or less abundant north to Manitoba, though it is rarely seen at that season to the eastward of Illinois. It breeds in Minnesota, Dakota, and Manitoba, and in the autumn part of the flocks go south along the Mississippi, while others pass eastward along the shores of the Great Lakes, and thence to Massachusetts, the most northern limit of the bird's range on the Atlantic side, where it is common during the first half of September, after which the flocks continue on a gradual movement southward.

Dr. Wheaton considered the species very rare in Ohio, and it was thought to be rare in Ontario until i 884, when my friend William Saunders found it common in the vicinity of London. The only nest yet taken was discovered by another friend and fellowworker Ernest Thompson. It was found near Carberry, Manitoba, in I883, sunk amid a mossy mound in a tamarack swamp, - "a dark, gray waste."

In the West, during the spring migrations, these birds are exceedingly active and very shy, moving incessantly among the branches in quest of insects, and when approached darting into the thickest covers; but those I saw on the Fresh Pond marsh at Cambridge fed chiefly on the ground, among the leaves, and when disturbed flew generally but a short distance to a low branch, and sat as composedly as a Thrush.

Thompson describes the song as similar to the Golden-crowned Thrush, and says it may be suggested by the syllables beecherbeecher-beecher-beecher-beecher-beecher, sung at the same pitch throughout; he adds, "but he also had another which I can recall to mind by the aid of the syllables freechaple, freechaple, freechaple, whorт."

This same writer says: "Connecticut Warbler is an unfortunate misnomer for this species," and he suggests "Swamp Warbler" or "Tamarac Warbler" or "Bog Black-throat." "This species," he writes, "has somewhat the manners of the Vireos, but is much more active and sprightly in its movements." 


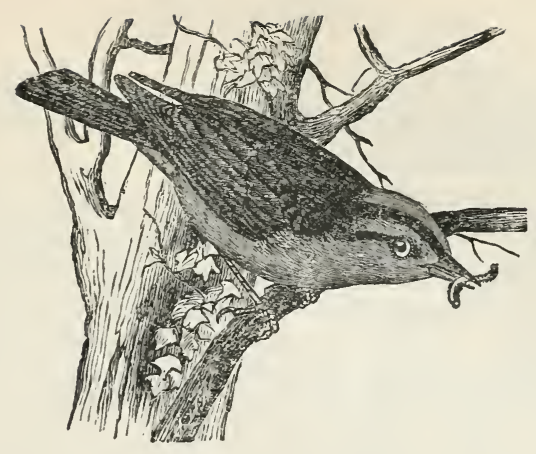

WORM-EATING WARBLER.

\section{Heliitherus vermivorus.}

CHAR. Above, olive; head buff, with four stripes of black; beneath, buff, paler on belly. Length $5^{1 / 2}$ to $5 \frac{3}{4}$ inches.

Nest. On the ground, often covered by a bush, or beside a fallen log; of leaves, moss, and grass, lined with moss. fine grass. or hair.

Eggs. 3-6 (usually 5); variable in shape and color; white, sometimes with buff or pink tint, marked with fine spots of reddish brown and lilac; $0.70 \times 0.55$.

These birds arrive in Pennsylvania about the middle of May, and migrate to the South towards the close of September; they were seen feeding their young in that State about the $25^{\text {th }}$ of June by Wilson, so that some pairs stay and breed there. They are very active and indefatigable insect-hunters, and have the note and many of the manners of the Marsh 'Titmouse or Chickadee. About the $4^{\text {th }}$ of October I have seen a pair of these birds roving through the branches of trees with restless agility, hanging on the twigs and examining the trunks, in quest probably of spiders and other lurking and dormant insects and their larvæ. One of them likewise kept up a constant complaining call, like the sound of tshe de de.

According to Richardson this species visits the fur countries, where a single specimen was procured at Cumberland House, on the banks of the Saskatchewan. It is found also in Maine and the British Provinces of New Brunswick and Nova Scotia. Dr. Bachman says that it breeds sparingly in the 
swamps of Carolina, as he observed a pair followed by three or four young ones nearly fledged, all of which already exhibited the markings on the head.

Richardson led Nuttall into a mistake regarding the distribution of this species. It is a Southern bird, breeding chiefly south of latitude $40^{\circ}$, and occurs but rarely along the northern limit of its range, - southern New England, the southern shores of Lake Erie, and southern Illinois. It has not been taken in the Provinces.

Usually these birds feed on the ground among the dead leaves, but sometimes rise amid the branches, as described by Nuttall. They are not "shy" birds, for they will remain on the nest until fairly driven off, and when feeding are apparently indifferent about being watched.

\section{SWAINSON'S IVARBLER.}

\section{HelinaIa SWAINSONII.}

Char. Above, dull olive, head and wings tinged with reddish brown; dark streak through the eyes; line over eyes and under parts white with yellow tint; sides tinged with olive. Length $5 \frac{1}{2}$ to 6 inches.

Nest. In a swamp, or near stagnant pool, or on dry upland; in canestalk or on bush, 4 to 10 feet from the ground; a bulky and inartistic affair of dead leaves, lined with roots and pine-needles.

Eggs. 3-4; white with blue tint, unmarked ; $0.75 \times 0.60$.

Dr. Bachman, who discovered this species near the banks of the Edisto River, in South Carolina, remarks : "I was first attracted by the novelty of its notes, four or five in number, repeated at intervals of five or six minutes apart. These notes were loud, clear, and more like a whistle than a song. They resembled the sound of some extraordinary ventriloquist in such a degree that I supposed the bird much farther off than it really was; for after some trouble caused by these fictitious notes, I observed it near me, and soon shot it." These birds appear to have a predilection for swampy, muddy places, usually more or less covered with water. They feed on coleopterous insects and the larvæ which infest the pond-lily. They usually keep in low bushes, and retire southward at the close of summer. They breed, it appears, in South Carolina. 
Until recently, naturalists knew nothing more of this species than Nuttall put into the above few lines; and for that information he was indebted to Audubon. Only three examples were taken between Audubon's time and I 873 , when Nathan C. Brown captured three more in Alabama; and eleven years afterwards, in 1884 , William Brewster collected fifty specimens in the vicinity of Charleston, and published in "The Auk" for January, I885, an interesting account of the bird's habits.

He reports that he met with this bird in dry, scrubby woods or open orange-groves, though it prefers the ranker growth of the swamps, to which it appears to be confined during the breeding season. Its song is said to be "very loud, very rich, very beautiful, while it has an indescribable tender quality that thrills the senses after the sound has ceased."

The distribution of the species has not yet been very satisfactorily determined, but it probably occurs in all the South Atlantic and Gulf States, and along the Mississippi valley north to Illinois and Indiana.

\section{PROTHONOTARY WARBLER.}

\section{Protonotaria citrea.}

Char. Head, neck, and under parts golden yellow; back bright olive; wings, tail, and rump, bluish ash ; inner webs of tail-feathers white. Length about $5 \frac{1}{2}$ inches.

Nest. On the margin of a stream or pond or in a swamp; a cavity in dead tree, often a deserted nest of Woodpecker or Chickadee, generally near the ground; lined with leaves and moss.

Eggs. 4-7 (usually 6); white, or with buff tint, thickly spotted with brownish red; $0.70 \times 0.55$.

This beautiful species inhabits the Southern States commonly in summer, being plentiful in the low, dark, and swampy forests of the Mississippi near New Orleans, as well as in Louisiana and the wilds of Florida. In these solitary retreats individuals are seen nimbly flitting in search of insects, caterpillars, larvæ, and small land shells, every now and then uttering a few creaking notes scarcely deserving the name of song. They sometimes, though very rarely, proceed as far north as Pennsylvania. They appear to affect watery places in swamps which abound with lagoons, and are seldom seen in the woods. According to VOL. I. - I 7 
Dr. Bachman, these birds breed in South Carolina, as he saw a pair and their young near Charleston.

This species is common in the Gulf States, and ranges along the Mississippi valley, being peculiarly abundant in southern Illinois and southwestern Indiana, but near the Atlantic is rarely seen north of Georgia. A few stragglers have been encountered in New England, while one has been taken at St. Stephen, New Brunswick, by Mr. George A. Boardman, and another near Hamilton, Ontario, by H. C. McIlwraith.

It is said to be more deliberate and thrushlike in its movements than are its sprightly congeners, the Dendroica. The song most frequently heard is described as a simple but pleasing whistle, like that of the solitary Sandpiper, though when the singer is near at hand, almost startling in its intensity. Mr. Brewster mentions hearing another song delivered on the wing, and intended for the ear of the mate alone. It is generally heard only after incubation has commenced, and is low, but very sweet, and resembles somewhat the song of a Canary, delivered in an undertone.

\section{BLUE-IVINGED WARBLER.}

\section{Helminthophila pinUS.}

CHAR. Male : above, bright olive; wings and tail dull blue; wings with two yellowish bars; outer tail feathers with white blotches; black line through the eye; crown and under parts bright yellow. Female: similar but under parts duller, and yellow on head restricted to forehead. Length about 5 inches.

Nest. In a tuft of grass amid thicket of underbrush or along margin of woods; bulky, and loosely made of dried leaves and vegetable fibre, lined with fine grass.

Eggs. 4-5; white, faintly speckled with brown; $0.60 \times 0.50$.

About the beginning of May this species enters Pennsylvania from the South, and frequents thickets and shrubberies in quest of the usual insect food of its tribe. At the approach of winter, very different from the Pine Warbler, with which it has sometimes been confounded, it retires to pass the winter in tropical America, having been seen around Vera Cruz in autumn by Mr. Bullock. On its arrival it frequents gardens, orchards, and willow trees, gleaning among the blossoms, but at length withdraws into the silent woods remote, from the 
haunts of men, to pass the period of breeding and rearing its young in more security.

The apparent distribution of this species, judged by the records of recent observations, is somewhat peculiar. It seems to be abundant in the southwestern portion of this Eastern Province, and rarely ranges east of the Alleghanian hills until north of $40^{\circ}$, when it spreads off to the shores of the Atlantic, though seldom going beyond latitude $42^{\circ}$. "It is a common summer resident of southern Connecticut, but is not known to occur regularly north of Hartford, and is most numerous in the country immediately bordering the Sound and in the lower valley of the Connecticut River" (Brewster). A few examples only have been taken in Massachusetts, and though common in Ohio it has not been seen in Ontario. Farther west it is found north to the southern portions of Michigan, Wisconsin, and Minnesota. It winters south to eastern Mexico and Guatemala.

The nests that have been discovered in recent years are not fashioned like that described by Wilson, for instead of being funnel-shaped, they have the ordinary cup-like form.

Opinions differ regarding the song, but I am inclined to believe that it is a rapid trill of strong, sweet tones, limited in compass and executed with little art, - a merry whistle rather than an artistic melody. "As a rule it consists of the two drawled wheezy notes sweé-chee; the first inhaled, the second exhaled. A less common

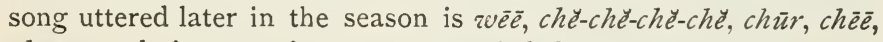
chiur, and is sometimes accompanied by peculiar kik notes" (Chapman). 


\section{GOLDEN-WINGED WARBLER.}

\section{HELMINTHOPHILA CHRYSOPTERA.}

CHAR. Male : above, bluish gray, sometimes tinged with olive; crown bright yellow; side of head yellowish white, with broad patch of black from bill through eyes; wings with large patch of bright yellow; blotches on tail white; beneath, white tinged with yellow; throat black; sides tinged with gray. Female : similar, but colors duller; patch from bill through eyes, grayish. Length about 5 inches.

Nest. Amid a tuft of long grass, in moist meadow or damp margin of woods ; constructed of shreds of bark, roots, etc., lined with fine grass.

Eggs. 4-6; white spotted with brown and lilac; $0.65 \times 0.50$.

This scarce species appears only a few days in Pennsylvania about the last of April or beginning of May. It darts actively through the leafy branches, and like the Titmouse examines the stems for insects, and often walks with the head downwards; its notes and actions are also a good deal similar, in common with the Worm-eating Warbler. I have never yet seen it in Massachusetts, and if it really does proceed north to breed, it must follow a western route.

The Golden-wing still remains a somewhat "scarce" bird, but it occurs regularly in Connecticut and southern Massachusetts, and in some few localities is often quite numerous. Its general breeding area lies north of latitude $40^{\circ}$, though nests have been found among the hills of Georgia and North Carolina. To the westward it breeds in Ohio, southern Michigan, Wisconsin, and Minnesota, and in the vicinity of London, Ontario, where Saunders reports it quite common. It winters south to Central America.

Note. - Two variations from the type, BREWSTER'S WARbLeR (H. leucobronchialis) and LAwRENCE'S WARBLER (H. lawrencei) are still placed on the "hypothetical list " by conservative writers. Both birds are supposed to be either hybrids between $H$. pinus and $H$. chrysoptera, or color phases. Lawrence's Warbler is rather rare, though it occurs regularly in Connecticut, but Brewster's Warbler is not uncommon in the Connecticut valley, and has been traced south to Virginia and west to Michigan. 


\section{BACHMAN'S WARBLER.}

\section{HELMINTHOPHILA BACHMANII.}

ChAr. Male : above, olive; head dull ashy; tail grayish with white patches; black band across crown; forehead and underparts yellow, with large patch of black on the breast; yellow band on wing. Female: similar, but duller and grayer; under parts paler. Length $4 \frac{1}{2}$ inches.

Nest. In a low tree.

Eggs. 4; dull white, heavily wreathed around larger end with dark brown and spotted with lilac; $0.74 \times 0.60$.

This species was first obtained a few miles from Charleston, S. C., in July I 833 , by Dr. Bachman, after whom it is named. It appears to be a lively, active species, frequenting thick bushes, through which it glides after insects, or occasionally, mounting on wing, it seizes them in the air. Several individuals were seen in the same neighborhood.

Nothing more was heard of this interesting bird than the little told by Audubon and Nuttall, until 1883, when Mr. H. B. Bailey described the nest and eggs from examples collected in Georgia, by Dr. S. W. Wilson, somewhere between 1853 and 1865 . The male and female secured by Dr. Bachman were the only specimens taken until I886, when a third was shot by Charles S. Galbraith, in Louisiana, and announced by Mr. George N. Lawrence in "The Auk" of January, 1887. A fourth, taken in Florida in March, 1887, was announced by Dr. Merriam, and during that year others were reported. Since then the bird has been discovered to te fairly common in the South Atlantic and Gulf States.

It is described as an active, quarrelsome bird, wary and difficult to approach. Its manner, when searching for food, is described as rather leisurely. The song is somewhat similar to the Parula. It frequents both shrubbery and high trees, but shows a preference for the latter and for a rather thick growth.

\section{TENNESSEE WARBLER.}

\section{HELMINTHOPHILA PEREGRINA.}

Char. Male : above, olive, brightest on rump, shading to ashy on head; wings and tail dusky; beneath, white, with faint tint of yellow; sides tinged with gray. Female: similar, but crown tinged with olive and under parts with more yellow. Young: similar to female, but crown olive and under tail-coverts white. Length $4^{1 / 2}$ to $4 \frac{3}{4}$ inches.

Nest. On a low bush in open woodland; made of grass, moss, and vegetable fibre, lined with hair. 
Eggs. $0-0$ (probably 4 or 5 ); white, wreathed around larger end with brown and purplish spots : $0.65 \times 0.50$.

This rare and plain species was discovered by Wilson on the banks of Cumberland River, in the State of Tennessee. It was hunting with great agility among the opening leaves in spring, and like the rest of the section to which it appertains, possesses a good deal of the habits of the Titmouse. Its notes were few and weak, and its food, as usual, smooth caterpillars and winged insects. It is still so rare that Audubon never saw more than three individuals, - two in Louisiana, and one at Key West in East Florida, all of which were males.

Ornithologists of the present day do not consider this Warbler quite so rare as did Nuttall and his contemporaries, though it is somewhat local in its distribution, and is only met with occasionally at many places within its range. In the Eastern States it is rather rare, excepting on the northern border of New York and New England, where it breeds; but it is more numerous in the Mississippi valley, and Dr. Coues found it migrating in abundance along the Red River, through Minnesota and Dakota, while Thompson reports it as "a common summer resident" in parts of Manitoba. Dr. Wheaton considered it rare in Ohio, but Saunders reports it "common at times" in the southern peninsula of Ontario, while McIlwraith has seen it but twice near Hamilton. It is rare in the Ottawa valley and near the city of Quebec, while common near Montreal. Comeau says it breeds in numbers near Point de Monts, on the north shore of the Gulf of St. Lawrence, and Macoun reports it common around Lake Misstissini. It is not uncommon in some few localities in New Brunswick, where it remains all summer. Very few nests have been discovered.

The bird is very wary and always on the alert, _ darting rapidly from branch to branch. The song is a sweet-toned, cheery whistle, - somewhat similar to that of the Nashville, "but so decidedly different," writes Mr. Bradford Torrey, " as never for a moment to be confounded with it." $\mathrm{He}$ adds : "The resemblance lies entirely in the first part; the notes of the concluding portion are not run together or jumbled, after the Nashville's manner, but are quite as distinct as are those of the opening measure." 


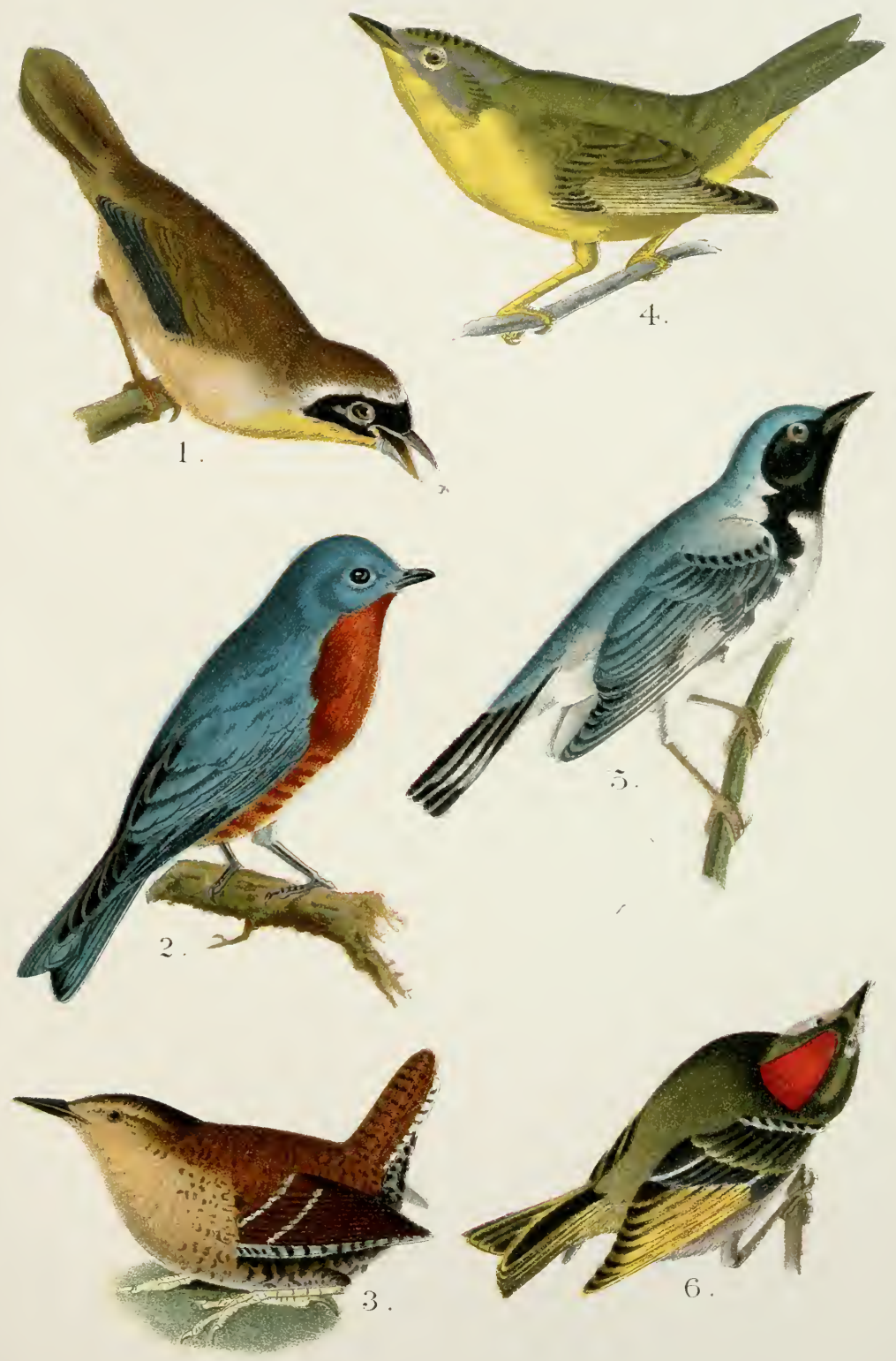

1. Maritand Yellow-Throat.

4. Nashville IVarbler.

2. Bluebird.

5. Black-Throated Blue Warbler.

3. Winter Wren.

6. Rubr-Crowned Kingllet. 



\section{NASH V I L L E W A R B E R.}

\section{HELMiNTHOPHILA RUFICAPILLA.}

CHAR. Above, olive, brighter on rump; head ashy gray, with concealed patch of reddish brown; yellow ring around the eyes; beneath, bright yellow, paler on the belly; sides shaded with olive. Length $4 \frac{1}{2}$ to 5 inches.

N'est. Amid a tuft of weeds in pasture or open woodland; composed of leaves and vegetable fibre, lined with grass, pine-needles, or hair.

Eggs'. 3-5 (usually 4); white or creamy, marked with fine spots of reddish brown and lilac; $0.60 \times 0.50$.

This rare species was discovered by Wilson in the vicinity of Nashville in Tennessee; it also exists in the neighboring States in summer, and occasionally proceeds as far north as Philadelphia, and even the neighborhood of Salem in this State [Massachusetts]. Its discoverer was first attracted to it by the singular noise which it made, resembling the breaking of small dry twigs, or the striking together of pebbles, for six or seven times in succession, and loud enough to be heard at the distance of thirty or forty yards. A similar sound, produced, no doubt, by the smart snapping of the bill, is given by the Stonechat of Europe, - which hence, in fact, derives its name. Audubon says, the male, while standing in a still and erect posture, utters a few low, eagerly repeated, creaking notes. This species has all the active habits of the family to which it more particularly belongs. Audubon says that these birds are not in fact rare, as he saw them in considerable numbers in the month of April, towards Texas, on their way eastward; he also saw them in Maine and the Provinces of New Brunswick and Nova Scotia. A few proceed to Labrador, and Dr. Richardson mentions the occurrence of a straggler in the fur countries.

However rare the Nashville may have been when Nuttall lived in Cambridge, it is not a rare bird here to-day. It is, indeed, a common summer resident throughout New England and the Maritine Provinces, and occurs in more or less abundance westward to Manitoba. It winters south to Mexico and Guatemala.

On the arrival of these birds in the spring they frequent the sub- 
urban gardens and orchards, but soon retire to a more secluded place to build; and hidden away amid the thicker bushes of their favorite haunts, are often overlooked by the collector, - the ornithological reporter, - and thus the species has acquired a reputation of being " uncommon."

The song is a typical Warbler-like performance, - a short trill of sweet notes, whistled with little variation in tone, and little effort at artistic execution; but I have not heard any of the "harsh" and "creaking" effects noted by some writers.

\section{ORANGE-CROWNED WARBLER.}

\section{Helimnthophila CELATA.}

Char. Above, olive, brightest on the rump; crown with concealed patch of brownish orange; line over and around the eyes, pale yellow; beneath, pale greenish yellow; sides shaded with olive. Length $4 \frac{1}{2}$ to $5^{1 / 4}$ inches.

Nest. On the ground among clumps of bushes; made of grass, moss, and plant stems, lined with hair.

Eggs. 4-6; white or creamy, marked, chiefly around the larger end, with spots of reddish brown and purplish slate; $0.65 \times 0.50$.

This species, first discovered, early in May, on the banks of the Missouri by my friend Mr. T. Say, appeared to be on its passage farther north. It is not uncommon in winter in the orange-groves of West Florida, where it proceeds to pass the season, around St. Augustine; and its note is described as a mere chirp and faint squeak, scarcely louder than that of a mouse.

According to Audubon, these birds breed in the eastern part of Maine and in New Brunswick and Nova Scotia. In the month of May we saw them abundant in the forests of the Oregon, where no doubt they breed. The song is weak, somewhat resembling that of most of the Sylvicolas.

Audubon must have gathered in all the New Brunswick Orange Crowns, for none have been seen there since his visit, nor can I learn of any having been observed elsewhere in eastern Canada, excepting the few discovered by McIlwraith and Saunders in 
southern Ontario, and one taken by Ernest D. Wintle near Mon. treal in $\mathrm{I} \delta 90$.

Accidental stragglers have been taken in New England, but it is chiefly a Western bird, breeding in the far north, though it winters in the Southern and Gulf States.

\section{KIRTLAND'S WARBLER.}

\section{DENDROICA KIRTLANDI.}

Char. Above, slaty brown, head bluish; head and back streaked with black; line across forehead and through the eyes, black; beneath, yellow, breast and sides spotted with black; white blotches on tail. Length $5^{1 / 2}$ to 6 inches.

Nest and Eggs. Unknown.

Only a few specimens of this bird, discovered by Dr. Kirtland, near Cleveland, in I $85 \mathrm{I}$, have as yet been seen, and these few were captured in South Carolina, Virginia, Ohio, Michigan, Wisconsin, and Missouri during the spring migrations. Mr. Charles B. Cory secured one in the Bahamas in winter. The habits of the bird are unknown, but Mr. Chubb, who shot a male and female near Cleveland in I880, says: "I am inclined to think they are rather terrestrial in their habits, frequenting bushy fields near woods." Mr. Chapman suggests the probability of these birds breeding "in the Hudson Bay region."

Note. - The Carbonated Warbler (Dendroica carbonata), mentioned by Nuttall on the authority of Audubon, who killed two specimens in Kentucky, has been placed on the "Hypothetical List" by the A. O. U. Committee, as has also the BLue MIountain Warbler (Dendroica montana) and the SMall-headed WarBLER (Sylvania microcephala), mentioned by Wilson and Audubon. No specimens of either have been taken in recent years. On this same list has been placed the Cincinnati WarbleR (Helminthophila cincinnatiensis), which is probably a hybrid of $H$. pinus and $G$. formosa.

TOWNSEND's WARBLER (Dendroica torunsendi), described by Nuttall and named in honor of its discoverer, is a rare bird of the Far West, and its claim to mention here rests on the accidental occurrence of one example near Philadelphia in 1868. 


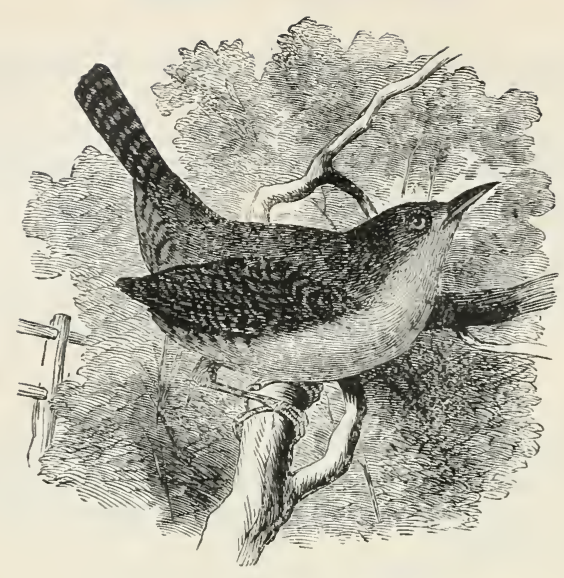

\section{HOUSE WREN.}

WOOD WREN.

\section{TROGLODYTES AËDON.}

CHAR. Above, reddish brown (sometimes with dark bars), darker on the head; below, brownish white, marked irregularly with dark lines; wings and tail with fine waved lines. Length about 5 inches.

Nest. On the eaves of houses or in a barn or hollow tree, etc.; made of grass, twigs, etc.; the hole generally filled with rubbish and lined with feathers.

Eggs. 7-9; white tinted with pink, densely marked with reddish brown; $0.65 \times 0.50$.

This lively, cheerful, capricious, and well-known little minstrel is only a summer resident in the United States. Its northern migrations extend to Labrador, but it resides and rears its young principally in the Middle States. My friend Mr. Say also observed this species near Pembino, beyond the sources of the Mississippi, in the Western wilderness of the $49^{\text {th }}$ degree of latitude. It is likewise said to be an inhabitant of Surinam, within the tropics, where its delightful melody has gained it the nickname of the Nightingale. This region, or the intermediate country of Mexico, is probably the winter quarters of our domestic favorite. In Louisiana it is unknown even as a transient visitor, migrating apparently to the east of 
the Mississippi, and sedulously avoiding the region generally inhabited by the Carolina Wren. It is a matter of surprise how this, and some other species, with wings so short and a flight so fluttering, are ever capable of arriving and returning from such distant countries. At any rate, come from where it may, it makes its appearance in the Middle States about the I 2 th or I $5^{\text {th }}$ of April, and is seen in New England in the latter end of that month or by the beginning of May. It takes its departure for the South towards the close of September or early in October, and is not known to winter within the limits of the Union.

Some time in the early part of May our little social visitor enters actively into the cares as well as pleasures which preside instinctively over the fiat of propagation. His nest, from preference, near the house, is placed beneath the eaves, in some remote corner under a shed, out-house, barn, or in a hollow orchard tree; also in the deserted cell of the Woodpecker, and when provided with the convenience, in a wooden box along with the Martins and Bluebirds. He will make his nest even in an old hat, nailed up, and perforated with a hole for entrance, or the skull of an ox stuck upon a pole; and Audubon saw one deposited in the pocket of a broken-down carriage. So pertinacious is the House Wren in thus claiming the convenience and protection of human society that, according to Wilson, an instance once occurred where a nest was made in the sleeve of a mower's coat, which, in the month of June, was hung up accidentally for two or three days in a shed near a barn.

The nest of this species, though less curious than that of some other kinds, is still constructed with considerable appearance of contrivance. The external approach is barricaded with a strong outwork of sticks, interlaced with much labor and ingenuity. When the nest, therefore, is placed beneath the eaves, or in some other situation contiguous to the roof of the building, the access to the inner fabric is so nearly closed by this formidable mass of twigs that a mere portion of the edge is alone left open for the female, 
just sufficient for her to creep in and out. Within this judicious fort is placed the proper nest, of the usual hemispherical figure, formed of layers of dried stalks of grass, and lined with feathers. The eggs, from 6 to 9, are of a reddish flesh-color, sprinkled all over with innumerable fine grains of a somewhat deeper tint. They generally rear two broods in the season: the first take to flight about the beginning of June, and the second in July or August. The young are early capable of providing for their own subsistence and twittering forth their petulant cry of alarm. It is both pleasant and amusing to observe the sociability and activity of these recent nurslings, who seem to move in a body, throwing themselves into antic attitudes, often crowding together into the old nests of other birds, and for some time roosting near their former cradle, under the affectionate eye of their busy parents, who have perhaps already begun to prepare the same nest for a new progeny. Indeed, so prospective and busy is the male that he frequently amuses himself with erecting another mansion even while his mate is still sitting on her eggs; and this curious habit of superfluous labor seems to be more or less common to the whole genus.

One of these Wrens, according to Wilson, happened to lose his mate by the sly and ravenous approaches of a cat, - an animal which they justly hold in abhorrence. The day after this important loss, our little widower had succeeded in introducing to his desolate mansion a second partner, whose welcome appeared by the ecstatic song which the bridegroom now uttered; after this they remained together, and reared their brood. In the summer of I 830 I found a female Wren who had expired on the nest in the abortive act of laying her first egg. I therefore took away the nest from under the edge of the shed in which it was built. The male, however, continued round the place as before, and still cheerfully uttered his accustomed song. Unwilling to leave the premises, he now went to work and made, unaided, another dwelling, and after a time brought a new mate to take possession; but less faithful than Wilson's bird, or suspecting some lurking danger, she 
forsook the nest after entering, and never laid in it. But still the happy warbler continued his uninterrupted lay, apparently in solitude.

The song of our familiar Wren is loud, sprightly, and tremulous, uttered with peculiar animation, and rapidly repeated; at first the voice seems ventriloquial and distant, and then bursts forth by efforts into a mellow and echoing warble. The trilling, hurried notes seem to reverberate from the leafy branches in which the musician sits obscured, or are heard from the low roof of the vine-mantled cottage like the shrill and unwearied pipe of some sylvan elf. The strain is continued even during the sultry noon of the summer's day, when most of the feathered songsters seek repose and shelter from the heat. His lively and querulous ditty is, however, still accompanied by the slower-measured, pathetic chant of the Red-eyed Flycatcher, the meandering, tender warble of the Musical Vireo, or the occasional loud mimicry of the Catbird; the whole forming an aërial, almost celestial concert, which never tires the ear. Though the general performance of our Wren bears no inconsiderable resemblance to that of the European species, yet his voice is louder, and his execution much more varied and delightful. He is rather a bold and insolent intruder upon those birds who reside near him or claim the same accommodation. He frequently causes the mild Bluebird or the Martin to relinquish their hereditary claims to the garden box, and has been accused also of sucking their eggs. Nor is he any better contented with neighbors of his own fraternity who settle near him, keeping up frequent squabbles, like other little busybodies, who are never happy but in mischief; so that upon the whole, though we may justly admire the fine talents of this petulant domestic, he is, like many other actors, merely a good performer. He is still upon the whole a real friend to the farmer and horticulturist, by the number of injurious insects and their destructive larvæ on which both he and his numerous family subsist. Bold and fearless, seeking out every advantageous association, and making up in activity what he may lack in strength, he does not confine his visits to the cottage or the 
country, but may often be heard on the tops of houses even in the midst of the city, warbling with his usual energy.

The House Wren is a common summer resident of Massachusetts, but is rarely seen north of this State.

The only instance of its occurrence in New Brunswick is that of a pair seen at Grand Falls by Mr. C. F. Batchelder. It is fairly common near Montreal and through southern Ontario, and is abundant in Manitoba. It winters in the Middle States and southward.

Note. - A Western form - distinguished from true aëdon by the prevalence of gray on its upper parts and its more distinct bars on the back - occurs from Illinois and Manitoba westward. This is WESTERN House Wren ( $T$. a. aztecus).

The Wood Wren (T. americanus), mentioned by Nuttall on the authority of Audubon, should have been referred to T. aëdon.

\section{WINTER WREN.}

\section{TROGLODYTES HIEMALIS.}

Char. Above, reddish brown, brightest on the rump, marked with dark waved lines; wings and tail with dark bars; under parts paler brown, belly and under tail-coverts with numerous dark bars. Length about 4 inches.

Nest. At the font of a moss-covered stump, or under a fallen tree, or amid a pile of brush; composed of twigs and moss, lined with feathers.

Eggs. 4-6; white, spotted, chiefly near the larger end, with reddish brown and purple; $0.70 \times 0.50$.

This little winter visitor, which approaches the Middle States in the month of October, seems scarcely in any way distinguishable from the Common Wren of Europe. It sometimes passes the winter in Pennsylvania, and according to Audubon even breeds in the Great Pine Swamp in that State, as well as in New York. Early in the spring it is seen on its returning route to the Northwest. Mr. Say observed it in summer near the base of the Rocky Mountains; it was also seen, at the same season, on the White Mountains of New Hampshire by the scientific exploring party of Dr. Bigelow, Messrs. Boott 
and Gray, so that it must retire to the Western or mountainous solitudes to pass the period of incubation. Mr. Townsend obtained specimens of this bird in the forests of the Columbia. During its residence in the Middle States it frequents the broken banks of rivulets, old roots, and decayed logs near watery places in quest of its insect food. As in Europe, it also approaches the farm-house, examines the wood-pile, erecting its tail, and creeping into the interstices like a mouse. It frequently mounts on some projecting object and sings with great animation. In the gardens and outhouses of the city it appears equally familiar as the more common House Wren.

The Wren has a pleasing warble, and much louder than might be expected from its diminutive size. Its song likewise continues more or less throughout the year, - even during the prevalence of a snowstorm it has been heard as cheerful as ever; it likewise continues its note till very late in the evening, though not after dark.

This species is common throughout the Eastern States, breeding in northern New England and north to the Gulf of St. Lawrence, and westward through northern Ohio and Ontario to Manitoba. During the summer it occurs also, sparingly, on the Berkshire Hills in Massachusetts, and along the crests of the Alleghanies to North Carolina. It winters from about $40^{\circ}$ southward.

Had Nuttall ever met with the Winter Wren in its summer haunts; had he heard its wild melody break the stillness of the bird's forest home, or known of the power controlled by that tiny throstle and of its capacity for brilliant execution; had he but once listened to its sweet and impassioned tones, and the suggestive joyousness of its rapid trills; had Nuttall, in short, ever heard the bird sing, - he could not, surely, have damned it with such faint praise.

The song of this Wren is not well known, for the bird seldom sings beyond the nesting period, and then is rarely heard away from the woodland groves. But once heard, the song is not soon forgotten: it is so wild and sweet a lay, and is flung upon the woodland quiet with such energy, such hilarious abandon, that it commands attention. Its merits entitle it to rank among the best of our sylvan melodies. 


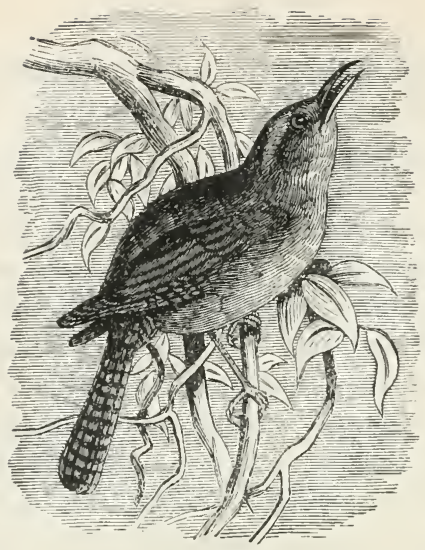

\section{CAROLINA WREN.}

\section{MOCKING WREN.}

\section{THRYOTHORUS LUDOVICIANUS。}

Char. Above, reddish brown, with fine black bars; below, tawny buff ; long line over the eye white or buff; wings and tail with dark bars Length $5^{1 / 2}$ to 6 inches.

Nest. In any available hole, often in hollow tree, sometimes in brush heap, usually in the woods ; composed of grass, leaves, etc., sometimes fastened with corn-silk, lined with feathers, grass, or horse-hair.

Eggs. 3-6; white, with pink or buff tint, thickly speckled around larger end with reddish brown; $0.75 \times 0.60$.

This remarkable mimicking and Musical Wren is a constant resident in the Southern States from Virginia to Florida, but is rarely seen at any season north of the line of Maryland or Delaware, though, attracted by the great river-courses, it is abundant from Pittsburg to New Orleans. A few individuals stray, in the course of the spring, as far as the line of New York, and appear in New Jersey and the vicinity of Philadelphia early in the month of May. On the $\mathrm{I} 7$ th of April, returning from a Southern tour of great extent, I again recognized my old and pleasing acquaintance, by his usual note, near Chester, on the Delaware, where, I have little doubt, a few remain and pass the summer, retiring to the South only 
as the weather becomes inclement. On the banks of the Patapsco, near Baltimore, their song is still heard to the close of November.

Our bird has all the petulance, courage, industry, and familiarity of his particular tribe. He delights to survey the meanders of peaceful streams, and dwell amidst the shady trees which adorn their banks. His choice seems to convey a taste for the picturesque and beautiful in Nature, himself, in the foreground, forming one of the most pleasing attractions of the scene. Approaching the waterfall, he associates with its murmurs the presence of the Kingfisher, and modulating the hoarse rattle of his original into a low, varied, desponding note, he sits on some depending bough by the stream, and calls, at intervals, in a slow voice, tee-yürrh tee-yürrh, or chr' $r^{\prime} r^{\prime} r^{\prime} r h$. In the tall trees by the silent stream, he recollects the lively, common note of the Tufted Titmouse, and repeats the peto peto peto peet, or his peevish katétédid, katétédid, katedid. While gleaning low, amidst fallen leaves and brushwood, for hiding and dormant insects and worms, he perhaps brings up the note of his industrious neighbor, the Ground Robin, and sets to his own sweet and liquids tones the simple toweet toweet toreeet. The tremulous trill of the Pine Warbler is then recollected, and $t r^{\prime} r^{\prime} r^{\prime} r^{\prime} r^{\prime} r^{\prime} r h$ is whistled. In the next breath comes his imitation of the large Woodpecker, woity woity woity and wotchy wotchy wotchy, or tshovee tshovee tshof, and tshooădee tshooădee tshooadeet, then varied to tshuvai tshuvai tshuvat, and toovaiiah toovaiiah toovaiiatoo. Next comes perhaps his more musical and pleasing version of the Blackbird's short song, wottitshee wottitshee wottitshee. To the same smart tune is now set a chosen part of the drawling song of the Meadow Lark, prečedo precĕdo preceet, then varied, recĕdo recĕdo receet and tecedo tecedo teceet; or changing to a bass key, he tunes sooteet sooteet soot. Once, I heard this indefatigable mimic attempt delightfully the warble of the Bluebird in the month of February. The bold whistle of the Cardinal Bird is another of the sounds he delights to imitate and repeat in his own quaint manner; such as vit-yiu vit-yiu vit-yù, and vishnu vishnu voL. I. - I 8 
vishnu, then his woitee woitee woitee and wiltee wiltee wiltee. Soon after I first heard the note of the White-eyed Vireo in March, the Carolina Wren immediately mimicked the note of teeah wĕwá wittee weewá. Some of these notes would appear to be recollections of the past season, as imitations of the Maryland Yellow-Throat (wittisee wittisee wittisee wit, and shewaidit shewaidit shewaidit), not yet heard or arrived within the boundary of the United States. So also his tsherry tsherry tsherry tshup is one of the notes of the Baltimore Bird, yet in South America.

While at Tuscaloosa, about the 2 oth of February, one of these Wrens, on the borders of a garden, sat and repeated for some time tshe-whiskee whiskee whiskee, then soolait soolait soolait; another of his phrases is tshukădee tshukădee tshukădeetshoo and chjübway chjübway chjübway, uttered quick; the first of these expressions is in imitation of one of the notes of the Scarlet Tanager. Amidst these imitations and variations, which seem almost endless, and lead the stranger to imagine himself, even in the depth of winter, surrounded by all the quaint choristers of the summer, there is still, with our capricious and tuneful mimic, a favorite theme more constantly and regularly repeated than the rest. This was also the first sound that I heard from him, delivered with great spirit, though in the dreary month of January. This sweet and melodious ditty, tsee-toot tsee-toot tsee-toot, and sometimes tsee-toot tseetoot seet, was usually uttered in a somewhat plaintive or tender strain, varied at each repetition with the most delightful and delicate tones, of which no conception can be formed without experience. That this song has a sentimental air may be conceived from its interpretation by the youths of the country, who pretend to hear it say swěet-heart swěet-heart swěet! Nor is the illusion more than the natural truth; for, usually, this affectionate ditty is answered by its mate, sometimes in the same note, at others, in a different call. In most cases it will be remarked that the phrases of our songster are uttered in 3's ; by this means it will generally be practicable to distinguish its performance from that of other birds, and particularly from 
the Cardinal Grosbeak, whose expressions it often closely imitates both in power and delivery. I shall never, I believe, forget the soothing satisfaction and amusement I derived from this little constant and unwearied minstrel, my sole vocal companion through many weary miles of a vast, desolate, and otherwise cheerless wilderness. Yet with all his readiness to amuse by his Protean song, the epitome of all he had ever heard or recollected, he was still studious of concealment, keeping busily engaged near the ground, or in low thickets, in quest of his food; and when he mounted a log or brush pile, which he had just examined, his color, so similar to the fallen leaves and wintry livery of Nature, often prevented me from gaining a glimpse of this wonderful and interesting mimic.

Like the preceding species, he has restless activity and a love for prying into the darkest corners after his prey, and is particularly attached to the vicinity of rivers and wet places, when not surrounded by gloomy shade. His quick and capricious motions, antic jerks, and elevated tail resemble the actions of the House Wren. Eager and lively in his contracted flight, before shifting he quickly throws himself forward, so as nearly to touch his perch previous to springing from his legs. In Tuscaloosa and other towns in Alabama he appeared frequently upon the tops of the barns and out-houses, delivering with energy his varied and desultory lay. At Tallahassee, in West Florida, I observed one of these birds chanting near the door of a cottage, and occasionally imitating, in his way, the squalling of the crying child within, so that, like the Mocking Bird, all sounds, if novel, contribute to his amusement.

This species is common in the Southern States and north to $40^{\circ}$, being extremely abundant in southern Illinois, and it occasionally wanders to northern Ohio and to New York, Connecticut, Massachusetts, and southern New Hampshire. Mr. Saunders reports that one was taken near London, Ontario, in February, 1891.

Note. - The Florida Wren (T.ludovicianus miamensis) is a larger, darker form, which is restricted to southeastern Florida. 


\section{BEWICK'S WREN. \\ LONG-TAILED HOUSE WREN. \\ THRYOTHORUS BEWICKII.}

CHAR. Above, chestnut brown; tail with dark bars; wings not barred; buff stripe over eye; below, dull white; flanks brown. Length 5 to $5 \frac{1}{2}$ inches.

Nest. Almost anywhere. In settled districts it is usually built in a crevice of a house or barn; but in the woods a hollow tree or stump is selected, or a clump of bushes. Composed of a mass of leaves, grass, etc., roughly put together.

Eggs. 4-7; white or with pink tint, thickly marked with fine spots of reddish brown and purple; $0.65 \times 0.50$.

For the discovery of this beautiful species of Wren, apparently allied to the preceding, with which it seems nearly to agree in size, we are indebted to the indefatigable Audubon, in whose splendid work it is for the first time figured. It was observed by its discoverer, towards the approach of winter, in the lower part of Louisiana. Its manners are very similar to those of other species, but instead of a song, at this season it only uttered a low twitter.

Dr. Bachman found this species to be the most prevalent of any other in the mountains of Virginia, particularly about the Salt Sulphur Springs, where they breed and pass the season. The notes bear some resemblance to those of the Winter Wren, being scarcely louder or more connected. From their habit of prying into holes and hollow logs they are supposed to breed in such situations. Mr. Trudeau believes that they breed in Louisiana. In the marshy meadows of the Wahlamet Mr. Townsend and myself frequently saw this species, accompanied by the young, as early as the month of May. At this time they have much the habit and manners of the Marsh Wren, and probably nest in the tussocks of rank grass in which we so frequently saw them gleaning their prey. They were now shy, and rarely seen in the vicinity of our camp.

Bewick's Wren is abundant along the Mississippi valley, but is rarely seen east of the Alleghanies or north of latitude $40^{\circ}$. 


\section{SHORT-BILLED MARSH WREN.}

\section{Cistothorus STELLARIS.}

ChAR. Above, brown, very dark on crown and back, and streaked everywhere with buffy; wings and tail with dark bars; below, buffy white, paler on throat and belly; breast and sides shaded with brown Length 4 to $4 \frac{1}{2}$ inches.

Nest. On the ground, amid a tuft of high grass, in fresh-water marsh or swampy meadow ; composed of grass, lined with vegetable down. Usually the tops of surrounding grass are weaved above the nest, leaving an entrance at the side.

Eggs. 6-8; white; $0.65 \times 0.50$.

This amusing and not unmusical little species inhabits the lowest marshy meadows, but does not frequent the reed-flats. It never visits cultivated grounds, and is at all times shy, timid, and suspicious. It arrives in this part of Massachusetts about the close of the first week in May, and retires to the South by the middle of September at farthest, probably by night, as it is never seen in progress, so that its northern residence is only prolonged about four months. In winter this bird is seen from South Carolina to Texas.

His presence is announced by his lively and quaint song of 'tsh 'tship, ă dăy' dăy dăy dăy', delivered in haste and earnest at short intervals, either when he is mounted on a tuft of sedge, or while perching on some low bush near the skirt of the marsh. The 'tsh 'tship is uttered with a strong aspiration, and the remainder with a guttural echo. While thus engaged, his head and tail are alternately depressed and elevated, as if the little odd performer were fixed on a pivot. Sometimes the note varies to 'tship 'tship 'tshia, $d h$ ' $d h$ ' $d h$ ' $d h$ ', the latter part being a pleasant trill. When approached too closely, which not often happened, as he never permitted me to come within two or three feet of his station, - his song became harsh and more hurried, like 'tship dă dă dă, and de de de de $d^{\prime \prime} d$ ' dh, or tshe de de de de, rising into an angry, petulant cry, sometimes also a low, hoarse, and scolding daigh daigh; then again on invading the nest the sound sank to a plaintive 'tsh 
tship, 'tsh tship. In the early part of the breeding season the male is very lively and musical, and in his best humor he tunes up a 'tship 'tship tship a dee, with a pleasantly warbled and reiterated $d e$. At a later period another male uttered little else than a hoarse and guttural daigh, hardly louder than the croaking of a frog. When approached, these birds repeatedly descend into the grass, where they spend much of their time in quest of insects, chiefly crustaceous, which with moths, constitute their principal food; here, unseen, they still sedulously utter their quaint warbling, and tship tship a day day day day may for about a month from their arrival be heard pleasantly echoing on a fine morning from the borders of every low marsh and wet meadow provided with tussocks of sedge-grass, in which they indispensably dwell, for a time engaged in the cares and gratification of raising and providing for their young.

The nest of the Short-billed Marsh Wren is made wholly of dry or partly green sedge, bent usually from the top of the grassy tuft in which the fabric is situated. With much ingenuity and labor these simple materials are loosely entwined together into a spherical form, with a small and rather obscure entrance left in the side; a thin lining is sometimes added to the whole, of the linty fibres of the silk-weed or some other similar material. The eggs, pure white and destitute of spots, are probably from 6 to 8 . In a nest containing 7 eggs there were 3 of them larger than the rest and perfectly fresh, while the 4 smaller were far advanced towards hatching; from this circumstance we may fairly infer that two different individuals had laid in the same nest, - a circumstance more common among wild birds than is generally imagined. This is also the more remarkable as the male of this species, like many other Wrens, is much employed in making nests, of which not more than one in three or four are ever occupied by the females.

The summer limits of this species, confounded with the ordinary Marsh-Wren, are yet unascertained; and it is singular to remark how near it approaches to another species inhabiting the temperate parts of the southern hemisphere in America, namely, the Sylvia platensis, figured and indicated by 
Buffon. The time of arrival and departure in this species, agreeing exactly with the appearance of the Marsh Wren of Wilson, appears to prove that it also exists in Pennsylvania with the following, whose migration, according to Audubon, is more than a month earlier and later than that of our bird. Mr. Cooper, however, has not been able to meet with it in the vicinity of New York, but Dr. Trudeau found its nest in the marshes of the Delaware.

This Wren occurs throughout the Eastern Province north to Massachusetts on the Atlantic, and in the west to Manitoba, breeding generally north of $40^{\circ}$, and wintering in the Gulf States. It is found in eastern Canada only on the marshes near Lake St. Clair.

\section{LONG-BILLED MARSH WREN.}

\section{CistothoRUS PALUSTRIS.}

CHAR. Above, dull reddish brown, darker on crown; back black, streaked with white; white line over eyes; wings and tail with dark bars; below, buffy white, shaded on sides with brown. Length 5 to $5 \frac{1}{2}$ inches.

Nest. In a salt marsh or reedy swamp of interior, fastened to reeds or cat-tails or a small bush; composed of grass and reeds, sometimes plastered with mud, lined with fine grass or feathers. It is bulky and spherical in form, the entrance at the side.

Eggs. 6-10; generally so thickly covered with dark-brown spots as to appear uniform chocolate with darker spots; $0.65 \times 0.50$.

This retiring inhabitant of marshes and the wet and sedgy borders of rivers arrives in the Middle States of the Union early in April, and retires to the South about the middle of October. It is scarcely found to the north of the State of New York, its place in New England being usually occupied by the preceding species, though a few individuals are known to breed in the marshes near Cambridge and Boston.

It is a remarkably active and quaint little bird, skipping and diving about with great activity after its insect food and their larvæ among the rank grass and rushes, near ponds and the low banks of rivers, where alone it affects to dwell, laying no claims to the immunities of the habitable circle of man, but content with its favorite marshes; neglected and seldom 
seen, it rears its young in security. The song, according to the observations of a friend, is very similar to that of the preceding, - a sort of short, tremulous, and hurried warble. Its notes were even yet heard in an island of the Delaware, opposite to Philadelphia, as late as the month of September, where they were still in plenty in this secluded asylum. Towards the close of the breeding season the song often falls off into a low, guttural, bubbling sound, which appears almost like an effort of ventriloquism.

The nest, according to Wilson, is generally suspended among the reeds and securely tied to them at a sufficient height above the access of the highest tides. It is formed of wet rushes well intertwisted together, mixed with mud, and fashioned into the form of a cocoa-nut, having a small orifice left in the side for entrance. The principal material of this nest, as in the preceding species, is, however, according to Audubon, the leaves of the sedge-grass, on a tussock of which it also occasionally rests. The young quit the nest about the 2oth of June, and they generally have a second brood in the course of the season. From the number of empty nests found in the vicinity of the residence of the Marsh Wren, it is pretty evident that it is also much employed in the usual superfluous or capricious labor of the genus. The pugnacious character of the males, indeed, forbids the possibility of so many nests being amicably occupied in the near neighborhood in which they are commonly found.

This Wren is common in suitable localities in Massachusetts, but has not been found farther northward. It occurs westward to the Pacific, and south (in winter) to the Gulf States. It appears on Canadian territory only in southern Ontario and Manitoba.

Note. - Worthington's Marsh Wren (C. palustris griseus) and Marian's Marsh Wren (C. $p$. mariana) have been discovered somewhat recently. Both are smaller than true palustris. Griseus is described as the palest of the three, and "its dark markings are less pronounced. It is restricted to the coast of South Carolina and Georgia," while mariance has been found only on the southwestern coast of Florida. The latter race is the darkest of the three. 


\section{RUBY-CROWNED KINGLET.}

\section{Regulus Calendula.}

CHAR. Above, olive, brighter on rump; crown with a concealed patch of rich scarlet, white at the base, - wanting in female and young; white ring around the eyes; wings and tail dusky, the feathers edged with dull buff; wings with two white bars; below, dull white tinged with buff. Length about $4 \frac{1}{4}$ inches.

Nest. In woodland, usually partially pensile, suspended from extrem. ity of branch, - often placed on top of branch, sometimes against the trunk, - on coniferous tree, Io to 30 feet from the ground; neatly and compactly made of shreds of bark, grass, and moss, lined with feathers or hair.

Eggs. 6-9; dull white or buff, spotted, chiefly around larger end, with bright reddish brown; $0.55 \times 0.43$.

These beautiful little birds pass the summer and breeding season in the colder parts of the North American continent, penetrating even to the dreary coasts of Greenland, where, as well as around Hudson's Bay and Labrador, they rear their young in solitude, and obtain abundance of the diminutive flying insects, gnats, and cynips, on which with small caterpillars they and their young delight to feed. In the months of October and November the approach of winter in their natal regions stimulates them to migrate towards the South, when they arrive in the Eastern and Middle States, and frequent in a familiar and unsuspicious manner the gardens and orchards; how far they proceed to the South is uncertain. On the I 2 th of January I observed them near Charleston, South Carolina, with companies of Sylvias busily darting through the evergreens in swampy situations in quest of food, probably minute larvæ. About the first week in March I again observed them in West Florida in great numbers, busily employed for hours together in the tallest trees, some of which were already unfolding their blossoms, such as the maples and oaks. About the beginning of April they are seen in Pennsylvania on their way to the dreary limits of the continent, where they only arrive towards the close of May, so that in the extremity of their range they do not stay more than three months. Wilson, 
it would appear, sometimes met with them in Pennsylvania even in summer; but as far as I can learn, they are never observed in Massachusetts at that season, and with their nest and habits of incubation we are unacquainted. In the fall they seek society apparently with the Titmouse and Golden-Crested Kinglet, with whom they are intimately related in habits, manners, and diet; the whole forming a busy, silent, roving company, with no object in view but that of incessantly gleaning their now scanty and retiring prey. So eagerly, indeed, are they engaged at this time that scarcely feeling sympathy for each other, or willing to die any death but that of famine, they continue almost uninterruptedly to hunt through the same tree from which their unfortunate companions have just fallen by the destructive gun. They only make at this time, occasionally, a feeble chirp, and take scarcely any alarm, however near they are observed. Audubon met with this species breeding in Labrador, but did not discover the nest; its song, he remarks, is fully as sonorous as that of the Canary, - as powerful and clear, and even more varied.

This species probably breeds from about latitude $45^{\circ}$ to the lower fur countries, and on the higher mountains to the southward. Few nests have been discovered. Rev. Frank Ritchie found one near Lennoxville, Quebec, and Harry Austen has taken another near Halifax, in which he found II eggs.

The full song is much more elaborate and more beautiful than the bird has usually been credited with, for it has been described by writers who have heard only the thin, weak notes more generally uttered. Mr. Chapman describes this song as mellow and flute-like, "loud enough to be heard several hundred yards; an intricate warble past imitation or description, and rendered so admirably that I never hear it now without feeling an impulse to applaud."

Note. - Cuvier's Kinglet (Regulus cuvieri) was placed on the "Hypothetical List" by the A. O. U. Committee. The single bird shot by Audubon in Pennsylvania is the only specimen that has been obtained. 


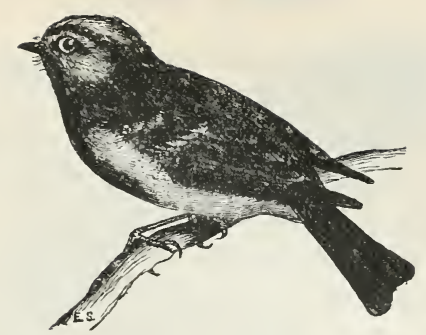

\section{GOLDEN-CROWNED KINGLET.}

\section{REGULUS SATRAPA.}

Char. Above, olive, brightest on the rump; crown with patch of orange red and yellow, bordered by black (female and young lacking the red); forehead and line over eyes and patch beneath, dull white; wings and tail dusky, the feathers edged with dull buff; two white bars on wings; below, dull white with buff tint. Length 4 inches

Nest. In damp coniferous woods, often wholly or partially pendent from small twigs near end of branch (sometimes saddled upon the branch) Io to 50 feet from the ground; usually made of green moss and lichens, lined at bottom with shreds of soft bark and roots, and often with feathers fastened to inside of edge, and so arranged that the tips droop over and conceal the eggs; sometimes the nest is a spherical mass of moss and lichens, lined with vegetable down and wool; the entrance at the side.

Eggs. 6-Io; usually creamy or pale buff, sometimes white, unmarked, or dotted with pale reddish brown and lavender over entire surface, often merely a wreath, more or less distinct around larger end; 0.55 $\times 0.45$.

These diminutive birds are found, according to the season, not only throughout North America, but even in the West Indies. They appear to be associated only in pairs, and are seen on their southern route, in this part of Massachusetts, a few days in October, and about the middle of the month, or a little earlier or later according to the setting in of the season, as they appear to fly before the desolating storms of the northern regions, whither they retire about May to breed. Some few remain in Pennsylvania until December or January, proceeding probably but little farther south during the winter. They are not known to reside in any part of New England, retiring to the same remote and desolate limits of the farthest North with the preceding species, of which they have most of 
the habits. They are actively engaged during their transient visits to the South in gleaning up insects and their lurking larvæ, for which they perambulate the branches of trees of various kinds, frequenting gardens and orchards, and skipping and vaulting from the twigs, sometimes head downwards like the Chickndee, with whom they often keep company, making only now and then a feeble chirp. They appear at this time to search chiefly after spiders and dormant concealed coleopterous or shelly insects; they are also said to feed on small berries and some kinds of seeds, which they break open by pecking with the bill in the manner of the Titmouse. They likewise frequent the sheltered cedar and pine woods, in which they probably take up their roost at night. Early in April they are seen on their return to the North in Pennsylvania; at this time they dart among the blossoms of the maple and elm in company with the preceding species, and appear more volatile and actively engaged in seizing small flies on the wing, and collecting minute, lurking caterpillars from the opening leaves. On the 2 Ist of May, I 835, I observed this species feeding its full-fledged young in a tall pine-tree on the banks of the Columbia River.

The range of this species is now set down as "Eastern North America, breeding from the northern border of the United States northward and southward along the Rockies and the Alleghanies; wintering south to Guatemala." Until quite recently it was supposed to be a migrant through Massachusetts, wintering in small numbers, but has been discovered breeding in both Berkshire and Worcester counties. It is a resident of the settled portion of Canada, though not common west of the Georgian Bay, and rarely breeding south of latitude $45^{\circ}$.

The song is a rather simple "twittered warble," shrill and highpitched. 


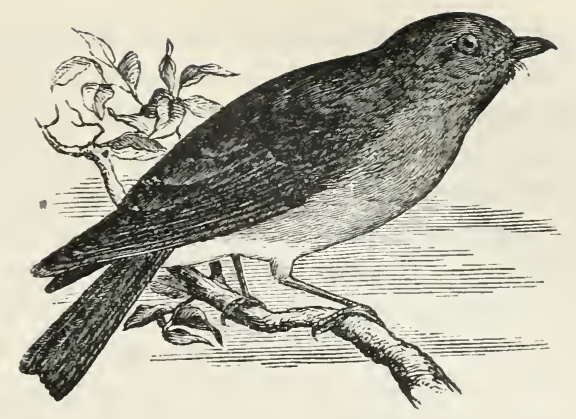

B L UEBIR D.

\section{Sialia SIALIS.}

Char. Male : above, azure blue, duller on cheeks; throat, breast, and sides reddish brown; belly and under tail-coverts white; shafts of feathers in wing and tail, black. Female : duller, blue of back mixed with grayish brown; breast with less of rufous tint. Length about $63 / 4$ inches.

Nest. In a hollow tree, deserted Woodpecker's hole, or other excavation or crevice, or in a bird-box ; meagrely lined with grass or feathers.

Eggs. 4-6; usually pale blue, sometimes almost white; $0.85 \times 0.65$.

These well-known and familiar favorites inhabit almost the whole eastern side of the continent of America, from the 48th parallel to the very line of the tropics. Some appear to migrate in winter to the Bermudas and Bahama islands, though most of those which pass the summer in the North only retire to the Southern States or the tableland of Mexico. In South Carolina and Georgia they were abundant in January and February, and even on the 12 th and 28 th of the former month, the weather being mild, a few of these wanderers warbled out their simple notes from the naked limbs of the long-leaved pines. Sometimes they even pass the winter in Pennsylvania, or at least make their appearance with almost every relenting of the severity of the winter or warm gleam of thawing sunshine. From this circumstance of their roving about in quest of their scanty food, like the hard-pressed and hungry Robin Redbreast, who by degrees gains such courage from necessity as to enter the cottage for his allowed crumbs, it has, without foundation, 
been supposed that our Bluebird, in the intervals of his absence, passes the tedious and stormy time in a state of dormancy; but it is more probable that he flies to some sheltered glade, some warm and more hospitable situation, to glean his frugal fare from the berries of the cedar or the wintry fruits which still remain ungathered in the swamps. Defended from the severity of the cold, he now also, in all probability, roosts in the hollows of decayed trees, - a situation which he generally chooses for the site of his nest. In the South, at this cheerless season, Bluebirds are seen to feed on the glutinous berries of the mistletoe, the green-brier, and the sumach. Content with their various fare, and little affected by the extremes of heat and cold, they breed and spend the summer from Labrador to Natches, if not to Mexico, where great elevation produces the most temperate and mild of climates. They are also abundant, at this season, to the west of the Mississippi, in the territories of the Missouri and Arkansas.

In the Middle and Northern States the return of the Bluebird to his old haunts round the barn and the orchard is hailed as the first agreeable presage of returning spring, and he is no less a messenger of grateful tidings to the farmer, than an agreeable, familiar, and useful companion to all. Though sometimes he makes a still earlier flitting visit, from the $3 \mathrm{~d}$ to the middle of March he comes hither as a permanent resident, and is now accompanied by his mate, who immediately visits the box in the garden, or the hollow in the decayed orchard tree, which has served as the cradle of preceding generations of his kindred. Affection and jealousy, as in the contending and related Thrushes, have considerable influence over the Bluebird. He seeks perpetually the company of his mate, caresses and soothes her with his amorous song, to which she faintly replies; and, like the faithful Rook, seeks occasion to show his gallantry by feeding her with some favorite insect. If a rival make his appearance, the attack is instantaneous, the intruder is driven with angry chattering from the precincts he has chosen, and he now returns to warble out his notes of triumph by the side of his cherished consort. The business of preparing and 
cleaning out the old nest or box now commences; and even in October, before they bid farewell to their favorite mansion, on fine days, influenced by the anticipation of the season, they are often observed to go in and out of the box, as if examining and planning out their future domicile. Little pains, however, are requisite for the protection of the hardy young, and a substantial lining of hay, and now and then a few feathers, is all that is prepared for the brood beyond the natural shelter of the chosen situation. As the Martin and House Wren seek out the favor and convenience of the box, contests are not unfrequent with the parties for exclusive possession; and the latter, in various clandestine ways, exhibits his envy and hostility to the favored Bluebird. As our birds are very prolific, and constantly paired, they often raise 2 and sometimes probably 3 broods in the season; the male taking the youngest under his affectionate charge, while the female is engaged in the act of incubation.

Their principal food consists of insects, particularly beetles and other shelly kinds; they are also fond of spiders and grasshoppers, for which they often, in company with their young, in autumn, descend to the earth, in open pasture fields or waste grounds. Like our Thrushes, they, early in spring, also collect the common wire-worm, or Iulus, for food, as well as other kinds of insects, which they commonly watch for, while perched on the fences or low boughs of trees, and dart after them to the ground as soon as perceived. They are not, however, flycatchers, like the Sylvicolas and Muscicapas, but are rather industrious searchers for subsistence, like the Thrushes, whose habits they wholly resemble in their mode of feeding. In the autumn they regale themselves on various kinds of berries, as those of the sour-gum, wild-cherry, and others; and later in the season, as winter approaches, they frequent the red cedars and several species of sumach for their berries, eat persimmons in the Middle States, and many other kinds of fruits, and even seeds, - the last never entering into the diet of the proper Flycatchers. They have also, occasionally, in a state of confinement, been reared and fed 
on soaked bread and vegetable diet, on which they thrive as well as does the Robin.

The song of the Bluebird, which continues almost uninterruptedly from March to October, is a soft, rather feeble, but delicate and pleasing warble, often repeated at various times of the day, but most frequently in early spring when the sky is serene and the temperature mild and cheering. At this season, before the earnest Robin pours out his more energetic lay from the orchard tree or fence-rail, the simple song of this almost domestic favorite is heard nearly alone; and if at length he be rivalled, at the dawn of day, by superior and bolder songsters, he still relieves the silence of later hours by his unwearied and affectionate attempts to please and accompany his devoted mate. All his energy is poured out into this simple ditty, and with an ecstatic feeling of delight he often raises and quivers his wings like the Mocking Orpheus, and amidst his striving rivals in song, exerts his utmost powers to introduce variety into his unborrowed and simple strain. On hearkening some time to his notes, an evident similarity to the song of the Thrush is observable; but the accents are more weak, faltering, and inclining to the plaintive. As in many other instances, it is nearly impossible to give any approximating idea of the expression of warbled sounds by words; yet their resemblance to some quaint expressions, in part, may not be useless, as an attempt to recall to memory these pleasing associations with native harmony: so the Bluebird often at the commencement of his song seems tenderly to call in a whistled tone 'hear - héar büty, buty? or merely hear - büty, and instantly follows this interrogatory call with a soft and warbling trill. So much is this sound like that which these birds frequently utter that on whistling the syllables in their accent, even in the cool days of autumn, when they are nearly silent, they often resume the answer in sympathy. During the period of incubation, the male becomes much more silent, and utters his notes principally in the morning. More importantly engaged, in now occasionally feeding his mate as well as himself, and perhaps desirous of securing the interesting occupa- 
tion of his devoted consort, he avoids betraying the resort of his charge by a cautious and silent interest in their fate. Gentle, peaceable, and familiar when undisturbed, his society is courted by every lover of rural scenery; and it is not uncommon for the farmer to furnish the Bluebird with a box, as well as the Martin, in return for the pleasure of his company, the destruction he makes upon injurious insects, and the cheerfulness of his song. Confident in this protection, he shows but little alarm for his undisturbed tenement; while in the remote orchard, expecting no visitor but an enemy, in company with his anxious mate he bewails the approach of the intruder, and flying round his head and hands, appears by his actions to call down all danger upon himself rather than suffer any injury to arrive to his helpless brood.

Towards autumn, in the month of October, his cheerful song nearly ceases, or is now changed into a single plaintive note of tshāy-w̌rt, while he passes with his flitting companions over the fading woods; and as his song first brought the welcome intelligence of spring, so now his melancholy plaint presages but too truly the silent and mournful decay of Nature. Even when the leaves have fallen, and the forest no longer affords a shelter from the blast, the faithful Bluebirds still linger over their native fields, and only take their departure in November, when at a considerable elevation, in the early twilight of the morning, till the opening of the day, they wing their way in small roving troops to some milder regions in the South. But yet, after this period, in the Middle States, with every return of moderate weather we hear their sad note in the fields or in the air, as if deploring the ravages of winter; and so frequent are their visits that they may be said to follow fair weather through all their wanderings till the permanent return of spring.

If the Bluebird ever tried the climate of Labrador, it evidently discovered that the weather there was not suitable, for now it rarely goes north of latitude $45^{\circ}$. A few pairs are seen every season about the farm-lands on the upper St. John, in New Brunswick, and Philip Cox has seen several at Newcastle, near the mouth of the Miramichi. Comeau found a pair breeding at Godbout, and Thompson reports that they have lately entered Manitoba.

VOL. I. - I 9 


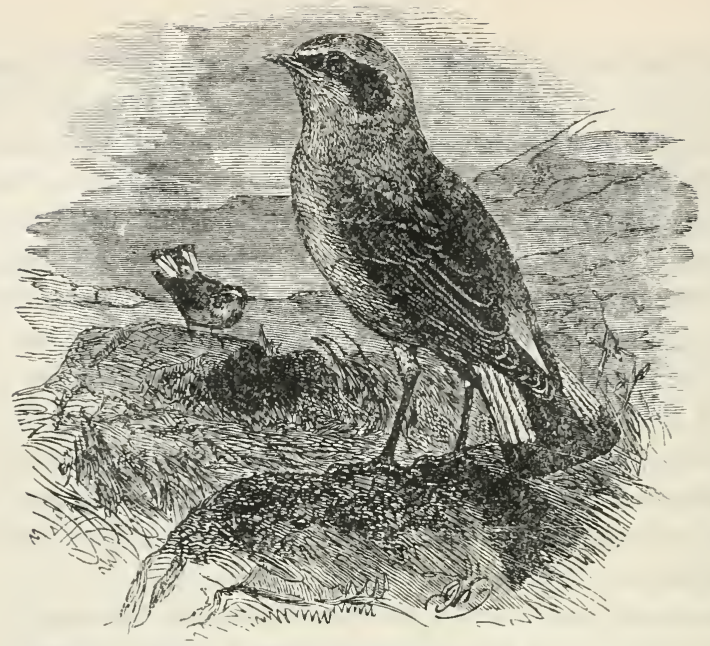

WHEATEAR.

\section{SAXICOLA ENANTHE.}

CHAR. Above, bluish gray; forehead and stripe over eyes white; patch on cheek and wings black; rump white; middle tail-feathers black, rest white, broadly tipped with black; under parts white. In the female the upper parts are brown, and under parts buff. Length $6 \frac{1}{2}$ inches.

Nest. In a crevice of a stone wall or a stone heap; made of plant stems and grass, lined with feathers, hair, or rabbit's fur.

Eggs. 5-7; pale blue, sometimes spotted with pale tawny, or purple; $0.85 \times 0.65$.

The first mention of the occurrence of this species in eastern America appeared in Holböll's account of the birds of Greenland, issued in $\mathbf{1} 846$; it had been reported previously from the Pacific coast by Vigors. In I 854 the name appeared in Cassin's work, and in Baird's "Report" of I 859 it was recorded as "accidental in the northern part of North America."

It should not be termed accidental at the present day, for it occurs regularly in Greenland and Labrador and at Godbout, on the St. Lawrence, and has been taken in winter in Nova Scotia, Maine, New York, Long Island, Louisiana, and Bermuda.

American writers formerly gave the vernacular name as "Stonechat," or "Stone Chat," - Coues alone adding Wheatear (as a synonym). 
The Stonechat is a different bird, though Magillivray called the present species the "White-rumped Stonechat." Throughout Europe the bird is commonly known as the "White-rump," and Saunders considers the name "wheatear" a corruption of white and ars, - the Anglo-Saxon equivalent of the modern word "rump."

In Europe and Asia the species is abundant, breeding from central Europe far to the northward, and migrating in winter to north. ern Africa. A few winter in the British Islands, though these may be of the Greenland race, which some authors think is a distinct form, - larger than those that breed in Europe,-as the Greenland birds are known to migrate across Great Britain. Ridgway states that the examples taken on our western coast are smaller and more like those found in central Europe.

Formerly large numbers were trapped in the autumn on the Southdowns in England, and marketed, being considered little inferior in delicacy to the famous Ortolans.

The favorite resorts of the Wheatear at all seasons are the lonely moors or open meadows by the sea-shore. It is an active bird and always alert, keeping up a perpetual flitting. It is very terrrestrial, though the Greenland race is said to perch on trees more frequently than the European bird.

The song is sweet and sprightly, and the male often sings while hovering over his mate.

Mr. Hagerup writes to me that the birds in Greenland sing at times very similarly to the Snow Buntings, - a song that he never heard from the Wheatears of Denmark, - and this song is rendered by both females and males. Seebohm writes: "The love notes form a short but pleasing song; and the more particularly are we apt to view his performance with favor, because it generally greets the ear in wild and lonely places." And again: "Sometimes he warbles his notes on his perch, accompanying them with graceful motion of the wings, and finally launching into the air to complete his song, the aerial fluttering seeming to give the performance additional vigor." Dixon has seen "two Wheatears in the air together, buffeting each other, and singing lustily all the time, with all the sweetness that love rivalry inspires." 


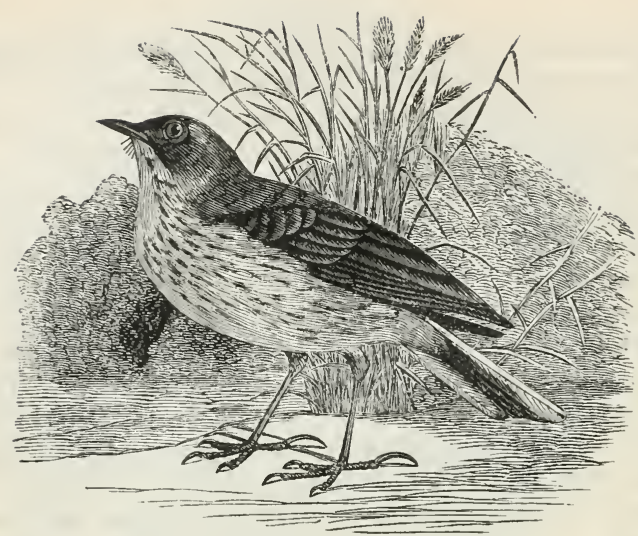

\section{AMERICAN PIPIT.}

TITLARK.

\section{ANTHUS PENSILVANICUS.}

CHAR. Above, olive brown, edges of the feathers paler; line over and around the eye pale buff ; wings dusky, edges of feathers pale brown; tail dusky, middle feathers olive brown, large patches of white on outer feathers; below, dull buff, breast and sides spotted with brown. Length $61 / 2$ inches.

Nest. On the ground, usually sheltered by stone or mound; a bulky affair of grass, stems, moss, and lichens, - sometimes only grass is used, - often loosely made, occasionally compact.

Eggs. 4-6; variable in color, usually dull white covered thickly with reddish brown and purplish brown; sometimes the markings so nearly conceal the ground color as to give appearance of a brown egg with gray streaks; $0.80 \times 0.60$.

This is a winter bird of passage in most parts of the United States, arriving in loose, scattered flocks from the North, in the Middle and Eastern States, about the second week in October. In the month of April we saw numerous flocks flitting over the prairies of Missouri, on their way, no doubt, to their breeding quarters in the interior. Audubon found these birds also in the summer on the dreary coast of Labrador. During the breeding season the male often rises on wing to the height of eight or ten yards, uttering a few clear and 
mellow notes, and then suddenly settles down near the nest or on some projecting rock. They leave Labrador and Newfoundland as soon as the young are able to fly, or about the middle of August. According to their well-known habits, they frequent open flats, commons, and ploughed fields, like a Lark, running rapidly along the ground, taking by surprise their insect prey of flies, midges, and other kinds, and when resting for an instant, keeping the tail vibrating in the manner of the European Wagtail. They also frequent the river shores, particularly where gravelly, in quest of minute shell-fish, as well as aquatic insects and their larvæ. At this time they utter only a feeble note or call, like tweet tweet, with the final tone often plaintively prolonged; and when in flocks, wheel about and fly pretty high, and to a considerable distance before they alight. Sometimes families of these birds continue all winter in the Middle States, if the season prove moderate. In the Southern States, particularly North and South Carolina, they appear in great flocks in the depth of winter. On the shores of the Santee, in January, I observed them gleaning their food familiarly amidst the Vultures, drawn by the rubbish of the city conveyed to this quarter. They likewise frequent the cornfields and rice-grounds for the same purpose. They emigrate to the Bermudas, Cuba, and Jamaica, and penetrate in the course of the winter even to Mexico, Guiana, and Brazil. They also inhabit the plains of the Oregon. They are again seen on their return to the North, in Pennsylvania, about the beginning of May or close of April.

The Titlark is distributed over North America at large, breeding in subarctic regions and wintering in the Gulf States and Central America. During the autumn migrations it is abundant on the moorlands along the coasts of New England and the Maritime Provinces.

Note. - Two European congeners of the Titlark, the White Wagtail (Motacilla alba) and the Meadow Pipit (Anthus pratensis) have been captured in Greenland, but should be considered merely as "accidentals" in that region.

SPRAGUE's PIPIT (Anthus spragueii), a bird of the western plains, has been taken near Charleston, S. C. 


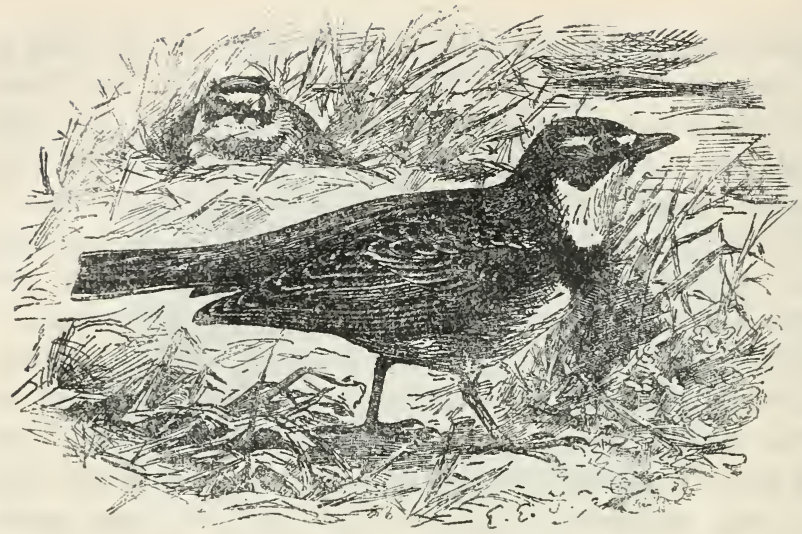

HORNED LARK.

SHORE LARK.

\section{OTOCORIS ALPESTRIS.}

CHAR. Above, dull grayish brown streaked with darker; nape, shoulders, and rump pink-vinaceous cinnamon; black bar across forehead and along sides of head, terminating in erectile horn-like tufts; throat and line over the eyes, yellow; black bar from nostril curving below the eyes; below, dull white, shaded on the sides with same color as back; breast tinged with yellow and bearing large black patch; middle tail-feathers like back, the rest black, with white patches on outer pair. Length about $7 \mathrm{r} / 2$ inches.

Nest. On the ground, amid a bed of moss; composed of grass, lined with feathers.

Eggs. 4-5; dull white with buff or purple tint spotted with purplish brown or olive brown and lilac; $0.93 \times 0.70$.

This beautiful species is common to the north of both the old and new continent; but, as in some other instances already remarked, the Shore Lark extends its migrations much farther over America than over Europe and Asia. Our bird has been met with in the Arctic regions by the numerous voyagers, and Mr. Bullock saw it in the winter around the city of Mexico, so that in their migrations over this continent these birds spread themselves across the whole habitable northern hemisphere to the very equator; while in Europe, according to the careful obser- 
vations of Temminck, they are unknown to the south of Germany. Pallas met with these birds round Lake Baikal and on the Volga, in the $53 \mathrm{~d}$ degree of latitude. Westward they have also been seen in the interior of the United States, along the shores of the Missouri.

They arrive in the Northern and Middle States late in the fall or commencement of winter. In New England they are seen early in October, and disappear generally on the approach of the deep storms of snow, though straggling parties are still found nearly throughout the winter. In the other States to the South they are more common at this season, and are particularly numerous in South Carolina and Georgia, frequenting open plains, old fields, common grounds, and the dry shores and banks of bays and rivers, keeping constantly on the ground, and roving about in families under the guidance of the older birds, who, watching for any approaching danger, give the alarm to the young in a plaintive call very similar to that which is uttered by the Skylark in the same circumstances. Inseparable in all their movements, like the hen and her fostered chickens, they roost together in a close ring or company, by the mere edge of some sheltering weed or tuft of grass on the dry and gravelly ground, and thickly and warmly clad, they abide the frost and the storm with hardy indifference. They fly rather high and loose, in scattered companies, and follow no regular time of migration, but move onward only as their present resources begin to fail. They are usually fat, esteemed as food, and are frequently seen exposed for sale in our markets. Their diet, as usual, consists of various kinds of seeds which still remain on the grass and weeds they frequent, and they swallow a considerable portion of gravel to assist their digestion. They also collect the eggs and dormant larvæ of insects when they fall in their way. About the middle of March they retire to the North, and are seen about the beginning of May round Hudson Bay, after which they are no more observed till the return of autumn. They arrive in the fur countries along with the Lapland Buntings, with which they associate; and being more shy, act the sentinel usually to 
the whole company in advertising them of the approach of danger. They soon after retire to the marshy and woody districts to breed, extending their summer range to the Arctic Sea. They are said to sing well, rising into the air and warbling as they ascend, in the manner of the Skylark of Europe. "The male," says Audubon, like the Common Lark, "soars into the air, sings with cheerfulness over the resort of his mate, and roosts beside her and his nest on the ground, having at this season a very remarkable appearance in the development of the black and horn-like egrets."

Happy Nuttall, to have died before "variety making" came into fashion! You had but one form of Horned Lark to deal with, while I am confronted with eleven. Fortunately a large number of these sub-species have never taken it into their horned heads to cross into the territory under present consideration, so I am saved from puzzling myself and my readers with their diagnosis.

The true alpestris is found during summer in the region between the Gulf of St. Lawrence and Greenland west to Hudson Bay, and in winter south to about latitude $35^{\circ}$. It is quite common along the New England shores while migrating and in winter.

The PRAIRIE Horned LARK (O. alpestris praticola) is a smaller bird with very gray back; line over eyes white; chin pale yellow.

This race is found in summer along the upper Mississippi valley and Great Lake region, eastward sparingly to Montreal, Vermont, and Long Island. It is resident over the greater portion of its range, but some few winter south to the Carolinas and Texas. 


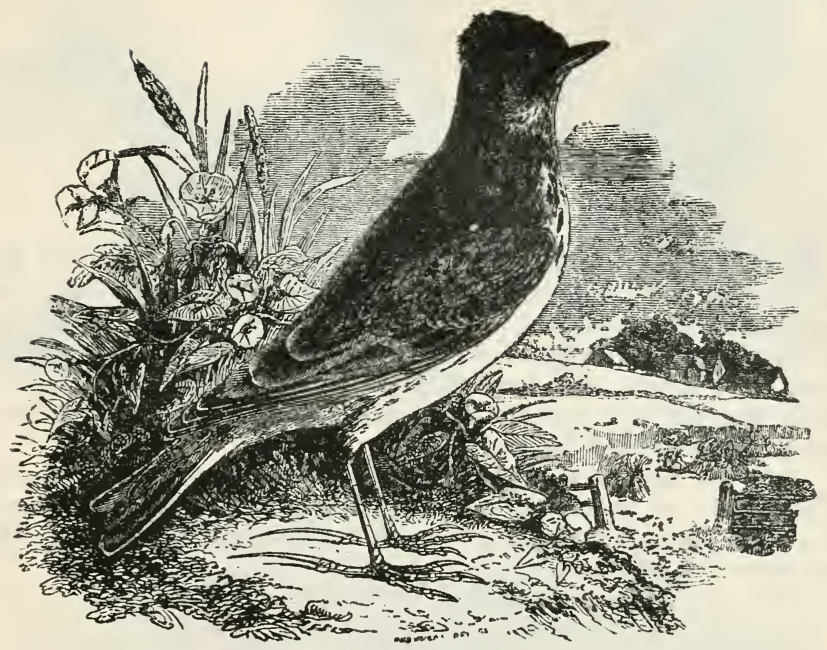

SKYLARK.

Alauda arvensis.

CHAR. Above, yellowish brown streaked with dark brown, darkest on back and crown; buff streak over the eye; wings brown, margined with buff and tipped with white; outer tail-feathers mostly white; below, pale buff, spotted and streaked with brown. Length about 7 inches.

Nest. In a meadow, under a tuft of grass; made of coarse and fine grass.

Eggs. 3-5; dull gray, marked with olive brown; $0.95 \times 0.70$.

Although not mentioned by Nuttall, this European bird becomes entitled to a place among the birds of America through its occurrence casually in Greenland and Bermuda. About I 886 a number of these birds were liberated in New York State and New Jersey, and in I888 a colony appeared established at Flatbush, Long Island; but the experiment has not been successful, for this colony has disappeared, and Mr. Frank M. Chapman, writing in 1895 , says: "At the present time the species is not known to exist in North America in a wild state." 


\section{DICKCISSEL.}

\section{BLACK-THROATED BUNTING.}

\section{SPIZA AMERICANA.}

CHAR. Male: above, gray brown, middle of back streaked with black; nape and side of head ash ; crown olive streaked with dusky; line over the eyes yellow; chin white; large patch of black on throat; two wing-bars chestnut; edge of wing yellow; below, white tinged with yellow; sides shaded with brown. Female: similar, somewhat smaller; throat without patch, but with black spots; less tinge of yellow on lower parts. Length 6 to 7 inches.

Nest. On the prairie or in a field or pasture or open scrubby woods; placed upon the ground or in a bush or low tree, sometimes 10 to 20 feet from ground; made of grass, weed-stalks, leaves, and roots, lined with fine grass or hair.

Eggs. 4-5; pale greenish blue, unspotted; $0.80 \times 0.60$.

These birds arrive in Pennsylvania and New England from the South about the middle of May, and abound in the vicinity of Philadelphia, where they seem to prefer level fields, building their nests on the ground, chiefly of fine withered grass. They also inhabit the prairies of Missouri, the State of New York, the remote northern regions of Hudson's Bay, and are not uncommon in this part of New England, dwelling here, however, almost exclusively in the high, fresh meadows near the saltmarshes. Their song, simple and monotonous, according to Wilson consists only of five notes, or rather two, the first being repeated twice and slowly, the second thrice and rapidly, resembling tshsp tship, tshe tshe tshé. With us their call is 'tic 'tic - tshĕ tshĕ tshĕ tship, and tship tship, tshë tshè tshĕ tship. From their arrival nearly to their departure, or for two or three months, this note is perpetually heard from every level field of grain or grass; both sexes also often mount to the top of some low tree of the orchard or meadow, and there continue to chirp forth in unison their simple ditty for an hour at a time. While thus engaged they may be nearly approached without exhibiting any appearance of alarm or suspicion; and though the species appears to be numerous, they live in harmony, and 

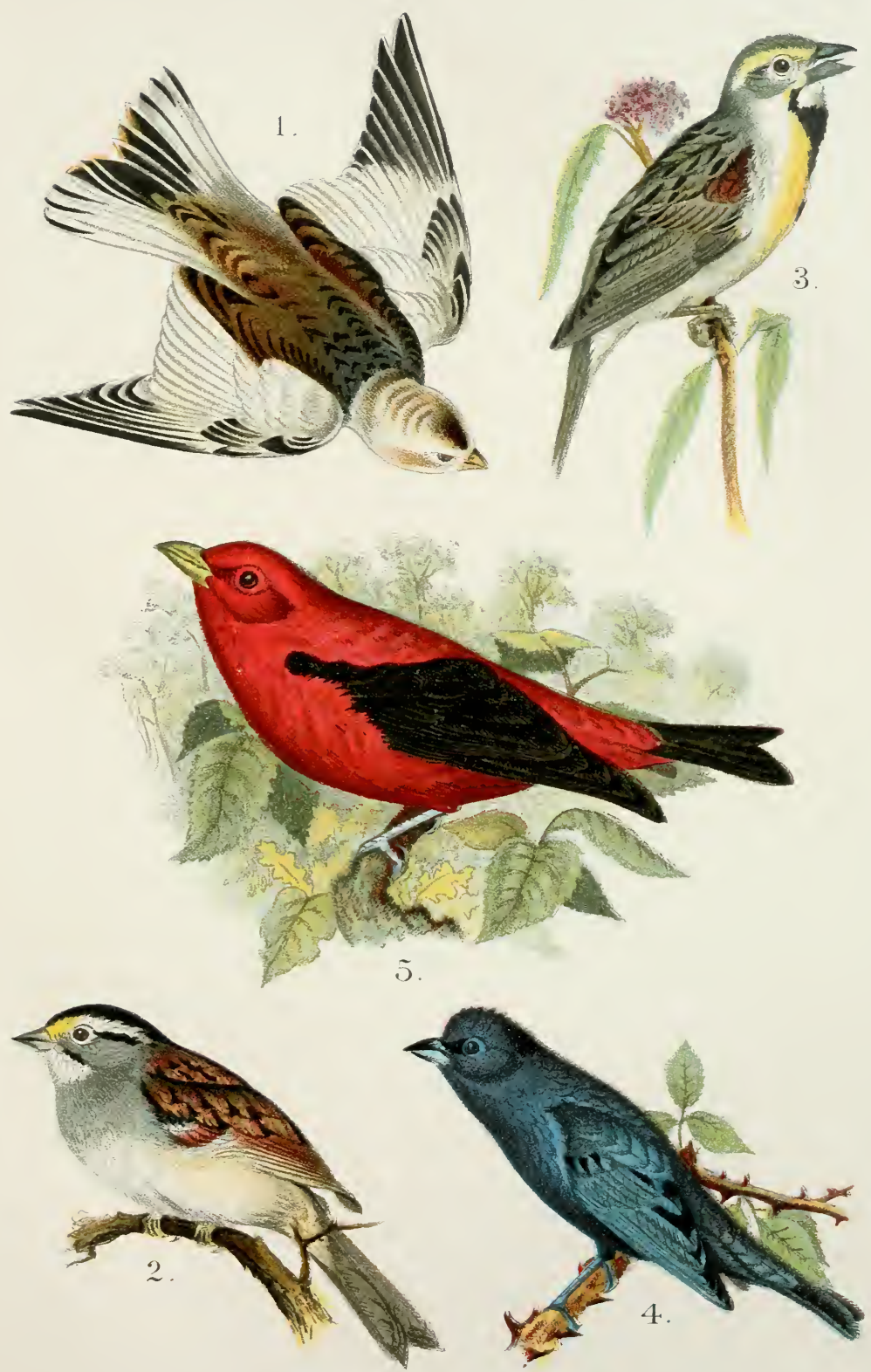

1. Snowflake.

3. Black-Throated Bunting. 5. Scarlet Tanager.

2. White-Throated Sparrow. 4. Indigo Bunting. 

rarely display any hostility to the birds around them, or amongst each other. In August they become mute, and about the beginning of September depart for the South, wintering as well as breeding in Texas and other parts of Mexico, but are not seen in the Southern States at any period of the winter. Their food consists of seeds, eggs of insects, and gravel, and in the early part of summer they subsist much upon caterpillars and small coleopterous insects; they are also among the many usual destroyers of the ruinous cankerworm.

This species is now restricted chiefly to the valley of the Mississippi, though it occurs sparingly in southern New England, but is merely accidental farther to the northward. The only examples that have been met with in Canada were the few that Mr. William E. Saunders found breeding at Point Pelee in southern Ontario.

Mr. William Brewster, writing of this species, says: "It is now unquestionably one of the rarest species known to breed within this region (New England). Moreover, within the past two decades it has practically disappeared from the Middle States, where it was formerly abundant, and at many localities west of the Alleghanies and east of the Mississippi its numbers have diminished steadily and more or less rapidly."

Note. - Townsend's Bunting (Spiza townsendii) was placed on the "Hypothetical List" by the A. O. U. Committee. The type specimen taken by Mr. Townsend in Pennsylvania remains unique.

The LaRk Bunting (Calamospiza melanocorys) has been seen in Massachusetts and Long Island, - the only instances of its occurrence east of the Great Plains. 


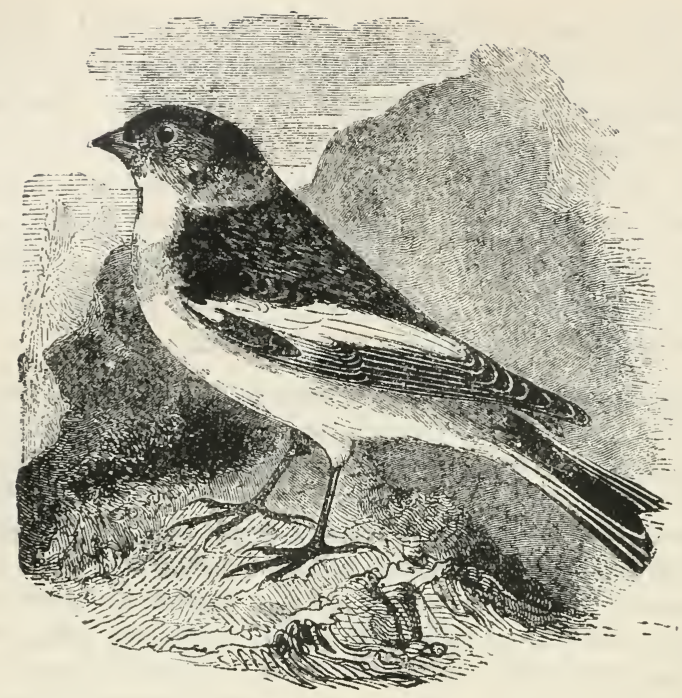

SNOWFLAKE.

\section{SNOW BUNTING. WHITE SNOW BIRD.}

\section{Plectrophenax Nivalis.}

Char. In summer, prevailing color white ; middle of back, wings, and tail mixed with black. In autumn the dark color is extended, the black being broadly margined with tawny brown, which gradually becomes white as winter advances. Length about $63 / 4$ inches.

Nest. On a barren hillside, under shelter of a rock or in a stone heap, sometimes in cavity of a sand-bank; compactly built of dry grass, plant stems, and moss, lined with feathers and hair.

Eggs. 4-6; dull white, with faint tint of blue or green, spotted, chiefly around larger end, with reddish brown and lavender; $0.90 \times 0.65$.

This messenger of cold and stormy weather chiefly inhabits the higher regions of the Arctic circle, whence, as the severity of the winter threatens, they migrate indifferently over Europe, eastern Asia, and the United States. On their way to the South they appear round Hudson Bay in September, and stay till the frosts of November again oblige them to seek out warmer quarters. Early in December they make their descent 
into the Northern States in whirling, roving flocks, either immediately before or soon after an inundating fall of snow. Amidst the drifts, and as they accumulate with the blast, flocks of these illwars fogel, or bad-weather birds, of the Swedes, like the spirits of the storm are to be seen flitting about in restless and hungry troops, at times resting on the wooden fences, though but for an instant, as, like the congenial Tartar hordes of their natal regions, they appear now to have no other object in view but an escape from famine and to carry on a general system of forage while they happen to stay in the vicinity. At times, pressed by hunger, they alight near the door of the cottage and approach the barn, or even venture into the out-houses in quest of dormant insects, seeds, or crumbs wherewith to allay their hunger; they are still, however, generally plump and fat, and in some countries much esteemed for the table. In fine weather they appear less restless, somewhat more familiar, and occasionally even at this season they chant out a few unconnected notes as they survey the happier face of Nature. At the period of incubation they are said to sing agreeably, but appear to seek out the most desolate regions of the cheerless North in which to waste the sweetness of their melody, unheard by any ear but that of their mates. In the dreary wastes of Greenland, the naked Lapland Alps, and the scarcely habitable Spitzbergen, bound with eternal ice, they pass the season of reproduction seeking out the fissures of rocks on the mountains in which to fix their nests about the month of May or June. A few are known to breed in the alpine declivities of the White Mountains of New Hampshire. The nest is here fixed on the ground in the shelter of low bushes, and formed nearly of the same materials as that of the Common Song Sparrow.

At times they proceed as far south in the United States as the State of Maryland. They are here generally known by the name of the White Snow Bird, to distinguish them from the more common dark-bluish Sparrow, so called. They vary in their color according to age and season, and have always a great predominance of white in their plumage. 
The Snow Buntings are seen in spring to assemble in Norway and its islands in great numbers; and after a stay of about three weeks they disappear for the season, and migrate across the Arctic Ocean to the farthest known land. On their return in winter to the Scottish Highlands their flocks are said to be immense, mingling, by an aggregating close flight, almost into the form of a ball, so as to present a very fatal and successful mark for the fowler. They arrive lean, but soon become fat. In Austria they are caught in snares or traps, and when fed with millet become equal to the Ortolan in value and flavor. When caged they show a very wakeful disposition, instantly hopping about in the night when a light is produced. Indulgence in this constant train of action and perpetual watchfulness may perhaps have its influence on this species, in the selection of their breeding places within the Arctic regions, where for months they continue to enjoy a perpetual day.

The food of these birds consists of various kinds of seeds and the larvæ of insects and minute shell-fish; the seeds of aquatic plants are also sometimes sought by them, and I have found in their stomachs those of the Ruppia, species of Polygonum, and gravel. In a state of confinement they shell and eat oats, millet, hemp-seed, and green peas, which they split. They rarely perch, and, like Larks, live much on the ground.

This harbinger of winter breeds in the northernmost of the American islands and on all the shores of the continent from Chesterfield Inlet to Behring's Straits. The most southerly of its breeding stations in America, according to Richardson, is Southampton Island, in the $62 \mathrm{~d}$ parallel, where Captain Lyons found a nest, by a strange fatality, placed in the bosom of the exposed corpse of an Esquimaux child. Well clothed and hardy by nature, the Snow Bunting even lingers about the forts of the fur countries and open places, picking up grass-seeds, until the snow becomes deep. It is only during the months of December and January that it retires to the southward of Saskatchewan, and it is seen again there on its return as early as the middle of February, two months after which it arrives in the $65^{\text {th }}$ parallel, and by the beginning of May it 
has penetrated to the coast of the Polar Sea. At this period it feeds upon the buds of the purple saxifrage (Saxifraga oppositifolia), one of the most early of the Arctic plants.

As the Snow Bunting sometimes begins to visit the United States in October, it appears pretty certain that some of these birds breed almost, if not quite, within the northern limits of the Union; and as stated elsewhere, a nest has been found near the rocky summit of the White Mountains of New Hampshire.

The Snow Bunting is usually restricted in summer to the higher latitudes, - from Labrador and the Great Slave Lake region to the Arctic Ocean, - but an occasional flock is seen farther southward, and nests have been taken in the White Mountains. In winter these birds range south to the Middle States, occasionally going as far as "Georgia and Kansas." Numbers spend the winter in New Brunswick, gathering in flocks of twenty to fifty. They are to be seen about the suburbs of St. John as well as on the margins of lakes in the deep forests.

Mr. A. Hagerup, who saw considerable of this bird when in Greenland, writes to me that the song is a sweet and pleasing melody, though rather disconnected, "delivered in short stanzas." "Warbling," he adds, " is perhaps the English word best suited to describe its character." 


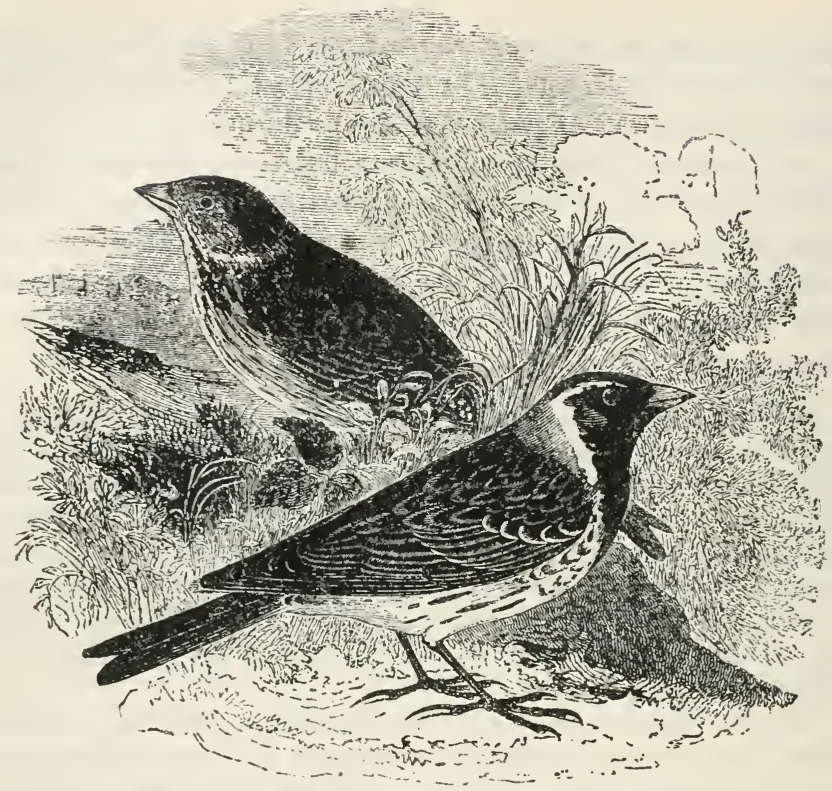

\section{LAPLAND LONGSPUR.}

\section{CALCARIUS Lapponicus.}

CHAR. Above, brownish black. the feathers edged with dull buff, wing-feathers with dull bay; head and throat rich black (female and young have the crown same as back); line from eyes and down side of throat, white; band of bright chestnut across hind-neck; tail with patches of white on outer feathers ; below, dull white, breast and sides marked with black; bill yellow, tipped with black; legs and feet black. Length about $6 \frac{1}{4}$ inches.

Nest. In swampy moorlands, amid deep moss or tuft of grass, or at the base of a mound ; composed of grass, plant-stems, roots, and moss, lined with feathers or deer's hair.

Eggs. 4-7; pale grayish brown or reddish brown, marked with dark brown; $0.80 \times 0.60$.

This species generally inhabits the desolate Arctic regions of both continents. In the United States a few stragglers from the greater body show themselves in winter in the remote and 
unsettled parts of Maine, Michigan, and the Northwestern Territories. Large flocks also at times enter the Union, and contrary to their usual practice of resting and living wholly on the ground, occasionally alight on trees. They leave the colder Arctic deserts in the autumn, and are found around Hudson Bay on their way to the South in winter, not making their appearance there before November. Near Severn River they haunt the cedar-trees, upon whose berries they now principally feed. They live in large flocks, and are so gregarious that when separated from their own species, or in small parties, they usually, in Europe, associate with the common Larks, or, in America, they join the roving bands of Snow Birds. In the fur countries they extend their migrations in the spring as far as the $65^{\text {th }}$ parallel, where they were seen about Fort Franklin by the beginning of May; at this time they fed much upon the seeds of the Alpine arbutus. They feed principally on seeds, and also on grass, leaves, buds, and insects. They breed on small hillocks, among moss and stones, in open marshy fields, and the nest is thickly and loosely constructed of moss and grass, and lined with a few feathers and deer's hair. The Longspur, like the Lark, sings only as it rises in the air, in which, suspended aloft, it utters a few agreeable and melodious notes.

The Longspur occurs in winter in South Carolina, Kentucky, and Kansas, though it is not common south of about $40^{\circ}$.

Of its song Mr. Hagerup writes to me: "It sounds best when the bird, after mounting up in the sky, drops slowly to the earth with extended wings. The song is not very long, but has a sweet, flute-like tone, and though the melody is attractive, it is almost melancholy in its wild plaintiveness, - as, indeed, all the notes of this species are."

Note. - The Chestnut-collared Longspur (Calcarius ornatus) has been taken in Massachusetts and Long Island.

SMITH's LoNGSPUR (Calcarius pictus), which occurs in the interior, - breeding from the Great Slave Lake district to the Arctic Ocean, - is found, in winter, in Illinois.

VOL. I. -20 


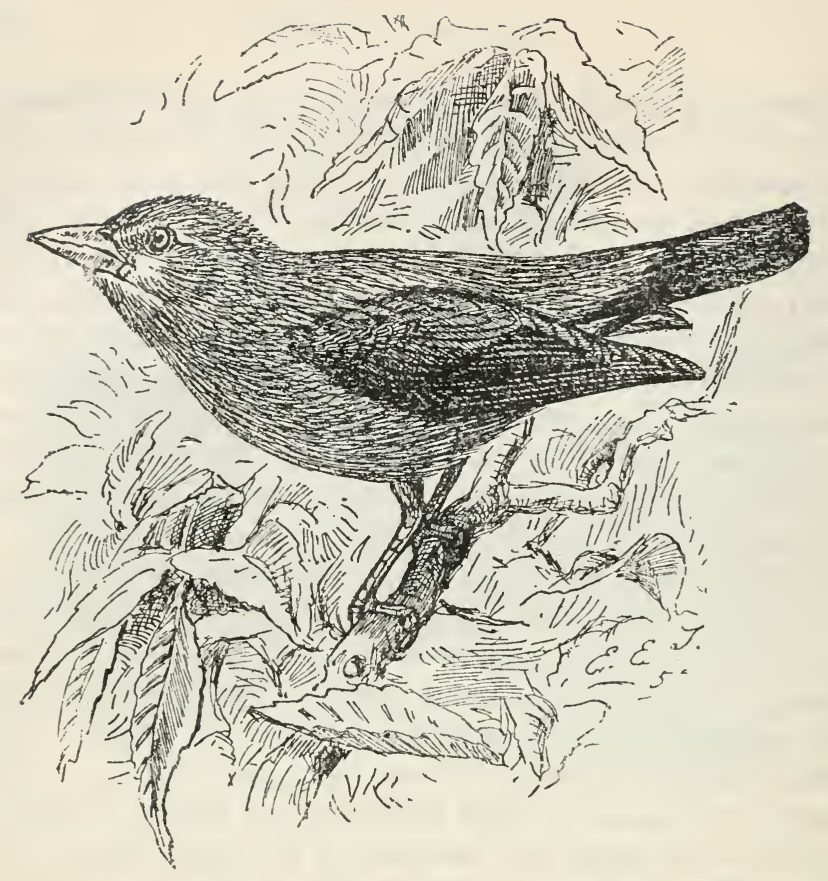

SCARLET TANAGER.

Piranga eRYThromelas.

CHAR. Male : scarlet, with black wings and tail. Male in winter: similar to female, but with black wings and tail. Female and young: above, olive; wings and tail dusky, the feathers edged with olive; below, greenish yellow. Length 7 to $71 / 2$ inches.

Nest. In a woodland grove, sometimes in an orchard, placed near the extremity of a horizontal limb io to 20 feet from the ground; composed of twigs, roots, or shreds of bark, and lined with roots, sometimes with pine-needles.

Eggs. 3-5 (usually 4); dull white or with blue tinge, thickly marked, with several shades of brown and lilac; $0.95 \times 0.65$.

This splendid and transient resident, accompanying fine weather in all his wanderings, arrives from his winter station in tropical America from the beginning to the middle of May, and extends his migrations probably to Nova Scotia as well as Canada. With the shy, unsocial, and suspicious habits of his gaudy fraternity, he takes up his abode in the deepest recess 
of the forest, where, timidly flitting from observation, he darts from tree to tree like a flashing meteor. A gaudy sylph, conscious of his brilliance and the exposure to which it subjects him, he seems to avoid remark, and is only solicitous to be known to his humble mate, and hid from all besides. $\mathrm{He}$ therefore rarely approaches the habitations of men, unless perhaps the skirts of the orchard, where he sometimes, however, builds his nest, and takes a taste of the early and inviting, though forbidden, cherries.

Among the thick foliage of the tree in which he seeks support and shelter, from the lofty branches, at times we hear his almost monotonous tship wïtee, tship-ïdee, or tshükadee, tshükadee repeated at short intervals and in a pensive undertone, heightened by the solitude in which he delights to dwell. The same note is also uttered by the female when the retreat of herself and young is approached; and the male occasionally utters in recognition to his mate, as they perambulate the branches, a low whispering 'tait in a tone of caution and tenderness. But besides these calls on the female, he has also during the period of incubation, and for a considerable time after, a more musical strain, resembling somewhat in the mellowness of its tones the song of the fifing Baltimore. The syllables to which I have hearkened appear like 'tshoove 'wait 'wait 'vehöwit wait, and 'wait 'vehŏwit vea wait, with other additions of harmony for which no words are adequate. This pleasing and highly musical meandering ditty is delivered for hours, in a contemplative mood, in the same tree with his busy consort. If surprised, they flit together, but soon return to their favorite station in the spreading boughs of the shady oak or hickory. The song resembles that of the Red-eyed Vireo in its compass and strain, though much superior, the 'wait wait being whistled very sweetly in several tones and with emphasis, so that upon the whole, our Piranga may be considered as duly entitled to various excellence, being harmless to the farmer, brilliant in plumage, and harmonious in voice.

These birds only sojourn long enough to rear their single brood, which are here fledged early in July, leaving us already 
for the South about the middle or close of August, or as soon as the young are well able to endure the fatigue of an extensive migration in company with their parents. The female shows great solicitude for the safety of her only brood, and on an approach to the nest appears to be in great distress and apprehension. When they are released from her more immediate protection, the male, at first cautious and distant, now attends and feeds them with activity, being altogether indifferent to that concealment which his gaudy dress seems to require from his natural enemies. So attached to his now interesting brood is the Scarlet Tanager that he has been known, at all hazards, to follow for half a mile one of his young, submitting to feed it attentively through the bars of a cage, and, with a devotion which despair could not damp, roost by in the branches of the same tree with its prison; so strong, indeed, is this innate and heroic feeling that life itself is less cherished than the desire of aiding and supporting his endearing progeny (Wilson).

The food of the Scarlet Tanager while with us consists chiefly of winged insects, wasps, hornets, and wild bees, as well as smaller kinds of beetles and other shelly tribes; it probably also sometimes feeds on seeds, and is particularly partial to whortleberries and other kinds which the season affords.

About the beginning of August the male begins to moult, and then exchanges his nuptial scarlet for the greenish livery of the female. At this period these birds leave us; and having passed the winter in the celibacy indicated by this humble garb, they arrive again among us on its vernal renewal, and so soon after this change that individuals are at this time occasionally seen with the speckled livery of early autumn, or with a confused mixture of green and scarlet feathers in scattered patches.

The Scarlet Tanager is common throughout this Eastern Province north to about latitude $44^{\circ}$, and occurs sparingly along the Annapolis valley, in Nova Scotia and along the valley of the St. John in New Brunswick, also near the city of Quebec and in the vicinity of Lake Winnipeg. It breeds from Virginia northward and winters in northern South America. 


\title{
SUMMER TANAGER.
}

\author{
SUMMER RED-BIRD.
}

\section{Piranga RUBRa.}

CHAR. Male: rich vermilion, duller above. Female and young: above, dull olive; below, dull buff. Length about $71 / 2$ inches.

Nest. On the edge of an open grove or by a roadside, placed near the extremity of a horizontal limb; composed of grass, leaves, and vegetable fibre, lined with grass.

Eggs. 3-4; bright green, sometimes with a tinge of blue, spotted, chiefly near the larger end, with various shades of brown and purple; $0.95 \times 0.65$.

This brilliant and transient resident, like the former species, passes the greatest part of the year in tropical America, whence in his gaudy nuptial suit he presents himself with his humble mate in the Southern States in the latter end of April or by the Ist of May. In Pennsylvania these birds are but rarely seen, though in the warm and sandy barren forests of New Jersey several pairs may usually be observed in the course of every season; farther north they are unknown, ceding those regions apparently to the scarlet species. They are not confined to any particular soil, though often met with in bushy, barren tracts, and are consequently common even to the west of the Mississippi, in Louisiana and the Territory of Arkansas, as well as Mexico; they also breed near the banks of that river around Natchez.

The nest is built in the woods on the low, horizontal branch of a tree, often in an evergreen ro or 12 feet from the ground. Both parents assist in incubation, and the young are fledged by the middle or latter end of June. They only raise a single brood in the season, and towards the middle or close of August the whole party disappear on their way to the South, though the young remain later than the old and more restless birds.

The note of the male, like that of the Baltimore Bird, is said to be a strong and sonorous whistle, resembling the trill or 
musical shake on the fife, and is frequently repeated. The note of the female is a chattering, and appears almost like the rapid pronunciation of tshicky-tukky-tuk, tshicky-tukky-tuk, and is chiefly uttered in alarm when any person approaches the vicinity of her nest. From the similarity of her color to the foliage of the trees, she is, however, rarely seen, and is usually mute; while the loquacity and brilliance of the male render him, as he flits timidly and wildly through the branches, a most distinguished and beautiful object.

The food of the Summer Red Bird is very similar to that of the preceding species; bugs, beetles, and stinging bees make part of his repast, as well as flies and cynips of various kinds, after which he often darts about until hindered by the approach of night. The late suppers are probably necessary, from the almost nocturnal habits of some of these insect tribes. After the period of incubation, and until their departure, whortleberries and other kinds of berries form no inconsiderable part of the food of these birds.

This species does not occur regularly north of New Jersey, southern Ohio, and southern Illinois. Occasionally stragglers are found in Connecticut and Massachusetts, and two examples have been taken in New Brunswick, one in Nova Scotia, four near Montreal, and one at Hamilton, Ontario.

Note. - Specimens of the Louisiana Tanager (Piranga ludoviciana) - a Western species - have been taken in New York, Connecticut, Massachusetts, and Maine.

\section{INDIGO BUNTING.}

\section{Passerina Cyanea.}

CHAR. Male: indigo blue, intense on head and throat, other parts tinged with green; black bar from bill to eyes; wings and tail brown, the edge of feathers tinged with blue. Female : above, brown; below, much paler, with dark streaks. Length about $5 \frac{1}{2}$ inches.

Nest. On the margin of a meadow or country road, or in an orchard or garden, in a bush or low tree, placed in an upright crotch; a rather 
clumsy and bulky affair of twigs, stems, grass, etc., lined with fine grass, etc., sometimes with horse-hair.

Eggs. 4-5; white, sometimes with blue or green tint, occasionally with a few fine spots of purplish brown; $0.75 \times 0.55$.

This very beautiful and rather familiar messenger of summer, after passing the winter in tropical America, towards the $15^{\text {th }}$ of May, decked in his brilliant azure livery of the nuptial season, again joyfully visits his natal regions in the Middle States; and about a week or ten days later his lively trill in the garden, orchard, or on the top of the house, its chimney, or vane, is first heard in this part of New England. Still later, accompanied by his mate, he passes on to Nova Scotia, and probably to the precincts of Labrador. After raising and training their only brood in a uniform and more humble dress, the whole family, in color like so many common Sparrows, begin to retire to the South from the first to the middle of September. They are also known in Mexico, where, as well as in the Southern States to the peninsula of Florida, they breed and pass the summer as with us. There is reason, however, to believe that they are less abundant, if seen at all, to the west of the Mississippi; but yet they are met with in the Western States up to the alluvial lands of that great natural boundary.

Their food in the early part of the season, as well as that of their young for a considerable time, is chiefly insects, worms, and caterpillars, as well as grasshoppers, of which they are particularly fond. They likewise eat seeds of various kinds, and are readily reared in a cage on the usual diet of the Canary.

Though naturally shy, active, and suspicious, particularly the brilliant male, they still at this interesting period of procreation resort chiefly to the precincts of habitations, around which they are far more common than in the solitary woods, seeking their borders or the thickets by the sides of the road; but their favorite resort is the garden, where, from the topmost bough of some tall tree which commands the whole wide landscape, the male regularly pours out his lively chant, and continues it for a considerable length of time. Nor is this song 
confined to the cool and animating dawn of morning, but it is renewed and still more vigorous during the noon-day heat of summer. This lively strain seems composed of a repetition of short notes; commencing loud and rapid, and then, slowly falling, they descend almost to a whisper, succeeded by a silent interval of about half a minute, when the song is again continued as before. The most common of these vocal expressions sounds like she tshe tshe-tshé tshéé tshée - tshé tshé tshe. The middle syllables are uttered lispingly, in a very peculiar manner, and the three last gradually fall; sometimes the song is varied and shortened into tshea tshea tshea tshrè, the last sound being sometimes doubled. This shorter song is usually uttered at the time that the female is engaged in the cares of incubation, or as the brood already appear, and when too great a display of music might endanger the retiring security of the family. From a young or imperfectly moulted male, on the summit of a weeping-willow, I heard the following singularly lively syllables, 'tle 'tle 'tle tă lee, repeated at short intervals. While thus prominently exposed to view, the little airy minstrel is continually on the watch against any surprise, and if he be steadily looked at or hearkened to with visible attention, in the next instant he is off to seek out some securer elevation. In the village of Cambridge I have seen one of these azure, almost celestial musicians, regularly chant to the inmates of a tall dwelling-house from the summit of the chimney or the point of the forked lightning-rod. I have also heard a Canary, within hearing, repeat and imitate the slowly lisping trill of the Indigo Bird, whose warble indeed often greatly resembles that of this species. The female, before hatching her brood, is but seldom seen, and is then scarcely distinguishable from a common Sparrow; nor is she ever to be observed beyond the humble bushes and weeds in which she commonly resides.

The nest of our bird is usually built in a low bush partly concealed by rank grass or grain; at times in the forks of a young orchard tree ro or 12 feet from the ground. I have also seen one suspended in a complicated manner in a trellised grape- 
vine. If left undisturbed, they often build in the same garden or orchard for several successive years. When in a bush, the nest is suspended betwixt two twigs, passing up on either side. Externally it is composed of coarse sedge-grass, some withered leaves, and lined with fine stalks of the same, and the slender hair-like tops of the bent-grass (Agrostis), with a very few cow-hairs; though sometimes they make a substantial lining of hair. The nest which I saw in the vine was composed outwardly of coarse strips of bass-mat, weeds, and some strings picked up in the garden, and lined with horse-hair and a few tops of bent-grass. The young here scarcely leave the nest before the end of July or the first week in August, and they raise usually but a single brood in the season. They appear to show great timidity about their nest, and often readily forsake it when touched, or when an egg is abstracted. Their usual note of alarm when themselves or their young are approached is a sharp tship, quickly and anxiously repeated, resembling almost the striking of two pebbles. They will not forsake their young, however ready they may be to relinquish their eggs; and they have been known to feed their brood very faithfully through the bars of a cage in which they were confined.

This species is a common summer resident from South Carolina to western Maine and the city of Quebec, and westward through Ontario and Illinois to the Great Plains. It also occurs occasionally in eastern Maine and the Maritime Provinces.

Note. - One example of the VARIEd Bunting (Passerina versicolor) has been captured in southern Michigan. Its usual habitat is the valley of the Rio Grande and Lower California. 


\section{PAINTED BUNTING.}

NONPAREIL.

\section{PASSERINA CIRIS.}

CHAR. Male: head and neck blue; eyelids red; back yellowish green ; rump red; wings dusky, glossed with green; tail purplish brown: below, vermilion. Female: above, olive; below, buff; wings and tail dusky edged with olive. Length $5^{1 / 4}$ inches.

Nest. In a thicket of low bushes; compactly made of twigs, roots, shreds of bark and grass, lined with fine grass or horse-hair, or fine roots.

Eggs. 4-5; dull white, or with blue tint, marked chiefly around larger end with purplish and reddish brown; $0.80 \times 0.60$.

This splendid, gay, and docile bird, known to the Americans as the Nonpareil, and to the French Louisianians as the Pape, inhabits the woods of the low countries of the Southern States, in the vicinity of the sea and along the borders of the larger rivers, from North Carolina to Mexico. It arrives from its tropical quarters in Louisiana and Georgia from the middle to the 2 oth of April; but impatient of cold, retires to the South early in October, and is supposed to winter about Vera Cruz. For the sake of their song as well as beauty of plumage, these birds are commonly domesticated in the houses of the French inhabitants of New Orleans and its vicinity; and some have succeeded in raising them in captivity, where plenty of room was allowed in an aviary. They are familiar also in the gardens and orchards, where their warbling notes are almost perpetually heard throughout the summer. Their song mach resembles that of the Indigo Bird, but their voice is more feeble and concise. Soon reconciled to the cage, they will sing even a few days after being caught. Their food consists of rice, insects, and various kinds of seeds; they collect also the grains of the ripe figs, and, frequenting gardens, build often within a few paces of the house, being particularly attached to the orangeries.

Their nests are usually made in the hedges of the orange, or on the lower branches of the same tree, likewise occasionally in a bramble or thorny bush. In the mildest climates in which 
they pass the summer, they raise two broods in the season. They are commonly caught in trap-cages, to which they are sometimes allured by a stuffed bird, which they descend to attack; and they have been known to survive in domestication for upwards of ten years.

This species is common in the South Atlantic and Gulf States, and has been taken north to southern Illinois and North Carolina.

Note. - The Grassquit (Euetheia bicolor) and the MeloDIOUS GRASSQUiT (Euetheia canora) - both West India birds have been taken in southern Florida, though they are merely accidental wanderers there.

\section{WHITE-CROWNED SPARROW.}

\section{ZONOTRICHIA LEUCOPHRYS.}

CHAR. Upper parts grayish brown, streaked with dull bay, and pale ash ; crown white, bordered by bands of black; lines of black and white from eyes to hind neck; wings with two white bars; tail dusky; below, gray, whitening on throat and belly; flanks shaded with brown. Length about 7 inches.

Nest. In an open woodland, on the ground or in a low bush, usually concealed in grass at the foot of a bush; firmly made of dried grass lined with fine grass, - sometimes with deer's hair or feathers, or roots.

Eggs. 4-6; greenish white or bluish white thickly spotted with reddish brown; $0.90 \times 0.65$.

This rare and handsome species is very little known in any part of the United States, a few stragglers only being seen about the beginning of winter, and again in May or earlier, on their way back to their Northern breeding-places, in the fur countries and round Hudson's Bay, which they visit from the South in May, and construct their nests in June in the vicinity of Albany Fort and Severn River. These are fixed on the ground, or near it, in the shelter of the willow-trees which they glean, probably with many other birds, for the insects which frequent them. 
At this season the male sings in a loud, clear, musical, but rather plaintive tone, the song consisting of six or seven notes; these he repeats at short intervals during the whole day. On the I $3^{\text {th }}$ of April, I835, I saw flocks of this species among the thickets in the vicinity of Santa Barbara, Upper California. They sung with a feeble, quaint note, to me unlike that of any other species, and almost similar to some of the notes of the Chickadee. As they depart from Hudson Bay in September, it is probable that they principally winter in the Canadian provinces, otherwise, as passengers farther south, they would be seen more abundantly in the United States than they are. Indeed, as they approach this part of New England only in small desultory parties in the winter, as in November and December, it is evident that they only migrate a short distance in quest of food, and return to the North at the approach of fine weather. While here they appear silent and solitary, and are not difficult to approach. Their food, as usual, is seeds of grasses, insects, and their larvæ.

This species is not so rare in our day as Nuttall evidently con. sidered it, for it now occurs quite regularly throughout this Eastern Province, though likely to appear in irregular numbers at any given locality. It breeds in northern Maine and New Brunswick, and north to sub-arctic regions. Nests have been found also in Vermont and New York. The birds are met with in winter from southern New England southward to Mexico. 


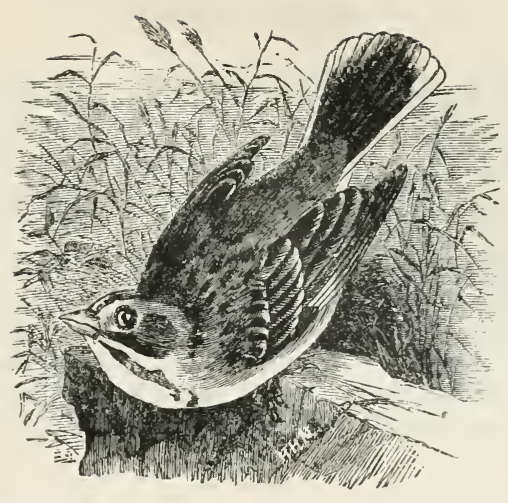

\section{LARK SPARROW.}

\section{LARK FINCH.}

\section{Chondestes grammacus.}

CHAR. Above, grayish olive; the back brown, with fine streaks of black; tail black, - excepting central feathers, - tipped with white, outer web of outer pair entirely white; crown chestnut, with median line of dull white; line over the eye dull white; white crescent under the eyes bordered by black, and behind by chestnut; below white tinged with brown; breast with patch of black. Length 6 to $61 / 2$ inches.

Nest. Usually amid a tuft of grass, but sometimes in a tree or bush; composed of grass and vegetable fibre.

Eggs. 3-5 (usually 4); white or with blue or buff tint, marked with spots and lines of dark brown or black; $0.8_{5} \times 0.65$.

For this species we are again indebted to Mr. Say, who observed it in abundance near the Council Bluffs and the neighboring country of the Missouri in the spring, as well as in the month of June. It appears to be wholly confined to the west side of the Mississippi, and probably extends into Mexico. These birds frequent the prairie grounds, and seldom if ever alight on trees; they sing sweetly, and, like the Larks, have the habit of continuing their notes while on the wing.

Mr. Townsend observes: "This species inhabits several hundred miles of the Platte plains in great numbers, as well as the banks of the Columbia River. It generally affects the low bushes of wormwood (Artemisia), from the summit of which 
it pours forth a variety of pretty notes." At the commencement of the pairing season the males are very pugnacious, fighting often on wing, and the conquering rival, repairing to the nearest bush, tunes his lively pipe in token of success.

The Lark Finch is common along the Mississippi valley north to Iowa and southern Michigan. It has been taken occasionally in Manitoba and in Ontario, and a few examples have appeared in New England, and southward along the Atlantic coast to Florida.

It is said to resemble the Grass Finch in general habits, and its song is somewhat similar.

\section{WHITE-THROATED SPARROW.}

PEABODY BIRD - OLD TOM PEABODY.

\section{ZONOTRICHIA ALBICOLLIS.}

CHAR. Back streaked, reddish brown, black and dull buff; sides of head and rump ashy; crown with median stripe of white bordered by stripes of black; stripes of yellow from bill to eyes; stripes of white over eyes; stripes of black through eyes; throat white; under parts grayish shading to white on the belly, the sides shaded with brown; wings with two white bars. Length $6 \frac{1}{2}$ to 7 inches.

Nest. In an old meadow or open woodland, or on the edge of a grove; placed on the ground upon a cushion of moss; composed of grass, stems, roots, etc., lined with fine grass or roots, - sometimes with hair or feathers.

Esgs. 4-5; pale greenish blue, thickly marked with several shades of reddish brown; $0.85 \times 0.60$.

These large and handsome Sparrows are seen in this part of Massachusetts only as transient visitors at the approach of winter, or in spring about the first week in May. In the Middle and Southern States they pass the inclement season, and appear there as a numerous species. A flock has been observed in the State of New York in the month of January. In their hibernal resorts they are seen in bands, and show a predilection for thickets, swamps, small streams, and the borders of ponds, where, among the tall and bleaching weeds, they continue to collect the seeds, and probably insect larvæ, which constitute their usual fare. While here they keep much on the ground, and seek out cool and shady situations, scratch- 
ing up the fallen leaves in quest of worms and other insects, and are at this time often very unsuspicious, allowing a near approach without betraying any alarm; but when in large flocks, they move about in timorous haste as soon as approached. About the $15^{\text {th }}$ of April they leave the Middle States, and retire to the high northern latitudes to breed, having been seen in Labrador, Newfoundland, and the fur countries up to the 66th parallel in summer. At the period of breeding the male sings with considerable energy and melody already in the early spring; also before their departure to the North, on fine mornings, they are heard to whisper forth a few sweet and clear notes, as in a revery of the approaching happiness of their more lively and interesting condition.

This Sparrow - known to the country people of the East as the "Peabody Bird" and "Kennedy Bird" - breeds abundantly in the northern portions of New York and New England as well as in the Maritime Provinces; and at the west in northern Michigan and Manitoba. According to Mr. Brewster, this bird breeds also "very commonly on Mount Graylock, sparingly in the northern part of Worcester County, Massachusetts, and occasionally in eastern Massachusetts." The bird winters sparingly in southern New England, and commonly thence southward to Florida.

The song, which is loud and sweet, is familiar in the district where the birds build, for they sing all day long, and are often heard during the night. It has been interpreted peá-peá-peábody. peábody-peabody; hence the name. 


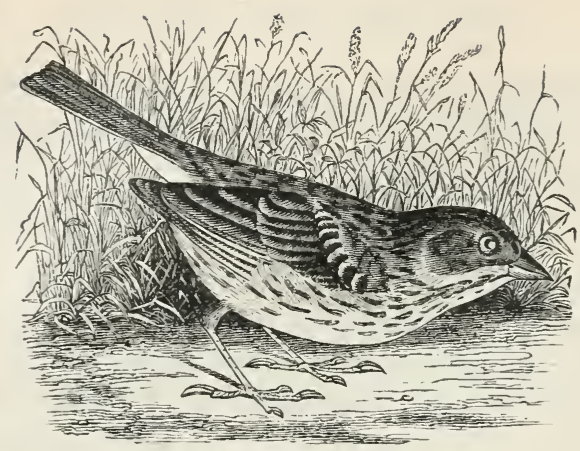

VESPER SPARROW.

\section{GRASS FINCH. BAY-WINGED BUNTING.}

\section{POOCÆTES GRAMINEUS.}

CHAR. Above, yellowish brown, streaked with darker; line over and around eyes, white; shoulder chestnut or bay; two white bars on wing; two outer tail-feathers partly white; below, white with buffy tinge; breast and sides streaked with brown. Length about $6 \frac{1}{4} /$ inches.

Nest. In a field, old meadow, open pasture, or roadside, on the ground, - usually hidden by tuft of grass or under a low bush; composed of grass and roots, and lined with fine grass, sometimes with hair.

Eggs. 4-6: grayish white, sometimes with green or pink tint, thickly marked with several shades of brown; $0.80 \times 0.60$.

This plain-looking Finch chiefly frequents dry pastures and meadows, and is often seen perched on the fences and in orchard trees; it also often approaches the public roads and gathers its subsistence tamely from various sources. It is abundant in all the States east of the Alleghanies, where many pass the whole year; yet great numbers also winter in the southern parts of the Union, proceeding as far as the maritime districts of Georgia and Florida. From the beginning of April to the beginning of June, the males sing with a clear and agreeable note, scarcely inferior to that of the Canary, though less loud and varied. On their first arrival, as with the Song Sparrow, their notes are often given in an under-tone of considerable sweetness. Their song begins at early dawn, and is again peculiarly frequent after sunset until dark, when, from 
the fence of some elevated pasture-field, in the cool of the summer evening, when other songsters have retired to rest, the Grass Sparrow, more than usually wakeful, after a silence which has perhaps continued nearly through the warmer part of the day, pipes forth his clear and slender, though now almost monotonous song, near to the favorite spot where his mate hatches or fosters her tender brood; and from all the neighboring meadows, at this silent hour, as the last rays of the sun are reflected from the dusky horizon, we hear a constant repetition of an echoing and shrill tsh 'tsh 'tshé te tshète tshĕte, with warbling tones blended and varied, at the beginning and close of this simple, rather pensive, but agreeable ditty. They are more common in fields than thickets, and run along the ground in the manner of the Lark. They likewise frequent ploughing fields, searching on the ground for insects, and are very fond of dusting themselves and basking in dry places.

Being nearly sedentary, they raise probably several broods in the season. Sometimes when started from the nest, the female simulates lameness with remarkable dexterity, so as very readily to draw off the attention of her enemies or intruders. The young are easily raised from the nest, and become very tame, clean, and domestic, but readily quarrel with each other.

The "Bay-winged Bunting" of earlier writers was named "Vesper Sparrow" by Wilson Flagg, from its habit of singing during the early evening. It breeds from Virginia and Kentucky to Manitoba and the Maritime Provinces, and is one of the most abundant Sparrows in New England and Ontario. It winters from Virginia southward.

The song is much more effective than Nuttall's description indicates. The voice is of sweet tone, and the theme, though simple, is exceedingly tender and plaintive.

VOL. I. $-2 \mathrm{I}$ 


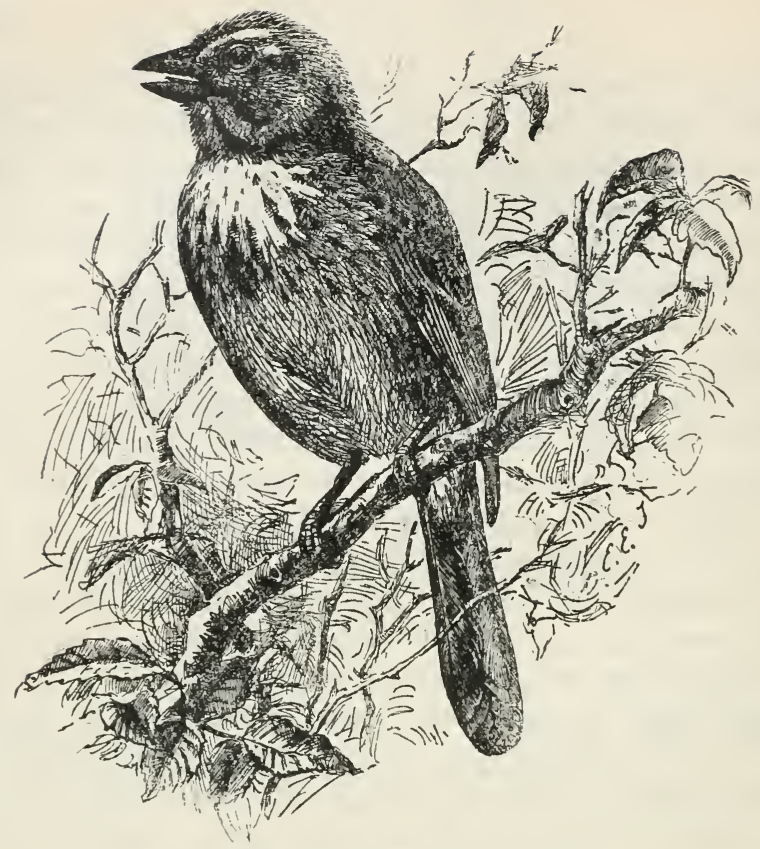

\section{SONG SPARROW.}

\section{Melospiza fasciata.}

CHAR. Back streaked with black, bay, and ash; crown bay, streaked with black and with two stripes of ash; wings grayish brown edged with dull rufous; tail grayish brown, with dark wavy cross-bars; below, white; breast, sides of throat, and sides of body spotted with brown, the spots forming a "patch" on the breast. Length 6 to $6 \frac{1}{2} 2$ inches.

Nest. In a field or open pasture, amid a tuft of grass or under a low bush, sometimes fastened to bush or vine, occasionally placed in a cavity in a tree ; composed of twigs, grass, roots, and leaves, lined with grass and roots, or hair.

Eggs. 3-7 (usually 4 or 5); dull white or with tint of green, blue, or pink, thickly marked with several shades of brown; occasionally unspotted; $0.80 \times 0.60$.

This familiar and almost domestic bird is one of the most common and numerous Sparrows in the United States; it is also, with the Bluebird, which it seems to accompany, one of the two earliest, sweetest, and most enduring warblers. 
Though many pass on to the Southern States at the commencement of winter, yet a few seem to brave the colds of New England as long as the snowy waste does not conceal their last resource of nutriment. When the inundating storm at length arrives, they no longer, in the sheltering swamps and borders of bushy streams, spend their time in gleaning an insufficient subsistence, but in the month of November begin to retire to the warmer States; and here, on fine days, even in January, whisper forth their usual strains. As early as the $4^{\text {th }}$ of March, the weather being mild, the Song Sparrow and the Bluebird here jointly arrive, and cheer the yet dreary face of Nature with their familiar songs. The latter flits restlessly through the orchard or neighboring fields; the Sparrow, more social, frequents the garden, barn-yard, or road-side in quest of support, and from the top of some humble bush, stake, or taller bough tunes forth his cheering lay, in frequent repetitions, for half an hour or more at a time. These notes have some resemblance to parts of the Canary's song, and are almost uninterruptedly and daily delivered, from his coming to the commencement of winter. When the birds first arrive, while the weather is yet doubtful and unsettled, the strain appears contemplative, and is often delivered in a peculiarly low and tender whisper, which, when hearkened to for some time, will be found more than usually melodious, seeming as a sort of revery, or innate hope of improving seasons, which are recalled with a grateful, calm, and tender delight. At the approach of winter, this vocal thrill, sounding like an Orphean farewell to the scene and season, is still more exquisite, and softened by the sadness which seems to breathe almost with sentiment, from the decaying and now silent face of Nature. Our songster, never remarkable for sprightliness, as the spring advances delivers his lay louder and more earnestly. He usually begins with a tsh' tsh' tshé te tshĕte tshěte, and blends in a good deal of quivering notes. Individuals also excel, and vary their song from time to time with very agreeable effect; and it is only because our familiar vocalist is so constantly heard and seen that so little value is set upon his agreeable, cheerful, and faithful perform- 
ance. When not attached to the garden, our Sparrow seems fond of frequenting low bushy meadows, streams, swamps, and watery situations, which afford him ready shelter, and his usual food of worms, insects, larvæ, and seeds. Such situations are also their favorite resorts when, in gregarious and miscellaneous flocks with other congeneric kinds, they are seen to crowd the sheltered marshes of the Southern States. They are also commonly seen nimbly running along the ground, and gliding through low thickets in quest of their insect fare; and in fine weather they dust themselves, and bask in the sun. They often likewise frequent the water, being fond of washing; and sometimes are seen to swim across small streams, particularly when disabled from flying by a gunshot wound.

The nest is usually formed of a considerable portion of fine dry grass neatly put together, and mostly lined with horse-hair. These birds are very prolific, raising as many as three broods in a season, the young being occasionally hatched, in the Middle States, from the close of April to the end of August. They are very solicitous for the safety of their young, keeping up at this time often a tiresome chirping; and on the destruction of the female and most of her young, I have known the remaining male, with unceasing and anxious attention, raise a solitary survivor of his ruined family with the most devoted affection. As they keep the young and their habitation so very clean, and are so prolific, it is a matter of surprise that they do not reoccupy the premises; instances are, however, not wanting in which they have been known to raise two broods in the same nest. Both parents join in the duty of incubation, and alternately feed each other while so engaged.

This species nests from South Carolina to Lake Mistassini, and from central Ohio and northern Illinois to Lake Winnipeg. It arrives at St. John, N. B., during the second week in April in immense flocks, and is usually accompanied by similar flocks of Robins and Juncos. Occasionally a few winter in the Maritime Provinces and in Quebec, while in eastern Massachusetts and Connecticut they are often quite numerous at that season. 


\section{SAVANNA SPARROW. GROUND SPARROW.}

\section{AMMODRAMUS SANDWICHENSIS SAVANNA.}

CHAR. Above, streaked with grayish brown, black, rufous, and gray; line over the eyes and edges of wings yellow; crown with median stripe of yellowish white; line from lower mandible yellowish white bordered by brown; below, white tinged with buff, breast and sides streaked with brown and black. Length $5 \frac{1}{2}$ inches.

Nest. In a salt-marsh or along a river bank, sometimes in a dry inland meadow, concealed by tall grass or tuft of weeds; composed of grass, sometimes mixed with fine roots, and occasionally lined with horse-hair.

Eggs. 3-6; variable in shape, size, and markings, usually dull white or with green tint, thickly spotted with dark brown, rich brown, and lilac; $0.70 \times 0.55$

This Sparrow, allied to the preceding, but far less familiar, is commonly seen in this part of New England from April to October, migrating towards the South in severe weather, though many pass the whole winter in the Middle States. In Georgia and West Florida these birds are rather numerous in the cold season, migrating in quest of food probably from the West; and the whole species generally show a predilection for the warm and sheltered vicinage of the sea, where the seeds and insects they feed on are most abundant. On their first arrival in Massachusetts they frequent the sandy beaches and shores of the bays in quest of Cicindela and other coleopterous insects which frequent such situations; and they are at this time exceedingly fat, though their moult is not yet completed. In summer this shy and timid species lives wholly in pastures or grass fields, and often descends to the ground in quest of food. Its nest, also laid in the grass and made of the dry blades of the same, very similar to that of the Song Sparrow, is usually built about the close of April.

In the month of March, in Georgia, I observed these Sparrows in the open grassy pine woods on the margins of small swamps or "galls." At times they utter a note almost exactly similar to the chirpings of a cricket, so that it might be easily mistaken for that insect. At other times they utter a few 
pleasant notes somewhat similar to the song of the Song Sparrow, but sufficiently distinct.

The Savanna Sparrow breeds more abundantly along the coast of Massachusetts than in the interior, and perhaps this may apply to all localities; but the opinion expressed by many writers that it is almost exclusively a bird of the sea-shore - of the salt-marshes - is far from correct. I traced it up the valley of the St. John as far as there were cleared fields or marshy meadows, and in no locality was it more abundant than at Fort Kent, - the most northern point of Maine. It occurs throughout the southern portions of Canada.

These birds are rarely seen off the ground; an occasional perch on a stone heap or a fence being the only deviation from this rule.

\section{IPSWICH SPARROW.}

\section{AMMODRAMUS PRINCEPS.}

ChA R. General appearance of a large pale Savanna Sparrow. Above, grayish brown, each feather streaked with black, rufous, and gray; crown stripe dull buff or buffy white; stripe over eyes similar but paler; wings blackish brown, edged with buff; tail grayish brown tipped with white; beneath, dull white tinged with buff ; chest and sides streaked with brown. Length 6 to $63 / 4$ inches.

Nest. In a cup-shaped hollow scratched in the sand and concealed by a tussock of grass or a low bush; made of grass compactly woven, with an outer shell of coarser material and lined with fine grass.

Eggs. 4-5; bluish or grayish white thickly marked with deep brown of several shades and some spots of purplish and grayish brown; $0.61 \times 0.8_{5}$.

This interesting bird was first described by Mr. C. J. Maynard from a specimen taken by him at Ipswich, Mass., in I868. For two years the type remained unique, and for several years later the species was supposed to be rare. It has since been found all along the Atlantic coast from Georgia to the Gulf of St. Lawrence. It usually frequents the sea-shore or salt-meadows near by, though Mr. N. C. Brown reports that he has seen it at Lake Umbagog, in the interior of Maine. I met with it in New Brunswick only for a few days during the second week of April, I883. When feeding on the sandy shore (the snow still covered the fields), in company with other Sparrows, it was not difficult to distinguish the Ipswich from their congeners, but it is difficult to define the distinguishing characteristics. 
In I 894 Dr. Jonathan Dwight, Jr., visited Sable Island, off Nova Scotia, and obtained several nests of this species with sets of eggs. His monograph, issued as a memoir of the Nuttall Ornithological Club, contains the only account that has been published of the habits of the bird, and from that paper I have taken the description of the nest and eggs given above.

Dr. Dwight describes these birds as tamer than they appear when on the migrations, yet they were so retiring he could not learn much of their "domestic affairs." The song, he says, is similar to that of the Savanna Sparrow, but is "a more polished and tuneful affair."

\section{BACHMAN'S SPARROW.}

\section{SUMMER FINCH.}

\section{Peucæa estivalis bachmaniI.}

Char. Above, rufous streaked with black and ash; lines over the eyes ash; edge of wing yellow; below, buff, sides shaded with ash, breast with brown. Length $61 / 4$ inches.

Nest. In open grassy woodland, half-cleared field, or old meadow; placed on the ground; made of dry grass or mixed with roots; sometimes the top is roofed, the entrance at the side.

Eggs. 4-5; white; $0.75 \times 0.60$.

This interesting species was first made known to Audubon by Dr. Bachman, who found it near the Edisto River, and afterwards breeding in the vicinity of Charleston, South Carolina, in the pine barrens. The discoverer remarks of this bird : "When I first heard its notes they so nearly resembled those of the Towee Bunting that I took it to be that bird. As soon as it is seen in the tall pine-trees where it usually sits to warble out its melodious notes, it darts down and conceals itself in the rank grass, through which it runs off like a mouse, and is flushed with difficulty." It is believed to breed on the ground. It is said to be the finest songster of the Sparrow family in the United States. Its notes are loud for the size of the bird, and heard nearly alone in the region it frequents. About the month of November it proceeds to migrate farther south, though a few stragglers still remain throughout the winter. According to Latham, its nest is usually on the ground among the grass, under small bushes; it is composed of dry 
grass for the most part, and the eggs are dusky white. $\mathrm{He}$ also adds that these birds inhabit Georgia the whole year, frequenting fences, brushwood, and thickets.

Some years ago in Georgia in the month of March I observed these Sparrows in the open grassy pine woods, on the margins of small swamps or galls. On being suddenly surprised, they often flew off a little distance, and then, if followed, descended to the ground, and ran and hid closely in the tall tufts of grass.

Their notes at this time were very long, piping, and elevated, and resembling often tshé tship tship tship tship tship $t s h i p$, then tshe ch' $t h^{\prime} t s h^{\prime} t s^{\prime} h t s^{\prime} h$. Some of these notes were as fine and lively as those of the Canary, - loud, echoing, and cheerful.

The food of this species consists of grass seeds, coleoptera, and a variety of small berries as they come in season. The sexes are nearly alike in plumage.

This species occurs in the Gulf States and north to South Carolina and southern Illinois, but the vicinity of Charleston, S. C., is the only locality in which it has been found in abundance. Very little is known of its habits or of its distribution.

Note. - The type of this species is larger and darker than bachmanii. It is restricted to southern Georgia and Florida, and has been named the Pine-woods Sparrow (Peucca astivalis).

\section{LINCOLN'S SPARROW.}

LINCOLN'S FINCH.

\section{Melospiza lincolnit.}

CHAR. Above, streaked with brown, gray, and black; below, white; band across the breast and on sides brownish yellow. Length about $5 \frac{1}{2}$ inches.

Nest. On the ground, amid low bushes, along the skirts of marshy meadow, or on a dry grassy hillock in an open woodland; composed of grass.

Eggs. 4-5; pale green or buffish, - sometimes almost white, - thickly spotted and blotched with reddish brown and lilac; $0.80 \times 0.60$. 
The habits of this boreal species, discovered by Audubon in Labrador, are very similar to those of the Song Sparrow. Like it, mounted on the topmost twig of some tree or tall shrub, it chants for hours together; or, diving into the thicket, it hops from branch to branch until it reaches the ground in quest of its usual fare of insects and berries. It moves off swiftly when watched, and if forced to take wing flies low and with rapidity to some considerable distance. It is met with usually near streams, in the sheltered valleys of that cold and desolate region. By the $4^{\text {th }}$ of July the young had left the nest, and in August they had begun their migrations to the South. Specimens have been obtained by Mr. W. Cooper near New York city.

Lincoln's Finch is now considered less "boreal " in its distribution than Nuttall and his contemporaries supposed, for though it has been found in Labrador and in the high Arctic regions of the West, yet nests have been discovered in Nova Scotia, northern New York, and Wisconsin, as well as on the higher mountains of the West down nearly to the Mexican border. It is a rare bird near the Atlantic, but is abundant along the Mississippi valley.

\section{GRASSHOPPER SPARROW.}

\section{YELLOW-WINGED SPARROW. YELLOW-WINGED BUNTING.}

\section{AMMODRAMUS SAVANNARUM PASSERINUS.}

CHAR. Above, streaked with bay, black, buff, and ash; crown blackish, with median line of buff; lines over the eye buff; bend of wing bright yellow; below, buff, shading to white on the belly. Length about 5 inches.

Nest. In a field, concealed by long grass; composed of grass, lined with horse-hair.

Eggs. 4-5; white, spotted with rich brown and lilac; $0.75 \times 0.60$.

This small Sparrow is a summer resident in the United States, in the distant territory of the Oregon, and is likewise, according to Sloane, a common species in the savannas or open glades of the island of Jamaica. From what little is known of it as a bird of the United States, it appears to 
remain in the sheltered plains of the sea-coast of New York and New Jersey until the very commencement of winter. It is also observed in the lower parts of Pennsylvania ; and about the middle of May, or later, they are occasionally seen in the gardens in Cambridge, Mass., on their way apparently to some other breeding-station. On these occasions they perch in sheltered trees in pairs, and sing in an agreeable voice somewhat like that of the Purple Finch, though less vigorously. In the West Indies they live much on the ground, and run like Larks, flying low when flushed, and soon alighting. Their nest is likewise fixed on the ground, among the grass, where they collect their usual fare of seeds and insects.

The majority of local students of bird life to-day consider this species more or less common in Massachusetts and Connecticut, and it is known to occur in parts of the more northern New Eng. land States, and in New York, Ohio, Ontario, and Michigan. One example has been taken in New Brunswick. Its supposed rarity by earlier observers was probably due to its usual concealment amid the tall grass and to its lack of an attractive song; for in spite of Nuttall's assurance to the contrary, modern observers have indorsed the opinion expressed by one of their leaders that " its best vocalization is scarcely stronger or more musical than the stridulation of a grasshopper."

\section{HENSLOW'S SPARROW.}

HENSLOW'S BUNTING.

\section{AMmodRamus HENSLOWII.}

CHAR. Above, streaked with olive brown, bay, and gray; crown olive gray, with two blackish stripes; edge of wing yellow; below, buff, paler on throat and belly; sides of throat and sides of body streaked with black. Length about 5 inches.

Nest. In a field, concealed amid long grass; made of grass with a lining of hair.

Eggs. 4-5; dull white, sometimes tinged with green, spotted with brown and lilac; $0.75 \times 0.60$.

This species, so much allied to the Yellow-winged Finch discovered by Audubon, is known to breed in New Jersey. 
As a winter bird of passage it is common in South Carolina, and equally abundant in the pine forests of Florida, seeking out by choice the light sandy soils overgrown with pines, though it keeps on the ground wholly, running with celerity, and threading its way through the grass with the nimbleness of a mouse.

Henslow's Sparrow breeds from southern New England to South Carolina, and from Ontario and Illinois southward, and has been found in New Hampshire and Vermont. It is more abundant to the westward than near the Atlantic seaboard.

\section{LE CONTE'S SPARROW.}

\section{LE CONTE'S BUNTING.}

\section{AMMODRAMUS LECONTEII.}

CHAR. General color reddish brown, streaked with brownish black, the feathers margined with pale buff ; crown with two black stripes separated by a narrow stripe of pale buffish gray; cheeks and stripes over the eyes buff; hind neck rufous; under parts buff, paler on the belly; no streaks on the breast. Bill small and slender; tail-feathers narrow, tapering, and extremely pointed. Length about 5 inches.

Nest. In a marsh or wet meadow, raised from the ground by tangled grass; made of fine grass.

Eggs. 3-?; delicate pink, with a few spots of brownish and of black towards the larger end ; $0.75 \times 0.50$. (Thompson.)

This interesting bird was first described by Audubon in the 1843 edition of his work, - issued after Nuttall had written. Audubon secured but one specimen, and only one other was discovered until I873, when Dr. Coues took several examples on the Dakota plains. Since then the species has been found by a number of naturalists, and it is now known to breed on the plains of Dakota, Minnesota, and Manitoba, migrating in the autumn through Illinois, Iowa, Kansas, etc., to South Carolina and Florida. It is by no means a rare bird, - Ridgeway thinks it abundant in Illinois, and Thompson reports it common in Manitoba; but, as Dr. Coues suggests, its retiring habits and the nature of its resorts have doubtless caused it to be overlooked.

The birds resemble Henslow's Sparrow, and the habits of the two species are similar. Only one nest and set of eggs have been discovered, and they were taken by Mr. Ernest Thompson on the Manitoba plains. 


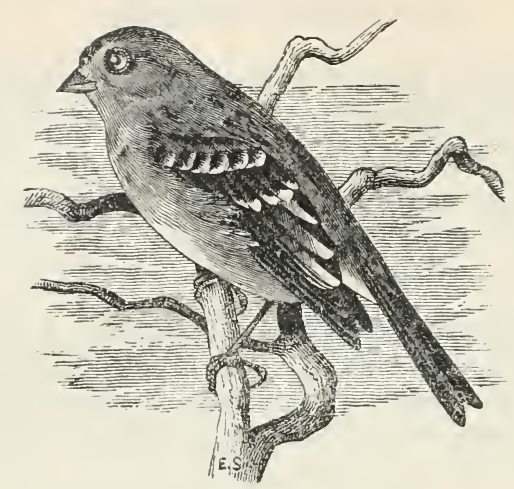

TREE SPARROW.

\section{SPIZELLA MONTICOLA.}

Char. Above, streaked with black, bay, and buff; crown chestnut, sometimes the feathers edged with ashy; sides of head and neck ashy; line from behind eyes chestnut ; wings with two white bars; edges of tailfeathers white; below, dull white, breast and throat tinged with ash; spot of brown on the breast; flanks shaded with brown. Length $6 \frac{1}{4}$ inches.

Nest. On the ground or in a low bush; made of grass, twigs, and roots, - sometimes cemented with mud, - lined with hair or feathers.

Eggs. 4-5; pale green or greenish blue, spotted with reddish brown; $0.75 \times 0.60$.

This handsome winter Sparrow arrives from the northern regions in New England about the close of October, withdrawing from Hudson Bay and the neighboring countries sometime in the month of September. The species consequently, like many more of our Fringillas, only measures its speed by the resources of subsistence it is able to obtain, and thus straggling southward as the winter advances, it enters Pennsylvania only about the beginning of November; there, as well as in the maritime parts of Massachusetts, and perhaps as far south as Virginia, the Tree Sparrow is often associated with the hardy Snow Birds, gleaning a similar kind of subsistence; and when the severity of winter commences, leaving the woods, gardens, and uplands in which it is an occasional visitor, it seeks in company the shelter of some bushy swamp, thickly shaded brook, or spring. Near Fresh Pond, in this vicinity, 
these birds are at that season numerous, and roost together near the margin of the reeds, almost in the society of the Blackbirds, who seek out a similar place of warmth and shelter as the chilling frosts begin to prevail.

At this cool and gloomy season, and down to the close of the first week in November, as they pass from branch to branch and play capriciously round each other, they keep up almost perpetually a low and pleasant liquid warble, not much unlike that of the Yellow Bird (Fringilla tristis), but less varied. Sometimes two or three at the same time will tune up s'weedit s'weedit weet, and s'waidit s'waidit weet, accompanied by some tremulous trilling and variation, which, though rather sad and querulous, is heard at this silent season with peculiar delight. In summer, during the breeding-time, they express considerable melody.

According to Mr. Hutchins they breed around the Hudson Bay settlements, making a nest in the herbage, formed externally of dry grass, and lined with soft hair or down, probably from vegetables, in the manner of the Yellow Bird. About the beginning of April they leave the Middle States for their summer quarters, and arrive around Severn River in May; they also probably propagate in Newfoundland, where they have been observed. With us they are still seen in numbers to the I 9 th of April.

Numbers of the Tree Sparrow winter regularly in the Maritime Provinces of Canada. Macoun reports the species common in summer at Lake Mistassini, which lies a little to the southward of Hudson Bay.

\section{CHIPPING SPARROW.}

CHIPPY. HAIR-BIRD.

\section{SPIZELLA SOCIALIS.}

CHAR. Above, streaked with grayish brown, black, and bay ; crown chestnut; forehead black; sides of head and neck ashy; dull white line over eyes; dusky stripe from bill through eyes; bill black; tail dusky with pale edgings ; wings with two white bars; below, dull white, tinged with ash on breast and sides. Length about $5 \frac{1}{2}$ inches. 
Nest. In a pasture, orchard, or garden, placed in a bush or low tree; composed of grass, - sometimes mixed with roots, - thickly lined with horse-hair.

Eggs. 4-5; bluish green, spotted, chiefly about the larger end, with brown, black, and lilac; $0.70 \times 0.50$.

This species, with the Song Sparrow, is probably the most numerous, common, and familiar bird in the United States, inhabiting from Nova Scotia to Florida, westward to the banks of the Missouri, and Mr. Townsend found it to be a common species in the Territory of Oregon. Aware of the many parasitic enemies of the feathered race which it has to encounter, who prowl incessantly, and particularly in quest of its eggs, it approaches almost instinctively the precincts of houses, barns, and stables, and frequently ventures into the centre of the noisy and bustling city, to seek in the cultivated court an asylum for its expected progeny. Soon sensible of favor or immunity, it often occupies with its nest the thick shrubs of the garden within a few yards of the neighboring habitation, by the side perhaps of a frequented walk, in the low rose-bush, the lilac, or any other familiar plant affording any degree of shelter or security, and will at times regularly visit the threshold, the piazza, or farm-yard for the crumbs which intention or accident may afford it. On other occasions the orchard trees are chosen for its habitation, or in the lonely woods an evergreen, cedar, or fir is selected for the purpose. It makes no pretensions to song, but merely chips in complaint when molested, or mounting the low boughs of some orchard tree or shrub, utters a quickly articulated ascending ' $t$ sh ' $t$ sh ' $t$ sh 'tsh 'tsh tshe tshe, almost like the jingling of farthings, and a little resembling the faint warble of the Canary, but without any of its variety or loudness. This note, such as it is, is continued often for half an hour at a time, but is little louder than the chirping of a cricket, and uttered by the male while attending his brooding mate. For many weeks through the summer and during fine weather this note is often given from time to time in the night, like the revery of a dream.

The nest of the Chipping Bird varies sometimes considerably in its materials and composition. The external layer, 
seldom so thick but that it may be readily seen through, is composed of dry stalks of withered grass, and lined more or less with horse or cow hair. The Cuckoo destroys many eggs of this timid, harmless, and sociable little bird, as the nests are readily discovered and numerous; on such occasions the little sufferer expresses great and unusual anxiety for the security of her charge, and after being repeatedly robbed, the female sits closely sometimes upon perhaps only two eggs, desirous at any rate to escape if possible with some of her little offspring. Two or more broods are raised in the season.

Towards the close of summer the parents and their brood are seen busily engaged collecting seeds and insects in the neighboring fields and lanes, and now become so numerous, as the autumn advances, that flitting before the path on either side as the passenger proceeds, they almost resemble the falling leaves of the season rustling before the cheerless blast; and finally, as their food fails and the first snows begin to appear, advertised of the threatening famine, they disappear and winter in the Southern States. In the month of January, in Georgia, during the continuance of the cool weather and frosty nights, I frequently heard at dusk a confused chirping or piping like that of frogs, and at length discovered the noise to proceed from dense flocks of the Chipping Sparrows roosting or huddling near together in a pile of thick brush, where, with the Song Sparrow also, they find means to pass the cool nights.

The Chipping Sparrow occurs throughout the Maritime Provinces and westward to the Rockies, northward to the Great Slave Lake region, and southward to Florida. It is abundant in Quebec and Ontario. It is very abundant in the Eastern States and the Eastern Provinces.

Note. - One example of BREwer's SPARrow (Spizella breweri), a bird that dwells chiefly on the western slopes of the Rockies, has been taken in Massachusetts. 


\section{FIELD SPARROW.}

\section{SPIZELLA PUSILla.}

CHAR. Above, streaked rufous, black, and buff; crown chestnut, with obscure median line of ash; hind neck, sides of head and neck ash; cheek shaded with brown ; wings with two white bars; below, white ; breast and throat tinged with yellow; bill reddish brown. Length $5 \frac{3}{4}$ inches.

Nest. In a field, pasture, or open woodland, amid a tuft of grass or in a tangled thicket, sometimes placed on a low bush or vine; composed of grass, twigs, and straw, lined with hair, fine roots, or fur.

Eggs. 3-5; dull white or with buff or green tint, usually thickly spotted with reddish brown; $0.70 \times 0.55$.

The Small Brown Sparrow arrives in Pennsylvania and New England from the Southern States, where it passes the winter, in the beginning of April. It is with us a shy, wild, and retiring species, partial to dry hills and pastures, and open, bushy, secluded woods, living much in trees. In autumn, indeed, the pair, accompanied by their brood, in small flitting flocks leave their native wilds, and glean at times in the garden or orchard; yet but little is now seen of them, as they only approach cultivated grounds a few weeks before their departure. These Sparrows, if indeed they are the same as those described by Wilson, in winter flock together in great numbers in the Southern States, and mingling with the Chipping Birds and other species, they now line the roads, fences, and straggling bushes near the plantations in such numbers as, with their sober and brown livery, to resemble almost a shower of rustling and falling leaves, continually haunting the advancing steps of the traveller in hungry, active flocks, driven by the storms of winter into this temporary and irksome exile. But no sooner does the return of early spring arrive than they flit entirely from the Southern wilds to disperse in pairs and seek out again their favorite natal regions of the North.

Our little bird has a pretty loud and shrill note, which may be heard at a considerable distance, and possesses some variety of tone and expression. Sometimes it is something like twe twee twai, tw 'tw 'tw' tw' 'tw 'tw' twe, beginning loud and 
slow, and going up and down, shrill and quick, with a reverberating tone almost as rapid as the drumming of the Ruffed Grouse. At other times the sound appears like te de de de de $d^{\prime} d^{\prime} d^{\prime} d^{\prime} d^{\prime} d^{\prime} d r^{\prime}$, rapid and echoing; then weet weet weed wat tè 'd' $d$ ' $d$ ' $d$ ' $d$ ' $d$, also weet weet weet weet' wt' wt' wt' $w t^{\prime} \mathrm{trr}$; the whole of these notes rising and running together into a short trill something like the song of the Canary, but less varied, and usually in a querulous or somewhat plaintive tone, though towards the close of summer I have heard individuals nearly as musical and warbling as the common Yellow Bird. These tones are also somewhat similar to the reverberations of the Chipping Bird, but quite loud and sonorous, and without the changeless monotony of that species. In fact, our bird would be worthy a place in a cage as a songster of some merit. Like most of the Sparrows, the food of this species consists of seeds and insects; and they also search the leaves and branches at times in quest of moths, of which they appear fond.

The Field Sparrow is a common summer resident of southern New England, but is rather rare north of Massachusetts. It has not been taken in the Maritime Provinces, though Mr. Neilson thinks it not uncommon near the city of Quebec, and it is common throughout Ontario and in Manitoba. It breeds southward to South Carolina and winters from the Southern States southward.

Note. - A few examples of the Clay-Colored Sparrow (Spizella pallida) wander every year from their usual habitat on the Great Plains to Iowa and Illinois.

VOL. I. -22 


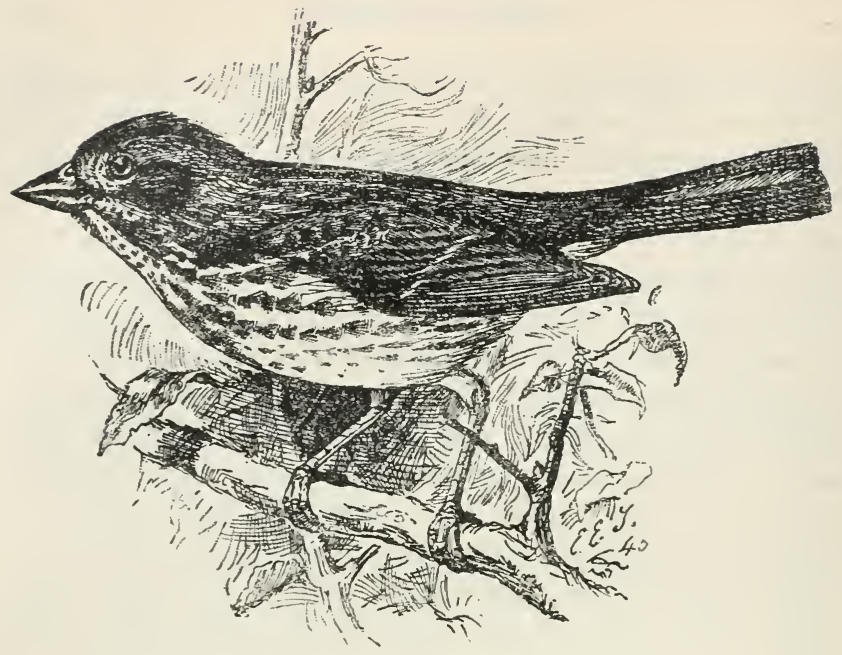

FOX SPARROW.

PASSERELla ILIACA.

Char. Above, foxy red (brightest on wings and rump) streaked with ash (in winter the ash is sometimes obscure); head and tail without streaks; wings with two white bars; below, white spotted with red. Length about 7 inches.

Nest. Amid moss, or on a low bush ; composed of grass and moss, lined with grass, roots, and feathers.

Eggs. 4-5; white with green or blue tinge, spotted and blotched with brown of several shades (sometimes the brown almost conceals the ground color); great variation in size, average about $0.80 \times 0.65$.

This large and handsome Sparrow, after passing the summer and breeding-season in the northern regions of the continent around Hudson Bay, and farther north and west perhaps to the shores of the Pacific, visits us in straggling parties or pairs from the middle of October to November. At this time it frequents low, sheltered thickets in moist and watery situations, where it usually descends to the ground and is busily employed in scratching up the earth and rustling among the fallen leaves in quest of seeds, worms, and insects, but more particularly the last. It migrates in a desultory manner, and sometimes arrives 
as far south as Georgia, passing the winter in the Southern States and retiring early in the spring to its favorite boreal retreats. These Sparrows are silent birds, rather tame and unsuspicious; when alarmed or separated their call is simply shep, shep; yet at times in the spring, a little before their departure, they whisper forth a few low and sweet notes indicative of the existence of vocal powers in the pairing season.

According to Richardson this species breeds in the woody districts of the fur countries up to the 68th parallel.

Nuttall was correct in his conjecture that the Fox Sparrow is a vocalist. It ranks as a peer of the best songsters of the entire Sparrow-Finch tribe.

I have heard the song frequently in New Brunswick, when cold storms have detained the birds on their journey north until the approach of their mating season. Sometimes they arrive there early in March, and pass on in a couple of weeks, without uttering any other note than a metallic cheep. But when they tarry until after the first week in April they then burst into full song, and sing almost continuously. It is a "fervent, sensuous, and withal perfectly rounded carol," writes William Brewster; and he adds: "It expresses careless joy and exultant masculine vigor rather than the finer shades of sentiment." The voice is strong, of wide com. pass, and sweet, rich tone.

Nests of this species have been found on the Magdalen Islands and in Newfoundland, where it is called the Hedge Sparrow, and Thompson reports it breeding in numbers on Duck Mountain in Manitoba.

\section{SLATE-COLORED JUNCO.}

\section{SNOW BIRD. WHITE BILL.}

JUNCO HYEMALIS.

Char. Male: upper parts, neck, and breast dark slate or blackish ash; belly white; outer tail-feathers and bill, white. Female : sinilar, but upper parts browner, breast paler. Length $61 / 4$ to $61 / 2$ inches.

Nest. In grassy woodland, or old meadow, or by the roadside, sometimes in the garden of a farm-house ; sheltered by a mound or stump, or amid long grass; composed, usually, of grass, sometimes mixed with roots or moss; lined with feathers, hair, fur, or moss. 
Eggs. 4-5; dull white, or tinted with green or buff, spotted chiefly around larger end with reddish-brown and lilac; $0.80 \times 0.60$.

This hardy and very numerous species, common to both continents, pours in flocks from the northern regions into the United States about the middle of October, where their appearance is looked upon as the presage of approaching winter. At this season they migrate into the Southern States in great numbers, and seem to arrive in augmenting hosts with the progress of the wintry storms and driving snows, before which they fly for food rather than shelter; for even during the descent of the whitening inundation, and while the tempest still rages without abatement, these hardy and lonely wanderers are often seen flitting before the blast, and, seeking advantage from the sweeping current, descend to collect a scanty pittance from the frozen and exposed ground, or stop to collect the seeds which still remain upon the unshorn weeds rising through the dreary waste. At such times they are also frequently accompanied by the Snow Bunting, the humbly dressed Yellow Bird, and the querulous Chickadee. Driven to straits, however, by hunger, they at length become more familiar, and are now seen about the barns and out-houses, spreading themselves in busy groups over the yard, and even approaching the steps of the door in towns and cities, and gleaning thankfully from the threshold any crumbs or accidental fragments of provision. Amidst all this threatening and starving weather, which they encounter almost alone, they are still lively, active, and familiar. The roads, presenting an accidental resource of food for these northern swarms, are consequently more frequented by them than the fields. Before the severity of the season commences, they are usually only seen moving in families; and the parents, watchful for the common safety, still continue by reiterated chirpings to warn their fullgrown brood of every approach of danger, and, withdrawing them from any suspicious observation, wander off to securer ground. At this time they frequent the borders of woods, seek through the thickets and among the fallen leaves for their usual food of seeds and dormant insects or their larvæ. Their 
caution is not unnecessary, for on the skirts of the larger flocks the famished Hawk prowls for his fated prey, and descending with a sudden and successful sweep, carries terror through all the wandering and retreating ranks.

In the latter end of March or beginning of April, as the weather begins to be mild, they re-appear in flocks from the South, frequenting the orchard trees, or retreating to the shelter of the woods, and seem now to prefer the shade of thickets or the sides of hills, and frequently utter a few sweet, clear, and tender notes, almost similar to the touching warble of the European Robin Redbreast. The jealous contest for the selection of mates already also takes place, soon after which they retire to the northern regions to breed; though, according to Wilson, many remove only to the high ranges of the Alleghany Mountains, where, in the interior of Virginia, and towards the western sources of the Susquehanna, they also breed in great numbers, fixing their nests on the ground or among the grass, the pairs still associating in near communion with each other. In the fur countries they were not observed by Richardson beyond the 57 th parallel.

The Junco breeds from northern New England northward, and on the higher hills south to North Carolina. It is an abundant summer resident of the Maritime Provinces, and winters there in small numbers. It also winters sparsely in northern New England, and from Massachusetts southward it is a common winter bird.

The song is very similar to that of the Chipping Sparrow. Though usually building its nest on the ground, a few have been found in other situations. Sheriff Bishop, of Kentville, N, S., recorded in the O. \& O. for September, I 888, finding nests on branches of low trees, in holes in apple-trees, etc.

Note. - Examples of SHufeldt's Junco ( $J$. hyemalis shufeldti), a western form, has been reported from several Eastern States.

Another species, the CARolina Junco ( $J \cdot h$.carolinensis), was first described by Mr. William Brewster from specimens obtained by him on the mountains of North Carolina in June, I885. It is larger and lighter colored than hyemalis, and has a horn-colored bill. 


\section{SWAMP SPARROW.}

\section{MELOSPIZA GeORGIANA.}

CHAR. Above, streaked with brown, black, and buff; crown bay, sometimes with indistinct median line of ash and streaks of black; forehead black; brown stripe behind eyes; sides of head and neck ash; below, dull white, breast shaded with ash, sides shaded with brown; wings and tail tinged with bay. Length about 5\%/4 inches.

Nest. Under cover of long grass, in a swamp or wet meadow; usually made entirely of grass, though sometimes weed-stems are added to the exterior, and hair is used in lining.

Eggs. 4-6; dull white, tinted with green, blue, or pink, blotched, often clouded, with lilac and several shades of brown; $0.80 \times 0.60$.

The aquatic habits of these common, though little known, birds is one of their most remarkable peculiarities. In New England they arrive from the Southern States, where they winter, about the middle of April, and take up their summer residence in the swamps and marshy meadows through which, often without flying, they thread their devious way with the same alacrity as the Rail, with whom they are indeed often associated in neighborhood. In consequence of this perpetual brushing through sedge and bushes, their feathers are frequently so worn that their tails appear almost like those of rats, and are very often flirted in the manner of the Wagtail. Occasionally, however, they mount to the tops of low bushes or willow-trees and chant forth a few trilling, rather monotonous minor notes, resembling, in some measure, the song of the Field Sparrow, and appearing like twé $t w$ ' $t w ' t w ' t w ' t w '$ twé, and twl' tw'l 'tw tw' twé, uttered in a pleasant and somewhat varied warble. These notes are made with considerable effort, and sometimes with a spreading of the tail. In the spring, on their first arrival, this song is delivered with much spirit, and echoes through the marshes like the trill of the Canary. The sound now resembles the syllables 'tw' 'tw 'tw 'twee 'twee 'tw 'twe 'twe, or 'tshp 'tshp 'tshe 'tsh 'tsh 'tsh 'tsh, beginning loud, sweet, and somewhat plaintive; and the song is continued till late in the morning, and after sunset in the evening. This reverberating tone is again somewhat similar 
to that of the Chipping Sparrow, but far louder and more musical. In the intervals the Swamp Sparrow descends into the grassy tussocks and low bushes in quest of his insect food, as well as to repose out of sight; and while here his movements are as silent and secret as those of a mouse. The rice plantations and river swamps are the favorite hibernal resorts of these birds in Louisiana, Georgia, and the Carolinas; here they are very numerous, and skulk among the canes, reeds, and rank grass, solicitous of concealment, and always exhibiting their predilection for watery places. In the breeding season, before the ripening of many seeds, they live much on the insects of the marshes in which they are found, particularly the smaller coleopterous kinds, Carabi and Curculiones. They extend their northern migrations as far as the coasts of Labrador and Newfoundland.

They probably raise two or three broods in a season, being equally prolific with our other Sparrows. They express extreme solicitude for their young even after they are fully fledged and able to provide for themselves; the young also, in their turn, possess uncommon cunning and agility, running and concealing themselves in the sedge of the wet meadows. They are quite as difficult to catch as field-mice, and seldom on these emergencies attempt to take wing. We have observed one of these sagacious birds dart from one tussock to another, and at last dive into the grassy tuft in such a manner, or elude the grasp so well, as seemingly to disappear or burrow into the earth. Their robust legs and feet, as well as long claws, seem purposely provided to accelerate this clinging and running on the uneven ground.

This species is a common summer resident throughout the settled portions of eastern Canada, and abundant on the St. Clair Flats and in Manitoba. It is common at that season in New England also, and breeds south to Pennsylvania. A few spend each winter in some marshes near Boston, and the flocks winter from that latitude to the Gulf.

Mr. Chapman tells us that in the South they frequently belie their name and resort to dry fields. 


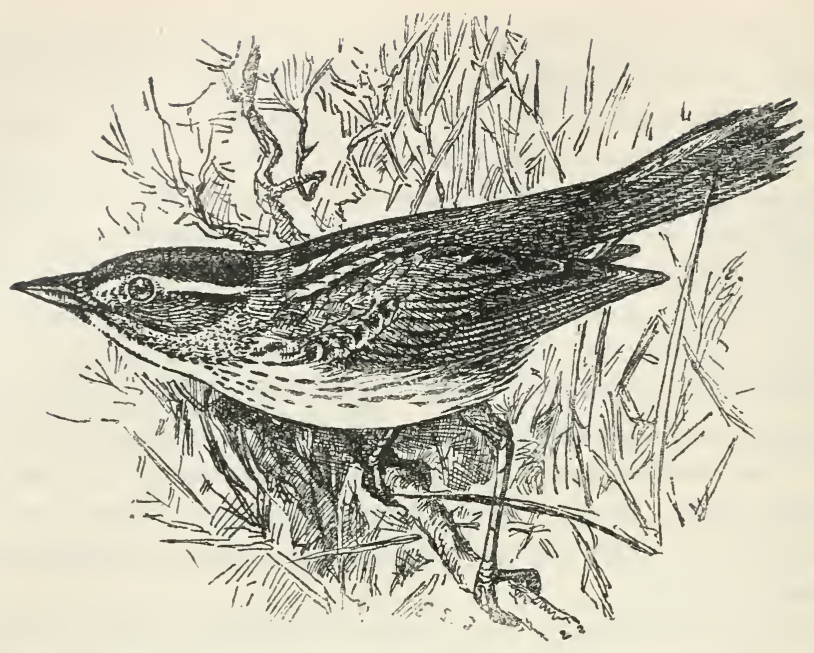

\section{SHARP-TAILED SPARROW.}

\section{SHORE FINCH.}

\section{AMMODRAMUS CAUDACUTUS.}

Char. Above, brownish gray tinged with olive; crown darker, with median stripe of ashy gray and two stripes of black; back streaked with black; stripes of buff above and below eyes meeting behind ear-coverts; wings edged with yellow; tail-feathers narrow, with acutely pointed tips; below, dull white, breast and sides tinged with buff and streaked with black. Length about $5 \frac{1}{4}$ inches.

Nest. In a salt-marsh or wet meadow, amid a cluster of reeds or tuft of sedges, to the stems of which it is sometimes fastened; a somewhat bulky structure of grass and weed-stems, lined with fine grass.

Eggs. 4-5; dull white or tinged with buff or green, thickly spotted with brown and lilac; $0.75 \times 0.55$.

The Shore Finch is an inhabitant of the low islands and marshy sea-coasts from Massachusetts to Texas, living on small shrimps, marine insects, and probably grass seeds, moving through the rank herbage nearly with the same agility and timidity as a Swamp Sparrow, to which in structure of the feet and stoutness of the bill it bears considerable affinity. 
These birds are not rare, though not so numerous as the Seaside Sparrow, with which they commonly associate.

These Finches frequent the water, and walk on the floating weeds as if on the land; throughout the winter they remain gregarious till spring, when they separate for the purpose of breeding. They are almost silent, a single tweet being now all they are heard to utter; and even in the spring, so defective are they in melody that their notes are scarcely worthy the name of a song. They nest on the ground, amid the short marsh-grass near the line of high-water mark; a slight hollow is made, and then lined with delicate grass. They raise two broods in the season in the Middle States.

"Sharp-tails" have been traced north to Prince Edward's Island, but in 1887 Mr. Jonathan Dwight, Jr., discovered that true caudacutus had not been taken beyond Portsmouth, N. H., the birds found to the northward of that point being a distinct variety, which he named subvirgatus.

\section{ACADIAN SHARP-TAILED SPARROW.}

\section{AMMODRAMUS CAUDACUTUS SUBVIRGATUS.}

CHAR. "Similar in size and coloring to $A$. caudacutus, but paler and much less conspicuously streaked beneath with pale greenish gray instead of black or deep brown. Bill averages smaller. Compared with nelsoni it is much paler and grayer, generally larger, and with a longer bill" (Dwight).

Nest and Egrs are not known to differ from those of true caudacutus.

The habitat of this newly discovered sub-species, or, rather, the limit of its range, has not yet been determined. Mr. Dwight gives it as "Marshes of southern New Brunswick, Prince Edward's Island, and probably Nova Scotia, and southward in migration along the Atlantic coast." In habits the present bird differs from caudacutus in frequenting fresh-water marshes and dry meadows on the margins of inland streams.

The song of this bird - if its few wheezy notes deserve such recognition - is a rather ludicrous effort, and suggests a bad cold in the head. Mr. Dwight represents it by the syllables lǐc-sēe- $\bar{e}-\bar{e}-o o p$. All I remember having heard from the specimens I encountered is the $s \bar{e} \bar{e}-\bar{e}-\bar{e}-\bar{e}-o o p$, delivered with apparent effort, as if choking. 


\section{NELSON'S SPARROW.}

\section{AMMOdRAMUS CAUDACUTUS NELSONI.}

CHAR. Differs from the type by the colors of the back being very sharply defined, the white a clearer shade, and the brown a richer and more decided umber; chest and sides deep buff. Size larger than true caudacutus. Length about $5 \frac{1}{2}$ inches.

Nest and Eggs similar to caudacutus.

Nelson's Sharp-tail was described by Mr. J. A. Allen in 1875. It is found in summer on the marshes of the Mississippi valley, from northern Illinois to Manitoba, and in winter on the Atlantic coast from Massachusetts (sparingly) to South Carolina, and west to Texas.

\section{SEASIDE SPARROW.}

\section{SEASIDE FINCH.}

\section{AMMODRAMUS MARITIMUS.}

CHAR. Above, dull olive brown, back and head with indistinct streaks of ashy; superciliary line and edge of wing yellow; below, dull white, the breast and sides with dark streaks. Length about 6 inches.

Nest. Hidden amid a tuft of grass or coarse sedges in a salt marsh or wet meadow; sometimes placed on the ground, often a few inches above it ; composed of dry grass.

Eggs. 4-6; dull white with green or buff tint, spotted with brown; $0.80 \times 0.60$.

This species is not uncommon in the maritime marshy grounds and in the sea islands along the Atlantic coast from Massachusetts to the Southern States. It confines its excursions almost wholly within the bounds of the tide-water, leaving its favorite retreats for more inland situations only after the prevalence of violent easterly storms. In quest of marine insects, crustacea, shrimps, and minute shell-fish, it courses along the borders of the strand with all the nimbleness of a Sandpiper, examining the sea-weeds and other exuviæ for its fare; it seeks out its prey also at dusk, as well as at other times, and usually roosts on the ground like a Lark. In short, it derives its whole subsistence from the margin of the ocean, 
and its flesh is even imbued with the rank or fishy taste to be expected from the nature of its food. At other times it remains amidst the thickest of the sea-grass, and climbs upon the herbage with as much dexterity as it runs on the ground. Its feet and legs for this purpose are robust, as in the Swamp Sparrow. It appears to rear two broods in the season. In May and June the Seaside Finch may be seen almost at all hours perched on the top of some rank weed near the saltmarsh, singing with much emphasis the few notes which compose its monotonous song. When approached it seeks refuge in the rank grass by descending down the stalks, or flies off to a distance, flirting its wings, and then, alighting suddenly, runs off with great nimbleness.

The Seaside Finch is now considered a rare bird in Massachusetts, though an abundant summer resident of the salt marshes of southern Connecticut. It breeds southward to North Carolina, and winters in the Southern States.

Note.-Scott's Seaside Sparrow (A. maritimus penin. sulc) was first described from specimens taken by Mr. W. E. D. Scott at Tarpon Springs, Florida, in 1888 . It is intermediate in coloration between $A$. nigrescens and $A$. maritimus.

This race is found in South Carolina and Florida, and along the Gulf coast to Texas.

The Dusky Seaside Sparrow (Ammodramus nigrescens) differs from maritimus in being black above, streaked with olive and gray; beneath white, streaked with black. It was described originally by Mr. C. J. Maynard, who captured the type specimen in $\mathrm{I} 872$, in southern Florida. He reported the bird as quite abundant in some localities, but no other collector has been successful in finding it. 


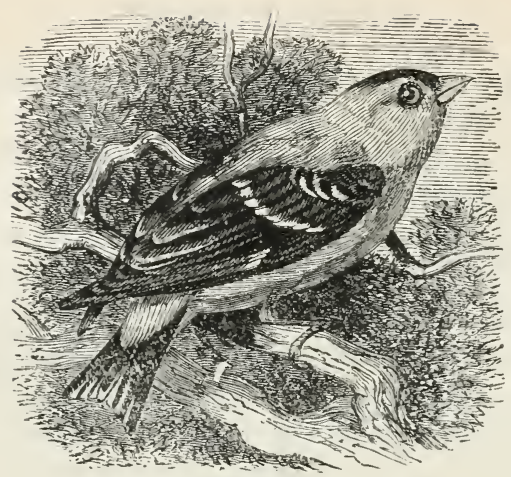

\section{AMERICAN GOLDFINCH.}

YELLOW BIRD. THISTLE BIRD. THISTLE FINCH. WILD CANARY.

\section{SPINUS TRISTIS.}

CHAR. Male in summer: bright gamboge yellow; crown, wings, and tail black; upper and under tail-coverts, wing and tail markings, white. In winter the male resembles the female, though with less olive tint. Female : above, olive brown; below, paler or yellowish ; forehead without black; wings and tail much the same as in the male. Length about $4 \frac{3}{4}$ inches.

Nest. In a pasture or orchard; usually placed in a crotch of a deciduous tree Io to 20 feet from the ground; a compact and gracefully formed cup, made of grass and vegetable fibre, lined with grass and plant down, and often with hair.

Eggs. 3-6; white with tint of green or greenish blue, occasionally marked with faint spots of brown; $0.65 \times 0.50$.

This common, active, and gregarious Goldfinch is a very general inhabitant of the United States. It is also found in summer in the remote interior of Canada, in the fur countries and near Lake Winnipique, in the $49^{\text {th }}$ degree of latitude, as well as in the remote territory of Oregon and the Rocky Mountains, on the banks of Lewis's River, where I found the nest as usual with white eggs. On the other hand, it is also met with in Mexico, and even in Guiana and Surinam in tropical America, where it frequents the savannas. Although many of these birds which spend the summer here leave at the approach of winter, yet hungry flocks are seen to arrive in 
this part of New England throughout that season; and sometimes, in company with the Snow Buntings, in the inclement months of January and February, they may be seen busily employed in gleaning a scanty pittance from the seeds of the taller weeds, which rise above the deep and drifted snows. As late as the $5^{\text {th }}$ of September I have observed a nest of the Yellow Bird with the young still unfledged. Their migrations are very desultory, and do not probably extend very far, their progress being apparently governed principally by the scarcity or abundance of food with which they happen to be supplied. Thus, though they may be numerous in the depth of winter, as soon as the weather relaxes in the month of March, scarcely any more of them are to be seen, having at this time, in quest of sustenance, proceeded probably to the southern extremity of the United States. Those observed in tropical America may be hibernal wanderers from the cooler parts of Mexico. At all events they select the milder climates of the Union in which to pass the breeding season, as at this time they are but rarely seen in the Southern States, Kentucky being about the boundary of their summer residence.

Naturally vagrant and wandering, they continue to live in flocks or in near vicinage, even throughout the greatest part of the selective season. As the fine weather of spring approaches they put off their humble winter dress, and the males, now appearing in their temporary golden livery, are heard tuning their lively songs as it were in concert, several sitting on the same tree enjoying the exhilarating scene, basking and pluming themselves, and vying with each other in the delivery of their varied, soft, and cheerful warble. They have also the faculty of sinking and raising their voices in such a delightful cadence that their music at times seems to float on the distant breeze, scarcely louder than the hum of bees; it then breaks out as it were into a crescendo, which rings like the loud song of the Canary. In cages, to which they soon become familiar and reconciled, their song is nearly as sonorous and animated as that of the latter. When engaged in quarrel they sometimes hurl about in a whole flock, some, as it were, interfering to 
make peace, others amused by the fray, all uttering loud and discordant chirpings. One of their most common whining calls while engaged in collecting seeds in gardens, where they seem to be sensible of their delinquency, is 'măy bé, 'măy bé. They have also a common cry like 'tsheveet' tshevee, uttered in a slender, complaining accent. These and some other twittering notes are frequently uttered at every impulse while pursuing their desultory waving flight, rising and falling as they shut or expand their laboring wings. They are partial to gardens and domestic premises in the latter end of summer and autumn, collecting oily seeds of various kinds and shelling them with great address and familiarity, if undisturbed often hanging and moving about head downwards, to suit their convenience while thus busily and craftily employed. They have a particular fondness for thistle seeds, spreading the down in clouds around them, and at this time feeding very silently and intently; nor are they very easily disturbed while thus engaged in the useful labor of destroying the germs of these noxious weeds. They do some damage occasionally in gardens by their indiscriminate destruction of lettuce and flower seeds, and are therefore often disliked by gardeners; but their usefulness in other respects far counterbalances the trifling injuries they produce. They are very fond, also, of washing and bathing themselves in mild weather; and as well as tender buds of trees they sometimes collect the Confervas of springs and brooks as a variety to their usual fare.

They raise sometimes two broods in the season, as their nests are found from the first week in July to the middle of September. In I83 I I examined several nests, and from the late period at which they begin to breed it is impossible that they can ever act in the capacity of nurses to the Cow Troopial. This procrastination appears to be occasioned by the lack of sufficiently nutritive diet, the seeds on which they principally feed not ripening usually before July.

Note. - The Black-headed Goldfinch (Spinus notatus), a Mexican bird, is credited with an accidental occurrence in Kentucky. 


\section{PINE SISKIN.}

\section{PINE FINCH. PINE LINNET.}

\section{SPINUS PINUS.}

Char. Above, olive brown or dark flaxen, streaked with dusky; wings and tail black, the feathers edged with yellow; wings with two buffish bars; below streaked with dusky and yellowish white. Length about $43 / 4$ inches.

Nest. Usually in a deep forest, on a horizontal branch of an evergreen tree 20 to 40 feet from the ground. It is fairly well built, as a rule, but is neither as compact nor graceful as the Thistle Bird's, and is composed of various materials, though generally grass, twigs, and pine-needles form the exterior, while the lining is either feathers or hair, or both.

Eggs. 3-5; pale green or greenish blue spotted with light reddish brown and lilac; $0.70 \times 0.50$.

Our acquaintance with this little northern Goldfinch is very unsatisfactory. It visits the Middle States in November, frequents the shady, sheltered borders of creeks and rivulets, and is particularly fond of the seeds of the hemlock-tree. Among the woods, where these trees abound, these birds assemble in flocks, and contentedly pass away the winter. Migrating for no other purpose but subsistence, their visits are necessarily desultory and uncertain. My friend Mr. Oakes, of Ipswich, has seen them in large flocks in that vicinity in winter. With us they are rare, though their favorite food is abundant. They are by no means shy, and permit a near approach without taking alarm, often fluttering among the branches in which they feed, hanging sometimes by the cones, and occasionally uttering notes very similar to those of the American Goldfinch. Early in March they proceed to the North, and my friend Audubon observed them in families, accompanied by their young, in Labrador in the month of July. They frequented low thickets in the vicinity of water, and were extremely fearless and gentle. Their summer plumage, as we have since also found in the Oregon Territory, where they abound and breed, is entirely similar to the garb in which they visit us in the winter, with the sole exception that the yellow of the wings is brighter. 
They sing on the wing in the manner of the Goldfinch. Their notes are clear, lively, and mellow, like as in that bird, but still sufficiently distinct; they fly out in the same graceful, deep curves, emitting also the common call-note at every effort to proceed.

The history of this interesting bird is but little better known today than when Nuttall wrote. Our ignorance is partly due to the irregular, nomadic habits of the bird, but chiefly because its favorite haunts are in out-of-the-way places, amid the deeper recesses of the forests, where few observers penetrate. At intervals large flocks visit the outskirts of settlements, and even look in upon the villages; but these are merely excursions by the way introduced into the migration programme. Its habitat is now given as "North America in general, breeding mostly north of the United States." In the east, nests have been found in New York State by Dr. C. Hart Merriam and Dr. A. K. Fisher, and the nest and eggs have been taken twice in Massachusetts; but the major portion of the eastern flocks go to the more northern portions of New England and beyond before settling down for the summer.

The dates usually given for the nesting are early in May; but a much earlier time is given by Dr. A. Leith Adams, an English naturalist who met with the species in New Brunswick. In his "Field and Forest Rambles," he writes: "It breeds early, and has its young flying before the first summer migrants arrive in April, when large flocks may be observed feeding on the buds of the hawthorn preparatory to their departure northward." He adds that it is a choice cage-bird, and is easily tamed. He kept some for several months, and when liberated they all returned to their cages after an absence of several days.

The biography of this species forms an interesting chapter in that interesting book, "The Land Birds and Game Birds of New England," by H. D. Minot, - a book, by the way, that has not received the recognition its merit deserves. 


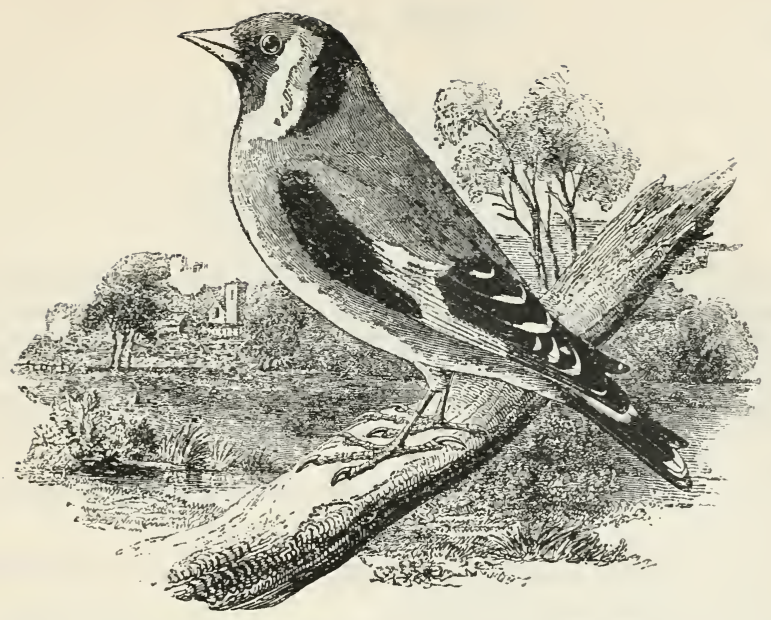

GOLDFINCH.

\section{CARDUELIS CARDUELIS.}

Char. Forehead and throat crimson; cheeks and lower throat white; crown and nape black, the latter being bordered by a narrow line of white; back brown; wings black, tipped with white and barred with yellow; tail-coverts white with black bases; three outer tail-feathers black, with white central spots, the remainder black, tipped with white; breast white, banded with brownish buff; flanks buffy; belly and under tail-coverts white. Length about 5 inches.

Nest. In an orchard or garden, placed in a fork of a tree or bush; a compact and neatly made structure of fine grass and moss, lined with grass and plant down, etc.

Eggs. 4-6; dull white tinged with blue or green, spotted and streaked with purplish brown; $0.70 \times 0.50$.

This European songster has been introduced within recent years, and though increasing slowly, appears to be thoroughly naturalized.

It is most abundant near Hoboken, N. J., where a number were set at liberty in 1878 , but examples have been taken in other States. A nest and eggs were discovered in Cambridge some ten years ago, and during the summer of I 890 a nest was taken near Worcester, Mass.

In Great Britain it is very common, and breeds north to Caithness, and one nest has been taken on the south side of Skye.

The young are fed on insects and larvæ; but Mr. Saunders says "the principal food of the Goldfinch consists of seeds of the thistle, knapweed, groundsel, dock, and other plants."

VOL. I. -23 


\section{HOUSE SPARROW.}

\section{ENGLISH SPARROW.}

\section{PASSER DOMESTICUS.}

CHAR. General color grayish brown, the back streaked with black; a narrow stripe of white over the eyes; cheeks with patches of chestnut and white ; sides and neck white; throat and breast black, sometimes washed with chestnut; wings brown with white bar; tail brown; belly dull white. Female: paler, without the black throat-patch. Length about 6 inches.

Nest. Anywhere and of any material, - usually a bulky affair, roughly made of dry grass and feathers.

Eggs. 4-7; grayish white speckled with rich brown and pale lavender; $0.85 \times 0.60$.

This is another introduced species; but about its naturalization there is, unfortunately, no doubt.

The history of the introduction of this bird, and its relation to American agriculture, is exhaustively treated in a volume prepared by Mr. Walter B. Barrows, under the direction of Dr. C. Hart Merriam, ornithologist to the Department of Agriculture, and issued from the Government Printing Office at Washington in 1889. From it we learn that the first importation of this Sparrow was made by Hon. Nicholas Pike, and the birds were liberated in Brooklyn, N. Y., in $185 \mathrm{I}$. The first batch did not thrive, so others - about a hundred - were brought over during 1852 and 1853 . In I 854 Colonel Rhodes, of Quebec, brought a number from England and liberated some in Portland, Me., the remainder being taken to Quebec. During the following ten years a few hundred were brought from Europe and scattered between Portland and New York, some thirty being turned out on Boston Common. About I869 a thousand were taken to Philadelphia, and several cities in the interior received each a few pairs.

From these imported birds have sprung the hosts of "ruffians in feathers" that have taken possession of every town and village, from Cape Breton to Florida, and west to the plains.

A few pairs were taken to southern Greenland, and though some lived through several winters, the entire flock at last perished.

Note. - The EUropean Tree Sparrow (Passer montanus) has also been introduced. A few years ago a number were liberated in St. Louis, and have become thoroughly naturalized there. This bird is closely related to the House Sparrow, which it resembles in appearance and in habits. The Tree Sparrow has not, however, increased so rapidly as its congener, nor proved so great a pest. 


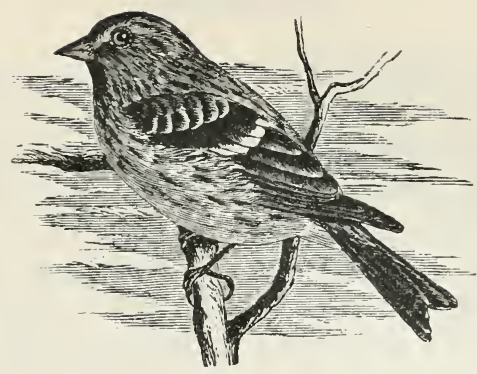

REDPOLL.

LESSER REDPOLL. REDPOLL LINNET.

ACANTHIS LINARIA.

CHAR. Above, brownish gray streaked with dusky; rump white, tinged with rose pink and streaked with dusky; forehead with patch of deep carmine; wings dusky brown with two white bars; below, white, sides heavily streaked with dusky; chin and throat dusky; breast deep rose pink. Bill extremely acute; in winter its color is yellow tipped with black, but in summer the color is dull blackish. (Female differs from male only in lacking the red tints on rump and breast.) Length $4 \frac{1}{2}$ to 5 inches.

Nest. In a low tree or amid a tuft of grass; composed of dry grass and moss lined with hair or feathers or plant down.

Eggs. 4-6; white tinged with green or blue, spotted with reddish brown; $0.65 \times 0.50$.

These elegant birds, which only pay us occasional and transient visits at distant intervals, are inhabitants of the whole Arctic circle to the confines of Siberia, and are found in Kamtschatka and Greenland as well as the colder parts of Europe. Arriving in roving flocks from the northern wilds of Canada, they are seen at times in the western parts of the State of New York with the fall of the first deep snow, and occasionally proceed eastward to the very city of New York, where in the depth of winter, and for several weeks, they have been seen gleaning their scanty food of various kinds of seeds in the gardens of the town and suburbs. Flocks are likewise sometimes seen in the vicinity of Philadelphia in severe winters, though at remote periods; as according to Mr. Ord they have not visited that part of Pennsylvania since the winter of 
I 8 1 3-14. They appear very unsuspicious while feeding in the gardens, or on the seeds of the alder-bush, one of their favorite repasts, and thus engaged allow a near approach while searching for their food in every posture, and sometimes head downwards. They are also fond of the seeds of the pine, the linden, and rape, and in the winter sometimes content themselves even with the buds of the alder. Wilson believed he heard this species utter a few interrupted notes, but nothing satisfactory is known of its vocal powers. Mr. Ord remarks that their call much resembles that of the common Yellow Bird, to which, indeed, they are allied. They are said to breed in the Highlands of Scotland, and to select the heath and furze for the situation of their nests, though they more commonly choose alder-bushes and the branches of the pine.

According to Richardson, these birds are among the few hardy and permanent residents in the fur countries, where they may be seen in the coldest weather on the banks of lakes and rivers, hopping among the reeds and carices or clinging to their stalks. They are numerous throughout the year even in the most northern districts, and from the rarity of their migrations into the United States it is obvious that they are influenced by no ordinary causes to evacuate the regions in which they are bred. Famine, in all probability, or the scarcity of food, urges them to advance towards the South. It is certain that they do not forsake their natal regions to seek shelter from the cold. This season, by the 7 th or 8 th of November (1833), before the occurrence of any extraordinary cold weather, they arrived in this vicinity (Cambridge, Mass.) in considerable flocks, and have not paid a visit to this quarter before to my knowledge for 10 or 12 years. They now regularly assemble in the birchtrees every morning to feed on their seeds, in which employment they are so intent that it is possible to advance to the slender trees in which they are engaged and shake them off by surprise before they think of taking wing. They hang upon the twigs with great tenacity, and move about while feeding in reversed postures, like the Chickadees. After being shot at they only pass on to the next tree and resume their feeding as 
before. They have a quailing call perfectly similar to that of the Yellow Bird (Fringilla tristis), twee twee, or tshe-veé; and when crowding together in flight make a confused chirping 'twit' itwit' twit'twit' twit, with a rattling noise, and sometimes go off with a simultaneous twitter. Occasionally they descend from their favorite birches and pick up sunflower seeds and those of the various weedy Chenopodiums growing in wastes. At length they seemed attracted to the pines by the example of the Crossbills, and were busily employed in collecting their seeds. As the weather becomes colder they also roost in these sheltering evergreens; and confused flocks are seen whirling about capriciously in quest of fare, sometimes descending on the fruit-trees to feed on their buds by way of variety. Though thus urged from their favorite regions in the north, there appeared no obvious reason for their movements, as we found them fat and not driven to migrate from any imminent necessity.

In Nuttall's day but two forms of Redpoll were recognized by naturalists, - linaria and canescens (=exilipes); but now there are five, - or six, if we count the hypothetical brewsterii. Similar as these appear to the casual observer, an expert can readily divide them when examples of the different races are compared, though it is sometimes difficult to refer a specimen with accuracy unless so compared.

The habitat of true linaria is now given as "northern portions of northern hemisphere, in North America; south in winter to Kansas and Virginia."

Note. - Holball's Redpoll (Acanthis linaria holballii) is larger than the type, with a proportionately longer bill. It is usually restricted to the northern coasts of Europe and Asia, but examples have been taken in Alaska, Quebec, Massachusetts, and New York.

The Greater Redpoll (Acanthis linaria rostrata) is still larger, - length $5^{1 / 4}$ to $5 \% / 4$ inches, - and the colors are darker, with the under parts more broadly striped. It is found in southern Greenland in summer, and in winter migrates to New England, Manitoba, and northern Illinois. 


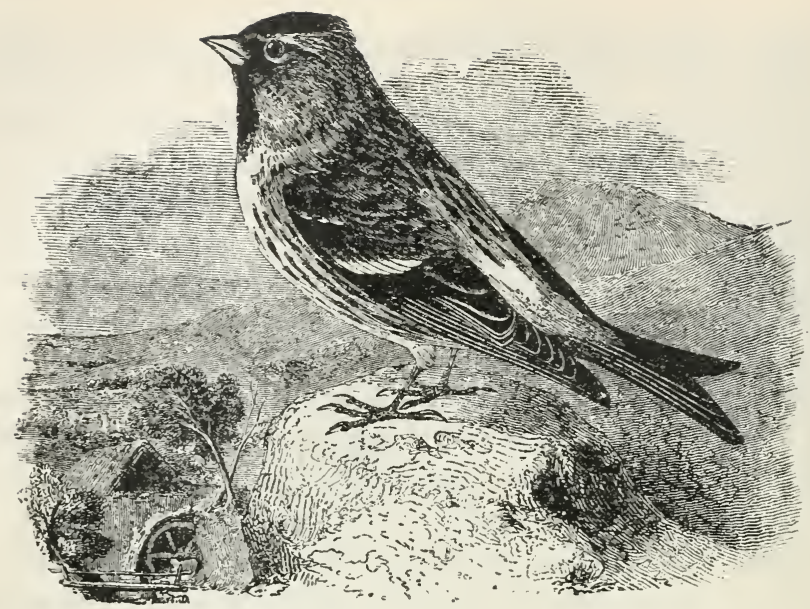

HOARY REDPOLL.

MEALY REDPOLL.

\section{ACANTHIS HORNEMANII EXILIPES.}

CHAR. Male: above, dull white streaked with dusky brown; crown crimson; rump white washed with pink; wings and tail dusky brown with two white bars; below, dull white sparsely streaked with dusky; chin and throat dusky; breast delicate rose pink. Female: similar, but without pink on breast and rump. Length 5 inches.

Similar to $A$. linaria, but colors paler, - the brown largely replaced by gray, and the red of a paler shade and more restricted.

Nest. In a low tree or on the ground; composed of grass and twigs lined with feathers.

Eggs. 3-5; white tinged with blue or green, spotted with reddish brown; $0.65 \times 0.50$.

This species, so nearly allied to the last, is met with partly in the same remote boreal regions in the summer, but is of much more rare occurrence; it is also found in the territory of Oregon, and stragglers have been obtained as far south as New Jersey and New York. In Maine it is less rare. These birds have a note very similar to the last species, but distinct. They are full of activity and caprice while engaged in feeding, making wide circles and deep undulations in their flight. Like 
Titmice also, they frequently feed and hang to the twigs in reversed postures.

This form summers in the Arctic regions, and in winter migrates southward, a few examples reaching the northern border of the United States.

Note. - The GReenland Redpoll (Acanthis hornemannii) is larger than exilipes, - length $5 \frac{1}{2}$ to $61 / 2$ inches. It breeds in Greenland and the eastern part of Arctic America, and in winter ranges as far south as Labrador.

BREWSTER's LINNET (Acanthis brewsterii) is a "Redpoll" without any red on its poll; it differs also from the other forms in lacking the dusky spot on the throat and in having a portion of its plumage tinged with yellow. The type specimen was taken at Waltham, Mass., in I 870 , and remains unique. The A. O. U. have placed the name in that "lock-up" for suspicious characters, the " hypothetical list."

\section{TOWHEE.}

\section{GROUND ROBIN. CHEWINK.}

\section{PIPILO ERYTHROPHTHALMUS.}

CHAR. Black with white belly and bay sides and vent; outer tailfeathers partly white; white spot on wing; iris red. Female and young tawny brown where the adult male is black.

Nest. Near the margin of woodland or in an overgrown pasture; usually placed on the ground and concealed in a tuft of grass or brushheap, or under a log or bush, - sometimes fastened to a low bush; loosely made of dry leaves, grape-vines, weed-stems, and grass, lined with fine grass, roots, or pine-needles.

Eggs. 4-6; dull white thickly marked with fine spots of warm, reddish brown and lilac; sometimes the marks are bolder; $0.95 \times 0.75$

This is a very common, humble, and unsuspicious bird, dwelling commonly in thick dark woods and their borders, flying low, and frequenting thickets near streams of water, where it spends much time in scratching up the withered leaves for worms and their larvæ, and is particularly fond of wire-worms (or Iuli), as well as various kinds of seeds and gravel. Its rustling scratch among the leafy carpet of the forest is often the only indication of its presence, excepting 
now and then a call upon its mate (tŏw-wee, tŏw-wee, tŏwweet), with which it is almost constantly associated. While thus busily engaged in foraging for subsistence, it may be watched and approached without showing any alarm; and taking a look often at the observer, without suspicion, it scratches up the leaves as before. This call of recognition is uttered in a low and somewhat sad tone, and if not soon answered it becomes louder and interrogatory, tow-wee towee? and terminates often with tozveet. These birds are accused of sometimes visiting the pea-fields to feed, but occasion no sensible damage.

In the pairing season and throughout the period of incubation the male frequently mounts to the top of some bush amidst the thickets where he usually passes the time, and from hence in a clear and sonorous voice chants forth his simple guttural and monotonous notes for an hour or so at a time, while his faithful mate is confined to her nest. This quaint and somewhat pensive song often sounds like $t$ 'sh' $d$ writée tĕ tĕ

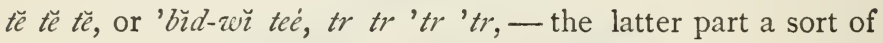
quaint and deliberate quivering trill; sometimes it sounds like 'bĭd tsherr ' $r$ ' 'rh, rrh 'wt, then ' $t$ 'wee twee t' tsher' $r$ 'r, also et se ya, ya 'ya ' $y a$ ' $y a$ ' $y a$; the latter notes, attempted to be expressed by whistled and contracted consonant syllables, are trilled with this sound.

Ground Robins, sometimes also called Tshe-zvink and Peewink, from another of their notes, are general inhabitants of Canada and the United States even to the base of the Rocky Mountains and the peninsula of Florida, in all of which regions, except the last, with Louisiana and the contiguous countries, they pass the summer and rear their young, migrating, however, from the Northern and Middle States in October, and returning again about the middle or close of April, according to the advancement of the season, at which time also the males usually precede the arrival of their mates. They pass the winter generally to the south of Pennsylvania, and are then very abundant in all the milder States in the Union.

They are said to show some address at times in concealing 


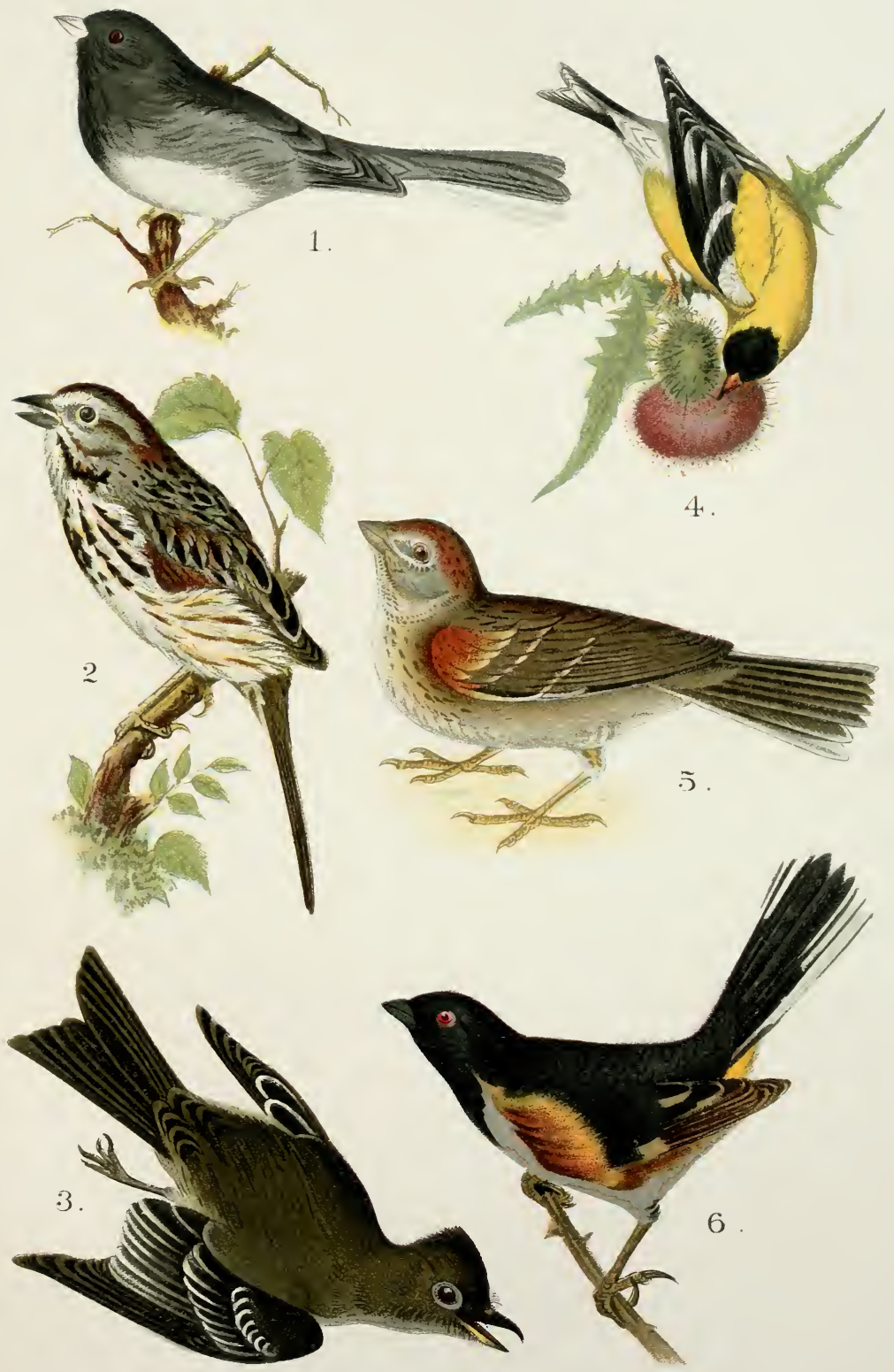

1. Snow Bird.

4. American Goldfinch.

2. Song Sparrow.

5 . Vesper Sparrow.

3. Phoebe.

6 . Towhee 

their nest, which is fixed on the ground in a dry and elevated situation and sunk beneath the surface among the fallen leaves, sometimes under the shelter of a small bush, thicket, or brier. According to the convenience of the site, it is formed of different materials, sometimes, according to Wilson, being made of leaves, strips of grape-vine bark, lined with fine stalks of dry grass, and occasionally in part hidden with hay or herbage. Most of the nests in this vicinity are made in solitary dry pine woods without any other protection than some small bush or accidental fallen leaves; and the external materials, rather substantial, are usually slightly agglutinated strips of red-cedar bark, or withered grass with a neat lining of the same and fallen pine leaves; the lining sometimes made wholly of the latter. The nest is also at times elevated from the ground by a layer of coarse leaf-stalks such as those of the hickory. The first brood are raised early in June, and a second is often observed in the month of July; but in this part of New England they seldom raise more than one. The pair show great solicitude for the safety of their young, fluttering in the path and pretending lameness with loud chirping when their nest is too closely examined.

The eastern form of the Towhee is not found west of Minnesota, Kansas, and Texas. In the more northern and unsettled portions of New England it is very rare or absent. It is common in Man. itoba and southern Ontario, but rare in Quebec; and one example, captured near St. John, N. B., in I88I, is the only known instance of its occurrence in the Maritime Provinces.

The flocks migrate in winter to the Southern States, settling in Virginia and southward.

Note. - The White-Eyed Towhee (Pipilo erythrophthalmus alleni) differs from the northern race chiefly in being of somewhat smaller size, and in the iris being white instead of red.

It was discovered during the spring of 1879 by Mr. C. J. Maynard in Florida, and is said to be distributed along the coast northward to South Carolina. 


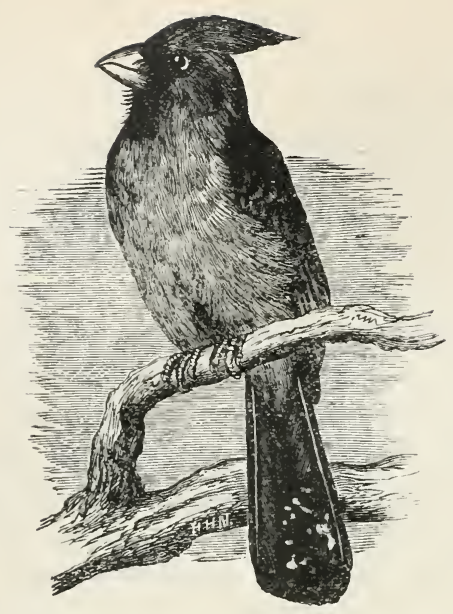

CARDINAL.

REDBIRD.

\section{CARDINALIS CARDINALIS.}

Char. Head with conspicuous crest. Male: above, bright vermilion, shaded with gray on the back; beneath, paler; forehead and throat black. Female : above, olive gray; beneath, buffy. Young similar to female, but duller. Length about 8 to $81 / 2$ inches.

Nest. In a variety of situations, most frequently amid a thicket of brambles or in a low tree; loosely made of twigs, strips of grape-vine, dry grass, weed-stems, lined with fine grass or roots, sometimes with hair.

Eggs. 3-5; dull white or tinged with blue, green, or buff; spotted with reddish brown and lilac; $1.00 \times 0.75$.

These splendid and not uncommon songsters chiefly reside in the warmer and more temperate parts of the United States from New York to Florida, and a few stragglers even proceed as far to the north as Salem in Massachusetts. They also inhabit the Mexican provinces, and are met with south as far as Carthagena; adventurously crossing the intervening ocean, they are likewise numerous in the little temperate Bermuda islands, but do not apparently exist in any of the West Indies. As might be supposed, from the range already stated, the Redbirds are not uncommon throughout Louisiana, Missouri, and Arkansas Territory. Most of those which pass the summer in 
the cooler and Middle States retire to the South at the commencement of winter; though a few linger in the sheltered swamps of Pennsylvania and near the shores of the Delaware almost through the winter. They also, at this season, probably assemble towards the sea-coast from the west, in most of the Southern States, where roving and skulking timid families are now seen flitting silently through thickets and swampy woods, eager alone to glean a scanty subsistence, and defend themselves from prowling enemies. At all times, however, they appear to have a predilection for watery groves and shaded running streams, abounding with evergreens and fragrant magnolias, in which they are so frequent as to be almost concomitant with the scene. But though they usually live only in families or pairs, and at all times disperse into these selective groups, yet in severe weather, at sunset, in South Carolina, I observed a flock passing to a roost in a neighboring swamp and bushy lagoon, which continued, in lengthened file, to fly over my head at a considerable height for more than twenty minutes together. The beautiful procession, illumined by the last rays of the setting sun, was incomparably splendid as the shifting shadowy light at quick intervals flashed upon their brilliant livery. They had been observed to pass in this manner to their roost for a considerable time, and, at daybreak, they were seen again to proceed and disperse for subsistence. How long this timid and gregarious habit continues, I cannot pretend to say; but by the first week in February the song of the Redbird was almost daily heard. As the season advances, roving pairs, living, as it were, only with and for each other, flit from place to place; and following also their favorite insect or vegetable fare, many proceed back to the same cool region in which they were bred, and from which they were reluctantly driven; while others, impelled by interest, caprice, and adventure, seek to establish new families in the most remote limits of their migration. Some of these more restless wanderers occasionally, though rarely, favor this part of New England with a visit. After listening with so much delight to the lively fife of the splendid Cardinal, as I travelled alone through the deep and 
wild solitudes which prevail over the Southern States, and bid, as I thought, perhaps an eternal adieu to the sweet voice of my charming companions, what was my surprise and pleasure, on the $7^{\text {th }}$ of May, to hear, for the first time in this State, and in the Botanic Garden, above an hour together, the lively and loud song of this exquisite vocalist, whose voice rose above every rival of the feathered race, and rung almost in echoes through the blooming grove in which he had chosen his retreat. In the Southern States, where these birds everywhere breed, they become familiarly attached to gardens, which, as well as cornfields, afford them a ready means of subsistence; they are also fond of the seeds of most of the orchard fruits, and are said occasionally to prey upon bees.

The lay of the Cardinal is a loud, mellow, and pleasingly varied whistle, delivered with ease and energy for a considerable time together. To give it full effect, he chooses the summit of some lofty branch, and elevating his melodious voice in powerful as well as soothing and touching tones, he listens, delighted as it were, with the powers of his own music, at intervals answered and encouraged by the tender responses of his mate. It is thus the gilded hours of his existence pass away in primeval delight, until care and necessity break in upon his contemplative reveries, and urge him again to pursue the sober walks of active life.

The song of the Redbird, like that of so many others, though possessed of great originality, often consists in part of favorite borrowed and slightly altered phrases. It would be a difficult and fruitless task to enumerate all the native notes delivered by this interesting songster; a few may be perhaps excused by those who wish, in their rural walks, to be made, in any way, acquainted with the language of the feathered vocalists that surround them. All the tones of the Cardinal are whistled much in the manner of the human voice. Late in February, while travelling in Alabama, I heard one crying woolit, wolit wolit wolit, then in a quicker tone butsh bütsh bütsh bütsh, and 'tshooway tshooway tshooway. At another time the song was 'wit a'wit, 'teu'; then tshevi tsheve 'teu', 
'whoit 'whoit 'whoit'tê' (the 'whoit an exact human whistle, and the teu tenderly emphatic). Another bird called téo téo téo, tshooé tshooe tshooe tshooe, then teo teo teo teo alone, or 'wóit 'wóit 'wóit 'wóit, with the last word delivered slower, and in a sinking, delicately plaintive tone. These phrases were also answered in sympathy by the female, at a little distance up the meandering brook where they were engaged in collecting their food. In Florida, about the $\mathrm{I} 2$ th of March, I heard a very fine Redbird singing 'whĭttoo wrttoo wĭdoo 'wr̈ddoo. $\mathrm{He}$ began low, almost in a whisper, but very clearly articulated, and gradually raised his voice to loudness, in the manner of the Nightingale. He now changed the strain into 'victu, wilt wilt wilt wilt; then 'víctu tshooé 'tshŏoe tshŏoe tshŏoe, afterwards tú tú 'victu, and 'victu tu tu, then varying 'tshooee, etc., in a lower key. On approaching this bird, to see and hear him more distinctly, he exhibited his anger by scolding in a hoarse tone almost like that of a squirrel, and from the season, and absence of respondence in the female, I imagine he already had a nest in the neighboring thicket. The bird, which frequented the Botanic Garden for several days, in the morning sang fearlessly and loudly, but at other times the pair hid themselves amongst the thickest bushes, or descended to the ground to feed among the grass and collect insects and worms; now and then however, in an undertone, as if afraid of attracting notice, he whispered to his mate teú teú teú, woit, 'woit 'woit, elevating his tone of recognition a little at the close of the call, and going over other of the usual phrases in the same whispering and slenderly rising voice. About the 4 th of July, the same pair, apparently, paid us a parting visit, and the male sang with great energy, 'tv' tw', 'wétŏ 'wetŏ 'wetó 'wetó 'wetó wait, then waitŭp waĭtŭp waĭtŭp waĭtŭp, tshow tshow tshŏw tshŏw tshow. On whistling any of these notes within hearing of the Cardinal, a response is almost certain, as this affectionate recognition is frequently answered by the female. His phrase may also be altered at will, by whistling some other than that which he repeats, as he often immediately answers in the call he hears, supposing it to be that of his approaching mate. 
On their arrival in the Middle States, in spring, violent contests sometimes ensue between the unmated and jealous males. When the dispute is for the present closed, the pair, probably for greater security, and dreading a recurring quarrel of doubtful issue, wander off to a remote distance from their usual abode, and in this way, no doubt, occasionally visit countries but little frequented by the rest of their species. Early in May, it seems, in Pennsylvania, according to Wilson, they begin to prepare their nests, which are often placed in an evergreen bush, cedar, laurel, or holly. They usually raise two broods in the season. As they are so easily domesticated immediately after being caught in trap cages, it is unnecessary to raise them from the nest. By this kind of unnatural confinement, the brilliant color of the male is found sometimes to fade until it becomes of a pale whitish red. They live, however, long in confinement, and an instance is known of one which had survived for $2 \mathrm{I}$ years. In the cage, they have not that variety of song which they exhibit in their native wilds; and this, judging from the frequent repetition of the same phrase, would appear to be a monotonous performance, if the variety of expression, tone, and key did not perpetually relieve and enhance the character of the lay. His song also continues for 6 or 8 months in the year, and is, even, as among the Thrushes, more lively in wet weather, the sadness of Nature, softening and soothing the tender vocalist into a lively, pathetic, and harmonious revery. So highly were these birds esteemed for their melody that, according to Gemelli Careri, the Spaniards of Havanna, in a time of public distress and scarcity, bought so many of these birds, with which a vessel was partly freighted, from Florida, that the sum expended, at Io dollars apiece, amounted to no less than i 8,00o dollars ! Indeed, Latham admits that the notes of our Cardinal "are almost equal to those of the Nightingale," the sweetest feathered minstrel of Europe. The style of their performance is, however, wholly different. The bold, martial strains of the Redbird, though relieved by tender and exquisite touches, possess not the enchanting pathos, the elevated and varied 
expression of the far-famed Philomel, nor yet those contrasted tones, which, in the solemn stillness of the growing night, fall at times into a soothing whisper, or slowly rise and quicken into a loud and cheering warble. A strain of almost sentimental tenderness and sadness pervades by turns the song of the Nightingale; it flows like a torrent, or dies away like an echo; his varied ecstasies poured to the pale moonbeams, now meet with no response but the sighing zephyr or the evermurmuring brook. The notes of our Cardinal are as full of hilarity as of tender expression; his whistling call is uttered in the broad glare of day, and is heard predominant over most of the feathered choir by which he is surrounded. His responding mate is the perpetual companion of all his joys and cares; simple and content in his attachment, he is a stranger to capricious romance of feeling, and the shades of melancholy, however feeble and transient, find no harbor in his preoccupied affections.

The Cardinal occurs sparingly in southern New England, and it has been occasionally seen in Massachusetts and northward. Two examples visited Halifax, N. S., in I87I. It is quite common in Ohio, and has been taken, across the lake, in Ontario, and westward to Iowa.

\section{EVENING GROSBEAK.}

\section{COCCOTHRAUSTES VESPERTINUS.}

Char. Dusky olivaceous, shading to yellowish on the rump; forehead, line over the eyes, and under tail-coverts, yellow; crown, wings, and tail black; secondaries mostly white; bill greenish yellow, conspicuously large. Female differs slightly from the male, but is readily identified. Length about $71 / 2$ to 8 inches.

Nest. In the deep forest, usually on a branch of a tall tree, sometimes in low bush; composed of twigs and roots, lined with roots or hair.

Eggs. 4-?; pale dull green, marked with pale brown spots.

This beautiful species inhabits the solitudes of the Northwestern interior, being met with from the extremity of the Michigan Territory to the Rocky Mountains. It is not uncommon towards the upper extremity of Lake Superior and 
the borders of Athabasca Lake; to the east of these limits these birds appear to be only transient visitors in spring and fall. They are common inhabitants of the fur countries, and particularly of the maple woods of the Saskatchewan, where they do not arrive from the South before the commencement of the month of June. In the pine woods of Oregon (according to Mr. Townsend) numerous flocks are seen about the middle of May, and at this time they are very tame and unsuspicious, moving about in considerable numbers throughout the whole of the day, and seem no way given to retiring before sunset. Their ordinary note while feeding consists of a single rather screaming call. At other times, particularly about mid-day, the male from the branches of some tall pine-tree utters a single warbling note much like the interrupted beginning of the Robin's song, but not so sweet. They feed upon the seeds of the pine and other trees, alighting upon the large limbs, and proceed by a series of hops to the very extremities of the branches. They also occasionally devour the larvæ of ants, and probably other kinds of insects.

The Evening Grosbeak occurs regularly in winter in Wisconsin, Illinois, Iowa, and Michigan, and occasionally in Ohio and Ontario. During the latter part of the winter of $1889-90$ numbers were seen eastward to Montreal and the New England States.

The flocks appeared in the vicinity of Hamilton about the middle of December. Mr. McIlwraith writes that the first he saw was a flock of about twenty or thirty, some of whom were on the bank of the Lake feeding, "while others were down on the sandy shore, picking gravel or dabbling themselves in the water. . . I I thought at first that the original flock had remained, but soon found that an easterly migration was going on, and that as one flock left another arrived. . . . During February few, if any, were observed here. In March the return trip commenced, but was in all respects different from the easterly one. The birds were then fewer in number, and all seemed excited and desirous to go west with the least possible delay." (Birds of Ontario.) 


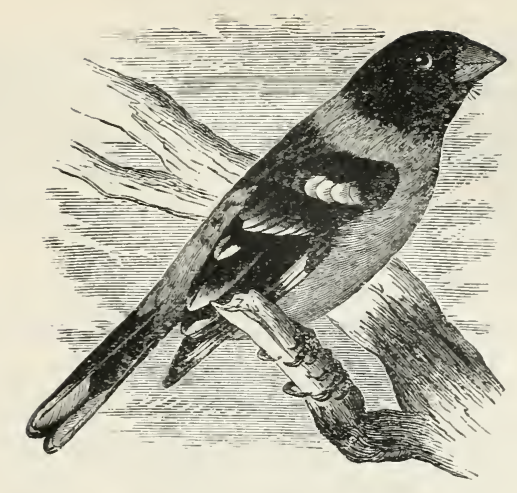

ROSE-BREASTED GROSBEAK.

Habia ludoviciana.

ChAR. Male : above, black; rump white; wings and tail black with white markings; below, white; breast and under tail-coverts deep rose pink. Female : above, streaked blackish and olive; crown with central stripe of white; rump white ; under parts dull white, streaked with brown; no red on the breast. Length $71 / 2$ to $81 / 2$ inches.

Nest. Usually on the margin of woods, or in a dense alder-swamp, occasionally in a garden or open pasture ; composed of grass, usnea moss, roots, stalks, and twigs, lined with fine grass, roots, or pine-needles.

Eggs. 3-5; dull green or bluish green variously marked with spots and blotches of reddish brown, lilac, and pale lavender; $1.00 \times 0.70$.

The remote Northwestern Territories of the Union, Canada, and the cool regions towards the Rocky Mountains appear to be the general residence of the Rose-breasted Grosbeak. A few pairs breed on the banks of the Mohawk, and probably in the interior of Pennsylvania. Mr. Say met with it in the spring, on the lower part of the Missouri ; and at Pembino, on the $5^{\text {th }}$ of August, in the 49th parallel. Dr. Richardson also observed it in the latitude of $53^{\circ}$, and Audubon found it breeding in Newfoundland. It has likewise been seen in Mexico and Texas. These are, no doubt, its proper natal regions, and the course of its migrations, from which it only ventures accidentally in severe winters, and is then transiently seen in pairs east of the Atlantic mountains, which constitute the general boundary of its range. It is thus seen occasionally in the

vOL. I. -24 
vicinity of Philadelphia, in the State of New York, particularly along the borders of Lake Ontario, and in Connecticut, but rarely in this part of New England. Pennant speaks of its arrival in the State of New York in May, where it has a nest of 5 eggs, and then retires in August. It is also unknown in the Southern States.

My friend Mr. Cooper remarks that though this species is rare in the vicinity of New York, a few probably breed in the woods of the Hudson, as at Tappan, 30 miles up that river, it . is frequently seen in the cherry-trees in the month of June, and is said to be common in the forests along the south shore of Lake Erie, and usually breeds there. It thrives very well in a cage, is a most melodious and indefatigable warbler, frequently in fine weather, as in its state of freedom, passing a great part of the night in singing, with all the varied and touching tones of the Nightingale.

While thus earnestly engaged, it seems to mount on tiptoe in an ecstasy of enthusiasm and delight at the unrivalled harmony of its own voice. The notes are wholly warbled, now loud, clear, and vaulting with a querulous air; then perhaps sprightly; and finally lower, tender, and pathetic. In short, I am not acquainted with any of our birds superior in song to the present, with the solitary exception of our Orphean Mocking Bird.

The Louisiana Grosbeak is fed with the usual kinds of birdseed, and in its wild state seems to be particularly fond of the kernels of the sour-gum berries; it probably also feeds upon the berries of the juniper, which abound in the regions it usually inhabits.

Though somewhat local in its distribution, this attractive bird occurs regularly throughout the Eastern States, but is uncommon in Maine, New Hampshire, and Vermont. It is found in some parts of New Brunswick, Nova Scotia, and Quebec, and is quite common in Ontario, and abundant in Manitoba.

Though generally selecting a secluded spot for nesting, a pair will occasionally wander away from the forest and thicket, and even build in the heart of a town. In 1890 a nest was built and a brood raised not a hundred yards from where I am penning these words, 
- almost within the shadow of Memorial Hall. The nest was laid upon a branch that hung over the sidewalk of Oxford Street, not more than ten or twelve feet from the ground, the tree being in the garden adjoining the residence of Mr. Francis Foster.

\section{BLUE GROSBEAK.}

\section{Guiraca Cæerulea.}

CHAR. Male : general plumage rich blue, darker on the back; feathers around base of bill, wings, and tail black; two bright rufous bands on the wings. Female: smaller; above, yellowish brown; below, dark buff. Length $6^{1 / 2}$ to 7 inches.

Nest. On a low branch of a tree or bush, situated along the margin of a wood, or in an open pasture or orchard, or by a roadside, - sometimes in an alder swamp or blackberry thicket; composed of leaves, weedstems, and grass, lined with horse-hair, roots, or fine grass; occasionally pieces of snake skin or newspaper are worked into the exterior.

Eggs. 3-4; light blue; $0.85 \times 0.65$.

This shy and almost solitary species chiefly inhabits the warmer parts of America from Brazil to Virginia; stragglers occasionally also visit the lower parts of Pennsylvania and New Jersey, and Bullock observed them on the tableland of Mexico. According to Wilson, it is nearly a silent bird, seldom singing in the cage, its usual note of alarm being merely a loud chuck; though at times its musical capacity under more favorable circumstances is suggested by a few low and sweettoned notes. It may be fed on Indian corn, hemp-seed, millet, and the kernels of several kinds of berries.

According to Audubon, these birds arrive in Louisiana about the middle of March. They proceed through Alabama, Georgia, and the Carolinas, in all which districts they breed; and although rarely seen in the Western States, Mr. Townsend and myself met with them in May on the borders of the Platte, near Scott's Bluffs, where they were already mated and breeding. They are sometimes met with along the Atlantic coast as far as New Jersey, and Audubon found a nest in that State within a few miles of Philadelphia. Their food consists 
principally of different sorts of seeds; they are also fond of those of rice, and grass of all kinds. At the period of breeding they sing with great sweetness and melody.

This species is still considered a Southern bird; but it regularly visits Pennsylvania, Kentucky, and Kansas, and has been taken in Massachusetts, Maine, and New Brunswick.

\section{PURPLE FINCH.}

\section{LINNET.}

\section{Carpodacus PURPUREUS.}

CHAR. Male: no "purple;" body rosy crimson, brightest on the head, darkest on the back, palest on the breast; belly white; wings and tail dusky; everywhere streaked more or less with brown and gray. Female and young: without red; streaked brown and gray, sometimes with olive tint. Length about $6 \frac{1}{4}$ inches.

Nest. Near a settlement and in some old pasture, open grove, park, or orchard; composed of twigs, weed-stems, roots, and bark, lined with fine grass or hair.

Eggs. 4-5; pale dull bluish green, variously marked with dark brown and lilac; $0.8_{5} \times 0.60$.

These brilliant and cheerful songsters inhabit the Northern and Western States during the summer, where they rear their young. They appear to have a great predilection for resinous evergreens, pine, and spruce, and feed upon the berries of the juniper and red cedar as well as the seeds of the tulip-tree and others; they likewise frequent gardens for the same purpose, and are particularly pleased with sunflower seeds and other oily kinds. When reduced to necessity they are observed to eat the buds of the beech and those of the fruit-trees, - probably for the sake of the stamens contained in them, of which they are greedy when displayed in the opening blossoms. The stipules of the expanding buds of the elm, which are sweet and mucilaginous, as well as the young capsules of the willow in the spring, also make a common part of their fare. Their food in summer, however, consists principally of insects and juicy berries, as those of the honeysuckle and others. 
Although the Purple Finch breeds and passes the season in this vicinity, yet as early as the close of September they leave us for the South; about which time and nearly to the close of October, small, hungry, roving flocks arrive from the more northern States and Canada or Newfoundland. At the same time likewise great numbers visit Pennsylvania, the maritime parts of New York and New Jersey, and many pass the winter in the Middle States, while others proceed as far south as the States of Louisiana, Florida, and Texas, returning north in the latter end of March or early in April, and arriving with us in the month of May to pass the most important period of their existence. Roving flocks are also seen here as early as the 24th of March, singing while they stay with great energy and cheerfulness; these in all probability proceed to Labrador or Newfoundland to breed. The males now have many bitter contests for the choice of their mates, and are very bold and pugnacious in confinement, attempting to destroy every other bird introduced into the same cage. They also bite severely when taken up wounded, but are directly reconciled to the cage, finding their most important wants so amply supplied; yet in this state they often refuse to sing, and after moulting into the humble plumage of the female, frequently remain so, without ever renewing their crimson dress. They are here exposed in cages for sale at high prices (by the name of Linnets), and sing pretty commonly in confinement. Their notes are very similar to those of the Warbling Vireo, but louder, and more agreeably diversified. From the tops of our lofty and spreading elms or shadowy spruce trees, where they delight to pass the time, their varied and very cheerful melody is often continued for hours almost without interval, and poured forth like a torrent. After a combat with a rival, his towering notes of victory burst out into rapture, and he now seems to triumph with loud and petulant hilarity. The song of this beautiful Finch is indeed much finer than that of the Canary; the notes are remarkably clear and mellow, and the trilling sweet and various, particularly on their first arrival. At times the warble is scarcely audible, and appears at a distance; 
it then, by a fine crescendo, bursts into loudness and falls into an ecstasy of ardent and overpowering expression; at such times the usual pauses of the song are forgotten, and like the varied lay of the Nightingale, the ravishing performer, as if in serious emulation, seems to study every art to produce the effect of brilliant and well-contrasted harmony. As he sits on the topmost bough of some tall sapling or more lofty tree, surveying the wide landscape, his proud voice and elevated action seem to bid defiance to competition; and while thus earnestly engaged, he seems to fear no spectator, however near may be his approaches. The rapidity of his performance and the preeminent execution with which it is delivered seem almost like the effort of a musical-box or fine-toned, quickly moving, delicate strain on the organ. While feeding in the month of March these birds also utter a querulous tshippee tshee, in nearly the same sad and liquid tone as that uttered by the Yellow Birds while thus engaged. The dull-colored birds, in the attire of the female, do not sing either so well or in the same manner as the crimson-colored individuals.

The nest of this species is, as I have observed in two instances in Cambridge, made in the horizontal branches of the balsam-fir. In the first, which I saw in the garden of Professor Farrar, it was made in a young tree about 6 feet from the ground. On approaching it the female sat still until I nearly touched her, and made very little complaint when off. The nest was coarse and substantial, very much like that of the Song Sparrow, composed of coarse grass and lined with fine root-fibres. From this nest was raised in a cage one of the young, which became exceedingly docile and affectionate, but was not remarkable for its song.

In winter the Purple Finch is found regularly, though sparingly, through the southern and central portions of New England and in Ontario, and occasionally as far north as New Brunswick. Its winter range extends southward as far as the Gulf States, while its breeding area extends from Long Island and Minnesota to the lower fur countries. 


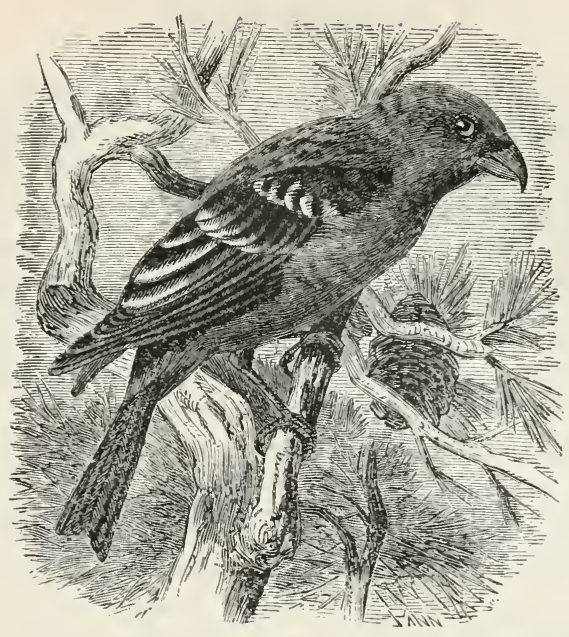

PINE GROSBEAK.

\section{Pinicola enUCleator.}

CHAR. Male : grayish brown, darkest on the back, shading to ashy on the rump, washed with rosy carmine, which is deepest on the crown and rump; wings and tail dusky, the wings with two white bands. Female and young: similar, but without the rosy coloring; head and rump washed with pale olive bronze. Length $81 / 4$ to 9 inches.

Nest. On the border of a swamp or the margin of a stream running through an evergreen forest; saddled on a low branch or in a crotch of a low bush, or placed in a crevice of a rock. A bulky, ill-made affair of moss, or twigs and roots or strips of bark, and lined with fine grass, roots, or vegetable fibre.

Eggs. 4-?; pale greenish blue marked with dark brown and lilac; I.05 $\times 0.75$.

These splendid and very hardy birds appear to dwell almost wholly within the cold and Arctic regions of both continents, whence, only in severe winters, a few migrate into Canada and the United States, where they are consequently of rare and uncertain occurrence. They have been seen in winter in the lower part of Missouri, and at the same season, occasionally, in the maritime parts of Massachusetts and Pennsylvania, and are observed to return to Hudson Bay as early as April. According to Mr. Pennant, they frequent the woods of pine and juniper, and are now possessed of musical talents; 
but as the period of incubation approaches they grow silent. Suited to the sterile climates they inhabit, their fare, besides the seeds of the pine, alpine plants, and berries, often consists of the buds of the poplar, willow, and other northern trees and shrubs; so that they are generally secure of the means of subsistence as long as the snows are not too overwhelming. The individuals as yet seen in the United States are wholly young birds, which, it seems, naturally seek out warmer climates than the adult and more hardy individuals.

According to Mr. T. McCulloch, of Pictou, Nova Scotia, in very severe winters flocks of these birds, driven from the pine forests by famine and cold, collect about the barns, and even enter the streets of Pictou, alighting in quest of food. A male bird at this season, caught in a trap, became very familiar, and as the spring approached he resumed his song in the mornings, and his notes, like those of the Rose-breasted Grosbeak, were exceedingly rich and full. As, however, the period for migration approached, his familiarity disappeared, and the desire of liberty seemed to overcome every other feeling. For four days in succession his food remained untouched, and his piteous wailing excited so much commiseration that at length he was released. The Pine Grosbeak is said to breed in Maine as well as in Newfoundland and Labrador.

The visits of this handsome bird to New England and the more southern portions of Canada are decidedly irregular. During an occasional winter the flocks are large and numerous, while again for several seasons but a few stragglers may appear.

Dr. Coues thinks that there is no question but that the bird is a "resident" in northern New England, breeding in some parts of Maine, New Hampshire, and Vermont; but I am much inclined to question it. Very possibly a few pairs may pass an occasional summer in that region, but I can find no evidence of the birds having been seen there with sufficient frequency to warrant their being termed residents.

The only known instances of this species having built in the vicinity of northern New England must be credited to New Brunswick. These are Boardman's hypothetical nest, found near St. Stephen; the unfinished nest which Banks discovered the parents at work upon, near St. John; and the nest with three 
young and one egg taken by Cox on the Restigouche, in latitude $47^{\circ}$. But excepting in these three instances, and a fourth where young birds were seen on the Tobique River, the species has been unknown as a summer resident in New Brunswick. Cox saw several examples along the Restigouche in July, I888, but I have hunted for them up and down the same river, from the Wagan to the Metapedia, both in July and September, without seeing or hearing so much as one.

It is said that the southern limit of its breeding area is in the vicinity of the 5oth parallel, though in the West it is somewhat farther north, as Thompson reports the bird a winter visitor only at Winnipeg and Portage la Prairie. From thence it ranges far north - to the Yukon and beyond. In winter the flocks spread over the country in varying abundance, as far south as Kansas and Maryland.

Some years ago I kept a male in confinement, and found him a delightful pet. He was healthy and happy in his cage, was easily tamed, being confiding and affectionate, and added to his other good qualities a sweet voice and pretty melody.

The song differs with the season. In winter it is strong and cheery, as befits a stalwart fellow who laughs at Jack Frost and makes merry when the north wind blows. But when the springtime comes he tells the old, old story in most gentle tones, - a whispered love song, sweet and tender, yet with a wild plaintiveness that makes it peculiarly pleasing. 


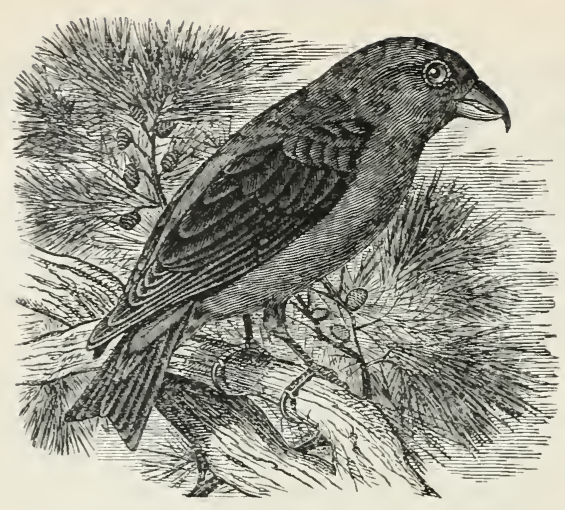

AMERICAN CROSSBILL.

\section{COMMON CROSSBILL. RED CROSSBILL.}

\section{LOXIA CURVIROSTRA MINOR.}

CHAR. Bill long and compressed, mandibles curved at the points, which cross or overlap. In young birds the bill is straight. Adult males: dull red, variable in shade; wings and tail blackish brown. Young males: yellowish olive. In changing plumage they display great variety of com. binations of yellow, olive, and red. Females : above, dull olive; rump and crown yellow; wings and tail as male; below, grayish. Length $5^{\mathrm{T} / 2}$ to 6 inches.

Nest. Usually in a dense wood, on a branch of an evergreen tree I 5 to 30 feet from the ground; made of twigs, strips of bark, weed-stems, and roots, lined thickly with grass, roots, hair, and feathers.

Eggs. 3-4; pale green dotted, near larger end, with brown and lavender; $0.75 \times 0.57$.

This more common species, like the preceding, inhabits the high northern and arctic regions of both continents, where it breeds, and is met with from Greenland to Pennsylvania, or farther south, according to the season and the success in obtaining food when driven to make a southern descent or migration. From September to April these birds are found inhabiting the extensive pine forests in the mountainous and interior districts of Pennsylvania and other States to the north; they also extend their winter migrations into the lower parts of the State of Missouri. They have occasionally been seen in the maritime parts of Massachusetts, but are less common 
here than the following species, generally taking, in their irregular incursions, a more interior and mountainous route. In the eastern chain of the Alleghanies, in Pennsylvania, according to Wilson, they appear to be at times very abundant visitors, feeding so steadily on the seeds of the white pine and hemlock spruce as to be approached without taking alarm. They have also a loud, sharp, and not unmusical note, chattering as they fly, and during the prevalence of deep snows become so tamed by hunger as to alight round the mountain cabins, even settling on the roofs when disturbed, and, like pigeons, descending in the next moment to feed as if they had never been molested. They are then easily trapped, and so eager and unsuspicious as to allow an approach so near that they may be knocked down with sticks. In these very familiar visits they are observed even to pick off the clay from the logs of the house, and to swallow the mere earth to allay the cravings of hunger. In cages they show many of the habits of the Parrot, climbing up the sides and holding the pine-cones given them in one claw while they extract the seeds. Like the same bird in Louisiana, they also do considerable damage at times in the orchard by tearing apples to pieces for the sake of getting at the seeds only. They feed likewise on the seeds of the alder, as well as the kernels of other fruits and the buds of trees. Scarcely any of these birds have yet been observed to breed within the United States, as they retire for this purpose to their favorite pine forests in high and more cool latitudes, where in security and solitude they pursue the duties of procreation. Dr. Brewer, of Boston, however, obtained eggs of these birds from Coventry, in Vermont. Like the preceding species, they often breed in winter in more temperate countries, as in January and February, and the young fly in March.

This bird was not observed by the naturalists of the northern expeditions in any part of the fur countries. It is, however, described by Forster. In the winter of $\mathrm{I}_{832}$, during or soon after a severe snow-storm, a large flock of these uncertain winter visitors were seen in a red-cedar grove near to Mount Auburn, in this vicinity. In 1833 , accompanied by the 
White-winged species, a flock of the same birds made their appearance as early as the IIth of November in some tall pine-trees in the same place they visited the last year in the depth of winter. They are very busy and unsuspicious, having very much the manners of Parrots in their feeding. At some distance beneath the trees where they are engaged, we can hear them forcing open the scales of the rigid pine cones with a considerable crackling, and the wings of the seeds fly about in all directions. Sometimes the little Redpolls also attend to snatch a seed or two as they are spread to the winds. They fly somewhat like the Yellow Birds, by repeated jerks and sinkings and risings in their course, but proceed more swiftly and directly to their destination; they also utter a rather loud and almost barking or fifing chirp, particularly the females, like 'tsh 'tship 'tsh 'tship. Their enemies seem also to follow them into this distant and unusual retreat. One evening, as they were uttering their quailing chirp, and about to roost in the pines, we heard an unusual cry, and found that the alarm was justly occasioned by the insidious and daring attack of a bold Butcher Bird (Lanius borealis), who had taken advantage of their bewildered confusion at the moment of retiring to repose. Besides their call and ordinary plaints, we hear, as I have thought, now and then, in the warmer part of the day, a rather agreeable, but somewhat monotonous, song. We found these birds, as well as the Redpolls, very fat and plump; and they devour a great quantity of pine-seeds, with which the œsophagus is perpetually gorged as full as in the gluttonous and tuneless Cedar Birds (Bombycilla).

The Red Crossbill is still known to be chiefly a winter visitor to New England and the Middle States, though every summer a small number may be met with in the more northern districts and on the crests of the Alleghanies south to Georgia. In April, I889, Mr. G. S. Miller, Jr., found a flock on Cape Cod, and upon dissecting several, he discovered evidence that they were nesting.

In northern Maine and New Brunswick numbers have been seen during the summer months; but even in these regions the bird is chiefly a winter visitor, and at that season it ranges to the Southern States. 


\section{WHITE-WINGED CROSSBILL.}

\section{LOXIA LEUCOPTERA.}

CHAR. Bill long and compressed, mandibles curved at the points, which cross or overlap. Male : dull rosy, clouded with dull dark brown on the back; wings and tail black; two broad white bars on the wings; belly dull white streaked with brown. Female : dull olive, paler beneath; rump buffy. Young : similar to female, but paler olive above, and more decided yellow beneath, streaked everywhere with dark brown. As the young mature they are subject to considerable variation. Length about 6 to $61 / 2$ inches.

Nest. In the deep forest, on an evergreen, amid the denser foliage near the centre of the tree; made of twigs and strips of birch bark, covered with moss (usnea), and lined with soft moss and hair.

Eggs. 3-?; pale blue, spotted and streaked near larger end with reddish brown and lilac; $0.80 \times 0.55$.

This beautiful and well-distinguished species inhabits the northern regions of the American continent only, whence, at irregular intervals, on the approach of winter, it arrives in the Northern and Middle States, and, as usual with the rest of this curious family, seeks out the pine and hemlock-spruce forests. Its visits to this State [Massachusetts] are very irregular. About two years ago, large, gregarious, famished flocks were seen near Newburyport and other neighboring towns in the vicinity of the sea-coast, at which time many were caught, killed, and caged. The habits of this bird are almost entirely similar to those of the preceding species. Its song is said to be mellow and agreeable, and in captivity it becomes gentle and familiar.

According to Mr. Hutchins, it arrives around Hudson Bay in March, and in May builds a nest of grass, mud, and feathers, fixed generally about half way up a pine-tree, and lays 5 white eggs marked with yellowish spots. The young fly about the end of June. It remains in this country till the close of November, after which it retires, probably to the South; and Wilson's bird was obtained in the Great Pine Swamp or forest of the Pokono (Pennsylvania), in the month of September, so that it may be possible that some few pairs breed in this situation. 
This species, according to Richardson, inhabits the dense white spruce forests of the fur countries, feeding principally on the seeds of the cones. It ranges through the whole breadth of the continent, and probably up to the 68th parallel, where the forests terminate. It is usually seen in the upper branches of trees, and when wounded still clings so fast as to remain suspended after death. In September, collecting in small flocks, they fly from tree to tree in a restless manner and make a chattering noise; and in the depth of winter they retire from the coast to seek shelter in the thick woods of the interior.

This interesting bird must still be written "irregular" in its occurrence in Massachusetts, though usually more or less abundant in winter down to the 4oth parallel, and occasionally ranging as far south as Virginia.

It is partially sedentary in northern New England and the Maritime Provinces of Canada, though much more abundant in winter than during the warm weather. Mr. Mcllwraith considers the bird a winter visitor only to southern Ontario, and Mr. Thompson makes a similar report for Manitoba though he thinks it may breed there. The nest is built in January and February, - I have known of numerous nests being discovered in New Brunswick in those months, - and it is probable that both young and old retire farther northward after the young birds are able to fly.

The flight of the Crossbills is undulating, like the flight of the American Goldfinch, and their songs are similar. They sing on the wing, and as a flock passes overhead on a clear winter's day their sweet voices come through the quiet air with pleasing effect. 


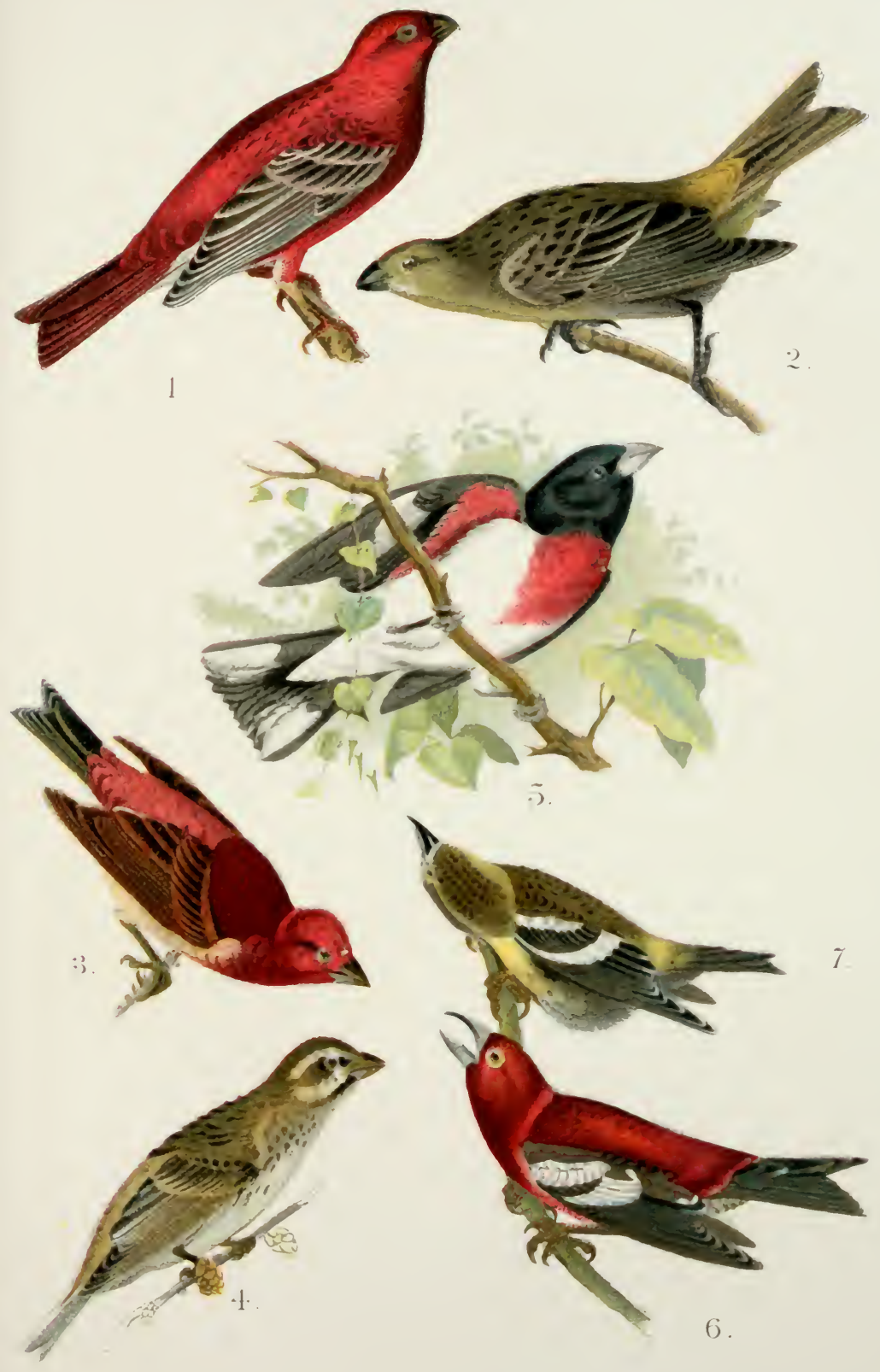

1-2. Pine Grosbeak.

j. Rose-Breasted (IInsbeak.

3-4. Purple Finch.

6-7. While-Ninged Cross Bill 



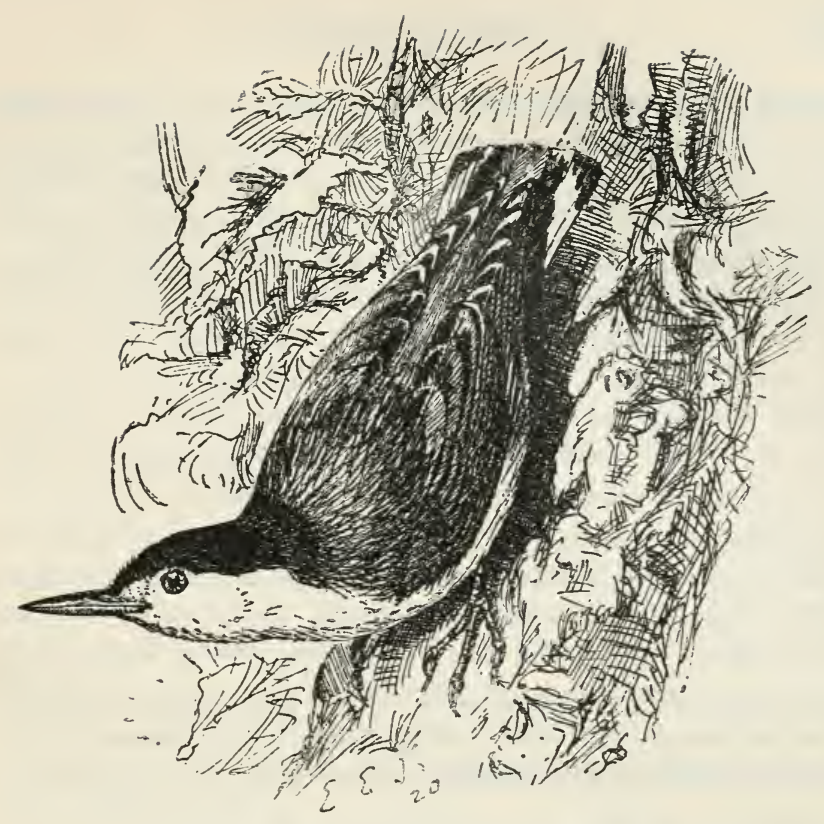

\section{WHITE-BREASTED NUTHATCH.}

\section{SitTA CAROLINENSis.}

CHAR. Above, bluish ash; top of head and neck black; wings black, blue, and white; tail black, marked with white; beneath, white; under tail-coverts reddish brown. Bill long and acute. Female and young similar, but black of head tinged with ashy or wanting. Length $53 / 4$ inches.

Nest. In open woodland, placed at the bottom of a cavity excavated in a dead tree or stump, - sometimes an old woodpecker's nest is used; made of leaves, grass, feathers, and hair.

Eggs. 4-8 (occasionally as many as 10, usually 5); white tinged with rose pink, and spotted with reddish brown and lilac; $0.80 \times 0.60$.

This species, so nearly allied to the European Nuthatch, resides permanently throughout North America, from Hudson Bay and Oregon to the tableland of Mexico, appearing only more common and familiar at the approach of winter in consequence of the failure of its food in its favorite sylvan retreats, which it now often forsakes for the open fields, orchards, or gardens, where, in pairs or small and sometimes contending 
parties, they cautiously glean a transient means of subsistence, and wander from place to place as the supply diminishes. At the welcome return, however, of the month of April, with the revival and renewal of its insect fare the Nuthatch becomes more domestic; and retiring into the forest with its mate, it prepares for its progeny in some hollow tree, or even in a rail of the neighboring fence. The male is now assiduously attentive to his sitting mate, supplying her regularly with food; on which occasion he affectionately calls her from the mouth of her dark and voluntary prison, where sometimes, in mere sociability, he attempts in his rude way to soothe her with his complaisant chatter. $\mathrm{He}$ is too affectionate to ramble from this favorite spot, where he not only accompanies his consort, but, sentinel-like, watches and informs her of every threatening danger. When the pair are feeding on the trunk of the same tree, or near to each other in the same wood, the faithful male is heard perpetually calling upon his companion at short intervals as he circumambulates the trunk. His approach is announced usually at a distance by his nasal $k \bar{a} n k k \bar{a} n k$, frequently repeated, as in spiral circles round the trunk of some tree he probes, searches, and shells off the bark in quest of his lurking prey of spiders, ants, insects, and their larvæ in general. So tight and secure is his hold that he is known to roost indifferently with his head up or down from the tree; and when wounded, while any spark of life remains, his convulsive and instinctive grasp is still firmly and obstinately maintained. Sometimes, with a sort of complaisant curiosity, one of the birds, when there is a pair, will silently descend nearly to the foot of the tree, where the spectator happens to stand, stopping, head downwards, and stretching out his neck, as it were, to reconnoitre your appearance and motives; and after an interval of silence, wheeling round, he again ascends to his usual station, trumpeting his notes as before. He seldom wholly quits the forest, but when baffled by the slippery sleet which denies him a foothold, he is sometimes driven to the necessity of approaching the barnyard and stables, or the precincts of the dwelling, where, occasionally mixing among 
the common fowls, entering the barn, examining its beams and rafters, he seems to leave no means untried to secure a subsistence.

This species is doubtless a resident in Ontario and New England, becoming more abundant during the winter months; but in the Maritime Provinces it is only a summer visitor.

\section{RED-BREASTED NUTHATCH.}

\section{SitTA CANADENSIS.}

CHAR. Above, ashy blue (top and side of head black on the male); broad stripe of white over the eyes; wings blackish, with ashy markings; outer tail-feathers black with white patches; beneath, reddish brown, - paler in the female; chin white; bill long and acute. Length $4 \frac{1}{2}$ inches.

Nest. In open woodland; an excavation in a decayed stub, lined with grass and roots. Often the entrance is surrounded with fir balsam.

Eggs. 4-6; white with pale roseate tint and thickly spotted with brown and lilac; $0.60 \times 0.50$.

The habits of these smaller birds are almost similar to the preceding; they have, however, a predilection for pine forests, feeding much on the oily seeds of these evergreens. In these barren solitudes they are almost certain to be found in busy employment, associating in pairs with the Chickadees and smaller Woodpeckers, the whole forming a hungry, active, and noisy group, skipping from tree to tree with petulant chatter, probing and rattling the dead or leafless branches, prying in every posture for their scanty food, and, like a horde of Tartars, proceed through the forest and leisurely overrun the whole of the continent to the very confines of the tropics, retiring north in the same manner with the advance of the spring.

The notes of this species of Nuthatch, though similar, are sharper than those of the preceding, resembling day day dait, and sounding almost like a child's trumpet. Its motions are also quicker. They cling to the bark of the tree and roost commonly with the head downwards, in the manner of their whole tribe.

vOL. I. -25 
This species has a more extended range than carolinensis, being found farther west and farther north. It breeds from northern New England and Manitoba northward and southward along the Alleghanies. In winter it ranges from New Brunswick to the Gulf States.

\section{BROWN-HEADED NUTHATCH.}

\section{SitTa PUSILla.}

CHAR. Above, ashy blue; top of head and neck brown; white spot on back of neck; wings black and bluish; middle tail-feathers like back, others black tipped with bluish; beneath, dull brownish white tinged with pale ash behind; throat white. Bill long, slender, and acute. Length 4 to $4 \frac{1}{2}$ inches.

Nest. In open woodland; an excavation in a dead stump, lined with grass, leaves, and feathers.

Eggs. 4-6; white, thickly marked with fine spots of reddish brown and pale lilac; $0.60 \times 0.50$.

This small species is seldom seen to the north of the State of Virginia. In the Southern States it is rather common, and is also met with in the island of Jamaica. Like the last, which it resembles in manners, it is very fond of pine-trees, and utters a similar note, but more shrill and chirping. Its food, besides the seeds of the pine, is usually the insects which infest the forest trees. In winter families of this species of 8 or Io individuals may be seen busily hunting in company, and keeping up a perpetual and monotonous screeping. It is less suspicious than most other sylvan birds, sometimes descending down the trunk of a tree watching the motions of the bystander; and if the intrusion happens to be near the nest, or while engaged in digging it out, the little harmless mechanic utters a sort of complaining note, and very unwillingly relinquishes his employment, which is instantly renewed on the removal of the observer.

This species is restricted to the Southern and Gulf States, rarely wandering north of Virginia and Maryland; but examples have been taken in New York, Missouri, Ohio, and Michigan. 


\section{BROWN CREEPER.}

\section{Certhia famillaris americana.}

CHAR. Above, grayish brown, each feather streaked with dull white; rump rufous; wings with a band of buffy white; beneath, dull white or pale gray. Length about $5 \frac{1}{2}$ inches.

Nest. In deep woods, placed behind a sliver of loose bark on a decayed tree or stub; made of shreds of bark and usnea moss firmly interwoven and set on a platform of twigs. It is sometimes lined with feathers.

Eggs. 4-8; white or creamy, - when freshly laid, tinted with pale roseate, - spotted with reddish brown; $0.60 \times 0.50$.

This industrious forager for insects, chiefly dwelling in the seclusion of the forest, is but seldom seen in the summer; but on the approach of winter, with other hungry wanderers of similar habits such as the small Woodpeckers and Nuthatches, it makes its appearance on the wooded skirts of the village, particularly among the pine-trees, and occasionally becomes familiar enough to pay a passing visit to the orchard. In this country, however, the species is neither common nor familiar, nor is it more abundant in the Northern than the Middle States, though its breeding range extends from Pennsylvania to Newfoundland.

The bill of the Creeper not being of sufficient strength to probe the wood, it rests contented with examining the crevices of the bark for insects and their eggs, proceeding leisurely upwards or downwards in straight or spiral lines towards the top of the tree, dodging dexterously to the opposite side from the observer, and only resuming its occupation when assured of solitude and safety. While thus employed it utters at short intervals a sharp, quick, rather grating note, by which its resort may be discovered, though it requires some time and a good eye to perceive it if on the upper branches of a tall tree. Though it lives chiefly on insects, it also, according to Wilson, collects the seeds of the pine for food, and is particularly fond of the vermin which prey on those kinds of trees. In the thick forests which it inhabits in the Northern and Western 
States about the middle of April, it commences the nest in the hollow trunk or branch of a tree which has been exposed to decay by injury or accident. Here in the accidental cavities or deserted holes of the squirrel or Woodpecker the Creeper deposits her eggs. The young creep about with great caution previous to taking to their wings.

The Brown Creeper is a common bird in New England, though in the southern portions it occurs in the winter only, its breeding area extending from Maine and Minnesota northward. In winter it ranges as far southward as the Gulf States. It is common in Ontario and Quebec, but less abundant in the Maritime Provinces. An interesting account of the breeding habits of this bird, written by Mr. William Brewster, appeared in the Nuttall Bulletin for July, I879.

Mr. Brewster credits the Creeper with a tender song, which falls upon the ear "like the soft sigh of the wind among the pine boughs."

\section{BAHAMA HONEY CREEPER.}

\section{Careba bahamensis.}

Cirar. Above, dark brown; rump yellow; stripe over eyes and un. der parts dull white; breast and edge of wing pale yellow; tail broadly tipped with white. Length $4 \frac{1}{2}$ inches.

Nest. In a low tree or bush; a large, pensile, dome-shaped structure, the entrance at the side; made of weed-stems and grass, and lined with plant down.

Eggs. 2-4; white, tinged with green and speckled with rufous : 0.65 $\times 0.50$.

The home of this species is on the Bahamas, but a straggler has been found on the coast of Florida. Mr. Gosse in his "Birds of Jamaica " gives an interesting account of this bird's habits. $\mathrm{He}$ describes it as obtaining its food in much the same manner as Humming Birds, - by probing the flowers; but instead of hovering in front of a flower, the Creeper alights on the tree. When examining a flower for the insects which are at the bottom of the cup, the bird throws its body into a variety of positions, sometimes with the back downward, the better to reach the interior of a blossom with its curved bill and peculiar tongue. The bird is unsuspecting and familiar, and freely resorts to the blossoming shrubs of a garden. 


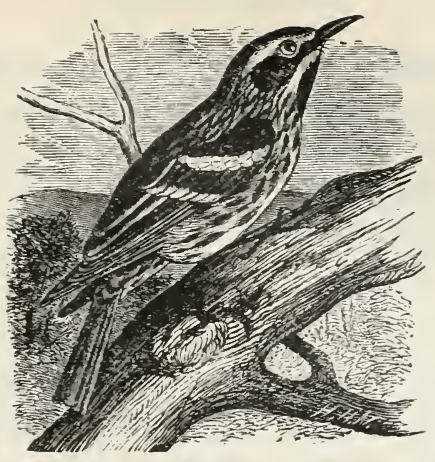

\section{BLACK AND WHITE WARBLER.}

\section{BLACK AND WHITE CREEPER.}

\section{MNIOTILTA VARIa.}

Char. Above, black striped with white, head, wings, and tail mostly black; beneath, white, more or less striped with black. Female and young without stripes on the throat. Length $4 \frac{1}{2}$ to $5 \frac{1}{2} / 2$ inches.

Nest. In open woodland or pasture; placed at the foot of a tree or stump, or at the base of a moss-covcred rock, sometimes in a hole; made of grass, moss, and shreds of bark, and lined with grass, hair, roots, and vegetable down.

Eggs. 4-5; creamy white, thickly spotted with pale reddish brown; $0.65 \times 0.50$

This remarkable bird, allied to the Creepers, is another rather common summer resident in most parts of the United States, and probably migrates pretty far to the north. It arrives in Louisiana by the middle of February, visits Pennsylvania about the second week in April, and a week later appears in the woods of New England, protracting its stay in those countries till the beginning of October, and lingering on the southern limits of the Union a month later, so that it does not appear to be much affected by the commencement of frost, and probably at this season occasionally feeds on berries. As numbers are observed round Vera Cruz toward the commencement of winter, and are described as inhabiting the West India islands, it is probable they pass the extremity of the winter beyond the southern boundary of the Union. 
Like the Creepers and Nuthatches, these birds are seldom seen to perch upon the branches of trees, but creep spirally around the trunk and larger boughs up and down, in quest of insects which alight upon or hide within the crevices of the bark. In this employment they display all the dexterity of the more regular climbers. For this purpose the hind toe is rather stout, and extends backward so as to balance with the anterior part of the foot, and allow a motion like that of the Creepers, from which genus they are at the same time wholly distinct.

At the period of breeding, the male scrapes out a little monotonous ditty in recognition of his mate, resembling somewhat the syllables te tshe tshe tshe tsh' tsheté, proceeding from high to low in a tolerably strong and shrill, but somewhat filing tone. As the season of incubation advances, this note, however, becomes more mellow and warbling, and though feeble, is very pleasing, bearing at this time some resemblance to that of the Redstart (Setophaga ruticilla). This song is like the ascending call of 'twee 'twee 'twee 'twee 'tweet. At the romantic estate of the Cold Spring place in Roxbury the proprietor, Mr. Newman, pointed out to me the nest of this bird, which on the $27^{\text {th }}$ of June contained four young about a week old. Other birds of this species I had seen fledged this year about the $I 7$ th of the same month, and as Wilson remarks the flight of the young in July, we may suppose that they raise two broods in the season. The nest was niched in the shelving of a rock on the surface of the ground, and was externally composed of coarse strips of the inner bark of the hemlock-trees, which overshadowed the situation. With these were mixed soft, dissected old leaves and a few stalks of dead grass; the lining was made of a thin layer of black hair. According to Audubon, these birds nest in Louisiana in some small hole in a tree, and employ dry moss and a lining of downy substances. The pair fed the young before us with affectionate attention, and did not seem more uneasy-at our presence than the common and familiar summer Yellow Bird. They crept about the trunks of the neighboring trees, often head downwards, like the Sittas, and carried large smooth caterpillars to their young. This is, 
in fact, at all times a familiar, active, and unsuspicious little visitor of the shady gardens and orchards, as well as woods and solitudes.

The Black and White Creeper, as this species is usually called, breeds from the Southern States to Fort Simpson. It is abundant in southern New England, and fairly common in the Maritime Provinces.

It was first classed with the Warblers by Spencer Baird in 1859 , and has been retained there by all later authorities. Nuttall considered that there were two species, one of which he named borealis; but it has not been considered valid, though Ridgway, in his "Manual," suggests the name $M$. varia borealis for a supposed Mississippi valley and Middle American race, which he describes as somewhat smaller than true varia; but he thinks the material at hand insufficient to warrant a positive decision, so we are saved the infliction of this much "hair-splitting."

\section{PURPLE MARTIN.}

PROGNE SUBIS.

CHAR. Male: lustrous black with purple tint, wings and tail with brownish tint. Female and young: browner above, and beneath grayish. Length $7 \frac{1}{2}$ inches.

Nest. In a box, or attached to the eave of a house; sometimes in a decayed tree; made of grass, leaves, etc.

Eggs: 4-6; white and glossy; $0.95 \times 0.75$.

According to the progress of the season in the very different climates of the United States, is measured the arrival of this welcome messenger of spring. Around the city of New Orleans, for example, the Purple Martin is seen from the Ist to the $9^{\text {th }}$ of February. At the Falls of the Ohio, it is not seen before the middle of March, and representatives do not arrive in the vicinity of Philadelphia until the first week in April ; on the $25^{\text {th }}$ of that month, or later, they visit the vicinity of Boston, and penetrate even to the cold regions of Hudson Bay, where they arrive in May and retire in August; about the 2 oth of the same month they also leave the State of Pennsylvania. The migrations of these birds are remarkably extensive, as they were seen by Mr. Swainson in great numbers around Per- 
nambuco. Mr. Townsend met with them on the Rocky Mountains, and Audubon observed them breeding in Texas. In Oregon we found them nesting in the knot-holes of the oaks, and they did not appear to court the society of man, as we seldom saw them near the fort. In their haste to return to their natal climes, they sometimes expose themselves to fatal accidents from changeable and unfavorable weather. In the maritime parts of Massachusetts, and probably throughout the State, a few years ago after a rainy midsummer, many were found dead in their boxes, and they have since been far less numerous than formerly.

This beautiful species, like many others of the family, seeks out the dwellings of man, associating itself equally with the master and the slave, the colonist and the aboriginal. To the Martin it is indifferent whether its mansion be carved and painted, or humbled into the hospitable shell of the calabash or gourd. Secure of an asylum for its mate and young, while under the protection of man it twitters forth its gratitude, and is everywhere welcomed to a home. So eager is it to claim this kind of protection that sometimes it ventures hostilities with the Bluebirds and domestic Pigeons, who are often forced to abandon their hereditary claims. Satisfied with the reception and success, like so many contented and faithful domestics, it returns year after year to the same station. The services of the Martin in driving away Hawks and Crows from the premises he claims, are also important inducements for favor; he has even the courage to attack the redoubtable Kingbird, when its visits are too familiar near the nest.

At the approaching dawn the merry Martin begins a lively twitter, which, continuing for half a minute, subsides until the twilight is fairly broken. To this prelude succeeds an animated and incessant musical chattering, sufficient, near the dwelling, to awaken the soundest sleeper. His early vigils are scarcely exceeded by the domestic Cock; the industrious farmer hears the pleasing call to labor, and associates with this favorite bird the idea of an economical, cheerful, and useful guest. 
In the Middle States, from the $5^{\text {th }}$ to the 2 oth of April, the Martins begin to prepare their nest, which is usually made of small green or dry leaves, straws, hay, and feathers, laid in considerable quantities. They rear two broods in the season. Several pairs also dwell harmoniously in the same box. The male, very attentive to his sitting mate, also takes part in the task of incubation; and his notes at this time have apparently a peculiar and expressive tenderness.

The food of the Martin is usually the larger winged insects, as wasps, bees, large beetles, such as the common Cetonias, or goldsmiths, which are swallowed whole. His flight possesses all the swiftness, ease, and grace of the tribe. Like the Swift, he glides along, as it were, without exertion. Sometimes he is seen passing through the crowded streets, eluding the passengers with the rapidity of thought; at others he sails among the clouds at a dizzy height like something almost ethereal.

The Purple Martin occurs throughout the Maritime Provinces, though nowhere common, and is extremely local in its distribution. It is rather rare near Quebec, but common at Montreal and throughout Ontario. Observers in Winnipeg consider the bird abundant there, and it is said to range north to the Saskatchewan valley. It breeds from the Gulf States northward, and winters in South America.

Small colonies of these Martins are found scattered through New England at widely separated localities, accepting, usually, the proffered hospitality of friendly villagers who provide them with homes, though an occasional coterie may be found nesting in the primitive manner of their ancestors, - rearing their broods in natural cavities of trees or in crevices of rocks, as was the custom of their race before the Europeans led them into more Sybaritic habits.

Note. - The Cuban Martin (Progne cryptoleuca) is a summer resident of southern Florida. 


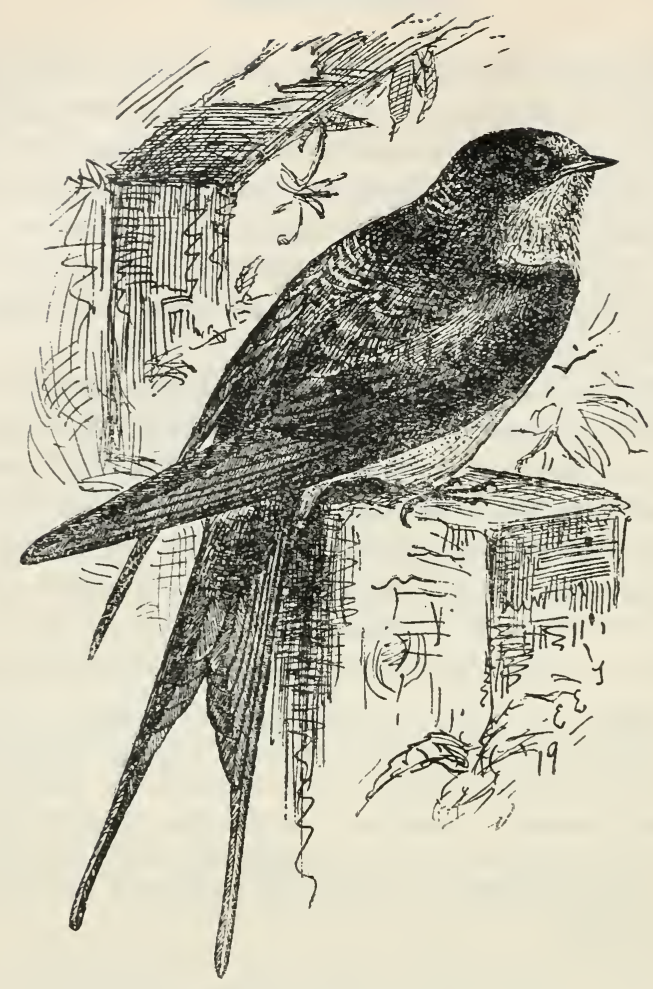

\section{BARN SIVALLOW.}

\section{Chelidon erythrogastra.}

CHAR. Upper parts steel blue; forehead, throat, and breast rich chestnut; belly paler; tail deeply forked, - outer feathers several inches longer than the inner. Length $5 \frac{1}{2}$ to $7 \frac{\pi}{2}$ inches.

Nest. Attached to a rafter of a barn or the side of a cave; cup shaped; made of pellets of mud bound with grass, and lined with grass and feathers.

Eggs. 3-6; white, variously marked with dark brown, reddish brown, or purplish brown and lilac; $0.75 \times 0.55$.

The Barn Swallows arrive in Florida and the maritime parts of Georgia about the middle of March, but are not seen in the Middle States before the last of that month or the beginning 
of April. Their northern migration extends to the sources of the Mississippi, the Rocky Mountains, and the fur countries, where, distant from the habitations of man, they inhabit caves, particularly those in the limestone rocks. They retire from Massachusetts about the I 8 th of September, and are observed in the same month and in October passing over the peninsula of Florida on their way to tropical America, where they probably pass the winter. I have seen a straggling pair in this vicinity even on the $5^{\text {th }}$ of October. The fleetness with which they move, and the peculiarity of their insect fare, are circumstances which would impel a prompt transition to more favorable climates. Accidental fits of torpidity, like those which occasionally and transiently take place with the Humming Bird, have undoubtedly happened to Swallows, without proving anything against the general migrating instinct of the species, which as long back as the time of Anacreon has been generally observed.

Early in May they begin to build against a beam or rafter, usually in the barn. The external and rounding shell is made of pellets of mud tempered with fine hay and rendered more adhesive by the glutinous saliva of the bird; within is laid a bed of fine hay, and the lining is made of loosely arranged feathers. They have usually two broods in the season, and the last leave the nest about the first week in August. Twenty or thirty nests may sometimes be seen in the same barn, and two or three in a cluster, where each pursues his busy avocation in the most perfect harmony. When the young are fledged, the parents, by their actions and twitterings, entice them out of the nest, to exercise their wings within the barn, where they sit in rows amid the timbers of the roof, or huddle closely together in cool or rainy weather for mutual warmth. At length they venture out with their parents, and, incapable of constant exercise, may now be seen on trees, bushes, or fence-rails, near some pond or creek convenient to their food; and their diet is disgorged from the stomachs or crops of their attentive parents. When able to provide for themselves, they are still often fed on the wing, without either party alighting; so aërial 
and light are all their motions that the atmosphere alone seems to be their favorite element. In the latter end of summer, parties of these social birds may be often seen by the sides of dusty roads, in which they seem pleased to bask.

About the middle of August they leave the barns, and begin to prepare for their departure, assembling in great numbers on the roofs, still twittering with great cheerfulness. Their song is very sprightly, and sometimes a good while continued. Some of these sounds seem like ' $t$ 'le 't'le 't'letalit, uttered with rapidity and great animation. A while before their departure, they are observed skimming along the rivers and ponds after insects in great numbers, till the approach of sunset, when they assemble to roost in the reeds.

The Barn Swallow is a common bird throughout this Eastern Province, and northward to Greenland and Alaska.

It winters in the West Indies and south to Brazil.

\section{CLIFF SWALLOW.}

\section{EAVE SIVALLOW.}

\section{Petrochelidon Lunifrons.}

CHAR. Above, dark steel blue; forehead dull white; wings and tail brownish black; rump rufous; chin, throat, and collar around neck deep chestnut; patch of blue black on breast; remaining under-parts pale gray tinged with rufous. Length about $5 \frac{1 / 4}{4}$ inches.

Nest. Fastened to the side of a cliff or the eave of a building; made of pellets of mud and lined with grass and feathers. Usually gourdshaped, the entrance at the mouth of the gourd, - sometimes open on top.

Eggs. 4-6; white, variously marked with shades of brown and purple; $0.80 \times 0.55$.

The Cliff Swallows have but recently come to the notice of naturalists. Their summer residence in the temperate parts of America is singularly scattered. They have long occupied the regions of the Rocky Mountains, extending to the banks of the Columbia, and the cliffs of the Missouri, and are probably to be found on other large Western rivers. According to 
Richardson they are extremely abundant in the fur countries. In I 8 5 they were observed for the first time at Henderson, on the banks of the Ohio, and at Newport in Kentucky. In I 8I 7 they made their appearance at Whitehall, near Lake Champlain, in the western part of the State of New York. In these places their increase seems to have kept pace with the time since their arrival, augmenting their nests from a single cluster to several hundreds in the course of four or five years. Vieillot observed one at sea off Nova Scotia, and they have, in fact, long been commonly known in that Province. In 1818 , as I learn from J. W. Boott, Esq., they began to build at Crawford's, near the base of the White Mountains of New Hampshire. In the summer of 1830 a few nests were seen by General Dearborn at Winthrop in Maine; he had also heard of one at Gardiner in the same State. The hibernal retreat of these birds would appear to be in the West Indies, as they were seen in Porto Rico by Vieillot, and one was also observed in St. Domingo by the same author.

In the Western States they arrive from the South early in April, and almost immediately begin to construct their nests. They commence their labor at the dawn, and continue their operations until near mid-day. The nests are made of pellets of sandy mud, disposed in layers until the fabric, with its entrance, assumes the form of a projecting retort, agglutinated to cliffs or the walls of buildings as convenience may offer. From the nature of the friable materials employed, the whole is frail, and would crumble in the possession of any but the airy owners. The internal lining is of straw and dried grass negligently disposed for the reception of the eggs. They raise but a single brood, who, with their parents, after several attempts at mustering, finally. disappear in August as suddenly as they came. Mr. Townsend says: "In the neighborhood of the Columbia River the Cliff Swallow attaches its nest to the trunks of trees, making it of the same form and materials as elsewhere." The face of Pillar Rock, an isolated columnar mass of basalt near Chinhook, at the estuary of the Columbia, was rendered still more fantastic and picturesque by the nests 
of the Cliff Swallow with which it was faced; a small colony having taken up their abode here. These were, as usual, made of pellets of mud, enclosed at the top, but without the retort necks.

Like the rest of their congeners, these birds are almost perpetually on the wing in quest of flies and other small insects which constitute their ordinary food. Their note does not appear to resemble a twitter, and according to Audubon it may be imitated by rubbing a moistened cork round in the neck of a bottle. In Kentucky, until the commencement of incubation, the whole party resorted to roost in the hollow limbs of the buttonwood-trees. However curious, it is certain that the birds have but recently discovered the advantage of associating round the habitations of men.

Numerous colonies of this species are found throughout New England and the Maritime Provinces, and a few pairs have been seen at Point de Monts, on the north shore of the Gulf of St. Lawrence, which is the limit of its northward range near the Atlantic, though in the interior it ranges much farther north. It breeds southward to the Gulf States, and winters in South America.

It is highly probable that the habit of breeding in large communities, and thus becoming "local" in distribution, will account for the report of their having moved eastward during the first half of the present century. As a matter of fact, Audubon discovered the species in Kentucky five years before Say found it among the Rockies. That the older writers knew so little about the bird should not be taken as evidence of its absence, - they failed to learn the history of several equally common species; and after the added years we are still ignorant of the breeding habits of some of these birds.

Note. - The Cuban Cliff Swallow (Petrochelidon fulva) has been taken in Florida. 


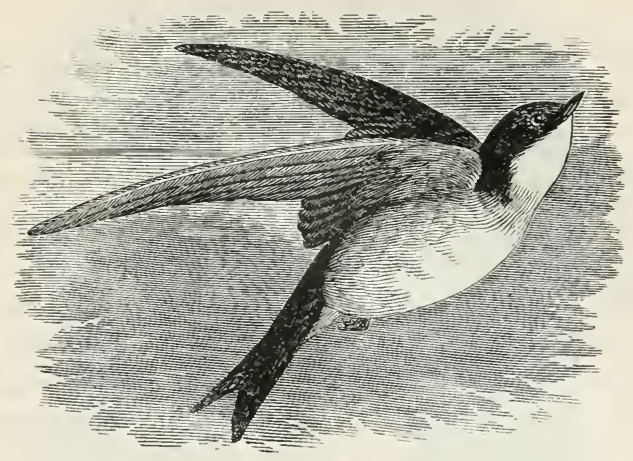

TREE SWALLOW.

WHITE-BELLIED SIVALLOW. SINGING SWALLOW.

TACHYCINETA BICOLOR.

CHAR. Above, rich steel blue, wings and tail with green reflections; beneath, white. Length about 6 inches.

Nest. In a cavity of a tall dead tree, - often a deserted Woodpecker'; hole, - sometimes in a bird box; made of grass and straw, lined with feathers.

Eggs. 4-9 (usually 5); white ; $0.75 \times 0.55$.

This species, less common than the Barn Swallow and nearly allied to the common Martin, arrives in Pennsylvania and New England about the middle of April, and extends its migrations over the continent nearly to the Arctic circle, having been seen by Dr. Richardson in the latitude of $53^{\circ}$; it is also abundantly dispersed over the Rocky Mountains and the Columbia River, where it breeds, as well as around Hudson Bay and throughout the Northern and Middle States. On its arrival, like many other species, it seeks out the society of man and frequently takes possession of the mansion of the Martin. When these advantages are unattainable it will be content with the eaves of some deserted dwelling, a hollow tree, its ancient residence, or even an horizontal branch when large and convenient.

The note of these birds is a shrill, lively, warbling twitter; but they are more quarrelsome and less sociable in the breed- 
ing season that the Barn Swallow. In the spring their protracted, angry contentions, and rapid chatter are often heard in the air. Their food is similar to that of the species above mentioned, and they make a snapping sound with the bill in the act of seizing their prey. They proceed to the South in September, and according to the observations of Audubon pass nearly, if not quite, the whole winter in the cypress swamps near to New Orleans, and probably in the Mexican vicinity. $\mathrm{He}$ observed them about the middle of December, and also near to the close of January. "During the whole winter many retired to the holes around houses, but the greater number resorted to the lakes, and spent the night among the branches of the wax-myrtle," whose berries at this season afford them a support on which they fatten, and are then considered as excellent food. About sunset they usually began to flock together at a peculiar call, and were then seen almost in clouds moving towards the neighboring lagoons or the estuaries of the Mississippi. Before alighting they perform their aërial evolutions to reconnoitre the place of roosting, soon after which they rapidly descend as it were in a spiral vortex almost like the fall of a water-spout, and when within a few feet of the waxmyrtles they disperse and settle at leisure ; but their twittering and the motions of their wings are heard throughout the night. At dawn they rise, at first flying low over the waters which they almost touch, and then rising gradually separate in quest of food. During their low flight numbers of them are often killed by canoe-men with the mere aid of their paddles (Aububon). This predilection for the borders of lakes and ponds led some of the ancient writers to believe that Swallows retired to the bottom of the water during the winter; and some fishermen on the coast of the Baltic pretended to have taken them up in their nets in large knots, clinging together by their bills and claws in a state of torpidity.

The Tree Swallow breeds from the Gulf States north to the fur countries, and winters from the Southern States to Central America. Mr. William Brewster believes that these birds have been driven from the cities of southern New England by the House Sparrows. 


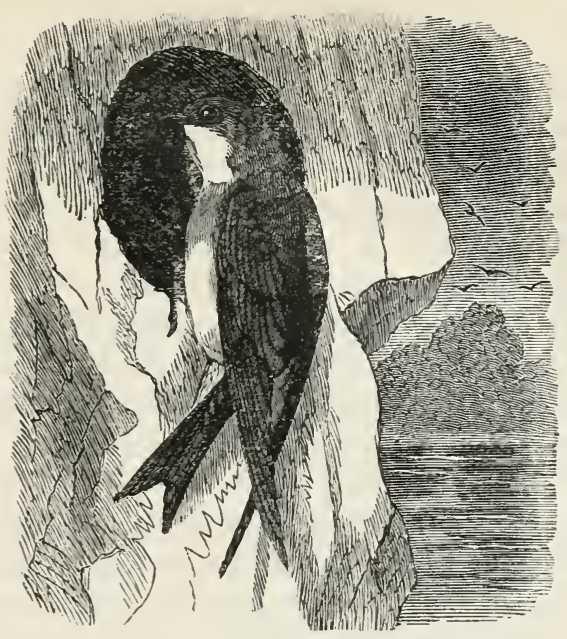

\section{BANK SIVALLOW.}

\section{SAND MARTIN.}

Clivicola RIPARIA.

CHAR. Above, dull grayish brown, which extends around the neck and across the breast; throat and belly white. Length about 5 inches.

Nest. At the end of a burrow excavated in a bank of sand or gravel, - usually within a few feet of the top; the bank generally near a stream of water; the excavation is 2 to 4 feet deep, and widens at the inner end, where a little dry grass and a few feathers are loosely placed, and on this cushion the eggs are laid.

Eggs. 4-6; white; $0.70 \times 0.50$.

These plain-looking and smaller birds, though equally gregarious with other kinds, do not court the protection or society of man, - at least their habitations are remote from his. They commonly take possession for this purpose of the sandy bank or bluff of a river, quarry, or gravel pit, 2 or 3 feet below the upper surface of the bank. In such places, in the month of April, they may be observed burrowing horizontally with their awl-like bills, when at length, having obtained a foot-hold in the cliff, they also use their feet and continue this labor to the depth of 2 or 3 feet. Many of these holes may be often seen within a few inches of each other. This species has generVOL. I. -26 
ally two broods in the season, and on the egress of the young in the latter end of May the piratical Crows often await their opportunity to destroy them as they issue from the nest. In rocky countries the birds often take possession of the clefts on the banks of rivers for their dwelling, and sometimes they content themselves with the holes of trees.

Their voice is only a low twitter of short lisping notes; and while busily passing backwards and forwards in the air around their numerous burrows, they seem at a distance almost similar to hiving bees. As they arrive earlier than other species, the cold and unsettled weather often drives them for refuge in their holes, where they cluster together for warmth, and have thus been found almost reduced to a state of torpidity. Dwelling thus shut up, they are often troubled with swarms of infesting insects, resembling fleas, which assemble in great numbers around their holes. They begin to depart to the South from the close of September to the middle of October. Although they avoid dwelling near houses, they do not fly from settled vicinities; and parties of six or more, several miles from their nests, have been seen skimming through the streets of adjacent villages in the province of Normandy.

They are found on both sides of North America, from the shores of the Atlantic to the borders of the Columbia; and in all the intermediate region suited to their manner of breeding. According to Audubon, they winter in great numbers in Florida, and breed from Labrador to Louisiana.

If the Bank Swallow was found in Labrador by Audubon it has since changed its habitat to the extent of deserting that country, for during recent years only one example has been seen on the northern side of the Gulf of St. Lawrence, though colonies have been found on Anticosti and the Magdalen Islands.

In the Far West these birds range to much higher latitudes, a few having been met with along the valley of the Mackenzie River, and in Alaska. They breed from the Gulf States northward, and winter in the tropics, ranging as far south as Brazil. They are locally common throughout the Eastern States and the adjoining Provinces. 


\section{ROUGH-WINGED SIVALLOW.}

\section{STELGIDOPTERYX SERRIPENNIS.}

CHAR. Above, grayish brown; beneath, brownish gray, whitening on the belly. Edge of wings rough to the touch; "outer web of the first primary with recurved hooklets" which are lacking on the young birds. Length 5 to $5^{1 / 4}$ inches.

Nest. In a cavity of a bank or in a crevice of a stone wall or bridge, usually near a stream; made of dry grass lined with feathers.

Eggs. 4-7; white; $0.75 \times 0.50$.

We are indebted to Audubon for the discovery of this species so much allied to the preceding, who first observed it near Bayou Sara, and afterwards in South Carolina. Of its habits he says nothing; but it is rarer, and he thinks its habitual residence may prove to be far to the westward, perhaps the valleys of the Columbia.

This species is more common in the Western Faunal Province than in the East; it is abundant in British Columbia, but Mr. Thompson has not put it in his "Birds of Manitoba." It occurs regularly, however, throughout the Eastern States north to New York, Ohio, and Illinois, and sparingly in Connecticut. It has also been found in parts of Ontario.

In appearance and habits it so closely resembles the Bank Swallow that it may be overlooked by the casual observer; it does not, however, confine its choice of a nesting site to a sand-bank, but will place its nest amid the stones of a wall or bridge, in a crevice of a building, or even in a knot-hole. It differs also from the Bank Swallow in being of a paler color, and both of these birds differ from our other swallows in wearing no metallic tints.

Note. - The Cuban Cliff Swallow (Petrochelidon fulva) and the BAHAMAN SWALlow (Callichelidon cyaneoviridis) have been added to the United States fauna by Mr. W. E. D. Scott, who captured examples on Dry Tortugas island during March and April, 1890. 


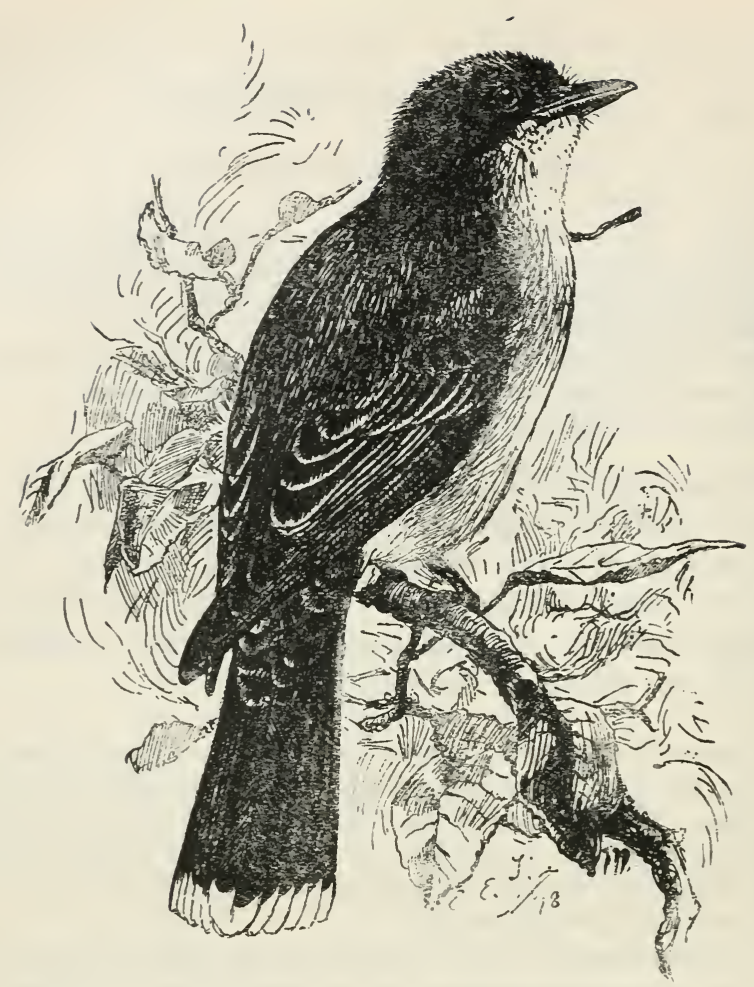

K I N G B I R D.

\section{BEE MARTIN.}

\section{TYRANNUS TYRANNUS.}

CHAR. Above, blackish ash, darker on the head; beneath, white; breast tinged with gray; tail black, tipped with broad band of white. Crown with concealed patch of yellow or orange red. Length 8 to 9 inches.

Nest. On a branch or in fork of a tree, in garden or pasture; composed of twigs, roots, and moss, lined with roots, horse-hair, and feathers. The exterior is loosely laid, but the interior is neat and compact.

Eggs. 4-5; creamy white, spotted with light and dark brown; 0.95 $\times 0.70$. 
This well-known, remarkable, and pugnacious bird takes up his summer residence in all the intermediate region from the temperate parts of Mexico to the uninhabited and remote interior of Canada. In all this vast geographical range the Kingbird seeks his food and rears his young. According to Audubon they appear in Louisiana by the middle of March; and about the 2oth of April Wilson remarked their arrival in Pennsylvania in small parties of five or six ; but they are seldom seen in this part of New England before the middle of May. They are now silent and peaceable, until they begin to pair, and form their nests, which takes place from the first to the last week in May or early in June, according to the advancement of the season in the latitudes of 40 and 43 degrees. The nest is usually built in the orchard, on the horizontal branch of an apple or pear tree, sometimes in an oak, in the adjoining forest, at various heights from the ground, seldom carefully concealed, and firmly fixed at the bottom to the supporting twigs of the branch. The outside consists of coarse stalks of dead grass and wiry weeds, the whole well connected and bedded with cut-weed down, tow, or an occasional ropeyarn and wool; it is then lined with dry, slender grass, root fibres, and horse-hair. The eggs are generally 3 to 5 , yellowish white, and marked with a few large, well-defined spots of deep and bright brown. They often build and hatch twice in the season.

The Kingbird has no song, only a shrill, guttural twitter, somewhat like that of the Martin, but no way musical. At times, as he sits watching his prey, he calls to his mate with a harsh tshéüp, rather quickly pronounced, and attended with some action. As insects approach him, or as he darts after them, the snapping of his bill is heard like the shutting of a watch-case, and is the certain grave of his prey. Beetles, grasshoppers, crickets, and winged insects of all descriptions form his principal summer food. I have also seen him collecting the canker-worms from the Elm. Towards autumn, as various kinds of berries ripen, they constitute a very considerable and favorite part of his subsistence; but with the excep- 
tion of currants (of which he only eats perhaps when confined), he refuses all exotic productions, contenting himself with blackberries, whortle-berries, the berries of the sassafras, cornel, viburnum, elder, poke, and five-leaved ivy. Raisins, foreign currants, grapes, cherries, peaches, pears, and apples were never even tasted when offered to a bird of this kind, which I had many months as my pensioner; of the last, when roasted, sometimes, however, a few mouthfuls were relished in the absence of other more agreeable diet. Berries he always swallowed whole, grasshoppers, if too large, were pounded and broken on the floor as he held them in his bill. To manage the larger beetles was not so easy ; these he struck repeatedly against the ground, and then turned them from side to side, by throwing them dexterously into the air, after the manner of the Toucan, and the insect was uniformly caught reversed, as it descended, with the agility of a practised cup-and-ball player. At length the pieces of the beetle were swallowed, and he remained still to digest his morsel, tasting it distinctly soon after it entered the stomach, as became obvious by the ruminating motion of his mandibles. When the soluble portion was taken up, large pellets of the indigestible legs, wings, and shells, as likewise the skins and seeds of berries, were, in half an hour or less, brought up and ejected from the mouth in the manner of the Hawks and Owls. When other food failed he appeared very well satisfied with fresh minced meat, and drank water frequently, even during the severe frosts of January, which he endured without much difficulty; basking, however, like Diogenes, in the feeble beams of the sun, which he followed round the room of his confinement, well satisfied when no intruder or companion threw him into the shade. Some very cold evenings he had the sagacity to retire under the shelter of a depending bed-quilt, was very much pleased with the warmth and brilliancy of lamp-light, and would eat freely at any hour of the night. Unacquainted with the deceptive nature of shadows, he sometimes snatched at them for the substances they resembled. Unlike the Vieros, he retired to rest without hiding his head in the wing, and was extremely watchful, 
though not abroad till after sunrise. His taciturnity and disinclination to friendship, and familiarity in confinement, were striking traits. His restless, quick, and side-glancing eye enabled him to follow the motions of his flying insect prey, and to ascertain precisely the infallible instant of attack. He readily caught morsels of food in his bill before they reached the ground, when thrown across the room, and on these occasions seemed pleased with making the necessary exertion. He had also a practice of cautiously stretching out his neck, like a snake, and peeping about either to obtain sight of his food, to watch any approach of danger, or to examine anything that appeared strange. At length we became so well acquainted that when very hungry he would express his gratitude on being fed by a shrill twitter and a lively look, which was the more remarkable as at nearly all other times he was entirely silent.

In a natural state he takes his station on the top of an apple-tree, a stake, or a tall weed, and betwixt the amusement of his squeaking twitter, employs himself in darting after his insect food. Occasionally he is seen hovering over the field, with beating wing, almost like a Hawk, surveying the ground or herbage for grasshoppers, which are a favorite diet. At other times these birds may be observed in companies flickering over still waters in the same employment, - the gratification of appetite. Now and then, during the heat of summer, they are seen to dip and bathe in the watery mirror; and with this washing, drying, and pluming, they appear to be both gratified and amused. During the season of their sojourn the pair are often seen moving about in company, with a rapid quivering of the wings and a continued tremulous, shrieking twitter. Their energetic and amusing motions are most commonly performed in warm and fine weather, and continue, with little interruption, until towards the close of August.

One of the most remarkable traits in the character of the Kingbird is the courage and affection which he displays for his mate and young; for on his first arrival he is rather timid, and readily dodges before the Swallow and Purple Martin. Indeed 
at this season I have seen the Spotted Sandpiper drive away a pair of Kingbirds because they happened to approach the premises of her nest. But he now becomes, on this important occasion, so tenacious of his rights as readily to commence the attack against all his feathered enemies, and he passes several months of the summer in a scene of almost perpetual contest; and not overrating his hostile powers, he generally finds means to come off with impunity. Eagles, Hawks, Crows, Jays, and in short every bird which excites his suspicion by its intentional or accidental approach, are attacked with skill and courage; he dives upon the heads and backs of the larger intruders, who become so annoyed and tormented as willingly to make a precipitate retreat. He pursues his foes sometimes for a mile ; and at length, assured of conquest, he returns to his prominent watch-ground, again quivering his wings in gratulation, and rapidly uttering his shrill and triumphant notes. $\mathrm{He}$ is therefore the friend of the farmer, as the scourge of the pilferers and plunderers of his crop and barn-yard. But that he might not be perfectly harmless, he has sometimes a propensity for feeding on the valuable tenants of the bee-hive; for these he watches, and exultingly twitters at the prospect of success as they wing their way engaged in busy employment ; his quicksighted eyes now follow them, until one, more suitable than the rest, becomes his favorite mark. This selected victim is by some farmers believed to be a drone rather than the stinging neutral worker. The selective discernment of the eyes of this bird has often amused me; berries of different kinds, held to my domestic Kingbird, however similar, were rejected or snatched as they suited his instinct, with the nicest discrimination.

As the young acquire strength for their distant journey, they may be seen in August and September assembling together in almost silent, greedy, and watchful parties of a dozen or more, feeding on various berries, particularly those of the sassafras and cornel, from whence they sometimes drive away smaller birds, and likewise spar and chase each other as the supply diminishes. Indeed, my domestic allowed no other bird to 
live in peace near him when feeding on similar food; and though lame of a wing, he often watched his opportunity for reprisal and revenge, and became so jealous that, instead of being amused by companions, sometimes he caught hold of them with his bill, and seemed inclined to destroy them for invading his usurped privileges. In September the Kingbird begins to leave the United States and proceeds to pass the winter in tropical America. During the period of migration southward, Audubon remarks that they fly and sail through the air with great ease at a considerable elevation; and they thus continue their silent retreat throughout the night until about the first of October, when they are no longer to be seen within the limits of the Middle States.

We now know that the Kingbird ranges throughout North America from the tropics to the lower fur countries, though not common west of the Rockies.

All lovers of birds and of justice will thank Mrs. Olive Thorne Miller for her noble defence of this chivalrous and much maligned bird, which appeared in the "Atlantic Monthly" for August, I89o. The systematists have dubbed him "tyrant of the tyrants," but his friends know him to be a true knight, the real "king of the air." Mrs. Miller credits the Kingbird with "a soft and very pleasing song," which she has heard "only in the very early morning."

Note. - The Arkansas KingBird ( $T$. verticalis) differs from tyrannus in being light ashy gray on head, neck, and breast, and other lower parts yellow. In size the two birds are much the same, some examples of the Western form being slightly larger.

Its habitat is the Western plains: but specimens have been taken in the Middle and Northern States. 


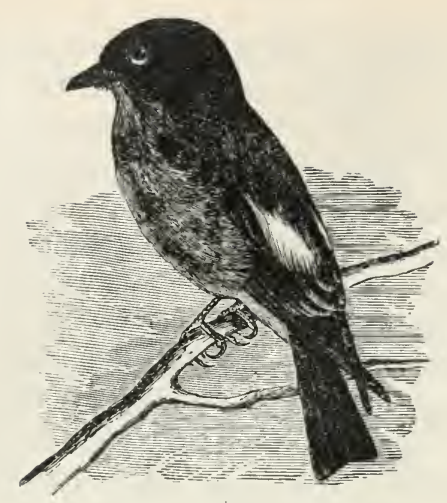

\section{OLIVE-SIDED FLYCATCHER.}

CONTOPUS BOREALIS.

CHAR. Above, dull olive brown, darker on head, paler on rump; tail dusky, tipped with gray; wings dusky, with gray band; lower parts yellowish white; flanks pale olive. Length $7 \frac{1}{4}$ to 8 inches.

Nest. Saddled on horizontal limb of tall tree ; of twigs and grass lined with grass and moss.

Eggs. 3-5; creamy white, spotted near larger end with reddish brown and pale purple; $0.85 \times 0.65$.

This remarkable species, which appertains to the group of Pewees, was obtained in the woods of Mount Auburn, in this vicinity, by Mr. John Bethune, of Cambridge, on the 7 th of June, I830. This, and a second specimen acquired soon afterwards, were females on the point of incubation. A third individual of the same sex was killed on the 2 Ist of June, I83 $\mathrm{I}$. They were all of them fat, and had their stomachs filled with torn fragments of wild bees, wasps, and other similar insects. I have watched the motions of two other living individuals who appeared tyrannical and quarrelsome even with each other; the attack was always accompanied with a whirring, querulous twitter. Their dispute was apparently, like that of savages, about the rights of their respective huntinggrounds. One of the birds, the female, whom I usually saw alone, was uncommonly sedentary. The territory she seemed 
determined to claim was circumscribed by the tops of a cluster of tall Virginia junipers or red cedars, and an adjoining elm and decayed cherry-tree. From this sovereign station, in the solitude of a barren and sandy piece of forest adjoining Mount Auburn, she kept a sharp lookout for passing insects, and pursued them with great vigor and success as soon as they appeared, sometimes chasing them to the ground, and generally resuming her perch with an additional mouthful, which she swallowed at leisure. On descending to her station she occasionally quivered her wings and tail, erected her blowsy cap, and kept up a whistling, oft-repeated, whining call of 'pü' $p \breve{u}$,

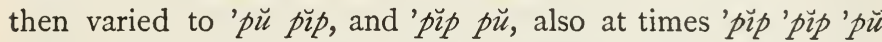

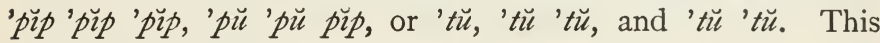
shrill, pensive, and quick whistle sometimes dropped almost to a. whisper or merely ' $p \breve{u}$. The tone was in fact much like that of the 'phü 'phü' phü of the Fish Hawk. The male, however, besides this note, at long intervals had a call of 'eh'phèbe-e or ' $h$ 'phebéa almost exactly in the tone of the circular tin whistle, or bird-call, being loud, shrill, and guttural at the commencement. The nest of this pair I at length discovered in the horizontal branch of a tall red cedar 40 or 50 feet from the ground. It was formed much in the manner of the Kingbird, externally made of interlaced dead twigs of the cedar, internally of the wiry stolons of the common cinquefoil, dry grass, and some fragments of branching Lichen or Usnea. It contained 3 young and had probably 4 eggs. The eggs had been hatched about the 2 oth of June, so that the pair had arrived in this vicinity about the close of May.

The young remained in the nest no less than 23 days, and were fed from the first on beetles and perfect insects, which appeared to have been wholly digested, without any regurgitation. Towards the close of this protracted period the young could fly with all the celerity of the parents; and they probably went to and from the nest repeatedly before abandoning it. The male was at this time extremely watchful, and frequently followed me from his usual residence, after my paying him a visit, nearly half a mile. These birds, which I watched 
on several successive days, were no way timid, and allowed me for some time previous to visiting their nest to investigate them and the premises they had chosen, without showing any sign of alarm or particular observation.

This bird appears to have been discovered in the fur countries about the same time as in the United States. According to Dr. Richardson, the specimen, figured so spiritedly in the "Northern Zoology of Canada," was shot on the banks of the Saskatchewan as it was flying near the ground.

In 1832 , about the middle of June, the same pair apparently had again taken possession of a small juniper not more than 300 yards from the tree they had occupied the preceding year, about 14 or 15 feet up which they had fixed their thin twiggy nest as in the preceding year. It contained 4 eggs, on which the female had commenced sitting; these, except in their superior size, were precisely similar with those of the Wood Pewee, - yellowish-cream color, with dark-brown and lavender-purple spots, rather thinly dispersed. Being unfortunate enough to shake out the two eggs I intended to leave in the nest, the pair had to commence their labors of preparing for a progeny anew; and a few days after, a second nest was made in another Virginian juniper at a very short distance from the preceding. The present year, however, they did not return to their accustomed retreat, and no individual was seen in this vicinity. In all places it appears, in fact, a scarce and widely dispersed species. Audubon has since observed this bird in other parts of Massachusetts, Maine, the Magdalen Islands, and the coast of Labrador. $\mathrm{He}$ has also seen it in Georgia and in Texas. This species is a common inhabitant of the dark fir-woods of the Columbia, where it arrives towards the close of May. We again heard, at intervals, the same curious call, like 'gh-phebéa, and sometimes like the guttural sound 'egh-phebee', commencing with a sort of suppressed chuck; at other times the note varied into a lively and sometimes quick p't-detoway. This, no doubt, is the note attributed by Wilson to the Wood Pewee. When approached, or when calling, we heard the $p u p u p u$. 
The Olive-sided Flycatcher is a rare summer resident in the southern portions of New England, but is quite common in Maine and New Brunswick, and ranges north to about the 5 oth parallel. It winters south to the tropics.

\section{CRESTED FLYCATCHER.}

\section{MYiaRCHUS CRINITUS.}

CHAR. Upper parts olive, inclined to brown on the head; belly bright yellow; throat and breast ashy gray; wings and tail dusky, marked with rufous. Head crested. Length $81 / 2$ to 9 inches.

Nest. In a cavity of a tree; of twigs, grass-roots, feathers, and usually a cast-off snake-skin.

Eggs. 4-6; light buffy brown, marked with lines of brown and purple; $0.85 \times 0.65$.

This species, nearly unknown in New England, arrives in Pennsylvania early in May, and builds his nest in the deserted holes of the Woodpecker or Bluebird. He also frequents the orchard, and is equally fond of bees with the Kingbird. $\mathrm{He}$ has no other note than a harsh squeak, which sounds like 'paĭp, 'païp, pay'üp, 'payzwip, with a strong accent on the first syllable. He preys actively on insects, which he collects from his stand, and, in short, has most of the manners and physiognomy of the whole section or family to which he belongs. The note of the male appears often delivered in anger and impatience, and he defends his retreat from the access of all other birds with the tyrannic insolence characteristic of the Kingbird.

Towards the and of summer these birds feed on berries of various kinds, being particularly partial to pokeberries and whortleberries, which for a time seem to constitute the principal food of the young. They remain in Pennsylvania till about the middle of September, when they retire to tropical America. In July, I 83 I, I observed a pair in an orchard at Acton, in this State (Massachusetts). They had reared a brood in the vicinity, and still appeared very stationary on the premises; their harsh 
payup, and sometimes a slender twittering, as they took the perch, were heard almost from morn to night, and resembled at first the chirp of a young Robin. They fed on the caterpillars or vermin of some kind which happened to infest the apple-trees. I was told that they utter a different and more musical note about sunrise ; but of this I cannot speak from my own knowledge. They are unknown in the vicinity of the sea-coast of Massachusetts. According to Audubon, they are found on the upper Missouri during summer. Many also pass the winter in the warmer parts of Florida. They also breed in Texas.

This species is common in the Eastern States north to Connecticut and northern Ohio and in southern Ontario. It is rare in portions of Massachusetts, but examples have been observed in Maine and New Brunswick. It breeds south to Florida, and winters in the tropics.

Those who know the bird best say it has the courage of the Kingbird, and a knack of quarrelling that is all its own.

\section{GRAY KINGBIRD.}

\section{TyRannus DOMINICENSIS.}

CHAR. Very similar to the Kingbird, but of paler color; the upper parts, including the head, being ashy gray. Its size is somewhat larger, about an inch in length.

Nest. In a tree ; composed of twigs, lined with roots or moss.

Egrs. 3-4; white, tinged with pale buff or salmon pink and spotted with brown and purple; $1.00 \times 0.75$.

This fine tropical species was discovered by Audubon on the Florida Keys, where it arrives about the first of April, and spreads over the peninsula as far as Cape Florida. It is common in Cuba and several other of the West India islands. Stragglers, however, appear to wander at times as far to the north as South Carolina; a pair and their nest having been found in a college yard, where they continued to return for several years in succession, rearing two broods in a season. Its whole demeanor so much resembles that of the common 
Kingbird that but for its superior size and note it might be mistaken for that species.

These birđs flutter while flying, and sometimes during the breeding season the pair, crossing each other's path, rise in spiral evolutions, loudly twittering as they ascend. When interrupted, alarmed by pursuit, or in quest of insects, they dart off with great velocity. If a large bird, as a Heron or Crow, or indeed any intruder, pass near their station, they immediately pursue it, and that often to a considerable distance. At the same time they appear careless of the approach of man except when the nest is invaded, when they fly about in great anger, snapping their bills and loudly chattering; but when relieved from their unwelcome visitors, they return to their stand with notes of exultation.

Nuttall, following Audubon, named this species the Pipiry Flycatcher. It is abundant in the West Indies and occurs in parts of Florida and along the coast to South Carolina. Examples have been taken on Long Island, and at Lynn, in Massachusetts.

It winters in the tropics.

\section{PHCEBE.}

PEWEE. PEWIT.

\section{SAYORNIS PHEBE.}

CHAR. Upper parts dull olive brown, darker on head; under parts whitish, changing to pale yellow on belly, and brownish on flanks ; wings and tail dusky, outer tail feathers and wing bar whitish; white ring around the eyes; bill and feet black. Head with inconspicuous crest. Length $6 \frac{1}{4}$ to 7 inches.

Nest. Attached to the under-side of a bridge, or to a rock, or the side of a cave; of twigs, roots, and moss, cemented with mud, lined with grass and feathers.

Eggs. 4-5; white, sometimes speckled with pale brown; $0.80 \times 0.55$.

This familiar species inhabits the continent of North America from Canada and Labrador to Texas, retiring from the Northern and Middle States at the approach of winter. How 
far they proceed to the South at this season is not satisfactorily ascertained; a few, no doubt, winter in the milder parts of the Union, as Wilson saw them in February in the swamps of North and South Carolina, where they were feeding on smilax berries, and occasionally even giving their well-known notes; but in the winter and early spring of 1830 , while employed in an extensive pedestrian journey from South Carolina to Florida and Alabama, I never heard or met with an individual of the species. Audubon found them abundant in the Floridas in winter.

These faithful messengers of spring return to Pennsylvania as early as the first week in March, remain till October, and sometimes nearly to the middle of November. In Massachusetts they arrive about the beginning of April, and at first chiefly frequent the woods.

Their favorite resort is near streams, ponds, or stagnant waters, about bridges, caves, and barns, where they choose to breed; and, in short, wherever there is a good prospect for obtaining their insect food. Near such places our little hunter sits on the roof of some out-building, on a stake of the fence, or a projecting branch, calling out at short intervals and in a rapid manner phebè phebè, and at times in a more plaintive tone phee-bè-ee. This quaint and querulous note, occasionally approaching to a warble, sometimes also sounds like pewait

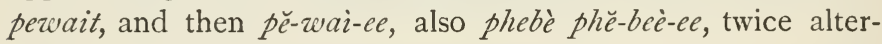
nated; the latter phrase somewhat soft and twittering. In the spring this not unpleasing guttural warble is kept up for hours together until late in the morning, and though not loud, may be heard to a considerable distance. From a roof I have heard these notes full half a mile across the water of a small lake; and this cheerful, though monotonous, ditty is only interrupted for a few seconds as the performer darts and sweeps after his retreating prey of flies, frequently flirting and quivering his tail and elevating his feathery cap, while sharply watching the motions of his fickle game.

In the Middle States he begins to construct his nest about the latter end of March, in Massachusetts not before the first 
week in April. The nest is situated under a bridge, in a cave, the side of a well 5 or 6 feet down, under a shed, or in the shelter of the low eaves of a cottage, and even in an empty kitchen; sometimes it rests on a beam, though it is frequently attached to the side of a piece of roofing timber in the manner of the Swallow.

According to the touching relation of Wilson, this humble and inoffensive bird forms conjugal attachments which probably continue through life; for, like the faithful Bluebirds, a pair continued for several years to frequent and build in a romantic cave in the forest which made part of the estate of the venerable naturalist, William Bartram. Here our unfortunate birds had again taken up their welcome lease for the summer, again chanted forth their simple lay of affection, and cheered my aged friend with the certain news of spring; when unexpectedly a party of idle boys, one fatal Saturday, destroyed with the gun the parents of this old and peaceful settlement; and from that time forward no other pair were ever seen around this once happy, now desolate spot.

Their attachment to particular places is indeed remarkable. About the middle of April, I 831, at the Fresh Pond Hotel, in this vicinity, three different nests were begun in the public boat-house, which may be here considered almost as a thoroughfare. Only one nest, however, was completed; and we could not help admiring the courage and devotedness with which the parents fed their young, and took their alternate station by the side of the nest, undaunted in our presence, only now and then uttering a 'tship when observed too narrowly. Some ruffian at length tore down the nest and carried off the brood; but our Pewit immediately commenced a new fabric, laid 5 additional eggs in the same place with the first, and, in haste to finish her habitation, lined it with the silvery shreds of a Manilla rope which she discovered in the contiguous loft over the boat-house. For several previous seasons the parents had taken up their abode in this vicinity, and seemed unwilling to remove from the neighborhood they had once chosen, in spite of the most untoward circumstances. In two other VOL. I. -27 
instances I have known a pair, when the nest and eggs were taken by some mischievous boys, commence a new nest in the same place, and laying a smaller number of eggs, raised a second brood. In one of those nests, under a bridge, the insidious Cowbird had also dropped her parasitic egg.

Towards the time of their departure for the South, which is about the middle of October, they are silent, and previously utter their notes more seldom, as if mourning the decay of Nature, and anticipating the approaching famine which now urges their migration. In the Middle States they raise two broods in the season; but in Massachusetts the Pewit rarely raises more than a single brood, unless, as in the instance related, they have had the misfortune to lose the first hatch. The young, dispersed through the woods in small numbers, may now and then be heard to the close of September exercising their feeble voices in a guttural phébé. But the old birds are almost wholly silent, or but little heard, as they flit timidly through the woods, when once released from the cares of rearing their infant brood; so that here the Phœbe's note is almost a concomitant of spring and the mildest opening of summer, it is, indeed, much more vigorous in April and May than at any succeeding period.

The Phœbe is an uncommon bird in the Maritime Provinces, but more common in the vicinity of Montreal and westward to Western Ontario, and in all the Eastern States. It breeds from Manitoba and Newfoundland to South Carolina, and winters in the Gulf States as well as in Cuba and Mexico.

Note. -- Mr. G. S. Miller, Jr., captured on Cape Cod, in September, I889, an example of SAY'S PHœBE (Sayornis saya), the first that has been taken to the eastward of the Great Plains. 


\section{WOOD PEWEE.}

\section{CONTOPUS VIRENS.}

CHAR. Upper parts olive brown, darker on the head; lower parts whitish, with dull yellow tinge; sides pale olive, extending across the breast; tail and wings dusky; wings with bars of whitish. Head with inconspicuous crest. Length 6 to $61 / 2$ inches.

Nest. On branch of a tree; of twigs and grass, covered exteriorly with lichens and lined with moss.

Eggs. 3-4; creamy white with spots of brown and lilac wreathed about the larger end; $0.75 \times 0.55$.

This species has much the appearance of the common Pewit Flycatcher, but differs essentially by its note and habits. The Wood Pewee appears generally to winter south of the United States, and scarcely arrives in Pennsylvania or New England before the middle of May; its migrations, in all probability, extend to Canada. According to Audubon, many of them winter in the southern extremity of the United States, and Mr. Townsend and myself frequently saw them in the dark forests of the Oregon. It is a solitary species, frequenting gloomy forests and dark orchards, where, watching on some dead and projecting branch for its insect prey, it sweeps at intervals amidst the shade, and the occasional snapping of its bill announces the success of its flight. It then again alights as before, sometimes uttering a sort of gratulatory low twitter, accompanied by a quivering of the wings and tail; and in the lapse of its employment, in a feeble, sighing tone, often cries pee-zvée or pee-é, and sometimes pe-zwee pervittitee or pervittee $p \bar{e}$-wee. This note is continued often till quite late in the evening, at which time many of the insect brood and moths are abundant. Most of these birds, indeed, appear capable of collecting their food by the feeblest light, the only season when some of their favorite prey ever stir abroad. This species also appears particularly fond of small wild bees. From June to September, its solitary notes are heard in the field and forest; after which time, preparing for its departure, and intently gleaning food in every situation, it sometimes approaches the city, 
often examines the courts and gardens, at the same time feeding and training its young to the habits of their subsistence, and about the first week in October it retires south to pass the winter.

The Pewee is a very expert and cautious flycatcher; and as if aware of the drowsiness of insects in the absence of the sun's broad light, he is on the alert at day-dawn after his prey. At this early period, and often in the dusk of evening, for the most part of summer till the middle of August, he serenades the neighborhood of his mansion from 3 to 4 or 5 o'clock in the morning, with an almost uninterrupted chanting ditty, sweet, but monotonous, like pé-ay pāy-wěe, pé-ay pày-wěe, then in a little higher and less sing-song tone, his usual and more serious pee-ă-wee. In dark and damp mornings this curious warble is sometimes continued nearly to 8 o'clock; and the effect of this tender, lulling lay in the gray dawn, before the awakening of other birds, and their mingling chorus, is singular and peculiarly pleasing. It is a gratulatory feeling of unmixed and placid delight, concomitant with the mild reviving light of the opening day and the perfect joy of the mated male, satisfied in every reasonable desire, - in short, a hymn of praise to the benevolent Author and Supporter of existence!

Towards the period of departure they become wholly silent; and driven to extremity, they may now be seen watching the stagnant pools and ponds, dipping occasionally into the still surface after their drowsy and languid prey. Like the Kingbird, this species at times displays a tyrannical disposition; and I have observed one to chase a harmless Sparrow to the ground for safety, who merely by inadvertence happened to approach the station he had temporarily chosen for collecting his insect game.

The notes of peto-wāy peto-wāy pee-way are never uttered by this species; but on the I 2 th of February, 1830 , in Alabama, I heard, at that season, a bird uttering this note, and several times afterwards I saw a rather large and dark Flycatcher in the pine woods, to which I attributed this call, and which must be a distinct species, as its notes bear no resem- 
blance to those of the Wood Pewee, - at this season probably in South America.

The Pewee, I believe, raises here but a single brood, which are not abroad before the middle of July. The nest is extremely neat and curious, almost universally saddled upon an old moss-grown and decayed limb in an horizontal position, and is so remarkably shallow, and incorporated upon the branch, as to be very easily overlooked. The body of the fabric consists of wiry grass or root-fibres, often blended with small branching lichens, held together with cobwebs and caterpillar's silk, moistened with saliva; externally it is so coated over with bluish crustaceous lichens as to be hardly discernible from the moss upon the tree. It is lined with finer root-fibres or slender grass stalks. Some nests are, however, scarcely lined at all, being so thin as readily to admit the light through them, and are often very lousy, with a species of acarus which probably infests the old birds.

The plaintive and almost pathetic note of the Wood Pewee is a familiar sound amid the orchards of New Brunswick, and the bird is of common occurrence through Quebec, Ontario, and Manitoba. It breeds south to Florida, and winters southward to Mexico and Guatemala.

\section{LEAST FLYCATCHER.}

CHEBEC.

\section{EMPIDONAX MINIMUS.}

CHAR. Upper parts olive; lower parts white, tinged with yellow; the breast washed with olive gray; wings with two bars of grayish white. Length 5 to $5^{1 / 2}$ inches.

Nest. On fork of a tree; of twigs and grass, lined with grass or feathers.

Eggs. 3-5; creamy white, usually unspotted; $0.65 \times 0.50$.

This is one of our most common summer birds in this part of New England, arriving from the South about the last week in April, and leaving us to retire probably to tropical America about the beginning of September or sometimes a little later. It also extends its migrations to Labrador and the Oregon 
Territory, and seems most abundant in the Northern and Eastern States. Though, like the preceding, these are solitary, retiring birds, and fond of the shade of the forest, yet in this vicinity their nests are numerous. On their first arrival, previous to pairing, they are engaged in constant quarrels about their mates, and often molest other birds whom they happen to see employed in pursuit of the same kind of food with themselves. Like the preceding species, they take their station on a low branch to reconnoitre the passing insects on which they feed, and from time to time make a circular sweep for their prey. When seated, they utter very frequently a sharp, unpleasant squeak, somewhat resembling that of the Kingbird, sounding like queàh, and sometimes 'tsh'ah, or tsheàh, tsheàh, and tshooé, with a guttural, snapping sound, succeeded by a kind of querulous, low twitter uttered as they fly from tree to tree, and chiefly at the instant of alighting. At other times they have a recognizing, rather low call of 'whit, 'whit, repeated at short intervals; again, in the warmest weather, I have heard one of these Pewees call something like the whistling of 'weet, 'weet, 'weet, 'will. Occasionally, when fighting or in flying, it also makes an echoing tshirr. It possesses all the habits of the Kingbird, catches bees, flies, and moths, exhibits a variety of quivering motions, and defends its nest with great courage against the approach of larger birds.

The nest of the Small Pewee is usually fixed in the slender, upright forks of a young forest tree from 6 to 20 or 30 feet from the ground. I have also found the nests on the horizontal branch of an apple-tree or forest tree. In most instances in the woods a gloomy, solitary situation is chosen. The materials of this fabric vary according to circumstances; for the first brood a very soft and warm nest is usually made of dry grass, willow, and cud-weed down in large quantities, partly felted or matted together externally with the saliva of the bird. Common tow, if convenient, is also occasionally employed when the nest is in an apple-tree, for which some neighboring graft is probably unravelled. The interior is usually formed of slender, narrow strips of bark, bass, and dry grass ; 
the lining is commonly of fine root-fibres, slender tops of bent grass, and at times a few hairs and feathers. Occasionally the principal external material consists of strips or strings of silkweed lint and the bark of the common virgin's bower. The nest is extremely neat and uniform, resembling a complete hemisphere. As nests may be found late in July, it is probable they have a second brood in the course of the season. They are extremely attached to their offspring, and keep up an incessant, almost choking tsheàh tsheàh when any person approaches the tree where they have their brood. The young and old now move about in company, and at this time feed on various kinds of berries, particularly those of the cornel and whortleberry. At length the young are seen to select each other's society, and rove about without any fixed resort, previous to their gradual departure. A pair, probably of the same brood, still lingered here in September, and like the little Parrots called Inseparable, appeared fondly to cherish each other's company. It was toward evening when I saw them, and at first they appeared inclined to roost in the shady willow-tree in which they had alighted. They nestled close to each other with looks and notes of tenderness and affection; wherever one went, the other instantly followed, and the same branch contained the same contented pair.

Nuttall followed Wilson in the mistake of supposing this species and acadicus to be identical, and in his account has mingled the biographies of the two. The latter is more southern in its distribution, the center of its breeding area being in the Middle States. "Chebec" is a common summer resident from Pennsylvania to the Gulf of St. Lawrence, and westward to the prairies. It winters south to Panama. 


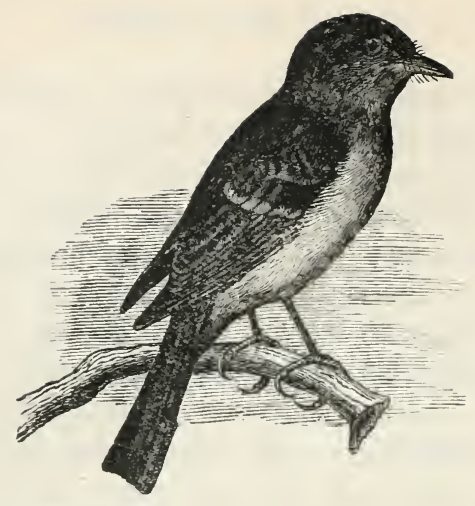

\section{TRAILL'S FLYCATCHER.}

\section{EMPIDONAX TRAILLII ALNORUM.}

Char. Upper parts olive brown, darker on the head, lighter on the rump; under parts whitish, the sides tinged with pale olive, which extends nearly across the breast, the belly tinged with yellow; wings dusky, with yellowish white bars. Length $5^{1 / 2}$ to 6 inches.

Nest. On an upright fork in a clump of alders or low deciduous tree, I to 8 feet from the ground; composed of grass roots or hempen fibre, lined usually with fine grass, sometimes with horse-hair or thistle-down.

Eggs. 3-4; creamy white or buff, boldly spotted with light and dark brown chiefly about the larger end ; $0.70 \times 0.53$.

This species, so nearly allied to the last, was first distinguished by Audubon. Its note resembles the syllable 'wheet, 'wheet, articulated clearly while in the act of flying. It was first observed on the wooded skirts of the prairies along the banks of the Arkansas. Mr. Townsend and myself observed it in various places in the skirts of the forests of the Columbia and Wahlamet during the summer, when it was breeding, but we could not discover the nest. Its motions are thus described by Audubon: "When leaving the top branches of a low tree this bird takes long flights, skimming in zig-zag lines, passing close over the tops of the tall grasses, snapping at and seizing different species of winged insects, and returning to the same trees to alight."

Traill's Flycatcher is chiefly a spring and autumn migrant through southern New England, though a few pairs breed as far 
south as Long Island. It is a common summer resident of Maine and of the northern part of Vermont and New Hampshire, and is not uncommon on the Berkshire hills in Massachusetts. It is common in New Brunswick. West of this region it breeds farther to the southward, being common in the middle of Ohio and in southern Illinois and Missouri. Mr. McIlwraith considers it uncommon in Ontario, and Mr. Thompson reports it common in Manitoba. It winters in Central America.

There has been considerable discussion over the breeding habits of this species, caused by the difference in habits of the Western birds from those which breed near the Atlantic. Here the favorite site is a clump of alders near a running stream, and the nest is placed within a foot or two of the ground; while in the West a small tree is generally selected, - sometimes an oak, - and the nest is placed as high as ten feet. The nest, in the West, is not so compactly or neatly made, and the materials are coarser. The note of this bird - for while the Flycatchers are not classed with the Oscines, or Singing-Birds, they add not a little to our forest melodies - is peculiar, though strictly of the family type. It sounds something like ke-wink delivered with a rising inflection and the accent on the final sound, which is prolonged, - quite a different note from the abrupt chebec of minimus. I have never heard the song uttered on the wing; but when the bird is perching, the head is tossed back, and the note is flung out with a decided emphasis of manner as well as of voice.

\section{ACADIAN FLYCATCHER.}

\section{EMPIDONAX VIRESCENS.}

CHAR. Upper parts olive, slightly darker on crown; under parts whitish, the sides tinged with pale olive, which reaches almost across the breast; belly tinged with pale yellow; wings and tail dusky; wing-bars buffy. Length $5^{1 / 2}$ to 6 inches.

Nest. In a tree, suspended on fork of twigs at the extremity of a low limb; rather loosely made of moss or grasses and shreds of bark bound with spider's webbing.

Eggs. 2-4; buff or creamy white, spotted, chiefly about the larger end, with reddish brown; $0.75 \times 0.55$.

The older writers had rather confused ideas regarding these small Flycatchers, and Nuttall supposed he was writing of the present species, when the bird he had in mind was minimus. 
The Acadian Flycatcher belongs to the Middle States rather than to New England, and has been taken but once north of the Connecticut valley. It is abundant in Ohio and Illinois, but has not been observed in Ontario. Mr. Thompson reports it as common in Manitoba. It breeds south to Florida, and winters in Central America.

I have not met with this species in the field, but those who have been so fortunate describe it as a shy bird, seeking the low, moist thicket and shaded groves rather than the open pastures. Dr. Coues thinks the nest "may be compared to a light hammock swung between forks." It is shallow and saucer-shaped, and so loosely made that the eggs may be seen from below. Dr. Wheaton states that so much loose grass is left on the outside of the nest "that it looks like a tuft of hay caught by the limb from a load driven under it."

Mr. Chapman tells us that the most common call of this bird is " a single spee or peet repeated at short intervals, and accompanied by a rapid twitching of the tail. A more peculiar note is a louder pee-e-yuk. The bird seems to articulate this note with difficulty, with bill pointing upward and wings trembling, like a fledgling begging for food."

\section{YELLOW-BELLIED FLYCATCHER.}

\section{EMPIDONAX FLAVIVENTRIS.}

ChaR. Upper parts dull olive, darker on the crown; under parts bright yellow, shaded with olive on the breast; wing-bars pale yellow; a yellow ring around the eye. Length $51 / 2$ to 6 inches.

Nest. Amid moss-covered roots of upturned tree or mossy log; of twigs, or vegetable fibre, or moss, lined with roots, or fine grass, or moss.

Eggs. 4; pale buff, sparingly spotted, mostly about larger end, with reddish brown; $0.70 \times 0.50$.

This species was discovered about $\mathrm{I} 843$, and for many years as late as 1880 - was considered a rare bird. Even now comparatively few persons are familiar with it, though it occurs throughout this Eastern Province. It is common in New England, breeding in the northern portion, and occurs on the higher hills elsewhere. I found it abundant in New Brunswick, and it has been traced northward to the lower Hudson Bay region. Macoun reports it common at Lake Mistissini. 
Dr. Wheaton considered it a common migrant through Ohio, but observers in Ontario have met with it so seldom as to think it rare, though Ridgway says the bird is common in Illinois, and Thompson found it in Manitoba.

The notes of this species have caused much discussion, - some writers claiming for it an individuality, and others insisting that it utters nothing different from the notes of traillii or minimus. The kil-lic of faviventris seems, to my ear, quite different from the $k e$-wink of Traill's, - which is rather sibilant, and is delivered with a rising inflection, - and differs also from the che-bec of the Least Flycatcher. While the latter delivers the last two notes abruptly and makes more or less pause after each couplet, the Yellow-bellied whistles four notes, kil-lic kil-lic, with but a short pause - a mere rest - between each pair, and delivers the notes with a trifle less abruptness. Dr. Dwight thinks the song "is more suggestive of a sneeze on the bird's part, than of any other sound with which it may be compared."

Other notes of the present species resemble pea and pe-we-yea. These are heard when a pair are in close companionship. They are soft, sweet, cooing-notes, delivered in a plaintive tone that suggests the tender pathos of the Pewee's.

Note. - The Fork-tailed Flycatcher (Milvulus tyrannus), a bird of Central and South America, has occasionally wandered north, and been taken in Mississippi, Kentucky, and New Jersey.

Also a few examples of the Scissor-Tailed Flycatcher (Milvulus forficatus), which rarely appears north or east of Texas, have been seen in Virginia, New Jersey, Connecticut, Ontario, and Manitoba, and one wandered to the shores of Hudson Bay. 


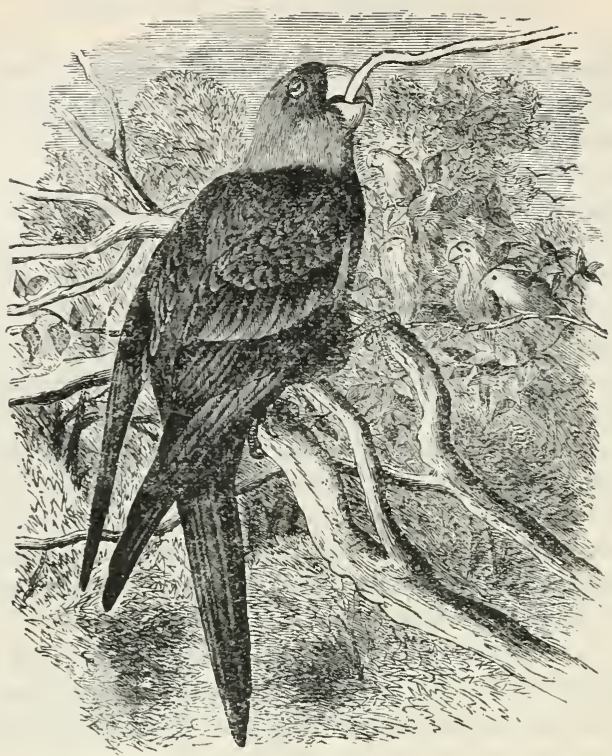

CAROLINA PAROQUET.

CAROLINA PARROT. PARAKEET.

CONuRUS CAROLINENSIS.

CHAR. Head and neck yellow; forehead and sides of head orange red; body and tail green, the belly tinged with yellow; wings green and yellow, the edges tinged with orange red. In immature specimens the yellow of head and neck is replaced by green. Length about 13 inches.

Nest. In dense woods or cypress swamp; placed on a fork near the end of a branch or in a hole in a tree. When on a branch it is made of cypress twigs loosely woven, and a nest in a hole is usually lined with cypress twigs. When abundant the birds generally build in large colonies.

Eggs. 2-5 (?); greenish white or creamy; 1.40 $\times 1.05$.

Of more than 200 species now known to belong to this remarkable and brilliant genus, the present is the only one found inhabiting the United States; it is also restricted to the warmer parts, rarely venturing beyond the State of Virginia. West of the Alleghanies, however, circumstances induce these birds commonly to visit much higher latitudes; so that, fol- 
lowing the great valley of the Mississippi, they are seen to frequent the banks of the Illinois, and occasionally to approach the southern shores of Lake Michigan. Straggling parties even have sometimes been seen in the valley of the Juniata in Pennsylvania, and a flock, to the great surprise of the Dutch inhabitants of Albany, are said to have appeared in that vicinity. They constantly inhabit and breed in the Southern States, and are so far hardy as to make their appearance, commonly in the depth of winter, along the woody banks of the Ohio, the interior of Alabama, the banks of the Mississippi and Missouri around St. Louis, and other places, when nearly all other birds have migrated before the storms of the season.

The Carolina Parrakeets in all their movements, which are uniformly gregarious, show a peculiar predilection for the alluvial, rich, and dark forests bordering the principal rivers and larger streams, in which the towering cypress and gigantic sycamore spread their vast summits, or stretch their innumerable arms over a wide waste of moving or stagnant waters. From these, the beech, and the hack-berry, they derive an important supply of food. The flocks, moving in the manner of wild Pigeons, dart in swift and airy phalanx through the green boughs of the forest ; screaming in a general concert, they wheel in wide and descending circles round the tall buttonwood, and all alight at the same instant, their green vesture, like the fairy mantle, rendering them nearly invisible beneath the shady branches, where they sit perhaps arranging their plumage and shuffling side by side, seeming to caress and scratch each other's heads with all the fondness and unvarying friendship of affectionate Doves. If the gun thin their ranks they hover over the screaming, wounded, or dying, and returning and flying around the place where they miss their companions, in their sympathy seem to lose all idea of impending danger. When more fortunate in their excursions, they next proceed to gratify the calls of hunger, and descend to the banks of the river or the neighboring fields in quest of the inviting kernels of the cockle-burr, and probabily of the bitterweed, which they extract from their husks with great dexterity. 
In the depth of winter, when other resources begin to fail, they, in common with the Yellow Bird and some other Finches, assemble among the tall sycamores, and hanging from the extreme twigs in the most airy and graceful postures, scatter around them a cloud of down from the pendant balls in quest of the seeds, which now afford them an ample repast. With that peculiar caprice, or perhaps appetite, which characterizes them, they are also observed to frequent the saline springs or licks to gratify their uncommon taste for salt. Out of mere wantonness they often frequent the orchards, and appear delighted with the fruitless frolic of plucking apples from the trees and strewing them on the ground untasted. So common is this practice among them in Arkansas Territory that no apples are ever suffered to ripen. They are also fond of some sorts of berries, and particularly of mulberries, which they eat piecemeal in their usual manner as they hold them by the foot. According to Audubon, they likewise attack the outstanding stacks of grain in flocks, committing great waste ; and on these occasions, as well as the former, they are so bold or incautious as readily to become the prey of the sportsman in great numbers. Peculiarity of food appears wholly to influence the visits and residence of this bird, and in plain, champaign, or mountainous countries they are wholly strangers, though common along the banks of all the intermediate watercourses and lagoons.

Of their manners at the interesting period of propagation and incubation we are not yet satisfactorily informed. They nest in hollow trees and take little if any pains to provide more than a simple hollow in which to lay their eggs, like the Woodpeckers. They are at all times particularly attached to the large sycamores, in the hollow trunks of which they roost in close community, and enter at the same aperture into which they climb. They are said to cling close to the sides of the tree, holding fast by the claws and bill; and into these hollows they often retire during the day, either in very warm or inclement weather, to sleep or pass away the time in indolent and social security, like the Rupicolas of the Peruvian caves, at 
length only hastily aroused to forage at the calls of hunger. Indeed, from the swiftness and celerity of their aërial movements, darting through the gleaming sunshine like so many sylvan cherubs decked in green and gold, it is obvious that their actions as well as their manners are not calculated for any long endurance; and shy and retiring from all society but that to which they are inseparably wedded, they rove abroad with incessant activity until their wants are gratified, when, hid from sight, they again relapse into that indolence which seems a relief to their exertions.

The Carolina Parrot is readily tamed, and early shows an attachment to those around who bestow any attention on its wants; it soon learns to recollect its name and to answer and come when called on. It does not, however, evince much, if any, capacity for mimicking human speech or sounds of any kind, and as a domestic is very peaceable and rather taciturn. It is extremely fond of nuts and almonds, and may be supported on the vegetable food usually given to other species. One which I saw at Tuscaloosa, a week after being disabled in the wing, seemed perfectly reconciled to its domestic condition; and as the weather was rather cold, it remained the greater part of the time in the house, climbing up the sides of the wire fender to enjoy the warmth of the fire. I was informed that when first caught it scaled the side of the room at night, and roosted in a hanging posture by the bill and claws; but finding the labor difficult and fruitless, having no companion near which to nestle, it soon submitted to pass the night on the back of a chair.

I fear that the story of this gorgeously apparalled bird is nearly finished. It is not quite exterminated yet, but of the large flocks that were once to be seen all over the Southern States, only a mere remnant can be found, and these are hidden amid the dense swamps of central Florida and along the lower valley of the Mississippi. The farmers and fruit-growers were obliged to kill large numbers, and later woman's vanity and man's greed have joined hands to carry on the slaughter. From the combined attack of such foes the remnant has but slight chance for escape. 


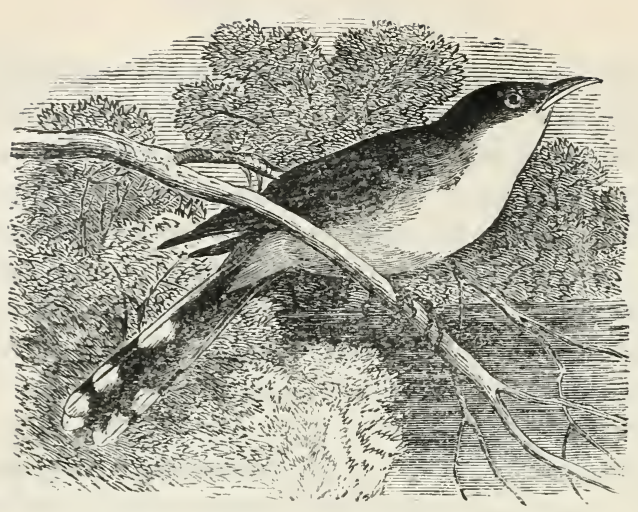

YELLOW-BILLED CUCKOO.

RAIN CROW.

COCCYZUS AMERICANUS.

ChAR. Upper mandible and tip of lower, black; rest of lower mandible and cutting edges of upper, yellow. Upper parts olive, with a slight metallic gloss, tinged with ash toward the bill; wings tinged with rufous; middle feathers of tail like back, remainder black tipped with white; beneath, white or creamy. Length about $\mathrm{I} 2$ inches.

Nest. In a thicket by the side of a stream or on the border of a swamp; placed in a bush or low tree. A flat, frail affair made of twigs loosely laid, sometimes lined with bark strips or grass.

Eggs. 2-6 (usually 4); pale dull green or bluish green; $1.25 \times 0.90$.

The American Cuckoo arrives in the middle and colder States of the Union about the close of April or the first week of May, and proceeds to the north as far as Nova Scotia. It probably winters in Mexico, and individuals pass no farther than the forests of Louisiana. We also met with it in the remote Territory of Oregon. Latham speaks of these birds also as inhabitants of the tropical island of Jamaica. They delight in the shady retirement of the forest, and are equally common in tall thickets and orchards, where, like piratical prowlers, they skulk and hide among the thickest boughs; and although, unlike the European Cuckoo, they are faithfully paired, yet the pair are seldom seen in the same tree, but, shy and watchful, endeavor to elude everything like close observation. 
The male, however, frequently betrays his snug retreat by his monotonous and guttural ków ków ków ków, or koo koo koo koo, and kó kŭk, kó kük, koo koo koo kuk, koo kŏ koo, koo $k \breve{o} k o o$, uttered rather low and plaintively, like the call of the Dove. At other times the kow kow kow, and 'tk' $t k$ 'tk 'tk 'tăk, or 'kh 'kh 'kh 'kh 'kah kow kow kow. kow, beginning slow, rises, and becomes so quick as almost to resemble the grating of a watchman's rattle, or else, commencing with this call, terminates in the distant cry of kow kow kow. From this note, supposed to be most clamorous at the approach of rain, it has received in Virginia and other States the name of RainCrow and Cow-Bird. At various seasons during the continuance of warm weather the vigil kow kŏw koow kow of the faithful male is uttered for hours at intervals throughout the night. The same notes, but delivered in a slower and rather tender strain, are given with great regularity likewise in the day as long as the period of incubation continues. He often steadfastly watches any approach to the nest, going to it occasionally to assure himself that it is unmolested; and at times he may be observed darting even at the dormant bat, who accidentally seeks repose beneath the shady leaves of some contiguous tree, so that he is no less vigilant in seeking the security of his own progeny than in piratically robbing the nests of his neighbors. There are two or three other species in Jamaica and other parts of tropical America possessing a note very similar to that of our bird, which also frequently approaches, when delivered in the plaintive mood, koo koo and koo koo koo, the usual sound of the European Cuckoo. There is a Mexican species (Cuculus ridibundus) which so simulates laughter as to have excited the superstition of the natives, by whom it is hated as a messenger of evil, its accidental note of risibility being construed into an ominous delight in misfortune.

The whole tribe of Cuckoos are in disgrace for the unnatural conduct of the European and some other foreign species, who, making no nests nor engaging in conjugal cares parasitically deposit their eggs one by one in the nests of other small birds, vOL. I. -28 
to whom the care of rearing the vagrant foundling is uniformly consigned.

But we may turn with satisfaction to the conjugal history of our own subject, which, early in May or soon after its arrival, may be at times observed obstinately engaged in the quarrels of selective attachment. The dispute being settled, the nest is commenced, and usually fixed either in the horizontal branches of an apple-tree or in a thicket, a thorn-bush, crab, cedar, or other small tree in some retired part of the woods. The fabric is usually very slovenly and hastily put together, and possesses scarcely any concavity for the reception of the young, who in consequence often fall out of their uncomfortable cradle. The nest is a mere flooring of twigs put together in a zig-zag form, then blended with green weeds or leaves and withered blossoms of the maple, apple, or hickory catkins. A nest near the Botanic Garden had, besides twigs, fragments of bass-mat, and was very uncomfortably heated, and damp with the fermentation of the green tops of a species of maple introduced into it, and the whole swarmed with thrush-lice or millipedes. The eggs are of a bluish-green color, often pale, varying in the shade and without spots; they are somewhat round and rather large. If they are handled before the commencement of incubation, the owner generally forsakes the nest, but is very tenacious and affectionate towards her young, and sits so close as almost to allow of being taken off by the hand. She then frequently precipitates herself to the ground, fluttering, tumbling, and feigning lameness, in the manner of many other affectionate and artful birds, to draw the intruder away from the premises of her brood. At such times the mother also adds to the contrivance by uttering most uncouth and almost alarming guttural sounds, like quà quàh gwaih, as if choking, as she runs along the ground. While the female is thus dutifully engaged in sitting on her charge, the male takes his station at no great distance, and gives alarm by his notes at the approach of any intruder; and when the young are hatched, both unite in the labor of providing them with food, which, like their own, consists chiefly of the hairy caterpillars, rejected by other birds, 
that so commonly infest the apple-trees, and live in communities within a common silky web. They also devour the large yellow cockchafer, Carabi, and other kinds of insects, as well as various sorts of berries; but their worst propensity is the parasitic habit of sucking the eggs of other birds, thus spreading ruin and dismay wherever they approach. They hatch several broods in a season, and I have seen a nest with eggs in it as late as the 28 th of August ! - though they usually take their departure in some part of the month of September. Considering the time they are engaged in breeding, they raise but few young, appearing to be improvident nurses and bad nestmakers, so that a considerable part of their progeny are either never hatched, or perish soon after. These birds are greatly attached to places where small birds resort, for the sake of sucking their eggs; and I have found it difficult at times to eject them, as when their nests are robbed, without much concern they commence again in the same vicinity, but adding caution to their operations in proportion to the persecution they meet with. In this way, instead of their exposing the nest in some low bush, I have with difficulty met with one at least in a tall larch, more than fifty feet from the ground. When wholly routed, the male kept up a mournful kóre kow kŏw for several days, appearing now sensible by experience of his own predatory practices.

Careless in providing comfort for her progeny, the American Cuckoo, like that of Europe, seems at times inclined to throw the charge of her offspring on other birds. Approaching to this habit, I have found an egg of the Cuckoo in the nest of a Catbird; yet though the habitation was usurped, the intruder probably intended to hatch her own eggs. At another time, on the $5^{\text {th }}$ of June, I 830 , I saw a Robin's nest with two eggs in it indented and penetrated by the bill of a bird, and the egg of a Cuckoo deposited in the same nest. Both birds forsook the premises, so that the object of this forcible entry was not ascertained, - though the mere appropriation of the nest would seem to have been the intention of the Cuckoo. 
This Cuckoo occurs throughout this Faunal Province north to New Brunswick, its breeding area extending south to Florida. Nuttall has not mentioned one peculiar habit of this bird, - that of laying eggs at such long intervals that young in very different stages of maturity are frequently found in the same nest, as also young birds and partially incubated eggs. The practice of laying its eggs in the nests of other birds is seldom indulged in, - indeed, the known instances are extremely rare.

\section{BLACK-BILLED CUCKOO.}

\section{RAIN CROW.}

\section{COCCYZUS ERYTHROPHTHALMUS.}

Char. Above, olive brown with a slight metallic gloss, tinged with ash toward the bill; wings slightly tinged with rufous; tail similar to back, outer feathers slightly tinged with gray, narrowly tipped with white. Beneath, white, tinged on the throat with pale buff. Bill black. Length about 12 inches.

Nest. On the edge of a swampy wood, usually in a retired situation placed generally in a low bush; made of twigs, strips of bark, moss, and catkins. Similar to the nest of the Yellow-billed, but somewhat firmer and more artistic.

Esgs. 2-6 (usually 4); deep glaucous green; r.10 $\times 0.80$.

This species, so nearly related to the preceding, is also equally common throughout the United States in summer, and extends its migrations about as far as the line of Nova Scotia or Newfoundland. This kind also exists in the island of St. Domingo and Guiana, and the birds which visit us probably retire to pass the winter in the nearest parts of tropical America. They arrive in Massachusetts later than the Yellowbilled Cuckoo, and the first brood are hatched here about the $4^{\text {th }}$ of June. In Georgia they begin to lay towards the close of April. Their food, like that of the preceding species, also consists of hairy caterpillars, beetles, and other insects, and even minute shell-fish. They also, like many birds of other orders, swallow gravel to assist digestion.

They usually retire into the woods to breed, being less familiar than the former, choosing an evergreen bush or sapling for the site of the nest, which is made of twigs pretty well 
put together, but still little more than a concave flooring, and lined with moss occasionally, and withered catkins of the hickory. The female sits very close on the nest, admitting a near approach before flying; the young, before acquiring their feathers, are of a uniform bright grayish blue; at a little distance from the nest the male keeps up the usual rattling call of kow kow kow kow, the note increasing in loudness and quickness; sometimes the call seems like $k h$ ' $k h$ ' $k h$ ' $k h$ ' ' $k h$ ' $k a h$, the notes growing louder, and running together like those of the Yellow-winged Woodpecker. This species has also, before rain, a peculiar call, in a raucous, guttural voice, like orrattotoo or worrattotoo. It is less timorous than the Yellowbilled kind; and near the nest with young, I have observed the parent composedly sit and plume itself for a considerable time without showing any alarm at my presence. It is equally addicted to the practice of sucking the eggs of other birds. Indeed, one that I saw last summer, kept up for hours a constant watch after the eggs of a Robin sitting in an apple-tree, which, with her mate, kept up at intervals a running fight with the Cuckoo for two days in succession.

This species is considered less abundant than the Yellow-billed, but it has much the same general distribution; it goes, however, farther north, having been taken in Newfoundland and Labrador, and is common in Manitoba, where the Yellow-billed is not found. The Black-billed is rather common in New Brunswick and Nova Scotia and throughout New England.

\section{MANGROVE CUCKOO.}

CocCYzus MINOR.

CHAR. Above, olive; head, ashy; below, buff with tawny tinge, paler towards the chi .; middle tail-feather olive, rest black, broadly tipped with white. Length 12 inches.

Nest. In a low tree or bush; loosely made of twigs.

Eggs. 3-4; pale green or bluish green; $1.25 \times 0.90$.

The Mangrove Cuckoo is especially a West Indian bird, but is a resident also of the Florida Keys, though not common there. A few examples have been met with in Louisiana. 
NOTE. - MAYNARD'S CUCKoo (C. minor maynardi), a smaller race, with paler lower parts, is found in the Bahama islands and in Southern Florida.

Note. - Nuttall made no mention in his book of the ANI (Crotophaga ani), a South American bird that had been found in Louisiana and Florida. It was but a straggler within the borders of the United States in his day, and is still considered a rare bird here. A few years ago one was taken near Philadelphia by Mr. John Krider.

\section{FLICKER.}

GOLDEN-WINGED WOODPECKER. PIGEON WOODPECKER. HIGH-HOLDER.

\section{COlaptes aUratus.}

CHAR. Male : above, olive brown barred with black; crown and sides of neck bluish gray; red crescent on nape; "moustache" black; rump white; beneath, pale brown with pink and yellow tints, each feather bearing a spot of black; breast with conspicuous black crescent; shafts and under surface of wings and tail golden yellow. Female : similar, but without the black "moustache." Length about $121 / 2$ inches.

Nest. In open woodland, pasture, or orchard; a cavity excavated in dead trunk, and unlined save for the fine chips made by the boring.

Eggs. 6-10 (usually 2 or 7); snow white, with surface like highly polished ivory; $1.10 \times 0.90$.

This beautiful and well-known bird breeds and inhabits throughout North America, from Labrador and the remotest wooded regions of the fur countries to Florida, being partially migratory only from Canada and the Northern States, proceeding to the South in October, and returning North in April. From the great numbers seen in the Southern States in winter it is evident that the major part migrate thither from the North and West to pass the inclement season, which naturally deprives them of the means of acquiring their usual sustenance. At this time also they feed much on winter berries, such as those of the sumach, smilax, and mistletoe. In the Middle States some of these birds find the means of support through the most inclement months of the winter. In New England they reappear about the beginning of April, soon after which 


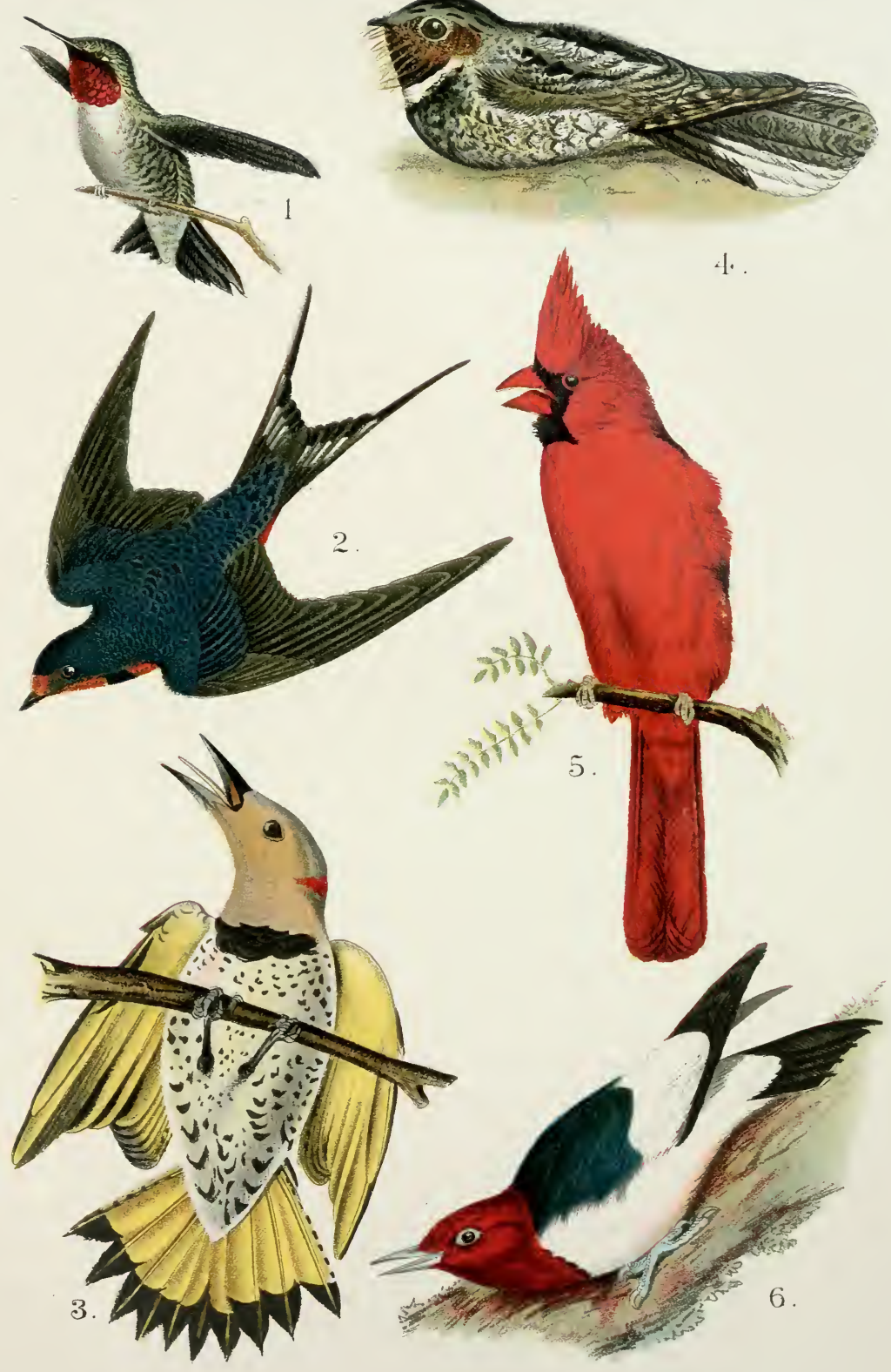

1. Rubr-Throated Hummingbird. 4. Thip-Poor-Will .
2. Barn Swallow.
5. Cardinal.
3. Flicker.
6. Red-Headed Woodpecker. 

they commence to pair and build; for this purpose they often make choice of the trunk of a decayed apple or forest tree, at different heights from the ground. When an accidental cavity is not conveniently found, confident in the formidable means provided them by nature, with no other aid than the bill, they have been known to make a winding burrow through a solid oak for 15 inches in length. At this labor, for greater security and privacy, they continue till late in the evening, and may be heard dealing blows as loud and successive as if aided by the tools of the carpenter. My friend Mr. Gambel observed the present spring (1840) a burrow of this kind in Cambridge, excavated out of the living trunk of a sassafras about 15 feet from the ground. It was about 8 inches in diameter and 18 inches deep, dug with a shelving inclination; and was continued at intervals for more than 4 weeks before it was completed. The eggs, about 6 , and pure white, are deposited merely upon the fragments of wood which line the natural or artificial cavity thus forming the nest. This cell, before the young are fledged, acquires a rank and disagreeable smell; and on inserting the hand into it, the brood unite in producing a hissing, like so many hidden snakes. They at length escape from this fetid den in which they are hatched; and climbing sometimes into the higher branches of the tree, are there fed until able to fly. At other times the young cling to their protecting cell with great pertinacity, so that the female will often call upon them for hours together (queàh queà $h)$, trying every art to induce them to quit their cradle, punishing them by fasting, till at length they are forced to come out and answer to her incessant plaint. If not disturbed, they will occasionally approach the farm-house; and I have known a pair, like the Bluebirds, repair to the same hole in a poplar-tree for several years in succession, merely cleaning out the old bed for the reception of their eggs and young. They incubate by turns, feeding each other while thus confined to the nest, and are both likewise equally solicitous in feeding and protecting their young; the food on this occasion is raised often from the throat, where it has undergone a preparatory 
process for digestion. In the month of March, in Florida and Alabama, I observed them already pairing, on which occasion many petulant quarrels daily ensued from a host of rival suitors, accompanied by their ordinary cackling and squealing. One of their usual complaisant recognitions, often delivered on a fine morning from the summit of some lofty dead limb, is 'wit a 'wit' 'wit 'wit 'wit 'wit'wit weet and woit a woit, woit woit woit woit, commencing loud, and slowly rising and quickening till the tones run together into a noise almost like that of a watchman's rattle. They have also a sort of complaining call, from which they have probably derived their name of pee ìt, pee ùt; and at times a plaintive quéàh quéàh. Occasionally they also utter in a squealing tone, when surprised, or engaged in amusing rivalry with their fellows, we-coggh we-cŏgh we-cŏgh we-cŏgh or wecйр wecŭp wecŭp.

The food of these birds varies with the season. They are at all times exceedingly fond of wood-lice, ants, and their larvæ; and as the fruits become mature, they also add to their ample fare common cherries, bird cherries, winter grapes, gumberries, the berries of the red-cedar, as well as of the sumach, smilax, and other kinds. As the maize too ripens, the Flicker pays frequent visits to the field; and the farmer, readily forgetful of its past services, only remembers its present faults, and closing its career with the gun, unthinkingly does to himself and the public an essential injury in saving a few unimportant ears of corn. In this part of New England it is known by the name of Pigeon Woodpecker, from its general bulk and appearance; and, to the disgrace of our paltry fowlers, it is in the autumn but too frequently seen exposed for sale in the markets, though its flesh is neither fat nor delicate. It is exceedingly to be regretted that ignorance and wantonness in these particulars should be so productive of cruelty, devastation, and injurious policy in regard to the animals with whose amusing and useful company Nature has so wonderfully and beneficently favored us. 


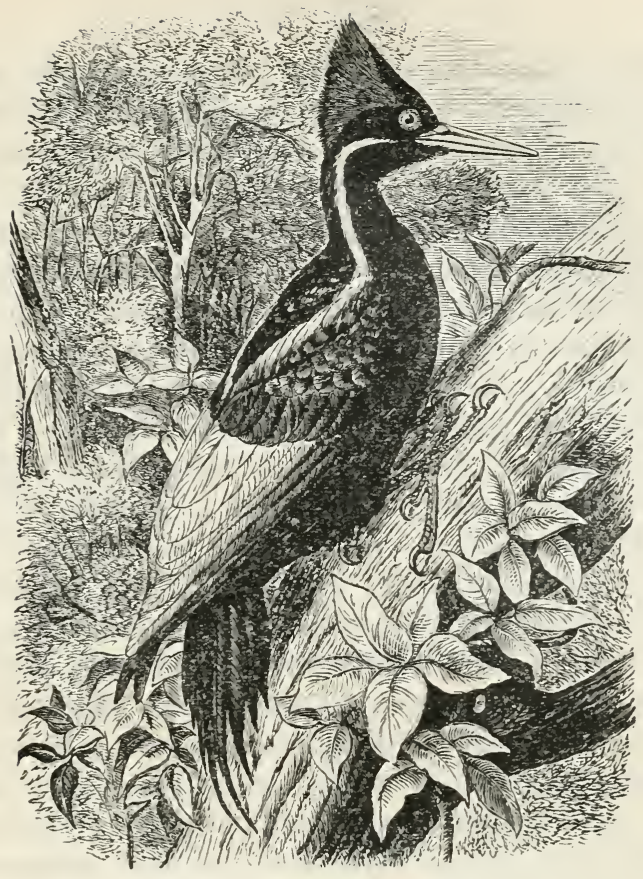

\section{IVORY-BILLED WOODPECKER.}

\section{CAMPEPHILUS PRINCIPALIS.}

CHAR. Glossy black; white stripe from bill down sides of neck; scapulars and secondaries white; bill ivory white. Male with crest of scarlet and black; female with crest of black. Length $2 \mathrm{I}$ inches.

Nest. In a cypress-swamp or deep forest; a cavity excavated in a live tree.

Eggs. 4-6; white; $1.40 \times 1.00$.

This large and splendid bird is a native of Brazil, Mexico, and the Southern States, being seldom seen to the north of Virginia, and but rarely in that State. $\mathrm{He}$ is a constant resident in the countries where he is found, breeding in the rainy season, and the pair are believed to be united for life. More vagrant, retiring, and independent than the rest of his family, he is never found in the precincts of 
cultivated tracts; the scene of his dominion is the lonely forest, amidst trees of the greatest magnitude. His reiterated trumpeting note, somewhat similar to the high tones of the clarinet (pait pait pait pait), is heard soon after day, and until a late morning hour, echoing loudly from the recesses of the dark cypress-swamps, where he dwells in domestic security without showing any impertinent or necessary desire to quit his native solitary abodes. Upon the giant trunk and mossgrown arms of this colossus of the forest, and amidst almost inaccessible and ruinous piles of mouldering logs, the high, rattling clarion and rapid strokes of this princely Woodpecker are often the only sounds which vibrate through and communicate an air of life to these dismal wilds. His stridulous, interrupted call, and loud, industrious blows may often be heard for more than half a mile, and become audible at various distances as the elevated mechanic raises or depresses his voice, or as he flags or exerts himself in his laborious employment. His retiring habits, loud notes, and singular occupation, amidst scenes so savage yet majestic, afford withal a peculiar scene of solemn grandeur on which the mind dwells for a moment with sublime contemplation, convinced that there is no scene in Nature devoid of harmonious consistence. Nor is the performance of this industrious hermit less remarkable than the peals of his sonorous voice or the loud choppings of his powerful bill. $\mathrm{He}$ is soon surrounded with striking monuments of his industry; like a real carpenter (a nick-name given him by the Spainards), he is seen surrounded with cartloads of chips and broad flakes of bark which rapidly accumulate round the roots of the tall pine and cypress where he has been a few hours employed; the work of half a dozen men felling trees for a whole morning would scarcely exceed the pile he has produced in quest of a single breakfast upon those insect larvæ which have already, perhaps, succeeded in deadening the tree preparatory to his repast. Many thousand acres of pine-trees in the Southern States have been destroyed in a single season by the insidious attacks of insects which in the dormant state are not larger than a grain of rice. It 
is in quest of these enemies of the most imposing part of the vegetable creation that the industrious and indefatigable Woodpecker exercises his peculiar labor. In the sound and healthy tree he finds nothing which serves him for food.

One of these birds, which Wilson wounded, survived with him nearly three days, but was so savage and unconquerable as to refuse all sustenance. When taken, he reiterated a loud and piteous complaint, almost exactly like the violent crying of a young child; and on being left alone in a tavern, in the course of an hour he had nearly succeeded in making his way through the side of the wooden house. He also cut the author severely in several places while engaged in drawing his portrait, and displayed, as long as he survived, the unconquerable spirit of a genuine son of the forest. From his magnanimous courage and ardent love of liberty, the head and bill are in high esteem among the amulets of the Southern Indians.

The nest of this species is usually made in the living trunk of the cypress-tree at a considerable height, both sexes alternately engaging in the labor. The excavation is said to be two or more feet in depth. The young are fledged and abroad about the middle of June. It is usually known by the name of "Large Log-cock." This species appears to live almost wholly upon insects, and chiefly those that bore into the wood, which never fail in the country he inhabits; nor is he ever known to taste of Indian corn or any sort of grain or orchard fruits, though he has a fondness for grapes and other kinds of berries.

This species is now restricted to the Gulf States and lower Mississippi valley. 


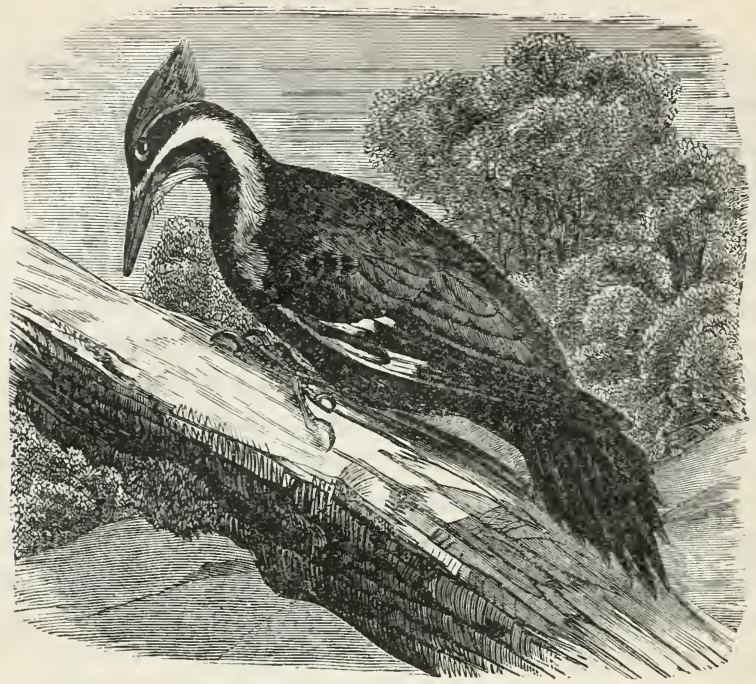

\section{PILEATED WOODPECKER.}

\section{LOG-COCK. BLACK WOODCOCK.}

\section{Ceophleus pileatus.}

CHaR. General color greenish black; wide stripe of white from the bill down the sides of the neck; chin, throat, and part of wings white or pale yellow. Male with scarlet crown, crest, and cheek patch. Female with crest partly black and no scarlet on cheek. Length about 18 inches.

Nest. In a deep forest or the seclusion of a swampy grove; excavated in high trees, and lined only with fine chips.

Eggs. 4-6; snow white and glossy; $1.25 \times$ 1.00.

This large and common Woodpecker, considerably resembling the preceding species, is not unfrequent in well-timbered forests from Mexico and Oregon to the remote regions of Canada, as far as the 63 d degree of north latitude ; and in all the intermediate region he resides, breeds, and passes most of the year, retiring in a desultory manner only into the Southern States for a few months in the most inclement season from the North and West. In Pennsylvania, however, he is seen as a resident more or less throughout the whole year; and Mr. 
Hutchins met with him in the interior of Hudson Bay, near Albany River, in the month of January. It is, however, sufficiently singular, and shows perhaps the wild timidity of this northern chief of his tribe, that though an inhabitant towards the s.rvage and desolate sources of the Mississippi, he is unknown at this time in all the maritime parts of the populous and long-settled State of Massachusetts. In the western parts of the State of New York he is sufficiently common in the uncleared forests, which have been the perpetual residence of his remotest ancestry. From the tall trees which cast their giant arms over all the uncleared river lands, may often be heard his loud, echoing, and incessant cackle as he flies restlessly from tree to tree, presaging the approach of rainy weather. These notes resemble ekerek rek rek rek rek rek rek uttered in a loud cadence which gradually rises and falls. The marks of his industry are also abundantly visible on the decaying trees, which he probes and chisels with great dexterity, stripping off wide flakes of loosened bark to come at the burrowing insects which chiefly compose his food. In whatever engaged, haste and wildness seem to govern all his motions, and by dodging and flying from place to place as soon as observed, he continues to escape every appearance of danger. Even in the event of a fatal wound he still struggles with unconquerable resolution to maintain his grasp on the trunk to which he trusts for safety to the very instant of death. When caught by a disabling wound, he still holds his ground against a tree, and strikes with bitterness the suspicious hand which attempts to grasp him, and, resolute for his native liberty, rarely submits to live in confinement. Without much foundation, he is charged at times with tasting maize. I have observed one occasionally making a hearty repast on holly and smilax berries.

This species is being driven back by "civilization," and is now found only in the deeper forests. Mr. William Brewster reports that a few pairs still linger in the northern part of Worcester County, Mass. 


\section{RED-HEADED WOODPECKER.}

\section{MELANERPES ERYTHROCEPHALUS.}

CHAR. Back, tail, and primaries blue black; head, neck, and breast crimson; belly, rump, and secondaries white. Length 9 to $9 \frac{1}{2}$ inches.

Nest. In woodland, pasture, or orchard; usually a cavity in a decayed tree.

Eggs. 4-6; glossy white; $1.00 \times 0.80$.

This common and well-known species is met with along the coast from Nova Scotia to the Gulf of Mexico, and inland in the region of the Rocky Mountains and about the sources of the Mississippi. In all the intermediate country, however extensive, it probably resides and breeds. At the approach of winter, or about the middle of October, these birds migrate from the North and West, and consequently appear very numerous in the Southern States at that season. Many of them also probably pass into the adjoining provinces of Mexico, and they reappear in Pennsylvania (according to Wilson) about the first of May. According to Audubon, they effect their migration in the night, flying high above the trees in a straggling file, at which time they are heard to emit a sharp and peculiar note, easily heard from the ground, although the birds themselves are elevated beyond the sight. Like the Log-cock, the present species is but rarely seen in the maritime parts of Massachusetts; this region is only occasionally visited by solitary stragglers, yet in the western parts of the State it is said to be as common as in the Middle States.

These birds live principally in old forests of tall trees, but are much less shy than most of the genus, frequently visiting the orchards in quest of ripe fruits, particularly cherries and juicy pears and apples, with which they likewise occasionally feed their young. They also at times eat acorns, of which they are said to lay up a store, and visit the maize-fields, being partial to the corn while in its juicy or milky state. In consequence of these dependent habits of subsistence, the Red-headed Woodpecker is a very familiar species, and even sometimes 
not only nests in the orchard which supplies him with sustenance, but ventures to rear his brood within the boundaries of the most populous towns. In the latter end of summer its reiterated tappings and cackling screams are frequently heard from the shady forests which border the rivulets in more secluded and less fertile tracts. It is also not uncommon to observe them on the fence-rails and posts near the public roads, flitting before the passenger with the familiarity of Sparrows. In the Southern States, where the mildness of the climate prevents the necessity of migration, this brilliant bird seems half domestic. The ancient live-oak, his cradle and residence, is cherished as a domicile; he creeps around its ponderous weathered arms, views the passing scene with complacence, turns every insect visit to his advantage, and for hours together placidly reconnoitres the surrounding fields. At times he leaves his lofty citadel to examine the rails of the fence or the boards of the adjoining barn; striking terror into his lurking prey by the stridulous tappings of his bill, he hearkens to their almost inaudible movements, and discovering their retreat, dislodges them from their burrows by quickly and dexterously chiselling out the decaying wood in which they are hid, and transfixing them with his sharp and barbed tongue. But his favorite and most productive resort is to the adjoining fields of dead and girdled trees, amidst whose bleaching trunks and crumbling branches he long continues to find an ample repast of depredating and boring insects. When the cravings of appetite are satisfied, our busy hunter occasionally gives way to a playful or quarrelsome disposition, and with shrill and lively vociferations not unlike those of the neighboring tree-frog, he pursues in a graceful, curving flight his companions or rivals round the bare limbs of some dead tree to which they resort for combat or frolic.

About the middle of May, in Pennsylvania, they burrow out or prepare their nests in the large limbs of trees, adding no materials to the cavity which they smooth out for the purpose. As with the Bluebird, the same tree continues to be employed for several years in succession, and probably by the same undi- 
vided pair. The eggs and young of this and many other birds occasionally fall a prey to the attacks of the common black snake. The young are easily tamed for a while, and when left at large come for some time regularly to be fed, uttering a cry to call attention. I have seen them feed on corn-meal paste, a large piece of which the bird would carry off to a distance and eat at leisure.

This species is common in Ontario and near Montreal, but is only an accidental visitor to other portions of eastern Canada. It is usually a rare bird to the eastward of the Hudson River, though it is said to be rather common in Western Vermont, and in the fall of 1881 it was quite common in other parts of New England.

The habit of this bird - in common with others of the family -to store nuts and grain for winter use, briefly alluded to by Nuttall, has been confirmed frequently by recent observers. An interesting paper on this subject by O. P. Hay appeared in the "Auk" for July, I 887 .

\section{RED-BELLIED WOODPECKER.}

\section{Melanerpes Carolinus.}

CHAR. Above, black and white in narrow bands; tail black and white; beneath, pale buff; belly rosy red. Male, with crown and back of head scarlet, which in the female is replaced by dull ash.

Nest. Usually in a secluded forest of tall trees; a cavity cut in a dead trunk or limb.

Eggs. 4-6; white and glossy; $1.00 \times 0.75$.

This species inhabits the whole North American continent, from the interior of Canada to Florida, and even the island of Jamaica, in all of which countries it probably rears its young, migrating only partially from the colder regions. This also, like the preceding, is unknown in all the eastern parts of Massachusetts, and probably New Hampshire.

The Red-bellied Woodpecker dwells in the solitude of the forest; amidst the tall and decayed trees only he seeks his less varied fare, and leads a life of roving wildness and independence, congenial with his attachment to freedom and liberty. Sometimes, however, on the invasion of his native haunts by 
the progress of agriculture, he may be seen prowling among the dead and girdled trees which now afford him an augmented source of support; and, as a chief of the soil, he sometimes claims his native rights by collecting a small tithe from the usurping field of maize. His loud and harsh call of 'tshoze 'tshow 'tshow 'tshow, reiterated like the barking of a cur, may often be heard, through the course of the day, to break the silence of the wilderness in which his congenial tribe are almost the only residents. On a fine spring morning I have observed his desultory ascent up some dead and lofty pine, tapping at intervals, and dodging from side to side, as he ascended in a spiral line; at length, having gained the towering summit, while basking in the mild sunbeams, he surveys the extensive landscape, and almost with the same reverberating sound as his blows, at intervals he utters a loud and solitary 'cur'rh in a tone as solemn as the tolling of the Campanero. $\mathrm{He}$ thus hearkens, as it were, to the shrill echoes of his own voice, and for an hour at a time seems alone employed in contemplating, in cherished solitude and security, the beauties and blessings of the rising day.

The nest, early in April, is usually made in some lofty branch; and in this labor both the sexes unite to dig out a circular cavity for the purpose, sometimes out of the solid wood, but more commonly into a hollow limb. The young appear towards the close of May or early in June, climbing out upon the higher branches of the tree, where they are fed and reared until able to fly, though in the mean time from their exposure they often fall a prey to prowling Hawks. These birds usually raise but one brood in the season, and may be considered, like the rest of their insect-devouring fraternity, as useful scavengers for the protection of the forest ; their attacks, as might be reasonably expected, being always confined to decaying trees, which alone afford the prey for which they probe.

This bird's breeding area lies between Florida and Maryland and northward through the interior to Southern Ontario, where it is quite common.

VOL. I. -29 


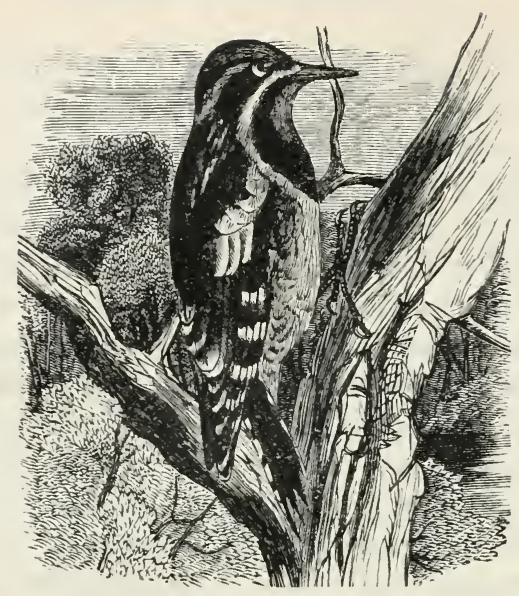

\section{YELLOW-BELLIED SAPSUCKER.}

\section{SPHYRAPICUS VARIUS.}

Char. Above, black and white, back tinged with yellow; crown and chin scarlet, bordered by black; cheeks black, bordered by white or pale yellow; breast black; belly pale yellow. In females the scarlet on chin is replaced by white. Length $81 / 2$ inches.

Nest. In woodland; a cavity in a dead trunk of large tree; sometimes excavated in a live tree.

Eggs. 4-7; white; $0.85 \times 0.60$.

This species, according to the season, extends over the whole American continent, from the $53 \mathrm{~d}$ degree to the tropics, where it is seen in Cayenne. With us it is most common in summer in the Northern and Middle States, and as far north as Nova Scotia. At this season it is seldom seen beyond the precincts of the forest, in which it selects the most solitary recesses, leaving its favorite haunts only at the approach of winter, and seeking, from necessity or caprice, at this roving season the boundaries of the orchard. The habits of this bird are but little different from those of the Hairy and Downy Woodpeckers, with which it is often associated in their foraging excursions. The nest, as usual, is made in the body of some decayed orchard or forest tree, the circular entrance to 
which is left only just sufficient for the passage of the parties. The depth of the cavity is about ${ }_{5}$ inches, and the eggs, 4 or upwards, are white. The principal food of these birds is insects, for they sometimes bore the trunks of the orchard trees.

The "sapsucking" habit of this species, denied by some of our most eminent naturalists, has been established by Mr. Frank Bolles, who published an interesting account of his observations in "The Auk" for July, i 89i.

For several days Mr. Bolles almost continuously watched a number of these birds while they operated on trees in the vicinity of his summer home at Chicarua, N. H. The birds drilled holes in maple, oak, birch, and ash trees, and drank the sap as it dripped from these holes. When one set of holes became "dry," others were drilled, eight to sixteen on each tree, the new holes being made higher up than the old. Some of the birds spent about nine tenths of the time in drinking the sap. Mr. Bolles placed under the trees cups made of birch bark and filled with maple syrup, which the birds drank freely. Later brandy was added, with amusing consequences, the mixture finally acting as an emetic. $\mathrm{He}$ moreover states that the sap was not used as a trap for insects, as some writers have supposed; and while the birds caught insects occasionally, these did not appear to form a large part of their diet. An examination of the stomachs of a few birds revealed but little insect remains, and that little was composed chiefly of ants.

\section{HAIRY WOODPECKER.}

\section{DRyobates VILLOSUS.}

CHAR. Above, black and white, the back with long, slender, loose hair-like feathers; beneath, white; outer tail-feathers white. Male with scarlet band at back of head, which in the female is black. In immature birds the crown is more or less tinged with red, or, sometimes with yellow. Length $8 \frac{1}{2}$ to 9 inches.

Nest. In open woodland, pasture, or orchard; a cavity in a dead trunk, without lining.

Eggs. $4-5$; white and glossy; $1.00 \times 0.70$.

This common and almost familiar species is a resident in most parts of America, from Hudson Bay to Florida, fre- 
quently approaching the cottage or the skirts of the town as well as the forest. It is likewise much attached to orchards, an active borer of their trunks, and an eager hunter after insects and larvæ in all kinds of decayed wood, even to stumps and the rails of the fences. In autumn it also feeds on berries and other fruits. In the month of May, accompanied by his mate, the male seeks out the seclusion of the woods, and taking possession of a hollow branch, or cutting out a cavity anew, he forms his nest in a deep and secure cavern, though sometimes a mere stake of the fence answers the purpose. In the Southern States these birds have usually two broods in the season, and raise them both in the same nest, which is not infrequently at no great distance from habitations. Their call consists in a shrill and rattling whistle, heard to a considerable distance. They also give out a single querulous note of recognition while perambulating the trunks for food.

The habitat of true villosus is now considered as restricted to North Carolina and Eastern Canada. At the Northwest it is represented by $D$. villosus leucomelas, a larger variety (length to to I I inches), and at the South by $D$. villosus audubonii, which measures about 8 inches in length.

\section{DOWNY WOODPECKER.}

\section{DRYOBATES PUBESCENS.}

Char. Similar to $D$. villosus, but smaller. Above, black and white, the back with long, slender, loose hair-like ("downy") feathers; beneath, white; outer tail-feathers barred. Male with scarlet band at back of head, which in the female is black. In immature birds the crown is more or less tinged with red, or, sometimes, with yellow. Length $6 \frac{1}{2}$ to 7 inches.

Nest. In open woodland, pasture, or orchard; a cavity in a dead trunk, without lining.

Eggs. 4-6; white and glossy; $0.80 \times 0.60$.

This species, the smallest of American Woodpeckers, agrees almost exactly with the $P$. villosus in its colors and markings. It is likewise resident throughout the same countries. About 
the middle of May also, the pair begin to look out a suitable deposit for their eggs and young. The entrance is in the form of a perfect circle, and left only just large enough for an individual to pass in and out. Both sexes labor for about a week at this task with indefatigable diligence, carrying on the burrow in some orchard tree, in two different directions, to the depth of 16 to 20 inches down; and to prevent suspicion the chips are carried out and strewn at a distance. The male occasionally feeds his mate while sitting; and about the close of June the young are observed abroad, climbing up the tree with considerable address. Sometimes the crafty House Wren interferes, and, driving the industrious tenants from their hole, usurps possession. These birds have a shrill cackle and a reiterated call, which they frequently utter while engaged in quest of their prey. In the autumn they feed on various kinds of berries as well as insects. No species can exceed the present in industry and perseverance. While thus regularly probing the bark of the tree for insects, it continues so much engaged as to disregard the approaches of the observer, though immediately under the tree. These perforations, made by our Sapsuckers, - as the present and Hairy species are sometimes called, - are carried round the trunks and branches of the orchard trees in regular circles, so near to each other that, according to Wilson, eight or ten of them may be covered by a dollar. The object of this curious piece of industry is not satisfactorily ascertained; but whether it be done to taste the sap of the tree, or to dislodge vermin, it is certain that the plant escapes uninjured, and thrives as well or better than those which are unperforated.

This diminutive and very industrious species is a constant inhabitant of the fur countries up to the $5^{8 \text { th }}$ parallel, seeking its food principally on the maple, elm, and ash, and north of latitude 54 degrees, where the range of these trees terminates, on the aspen and birch. The circles of round holes which it makes with so much regularity round the trunks of living trees are no doubt made for the purpose of getting at the sweet sap which they contain. In the month of February, I830, I 
observed these borers busy tapping the small live trunks of several wax-myrtles (Myrica cerifera); and these perforations were carried down into the alburnum, or sap-wood, but no farther : no insects could be expected, of course, in such situations, and at this season very few could be obtained anywhere. On examining the oozing sap, I found it to be exceedingly saccharine, but in some instances astringent or nearly tasteless. To a bird like the present, which relishes and devours also berries, I make no doubt but that this native nectar is sought after as agreeable and nutritious food, in the same manner as the Baltimore Bird collects the saccharine secretion of the fruit blossoms; and in fact I have observed the Woodpecker engaged in the act of sipping this sweet fluid, which so readily supplies it on all occasions with a temporary substitute for more substantial fare. Sometimes, however, on discovering insects in a tree, it forgets its taste for the sap, and in quest of its prey occasionally digs deep holes into the trees large enough to admit its whole body.

The Downy Woodpecker is found throughout the eastern and northern portions of North America, and like its congener, the Hairy, is a resident, rather than a migratory species, breeding usually wherever it is found. There is no such difference in the two birds as is represented by the names "hairy" and "downy;" the long feathers of the back from which the names are derived are exactly similar. The differentiation lies in the size of the birds and in some markings on the tail-feathers.

\section{THE RED-COCKADED WOODPECKER.}

\section{DRYOBATES BOREALIS.}

CHAR. Above, black and white, barred transversely; crown, black; sides of head with white patch, bordered, above, by red stripe; beneath, white, sides streaked with black. Length $7^{1 / 2}$ to $8 \frac{1}{2}$ inches.

Nest. In pine woods; an excavation in a decayed trunk or living tree.

Eggs. 4-6; white, with but little gloss; $0.95 \times 0.70$.

This species, remarkable for the red stripe on the side of its head, was discovered by Wilson in the pine woods of 
North Carolina, whence it occurs to the coast of the Mexican Gulf, and as far to the north and west as New Jersey and Tennessee. It is a very active and noisy species, gliding with alertness along the trunks and branches of trees, principally those of oak and pine. At almost every move it utters a short, shrill, and clear note, audible at a considerable distance. In the breeding season its call, still more lively and petulant, is reiterated through the pine forests, where it now chiefly dwells. These birds are frequently seen by pairs in the company of the smaller Woodpeckers and Nuthatches in the winter season, and they now feed by choice principally upon ants and small coleoptera.

In Florida they are already mated in the month of January, and prepare their burrows in the following month. The nest is frequently in a decayed trunk 20 to 30 feet from the ground. In the winter season, and in cold and wet weather, this bird is in the habit of roosting in its old nests or in the holes of decayed trees, and frequently retreats to such places when wounded or pursued.

The habitat of this species as at present determined is the Southeastern States, including North Carolina and Tennessee, and Westward to Indian Territory.

\section{ARCTIC THREE-TOED WOODPECKER.}

BLACK-BACKED WOODPECKER.

PiCOIDES ARCTICUS.

Char. Only three toes. Above, black; white stripe on side of head; outer tail-feathers white; beneath, white barred with black. Adult male with square patch of yellow on the crown. Length $9 \frac{1}{2}$ to ro inches.

Nest. In a deep forest, an excavation in a dead tree.

Eggs. 4-6; white and glossy; $0.95 \times 0.75$.

This species is an inhabitant of the northern regions from Maine to the fur countries, dwelling among deep forests in mountainous regions. Its voice and habits are indeed precisely similar to those of the Spotted Woodpeckers, to which it 
is closely allied. Its food consists of insects, their eggs and larvæ, to which it sometimes adds, according to the season, seeds and berries. Audubon had the good fortune to meet with it in the pine forests of the Pokono Mountains in Pennsylvania. It is, however, sufficiently common in the dreary wilds around Hudson Bay and Severn River. It is remarkable that a third species, so nearly allied to the present as to have been confounded with it merely as a variety, is found to inhabit the woods of Guiana. In this (the Picus undulatus of Vieillot) the crown, however, is red instead of yellow; the tarsi are also naked, and the black of the back undulated with white.

This species occurs somewhat sparingly in winter in northern New England and southern Canada, and sometimes wanders in numbers to Massachusetts, Connecticut, and New York State. Occasionally one is met in summer in northern Maine and New Brunswick.

\section{AMERICAN THREE-TOED WOODPECKER.}

BANDED-BACKED WOODPECKER.

\section{PicoIdes AMERICANUS.}

CHAR. Only three toes. Above, black, thickly spotted with white about the head and neck; back barred with white; beneath, white; sides barred with black. Adult male with yellow patch on the crown. Length about 9 inches.

Nest. In a deep forest; an excavation in a dead tree.

Eggs. 4- ?; cream white; $0.90 \times 0.70$.

According to Richardson, this bird exists as a permanent resident in all the spruce-forests between Lake Superior and the Arctic Sea, and is the most common Woodpecker north of Great Slave Lake. It resembles $P$. villosus in its habits, seeking its food, however, principally on decaying trees of the pine tribe, in which it frequently burrows holes large enough to bury itself.

This is an uncommon winter visitor as far south as northern New England, though it has been taken in Massachusetts, and Dr. Merriam has found a nest in the Adirondacks. 


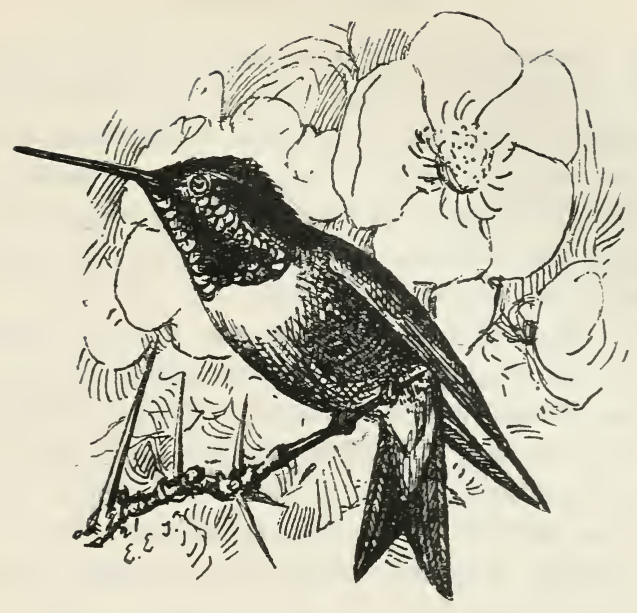

\section{RUBY-THROATED HUMMINGBIRD.}

\section{Trochilus COLUBRIS.}

CHAR. Above, metallic green; wings and tail brownish violet or bronzy; chin velvety black; throat rich ruby, reflecting various hues from brownish black to bright crimson; belly whitish. Female and young without red on the throat, which is dull gray; tail-fcathers barred with black and tipped with white. Length 3 to $3 \frac{1}{4}$ inches.

Nest. In an orchard or open woodland; placed on a horizontal branch or in a crotch; made of plant down firmly felted and covered exteriorly with lichens.

Eggs. 2-?; white, with rosy tint when fresh; $0.50 \times 0.30$.

This wonderfully diminutive and brilliant bird is the only one of an American genus of more than a hundred species, which ventures beyond the limit of tropical climates. Its approaches towards the north are regulated by the advances of the season. Fed on the honeyed sweets of flowers, it is an exclusive attendant on the varied bounties of Flora. By the Ioth to the 2 oth of March, it is already seen in the mild forests of Louisiana and the warmer maritime districts of Georgia, where the embowering and fragrant Gelsemium, the twin-leaved Bignonia, with a host of daily expanding flowers, invite our little sylvan guest to the retreats it had reluctantly 
forsaken. Desultory in its movements, roving only through the region of blooming sweets, its visits to the Northern States are delayed till the month of May. Still later, as if determined that no flower shall "blush unseen, or waste its sweetness on the desert air," our little sylph, on wings as rapid as the wind, at once launches without hesitation into the flowery wilderness of the north.

The first cares of the little busy pair are now bestowed on their expected progeny. This instinct alone propelled them from their hibernal retreat within the tropics ; strangers amidst their numerous and brilliant tribe, they seek only a transient asylum in the milder regions of their race. With the earliest dawn of the northern spring, in pairs, as it were with the celerity of thought, they dart at intervals through the dividing space, till they again arrive in the genial and more happy regions of their birth. The enraptured male is now assiduous in attention to his mate; forgetful of selfish wants, he feeds his companion with nectared sweets, and jealous of danger and interruption to the sole companion of his delights, he often almost seeks a quarrel with the giant birds which surround him : he attacks even the Kingbird, and drives the gliding Martin to the retreat of his box. The puny nest is now prepared in the long-accustomed orchard or neighboring forest. It is concealed by an artful imitation of the mossy branch to which it is firmly attached and incorporated. Bluish-gray lichens, agglutinated by saliva and matched with surrounding objects, instinctively form the deceiving external coat; portions of the cunning architecture, for further security, are even tied down to the supporting station. Within are laid copious quantities of the pappus or other down of plants; the inner layer of this exquisite bed is finished with the shortwood of the budding Platanus, the mullein, or the soft clothing of unfolding fernstalks. Incubation, so tedious to the volatile pair, is completed in the short space of ten days, and in the warmer States a second brood is raised. When the nest is approached, the parents dart around the intruder, within a few inches of his face; and the female, if the young are out, often resumes her 
seat, though no more than three or four feet from the observer. In a single week the young are on the wing, and in this situation still continue to be fed with their nursing sweets by the assiduous parents:

Creatures of such delicacy and uncommon circumstances, the wondrous sports of Nature, everything appears provided for the security of their existence; the brood are introduced to life in the warmest season of the year: variation of temperature beyond a certain medium would prove destructive to these exquisite forms. The ardent heats of America have alone afforded them support; no region so cool as the United States produces a set of feathered beings so delicate and tender; and, consequently, any sudden extremes, by producing chill and famine, are fatal to our Humming Birds. In the remarkably wet summer of I83 I very few of the young were raised in New England. In other seasons they comparatively swarm, and the numerous and almost gregarious young are then seen, till the close of September, eagerly engaged in sipping the nectar from various showy and tubular flowers, particularly those of the trumpet Bignonia and wild balsam, with many other conspicuous productions of the fields and gardens. Sometimes they may also be seen collecting dimunitive insects, or juices from the tender shoots of the pine-tree. While thus engaged in strife and employment, the scene is peculiarly amusing. Approaching a flower, and vibrating on the wing before it, with the rapidity of lightning the long, cleft, and tubular tongue is exerted to pump out the sweets, while the buzzing or humming of the wings reminds us of the approach of some larger sphinx or droning bee. No other sound or song is uttered, except occasionally a slender chirp while flitting from a flower, until some rival bird too nearly approaches the same plant; a quick, faint, and petulant squeak is then uttered, as the little glowing antagonists glide up in swift and angry gyrations into the air. The action at the same time is so sudden, and the flight so rapid, that the whole are only traced for an instant, like a gray line in the air. Sometimes, without any apparent provocation, the little pugnacious vixen will, for 
mere amusement, pursue larger birds, such as the Yellow Bird and Sparrows. To man they show but little either of fear or aversion, often quietly feeding on their favorite flowers when so nearly approached as to be caught. They likewise frequently enter the green houses and windows of dwellings where flowers are kept in sight. After feeding for a time, the individual settles on some small and often naked bough or slender twig, and dresses its feathers with great composure, particularly preening and clearing the plumes of the wing.

The old and young are soon reconciled to confinement. In an hour after the loss of liberty the cheerful little captive will often come and suck diluted honey, or sugar and water, from the flowers held out to it; and in a few hours more it becomes tame enough to sip its favorite beverage from a saucer, in the interval flying backwards and forwards in the room for mere exercise, and then resting on some neighboring elevated object. In dark or rainy weather it seems to pass the time chiefly dozing on the perch. It is also soon so familiar as to come to the hand that feeds it. In cold nights, or at the approach of frost, the pulsation of this little dweller in the sunbeam becomes nearly as low as in the torpid state of the dormouse; but on applying warmth, the almost stagnant circulation revives, and slowly increases to the usual state.

Near the Atlantic this frail creature nests regularly as far north as the Laurentian hills of Quebec, and breeds in more or less abundance southward to Florida and westward to the Plains. It is an abundant summer resident of the Maritime Provinces.

The fact that insects form a staple diet of these diminutive birds has been satisfactorily proved, though formerly they were supposed to feed entirely on honey. Honey doubtless forms a part of their food, and they also drink freely of the sweet sap which the Woodpeckers draw from the maple and birch.

Another mistake regarding the Humming Birds, - that they never alight while feeding, - has been rectified by several trustworthy observers. The birds have been seen to alight on the leaves of the trumpet-flower while gathering honey, and also to rest on the tapped trees while they leisurely drank of the flowing sap.

The young birds are fed by regurgitation. 


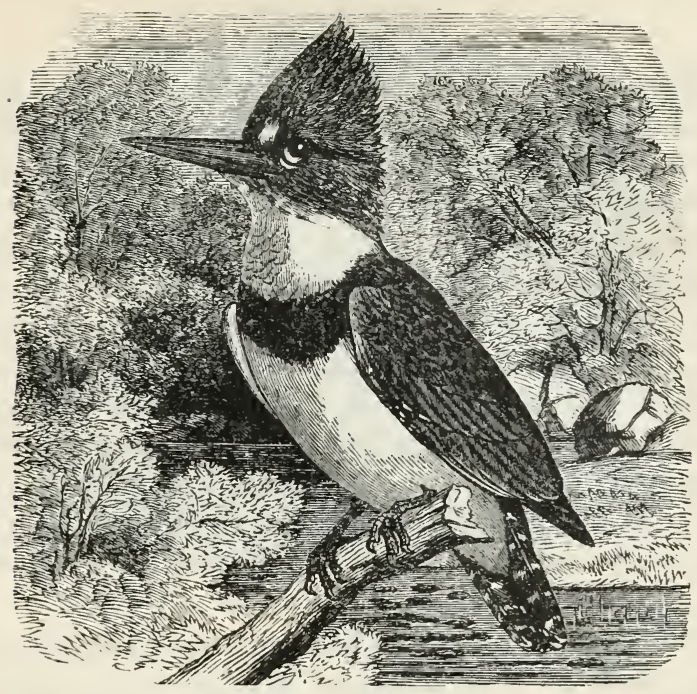

BELTED KINGFISHER.

Ceryle alcyon.

Char. Above, slaty blue; head with long crest; beneath, white. Male with blue band across breast. Female and young with breast-band and sides of belly pale chestnut. Length 12 to 13 inches.

Nest. An excavation in a sandbank, - usually by the side of a stream; lined with grass and feathers.

Eggs. 6-8; white and glossy; 1.35 × r.05.

This wild and grotesque-looking feathered angler is a wellknown inhabitant of the borders of fresh waters from the remote fur countries in the 67 th parallel to the tropics. Its delight is to dwell amidst the most sequestered scenes of uncultivated nature, by the borders of running rivulets, near the roar of the waterfall, or amidst the mountain streamlets which abound with the small fish and insects that constitute its accustomed fare. Mill-dams and the shelving and friable banks of watercourses, suited for the sylvan retreat of its brood, have also peculiar and necessary attractions for our retiring Kingfisher. By the broken, bushy, or rocky banks of 
its solitary and aquatic retreat, this bird may often be seen perched on some dead and projecting branch, scrutinizing the waters for its expected prey. If unsuccessful, it quickly courses the meanders of the streams or borders of ponds just above their surface, and occasionally hovers for an instant, with rapidly moving wings, over the spot where it perceives the gliding quarry; in the next instant, descending with a quick spiral sweep, a fish is seized from the timid fry, with which it returns to its post and swallows in an instant. When startled from the perch, on which it spends many vacant hours digesting its prey, it utters commonly a loud, harsh, and grating cry, very similar to the interrupted creakings of a watchman's rattle, and almost, as it were, the vocal counterpart to the watery tumult amidst which it usually resides.

The nest-a work of much labor - is now burrowed in some dry and sandy or more tenacious bank of earth, situated beyond the reach of inundation. At this task both the parties join with bill and claws, until they have horizontally perforated the bank to the depth of 5 or 6 feet. With necessary precaution, the entrance is only left sufficient for the access of a single bird. The extremity, however, is rounded like an oven, so as to allow the individuals and their brood a sufficiency of room. This important labor is indeed prospective, as the same hole is employed for a nest and roost for many succeeding years. Here the eggs are deposited. Incubation, in which both parents engage, continues for sixteen days; and they exhibit great solicitude for the safety of their brood. The mother, simulating lameness, sometimes drops on the water, fluttering as if wounded, and unable to rise from the stream. The male also, perched on the nearest bough, or edge of the projecting bank, jerks his tail, elevates his crest, and passing to and fro before the intruder, raises his angry and vehement rattle of complaint (Audubon). At the commencement of winter, the frost obliges our humble Fisher to seek more open streams, and even the vicinity of the sea; but it is seen to return to Pennsylvania by the commencement of April. 


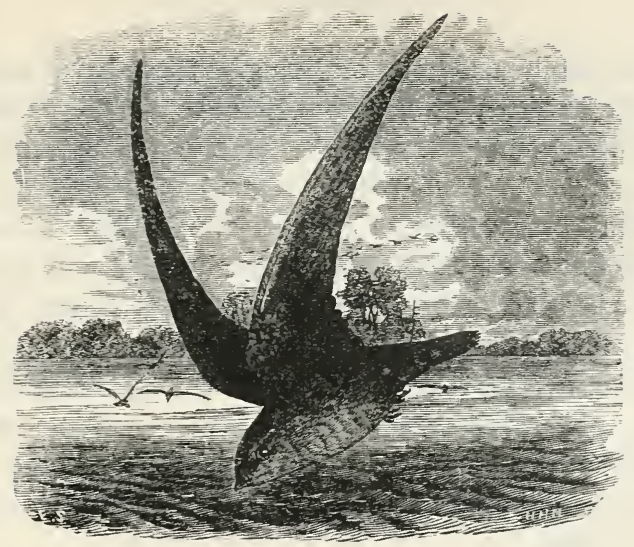

C H I M N EY SWIFT.

CHIMNEY SWALLOW.

ChæTURA PELAGiCA.

CHAR. General color sooty brown, paler on the throat and breast, tinged with green above. Length about $5 \frac{1}{4}$ inches.

Nest. Usually in a chimney, sometimes in a hollow tree or a barn; made of twigs cemented with saliva.

Eggs. 4-5; white; $0.70 \times 0.50$.

This singular bird, after passing the winter in tropical America, arrives in the Middle and Northern States late in April or early in May. Its migrations extend at least to the sources of the Mississippi, where it was observed by Mr. Say. More social than the foreign species, which frequents rocks and ruins, our Swift takes advantage of unoccupied and lofty chimneys, the original roost and nesting situation being tall, gigantic hollow trees such as the elm and buttonwood (Platanus). The nest is formed of slender twigs neatly interlaced, somewhat like a basket, and connected sufficiently together by a copious quantity of adhesive gum or mucilage secreted by the stomach of the curious architect. This rude cradle of the young is small and shallow, and attached at the sides to the wall of some chimney or the inner surface of a hollow 
tree; it is wholly destitute of lining. 'They have commonly two broods in the season. So assiduous are the parents that they feed the young through the greater part of the night; their habits, however, are nearly nocturnal, as they fly abroad most at and before sunrise, and in the twilight of evening. The noise which they make while passing up and down the chimney resembles almost the rumbling of distant thunder. When the nests get loosened by rains so as to fall down, the young, though blind, find means to escape, by creeping up and clinging to the sides of the chimney walls; in this situation they continue to be fed for a week or more. Soon tired of their hard cradle, they generally leave it long before they are capable of flying.

On their first arrival, and for a considerable time after, the males, particularly, associate to roost in a general resort. This situation, in the remote and unsettled parts of the country, is usually a large hollow tree, open at top. These well-known Swallow trees are ignorantly supposed to be the winter quarters of the species, where, in heaps, they doze away the cold season in a state of torpidity; but no proof of the fact is ever adduced. The length of time such trees have been resorted to by particular flocks may be conceived, perhaps, by the account of a hollow tree of this kind described by the Rev. Dr. Harris in his Journal. The Platanus alluded to, grew in the upper part of Waterford, in Ohio, two miles from the Muskingum, and its hollow trunk, now fallen, of the diameter of $5 \mathrm{I} / 2$ feet, and for nearly i 5 feet upwards, contained an entire mass of decayed Swallow feathers, mixed with brownish dust and the exuviæ of insects. In inland towns these birds have been known to make their general roost in the chimney of the court-house. Before descending, they fly in large flocks, making many ample and circuitous sweeps in the air; and as the poirt of the vortex falls, individuals drop into the chimney by degrees, until the whole have descended, which generally takes place in the dusk of the evening. They all, however, disappear about the first week in August. Like the rest of the tribe, the Chimney Swift flies very quick, and with but slight 
vibrations of its wings, appearing as it were to swim in the air in widening circles, shooting backwards and forwards through the ambient space at great elevations, and yet scarcely moving its wings. Now and then it is heard to utter, in a hurried manner, a sound like tsip tstp tsip tsee tsee. It is never seen to alight but in hollow trees or chimneys, and appears always most gay and active in wet and gloomy weather.

Near the Atlantic border this species is found north to $50^{\circ}$, but in the West it ranges still farther northward.

\section{H UCK-WILL'S-W I D OW.}

\section{ANTROSTOMUS CAROLINENSIS.}

Char. Gape extremely wide, the rictal bristles with lateral filaments. General color reddish brown mottled with black, white, and tawny ; throat with collar of pale tawny, terminal third of outer tail-feathers white or buffy; under parts tawny white. Length II to 12 inches.

Nest. In open woods or dense thicket. No attempt is made at building a receptacle for the eggs, which are laid on the bare ground or upon fallen leaves.

Eggs. 2; white or buffish, marked with brown and lavender; 1.40 $\times 1.00$.

The Carolina Goatsucker is seldom seen to the north of Virginia, though in the interior its migrations extend up the shores of the Mississippi to the 38 th degree. After wintering in some part of the tropical continent of America, it arrives in Georgia and Louisiana about the middle of March, and in Virginia early in April. Like the following species, it commences its singular serenade of 'chuck-'will's-widow in the evening soon after sunset, and continues it with short interruptions for several hours. Towards morning the note is also renewed until the opening dawn. In the day, like some wandering spirit, it retires to secrecy and silence, as if the whole had only been a disturbed dream. In a still evening this singular call may be heard for half a mile, its tones being slower, louder, and more full than those of the Whip-poor-will. The species is particularly numerous in the vast forests of the Mississippi, VOL. I. -30 
where throughout the evening its echoing notes are heard in the solitary glens and from the surrounding and silent hills, becoming almost incessant during the shining of the moon; and at the boding sound of its elfin voice, when familiar and strongly reiterated, the thoughtful, superstitious savage becomes sad and pensive. Its flight is low, and it skims only a few feet above the surface of the ground, frequently settling on logs and fences, whence it often sweeps around in pursuit of flying moths and insects, which constitute its food. Sometimes these birds are seen sailing near the ground, and occasionally descend to pick up a beetle, or flutter lightly around the trunk of a tree in quest of some insect crawling upon the bark. In rainy and gloomy weather they remain silent in the hollow log which affords them and the bats a common roost and refuge by day. When discovered in this critical situation, and without the means of escape, they ruffle up their feathers, spread open their enormous mouths, and utter a murmur almost like the hissing of a snake, thus endeavoring, apparently, to intimidate their enemy when cut off from the means of escape.

This species also lays its eggs, two in number, merely on the ground, and usually in the woods; if they be handled, or even the young, the parents, suspicious of danger, remove them to some other place. As early as the middle of August, according to Audubon, these birds retire from the United States; though some winter in the central parts of East Florida.

The general habitat of this species is the South Atlantic and Gulf States and the lower Mississippi valley. Near the Atlantic the bird ranges to North Carolina, and Mr. Ridgeway reports it not uncommon in southern Illinois. It winters in the Gulf States and southward. 


\section{W H I P - P O O R - W I L L.}

\section{ANTROSTOMUS VOCIFERUS.}

ChAR. Gape extremely wide; rictal bristles without lateral filaments. General color dull gray brown, mottled with black, white, and tawny; throat with collar of white or tawny; outer tail-feathers partly white; under parts gray mottled with black. Length $9 \frac{1}{2}$ to io inches.

Nest. In dense woods or shady dells; eggs laid on the ground or amid dry leaves.

Eggs. 2; white or buffy marked brown and lavender; I.I2 $\times 0.85$.

This remarkable and well-known nocturnal bird arrives in the Southern States in March, and in the Middle States about the close of April or the beginning of May, and proceeds in its vernal migrations along the Atlantic States to the centre of Massachusetts, being seldom seen beyond the latitude of $43^{\circ}$; and yet in the interior of the continent, according to Vieillot, it continues as far as Hudson Bay, and was heard, as usual, by Mr. Say at Pembino, in the high latitude of $49^{\circ}$. In all this vast intermediate space, as far south as Natchez on the Mississippi, and the interior of Arkansas, these birds familiarly breed and take up their temporary residence. Some also pass the winter in the interior of East Florida, according to Audubon. In the eastern part of Massachusetts, however, they are uncommon, and always affect sheltered, wild, and hilly situations, for which they have in general a preference. About the same time that the sweetly echoing voice of the Cuckoo is first heard in the north of Europe, issuing from the leafy groves as the sure harbinger of the flowery month of May, arrives amongst us, in the shades of night, the mysterious Whip-poor-will. The well-known saddening sound is first only heard in the distant forest, re-echoing from the lonely glen or rocky cliff; at length the oft-told solitary tale is uttered from the fence of the adjoining field or garden, and sometimes the slumbering inmates of the cottage are serenaded from the low roof or from some distant shed. Superstition, gathering terror from every extraordinary feature of nature, has not suffered this harmless nocturnal babbler to escape suspicion, and his 
familiar approaches are sometimes dreaded as an omen of misfortune.

In the lower part of the State of Delaware, I have found these birds troublesomely abundant in the breeding season, so that the reiterated echoes of 'whipp-'whip-pŏor-will, 'whip-pĕruwill, issuing from several birds at the same time, occasioned such a confused vociferation as at first to banish sleep. This call, except in moonlight nights, is continued usually till midnight, when they cease until again aroused, for a while, at the commencement of twilight. The first and last syllables of this brief ditty receive the strongest emphasis, and now and then a sort of guttural cluck is heard between the repetitions; but the whole phrase is uttered in little more than a second of time.

Although our Whip-poor-will seems to speak out in such plain English, to the ears of the aboriginal Delaware its call was wecoális, though this was probably some favorite phrase or interpretation, which served it for a name. The Whip-poorwill, when engaged in these nocturnal rambles, is seen to fly within a few feet of the surface in quest of moths and other insects, frequently, where abundant, alighting around the house. During the day the birds retire into the darkest woods, usually on high ground, where they pass the time in silence and repose, the weakness of their sight by day compelling them to avoid the glare of the light.

The female commences laying about the second week in May in the Middle States, considerably later in Massachusetts; she is at no pains to form a nest, though she selects for her deposit some unfrequented part of the forest near a pile of brush, a heap of leaves, or the low shelving of a hollow rock, and always in a dry situation; here she lays two eggs, without any appearance of an artificial bed. This deficiency of nest is amply made up by the provision of nature, for, like Partridges, the young are soon able to run about after their parents; and until the growth of their feathers they seem such shapeless lumps of clay-colored down that it becomes nearly impossible to distinguish them from the ground on which they repose. 
Were a nest present in the exposed places where we find the young, none would escape detection. The mother also, faithful to her charge, deceives the passenger by prostrating herself along the ground with beating wings, as if in her dying agony. The activity of the young and old in walking, and the absence of a nest, widely distinguishes these birds from the Swallows, with which they are associated. A young fledged bird of this species, presented to me, ran about with great celerity, but refused to eat, and kept continually calling out at short intervals $p \dot{e}-\bar{u} g h$ in a low, mournful note.

After the period of incubation, or about the middle of June, the vociferations of the males cease, or are but rarely given. Towards the close of summer, previously to their departure, they are again occasionally heard, but their note is now languid and seldom uttered; and esrly in September they leave us for the more genial climate of tropical America, being there found giving their usual lively cry in the wilds of Cayenne and Demerara. They enter the United States early in March, but are some weeks probably in attaining their utmost northern limit.

Their food appears to be large moths, beetles, grasshoppers, ants, and such insects as frequent the bark of decaying timber. Sometimes, in the dusk, they will skim within a few feet of a person, making a low chatter as they pass. They also, in common with other species, flutter occasionally around the domestic cattle to catch any insects which approach or rest upon them; and hence the mistaken notion of their sucking goats, while they only cleared them of molesting vermin.

The Whip-poor-will is a common summer resident throughout New England, and is not uncommon in the Maritime Provinces. It is common also in Ontario, and Dr. Robert Bell reports finding it in the southern parts of the Hudson Bay region. Mr. Thompson reports it common in Manitoba. These birds winter in Florida and southward. 


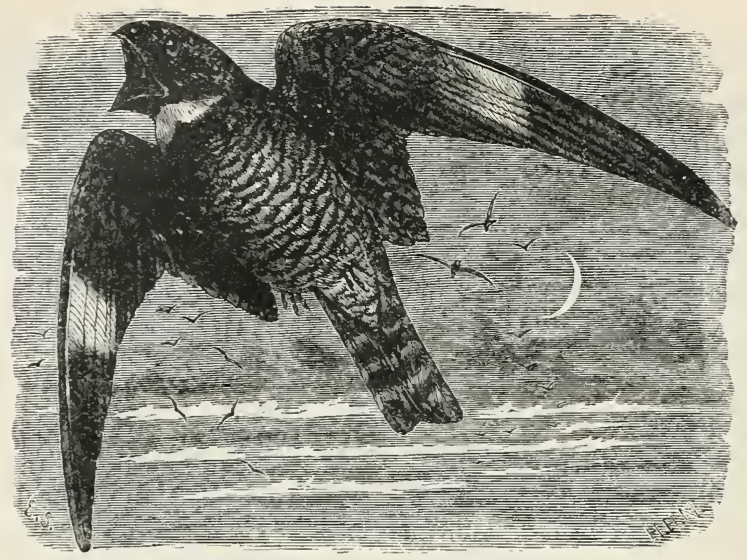

NIGHTHAWK.

GOATSUCKER. BULL BAT.

Chordeiles virginianus.

CHAR. Male: above, dull black mottled with brown and gray; wings brown, a patch of white on five outer primaries; tail dusky, with bars of gaay and a patch of white near the extremity; lower parts reddish white with bars of brown; throat with patch of white. Female : similar, but without white on the tail. Length about $9 \frac{1}{2}$ inches.

Nest. Usually in open woods; the eggs generally laid upon a rock or on the turf, - sometimes they are laid on a gravel roof in a city.

Eggs. 2; dull white or buff, thickly mottled with brown, slate, and lilac: $1.25 \times 0.85$.

Towards the close of April the Nighthawks arrive in the Middle States, and early in May they are first seen near the sea-coast of Massachusetts, which at all times appears to be a favorite resort. In the interior of the continent they penetrate as far as the sources of the Mississippi, the Rocky Mountains, and the Territory of Oregon; they are likewise observed around the dreary coasts of Hudson Bay and the remotest Arctic islands, breeding in the whole intermediate region to the more temperate and elevated parts of Georgia. They are now commonly seen towards evening, in pairs, sailing round in sweeping circles high in the air, occasionally descending lower 
to capture flying insects, chiefly of the larger kind, such as wasps, beetles, and moths. About the middle of May, or later, the female selects some open spot in the woods, the corner of a corn-field or dry gravelly knoll, on which to deposit her eggs, which are only two, and committed to the bare ground, where, however, from the similarity of their tint with the soil, they are, in fact, more secure from observation than if placed in a nest. Here the male and his mate reside during the period of incubation, roosting at a distance from each other on the ground or in the neighboring trees; and in consequence of the particular formation of their feet, like the rest of the genus, they roost or sit lengthwise on the branch. During the progress of incubation the female is seen frequently, for some hours before nightfall, playing about in the air over the favorite spot, mounting in wide circles, occasionally propelled by alternate quick and slow vibrations of the wings, until at times he nearly ascends beyond the reach of sight, and is only known by his sharp and sudden squeak, which greatly resembles the flying shriek of the towering Swift. At other times he is seen suddenly to precipitate himself downwards for 60 or 80 feet, and wheeling up again as rapidly; at which instant a hollow whirr, like the rapid turning of a spinning-wheel or a strong blowing into the bung-hole of an empty hogshead, is heard, and supposed to be produced by the action of the air on the wings or in the open mouth of the bird. He then again mounts as before, playing about in his ascent and giving out his harsh squeak till in a few moments the hovering is renewed as before; and at this occupation the male solely continues till the close of twilight. The European Goatsucker is heard to utter the hollow whirr when perched and while holding it head downwards, so that it does not appear to be produced by the rushing of the air. The female, if disturbed while sitting on her charge, will suffer the spectator to advance within a foot or two of her before she leaves the nest; she then tumbles about and flutters with an appearance of lameness to draw off the observer, when at length she mounts into the air and disappears. On other 
occasions the parent, probably the attending male, puffs himself up as it were into a ball of feathers; at the same time striking his wings on the ground and opening his capacious mouth to its full extent, he stares wildly and utters a blowing hiss like that of the Barn Owl when surprised in his hole. On observing this grotesque manœuvre, and this appearance so unlike that of a volatile bird, we are struck with the propriety of the metaphorical French name of Crapaud volans, or Flying Toad, which this bird indeed much resembles while thus shapelessly tumbling before the astonished spectator. The same feint is also made when he is wounded, on being approached. Like some of the other species, instinctively vigilant for the safety of their misshapen and tender brood, these birds also probably convey them or the eggs from the scrutiny of the meddling observer. In our climate they have no more than a single brood.

Sometimes the Nighthawk, before his departure, is seen to visit the towns and cities, sailing in circles and uttering his squeak as he flies high and securely over the busy streets, occasionally sweeping down, as usual, with his whirring notes; and at times he may be observed, even on the tops of chimneys, uttering his harsh call. In gloomy weather these birds are abroad nearly the whole day, but are most commonly in motion an hour or two before dusk. Sometimes indeed they are seen out in the brightest and hottest weather, and occasionally, while basking in the sun, find means to give chase to the Cicindeli, Carabi, and other entirely diurnal insects, as well as grasshoppers, with which they often gorge themselves in a surprising manner; but they probably seldom feed more than an hour or two in the course of the day. On Wappatoo Island, at the estuary of the Wahlamet, they were till the Ioth of September numerous and familiar, alighting often close to the dwellings, in quest probably of crawling insects which come out in the dark.

About the middle of August they begin their migrations towards the south, on which occasion they may be seen in the evening moving in scattered flocks consisting of several hun- 
dreds together, and darting after insects or feeding leisurely as they advance towards more congenial climes. For two or three weeks these processions along the rivers and their banks, tending towards their destination, are still continued. Mingled with the wandering host are sometimes also seen the different species of Swallow, - a family to which they are so much allied in habits and character; but by the 2 oth of September the whole busy troop have disappeared for the season.

I have observed Nighthawks flying over the city of St. John, in New Brunswick, during most of the summer months, and have known of the eggs being found frequently on gravel roofs in that city.

Note. - The Florida Nighthawk (C. virginianus chapmani), a smaller race, breeds in Florida and westward on the Gulf coast. 




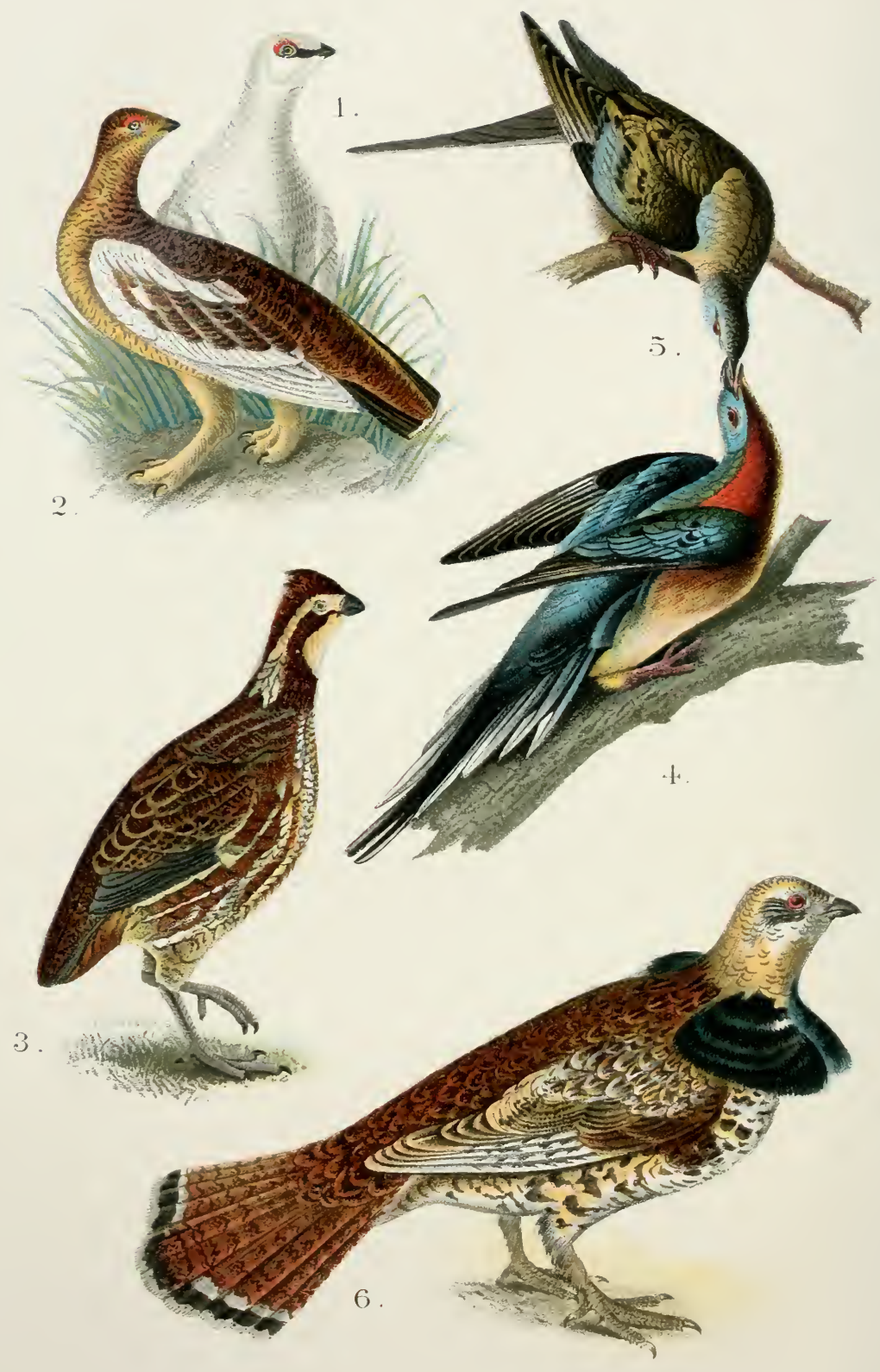

1-2. Rock Ptarmigan.

3. Partridģe.

4-5. Passenģer Piģeon.

6. Ruffed Grouse. 
PART II.

GAME AND WATER BIRDS. 



\section{PART II. \\ GAME AND WATER BIRDS.}

\section{CONTENTS.}

\begin{tabular}{|c|c|c|c|c|c|c|c|c|c|c|c|c|c|}
\hline & & & & & & $\mathrm{PAC}_{\mathrm{AC}}$ & & & & & & & AGE \\
\hline LBATROSS, & $\mathrm{Y}$ & $11 \mathrm{c}$ & & d & & . 277 & Duck, Ruddy & 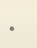 & & • & - & - & \\
\hline Great & VI & & & & - & . 278 & Sc & . & . & . & - & . & \\
\hline $\begin{array}{l}\text { Great } \\
\text { Razor- }\end{array}$ & bille & ed . & & & & $\begin{array}{l}.414 \\
.410\end{array}$ & Wood & - & & & . & & \\
\hline et & ( & . & & & & 106 & EGRET Reddish & · & $\cdot$ & - & - & . & $\dot{\cdot}$ \\
\hline E & . . & $\cdot \cdot$ & 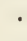 & . & . & - $3^{I I}$ & Eider : . & . & . & • & • & - & \\
\hline . & $\therefore$ & $\cdot \cdot$ & & & 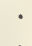 & .99 & King · & - & · & & - & • & \\
\hline Least & & . & 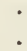 & • & . & 102 & hern & . & . & & 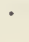 & & \\
\hline White & . & . . & & & & . 23 & INGO & & & & & & \\
\hline$y \cdot$. & . & & & & & . 379 & 'ulmar . & - & & & & & \\
\hline . & . & .. & & & & . 293 & Lesser & . & . & & & & \\
\hline head & . . & • $\cdot$ & 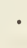 & & & - 347 & ALL $\cdot$ & & & & & & \\
\hline &. & & & & - & - I97 & allinule, Flori & & . & & . & . & \\
\hline rant & & & & & & $\cdot 369$ & Purpl & & & - & - & • & \\
\hline & Doub & ble-c & & & & . 372 & n & & & & · & - & \\
\hline , I & $\mathrm{e} \mathrm{Br}$ & own & . & & . & . 76 & rodwit, $\mathrm{H}$ & nia & & - & & & \\
\hline $\mathrm{S}$ & 1 & & & & & . 77 & Marble & & & - & & & \\
\hline 1 & & ng . & - & & • & . 73 & Golden-eye • & & & . & & - & \\
\hline rlew, Es & imo & & - & & - & . 122 & Barn & & & & - & - & \\
\hline $\mathrm{H}$ & $n$ & hian & . & & . & . I & se, & & & & - & - & \\
\hline $\mathrm{Lc}$ & ig & illed & 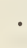 & & & & & & . & & . & . & \\
\hline VE, & & & . & & • & & & & & & & • & \\
\hline$M$ & ag & $g$. & - & & & . 1 & & & ted & & & & \\
\hline Zer & ida & . & . & . & • & . $\mathrm{I}$ & rebe, $\mathrm{H}$ & & 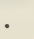 & . & . & & $\cdot 3^{8}$ \\
\hline zie & & & & & . & . 40 & & & & . & & & - $3^{8}$ \\
\hline & & $\cdot$ & • & • & - & - & & & . & & & • & \\
\hline , 1 & & & - & 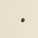 & • & $\cdot 3$ & Grouse, C & & . & . & . & . & . \\
\hline & & ack & . & - & . & . 3 & & & & 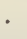 & & & \\
\hline & quir & & . & . & . & $\cdot 3$ & & & ed & . & • & 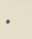 & \\
\hline & ador & & - & $\cdot$ & - & $\cdot 3$ & 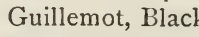 & & & · & & - & \\
\hline & $\mathrm{Sc}$ & $\mathrm{p}$ & 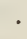 & . & & . & I, B & & - & . & & & \\
\hline & & & & & & & Franklin's & & & & & - & \\
\hline
\end{tabular}




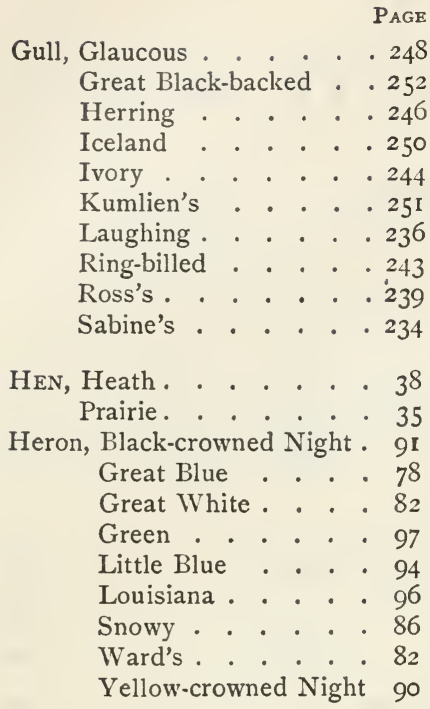

IBIS, Glossy · . . . . . . 114

Scarlet . . . . . I12

White . . . . . I12

Wood . . . . . . 110

JAEGER, Long-tailed . . . . 259

Parasitic . . . . 258

Pomarine. . . 257

KiLLDEER . . . . . . 62

Kittiwake . . . . . . $24 \mathrm{I}$

Knot . . . . . . . 140

LIMPKIN . . • • . . IO2

Loon . . . . . . . 388

Black-throated . . . 391

Red-throated. . . . 393

MALlard . . . . . 303

Man-of-war Bird . . . . 373

Merganser . . . . . . 358

Hooded . . . 363

Red-breasted . . 360

Murre . . . . . . . . 398

Brünnich's . . . . $40 \mathrm{I}$
PAGE

Noddy . . . . . . 232

Old-squaW . . . . . . 355

Oyster-catcher . . . . 54

Pelican, Brown . . . . 368

White . . . 364

Petrel, Leach's . . . . . . 263

Stormy . . . . . 267

Wilson's . . . . 264

Phalarope, Northern . . . 207

Red . . . . 205

Wilson's . . . 2 I I

Pheasant, English . . . . 22

Pigeon, Passenger. . . . I

White-crowned . . 7

Pintail . . . . . . 309

Plover, Black-bellied . . . 68

Golden . . . . 57

Piping . . . . 59

Ringed . . . . . 66

Semi-palmated . . 64

Wilson's . . . 6I

Prairie Hen . . . . . . 35

Ptarmigan, Rock . . . . 47

Welch's . . . 48

Willow . . . 43

Puffin . . . . . . 406

QUAIL-DOVE, Blue-headed . . I4

Key West . 9

RAIL, Black . . . . . . 196

Clapper . . . . 183

King . . . . . . 188

Virginia . . . . 180

Yellow . . . . 194

Redhead . . . . . 340

Ruff . . . . . . . 150

SAnderling • . • . . 49

Sandpiper, Baird's . . . 142

Bartramian . . 164

Buff-breasted . . 132

Curlew . . . I 25

Least . . . . 136

Pectoral . . . I30

Purple . . . I34 


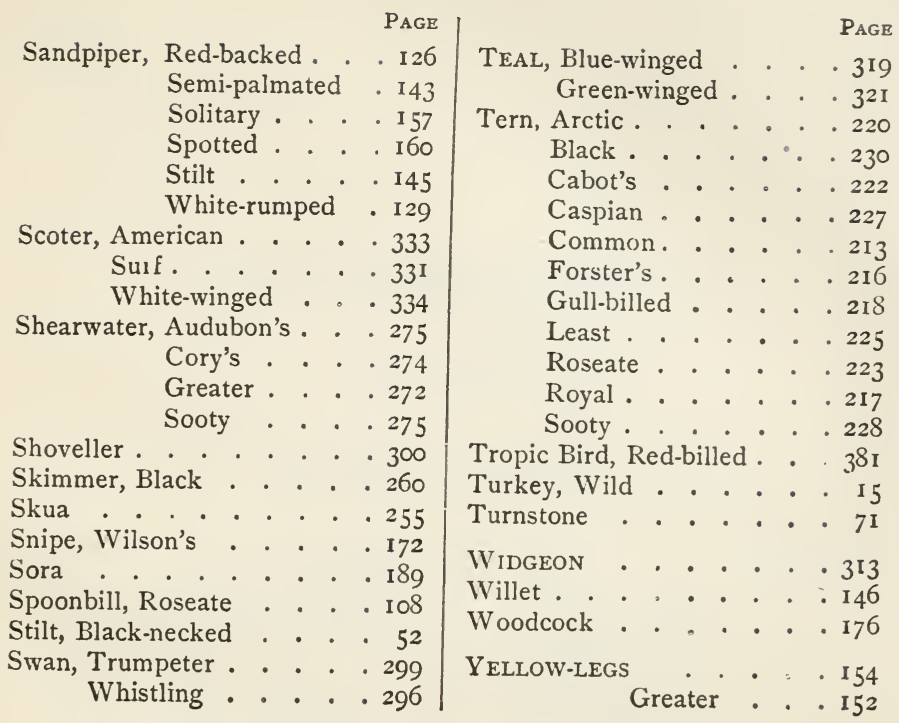





\section{ILLUSTRATIONS IN PART II.}

\section{COLORED PLATES.}

\footnotetext{
Plate XI. . . . Frontispiece

I. Rock Ptarmigan (Male).

2. Rock Ptarmigan (Female).

3. PARTRIDGe.

4. Wild Pigeon (Male).

5. Wild Pigeon (Female)

6. Ruffed Grouse.
}

Plate XII. . . . Page 42

I. Piping Plover.

2. Semi-Palmated Plover.

3. Golden Plover.

4. Prairie hen.

5. Canada Grouse.

Plate XIII. . . Page 100

I. White-Rumped SAndpiper.

2. КNot.

3. BitTern

4. SANDERling.

5. KilldeER.

Plate XIV. . . . Page 152

I. Greater Yellow-Legs.

2. REDDISH EGRET.

3. Red-Breasted Snipe.

4 Long-Billed Curlew.
Plate XV. . . . Page I82

I. SORA.

2. VIRGINIA RAIL.

3. Clapper Rail.

4. Yellow Rail.

5. Flamingo.

Plate XVI. . . Page 238

I. Northern Phalarope.

2. Bonaparte's Gull.

3. Wilson's TERN.

4. Herring Gull (Adult Male).

5. Herring Gull (Young, First Autumn).

Plate XVII. . . Page 264

I. BRANT.

2. Wilson's Petrel.

3. Roseate Tern.

4. Canada Goose.

Plate XVIII. . . Page 316

I. WOODCOCK.

2. Canvas-Back Duck.

3. Mallard Duck.

4. Black DuCK.

5. RUdDY DUCK. 
Plate XIX.

Page 350

I. Gadwall Duck.

2. Scaup Duck.

3. American Golden-Eye.

4. Harlequin Duck.

5. Surf DuCk.

Plate XX. . . . Page 372

I. Double-Crested CormorANT.

2. LoON,

3. BRÜNNICH'S MURRE.

4. Puffin.

5. King Eider.

\section{ILLUSTRATIONS IN THE TEXT.}

No.

87. Passenger Pigeon . . I

88. Key West Quail-Dove 9

89. Mourning Dove • . II

90. Wild TuRkey • . . 15

9I. Вов-White . . . 23

92. Prairie Hen . . . 35

93. Sharp-Tailed Grouse 39

94. SANDERLING • . . . 49

95. AMERICAN Oyster-

Catcher . . . 54

96. Ring Plover . . . 66

97. Black-Bellied Plover 68

98. TuRnSTONE . . . . 7 I

99. Snowy Heron •. . 86

IOO. Black-Crowned Night

HERON . . . . 9I

IOI. Flamingo . . . . 104

I02. Roseate Spoonbill . IOS

103. IVOOD IBIS . . . . IIO

I04. Glossy IbIS . . . II4

I05. Hudsonian Curlew . 120

106. CuRlew SANDPIPER - 125

107. Buff-Breasted SAND-

PIPER . . . . I 132

108. Purple Sandpiper . . I34

IO9. KNOT . . . . . . I 40

i IO. Semi-Palmated SandPIPER • . . . I 143

III. Willet . . . . . . 146

II 2. RUFF . . . . . I50

113. Solitary SANDpiper . I57

No.

Page

II 5. Marbled Godwit • 166

II6. Wilson's SNIPE . . I 172

I17. Virginia RaIL . . I80

II8. KING RAIL . • • . 188

II9. Yellow Rail. . . I94

i 20. American Coot . . . I97

I2I. Red Phalarope . . 205

122. COMMON TERN . . 213

123. Gull-Billed Tern . . 218

124. ARCTiC TERn . . . 220

125. Caspian Tern . . 227

126. Black Tern . . . 230

I27. SABine's Gull • . 234

I28. Laughing Gull • 236

129. Kittiwake . • . . 24 I

I3O. Ivory Gull . . . 244

I3I. Herring Gull . . 246

132. Glaucous Gull . . 248

133. Great Black-Backed

Gull . . . . 252

134. SkUA . . . . . 255

135. Pomarine Jaeger • . 257

I36. Leach's Petrel . . 263

I37. Fulmar . . . . . . 269

139. Greater Shearwater 272

I39. Yellow-Nosed AlbaTROSS . . . . 277

I40. Greater SNow Goose 28I

I4I. AMERICAN White-

Fronted Goose . 284

142. Canada Goose . . 285

F43. Brant . . . . 293 


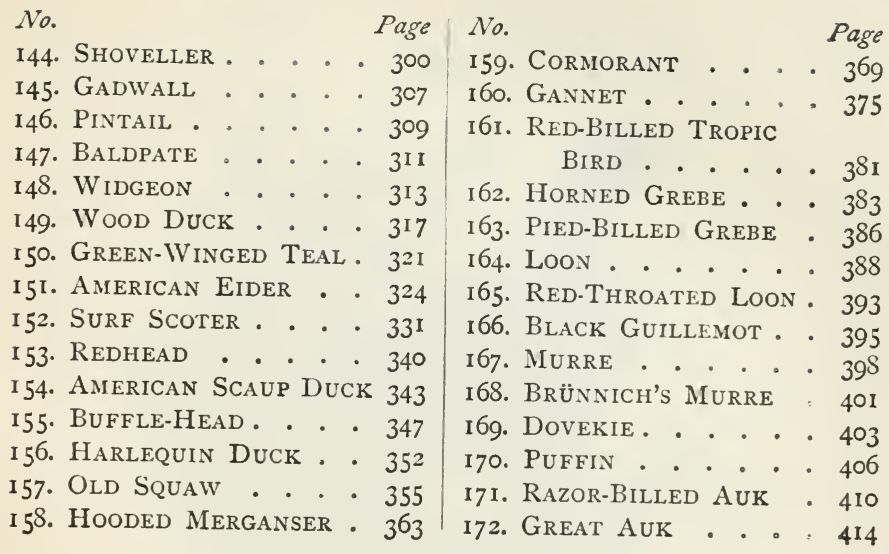





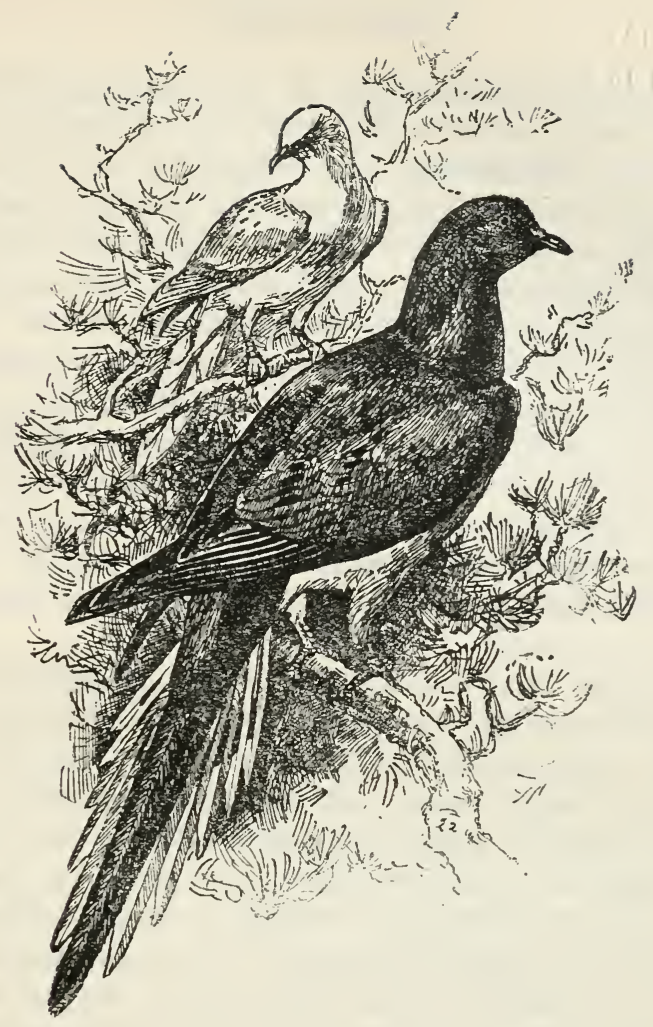

PASSENGER PIGEON.

WILD PIGEON.

ECTOPISTES MIGRATORIUS.

Char. Above, grayish blue, deeper on head and rump, back tinged with brown; primaries blackish with border of pale blue; middle tailfeathers dusky, the remainder shading through blue to white; neck with metallic reflections of golden purple and wine color; under parts brownish red with a purple tint shading through purplish pink to white.

Nest. In tree, - a frail platform of twigs.

Eggs. I or 2; dull white; $1.45 \times 1.05$.

The Wild Pigeon of America, so wonderful for its gregarious habits, is met with more or less according to circumstances VOL. II. - I 
from Mexico to Hudson Bay, in which inhospitable region it is seen even in December, weathering the severity of the climate with indifference, and supporting itself upon the meagre buds of the juniper when the ground is hidden by inundating snows. To the west it is found to the base of the Northern Andes, or Rocky Mountains, but does not appear to be known beyond this natural barrier to its devious wanderings. As might be supposed from its extraordinary history, it is formed with peculiar strength of wing, moving through the air with extreme rapidity, urging its flight also by quick and very muscular strokes. During the season of amorous address it often flies out in numerous hovering circles; and while thus engaged, the tips of the great wingfeathers are heard to strike against each other so as to produce a very audible sound.

The almost incredible and unparalleled associations which the species form with each other appear to have no relation with the usual motives to migration among other birds. A general and mutual attachment seems to occasion this congregating propensity. Nearly the whole species, which at any one time inhabit the continent, are found together in the same place; they do not fly from climate, as they are capable of enduring its severity and extremes. They are even found to breed in the latitude of $5 \mathrm{I}$ degrees, round Hudson Bay and the interior of New Hampshire, as well as in the $32 \mathrm{~d}$ degree in the dense forests of the great valley of the Mississippi. The accidental situation of their food alone directs all their movements; while this continues to be supplied they sometimes remain sedentary in a particular district, as in the dense forests of Kentucky, where the great body remained for years in succession, and were scarcely elsewhere to be found; and here, at length, when the mast happened to fail, they disappeared for several years.

The rapidity of flight, so necessary in their vast domestic movements, is sufficiently remarkable. The Pigeons killed near the city of New York have been found with their crops full of rice collected in the plantations of Georgia or Carolina; 
and as this kind of food is digested by them entirely in twelve hours, they must have travelled probably three or four hundred miles in about the half of that time, or have sped at the rate of a mile in a minute. With a velocity like this, our Pigeon might visit the shores of Europe in less than three days; and, in fact, according to Flemming, a straggler was actually shot in Scotland in the winter of 1825 . Associated with this rapidity of flight must also be the extent and acuteness of its vision, or otherwise the object of its motions would be nugatory; so that while thus darting over the country almost with the velocity of thought, it still keeps up a strict survey for its fare, and in passing over a sterile region sails high in the air with a widely extended front, but instantly drops its flight at the prospect of food, flying low till it alights near an ample supply.

The associated numbers of Wild Pigeons, the numerous flocks which compose the general swarm, are without any other parallel in the history of the feathered race; they can indeed alone be compared to the finny shoals of herrings, which, descending from the Arctic regions, discolor and fill the ocean to the extent of mighty kingdoms. Of their amazing numbers and the circumstances attendant on this fact, the reader will do well to consult the indefatigable Wilson and the celebrated Audubon. Our limits and more bounded personal information will not allow us to enlarge on this curious and extraordinary subject. To talk of hundreds of millions of individuals of the same species habitually associated in feeding, roosting, and breeding, without any regard to climate or season as an operating cause in these gregarious movements, would at first appear to be wholly incredible if not borne out by the numerous testimony of all the inhabitants of the neighboring districts. The approach of the mighty feathered army with a loud rushing roar and a stirring breeze, attended by a sudden darkness, might be mistaken for a fearful tornado about to overwhelm the face of Nature. For several hours together the vast host, extending some miles in breadth, still continues to pass in flocks without diminution. The whole air is filled 
with birds; their muting resembles a shower of sleet, and they shut out the light as if it were an eclipse. At the approach of the Hawk their sublime and beautiful aërial evolutions are disturbed like the ruffling squall extending over the placid ocean; as a thundering torrent they rush together in a concentrating mass, and heaving in undulating and glittering sweeps towards the earth, at length again proceed in lofty meanders like the rushing of a mighty animated river.

But the Hawk is not their only enemy: tens of thousands are killed in various ways by all the inhabitants far and near. The evolutions of the feeding Pigeons as they circle round are both beautiful and amusing. Alighting, they industriously search through the withered leaves for their favorite mast; those behind are continually rising and passing forward in front, in such rapid succession that the whole flock, still circling over the ground, seem yet on the wing.

As the sun begins to decline, they depart in a body for the general roost, which is often hundreds of miles distant, and is generally chosen in the tallest and thickest forests, almost divested of underwood. Nothing can exceed the waste and desolation of these nocturnal resorts; the vegetation becomes buried by their excrements to the depth of several inches. The tall trees for thousands of acres are completely killed, and the ground strewed with massy branches torn down by the clustering weight of the birds which have rested upon them. The whole region for several years presents a continued scene of devastation, as if swept by the resistless blast of a whirlwind. The Honorable T. H. Perkins informs me that he has seen one of these desolated roosting-grounds on the borders of Lake Champlain in New York, and that the forest to a great extent presented a scene of total ruin.

The breeding-places, as might naturally be expected, differ from the roosts in their greater extent. In 1807 , according to Wilson, one of these immense nurseries, near Shelbyville in Kentucky, was several miles in breadth and extended through the woods for upwards of forty miles. After occupying this situation for a succession of seasons they at length abandoned 
it, and removed sixty or eighty miles off to the banks of Green River in the same State, where they congregated in equal numbers. These situations seem regulated by the prospect of a supply of food, such as beech and oak mast. They also feed on most kinds of pulse and grain, as well as whortleberries, with those of the holly and nettle tree. Wilson often counted upwards of ninety nests in a single tree, and the whole forest was filled with them. These frail cradles for the young are merely formed of a few slender dead twigs negligently put together, and with so little art that the concavity appears scarcely sufficient for the transient reception of the young, who are readily seen through this thin flooring from below. The eggs are white, as usual, and only two in number, one of them abortive, according to Wilson, and producing usually but a single bird. Audubon, however, asserts that there are two, as in the tame Pigeons, where the number of the sexes in this faithful tribe are almost uniformly equal. Their cooing call, billing, and general demeanor are apparently quite similar to the behavior of the domestic species in the breeding-season. Birds of prey, and rapacious animals generally, are pretty regular attendants upon these assailable communities. But their most destructive enemy is man; and as soon as the young are fully grown, the neighboring inhabitants assemble and encamp for several days around the devoted Pigeons with wagons, axes, and cooking utensils, like the outskirts of a destructive army. The perpetual tumult of the birds, the crowding and fluttering multitudes, the thundering roar of their wings, and the crash of falling trees, from which the young are thus precipitated to the ground by the axe, produces altogether a scene of indescribable and almost terrific confusion. It is dangerous to walk beneath these clustering crowds of birds, from the frequent descent of large branches broken down by the congregating millions; the horses start at the noise, and conversation can only be heard in a shout. These squabs, or young Pigeons, of which three or four broods are produced in the season, are extremely fat and palatable, and as well as the old birds killed at the roosts are often, with 
a wanton prodigality and prodigious slaughter, strewed on the ground as fattening food for the hogs. At the roosts the destruction is no less extensive; guns, clubs, long poles, pots of burning sulphur, and every other engine of destruction which wanton avarice can bring forward, are all employed against the swarming host. Indeed for a time, in many places, nothing scarcely is seen, talked of, or eaten, but Pigeons.

In the Atlantic States, where the flocks are less abundant, the gun, decoy, and net are put in operation against the devoted throng. Twenty or even thirty dozen have been caught at a single sweep of the net. Wagon-loads of them are poured into market, where they are sometimes sold for no more than a cent apiece. Their combined movements are also sometimes sufficiently extensive. The Honorable T. H. Perkins remarks that about the year $\mathrm{x} 798$, while he was passing through New Jersey, near Newark, the flocks continued to pass for at least two hours without cessation; and he learnt from the neighboring inhabitants that in descending upon a large pond to drink, those in the rear, alighting on the backs of the first that arrived (in the usual order of their movements on land to feed), pressed them beneath the surface, so that tens of thousands were thus drowned. 'They were likewise killed in great numbers at the roosts with clubs.

Down to twenty years ago immense flocks of Pigeons were seen yearly in every State of New England, and they nested in communities that were reckoned by thousands. Now, in place of the myriads that gathered here, only a few can be found, and these are scattered during the breeding-season, - each pair selecting an isolated site for the nest.

Twenty years ago the Wild Pigeon was exceedingly abundant in the Maritime Provinces of Canada; now it is rare. McIlwraith sends a similar report from Ontario. Wheaton, in Ohio, finds it "irregular and uncommon," and writes of the "throngs" that formerly nested there. Ridgeway says nothing of its occurrence in Illinois to-day, but repeats the story of the older observers, to whom it was familiar. Warren says it appears in Pennsylvania in the fall, but no longer in the abundance of former years. Today we must go to the upper regions of the Mississippi valley and 
to the heavily timbered districts of Michigan to find large flocks of Pigeons, and even there we can find but a remnant of the hosts that assembled in those regions a few years ago.

The most important of recent contributions to the biography of this species is Mr. William Brewster's article in "The Auk" for October, 1889. He tells there of a "nesting" in Michigan in 1877 that covered an area twenty-eight miles long and three to four miles wide, and says: "For the entire distance of twenty-eight miles every tree of any size had more or less nests, and many trees were filled with them."

Brewster visited Michigan in $\mathbf{1} 888$, and heard that a large flock had passed over the northern section of the southern penninsula, but it had gone farther north before nesting, - he could not find it. He thinks the flock was sufficiently large to stock the Western States again, were these birds protected for a few years from the terrific slaughter that now imperils their existence; for it is simply this slaughter that has diminished the numbers of the birds. There is no mystery about their disappearance, as many writers have tried to represent. Doubtless this species has been irregular in appearing in any given locality at all times, the movements of the flocks being influenced by the food supply. But the Pigeons have been exterminated in the East just as they are being exterminated in the West, - by "netting." One old netter told Mr. Brewster that during $\mathbf{1} 88 \mathrm{I}$ as many as five hundred men were engaged in netting Pigeons in Michigan, and, said he, "They captured on the average twenty thousand apiece during the season." At this rate the Pigeon will soon join the buffalo on that list so disgraceful to humanity, "the extinct species," - a list that will be filled rapidly if a check is not put on men's avarice and the law's shameful negligence.

\section{WHITE-CROWNED PIGEON.}

\section{Columba leucocephala.}

CHAR. General color dark slate blue, darker on wings and tail, paler below; upper part of head white; cape on hind neck of rich maroon, and below it a band of metallic green, each feather bordered with scale-like patches of black. Length about $\mathrm{I}_{3} \mathrm{1} / 2$ inches.

Nest. In low tree or bush, made of twigs and roots, lined with grass.

Eggs. 2 ; white; $1.40 \times 1.05$.

This species, well known as an inhabitant of Mexico and the West Indies, is also gregarious, and found in great numbers 
on the rocks of the Florida Keys, where it breeds in society and when first seen in the spring feeds principally upon the beech-plum and the berries of a kind of palm. From the peculiar selection of its breeding-places it is known in some of the West Indies, particularly Jamaica, St. Domingo, and Porto Rico, by the name of Rock Pigeon. It likewise abounds in the Bahama islands, and forms an important article of food to the inhabitants, - particularly the young birds as they become fully grown.

According to Audubon, these birds arrive on the southern keys of the Floridas, from the island of Cuba, from the 2 oth of April to the Ist of May, remaining to breed during the summer season. They are at all times extremely shy and wary, remaining so indeed even while incubating, skipping from the nests and taking to wing without noise, and remaining off sometimes as much as half an hour at a time. In the month of May the young squabs are nearly able to fly, and are killed in great numbers by the wreckers who visit the keys. The nest is placed on the summit of a cactus shoot a few feet from the ground or on the upper branches of a mangrove, or quite low impending over the water; externally it is composed of small twigs, and lined with grass and fibrous roots. The eggs are two, white, rather roundish, and as large as those of the domestic Pigeon. This bird has apparently several broods in the season. His cooing may be heard to a considerable distance; after a kind of crowing prelude he repeats his koo koo koo. When suddenly approached, he utters a hollow guttural sound, like the Common Pigeon. White-crowned Pigeons are easily domesticated, and breed in that state freely. About the beginning of October they are very numerous, and then return to pass the winter in the West India islands. 


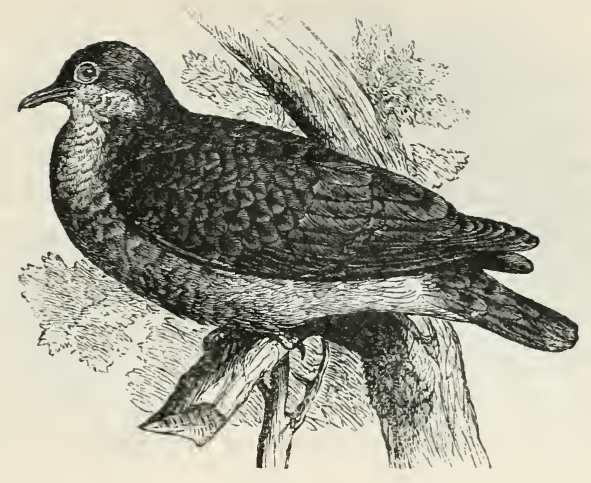

\section{KEY WEST QUAIL-DOVE.}

\section{PARTRIDGE PIGEON.}

\section{Geotrygon martinica.}

CHAR. Above, reddish purple, the neck and head with metallic reflections of green; below, pale vinaceous, fading to white on chin, and to buff on under tail-coverts; white of chin extends below the eyes. Length about II inches. twigs.

Nest. In low branches, sometimes on the ground; made of light

Eggs. 2; white; $1.40 \times 1.00$.

This beautiful species, originally discovered in Jamaica, was found by Audubon to be a summer resident on the island of Key West, near the extremity of East Florida; it retires in winter to the island of Cuba. Its flight is low, swift, and protracted, keeping in loose flocks or families of from five or six to a dozen. These dwell chiefly in the tangled thickets, but go out at times to the shore to feed and dust themselves. This bird contracts and spreads out its neck in the usual manner of Pigeons. Its cooing is not so soft or prolonged as that of the Common Dove; the sound resembles whoe whoeoh-oh-oh-oh. When surprised, it gives a guttural, gasping sound, somewhat like that of the Common Pigeon in the same circumstances. Quail Doves keep usually near shady secluded ponds in the thickest places, and perch on the low branches of the trees. The nest is formed of light dry twigs, sometimes 
on the ground, on the large branches of trees, or even on slender twigs. On the 2 oth of May it will contain two white eggs, almost translucent. In July these pigeons come out of the thickets in flocks of all ages, and frequenting the roads to dust themselves, are then easily procured and considered good food. They feed chiefly on berries and seeds, and particularly the sea-grape. They depart for Cuba or the other West India islands about the middle of October.

This species is now met with only on Key West and the extreme southern islands of Florida, and even there is a rare bird.

Note. - A specimen of the RUdDy QuAIL-Dove (Geotrygon montana) was captured on Key West in December, $1888,-$ the first taken within the borders of North America.

\section{ZENAIDA DOVE.}

\section{ZENAIDA ZENAIDA.}

CHAR. Above, olive gray with a red tinge; top of head and under parts purplish red; neck with metallic reflections; a black patch on wing-coverts; tail with terminal band of black tipped with white. Length about to inches.

Nest. In low bush; a slight affair of fine twigs. The nests are sometimes placed on the sand and concealed by tufts of grass, and these ground-nests are compactly built of leaves and grass.

Eggs. 2 ; white ; $1.20 \times 0.95$.

This beautiful little species inhabits the Keys of Florida, but is rare. Individuals have been found in the neighboring island of Cuba. They keep much on the ground, where they dust themselves and swallow gravel to assist digestion. When rising on the wing, the same whistling noise is heard from the motion of their wings, as is the case of the common Carolina Turtle Dove. 


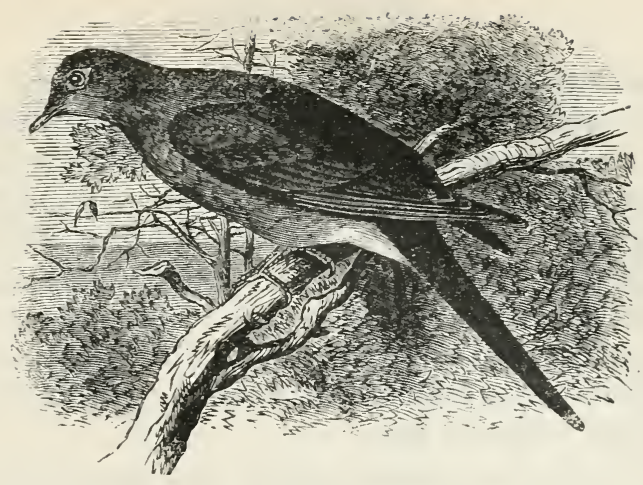

\section{MOURNING DOVE.}

CAROLINA DOVE. TURTLE DOVE.

\section{ZENAIDURA MACROURA.}

CHAR. Male: above, grayish blue, the back washed with brownish olive; sides of head and neck and breast purplish red; belly buffish; sides of neck with metallic reflections; a black spot on the cheeks; tail with bar of black, outer feathers broadly tipped with white. Female: similar, but duller; breast brownish. Length about 12 inches.

Nest. In a tree or bush or on fence rail or rock, - a mere platform rudely made of twigs.

Eggs. 2-4 (usually 2); white; I.I $5 \times 0.85$.

This almost familiar Pigeon in the course of the spring leisurely migrates through the interior as far as to Canada, though in the Eastern States it is rarely met with to the north of Connecticut. Many appear sedentary in the warmer States, where they breed as far south as Louisiana. They are also said to inhabit the Antilles, and we saw them not uncommon in the Territory of Oregon. In the warmer parts of the Union they commence laying early in April, and in South Carolina I heard their plaintive $\operatorname{coo}$ on the 29 th of January; but at the extremity of their range they scarcely begin to breed before the middle of May. They lay, as usual, two eggs, of a pure white, and make their nest in the horizontal branches of a tree. It is formed of a mere layer of twigs so loosely and slovenly put together as to appear scarcely sufficient to prevent the young from falling out. 
By the first fine days of the early Southern spring we hear from the budding trees of the forest, or the already blooming thicket, the mournful call of the Carolina Turtle Dove, commencing as it were with a low and plaintive sigh, a'gh cóo cóo $\dot{c o o}$, repeated at impressive intervals of half a minute, and heard distinctly to a considerable distance through the still and balmy air of the reviving season. This sad but pleasing note is also more distinguished at this time, as it seeks the noon-day warmth in which to utter its complaint, and where it is now heard without a rival.

The flight of this species is rapid and protracted, and, as usual in the genus, accompanied by a very audible whistling noise; the birds fly out often in wide circles, but seldom rise above the trees, and keep out near the skirt of the forest or round the fences and fields, which they visit with considerable familiarity, gleaning after the crop has been removed, and seldom molesting the farmer except by now and then raising up a few grains in sowing time, which may happen to be exposed too temptingly to view. The usual food of this species is various kinds of grain and small acorns, as well as the berries of the holly, dogwood, poke, whortle, and partridge berries, with other kinds according to the season. In the nuptial period the wide circling flight of the male is often repeated around his mate, towards whom he glides with wings and tail expanded, and gracefully alights on the same or some adjoining tree, where she receives his attentions or fosters her eggs and infant brood. On alighting, they spread out their flowing train in a graceful attitude, accompanying the motion by a clucking and balancing of the neck and head evincing the lively emotion and mutual affection they cherish. When the female now confines herself to her eggs, her constant mate is seen feeding her with a delicate and assiduous attention.

The roosting places preferred by the Carolina Turtle Doves are among the long and unshorn grass of neglected fields, in the slight shelter of corn-stalks, or the borders of meadows; they also occasionally seek harbor among the rustling and falling leaves, and amidst the thick branches of various ever- 
greens. But in every situation, even though in darkness, they are so vigilant as to fly at the instant of approach. They do not huddle together, but take up their rest in solitude, though a whole flock may be in the same field; they also frequently resort to the same roosting places, if not materially molested. It is a hardy species, enduring considerable cold, and individuals remain even in the Middle as well as the Southern States throughout the year. These birds are far less gregarious and migratory than is the common Wild Pigeon. When their food becomes scanty in the fields in the course of the winter, they approach the farm, feeding among the poultry with the Blackbirds, Sparrows, and other guests of the same accidental bounty, and if allowed without reprisal, appear as gentle as Domestic Doves. Raised from the nest, they are easily tamed, and instances are known of their breeding in confinement. Their flesh is also much esteemed, and by some considered as scarcely inferior to that of the Snipe or Woodcock.

The Mourning Dove is a common summer resident of portions of southern New England, and occurs sparingly northward to New Brunswick. Mr. McIlwraith reports it breeding sparingly in southern Ontario.

\section{GROUND DOVE.}

\section{COlumibigallina PASSERINA TERRESTRIS.}

CHAR. Back and rump grayish olive, head and neck purplish red glossed with blue, the feathers edged with grayish olive; wings like back, but tinged with purple and spotted with steel blue; central tail-feathers like back, outer feathers blackish with paler tips; lower parts purplish red, the feathers of the breast streaked with grayish olive; bill yellow, tipped with black; feet yellow. Female and young paler, grayer, and without the purple tints. Length $6 \frac{1}{2}$ inches.

Nest. On a tree, usually on a low branch, but sometimes I 5 to 20 feet from the ground; little more than a platform of twigs.

Eggs. 2; dull white or creamy; $0.85 \times 0.65$.

The Ground Dove is an inhabitant of all the States of the Union south of Virginia, and is met with also in the West Indies. It is common in the sea islands of the Southern 
States, particularly in South Carolina and Georgia, where it is seen in small flocks of from fifteen to twenty. These birds are found usually upon the ground, and prefer the open fields and cultivated tracts to the woods; their flight is seldom protracted, as they fly out commonly only to short distances, though on the approach of winter they retire to the islands and milder parts of the continent, arriving again at their northern resorts early in April. Like some other species, they have a frequent jetting motion with the tail, and the usual tender cooing and gesticulations of the tribe. They feed on various seeds and berries, particularly on those of the toothache tree, near which they are frequently seen in the season. They likewise feed on rice and other small grain, and become easily tamed and reconciled to the cage; in this way they are also occasionally fattened for the table, and are particularly esteemed by the French planters.

The Ground Dove is still a common bird in the South, and wanders occasionally as far north as the District of Columbia.

\section{BLUE-HEADED QUAIL-DOVE.}

\section{STARNENAS CYANOCEPHALA.}

Char. Above, olive brown; crown rich blue, bordered by black; a wide stripe of white from chin to back of neck; below, russet, the breast tinged with purple; throat black, edged with white. Length II inches.

Nest. On a tree or low bush; a platform of loosely arranged twigs.

Eggs. I-2; white; $1.40 \times 1.05$.

This species was observed by Audubon on the island of Key West early in May, - probably soon after its arrival from Cuba, where it abounds. It is rarely to be seen, from its habit of keeping on the ground and living among dense thickets. These birds also inhabit Jamaica and Cuba, and in the latter island they are commonly caught in traps, and brought to market in great numbers, being esteemed as food. "They admit of being tamed, but when tame refuse to propagate. The tail is carried downwards, as in the Partridge. They keep in small bands, are chiefly seen on the ground, on which they often squat, and do not roost on trees. 


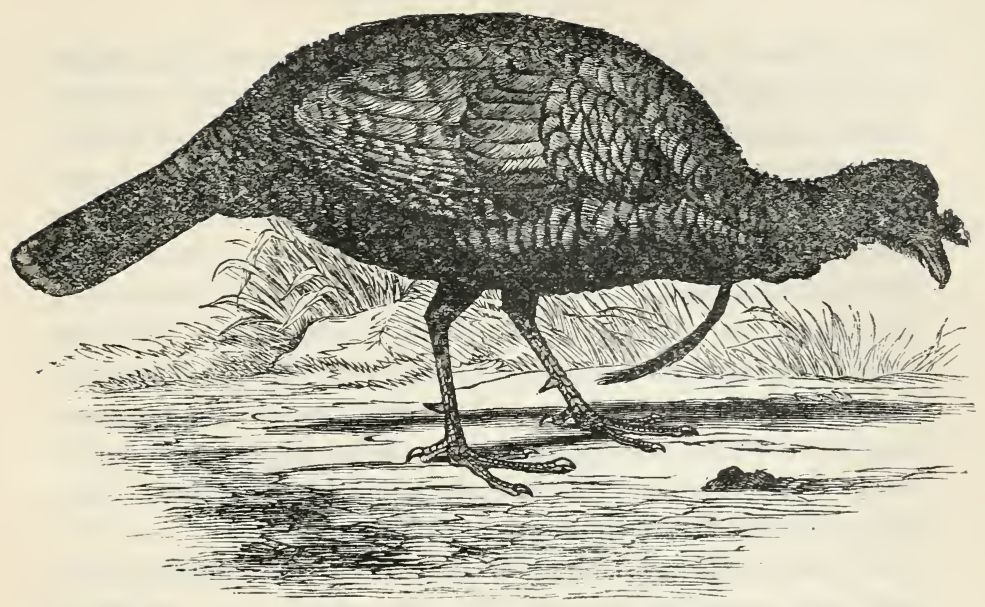

\section{WILD TURKEY.}

\section{MELEAgRis Gallopavo.}

ChAR. General plumage coppery bronze, with metallic reflections of copper color, green, and purple, the feathers edged with rich black; head and neck naked, and of blue color studded with excrescences of purplish red; tail dark chestnut, with bars and a broad subterminal band of black; upper tail-coverts and tips of tail-feathers chestnut; wings dusky, banded by dull white. Male with a conspicuous tuft of bristles depending from the breast. Female similar, but paler and duller Length about 48 inches.

Nest. Under a bush or amid thick undergrowth or tall weeds, or beneath brush heap; a depression in the ground - natural or scratched out - lined with leaves, grass, or feathers.

Eggs. IO-I 5 (usually I2); rich cream color or pale buff, spotted with bright brown; size variable, averaging about $2.50 \times$ r.So.

The Wild Turkey, once prevalent throughout the whole continent of North America, from Mexico and the Antilles to the forests of Lower Canada, is now, by the progress and density of population, chiefly confined to the thickly wooded and uncultivated tracts of the Western States, being particularly abundant in the unsettled parts of Ohio, Kentucky, Illinois, Indiana, and throughout the vast forests of the great valleys of the Mississippi and Missouri. On the banks of the latter 
river, however, where the woods disappear beyond the confluence of the Platte, the Turkey no longer appears; and the feathers of the wings, for the purpose of pluming arrows, form an article of small commerce between the other natives and their Western countrymen. For a thousand miles up the Arkansas and Red River, in the wooded alluvial lands, they are not uncommon. They are met with in small numbers in Tennessee, Alabama, and West Florida, and are also abundant in Texas; but none have been found in the Rocky Mountains or to the westward of them. From the Atlantic States generally they are now nearly extirpated. According to Audubon, a few of these valuable birds are yet found in the States of New York, Massachusetts, Vermont, and Maine.

The Wild Turkey is neither gregarious nor migratory, but from the necessity of wandering after food; it is otherwise resident throughout the whole of the vast region it inhabits, including the greatest diversity of climate, and it is prolific in proportion to its natural resources; so that while in the United States and Canada it only breeds once in the year, in Jamaica and the other West India islands it is said to raise two or three broods in the same period. In quest of mast, these birds therefore spread themselves through the country and insensibly assemble in considerable numbers to the district where their food abounds. These movements are observed to take place early in October. The males, or gobblers, as they are often called, from their note, are now seen apart from the other sex in companies varying from ten to a hundred. The females move singly, or accompanied by their almost independent brood, who all at first assiduously shun the persecuting society of the selfish male. Yet after a while, when their food proves abundant, separate mixed flocks of all ages and sexes often promiscuously join in the bounteous repast. Their migration - very unlike that of the rapid Pigeons - is made almost entirely on foot until their progress is perhaps arrested by a river. Their speed, however, is very considerable, and when surprised they more commonly trust to their legs than their wings, running nearly with the velocity of a 
hound. On meeting with an impediment of this kind, after considerable delay they ascend to the tops of the tall trees, and at the cluck of the leader they launch into the air for the opposite shore. The transit is a matter of little difficulty, though considerable labor, for the older birds; but the younger and less robust sometimes fall short of the bank, and are either drowned or attain the land by swimming. After crossing, it is remarked that they often become an easy prey to the hunter, as they seem bewildered by the new country in which they have arrived, or more probably are fatigued by the novelty and extent of their excursion. After long journeys and privations, particularly in frosty weather or while the ground is covered with snow, they are sometimes reduced to the necessity of making their appearance near farm-houses, where they now and then even associate with the poultry and enter the stables and cribs after grain. In this desultory and foraging manner they spend the autumn and winter.

According to the latitude and the advancement of the season, though always very early in the spring, they begin to be actuated by the instinct of propagation. The males commence their gobbling and court the society of their retiring mates. The sexes roost apart, but in the same vicinity, and at the yelp of the female the gobbling becomes reiterated and extravagant. If heard from the ground, a general rush ensues to the spot; and whether the hen appears or not, the males, thus accidentally brought together, spread out their train, quiver and depress their rigid wings, and strutting and puffing with a pompous gait, often make battle, and directing their blows at the head, occasionally destroy each other in a fit of jealousy. As with our domestic fowls, several hens usually follow a favorite cock, roosting in his immediate neighborhood until they begin to lay, when they withdraw from his resort to save their eggs, which he would destroy if discovered. The females are therefore seen in his company only for a few hours in the day. Soon after this period, however, the male loses his ardor, and the advances of affection now become reversed, the hen seeking out the society of her reluctant mate. In moonlight nights VOL. II. -2 
the gobbling of the male is heard at intervals of a few minutes for hours together, and affords often a gratifying means of their discovery to the wakeful hunter. After this period the males become lean and emaciated so as to be even unable to fly, and seek to hide themselves from their mates in the closest thickets, where they are seldom seen. They now also probably undergo their moult, and are so dry, lean, and lousy, until the ripening of the mast and berries, as to be almost wholly indigestible and destitute of nutriment as food. So constant is this impoverished state that the Indians have a proverb, "As lean as a Turkey in summer."

About the middle of April, in Kentucky, the hens begin to provide for the reception of their eggs and secure their prospects of incubation. The nest, merely a slight hollow scratched in the ground and lined with withered leaves, is made by the side of a fallen log or beneath the shelter of a thicket in a dry place. The eggs, from ro to 15 , are whitish, covered with red dots and measuring two and seven eighths inches in length by two in breadth, and rather pointed. While laying, the female, like the domestic bird, always approaches the nest with great caution, varying the course at almost every visit and often concealing her eggs entirely by covering them with leaves. Trusting to the similarity of her homely garb with the withered foliage around her, the hen, as with several other birds, on being carefully approached sits close without moving. She seldom indeed abandons her nest, and her attachment increases with the growing life of her charge. The domestic bird has been known, not unfrequently, to sit steadfastly on her eggs until she died of hunger. As soon as the young have emerged from the shell and begun to run about, the parent by her cluck calls them around her and watches with redoubled suspicion the approach of their enemies, which she can perceive at an almost inconceivable distance. To avoid moisture, which might prove fatal to them, they now keep on the higher sheltered knolls; and in about a fortnight, instead of roosting on the ground, they begin to fly at night to some wide and low branch, where they still continue to nestle 
under the extended wings of their protecting parent. At length they resort during the day to more open tracts or prairies, in quest of berries of various kinds, as well as grasshoppers and other insects. The old birds are very partial to pecan nuts, winter grapes, and other kinds of fruits. They also eat buds, herbs, grain, and large insects; but their most general and important fare is acorns, after which they make extensive migrations. By the month of August the young are nearly independent of their parent, and become enabled to attain a safe roost in the higher branches of the trees. The young cocks now show the tuft of hair upon the breast and begin to strut and gobble, and the young hens already purr and leap.

One of the most crafty enemies which the Wild Turkey has to encounter is the lynx, or wild-cat, who frequently seizes his prey by advancing round and waiting its approach in ambush.

Like most other Gallinaceous birds, these Turkeys are fond of wallowing on the ground and dusting themselves. When approached by moonlight, they are readily shot from their roosting-tree, one after another, without any apprehension of their danger, though they would dodge or fly instantly at the sight of the Owl. The Gobblers, during the season of their amorous excitement, have been known even to strut over their dead companions while on the ground, instead of seeking their own safety by flight.

In the spring the male Turkeys are called by a whistle made of the second joint-bone of the wing of the bird, which produces a sound somewhat similar to the voice of the female; and on coming up to this call they are consequently shot. They are likewise commonly caught in quadrangular pens made of logs crossing each other, from which is cut a slanting covered passage sufficient to allow the entrance of the Turkey. Corn is then scattered in a train to this cage for some distance as well as within; and the neighboring birds in the surrounding woods having discovered the grain, call on each other by a clucking, and entering one at a time, they become secured in the pen, as, for the purpose of escape, they constantly direct their view upwards instead of stooping to go out by the path which they had entered. 
The male Wild Turkey weighs commonly from 15 to 18 pounds, is not unfrequently as much as 25 , and sometimes, according to Audubon, even 36 . The hen commonly weighs about 9 pounds, and the usual price for a Turkey from the Indians is 25 cents. The domestic bird, when irritated by the sight of any remarkable object, struts out with expanded tail, and drooping his stiffened wings, swells out his wattles, which become red and turgid, and advancing with a grave and haughty air, utters a humming sound, now and then accompanied by a harsh and dissonant ruk, orook, orook, repeating it at every whistle or unusual sound that strikes his ear. The exhibition of a red rag is also sure to excite his wrath and induce him to rush with stupid temerity at the disagreeable object which he exerts himself to injure or destroy. A whole flock sometimes will unite in chasing a common cock from the poultry yard in consequence merely of some whimsical antipathy. From these singular dislikes, this cowardice and folly, the Turkey bears in France the same proverbal imputation of stupidity which in England is bestowed on the Goose. The feathers of the wild bird, attached to strips of bass, were anciently employed by the aborigines for tippets and cloaks, and were so arranged that the brilliant surface formed the outside of the dress; and in later times similar dresses have also been made by the Cherokees.

The Turkey was first sent from Mexico to Spain in the sixteenth century, and in the reign of Henry VIII., in the year I 524, it was introduced into England, and soon after into France and other portions of Europe.

Since Nuttall wrote, this famous bird has become extinct in the New England States, as well as in Canada. Very early in colonial days it had disappeared from the Province of Quebec, for at the height of its abundance this bird was found only within a limited area along the valley of the Ottawa, in the vicinity of the Chaudière Falls, - if I correctly interpret the words of Pierre Bouche, who was governor of the Province in 1663. By some chance several small flocks survived to a much later date in Ontario. McIlwraith reports that it was numerous along the southern border as late as 1856 , and he thinks a few still remain. 
In New England, as in Quebec, the early settlers made havoc with the flocks, and drove into the wilderness those they did not destroy. John Josselyn, writing in 1672 , states that the bird was becoming rare, while thirty years before it had been abundant; but probably Turkeys were plentiful during part, at least, of the last century, though frequenting less accessible localities. They were, however, being gradually reduced in numbers by the combined attacks of the whites and Indians, and the lessened flocks continued retiring farther and farther from the settlements.

In Connecticut the year 1813 is given as that in which the last example was seen, while a few remained hidden among the hills of southern Vermont until I 842 ; and the last Wild Turkey that is known to have been seen in Massachusetts was shot on Mount Tom in 1847 .

At the present day some small flocks are to be found in a few of the heavily timbered and thinly populated districts of Michigan, Illinois, Indiana, Ohio, and Pennsylvania, and in the wild mountainous regions of the Southern States. A few may be hidden also in isolated forests in Louisiana and Mississippi; but in all of these States the number of birds must be small, and is being rapidly reduced. Probably nowhere east of the Mississippi River are Turkeys at all numerous, excepting in Florida, and in that State they may continue numerous long after they have been exterminated elsewhere, owing to the almost inaccessible nature of the country to which the remaining flocks have retreated. Beyond the Mississippi these birds are still common, especially along the lower Rio Grande and (probably) in Indian Territory and southern Missouri, though Colonel Goss reports them diminishing rapidly in Kansas.

Farther west, Wild Turkeys are plentiful; but the major portion of these are of the Mexican form, which differs from the type principally in having the upper tail-coverts and the tips of the tailfeathers whitish instead of chestnut.

Note. - The Florida Wild Turkey ( $M . g$. osceola) has lately been separated from true gallopavo, being smaller and with "broken white markings" on the wings. 


\section{ENGLISH PHEASANT.}

\section{Phasianus COLChicus.}

CHAR. Male : plumage exquisitely beautiful, but too variegated to be minutely described in a short paragraph. The principal colors are brown of several shades, orange-red, yellow, and black ; and these are distributed in handsome markings and pencillings. Head and neck steel blue, with metallic reflections of green and purple; breast golden red, each feather edged with velvet black; tail-feathers very long, - the two middle feathers sometimes measuring two feet, - yellowish brown, with narrow bars of black. Female : duller ; yellowish brown, with markings of darker brown and some black. Length of male, including tail-feathers, about 3 feet; of female about 2 feet.

Nest. In thicket or dense hedge, a slight hollow scratched out by female, partially lined with loosely arranged leaves and grass. Occasionally a deserted nest in a tree has been used.

Eggs. 8-14 (usually about 12, sometimes I6 or 20), olive brown, sometimes bluish green; $1.85 \times 1.45$.

I have called this the "English" Pheasant to distinguish it from other species that have been introduced into this country. In England it is known as "Pheasant," or "Common Pheasant." It is not indigenous to Great Britain, though when it was introduced there is not known, some writers asserting that it was carried by the Romans, while others consider the Norman Conquest responsible for its introduction. The true home of the bird is the valleys of the Caucasus and the eastern shores of the Caspian Sea, but it has been introduced into almost every country of Europe. In Great Britain very few thorough-bred specimens are to be found, most of the birds displaying a collar of white, - which proves their relationship to the Ring-necked Pheasants brought from China. Other species, as well, have been introduced and successfully bred with both true colchicus and hybrids.

Within a few years the present species has been introduced into this country by Mr. C. B. Cory - who loosed several pairs on Great Island, off the southern shore of Cape Cod - and by a club of sportsmen who have stocked Jekyl Island, on the Georgian coast. Both colonies have become naturalized and are increasing. Several other species have been imported from China and Japan, and liberated in Oregon and British Columbia, where they are increasing rapidly. 


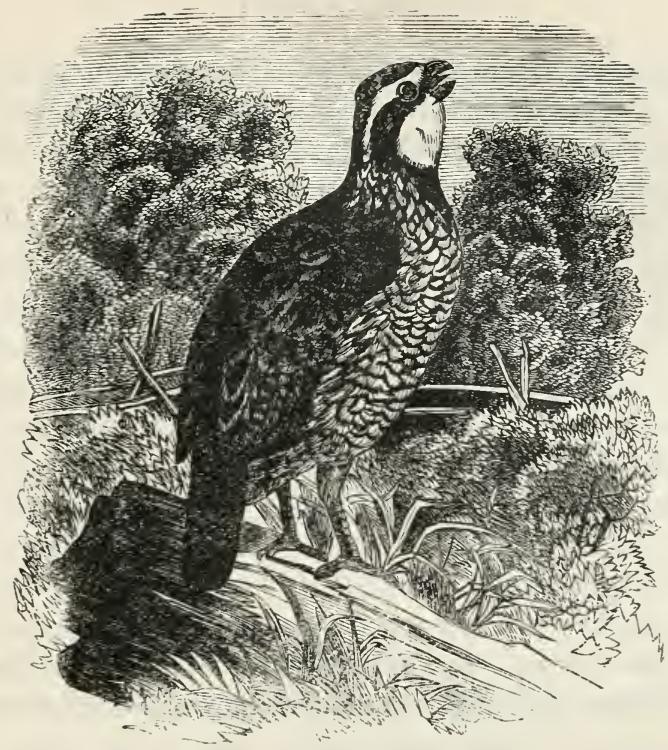

BOB-IVHITE.

QUAIL. PARTRIDGE.

COLINUS VIRGINIANUS.

CHAR. Above, reddish brown, mottled with gray, black, white, and buff; stripe over eyes and patch on throat white or buffy white, darkest in females; lower parts buffy white with brown and black markings. Length about 10 inches.

Nest. In pasture or field, hid amid thick growth or under a bush or tuft of long grass ; made of grass, weeds, and leaves loosely arranged.

Eggs. 8-20 (usually I 5 to I8, and a set of 28 has been recorded); white; I.20 X 1.00 .

The Partridge of America, exceedingly prolific, has extended its colonies from the inclement coasts of New England and the western plains of Missouri to the mild latitudes of Mexico and Honduras. In Jamaica, where it has long been introduced and naturalized, the inhabitants distinguish it as the Partridge, - an appellation sufficiently prevalent in various parts of the United States. At the north, these birds are rarely seen to the 
extremity of New Hampshire, and this limit, no doubt, is determined by the length and severity of the winters which prevail in this rigorous climate. They seldom migrate, except to short distances in quest of food, and consequently often perish beneath deep drifts of snow, so that their existence is rendered impossible in the Arctic winters of our high latitudes. Indeed, sometimes they have been so thinned in this part of the country that sportsmen acquainted with their local attachments have been known to introduce them into places for breeding and to prevent their threatened extermination. So sedentary are the habits of this interesting bird that until the flock is wholly routed by the unfeeling hunter they continue faithfully attached to the neighborhood of the spot where they have been raised and supported.

Johnston, Willoughby, and Ray distinguished the Mexican bird by the quaint title of the "Quail's Image." 'The first settlers of New England also thought they saw in this familiar bird the Quail of the country they had relinquished. The two birds are, however, too different to require any critical comparison. Ours is even justly considered by European ornithologists as the type of a peculiar American genus, to which has been given the name of ORTyx by Stevens, - the original appellation of the Quail, or Yerdix coturnix, as known to the ancient Greeks. The name of Courn, contracted by Buffon from the barbarous appellation of some Mexican species, has been adopted by Cuvier, Temminck, and Vieillot.

Although there is some general resemblance between the Quail of the old and new continent in their external appearance, their habits and instincts are exceedingly different. The true Quail is a noted bird of passage, with a favorable wind leaving Europe for the warmer parts of Asia at the approach of winter ; and with an auspicious gale again returning in the spring, in such amazing numbers that some of the islands of the Archipelago derived their name from their abundant visits. On the west coast of Naples, within the small space of four or five miles as many as a hundred thousand have been taken in a day by nets. Our Partridge, though occupying so wide an extent of the 
Atlantic and Western States, and even penetrating into Mexico, is scarcely ever a bird of passage; it only assembles in single families, which may sometimes be reduced to four or five by accidents, and at others increased to twenty or thirty. The instinctive sociability of this bird continues uniformly, until interrupted in the spring by the desire of pairing. At this season the eager call of the male is often heard, but it nearly ceases when he is mated, and is only long continued by those who are dissatisfied and have been unsuccessful in their connections; and by imitating the reply of the female, the male is easily decoyed to approach towards the enemy who thus allures him. On these occasions, when the rival candidates happen to meet, they exhibit, the only time in their lives, a quarrelsome disposition, fighting with obstinacy, until the contented victor at last gains the field. with his submissive mate. The conjugal selection being now concluded, they are not exceeded by any of the feathered race in their mutual attachment and common affection for their brood. In the vagrant Quail, the want of reciprocal and durable attachment gives rise to a wholly different character in instinctive morality, a common concubinage prevailing among them, as with our Cow Troopials. Instead of the mild sociability so prevalent with our Partridge, they are pugnacious to a proverb: "As quarrelsome as Quails in a cage," was an ancient reproof to striving children. Their selfishness forbids all mutual alliance, and they only find safety from each other in roaming solitude.

Partridges are not partial to the depths of the forest, though they sometimes seek the shelter of trees, and perch on the low branches or hide amongst the brush and underwood. Their favorite food, however, commonly conducts them to the open fields, where they glean up various kinds of grain, and are particularly fond of rye and buckwheat, as well as Indian corn; and when not too much disturbed by the sportsman, will often, particularly in the autumn and winter, fearlessly assemble along the most public roads, or around the barn and stable, in search of a scanty pittance among the domestic fowls; like them, also, very industriously scratching up 
straw, and probably the ground, in quest of grain and insects which, with seeds and various kinds of buds and berries, as well as broken acorns, according to the season, often constitute a considerable part of their native diet.

Remaining with us commonly the whole year, the little social band often suffer from the inclemency of the seasons. At this time they perch together on some rising ground beneath the shelter of brush or briers, and forming a close circle, with their heads outward to discern any approach of danger, they thus greatly aid each other by their mutual warmth to resist the chilling effects of frost. It is probable, however, they have no great fear of snow when together, as they may often be seen patiently encountering the storm, as its white wreaths invade them, and frequently on the arrival of a thaw, unfortunate coveys, suspecting no danger, are found buried beneath the inundating waste, huddled together in their accustomed manner. They are observed even, on the approach of danger, to rush into the snow for shelter; and it is only when the drift becomes so consolidated by a frozen glazing of sleet as to resist all their efforts to move that it proves their grave, rather than their retreat.

As they happen to afford a favorite and delicate article of food, every means which gun and trap can effect are put in operation against the innocent race. Their very sociability often affords means for their destruction; for while crowded together in a ring, a dozen or more have been killed at a shot; and the small remains of the unfortunate covey, feeling their weakness and solitude, are said to join some neighboring brood, for whom they soon form the same friendly attachment they had for the fraternity they have lost.

From the latter end of August to the month of March, the markets of all our principal cities are often stocked with this favorite game.

Some time in the month of May the Quail, at the bottom of a sheltering tuft of grass, scratches out a cavity for her nest, which is usually lined substantially with such withered leaves and dry grass as happen to be convenient. Though generally 
open, it is sometimes partially covered by art and accident; but no studious concealment is ever practised by this artless bird. The eggs are from ${ }_{5} 5$ to 20 ; and unlike the spotted charge of the true Quail, are white, and rather suddenly narrowed at the smaller end. The period of incubation is about four weeks. They have generally two broods in a season, as young birds scarcely fledged may be observed here as late as the beginning of October. When this happens, it is not uncommon to find both coveys still associating with their parents. Like most other Gallinaceous birds, the young run about as soon as they are freed from the shell, and gain the complete use of their wings in about a fortnight from hatching. They are now attentively conducted by the mother, and occasionally by either parent, in quest of their appropriate food, and called together in a voice resembling the low twittering of chickens. At times they shelter beneath the wings of the mother; but if the little busy flock are startled by danger, artifice rather than courage is the instinctive means of safety employed by all the party. The parents flutter in the path in real as well as simulated distress ; and the young, instantly aware of their critical situation, make no useless attempts to fly, but vanish singly, and closely hiding among the withered grass, which they almost resemble in color, are thus fortunately rendered nearly altogether invisible. The alarm at length dissipated, the tender, cautious call of the parents again reassembles the little grateful family.

The eggs of the Quail have been often hatched by the domestic hen; but the vagrant disposition of the diminutive brood, the difficulty of procuring their proper food, and the superior attention they require over chickens, prevent the possibility of their domestication; and even when they have survived the winter in this state, the return of spring leads them to wander off in compliance with that powerful instinct which inspires them to a mutual separation.

So familiar are these little birds that occasionally, as described by Wilson, they have been known to lay their eggs in the nest of the domestic hen, when situated at any considerable 
distance from the habitation. From two eggs thus deposited were raised a pair of young Quails which, when abandoned by the hen, showed their social attachment by accompanying the cows. These they followed night and morning from the pasture, and when the cattle were housed for the winter our little Partridges took up their humble abode in the stable. But even these, so docile, and separated from all their race, on the return of spring obeyed the instinct of nature, and wandered away to their congenial woods and thickets. It is probable at times, as asserted by observers, that our Quails, like some other birds, lay their eggs in the nests of each other, - a fact which would only be in accordance with their usual friendship and mutual familiarity.

The American Quail, according to Wilson, has likewise, in turn, been employed to hatch the eggs of the domestic hen, which she brought out, defended, and fed as her own offspring. She even succeeded in imparting to them a portion of her own instinct to such a degree that when alarmed they hid in the grass and ran timidly from sight like so many young Partridges, exhibiting all the wildness of unreclaimed birds. A flock of these Quails, however attentively fed, and confined, always exhibit a great degree of fear and shyness; their attachments remaining truly natural, they appear only to recognize the company of each other. But a solitary individual becomes friendly and familiar to the hand that feeds it, and for want of more congenial society forms a similar attachment to its keeper. In the month of September, the little brood, now nearly full grown, assemble in families; and at this period, as well as in the spring and early part of summer, the clear, whistling call of the male is often heard. This well-known note is very similar to the pronunciation of the words 'bob white, to which is often added a suppressed introductory whistle. While seated, perhaps on a fence-rail, or the low limb of an orchard tree, this peculiar note, sometimes interpreted in showery hay-weather into the augury of more wert, more wet, continues uninterruptedly, at short intervals, for more than half an hour at a time. Du Pratz says these birds are known 
to the aborigines by the name of ho-ouy ('ho-wee), which is also imitative of the call they sometimes utter, as I have heard, early in the morning, from a partly domesticated covey. When assembled in a corner and about to take wing, the same low, chicken-like twittering, as is employed by the mother towards her more tender brood, is repeated; but when dispersed, by necessary occupation, or alarm, they are reassembled by a loud and oft-repeated call of anxious and social inquiry. This note, 'ho-wee, is, however, so strongly instinctive as to be commonly uttered without occasion, by the male even in a cage, surrounded by his kindred brood; so that this expression, at stated times, is only one of general sympathy and satisfaction, like that of a singing bird uttered when solitary and confined to a cage.

In consequence of the shortness and concavity of its wings, in common with most other birds of the same family the American Quail usually makes a loud whirring noise in its flight, which is seldom long continued, always laborious, and generally so steady as to afford no difficult mark for the expert sportsman. According to the observations of Audubon, the flight of our Partridge and Grouse, when not hurried by alarm, is attended with very little more noise than that of other birds. Whatever may be the fact, when our little Partridges alight on the ground, they often run out to very considerable distances, when not directly flushed, and endeavor to gain the shelter of briers and low bushes, or instinctively squat among the fallen leaves of the woods, from which, with their brown livery, it is difficult to distinguish them. No great destruction is made among them while on the wing, as they do not take a general alarm on being approached, but rise at intervals only by two or three at a time.

Bob-White has been so long and so persistently called by this nickname that that conservative body, the American Ornithologists' Union, has been constrained to approve of it, and has dignified it with their sanction, - throwing to the winds for one brief moment the "canon of priority," and adopting Seebohm's favorite auctorum plurimorum. The bird is also known as "Quail" in 
New England, and as "Partridge" farther south. Bob-White is still a common bird in southern New England, though of somewhat local distribution. It is rarely found north of Massachusetts, but a few scattered flocks are occasionally met with along the southern borders of the three northern States.

In Canada it occurs only in the southern peninsula of Ontario north to Gravenhurst, and though quite common near London and Hamilton, is reported "rare" about Toronto and Lucknow.

Note. - The Florida Bob-white (Colinus virginianus floridanus) is a smaller race with darker colors and broader black markings. It is found in the northern and middle regions of Florida.

The CUBAN BoB-White (C. virginianus cubanensis) differs chiefly from the type in the markings of the plumage. It is restricted in the United States to the southwestern or tropical region of Florida.

The Messina QuaIL (Coturnix coturnix) has been imported from Europe by hundreds during the last fifteen years and let loose in various parts of the country; but though a few young and old birds appeared in the neighborhood for a year or two following their release, the effort to naturalize the species is considered a failure. In 1878 a number were released near St. Stephen, New Brunswick, and during the next three years I heard occasionally of small bevies being seen near the Bay of Fundy shore between St. Stephen and St. John, as well as in the Kennebecasis valley as far east as Sussex; but either the climate or the food was unsuited to them.

\title{
RUFFED GROUSE.
}

\author{
PHEASANT. PARTRIDGE. BIRCH PARTRIDGE.
}

BONASA UMBELLUS.

CHAR. Upper parts mottled brown and gray, with markings of black and dull white; head with crest; a "ruff" of long black feathers on sides of neck; tail with broad sub-terminal band of black; under parts pale tawny, throat unmarked, breast and belly barred with brown; legs completely covered with feathers. Length I 6 to I8 inches.

Nest. Amid a thicket or under cover of a bush, - usually on border of heavy timber; a mere cushion of leaves, grass, moss, etc.

Eggs. 6-20 (usually Io or I2); color varies from pale cream to dark buff, often marked with faint spots of brown; I.60 × I.I 5 . 
This beautiful species of Grouse, known by the name of Pheasant in the Middle and Western States, and by that of Partridge in New England, is found to inhabit the continent from Hudson Bay and the parallel of $56^{\circ}$ to Georgia, but are most abundant in the Northern and Middle States, where they often prefer the most elevated and wooded districts; and at the South they affect the mountainous ranges and valleys which border upon or lie within the chains of the Alleghanies. They are also prevalent in the Western States as far as the line of the Territory of Mississippi; and though not found on the great Western plains, they reappear in the forests of the Rocky Mountains and follow the Columbia nearly to the Pacific.

Although, properly speaking, sedentary, yet at the approach of autumn, according to Audubon, they make, in common with the following species, partial migrations by single families in quest of a supply of food, and sometimes even cross the Ohio in the course of their peregrinations. In the northern parts of New England they appear also to be partially migratory at the approach of winter, and leave the hills for lower and more sheltered situations. So prompt, indeed, at times are their movements that in November, I83I, in travelling nearly to the extremity of New Hampshire, not a single bird of the species was now to be seen, as they had no doubt migrated southward with the first threatening and untimely snow which had fallen, being indeed so unusually abundant previousiy to that period as to sell in the market of Boston as low as twelve and a half cents apiece. Although elevated countries and rocky situations thickly overgrown with bushes and dense evergreens by rivers and brooks are their chosen situations, yet at times they frequent the lowlands and more open pine-forests in the vicinity of our Northern towns and cities, and are even occasionally content to seek a retreat far from their favorite hills in the depth of a Kentucky cane-brake or the barrens of New Jersey. They are somewhat abundant in the shrubby oak-barrens of Kentucky and Tennessee, in which their food abounds. This consists commonly in the spring and fall of 
the buds of trees, the catkins of the hazel and alder, even fern-buds, acorns, and seeds of various kinds, among which I have met with the capsules, including the seeds of the common small Canadian Cistus (Helianthemum). At times I have seen the crop almost entirely filled with the buds of the apple-tree, each connected with a portion of the twig, the wood of which appears to remain a good while undigested; cinquefoil and strawberry-leaves, buds of the Azaleas and of the broad-leaved Kalmia, with the favorite partridge-berries (Gaultheria procumbens), ivy-berries (Cissus hederacea), and gravel pebbles are also some of the many articles which form the winter fare of our bird. In summer it seems often to prefer berries of various kinds, particularly dewberries, strawberries, grapes, and whortleberries.

In the month of April the Ruffed Grouse begins to be recognized by his peculiar drumming, heard soon after dawn and towards the close of evening. At length, as the season of pairing approaches, it is heard louder and more frequent till a later hour of the day, and commences again towards the close of the afternoon. This sonorous, crepitating sound, strongly resembling a low peal of distant thunder, is produced by the male, who as a preliminary to the operation stands upright on a prostrate log, parading with erected tail and ruff and with drooping wings in the manner of the Turkey. After swelling out his feathers and strutting forth for a few moments, at a sudden impulse, like the motions of a crowing Cock, he draws down his elevated plumes, and stretching himself forward, loudly beats his sides with his wings with such an accelerating motion, after the first few strokes, as to cause the tremor described, which may be heard reverberating in a still morning to the distance of from a quarter to that of half a mile. This curious signal is repeated at intervals of about six or eight minutes. The same sound is also heard in autumn as well as spring, and given by the caged bird as well as the free, being, at times, merely an instinctive expression of hilarity and vigor. To this parading ground, regularly resorted to by the male for the season, if undisturbed, the female flies with alacrity; but, 
as with other species of the genus, no lasting individual attachment is formed, and they live in a state of limited concubinage. The drumming parade of the male is likewise often the signal for a quarrel; and when they happen to meet each other in the vicinity of their usual and stated walks, obstinate battles, like those of our domestic fowls for the sovereignty of the dung-hill, but too commonly succeed. When this sound, indeed (according to Audubon), is imitated by striking carefully upon an inflated bladder with a stick, the jealous male, full of anger, rushes forth from his concealment and falls an easy prey to the wily sportsman.

Some time in May a female selects some thicket or the side of a fallen log in the dense part of the woods for the situation of her nest. This is formed merely of a handful of withered leaves collected from the surrounding and similar surface of the ground. The eggs, ten to fifteen, more or less, are of a uniform dull yellowish color. The young run about as soon as hatched, and in about a week or ten days are able in some degree to make use of their wings. The mother now leads them out in search of their appropriate and delicate food, and broods them at night beneath her wings like the common hen; she likewise defends them by every stratagem which affection can contrive. On the appearance of an enemy she simulates lameness, to impose on the unwelcome spectator; while the young themselves squat on the ground, by which they are secured, from their similarity to its surface.

During summer these birds are fond of basking and dusting themselves, and for this purpose are now and then seen in the public roads. When flushed, and on the instant of rising from the ground, the bird usually utters a cackling note quickly repeated about half a dozen times, and also before rising utters a very peculiar lisping whistle. Like the Ptarmigan, the Ruffed Grouse when alarmed in winter is frequently known to plunge into the soft snow and burrow out at such a distance as frequently to elude the pursuit of the hunter. Besides other successful methods of destruction which await the devoted Grouse, snares and traps of various kinds are employed to VOI. II. -3 
arrest them. They are even smoked to death in the same manner as the Wild Pigeons in the Western country, while sleeping harmlessly and unsuspectingly on their leafy roosts. By this system of indiscriminate extirpation they are now greatly thinned throughout the more populous parts of the Union, and sell in Philadelphia and New York from seventyfive cents to a dollar apiece. The common price of these birds (decidedly, as I think with Audubon, superior in flavor to the Pinnated Grouse) is in the market of Boston from 40 to 50 cents the pair, showing how much more abundant the species is in the rocky regions of New England than in any other part of America. Deleterious effects have sometimes occurred from eating this game, supposed to arise from their feeding on the buds of the broad-leaved Kalmia; yet most persons eat them with safety at all seasons of the year, even when these kind of buds have been found almost filling the stomach.

The systematists have recently separated the Ruffed Grouse distributed over the Northern and Middle States and the more southern sections of Canada from those found along the northern border of New England and in the adjacent portions of Canada, making the latter a sub-species and giving to it the name of CANAdian RUFFed Grouse (B. umbellus togata).

The Canadian race is in general darker colored, and lacks a reddish tinge on the back; also the markings of the under parts are more conspicuous.

The range of true umbellus is from Vermont to Virginia and the hills of Georgia, and west to Minnesota.

"Birch Partridges," as they are commonly called by the gunners of northern Maine and the Maritime Provinces, are still fairly abundant, though the markets have been generously supplied with them every year. 


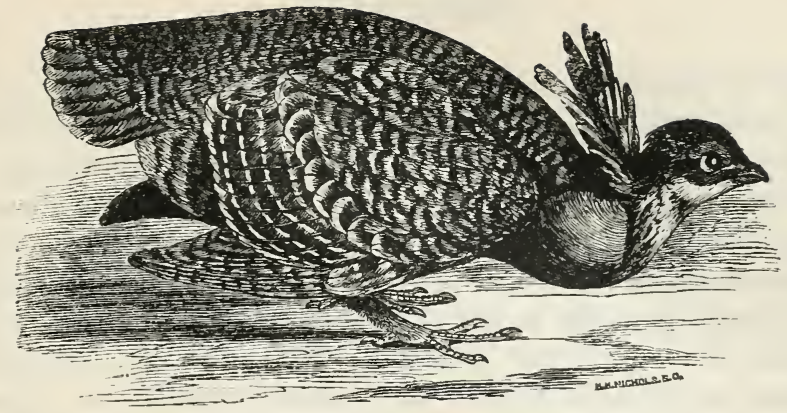

PRAIRIE HEN.

PRAIRIE CHICKEN. PINNATED GROUSE.

TYMPANUCHUS AMERICANUS.

CHAR. Above, brownish ochraceous, tinged with gray; back barred with black; below, white, barred with dusky brown; throat buffish; head with slight crest; erectile tufts of 7 to Io long stiff feathers on sides of neck, and below these, patches of bare and elastic skin. Length about 18 inches.

Nest. On the open prairie amid tufts of long grass or at the foot of a bush; a slight hollow scratched out and thinly lined with grass and feathers.

Eggs. 8-16 (usually about 12); dull buff or greenish yellow, sometimes with a reddish tinge, and occasionally spotted slightly with brown; $1.70 \times 1.25$.

Choosing particular districts for residence, the Grouse, or Prairie Hen, is consequently by far less common than the preceding species. Confined to dry, barren, and bushy tracts of small extent, these birds are in several places now wholly or nearly exterminated. Along the Atlantic coast they are still met with on the Grouse plains of New Jersey, on the brushy plains of Long Island, in similar shrubby barrens in Westford, Connecticut, in the island of Martha's Vineyard on the south side of Massachusetts Bay, and formerly, as probably in many other tracts, according to the information which I have received from Lieut.-Governor Winthrop, they were so common on the ancient bushy site of the city of Boston that laboring people or servants stipulated with their employers not to have the Heath Hen brought to table oftener than a few times in the 
week. According to Wilson, they are also still met with among the scrub-oak and pine-hills of Pocono, in Northampton county, Pennsylvania. They are also rather common throughout the barrens of Kentucky and on the prairies of Indiana, and as far south as Nashville in Tennessee, but I believe nowhere more abundant than on the plains of Missouri, whence they continue to the Rocky Mountains. Dislike of moisture, as with the Turkey, but principally the nature of their food, appears to influence them in the choice of their resort. The small acorns of the dwarf-oaks, and various kinds of wild fruits, as strawberries, whortleberries, and partridge-berries, with occasional insects abounding in these wooded thickets, appear to be the principal inducement to their residence; from which they rarely wander at any season, unless compelled by a failure of their usual food, and so become, notwithstanding the almost inaccessible nature of the ground, a sure prey to the greedy and exterminating hunter. In the Western States, where they appear as an abundant species, they are at times observed to traverse the plains and even cross extensive rivers in quest of the means of subsistence. In winter they likewise feed on buds as well as mast, sometimes swallowing leaves, and occasionally the buds of the pine. At times, if convenient, they have been known to visit the buckwheat field for their fare, or even devour the leaves of clover. In wintry storms they seek shelter by perching in the evergreens; but in spring and summer they often roost on the ground in company. They feed mostly in the morning and evening; and when they can stir abroad without material molestation, they often visit arable lands in the vicinity of their retreats. In the inclemency of winter, like the Quail, they approach the barn, basking and perching on the fences, occasionally venturing to mix with the poultry in their repast, and are then often taken in traps.

The season for pairing is early in the spring, in March or April. At this time the behavior of the male becomes remarkable. Early in the morning he comes forth from his bushy roost and struts about with a curving neck, raising his ruff, expanding his tail like a fan, and seeming to mimic the ostenta- 
tion of the Turkey. He now seeks out or meets his rival, and several pairs at a time, as soon as they become visible through the dusky dawn, are seen preparing for combat. Previously to this rencontre, the male, swelling out his throat, utters what is called a tooting, - a ventriloquial, humming call on the female, three times repeated; and though uttered in so low a key, it may yet be heard three or four miles in a still morning. About the close of March in the plains of Missouri we heard this species of Grouse tooting or humming in all directions, so that at a distance the sound might be taken almost for the grunting of the bison or the loud croak of the bull-frog. While uttering his vehement call, the male expands his neck-pouches to such a magnitude as almost to conceal his head, and blowing, utters a low drumming bellow like the sound of ' $k$ '-tom-boo, ' $k$ '-tom-boo, once or twice repeated, after which is heard a sort of guttural squeaking crow or $k \bar{o} \dot{a} k, k \bar{o} a k, k o a k$. In the intervals of feeding we sometimes hear the male also cackling, or as it were crowing like ' $k o$ ko ko ko, kooh kooh. While engaged in fighting with each other, the males are heard to utter a rapid, petulant cackle, something in sound like excessive laughter. The tooting is heard from before daybreak till eight or nine o'clock in the morning. As they frequently assemble at these scratching-places, as they are called, ambuscades of bushes are formed round them, and many are shot from these coverts.

The female carefully conceals her nest in some grassy tussock on the ground, and is but seldom discovered. The eggs are from ten to twelve, and of a plain brownish color. The young are protected and attended by the female only, who broods them under her wings in the manner of the common fowl, and leads them to places suitable for their food, sometimes venturing with her tender charge to glean along the public paths. When thus surprised, the young dart into the neighboring bushes, and there skulk for safety, while the wily parent beguiles the spectator with her artful pretences of lameness. The affectionate parent and her brood thus keep together throughout the whole season. By the aid of a dog 
they are easily hunted out, and are readily set, as they are not usually inclined to take wing. In the prairies, however, they not unfrequently rise to the low boughs of trees, and then, staring about without much alarm, they become an easy prey to the marksman.

The ordinary weight of a full-grown bird is about three pounds, and they now sell, when they are to be had, in New York and Boston, from three to five dollars the pair. They have been raised under the common hen, but prove so vagrant as to hold out no prospect of domestication.

This species is common now only in the prairie region of Indiana and Illinois and westward; a few scattered flocks occur in the adjacent States and in southwestern Ontario.

It is supposed that the Pinnated Grouse, which occurred in the Atlantic States in Nuttall's day, should be referred to the Heath Hen, - a distinct race, a remnant of which is still found on Martha's Vineyard.

\section{HEATH HEN.}

\section{TyMrPanuchus CUPIDO.}

Char. Similar to the Prairie Hen, but reddish brown above, and beneath rusty white, barred with dark reddish brown ; neck tufts composed of four or five acutely lance-pointed feathers.

Nest. In woodland of scrub-oak or pine; a slight hollow, thinly lined with leaves and feathers.

Eggs. 6-8; yellowish green and unspotted; 1.70 $\times$ I.25.

This interesting bird was discovered in 1885 by Mr. William Brewster; or rather, to be more exact, at that date the discovery was made that the birds of Martha's Vineyard were distinct from the Western Prairie Hen, - distinct in coloration as well as in habits, - the one being a bird of the open prairie, the other haunting groves of scrub-oak or low pines, and feeding largely on acorns.

Mr. Brewster tells us ("Auk," January, I885) that the bird is common on Martha's Vineyard, and is so well protected as not likely to become extinct. 


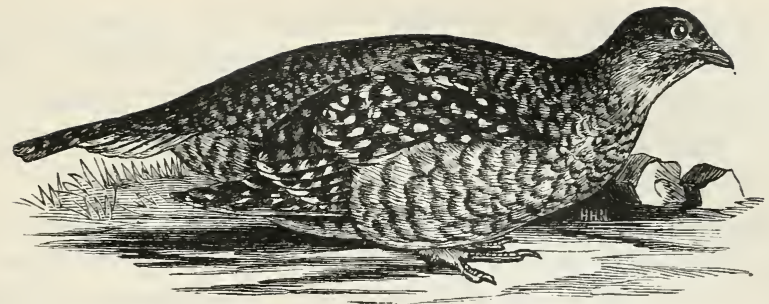

SHARP-TAILED GROUSE.

PRAIRIE CHICKEN.

Pediocetes phasianellus.

CHAR. Above, black and brown irregular stripes; wings and wing. coverts spotted with white; head with slight crest, a naked patch of orange color over the eyes; two middle tail-feathers longer than the others; lower parts white, with dark V-shaped markings; legs and feet feathered. Length about 17 inches.

Nest. In open woodland or on border of grove, or in thicket along a stream, hidden under brush or at foot of a low bush; a slight depression in the ground scantily lined with grass and feathers.

Eggs. 6-14 (usually about I2); reddish brown or yellowish brown, marked with fine spots of a darker shade of brown; $1.70 \times 1.25$.

This curious species of Grouse is also principally an inhabitant of the coldest habitable parts of the American continent, being found around Hudson Bay in the larch thickets throughout the whole year. It is not uncommon in the forests of the Rocky Mountains, and Mr. Say saw it in the spring likewise in Missouri but little beyond the settlements, at which season it also visits the vicinity of Fort William, on Lake Superior. We met with it on Larimie's Fork of the Platte in June, where it was breeding. As an article of food it proved plump and well flavored, superior almost to any other of the large species in the United States. These birds are, as usual, shy and solitary, living oniy in pairs throughout the summer, when they subsist much upon berries. In autumn and winter they are seen moving in families, and frequent the thickets of juniper and larch, on whose buds, as well as those of the birch, alder, and poplar, they now principally live. They usually keep on the ground, 
but if disturbed, take to trees. When hard pressed by the hunter, they sometimes seek safety by plunging into the snow, and quickly burrowing beneath it, come out at a distance, and often from a situation the least expected, so that they frequently make good their retreat from their enemies.

The Sharp-tailed Grouse makes its nest on the ground, near some bush, with loose grass and a few feathers; the eggs are from 9 to $\mathbf{3} 3$, white, with dusky spots. The young are hatched about the middle of June, and utter a puling note something like chickens. Unsuccessful attempts have been made to domesticate them. The male has a shrill, rather feeble, crowing note ; and both sexes, when disturbed, and on taking wing, repeat a reiterated cry of $k u k, k u k, k u k$, accompanied by a smart flirting of the tail-feathers, nearly similar to the opening and closing of a fan. In the breeding-season the male struts about proudly, in the usual manner of the genus and order to which he belongs. The weight of this bird is about two pounds, and the flesh is light brown when cooked, and is much esteemed.

The northern limit of the range of this species, according to Richardson, is Great Slave Lake, in 6r degrees; and its most southern recorded station is in $4 \mathrm{I}$ degrees, on the Missouri. It abounds on the outskirts of the Saskatchewan plains, and is found throughout the woody districts of the fur countries, in open glades and thickets on the borders of lakes, particularly in the partially cleared tracts contiguous to the trading posts. In winter, like the Pinnated Grouse, it perches generally on trees, but in summer it is much on the ground, and is at all times associated in coveys of ten to sixteen individuals. Early in spring a family of these birds selects a level spot, whereon they meet every morning, and run round in a circle of fifteen or twenty feet diameter, on which the grass becomes worn quite bare. On approaching this ring, the birds squat close to the ground, but in a short time stretch out their necks to survey the intruder, and if not scared by any nearer advance, they soon resume their circular course, some running to the right, and others to the left, thus meeting and crossing each 
other. These "Partridge dances" last for a month or more, until concluded by the more serious employ of incubation. In imitation of this curious amusement of the Sharp-tailed Grouse, the Indians of the upper Missouri have what they call a Partridge-Dance, in which the old men chiefly join.

The true Sharp-tail is not found south of the Canadian border. It occurs in the wooded districts along the north shore of Lake Superior, and thence north to the timber limit, and west to British Columbia and Alaska.

Note. - The "Prairie Chicken" is a paler race, called by the systematists the Prairie Sharp-Tailed Grouse ( $P$. phasianellus campestris). It differs from the type in displaying more of the gray shades, with tints of buff and drab, and less of the red tinge in the upper parts. Also the dark tints are much paler in campestris, so that the white spots on the wings do not stand in such marked contrast. This sub-species ranges east to the prairie districts of Illinois and Wisconsin, and is reported by Mr. Thompson as abundant in Manitoba.

\section{CANADA GROUSE.}

SPOTTED GROUSE. SPRUCE PARTRIDGE.

DendRagapus CaNadeNsis.

CHAR. Male: prevailing color black, varied above irregularly with gray and tawny; below, spotted with white; a comb of reddish colored naked skin over the eyes; tail with terminal band of orange brown; legs feathered to the toes. Female : prevailing color brown, varied with black and gray. Length about 16 inches.

Nest. In deep forest, hidden by $a$ low hanging branch; a mere depression in the turf; sometimes leaves, grass, and bits of moss are loosely arranged as a lining.

Eggs. 8-14 (usually about 10); ground color varies from dull white to buff and reddish brown, marked irregularly with several shades of reddish and orange brown and umber; $1.70 \times 1.20$.

This dark species of Grouse inhabits the cold regions of Hudson Bay up to the $67^{\text {th }}$ parallel, throughout the whole year, where it frequents the bushy plains. To the south of this country it appears to seek out the alpine elevations, 
being met within the White Mountains of New Hampshire and throughout a great portion of the Northern Andes, towards the sources of the Missouri and Oregon. In winter it visits Canada, the interior of Maine, Michigan, sometimes the State of New York; and it even breeds round Halifax in Nova Scotia, as well as in the State of Maine. In Canada it is known by the name of the Wood Partridge; by others it is called the Cedar, or Spruce, Partridge. Sometimes the birds are sent in a frozen state from Nova Scotia and New Brunswick to Boston.

The favorite resort of this species is in pine and spruce woods and cedar swamps, which they frequent in the winter for the purpose of feeding on the buds, oily seeds, and evergreen foliage, to which they also add juniper-berries. Their flesh, though palatable at all times, is considered best in summer, when they feed much on berries, as the buds of the resinous evergreens communicate an unpleasant flavor to the game. As usual, they nest on the ground with little art, in the slight shelter of fallen leaves and bushes, and are said by Audubon to lay 8 to I 4 eggs of a deep fawn color, irregularly splashed with different tints of brown. They are readily approached, and sometimes are said to be so unsuspicious as, like the Ptarmigan, to allow of being knocked down with a stick; and round Hudson Bay are commonly caught by the aborigines in a simple noose fastened to a stake. When much disturbed, however, they betake themselves to trees, where they are readily approached and shot down.

In the month of May, where they breed, in the State of Maine, the male struts before his mate, and beating his wings briskly against his body, produces a drumming noise, clearer than that of the Ruffed Grouse, which can be heard to a considerable distance. The males leave their mates as soon as incubation has commenced, and do not join them again until late in autumn.

The "Spruce Partridge," as the bird is called by the gunners "down East," is a fairly common resident of the timber districts in northern New England and the Provinces; it occurs also in the 

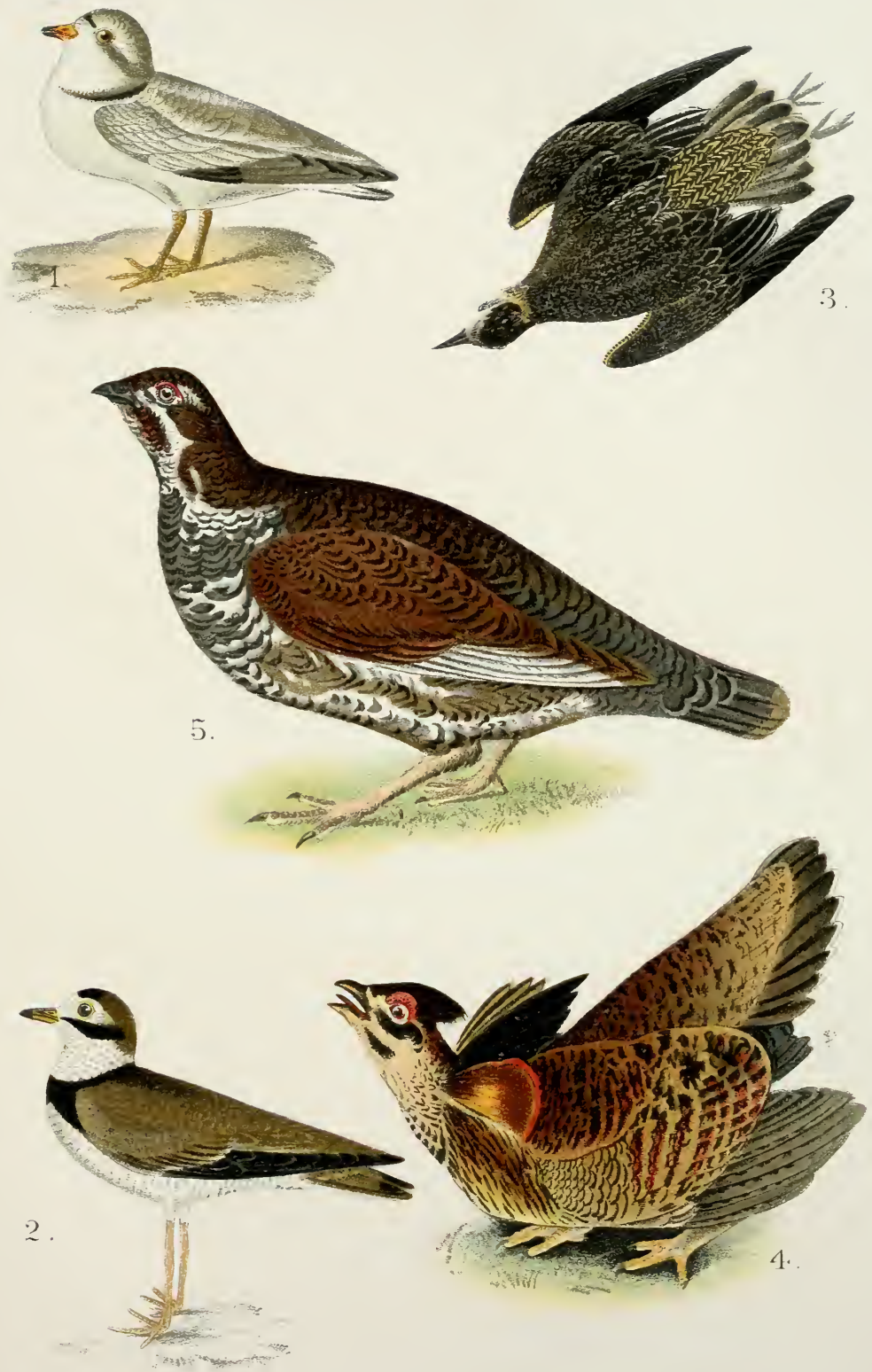

1. Piping Plover.

3. Golden Plover.

ว. Canada Grouse.

2. Semi-Palmated Plover.

4. Prairie Hen. 

forest regions of northern New York, and westward to Minnesota and north to Labrador.

The retiring disposition of the bird has caused its habits to be little known, and the nest is generally so well concealed that few collectors have succeeded in procuring specimens of the eggs. Several pairs of these birds have been successfully domesticated by Mr. Watson Bishop, of Kentville, Nova Scotia, and an article from his pen, published in the "Ornithologist and Oologist" for January, I889, contains much that is new concerning their habits. The birds were easily tamed, and soon became so fearless as to hop on Mr. Bishop's knee and take food from his hand.

When strutting before the hen, the male poses and puffs after the manner of a Gobbler. The feathers on his breast and collar are raised on end ; the combs over the eyes, which can be enlarged at will, almost meet above the crown; and the erect and expanded tail is kept swaying from side to side with a silk like rustling. The females during the nesting season are very quarrelsome, so that only a few can be kept in one pen; but this unfriendliness disappears after the broods scatter.

The hen will occasionally cover the first egg with grass, but not often, though after several eggs have been deposited, she usually flings behind her, with her claws, any leaves, grass, or similar material that may chance to lie near the nest. But she never turns to arrange this covering; though when on the nest she will sometimes pick up with her bill any straws that may be within reach, and these she tucks under her.

The first egg of a clutch has the least amount of marking, and the number of spots increases with each successive egg. The spots are entirely on the surface, and are easily rubbed off.

\section{WILLOW PTARMIGAN.}

\section{WHITE GROUSE.}

\section{LAGOPUS LAGOPUS.}

CHAR. Bill black; legs and feet thickly feathered to the claws. Win. ter plumage pure white; tail-feathers black, tipped with white. Male in summer: head and neck chestnut; body orange brown, more tawny on back and rump, barred with black; wings mostly white. Female : similar, but more heavily barred with black. Length about 16 inches.

Nest. A mere depression, with a slight lining of leaves and grass, sometimes a few feathers.

Eggs. 8-16 (usually about 10); buff or reddish brown, marked with darker brown; $1.80 \times \mathbf{1 . 2 5}$. 


\section{White Grouse, or Ptarmigan.}

The Ptarmigan is one among the very few animated beings which, by choice and instinct, constantly reside in the coldest Arctic deserts, and in the lofty mountains of central Europe, where, as the snow begins to melt away, it seeks out its frozen bed by ascending to the limits of eternal ice. Like so many other animals of this inclement boreal region, this bird is common to both the old and new continent. It is met with in Siberia, Kamtschatka, Greenland, most parts of northern Europe, the Highlands of Scotland, and even as far south as the romantic scenes of the lakes of Cumberland, a few being still seen in the lofty hills which surround the vale of Keswick, as well as in Wales. This species has scarcely been met with on the American continent, except on Melville Island and Churchill River.

The Ptarmigan feeds on many sorts of berries, particularly the crow-berry (Empetrum nigrum) and cow-berry (Vaccinium vitis idaa), as well as the tops of the same plant; it also collects catkins, buds, and the young shoots of the pine, heath, rosehips, and sometimes the different kinds of lichens, which it searches out in the extensive burrows it makes beneath the snow. To all this bill of frugal fare, it also sometimes adds a few insects. These birds search out their food chiefly in the morning and evening, and in the middle of the day are observed sometimes to bask in the sun. Like the Esquimaux of the human family, whose lot is cast in the same cold and dreary region, they seek protection from the extreme severity of the climate by dwelling in the snow; it is here that they commonly roost and work out subterraneous paths. In the morning, as soon as they leave their frozen dens, they fly out vigorously into the air in an upward direction, shaking the snow from their warm and white clothing. While thus feeding they socially call on one another at intervals in a loud tone, and sometimes utter a sort of cackling cry, almost like a coarse and mocking laugh.

The nest, about the middle of June, is made in open places 
where moss abounds, or in the shelter of the low, creeping bushes, forming the only woody growth of these naked and sterile regions. The eggs, 7 to $\mathrm{I}_{5}$, are oblong, of a rufous yellow, from the great number of large and small spots of black or of reddish hlack with which they are covered. From the lingering attachment of the male to his mate when killed, it is probable that the species may be monogamous, or even constantly mated. After the young are fully grown, and released from the care of their parents, they and the old are seen to assemble in flocks of two or three hundred, about the beginning of October, when they appear to migrate a little to the south in quest of food, or rather from the mountains towards the plains. At this time they are seen in great numbers round Hudson Bay, where they assemble for subsistence; and as the store diminishes, they push their tardy migrations in other directions for a fresh supply. Unsuspicious of the wiles and appetites of man, Ptarmigans appear often as tame as domestic chickens, more particularly when the weather is mild; they are allured even by crumbs of bread, and on throwing a hat towards them, or any strange object, they are so attracted by the appearance as to allow of an approach so near that a noose may be thrown round their necks, or, approached from behind, they may be knocked down with poles. Sometimes, however, they become wild enough to fly, but soon grow weary, and as tame as usual. When about to fly off to a distance from the hunters, they are instantly brought to settle down by imitating the cry of their enemy the Hawk. At times, trusting to the concealment of their winter livery, they will remain motionless upon the snow, from which they are still distinguishable by their more dazzling whiteness.

They are much esteemed as food in every country where they occur, and are commonly taken in nets, which are merely made to fall over the place where they assemble, or to which they are driven; and so numerous are they at Hudson Bay that fifty or seventy are sometimes obtained at a single haul of a net about twenty feet square. Between November and April as many as ten thousand are taken for the use of the settle- 
ment; and in Europe, during the winter, they are carried in thousands to the market of Bergen in Norway, and when halfroasted or jerked, are put into barrels and transported to other countries as an article of commerce.

\section{Willow Grouse, or Large Ptarmigan.}

This larger species, called the Willow Grouse by Hearne, the Wood Grouse of the Norwegians, is another inhabitant of both continents, extending its residence to the eternal limits of the polar ice. In America they abound around Hudson Bay, where they are said to breed along the coast, making their nests on dry ridges on the ground. In the ancient continent they shelter their nests in the high tufts of the heath, and in the dwarf willows. Their eggs, Io to I 2, are longer than those of the preceding species, of a muddy white, or inclining to pale rufous, covered and marbled with great numbers of spots, of the color of clotted blood. They even breed in Labrador about the beginning of June. According to Audubon, they are sometimes seen in the State of Maine and around Lake Michigan. This species also appears to be monogamous, as both sexes remain together and show an equal anxiety for the safety of their brood.

It is somewhat remarkable that this species, still more boreal than the Common Ptarmigan in Europe and Asia, should constantly inhabit to the south of that species in North America, where it seems, as it were, to have usurped its residence. The general habits of these birds are very similar to those of the preceding. Like them, they become gregarious at the setting in of winter, roaming after their food in flocks of as many as two hundred, living then and at most seasons on the tops, buds, and even seeds of the dwarf-willow, and hence called Willow Partridges. They also subsist on most kinds of northern berries, and many other kinds of buds and leaves, with the tops of the heath and the seeds of the birch. As food, this species is preferred to the smaller Ptarmigan.

Nuttall followed Audubon in thus separating this species and recognizing as a distinct form the White Ptarmigan, - the ameri- 
canus of Audubon, - but Baird doubted its validity, and it has been entirely omitted from recent works. I have given above the two biographies as they appeared in Nuttall's book, for together they tell about all that is known of the present species.

The Willow Ptarmigan ranges through boreal America from Labrador to Alaska, and in winter is quite abundant on the north shore of the Gulf of St. Lawrence. During some seasons a number have wandered sufficiently near to Quebec and Montreal to get into the markets.

There are only two instances recorded of the occurrence of this bird south of the St. Lawrence, - one secured by Mr. C. B. Cory on the Magdelen Islands, and the second shot by Dr. C. Hart Merriam in Lewis County, northern New York.

Note. - A variety of this species-Allen's Ptarmigan (L. lagopus alleni) was described by Dr. Stejneger in I884. It differs from true lagopus in having the wing-feathers mottled with black, and black shafts. This race is restricted to Newfoundland.

\section{ROCK PTARMIGAN.}

\section{LAGOPUS RUPESTRIS.}

Char. Similar to the Willow Ptarmigan, but smaller (length about I 4 inches), and in summer displays more black and less of the rufous tint. Also distinguished by a line of black running through the eyes.

Nest. A mere depression, with a slight covering of grass and moss.

Eggs. 8-I6 (usually Io); buff or pale reddish brown, marked with darker brown; $1.70 \times 1.20$.

This species is nearly allied to the Common Ptarmigan, but is smaller, has more of the brownish yellow in its summer dress, broader bars of black, and none of the cinereous tint which prevails in the livery of the Ptarmigan. In winter it is only distinguishable by its size. This species is, according to Hutchins, numerous at the two extremities of Hudson Bay, but does not appear at the middle settlements (York and Severn factories) except in very severe seasons, when the Willow Grouse are scarce. It abounds in Melville Island in the dreary latitude of 74 and 75 degrees in the short summers 
of that frigid and cheerless region. It is also found on Melville Peninsula and the Barren Grounds, and indeed seldom proceeds farther south in winter than the $63 \mathrm{~d}$ parallel in the interior, but descends along the coasts of Hudson Bay to latitude $5^{8}$ degrees, and in severe seasons still farther to the south. It is met with in the range of the Rocky Mountains as far to the south as the latitude of 55 degrees. In its habits and mode of living it resembles the Willow Grouse, but does not retire so far into the woody country in winter. It frequents the open woods on the borders of lakes at the same season, particularly in the $65^{\text {th }}$ parallel, though the bulk of the species remains on the skirts of the Barren Grounds. It hatches in June.

The usual habitat of this species is the barren ground region of the Arctics, though one example was shot on Anticosti by Mr. William Brewster.

Note. - In Reinhardt's Ptarmigan (L. mupestris reinhardi) the male in summer plumage is more mottled, above, than true rupestris, and the female is black, above, varied with grayish buff.

This race is found in Greenland and on the western shore of Cumberland Bay and the northern extremity of Labrador.

\section{WELCH'S PTARMIGAN.}

\section{LAGOPUS WELCHI.}

CHAR. In winter similar to rupestris. Male in summer: above, dark brownish gray blended with whitish gray and reddish gray; head and neck lighter; wings white; breast and sides like back; throat, belly, and legs white; tail dusky gray; bill and claws black. Female: similar, but of lighter color, and the back and breast tinged with yellow. Length about 15 inches.

Nest and Eggs. Unknown, but probably similar to rupestris.

This species, which is closely related to the Rock Ptarmigan, is restricted to Newfoundland, where it ranges over the rocky hills and barrens of the interior. It was first described by Brewster, in I885, from specimens taken by George O. Welch, of Lynn. 


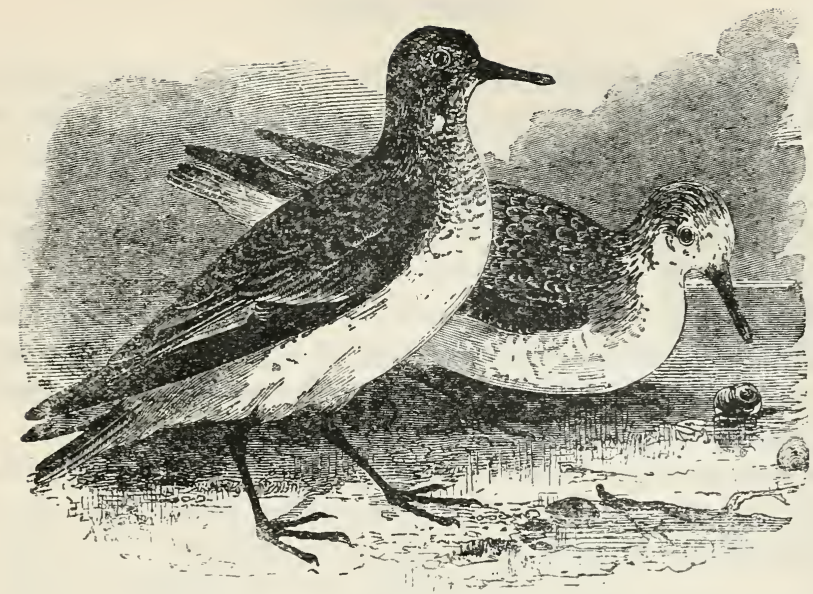

SANDERLING.

\section{RUDDY PLOVER. BEACH-BIRD.}

\section{CALIDRIS ARENARIA.}

CHAR. No hind toe; bill somewhat similar to a Plover. In summer: above, mottled rufous and blackish brown, most of the feathers tipped with grayish white; head and neck pale chestnut spotted with brown; wing-coverts tipped with white; outer tail-feathers white; lower parts white. In winter the rufous tints are replaced by pearl gray, and the spring plumage displays a mixture of the two. In young birds the head, neck, and back are tinged with buff. Length about 8 inches.

Nest. Under a bush or amid a tuft of weeds; a depression lined with dry grass.

Eggs. 2-4; greenish buff or brownish olive, spotted chiefly around the larger end with brown; $1.40 \times 0.95$.

The Sanderlings, in accumulating flocks, arrive on the shores of Massachusetts from their remote northern breeding-places towards the close of August. They are seen also about the same time on the coast of New Jersey and still farther to the South, where they remain throughout the greater part of the winter, gleaning their subsistence exclusively along the immediate borders of the ocean, and are particularly attached to sandy flats and low, sterile, solitary coasts divested of vegeVOL. II. -4 
tation and perpetually bleached by the access of tides and storms; in such situations they are often seen in numerous flocks running along the strand, busily employed in front of the moving waves, gleaning with agility the shrimps, minute shell-fish, marine insects, and small moluscous animals which ever-recurring accident throws in their way. The numerous flocks keep a low circling course along the strand, at times uttering a slender and rather plaintive whistle nearly like that of the smaller Sandpipers. On alighting, the little active troop, waiting the opportunity, scatter themselves about in the rear of the retiring surge. The succeeding wave then again urges the busy gleaners before it, when they appear like a little pigmy army passing through their military evolutions; and at this time the wily sportsman, seizing his opportunity, spreads destruction among their timid ranks; and so little are they aware of the nature of the attack that after making a few aërial meanders the survivors pursue their busy avocations with as little apparent concern as at the first. The breeding-place of the Sanderlings, in common with many other wading and aquatic birds, is in the remote and desolate regions of the North, since they appear to be obliged to quit those countries in America a little after the middle of August. According to Mr. Hutchins, they breed on the coast of Hudson Bay as low as the $55^{\text {th }}$ parallel; and he remarks that they construct, in the marshes, a rude nest of grass, laying four dusky eggs, spotted with black, on which they begin to sit about the middle of June.

Flemming supposes that those seen in Great Britain breed no farther off than in the bleak Highlands of Scotland, and Mr. Simmonds observed them at the Mull of Cantyre as late as the second of June. They are found in the course of the season throughout the whole Arctic circle, extending their migrations also into moderate climates in the winter. They do not, however, in Europe proceed as far south as the capital of Italy, as we learn from the careful and assiduous observations of the Prince of Musignano. According to Latham the Sanderling is known to be an inhabitant even of the remote 
coast of Australia, and is found on the shores of Lake Baikal in Siberia. In the month of May, or as soon as they have recovered from the moult of spring, they leave us for the north, but are seldom in good order for the table until autumn, when, with their broods, they arrive remarkably plump and fat, and are then justly esteemed as a delicacy by the epicure. Besides the various kinds of insect food already mentioned on which they live, they likewise swallow considerable portions of sand in order apparently to assist the process of digestion.

The Sanderling is almost cosmopolitan in its distribution, and is usually abundant wherever it occurs. In America it breeds in high Arctic regions, and winters in the far South, - some flocks going to Chili and Patagonia; and in their migrations the birds follow the water-ways of the interior as well as the coast-line.

A few stragglers have been seen on the New England shores in summer, but no nest has been found south of about latitude $55^{\circ}$; and Captain Feilden reports finding a number breeding on the shores of the Frozen Ocean, at the extreme northern limit of animal life.

Flemming's opinion that some of these birds nested in Scotland has not been confirmed by recent observers. Even on the Faroe Islands the Sanderling occurs as a migrant only; but nests have been taken in Iceland.

These birds are exceedingly active and by no means shy. When flushed they fly out to sea, but soon return; and when a flock is fired into, the remnant make no great effort to escape, though a wounded bird will dive into the surf or swim off on the surface of the water.

The food of the Sanderling while in this region is confined chiefly to small bivalves and crustaceans; but on its breeding. ground the bird is more insectivorous, and has been known to eat also the buds of plants. 


\section{BLACK-NECKED STILT.}

\section{Himantopus mexicanus.}

CHAR. Legs bright pink and exceedingly long; bill black, slender, and longer than the head; crown, back of neck, back, and wings black; forehead, patch over the eyes, throat, and under parts white. Length about 15 inches.

Nest. On marshy margin of stream or pond; a slight depression in the turf, lined with dry grass. Sometimes - if the ground is very wet - a high platform is built, of weed-stems and twigs.

Eggs. 3-4; pale olive or greenish buff, spotted with brownish black; size exceedingly variable, average about $1.75 \times 1.20$.

The Black-necked Stilt is common to many parts of South as well as North America; it is known at any rate to inhabit the coast of Cayenne, Jamaica, and Mexico. In the United States it is seldom seen but as a straggler as far to the north as the latitude of $4 \mathrm{I}^{\circ}$. About the $25^{\text {th }}$ of April, according to Wilson, the Stilts arrive on the coast of New Jersey in small flocks of twenty or thirty together. These again subdivide into smaller parties, but they still remain gregarious through the breeding-season. Their favorite residence is in the higher and more inland parts of the greater salt-marshes, which are interspersed and broken up with shallow pools, not usually overflowed by the tides during summer. In these places they are often seen wading up to the breast in water, in quest of the larvæ, spawn, flies, and insects which constitute their food.

In the vicinity of these bare places, among thick tufts of grass, small associations of six or eight pair take up their residence for the breeding-season. They are, however, but sparingly dispersed over the marshes, selecting their favorite spots, while in large intermediate tracts few or none are to be seen. Early in May they begin to make their nests, which are at first slightly formed of a mere layer of old grass, just sufficient to keep the eggs from the moisture of the marsh; in the course of incubation, however, either to guard against the rise of the tides, or for some other purpose, the nest is in- 
creased in height with the dry twigs of salt marsh shrubs, roots of grass, sea-weed, and any other coarse materials which may be convenient, until the whole may now weigh two or three pounds. The eggs, four in number, are of a dark yellowish drab, thickly marked with large blotches of brownish black. These nests are often situated within fifteen or twenty yards of each other, the respective proprietors living in mutual friendship.

While the females are sitting, their mates are either wading in the adjoining ponds, or traversing the marshes in the vicinity; but on the approach of any intruder in their peaceable community, the whole troop assemble in the air, and flying steadily with their long legs extended behind them, keep up a continual yelping note of click, click, click. Alighting on the marsh, they are often seen to drop their wings, and standing with their legs half bent, and trembling, they seem to sustain their bodies with difficulty. In this singular posture they will sometimes remain for several minutes, uttering a curring sound, and quivering their wings and long shanks as if in the act of laboriously balancing themselves on the ground. A great deal of this motion is, however, probably in manœuvre, to draw the spectators' attention from their nests.

Although so sedentary in the breeding-season, at times they extend their visits to the shores, wading about in the water and mud in quest of their food, which they scoop up with great dexterity. On being wounded, while in the water, they sometimes attempt to escape by diving, - at which, however, they are by no means expert. In autumn their flesh is tender and well flavored. They depart for the South early in September, and proceed probably to pass the winter in tropical America.

The Stilt is a rare bird in this Eastern faunal province, excepting in Fiorida. It is occasionally seen along the sandy beaches of Massachusetts, and a few examples have been taken in Maine and New Brunswick and in Michigan. 


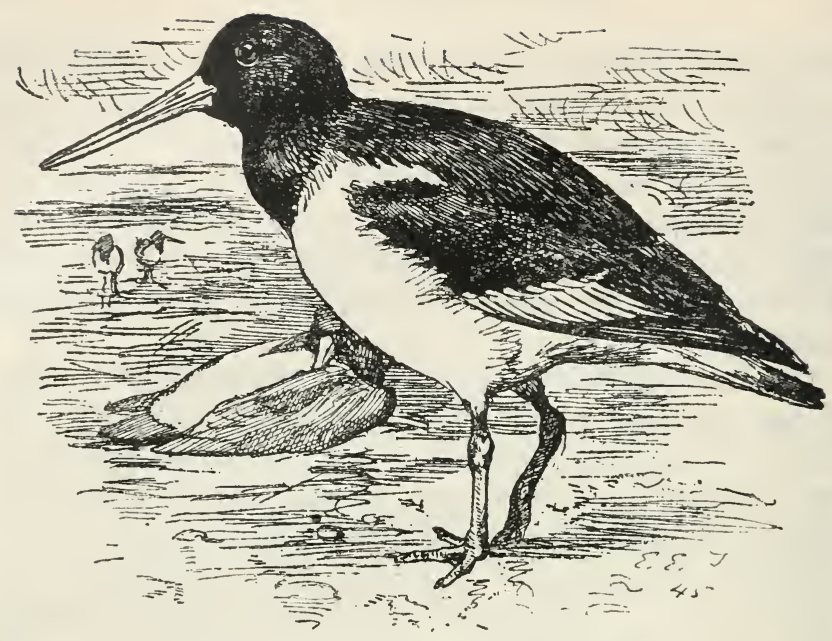

\section{AMERICAN OYSTER-CATCHER.}

\section{HÆMatopus palliatus.}

Char. Bill red, long, stout, straight, and compressed towards the point ; feet red, no hind toe, outer and middle toes united by a membrane as far as the middle joint. Head and neck black, changing to blackish brown on back and wings ; rump, wing-band, tail, and belly white. Length I8 inches.

Nest. On the border of a salt-marsh or upper edge of a sea-beach; a mere depression scratched in the sand.

Eggs. 2-3; bluish white or pale buff marked with several shades of brown; $2.20 \times \mathrm{I} .55$.

The Oyster-catcher is common to the north of both continents, breeding in Great Britain, France, Norway, and along the borders of the Caspian; it is even seen as far south as Senegal in Africa. But though common in New Jersey and the Southern States as far as the Bahamas, where these birds likewise pass the period of reproduction, they are but rarely seen to visit the coast of Massachusetts. In Europe they are said to retire somewhat inland at the approach of winter; in the United States they are seen at this season along the coasts which lie south of Cape Hatteras, on the borders of 
the Atlantic. They return to New Jersey by the close of April, and frequenting the sandy sea-beach, are now seen in small parties of two or three pairs together. They are generally wild and difficult to approach, except in the breedingseason, and at times may be seen walking erectly and watchfully along the shore, now and then probing the sand in quest of marine worms, mollusca, and minute shell-fish. Their larger prey is sometimes the small burrowing crabs called fiddlers, as well as mussels, solens, and oysters, their reputed prey in Europe. They seldom, however, molest the larger shellfish in the United States, preferring smaller and less precarious game. Catesby, at the same time, asserts that he found oysters in the stomach, and Willoughby adds that they sometimes swallowed entire limpets. According to Belon, the organ of digestion is indeed spacious and muscular, and the flesh of the bird is black, hard, and rank flavored. Yet in the opinion of some, the young, when fat, are considered as agreeable food. The nests of the Oyster-catchers are said often to be made in the herbage of the salt-marshes, but on the Atlantic coast these birds commonly drop their eggs in slight hollows scratched in the coarse sand and drift, in situations just sufficiently elevated above the reach of the summer tides. The eggs are laid from the first to the third week in May, and from the $x_{5}$ th to the $25^{\text {th }}$ the young are hatched, and run about nimbly almost as soon as they escape from the shell. At first they are covered with a down nearly the color of the sand, but marked with a line of brownish black on the back, rump, and neck. In some parts of Europe Oyster-catchers are so remarkably gregarious in particular breeding-spots that a bushel of their eggs in a few hours might be collected from the same place.

Like Gulls and other birds of this class, incubation costs much less labor than among the smaller birds, for the female sits on her eggs only during the night and morning, or in cold and rainy weather; the heat of the sun and sand alone being generally sufficient to hatch them, without the aid of the bird by day. The nest is, however, assiduously watched with the 
usual solicitude of parental affection, and on the least alarm the male starts off with a loud scream, while the female, if present, to avoid the discovery of her charge, runs out some distance previous to taking wing. The young, as soon as released from the shell, follow the guiding call of the mother, and on any imminent danger threatening, instinctively squat on the sand, when, from the similarity of their color, it is nearly impossible to discover their artless retreat. On these occasions, the parents make wide circuits on either hand, now and then alighting, and practising the usual stratagem of counterfeited imbecility, to draw away attention from their brood. The note of this species consists commonly of a quick, loud, and shrill whistling call like 'wheep, 'wheep, wheo, or peep, peep, often reiterated, as well at rest as while on the wing.

While migrating, they keep together in lines like a marshalled troop, and however disturbed by the sportsman, they still continue to maintain their ranks. At a later period the flock will often rise, descend, and wheel about with great regularity, at the same time bringing the brilliant white of their wings into conspicuous display. When wounded, and at other times, according to Baillon, they betake themselves to the water, on which they repose, and swim and dive with celerity. They have sometimes also been brought up and tamed so as to associate familiarly with ducks and other poultry.

This bird is still rare in New England, though plentiful along the shores of the Middle States. Two examples have been taken on the Bay of Fundy.

Mr. Walter Hoxie, in the "Ornithologist and Oologist" for August, 1887, gave an interesting account of a pair of these birds moving their eggs when the nest was discovered. While Mr. Hoxie was watching the parents they carried the eggs about one hundred yards from the old nest, and deposited them safely in a nest which he saw the birds prepare.

Note. - The European Oyster-CATcher (Hamatopus ostralegus) occurs occasionally in Greenland. 


\section{AMERICAN GOLDEN PLOVER.}

COMMON PLOVER. WHISTLING PLOVER. PALE-BELLY. GREEN PLOVER.

\section{CharadriUs DOMINICUS.}

Char. No hind toe. Above, spotted with black and lemon yellow; forehead and line over the eyes white; tail grayish brown with imperfect bars of ashy white; beneath, black. In winter plumage the black of the lower parts is replaced by mottled gray and white, the throat and breast spotted with dusky.

Nest. At the upper edge of a sea-beach; a mere depression in the soil lined with a few bits of grass.

Eggs. 3-4 (usually 4); of sharply pointed pyriform shape; dark brownish buff, sometimes tinged with drab or grayish white; spotted and blotched with various shades of brown; $2.00 \times 1.40$.

The Common Plover is, according to the season of the year, met with in almost every part of the world, particularly in Asia and Europe, from Kamtschatka to China, as well as in the South Sea Islands; and on the present continent from Arctic America, where it breeds, to the Falkland Islands; it is also seen in the interior at least as far as Missouri. It breeds in Siberia and in the northern parts of Great Britain, but not in France or Italy, where it is also common. At such times it selects the high and secluded mountains, sheltered by the heath, where, without much attempt at a nest, the female deposits about four, or sometimes five, eggs of a pale-olive color, marked with blackish spots.

These Plovers arrive on the coast of the Middle and Northern States in spring and early autumn. Near to Nantasket and Chelsea Beach they are seen on their return from their inclement natal regions in the north by the close of August, and the young remain in the vicinity till the middle of October, or later, according to the state of the weather. They live principally upon land insects, or the larvæ and worms they meet with in the saline marshes, and appear very fond of grasshoppers. About the time of their departure they are, early in the morning, seen sometimes assembled by thousands; but they all 
begin to disperse as the sun rises, and at length disappear high in the air for the season. They usually associate, however, in small flocks and families, and when alarmed, while on the wing, or giving their call to those who are feeding around them, they have a wild, shrill, and whistling note, and are at most times timid, watchful, and difficult to approach. Though they continue associated in numbers for common safety during the day, they disperse in the evening, and repose apart from each other. At day-break, however, the feeling of solitude again returns, and the early sentinel no sooner gives the shrill and well-known call than they all assemble in their usual company. At this time they are often caught in great numbers by the fowler, with the assistance of a clap-net stretched, before dawn, in front of the place they have selected to pass the night. The fowlers, now surrounding the spot, prostrate themselves on the ground when the call is heard; and as soon as the birds are collected together, they rise up from ambush, and by shouts and the throwing up of sticks in the air, succeed so far in intimidating the Plovers that they lower their flight, and thus striking against the net, it falls upon them. In this and most other countries their flesh, in the autumn, and particularly that of the young birds, is esteemed as a delicacy, and often exposed for sale in the markets of the principal towns.

The Golden Plover is common, and in some localities abundant, in the autumn along the shores of New England and the Maritime Provinces, but in the spring migrations it is rarely or never seen.

Dr. Wheaton found it abundant in the spring, and common in the fall, in Ohio ; but some observers in Ontario consider it a rare bird in that province.

Note. - The European Golden Plover (Charadrius apricarius) has been seen occasionally in Greenland. 


\section{PIPING PLOVER.}

\section{EgIalitis aleloda.}

CHAR. Above, pale ash tinged with pale brown; forehead and interrupted ring about the neck black; below, white; black patches on side of chest; feet orange; bill orange, tipped with black. In young birds the black of the head and neck is replaced by brown. Length $6 \frac{1}{4}$ to $7 \frac{1}{2}$ inches. sand.

Nest. Amid the shingle of a sea-beach; a shallow depression in the

Eggs. 2-4 (usually 4); pale buff or creamy, marked with fine spots of blackish brown and a few spots of lavender; $1.30 \times 1.00$.

This species is a common inhabitant of our sea-coast, arriving in the Middle States from its Southern hibernal retreats towards the close of April. It does not, however, proceed so far to the north, but resides and breeds in the United States, from the shores of New Jersey to Nova Scotia. Along the low, sandy, and solitary borders of the sea, in small scattering flocks, the Piping Plovers are therefore seen throughout the summer, rapidly coursing over the strand, either in quest of their food or to elude the search of the intruding spectator. After gliding swiftly along for a little distance, they often stop for a short interval to watch any approach or pick up some insect, occasionally bending forward and jerking the head up in a balancing attitude; when still, their pale livery so nearly resembles the color of the sand that for the instant they are rendered nearly invisible. On approaching their nests, which are mere shallow hollows in the sand and gravel, they usually exhibit considerable emotion, running along with outspread wings and tail, and fluttering as if lame, to attract attention from their eggs and young. They will sometimes practise this artifice at a considerable distance from their brood, and often follow the spectator for a mile or two, making their shrill, mournful, monotonous call, frequently alighting and running, with a view to deception, near any place which happens to be examined; and by these reiterated feints and fears it becomes often nearly impossible to discover their breeding-haunts. About 
the 2 oth of May, or later, as they proceed to the North, they commence laying, the eggs, being about four, rather large, of a pale cream color, or nearly white, irregularly spotted and blotched nearly all over with blackish brown and many subdued tints of a much paler color.

The cry of this species, uttered while running along the strand, is rather soft and musical, consisting chiefly of a single, varied, and repeated plaintive note. On approaching the breeding-spot, the birds wheel around in contracting circles, and become more clamorous, piping out, in a tone of alarm, ' $k e$-bee, ${ }^{1}$ and $k e e b, k e e b$, then falling off into a more feeble kée$b o o$, with occasionally a call of kib. At times, in the same sad and wild accent with the vociferous Lapwing, we hear a cry of kee-wee, and even the same pai-wee, pee-voo, and pai-voo. When in hurry and consternation, the cry resembled 'pit, 'pit, 'pit, 'pt. Sometimes, in apparent artifice, for the defence of their tender brood, besides practising alarming gestures, they even squeak like young birds in distress.

The food of this species is quite similar with that of the Semi-palmated Ring Plover; indeed, the birds are scarcely to be distinguished but by the paleness of the plumage in the present species, and the shortness of the web between the exterior toes. They are usually fat, except in the breedingseason, and much esteemed as game.

The Piping Plover is a common summer resident of New England and the Maritime Provinces, though rare in some localities on the Bay of Fundy. Mr. C. B. Cory found it abundant on the Magdalen Islands.

Mr. Thompson thinks it a migrant near Toronto; but Mr. Saunders found it breeding at Point Pelee, on Lake Erie.

Note. - The Belted Piping Plover ( $E$. meloda circumcincta) is a Western variety, restricted chiefly to the Missouri River region, though it has been occasionally seen on the Atlantic coast. It differs from true meloda in having "the black patches on the sides of the chest more or less completely coalesced" instead of separated.

1 The first syllable uttered with a guttural lisp. 


\section{WILSON'S PLOVER.}

\section{Ægialitis wiLsonia.}

Char. Above, olive ash or pale ashy brown, tinged on the nape with rufous; under parts and forehead white; patches on front of crown, and band on breast black; tail dark olive; bill black, long, and stout. Length about $73 / 4$ inches. Easily distinguished from the other small "ringnecked" Plover by its large black bill.

Nest. Amid the shingle on a sea-side beach; an extremely slight hollow in the sand, without lining.

Eggs. Usually 3; pale olive-buff thickly marked with blackish brown; size variable, average $1.30 \times$ I.00.

This species was described by Ord in $18 \mathrm{r} 3$, and dedicated to his friend Wilson. It is a Southern bird, and restricted probably to the sea-coast, though some few observers have reported finding it in the interior. It was "not very common" on Long Island in Giraud's day, and later authorities have reported it extremely rare there; but it occurs in more or less abundance from Virginia to Florida and on both coasts of Central America. A few examples have been credited to New England, and Colonel Goss shot one on Brier Island, at the mouth of the Bay of Fundy.

Dr. Coues describes the habits of this Plover as much the same as those of its congener, the Semi-palmated. He says the Wilson's Plovers move north in flocks of six to twenty; but these separate on the nesting ground, and two nests are never placed in close neighborhood. They are gentle and unsuspicious birds; but when a nest is approached, the parents become intensely excited, flitting to and fro hurriedly and wildly, and continually uttering cries of alarm and dismay in most pathetic tones. Their note is described as "half a whistle and half a chirp, and very different from the clear mellow piping of the other species."

They begin to lay about the middle of May or first of June, according to location. The young run as soon as they are clear of the shell, and easily escape detection by squatting on the sand, which is very similar in color.

The flight of Wilson's Plover is swift and graceful; and as the birds skim above the water - barely clearing the crests of the waves - they continually utter their cry in clear, soft tones. Giraud described them as of a sociable tendency; but Audubon thought they rarely mingled with other species, and called them solitary. Their food is small shell-fish, worms, and insects, with which they mingle fine particles of sand. 


\section{KILLDEER.}

\section{ÆGIALITIS VOCIFERA.}

CHAR. Above, grayish brown; band on forehead above and behind eyes white bordered with black; two bands across chest black; rump and base of tail rufous; tail with subterminal band of black and tipped with white; patch of white on wing; under parts white. Length 10 inches.

Nest. On the edge of a sandy beach or margin of a marshy meadow; a mere depression in the sand or turf, sometimes slightly lined with dry grass.

Eggs. Usually 4; buff, sometimes drabish, marked with fine spots of dark brown; $1.55 \times$ I.10.

The well-known, restless, and noisy Killdeer is a common inhabitant throughout the United States, in nearly all parts of which it is known to breed, wintering, however, generally to the south of Massachusetts. In the interior it also penetrates to the sources of the Mississippi, the remote plains of the Saskatchewan, and Vieillot met with it even in St. Domingo. On the return of spring it wanders from the coast, to which it had been confined in winter, and its reiterated and shrill cry is again heard as it passes through the air, or as it courses the shore of the river, or the low meadows in the vicinity of the sea. About the beginning of May it resorts to the fields or level pastures which happen to be diversified with pools of water, and in such situations, or the barren sandy downs in the immediate vicinity of the sea, it fixes upon a place for its nest which is indeed a mere slight hollow lined with such straw and dry weeds as come most convenient. In one instance Wilson saw a nest of the Killdeer curiously paved and bordered with fragments of clam and oyster shells; at other times no vestige of an artificial nest was visible. The eggs, usually four, large and pointed at the smaller end, are of a yellowish cream color thickly marked with blackish blotches.

At all times noisy and querulous to a proverb, in the breeding-season nothing can exceed the Killdeer's anxiety and alarm; and the incessant cry of kildeer, kildeer, or te te de dit, and te dit, as they waft themselves about over head or descend 
and fly around you, is almost deafening. At the same time, to carry out this appearance of distress they run along the ground with hanging wings, counterfeiting lameness to divert the intention of the intruder. Indeed, no person can now approach the breeding-place, though at a considerable distance, without being molested with their vociferous and petulant clamor. During the evening and till a late hour, in moonlight nights, their cries are still heard both in the fall and spring. They seek their fare of worms and insects often in the twilight, so that their habits are in some degree nocturnal; but they also feed largely on grasshoppers, crickets, carabi, and other kinds which frequent grassy fields by day.

The flight of these birds is remarkably vigorous, and they sometimes proceed at a great height in the air. They are also fond of washing themselves and wading in the pools, which they frequent for insects; their gait is perfectly erect, and, like most of their tribe, they run with great celerity. As game, their flesh, like that of the Lapwing, is musky, and not generally esteemed; in the fall, however, when fat they are by some considered as well flavored. Towards autumn families descend to the sea-shore, where their behavior now becomes more circumspect and silent.

At one time the Killdeer was not uncommon in New England, but of late years it has been quite rare, though a few pairs still breed on Rhode Island. It is seldom seen in the Maritime Provinces, but is common along the Great Lakes. Farther west it ranges north to the Saskatchewan.

An extraordinary flight of these birds visited the New England coast late in November, I888. Dr. Arthur P. Chadbourne - who contributed a paper on the subject to "The Auk" for July, I889proved by reports received from various points on the Atlantic coast that the birds had been driven off shore by a severe gale while migrating along the Carolinian coast, and had been carried north on the eastern edge of the storm and finally to the land. After the storm the birds were abundant for several days from Nova Scotia to Rhode Island. 


\section{SEMI-PALMATED PLOVER.}

ÆGialitis SEMipalmata.

CHAR. Above, brownish ash; forehead white, bordered with black; cheeks black; throat and band round neck white; breast and band round neck black; bill orange, tipped with black; under parts white. Length about 7 inches.

Nest. On the margin of a salt-marsh or a swampy inlet of the sea; a slight hollow partially lined with grass or weeds.

Eggs. 2-4 (usually 4); greenish buff or olive drab, marked with several shades of brown; size variable, average $1.30 \times 0.95$.

This small species, so nearly related to the Ring Plover of Europe, arrives from the South along our sea-coasts and those of the Middle States towards the close of April, where it is seen feeding and busily collecting its insect fare until the close of May. These birds then disappear on their way farther north to breed, and in the summer are even observed as far as the icy shores of Greenland. According to Richardson they abound in Arctic America during the summer, and breed in similar situations with the Golden Plover. Mr. Hutchins adds, its eggs, generally four, are dark colored and spotted with black. The aborigines say that on the approach of stormy weather this species utters a chirping noise and claps its wings, as if influenced by some instinctive excitement. The same, or a very similar species, is also met with in the larger West India islands and in Brazil according to the rude figure and imperfect description of Piso.

The early commencement of inclement weather in the cold regions selected for their breeding haunts induces the Ring Plovers to migrate to the South as soon as their only brood have acquired strength for their indispensable journey. Flocks of the old and young are thus seen in the vicinity of Boston by the close of the first week in August, and they have been observed on the shores of the Cumberland, in Tennessee, by the ninth of September.

The Semi-palmated Ring Plover, though so well suited for an almost aquatic life, feeds on land as well as marine insects, collecting weavels and other kinds, and very assiduously cours- 
ing the strand at low water. In general, when not too eagerly hunted, they are but little suspicious, and may readily be approached by the fowler, as well as detained sometimes by whistling in imitation of their quailing call. On most occasions, and when flushed, they utter a reiterated, sharp, twittering, and wild note, very much in unison with the ceaseless echoes of the breaking surge and the lashing of the waves, near which they almost perpetually course, gliding and running with great agility before the retiring or advancing waters. Their flesh is commonly fat and well flavored, and in early autumn they are not uncommon in the markets of Boston and New York.

These pretty and interesting birds are abundant throughout the United States during both the spring and the autumn migrations; but excepting an occasional pair that are found in Maine, none breed south of the Canadian boundary. Dr. Louis B. Bishop reported numbers breeding on the Magdalen Islands, in 1888 , and the birds are abundant during the summer on the coast of Labrador. In winter they range into South America, many going as far as Brazil and Peru.

VOL. II. -5 


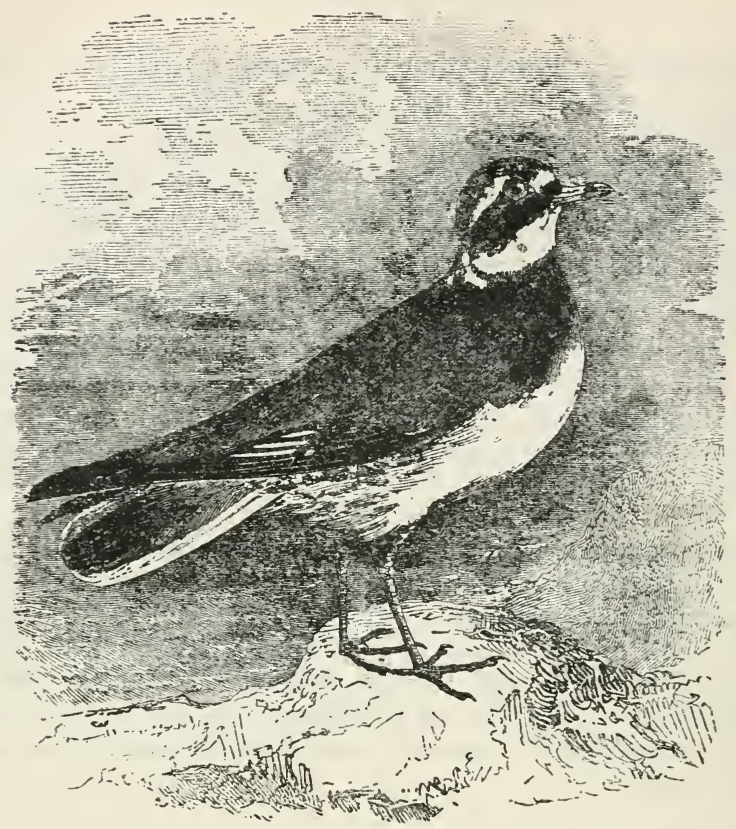

RING PLOVER.

\section{Egialitis hiaticula.}

Char. Above, rich brown; forehead and stripe behind the eyes white ; crown, cheeks, and collar black, - the collar widest on the breast; patch on wings white; central tail-feathers brown, tipped with white; outer feathers mostly white; beneath, white; bill yellow, tipped with black. Length $7 \frac{3}{4}$ inches.

Nest. A cavity among the pebbles of a sea-washed beach, sometimes slightly lined with weeds, - occasionally the lining is of small stones about the size of peas. I.00.

Eggs. Usually 4; dull buff, marked with brownish black; I.40 $\times$

This European bird, known to many of the old country gunners as the Ringed Dotterell, and closely allied to our well-known Semipalmated Plover, was found by Kumlien breeding in numbers on the western shore of Cumberland Bay. The same observer reports it common also at Disco Island, Greenland. It is not known to 
occur regularly elsewhere in America, though one example has been taken at Great Slave Lake ; but it is found throughout Europe, and ranges over northern Asia to Bering's Straits. It is met with throughout the entire year in England, breeding as far south as Kent and Sussex, and ranges north to lat. $80^{\circ} 45^{\prime}$, and south (in winter) to the shores of Africa.

Seebohm thinks that the bird found nesting in the British Islands is a larger and lighter-colored race, laying a larger egg; and he proposes to make it a sub-species and name it hiaticula major.

Like others of the family, the Ringed Plover feeds on small thinshelled crustaceans, such as shrimps, etc., and sea-worms, as well as on insects, which it catches with much adroitness; and with its food it mingles small pebbles and particles of sand to aid digestion.

The usual note of this bird is a melodious whistle; but the callnote is harsh, while the cry of alarm, though noisy, is rather plaintive. This last note has been written perw-y-et and too-it. The male, however, uses a distinct call-note during the mating-season. It is the same note as the usual call, but repeated so rapidly it forms a trill, and it is also delivered in more liquid tones.

This Plover is described by Seebohm as a wild, wary bird when feeding in its winter-quarters, but quite the opposite when on its breeding-grounds in the Far North. It there becomes an unobtrusive little creature, neither shy nor wary, and rarely displaying more than a shade of anxiety in its actions, - running but a little distance from an intruder, or flying to an adjacent knoll to watch his movements; sometimes squatting close to the sand until almost under one's feet. It runs with great swiftness, pausing now and then, and darting away again. Keeping close to the edge of the water, it follows the receding waves picking up what food may have been stranded, and hastening shoreward as the waves return.

Note. -- A few examples of the Mountain Plover (Aggialitis montana) have been taken in Florida. The usual habitat of this species is from the Great Plains westward. 


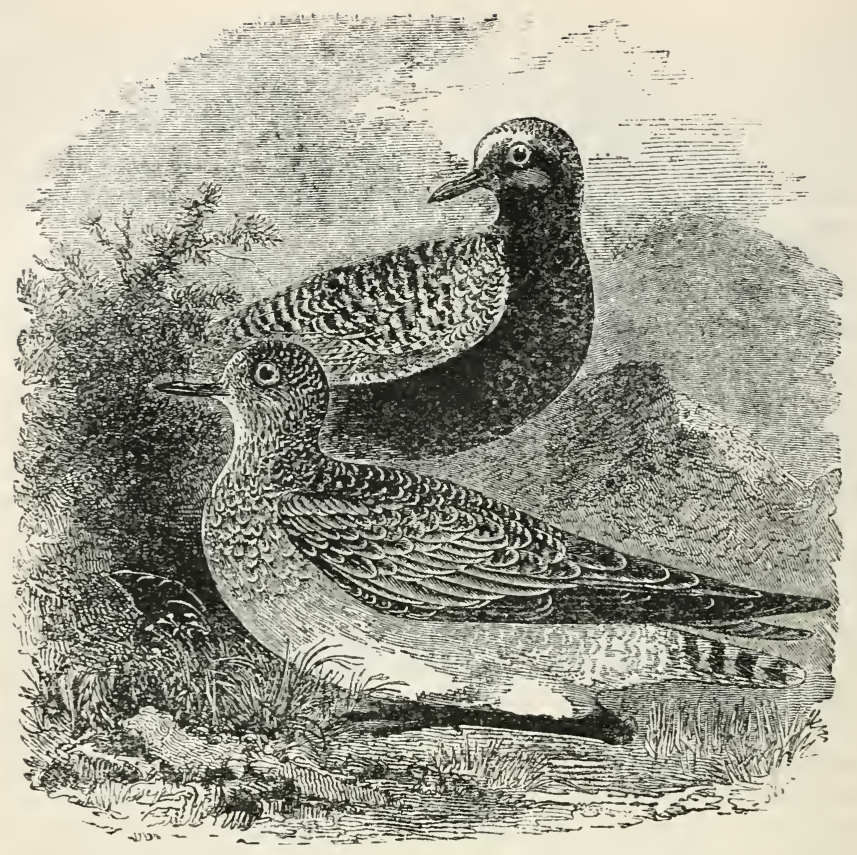

BLACK-BELLIED PLOVER.

BEETLE-HEAD. BULL-HEAD. SWISS PLOVER.

Charadrius squatarola.

CHAR. Summer plumage: above, spotted black and white or ashy; beneath, black. Winter plumage . above, spotted black and brownish yel. low; beneath, black mixed with white. Distinguished from all other Plovers by having a hind toe. Length about 12 inches.

Nest. On dry hill-side; a slight depression in the soil, lined with a few leaves and bits of grass.

Eggs. 4, buffish olive or greenish drab thickly marked with brownish black; $2.00 \times 1.40$.

The Black-bellied or large Whistling Field Plover is met with in most parts of the northern hemisphere, and in America is known to breed from the open grounds of Pennsylvania to the very extremity of the Arctic regions. It is common around 
Hudson Bay. How far this bird extends its migrations to the southward is not satisfactorily ascertained, though there is little doubt but that it ranges to the confines of Mexico, and it has been seen in considerable numbers in Louisiana and the Carolinas during the winter. According to Wilson it generally arrives in the inland parts of Pennsylvania in the latter part of April; and less timid than the Golden Plover, it often selects the ploughed field for the site of its nest, where the ordinary fare of earth-worms, larvæ, beetles, and winged insects now abounds. The nest, as in most of the birds of this class, is very slightly and quickly made of a few blades of stubble or withered grass, in which are generally deposited four eggs, large for the size of the bird (being scarcely a line short of two inches in length), of a cream color slightly inclining to olive, and speckled nearly all over with small spots and blotches of lightish brown, and others of a subdued tint, bordering on lavender purple; the specks, as usual, more numerous towards the large end. In the more temperate parts of the United States it rears often two broods in the season, though only one in Massachusetts, where, indeed, the nests are of rare occurrence. During the summer the young and old now feed much upon various kinds of berries, particularly those of the early bramble, called dew-berries; and their fiesh at this time is highly esteemed. About the last week in August the Betelheaded Plovers (as they are called in New England) descend with their young to the borders of the sea-coast, where they assemble in great numbers from all their Northern breedingplaces. Now passing an unsettled and roving life, without any motive to local attachment, they crowd to such places as promise them the easiest and surest means of subsistence; at this time small shell-fish, shrimps, and other minute marine animals, as well as the grasshoppers, which abound in the fields, constitute their principal fare.

The Black-bellied Plover is at all times extremely shy and watchful, uttering a loud, rather plaintive whistling note as it flies high and circling in the air, and is so often noisy, particularly in the breeding-season, as to have acquired among many 
of the gunners along the coast the name of the Black-bellied Killdeer. From a supposed similarity, probably in the note, it is remarkable that the inhabitants of the Faroe Islands denominate the Oyster-catcher kielder, and in Iceland the male is named tilldur, and the female tilldra. Indeed, the compass of voice in a great portion of this tribe of birds, more or less related to the Plovers, is remarkable for its similarity. The Betel-headed Plovers usually linger round the sea-coast in the Middle States till the commencement of November, when, the frosts beginning sensibly to diminish their prospect of subsistence, they instinctively move off towards the South, proceeding probably, at this time, under the shade of twilight, as moving flocks are nowhere, as far as I can learn, seen by day. About the middle of September in the marshes of Chelsea (Mass.), contiguous to the beach, they sometimes assemble at day-break in flocks of more than a thousand individuals together, and soon after disperse themselves in companies to feed, on the shores, upon small shell-fish and marine insects. This crowding instinct takes place a short time previous to their general migration southward.

Wilson originated the error that this species breeds in the mountains of Pennsylvania, and Audubon, Richardson, Nuttall, and others have helped to perpetuate it. There is no good evidence obtainable that the bird has nested south of the Hudson Bay district, but numerous observers have met with it in summer on the Barren Ground region and along the shores of the Arctic Ocean. It has been found in winter in the West Indies and South America On its spring migration it goes north by various routes, across the interior as well as along the coast-line, - but on the Atlantic shores it is more abundant in autumn than in spring.

I did not meet with any examples during spring on the Bay of Fundy or the New Brunswick shores of the Gulf of St. Lawrence, but Mr. Boardman informs me that the species occurs sparingly at the mouth of the St. Croix River. Stearns reported it common in southern Labrador, but Turner did not find it at Ungava.

Note. - Occasionally an example of the LAPWing (Vanellus vanellus) - a European species - visits Greenland. It has been taken on Long Island also. 


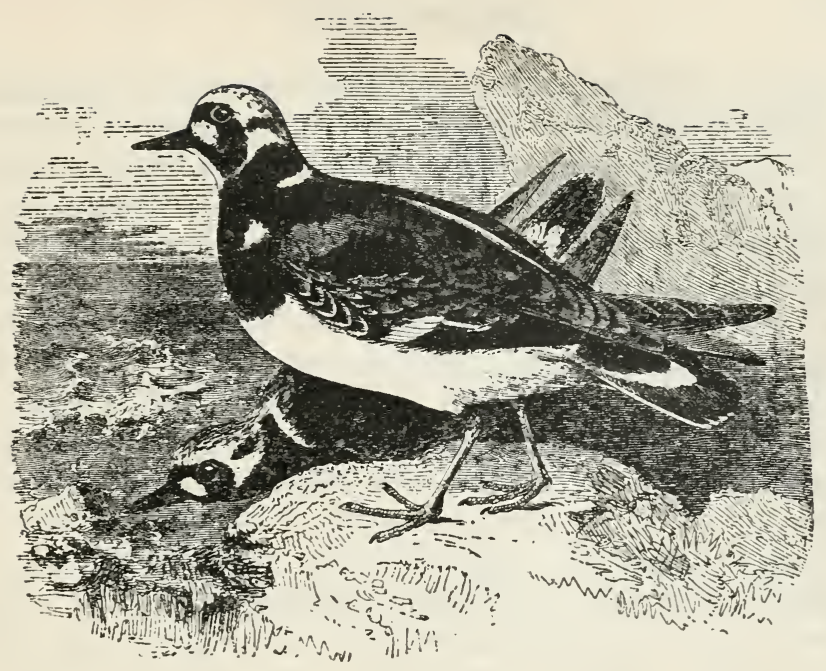

TURNSTONE.

\section{CHICKEN PLOVER. BRANT BIRD, RED-LEGGED PLOVER.}

\section{ARENARIA INTERPRES.}

CHAR. Head, neck, breast, and shoulders variegated black and white; back streaked chestnut and black; wings with band of white; rump white; tail-coverts and most of tail-feathers dark brown; beneath, white. Legs and feet orange red; hind toe turning inward. Bill black, stout, and acute. Length 9 inches.

Nest. Under shelter of bushes or among herbage near the sea-shore; a slight depression, lined with a few leaves and blades of grass or weedstems.

Eggs. 2-4 (usually 4); greenish gray, spotted and streaked with brown and bluish ash; $1.60 \times$ 1.10.

These singular marine birds are not only common to the whole northern hemisphere, but extend their colonies even to Senegal and the Cape of Good Hope, in the southern half of the globe. Their favorite breeding-resorts are, however, confined to the inclement regions of the North, to which they are in no haste to return, but linger along the coast in the temperate climates for several months before they attain to the remote and desolate shores of their nativity. Their southern 
progress in America is in all probability continued as far as the tropics, since their race even extends itself into the other hemisphere. Buffon, in fact, figures a specimen of the young bird from Cayenne. In New Jersey, according to Wilson, these birds arrive in the month of April, and there linger until June, very soon after which they are seen at their breeding-quarters on the shores of Hudson Bay and along the desolate strand of the Arctic Sea, where they have been met with by the northern navigators as far as the $75^{\text {th }}$ parallel. They already begin to depart from these remote boreal regions in August, in which month, and even towards the close of July, I have seen young birds for sale in the market of Boston. They visit the shores of Great Britain also about the same time, arriving thence probably from the Arctic shores of Siberia. Five or six weeks later they are observed to visit the borders of the Delaware, and proceed onward to the South as the weather increases in coldness. The most southern summer residence of these birds known, if Mr. Flemming be correct, is the Scottish isles of Zetland. They are also said to inhabit the isles of the Baltic during summer. In a mere depression of the sand or gravel, along the sea-coast, they are said to drop their eggs, which are four in number, and according to Mr. Hutchins are of an olive green spotted with blackish brown.

This bird is naturally of a wild and solitary disposition, coursing along the shore by pairs or in small families which have been bred together. In the months of May and June, in New Jersey, they almost wholly feed upon the spawn of the king-crab, or horse-foot (Monoculus polyphemus, Lin.), which affords them and other animals an abundant and almost inexhaustible supply.

The Turnstone, while flying, often utters a loud twittering note, and runs at times with its wings lowered, but is less swift in its movements than most of the Sandpipers, and more patient and intent in obtaining its fare. Like the Woodpeckers, it is content to search over the same place for a considerable length of time; the mechanism of its bill seems well provided for this purpose, and it is often seen in this way 
turning over stones and pebbles from side to side in search of various marine worms and insects. The young feed also upon shrimps and different kinds of small shell-fish, particularly minute mussels which are occasionally cast up by the tides. According to Catesby, this habit, of turning over stones in quest of insects is retained by the species even when subjected to domestication.

The Turnstone is a common spring and autumn migrant throughout this Eastern region, but near the Atlantic is found only on the sea-shore. It makes its nest in the Arctic regions, from. Hudson Bay northward, and during the winter ranges throughout South America to the Straits of Magellan.

The food of these birds is the usual shore-bird diet; but they have been known to thrive upon boiled rice and bread soaked in milk. They make interesting pets, as they are gentle and confiding, and are readily reconciled to confinement.

\section{WHOOPING CRANE.}

\section{GREAT WHITE CRANE.}

\section{Grus aMERICANA.}

CHAR. General plumage white; outer wing-feathers, or primaries, black; crown and cheeks nearly naked and colored orange red, the sparse hair-like feathers black; tail covered with long and graceful plume-feathers. Bill greenish yellow, 6 inches long, stout, and pointed. Length over 4 feet.

Nest. On a dry mound in a marsh or on margin of a swamp; made of heavy marsh grass and placed on high platform of sedges.

Eggs. 2-3; rough and coarse, bluish ash sometimes tinged with brown; marked with pale brown; $3.80^{\circ} \times 2.60$.

This stately Crane, the largest of all the feathered tribes in the United States, like the rest of its family dwelling amidst marshes and dark and desolate swamps, according to the season is met with in almost every part of North America, from the islands of the West Indies, to which it retires to pass the winter, to the utmost habitable regions and fur countries of the North. A few of these birds hibernate in the warmer parts of the Union, and some have been known to linger through 
the whole of the inclement season in the swamps of New Jersey, near to Cape May. When discovered in their retreats, they are observed wandering along the marshes and muddy flats near the sea-shore, in quest of reptiles, fish, and marine worms. Occasionally they are seen sailing along from place to place with a heavy, silent flight, elevated but little above the surface of the earth. Ever wary, and stealing from the view of all observers, these gaunt shades of something which constantly avoids the social light impress the mind no less with curiosity than aversion; and it is surprising that, furtive and inharmonious as owls, they have not excited the prejudice of the superstitious.

At times they utter a loud, clear, and piercing cry that may be heard to a very considerable distance, and which, being not unaptly compared to the whoop or yell of the savages when rushing to battle, has conferred upon our bird his peculiar appellation. Other species of the genus possess also the same sonorous cry. When wounded they attack those who approach them with considerable vigor, so much so as to have been known to dart their sharp and dagger-like bill through the incautious hand held out for their capture. Indeed, according to Dr. Richardson, they have sometimes driven the fowler fairly out of the field.

In the winter season, dispersed from their native haunts in quest of subsistence, they are often seen prowling in the low grounds and rice-fields of the Southern States in quest of insects, grain, and reptiles; they swallow also mice, moles, rats, and frogs with great avidity, and may therefore be looked upon at least as very useful scavengers. They are also at times killed as game, their flesh being well flavored, as they do not subsist so much upon fish as many other birds of this family. It is with difficulty, however, that they can be approached or shot, as they are so remarkably shy and vigilant. They build their nests on the ground, after the manner of the common Crane of Europe, selecting a tussock of long grass in some secluded and solitary swamp, raising its sides to suit their convenience so as to sit upon it with extended legs. The 
eggs are two in number, as large as those of the swan, and of a bluish-white color blotched with brown.

Whooping Cranes rise with difficulty from the ground, flying low for a time, and thus afford an easy mark for the sportsman. At other times they fly around in wide circles as if reconnoitring the surrounding country for fresh feeding ground; occasionally they rise spirally into the air to a great height, mingling their screaming voices together, which are still so loud, when they are almost out of sight, as to resemble a pack of hounds in full cry. Early in February Wilson met with several of these Cranes in South Carolina; at the same season and in the early part of the following month I heard their clamorous cries nearly every morning around the enswamped ponds of West Florida and throughout Georgia, so that many individuals probably pass either the winter or the whole year in the southern extremity of the Union.

It is impossible to describe the clamor of one of these roosting flocks, which they begin usually to utter about sunrise. Like the howling-monkeys, or preachers, of South America (as they are called), a single individual seemed at first as if haranguing or calling out to the assembled company, and after uttering a round number of discordant, sonorous, and braying tones, the address seemed as if received with becoming applause, and was seconded with a reiteration of jingling and trumpeting hurrahs. The idea conveyed by this singular association of sounds was so striking, quaint, and ludicrous that I could never hear it without smiling at the conceit. Captain Amidas (the first Englishman who ever set foot in North America) thus graphically describes their clamor on his landing on the isle of Wokokou, off the coast of North Carolina, in the month of July: "Such a flock of Cranes (the most part white) arose under us, with such a cry, redoubled by many echoes, as if an army of men had shouted all together." But though this display of their discordant calls may be amusing, the bustle of their great migrations and the passage of their mighty armies fills the mind with wonder. In the month of December, I $8 \mathrm{r}$, while leisurely descending on the bosom of 
the Mississippi in one of the trading boats of that period, I had an opportunity of witnessing one of these vast migrations of the Whooping Cranes, assembled by many thousands from all the marshes and impassable swamps of the North and West. The whole continent seemed as if giving up its quota of the species to swell the mighty host. Their flight took place in the night, down the great aërial valley of the river, whose southern course conducted them every instant towards warmer and more hospitable climes. The clangor of these numerous legions passing along high in the air seemed almost deafening; the confused cry of the vast army continued with the lengthening procession, and as the vocal call continued nearly throughout the whole night without intermission, some idea may be formed of the immensity of the numbers now assembled on their annual journey to the regions of the South.

The Whooping Crane is almost entirely confined to the central portions of the continent, breeding from about the forty-third parallel northward, and wintering in Texas and the swampy interior of Florida. It is doubtful if this species ever occurred in New England, and at this day it is not seen near the Atlantic to the north of the Chesapeake. It is a rare spring and fall migr int in Ohio, and a few pairs nest annually in the prairie region of Illinois.

\section{LITTLE BROWN CRANE.}

\section{Grus Canadensis.}

CHAR. General color bluish gray, washed in places with tawny; cheeks and throat ashy, sometimes white; crown partially covered with black hair-like feathers; wings ashy brown; bill blackish. Young brownish gray washed with tawny. Length about 3 feet.

Nest. On the marshy bank of a river or pond; a hollow in the turf lined with dry grass.

Eggs. Usually 2; olive drab or ashy yellow or sea-green, marked with brown; $3.65 \times 2.30$.

For the distribution of this species, see the account of the Sandhill Crane. 


\section{SANDHILL CRANE.}

\section{BROWN CRANE.}

\section{Grus meXicana.}

Char. Similar to the Little Brown Crane, but larger. Length about 4 feet.

Nest and Eggs. Similar to the smaller race. The eggs larger; 4.00 $\times 2.45$.

This species, scarcely inferior to the americana in magnitude, visits all parts of the fur countries in summer up to the shores of the Arctic Sea, and is indeed, according to the season, spread more or less throughout North America, having been observed in Mexico, Louisiana, and Florida. It also probably breeds in the interior of the continent, as Major Long saw it in the Illinois country on the I $5^{\text {th }}$ of July. As early as the 7 th of February Kalm observed flocks passing over New Jersey and Pennsylvania on their way either to the North or West; but as the Atlantic coast has become more settled and populous, these shy birds have, for the most part, altered their route, and now proceed more within the wilder interior of the continent. In May they are seen about Hudson Bay; and like the Whooping Crane, which they resemble in manners, they nest on the ground, laying two eggs, of an oil green, irregularly and rather thickly spotted with yellowish brown and umber, the spots confluent and dark on the greater end. The flesh is accounted good food, resembling that of the Swan (Cygnus buccinator) in flavor.

It is not surprising that the older writers should have treated canadensis and mexicana as one species, for in appearance and in general distribution they are very similar, though the larger of the two may be termed a Southern race, as it breeds south to Florida, while the smaller race breeds north to the Arctic regions; but both forms are found on the Western plains.

Along the valley of the Mississippi these birds are very abundant; but excepting an occasional wanderer, they are seen to the eastward of that river in Georgia and Florida only. One example of the Little Brown Crane has been shot in Rhode Island and another in South Carolina. 


\section{GREAT BLUE HERON,}

BLUE CRANE.

ARDEA HERODIAS.

CHAR. General color ashy blue, darker on the wings; thighs and edge of wings chestnut; crest white, bordered by black, from which extend two long, slender black feathers; spots of dusky and chestnut on front of the neck; under parts dusky, broadly striped with white; long and slender plumes of pale pearly gray hang from the breast and fall gracefully over the wings (these plumes are wanting in the autumn); bill longer than the head, stout, and acute, of yellow color; legs and feet black. Length about 42 to 50 inches.

Nest. Usually with a community situated in a sycamore or cypress swamp, or (at the North) in a grove of deciduous trees; placed on the upper branches of tall trees, - sometimes on bare rocks; made of small dry twigs, and lined each year with fresh green twigs.

Eggs. 3-5 (usually 4); greenish blue; $2.50 \times 1.50$.

The Great Heron of America, nowhere numerous, may be considered as a constant inhabitant of the Atlantic States, from New York to East Florida, in the storms of winter seeking out open springs, muddy marshes subjected to the overflow of tides, or the sheltered recesses of the cedar and cypress swamps contiguous to the sea-coast. As a rare or accidental visitor, it has been found even as far north as Hudson Bay, and commonly passes the breeding-season in small numbers along the coasts of all the New England States and the adjoining parts of British America. Mr. Say also observed this species at Pembino, in the 49th parallel. Ancient natural heronries of this species occur in the deep maritime swamps of North and South Carolina; similar associations for breeding exist also in the lower parts of New Jersey. Its favorite and long-frequented resorts are usually dark and enswamped solitudes or boggy lakes, grown up with tall cedars, and entangled with an under-growth of bushes and Kalmia laurels. These recesses defy the reclaiming hand of cultivation, and present the same gloomy and haggard landscape they did to the aborigines of the forest, who, if they existed, might still pursue through the tangled mazes of these dismal swamps the retreating bear and 
timorous deer. From the bosom of these choked lakes, and arising out of the dark and pitchy bog, may be seen large clumps of the tall cypress (Cupressus disticha), like the innumerable connecting columns of the shady mangrove, for sixty or more feet rising without a branch; and their spreading tops, blending together, form a canopy so dense as almost to exclude the light from beneath their branches. In the tops of the tallest of these tree the wary Herons, associated to the number of ten or fifteen pair, construct their nests, each one in the top of a single tree; these are large, formed of coarse sticks, and merely lined with smaller twigs. The eggs, generally four, are somewhat larger than those of the hen, of a light-greenish blue, and destitute of spots. The young are seen abroad about the middle of May, and become extremely fat and full grown before they make any effective attempts to fly. They raise but a single brood; and when disturbed at their eyries, fly over the spot, sometimes honking almost like a goose, and at others uttering a loud, hollow, and guttural grunt.

Fish is the principal food of the Great Herons, and for this purpose, like an experienced angler, they often wait for that condition of the tide which best suits their experience and instinct. At such times they are seen slowly sailing out from their inland breeding-haunts during the most silent and cool period of the summer's day, selecting usually such shallow inlets as the ebbing tide leaves bare or accessible to their watchful and patient mode of prowling; here, wading to the knees, they stand motionless amidst the timorous fry till some victim coming within the compass of their wily range is as instantly seized by the powerful bill of the Heron as if it were the balanced poniard of the assassin or the unerring pounce of the Osprey. If large, the fish is beaten to death, and commonly swallowed with the head descending, as if to avoid any obstacle arising from the reversion of the fins or any hard external processes. On land the Herons have also their fare, as they are no less successful anglers than mousers, and render an important service to the farmer in the destruction they make among most of the reptiles and meadow shrews. 
Grasshoppers, other large insects, and particularly dragon-flies they are very expert at striking, and occasionally feed upon the seeds of the pond-lilies contiguous to their usual haunts. Our species, in all probability, as well as the European Heron, at times also preys upon young birds which may be accidentally straggling near their solitary retreats. The foreign kind has been known to swallow young snipes and other birds when they happen to come conveniently within reach.

The Heron, though sedate in its movements, flies out with peculiar ease, often ascending high and proceeding far in its annual migrations. When it leaves the coast and traces on wing the meanders of the creek or river, it is believed to prognosticate rain; and when it proceeds downwards, dry weather. From its timorous vigilance and wildness it is very difficult to approach it with a gun; and unheeded as a depredator on the scaly fry, it is never sought but as an object of food, and for this purpose the young are generally preferred.

The present is very nearly related to the Common Heron of Europe, which appears to be much more gregarious at its breeding-places than ours; for Pennant mentions having seen as many as eighty nests on one tree, and Montague saw a heronry on a small island in a lake in the north of Scotland whereon there was only one scrubby oak-tree, which being insufficient to contain all the nests, many were placed on the ground sooner than the favorite situation should be abandoned. The decline in the amusement of hawking has now occasioned but little attention to the preservation of heronries, so that nine or ten of these nurseries are nearly all that are known to exist at present in Great Britain. "Not to know a Hawk from a Heronshaw" (the former name for a Heron) was an old adage which arose when the diversion of Heron-hawking was in high fashion; and it has since been corrupted into the absurd vulgar proverb, "not to know a hawk from a handsaw"! As the Rooks are very tenacious of their eyries, and piratical to all their feathered neighbors, it might be expected that they would at times prove bad and encroaching neighbors to the quiet Herons; and I have been credibly informed by a friend 
that at Mr. Wilson's, at Dallam Tower, near Milthorp in Westmoreland, a battle took place betwixt the Rooks and Herons for the possession of certain trees and old nests which was continued for five days in succession, with varying success and loss of life on both sides, when, I believe, they at length came to the sage conclusion that their betters had at times acceded to after an equally fruitless contest; namely, to leave things in statu quo ante bellum.

The European Heron appears to give a preference to freshwater fish, and for the purpose of taking its prey, gently wades into the water where they abound, and standing on one leg up to the knee, with its head drawn in, reclined upon its breast, it quietly watches the approach of its prey. It has been remarked by many that the fish generally swarm around the Herons, so as to afford an ample supply without much exertion; and Bechstein remarks, after repeated observations, that the source of this attraction to the Heron is merely the excrement of the bird, which the fish, according to experiment, devour with avidity. Its time of fishing, like that of our own species, is usually before or after sunset. Though there is no ground for believing that the Heron acquires a macilent constitution by privation, it is certain that in Europe, from a scarcity of food, it becomes extremely lean. It is known frequently to feed by moonlight, at which time it becomes tolerably fat, being then unmolested; and it is observed that the fish at this time come into the shoaler waters.

The Great Blue Heron is not an abundant bird, but it is found more or less commonly throughout this Eastern region north to about the 48th parallel.

There are two heronries of this species within a few miles of St. John, N. B., where one hundred to two hundred pairs breed annually. They are in groves of white birch about a mile back from the river. I have found this bird also in the heart of the wilderness districts fishing in the smaller streams and along the margins of the rivers.

Note. - A few examples of the Blue Heron (Ardea cinerea)the "Common Heron" of European books - have been taken in southern Greenland.

VOL. II. -6 


\title{
WARD'S HERON.
}

\author{
ARDEA WARDI.
}

ChAR. Similar to the Great Blue Heron, but larger and of paler tint; under parts white, narrowly streaked with black; plumes silvery gray; legs and feet olive. Length 48 to 54 inches.

Nest. With a community in a swampy grove; placed on a high branch of a tall mangrove; made of twigs and lined with fresh green twigs.

Eggs. $3-4$; bluish green; $2.65 \times 1.85$.

This species was first described by Mr. Ridgway, from specimens taken by Mr. Charles W. Ward in $\mathrm{I} 88 \mathrm{I}$.

There has been considerable discussion concerning the status of these large Herons, some authorities expressing the opinion that both Ward's Heron and the Great White Heron are but geographical races of the Great Blue Heron ; but the weight of opinion is in favor of considering the three as distinct species.

Ward's Heron is said to be dichromatic, - having a dark and light phase of plumage; the light-colored birds being indistinguishable from occidentalis.

In habits the present species does not differ from the Great Blue Heron; but Ward's Heron has been found in Florida only.

\section{GREAT WHITE HERON.}

\section{FLORIDA HERON. WURDEMAN'S HERON.}

ARDEA OCCIDENTALIS.

CHAR. White phase. Plumage white; crest with two long narrow plumes, and plumes droop over the breast and wings also; bill yellow; legs yellow and olive, feet brown. Blue phase. Similar to herodias, but larger and lighter in color,- the head and crest white, and the under parts with less black; legs and feet yellowish olive. Length 45 to 54 inches.

Nest. With a community; placed usually on a low branch of a mangrove, sometimes on a high branch; a platform of dry twigs.

Eggs. 3-4; bluish green; size variable, average about $2.60 \times 1.85$.

This is doubtless the "Great White Crane" mentioned by Nuttall as found by Audubon in Florida. The description was not published until 1835, after Nuttall's work had been issued.

In 1859 Spencer Baird described the blue-colored bird as a dis- 
tinct species, which he named $A$. wurdemanni; and in the "Key," issued in 1872 , Coues also gave wurdemanni specific rank. In the "History of North American Birds," issued in I884, for which work Baird and Ridgway contributed the technical matter, wurdemanni was relegated to the synonymy of occidentalis; and to the opinion thus emphasized, that the blue color merely represents a dichromatic phase of the White Heron, Coues added the weight of his authority in the 1887 edition of the "Key." Ridgway, however, in his "Manual," also published in 1887 , returned to Baird's first decision, and gave wurdemanni specific rank; but the A.O.U. still retain it on their "hypothetical list," adding in a note that it is believed to be the colored phase of occidentalis or an abnormal specimen of wardi. This last suggestion has been made by several writers as a possible solution of the problem which these birds offer, while others have contended that botb blue and white specimens, as well as those referred to wardi, are but variations of the Great Blue Heron. I have treated the blue bird as a phase of the present species partly because this seemed the most convenient pigeon-hole in which to place the fact of its existence, but more especially because I think this is where it will finally rest.

The difficulty in reaching a decisive solution of this problem lies chiefly in the fact that very little reliable evidence has been obtained. The birds are found only in an out-of-the-way corner of southwestern Florida and in Jamaica, and even in these localities are not common, - indeed, blue-colored specimens are quite rare. And the problem is likely to remain unsolved for many a year to come, if not forever; for the plume-hunters have discovered the haunts of the White Herons, and are gathering them in, - shooting the birds, cutting off their plumes, and throwing the carcases to the Vultures, - in an effort to meet the demands of fashion.

In habits the White Heron does not differ materially from its more common congeners. It is a little less inclined for companionship, and is somewhat fiercer.

Examples of this species have been taken in Indiana and Illinois, but these were probably accidental wanderers. 


\section{AMERICAN EGRET.}

\section{ARDEA EGRETTA.}

CHAR. Plumage white; no crest; long silky plume-feathers, from the back, fall over the wings and tail; bill yellow; legs and feet black. Length about 38 inches.

Nest. With a community amid a swamp or on the border of a lake; placed on a high branch of a cypress or mangrove tree, sometimes on a low bush close to the water; made of twigs.

Eggs. 2-5; bluish green; size variable, average $2.30 \times 1.50$.

This tall and elegant Heron is in America chiefly confined to the warmer and more temperate regions. From Guiana, and even far beyond the equator in South America, it is seen to reside as far to the north as the State of New York. In the old continent the very nearly allied $A$. alba is met with on the borders of the Caspian and Black Seas, on the shores of the Irtish and the lakes of Tartary, even as far as the $53 \mathrm{~d}$ parallel; and a straggler is now and then met with in Great Britain. Towards the close of February our species is seen to arrive in Georgia from its warmer hibernal resorts. At all times it appears to have a predilection for swamps, rice-fields, and the low, marshy shores of rivers and lagoons, where from its size and color it becomes conspicuous at a distance, yet from its vigilance and timidity rarely allows of an approach within gunshot. It is known to breed in several of the great cedar-swamps in the lower maritime parts of New Jersey. Like most of the tribe, it associates in numbers at the eyries, and the structure and materials of the nest are entirely similar to those of the Snowy Heron. The eggs, about four, are of a pale blue color. In July and August, the young are seen abroad in the neighboring meadows and marshes in flocks of twenty or thirty together. It is particularly frequent in the large and deep tide ditches in the vicinity of Philadelphia. Its food, as usual, consists of frogs, small fish, lizards, mice, and moles, insects, small water-snakes, and at times the seeds of the pond-lilies. 
This Egret does not occur regularly near the Atlantic coast north of New Jersey, but it is a rather common visitor to Ohio, and a small number of the birds are seen every year in the southern portions of Ontario and Illinois. Stragglers are found occasionally in New England, and a few have been met with on the Bay of Fundy and the Gulf of St. Lawrence.

The birds are said to breed no farther north than Virginia and Illinois, though wandering beyond these latitudes after the young broods are independent of assistance.

The food of this bird consists chiefly of small fish, frogs, lizards, and such ; but it refuses nothing eatable that comes within its reach, and is expert at catching mice and insects. Although shy when in a wild state, it is easily reconciled to captivity, says Dr. Brewer; and its elegant plumage and graceful carriage combine to make it an attractive ornament to courtyard or garden.

Unfortunately, and to man's, or woman's, discredit, very few of these birds are now to be seen, - they have been slaughtered for their plumes. Mr. W. E. D. Scott, who is familiar with the heronries of Florida, tells us of one of these breeding-grounds, where "thousands" were nesting six years before, but was entirely deserted when he visited it in 1887 . He saw only two or three frightened birds; the "thousands" had been exterminated by the plume-hunters. 


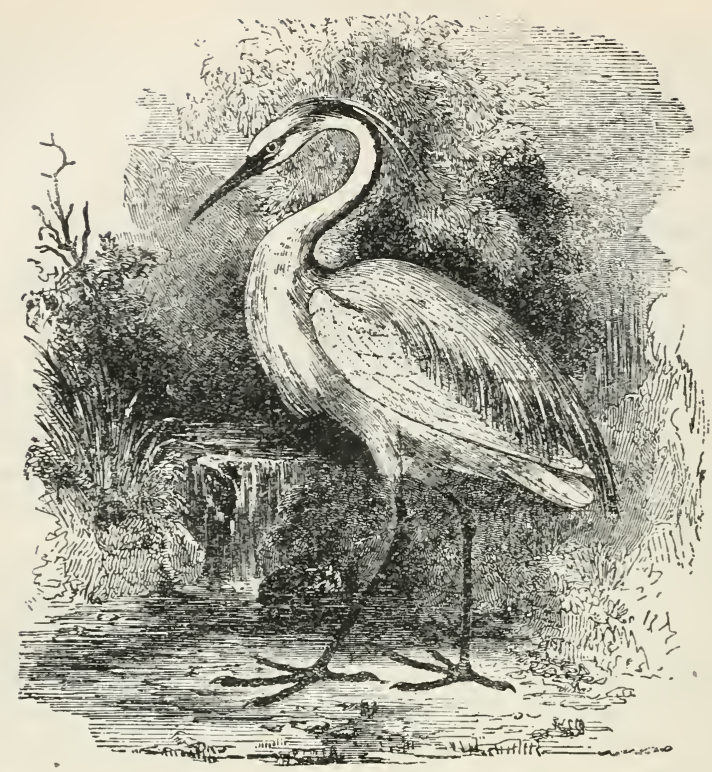

\section{SNOWY HERON.}

LITTLE WHITE EGRET. SMALL WHITE HERON.

\section{ARDEA CANDIDISSINIA.}

Char. Plumage pure white; crest long, with numerous elongated hair-like plumes extending down the back of the neck; plumes on the breast and back long and hair-like, those of the back reaching to the end of the tail or beyond, and recurved at the tips. (These plumes are worn only during the nesting season, and are not seen on young birds.) Bill black, yellow at the base; legs black, feet yellow. Length 20 to 27 inches.

Nest. With a community; placed usually on a low cedar or willow, a mere platform of dry twigs.

Eggs. 2-5 (usually 4); greenish blue: $1.85 \times 1.25$.

This elegant Heron, so nearly related to the little Egret of Europe, inhabits the marshes and swamps of the sea-coast nearly from the isthmus of Darien to the estuary of the St. Lawrence, generally omitting, however, the maritime range of 
the central parts of New England. It arrives in the United States from the South early in April, and passing inland, at length proceeds up the valley of the Mississippi, and even ascends the borders of the Arkansas, thus pursuing an extensive inland route to the final destination in the wilds of Canada. It departs from the Middle States, towards its hibernal destination in the South, in the course of the month of October.

Like most of the summer visitors of this family, the Snowy Heron confines its residence to the salt-marshes, where its brilliant whiteness renders it a conspicuous object at a distance. Its food, as usual, consists of small crabs, worms, snails, frogs, and lizards, to which fare it also adds at times the seeds of the pondlilies and other aquatic plants. About the midlle of May nestbuilding commences; and Wilson describes one of these heronries situated in a sequestered clump of red cedars, at Summer's Beach, on the coast of Cape May. The spot chosen, with the usual sagacity of the tribe, was separated on the land side by a fresh-water pond, and sheltered from the view of the Atlantic by ranges of sand-hills. The cedars, though low, were so densely crowded together as scarcely to permit a passage through them. Some of the trees contained three or four nests in each, constructed wholly of sticks. The eggs, about three in number, were of a pale greenish-blue color, and measured one inch and three quarters in length. On approaching the premises, the birds silently rose in great numbers; and alighting on the tops of the neighboring trees, they appeared to watch the result of the intruding visit in silent anxiety. Assembled with them were numbers of the Night Herons, and two or three of the purple-headed species. Great quantities of egg-shells lay scattered under the trees, occasioned by the depredations of the Crows who were hovering in the vicinity. Wherever the Snowy Herons happen to wander through the marshes, or along the borders of the rivers and inlets, they regularly return in the evening to their favorite roost in the cedars of the beach.

The young, of both this and the preceding species, are generally fat, and esteemed by some as palatable food. 
The Snowy Heron occurs regularly, in summer, from the Gulf States to Long Island. It is occasionally seen also along the Atlantic coast as far as Nova Scotia, and in the interior has been taken in Ohio and Ontario.

One writer has called this species a scraper, or raker, because it uses its legs and claws to start from their hiding-places the animals it desires to secure for food. In this movement it is said to surpass all other species in adroitness and rapidity, using the feet so rapidly as to cause the whole body to quiver. The scraping is done sometimes in water so deep that it reaches to the bird's belly.

Our bird wears the most beautiful plumes of all the Herons, and in consequence has been nearly exterminated by the plume-hunters. Instead of the thousands that gathered at their heronries a few years ago, only a few scattered birds can now be found.

\section{REDDISH EGRET.}

\section{PEALE'S EGRET.}

\section{ARDEA RUFESCENS.}

Char. Colored phase. General plumage grayish blue, darker on the back, paler below; head and neck with long, narrow feathers, - longest on the back of the neck and the lower part of the breast, - of rich reddish brown, sometimes tinged with purple; scapular plumes and train - the latter extending beyond the tail - grayish blue, tinged with brown towards the ends; bill pink, tipped with black; legs blue, claws black.

White phase. Plumage entirely white: bill pink, tipped with black; legs and feet olive, soles yellow. Length about 30 inches.

Young of both phases similar to the adult, but lacking the nuptial plumes. Sometimes the blue and white colors are displayed by the same specimen in a "pied" form.

Nest. With a community close by the sea-shore; placed on a low tree or bush, sometimes on the ground, - a platform of dry twigs.

Eggs. 2-6 (usually 3); pale blue tinged with green; size variable, average about $1.90 \times 1.45$.

This is another of those dichromatic species that have caused confusion and controversy, and given to both systematists and book-makers a deal of trouble.

The white phase has in this instance been made to play the shuttlecock; and appearing first as a distinct species, under the name of "Peale's Egret," it has been tossed hither and yon by the numerous writers who have laid claim to a solution of the problem which these varied phases of plumage present. At one time made out to be the young of $A$. rufa, later set up as a white phase of this species, again seized upon by the hungry variety-makers 
eager to convert it into a geographical race, it was at last, through the conservatism of the A. O. U., laid to rest in that refuge for questionable cases, the "hypothetical list," there to await the gathering of more decisive data.

In the mean time, as it becomes necessary for me to describe its characteristics, I treat the white bird as an individual variation or phase of the present species, because I think this will be its ultimate destiny. But these white specimens have always been comparatively rare, - in a flock of thirty birds not more than four or five will wear white plumes, - - and the plume-hunters may exterminate them before any naturalist can have any opportunity to make further study of their origin. Indeed, as I write, the remnant may be yielding their plumes to the insatiable crew, for the heronries of the South have been almost wiped out during the last few years.

Nuttall makes no mention of the Reddish Egret, though he does give a short note telling of the discovery of pealei, - the white phase. Our bird is not well known even at this day, few observers having met with it. It occurs regularly within the United States only in Florida and along the Gulf coast, though examples occasionally wander up the Mississippi valley as far as Illinois.

These birds are said to begin breeding in March, and eggs have been taken through April. The young are nearly naked when hatched, wearing nothing but a few patches of down; but it is a disputed point whether all the young are white, or a part of them are blue. Audubon says that they are fed by regurgitation, grow fast, and soon become noisy. They leave the nest when about seven weeks old, fully fledged and able to fly.

The favorite feeding-ground of these Egrets is a mud flat over which the outgoing tide leaves but about six to ten inches of water. In this they stand, and silently and motionless watch for their prey, or using their feet among the water-plants, drive the fish - their principal food - from under cover. If they miss the object at their first dart, they give chase; and though appearing so clumsy and awkward as to present a ridiculous figure while in pursuit of a scudding fish, are much more expert at this chasing than are any others of their kin. The red-and-blue specimens and the white always gather in one flock, and it has been remarked that they quarrel with each other persistently, - white against white, as well as white against red; but neither white nor red birds have been observed to attack any other species.

The flight of this species is strong and graceful, and when two males combat in mid-air their evolutions are performed with rare skill. Like many other birds, - aye, like most birds, - this Egret is less shy during the breeding-season than at other times. Some observers deny them all credit for shyness, but admit that they seem 
extremely fearless when mate and young demand their protection. Said Audubon, writing of the fearlessness of the Herons during this period, "As the strength of their attachment toward their mates or progeny increases through the process of time, as is the case with the better part of our own species, lovers and parents perform acts of heroism which individuals having no such attachment to each other would never dare to contemplate." He was of the opinion that under the influence of affection the thoughts of birds change; they become careless of themselves, and thus appear fearless and indifferent to danger. No one can study birds in the field without becoming convinced that these creatures have thoughts, and that they are capable of heroic devotion. Few men will fight more valiantly for home and young than will many of these timid and gentle birds.

\section{YELLOW-CROWNED NIGHT HERON.}

\section{NyCTICORAX viOLACEUS.}

Char. General plumage ashy blue, darker on wings and tail, paler beneath; feathers of upper parts with medial stripe of black; dorsal plumes narrow and extremely long, reaching beyond the tail; crown, patch on side of head, and long narrow plumes creamy yellow; bill stout and black, sometimes tinged in patches with greenish yellow; legs yellowish green. Young grayish brown, feathers of upper parts with medial stripe of pale buff. Length 22 to 28 inches.

Nest. In a community usually near a stream; placed on a lower branch of a tree, - a mere platform of dry twigs.

Eggs. 3-6 (usually 4); pale and dull blue, slightly tinged with green; $2.00 \times \mathrm{I} .45$.

This species has been frequently named the White-crowned Night Heron by authors because the yellow color of the head and plumes fades very soon after death, and finally the feathers become entirely white. It is found in the warmer portions of this Eastern Province, breeding in the Carolinas and the Ohio valley, and south to the Gulf States. It is found also in South America. Occasionally examples are met with to the northward of the usual habitat, two having been captured in Massachusetts.

In habits, as in appearance, this bird differs little from its Northern congener, though it is less tamable and not so easily domesticated; rebelling to the end against captivity, and yearning ever for a return to the freedom of a wild life. Sometimes these birds search for food during the daytime, but in general they are strictly nocturnal, and feed as well as migrate at night. Their diet consists chiefly of small reptiles and young birds. 


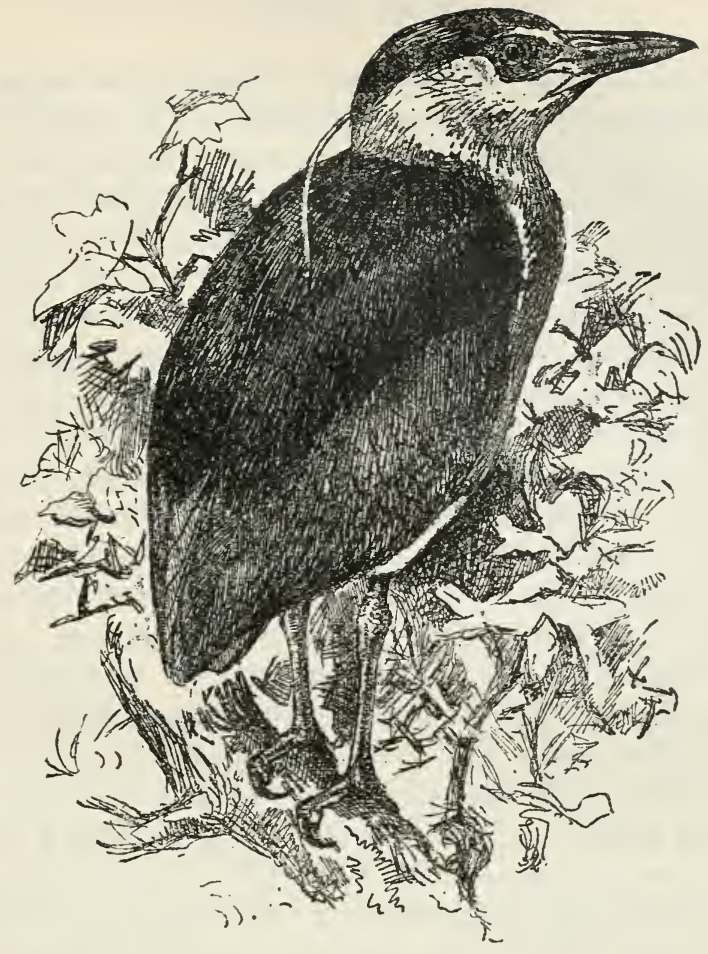

\section{BLACK-CROWNED NIGHT HERON.}

SQUAWK. QUA BIRD.

\section{NyCTICORAX NYCTICORAX NÆVIUS.}

Char. Top of head and back greenish black; forehead, sides of head, and throat white; wings and sides of neck bluish gray ; no plumes excepting two long narrow white feathers at back of head; lower parts white tinged with pale creamy yellow. Young: above, grayish brown; beneath, dull white, streaked with brownish. Body stout; bill thick and black; legs short and yellow. Length 23 to 26 inches.

Nest. In a community situated near the bank of a stream; placed on an upper branch of a tall tree, - sometimes placed on the ground in a swamp ; a simple platform of dry twigs.

Eggs. 4-6; pale green tinged with blue; $2.00 \times 1.50$.

The Great Night Heron of America extends its migrations probably to the northern and eastern extremities of the United 
States, but is wholly unknown in the high boreal regions of the continent. In the winter it proceeds as far south as the tropics, having been seen in the marshes of Cayenne, and their breeding-stations are known to extend from New Orleans to Massachusetts. It arrives in Pennsylvania early in the month of April, and soon takes possession of its ancient nurseries, which are usually (in the Middle and Southern States) the most solitary and deeply shaded part of a cedar-swamp, or some inundated and almost inaccessible grove of swamp-oaks. In these places, or some contiguous part of the forest, near a pond or stream, the timorous and watchful flock pass away the day until the commencement of twilight, when the calls of hunger and the coolness of evening arouse the dozing throng into life and activity. At this time, high in the air, the parent birds are seen sallying forth towards the neighboring marshes and strand of the sea in quest of food for themselves and their young; as they thus proceed in a marshalled rank at intervals they utter a sort of recognition call, like the guttural sound of the syllable 'kwàh, uttered in so hollow and sepulchral a tone as almost to resemble the retchings of a vomiting person. These venerable eyries of the Kwah Birds have been occupied from the remotest period of time by about eighty to a hundred pairs. When their ancient trees were levelled by the axe, they have been known to remove merely to some other quarter of the same swamp; and it is only when they have been long teased and plundered that they are ever known to abandon their ancient stations. Their greatest natural enemy is the Crow; and according to the relation of Wilson, one of these heronries, near Thompson's Point, on the banks of the Delaware, was at length entirely abandoned through the persecution of these sable enemies. Several breeding-haunts of the Kwah Birds occur among the red-cedar groves on the seabeach of Cape May; in these places they also admit the association of the Little Egret, the Green Bittern, and the Blue Heron. In a very secluded and marshy island in Fresh Pond, near Boston, there likewise exists one of these ancient heronries; and though the birds have been frequently robbed of their eggs in 
great numbers by mischievous boys they still lay again immediately after, and usually succeed in raising a sufficient brood. The nests, always in trees, are composed of twigs slightly interlaced, more shallow and slovenly than those of the Crow; and though often one, sometimes as many as two or three nests are built in the same tree. The eggs, about four, are as large as those of the common hen, and of a pale greenish blue color. The marsh is usually whitened by the excrements of these birds; and the fragments of broken egg-shells, old nests, and small fish which they have dropped while feeding their young, give a characteristic picture of the slovenly, indolent, and voracious character of the occupants of these eyries.

On entering these dark and secluded retreats of the Night Heron, the ear is assailed by the confused and choking noise uttered by the old and young, which, however, instantly ceases the moment the intruder is observed; and the whole throng, lately so clamorous, rise into the air in silence, and fly to the tops of the trees in some other part of the wood, while parties of the old birds, of from eight to ten, make occasional reconnoitring circuits over the spot, as if to observe what may be going on in their surprised domicile.

However deficient these nocturnal birds may be in vision by day, their faculty of hearing is so acute that it is almost impossible, with every precaution, to penetrate near their residence without being discovered. As soon as the young are able to fly, and long before they are capable of sustained flight, they climb to the highest part of the trees near their nests, as if to solicit the attention and watch the return and protection of their officious parents; and yet, with every precaution, the young fall victims to the prowling Hawks, who, hovering round, make an occasional sweep among their timorous ranks.

About the middle of October the Qua Birds begin to retire from this part of Massachusetts towards their southern winter quarters, though a few of the young birds still linger occasionally to the 29 th or 3 oth of that month. Their food consists chiefly of small fish, which they collect in the twilight or 
towards night, and in the wide gullet which commences at the immediate base of the bill they probably carry a supply for the use of their young.

In the month of October I obtained two specimens of the young Night Heron in their second plumage; these were so extremely fat that the stomach was quite buried in cakes of it like tallow. Their food had been Ulva latissima, small fish, grasshoppers, and a few coleopterous insects; so that at this cool season of the year these birds had ventured out to hunt their fare through the marsh by day, as well as evening. In the stomach of one of these birds, towards its upper orifice, were parasitic worms like tænia. About the time of their departure the young, in their plumbeous dress, associate together early in the morning, and proceed in flocks, either wholly by themselves, or merely conducted by one or two old birds in a company.

I have visited two heronries of this species in northern New Brunswick, on streams emptying into the Gulf of St. Lawrence at about latitude $47^{\circ}$. It is common in the Muskoka district of Ontario, and Mr. Gunn reports it numerous at. Shoal Lake in Manitoba. He found the nests placed on the ground among the reeds.

The bird is a common summer resident of New England, though extremely local in its distribution. The heronry at Fresh Pond, Cambridge, which was celebrated in former years, has been deserted for some time.

\section{LITTLE BLUE HERON.}

BLUE EGRET.

\section{ARdea CCERUlea.}

CHAR. General plumage dark ashy blue; head and neck rich maroon; plumes on back of head, breast, and back, the last extending over and beyond the tail ; bill slender, curved at the point, and of blue color shading to black at the tip; legs and feet black; eyes yellow. Sometimes the plumage is "pied," - of blue and white, - and occasionally it is almost entirely white, with some traces of blue. The young are usually white, spotted more or less with blue. Length 22 to 26 inches.

Nest. Usually in a large community or "heronry;" placed on a top branch of a tree or bush; made of twigs loosely laid.

Eggs. 2-5; bluish green; size variable, averaging about I.75 $\times$ I.30. 
The Blue Heron may be considered almost a restricted native of the warmer climates of the United States, from whence it migrates at the approach of winter into the tropical parts of the continent, being found in Cayenne, Mexico, and the island of Jamaica. The muddy shores of the Mississippi from Natchez downward are its favorite resort.

In the course of the spring, however, a few migrate to New England, restricting their visits, like many other of the tender species, to the confines of the ocean and its adjoining marshes, where their proper food of reptiles, worms, and insect larvæ abound. They also often visit the fresh-water bogs in the vicinity of their eyries, and move about actively, sometimes making a run at their prey. Like the Snowy Herons, with which they sometimes associate, they are also, when the occasion requires, very silent, intent, and watchful. These nocturnal and indolent birds appear tacitly to associate and breed often in the same swamps, leading towards each other, no doubt, a very harmless and independent life. Patient and timorous, though voracious in their appetites, their defence consists in seclusion, and with an appropriate instinct they seek out the wildest and most insulated retreats in nature. The undrainable morass grown up with a gigantic and gloomy forest, imperviously filled with tangled shrubs and rank herbage, abounding with disgusting reptiles, sheltering wild beasts, and denying a foot-hold to the hunter, are among the chosen resorts of the sagacious Herons, whose uncouth manners, harsh voice, rank flesh, and gluttonous appetite allow them to pass quietly through the world as objects at once contemptible and useless; yet the part which they perform in the scale of existence, in the destruction they make amongst reptiles and insects, affords no inconsiderable benefit to man.

A few of the Blue Herons, for common safety, breed among the Night Herons, the Snowy species, and the Green Bittern, among the cedars (or Virginian junipers) on the sea-beach of Cape May.

The Blue Egret nests regularly, though in small numbers, as far north as Virginia and Illinois. An occasional straggler has 
been taken in New England, and in 1884 one was shot near Halifax, N. S.

Some naturalists place this among the dichromatic species, while others consider that the white phase, so called, is seen only in young birds, - that all the young are white or pied.

\section{LOUISIANA HERON.}

\section{ARDEA TRICOLOR RUFICOLLIS.}

CHAR. Above, ashy blue, darker on head and neck; crest reddish purple, excepting the long narrow plume-feathers, which are white; plumes of the breast mixed, maroon and blue; train of straight hair-like plumes from the back extending beyond the tail, of light drab color, lighter towards the tips ; under parts white. Length 24 to 27 inches.

Nest. Usually in a community ; placed on a low tree or bush ; made of small twigs.

Eggs. 2-6; blue with a slight tinge of green; $1.75 \times 1.35$.

This richly apparelled bird, sometimes called the "Lady of the Waters," occurs in numbers in the Carolinas and southward to the Gulf, and is very abundant in Central America. An occasional straggler has been found as far north as Long Island and Indiana.

Those who are familiar with the bird's habits say that it is extremely sociable, and is usually found in company with other species, - the White Egret, Blue Heron, Night Heron, etc. In its movements are combined rare grace and dignity. Even when hunting for prey it displays less impetuosity than any other of the group. The usual feeding-place is a sand-bar or shallow pond, and there it saunters with stately tread, or stands calmly waiting and watching. If a coveted leech or water-bug halts beyond reaching distance, the Heron stalks upon it in a crouched and cat-like attitude, and then strikes quick and straight. The flight is rather irregular, but is swifter than that of any other Heron. If one of a flock is wounded, its companions hover about it with cries of sympathetic interest. 


\section{GREEN HERON.}

\section{ARDEA VIRESCENS.}

CHAR. The smallest of the Heron family, excepting the Least Bittern. Top of head and crest dark metallic green; rest of head and neck rich chestnut, sometimes with a tint of maroon; throat with a line of white with dark spots; back dark ash, more or less tinged with green; wings and tail dark green; under parts brownish ash. Length 16 to 20 inches.

Nest. On the border of a swamp or near the margin of a stream, placed on a branch of tree or bush; made of small twigs loosely laid.

Eggs. $3-6$; bright blue of a rather pale shade, strongly tinged with green; $1.50 \times 1.15$.

The Green Bittern, known in many parts much better by a contemptible and disgusting name, is the most common and familiar species of the genus in the United States. Early in April, or as soon as the marshes are so far thawed as to afford these birds the means of subsistence, they arrive in Pennsylvania, and soon after are seen in New England, but are unknown in the remote and colder parts of Canada. Many winter in the swamps of the Southern States, though others retire in all probability to the warmer regions of the continent, as they are observed at that season in the large islands of Hayti and Jamaica.

In common with other species, whose habits are principally nocturnal, the Green Bittern seeks out the gloomy retreat of the woody swamp, the undrainable bog, and the sedgy marsh. It is also a common hermit on the inundated, dark willow and alder shaded banks of sluggish streams and brushy ponds, where it not only often associates with the kindred Kwa Birds and Great Herons, but frequently with the more petulant herd of chattering Blackbirds. When surprised or alarmed, it rises in a hurried manner, uttering a hollow guttural scream and a ' $k$ ' $w$, ' $k$ ' $w$, ' $k$ ' $w$, but does not fly far, being very sedentary ; and soon alighting on some stump or tree, looks round with an outstretched neck, and balancing itself for further retreat, frequently jets its tail. It sometimes flies high, with neck reclining and legs extended, flapping its wings and proceedvOL. II. -7 
ing with considerable expedition. It is also the least shy of all our species, as well as the most numerous and widely dispersed, being seen far inland, even on the banks of the Missouri, nearly to the River Platte, and frequent near all the maritime marshes, and near ponds and streams in general. It is also particularly attracted by artificial ponds for fish, not refraining even to visit gardens and domestic premises which any prospect of fare may offer. It is at the same time perhaps as much in quest of the natural enemy of the fish, the frog, as of the legitimate tenants of the pond. These bold and intrusive visits are commonly made early in the morning or towards twilight, and it not unfrequently, when pressed by hunger, or after ill-success, turns out to hunt its fare by day, as well as dusk; and at such times collects various larvæ, particularly those of the dragon-fly, with grasshoppers and different kinds of insects. At other times it preys upon small fish, crabs, and frogs, for which it often lies patiently in wait till they reappear from their hiding-places in the water or mud, and on being transfixed and caught, - an operation which is effected with great dexterity, - they are commonly beaten to death, if large, and afterwards swallowed at leisure.

The Small Bittern in the Middle States usually begins to build about the $5^{\text {th }}$ of April, sometimes in solitary pairs, in dark and swampy woods, at other times in companies, and as already remarked, by similarity of taste and habit frequently joins the heronries of the larger species as its sort of humble dependant and watchful defender of the general eyry. The young, as usual, slowly acquire the full use of their limbs, and remain patiently in the nest until able to fly.

The Green Heron is a common summer resident of New England, and though usually rather rare as far north as the Maritime Provinces, is sometimes quite common there. It is common also in Ontario and abundant in Ohio, and occurs westward to the Mississippi and northward to Manitoba. In winter the major portion of these birds retire to the West Indies and northern South America, though a few remain in the Gulf States. 


\section{AMERICAN BITTERN.}

STAKE DRIVER.

\section{Botaurus LENTIGINOSUS.}

CHAR. Upper parts brownish buff thickly spotted or mottled"freckled" - with reddish brown and black; neck buff; line down the throat white, spotted with brown; a patch of black or dark brown or gray on the sides of the neck; under parts pale buff striped with brown; bill rather short, stout, and of yellow color; legs yellowish green. Length 25 to 30 inches.

Nest. In a swamp or reedy marsh, placed on the ground; a thick mat of coarse grass loosely laid.

Eggs. 3-5; brownish drab, sometimes with an olive tint; $1.90 \times 1.45$.

The Bittern of America, though apparently nowhere numerous, from its retiring habits, is found in almost every part of the continent where there exist extensive marshes either maritime or inland, up to the $5^{8 \text { th }}$ parallel, and is found in the morasses and willow-thickets of the interior throughout the fur countries. From the inclement regions it retires in the winter, while in other parts it is permanently resident. It is said to revisit Severn River, at Hudson Bay, about the beginning of Jume, nesting in the swamps among the sedges. It breeds also in several parts of Massachusetts, young birds being met with in the Fresh Pond marshes and other places in the vicinity of Boston about the middle of summer.

During the day the Night Hen, as it is here called, remains hidden in the reeds and sedge, and rarely comes out till the approach of night. When disturbed in its retreat, it flies off with a hollow 'kwa, or kowk, kowk, and sometimes gives a loud squeak of alarm; at this time, as it flies heavily and at no great height, it is easily shot down. These birds are also sometimes obtained by lying in wait for them as they sally out in the evening towards the salt-marshes, in a particular direction, in quest of food.

In the breeding-season and throughout a great part of the summer we often hear the loud booming note of this bird from the marshes of Fresh Pond, morning and evening, and some- 
times even during the day. Instead of the bump, or böomp, however of the true Bittern, the call is something like the

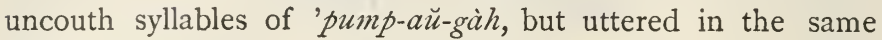
low, bellowing tone.

The cry of the European Bittern, so similar to that of our own species, is thus elegantly described by Goldsmith in his "Animated Nature." "Those who have walked in a summer's evening by the sedgy sides of unfrequented rivers must remember a variety of notes from different water-fowl, - the loud scream of the Wild Goose, the croaking of the Mallard, the whining of the Lapwing, and the tremulous neighing of the Jacksnipe; but of all these sounds there is none so dismally hollow as the booming of the Bittern. It is impossible for words to give those who have not heard this evening call an adequate idea of its solemnity. It is like the interrupted bellowing of a bull, but hollower and louder, and is heard at a mile's distance, as if issuing from some formidable being that resided at the bottom of the waters. This is the Bittern, whose windpipe is fitted to produce the sound for which it is remarkable; the lower part of it, dividing into the lungs, being supplied with a thin loose membrane that can be filled with a large body of air and exploded at pleasure. These bellowings are chiefly heard from the beginning of spring to the end of autumn, and are the usual calls during the pairing season."

The American bird, no less than the true Bittern, is considered by many as excellent food.

The Bittern is still a familiar bird throughout temperate North America, breeding from the Middle States northward; but, like many another bird whose form is familiar, the Bittern's habits are known only to the few, and many erroneous opinions of its characteristics have been current.

The "booming of the Bittern" has been a favorite topic of controversy; but probably that matter has been finally settled by an account of the performance contributed to "The Auk" for January, I889, by Mr. Bradford Torrey.

Mr. Torrey described the performer as first filling its crop with air, opening the bill and shutting it with a click, repeating this several times. Then, while the bill is kept tightly closed, the air 

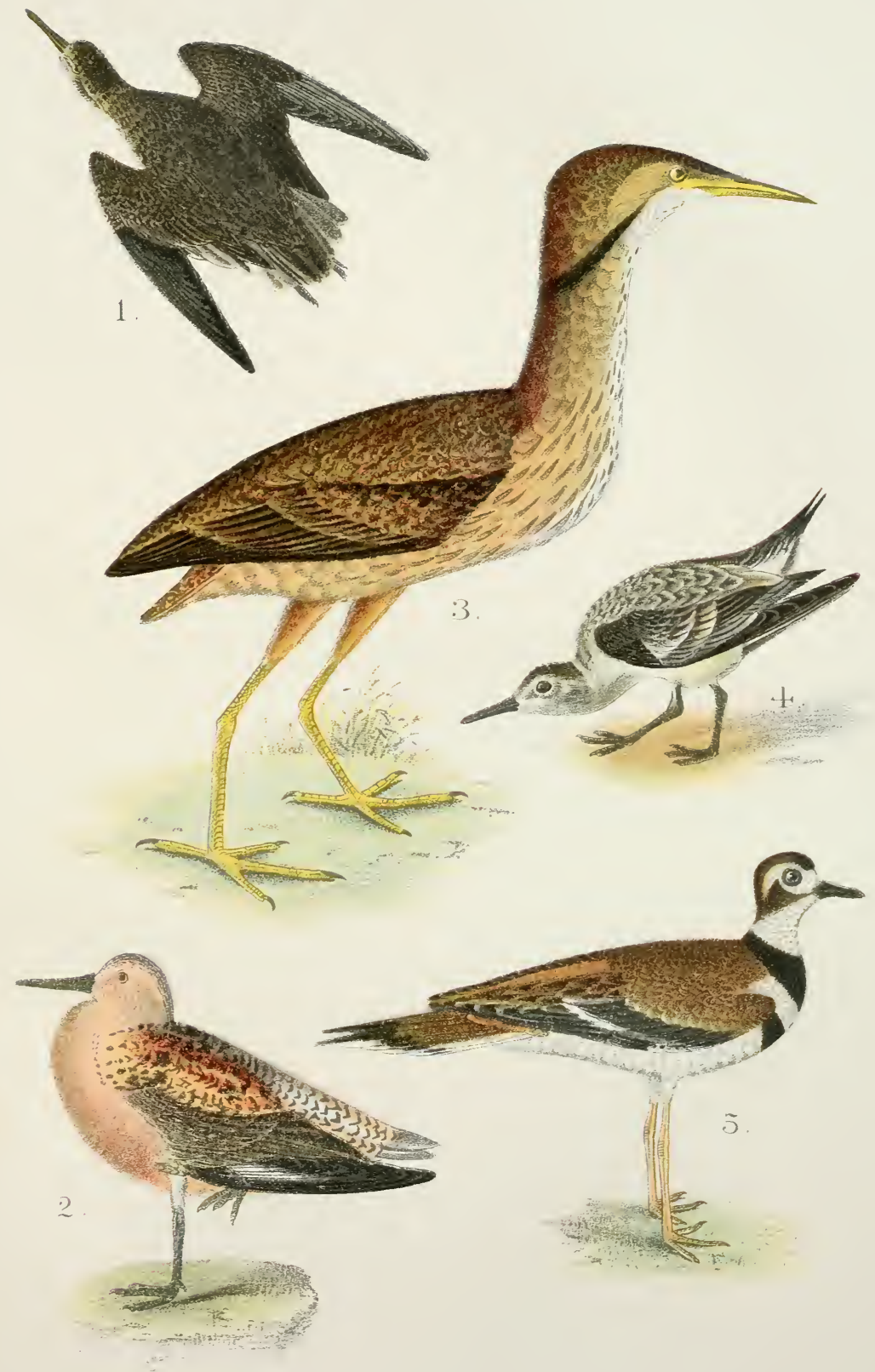

1. White-Rumped Sandpiper.

4. Sanderling.

3. Bittern. 

from the crop is forced through the throat, producing a deep hollow sound in three distinct syllables. The quality of the notes suggests their being emitted under water; and this has given rise to the theory, so strongly urged by many writers, that the performer held its bill under water. The emission of the sound is accompanied by convulsive movements, as if the bird was vomiting.

The Bittern's fondness for retirement has been exaggerated; for though it does dwell in the wilderness, - on the marshy margins of streams and lakes, and in the depths of swamps, - I have frequently found the nest close to a bustling village; one within sound of children's voices playing around a school-house.

\section{LEAST BITTERN.}

ARDETTA EXILIS.

CHAR. Adult male : crown, back, and tail black, glossed with green; narrow stripe of buff on each side of back; back of neck chestnut ; wings buff and rufous; under parts pale buff. Female: similar to male, but black of head and back mostly replaced by brown. Length about 13 inches.

Nest. Usually amid the rank grass and rushes on the marshy margin of a pond; placed on the ground and made of coarse grass or dead rushes.

Eggs. 3-5; dull white with a pale tinge of blue or green ; $1.20 \times 0.95$.

The Least Bittern has not so extended a distribution as its larger congener, but it is found regularly as far north as Massachusetts, and stragglers have been captured in Maine and New Brunswick. It is common in southern Ontario, and occurs in Illinois and north to Manitoba, and breeds south to the Gulf States.

Though a shy bird, courting retirement and rarely appearing outside the shelter of its reedy haunts, it seems to be indifferent to adjacent noises. For years some pairs have spent the summer in a marshy tract close to the busiest district of the town of Brookline, within a stone's throw of a street-car track and a playground; and Fresh Pond marsh, near Cambridge, has long been a favorite resort.

The food of this Bittern consists chiefly of small fish, lizards, and young frogs; but it will not refuse a chance to vary this diet with a mouse or shrew. It utters several notes; but that most commonly heard is a hoarse croak, though during the nesting-season a cooing note is heard that is low and soft and sweet. When 
startled it gives a cry resembling the qua of the Night Heron, and displays a Rail-like disposition to hide amid the grass rather than fly from danger. Some observers think its flight is feeble and cannot be sustained, while others affirm that the bird is capable of prolonged flight.

\section{CORY'S LEAST BITTERN.}

\section{ARDETTA NEOXENA.}

Char. Similar to B. exilis, but smaller, and lacking the stripes of buff on the sides of the back; lower tail-coverts black; wing-coverts chestnut. Length about II inches.

Nest. In a swamp on border of lake; on a low bush two and a half feet above the surface of the water; built of twigs and lined with leaves.

Eggs. —— ?

This species was described by Mr. Charles B. Cory in I 886 from the type which was taken in Florida by Mr. R. T. Stuart. Since then some thirteen examples have been reported, five from Florida, one from Michigan, and seven from Toronto.

The habits of the bird are supposed to be similar to those of exilis. Mr. Scott's example was discovered while walking on the leaves of pond-lilies, and when startled it retreated to the tall grass on the margin of the pond.

Mr. Menge, who collected several of the Florida specimens, discovered a nest with four young birds. He writes :-

"I had one of the old birds in my hand, which I think was the female. She was not inclined to fight and would not leave the nest. The other old bird was two or three feet from me, and seemed a much larger bird. I did not disturb them, and when I let the old bird go she hopped back on her nest as though she was accustomed to being handled." (R. A. Chapman, "The Auk," January, I\$96, p. 14.)

\section{LIMPKIN.}

\section{COURLAN.}

ARAMUS Giganteus.

CHAR. Prevailing color dark brown glossed with purple; head, neck, and back striped with white; throat white. General appearance rather Heron-like. Length about 26 inches. 
Nest. Amid rushes or upon a low bush, on the margin of a pond or stream; made of vine-leaves and grass.

Eggs. 4-8; buffy white or grayish white spotted with brown and gray; variable in size, average about $2.40 \times 1.70$.

This singular bird principally inhabits Cayenne, Brazil, and Paraguay, where it is rather common; it is numerous in the island of Cuba and other warm parts of America. In the United States, Florida appears to be its most natural residence, and a few instances have occurred of its visiting the Middle States. The Courlan leads a solitary life, or only associates by pairs. By night as well as day it is heard crying out in a loud and sonorous voice carau! and is well entitled to the name of the supposed "crying-bird" of Bartram. Mollusca, frogs, and other aquatic animals are its ordinary food. It is very shy, carefully hiding itself; but when aware of being discovered, it starts rapidly to a great elevation, and its flight is long continued. It also walks with great agility, but never willingly wades into the water. It alights on the summits of trees, and builds in the grass, near stagnant water, concealing the nest with much art. The young are covered with blackish down when hatched, and soon follow their parents. Like the Rail, this bird runs swiftly through the grass, compressing its narrow body so as to pass through a small hole, and is very difficult to catch when wounded.

This species has been named Limpkin by naturalists, because that is the name by which it is known in Florida, - the only State of the Union in which the bird is found. The name is said to have been suggested by the walk of the bird, its movements resembling the motions of a lame person.

In Jamaica it is called the "Clucking Hen," from its habits of sauntering along and deliberately clucking like a fowl.

Dr. Bryant reported finding a nest containing fifteen eggs; but five or six has been the usual number of the sets taken during recent years. 


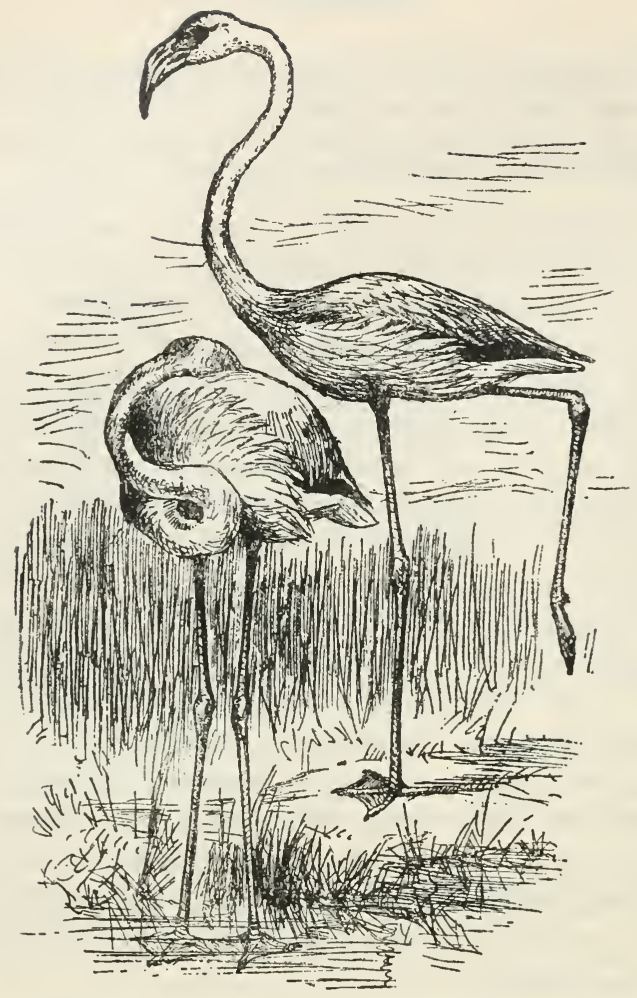

\section{FLAMINGO.}

\section{Phenicopterus RUBer.}

CHAR. General color bright pink, deepest on breast and wings; primary and secondary feathers of wings black; base of bill yellow, terminal half black. Legs red. The young are paler, the pink tints deepening with age. Length about 4 feet. Stature nearly 5 feet.

Nest. Usually in a colony, situated on the shore of a shallow lagoon or pond, or on a mud island, - a saucer-like depression in the mud, with a rim or bulwark 3 to 6 inches in height. Sometimes a cone-shaped mound of mud is built up from the bottom of the lagoon and raised 8 to ro inches or higher above the water level.

Eggs. 2 ; white, much elongated, and with a rough plaster-like surface; $3.60 \times 2.20$. 
The Flamingo of America is found chiefly in the tropical regions, whence it appears to emigrate in summer on either side the equator, in the southern hemisphere visiting Brazil, Peru, Chili, and Buenos Ayres, on the shores of La Plata. It is also seen in Cayenne (where it is known by the name of Tococo, from the usual sound of its call) and in various islands of the West Indies. It breeds in Cuba and the Bahamas, is not infrequent at certain seasons on the coast of Florida, and sometimes solitary individuals are observed even in the Middle States; but in the Union generally the species may be considered as rare. When seen at a distance, such is the brilliancy of their dress and the elevation at which the birds stand that they appear like a troop of soldiers being arranged alongside of each other in lines, while on the borders of rivers and estuaries near the sea they assemble in search of their food, which consists chiefly of small fish, spawn, and aquatic insects. They collect their prey by plunging in the bill and part of the head, and from time to time trample with their feet to disturb the water and raise it from the bottom. While the rest are thus employed in seeking their subsistence, one of them stands sentinel, and on the first note of alarm, a kind of trumpet-call, he takes to wing, and the whole flock immediately follow.

The flesh of the American Flamingo is accounted pretty good food, and that of the young is thought by some equal to the Partridge. Davies, in his "History of Barbadoes," says it is commonly fat and accounted delicate; while of the transatlantic species Dillon remarks that the inhabitants of Provence always throw away the flesh, as it tastes fishy, and make use only of the feathers as ornaments. But of this kind, celebrated in history, the ancients esteemed the tongue as an exquisite dainty, and Philostratus reckoned it among the delicacies of entertainments.

The claim of the Flamingo to recognition here rests upon its occurrence on the southwestern coast of Florida, where it is said to reside throughout the year. It also occurs casually at other points 
on the Gulf coast. Audubon credits it with occurring along the Atlantic coast to Charleston, S. C., as late as 1830.

The old notion that when sitting on the eggs the bird's legs dangle awkwardly on each side of a high cone-shaped nest has been discarded, recent observers affirming that the feet are drawn up under the sides of the body, the nest being close to the ground, or no higher than is necessary to protect the eggs from the water with which they may be surrounded.

When on the nest the neck is gracefully curved and the head neatly tucked away among the feathers of the back, like a Swan's; but when flying, the Flamingo does not curve its neck, as a Heron will, but carries both neck and legs outstretched and rigid.

\section{AMERICAN AVOCET.}

\section{RECURVIROSTRA AMERICANA.}

CHAR. Back and most of wings black, remainder of plumage white, excepting head and neck, which are pale brown in summer and pale gray in winter; feet webbed; legs blue; bill black, long, and recurved. Length about 17 inches.

Nest. A bulky affair of dry grass or seaweed lined with fine grass; placed amid tall herbage on the marshy margin of a pond.

Eggs. 3-4; buff or reddish drab, sometimes with an olive tint, covered with spots of brown of several shades; size variable, average about $2.00 \times 1.35$.

The American Avocet, supposed to winter in tropical America, arrives on the coast of Cape May, in New Jersey, late in April, where it rears its young, and retires to the South early in the month of October. In the spring it was observed by Mr. Say in the lower part of Missouri. It is also known to visit Nova Scotia, though scarcely ever seen in the State of Massachusetts. Dr. Richardson also found it abundant in the Saskatchewan plains as far as the $53 \mathrm{~d}$ parallel, where it frequents shallow lakes, feeding on insects and fresh-water crustacea. In New Jersey it seems to have a predilection for the shallow pools of the salt-marshes, wading about often in search of prey, which consists of marine worms, small paludinas, turbos, etc., to which, like the European species, it sometimes adds small Fuci or marine vegetables. 
The Avocets near their breeding-places are very noisy, quailing, and clamorous, flying around in circles near their invaders, and in a sharp but plaintive tone uttering 'clik, 'clik, 'clik, in the manner of the Stilts or Long Legs (Himantopus), with which at times they familiarly associate in small numbers to pass the important period of reproduction. Like them also they alight on the marsh or in the water indifferently, fluttering their loose wings and shaking their tottering and bending legs as if ready to fall, keeping up at the same time a continual yelping. The nest, in the same marsh with the Stilts, was hidden in a thick tuft of grass or sedge at a small distance from one of their favorite pools. It was composed of small twigs of some marine shrub, withered grass, sea-weeds, and other similar materials, the whole raised to the height of several inches.

Buffon, theorizing on the singular structure of the bill of the Avocet, supposes it to be "one of those errors or essays of Nature which, if carried a little further, would destroy itself; for if the curvature of the bill were a degree increased, the bird could not procure any sort of food, and the organ destined for the support of life would infallibly occasion its destruction." As it happens, however, and not as might be imagined, the Avocet, no less than the Crossbill, continues not only to live, but to vary its fare and obtain it with facility. Even the sloth, that triumph on the occasional imbecility of Nature, so wretched and lost upon the plain ground, for which the motions of its peculiar and unequal limbs are not calculated, climbs up a tree with facility, and, like the tribe of monkeys, is perfectly at ease in its accustomed arboreal retreat. Let us then more wisely content ourselves to observe Nature in all her ingenious paths, without daring, in our ignorance, to imagine the possible failure of her conservative laws.

The Avocet is a rather uncommon bird near the Atlantic coast, and north of New Jersey is merely a straggler, a few examples having been taken in Connecticut, Massachusetts, Maine, and New Brunswick. On the alkali plains of the West it is quite abundant, and ranges as far north as Great Slave Lake. 


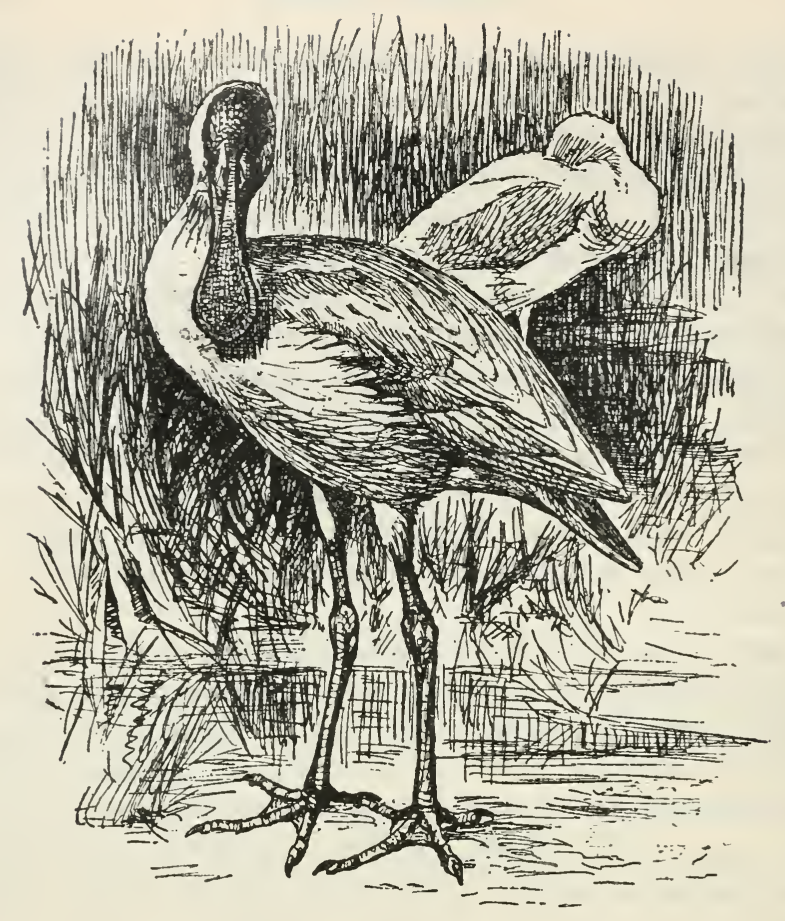

ROSEATE SPOONBILL.

\section{AJAJA AJAJA.}

Char. Head bare, skin green, orange, and black; bill long, broad, flat, and widened towards the end; neck, breast, and back white; short plumes of breast, wings, and tail rich carmine; tail and patch on neck buff; under parts deep rose color. Length about 30 inches.

Nest. In a colony, placed amid the tall grass of a salt marsh near the mouth of a river or on a marshy sea island; made of twigs loosely arranged, - a mere platform, raised several inches from the ground.

Eggs. 5-7; dull white or pale buff, spotted with brown; $2.60 \times 1.75$.

The Red or American Spoonbill chiefly dwells within the tropical regions of the continent, being common in Jamaica and other of the West India islands, as well as in Mexico, 
Guiana, and Brazil. In the southern hemisphere it is said to exist in Peru and as far down the coast of South America as Patagonia. North of the equator it migrates in summer into Florida, and is met with to the confines of the Altamaha, in Georgia. Wilson's specimen was obtained up the Mississippi, at the town of Natchez (about the latitude of $32^{\circ}$ ). Some are also occasionally met with on the river shores of the Alabama, and in other parts of that State. A straggler has been known to wander as far as the banks of the Delaware.

According to the relation of Captain Henderson, in his account of Honduras, this species is more maritime in its habits than that of Europe, as it wades about in quest of shellfish, marine insects, fry, and small crabs; and in pursuit of these, according to him, it occasionally swims and dives.

The European, or white, species appears to reside in much cooler climes than the American, being abundant in Holland, and even at times visiting the shores of the South and West of England in whole flocks. It is there, however, a bird of passage, and in migrations accompanies the flocks of Swans.

At the present day Spoonbills are found regularly no farther north than the maritime districts of the Gulf States, though an occasional bird wanders up the valley of the Mississippi, ranging at times as far as southern Illinois.

They were abundant in Florida not many years ago, but the plume-hunters have almost exterminated them there. At present they are more numerous on the shores of Texas than elsewhere. 


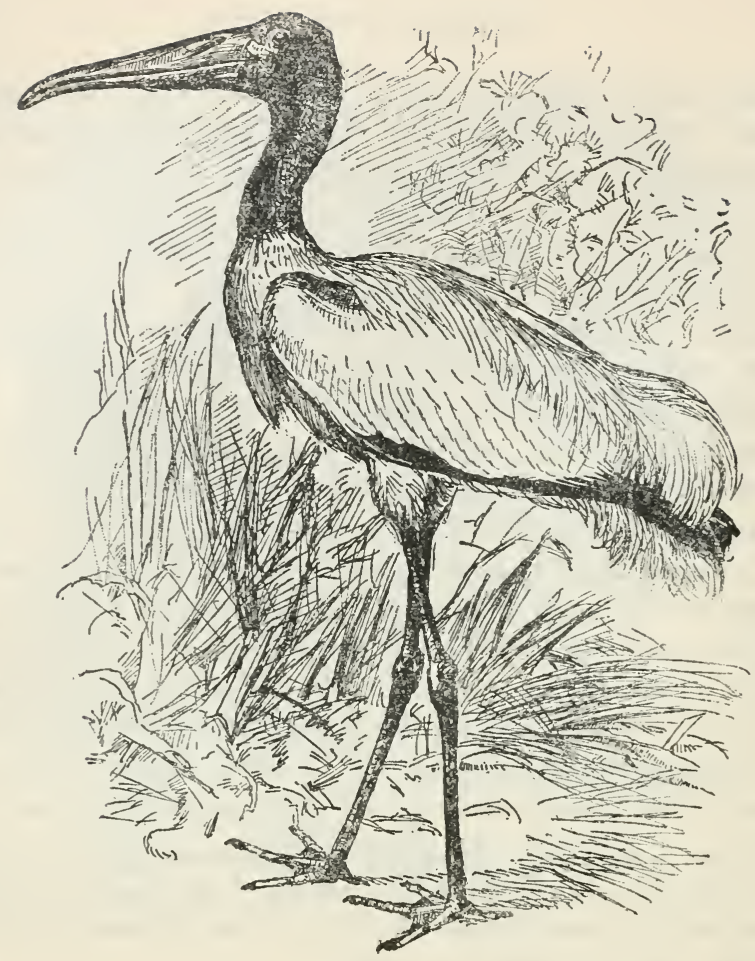

\section{WOOD IBIS.}

WOOD STORK.

\section{TANTALUS LOCULATOR.}

CHAR. General color white ; tail and part of wings black, with metallic reflections; head and upper half of neck bare, the skin hard, rough, and of a dusky color. Length about 40 inches.

Nest. In a colony situated amid a dense cypress-swamp, placed on an upper branch of a tall tree; a loosely arranged structure of twigs, lined with moss, - the size increasing by yearly additions.

Eggs. 2-3; white, spotted with brown; the surface rough; $2.75 \times 1.75$.

This is another tribe of singular wading birds, which emigrate in the summer to a certain distance on either side of the equator; being found occasionally as far north as Virginia, and as far south, in the other hemisphere, as the savannahs of 
Cayenne and Brazil, and in other parts of South America. In the compass of the United States their principal residence is in the inundated wilds of the peninsula of East Florida, and they are not uncommon in Mississippi, Alabama, Carolina, and Georgia, withdrawing from the north, however, at the commencement of cold weather or about the month of November.

According to Bartram, who had many opportunities of observing them in Florida, they are solitary and indolent birds, seldom associating in flocks, and usually frequent the banks of the principal rivers, marshes, and savannahs, especially such as are inundated, as well as the larger deserted rice-plantations contiguous to the sea-coast. Here, alone, the feathered hermit stands listless, on the topmost limb of some tall and decayed cypress, with his neck drawn in upon his shoulders, and his enormous bill resting like a scythe upon his breast. Thus pensive and lonely, he has a grave and melancholy aspect, as if ruminating in the deepest thought; and in this sad posture of gluttonous inactivity these birds probably, like Herons, pass the greatest part of their time, till, awakened by the calls of hunger, they become active in quest of their prey of snakes, young alligators, fish, frogs, and other reptiles. They are easily approached and shot, when abandoned to repose, and are by many of the inhabitants accounted as excellent food.

This Ibis is found in all the Southern States, though at present it is not a common bird anywhere within our borders, excepting in portions of Florida. Stragglers have been met with north to New York, Ohio, Indiana, and Wisconsin.

Bartram's account of the hermit-like habits of the bird, quoted by Nuttall, was criticised by Aubudon, who rarely met with a solitary example, - the birds were always in flocks; but Dr. Henry Bryant states that he never saw a flock of Wood Ibises excepting at their breeding-place. The principal food of this species is small fish, which are caught in the shallow waters, the Ibis scratching or "raking" the bottom to startle its prey; but a meal of frog, turtle, bird, or snake is never neglected, and a young alligator is not safe within reach of the bird's long and powerful bill. 


\section{SCARLET IBIS.}

GUara RUBra.

CHAR. Entire plumage deep scarlet, excepting the tips of the longest wing-feathers, which are black. Length about 30 inches.

Nest. In a colony, amid a thicket of small trees and vines; placed on a low tree or bush, - a mere platform of loosely arranged twigs and leaves. Eggs. 2-3; dull white or pale gray, spotted with brown; $2.10 \times 1.45$.

Nuttall followed Wilson in crediting the Scarlet Ibis to the Southern States; but its appearance within our borders during recent years has been merely casual, and it has not been seen elsewhere than in Florida and Louisiana.

\section{WHITE IBIS.}

\section{Guara Alba.}

CHAR. Entire plumage pure white, excepting the tips of the longest wing-feathers, which are black. In freshly killed specimens the white is tinged with a delicate shade of pink. Length about 24 inches.

Nest. In a colony, amid tall marsh-grass by the sea-shore or near a pond in the woods; a compactly woven structure, sometimes deeply hollowed, but often quite shallow, made of reeds or twigs and lined with green leaves; fastened to upright reeds or placed on a bush or low tree.

Eggs. 3-5; dull white tinted with green or blue, and marked with brown spots; $2.25 \times 1.50$.

This species, so extremely like the preceding, except in its permanent white color, is likewise common in the tropical parts of the American continent, particularly the Caribbee Islands, and extends its residence at least as far south beyond the equator as the coast of Brazil. Wilson observes that the species appeared to be pretty numerous on the borders of Lake Pontchartrain, near New Orleans, in the month of June; he also saw it on the low keys or islands off the coast of Florida. These birds rarely proceed to the north of Carolina, which they visit only for a few weeks towards the close of summer, - collected probably from their dispersed breeding-places, a little 
previous to the period of their migration back again to the South, which takes place on the return of cool weather. Their food and haunts are altogether similar with those of the preceding species, and, like them, they seldom remove to any great distance from the sea. Mr. Bartram remarks that "they fly in large flocks or squadrons, evening and morning, to and from their feeding-places or roosts, and are usually called Spanish Curlews. They subsist principally on cray-fish, whose cells they probe, and with their strong pinching bills drag them out." They also feed on fry and aquatic insects, and their flesh is sometimes eaten, but not much esteemed.

Birds of this species may frequently be seen standing on the dead branches of trees and on the shore, resting on one leg, with the body in an almost perpendicular position, and the head and bill resting on the breast, - which, indeed, appears to be their common mode of reposing, in consequence of which, and as a proof of the habitual indolence of the species, the plumage, as in the Wood Ibis, on the ridge of the neck and upper part of the back, is evidently worn by the constancy of this habit.

Sometimes, according to Bartram, during the prevalence of high winds and in thunder-storms, they may be seen collected into numerous flocks, driving to and fro, or turning and tacking about high in the air, during which evolutions with the contending currents of the wind their silvery plumage gleams and sparkles with unusual brilliance as it reflects the flashing light from amidst the dark and hovering clouds.

The White Ibis has been until quite recently a common bird in some localities in the Southern States. It occurs regularly on the Atlantic shore to North Carolina (occasional stragglers have been seen in New Jersey), and along the valley of the Mississippi ranges farther north, - to Indiana and southern Illinois.

YOL. II. -8 


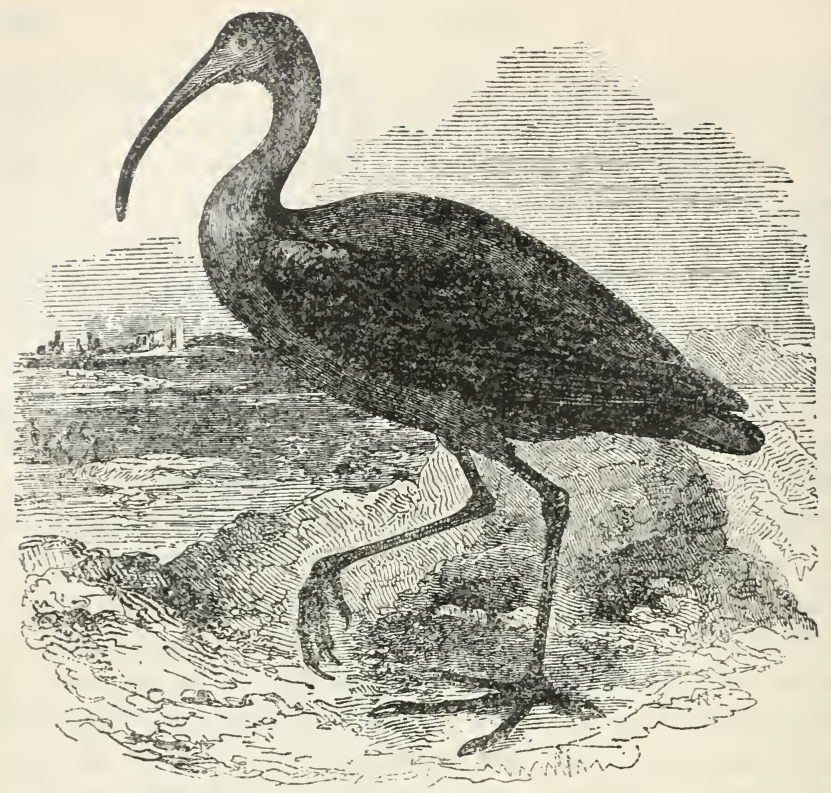

\section{GLOSSY IBIS.}

\section{Plegadis autumnalis.}

CHAR. Back, wings, and tail dark purple with metallic reflections of green and bronze; head, neck, wing-coverts, and under parts rich chestnut, tinged with purple; bill brown; legs greenish brown. Length about 24 inches.

Nest. In a colony, situated in a marsh or swamp on the bank of a river, lake, or shallow lagoon; a compact structure more neatly built than the nest of any of the Herons, composed of dead reeds or twigs and grass; fastened to upright reeds or placed on a platform of bent reeds, sometimes in a bush or tree growing in the water, and occasionally the platform bearing the nest floats upon the water.

Eggs. $3-4$; light blue, or dark blue with a green tinge; $2.00 \times 1.45$.

The Glossy Ibis appears to be within the temperate and warmer regions almost a general inhabitant of the world. On the borders of rivers and lakes it is seen, for example, abundant as a bird of passage in Poland, Hungary, Turkey, and the Grecian Archipelago; it visits the borders of the 
Danube, and is seen sometimes in Switzerland and Italy, though rarely in England and Holland; and is for seven months a periodical visitor in Egypt, where, in common with the Sacred Ibis, it was revered and embalmed in the vast catacombs of Saccara and Memphis. It arrives in that country in October, and leaves it in the month of March. It is known to breed up the rivers of the Caspian and Black Seas, and to spread into Russia, Siberia, Tartary, Denmark, occasionally into Sweden, and perhaps Lapland, for the same purpose; remaining in those countries till driven to migrate by the inclemency of approaching winter, at which period it appears to arrive in Africa and Asia. It is a still more rare and accidental visitor in the United States than in England. A specimen has occasionally been exposed for sale in the markets of Boston, and individuals are, at distant intervals, shot off Long Island and on the shores of New Jersey. At very irregular periods in the spring season, small flocks are thus seen on the coasts of the Middle States and as far south as Maryland and Virginia. Vieillot also asserts their occasional appearance even in Cayenne, Iceland, and Greenland; and they are found common along the rivers in the island of Java and in the Celebes.

The Ibises ordinarily dwell together in flocks in marshy and inundated grounds, exploring for their food with great regularity, side by side advancing, like disciplined troops in an extended line, perambulating the meadows they visit in preference to making a desultory flight, and for hours they are observed boring the same spot with their long and sensitive bills, when their prey is abundant. Sedate in their movements, elevating their feet high in walking, and as it were measuring their steps, they seem by the delicacy of their actions as if conscious of the veneration and high regard symbolically bestowed upon them by the nations of antiquity. When, however, alarmed, they rise high in the air, in a wide spiral range, uttering loud cries, like Geese, and having attained a safe elevation, they file off in a horizontal direction, uttering at intervals a low and hoarse sound, and their flight being vigorous, they soon disappear from sight. They are said to nest in 
trees; but of their manners during the period of reproduction we are still wholly ignorant, and Temminck believes that they retire to breed in the wilds of Asia, though Montague thinks their vernal migrations are directed to the less-inhabited parts of the North, where they find security about the rivers and interior lakes to propagate, and whence they retire as the winter approaches and as their food begins to fail, spreading themselves at this season over the southern parts of Europe and the adjoining continents. According to Oedman, they have been known to breed, for several years in succession, in the isle of Oland, in the Baltic.

The food of the Ibis is merely insects, worms, river shellfish, and vegetables, which is likewise the real fare of the nearly allied, Sacred Ibis, of the Egyptians (Ibis religiosa, Cuvier), neither of whom show any predilection for devouring serpents or large reptiles, - for which purpose, in fact, the structure of their long and falciform bills is wholly unfitted.

From the supposed utility of the Ibis in destroying noxious reptiles, it was held in the greatest veneration by the Egyptians; to kill it was forbidden under pain of death; large flocks were kept in temples, and when they died, were embalmed, inurned, and deposited with the mummies in the sacred receptacles of the dead. These bird-pits, as they are still called, are scattered over the plains of Saccara, and are filled with the numerous remains of this and the Egyptian species. So highly was it honored that the Ibis became the characteristic hieroglyph of the country, repeated upon all the monuments, obelisks, and national statues. The abundance of their remains in the catacombs proves, indeed, the familiarity which the species had contracted with the indulgent inhabitants of its favorite country; and, like the Stork of Europe, venerated for its supposed piety, it gained credit, in the prejudices of the ignorant, for benefits which it never conferred. Diodorus Siculus, however, only adds, what appears by no means improbable, that, impelled by hunger on their first arrival, night and day the Ibis, walking by the verge of the water, watches reptiles, searching for their eggs, and 
destroying all the beetles and grasshoppers which it finds. Thus accustomed to favor and immunity (like our own Vulture scavengers), in Egypt these birds advanced without fear into the midst of the cities. Strabo relates that they filled the streets and lanes of Alexandria to such a degree as to become troublesome and importunate; and Hasselquist remarks that in Lower Egypt as soon as the Nile becomes freed from its inundations, they arrive in such numbers as to be seen morning and evening frequenting the gardens and covering whole palm-trees with their flocks. The Egyptian Ibis is likewise said to construct its nest familiarly in the clustering fronds of the date-palm, where it lays four eggs, and sits, according to the fanciful calculation of Elian, as many days as the star Isis takes to perform the revolution of its phases.

To enumerate the various fictions and falsehoods with which the ancients have chosen to embellish the history of the Ibis would be as vain and useless to the naturalist as to the sober historian. Even Josephus has the credulity to relate that when Moses made war on the Ethiopians, he carried, in cages of papyrus, a great number of the Ibis, to oppose them to the serpents! Fables of this kind are now no longer capable of being substituted for facts, and the naturalist contents himself with the humbler, but more useful, employment of simply describing and delineating nature as it issued from the hands of its omnipotent Creator. This superstition has also had its day, and the Ibises, no longer venerated even in Egypt, are in the autumn commonly shot and ensnared by the Arabs for food; and the markets of the sea-coast are now abundantly supplied with them as game, together with the white species, both of which are ignominiously exposed for sale deprived of their heads, - a spectacle from which the ancient Egyptians would have recoiled with horror. So fickle and capricious, because unreasonable, is the dominion of superstition!

The Glossy Ibis is a rare bird in this faunal province, but it occurs as an occasional visitor north to Massachusetts and Ontario, and in 1878 was seen on Prince Edward's Island. The nest has not been found north of Florida. 


\title{
LONG-BILLED CURLEW.
}

\author{
SICKLE-BILL.
}

\section{NUMENIUS LONGIROSTRIS.}

CHAR. Upper parts mottled gray, black, and pale rufous, - rufous being the prevailing tint; under parts pale cinnamon, the neck and breast with dusky streaks; secondary quills rufous, primaries brownish black; bill black; legs brownish black. Length about 25 inches.

Nest. On the ground, sometimes in wet meadows; a slight depression, lined, sparingly, with grass.

Eggs. 3-4 (very variable in size, color, and markings); olive drab to pale buff, thickly speckled and blotched with brown, sometimes spotted with lilac also; average size about $2.60 \times 1.80$.

The Long-billed Curlew is seen in the marshes of New Jersey about the middle of May on its way farther north, and in September or the latter end of August on its return from its breeding-places. How far south it retires in the course of the winter, has not been ascertained; but a few, no doubt, winter in the marshes of South Carolina, as I have observed specimens on the muddy shores of the Santee, near Charleston, in the month of January. Its southern migration in all probability is bounded by the shores of the Mexican Gulf. Like most species of the genus, it retires into the desolate regions of the North to breed. Dr. Richardson believes that it frequents the plains of the Saskatchewan and the Columbia at this season, and it is known to visit the neighborhood of Hudson Bay. In Major Long's expedition it appears that some of these birds were observed as far inland as the Illinois, latitude $42^{\circ}$, on the 15 th of June, - which might be supposed about the time of breeding. According to Wilson, a few instances have been known of one or two pairs remaining in the salt-marshes of Cape May the whole summer; and they were believed to nest there on the ground, laying four eggs in size and color much resembling those of the Clapper Rail. Indeed, it will probably be found that many birds now supposed to pass the period of reproduction in the remote regions of 
the North only separate into solitary pairs, and disperse themselves through the vast wilds of the interior of North America.

The Long-billed Curlews fly high and rapidly, generally throwing themselves, when in company, into an angular wedge, after the manner of Wild Geese, uttering, as they fly, and when at all alarmed, a loud, short, whistling, and almost barking note, sometimes, as in other species of the family, strongly resembling the sibilation of the word kurlew, and whence they derive their characteristic name, which has been adopted into so many of the European languages. By a dexterous imitation of this note a whole flock may sometimes be enticed within gunshot; and the cries of the wounded continue the sympathetic enticement, while the fowler, repeating his shots, carries havoc among the quailing throng. Their food consists principally of insects, worms, and small crabs. The young and old also, on their arrival from the North, where they feed on various kinds of berries, still continue their fondness for this kind of food, and now frequent the uplands and pastures in quest of the fruit of the bramble, particularly dewberries, on which they get so remarkably fat at times as to burst the skin in falling to the ground, and are then superior in flavor to almost any other game-bird of the season. In the market of Boston they are seen as early as the 8th of August, having already raised their brood and proceeded thus far towards their winter-quarters.

The Sickle-bill is an abundant bird from the Pacific to the Mississippi; but eastward of that river it is common only in the South. ern States and around the Great Lakes; while in New England it is quite rare, and occurs chiefly during the autumn migration. In the West it ranges to the Saskatchewan valley, about latitude $55^{\circ}$; but on the Atlantic it has not been taken north of Baie de Chaleur, on the Gulf of St. Lawrence.

Our Eastern birds probably raise their broods in the region lying immediately south of Hudson Bay, and then journey eastward through the valleys of the St. Lawrence and its tributaries until reaching the sea, along which the birds proceed to their winter quarters in the West Indies.

Mr. George A. Boardman heard a report several years ago that this species had been discovered breeding on Prince Edward's Island; but this has not been confirmed by recent observations. 


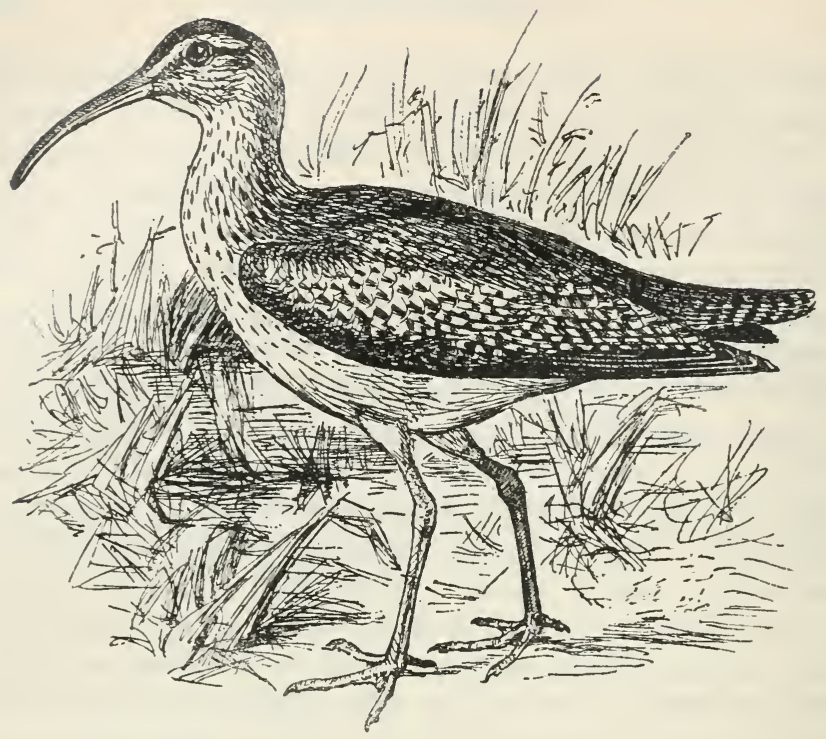

\section{HUDSONIAN CURLEW.}

\section{JACK CURLEW.}

\section{NUMENIUS HUDSONICUS.}

Char. Upper parts blackish brown mottled with buff, the latter prevailing on the wing-coverts; wings dusky; crown dusky brown, with median stripe of buff; stripe of brown on side of head; rest of head, neck, and under parts light buff; breast spotted with brown. Length about 17 inches.

Nest. Usually near the margin of a lake or stream; a slight depression, lined with grass or leaves.

Eggs. 3-4; drab with a tint of green or buff, marked with several shades of brown, $2.25 \times$ r.6o.

The Short-Billed Curlew, after passing the winter south of the United States, arrives in large flocks on the coast of New Jersey early in May, frequenting the salt-marshes, muddy ponds, shoals, and inlets, feeding at this time on small worms, land and marine insects, fry, minute shell-fish, and sometimes the seeds of aquatic vegetables, which it usually collects at the recess of the tide in company with various other 
waders, and at high water retires into the marshes, and sometimes to the dry ridges and pastures, particularly at a later period, in June, where, accompanied by the Long-Billed species, it feeds much on dewberries, becoming very fat and well flavored. In the northern regions and the fur countries, to which these birds retire to breed, they also collect crowberries (Empetrum nigrum) for food. In June they take their departure to the North; collecting together from the marshes in one general flock, they rise to a considerable elevation about an hour before sunset, and forming a long angular phalanx, keep up a constant whistling on their march, as if conversing with each other, in order to forget or lessen the toil and hazard of their adventurous journey. Their flight is steady, like that of the Woodcock, and in consequence of their sympathy for each other, they readily come within gunshot of those who can imitate their call. While thus beating the air in company, the transient glittering of their speckled wings, as they glide along in ease and elegance, presents an interesting spectacle no less beautiful than amusing. Arriving, at length, in their natal regions in the wilds of the North, they soon obey the instinct of their species, and making a nest on the ground, lay about four eggs, which, according to Mr. Hutchins, are of a light bluish-gray color, marked with black (or dark-brown) spots. From the middle of August to the beginning of September they arrive in the vicinity of Massachusetts Bay and other parts of New England, frequenting the pastures as well as marshes, and fatten upon grasshoppers and berries till the time of their departure, about the close of September; and they wholly disappear from New Jersey on their way to the South, early in the month of November. Previous to their departure they again assemble in large flocks near the seabeach, being constantly gregarious in all their journeys. In an island of the Piscataqua, near Plymouth (New Hampshire), a friend informs me that they had, in the autumn, been seen together in a dense flock of many thousands, thickly covering several acres of ground with their numbers.

When much hunted, they become extremely shy and diffi- 
cult to approach; yet the same bird, shot at three or four different times, and recovering when about to be picked up, still, notwithstanding this persecution, continued to feed again in the same spot. These birds, though so exquisite in flavor, in the autumn, when as abundant as usual, are sold in Boston market for about twenty to twenty-five cents each. As early as the I 8 th of July I have met with individuals of this species, one of which on dissection proved to be an old and barren male who in all probability had remained behind the flock in the same vicinity where he had arrived in the spring, having no incentive to migration. Whether other specimens, killed at this season before the return of the general flock, are influenced by the same cause to linger behind or wander from the rest, I am unable to say.

The Jack Curlew is well known to gunners along the Atlantic coast, where it occurs during both migrations. The flocks do not cross the Gulf of St. Lawrence, but follow the southern shore till well inland, when they fly north to Hudson Bay and the Barren Lands, near the Arctic Ocean, where they breed.

A few stragglers from the main flocks have been taken in Labrador and Greenland, and a few wander inland through Ohio and the Eastern States.

\section{ESKIMO CURLEW.}

\section{SHORT-BILLED CURLEW. DOUGH-BIRD.}

NUMENIUS BOREALIS.

CHAR. Upper parts blackish brown, spotted with buff; crown streaked, but without distinct median line; under parts light buff; neck, breast, and sides streaked or spotted with dusky. Length about 14 inches.

Much like hudsonicus, but easily distinguished, borealis being of smaller size, with a shorter bill, and lacking the light-colored streak across the crown.

Nest. Amid the rocks of dry ridges, adjacent to lakes and ponds; a slight depression, lined with grass and leaves.

Eggs. 3-4; olive, with a tinge of green or brown predominating, marked with several shades of brown; $2.05 \times 1.45$.

The Small Curlew in the course of its vast migrations occasionally visits almost every part of the American continent, 
penetrating even into the remote territories of the west, coursing along the great valley of the Mississippi, and extending its wanderings into the southern hemisphere as far as Brazil and Paraguay. These birds arrive at Hudson Bay in April or early in May, but breed to the north of Albany Fort, returning to the marshes with their young in August, and retire from that country early in September. Indeed, accompanied probably by the preceding, they frequent in summer the wide extent of Barren Lands within the Arctic circle, feeding usually on aquatic insects, their larvæ, and when ripe, the fruit of the crowberry (Empetrum nigrum). On the $\mathrm{r} 3^{\text {th }}$ of June, $\mathrm{I} 822$, Dr. Richardson discovered one of these Curlews sitting on three eggs on the shore of Point Lake. When approached, she ran a short distance from the nest, crouching near to the ground, and then stopped to watch the motions of her encroaching visitor.

About the close of August or beginning of September these Curlews, accompanied by birds of the preceding species, arrive on the shores of Massachusetts Bay; and frequenting the marshes and adjoining pastures, feed at this time much upon grasshoppers, coleoptera, and earth-worms, which they collect principally towards evening or early in the morning. On their way to the South they also visit Nova Scotia and Newfoundland, where they remain till the approach of winter; and in New Jersey these birds linger on till the month of November, when they apparently, without further delay, pass on to the south of the United States, for in other parts of the Union they appear to be wholly unknown. Like the other species, they are remarkably gregarious, each company seeming to follow some temporary leader; and on starting to wing, a sort of watch-cry is heard, resembling the whistling pronunciation of the word bee-bee. On their arrival from the North they are very fat, plump, and well flavored, and included, like both the preceding species and the Marbled Godwit, under the general name of Doebirds, they are sought out by epicures and enhance the value of a table entertainment. Pennant remarks, on the authority of Hutchins, that one year, from the $9^{\text {th }}$ of 
August to the 6th of September, they were seen in flocks innumerable on the hills about Chatteux Bay, on the coast of Labrador, soon after which they all departed for the South; at this time they kept chiefly on the open grounds, and feeding on crowberries, were very fat and well flavored.

A few of these birds migrate northward along the Atlantic coast, and some wander by the way of the Great Lakes; but the route taken by the majority is up the valley of the Mississippi and across the plains, where they have been met with in "immense flocks" during May. They spend the summer on the Barren Lands within the Arctic circle, and after raising their broods, start on the migration southward, crossing to Labrador, where several naturalists have found them in great abundance. But though so abundant in that region, comparatively few pass southward through the Maritime Provinces, and they are reported as uncommon all along the Atlantic shore of the United States; so it is supposed that the larger number fly direct from Labrador to South America, over which country they roam during the winter, ranging to its southernmost point.

Dr. Coues, who met with large numbers of these birds in Labrador, states that their principal food was crowberry, or "curlewberry," as the natives call it ; but they also fed extensively on a small snail which adhered to the rocks on the sea-shore and were left uncovered at low tide.

Mr. G. H. Mackay, in his interesting biography of the species, says the birds are met with on the uplands, as well as on the seashore, feeding on insects and seeds, much after the habit of some of the Plovers. 


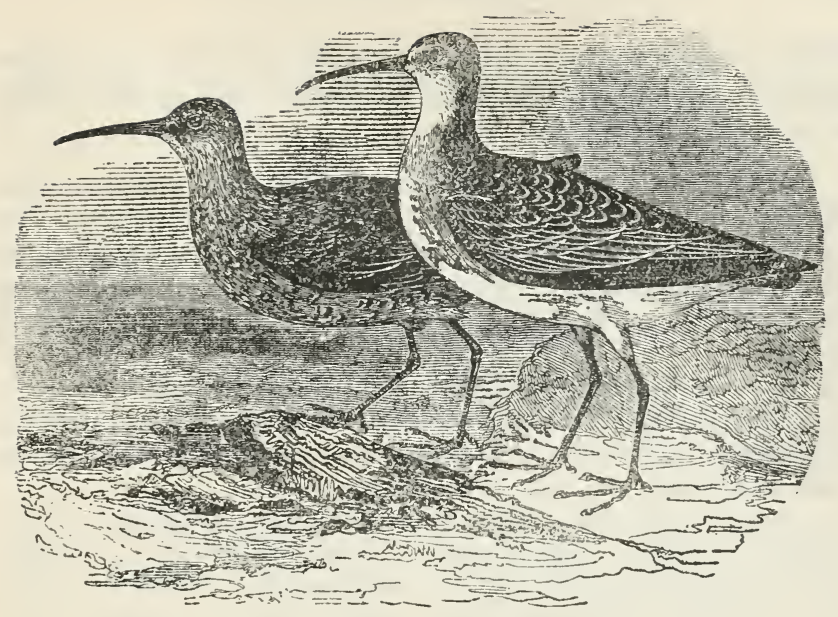

\section{CURLEW SANDPIPER.}

\section{Tringa FERRUGinea.}

Char. Bill long, slender, and decurved. Adult in summer: uppes parts mottled black, gray, and rufous; wings and tail ashy gray; tailcoverts pale buff barred with black; under parts rich chestnut, Adult in winter: upper parts grayish brown; tail-coverts white; under parts white; chest with a few indistinct streaks of gray. Young: like adult in winter, but feathers of upper parts margined with buff; neck streaked with brown. Length about $81 / 2$ inches.

Nest. On the margin of a lake or stream; a slight depression, lined with dry grass.

Eggs. - ?, "pale grayish or greenish buffy, spotted with deep brown, etc.: $1.50 \times 1.04$ " (Ridgruay).

Of this species very little is known. It is found on the seacoast and by the borders of lakes, and is sometimes seen in the interior of the countries it frequents. Like most species of the genus, it is migratory in the spring and autumn, and at such times proceeds in flocks along the coast or on the borders of large rivers. The food of this bird is usually small insects and worms, as well as the herbage of some of the sea-weeds (Fuci). So wide are the devious wanderings of this cosmopolite pigmy that Temminck obtained a specimen from 
Senegal, another from the Cape of Good Hope (as is also indicated by Latham's name of the Cape Curlew), and a third from North America.

The Curlew Sandpiper is not an uncommon bird in Europe, but, excepting in Greenland and Alaska, few examples have been met with in America, and those were seen along the New England coast and in Ontario. It is supposed to breed throughout the entire Arctic regions, but of its nesting habits very little is known.

Though an exceedingly active bird, when feeding, it proceeds quite leisurely with its migrations, and while on these journeys frequents the salt-marshes and the tide-washed sandbars near the mouths of rivers.

In many habits and in flight it resembles the Dunlin, for which it is often mistaken. This mistake is liable to be made in winter, when the plumage of the two are very similar. In summer dress our bird appears somewhat like a small edition of the Knot.

\section{RED-BACKED SANDPIPER.}

DUNLIN. BLACK-BREAST. BLACK-BELLIED SANDPIPER. BLACK-HEART. WINTER SNIPE.

\section{TRINGA ALPINA PACIFICA.}

CHAR. Adult in summer: upper parts chestnut, streaked with black; wings and tail ashy gray; throat and breast grayish white with dark streaks ; lower breast black; belly white. Adult in winter : upper parts brownish gray or ashy gray; under parts white, neck and chest streaked sparingly with gray. In young birds the feathers on the upper parts are bordered with rufous or buff, the top of the head is light chestnut and black, and the under parts are white, spotted with black. Length 8 to $81 / 2$ inches.

Nest. Amid long grass on a salt-marsh or beneath a bunch of heather on a moor or hillside, - a slight depression, lined with grass, leaves, or moss.

Eggs. 4; dull buff tinged with brown or olive, marked with chestnut; I. $45 \times 1.00$.

The Dunlin, or Red-backed Sandpiper, of the United States, according to the season of the year, is met with throughout the northern hemisphere, penetrating, in America, during the summer season, to the utmost habitable verge of the Arctic 
Circle, and even breeding in that remotest of lands, the everwintry shores of Melville Peninsula. It likewise inhabits Greenland, Iceland, Scandinavia, the Alps of Siberia, and the coasts of the Caspian. In the southern hemisphere it sometimes even wanders as far as the Cape of Good Hope, and is found in Jamaica, other of the IVest India islands, and Cayenne. In the autumn it is seen around Vera Cruz, and, with other Sandpipers probably, is exposed for sale in the markets of Mexico. At the same time many, as the Purres, in their winter dress, remain through the greatest part of the winter within the milder limits of the Union, frequenting at times in great numbers the coasts of both Carolinas during the month of February, flitting probably to and fro with every vacillating change of temperature, being naturally vagabond and nowhere fixed for any considerable time until their arrival at the Ultima Thule of the continent, where they barely stay long enough to rear a single brood, destined, as soon as they are able, to wander with the rest and swell the aërial host, whose sole delight, like the untiring Petrels of the storm or the ambitious Albatross, is to be in perpetual action, and are thus, by their associated numbers, obliged perpetually to rove in quest of their transient, periodical, and varying prey.

In the Middle States the Dunlins arrive on their way to the North in April and May, and in September and October they are again seen pursuing the route to their hibernal retreat in the South. At these times they often mingle with the flocks of other strand birds, from which they are distinguishable by the rufous color of their upper plumage. They frequent the muddy flats and shores of the salt-marshes at the recess of the tide, feeding on the worms, insects, and minute shell-fish which such places generally afford. They are also very nimble on the strand, frequenting the sandy beaches which bound the ocean, running, and gleaning up their prey with great activity on the reflux of the waves.

These birds when in their hibernal dress are seen, in conjunction with several species, sometimes collecting together in such flocks as to seem at a distance like a moving cloud, vary- 
ing in form and appearance every instant while they perform their circuitous, waving, and whirling evolutions along the shores with great rapidity; alternately bringing their dark and white plumage into view, they form a very grand and imposing spectacle of the sublime instinct and power of Nature. At such times, however, the keen gunner, without losing much time in empty contemplation, makes prodigious slaughter in the timid ranks of the Purres; while as the showers of their companions fall, the whole body often alight or descend to the surface with them, until the greedy sportsman becomes satiated with destruction.

The Dunlins breed plentifully on the Arctic coasts of America, nesting on the ground in the herbage, laying three or four very large eggs of an oil-green, marked with irregular spots of liver-brown of different sizes and shades, confluent at the larger end. Mr. Pennant also received the eggs of this kind from Denmark, so that the range in which they breed, no less than that in which they migrate, is very extensive.

This species, still abundant throughout the continent, and breed. ing in the Far North, is called "Winter Snipe" by the gunners of New Jersey and southward; but that name is given by the New Englanders to the Purple Sandpiper, which is not seen farther south. The names Ox-bird and Purre, given to the present species by Nuttall, were the names by which the summer and winter phases of the Dunlin were designated formerly by English writers.

Mr. D. G. Elliot tells us that in the far north, when the pairing time arrives, "the males pursue the females, uttering a musical trilling note which falls upon the ear like the mellow tinkle of large water drops falling rapidly into a partly filled vessel. It is not loud, but has a rich full tone difficult to describe, but pleasant to hear among the discordant notes of the various water fowl, whose hoarse cries arise on all sides."

Note. - The European DunLin (Tringa alpina) is smaller than the American race, and of a duller tint. It occurs in Greenland and breeds there, and an occasional example wanders to the shores of Hudson Bay. One has been taken on Long Island. 


\title{
WHITE-RUMPED SANDPIPER.
}

\author{
BONAPARTE'S SANDPIPER.
}

\section{TRINGA FUSCICOLLIS.}

CHAR. Upper parts brownish gray, striped with black and tinged with rufous; wings ashy brown; rump brownish ash; upper tail-coverts white; tail grayish brown, the two middle feathers darker; under parts white, the breast washed with gray. In winter the upper parts are entirely brownish gray. Bill short and blackish brown, paler at the base; legs brownish olive. Length about $7 \frac{1}{2}$ inches.

Nest. On a low lying sea-shore or near the muddy margin of a lake or stream close by the sea, - a slight depression, lined with dead leaves.

Eggs. 4 ; olive or olive brown or grayish buff, marked with chestnut and dark brown; sometimes marked also with pale brown and purplish gray; $1.35 \times 0.95$.

This species, so nearly related to the preceding, is also common to both continents, penetrating inland in America to the western plains of the Mississippi, and inhabiting the shores of the small lakes which skirt the plains of the Saskatchewan, and probably the remoter wilds of the Arctic circle. According to Bonaparte these birds are rather common on the coast of New Jersey in autumn, and Mr. Oakes met with several in the vicinity of Ipswich, in Massachusetts. They are either seen in flocks by themselves or accompanying other Sandpipers, which they entirely resemble in their habits and food, frequenting marshy shores and the borders of lakes and brackish waters. They associate in the breeding-season, and are then by no means shy; but during autumn, accompanying different birds, they become wild and restless. Their voice resembles that of the Dunlin, but is more feeble; and they nest near their usual haunts, by lakes and marshes.

This is the Schinz's Sandpiper of Nuttall and Bonaparte. It is a common bird in eastern North America, migrating northward along the Mississippi valley as well as by the Atlantic coast, and breeding in the Arctic regions, - from Labrador to the Polar Sea.

During the migrations numbers of these birds appear along the New England shores in company with several of their smaller allies, from which they are readily distinguished by their conspicVOL. II. -9 
uous white tail-coverts. Their note, also, is peculiar, - a low soft weet.

In habits they differ little from other Sandpipers, - a little more confiding and heedless perhaps, and more frequently found on the mud-flats and among the sea-weed than on the sand.

\section{PECTORAL SANDPIPER.}

\section{JACK SNIPE. GRASS SNIPE. KRIEKER.}

\section{TRINGA MACULATA.}

CHAR. Upper parts dusky brown, the feathers margined with buff and rufous; rump and tail-coverts dusky; cheeks and throat dull white streaked with brown; breast buffy gray streaked with dusky; chin and belly white. In winter the plumage is plain gray and white, sometimes tinged with pale rufous and buff. Length about $83 / 4$ inches.

Nest. Amid a tuft of grass on a dry mound or hill side.

Eggs. 4; pale buff, greenish drab, or olive brown, thickly blotched with rich red brown; $1.50 \times 1.05$.

This conspicuous species of Sandpiper, first detected by Mr. Say, is by no means uncommon in various parts of the United States, migrating north, and perhaps west, to breed, as it is common in the remote plains of the Mississippi. These birds have been killed in abundance on the shores of Cohasset and in other parts of Massachusetts Bay, and brought to the markets of Boston, being very fat and well flavored. They arrive in flocks about the close of August, and continue here, as well as in New Jersey, till the month of September, and perhaps into October. In some instances solitary individuals have been killed in the marshes of Charles River, in Cambridge, about the $22 \mathrm{~d}$ of July. These were in company with the flocks of small Sandpipers; but whether pairs may perhaps breed in the neighboring marshes or not, we have not had the means of ascertaining.

While here, they feed on small coleoptera, larvæ, and the common green Ulva lattissima, as well as some species of Fucus, or sea-weed, on which they become very fat. They utter a low, plaintive whistle when started, very similar to that 
of some other species. Like the Snipe, they seem fond of damp meadows and marshes, and solitary individuals are often surprised by the sportsman in the manner of that bird.

The Pectoral Sandpiper breeds in the Arctic and subarctic regions of North America, - from Greenland to Alaska, - and in winter retires to the West Indies and southward. Large flocks of these birds migrate north and south across the prairies and through the valley of the great rivers of the West, but along the Atlantic seaboard only a scattered few are seen in the spring, though during the early autumn they appear in numbers. While on our coasts they mingle sociably with other small Sandpipers, but some of their manners and habits suggest the Snipe rather than the Sandpiper. They frequent the salt-marshes and seaside meadows more than the sandy beaches, and the erratic flight of a flock when suddenly flushed is peculiarly Snipe-like.

Nothing definite was known of the breeding-habits of these birds until recently, when our naturalists discovered them nesting in Alaska. Murdock found numbers at Point Barrow; then Nelson made a study of them at St. Michael's in 1879; and in 1883 the members of Lieutenant Ray's party at Point Barrow were fortunate enough to secure several nests with eggs.

In the mating season, which occurs after they have reached the vicinity of their nesting ground, the males become intensely excited in their efforts to gain the attention of the females and to keep near to one chosen for a mate. They run along the sand with wings extended, or take short flights close to the ground, passing to and fro in front of the amorita, or whirling in graceful curves in the air above her, all the while uttering a deep and hollow booming, which resembles hoo, hoo, hoo, hoo, or too-u, too-u, too-u, rapidly repeated in liquid musical tones. "Whenever he pursues his love-making," says Mr. Nelson, "his rather low but pervading note swells and dies in musical cadences, which form a striking part of the great bird chorus heard at this season in the North." During these performances the throat and breast are filled with air and puffed out to twice their natural extent, - whence the name Pectoral. When not thus inflated, the air-sac hangs an inch or more below the general contour of the neck. While with us these birds do not display this inflated breast, and the only note we hear from them is a low soft tweet. 


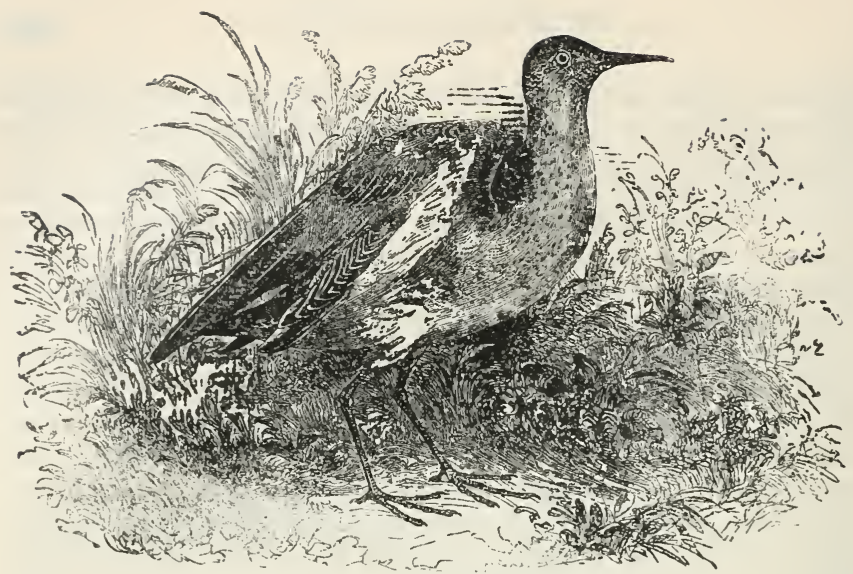

\section{BUFF-BREASTED SANDPIPER.}

\section{TRYNGITES SUBRUFICOLLIS.}

CHAR. Upper parts yellowish brown mottled with black; central tailfeathers greenish black, others paler and barred towards the tips; under parts buffish with a rufous tinge, the linings of the wings paler and beautifully marbled with black; breast with a few dark spots. Length about 8 inches.

Nest. On a knoll in a grassy plain or near a river bank, - a slight depression lined with a little moss or grass, or a few leaves.

Eggs. 4; pale reddish buff sometimes tinged with olive, profusely marked with lavender and rich reddish brown of several shades; 1.45 $\times 1.00$.

This elegant species, some seasons, is not uncommon in the market of Boston in the month of August and September, being met with near the capes of Massachusetts Bay. My friend Mr. Cooper has also obtained specimens from the vicinity of New York; and it was first discovered by Veillot in the then Territory of Louisiana, so that, coursing along the shores of the Mississippi, and thus penetrating inland, it probably proceeds, as well as in the vicinity of the sea-coast, to its northern destination to breed, and is often here associated with the Pectoral Sandpiper, which it resembles very much in size and bill, though perfectly distinct in plumage. As 
a proof how wide it wanders, this species has also been rarely obtained even in France and England, and a specimen figured in the Linnæan Transactions of London is there given as a new addition to the fauna of Great Britain. It was shot in September, I 826, in the parish of Melbourne, Cambridgeshire, in company with the Siberian Plover, or Guignard (Charadrius morinellus).

Its food while here consists principally of land and marine insects, particularly grasshoppers, which, abounding in the autumn, become the favorite prey of a variety of birds; even the Turnstone at this season, laying aside his arduous employment, is now content to feed upon these swarming and easily acquired insects.

This Sandpiper is distributed throughout North America, breeding in Arctic and Sub-arctic regions. It is a rather rare visitor to this northeastern section, though more frequently seen in the autumn than during the spring migrations, the bulk of the flocks going north by the western inland routes, and nesting on the dry plains in the Barren Ground region, adjacent to the Mackenzie and Anderson Rivers. These birds must migrate very rapidly and make but few halts; for while they are quite abundant on their nesting-ground, they are rarely seen while migrating. They range in winter through the West Indies and southward as far as Brazil and Peru.

The Buff-breasted Sandpiper is a bird of the dry upland rather than of the marsh or the sandy beach. Its principal food consists of insects, - beetles, grasshoppers, and such; but it varies its diet with small marine forms, and does not object to an occasional meal of small fruit and berries. The birds are very tame, and are usually met with in small flocks of ten or fifteen. The note, which is generally heard as the bird rises from the ground, is a low tweet, repeated several times. 


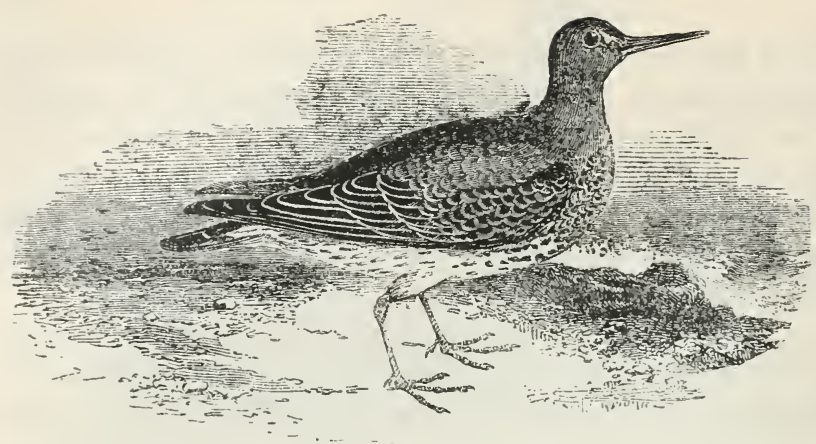

PURPLE SANDPIPER.

WINTER SNIPE. ROCK SNIPE.

\section{TRINGa MaRITIMA.}

ChaR. Distinguished from other Sandpipers by its short legs, short thick body, and dark color. Adult in summer : upper parts brownish gray, darker on the back, which is spotted with rufous and buffish white; rump and central tail-feathers dull brown, outer tail-feathers ashy gray; wings grayish brown; under parts gray, paler on the belly; throat and breast thickly spotted with dark brown. In winter the upper parts are purplish ash, and the breast ashy brown or mouse gray; the belly white. Length variable, averaging about $81 / 2$ inches.

Nest. Usually amid a tuft of grass near a rocky sea-shore, but often on high hills; generally a little hollow scraped in the soil and lined with some moss or leaves; but nests have been found composed of dried grass and sunk quite deep in the ground.

Eggs. 4 ; pale olive, green or dull buff, marked with lilac and brown; I.45 X 1.00 .

The Purple Sandpiper is another of those wandering species common to the cold regions of both continents, confining its visits principally to the rocky and shelving sea-coasts, where it obtains in more abundance the minute crustacea, mollusca, and the fry of shell-fish which adhere commonly to the seaweeds or Fuci in such situations; and so peculiar is this habit that in Holland, where it is now common, it has only appeared with the existence and advancement of the artificial moles which have been built. In Norway along the rocky 
shores of the Baltic, and on similar coasts of the Mediterranean, in the West of England, and around Hudson Bay, these birds are common. In Russia, Siberia, and Iceland they are also found, but less frequently. In the warmer parts of America they are rare. Leaving the inclement coasts of their nativity, they proceed probably by Greenland, and migrate directly to the rocky coasts of Norway, and in the course of the winter visit for a while the colder parts of Europe. According to Dr. Richardson, they breed abundantly on the shores of Hudson Bay, as well as in that coldest and most desolate of boreal climates, Melville Peninsula, laying the usual number of eggs, which are of a pyriform figure sixteen and a half lines long, and an inch across at the larger end. They are yellowish gray, interspersed with small irregular spots of pale hair-brown, more abundant at the larger end, and rare at the other. This bird is seldom seen inland or on the borders of rivers, where its appearance is accidental ; its piping note is very similar to that of other species; is not shy, often caught in snares, and the flesh accounted palatable.

The Purple Sandpiper is an abundant bird along the shores of New Brunswick and Nova Scotia during the winter months, appearing in large flocks, and feeding on the rocks and the stony beaches. So large are the flocks, and so compactly do the birds rise when flushed, that I have known sixty-five to be killed at one shot.

In Massachusetts this bird is rather uncommon, and is seen only in small groups of three or four, and similar groups are occasionally seen on Long Island. It occurs on the shores of the Great Lakes, and Mr. D. G. Elliot says " it is not uncommon on the shores of Lake Michigan, and has been noted as occurring in Missouri."

Mr. Hagerup reports that a few individuals remain in Greenland during the winter months. 


\section{LEAST SANDPIPER.}

PEEP.

TRINGA MINUTILla.

CHAR. Upper parts mottled black, rufous, and dull white, darker on the rump; a light stripe over the eyes; under parts white, spotted with dusky; breast and sides washed with ashy brown; toes without web. The smallest of the Sandpipers. Length $5^{1 / 2}$ to 6 inches.

Nest. Usually on a dry hill bordering a lake or pond, but sometimes amid moss close by the sea-shore, - a slight depression, scantily lined with grass and leaves.

Eggs. 4; buff or drab thickly marked with brown and lilac; $1.15 \times$ 0.85 .

This small and nearly resident species may be considered as the most common and abundant in America, inhabiting the shores and marshes of the whole continent both to the north and south of the equator, retiring probably with the inclemency of the season, indifferently, from either frigid circle towards the warmer and more hospitable regions within the tropics. These birds are consequently seen, spring and autumn, in all the markets of the Union as well as in those of the West Indies, Vera Cruz, and in the interior as far as Mexico. Captain Cook also found them on the opposite side of the continent, frequenting the shores of Nootka Sound. The great mass of their pigmy host retire to breed within the desolate lands of the Arctic circle, where, about the 2 oth of May, or as soon as the snow begins to melt and the rigors of the long and nocturnal winter relax, they are again seen to return to the shores and the swampy borders of their native lakes in the inclement parallel of 66 degrees. Though shy and quailing on their first arrival, with many other aërial passengers of like habits, they contribute to give an air of life and activity to these most dreary, otherwise desolate and inhospitable regions of the earth. Endowed with different wants and predilections from the preceding hosts, whose general livery they wear, they never seemingly diverge in their passage so far to the eastward as to visit Greenland and the contiguous 
extremity of northern Europe, being unknown in the other continent; and migrating always towards the south, they have thickly peopled almost every part of the country that gave them birth.

The Peeps, as they are here called, are seen in the saltmarshes around Boston as early as the 8th of July, - indeed, so seldom are they absent from us in the summer season that they might be taken for denizens of the State or the neighboring countries, did we not know that they repair at an early period of the spring to their breeding-resorts in the distant north, and that as yet, numerous and familiar as they are, the nest and history of their incubation are wholly unknown.

When they arrive, now and then accompanied by the Semipalmated species, the air is sometimes, as it were, clouded with their flocks. Companies led from place to place in quest of food are seen whirling suddenly in circles with a desultory flight, at a distance resembling a swarm of hiving bees seeking out some object on which to settle. At this time, deceiving them by an imitation of their sharp and querulous whistle, the fowler approaches, and adds destruction to the confusion of their timorous and restless flight. Flocking together for common security, the fall of their companions and their plaintive cry excites so much sympathy among the harmless Peeps that, forgetting their own safety, or not well perceiving the cause of the fatality which the gun spreads among them, they fall sometimes into such a state of confusion as to be routed with but little effort, until the greedy sportsman is glutted with his timorous and infatuated game. When much disturbed they, however, separate into small and wandering parties, where they are now seen gleaning their fare of larvæ, worms, minute shellfish, and insects in the salt-marshes or on the muddy and sedgy shores of tide-rivers and ponds. At such times they may be very nearly approached, betraying rather a heedless familiarity than a timorous mistrust of their most wily enemy; and even when rudely startled they will often return to the same place in the next instant to pursue their lowly occupation of scooping in the mud, - and hence probably originated the 
contemptible appellation of humility, by which they and some other small birds of similar habits have been distinguished. For the discovery of their food their flexible and sensitive awllike bills are probed into the mire, marshy soil, or wet sand, in the manner of the Snipe and Woodcock, and in this way they discover and rout from their hidden retreats the larvæ and soft worms which form a principal part of their fare. At other times they also give chase to insects, and pursue their calling with amusing alacrity. When at length startled or about to join the company they have left, a sharp, short, and monotonous whistle like the word peet or peep is uttered, and they instantly take to wing and course along with their comrades. On seeing the larger marsh-birds feeding, as the Yellow-Shanks and others, a whirling flock of the Peeps will descend amongst them, being generally allowed to feed in quiet; and on the approach of the sportsman these little timorous rovers are ready to give the alarm. At first a slender peep is heard, which is then followed by two or three others, and presently peet 'pip 'pip ' $p$ ' $p$ murmurs in a lisping whistle through the quailing ranks as they rise swarming on the wing, and inevitably entice with them their larger but less watchful associates. Towards evening, in fine weather, the marshes almost re-echo with the shrill but rather murmuring or lisping, subdued, and querulous call of peet, and then a repetition of pé-dèe, pé-dèe, ďe děe, which seems to be the collecting cry of the old birds calling together their brood; for when assembled, the note changes into a confused murmur of péet, péet, attended by a short and suppressed whistle.

At most times, except in the spring, they are fat and well flavored, though less esteemed than many of the other species from their smallness and an occasional sedgy taste which deteriorates them. From the oily and deliquescent nature of the fat which loads the cellular membrane in this hyperboreal natal family of birds, we may, perhaps, perceive a constitutional reason why most of them thrive better and have such a predilection for those cool and temperate climates in which they renew their exhausted vigor and acquire the requisite 
strength and energy necessary for the period of reproduction. It is indeed certain that those stragglers which, from age or disability, remain, as it were hermits, secluded from the rest of the wandering host, do neither propagate nor fatten while thus detained through summer in the warmer climates. Of this fact we have already mentioned instances, in the case of straggling Curlews killed in this vicinity by the I 8 th of July, - a period when the main mass of the species are engaged in feeding or just hatching their tender young.

This little Sandpiper, which we have named in honor of Wilson (certainly not being the species first intended as Tringa pusilla), leaves us by the close of September, and departs from the Middle States towards its remote hibernal retreats in the course of the month of October. The present species and some others appear occasionally to feed partially on vegetable substances as well as on animals, as I have found in their stomachs pieces apparently of zostera roots and flowers of the marsh plantain.

The Peeps still throng our shores each spring and autumn, and are the same active and confiding creatures that Nuttall found them. Their general breeding-area is from Labrador to the Arctic Ocean, but a few nests have been discovered south of the St. Lawrence; for the nesting habits of these birds are no longer unknown. 


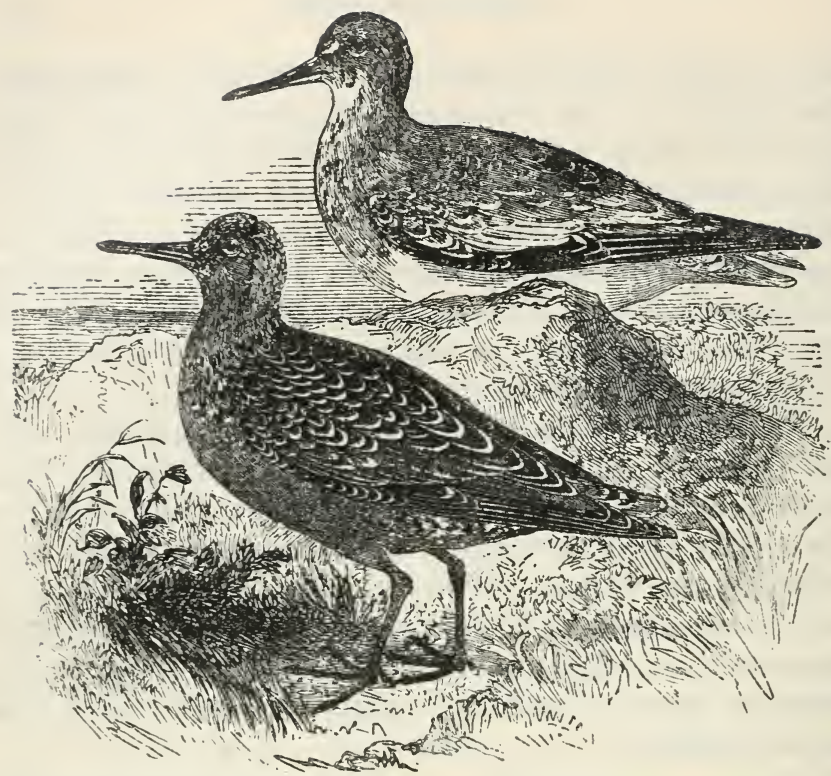

KNOT.

RED-BREASTED SNIPE. ROBIN SNIPE.

TRINGa CANUTUS.

CHAR. Adult in summer : above, mottled black and gray, tinged with dull rufous; rump ashy white, with dark bars ; tail gray, edged with dull white; under parts and line over the ejes rich chestnut; paler on the belly. Adult in winter: above, ashy gray; below, white, the neck streaked with dusky. Young: much like the adult in winter plumage, but the feathers of the upper parts are bordered with lines of pale buff and brown, and the breast is tinged with buff. Length about $101 / 2$ inches.

Nest. Usually on the margin of a lake or stream, - a slight depression, lined with leaves and grass.

Eggs. 4-9; "light pea green, closely spotted with brown in small specks about the size of a pin-head " (Greely), or "dun-color, fully marked with reddish" (Hutchins); 1.10 X 1.00.

This large and variable species, described under such a variety of names, is again a denizen of both continents, passing the summer, or reproductive season, in the utmost habitable 
limits of the Arctic Circle. Captain Parry's adventurous party found it breeding on Melville Peninsula and in other parts of those hyperboreal regions, as on Seal Islands, probably, near Chatteux Bay, as well as in the vicinity of Hudson Bay down to the $55^{\text {th }}$ parallel. It is also supposed to breed in Denmark and in the Orkney Islands. It is likewise met with in Iceland, on the shores of the Caspian, and on the banks of the Don and Choper in Russia; and continuing eastward towards the American continent, in that direction, is again found in Siberia, and on the other side of the boreal circle at Nootka Sound.

About the middle of August, flocks of the Knot, still clad in their nuptial and summer plumage, appear on the shores and in the marshes at the eastern extremity of Massachusetts Bay, particularly around Chatham and the Vineyard. In many, however, the moult of autumn has already commenced; but in the nearer vicinity of Boston, flocks of the young only are seen disguised in the elegantly marked and-sober gray of winter. When not harassed, they are by no means shy, allowing of a pretty near approach while busily and sedately employed in gleaning their food along the strand, chiefly at the recess of the tide, where, in friendly company with the small Peep and other kindred species, the busy flocks are seen gleaning up the rejectamenta of the ocean, or quickly and intently probing the moist sand for worms and minute shell-fish, running nimbly before the invading surge, and profiting by what it leaves behind. They seem like a diminutive army, marshalled in rank, and spreading their animated lines, while perpetually engaged in an advance or retreat before the break of the resounding and ceaseless waves. Bred in solitudes remote from the haunts of men, the young, in particular, seem unconscious of danger from the fowler, and a flock may sometimes be successively thinned by the gun, till the whole are nearly destroyed; when wounded, however, they take to the water and swim with ease.

On the coast of New Jersey and other parts of the Middle States they arrive in October, and are seen along the strand 
in flocks, but disappear early in December, on their way south to their winter quarters within the tropics. On their return they appear on the coast of the Middle States early in May, on their way to their congenial retreats in the North; but at this time few are to be seen, compared with the accumulating flocks of autumn; while at the same season in Holland they are most abundant. Some of these birds in their rufous plumage have been observed to linger on the neighboring coast till the 2 oth of July, so that they must either have bred in the vicinity, or have passed the season in celibacy, lingering behind the migrating flocks, - a habit which appears to be more or less common with many other of the aquatic and wading birds.

The Knot is found throughout North America, breeding in the Arctic regions, wintering in Florida (sparingly) and southward, and migrating by inland routes as well as along the sea-coast. It is a common bird on the New Engalnd shores in spring and autumn, but rare in the Mississippi valley.

\section{BAIRD'S SANDPIPER.}

\section{TRINGA BAIRDII.}

CHAR. Upper parts grayish buff, varied with dusky; stripe over eyes white; middle tail-feathers dusky, others gray; chest tinged with buff and streaked with dusky, other under parts white; bill and feet black. Length about $7 \frac{1}{2}$ inches.

Nest. On the margin of a lake or pond; a slight depression, hidden by tall grass and lined with leaves and grass.

Eggs. 4; buffish or creamy, spotted with rich reddish brown; 1.30 $\times$ 0.90 .

Baird's Sandpiper was described by Coues in 186r from specimens taken in the West, and it was not until 1870 that the bird was known to occur on the Atlantic. Up to the present a few examples only have been captured to the eastward of the Mississippi valley, and very little is known of the bird's distribution. Reports from different sections of the country lend probability to the conclusion that the bulk of these Sandpipers migrate across the Great Plains and nest along the Mackenzie River valley north of latitude $60^{\circ}$ and in Alaska. They are abundant on the plains and amid the foot hills of the Rockies. In winter they range to Chili and the Argentine Republic. 


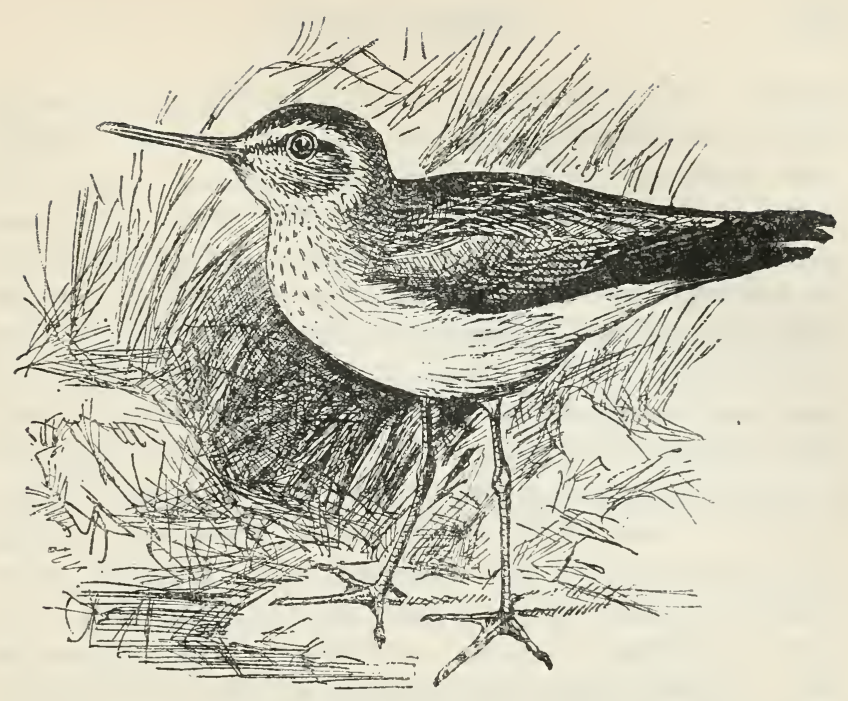

\section{SEMI-PALMATED SANDPIPER.}

EREUNETES PUSILLUS.

Char. Feet with two webs extending about half-way up the toes. Upper parts mottled brownish gray, tinged with rufous or buff, each feather with a central stripe of blackish; rump darker; under parts white, the breast washed with rufous and marked with dusky. In winter plumage there is no trace of the rufous or buff tints. Length about 6 inches.

Nest. Usually on the margin of a pool by the sea or an inland pond, - a slight depression scantily lined with leaves and grass; sometimes hidden in a tussock of grass.

Eggs. 3-4; pale-gray or with buff, drab, or olive tint, variously marked with brown; $1.20 \times 0.85$.

Commonly associated with other species of the same size, plumage, and habits, it is not easy to offer any remark concerning it which can be considered as exclusive. It is spread equally over the North American continent, from the confines of the Arctic circle probably to the West Indies. According to Wilson, it arrives and departs with the Sanderling, and associates with the Dunlin when in its autumnal dress, in this case forming flocks apart from each other; but with the Peep it is sometimes so blended as to be unknown till brought to the 
ground. In the salt-marshes near Boston they are not uncommon in small numbers, but some seasons are seen whirling about wildly in large and separate flocks, and so timorous and roving as to give the alarm to the other larger birds associated around them. Along the shores of New Jersey they are numerous, and Mr. Hutchins, who described this species, without publishing his description, as early as the year I 770 , says that they arrive at Severn River, in the fur countries, in great numbers about the middle of May. Towards autumn these birds utter a chirping call, and in September they retire to the southward, soon after which they are seen in Massachusetts on most of the muddy shores, which they frequent at the recess of the tide, dwelling more exclusively in the immediate vicinity of the ocean than the Peep. When dispersed or alarmed, they give a quailing call, like 'to-weet, 'toweet. At other times, when startled, they utter a shrill clattering whistle, and are always noisy and querulous. Like the small land-birds, they may sometimes be seen washing themselves with great satisfaction in the salt pools and plashes, and when wounded swim with considerable vigor. While here they feed upon diminutive coleoptera, very small shrimps, minute shell-fish, which they probe out of the sand, some mollusca, and occasionally the roots of the Zostera marina; they also swallow considerable quantities of small gravel, and becoming very fat, are nearly as well flavored as the Snipe, being very superior to the other small species.

This species breeds in the Far North, and winters on the shores of the Gulf of Mexico and southward, journeying to and fro along the inland rivers as well as by the sea-coast. It is still abundant in New England, but flocks are not so numerous as formerly.

Note. - A few examples of the Western Sandpiper ( $E$. occidentalis) have been taken in New England. It is very similar to pusillus, but has a longer bill and tarsus, and the plumage of the upper parts is more distinctly rufous. 


\section{STILT SANDPIPER.}

\section{Micropalama himaNTOPUS.}

CHAR. Bill nearly as long as a Snipe's; legs much longer. Upper parts mottled gray, black, and bay, or buff; wings darker; upper tailcoverts white, barred with dusky; tail ashy gray; under parts dull white, streaked and barred with dusky. In winter the prevailing color of the upper parts is ashy gray. Length about 9 inches.

Nest. Near the sea-shore or on border of a lake, - a slight depression scantily lined with leaves and grass. It is sometimes hid in a tussock of grass.

Eggs. 3-4; light drab or buffy white, marked with rich brown and purplish gray; $1.45 \times 1.00$.

Nuttall wrote of this as of three species, - Stilt Sandpiper, Long-legged Sandpiper, and Douglas' Stilt Sandpiper. These names apply to but one bird.

The present species was first described by Bonaparte in 1826 , but until within recent years it was thought to be exceedingly rare. As late as 1868 there was no record of its occurrence in New England, and even in $188 \mathrm{I}$ the announcement that my friend Fred Daniel had secured one of three examples he had discovered on the flats near St. John, N. B., was hailed as "important."

We now know that the bird is not at all rare, and that its former apparent scarcity was due to its rapid migrations.

The Stilt Sandpiper breeds in the Arctic regions, and winters on the shores of the Gulf of Mexico, and southward to Brazil and Peru. On the passage north and south it makes long flights and a few short halts; but small flocks have been seen at numerous localities on the Atlantic coast and along the Mississippi valley route. Several have been taken on the shores of the Great Lakes.

As far as its habits and manners are known, it appears to resemble somewhat the Dowitcher and the Yellow-legs, with which it frequently associates. It walks sedately like a Curlew, and has little of the vivacity so conspicuous in the Sandpiper. Our bird generally feeds along the margin of the beach, wading into the water and following the edge of the wave as the water flows out and in. It often probes into the sand, and acts as though securing something by suction. On dissection, evidence has been found that the bird's food was at least partially composed of small shellfish and worms. When disturbed, it utters a sharp tweet tweet before flying.

VOL. II. - 10 


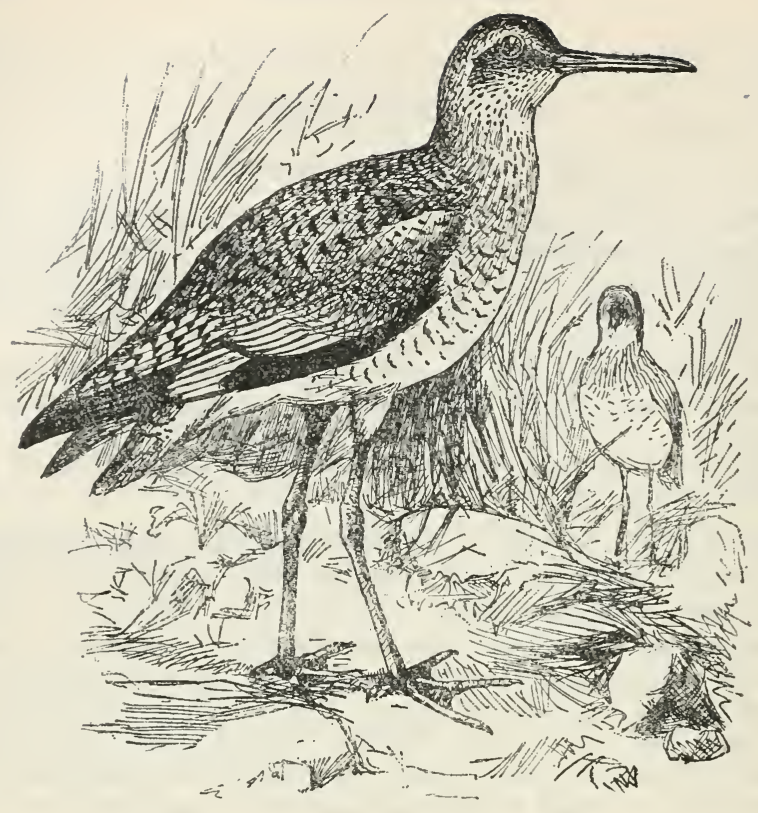

WILLET.

SyMPHEMIA SEMIPALMATA.

CHAR. Upper parts brownish olive, spotted and streaked with dusky; wings with large patch of white; tail-coverts white; tail ashy, with dark bars; under parts white, the breast spotted with dusky, the sides washed with buff and barred with dusky. In winter the upper parts are plain ashy gray, and the lower parts dull white, unspotted. Bill dusky; legs bluish gray. Length about 16 inches.

Nest. Hid amid grass or rushes on a salt meadow or inland marsh, a slight depression, scantily lined with grass.

Eggs. 4; olive with varying tints from brown to gray, marked with rich brown and lilac; $2.15 \times 1.50$.

The Willet, as this well-known and large species is called, inhabits almost every part of the United States, from the coast of Florida to the distant shores and saline lakes in the vicinity of the Saskatchewan, up to the $5^{6}$ th parallel of latitude, where, as they pass the summer, they no doubt propagate there, as well 
as in the Middle States of the Union. Their appearance in the north of Europe is merely accidental, like the visit of the Ruff in America, which has, indeed, no better claim in our Fauna than that of the Willet in Europe, both being stragglers from their native abodes and ordinary migrating circuits. From the scarcity of this species on the shores of Massachusetts Bay, it is more than probable that their northern migrations are made chiefly up the great valley of the Mississippi; and they have been seen in the spring by Mr. Say, near Engineer Cantonment, on the bank of the Missouri. A few straggling families or flocks of the young are occasionally seen about the middle of August on the muddy flats of Cohasset beach; but they never breed in this part of New England, though nests are found in the vicinity of New Bedford.

The Willet probably passes the winter within the tropics, or along the extensive shores of the Mexican Gulf. About the middle of March, however, its lively vociferations of pill-zwillwillet, pill-will-willet begin commonly to be heard in all the marshes of the sea-islands of Georgia and South Carolina. In the Middle States these birds arrive about the $5^{\text {th }}$ of April, or sometimes later, according to the season; and from that period to the close of July their loud and shrill cries, audible for half a mile, are heard incessantly throughout the marshes where they now reside. Towards the close of May the Willets begin to lay. Their nests, at some distance from the strand, are made in the sedge of the salt-meadows, composed of wet rushes and coarse grass placed in a slight excavation in the tump; and during the period of incubation, as with some other marsh-birds, the sides of the nest are gradually raised to the height of five or six inches. The eggs, about four, very thick at the larger end, and tapering at the opposite, are two thirds the size of a common hen's egg (measuring over two inches in length, by one and a half in the greatest breadth); they are of a pale bright greenish olive (sometimes darker), largely blotched and touched with irregular spots of a bright blackish-brown of two shades, mixed with a few other smaller touches of a paler tint, the whole most numerous at the great 
end. According to Wilson, the eggs are very palatable as food. The young, covered with a gray-colored down, run off as soon as freed from the shell, and are led about by the mother in quest of their proper food, while the vociferous male keeps careful watch for their safety. On entering these breedingplaces the spectator is beset by the Willets flying wildly around and skimming over his head with the clamorous cry of pill-willwillet, accompanied at times, when much excited and alarmed by an approach to the nest, with a loud clicking note, in the manner of the Avocet. Exhausted with their vigilant and defensive exertions, at times they utter a sad and plaintive note, and occasionally alighting, slowly close their long, silvery, and party-colored wings, as if acting a part to solicit compassion. Among their most common and piratical enemies are the Crows, who roam over the marshes in quest of eggs, and as soon as they appear are attacked by the Willets in united numbers, who with loud vociferations pursue them off the ground. During the term of incubation the female, fatigued with her task, and occasionally leaving her eggs to the influence of the ardent sun, resorts to the shore, and deeply wading, washes and dresses her plumage, frequently emerging, and performing her ablutions with an air of peculiar satisfaction. Indeed, the Willets generally wade more than most of their tribe; and when disabled from flying by a wound, they take to the water without hesitation, and swim with apparent ease. The peculiar note which characterizes and gives name to this remarkable species of Chevalier is only uttered by the adults; and the call of the young when associated by themselves appears to be a kind of shrill and plaintive whistle almost like that of the Curlew. The Willet subsists chiefly on small shell-fish, aquatic insects, their larvæ and mollusca, in quest of which it constantly resorts to the muddy shores and estuaries at low water. In the fall, when the flocks of young birds associate, which may be easily known by the grayness of their plumage, they are selected by the gunners in preference to the older and darker birds, being tender, fat, and fine-flavored game. In the months of October and November they gradually pass on to 
their winter quarters in the warmer parts of the continent. Transient flocks of the young, bred in high latitudes, visit the shores of Cohasset by the middle of August; but timorous, wild, and wandering, they soon hasten to rejoin the host they had accidentally forsaken.

The Willet is found throughout temperate North America; but the birds breeding on the Great Plains have lately been separated from typical semipalmata. The general breeding area of the present race is given by Mr. D. G. Elliot as "from latitude $56^{\circ}$ to Texas." The bird is rarely seen in New England and the Maritime Provinces in summer, though quite common in both regions during the fall migration, and breeding in numbers to the southward of Long Island. Only a few examples have been seen in the region of the Great Lakes, though farther south it is not uncommon in the interior.

Note. - In 1887 Mr. William Brewster discovered that the Willets breeding west of the Mississippi differed from Eastern birds in size, color, and markings, the Western race being "larger, with a longer, slenderer bill; the dark markings above fewer, finer, and fainter on a much paler (grayish drab) ground; those beneath duller, more confused, or broken, and bordered by pinkish salmon, which often spreads over or suffuses the entire under parts excepting the abdomen. Middle tail-feathers either quite immaculate or very faintly barred. ... In the plain gray and white winter dress the two forms appear to be distinguished only by size" (Brewster).

Mr. Brewster named the new form the Western Willet $(S$. semipalmata inornata). This race breeds on the plains west to the Rocky Mountains "from the source of the Saskatchewan to California," and in winter is found on the coasts of the South Atlantic and Gulf States. 


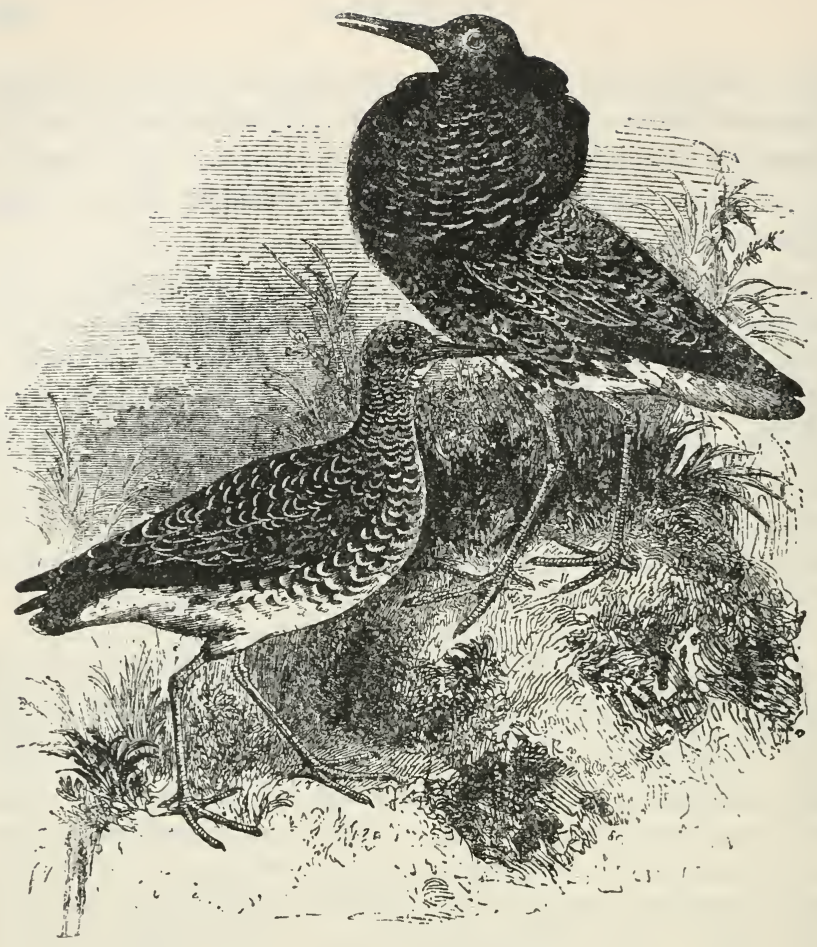

RUFF.

\section{Pavoncella pugnax.}

CHAR. Upper parts variable, but usually mottled black, chestnut, buff, and gray; lower back dark brown, with margin of chestnut or buff; wings and tail dusky brown; neck and breast buff; belly dull white. During the mating season - May and June - the male drops the feathers from the sides of the face, and reddish warts appear there; at this time, also, he wears a shield-like erectile ruff, - whence the name. Length about I 2 inches.

Nest. On a dry knoll in a swamp in the midst of a clump of coarse grass or sedges; a slight depression lined with dead grass.

Eggs. 4; pale olive or olive gray, spotted with reddish brown; 1.60 $\times$ I.15.

The Ruff is a distinctly European species, - it is rare on the British Isles, - but so many examples have been taken on this 
side of the Atlantic that the bird's claim to consideration in the present connection cannot be ignored. Yet it must be considered as a straggler only, - an accidental wanderer. Its breeding area lies amid the desolate tundras of northern Siberia, and southward to the fountains of the Danube and the upper valley of the Amoor. From there it migrates in the autumn into Africa and southern Asia.

The examples that have been obtained in America were taken chiefly along the Atlantic shore between Long Island and the Bay of Fundy. There is only one specimen recorded from the Great Lake region, - taken near Toronto.

The Ruff differs from all others of the Waders in appearance and in habits. The long feathers of the male render him easily distinguished, and his polygamous habits quite as thoroughly separate him. Instead of wooing a mate after the manner of their congeners, these wild libertines fight for a bevy of mistresses, the pluckiest fighter winning the largest harem.

These contests are not rough-and-tumble mêlée, but orderly conducted duels. They occur on a common battle-ground, where generation after generation of the birds assemble to do combat for the possession of the females, - called Reeves, - and these gather within sight and urge on their favorites. The battle-grounds are in the midst of a swamp, and usually on an elevated knoll in an open space.

During the encounter the combatants appear intensely excited and act as if in desperation, and the excitement of the occasion is increased by the wild screams of the Reeves. The duels are not to the death, however, nor are they in the least degree bloody affairs. These birds have sense enough to spar for points; slugging is barred. The attack is made wholly with the bill, - they never strike with the foot, like a game-cock, as some writers have stated, - and a few rounds end the affray, with no more harm to the participants than an encounter with foils to human rivals. The weaker bird retires, and the victor awaits another adversary. Occasionally two or three duels are in progress at one time.

As might be expected, such habits are not conducive to domestic felicity. The Reeve is soon abandoned by her temporary lover, and when nesting-time arrives she is forced to build her nest alone, and alone she rears her barbaric brood. 


\section{GREATER YELLOW-LEGS.}

TELL-TALE. TATTLER. STONE SNIPE. WINTER YELLOWLEG.

\section{TOTANUS MELANOLEUCUS.}

CHAR. Upper parts dark ash varied with gray and white; upper tailcoverts white; under parts white, breast and sides with dark streaks. In winter the plumage is paler, the breast almost immaculate. Bill long and slender; legs long. Length about 14 inches.

Nest. On the edge of marsh or open swamp; a slight depression lined with grass and weed stems.

Eggs. 4; dull gray or dark buff marked with brown and lilac; $1.45 \times$ I.20.

The Greater Yellow-Shanks, or Tell-Tale, so remarkable for its noise and vigilance, arrives on the coast of the Middle States early in April, and proceeding principally by an inland route, is seen in abundance as far north as the plains of the Saskatchewan, where, no doubt, in those desolate and secluded marshes, far from the prying eye and persecuting hand of man, the principal part of the species pass the period of reproduction, reappearing in the cooler parts of the Union towards the close of August; yet so extensive is the breeding-range of the Tell-Tale that many continue to occupy the marshes of the Middle States until the approach of cold weather in the month of November, breeding in their favorite resorts on the borders of bogs, securing the nest in a tuft of rank grass or sedge, and laying four eggs of a dingy white irregularly marked with spots of dark brown or black, and which, according to Mr. Hutchins, are large for the size of the bird, and of similar markings in their Northern breeding-places. In Massachusetts, as with many other birds, the present is so uncommon a species that it may be considered almost as a straggler, arriving in autumn with the few flocks which touch at the coast of Labrador and Newfoundland, confining their visits, with Curlews, Godwits, and many other wading birds, chiefly to the eastern extremity of Cape Cod and Cape Ann, where multitudes of these birds transiently assemble in spring and autumn (partic- 


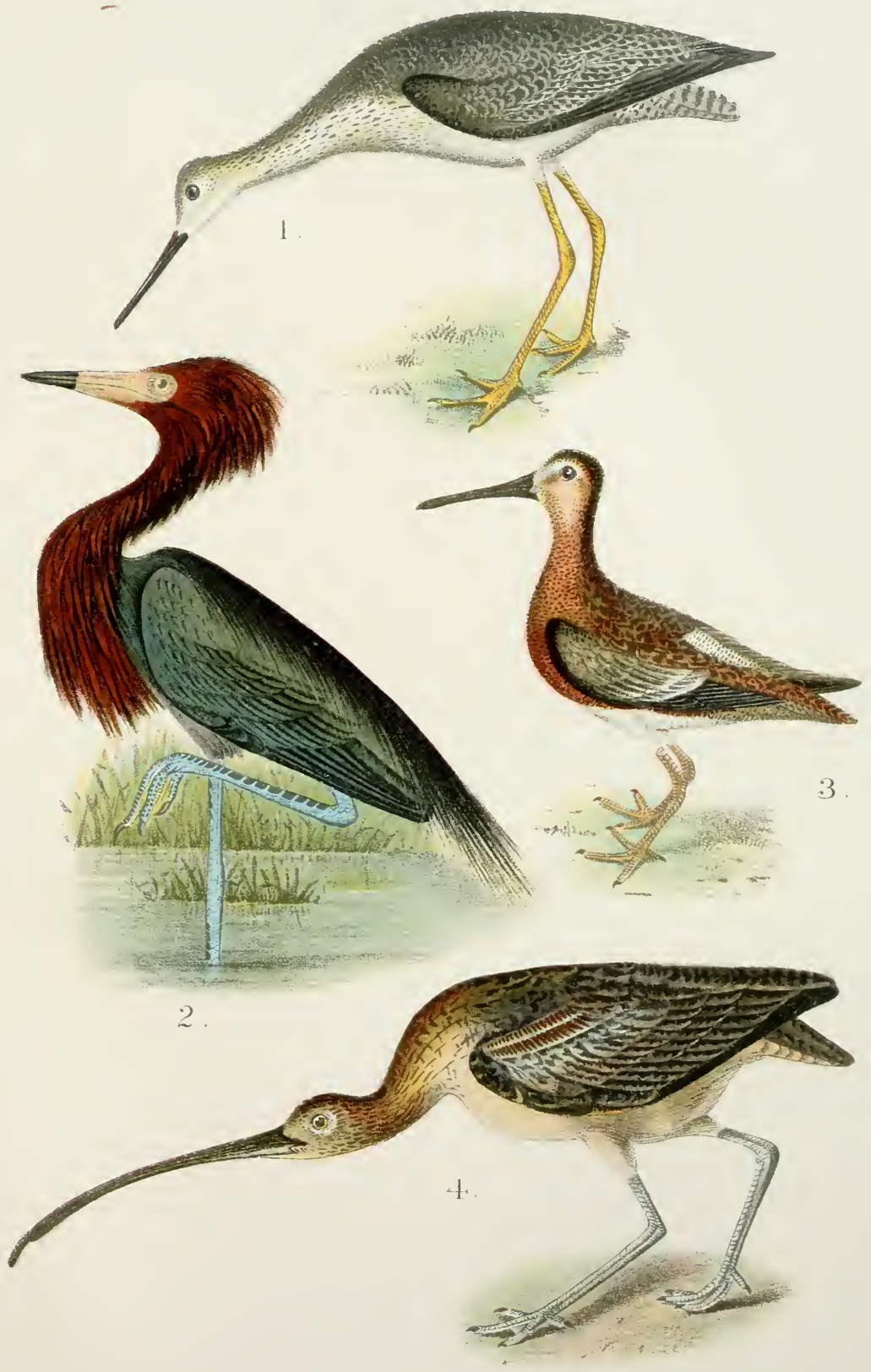

1. Greater Lellow-I.eģs

2. Reddish Egrel.

3. Red-Breasted Snipe

4. Long-Billed Curlew. 

ularly in the vicinity of Chatham and Ipswich), and of which but few penetrate inland, their next visit being usually to the shores of Long Island in their further progress to the South. In the spring, however, avoiding the long-continued eastwardly storms of this climate, they are led to go inland by a more favorable route, and have been seen at this season by Mr. Say on the banks of the Missouri on their way to the interior of the continent.

The vociferous vigilance of the Tell-Tale has justly stigmatized him with the present name; for no sooner does the gunner appear than his loud and shrill whistle of about four rapidly repeated notes is instantly heard as he mounts on wing, and proves generally so good a warning to all the rest of his feathered neighbors, and particularly the vigilant Ducks, that the whole, to the frequent disappointment of the fowler, at once accompany their faithful and officious sentinel. At times, indeed, without any particular motive to excitement, except perhaps that of hilarity and vigor, they are seen to rise high in the air, chattering so loudly as still to be heard when beyond the reach of the eye. From their note they are called by the Cree Indians of Hudson Bay Sasashew, and in this part of New England they are usually known by the name of the Winter Yellow-Leg.

The Tell-Tales, after taking up a summer residence in the marshes, are no longer gregarious until the return of winter, when, with the addition of the young, they rove about in small parties until their final departure for the South. Like most of the species, they frequent watery bogs and the muddy margins of creeks and inlets, where they are often seen in quest of food or standing in a watchful posture, alternately balancing themselves, raising or lowering the head and tail, and on the least appearance of danger or surprise, which they readily perceive from the elevation of their legs and the open places in which they feed, their loud whistle is instantly heard and the timorous and less watchful flocks are again in motion. They sometimes penetrate, singly or in small numbers, some way inland along the muddy shores of estuaries and rivers to the 
extent of tide-water. Although they live principally upon the insects and larvæ they find in the marshes, at a later period they also pay occasional visits to the strand in quest of mollusca, small shrimps, and minute shell-fish, the ordinary fare of the true Sandpipers. In the fall, when fat, their flesh is highly esteemed, and they are frequently brought to market.

The Tell-Tale occurs throughout this Eastern Province, breeding from about latitude 50 degrees northward, and wintering in Brazil and Chili. In the West it breeds as far south as Iowa and Northern Illinois. On the Atlantic coast the birds are known as migrants chiefly, though Mr. Brewster reports finding numbers on Anticosti in summer, and a few have been seen in New England at that season.

\section{YELLOW-LEGS.}

SUMMER YELLOW-LEGS. LESSER YELLOW-LEGS.

TOTANUS FLAVIPES.

CHAR. Upper parts dark ash varied with black, white, and gray; upper tail-coverts white, streaked with dusky; tail ashy, barred with white; wings dusky; under parts white, the breast and sides streaked with dusky. In winter the plumage is paler; the upper parts are plain ash, with few and less distinct markings. Length about I I inches.

Nest. Amid the bushes on the margin of a marsh or lake; a slight depression scantily lined with grass or leaves.

Eggs. 4; dull buff or pale drab, marked with brown and dull lilac; I.70 $\times$ I.I 5 .

The Yellow-Shanks, in certain situations, may be considered as the most common bird of the family in America. Its summer residence, or breeding-station, even extends from the Middle States to the Northern extremity of the continent, where it is seen, solitary or in pairs, on the banks of rivers, lakes, or in marshes, in every situation contiguous to the ocean. And though the young and old are found throughout the warm season of the year in so many places, the nest and eggs are yet entirely unknown. Calculating from the first appearance of the brood abroad, the females commence laying by the middle of June, and are seen in this neighborhood at 
that season. These birds reside chiefly in the salt-marshes, and frequent low flats and estuaries at the ebb of the tide, wading in the mud in quest of worms, insects, and other small marine and fluviatile animals. They seldom leave these maritime situations, except driven from the coast by storms, when they may occasionally be seen in low and wet meadows as far inland as the extent of tide-water. The Yellow-Shanks have a sharp whistle of three or four short notes, which they repeat when alarmed and when flying, and sometimes utter a simple, low, and rather hoarse call, which passes from one to the other at the moment of rising on the wing. They are very impatient of any intrusion on their haunts, and thus often betray, like the preceding, the approach of the sportsman to the less vigilant of the feathered tribes, by flying around his head, with hanging legs and drooping wings, uttering incessant and querulous cries.

How far they proceed to the South in the course of the winter is yet unknown; they however, I believe, leave the boundaries of the Union. At the approach of winter, previous to their departure for the South, they are observed to collect in small flocks and halt for a time on the shores of Hudson Bay. Accumulated numbers are now also seen to visit New England, though many probably pass on to their hibernal retreats by an inland route like the preceding, having indeed been seen in the spring on the shores of the Missouri in particular situations by Mr. Say. They also seem to reside no less in the interior than on the coast, as they were observed on the shores of Red River, of Lake Winnipeg (latitude 49 degrees), on the IIth of August by the same gentleman; thus subsisting indifferently on the productions of fresh as well as salt water. At the approach of autumn small flocks here also accompany the Upland Plover (Totanus bartramius), flying high and whistling as they proceed inland to feed, but returning again towards the marshes of the sea-coast to roost. Sometimes, and perhaps more commonly at the approach of stormy weather, they are seen in small restless bands roving over the salt-marshes and tacking and turning along the meanders of 
the river, now crossing, then returning; a moment alighting, the next on the wing. They then spread out and reconnoitre; again closing in a loose phalanx, the glittering of their wings and snow-white tails are seen conspicuous as they mount into the higher regions of the air ; and now intent on some more distant excursion, they rise, whistling on their way, high over the village spire and beyond the reach of danger, pursue their way to some other clime or to explore new marshes and visit other coasts more productive of their favorite fare. While skimming along the surface of the neighboring river, I have been amused by the sociability of these wandering waders. As they course steadily along, the party, never very numerous, would be joined by some straggling Peeps, who all in unison pursue their route together like common wanderers or travellers, pleased and defended by the access of any company.

Being a plentiful species, particularly in the latter end of summer, when the young begin to flock, it is frequent in the markets of Boston, New York, Philadelphia, and Baltimore, with us more particularly abundant about the middle of August ; and being then fat and well flavored, is esteemed for the table. From the sympathy of these birds for each other, they may be shot with facility if the sportsman, on the first discharge, permits the wounded birds to flutter about, as in that case the flock will usually make a circuit, and alighting repeatedly at the cries of their wounded companions, the greater part of them may be shot down before they perceive the real nature of their danger. Like Plovers, they can also be called around the sportsman by an imitation of their whistle.

This species is more abundant in the Mississippi Valley than the Greater Yellow-Legs; but on the Atlantic shores the smaller bird is seldom seen in the spring, and is not always common during the autumn. It breeds from Minnesota, Northern Illinois, Ohio, and Northern New York northward to the Arctic, and winters in South America. 


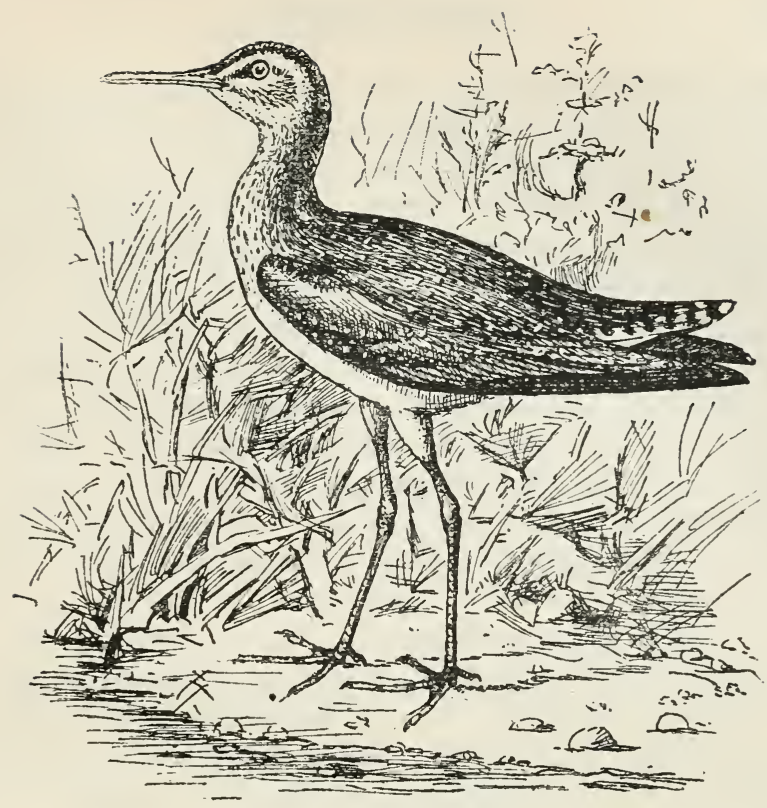

\section{SOLITARY SANDPIPER.}

GREEN SANDPIPER.

\section{TOTANUS SOLITARIUS.}

CHAR. Upper parts brownish olive, spotted and streaked with white; wings and tail dusky, outer tail-feathers white with dark bars; under parts white, breast and sides with dark markings. In winter the plumage of the upper parts is dark ash, and the markings are less distinct.

Nest. On a dry knoll in a wet meadow or on the margin of a pond, a slight depression scantily lined with grass.

Eggs. ? pale buff thickly marked with brown and lilac; $1.30 \times 0.90$.

The Solitary Tatler of Wilson is probably, with the change of seasons, a general inhabitant of the whole North American continent. Early in May it arrives in Pennsylvania from the South, and a few individuals remain to breed, according to the above author, in the marshy solitudes of the mountains of Virginia, Kentucky, and Pennsylvania ; the greater part of the 
species proceed, however, to the boreal regions as far as the extremity of the continent. According to Richardson, it makes no nest, but merely deposits its eggs on the bare beach or the gravelly banks of rivers; in such situations or near mountain springs, brooks, or pools, these birds are seen solitary or by pairs, running swiftly when alarmed or in pursuit of their prey, and seldom taking wing until hard pressed, on which occasion they make a short circular flight, and soon alight near the same place to renew their search for subsistence. Occasionally the Tatler stops and watches the observer, often nodding or balancing its head and tail almost in the manner of the European Wagtail (Motacilla). It is extremely unsuspicious of danger, proceeding in its usual occupation almost unconcerned when nearly approached; in fact, the safety of these birds is in no small measure due to their solitary and retiring habits, as they are never seen on the strand of the sea, nor collected into flocks, so as either to fall in the principal path of the fowler, or to present themselves in sufficient numbers for a successful shot. Their flesh, however, is well flavored, and they are usually fat.

In Massachusetts Solitary Tatlers are only seen at the commencement of cool weather. About the beginning of September they arrive in single pairs apparently from the North, at which time also they are supposed to descend from their breeding-resorts in the mountains, and now frequent the miry borders of tide-water streams and estuaries, as weli as small ponds, and, in short, any situation which affords the means of subsistence with little labor. They feed principally upon insects such as small coleoptera and caterpillars.

A pair, but oftener a single individual, have usually frequented very familiarly the small fish-pond in the Botanic Garden in Cambridge. Attracted by the numerous Donatias and their larvæ, which feed upon the water-lily (Nymphaa odorata), I observed one of them tripping along upon the sinking leaves with great agility, expanding its wings and gently flitting over the treacherous element in the manner of the Rail. At another time probably the same individual (who at first 
was accompanied by a mate) was seen day after day collecting insects, and contentedly resting in the interval on the border of the pond. The water having been recently let off, the lily leaves and insects were covered with mud; as soon then as our little familiar and cleanly visitor had swallowed a few of these insects, he washed them down with a drink of the water, and at the same time took the precaution to cleanse his bill and throat. Indeed, it is remarkable that however dirty the employment of these shore-birds may be, so neat are they in all their habits that not a stain or a soil is allowed for a moment to remain upon their limbs or plumage. This species is usually silent except when suddenly flushed, at which times it utters a sharp whistle like most of the other kinds to which it is related.

This bird is said to swim and dive with great facility when disabled from flying, and proceed under water like the Divers.

The Solitary Sandpiper is a rather common bird, breeding from about latitude $45^{\circ}$ to the lower fur countries. A few pairs remain in New England during the summer months.

Until quite recently the nest and eggs of this bird were unknown, and even now so few have been discovered, and these few so imperfectly identified, that fresh discoveries will be welcomed.

My friend Banks thinks he found an egg on the shore of Lily Lake, near St. John, in 1880 , and very probably he is correct; but he could not prove it absolutely, for he could not get sight of the parent on the nest or moving away from it. The nest was in an open meadow, and within sight for a considerable distance; but though the egg was always warm when visited, the parent managed to elude discovery. The only bird of the family seen in that vicinity during the time the nest was under observation being of the present species, and the nest and egg being somewhat different from those other shore-birds known to breed there, led Banks to suppose that the Solitary must be the parent. The egg found by Banks was pale buff marked with brown, but a set of eggs taken in Vermont by Mr. Richardson, the only authentic set recorded, were described by Dr. Brewer as "light drab."

Note. - One example each of the Green Shank (Totanus nebularius) and the GREEN SANDPIPER ( $T$. ochropus), both birds of the Old World, have been taken on the Atlantic coast, the firstnamed in Florida, the other in Nova Scotia. 


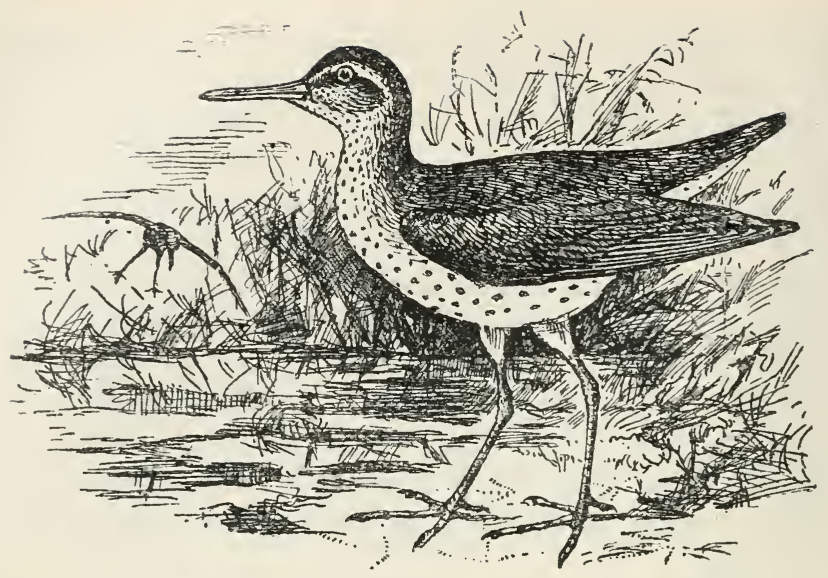

SPOTTED SANDPIPER.

TIP-UP. TEETER-TAIL. PEET-WEET.

ACTITIS MACULARIA.

CHAR. Above, bright ash, tinged with green of a metallic lustre and marked with black spots; white line over the eyes; wings dusky; under parts white, profusely spotted with dull brown. In winter the upper parts are grayish olive, and the under parts white without spots. Length about $7 \mathrm{I} / 2$ inches.

Nest. Near the shore of river or lake or on the margin of a pasture, under a bush, or amid tussock of grass or weeds, - a slight depression lined with grass, moss, or leaves.

Eggs. 4; dull buff or creamy, spotted with dark brown; $1.25 \times 0.90$.

The Peet-Weet is one of the most familiar and common of all the New England marsh-birds, arriving along our river shores and low meadows about the beginning of May from their mild or tropical winter-quarters in Mexico, and probably the adjoining islands of the West Indies. By the 2 oth of April, Wilson observed the arrival of these birds on the shores of the large rivers in the State of Pennsylvania. They migrate and breed from the Middle States in all probability to the confines of the St. Lawrence or farther, but were not seen by Dr. Richardson or any of the Arctic voyagers in the remote 
boreal regions or around Hudson Bay, as had been asserted by Hutchinson.

As soon as the Peet-Weet arrives on the coasts, small roving flocks are seen at various times of the day coursing rapidly along the borders of our tide-water streams, flying swift and rather low, in circuitous sweeps along the meanders of the creek or river, and occasionally crossing from side to side in a more sportive and cheerful mien than they assume at the close of autumn, when foraging becomes less certain. While flying out in these wide circuits, agitated by superior feelings to those of hunger and necessity, we hear the shores re-echo the shrill and rapid whistle of 'weet, 'weet, 'weet, 'weet, usually closing the note with something like a warble as they approach their companions on the strand. The cry then again varies to 'peet, weet weet weet, beginning high and gradually declining into a somewhat plaintive tone. As the season advances, our little lively marine wanderers often trace the streams some distance into the interior, nesting usually in the fresh meadows among the grass, sometimes even near the house; and I have seen their eggs laid in a strawberry bed, whence the young and old, pleased with their allowed protection, familiarly probed the margin of an adjoining duck-pond for their usual fare of worms and insects.

Like the preceding species, but more frequently, they have the habit of balancing or wagging the tail, in which even the young join as soon as they are fledged. From the middle to the close of May, as they happen to arrive in the different climates chosen for their summer residence, the pairs seceding from their companions seek out a site for their nest, which is always in a dry, open field of grass or grain, sometimes in the seclusion and shade of a field of maize, but most commonly in a dry pasture contiguous to the sea-shore; and in some of the solitary and small sea-islands, several pairs sometimes nest near to each other, in the immediate vicinity of the noisy nurseries of the quailing Terus. The nest, sunk into the bosom of a grassy tuft, is slightly made of its withered tops, and with a thin lining of hay or bent. The eggs, four in number, are of a VOL. II. - II 
grayish yellow or dull cream color marked with a great number of specks and spots of dark brown, with a very few of a somewhat lighter shade, the whole most numerous at the larger end; they are about one and one fourth inches in length, and very wide at the greater end. On being flushed from her eggs, the female goes off without uttering any complaint; but when surprised with her young, she practises all the arts of dissimulation common to many other birds, fluttering in the path as if badly wounded, and generally succeeds in this way so far to deceive a dog, or perhaps squirrel, as to cause them to overlook the brood for whose protection these instinctive arts are practised. Nor are the young without their artful instinct, for on hearing the reiterated cries of their parents, they scatter about, and squatting still in the withered grass, almost exactly their color, it is with careful search very difficult to discover them, so that nine times out of ten they would be overlooked, and only be endangered by the tread, which they would endure sooner than betray their conscious retreat.

At a later period the shores and marshes resound with the quick, clear, and oft-repeated note of peet weret, peet wěet, followed up by a plaintive call on the young of peet, peet peet? peet? If this is not answered by the scattered brood, a reiterated 'weet, 'weet, 'weet, 'wait 'wait is heard, the voice dropping on the final syllables. The whole marsh and the shores at times echo to this loud, lively, and solicitous call of the affectionate parents for their brood. The cry, of course, is most frequent towards evening, when the little family, separated by the necessity of scattering themselves over the ground in quest of food, are again desirous of reassembling to roost. The young as soon as hatched run about in the grass, and utter from the first a weak, plaintive peep, at length more frequent and audible; and an imitation of the whistle of 'peet weet is almost sure to meet with an answer from the sympathizing broods which now throng our marshes. When the note appears to be answered, the parents hurry and repeat their call with great quickness. The late Mr. William Bartram, so long and happily devoted to the study of Nature, with which 
he delighted to associate, informed Wilson of the spirited defence which one of these Peet-Weets made of her young against the attacks of a Ground Squirrel. The place was on the river shore; the female had thrown herself, with her two young behind her, between them and the land; and at every attempt of the enemy to seize them by a circuitous sweep, she raised both her wings almost perpendicularly, and assuming this formidable appearance, rushed towards the squirrel, who, intimidated by this show of resistance, instantly retreated; but soon returning, was met, as before, in front and flank by the resolute bird, who, with her wings and plumage bristled up, seemed swelled to twice her usual size. The young crowded together behind her, sensible of their peril, moving backwards and forwards as she advanced or retreated. In this way the contest endured for about ten minutes, when, as the strength of our little heroine began to fail, the friendly presence of the humane relater put an end to the unequal and doubtful contest.

Young and old, previous to their departure, frequent the seashores like most of the species, but never associate with other kinds nor become gregarious, living always in families till the time of their departure, which usually occurs about the middle of October. While near the shore they feed on small shrimps, coleoptera, and probably also mollusca.

The Spotted Sandpiper is abundant throughout North America. It breeds in New England (though sparingly to the southward of latitude $43^{\circ}$ ), westward to the Pacific and northward to Alaska. Mr. D. G. Elliot says: "In the Rocky Mountains this species is found at high elevations, even up to the limit of timber, and is as much at home at such lofty heights as at the level of the sea." 


\title{
BARTRAMIAN SANDPIPER.
}

\author{
UPLAND PLOVER. FIELD PLOVER.
}

\section{BARTRAMIA LONGICAUDA.}

CHAR. Upper parts brown, varied with buff and black; crown dusky and divided by line of buff; wings and rump dusky; outer tail-feathers rich buff and with a subterminal band of black and tips of white; under parts light buff, paler on chin; breast streaked with dusky. Bill about as long as the head; legs rather long. Length about $\mathrm{I} 2$ inches.

Nest. In an open pasture or old meadow, - a mere depression in the turf.

Eggs. 4; pale buff or creamy, marked with brown and lavender; I.80 $\times 1.25$.

Bartram's Tatler, known here by the name of the Upland Plover, so very distinct from the rest of the tribe with which it is associated in the systems, is one of the most common birds along the sea-coast of Massachusetts, making its appearance, with its fat and well fed-brood, as early as the 2 oth of July, becoming more abundant towards the middle of August, when the market of Boston is amply supplied with this delicate and justly esteemed game.

According to the season of the year, these birds are found throughout the continent, many retiring south of the equator to pass the winter. They are observed in May already busily gleaning coleopterous insects on the remote boreal plains of the Saskatchewan, and abound in the extensive prairies west of the Mississippi. At this time and in June they are seen common also in Worcester County (Mass.), and are believed to breed there. They are equally frequent on the plains of Long Island and New Jersey, and in similar bare and dry pastures in various parts of Massachusetts, particularly about Sekonk, and in Rhode Island near to the sea-coast, where they pass the greater part of the summer. Wilson, who first described the species, met with it in the meadows of the Schuylkill, pursuing insects among the grass with great activity. The breeding-range of this species extends, in all probability, from Pennsylvania to the fur countries of Upper Canada, as 
well as westward on either side of the Mississippi. Scattering broods and nests made in dry meadows are not uncommon a few miles from Salem, where Mr. N. West informs me he saw the young just fledged during the present season (1833) in the month of July.

While here they feed much upon grasshoppers, which now abound in every field, and become so plump as to weigh upwards of three quarters of a pound. They keep together usually in broods or small companies, not in gregarious swarms like the Sandpipers, and when approached are, like Plovers, silent, shy, and watchful, so that it requires some address to approach them within gunshot. They run fast, the older birds sometimes dropping their wings and spreading the tail, as if attempting to decoy the spectator from paying attention to their brood. On alighting they stand erect, remain still, and on any alarm utter three or four sharp, querulous whistling notes as they mount to fly. In the pastures they familiarly follow or feed around the cattle, and can generally be best approached from a cart or wagon; for though very wary of man, they have but little apprehension of danger in the company of domestic animals. In August the roving families now approach the vicinity of the sea, resorting to feed and roost in the contiguous dry fields. In the morning as they fly high in the air in straggling lines, their short warbling whistle is sometimes heard high overhead, while proceeding inland to feed, and the same note is renewed in the evening as they pass to their roosts. It is also very probable that this is usually the time they employ in their migrations to the South, which commence here early in September and by the middle of that month a few stragglers only are found.

The Upland Plover is still abundant in New England during the migrations, and some breed here; but in the Maritime Provinces the bird is uncommon, and it has not been taken on the north side of the Gulf of St. Lawrence. It is rarely met with in the region of the Great Lakes, but is very abundant on the western plains, where the birds congregate in immense flocks, - "sometimes in thousands." Their winter home is on the pampas of the Argentine Republic. 


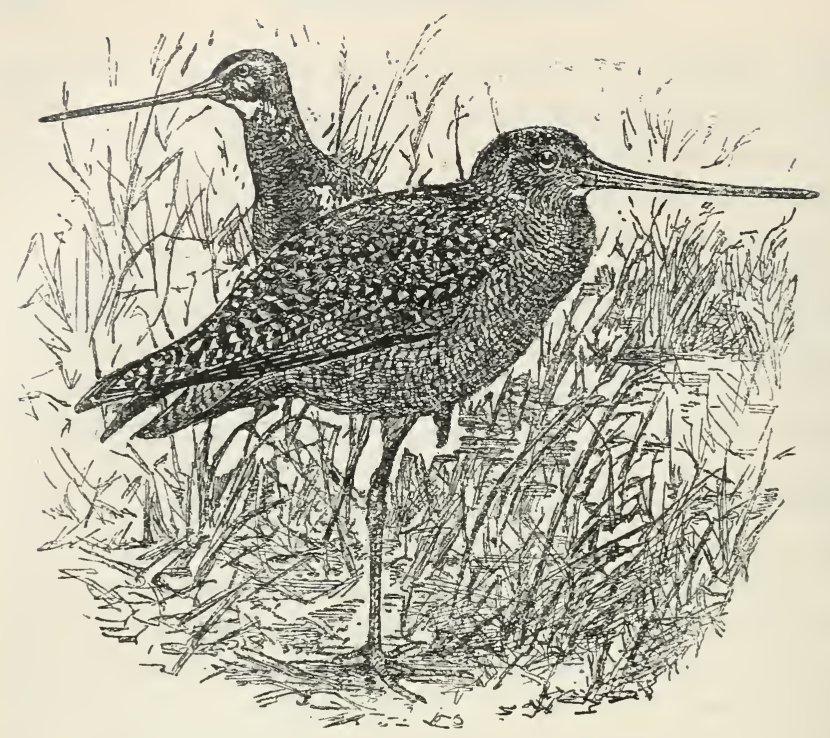

\section{MARBLED GODWIT.}

MARLIN.

\section{LIMOSA FEDOA.}

CHAR. Prevailing color dull rufous varied with black; rump and tail barred; bill pinkish ; legs and feet black. Length $I 7$ to 20 inches.

Nest. Near a stream or lake, - a slight depression sparingly lined with grass.

Eggs. 3-4; pale buff or olive, marked with brown and lavender; $2.25 \times 1.60$.

The Marbled Godwit is only a transient visitor along the seacoasts of the United States in the spring and fall on its way to and from its breeding-place in the North. According to Richardson, it abounds in the summer season in the interior of the fur countries, being particularly plentiful on the Saskatchewan plains, where it frequents marshes and bogs, walking on the surface of the swamp-moss (Sphagna), and thrusting down its bill to the nostrils in quest of worms and leeches, which it discovers by the sensitive point of its bill, thus finding means to 
obtain a kind of food which would otherwise be imperceptible to any other sense. It no doubt likewise varies this fare and feeds also upon insects and larvæ. These birds arrive on the coasts of the Middle States in the month of May, and linger on till some time in June. Many, however, at this time have already arrived at their ultimate destination in the North, so that it is not improbable but some of these Godwits may breed in more temperate regions to the west as well as north, selecting the high plains of the Rocky Mountains in situations sufficiently moist. At all events, they are seen in the lower part of Missouri in the course of the spring, but migrate like most other waders along the sea-coast in the way to their tropical winter quarters.

The Marbled Godwit in large flocks appears in the saltmarshes of Massachusetts about the middle of August, particularly towards the eastern extremity of the bay, round Chatham and the Vineyard; their stay is, however, very short, and they at the same time, no doubt, visit the eastern coast of Long Island. On these occasions they assemble by many hundreds together, and usually associate with the Short-Billed Curlews, they themselves being called Red Curlews, - though here they are distinguished also by the name of Doebirds, and, being at this season fat, are highly esteemed for the table. They are very shy and cautious; but when once confused by the fall and cries of any of their companions, great destruction may be made among them before they recover from the delusion: they thus make repeated circuits round the wounded and complaining, and may be enticed within gunshot by imitating their whistling call, after the manner of the Curlew. Indeed, without some contrivance of this kind they can seldom be approached.

These birds are abundant in the West, but on the Atlantic coast they appear only in small flocks during the spring and autumn migrations. They breed from Iowa to the Saskatchewan, and winter in Central America and southward. 


\title{
HUDSONIAN GODWIT.
}

\author{
RING-TAILED MARLIN.
}

LiMOSA HÆMASTICA.

CHAR. Upper parts dusky, mottled with buff; head and neck rufous, streaked with dusky; rump dusky; tail-coverts mostly white; tail dusky, tipped with white; under parts rich chestnut, barred with dusky. Length I 4 to 16 inches.

Nest. Near a stream or lake, - a slight depression, lined with a few leaves or bits of grass.

Eggs. 3-4; grayish olive or hair brown, spotted with darker brown; $2.20 \times \mathrm{J} .40$.

The Hudsonian, or American Black-tailed Godwit, though abundant in the Barren Grounds near the Arctic Sea, where it breeds, is an uncommon visitor in the Eastern and Middle States of the Union, although, from all analogy and the impossibility of the species subsisting through the winters of its natal regions, we are certain that the whole retire into mild climates to pass the winter. They probably, like some other birds of the same countries, retire southward by an inland route, or even pass the autumn on the shores of the northwestern coast of the continent. Be this as it may, the present bird is among our greatest rarities, as I have seldom seen more than two or three pair in the course of the season; these are found on the neighboring coast of the Bay, and called by the market people of Boston, Goose Birds. I obtained a solitary pair of these stragglers about the 8th of September; they were very fat and well flavored, scarcely distinguishable in this respect from the Curlew, and appeared to have been feeding on some Ulva or other vegetable substance. Several pair of young and old birds were brought to market this year ( 1833 ), from the 6th to the 3 oth of the same month. An individual now in the Philadelphia Museum was shot also near the coast of Cape May, in New Jersey. They sometimes associate with the Plovers, and descending to the marshes and the strand, feed upon minute shell-fish, shrimps, and the roots of the Zostera. According to Richardson, they frequent boggy lakes, like the 
preceding probing the Sphagnum and mud in quest of insects and minute shell-fish. The manners of this bird are similar to those of the L. fedoa, and in most respects it makes an approach to the Black-tailed species of Europe; it is, however, somewhat larger, and readily contradistinguished.

The Hudsonian Godwit is more frequently seen on the Atlantic coast than is its larger relative, but it is not at all common, and is seen only or generally in the autumn. It breeds in the higher Arctic regions, - on the Barren Grounds, - and winters in South America.

Note. - The Black-TAIled Godwit (Limosa limosa) occurs occasionally in Greenland.

\section{DOWITCHER.}

BROWN-BACK. ROBIN-SNIPE. RED-BREASTED SNIPE. GRAY SNIPE.

\section{MACRORHAMPUS GRISEUS.}

ChAR. Summer: above, dusky, varied with bay; rump white, barred with dusky ; tail with black and buff bars ; below, bay, varied with dusky. In winter the upper parts are dark gray, the rump pure white, and the lower parts white, shaded on the breast with gray. Length about $10 \mathrm{~T} / 2$ inches. Similar to Wilson's Snipe, but distinguished by its longer legs.

Nest. On marshy border of pond or stream, - a depression in the turf lined with leaves and grass.

Eggs. 4; pale olive brown, spotted with dark brown; 1.70 X 1.15.

The Red-breasted Snipe begins to visit the sea-coast of New Jersey early in April, arriving from its winter quarters, probably in tropical America. After spending about a month on the muddy marshes and sand-flats left bare by the recess of the tides, a more powerful impulse than that of hunger impels the wandering flocks towards their natal regions in the North, where, secluded from the prying eye of man, and relieved from molestation, they pass the period of reproduction, the wide range of which continues, without interruption, from the borders of Lake Superior to the shores of the Arctic Sea. On the 
plains of the Saskatchewan, according to Richardson, they feed much upon leeches and coleoptera, for which, no doubt, they probe the mud and sphagnum of the bogs and marshes, - a habit which they also pursue while here, on their way to the South, particularly collecting the larvæ of aquatic insects, such as Libellula and others. The nest and eggs of this species are yet unknown. The ovaries in females killed in May were already swelled to the size of peas. By the 2 oth of July or beginning of August they revisit the shores of New England and the Middle States in large flocks recruited by their young. These are already full grown, in good condition for the table, and are at all times greatly esteemed for their excellent flavor.

The Red-breasted Snipes are always seen associated in flocks, and though many are bred in the interior around the Great Northern Lakes, they now all assemble towards the sea-coast, as a region that affords them an inexhaustible supply of their favorite food of insects, mollusca, and small shellfish; and here they continue, or a succession of wandering and needy bands, until the commencement of cold weather advertises them of the approach of famine, when, by degrees, they recede beyond the southern limits of the Union. While here they appear very lively, performing their aërial evolutions over the marshes at a great height sometimes in the air, uttering at the same time a loud, shrill, and quivering whistle, scarcely distinguishable from that of the Yellow-Legged Tatler (something like

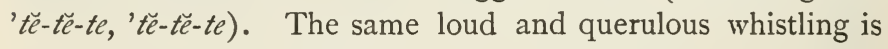
also made as they rise from the ground, when they usually make a number of circuitous turns in the air before they descend. At all times gregarious, in the autumn and spring they sometimes settle so close together that several dozens have been killed at a single shot. While feeding on the shores or sandbars, they may be sometimes advantageously approached by a boat, of which, very naturally, they have but little fear or suspicion; nor are they at any time so shy as the Common Snipe, alighting often within a few rods of the place where their companions have been shot, without exhibiting alarm until harassed by successive firing. Besides mollusca, they occasionally vary 
their fare with vegetable diet, such as the roots of the Zostera marina; and I have also found in their stomachs the whitish oval seeds of some marsh or aquatic plant. They likewise, in common with the Sandpipers and many other wading birds, swallow gravel to assist the trituration of their food.

We know to-day something more than Nuttall could tell us of the nesting habits of the Dowitcher, or "Deutscher's Snipe," as the bird was originally called, to distinguish it from the "English Snipe," now known as Wilson's. Our bird is still called "German Snipe" at some localities on the coast.

A number of nests have been taken in the Far North, where the birds find suitable feeding-grounds in the bogs and marshes amid the barren lands bordering the Arctic Ocean. Stragglers from the main flocks are met with in summer throughout the fur countries and down to the forty-fourth parallel; but it does not follow that - they breed so far to the southward. Large flocks appear on the Atlantic coast during both the spring and autumn migrations, though they seem to pass over New Brunswick and Nova Scotia without alighting, in the spring. But they move northward rapidly and with few stoppages, while they return quite leisurely and are therefore considered more abundant in the autumn in all localities.

In the vicinity of the Great Lakes the birds are rarely seen, though it is known that large flocks journey north and south by way of the Mississippi Valley and across the Great Plains. In winter the birds are found in the West Indies and Brazil.

Note. - The Long-Billed Dowitcher ( $M$. scolopaceus) has lately been separated from griseus. It is a larger bird, with a longer bill; and though chiefly confined to the Western Province, examples are seen regularly on the Atlantic coast. 


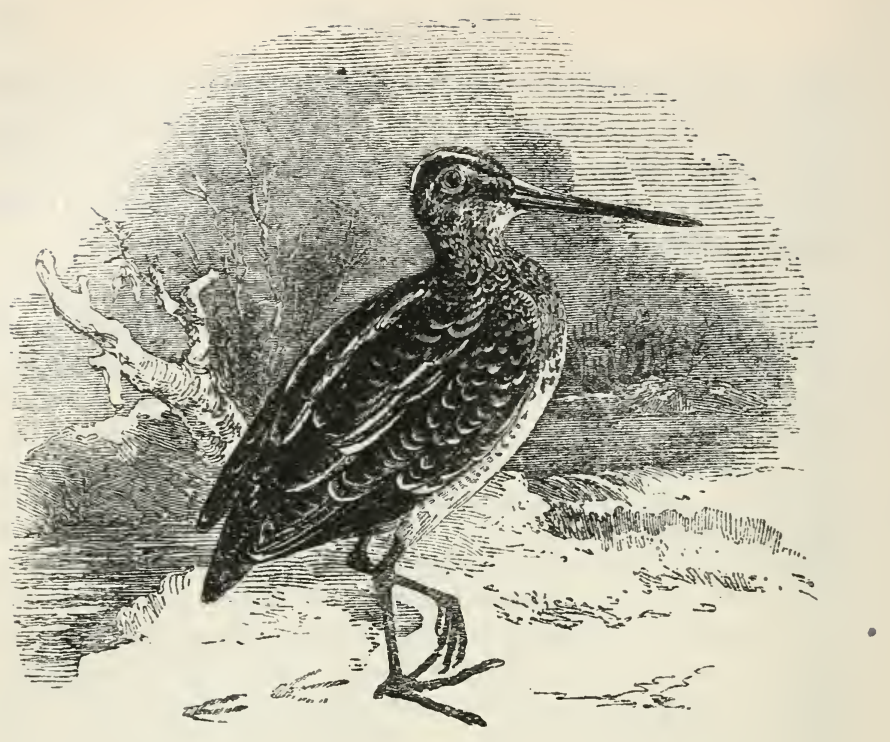

\section{WILSON'S SNIPE.}

ENGLISH SNIPE. COMMON SNIPE. JACK SNIPE. SHAD BIRD.

Gallinago jelicata.

CHAR. Above, mottled brown, black, and buff; tail with subterminal bars of rufous and black; crown dusky, with medial stripe of buff; neck and breast pale brown, spotted with dusky; belly white, sides with dark bars. Length about II inches.

Nest. Amid a tussock of grass or bunch of moss in a wet meadow or margin of a marsh, - a slight depression in the turf sparingly lined with grass, leaves, or feathers.

Eggs. $3-4$; olive of various shades, spotted with brown and lavender; I. $55 \times$ I.10.

The Snipe of North America, so nearly related to that of Europe, is found, according to the season, in every part of the continent, from Hudson Bay to Cayenne, and does not appear, indeed, sufficiently distinct from the Brazilian Snipe of Swainson, which inhabits abundantly the whole of South America as far as Chili. Many winter in the marshes and inundated river grounds of the Southern States of the Union, where they are 
seen in the month of February, frequenting springs and boggy thickets; others proceed along the coast of the Gulf of Mexico, and even penetrate into the equatorial regions.

By the second week in March, flocks of Wilson's Snipe begin to revisit the marshes, meadows, and low grounds of the Middle States, and soon after they arrive in New England. In mild and cloudy weather, towards evening, and until the last rays of the setting sun have disappeared from the horizon, we hear, as in the North of Europe, the singular tremulous murmurings of the Snipes, making their gyratory rounds so high in the air as scarcely to be visible to the sight. This humming, or rather flickering and somewhat wailing, sound has a great similarity to the booming of the Night Hawk (Caprimulgus), but more resembles the sound produced by quickly and interruptedly blowing into the neck of a large bottle than the whirring of a spinning-wheel. But however difficult and awkward may be our attempts to convey any adequate idea of this quailing murmur, it seems to be, to its agent, an expression of tender feeling or amatory revery, as it is only uttered at the commencement and during the early part of the pairing season, while hovering over those marshes or river meadows which are to be the cradle and domicile of their expected progeny, as they have already been of themselves and their mates. This note is probably produced by an undulatory motion of air in the throat while in the act of whirling flight, and appears most distinct as the Snipe descends towards the ground. However produced, the sound and its originators are commonly so concealed by the fast-closing shades of night, and the elevation from whence it issues in cloudy weather, that the whole seems shrouded in mystery. My aged maternal parent remembered, and could imitate with exactness, this low, wailing murmur, which she had for so many years heard over the marshes of my native Ribble, in the fine evenings of spring, when all Nature seemed ready to do homage for the bounties of the season; and yet at the age of seventy, the riddle had not been expounded with satisfaction.

Over the wide marshes of Fresh Pond, about the middle of 
April, my attention was called to the same invisible voice, which issued from the floating clouds of a dark evening; the author was here called the Alewife Bird, from its arrival with the shoals of that fish in the neighboring lake. From the elevation at which the sound issued, probably, it appeared less loud and distinct than that which I have since heard from the English Snipe. I imagined then that the noise was made by the quick and undulatory fanning of the wings; but this would not produce the shrillness of tone by which it is characterized, as any one may satisfy himself by hearkening to the very different low buzz made by the wings of the Humming Bird. In this instance, as well as in the former, all my sporting acquaintance were familiar with this quivering call, but had never decided upon its author. At the same time I observed, flying high and rapid, a pair of these Snipes, probably instigated by anger and jealousy, who then uttered a discordant quacking sound, - something like the bleat they make when they have descended to the ground, and which they accompany with an attitude of peculiar stupidity, balancing the head forwards, and the tail upwards and downwards, like the action of some automaton toy, jerked and set in motion by a tight-drawn string.

After incubation, which takes place rather early in the spring, the humming is no longer heard, and the sprightly aerial evolutions which appeared so indefatigable have now given way to sedater attitudes and feebler tones. A few pairs no doubt breed in the extensive and almost inaccessible morasses of Cambridge ponds or lagoons; and I have been informed that they select a tuft of sedge for the foundation of the nest, which is constructed with considerable art. The eggs, like those of the European species, about four, are perhaps alike olivaceous and spotted with brown. These birds probably scatter themselves over the interior of the continent to breed, nowhere associating in great numbers; nor are they at all common in the hyperboreal retreats chosen by so many of the other wading birds. My friend Mr. Ives, of Salem, also informs me that a few pairs of this species breed in that vicinity.

The Snipe, almost nocturnal in its habits, conceals itself with 
assiduity in the long grass, sedge, and rushes of its enswamped and boggy retreat. Aware of danger from the approach of the sportsman, it springs at a distance with great rapidity, uttering usually a feeble squeak; and making several inflections before it țakes a direct course, it becomes very difficult to shoot, and is more easily caught with a snare or springe similar to that which is set for Woodcocks. Being deservedly in high repute as an exquisite flavored game, great pains are taken to obtain Snipes. In the spring season on their first arrival they are lean; but in the autumn, assembled towards the coast from all parts of the interior, breeding even to the banks of the Mississippi, they are now fat and abundant, and, accompanied by their young, are at this time met with in all the low grounds and enswamped marshes along the whole range of the Atlantic; but ever shy and dexterous, they are only game for the most active and eager sportsmen. When on the wing they may, like many other birds of this family, be decoyed and attracted by the imitation of their voice. They are, like the European Snipe, which migrates to winter in England, by no means averse to cold weather, so long as the ground is not severely frozen in such a manner as to exclude their feeding; so that even in Massachusetts they are found occasionally down to the middle of December. They are nowhere properly gregarious, but only accidentally associate where their food happens to be abundant. For this purpose they are perpetually nibbling and boring the black, marshy soil, from which they sometimes seem to collect merely the root-fibres which it happens to contain, though their usual and more substantial fare consists of worms, leeches, and some long-legged aquatic insects; the Snipe of Europe also seizes upon the smaller species of Scarabaus. Their food, no doubt, is mixed with the black and slimy earth they raise while boring for roots and worms, and which in place of gravel, or other hard substances, appears to be the usual succedaneum they employ to assist their digestion and distend the stomach.

The habits of this bird are well known to every sportsman in North America, for it ranges throughout the continent, and is 
common at times in almost every suitable locality. Its general breeding area extends from Hudson Bay and Alaska southward to about latitude $45^{\circ}$, and a few nests have been taken south of that line. In winter the birds are found in the Gulf States and southward.

Note. - The European Snipe (Gallinago gallinago), which is somewhat similar in appearance to the American bird, occurs regularly in Greenland, and has been taken in Bermuda.

\section{AMERICAN WOODCOCK.}

BOG-SUCKER.

\section{PHII.OHELA MIINOR.}

CHAR. Above, mottled tawny, black, and gray; beneath, pale rufous or tawny buff, tinged with gray. Head peculiar; neck short; body stout; bill long and straight; legs and tail short. Length about i I inches.

Nest. Sometimes in a wet meadow or on the margin of a swamp, but often in a dry woodland or on a shaded hillside, - placed amid a tuft of grass or at the foot of a tree or stump; a slight depression sparingly lined with leaves or grass.

Eggs. 4; creamy or pale buff spotted with brown and lavender; I. $55 \times 1.15$.

The American Woodcock, like the Snipe, appears again to be a near representative of that of Europe, whose manners and habits it almost entirely possesses, differing, however, materially in the temperature of the climates selected for its residence, confining itself in the summer to the south side of the St. Lawrence, breeding in all the intermediate space as far as the limits of the Middle States, and retiring in winter for the most part either to or beyond the boundary of the Union. The European species, on the contrary, courting cooler climates, winters in Great Britain and the North of Europe, and retires as early as March to breed in the Alps or in the frigid wilds of Sweden, Norway, Russia, and penetrates even to the icy shores of Greenland and the heaths of Iceland. About the same period, early in March, the American Woodcock revisits Pennsylvania, and soon after the New England or Eastern 
States. Indeed, so sedentary are these birds at times that a few are known to winter in the sheltered forests and open watery glades of Pennsylvania; at the same season also many are seen in the vicinity of Natchez in Mississippi. According to their usual habits, they keep secluded in the woods and thickets till the approach of evening, when they sally forth to seek out springs, paths, and broken soil, in quest of worms and other insects on which they feed. They now disperse themselves over the country to breed, and indicate their presence in all directions by the marks of their boring bills, which are seen in such soft and boggy places as are usually sheltered by thickets and woods. They also turn over the fallen leaves from side to side with their bills in quest of lurking insects, but never scratch with their feet, though so robust in their appearance. The sensibility possessed by the extremity of the bill, as in the Snipe, is of such an exquisite nature that they are enabled to collect their food by the mere touch without using their eyes, which are set at such a distance and elevation in the back part of the head as to give the bird a remarkable aspect of stupidity. When flushed or surprised in their hidingplaces, they only rise in a hurried manner to the tops of the bushes or glide through the undergrowth to a short distance, when they instantly drop down again, and run out for some space on touching the ground, lurking as soon as they imagine themselves in a safe retreat. At times in open woods they fly out straight with considerable vigor and swiftness; but the effort, from the shortness of the wing, is always attended with much muscular exertion.

During the mating season, in the morning as well as evening, but more particularly the latter, the male in the vicinity of his mate and nest rises successively in a spiral course like a Lark. While ascending he utters a hurried and feeble warble; but in descending, the tones increase as he approaches towards the ground, and then, becoming loud and sweet, pass into an agreeable, quick, and tumultuous song. As soon as the performer descends, the sound ceases for a moment, when with a sort of stifled utterance, accompanied by a stiff and balancing VOL. II. - I 2 
motion of the body, the word blaik, and sometimes paip paip, is uttered. This uncouth and guttural bleating seems a singular contrast to the delightful serenade of which this is uniformly the close. I heard this piping and bleating in the marshes of West Cambridge on the $15^{\text {th }}$ of April, and the birds had arrived about the first week in that month. This nocturnal music continued at regular intervals, and in succession until near nine o'clock in the evening, and is prolonged for a number of days during the period of incubation, probably ceasing with the new cares attendant on the hatching of the brood. The female, as in the European species, is greatly attached to her nest, and an instance is related to me of a hen being taken up from it and put on again without attempting to fly. Mr. Latham mentions a female of the Common Woodcock sitting on her eggs so tamely that she suffered herself to be stroked on the back without offering to rise, and the male, no less interested in the common object of their cares, sat also close at hand. The European species has had the credit of exercising so much ingenuity and affection as to seize upon one of its weakly young and carry it along to a place of security from its enemies. Mr. Ives, of Salem, once on flushing an American Woodcock from its nest, was astonished to see that it carried off in its foot one of its brood, the only one which happened to be newly hatched; and as the young run immediately on leaving the shell, it is obvious that the little nursling could be well reared, or all of them as they might appear, without the aid of the nest, now no longer secured from intrusion. In New England this highly esteemed game is common in the markets of Boston to the close of October, but they all disappear in the latter part of December. In this quarter of the Union they are scarcely in order for shooting before the latter end of July or beginning of August; but from this time to their departure they continue in good condition for the table.

The springes, or springers, set for Woodcocks in Europe in places they are found to frequent by the evidence of their borings, etc., are commonly formed of an elastic stick, to 
which is fastened a horse-hair noose put through a hole in a peg fastened into the ground, to which a trigger is annexed; and in order to compel the Woodcock to walk into the trap, an extended fence is made on each side by small sticks set up close enough to prevent the bird passing between them. These concentrate at the trap, so that in this funnel-shaped fence the bird in feeding is made to pass through the narrow passage, and is almost to a certainty caught by the legs.

As the season advances and food begins to fail, by reason of inclement and cold weather, the Woodcocks leave the interior; and approaching the shelter of the sea-coast and the neighboring marshes, they now become abundant, and are at such times late in autumn killed in great numbers. These are also their assembling points previous to their southern migrations, which are performed in a desultory and irregular manner, their motions, as usual, being mostly nocturnal or in the twilight; and though many are now met with in the same low meadows and marshes, they are brought together by common necessity, and never move in concerted flocks. At this season their movements are not betrayed by any note or call; the vocal powers of the species are only called into existence at the period of propagation; at other times they move and start to wing in silence. The young run or wander off as soon as they are hatched, are at this period covered with a brownish-white down, and on being taken utter a slender bleat or clear and long-drawn péep.

This famous game-bird is common in the Maritime Provinces, but is rarely found on the northern side of the Gulf of St. Lawrence. It is common also in Southern Ontario, but in the Muskoka district is rather rare. It is known to breed throughout its Canadian range, and southward through the Middle States and westward to the Plains. It winters in the Southern States.

Note. - The European Woodcock (Scolopax rusticola), a much larger bird, occurs occasionally on this side of the Atlantic. 


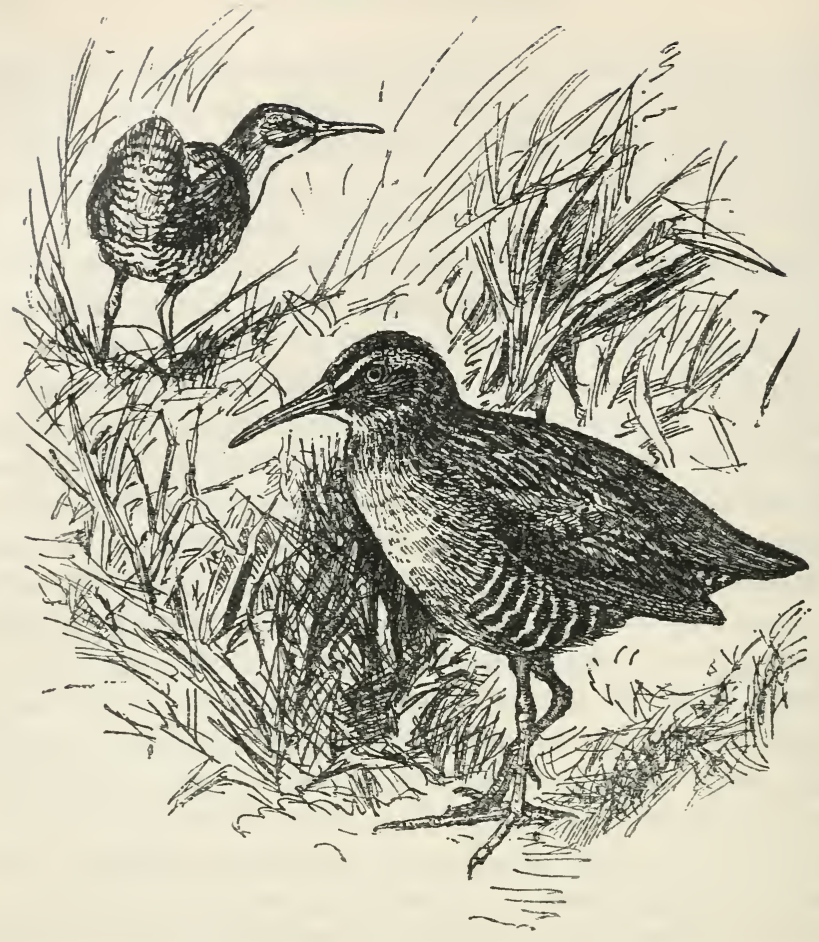

VIRGINIA RAIL.

RED-BREASTED RAIL. LESSER CLAPPER RAIL.

RALLUS VIRGINIANUS.

CHAR. General coloration rufous. Above, tawny olive striped with dusky; wing-coverts rich bay; crown dusky; below, light reddish brown, paler on the belly. Length about $9 \frac{1}{2}$ inches.

Nest. On the ground amid a tuft of grass on the marshy margin of a lake or stream, sometimes in a salt-marsh, usually placed close to the water's edge, - a deep, saucer-shaped affair of reed-stalks and grass, and rather compactly built.

Eggs. 6-I 2 (usually 8); pale cream or reddish buff, spotted with brown and lavender; $1.25 \times 0.90$.

The Virginian or Lesser Clapper Rail, scarcely distinguishable from the preceding but by its inferior size, is likewise a 
near representative of the Water Rail of Europe, with whose habits in all respects it nearly agrees. But in every part of America it appears, to be a rare species compared with the Mud Hen or common Clapper Rail. It is also wholly confined to the fresh-water marshes, and never visits the borders of the sea. In New Jersey it is indeed ordinarily distinguished as the Fresh-Water Mud Hen; so constant is this predilection, connected probably with its choice of food, that when met with in salt-marshes it is always in the vicinity of fresh-water springs, which ooze through them or occupy their borders. From this peculiarity in its choice of wet grounds, it is consequently seen in the interior, in the vicinity of bogs and swampy thickets, as far west as the States of Ohio, Kentucky, and probably Illinois and Michigan. Its migrations, however, along the neighborhood of the coast do not extend probably farther than the shores of the St. Lawrence, as it is unknown in the remote fur countries of the North, and retires from the Middle States in November at the commencement of frost. It revisits Pennsylvania early in May, and is soon after seen in the fresh marshes of this part of Massachusetts. How far it retires, in the course of the winter, towards the South, is yet unknown, though from its absence, apparently, from the warmer parts of the continent, it probably migrates little farther than the southern extremity of the Union. Its habit of closely hiding in almost inaccessible swamps and marshes renders it a difficult task even to ascertain its presence at any time; and, like the preceding, it skulks throughout most part of the day in the long sedge and rushes, only venturing out to feed in the shade and obscurity of the twilight. Its food is most commonly marsh insects and their larvæ, as well as small worms and univalve shell-fish, it rarely, if ever, partaking of vegetable diet.

The Virginian Rail commences laying soon after its arrival in the early part of May. The nest, situated in the wettest part of the marsh, is fixed in the bottom of a sedgy tussock and composed of withered grass and rushes. The eggs are similar to those of the European Water Rail, being of a dirty white or pale cream color, sprinkled with specks of brownish 
red and pale purple, most numerous at the great end. In the Middle States this bird is believed to raise two broods in the season. The female is so much attached to her eggs, after sitting, as sometimes to allow of being taken up by the hand rather than desert the premises, - which affection appears the more necessary as the male seems to deserts his mate and leave her in the sole charge of her little family.

About the I8th of June, in this vicinity, in a wet part of the salt-marsh making into a fresh meadow near Charles River, one moonlight evening as late as nine o'clock I heard a busy male of this species calling out at short intervals in a guttural, creaking tone, almost like the sound of a watchman's rattle, 'kut-ă-cuit tee-àh, - the call sometimes a little varied. At this time, no doubt, his mate was somewhere sitting on her eggs in some tuft of the tall marine grass (Spartina glabra) which overhung the muddy inlet near which he took his station. The young, for some time after being hatched, are covered wholly with a jet-black down, and running with agility, are now sometimes seen near the deep marshes, straying into the uplands and drier places, following the careful mother much in the manner of a hen with her brood of chickens. When separated from the parent at a more advanced age, their slender peep, peep, peep, is heard and soon answered by the attentive parent. The female when startled in her watery retreat often utters a sharp, squeaking scream apparently close at hand, which sounds like 'keek, 'keek, 'kek; on once approaching, as I thought, the author of this discordant and timorous cry, it still slowly receded, but always appeared within a few feet of me, and at length pressing the pursuit pretty closely, she rose for a little distance with hanging legs, and settled down into a ditch among some pond-lily leaves, over which she darted and again disappeared in her paths through the tall sedge, screaming at intervals, as I now found, to give warning to a brood of young which had at first probably accompanied her and impeded her progress.

When seen, which is but rarely, the Virginian Rail, like the other species, stands or runs with the neck outstretched and 
PI.XV.

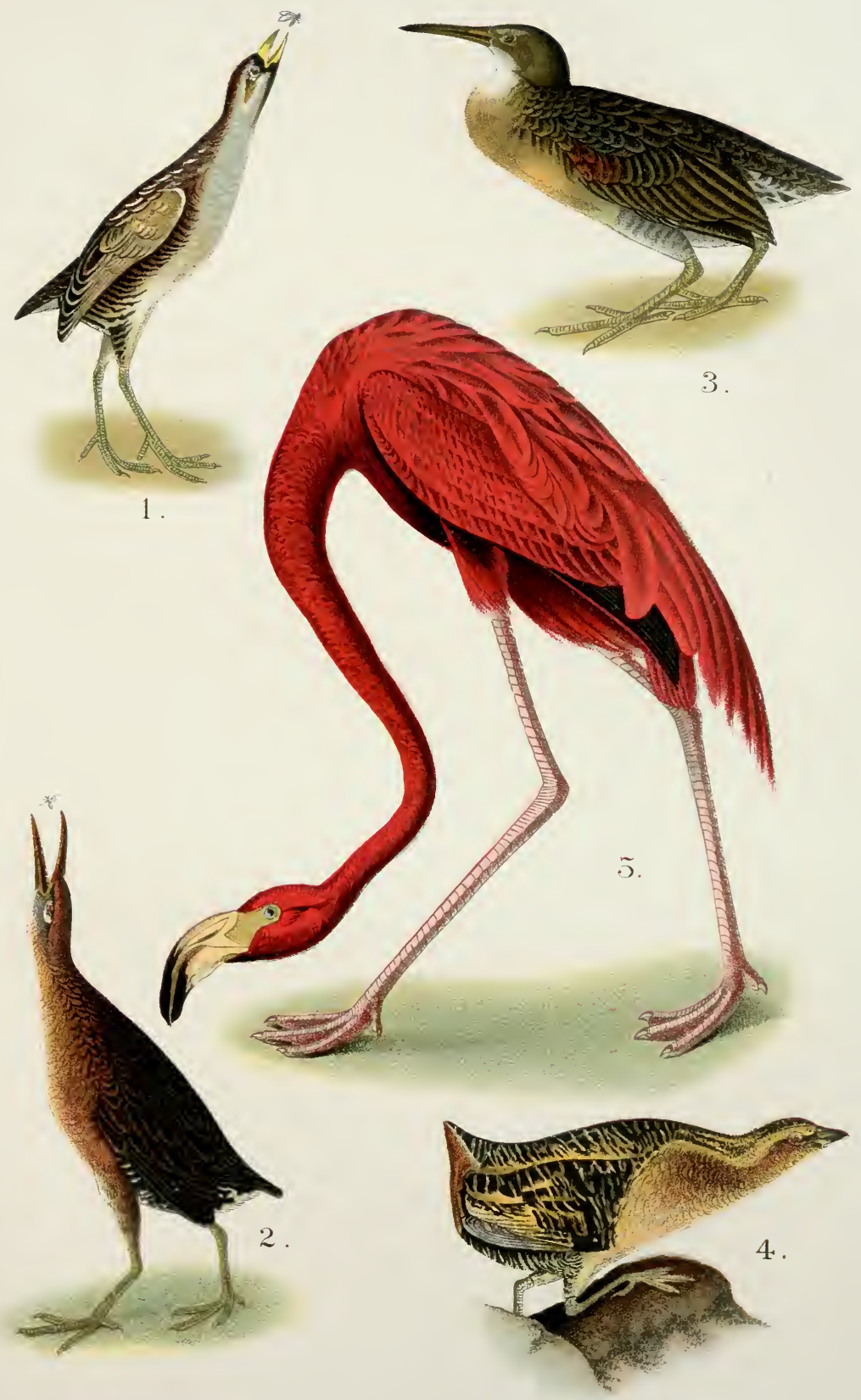

1. Sora.

3. Clapper Rail.

5. Flamingo.

2. Virginia Rail.

4. Yellow Rail. 

with the short tail erect and frequently jerked. It is never seen to perch on trees or shrubs, and is most of the time on its feet. Its flesh is scarcely inferior to that of the Common Rail, but its scarcity and diminutive size relieve it from much attention as game. Late in autumn, a little time previous to their departure, these birds occasionally wander out into the neighboring salt-marshes, situated at a distance from the sea, - a route by which in all probability they proceed in a solitary and desultory manner towards the milder regions of the South. At this time also they often roost among the reeds, by ponds, in company with the different kinds of Blackbirds, clinging, no doubt, to the fallen stalks on which they pass the night over the water. They swim and dive also with ease and elegance; but like their whole tribe of Long-Footed Birds, they are swiftest on land, and when pushed depend upon their celerity over the covered marsh as a final resort.

This Rail is a common summer visitor to the Maritime Provinces and westward to Manitoba, but rarely ranges north of the fiftieth parallel. Its breeding area extends southward to Long Island and Pennsylvania.

\section{CLAPPER RAIL.}

SALT-WATER MEADOIV HEN. MUD HEN. BIG RAIL.

\section{RALLUS CREPITANS.}

CHAR. Above, ashy gray striped with brown and tinged with olive; wings and tail brown; below, pale buff, flanks darker and barred with white; breast shaded with ash; throat white. General coloration gray without rufous tint. Bill long, slender, and decurved. Length $13 \frac{1}{2}$ to $15 \mathrm{~T} / 2$ inches.

Nest. Artfully concealed amid the rank grass of a salt-marsh, - a loosely arranged cushion of dry rushes and grass.

Eggs. 6-I3 (usually about 9); pale buff, marked with reddish brown and lavender; size extremely variable, average about I.70 $\times$ I.20.

The Clapper Rail is a numerous and well-known species in all the Middle and Southern States, but is unknown in this part of New England, or in any direction farther to the north, being unnoticed by Richardson in his "Northern Zoology." 
According to Wilson, these Rails arrive on the coast of New Jersey about the 2 oth of April, and probably winter within the southern boundaries of the Union, or in the marshes along the extensive coast of the Mexican Gulf, as they are seen by February on the shores of Georgia in great numbers. In the course of their migrations, in the hours of twilight, they are often heard on their way, in the spring, by fishermen and coasters. Their general residence is in salt-marshes, occasionally penetrating a short distance up the large rivers as far as the bounds of tide-water. In the vast flat and grassy marshes of New Jersey, intersected by innumerable tidewater ditches, their favorite breeding-resorts, they are far more numerous than all the other marsh-fowl collectively.

The arrival of the Mud Hen (another of their common appellations) is soon announced through all the marshes by its loud, harsh, and incessant cackle, heard principally in the night, and is most frequent at the approach of a storm. About the middle of May the females commence laying, dropping the first egg into a slight cavity scratched for its reception, and lined with a small portion of dry grass, as may be convenient. During the progress of laying the complement of about ten eggs, the nest is gradually increased until it attains about the height of a foot, - a precaution or instinct which seems either to contemplate the possibility of an access of the tide-water, or to be a precaution to conceal the eggs or young, as the interest in their charge increases. And indeed to conceal the whole with more success, the long sedge grass is artfully brought together in an arch or canopy; but however this art and ingenuity may succeed in ordinary cases, it only serves to expose the nest to the search of the fowler, who can thus distinguish their labors at a considerable distance. The eggs, more than an inch in breadth, and about one and three fourths in length, are of the usual oval figure, of a yellowish white or dull cream color sparingly spotted with brown red and a few other interspersed minute touches of a subdued tint bordering on lilac purple; as usual, there are very few spots but towards the obtuse end. The eggs are much 
esteemed for food, being frequently collected by the neighboring inhabitants; and so abundant are the nests in the marshes of New Jersey that a single person, accustomed to the search, has been known to collect a hundred dozen in the course of a day. Like other gregarious and inoffensive birds, they have numerous enemies besides man; and the crow, fox, and minx come in for their share, not only of the eggs and young, but also devour the old birds besides. From the pounce of the Hawk they can more readily defend themselves by dodging and threading their invisible paths through the sedge. The nature of the ground they select for their nurseries and its proximity to the sea, renders their thronging community liable also to accidents of a more extensively fatal kind; and sometimes after the prevalence of an eastwardly storm, not uncommon in the early part of June, the marshes become inundated by the access of the sea, and great numbers of the Rails perish, - at least, the females, now sitting, are so devoted to their eggs as to remain on the nest and drown rather than desert it. At such times the males, escaping from the deluge, and such of their mates as have not yet begun to sit, are seen by hundreds walking about, exposed and bewildered, while the shores for a great extent are strewed with the dead bodies of the luckless females. The survivors, however, wasting no time in fruitless regret, soon commence to nest anew ; and sometimes when their nurseries have been a second time destroyed by the sea, in a short time after, so strong is the instinct and vigor of the species that the nests seem as numerous in the marshes as though nothing destructive had ever happened.

The young of the Clapper Rail are clad, at first, in the same black down as those of the Virginian species, and are only distinguishable by their superior size, by having a spot of white on their auriculars, and a line of the same color along the side of the breast, belly, and fore part of the thigh. They run very nimbly through the grass and reeds, so as to be taken with considerable difficulty, and are thus, at this early period, like their parents, without the aid of their wings, capable of elud- 
ing almost every natural enemy they may encounter. Indeed, the principal defence of the species seems to be in the vigor of their limbs and the compressed form of their bodies, which enables them to pass through the grass and herbage with the utmost rapidity and silence. They have also their covered paths throughout the marshes, hidden by the matted grass, through which they run like rats, without ever being seen; when close pressed, they can even escape the scent of a dog by diving over ponds or inlets, rising and then again vanishing with the silence and celerity of something supernatural. In still pools this bird swims pretty well, but not fast, sitting high on the water with the neck erect, and striking with a hurried rapidity indicative of the distrust of its progress in that element, which it immediately abandons on approaching the leaves of any floating plants, particularly the pond-lilies, over whose slightly buoyant foliage it darts with a nimbleness and dexterity that defies its pursuers, and proves that however well it may be fitted for an aquatic life, its principal progress, and that on which it most depends when closely followed, is by land rather than in the air or the water. When thus employed, it runs with an outstretched neck and erected tail, and, like the wily Corn Crake, is the very picture of haste and timidity. On fair ground these birds run nearly as fast as a man. When hard pushed they will betake themselves sometimes to the water, remaining under for several minutes, and holding on closely to the roots of grass or herbage with the head downwards, so as to render themselves generally wholly invisible. When roused at length to flight, they proceed almost with the velocity and in the manner of a duck, flying low and with the neck stretched; but such is their aversion to take wing, and their fondness for skulking, that the marshes in which hundreds of these birds dwell may be crossed without one of them ever being seen; nor will they rise to a dog till they have led him into a labyrinth and he is on the very point of seizing them.

The food of the Clapper Rail consists of various insects, small univalve shell-fish, and crustacea (minute crabs, etc.). Its flesh is dry, tastes sedgy, and is far inferior in flavor to 
that of the Common Rail or Sora. Early in October these birds retire to the South, and probably migrate in the twilight or by the dawn of morning.

The Clapper Rail is abundant along the Atlantic coast north to Long Island. It occurs occasionally on the Connecticut shores, but is merely an accidental wanderer within the Massachusetts boundaries, and but one example has been reported north of Boston Harbor, - captured near Portland, Maine, some years ago. Its breeding range extends from Connecticut to the Gulf States, and it is found in winter throughout the Southern States.

Note. - The Louisiana Clapper Rail ( $R$. crepitans saturatus) was discovered by $\mathrm{Mr}$. H. W. Henshaw and described in I880. It is a smaller bird than the type, - length about thirteen inches, - and is of brighter-colored plumage. The brown of the upper parts is of a richer tint and is more deeply tinged with olive: while the breast wears a richer shade of brown. The bird has been found on the coast of Louisiana only.

ScotT's RAIL, as it was named by Mr. Sennett, the describer, or Florida Clapper Rail, as it will be booked probably ( $R$. scottii), was discovered in I886. It is the darkest of the group, - very dark brown or nearly black above, and lower parts brown. The bird appears to be sedentary on the west coast of Florida, and has been taken nowhere else. 


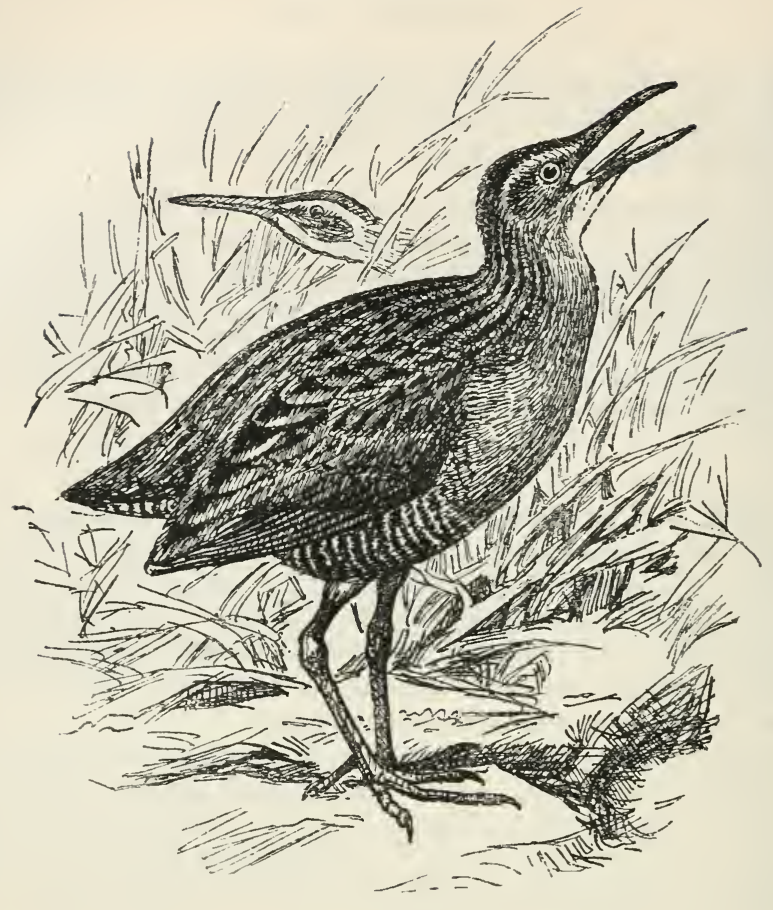

KING RAIL.

RED-BREASTED RAIL. FRESHIVATER MARSH HEN.

Rallus ELEgans.

CHAR. Upper parts rich olive brown of varying shades, - sometimes with a yellow tinge, - striped with black; crown dark brown; a line of cinnamon over the eyes, and a line of dusky through the eyes ; wings brown, of varying shades; under parts deep cinnamon, darkest on the breast, fading to dull white on throat and belly; sides and flanks brown or dusky, with broad stripes of white. Length 17 to 19 inches.

Nest. Hid amid a tuft of rank grass in a fresh-water marsh; placed on the ground, though sometimes fastened to the grass and weeds that surround it; made of grass and weed stems.

Eggs. 6-12; ground color varies from pale buff to creamy white, marked, sparingly, with reddish brown or purplish brown and lilac; size variable, average about $1.70 \times 1.20$. 
Nuttall must have confounded the present species with the Clapper Rail, for he makes no mention of the King Rail. Wilson figured the bird, but gave no description of its plumage or habits, and the first account of the species was given by Audubon in 1835 .

The King Rail is not so widely dispersed, nor is it so abundant, as most of its congeners; but some writers have been in error in representing its distribution as exceedingly limited. It occurs regularly throughout the Southern and Middle States, and is plentiful in Ohio, Illinois, Wisconsin, and Ontario. In New England the bird has been seen but rarely, though examples have been taken in Connecticut, Massachusetts, and Maine. I have examined in the flesh one that was shot near St. John, N. B.

In habits our bird is very similar to the Clapper Rail, differing chiefly in its preference for a marsh that is drained by a sluggish stream of fresh water.

\section{SORA.}

CAROLINA RAIL. CAROLINA CRAKE. COMMON RAIL.

PORZANA CAROLINA.

CHAR. Above, olive brown varied black and gray; front of head, stripe on crown, and line on throat, black; side of head and breast ashy gray or slate; sides of breast spotted with white; flanks barred slate and white; belly white. Bill short and stout. Length 8 to $9 \frac{1}{2}$ inches.

Nest. In a wet meadow or reedy swamp, sometimes in a salt-water marsh; a rude structure of loosely arranged grass weed stems and rushes hid in a tussock of rank grass or coarse sedges.

Eggs. 6-I4 (usually 8); dark buff or yellowish drab, often tinged with olive, spotted with reddish brown and lilac; 1.20 $\times 0.90$.

The Sora, or Common Rail, of America, which assemble in such numbers on the reedy shores of the larger rivers in the Middle and adjoining warmer States at the approach of autumn, and which afford such abundant employ to the sportsman at that season, like most of the tribe to which it belongs is a bird of passage, wintering generally south of the limits of the Union. These Rails begin to make their appearance in the marshes of Georgia by the close of February; and on the $2 \mathrm{~d}$ of May Wilson observed them in the low watery meadows below Philadelphia. In the remote fur countries of the North 
up to the $62 \mathrm{~d}$ parallel they are common through the summer, and were observed by Dr. Richardson to be particularly abundant on the banks of the small lakes that skirt the Saskatchewan plains. In the vast reedy marshes, swamps, and lagoons of these desolate regions the greater part of the species are no doubt reared, as but few of them are ever known to breed in the warmer parts of the continent; and the history of their manners at the period of incubation is therefore still a blank. The observations of persons not conversant with the nice distinctions necessary in natural history ought to be received with caution, as they might easily confound the mere young of the present and the preceding species as one and the same. The alleged nest, eggs, and young birds covered with a black down mentioned by Wilson agree perfectly with the Virginian Rail ; but the length of the bill and any other discriminating particulars are wholly omitted. We may conclude, therefore, up to the present time that the actual young and nest of the Soree are yet unknown, and that all which has been said on this subject is but conjecture or a misapplication of facts belonging to the preceding species.

Like the other migrating waders, the Rails, accompanied by their swarming broods, bred in the North and West, begin to show themselves on the reedy borders of the Delaware and other large waters of the Middle States, whose still and sluggish streams, spreading out over muddy flats, give birth to an abundant crop of the seeds of the Wild Rice, now the favorite food of the Rails and the Rice Birds. On first arriving from the labor and privation incident to their migrations, they are lean, and little valued as food; but as their favorite natural harvest begins to swell out and approach maturity, they rapidly fatten, and from the middle of September to the same time in October they are in excellent order for the table, and eagerly sought after wherever a gun can be obtained and brought into operation.

Walking by the borders of these reedy rivers in ordinary seasons, you hear in all directions the crowding Rails squeaking like young puppies. If a stone be thrown in amongst them, there is a general outcry through the reeds; a confused and 
reiterated 'kuk'kuk 'kuk' $k$ ' $k$ ' $k$ ' $k$, resounds from the covered marsh, and is again renewed by the timid throng on the discharge of a gun or any other sudden noise within their hearing. The Rails, however numerous, are scarcely visible, unless it be at or near to high water; for when the tide is down they have the art so well to conceal themselves among the reeds that you may walk past and even over them, where there are hundreds, without seeing probably a single individual.

The flight of the Rails while confined among the Rice Reeds is low, feeble, and fluttering, with the legs hanging down as if the effort were unnatural and constrained, - which may, no doubt, at times be produced by the extreme corpulency which they attain in a favorable season for food; yet occasionally they will rise to a considerable height, and cross considerable streams without any reluctance or difficulty; so that however short may be their wings, the muscles by which they are set in motion are abundantly sufficient to provide them the means of pursuing the deliberate stages of their migratory course. Wherever the Zizania and its nutritious grain abounds, there the Rails are generally seen. In the reedy lakes of Michigan as well as the tide-water streams of the Atlantic these birds are found congregated in quest of their favorite food. In Virginia they are particularly abundant along the grassy banks of James River within the bounds of tide-water, where they are often taken in the night while perched among the reeds; being stupefied by the glare of a fire carried in among them, they are then easily approached by a boat, and rudely knocked on the head with a paddle, - sometimes in such quantities that three negroes in as many hours have been known to kill from twenty to eighty dozen.

Fear seems to be a ruling passion among the whole tribe of Rails and their kindred allies. With faculties for acting in the day, timidity alone seems to have rendered them almost nocturnal in their actions; their sole address and cunning seems entirely employed in finding out means of concealment. This is particularly the case when wounded; they then swim out and dive with so much caution as seldom to be seen again 
above water. They even cling with their feet to the reeds beneath that element, where they would sooner endure suffocation than expose themselves with any chance of being seen; they often also skulk on ordinary occasions under the floating reeds, with nothing more than the bill above water. At other times when wounded they will dive, and rise under the gunwale of the sportsman's boat, and secreting themselves there, have the cunning to go round as the vessel moves until, given up as lost, they find an opportunity of completing their escape.

According to the observations of Mr. Ord, the females more particularly are sometimes so affected by fear or some other passion as to fall into sudden fits and appear stretched out as lifeless, recovering after a while the use of their faculties, and falling again into syncope on merely presenting the finger in a threatening attitude. At such times and during their obstinate divings they often fall victims, no doubt, to their enemies in the watery element, as they are sometimes seized by eels and other voracious fish, who lie in wait for them; so that the very excess of their fear and caution hurries them into additional dangers, and frustrates the intention of this instinct for preservation. The swooning to which they appear subject is not uncommon with some small and delicate irritable birds, and Canaries are often liable to these death-like spasms, into which they also fall at the instigation of some immaterial or trifling excitement of a particular kind.

During the greater part of the months of September and October, the market of Philadelphia is abundantly supplied with this highly esteemed game, and they are usually sold at from fifty cents to a dollar the dozen. But soon after the first frosts of October or towards the close of that month, they all move off to the South. In Virginia they usually remain until the first week in November. In the vicinity of Cambridge (Mass.), a few, as a rarity, only are now and then seen in the course of the autumn in the Zizania patches which border the outlet of Fresh Pond; but none are either known or suspected to breed in any part of this State, where they are, as far as I can learn, everywhere uncommon. 
The usual method of shooting Rail on the Delaware, according to Wilson, is as follows. The sportsman proceeds to the scene of action in a batteau with an experienced boatman, who propels the boat with a pole. About two hours before high water they enter the reeds, the sportsman taking his place in the bow ready for action, while the boatman on the stern seat pushes the craft steadily through the reeds. The Rails generally spring singly as the boat advances, and at a short distance ahead are instantly shot down, while the boatman, keeping his eye on the spot where the bird fell, directs the vessel forward, and picks up the game as the gunner is loading. In this manner the boat continues through and over the wild-rice marsh, the birds flushing and falling, the gunner loading and firing, while the helmsman is pushing and picking up the game, which sport continues till an hour or two after high water, when its shallowness and the strength and weight of the floating reeds, as also the unwillingness of the game to spring as the tide decreases, oblige them to return. Several boats are sometimes within a short distance of each other, and a perpetual cracking of musketry prevails along the whole reedy shores of the river. In these excursions it is not uncommon for an active and expert marksman to kill ten or twelve dozen in the serving of a single tide.

We now know that the Sora breeds abundantly in Wisconsin and the northern portions of Illinois, Indiana, and Ohio, as well as in the more Eastern States. It is probable that the southern limit of its breeding area is in the vicinity of latitude $42^{\circ}$, while its northern range does not extend beyond the $62 \mathrm{~d}$ parallel. The birds winter in the West Indies and northern South America. 


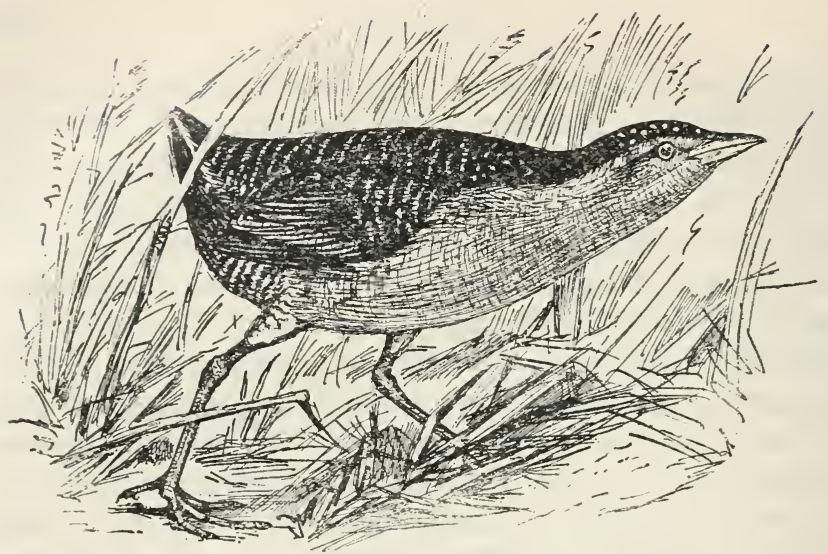

YELLOW RAIL.

CRAKE.

Porzana NOVEBORACENSIS.

CHAR. Above, brownish buff, varied with black and white ; tail black; below, buff, pale on the belly, deepest on the breast; flanks dusky, barred with dull white; under tail-coverts rufous. Length 6 to $7 \frac{1}{2}$ inches.

Nest. In a marsh or reedy margin of a stream or pond; a loosely constructed affair of grass and weed stems, hid in a bunch of sedges or reeds.

Eggs. 5-9 (usually about 6); deep buff or creamy, spotted at the larger end with reddish brown; $1.10 \times 0.85$.

The Yellow-breasted Rail, though found sparingly in many parts of the Union and in Canada, is everywhere rare. It has been met with, apparently, as a mere straggler in the vicinity of New York and Philadelphia in the depth of winter, and has likewise been seen in Missouri, probably on its spring passage towards the North. Where it winters, whether in the Southern States or in still milder climes, is yet unknown.

Mr. Hutchins says, "This elegant bird is an inhabitant of the marshes" on the coast of Hudson Bay, near the mouth of Severn River, "from the middle of May to the end of September. It never flies above sixty yards at a time, but runs with great rapidity among the long grass near the shores. In the morning and evening it utters a note which resembles the 
striking of a flint and steel; at other times it makes a shrieking noise." It is evident, therefore, that the Yellow-breasted Rail is principally a Northern species, which migrates mostly through the western interior of the continent, and is therefore very rare in the Atlantic States.

Like all the other species, the present inhabits swamps, marshes, and the reedy margins of ditches and lakes. In the vicinity of West Cambridge, and throughout the vast extent of wet marsh-land which stretches over the face of the country, and is but rarely visited by man, among the Virginia Rails and a few stragglers of the Sora we occasionally meet with this small and remarkable species. The first individual ever brought to me, late in autumn, was surprised, while feeding on insects or seeds, by the margin of a small pool overgrown with the leaves of the water-lily (Nymphaa odorata). Without attempting either to fly or swim, it darted nimbly over the floating leaves, and would have readily escaped, but for the arrest of the fatal gun, which baffled its cunning and precaution. When wounded, this bird also swims and dives with great address.

On the 6 th of October, I 83 , having spent the night in a lodge on the borders of Fresh Pond, employed for decoying and shooting ducks, I heard about sunrise the Yellow-breasted Rails begin to stir among the reeds (Arundo phragmitis) that thickly skirt this retired border of the lake, and in which, among a host of various kinds of Blackbirds, they had for some time roosted every night. As soon as awake, they called out in an abrupt and cackling cry, 'krèk, 'krèk, 'krèk, 'krèk, kük ' $k$ ' $k h$, which note, apparently from the young, was answered by the parent (probably the hen), in a lower soothing tone. The whole of these uncouth and guttural notes have no bad resemblance to the croaking of the tree-frog, as to sound. This call and answer, uttered every morning, is thus kept up for several minutes in various tones, till the whole family, separated for the night, have met and satisfactorily recognized each other. These are, no doubt, migrating broods who have arrived from the North about the time stated for their departure by Mr. 
Hutchins. By the first week in November their cackling ceases; and as they seem to migrate hither without delay, and with great expedition for a bird with such short wings, it is probable they proceed at once to the swamps of the Southern States.

This species is not as abundant as either the Virginia Rail or the Sora, but it is not so rare as many writers have supposed. It is such a skulker and hides so quickly that it generally escapes observation even when close at hand. The bird is a summer resident of New England and the Maritime Provinces, and has been taken in the Hudson Bay district. It is quite common in Ohio, and has been found nesting in Illinois. It winters in the Southern States.

\section{BLACK RAIL.}

\section{Porzana janiaicensis.}

CHAR. Head, neck, and lower parts dark slate or dusky; back rich brown; wings and tail brownish black, marked with white; belly and flanks barred with white. Length about 5 inches.

Nest. In a wet meadow or reedy marsh, hid amid the rank grass; a compactly made, deep cup of grass and weed stems.

Eggs. 8-10; dull white or creamy, marked all over with fine spots of reddish brown; $1.00 \times 0.80$.

This, the smallest of our Rails, was not mentioned by Nuttall, though it had been discovered long before his time, and was given by Audubon. It has always been considered a rare bird, being seldom found on the Atlantic coast, and only a few examples being seen north of New Jersey - in Connecticut and Massachusetts. In the western division of this Eastern Province it is more common, and goes somewhat farther north; a number of nests having been taken in northern Illinois. In habits this species does not differ materially from its congeners.

Note. - The Spotted Crake (Porzana porzana), an Old World species, occasionally visits Greenland.

The CORN CRAKE, or LANd RaIl (Crex crex), also an Old World species, occurs regularly in Greenland, and has been taken on Long Island and Bermuda. 


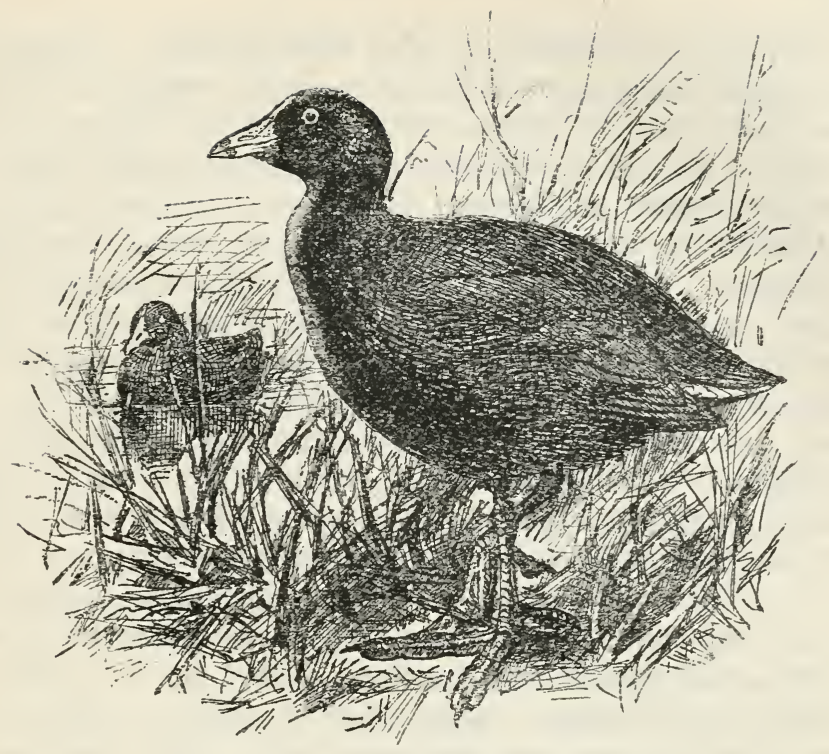

AMERICAN COOT.

COOT. MUD HEN. MARSH HEN. MEADOW HEN. MOOR HEN. CROW DUCK.

\section{Fulica americana.}

CHAR. General plumage dark slate, shading to dull black on the head, and to gray on the belly; edge of the wings and tips of the secondaries white; frontal shield and spots on the bill dark brown; feet greenish, toes with conspicuous lobes or "flaps." Length from I3 to I6 inches. The "frontal shield" is a horny plate which extends from the bill over the forehead. It is one distinguishing character of the Coots and Gallinules.

Nest. Amid the reeds or rank grass on the margin of a secluded pond or sluggish stream, sometimes on a knoll near the water, attached to the reeds, often floating on the water; a bulky affair of loosely arranged reeds or sedge-stems, scantily lined with grass, and placed on a high platform. This platform sometimes rests on the tops of the surrounding reeds, which are bent down to receive it.

Eggs. 6-15 (usually about 10); pale buff, profusely spotted with dark brown and lilac; size very variable, average about $1.90 \times \mathbf{1 . 4 0}$. 
The Coot of America, so very similar to that of Europe, according to the season is found in almost every part of the continent, from the grassy lakes that skirt the Saskatchewan plains, in the $55^{\text {th }}$ parallel, to the reedy lagoons of East Florida and the marshes of Jamaica. To the west, the species seems to inhabit the waters of the Columbia, in the remote Territory of Oregon. Mr. Say observed it also in the lower part of Missouri, and in Long's Expedition it was seen in Lake Winnipeg on the 7 th of June. Mr. Swainson has also received specimens from the distant tableland of Mexico. We may therefore conclude almost with certainty that the Coot of America, indifferent to climate, dwells and breeds in every part of the North American continent, over a range of probably more than fifty degrees of latitude! Nocturnal in their habits, and dispersing themselves far and wide over every watery solitude, these birds seem in many places to have disappeared for the season, until they in large numbers, swelled by their prolific broods, and impelled at the approach of winter to migrate for food, now begin to show themselves in the lakes, pools, and estuaries in the vicinity of the sea, from which they gradually recede towards the South as the severity of the season compels them, being unable to subsist amidst the ice. In this way they proceed, accumulating in numbers as they advance, so that in the inundated and marshy tracts of Florida, particularly along the banks of the St. Juan, they are seen in winter, congregated in vast and noisy flocks. In the milder latitudes, their whole migrations will be limited to a traverse from the interior to the vicinity of the sea, while those which visit the wilderness of Upper Canada, where they are abundant in the summer, will probably migrate from twenty-five to thirty degrees every spring and autumn.

The Coots arrive in Pennsylvania about the beginning of October. They appear in Fresh Pond, Cambridge, about the first week in September. A pair took up their residence in this small lake about the $5_{5}$ th of April; and in June they are occasionally seen accompanied by their young. The nest, eggs, and manners during the period of reproduction are yet 
unknown. Timorous and defenceless, they seek out the remotest solitudes to breed, where, amidst impassable bogs and pools, the few individuals which dwell in the same vicinity are readily overlooked and with difficulty discovered, from the pertinacity of the older birds in hiding themselves wholly by day. It is therefore only when the affections and necessities of the species increase that they are urged to make more visible exertions, and throw aside, for a time, the characteristic indolence of their furtive nature. We now see them abroad, accompanied by their more active and incautious offspring, night and morning, without exhibiting much timidity, the young sporting and feeding with careless confidence in their fickle element. They are at this time easily approached and shot, as they do not appear to dive with the same promptness as the European species.

The old birds, ever watchful and solicitous for their brood, with which they still appear to associate, when alarmed utter at times a sort of hoarse ' $k r u k$, which serves as a signal either to dive or swim away. At this season of the year Mr. N. Wyeth informs me that he has heard the Coot repeatedly utter a whizzing sound, which he can only compare to the plunge of large shot when fired into water. It might possibly be the small and bouncing leaps with which the associated young of the common species amuse themselves at almost all hours of the day. In East Florida, where they appear, according to Bartram, to assemble and breed in great numbers, they are very chattering and noisy, and may be heard calling on each other almost night and day. With us they are, however, very taciturn, though tame, and with many other birds appear to have no voice but for the exciting period of the nuptial season.

The Coots of Europe have many enemies in the predacious birds which surround them, particularly the Moor Buzzard, which not only destroys the young, but sucks the eggs to such an extent that notwithstanding their great prolificacy, they laying from twelve to eighteen eggs, the numbers are so thinned by depredation that not above one tenth escape the talons of 
rapacious species. Indeed, it is only the second hatch, of about eight eggs, more securely concealed among the flags on the margins of pools, that ever survive to renew the species. The nest, secreted in this manner among the rank herbage, is placed on the surface of the water, but raised above it by piling together a quantity of coarse materials, in order to keep the eggs dry. In this buoyant state a sudden gale of wind has been known to draw them from their slender moorings, and nests have thus been seen floating on the water, with the birds still sitting upon them, as in the act of navigating over the pool on which they had resided. The female is said to sit twentytwo or twenty-three days; the young, now covered with a black down, quit the nest as soon as they are hatched, and are then cherished under the wings of the mother, and sleep around her beneath the reeds; she also leads them to the water, in which they swim and dive from the moment of their liberation from the shell.

When closely pursued in the water, the Coot sometimes makes for the shore, and from the compressed form of its body, though so awkward in its gait, can make considerable progress through the grass and reeds. When driven to take wing on the water, it rises low and with reluctance, fluttering along the surface with both the wings and feet pattering over it, for which reason, according to Lawson, in his "History of Carolina," they had in that country received the name of Flusterers.

The food of the American Coot, like that of the other species, is chiefly vegetable; it lives also upon small fluviatile shells and aquatic insects, to all which it adds gravel and sand, in the manner of common fowls. A specimen which I examined on the Igth of September had the stomach, very capacious and muscular, filled with tops of the water milfoil (Myriophyllum verticillatum), and a few seeds or nuts of a small species of bur-reed (Sparganium). From the contents of the intestines, which were enormous, aquatic vegetables appeared now to be their principal food.

In the month of November the Coot leaves the Northern and Middle States, and retires by night, according to its usual 
habits, to pass the winter in the warmer parts of the Union, and probably extends its journeys along all the shores of the Mexican Gulf.

The Coot is still a common bird throughout the temperate portions of North America, and examples have been taken in Greenland and Alaska. It winters in the Southern States and southward through the West Indies and Central America.

Note. - The European Cоот (Fulica atra) has been taken in Greenland.

\section{PURPLE GALLINULE.}

\section{IONORNIS MARTINICA.}

CHAR. Back bright olive; wings of deeper green and shaded with blue; head, neck, and breast rich bluish purple; belly darker; frontal shield blue; bill red, tipped with yellow; legs yellow. Length about I $31 / 2$ inches.

Nest. In a marsh; fastened to rank grass or reeds, and hidden by the stems to which it is attached, - made of dried and fresh grass and reeds loosely arranged.

Eggs. 7-12 (usually about 9); pale buff or creamy, spotted chiefly around the larger end with reddish brown and lavender; $1.70 \times 1.15$.

This very splendid but incongruous species of Gallinule is in the United States a bird of passage, wintering in tropical America, and passing the summer, or breeding-season, in the marshes of Florida and the contiguous parts of the State of Georgia, where it arrives in the latter part of April, retiring south with its brood in the course of the autumn, and probably wintering, according to its habits, in the swampy maritime districts along the coast of the Mexican Gulf. An instance is given by Mr. Ord of one of these birds being driven out to sea and taking shelter on board of a vessel bound from New Orleans to Philadelphia, while in the Gulf. This happened on the $24^{\text {th }}$ of May, and therefore could only have been a bewildered straggler accidentally carried out to sea without any intention of migrating; nor is it probable that a bird of such 
short wings as those which characterize the genus would make the attempt to travel any considerable distance over sea while a route by land equally favorable for the purpose offered. Little reliance, therefore, is to be placed upon these accidents as proving the maritime migratory habits of birds. Several hundred miles from land, towards the close of last June (1833), in the latitude of the Capes of Virginia, the vessel in which I was sailing for the port of New York was visited by two or three unfortunate Swallows, who, overcome by hunger and fatigue, alighted for a while on the rigging of our ship, whence they, in all probability, proceeded farther out to sea and perished. At this season of the year they could not be migrating, but had wandered out upon the barren bosom of the deceiving ocean, and would, in consequence of exhaustion and famine, soon after fall a prey to the remorseless deep.

The Martinico Gallinule while in the Southern States frequents the rice-fields, rivulets, and fresh-water pools in company with the more common Florida species. It is a vigorous and active bird, bites hard when irritated, runs with agility, and has the faculty, like the Sultanas, of holding on objects very firmly with its toes, which are extremely long, and spread to a great extent. When walking, it jerks its tail like a common Gallinule. In its native marshes it is very shy and vigilant; and continually eluding pursuit, can be flushed only with the aid of a dog.

This richly apparelled and beautiful bird is found regularly and is quite common in all the Southern and Gulf States, and stragglers are frequently seen northward to New England and westward to Wisconsin. The only examples reported from Canada have been taken in Nova Scotia and New Brunswick. These birds do not leave the United States in winter, as Nuttall supposed; they are found in the South throughout the year.

They are called "Sultanas" in Jamaica, where Mr. Gosse found them quite common; and this writer states that those he saw were extremely indifferent to his approach, allowing him to walk to within a few feet of where they were feeding, without manifesting any fear.

Audubon states that after the brood is hatched the family retires 
from the vicinity of the pools and streams to the interior of the savannas; but towards autumn they return again to the margins, and at this later season they became shy and more vigilant.

These birds partake of a variety of food, their favorite diet being a mixture of water-snails and plantains.

\section{FLORIDA GALLINULE.}

COMMON GALLINULE. RED-BILLED MUD HEN. WATER HEN.

\section{Gallinula galeata.}

CHAR. Uniform grayish black, the back tinged with olive brown, the belly paler than the breast; flanks striped with white; bill and frontal shield bright red, the bill tipped with yellow; legs greenish. Length about $13 \frac{1}{2}$ inches.

Nest. In a swamp or marsh, - a bulky and clumsily arranged affair of reeds or flags scantily lined with coarse grass. The nest is sometimes placed on a platform made by bending down the tops of the surrounding flags or rushes, or it is fastened to the stems of the flags or to the branches of a bush. Occasionally a nest is found suspended over the water upon which it floats as the tide rises, but usually the chosen situation is on a dry knoll.

Eggs. 7-I3; ground color varies from brownish buff to creamy, spotted with dark brown; size variable, average about $1.85 \times 1.25$.

This species of Gallinule, so closely related to that of Europe, is common in Florida, in the Antilles, in Jamaica, Guadaloupe, and the isle of Aves, where it has to dispense with the use of fresh water. It is seen frequenting pools, lagoons, and streams, and extends over a great portion of the continent of South America. In the Middle and Northern States of the Union it appears to be quite accidental, though as a straggler it has been seen and shot as far north as Albany, in the State of New York. Its range to the north is therefore much more limited than its European analogue. Its voice is uncouth, but sonorous, and its cry or call resembles ' $k a$, ' $k a$, ' $k a$ ! $\mathrm{Mr}$. Audubon met with this species in great numbers in Florida towards the source of the St. John's in the month of March.

This species is unknown in Canada or the northern parts of America. 
Either this bird has increased the limit of its range since Nuttall stalked our marshes, or the modern bird-hunter is provided with increased power of observation, keener vision, and more accurate perception, for recent reports concerning the distribution of the Gallinule differ considerably from Nuttall's account.

It is true the Florida Gallinule is at home in the tropical portions of the continent, but it occurs regularly and in numbers throughout the warm temperate area north to New England and Canada, and west to the Mississippi valley. It is quite common on Cape Cod, and nests have been found near Fresh Pond, Cambridge, and in Vermont.

A few stragglers only have visited the Maritime Provinces; but the bird breeds in numbers in Ontario, and is not uncommon around Ottawa and Montreal. In Illinois and Wisconsin it is quite common. But it is a shy and retiring bird, leaving its haunts amid the rank marsh-grass and the rushes only when impelled by the migratory instinct, and then the bird steals off under cover of the darkness.

In an interesting contribution to "The Auk," Mr. Brewster tells us that the movements of this Gallinule when walking or swimming is peculiarly graceful, but when on the wing its appearance is ludicrously awkward.

The notes of the bird are numerous and of great variety of tone and compass, varying from a harsh scream to a low hen-like cluck. "Speaking generally," writes Mr. Brewster, "the notes were all loud, harsh, and discordant, and nearly all curiously hen-like." He adds, "I certainly know of no other bird which utters so many different sounds." Some of the notes are like a drawling keé-ar-r, kreé-ar-r; or more rapidly uttered they produce a sound like $k r-r-r-r-r$, and are varied with kruc-kruc, or a low kloc-kloc. At times a note like ticket-ticket-ticket-ticket is heard, and again a single abrupt explosive kup like the cry of a startled frog. 


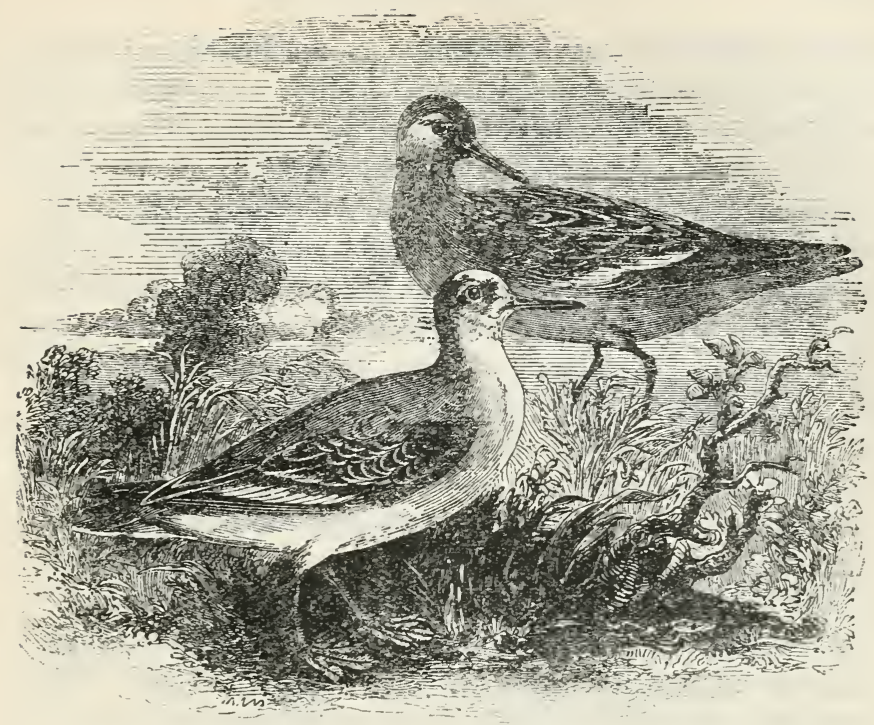

RED PHALAROPE.

GRAY PHALAROPE. SEA GOOSE. WHALE BIRD.

Crymophilus fulicarius.

Char. Female in summer: above, black, the feathers of the neck and back with a rufous or buff margin; wings gray, tipped with white; cheeks white ; bill orange ; under parts reddish chestnut ; legs and feet yellow ; toes lobed. Male: duller, white on cheek less defined, and head streaked with rufous or buff. In winter the rufous tints disappear and the plumage of the upper parts becomes gray and the under parts white, while the bill turns black. Length about $8 \frac{1}{4}$ inches.

Nest. On a knoll in the spongy margin of a pond or saline pool, - a slight depression in the peat or moss, scantily lined with grass, moss, or leaves.

Eggs. 3-4; olive buff or sea green, spotted with dark brown and purplish brown; $1.25 \times 0.90$.

The Flat-Billed or Red Phalarope inhabits the whole Arctic Circle during summer, where, in the security of solitude, it passes the important period of reproduction. It is observed 
in the north and east of Europe, in abundance in Siberia, upon the banks of lakes and rivers, and it extends its vernal migrations to the borders of the Caspian. These birds abound in the hyperboreal regions of America, breeding on the North Georgian Islands and on the remote and wintry coasts of Melville Peninsula. The late enterprising and scientific northern navigators, on the roth of June, in the latitude of 68 degrees, saw a company of these daring little voyagers out at sea, four miles from land, swimming at their ease amidst mountains of ice. They are seen also by mariners between Asia and America. According to Mr. Bullock, Red Phalaropes are found common in the marshes of Sunda and Westra, the most northerly of the Orkney Isles, where they pass the breeding-season, and are there so tame, and so little alarmed by the destructive arts of man, as to suffer the report of a gun without fear, so that Mr. Bullock killed as many as nine of them without moving from the spot where he made the first discharge. When swimming in pools, this bird is seen continually dipping its bill into the water, as if feeding on some minute insects, and while thus engaged it will often allow of a very near approach. When disturbed these birds fly out a short distance only, like the Dunlins. Sometimes, though rarely, they are seen to approach the shore or the land in quest of food; but their proper element is the water, and more particularly that of the sea or saline pools.

The Flat-Billed Phalarope breeds around Hudson Bay in the month of June, soon after its arrival from its tropical winter quarters; for this purpose, it selects some dry and grassy spot, wherein it lays about four eggs of an oil-green color, crowded with irregular spots of dark umber-brown, which become confluent towards the obtuse end. The young take to wing in July or early in August, and they leave the inclement shores of their nativity in the month of September. At this period, as well as in the spring, a few stragglers visit the United States, where individuals have been occasionally shot in the vicinity of Philadelphia and Boston. These and other species are also seen in the autumn about Vera Cruz, where they are 
sold with other game in the market. Their visits in England and Germany are equally rare as in the United States, and individuals have been known sometimes to stray into Switzerland, having been shot on the Lake of Geneva.

These interesting birds breed in the high Arctic regions and winter south to the shores of the Middle States. They are usually found on the sea or along the coast; but a number have been seen on the Great Lakes, and occasional examples have wandered to the Ohio valley.

Explorers have met with large numbers of these birds on the borders of the Arctic Ocean, and it is probable that few of them breed south of latitude $65^{\circ}$. They are exceedingly abundant in the Bay of Fundy during the migrations, and Mr. Boardman thinks a few pairs have nested in that vicinity. The nests were not discovered, but young birds were seen.

Among some peculiarities of the habits of this bird is the female's preference for conducting the courtship, which she carries on in a vigorous fashion of her own. After capturing her lord,- or, to be more exact, subduing her slave, - the female takes her ease, while the male attends to the domestic affairs and hatches the eggs. The female is much the handsomer of the two, and is also larger.

\section{NORTHERN PHALAROPE.}

\section{RED-NECKED PHALAROPE. SEA GOOSE.}

\section{PhalaRopus LOBATUS.}

CHAR. Above, dark ash, paler on the head and rump, the back striped with rufous or buff; wings dusky with a white bar; tail brownish gray; chin white; breast and sides of neck chestnut; beneath, white; bill black, slender, and tapering; legs greenish. Length about $7 \frac{1}{2}$ inches.

In winter the prevailing color is grayish, the forehead and crown mostly white, and a line of dusky through the eyes.

The male is smaller than the female and of duller plumage, the rufous tint less conspicuous, and the colors less defined.

Nest. In a swamp or bog on the margin of a pool, - a slight depression in the peat scantily lined, and concealed amid a tuft of grass.

Eggs. 3-4; pale olive buff or sea-green, thickly covered by spots of dark brown; average size about $1.20 \times 0.80$.

The geographical range of the Hyperborean Phalarope, as its name implies, is nearly, if not quite, similar with that of the 
preceding species. In summer it dwells and breeds generally within the Arctic Circle in both continents. It penetrates into Greenland, Iceland, and Spitzbergen, is abundant in the north of Scotland, in the Orkneys and Hebrides, is equally prevalent in Lapland, on the northern coasts of Siberia, and between Asia and America, a transient visitor on the shores of the Baltic, and seen only accidentally in Germany and Holland. It sometimes, though very rarely, penetrates inland as far as the lakes of Switzerland, and in its natal regions visits lakes of fresh as well as salt water. At the period of their migrations, in May and August, these birds betake themselves to the open sea, particularly in autumn, and are then gregarious, assembling in flocks; at other times they are seen in pairs, and, like the preceding, have a constant habit of dipping the bill into the water, as if in the act of collecting the minute mollusca which may be floating in it. They are also often seen on the wing, and are said by Willoughby to utter a shrill, clamorous cry, or twitter, resembling that of the Greater Tern.

In Arctic America, where this Phalarope resides in the mild season, it is seen to seek out shady pools, in which it swims with peculiar ease and elegance, its attitudes much resembling those of the Common Teal.

These birds arrive to breed around Hudson Bay about the beginning of June, and old and young are seen to frequent the sea-coast previous to their departure, which takes place often soon after the middle of August, on the 16 th or 17 th of which they are occasionally killed in different parts of Massachusetts Bay and near Newport in Rhode Island. They likewise probably pay a transient visit to the coast of New Jersey, as they do also, at times, to Long Island, and finally repair to the mild shores of the Mexican Gulf, being seen in the markets of Mexico and Vera Cruz. Migrating probably by sea and outside of the land, they but rarely visit the coast in any part of the United States. Straggling families of the old and young are met with in the vicinity of Boston nearly every year about the beginning of May and the middle of August, commonly in salt-water pools near the sea, and, as usual, they 
are seen perpetually dipping their bills into the water, or with a reclined neck swimming and turning about in their favorite element, with all the ease and grace of a diminutive swan. In Iceland Hyperborean Phalaropes arrive about the middle of May; and waiting the complete thawing of the ice, they are seen, for a time, assembled in flocks out at sea several miles from the shore. 'This gregarious association breaks up early in June, when seceding pairs retire to breed by the mountain ponds. They are very faithful to their mates and jealous of intrusion from strangers of the same species, on which occasions the males fight with obstinacy, running to and fro upon the water at the time even when the females are engaged in incubation. When the young are exposed to any danger, the parents are heard to express their alarm by a repeated 'prip, 'prip. At the commencement of August, as in the glacial regions of America, the whole retire to the open sea previous to their migration to the South, and by the end of that month they are no longer to be found in that island.

The food of this species is said to be chiefly worms, winged insects, particularly diptera, and such other kinds as frequent the surface of the water. In specimens which I have examined, the stomachs contained some small gravel and the remains of aquatic coleopterous insects, as the different kinds of small water-beetles. These individuals, which were young birds beginning to moult, had therefore varied their fare by a visit to some fresh-water pool or lake, and like their kindred Sandpipers, had landed on the shore in quest of gravel. They were likewise fat and very finely flavored. The old birds, hunted as food by the Greenlanders, are said, however, to be oily and unpalatable, which may arise probably from the nature of the fare on which they subsist in high latitudes, - if the birds alluded to are not, in fact, the small Petrels instead of Phalaropes; though the inhabitants using the skins medicinally, to wipe their rheumy and diseased eyes, seems to decide pretty nearly in favor of the present bird.

In the spring of 1832 , about the beginning of May, so dense a flock was seen on the margin of Chelsea Beach, in this VOL. II. - I4 
vicinity, that nine or ten individuals were killed out of it at a single shot; these were nearly all old birds, and on being eaten proved quite palatable. Mr. Audubon informs me that in the month of May last (1833), he met with flocks of these Phalaropes about four miles out at sea off the Magdalen Islands, where they are known to the fishermen by the name of "Sea Geese," appearing more or less every year. At this time they were in very dense flocks of about one hundred together, so close as nearly or wholly to touch each other. On being approached they were very shy and wild, and as they rose to fly, in the manner of the Sandpipers, uttered a faint, clear cry of 'twee 'tweet. Like Tringas, too, they alight on the shore or the ground, and run with agility. They also at times settle on ,the driftweed and Fuci in order to glean up any insects which may occur. They squat on the ground like Snipes.

It is remarkable enough that all these flocks consisted of birds of both sexes assembling to breed and in imperfect plumage. In none were the sides and front of the neck wholly red. They had a broad patch of red below the ears, not extending in front, and the blackish gray feathers of the back and scapulars were edged, in the latter, nearly round with pale dull rufous. The females were paler in all parts, the scapulars merely edged with whitish rufous. The brightest of these birds answers to Temminck's description of the female of the species, while Bonaparte asserts that the females are always much brighter or redder than the males in their most complete plumage. We have, therefore, the following distinct stages of appearance in this species: The young of the year; the young of the second year, differing in the appearance of the sexes; the adults of both sexes (probably not then wholly alike); and finally the gray livery of winter, distributed according to the variations in the preceding plumage. We shall then have, at this rate, six or seven different states of plumage to this single species of Phalarope.

This species breeds in the Far North, and is met with off our coasts as the flocks journey to and from their winter quarters in the tropics. 
I have seen the birds only as they have loitered awhile in the Bay of Fundy; but they gave me no grounds for thinking them the wild and shy things Audubon tells about. I thought them exceptionally heedless of my presence, - confiding, in fact, - for I frequently ran into a flock that barely made way for my boat. Mr. William Jefferies makes a similar report of the flocks he saw off Swampscott in August, 1890 .

The females of this species are rather more decorous than are some of their cousins, though they do not believe in living alone if a bit of management will secure a partner; but they are helpmates, - they share in the wearisome task of incubation and in caring for the youngsters ; and their consideration and their constancy, which is unimpeachable, is rewarded by a chivalrous devotion.

\section{WILSON'S PHALAROPE.}

SEA GOOSE.

\section{PHALAROPUS TRICOLOR.}

CHAR. Summer: above, dark ashy gray, paler on the crown and rump; throat, cheeks, and line over the eyes white; sides of the neck rich chestnut; wings brownish gray, outer feathers (primaries) dusky; beneath, white, the breast tinged with pale chestnut; bill long, slender, and acute, and of black color. Length $9^{1 / 2}$ inches.

In winter the plumage is ashy gray and lacks the rufous tints.

The female is larger and more highly colored and much more beautiful than the male.

Nest. In a marsh or wet meadow adjacent to a lake or pond, - a slight depression scattered in the soil amid a tuft of grass, and sparsely lined with grass.

Eggs. 3-4; grayish buff or dark buff, thickly spotted with brown of several shades; $1.30 \times 0.90$.

This elegant Phalarope, first noticed by Wilson in a museum at Albany, was afterwards dedicated to his name and memory when he was no longer conscious of the honor. Hurried to the tomb from amidst his unfinished and ill-requited labors, his favorite Orpheus and Wood Thrush pour out their melody in vain. The Blue Bird, which hastens to inform us of the return of spring and of the approach of flowers, delights no longer the favorite of their song. Like his own beautiful and strange 
bird, now before us, his transient visit, which delighted us, has ended; but his migration, no longer to be postponed, has exceeded the bounds of the earth, and spring and autumn, with their wandering hosts of flitting birds, may still return, while he, translated to the Elysian groves, will only be remembered in the thrill of the plaintive nightingale.

Wilson's Phalarope, unlike the preceding, has no predilection for the ultimate range of the Arctic Circle, confining its residence, consequently, to the shores of America; it is unknown in summer beyond the $55^{\text {th }}$ parallel, passing the period of reproduction on the plains of the Saskatchewan, being also a stranger to the coasts of Hudson Bay. Taking the interior of the continent for its abode, it is not uncommon on the borders of lakes in the vicinity of the city of Mexico.

From the structure of its legs and feet this remarkable species, so distinct from the others, appears more suited for a wading or walking than an eminent swimming bird. In the United States it can only be considered as a straggler, of which a specimen has been obtained near Philadelphia in May, and another in the State of New York. As yet we have never met with it in this vicinity.

The "Swimming Sandpiper," as this bird has been called, - a name that describes it precisely, - is restricted chiefly to the interior, though stragglers have been taken on the shores of New England and the Provinces. It is now known to breed abundantly in Illinois, Wisconsin, Iowa, and Dakota, and northward to the Saskatchewan valley. In winter the flocks range to Brazil and Patagonia.

In habits the bird more closely resembles the Sandpipers than does its congeners, seldom swimming except when wounded, and wading knee-deep to glean its food. The female, however, with true Phalaropian scorn for the proprieties, manages her courtship, - and manages too her reluctant lover, - and after a brief - very brief - honeymoon, she resigns charge of domestic arrangements to her henpecked partner, who meekly sits on the eggs until they are hatched. 


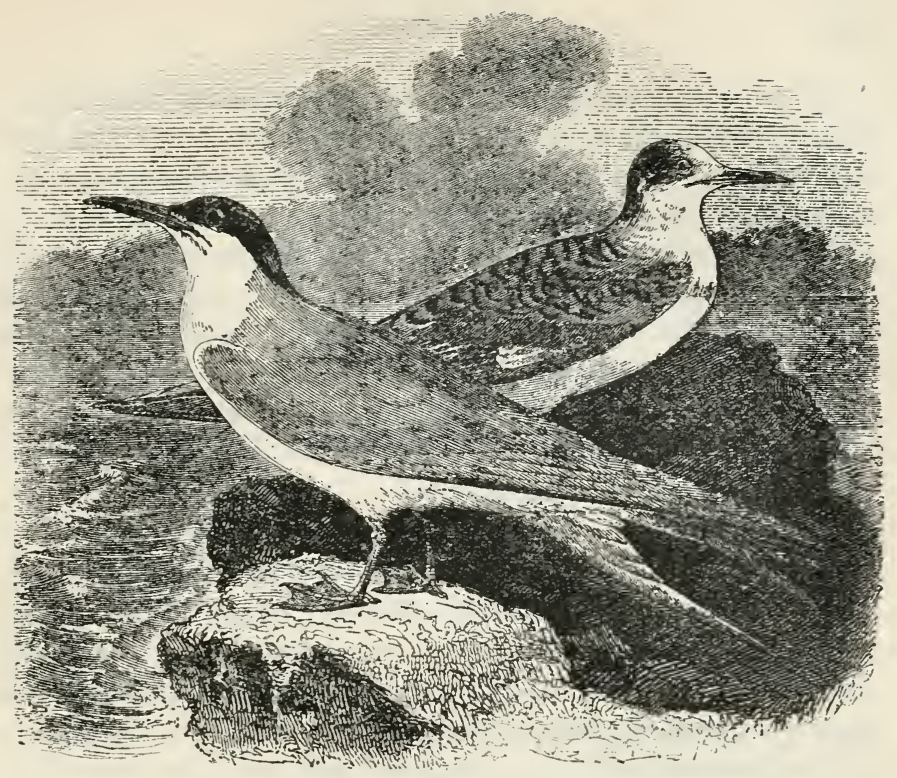

COMMON TERN.

WILSON'S TERN. SEA SWALLOW. SUMMER GULL. MACKEREL GULL.

\section{STERNA HIRUNDO.}

CHAR. Mantle deep pearl gray; crown and nape black; rump and tail white; beneath, pale gray, shading to white on the throat; bill and legs orange red. Tail deeply forked. Length 13 to 16 inches.

In winter the under parts are pure white, and the crown is mottled with white.

The young birds have bars of brown on the mantle, and the crown is of a brownish tinge; also, the bill and legs bear a yellow tinge in summer, and turn to nearly black in winter.

Nest. On the sand or amid shingle or short herbage near water, a slight depression, sometimes sparsely lined with grass or weeds; occasionally a rather bulky nest is made of straw or sea-weed.

Eggs. 2-5 (usually 3 ); the ground color varies, olive and buff tints prevailing; the marking also varies, but is always profuse and of several shades of brown; the size averages about $1.60 \times 1.15$.

The Common Tern is an inhabitant of both continents, being met with on the coasts of most parts of Europe as far 
north as the ever-inclement shores of Greenland and Spitzbergen; it is also found on the Arctic coasts of Siberia and Kamtschatka. In the winter it migrates to the Mediterranean, Madeira, and the Canary Islands. In America it breeds along all the coasts of the Northern and Middle States, and penetrates north into the fur countries up to the 57 th parallel of latitude. It also breeds on the sand-bars of the Great Western Lakes, being frequent in those of Erie, Huron, and Superior. In short, no bird is more common along the sea-coasts and lakes of the whole northern hemisphere, within the limits of cool or moderate temperature.

These Terns arrive on the coast of New Jersey about the middle of April, and soon after they are seen on the shores of New England, where they are known by the name of the Mackerel Gull, appearing, with the approach of that fish, towards the places of their summer residence. In New York they are dignified, for the same reason, with the appellation of the Sheep's-Head Gull, prognosticating also the arrival of that dainty fish in the waters of the State. About the middle of May, still gregarious as they arrive, they commence with the cares of reproduction. Artless in contrivance, the Terns remedy the defect of a nest by selecting for their eyries insulated sand-bars, wide beaches, but most commonly desolate, bare, and small rocky islets, difficult of access, and rarely visited by anything but themselves and birds of similar habits. A small hollow scratch on the surface of the shelving rock, with the aid of a little sand or gravel merely sufficient to prevent the eggs from rolling off, are all the preparations employed by these social and slovenly birds. The eggs are left exposed purposely to the warming influence of the sun, the parent sitting on them only in the night or during the existence of wet and stormy weather. They are about $\mathrm{I} 3 / 4$ inches long by $\mathrm{I} / 4$ in width, of a dull yellowish or pale whitish olive, with darkbrown blotches and spots, and others of a pale hue beneath the surface, the whole often disposed in a sort of irregular ring towards the obtuse end. Other eggs, again (as if of a different species of bird), are spotted almost equally all over. 
From the variety in the appearance of the eggs, it is pretty obvious that the females indifferently and frequently lay in each other's nests, in the manner of our common fowls in a state of domestication. Though to all appearance thus abandoned to accident, the nests are constantly under the surveillance of the Terns, and the appearance of an intruding visitor on the solitary spot chosen for their breeding retreat fills the whole neighboring troop with dismay and alarm; and in defence of their young they are very bold, clamorous, and resentful, sweeping round and darting down so close to the visitor as sometimes to touch his hat, making at the same time a hoarse and creaking sound, and occasionally uttering a plaintive, long-drawn 'pté-way; and when much irritated and distressed by the fall of their companions or their brood by the gun, we hear a jarring $k^{\prime} k, k^{\prime} k, k^{\prime} k$, as well as a piping plaint; and at times they utter a bark almost like so many puppies. On a rocky islet near Nahant, in the vicinity of Boston, known by the name of the Egg Rock, thirty or forty pairs annually breed, and among these, others are also distinguished by the name of 'pee-boos, from the sound of their usual note.

The young are often hatched at intervals of a day or two from each other, and are carefully fed and watched for several weeks before they are in a condition to fly. At first they are fed on small fish and insects, such as grasshoppers and beetles, the hard and indigestible parts of which food appearing to be rejected by the bill in the manner of rapacious birds. The young are afterwards fed without alighting, as they skim over the spot; and then they merely drop the fish among the brood, when the strongest and most active are consequently the best served. The young at length launch out into the marshes for themselves in quest of insects; while thus engaged, at the warning voice of their parents, or the approach of an enemy, they instantly squat down, and remain motionless until the danger be over. As soon as the young are able to fly, they are led by the old to the sand shoals and ripples where fish are abundant, and occasionally feeding them, they learn by example to provide for themselves. 
While flying, the Tern exhibits uncommon watchfulness; beating the air with a steady wing, and following the track of the vessel with an easy flight, this bird may be observed, with quick eye and moving head, minutely scanning the haunts and motions of its finny prey. At the approach of winter it retires south of the limits of the Union.

In America this Tern is chiefly confined to the Eastern Province, and is a common bird throughout its range.

\section{FORSTER'S TERN.}

\section{STERNA FORSTERI.}

CHAR. Above, pearl gray, paler on the wings and tail ; crown and nape black; beneath, white; bill orange, the terminal third blackish; legs and feet orange; claws black. Length 12 to 15 inches.

In winter the head and neck are white, the nape is tinged with gray, and on the side of the head is a broad black band.

Nest. On a marshy margin of lake or stream, or on a grassy island; loosely made of reeds and sedges, and lined with grass.

Eggs. 2-3; varying from pale buff or olive to olive brown, marked brown and pale lilac; average size about I.80 $\times 1.25$.

Nuttall wrote in a note to the Common Tern that the bird described by Richardson as Sterna hirundo appeared to be a distinct species, distinguished by the pearl-gray tail and other characters, and he proposed for this probable new species the name of Sterna forsteri, in honor of the eminent naturalist and voyager who first suggested these distinctions. Having been recognized by naturalists as a valid species, the name thus proposed has been adopted for it.

In appearance, as in manners, the bird is very similar to the Common Tern, though the present species displays a decided preference for a grass-covered nesting site, and is inclined to remain near fresh water.

It is a rare bird along the Atlantic coast, excepting at Cobb's Island, off Virginia, but is abundant on the inland waters of the west, north to Manitoba. A number nest every year on the St. Clair Flats, Ontario; but the only examples that have been taken in Canada to the eastward of that point were obtained at Lake Mistassini, Quebec, and on Prince Edward's Island.

In winter the flocks range southward as far as Brazil. 


\section{ROYAL TERN.}

\section{CAYENNE TERN. GANNET STRIKER.}

\section{S'TERNA MAXIMA.}

CHAR. Mantle pearl gray; tail with less of the bluish tint; rump nearly white; crown and nape black; primaries silvery gray, the inner webs with a dark stripe next the shaft, and inner edge white; under parts white ; bill orange ; legs and feet black. Length 18 to $2 \mathrm{I}$ inches.

After the mating season, - the spring months, - the crown becomes more or less white, and in winter the nape also has white feathers mixed with the black.

Nest. No attempt is made to construct a receptacle for the eggs, which are laid on the sand of a sea-beach or on the edge of a marshy lagoon.

Eggs. I-4; buffy or yellowish drab, marked with brown or pale lilac; average size about $2.65 \times 1.75$.

Nuttall makes bare mention of this handsome bird, - la grande Hirondelle-de-mer de Cayenne of Buffon, - knowing nothing of its habits or distribution, and in error gives $S$. caspia as a synonym; but the Caspian Tern is a larger bird and quite distinct. Our bird is not exclusively American, as Nuttall supposed, for Dalgleish found it on the west coast of Africa. In the United States it is confined chiefly to the tropical and warm temperate regions, seldom ranging north of latitude $40^{\circ}$, though a few examples have wandered to the Great Lakes and as far up the coast-line as Massachusetts.

The centre of its abundance is along the Gulf shore, the birds being especially numerous in Florida and Texas, though they are also rather common at Cobb's Island, Virginia. Mr. Chapman says that "during the winter it is about the only Tern one sees in Florida waters. It is a strong active bird on the wing, and a reckless dashing diver."

The name of "Gannet-striker" - often shortened to "Gannet" - has been given to the Royal Tern from its Gannet-like performance of descending upon its prey from the wing, darting down perpendicularly and swiftly, plunging under the surface of the water, but soon reappearing, and mounting into the air again with considerable difficulty. 


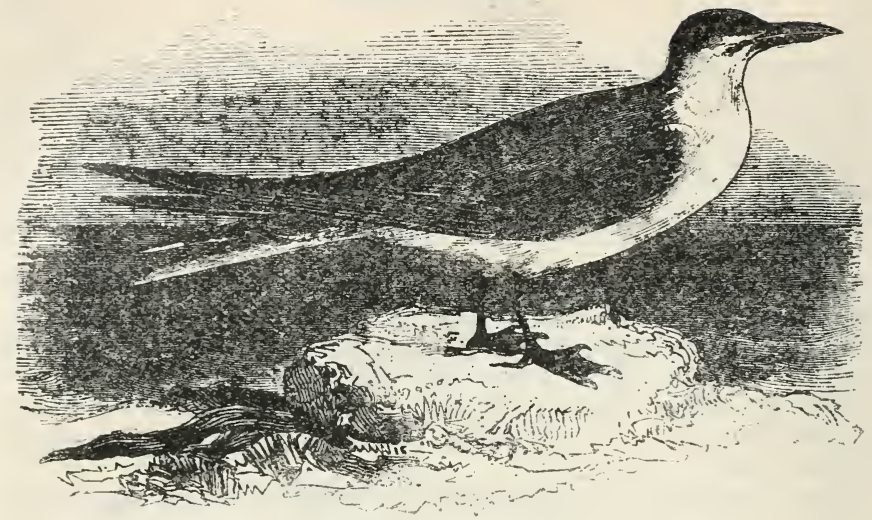

\section{GULL-BILLED TERN.}

MARSH TERN.

\section{GeLOCHELIDON NiLOTICA.}

CHAR. Upper parts pale pearl gray; crown and nape black; under parts white; bill short, stout, gull-shaped, and of black color; legs and feet dusky. Length about i 3 to I 5 inches.

In winter the crown and nape are pale gray, and a bar of darker gray runs through the eyes.

Nest. A slight depression in the sand of a sea-beach or river-bank, sometimes amid the low grass on the margin of a marsh; occasionally lined with grass or sea-weed.

Eggs. 3-4; light buff or pale olive, marked with brown and lavender; average size about $1.80 \times 1.30$.

This bird, though rare in England, is very common in eastern Europe, particularly in Hungary and on the confines of Turkey. In the new continent it inhabits the whole coast of the Atlantic from New England to Brazil. In Europe it affects the covert of rushy marshes in the vicinity of the Great Lakes, and rarely ever visits the sea-coast or the ocean. It has also been seen inland, in Missouri, by Mr. Say, and probably penetrates still farther into the interior to the coasts of the Great Lakes of the North American continent. Wilson first observed these birds on the shores of Cape May, in New Jersey, where parties were engaged darting down like Swal- 
lows over the salt-marshes, in quest of some aquatic insects or spiders which occur upon the surface of the water. Their food while here appears wholly composed of insects; in Europe also their fare is similar, and they feed upon lepidopterous insects or moths as well as other kinds, showing indeed by this peculiarity of appetite their independence on the produce of the ocean, and their indifference to salt water as preferred to fresh.

The Marsh Terns keep apart by themselves, and breed in company on the borders of the salt-marshes among the driftgrass, preparing no artificial nest, laying three or four eggs of a greenish olive spotted with brown. The voice of this species is sharper and stronger than that of the Common Tern.

This Tern is common along the Atlantic and Gulf coasts of the Southern States, breeding as far north as Southern New Jersey, and occasionally examples wander to Long Island and the Great Lakes. One has been taken in Massachusetts, and one in the Bay of Fundy.

Though not a fish-eating Tern, this bird is rarely found away from the sea-shore in America. It utters a variety of notes, the most common being fairly represented by the syllables kay-wek, $k a y$-wek. One note is described as a laugh, and is said to sound like hay-hay-hay. 


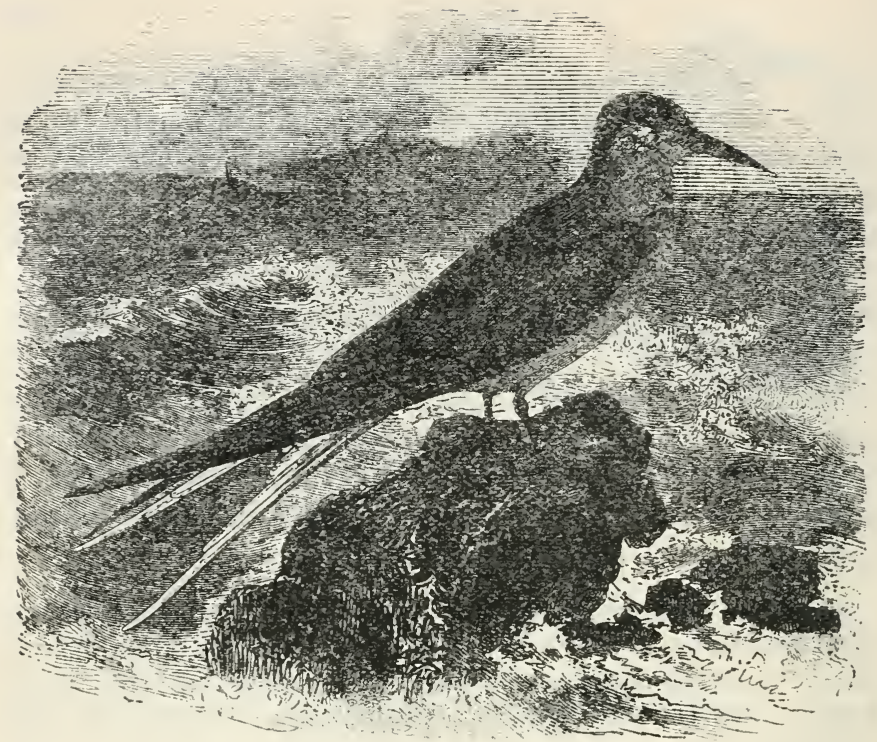

\section{ARCTIC TERN.}

\section{STERNA PARADISEA.}

CHAR. Mantle pearl gray; darker on the wings; rump and tail white ; tail deeply forked; lower parts gray tinged with pearl gray almost as dark as the mantle; paler on the throat; bill and feet deep carmine. Length I 4 to 17 inches.

In winter the lower parts are whiter, and the crown has more white than black feathers; also the bill and feet are dusky.

Nest. On the sand of a sea-beach, often amid shingle or drifted seaweed; sometimes a slight hollow sparsely lined with grass or weed-stems.

Eggs. 2-4; not easily distinguished from those of $S$. hirundo, but usually of a darker ground color and more heavily marked; ground color varies from buff to buffish brown, and olive to olive brown, the markings of several shades of brown; average size about I.55 $\times$ I.1 5 .

The name of this bird - like the names of too many other species - is misleading; for while the bird ranges through the Arctic region and nests have been discovered as far north as latitude $82^{\circ}$, yet numbers breed on the islands of the Bay of Fundy and the coasts of Maine and Massachusetts. It is said to have been abundant in the last-named State some years ago. 
The peculiar distribution of this species, and the supposition that the flocks never migrate down the shores of the Pacific, have led some naturalists to suggest that the birds were originally confined to the Atlantic Ocean, though ranging on both its eastern and western shores. The breeding area, they say, was gradually extended east and west, one division of the birds going off along the northern shore of America, the other across the end of Europe and Asia, advanced flocks of each division finally meeting at Bering Sea. But at the approach of winter these flocks separated at that point, and ignoring the Pacific route to a milder climate, they followed "hereditary instincts" and returned to the Atlantic, each division migrating along its own path and wintering on its own chosen shore, - the flocks of one wing ranging to the Middle States, the others to the Canary Islands.

The hypothesis is interesting and the facts are in the main correct; but it has been strongly hinted that the hypothesis has been cruelly disturbed by the birds themselves, - they have turned up in California. The hypothesis should not, however, be abandoned because a few individuals have forsaken the traditions of their race, - that is a common weakness of those who "go west." Enough Arctic Terns still follow the ways of their fathers when migrating, to prove the strength of this inherited tendency.

In habits as well as in general appearance and manners this species differs but slightly from the Common Tern. Our bird is perhaps more graceful on the wing, though both fly with wonderful grace and ease, and the Arctic Tern displays more boldness in defence of its young or of a wounded companion. It seems utterly fearless, and will advance so close as to strike with its pinions a hand that menaces its young; and when a colony is invaded by any marauder, the Arctic Tern is the first to lead an attack upon the intruder, and the attack is so fierce that the colony is usually saved.

The Arctic Terns frequent rocky islands and secluded portions of the mainland, and in these localities the birds gather in large communities. They may be seen sitting on a rock or stump, watching for their prey, in Kingfisher fashion. They float buoyantly on the water, but rarely dive beneath the surface.

Mr. Brewster considers their notes vary little from those of the Common Tern though they can be distinguished. The usual cry of the Arctic Tern resembles that of its congener, "but is shriller, ending in a rising inflection, and sounding very like the squeal of a pig." 


\section{CABOT'S TERN.}

\section{SANDWICH TERN.}

\section{STERNA SANDVICENSIS ACUFLAVIDA.}

CHAR. Upper parts pale pearl gray, much paler on rump and tail; tail deeply forked; crown and nape black; under parts white tinged with pink; bill black tipped with pale buff; legs and feet black. Length I4 to I6 inches.

Nest. A slight hollow scratched in the sand of a sea-beach or on a grassy island; sometimes lined with grass or dry sea-weed.

Eggs. 2-4 (usually 3); ground color varies from white through cream color to brownish buff; sometimes tinged with olive; the markings are varied, but always profuse, and of several shades of brown and pale gray; size variable, average about $2.00 \times 1.40$.

Few species have a wider geographic range than the Sandwich Tern. It was first observed in England by Mr. Boys, of Sandwich, where it is not uncommon, and was afterwards published by Latham. It is readily confounded with the Common Tern (Sterna hirundo), but is superior in size, besides possessing other differences; it is rather rare on other parts of the English coast. It is believed to breed on the shores of Sandwich, and retires south in autumn, where it is probably afterwards seen migrating to the coast of Africa to pass the winter, and the young birds have been brought from the distant shores of New Zealand. According to Temminck it is very abundant in the isles of North Holland, and chiefly frequents the sea-coast, though sometimes it has been known to wander into the interior and visit fresh waters. In the Leverian Museum there existed, some years ago, a specimen of the young bird from South America; but it was left for our indefatigable friend Audubon to discover this interesting cosmopolite within the boundary of the United States. In $1_{3} 82$ he with his party obtained a considerable number of specimens in summer plumage during the month of May in East Florida, and they were particularly abundant in the vicinity of Indian Key, about thirty miles from Cape Sable. In this place in the usual manner of the genus they breed together in large communities. 
Cabot's Tern differs but slightly in coloration of plumage from the Sandwich Tern of England; but our bird is confined to the tropical and warm temperate regions, occurring in numbers no farther north than Florida, though occasionally represented by a wanderer along the coast even to Massachusetts. It is pre-eminently a sea-bird, and is rarely found inland.

To write of the bird's habits would necessitate a repetition of what has been said of others of this group; for Cabot's Tern displays little originality or individuality in its methods, though it may be credited with great power of sustained flight, and more than many of the Terns deserves the name "Sea Swallow," so generally applied to the entire group; but instead of pursuing flies it preys solely upon fish. Its strength of wing and skill enable it to outride the severest storms, and flocks of these birds may be seen dipping into crested waves or skimming over angry breakers to seize the prey that may be brought to the surface by the gale.

\section{ROSEATE TERN.}

\section{STERNA DOUGALli.}

CHAR. Upper parts delicate pearl gray, paler on the tail ; crown and nape deep black; lower parts delicate rose pink, which fades to white after death; bill black; legs and feet red; wings short, primaries dusky; tail long and deeply forked. Length about $15^{1 / 2}$ inches.

Nest. A slight hollow in the sand of a sea-beach or barren sea-island, often amid the coarser shingle; sometimes sparsely lined with beach-grass or sea-weed.

Eggs. 2-4 (usually 3); ground color varied from light to dark buff and pale to deep olive; profusely and irregularly marked with several shades of brown; average size about $1.55 \times$ r.15.

Eggs of the Common, Arctic, and Roseate Terns are too much alike to be distinguished. Those of the present species are said to be slightly lighter in color as a rule.

The Roseate Tern, so frequently associated with and confounded in the character of the Common Tern, is another species common to the colder and temperate parts of both continents, being frequent upon the coasts of Scotland and England, particularly the former. It is also found in Norway, and probably also upon the borders of the Baltic, visiting the northern coasts of the ocean in small numbers, 
associated with flocks of the Great Tern. The particular places of resort for the present species, according to Dr. M'Dougal, are two small, flat, and rocky islands in the Firth of Clyde called Cumbrae Islands, chiefly about Milford Bay. On these islands the Common Tern swarms to such a degree that it was scarcely possible to step without treading upon the young birds or eggs. The new species here described was shot by accident, without its being distinguished until it lay dead upon the ground, when the Doctor's attention was attracted by the beautiful pale roseate hue of the breast. There did not here appear to be more than about one in two hundred of the present with the Common Tern; but they were at length easily singled out by the comparative shortness of their wings, whiteness of their plumage, and by the elegance and slowness of their aërial motion, often sweeping along or resting in the air almost immovable, like the soaring of a Hawk; and they were also distinguishable by the comparative inferiority of their size.

In the United States these birds are sparingly seen with the Common Tern, as I have obtained an individual on the coast at Chelsea Beach; and they may breed on the neighboring isle of Egg Rock or in similar places in the temperate parts of the Union.

This beautifully tinted and graceful bird is of rather southern habitat, only a small number breeding northward of southern Massachusetts on this side of the Atlantic, though a few examples have wandered along the coast as far as the Bay of Fundy. It is almost exclusively a bird of the open ocean, seldom even frequenting the salt-lagoons; but several have been captured on the Great Lakes. Large numbers once gathered at Muskegat Island, one of the Nantucket group; but of late years they have shared the fate of all their kindred and been slaughtered by milliners' assistants that their wings might adorn my lady's hat, until now very few remain. Says William Brewster, writing of Muskegat: "Were it not for man, - who, alas! must be ranked as the greatest of all destroyers, - the Terns would here find an asylum sufficiently secure from all foes." He graphically tells of the shooting of hundreds of the birds by yachting parties, "either in wanton sport or for their wings, which are presented to fair companions;" and adds: "Then the 
graceful vessel spreads her snowy sails and glides blithely away through the summer seas; all is gayety and merriment on board. But among the barren sand-hills, fast fading in the distance, many a poor bird is seeking its mate, many a downy orphan is crying for the food its dead mother can no longer supply, many a pretty speckled egg lies cold and deserted. Buzzing flies settle upon the bloody bodies, and the tender young pine away and die. A graceful, pearl-tinted wing surmounts a jaunty hat for a brief season, and then is cast aside, and Muskegat lies forgotten, with the bones of the mother and her offspring bleaching on the white sand. This is no fancy sketch; all the world over the sad destruction goes on. It is indeed the price of blood that is paid for nodding plumes. Science may be, nay, certainly is, cruel at times; but not one tithe of the suffering is caused by her disciples that the votaries of the goddess Fashion yearly sanction."

\section{LEAST TERN. \\ SILVERY TERN. LITTLE STRIKER.}

\section{STERNA ANTILLARUM.}

CHAR. Upper parts pale pearl gray of a silvery tint ; crown and nape black, the forehead with a patch of white; outer wing-feathers dusky; under parts white; bill yellow, tipped with black; legs and feet orange. Length about 9 inches.

Nest. A slight hollow in the sand of a sea-beach.

Eggs. 2-4 (usually 3); pale to deep buff, sometimes tinged with olive, profusely blotched with brown and lavender; average size about 1.25 $\times 0.95$.

The Silvery Tern, apparently of Temminck, and the Lesser Tern of Wilson, is an inhabitant of the American continent, and was first detected as distinct from the European species by Prince de Neuwied, in Brazil. In the United States it arrives from its hybernal retreat later than the Common Tern, and is not met with so far to the north, being unknown in the Canadian fur countries. These birds are, however, common in the Middle and New England States, being frequently seen coasting along the shores or over pools and salt-marshes in quest of the insects and small shrimps which constitute their favorite fare; they also occasionally dart down upon small fish VOL. II. - I 5 
and fry, hovering, suspended in the air, for a moment over their prey, like so many small Hawks, and with equal promptness dash headlong into the water after it, seizing it with the bill, as the feet are incapable of prehension. The Silvery Tern sometimes makes extensive incursions along the river courses, and has been shot several hundred miles from the sea, its principal place of residence.

In the latter end of May or beginning of June the female commences laying. The eggs are merely deposited in a slight scratch in the sand, and left to hatch in the heat of the sun; the bird, as usual, sitting on them only during the night and in wet and stormy weather. On approaching their breedingplaces the old birds assemble in crowds around the intruder, and after a good deal of vociferation, flying round in wide circuits, they often approach within a few yards of one's head, squeaking almost like so many young pigs, and appear to be very irritable and resentful. At other times, when not excited or alarmed, they are tame and unsuspicious, particularly the young birds, often heedlessly passing the spectator within a few yards while tracing the windings of the shore in quest of their prey.

This is a bird of the tropical and warm-temperate regions, breeding chiefly from the Middle States southward, and wintering in Central America. The Nantucket Islands were a favorite resort some years ago, but few examples are found there now. Occasionally stragglers wander along the coast as far as Labrador, and a few have been seen on the Great Lakes and in Minnesota. Its voice is described as "a sharp squeak, much like the cry of a very young pig following its mother." 


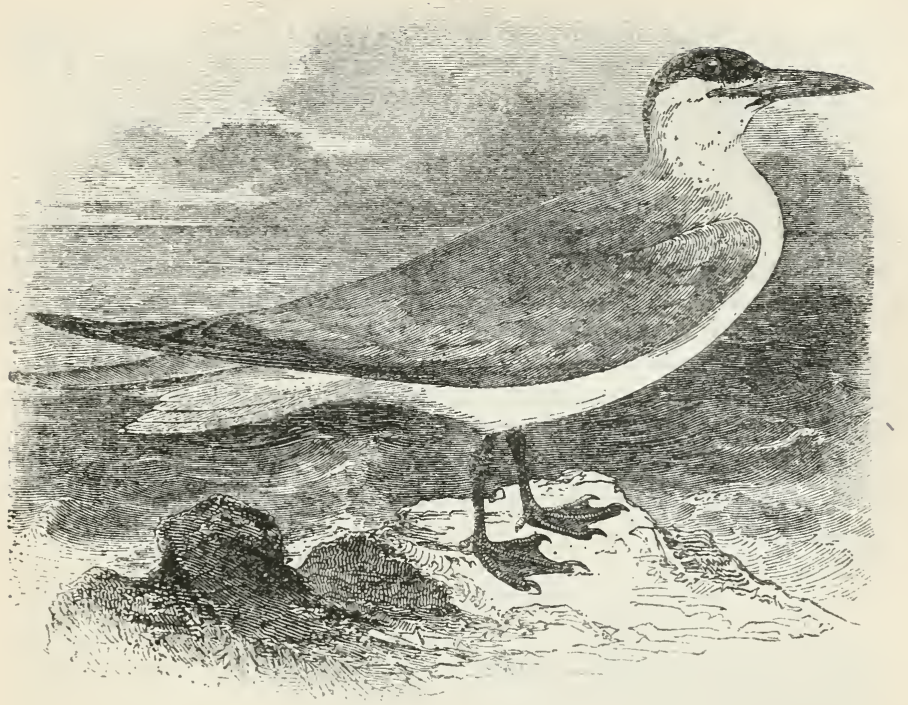

\section{CASPIAN TERN.}

\section{GANNET STRIKER.}

\section{STERNA TSCHEGRAVA.}

CHAR. Mantle pale pearl gray; tail and wings silvery; crown and nape black; under parts white; bill red, tipped with black; legs and feet black. In winter the black cap is streaked with white. In immature birds the upper parts are light gray mottled with brownish gray; bill yellowish brown; legs and feet brown. The largest of the Terns. Length $2 \mathrm{I}$ inches or more.

Nest. A slight hollow in the sand, sometimes lined with a little grass or sea-weed.

Eggs. 2-3; buff of various shades, sometimes tinged with olive, marked with brown and lavender; average size $2.60 \times 1.75$.

This Tern received its name from Pallas, who discovered it on the shores of the Caspian Sea. It was first described in 1770 , but was not known to the earlier American naturalists, Baird's work of 1858 being the first in which its name appears.

It is not abundant in this country, or indeed in any country excepting in a few localities, though cosmopolitan in its distribution 
and ranging over inland waters as well as on the sea. It has been found breeding on Cobb's Island, Virginia, but along the New England shores it is seen in the spring and autumn chiefly, indicating a Northern nesting ground, though few specimens have been taken in the Arctic regions. It is said that nests have been taken on the shores of Texas and in Great Slave Lake, - which would give the bird an extensive breeding area, though the nesting sites are in widely separated localities. It might almost be said of this bird that it ranges over the entire globe, and breeds throughout its range.

The cry of the bird is loud and harsh, resembling the syllables kay-owk, or key-rak; though when a nesting site is menaced, or a pair meets in contention for a coveted mouthful, the cry is reduced to a sharp $k o k$, or $k a k$, or kowk.

The Caspian Tern preys chiefly on fish; but several naturalists have reported finding the remains of eggs and young birds in its stomach.

Note. - A few examples of Trudeau's Tern (Sterna trudeaui), a South American species, have wandered north as far as Long Island; and the BRIDLED TERN ( $S$. ancthetus), also a tropical bird, has been taken off the coast of Florida.

\section{SOOTY TERN.}

\section{STERNA FULIGINOSA.}

CHAR. Upper parts sooty black; forehead, outer tail-feathers, and under parts white; bill, legs, and feet, deep black. Length about 16 inches.

Nest. A slight hollow in the sand of an open sea-beach; sometimes amid the thicket of herbage bordering the beach.

Eggs. I-3 (usually I); white to pale buff, spotted with reddish brown and lilac; average size $2.00 \times$ I.40.

These Terns generally inhabit the tropical seas, being widely dispersed into either hemisphere. On the Isle of Ascension they breed in swarms. The flocks which possess the various parts of the island, perpetually breeding, in this mild latitude were found laying at different times. In some places the young were hatched and grown, in others newly laid eggs were seen. They uttered a sharp and shrill cry, and were so fearless of the men who visited the island as to fly almost 
among them. The species is migratory, however, even in these mild climates.

Along the coasts of Georgia and Florida Wilson observed these Terns in numerous flocks in the month of July. They were very noisy, and darted down headlong after small fish. Birds of this species frequently settle on the rigging of ships at sea, and, in common with their relatives, are called Noddies by the sailors.

The Sooty Tern occurs regularly north to the Carolinas, and occasionally wanders to the shores of Massachusetts. It is almost exclusively a sea-bird, feeding chiefly upon fish, which it catches by swooping to the surface, not by dropping into the water. It rarely floats upon the water, but its flight is powerful and rapid.

"It breeds in colonies in little-frequented islands in the West Indies, and may be seen fishing in flocks which hover low over the water" (Chapman).

Note. - A few examples of the White-winged Black Tern (H. leucoptera) have wandered to America. One was taken by Professor Kumlien in Wisconsin, and six were seen by Professor Macoun on a lake near Winnipeg. 


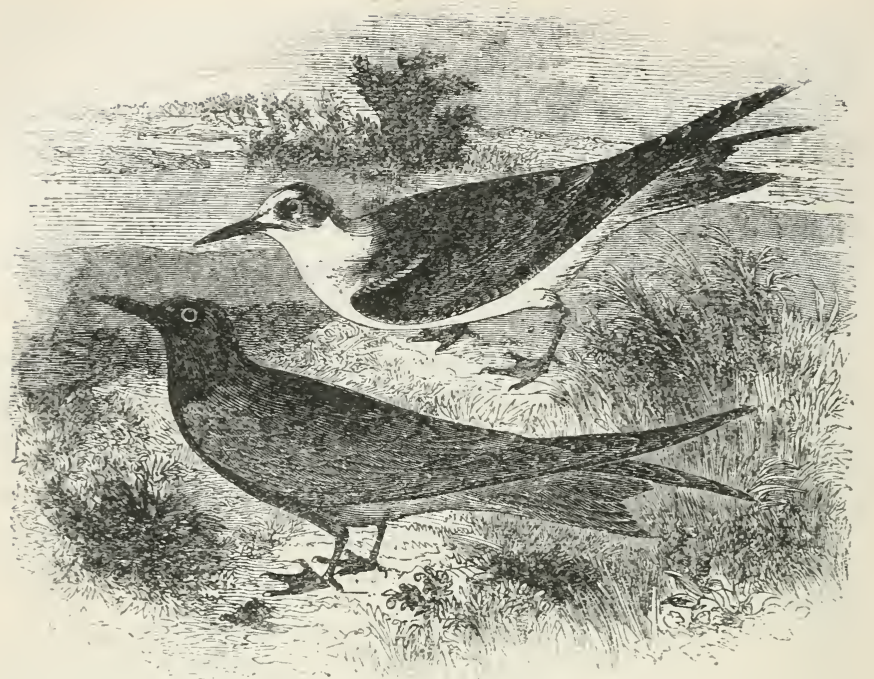

BLACK TERN.

SHORT-TAILED TERN.

\section{HYDROCHELIDON NIGRA SURINAMIENSIS.}

Char. Upper parts, deep slate gray; head, neck, and under parts black; lower tail-coverts white; bill black; legs and feet dusky or reddish brown. In winter the black is mostly replaced by white, the crown gray. Length about $9^{1 / 2}$ inches.

Nest. A slight hollow in the muddy soil of a reedy marsh, sometimes sparsely lined with grass; often placed on a platform of floating herbage, and then is made of reeds or coarse sedges firmly constructed.

Eggs. 3; ground color varies from grayish buff to yellowish brown, sometimes tinged with olive; profusely marked with several shades of brown and purplish gray; average size about $\mathrm{I} .40 \times 1.00$.

This is another aquatic bird common to the northern regions of both continents, extending its residence to the limits of the Arctic Circle, and breeding in the fur countries of the interior upon the borders of lakes and in swamps. It is also very common in Holland and in the great marshes of Hungary, and has been observed round the salt lakes of Siberia and Tartary. 
In Europe it is met with as far as Iceland. In all situations it appears to prefer the borders of rivers, lakes, or marshes to the vicinity of the sea, except when engaged in its migrations.

This Tern is a common summer inhabitant of England, appearing, according to Montagu, in Romney Marsh, in Kent, about the latter end of April, breeding on the sedgy borders of pools, and though very near to the sea, it is rarely seen on the shores till after the breeding-season, and is then uncommon. These birds breed likewise in the fens of Lincolnshire, making a nest of flags or broad grass upon a tuft just elevated above the surface of the water.

The young of this species are rather common on the coasts of New Jersey during autumn, on their way still farther south to pass the winter. Wilson observed a flock of these driven inland as far as the meadows of the Schuylkill, by a violent storm from the northeast. Hundreds of them were to be seen at the same time, accompanied by flocks of the Yellow-Legs and a few Purres (Tringa alpina). Famished by the accident which had impelled them from their usual abodes, they were now busy, silent, and unsuspicious, darting down after their prey of beetles, grasshoppers, and other insects, now afloat by the inundation, without hesitating, though perpetually harassed by gunners, who had assembled to view the extraordinary spectacle of these rare flocks of wandering birds. In ordinary, as in Europe, they frequent mill-ponds and freshwater marshes, in preference to the bays and the sea-coast.

The Black Tern is a common bird on the lakes of the interior north to Alaska, and is seen on the sea-coast chiefly during the fall migration. It breeds southward to the Middle States, west of the Alleghanies. Occasional examples occur along the Massachusetts shore, and some have been taken at Grand Menan.

In "Birds of Manitoba" Thompson writes :- "It seems not to subsist on fish at all, but chiefly on dragon flies and various aquatic insects. It finds both its home and its food in the marshes usually, but its powers of flight are so great that it may also be seen far out on the dry open plains, scouring the country for food at a distance of miles from its nesting ground." 


\section{NODDY.}

\section{ANOUS STOLIDUS.}

CHAR. Plumage deep sooty brown, darker on wings and tail, paler on neck; crown hoary gray, shading to white on the forehead. Length about ${ }_{1} 5$ inches.

Nest. Usually in a tree or low bush, sometimes on a cliff of a rocky island, made of twigs lined with leaves and grass.

Eggs. I ; pale buff, sometimes tinged with slate, spotted with brown and lavender; $2.00 \times 1.35$.

These common and well-known birds inhabit all parts of the tropical seas, and migrate occasionally as far as the coasts of the United States, at which times they are generally seen in flocks, and are by no means rare. Familiar to mariners who navigate in the equatorial regions, the Noddy, like the voyager, frequents the open seas to the distance of some hundreds of leagues from the land, and with many other birds of similar appetites and propensities, it is seen in great flights assiduously following the shoals of its finny prey. It pursues them by flying near the surface of the water, and may now be seen continually dropping on the small fish, which approach the surface to shun the persecution of the greater kinds by which they are also harassed. A rippling and silvery whiteness in the water marks the course of the timid and tumultuous shoals, and the whole air resounds with the clangor of these gluttonous and greedy birds, who, exulting or contending for success, fill the air with their varied but discordant cries. Where the strongest rippling appears, there the thickest swarms of Noddies and sea-fowl are uniformly assembled. They frequently fly on board of ships at sea, and are so stupid or indolent on such occasions as to suffer themselves to be taken by the hand from the yards on which they settle; they sometimes, however, when seized, bite and scratch with great resolution, leading one to imagine that they are disabled often from flight by excessive fatigue or hunger.

The Noddies breed in great numbers in the Bahama Islands, laying their eggs on the bare shelvings of the rocks; they also 
breed on the Roca Islands and various parts of the coast of Brazil and Cayenne. According to the accounts of voyagers, they lay vast numbers of eggs on certain rocky isles contiguous to St. Helena, and the eggs are there accounted a delicate food. Some have imagined that the appearance of the Noddy at sea indicates the proximity of land; but, in the manner of the Common Tern, these birds adventure out to sea, and like the mariner himself, the shelter of whose friendly vessel they seek, they often voyage at random for several days at a time, committing themselves to the mercy of the boundless ocean; and having at certain seasons no predilection for a peculiar climate, the roving flocks or stragglers find a home on every coast.

This Tern never comes up the Atlantic coast beyond the Southern States, but is common around Florida and on the Gulf shores. 


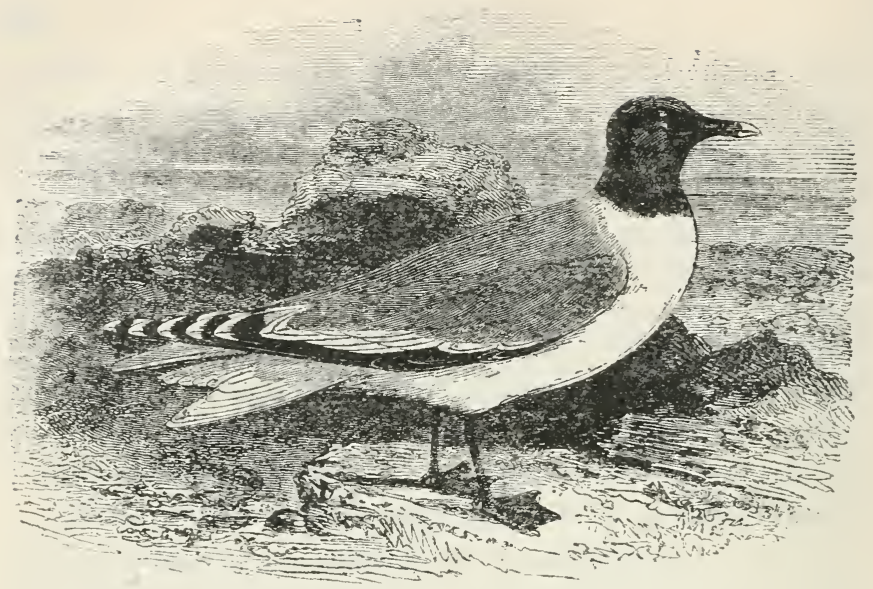

\title{
SABINE'S GULL.
}

\author{
FORKED-TAIL GULL.
}

\section{XeMia SABINII.}

Char. Mantle deep bluish gray, - French gray; head and neck dark slaty gray, bordered by a collar of black; quills black tipped with white; tail and under parts white; bill black tipped with red, which in dried skins becomes yellowish. In winter the head is white, and the nape slaty gray. The young birds are similar to the winter plumage of the adults, but the mantle is more or less varied with brown and buff, and the tail has a terminal band of black. Length about $\mathrm{I}_{4}$ inches.

Nest. On an island, usually in a lake, sometimes near the coast, - generally a depression in the mossy turf, sparsely lined with grass, occasionally on the bare ground or in sand.

Eggs. 2-3 (usually 2); ground color of various shades of brown tinted with olive, marked with fine spots of dark brown and gray; average size about $1.75 \times 1.25$.

This interesting species was discovered by Captain Sabine at its breeding-station on some low rocky islands lying off the west coast of Greenland, associated in considerable numbers with the Arctic Tern, the nests of the two birds intermingled. It is analogous to the Tern, not only in its forked tail and in its choice of a breeding-place, but also in the boldness which it displays in the protection of its young. The parent birds flew 
with impetuosity towards those who approached their nests, and when one was killed, its mate, though frequently fired at, continued on the wing close to the spot. The birds were observed to collect their food from the sea-beach, standing near the edge of the water, and gleaning the marine insects which were cast on the shore. When newly killed, the plumage of the under parts had a delicate pink blush.

Like most of the black-headed members of this group, Sabine's Gull displays a preference for inland waters, especially in the nesting season, though it never builds far away from the sea. Its breeding area lies in the Far North, near the shores of the Arctic Ocean; but in winter it ranges to New England and to the Great Lakes. It is not common, however, so far south; probably more examples have been seen about the mouth of the Bay of Fundy than elsewhere along our shores.

Note. - Nuttall gave a place in his work to the Littue Gull (Larus minutus) ; but while the bird was mentioned in the "History of N. A. Birds," and in Ridgway's "Manual," it was omitted from the first edition of "The A. O. U. Check List," though it has been recognized in the edition recently issued. Examples have been reported from Bermuda and Long Island, but the bird cannot be considered more than an accidental straggler from the eastern hemisphere. 


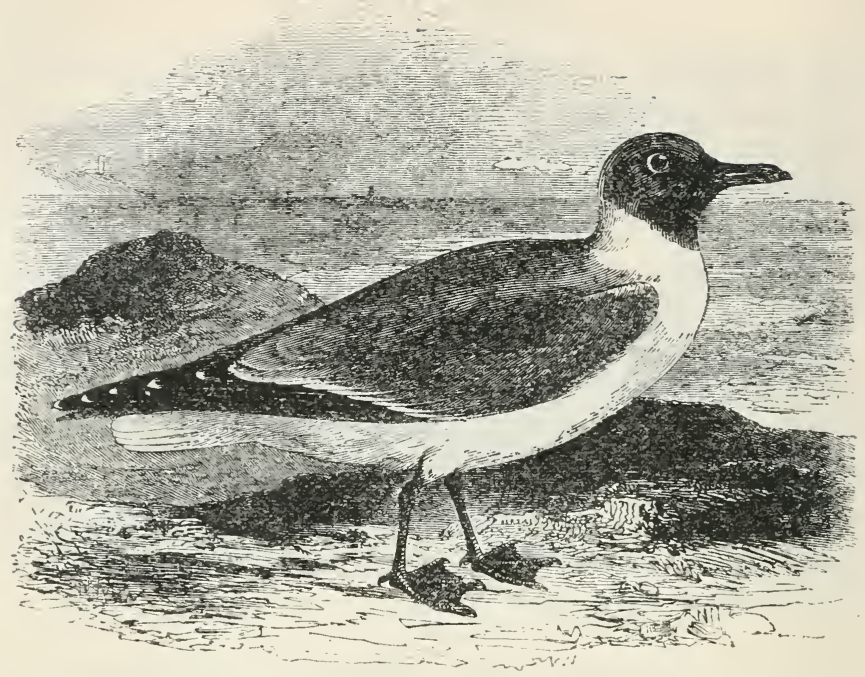

\section{LAUGHING GULL.}

\section{BLACK-HEADED GULL.}

\section{LARUS ATRICILLA.}

CHAR. Mantle deep slaty gray; head and neck dark brownish slate; outer wing-feathers black; tail and under parts white, slightly tinged with pale pink; bill and feet dull red.

In winter the under parts lose the pink tint, and the head is white. Length about 16 inches.

Nest. On a grassy island, hid amid a tussock of sedges or in the sand of a sea-beach; a slight depression in the turf lined with fine grass.

Eggs. 3-5; dull white or pale slate tinged with green or blue, marked profusely with brown and lilac; average size about $2.20 \times 1.55$.

This species, very common in most parts of America, is also frequent in Europe, particularly in the warmer parts, as the coasts of Sicily, Spain, and the islands of the Mediterranean; elsewhere in that continent it is rare and accidental. In America it is found as far south as Cayenne and Mexico, but does not appear to inhabit far north of the limits of the Union. On the coast of New Jersey it makes its appearance in the latter part of April, and is soon discovered by its familiar- 
ity and noise ; companies are even seen at times around the farm-house, or coursing along the river shores, attending upon the track of the fishermen for garbage, gleaning among the refuse of the tide ; or, scattering over the marshes and ploughing fields, they collect, at this season, an abundant repast of worms, insects, and their larvæ. Great numbers are also seen collected together to feed upon the prolific spawn of the kingcrab. While thus engaged, if approached they rise, as it were, in clouds, at the same time squalling so loudly that the din may be heard for two or three miles.

The Black-Headed Gulls breed in the marshes of New Jersey, but are not seen during the breeding-period in New England, and are indeed at all times rare in this quarter. Being apparently a somewhat tender species, they retire to the South early in autumn, and on commencing their migrations, if the weather be calm, they are seen to rise up in the air spirally, all loudly chattering as it were in concert, like a flock of cackling hens, the note changing at short intervals into a ' haw, 'ha 'ha 'ha 'haw, the final syllable lengthened out into an excessive and broad laugh. After ascending to a considerable height, they all move off, by common consent, in the line of their intended destination.

On the $4^{\text {th }}$ of March (I830), while at Beaufort, North Carolina, in company with several other species I saw a small flock of these Risible Gulls, which every now and then, while amusing themselves by fishing and plunging after their prey of fry, burst out very oddly into an oh oh agh agh, or a coarse, laughing scream.

The Laughing Gulls used to breed in numbers on the Nantucket islands, but they have been nearly exterminated, though during the last few years, thanks to the efforts of Mr. George H. Mackay, of Boston, the colony there has been protected and is increasing. To the southward these birds are still common, being particularly abun. dant on the Florida coast and among the West India islands. 


\section{FRANKLIN'S GULL.}

\section{LARUS FRANKLINII.}

CHAR. Mantle deep bluish gray; head dark sooty slate color, a patch of white over the eyes; outer wing-feathers barred with black and tipped with white; tail pale pearl gray; under parts white, tinted with rose pink; bill bright red, barred near the end with black; legs dull red. In winter the head is white. Length about 14 inches.

Nest. In a reedy marsh or woody swamp; made of flags or other coarse herbage.

Eggs. 3; pale to dark buff or drab, sometimes tinged with olive, profusely marked with several shades of brown; $2.10 \times 1.40$.

Franklin's Gull is chiefly confined to the western division of this continent, nesting in suitable localities amid the plains from about latitude $43^{\circ}$ to the Saskatchewan valley, where it is abundant. Small numbers have been found nesting in Iowa and Wisconsin. In autumn the flocks migrate southward and range through Central America, some going as far as Peru.

These birds build in communities and are very noisy. While on the wing they utter constantly a shrill and plaintive cry.

\section{BONAPARTE'S GULL.}

\section{LARUS PHILADELPHIA.}

CHAR. Mantle pearl gray; head and neck or hood grayish black or deep slate color; white patches over the eyes; outer wing-feathers with a subterminal bar of black tipped with white, excepting outer web of first primary, which is entirely black; tail white; under parts white, tinged with rose pink; bill black and slender; legs and feet bright red. In winter the head is white, with a dusky spot on the cheeks and a tinge of gray on the nape. In young birds the head and back are more or less tinged with brown, and the tail has a terminal band of black. Length about I4 inches.

Nest. Usually in a tree, sometimes on a high branch, often in a low bush amid a woody swamp; made of twigs and lined with grass or moss.

Eggs. 3-4 (usually 3); pale to dark brown, often tinged with olive, marked with brown and lavender; $2.00 \times 1.40$.

This elegant Gull is common in all parts of the fur countries, where it associates with the Terns, and is distinguished by its 


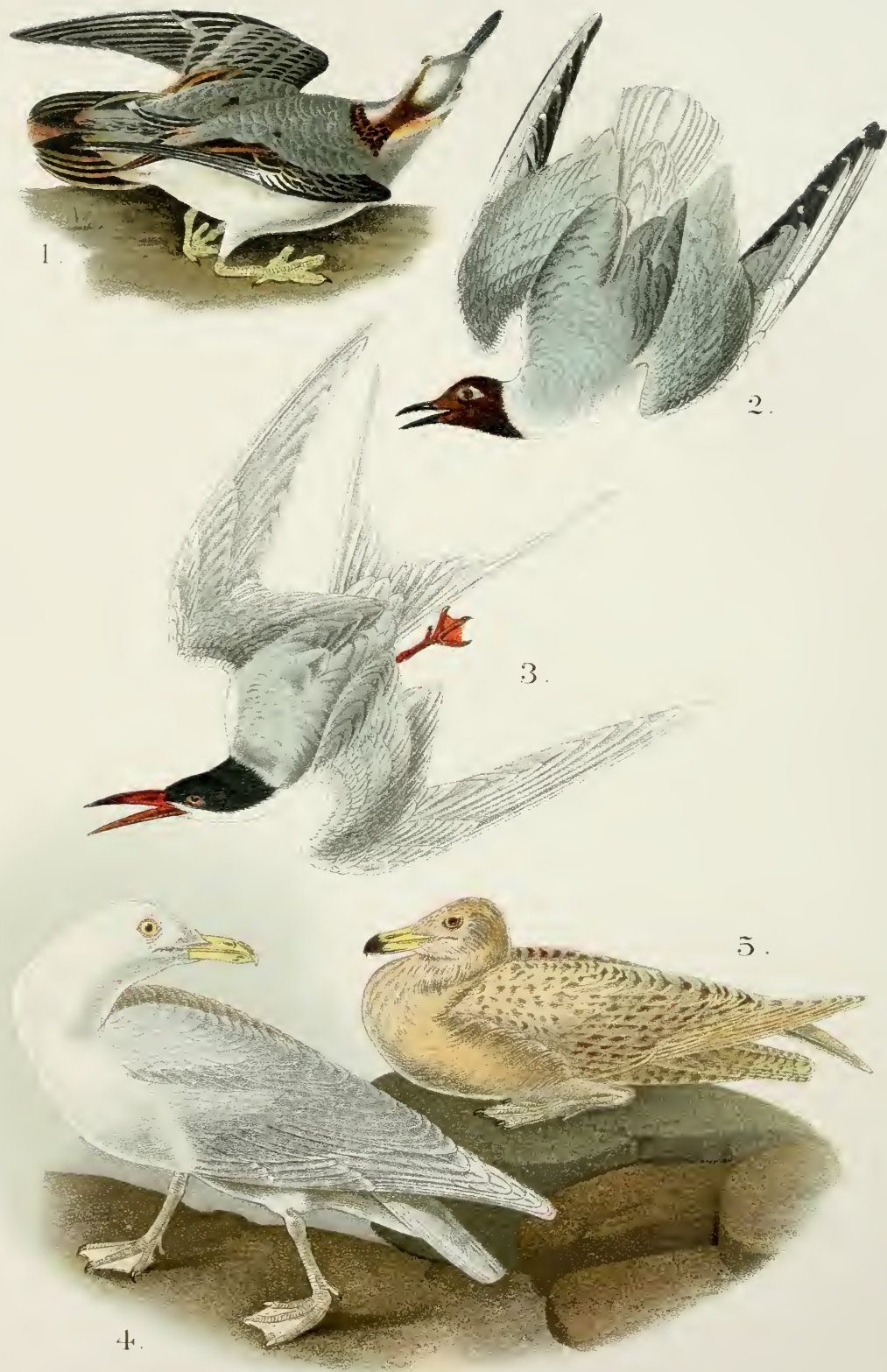

1. Northern Phalarope.

3. Common Tern.

2. Bonaparte's Gull. 4-j. Herring Gull. 

peculiar shrill and plaintive cry. Small flocks, early in autumn, are occasionally seen on the coast of Massachusetts, and sometimes high in the air their almost melodious whistling is heard as they proceed on their way to the South, or inland to feed. Their prey appears to be chiefly insects; and two which I had an opportunity of examining were gorged with ants and their eggs, and some larvæ of moths in their pupa state. These birds both old and young are good food.

Bonaparte's Gull ranges throughout North America, breeding in Manitoba and northward, and migrating by inland and coast routes to and from its winter resorts in the southern portions of the United States.

Small numbers of these Gulls are seen on the New England coast during the summer, but no evidence has been produced of their having nested in this vicinity. It has been suggested that the examples that loiter through the summer without reaching the breeding-grounds are immature or unfertile birds. In the autumn - from early August on - large flocks of these birds swarm along the coast.

\section{ROSS'S GULL.}

WEDGE-TAILED GULL.

RHodosteTHIA ROSEA.

CHAR. Mantle pearl gray; head and tail white; a narrow collar of black around the neck, and a few black feathers near the eyes; outer feather of the wings black; tail long, pointed, and wedge-shaped; bill slender and black; legs and feet dull red, — "terra cotta,"- claws black. Length $13 \frac{1}{2}$ inches.

In winter the black collar is absent, and the crown is tinged with gray. Young birds are distinguished by a band of brownish black on wings and tail.

Nest and Eggs. Unknown.

Although discovered so long ago as I 823 , very little is yet known of the habits or distribution of this Gull. So late as I88I, only twenty-three specimens were to be found in the museums of the world, and the species was supposed to be exceedingly rare, until the American expedition to Point Barrow saw large loose flocks 
during September and October coming in from the sea to the westward, and rapidly passing along the coast towards the northeast.

They were migrating evidently; but whither? and where had they come from, - where had they been nesting? These questions are still unanswered. It has been suggested that the birds may turn southward, and winter in the interior of this continent, - possibly in the Barren Ground region. But a more probable supposition is that offered, I think by Lieutenant Ray, that the flocks move eastward until they meet the floating ice, and then wheel seaward and remain amid the "fields" during the winter months, drifting southward, - too far from land to be observed, and feeding at the edge of the "pack."

But these are speculations only. It has been determined, however, that the species is abundant in the vicinity of Bering Sea and breeds somewhere along the Siberian shore of the Arctic Ocean, that it occurs as an occasional visitor only in other portions of the Arctic region, and as an accidental straggler elsewhere.

Upon what land the nest is placed is still unknown. It must lie somewhere in the frozen region to the westward or northward of Wrangel Island, and may be amid the Liakoff isles, or on some undiscovered island still closer to the Pole. 


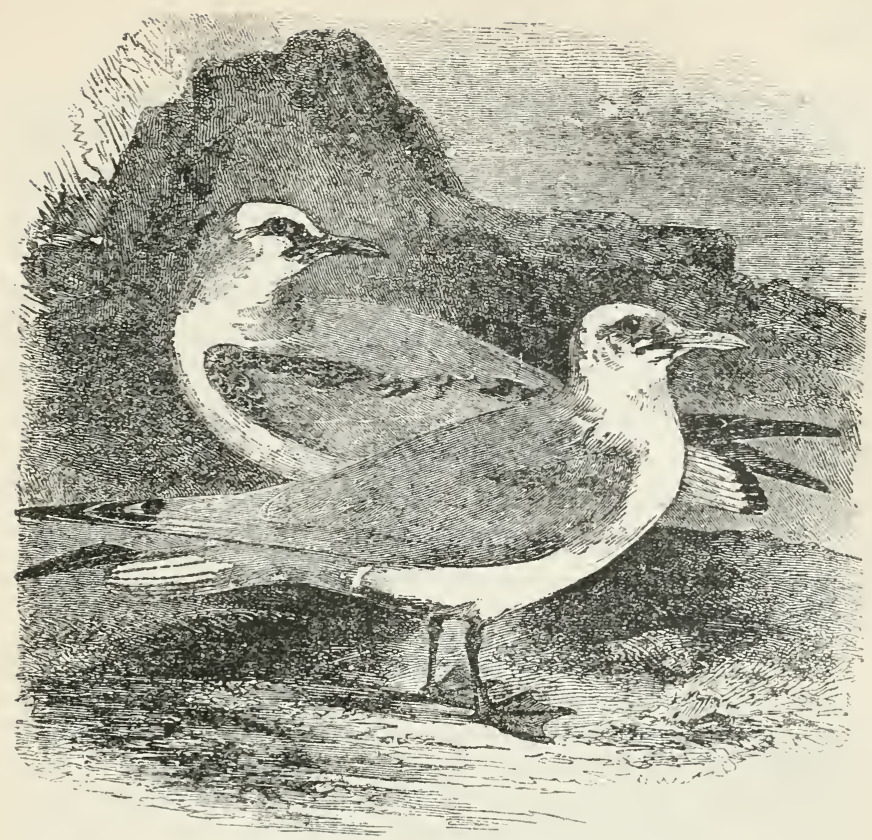

\section{KITTIWAKE.}

\section{RISSA TRIDACTYLA.}

Char. Mantle deep pearl gray; head, neck, tail, and under parts white; ends of outer wing-feathers - the primaries - black, tipped with white; bill greenish yellow ; legs and feet black. Length $15 \frac{1}{2}$ inches.

In winter the back of the neck is more or less suffused with gray. Young birds have a black bill; patch on back of neck, shoulders, and terminal band on the tail brownish black.

Nest. In a colony on the ledges of a cliff or on the mossy turf of an island, occasionally amid the sand or shingle of a sea-beach; usually made of sea-weed or other coarse herbage from "the drift," lined with grass or moss; sometimes a few feathers are added. Each year the bulk is increased by the addition of material. Nests have been found which were mere depressions in the sand, sparsely lined with grass.

Eggs. 2-4; buff of various shades of brown tinted with olive, marked with brown and lavender; average size $2.20 \times$ ז.60.

The Kittiwake, or Tarrock, is found in the north of both continents. It inhabits Newfoundland, Labrador, the islands in the Gulf of the St. Lawrence, the coasts of the Pacific,

voL. II. -16 
Spitzbergen, Greenland, Iceland, and the north of Europe, as well as the Arctic coast of Asia and Kamtschatka. It likewise breeds in some of the Scottish islands, and is generally found about saline lakes and the interior seas and gulfs, but is less frequent on the borders of the ocean. In autumn these birds spread themselves over the banks of rivers and lakes. They feed upon fish, fry, and insects, and nest upon the rocks near the sea-coast, laying three eggs of an olivaceous white, marked with a great number of small dark spots and other grayish ones less distinct. In Iceland they inhabit the cliffs of the coast in vast numbers, and utter loud and discordant cries, particularly on the approach of rapacious birds, as the Sea Eagle, which probably prey upon their young. Both their flesh and eggs are esteemed as good food.

The Kittiwake is more strictly a bird of the ocean than Nuttall's remarks imply. In the Far North - in Greenland and along the shores of the Arctic Ocean - the nesting site of a colony is usually at the head or inland end of a fjord or bay; but in milder latitudes the chosen site is a craggy cliff. against which the angered waves dash with unbroken force. Small colonies are found along our coast as far south as the mouth of the Bay of Fundy; but farther north the number of birds nesting in a community is very large. At one famous range of cliffs in Norway the number of breeding birds has been estimated by a careful naturalist at half a million. In the winter these birds visit the New England shores and extend their range as far south as Virginia, and at that season a few examples visit the Great Lakes.

Our bird differs but little in its habits from other oceanic Gulls. Feeding chiefly on fish, but accepting any diet that drifts within range of its keen sight; drinking salt water in preference to fresh; breasting a gale with ease and grace - soaring in mid-air, skimming close above the crested waves, or swooping into the trough for a coveted morsel; resting upon the rolling billows and sleeping serenely as they roll, with head tucked snugly under a wing; wandering in loose flocks and making comrades of other wanderers; devoted to mate and young and attached to all its kin, - wherever seen or however employed, the Kittiwake is revealed as a typical gleaner of the sea.

The name is derived from the bird's singular cry, which resembles the syllables kitti-aa kitti-aa. 
Note. - Nuttall stated that the European Common Gull ( $L$. canus) - also called SEAMEw, from its feline cry-occurs regularly in winter on our shores; but in this statement he was merely following Richardson, who confounded this species with the Ringbilled Gull. The only known instance of the occurrence of the Seamew on this side of the Atlantic is the taking of one example in Labrador by Dr. Coues.

\section{RING-BILLED GULL.}

\section{LARUS DELAWARENSIS.}

CHAR. Mantle deep pearl gray; head, neck, tail, and under parts white; outer wing-feathers black, tipped with white, the other primaries more or less barred with black and tipped with white; bill greenish yellow, with a band of black near the end and tipped with orange ; legs and feet yellow, sometimes tinged with green.

In winter the head and nape are spotted with pale dusky. Young birds are mottled white and dusky; on the upper parts the dark tint prevails, varied on the back with pale buff, and the lower parts are mostly white; tail dusky, tipped with white and pale gray at the base; shoulders gray; bill dusky, fading toward the base. Length $191 / 2$ inches.

Nest. On a grassy island in a lake or on an ocean cliff, - made of coarse grass or sea-weed.

Eggs. 2-3; ground color varied from pale to dark buff, sometimes tinged with green or slate; profusely marked with several shades of brown and lilac; average size about $2.40 \times 1.70$.

The Ring-billed Gull is distributed throughout this continent, but is more abundant on the saline lakes of the plains than along the sea-coast. In the West the breeding area extends from Southern Minnesota to Great Salt Lake, but on the coast this Gull does not nest farther south than Newfoundland. It is rather common during spring and fall on the New England coast, and in winter ranges from Long Island to the West Indies. Only a few examples have been taken on the Great Lakes.

The chief summer diet of this species, in the interior, is grasshoppers, which the birds catch in the air as well as on the ground. 


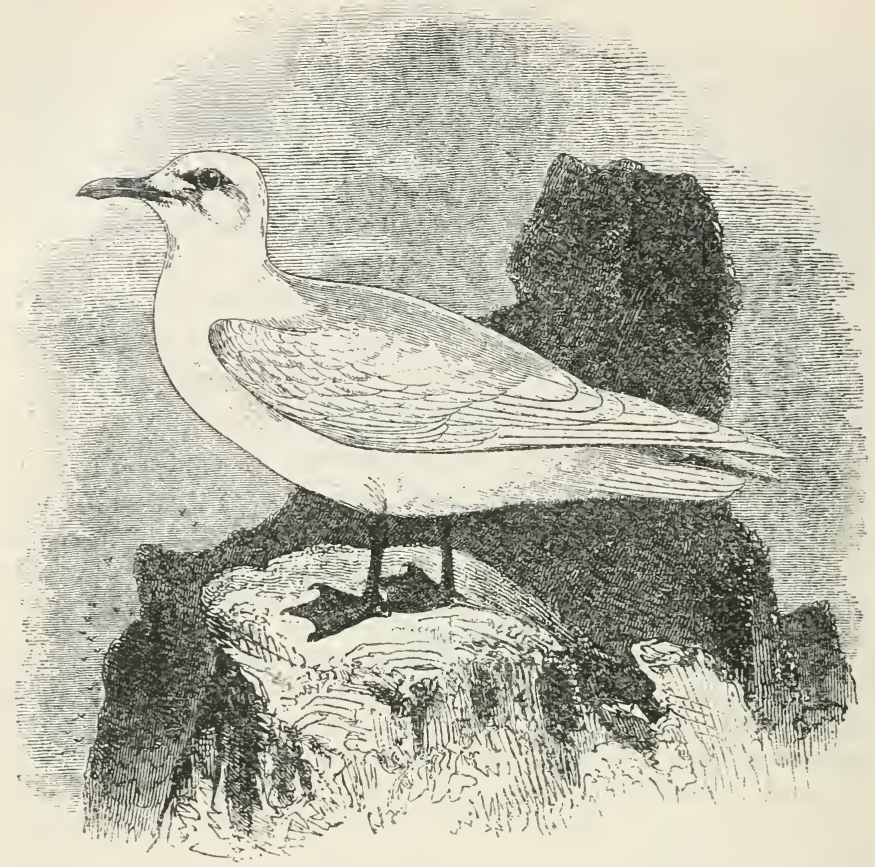

\section{IVORY GULL.}

\section{Gavia ALBA.}

CHAR. Entire plumage white; bill yellow, shading to greenish gray at the base; legs and feet black. Length 18 inches.

In immature birds the upper parts are more or less spotted with brownish gray; wings and tail tipped with dusky brown; bill black.

Nest. On a sea-beach or high cliff, - a slight depression in the soil, sparsely lined with grass or moss, sometimes made of moss and sea-iveed, with a thin lining of down and feathers.

Eggs. I-2; pale to dark buff, more or less tinted with olive, sometimes olive drab, marked with several shades of brown and lilac; aver. age size about $2.40 \times$ I.70.

This beautiful species, called sometimes the Snow Bird, from the pure whiteness of its plumage, is found in great numbers on the coasts of Spitzbergen, Greenland, Davis's Straits, on Baffin's Bay, and on various parts of the northern shores of the 
American continent. It seldom migrates far from its natal regions, is a pretty constant attendant on the whale-fishers, and preys on blubber, dead whales, and other carrion. Dr. Richardson observed it breeding in great numbers on the high broken cliffs which form the extremity of Cape Parry, in latitude $70^{\circ}$. It is also found on the Pacific coast as far as Nootka Sound, and commonly wanders far out to sea, seldom approaching the land but during the period of incubation. Its only note consists of a loud and disagreeable scream.

This Gull has been seen but seldom on the American shore of the Atlantic south of Greenland, and Mr. Hagerup considers it a rare bird in the southern portion of that country, though it is said to occur regularly at Labrador and Newfoundland. Mr. Boardman reports that two examples have been sent to him from Grand Menan, and in the winter of I 880 I examined a freshly killed Gull that a "boatman" told me he had shot the day before off the harbor of St. John. The skin was identified at the Smithsonian Institution as an immature Ivory Gull. On the English coast this species is more frequently seen, and examples have been taken in France and Switzerland; but it is only a straggler outside the Arctic Circle. The species is circumpolar in its range, but breeds in greatest abundance on the islands which lie to the northward of Europe.

The Ivory Gulls appear to spend most of the time amid the packice, often at a long distance from the land. They are ravenous feeders, and omnivorous in their diet, refusing nothing. Small rodents and shell-fish are alike fair game to these gluttons, and they feast with apparent relish on putrid blubber, or even seals' excrement. The cry is said to be a loud and disagreeable scream. 


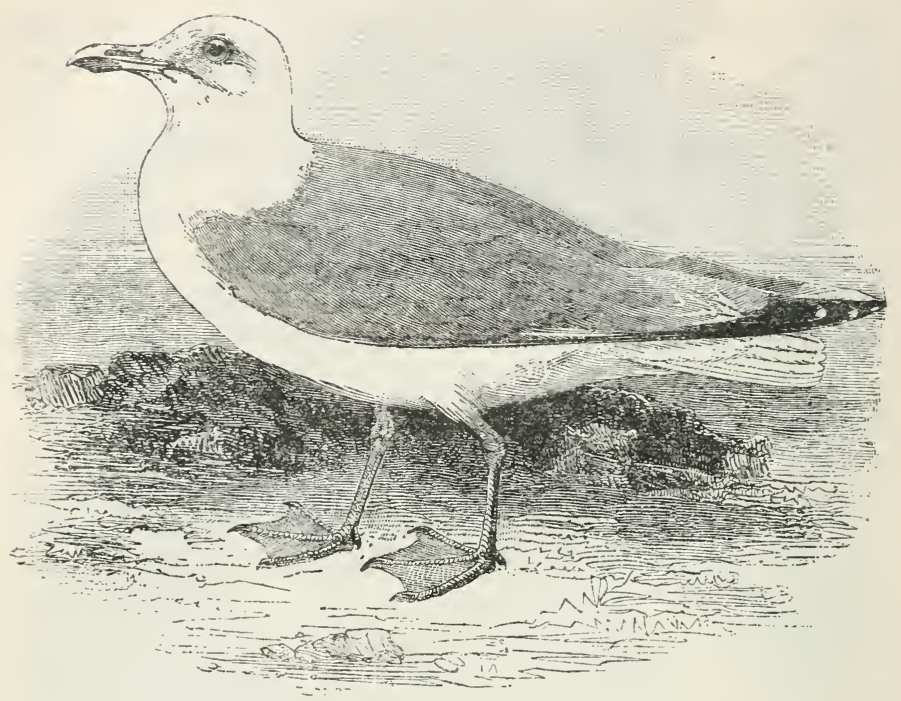

\section{HERRING GULL.}

\section{LARUS ARGENTATUS SMITHSONIANUS.}

CHAR. Mantle deep pearl gray; head, tail, and under parts white; outer wing-feathers mostly black, tipped with white; bill yellow, with a bar of red at the angle; legs and feet flesh color. Length about 24 inches.

In winter the head and neck are streaked with gray. Immature birds are mottled brownish gray and dull white; wings dusky; tail dusky or gray, with a subterminal bar of dusky; bill blackish. In younger specimens the dark tints prevail, some being almost uniformly dusky brown. They do not acquire full plumage for four or five years.

Nest. Usually on a cliff, often on a beach or grassy island, sometimes in a tree or under shelter of a bush, - generally a slight affair, a thin mat of loosely arranged grass or moss; though nests placed in trees are bulky and compact.

Eggs. 2-3 (usually 3); pale to dark buff, more or less tinged with green, sometimes nearly olive drab; marked with several shades of brown and lavender; average size about $2.85 \times$ I.95.

The Herring Gull is common to the milder as well as cold countries of both continents. It is seen sometimes on the 
borders of lakes and rivers, though these visitors are chiefly the young.

Mr. Audubon found these birds breeding abundantly on Grand Menan Island, in the Bay of Fundy, on low fir-trees as well as on the ground, the nest being large and loose, composed of sea-weeds, roots, sticks, and feathers. They are very resentful and clamorous when approached, screaming or barking with a sound like akak kakak. This Gull also inhabits other islands, and he found it again in Labrador. It is ravenous, and tyrannical to other small birds. The young and the eggs are considered as palatable food, though the principal food of the bird is fish or floating matter.

This is the Common Gull of our harbors and inland lakes, occurring in abundance throughout this continent, and breeding from latitude $45^{\circ}$ northward. Turner found it abundant on Hudson Straits, but Hagerup saw very few examples in Southern Greenland. In winter these birds are seen in numbers on the Great Lakes and the larger rivers and lakes of the interior, as well as along the seacoast from the Gulf of St. Lawrence to Cuba.

Mr. Chapman considers "this species is by far the most abundant winter Gull along the coast of the Middle and Southern States."

Although Herring Gulls appear at times both shy and fierce, they are easily domesticated if taken young, and make pleasant pets. They thrive on a mixed diet, and feast on cold porridge or dead rat with equal relish.

Their formula for disposing of a rat is unique. First break the rat's bones by crunching them with the bill; then dip the carcase in water, and when thoroughly soaked, swallow it whole, - head first.

Note. - The European form of the Herring Gull (L. argentatus) is said to occur occasionally on this side of the Atlantic. 


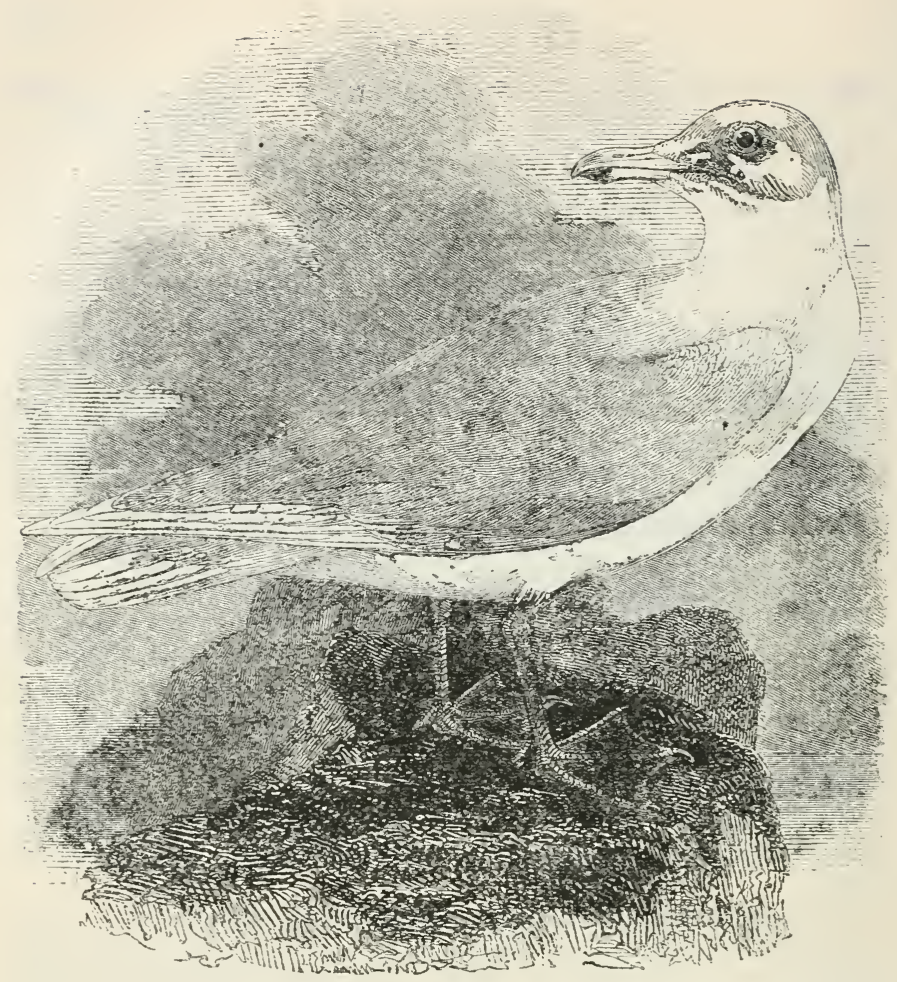

\section{GLAUCOUS GULI.}

\section{BURGOMASTER. \\ LARUS GLAUCUS.}

CHAR. Mantle pale pearl gray, rest of plumage white; bill yellow, with a patch of orange at the angle; legs and feet bright pink. Length about 32 inches; female somewhat smaller.

In winter the head and neck are streaked with pale brownish gray. Immature birds are mottled grayish brown and pale gray; the first plumage is the darkest. In the spring, before the young assume the pearl mantle, their entire plumage becomes white.

Nest. Usually on a cliff, sometimes on a low, grassy island or sandy beach; a slight affair of sea-weed or moss or grass.

Eggs. 2-3; stone drab or olive buff, sometimes pale buff, marked with brown and ashy gray; average size.about $3.00 \times 2.00$. 
This large species is almost wholly confined to the hyperboreal regions, where it inhabits both continents indifferently. It is common in Russia, Greenland, and in all the Arctic and polar seas. In Baffin's Bay and the adjoining straits and coasts it is seen in considerable numbers during the summer. Its winter resorts are yet unknown. From its great rarity in the United States it is probable that this Gull may not migrate far from its summer residence, as there can be no reason why it should proceed south along the Pacific in preference to the Atlantic coast.

These birds are almost continually on the wing, uttering often a hoarse cry, like the Raven. They are extremely tyrannical, greedy, and voracious, preying not only on fish and small birds, but also on carrion, and are said to attend on the walrus to feed on its excrement. They wrest prey from weaker birds, and are often seen hovering in the air or seated on some lofty pinnacle of ice, whence, having fixed their eye upon some favorite morsel, they dart down on the possessor, which, whether Fulmar, Guillemot, or Kittiwake, must instantly resign the prize. The Auk, as well as the young Penguin, they not only rob, but often wholly devour. Pressed by hunger, they sometimes even condescend to share the crow-berry with the Ptarmigan. When not impelled by hunger, they are rather shy and inactive birds, and much less clamorous than others of the genus.

This species is rather boreal in its range, breeding chiefly in the Arctic Ocean, though Mr. Chapman gives its breeding area as "from southern Labrador northward." Farther south it is a straggler merely, though in the Bay of Fundy it is sometimes quite common in mid-winter, and examples have been seen along the New England shores and southward to Long Island and on the Great Lakes.

Nuttall has put into the few lines given above all the peculiar habits of the bird, which combine with some Gull-like traits many of the coarse characteristics of both the Falcon and Vulture.

Some observers have reported that the flocks are at times very noisy, particularly when settling for the night; but those I have met with in winter have been rather silent. Their cry is harsh, and at times very loud; it sounds something like the syllables $k u k$-lak', - I have seen it written cut-leek. 


\section{ICELAND GULL.}

\section{WHITE-IVINGED GULL.}

\section{LARUS LEUCOPTERUS.}

CHAR Mantle pale pearl gray, rest of plumage white; bill yellow, with a patch of orange at the angle; legs and feet bright pink. Length about 25 inches, the female smaller. In winter the head and neck are streaked with pale brownish gray. Young birds are mottled grayish brown and pale gray, and become whiter with each moult.

Nest. On a cliff or sandy beach; when in the sand, it is a mere depression slightly lined with grass, but when a rock is chosen for the site a compact structure is formed of sea-weed and grass lined with moss.

Eggs. 2-3; pale or dark buff more or less tinged with green, sometimes almost olive drab; average size about $2.75 \times$ i.So.

Iceland Gull is a misnomer for this bird, as it appears in Iceland in winter only, and then in very small numbers. The true home of this Gull is in that portion of the Arctic Ocean which lies north of America, and its breeding area extends from Greenland to Alaska; elsewhere it is but a visitor.

During the winter these birds range along the Atlantic shores from Labrador to Long Island, though they are not numerous south of the Bay of Fundy. A few examples have been taken on the Great Lakes.

In appearance this species is a small edition of the Glaucous Gull, there being no perceptible difference in the coloration; but their habits are quite different.

The flight of the Iceland Gull, its feeding habits, and its manners generally, suggest a close affinity to the Herring Gull rather than to the Burgomaster. 


\section{KUMLIEN'S GULL。}

\section{LARUS KUMLIENI.}

Char. Mantle and wings pearl gray; wings tipped with white, the outer primaries having a sub-terminal space of ashy gray; bill yellow, with a spot of red at the angle; legs and feet bright pink. Length about 24 inches.

Immature birds are more or less moitled with dusky or brownish gray, very young specimens being very dark.

Nest. On a cliff.

Eggs. Not known.

This species was described in 1883 by Mr. William Brewster from specimens that had been taken in winter in the Bay of Fundy. Kumlien found the bird breeding in numbers on the shores of Cumberland Gulf ; but it is not known to breed in Greenland, nor have nests been discovered elsewhere. In the second edition of the A. O. U. "Check-List" the distribution of this species is given thus : "North Atlantic coast of North America, breeding in Cumberland Gulf ; south in winter to the coasts of the Middle States." Of the bird's distribution and of its distinctive habits nothing farther is known.

In coloration this species is a connecting link between leucopterus and argentatus.

Note. - The Siberian Gull (Larus affinis) occasionally visits Greenland. 


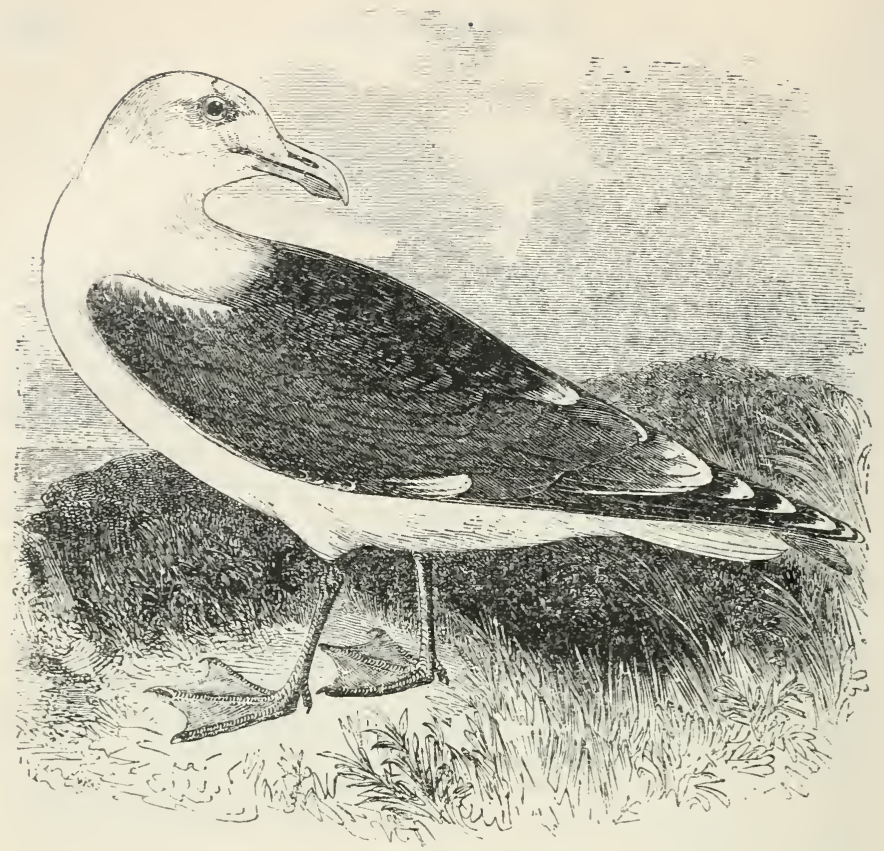

\section{GREAT BLACK-BACKED GULL.}

\section{SADDLE-BACK. COBB.}

\section{LARUS MARINUS.}

CHAR. Mantle slaty brown; outer wing-feathers more or less black, tipped with white; rest of plumage white; bill yellow, red at the angle; legs and feet pink. Length about 30 inches.

The full plumage is not assumed until the fourth year Immature birds are mottled brown and white, very young specimens having the upper parts almost entirely brown, and the bill dusky.

Nest. On an inaccessible cliff by the sea, or upon a rocky island in a lake, - a mere depression in the turf, lined with grass or sea-weed ; sometimes a bulky affair made of coarse herbage and lined with grass and a few feathers.

Eggs. 2-3 (usually 3); buffish gray to deep buff, sometimes slightly tinged with olive, boldly blotched with brown and gray; average size about $3.00 \times 2.10$.

The Saddle-back, or Black-backed Gull, is a general denizen of the whole northern hemisphere, and extends its residence in 
America as far as Paraguay. At the approach of winter it migrates not uncommonly as far as the sea-coasts of the Middle and extreme Southern States. If Mr. Audubon be correct in considering $L$. argentatoides as a state of imperfect plumage of the present species, it breeds as far north as the dreary coasts of Melville Peninsula. It is also found in Greenland, Iceland, Lapmark, and the White Sea. It is also abundant in the Orkneys and Hebrides in Scotland, but is a winter bird of passage on the coasts of Holland, France, and England. It rarely visits the interior or fresh waters, and is but seldom seen as far south as the Mediterranean.

The Black-backed Gull feeds ordinarily upon fish, both dead and living, as well as on fry and carrion, - sometimes also on shell-fish; and, like most of the tribe of larger Gulls, it is extremely ravenous and indiscriminate in its appetites when pressed by hunger. It watches the bait of the fisherman, and often robs the hook of its game. As Mr. Audubon justly and strongly remarks, it is as much the tyrant of the sea-fowl as the Eagle is of the land-birds. It is always on the watch to gratify its insatiable appetite; powerfully muscular in body and wing, it commands without control over the inhabitants of the ocean and its borders. Its flight is majestic, and, like the Raven, it soars in wide circles to a great elevation, at which times its loud and raucous cry or laughing bark of 'cak, 'cak, 'cak is often heard. Like the keen-eyed Eagle, it is extremely shy and wary, most difficult of access, and rarely obtained but by accident or stratagem. It is the particular enemy of the graceful Eider, pouncing upon and devouring its young on every occasion, and often kills considerable-sized Ducks. In pursuit of crabs or lobsters it plunges beneath the water; has the ingenuity to pick up a shell-fish, and carrying it high in the air, drops it upon a rock to obtain its contents; it catches moles, rats, young hares; gives chase to the Willow Grouse, and sucks her eggs or devours her callow brood; it is even so indiscriminate in its ravenous and cannibal cravings as to devour the eggs of its own species. In short, it has no mercy on any object that can contribute in any way to allay the cravings of 
its insatiable hunger and delight in carnage. Though cowardly towards man, before whom it abandons its young, its sway among the feathered tribes is so fierce that even the different species of Lestris, themselves daring pirates, give way at its approach.

In Europe the Saddle-backed Gulls breed as far south as the Lundy Islands in the Bristol Channel, in England. Mr. Audubon, who lately visited the dreary coast of Labrador, found them breeding there on rocks, laying about three eggs, large, and of a dirty dull brown, spotted and splashed all over with dark brown. The young as soon as hatched walk about among the rocks, patiently waiting the return of their parents, who supply them amply with food until they become able to fly, after which, as among the true rapacious birds, they are driven off and abandoned to their own resources.

This species, like others, does not attain its complete plumage until the third year. The full-plumaged are dark-colored birds, breeding together. The eggs and young are eatable; the latter, taken before they are able to fly, are pickled in large quantities, and used in Newfoundland for winter provision.

The Saddle-back breeds from the Bay of Fundy to high latitudes, and in winter is found along the coast from Greenland to Long Island, and occasionally to Virginia and South Carolina. A few examples visit the Great Lakes. It is not frequently seen in the harbors of New England, but on the open sea-shore is quite common.

Mr. Brewster reports that these birds have "four distinct cries : a braying $h a-h a-h a$, a deep keow, keow, a short barking note, and a long-drawn groan, very loud and decidedly impressive." 


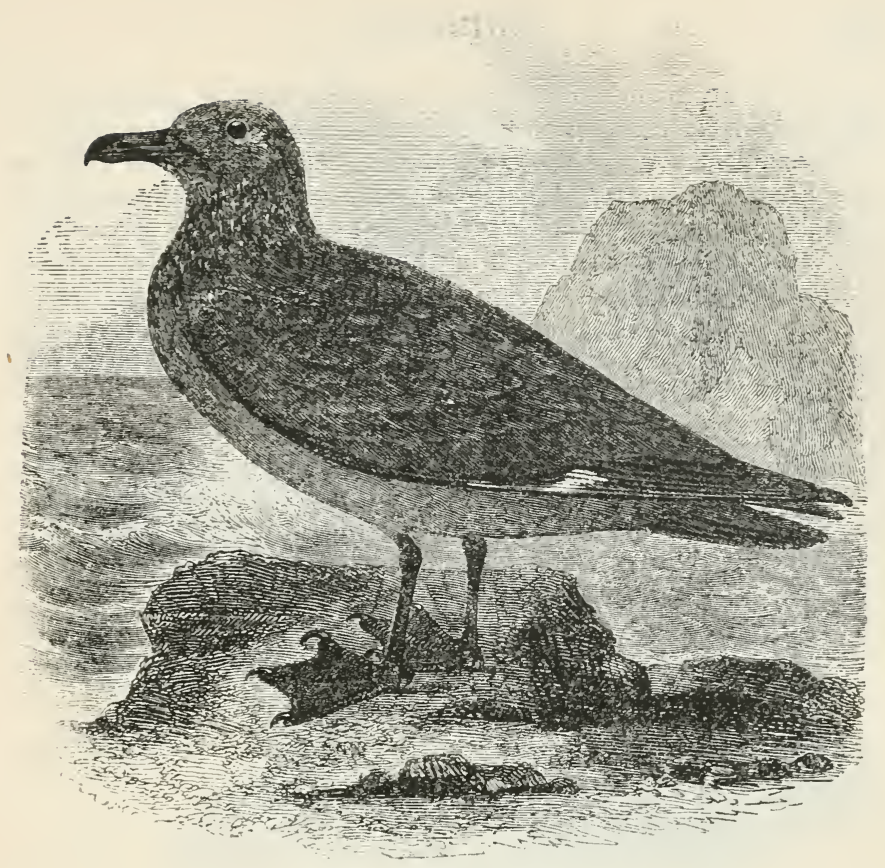

\section{SKUA.}

\section{PARASITIC GULL.}

\section{MEgALESTRIS SKUA.}

CHAR. Upper parts sooty brown, varied with reddish brown and dull white, the nape spotted with buff; wings and tail brown, shading to white at the base, which on the wing forms a conspicuous patch when in flight; under parts paler brown, the breast varied with rufous ; bill, legs, and feet, black. Length about 22 inches.

Nest. On an inaccessible ocean island; a hollow pressed in the moss and sparsely lined with grass and a few feathers.

Eggs. I-3 (usually 2); pale to dark buff or buffish brown, sometimes with a slight tinge of olive, marked with darker brown and gray; average size about $2.80 \times 2.00$.

This Sea-Falcon, with raptorial beak and claws, and Hawk-like quality of character, - preying upon the weak and the small of its own race, robbing those it cannot kill, and by way of individuality adding to its relish for flesh and fish a partiality for eggs, - this 
pirate of the main, daring and strong, and wary as bold, has too slight claim for recognition here to demand an extended notice.

These birds live as solitary as Eagles, but defend their nests as few Eagles dare, attacking fiercely man or dog venturing to approach, and displaying a front that few dogs care to close upon. The nests are built chiefly within the Arctic Circle and in northern Europe, and the birds visit our waters only in winter, and but rarely then; and the few examples that do wander this way are never seen near the shore, but are met with by the fishermen, whose boats they follow for the refuse.

In the A. O. U. Check-List the statement is made that the bird is "apparently rare on the coast of North America," and North Carolina is given as the southern limit of its range. Mr. Chapman reports that there is "one record" of the bird having been captured on the shore of Long Island. 


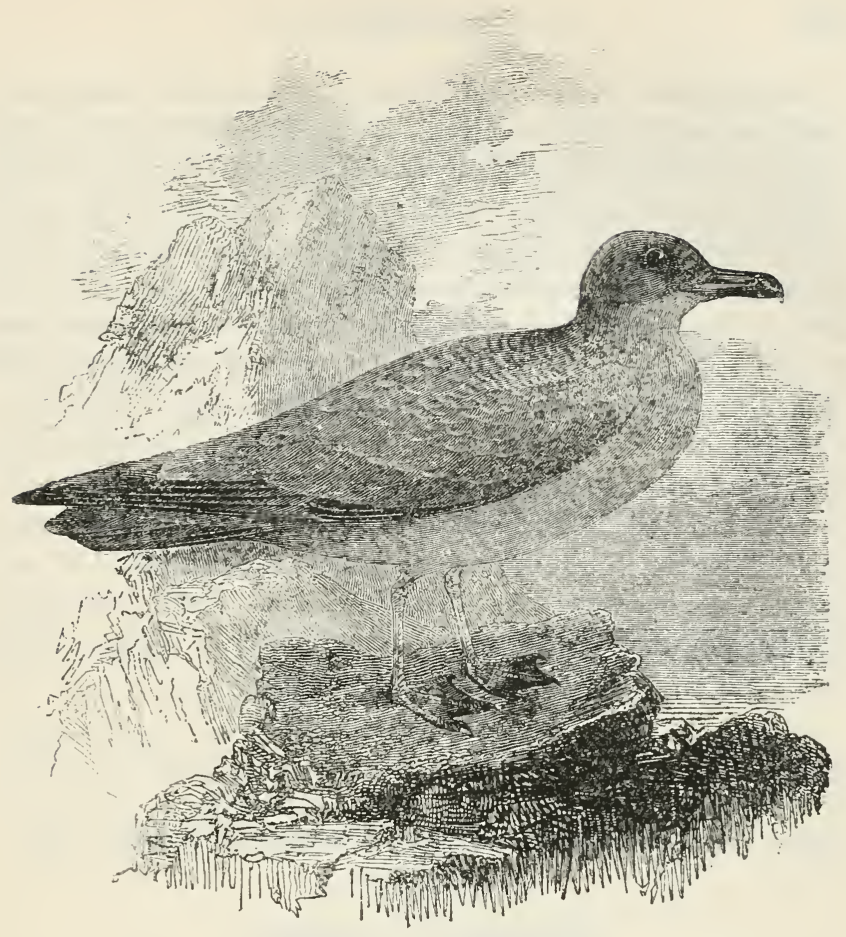

POMARINE JAEGER.

\section{STERCORARIUS POMARINUS.}

CHAR. Light phase: Top of head and upper parts sooty brown or dusky; neck and under parts white, the neck tinged with yellow. Dark phase : Entirely dark sooty brown or slaty black; the two middle tailfeathers project beyond the other and are twisted. Bill dark gray, tipped with black; legs and feet black. Length about $2 \mathrm{I}$ inches.

Some naturalists think the dark phase assumed by this genus is merely melanistic; but numerous examples are met with that combine variations of the two, these " pied "forms being in the majority rather than exceptional. Young birds are more or less mottled with buff.

Nest. On a dry knoll of a moorland marsh or tundra, sometimes on a rock, - a mere hollow stamped in the moss.

Eggs. 2; pale to dark olive, tinged with russet and boldly marked with brown; average size $2.35 \times 1.65$.

VOL. II. - I7 
This species chiefly inhabits the Arctic seas of both continents, whence it migrates short distances in winter, and is then seen in Sweden and Norway, and perhaps also in the Orkneys and the west of Scotland; the old very rarely visit the banks of the Rhine and the coasts of the ocean; the young are more given to wandering, and are sometimes even seen upon the lakes of Switzerland and Germany. According to Richardson, the Pomarine Jaeger is seen in the Arctic seas of America and about the northern outlets of Hudson Bay. Mr. Audubon obtained specimens on the coast of Labrador. It subsists on putrid and other animal substances thrown up by the sea, and also on fish and other matters which the Gulls disgorge when pursued by it; it also devours the eggs of sea-birds. It goes more to sea in winter, and also towards the south, arriving at Hudson Bay in May, coming in from seaward. It is rare and accidental on the coast of the United States.

This ocean prowler and parasite breeds in the Arctic regions, and in winter roams on the open sea, wandering from the latitude of New York southward. It occurs occasionally in the Bay of Fundy, and a few examples have been taken on the Great Lakes.

\section{PARASITIC JAEGER.}

ARCTIC JAEGER. RICHARDSON'S JAEGER. MAN-OF-WAR.

\section{STERCORARIUS PARASITICUS.}

CHAR. Light phase: Upper parts slaty brown; top of head grayish brown; rest of head and neck white, varied with yellow; under parts white. Dark phase: Entire plumage sooty slate. Shafts of primaries white; middle tail-feathers long, narrow, and pointed; bill slaty gray tipped with black; legs and feet black. Length about 20 inches.

Young birds of both phases are mottled and more or less varied with buff. Adults also are met with in a mixed plumage, and these mottled specimens are much more numerous than birds in full plumage.

Nest. On an open moorland near the sea or the margin of a lake, or upon an ocean island, - a mere hollow in the mossy turf, slightly lined with grass and leaves.

Eggs. I-3 (usually 2); olive green, sometimes deeply tinged with yellow or reddish brown, marked with brown of several shades and lilac; average size about $2.30 \times 1.60$. 
This species has been incorrectly named the Arctic Jaeger, - or Skua, as the birds of this group are called by British Ornithologists, - for it is less Arctic in its distribution than either of its relatives. All this group breed in high latitudes; but while the other species build within the Arctic Circle, the Parasitic Jaeger nests in numbers in Southern Greenland and throughout the higher portions of the fur countries, and nests have been found in Scotland. In winter this bird is common along the coast, ranging from Long Island to Brazil.

The Jaegers are very similar in their habits. All are strong birds, of swift and skilful flight, and all obtain their chief food supply by robbing the Gulls of their prey.

The Kittiwake is the victim most frequently selected by the Parasitic Jaeger, and the little Gull has small chance for escape from its more powerful antagonist, who pursues and attacks until the coveted fish is dropped. But our bird does not limit its diet to fish, - -young Gulls and eggs are quite as acceptable to the Jaeger's palate, - nor does it refuse any carrion the drift may offer, and in extremity will feast on crow-berries.

\section{LONG-TAILED JAEGER.}

\section{BUFFON'S SKUA.}

\section{StERCORARIUS LONGICAUDUS.}

CHAR. Upper parts dark brownish slate, shading to darker on wings and tail; top of head sooty black; rest of head and neck buffish yellow, paler on the throat; breast white, shading into the grayish brown of the belly; shafts of two outer primaries white; middle tail-feathers narrow and pointed, and extending four to eight inches beyond the lateral feathers; bill grayish black; legs olive gray, feet black. Length about 23 inches.

Young birds are grayish brown, more or less barred with white and buff. Distinguished from arcticus by its rather smaller and slimmer form and the greater length, usually, of the central tail-feathers, also by the grayer tints of the back and the absence of white on all the primaries excepting the outer two.

Nest. In a colony on a barren moorland or tundra near the sea, or by an inland lake or upon an island, - a slight hollow stamped in the turf or soil and lined with a few bits of grass or leaves.

Eggs. I-3 (usually 2); pale to dark olive, sometimes reddish buff, marked with brown and gray; average size about $2.10 \times 1.50$. 
This is the most northerly in its range of the Jaegers, and has the widest distribution. Its breeding area lies exclusively within the Arctic Circle, and follows that line throughout its circuit. These birds appear off the New England coasts during the spring and fall, and at those seasons are common in the Bay of Fundy. They winter southward as far as the Gulf of Mexico.

In its habits the Long-tailed Jaeger does not differ materially from the other species.

\section{BLACK SKIMMER.}

\section{SCISSOR-BILL.}

RYNCHOPS NIGRA.

CHAR. Upper parts black, deeper on the wings; outer tail-feathers white; forehead, patch on the wings, and under parts white; bill long and compressed, the lower mandible much longer than the upper; basal half of bill bright red, the rest black; legs and feet red. Length I7 to I9 inches.

Nest. A slight hollow scratched in the sand of a sea-beach or barren island.

Eggs. 2-5; creamy white or pale buff boldly marked with rich brown and lilac; average size about $1.75 \times 1.35$.

The Cut-water, or Black Skimmer, is a bird of passage in the United States, appearing in New Jersey from its tropical winter quarters early in May. Here it resides, and breeds in its favorite haunts along the low sand-bars and dry flats of the strand, in the immediate vicinity of the ocean. The nests of these birds have been found along the shores of Cape May about the beginning of June, and consist of a mere hollow scratched out in the sand, without the addition of any extraneous materials. As the birds, like the Terns and Gulls, to which they are allied, remain gregarious through the breeding-season, it is possible to collect a half bushel or more of the eggs from a single sand-bar within the compass of half an acre; and though not very palatable, they are still eaten by the inhabitants of the coast. The female only sits on her nest during the night or in wet and stormy weather; but the young 
remain for several weeks before they acquire the full use of their wings, and are during that period assiduously fed by both parents. At first they are scarcely distinguishable from the sand by the similarity of their color, and during this period may often be seen basking in the sun and spreading out their wings upon the warm beach. The pair, retiring to the South in September or as soon as their young are prepared for their voyage, raise but a single brood in the season.

The Skimmer is, I believe, unknown to the north of the seacoast of New Jersey, and probably passes the period of reproduction along the whole of the southern coast of the United States. The species is also met with in the equatorial regions, where it is alike resident as far as Surinam, but never penetrates into the interior, being, properly speaking, an oceanic genus. Its voice, like that of the Tern, is loud, harsh, and stridulous. In quest of its usual prey of small fish and mollusca, it is frequently observed skimming close along shore about the first of the flood tide, proceeding leisurely with a slowly flapping flight, and balancing itself on its long and outstretched wings; it is seen every now and then to dip, with bended neck, its lower mandible into the sea, and with open mouth receives its food, thus gleaning and ploughing along the yielding surface of the prolific deep. The birds keep also among the sheltered inlets which intervene between the mainland and the sea, where they roam about in companies of eight or ten together, passing and repassing at the flood tide, like so many grotesque and gigantic Swallows, the estuaries of the creeks and inlets which penetrate into the salt-marshes, exhibiting the necessary alertness in the capture of their approaching prey, which often consists of small crabs and the more minute crustaceous animals which abound in such situations, and around the masses of floating sea-weed and wrecks. But though so exclusively maritime, the range of the Cutwaters is entirely limited to the peaceful and calm borders of the strand; notwithstanding the vast expansion of their long wings, they have no inducement to follow the adventurous flight of the Petrel, as the ever-agitated and wave-tossed sur- 
face of the restless deep would be to them, with the peculiar mechanism of their bill, a barren void over which they consequently never roam, and on whose bosom they rarely ever rest, preferring, with the Terns, when satisfied with food, the calm, indolent, and surer repose of the isolated shoal left bare by the recess of the tide, where, associated in flocks, they are often seen to rest from their toilsome and precarious employ.

The Skimmer continues to this day to make its nest on the sands of the New Jersey shore, and thence southward, and is rather common on the coast of Virginia and Florida. Fishermen have reported that Skimmers nested on Muskegat many years; but they have ceased coming so far north regularly, though occasionally, after the breeding season is over, an individual makes an excursion along the New England shore, and several have been seen in the Bay of Fundy. 


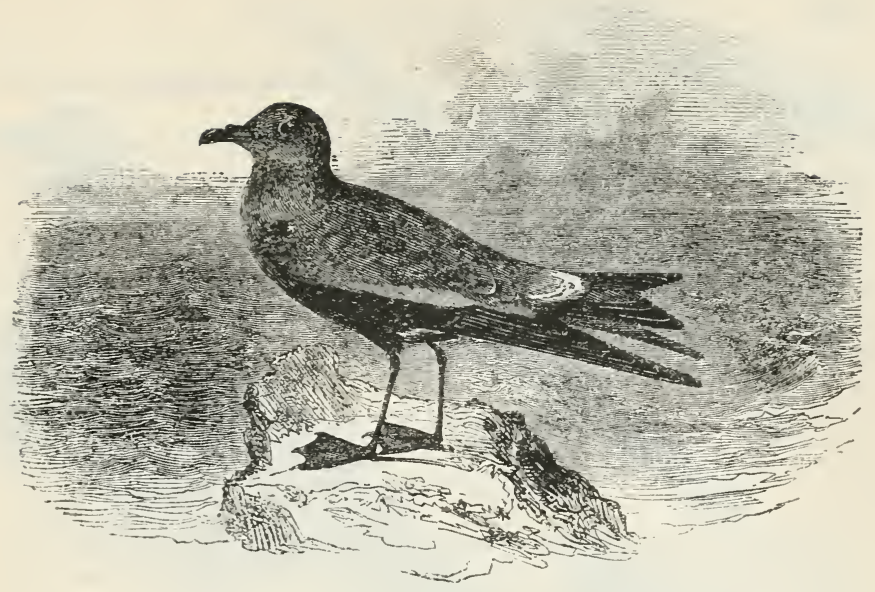

\section{LEACH'S PETREL.}

\section{FORK-TAILED PETREL.}

\section{OCEANODROMA LEUCORHOA.}

Char. Upper parts dull black; upper tail-coverts white; tail forked; under parts sooty black; bill, legs, and feet black. Length about $\delta$ inches.

Nest. A thin cushion of grass or moss at the end of a burrow in the soil at the top of an ocean cliff.

Eggs. I ; white, marked chiefly around the larger end with fine spots of reddish brown and lilac; average size about $1.30 \times 1.00$.

This is a bird of the northern hemisphere, being as common on the Pacific Ocean as on the Atlantic. Its chief breeding-station on our shores is among the islands at the mouth of the Bay of Fundy; but the open ocean is the bird's true home.

Leach's Petrels are seldom seen about their nesting site during the day, though in the evening they assemble there; and when fluttering through the twilight or under the moon's guidance, they have the appearance of a foraging squad of bats, though the bird's wild, plaintive notes betray their race. The Petrels are not strictly nocturnal, however; for while one of a pair sits close on the nest all day, - and this one has been generally the male, in my experience, - the mate is out at sea.

When handled, these birds emit from mouth and nostrils a small quantity of oil-like fluid of a reddish color and pungent, musk-like 
odor. The air at the nesting site is strongly impregnated with this odor, and it guides a searcher to the nest.

Petrels appear very helpless on the land, walking or rising on the wing with difficulty; but in the air they are as graceful as swal. lows, and fly with equal skill. A storm is their delight, and the trough between white-capped waves a favorite feeding place. The birds skim close to the water, and continually dip their feet into it as they fly.

\section{WILSON'S PETREL.}

\section{OCEANITES OCEANICUS.}

CHAR. General plumage sooty black, darker on wings and tail ; tailcoverts white; tail square; bill and legs black; webs of the feet yellow at their bases. Length about $7 \frac{1}{2}$ inches.

Nest. In crevices of rocks or amid loose fragments.

Eggs. I ; white, marked chiefly around the larger end with fine spots of purplish red; average size about $\mathrm{I} .30 \times 0.90$.

This ominous harbinger of the deep is seen nearly throughout the whole expanse of the Atlantic, from Newfoundland to the tropical parts of America, whence it wanders even to Africa and the coasts of Spain. From the ignorance and superstition of mariners, an unfavorable prejudice has long been entertained against these adventurous and harmless wanderers; and as sinister messengers of the storm, in which they are often involved with the vessel they follow, they have been very unjustly stigmatized by the name of Stormy Petrels, Devil's Birds, and Mother Carey's Chickens. At nearly all seasons of the year these Swallow-Petrels in small flocks are seen wandering almost alone over the wide waste of the ocean.

On the edge of soundings, as the vessel loses sight of the distant headland and launches into the depths of the unbounded and fearful abyss of waters, flocks of these dark, swiftflying, and ominous birds begin to shoot around the vessel, and finally take their station in her foaming wake. In this situation, as humble dependants, they follow for their pittance of fare, constantly and keenly watching the agitated surge for 


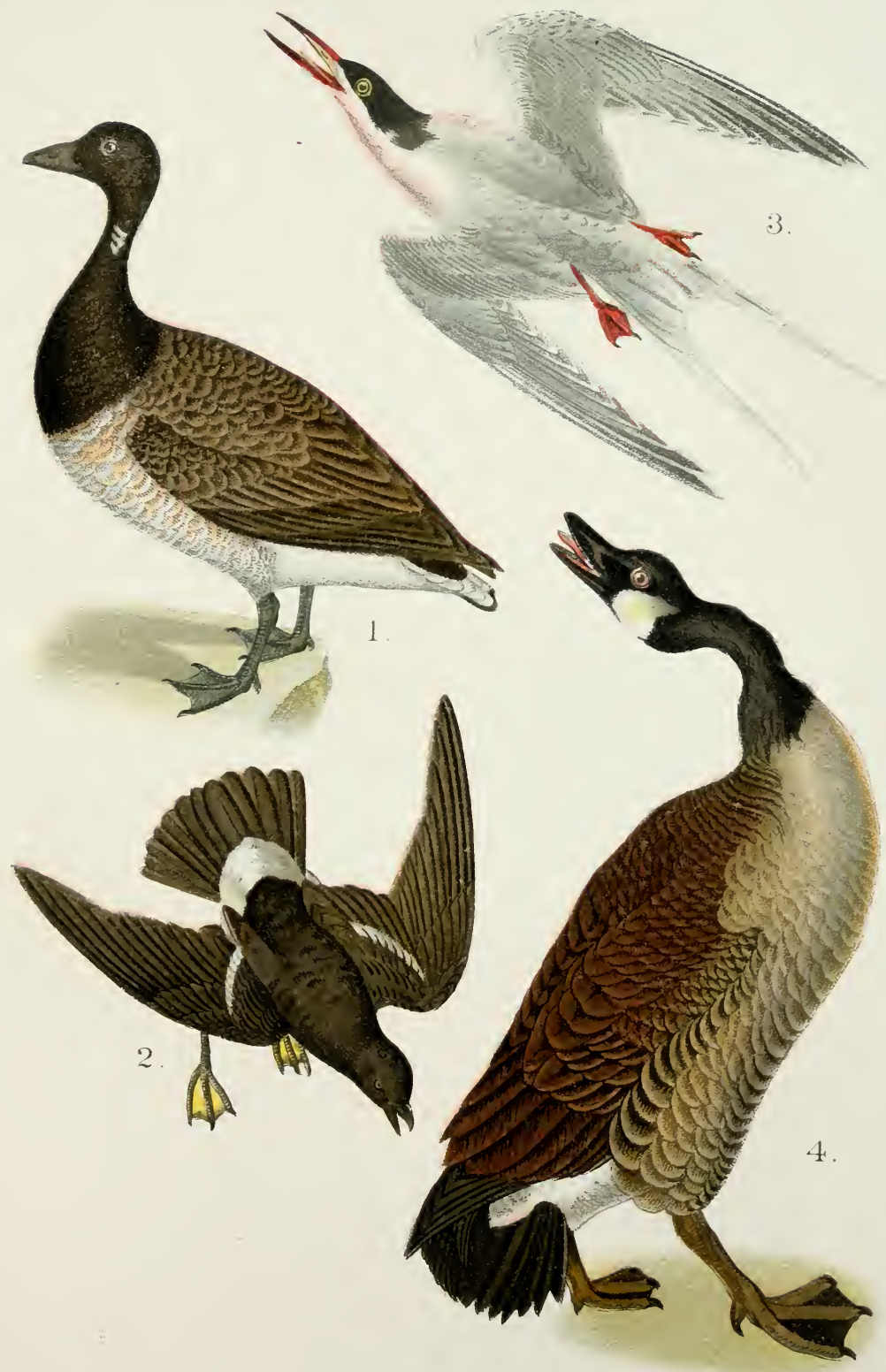

1. Brant .

2. Wilson's Petrel.
3. Roseate Tern .

4. Canada Goose. 

floating mollusca, and are extremely gratified with any kind of fat animal matter thrown overboard, which they invariably discover, however small the morsel, or mountainous and foaming the raging wave on which it may happen to float. On making such discovery they suddenly stop in their airy and swallowlike flight, and whirl instantly down to the water. Sometimes nine or ten thus crowd together like a flock of chickens scrambling for the same morsel; at the same time, pattering on the water with their feet, as if walking on the surface, they balance themselves with gently fluttering and outspread wings, and often dip down their heads to collect the sinking object in pursuit. On other occasions, as if seeking relief from their almost perpetual exercise of flight, they jerk and hop widely over the water, rebounding, as their feet touch the surface, with great agility and alertness.

There is something cheerful and amusing in the sight of these little voyaging flocks steadily following after the vessel, so light and unconcerned, across the dreary ocean. During a gale it is truly interesting to witness their intrepidity and address. Unappalled by the storm that strikes terror into the breast of the mariner, they are seen coursing wildly and rapidly over the waves; descending their sides, then mounting with the breaking surge which threatens to burst over their heads, sweeping through the hollow waves as in a sheltered valley, and again mounting with the rising billow, they trip and jerk sportively and securely on the surface of the roughest sea, defying the horrors of the storm, and, like some magic being, seem to take delight in braving overwhelming dangers. At other times we see these aërial mariners playfully coursing from side to side in the wake of the ship, making excursions far and wide on every side, now in advance, then far behind, returning again to the vessel as if she were stationary, though moving at the most rapid rate. A little after dark they generally cease their arduous course and take their interrupted rest upon the water, arriving in the wake of the vessel they had left, as I have observed, by about nine or ten o'clock of the following morning. In this way we were followed by the same 
flock of birds to the soundings of the Azores, and until we came in sight of the Isle of Flores.

According to Buffon, the Petrel acquires its name from the Apostle Peter, who, as well as his Master, is said to have walked upon the water. At times we hear from these otherwise silent birds by day, a low weet, weet, and in their craving anxiety apparently to obtain something from us, they utter a low, twittering 'pe-üp, or chirp. In the night, when disturbed by the passage of the vessel, they rise in a low, vague, and hurried flight from the water, and utter a singular guttural chattering like kük $k u k$ $k^{\prime} k, k^{\prime} k$, or something similar, ending usually in a sort of low twitter like that of a Swallow.

These Petrels are said to breed in great numbers on the rocky shores of the Bahama and the Bermuda Islands and along some parts of the coast of East Florida and Cuba. Mr. Audubon informs me that they also breed in large flocks on the mud and sand islands off Cape Sable in Nova Scotia, burrowing downwards from the surface to the depth of a foot or more. They also commonly employ the holes and cavities of rocks near the sea for this purpose. The eggs, according to Mr. Audubon, are three, white and translucent. After the period of incubation they return to feed their young, only during the night, with the oily food which they raise from their stomachs. At these times they are heard through most part of the night making a continued cluttering sound, like frogs. In June and July, or about the time that they breed, they are still seen out at sea for scores of leagues from the land, the swiftness of their flight allowing them daily to make these vast excursions in quest of their ordinary prey; and hence, besides their suspicious appearance in braving storms, as if aided by the dark Ruler of the Air, they breed, according to the vulgar opinion of sailors, like no other honest bird; for taking no time for the purpose on land, they merely hatch their egg under their wings as they sit on the water.

The food of this species, according to Wilson, appears to consist of the gelatinous spora of the gulf-weed (Fucus natans), as well as small fish, barnacles, and probably many 
small mollusca. Their flesh is rank, oily, and unpleasant to the taste. Their food is even converted into oil by the digestive process, and they abound with it to such a degree that, according to Brunnich, the inhabitants of the Faro Isles make their carcases serve the purpose of a candle by drawing a wick through the mouth and rump, which being lighted, the flame is for a considerable time supported by the fat and oil of the body.

Audubon led Nuttall astray regarding the breeding of Wilson's Petrel, confounding it with Leach's Petrel. The nesting-place of the present species and the appearance of the egg were unknown until a few years ago, when the members of the Transit of Venus Expedition discovered a colony of the birds on Kerguelen Island, in the Southern Ocean, and brought back some of the eggs, which were taken during January and February.

Wilson's Petrel, therefore, would have little reason upon which to rest a claim to be ranked as an "American" bird, were it not for the "three mile-limit" clause in international law. These birds come towards the shore and into the harbors and creeks in search of food. During the summer they are met with all along our coast, from northern Labrador to the tropics.

\section{STORMY PETREL. \\ MOTHER CAREY'S CHICKEN. \\ PROCELLARIA PELAGICA.}

CHAR. General plumage sooty black or blackish brown; upper tail feathers white, tipped with black; tail square or slightly rounded; bill, legs, and feet black. Length about $5 \frac{3 / 4}{4}$ inches.

Nest Usually in a burrow, sometimes in a crevice of a rock or amid loose stones; generally a thin cushion of weed-stems or grass, but often the egg is laid on the bare soil.

Eggs. I ; white, faintly marked with fine spots of reddish brown; average size $1.15 \times 0.85$.

Of the three species of Swallow-like Petrels that are seen regularly on the North Atlantic, the present is the rarest; and this is seldom seen near the shore, and never south of New England. It breeds abundantly on the British Islands and along the coast of Norway, and is said to breed in the Mediterranean Sea, on the 
African coast. In winter it wanders south to the Azores and Canaries.

The Stormy Petrel, or Least Petrel, as it was formerly called, is the smallest of the web-footed birds, and on the wing has something of the appearance of a Barn Swallow. It has completely webbed feet, and can swim with ease, but is very seldom seen upon the surface of the water, though it has a curious habit of skimming close to the surface and paddling the water with its feet, whence is said to have originated the name of Petrel, or "Little Peter." The bird is rarely seen walking on the land, though it can walk with ease and is rather graceful; but the head and body are carried so far in advance of the feet as to make the Petrel appear unsteady.

Like others of this group, the Stormy Petrel does not often appear about its nesting site during the day, and those examples that have been captured alive have shown so little inclination to display any activity before the approach of sunset that the species has been considered nocturnal; but those that are met with on the open ocean are busily engaged gleaning food through all hours of the day.

This is a rather silent bird, and its notes are heard only when the bird is on or near the nest. Hewitson tells of being guided to the nests by the "singing" of the parents, which he describes as resembling the chatter of Swallows.

The name of Mother Carey's Chicken, thought by some philologists to be a corruption of Mater cara, was originally applied to this species by seamen, but it is now applied to all the small Petrels.

Sailors fancy that the appearance of these birds is an evil omen and foretells a storm, - which is partly true, for they revel in a storm and seek it. The Petrels have no dread of winds or waves, and find their harvest amid the tumult, fearlessly gleaning their food from the curling seas.

Note. - Examples of several species of Petrel occasionally wander into our waters from their customary cruising area. These are the BlACK-CAPPED PETREL (Astrelata hasitata), from the tropics; PeAle's Petrel (AEstrelata gularis), from the Antarctic; Bulwer's Petrel (Bulweria bulweri), from the eastern side of the Atlantic; White-Bellied Petrel (Cymodroma grallaria), from the tropics; White-FAced Petrel (Pelagodroma marina), from the Southern Ocean. 


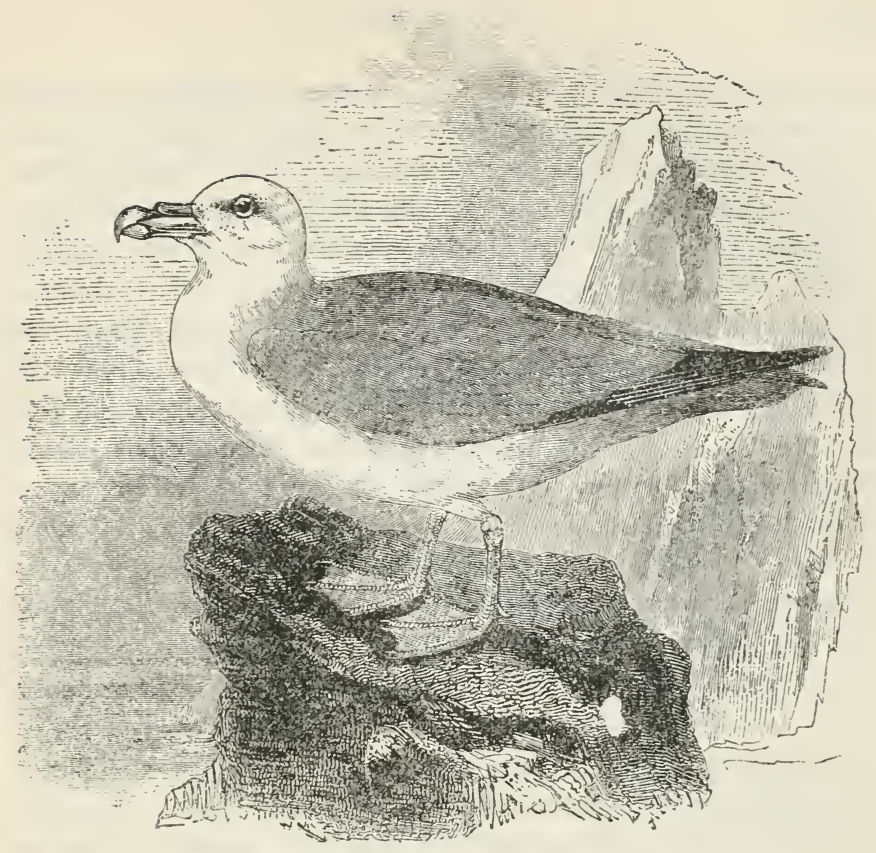

FULMAR.

WHITE HAGDON. NODDY.

FULMARIS GLACIALIS.

CHAR. Mantle and tail bluish gray; wings dusky; head, neck, and under parts white; bill greenish yellow; legs and feet pale flesh-color. Length about 19 inches. Numerous examples, supposed to be immature birds, have the white portions clouded with gray, and the mantle tinged with brown.

Nest. A deep hollow scratched in the soil on a grassy shelf of a cliff; sometimes on a bare rock, - usually a thin cushion of grass or moss; often the egg is laid on the soil.

Egg. I ; white, with a rough, chalk-like surface, sometimes with a few spots of reddish brown; average size $2.90 \times 2.00$.

Surrounded by an eternal winter, the Fulmars dwell nearly at all seasons of the year upon the Arctic seas. Harbingers of storm and danger, they choose the wildest and most desolate of regions, where, congregating amidst the floating ice, they 
seek out the resorts of the whale, on whose carcase and those of other cetaceous animals they often make a gratifying feast, and are well known to the whale-fishers who frequent these hyperboreal seas. They attend the ships in all their progress. Emphatically birds of the tempest, these Petrels ride securely amidst its hcrrors, profiting by the agitation and destruction which it spreads around. Aware of the object which the whaler has in quest, they follow the vessel and watch the result. As soon as a whale is moored to the side of the ship and begins to be cut up, an immense muster takes place, sometimes exceeding a thousand, of these greedy birds, all stationed in the rear, watching for the morsels which are wafted to leeward. The peculiar chuckling note by which they express their eager expectation, their voracity when seizing on the fat, and the large pieces which they swallow, the envy shown towards those who have obtained the largest of these morsels, and often the violent measures taken to wrest it from them, afford to the sailors curious and amusing spectacles. The surface of the sea is sometimes so covered with them that a stone cannot be thrown without one being struck. When an alarm is given, innumerable wings are instantly in motion, and the birds, striking their feet against the water to aid their flight, cause a loud and thundering plash.

The Petrel is not uncommon in some of the islands off the north of Scotland. At St. Kilda, one of the Hebrides, it breeds, and supplies the inhabitants with a vast quantity of oil, which is used for culinary as well as medicinal purposes. According to Pennant, " no bird is of such use to the islanders as this; it supplies oil for their lamps, down for their beds, a delicacy for their tables, a balm for their wounds, and a medicine for their distempers." $\mathrm{He}$ adds "that it is a certain prognostication of the change of winds. If it come to land, no west wind is expected for some time, and the contrary when it returns and keeps to sea."

Its food is chiefly fish, particularly those that are the most fat; its stomach is indeed generally charged with oil, which it has the power of ejecting forcibly from the bill and nostrils as 
a mode of defence. It attends the fishing vessels on the banks of Newfoundland, feeding on the liver and offal of the cod-fish which is thrown overboard, and is known to the sailors by the quaint name of John Down. It is also taken by means of a hook baited in this manner with the offal, and the inhabitants of Baffin's and Hudson's Bay are said to salt them for winter provision; though Pennant, in the "Arctic Zoology," adds that their flesh is rank and fetid in consequence of their unpleasant food, yet they are still considered as no indifferent dish by the hungry Greenlanders, and they breed usually about Disco. Like the birds of the preceding and nearly allied genus, they nest in holes in the rocks in great companies at St. Kilda about the middle of June, laying but one large, white, and brittle egg. The Fulmar is now and then, though very rarely, seen on the temperate coasts of Europe and the United States. The feathers are very close and full, clothed below with a thick and fine down.

Fulmars are common from the Newfoundland banks northward, and in winter a few stragglers are met with off the New England coast. This form is not known to breed on the eastern side of the Atlantic.

\section{LESSER FULMAR.}

\section{WHITE HAGDON. NODDY.}

FULMARUS GLACIALIS MINOR.

CHAR Similar in coloration to glacialis, but smaller. Length averages about 18 inches.

Nest and Eggs. Similar to glacialis, the eggs averaging somewhat smaller.

Mr. Hagerup thinks it probable that this is the form that breeds in numbers on the western coast of Greenland north of latitude $69^{\circ}$. In winter a few of these birds are met with off the New England coast.

The habits of this variety do not differ from those of the type, and the two forms can be separated only by their size. 


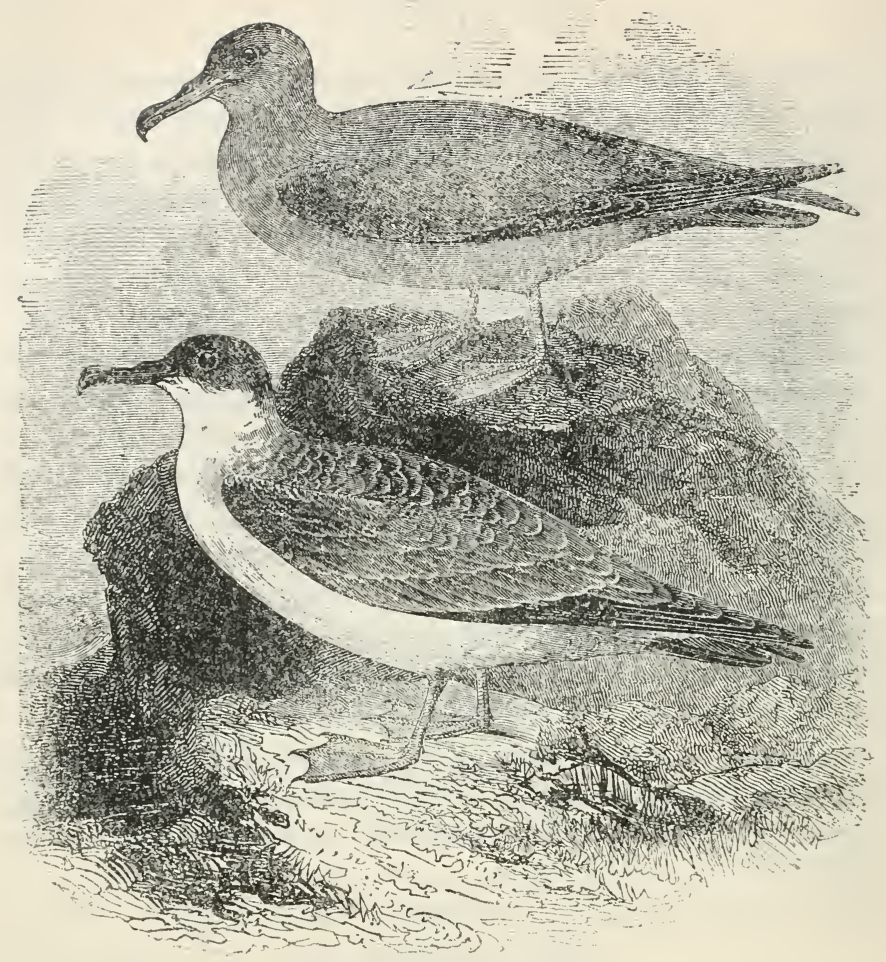

GREATER SHEARWATER.

HAGDON.

\section{PUFFINUS MAJOR.}

CHAR. Mantle grayish brown, the feathers edged with pale brown; top of head and nape grayish brown, paler on the neck; wings and tail blackish brown; tail-coverts broadly tipped with white; under parts white, the belly shaded with brownish gray; the white feathers of the neck separated abruptly from the dark feathers of the crown and nape; bill brownish black; legs and feet dull yellowish pink, turning to yellow in dried skins. Length about 19 inches.

Nest and Eggs. Unknown.

The Cinereous Puffin, or Wandering Shearwater, visits every part of the great Atlantic Ocean, from the banks of Newfoundland to Senegal and the Cape of Good Hope. It is also com- 
mon in the Mediterranean and on the southern coasts of Spain and Provence, but never proceeds to the Adriatic.

On approaching the banks of Newfoundland, but far west of soundings, we see the soaring and wandering Lestris, and every day the wild Shearwaters, but more particularly in blowing and squally weather; sometimes also in fine weather we see them throughout the day. Their course in the air is exceedingly swift and powerful. With their long wings outstretched and almost motionless, they sweep over the wild waves, fearless of every danger, flying out in vast curves, watching at the same time intently for their finny prey. Like the Petrels, these Shearwaters are often seen to trip upon the water with extended feet and open wings; they likewise dive for small fish, and find an advantage in the storm, whose pellucid mountain waves bring to view the shiny prey to more advantage, - the birds are therefore often seen most active at such times, watching the sweeping billow as it rises and foams along, harassing and pursuing their quarry with singular address, snatching it from the surface, or diving after it through the waves, on which they are often seen to sit, mounting to the sky or sinking into the yawning abyss of the raging deep.

The Greater Shearwater probably breeds on the islands of the North Atlantic, though no authentic account of the nest and eggs has been published. Some eggs received from Greenland, and supposed by good authorities to be of this species, are described as white, and averaging about $2.80 \times 1.90$.

The name Cinereous, applied to this bird by Nuttall, is now restricted to an allied species, Puffinus kuhlii, which breeds on various islands in the Mediterranean and on the Azores.

Our bird is numerous on the shores of Greenland up to about latitude $65^{\circ}$, and is quite common off the New England coasts during the winter, though usually far away from the shore.

The fishermen call it the "Hagdon," in common with others of the genus and the Fulmar.

In the illustration the Greater Shearwater is represented by the lower figure; the upper one represents the Sooty Shearwater.

VOL. II. - I8 


\section{CORY'S SHEARWATER.}

\section{PUfFINUS BOREALIS.}

CHAR. Mantle brownish gray, the feathers shading to paler at the tips; crown and nape brownish gray, the feathers on the nape tipped with white; sides of head and neck mottled white and gray; wings and tail brownish gray, darker than mantle; under parts white; bill yellowish at base, shading to black towards the tip; legs and feet dull orange. Length about $2 \mathrm{I}$ inches.

Nest and Eggs. Unknown.

Cory's Shearwater was described in I88I by Mr. Charles B. Cory from specimens taken off Cape Cod during October, I880. Since that date a number of examples have been taken along the New England coast in September and October, and in the autumn of I 886 an immense number were seen off the Nantucket islands.

Writing of this flight, Prof. S. F. Baird said: "The Shearwaters occurred in flocks of perhaps from fifty to two or three hundred, the bunches being generally found quietly resting on the waters and feeding, while swimming, upon the herrings that were so abundant in the vicinity. The birds were very tame, but approach to them could be best made by a steam-launch, which would almost run over them before they would start to fly. A dozen birds were killed by the discharge of two guns from a launch. About a hundred specimens were secured, and thousands could easily have been killed if neccssary."

This species is not known to differ in its habits from other members of the genus, and in appearance is similar to P. major, though borealis is readily distinguished by its yellow bill, the paler tint of the brown in the upper parts, and by the absence of a distinct line of demarcation between the white and dark feathers on the neck.

Mr. Howard Saunders, a noted English authority on this family of birds, considers that $P$. borealis is identical with $P$. kuhlii. 


\title{
SOOTY SHEARWATER.
}

\author{
BLACK HAGDON.
}

PUFFINUS STRICKLANDI.

CHAR. Upper parts dark sooty brown; under parts paler and varied with grayish; wings and tail dusky or blackish; bill and legs dusky. Length about 17 inches.

Nest and Eggs. Unknown.

The Black Hagdon of the fishermen - represented by the upper figure of the illustration on page 272 - is a common bird on the North Atlantic between Newfoundland and the Carolinas during the autumn and winter months, though it appears to have escaped the notice of Nuttall and his contemporaries.

This bird is not known to breed on our shores, nor has any breeding-place of the species been discovered, though it is very probable that its nesting habits are similar to those of the Pacific form, $P$. griseus, which our bird very closely resembles in appearance, and with which it may be identical, as it is considered by some British authorities.

Nests of griseus discovered in the South Pacific were placed at the end of a burrow, which ran horizontally three or four feet, and then turned to the right or left. The single egg, which was placed on a rude cushion made of twigs and leaves, was of white color, and measured on the average about $2.60 \times$ I.70.

\section{AUDUBON'S SHEARWATER.}

\section{Puffinus auduboni.}

CHAR. Upper parts sooty black or dusky, darker on wings and tail ; under parts white; bili lead blue; outside of legs black, inside and webs yellowish. Length about II inches.

Nest. In a crevice of a rock or amid loose fragments of stone, - a slight affair of loosely arranged twigs.

$E g g$. I ; white (similar in appearance to oval eggs of the domestic fowl, but with thinner shell and more highly polished surface); average size about $2.05 \times 1.40$.

This species breeds in large numbers on the Bermuda and Bahama Islands and southward, and is seen off the shores of the mainland, occasionally wandering as far north as Long Island. It 
is abundant along the eastern side of the Atlantic, and is said to breed on some of the islands lying off the west coast of Africa.

It is described as a stupid bird, offering no resistance when taken from the nest, and as appearing dazed and almost helpless when placed on the land. The flight of the bird is strong and graceful, and Audubon says it can dive and swim with the ease of a Duck.

There are conflicting statements regarding the nocturnal habits of the species, some observers representing them as feeding through the day, while others think that during the day these birds are inactive and silent, resting upon the water, usually far out from the land, and very rarely feeding; but at night they are actively occupied in catching and devouring fish, and at that time their mournful cry is continually in the air. There is good reason for believing that both statements are correct, - that these birds feed in the daytime when food is abundant, but that they are generally more active after sunset.

Note. - The Manx Shearwater ( $P$. puffinus), which breeds on the coast of England, is credited with appearing occasionally near to our coast. 


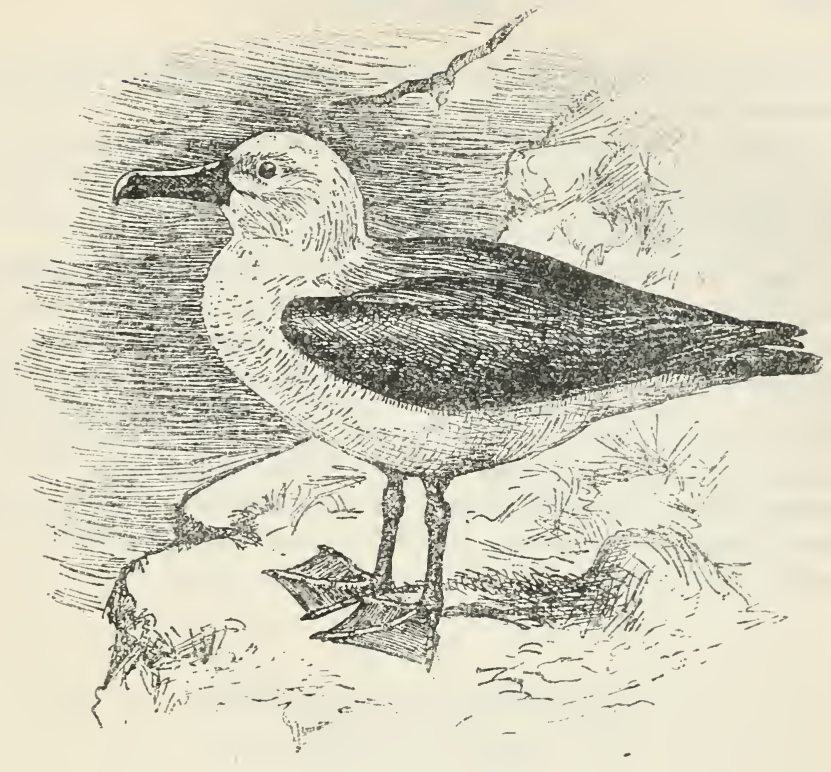

\section{YELLOW-NOSED ALBATROSS.}

\section{ThaLASSOGERON CULMINATUS.}

CHAR. Mantle dark bluish slate, shading to brownish on wings and head; rump white; tail grayish; under parts white. Length about 36 inches.

Nest. In an exposed situation on an ocean island; a bulky structure of coarse herbage and mud lined with fine grass and feathers. As new material is added each succeeding year, the height is increased.

Egg. I ; dull white, sparsely marked with purplish brown and lavender; average size $4.25 \times 2.65$.

The claim of this species to recognition here is based upon the capture of an immature bird near the mouth of the river St. Lawrence in I885. I examined the skin, which is preserved in the Museum of Laval University, at Quebec, and was told by the curator, Mr. C. E. Dionne, that he purchased it from the fisherman who shot the bird. The claim is slight, but there is no reason why it should be ignored.

This bird had wandered far away from the usual habitat of the species, for the Yellow-nosed Albatross is seldom seen anywhere 
but in the Southern Pacific, a few examples only having been observed as far north as the coast of California.

It should be remembered, however, that this entire family of birds are noted wanderers, - the most extensive wanderers of all this wandering race, - and their strength of wing and power of endurance render them capable of any journey.

There is something truly sublime, as Hammerton has suggested, in the travelling of these sea-birds. "Think of one of these birds," he writes, "leaving some barren rock in the ocean, and without further preparation than the unfolding of his mighty wings, setting forth on a voyage of two or three hundred leagues! . . . Nothing but the natural forces aid him; he propels himself by his own un. wearied pinions, and seeks his food in the waves below. Selfreliance of that genuine kind is quite beyond us. ... The great lonely birds are self-reliant; and what a noble absence of fear is needed for the daily habit of their lives!"

\section{WANDERING ALBATROSS.}

Diomedea exulans.

CHAR. Prevailing color yellowish white; tail sooty black; wingcoverts more or less varied with dusky. Average length about 50 inches. Young birds are uniform sooty brown, and become white, gradually the white feathers increasing at each moult.

Nest. In an open situation on an ocean island, - a bulky structure of coarse herbage and mud, lined with fine grass and feathers. By the yearly addition of fresh material the nest rises to mound-like proportions, some having been seen as high as eight feet.

Egg. I ; white, the surface rough, sometimes marked on the larger end with dull brown; average size $4.95 \times 3.15$.

The Albatross inhabits the Atlantic as well as the Pacific, and sometimes wanders accidentally to the coasts of the central parts of the Union. Vagabond, except in the short season of reproduction, these birds are seen to launch out into the widest part of the ocean; and it is probable that according to the seasons, they pass from one extremity of the globe to the other. Like the Fulmar, the constant attendant upon the whale, the Albatross, no less adventurous and wandering, pursues the tracks of his finny prey from one hemisphere into another. When the flying-fish fails, these birds have recourse to 
the inexhaustible supply of molluscous animals with which the milder seas abound. They are nowhere more abundant than off the Cape of Good Hope, where they have been seen in April and May, sometimes soaring in the air with the gentle motion of a kite, at a stupendous height; at others nearer the water, watching the motions of the flying-fish, which they seize as they spring out of the water, to shun the jaws of the larger fish which pursue them. Vast flocks are also seen round Kamtschatka and the adjacent islands, particularly the Kuriles and Bering's Island, about the end of June. Their arrival is considered by the natives of these places as a sure presage of the presence of the shoals of fish which they have thus followed into these remotest of seas. That want of food impels them to undertake these great migrations appears from the lean condition in which they arrive from the South; they soon, however, become exceedingly fat. Their voracity and gluttony is almost unparalleled, - it is not uncommon to see one swallow a salmon of four or five pounds weight; but as the gullet cannot contain the whole at once, part of the tail end will often remain out of the mouth; and they become so stupefied by their enormous meals as to allow the natives to knock them on the head without offering any resistance. They are often taken by means of a hook baited with a fish, though not for the sake of their flesh, which is hard and unsavory, but on account of their intestines, which the Kamtschadales use as a bladder to float the buoys of their fishing-nets. Of the bones they also make tobacco-pipes, needle-cases, and other small implements. When caught, however, these birds defend themselves stoutly with the bill, and utter a harsh and disgusting cry. Early in August they quit these inhospitable climes for the more genial regions of the South, into which they penetrate sometimes as low as the latitude of $67^{\circ}$.

In Patagonia and the Falkland Islands they are known to breed, but not in the northern hemisphere, to which they probably migrate only in quest of food. They repair to this southern extremity of the American continent about the time they leave the northern regions, being seen at the close of Sep- 
tember and beginning of October (the spring of this hemisphere) associated to breed with other birds of similar habits. The nests are made on the ground with earth and sedge, of a round, conic form, elevated to the height of three feet, leaving a hollow in the summit for the egg, - for the Albatross lays but one, which is larger than that of a Goose, white, with dull spots at the larger end; this is good food, the white never growing hard with boiling. While the female is sitting, the male is constantly on the wing, and supplies her with food. During this time the female is so tame as to allow herself to be pushed off the nest while her eggs are taken. But the most destructive enemy of this bird is the Hawk, which steals the egg whenever the female removes from it. As soon as the young are able to leave the nest, the Penguins take possession of it, and without further preparation hatch their young in turn.

The Albatross, though so large a bird, suffers itself to be teased and harassed while on the wing by the Skua Gull, or Lestris, from which it often alone finds means to escape by settling down into the water, but never attempts resistance.

A few examples of this species have been met with off the coasts of Florida; but it has not been seen elsewhere near our shores during recent years. 


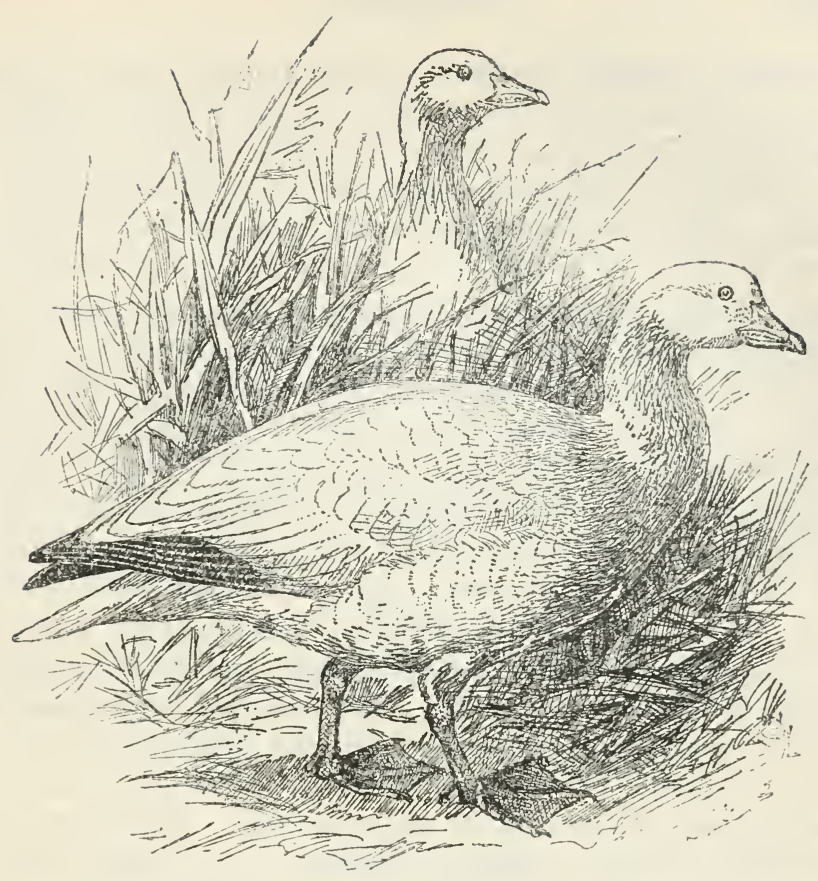

\section{GREATER SNOW GOOSE.}

WAVEY. WHITE BRANT.

Chen hyperborea Nivalis.

CHAR. Plumage white; head washed with rufous; wing-coverts and wings ashy gray, the latter shading to black at the ends; bill and feet purplish red. Length about 33 inches.

In young birds the upper parts are pale gray, the feathers of the back edged with white; rump and under parts white.

Nest. Usually on the marshy margin of a lake or stream, - a loosely made structure of coarse herbage and twigs lined with grass and feathers.

Eggs. Unknown.

The Snow Goose, common to the north of both continents, breeds, according to Richardson, in the Barren Grounds of Arctic America in great numbers, frequenting the sandy shores of rivers and lakes. These birds are very watchful, employing 
one of their number usually as a sentinel to warn them of any approaching danger. The young fly about the close of August, and the whole depart southward about the middle of September. Early in November they arrive in the river Delaware, and probably visit Newfoundland and the coasts of the Eastern States in the interval, being occasionally seen in Massachusetts Bay. They congregate in considerable flocks, are extremely noisy and gabbling, their notes being shriller than those of the Canada or Common Wild Goose. They make but a short stay in the winter, proceeding farther south as the severity of the weather increases. The Snow Geese already begin to return towards the North by the middle of February, and until the breaking up of the ice in March, are frequently seen in flocks on the shores of the Delaware and around the head of the bay. At this time they are observed to feed on the roots of the reeds, tearing them up like hogs. In their breedingresorts in the fur countries they crop rushes and collect insects, and in autumn principally berries for food, particularly those of the crow-berry. At this time they are seldom seen on the water, except in the night or when moulting. When well fed the flesh is excellent, being far superior to the Canada Goose in juiciness and flavor. It is said the young do not attain the full plumage of the old birds before their fourth year, and until that period they appear to keep in separate flocks. They are numerous at Albany Fort, in the southern part of Hudson Bay, where the old birds are rarely seen; and, on the other hand, the adult birds in their migrations visit York Factory in great abundance, but are seldom accompanied by the young. They make their appearance in these remote countries in spring, a few days later than the Canada Goose, and pass in large flocks both through the interior and along the coast. At this season they were also seen by Mr. Say in the Territory of Missouri; many migrating north, probably up the great valley of the Mississippi.

The Snow Goose is also met with commonly on the western side of America, as at Aoonalashka and Kamtschatka, as well as in the estuary of the Oregon, where they were seen by Lewis 
and Clarke. They are very abundant in Siberia, and the natives often take them in nets by means of rude decoys. In that frozen climate they afford a great article of subsistence; each family killing thousands in a season, which are laid up in bulk, in holes in the earth, and made use of as occasion requires.

The breeding area of this variety is not known with certainty, but it probably lies in the Barren Ground region between Greenland and the Mackenzie River, the larger number of the birds nesting towards the western limit of their range.

The birds winter on the Atlantic shores of the Southern States and in the West Indies, and go north chiefly by way of the Mississippi valley. Only a few individuals are seen on the New England and Canadian shores. Immense flocks are met with on the Great Plains.

Note. - The Lesser Snow Goose (Chen hyperborea), the Western form of this species, which breeds in Alaska, is found in winter occasionally in southern Illinois, and casually in New England.

\section{BLUE GOOSE.}

\section{BLUE WAVEY.}

\section{Chen CerRulescens.}

CHAR. Back grayish brown; head, neck, and rump white; wings bluish gray, shading to black on ends; tail dusky; under parts white; bill and feet purplish red. Length about 25 inches.

Nest and Eggs. Unknown.

After much contention and relegation for a time to the "Hypothetical List," under the supposition that it was the young of the Snow Goose, this has been admitted as a valid species.

Its breeding area lies along the shores of Hudson Bay, and its winter home is on the Gulf coast, whence it migrates chiefly along the valley of the Mississippi. Mr. William Dutcher reports that the bird is " an accidental visitor" to Long Island.

In habits the Blue Goose does not differ materially from its allies. 


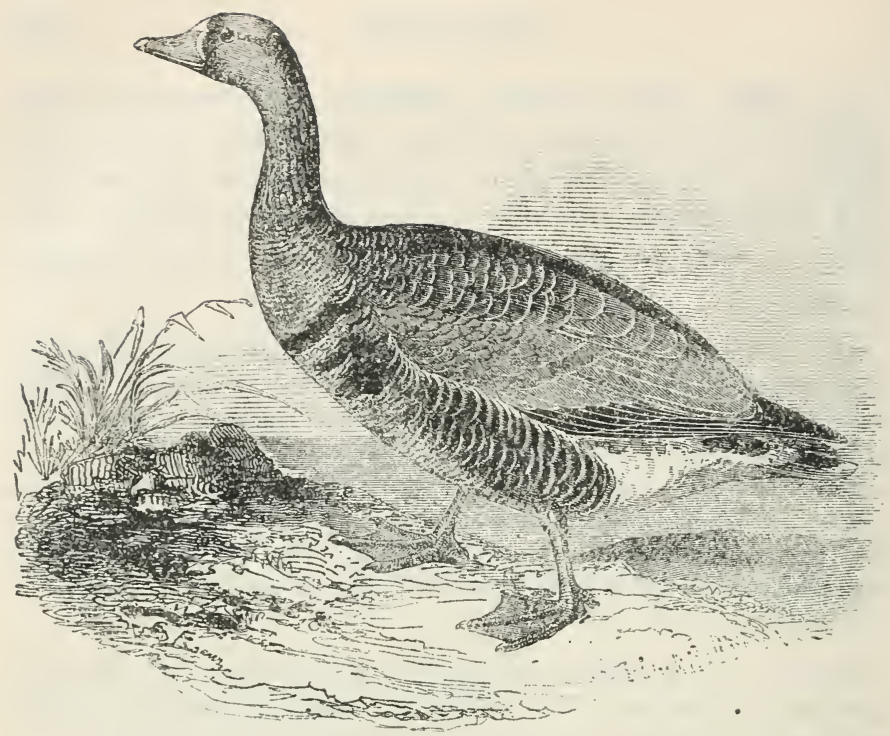

\section{AMERICAN WHITE-FRONTED GOOSE.}

\section{LAUGHING GOOSE.}

\section{ANSER ALBIFRONS GAMBELI.}

ChAR. Upper parts brownish ash, the feathers paler on the edges; forehead and rump white; wings and tail dusky; under parts brownish gray, blotched with black; bill yellow, with white nail; legs and feet orange. Length about 30 inches.

Nest. Amid rank grass and made of coarse herbage and lined with grass and feathers, - sometimes a mere depression at the summit of a grassy mound or in the sand on the bank of a river, lined with feathers and down.

Eggs. 5-7; "dull greenish yellow" (?) ; $3.15 \times 2.05$.

The White-fronted Goose breeds chiefly in the interior of the continent on the skirts of the forest portions of sub-arctic regions, and winters in Mexico and the West Indies. During the migrations this Goose is rare along the Atlantic coast, but plentiful on the plains, and quite common about the Great Lakes.

Numbers of this species nest in Greenland, but they are said to be of the European race, - true albifrons, - and they probably migrate southward by the way of Iceland and the British Isles.

The name of Laughing Goose is derived from the call, which is loud and trumpet-like. It sounds something like wah, wah, wah, wah, repeated rapidly. 


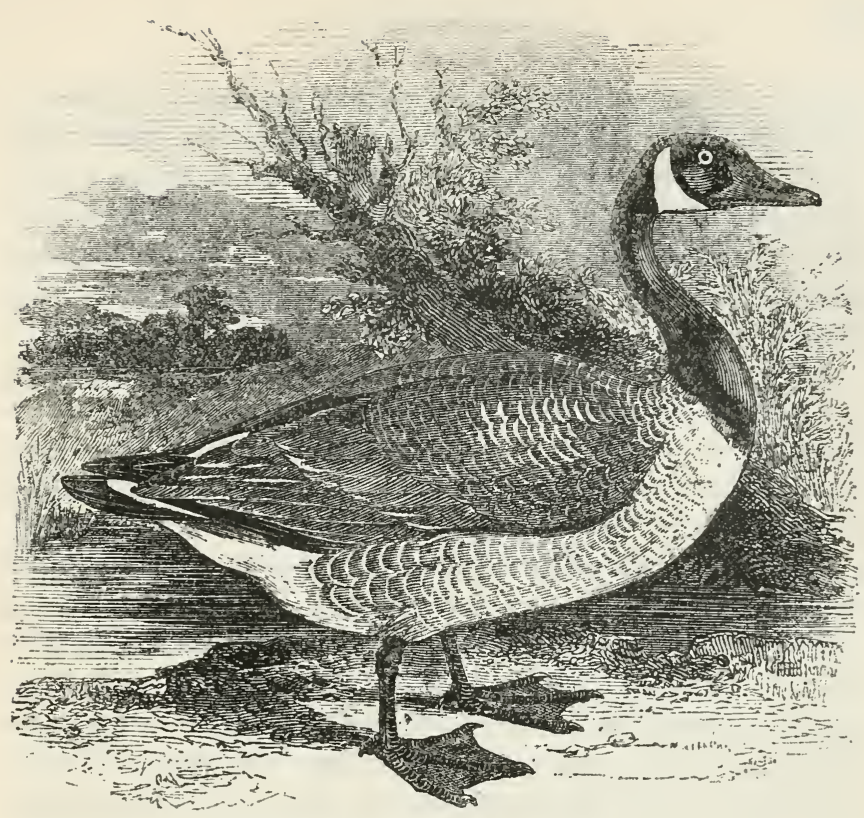

\section{CANADA GOOSE.}

WILD GOOSE.

\section{BRANTA CANADENSIS.}

CHAR. Mantle grayish brown, the feathers with paler edges; head and neck black, a broad white patch on. the throat; tail black, tail-coverts white; under parts gray, shading to white on the under tail-coverts; bill and legs black. Length about 36 inches.

Nest. In a variety of situations, but usually on the ground and made of twigs and grass loosely laid and lined with feathers and down.

Eggs. 5-7; pale dull green ; $3.50 \times 2.50$.

The Common Wild Goose of America is known familiarly in every part of the Union as a bird of passage to and from its breeding-places in the interior and north of the continent. The arrival of these birds in the desolate fur countries of Hudson Bay is anxiously looked for and hailed with joy by the aborigines of the woody and swampy districts which they frequent, who depend principally upon them for subsistence during the 
summer. They make their appearance at first in flocks of twenty or thirty, which are readily decoyed within gunshot by the hunters, who set up stales, or stuffed birds, and imitate their call. Two or three are so frequently killed at a shot, in this way, that the usual price of a Wild Goose is a single charge of ammunition. This vernal flight of the Geese continues from about the middle of April to the same time in May; their appearance of course coinciding with the thawing of the swamps and marshes, though their usual food of grass and berries is accessible at most times when not buried up in the snow. These fruits are often, indeed, only mellowed by the frost, and when stripped of their wintry wreath are again ready for food, as they were in the autumn before their disappearance beneath the snow. At such times, according to Dr. Richardson, the Wild Goose makes an abundant repast of the farinaceous berries of the silvery buckthorn as well as of other kinds which have escaped destruction. After feeding in a desultory manner for about three weeks, these birds retire from the shores of Hudson Bay, their great rendezvous, and disperse in pairs through the country between the 5 oth and 67 th parallels, to breed, but are seldom or never seen on the coasts of the Arctic Sea; yet Mr. Audubon found them breeding on the shores of Labrador. They lay six or seven greenish-white eggs in a coarse nest usually made on the ground, but some pairs occasionally breed on the banks of the Saskatchewan, in trees, making use, on these occasions, of the deserted eyries of the Ravens or Fishing Hawks. The call, or honk, is imitated by a prolonged nasal pronunciation of the syllable wook frequently repeated.

Solitude and suitable food seem principally to influence the Canada Goose in the selection of its breeding-place ; it is therefore not improbable but that many pairs pass the period of reproduction in the swampy and retired marshes of the Great Northwestern Lakes. At any rate, in the month of March (1810) many Wild Geese were nesting in the shave-rush bottoms of the Missouri no farther up than Fire Prairie, considerably below the junction of the river Platte; so that the breeding range of the Canada Goose probably extends through not 
less than 30 degrees of latitude. In July it appears, after the young birds are hatched, in the fur countries ; the parents moult ; and advantage being then taken of their helplessness, vast numbers are killed in the rivers and small lakes when thus disabled from flight. At such times, when chased by a canoe, and frequently obliged to dive, they soon become fatigued, and making for the shore in order to hide, are quickly overtaken, and fall an easy prey to their pursuers.

Attached to particular places of resort at the period of migration, the Geese in autumn, instinctively advertised of the approaching winter, and of the famine which to them necessarily attends in its train, are again seen to assemble on the sea-coast, courting the mildness of its temperature and its open waters, which seem to defy the access of frost. They thus continue to glean the marshes along the shores, till the increasing severity of the weather urges them to a bolder and more determined flight from the threatening dangers of their situation. They now in vast array begin to leave the freezing shores of Hudson Bay. Like the rest of their gabbling and sagacious tribe, at the call of their momentarily elected leader they ascend the skies, wheeling round, as if to take a final leave of their natal shores, and sensible to the breeze, arranged in long converging lines $(>)$, they survey their azure route, and instinctively follow the cheering path of the mid-day sun, whose feeble gleams alone offer them the hope of arriving in some more genial clime. The leader, ambitious of his temporary station, utters the cheering and reiterated cry; his loud but simple clarion, answered by the yielding ranks, dispels the gloom of solitude through which they laboriously wander to uncertain and perhaps hostile lands. At length they come in sight of the habitations of men. Suspicious of these appearances, they urge their flight higher and more silently in the air. Bewildered by fogs, however, they often descend so low and honk so loud as to give sufficient notice of their approach to the ambitious gunner, who thus pours destruction among the alarmed and confused flock. They also hear, or think they hear, a wandering companion lost from 
their cherished ranks ; they approach the object, and it is but a domestic traitor of their species, or the well-imitated call of the wily fowler. Towards evening, desirous of relieving the toil and hunger of his adventurous band, the intelligent leader reconnoitres from his lofty station the resting-place of his charge; he espies the reedy river or silent lake, whose grassy margins offer the necessary supply and cover to their lodgment. His loud call now redoubles at the pleasing prospect, and they all alight, and silently repose in darkness upon the still water. Early in the morning they renew their wandering course, and according to the time and season, visit every part of the Union, to the shores of the Mexican Gulf.

The autumnal flight of the Canada Geese to the coast of Hudson Bay, and their residence there, continues for three weeks or a month previous to their departure for the South, which usually takes place in September. Early in October they arrive on the coasts of the Eastern and Middle States.

The residents of Hudson Bay depend greatly on Geese for their supply of winter provision; and according to Hutchins, in favorable years they kill three or four thousand, and barrel them up for use. These are obtained chiefly by means of ambuscade and decoy, bough-huts being made by the Indians in lines over the marshes they frequent to feed. Mimicking their call, they are brought within gunshot, and the deception is also enhancea by stales and setting up the dead birds on sticks, in living attitudes. Thus in a good day a single native will kill as many as two hundred. When the frosts begin, the Geese are readily preserved, with the feathers on, in a frozen state, and thus afford a durable supply of fresh provision. The feathers also constitute an article of commerce.

In the shallow bays and marshy islands some Geese continue the whole winter in New Jersey and the Southern States, through which they spread themselves to the very extremity of Florida. Their principal food is the sedge roots and other herbage; they also crop Ulvas and tender marine plants, and swallow quantities of gravel. They swim with ease and elegance, and when 
disabled in the wings, dive well and become difficult to capture. When the shallow bays and ponds are frozen, they seek the mouths of inlets near the sea, in quest of their fare.

The Canada Goose is now completely domesticated, and is as familiar, breeds as freely, and is in every respect as valuable as the common Gray Goose. Even in Buffon's time, "many hundreds inhabited the great canal at Versailles, where they bred familiarly with the Swans;" and he also adds, "There is at present a great number on the magnificent pools that decorate the charming gardens of Chantilly." The female, in a state of domesticity, still with instinctive caution seeks out the most solitary place for her nest, not far from the water. These birds are also extremely watchful, and the gander often very resentful and clamorous against any stranger who happens to approach the place where his consort is breeding. He often engenders with the Goose of the common species, and the hybrids are greatly esteemed for the superiority of their flavor.

The natural desire of periodical migration is strongly exhibited by Canada Geese while in a state of domestication; and though at all other times reconciled to accustomed and voluntary captivity, they are often heard instinctively to hail the passing flocks as they pursue their yielding way high in the air. Individuals have been known to leave the premises where they appeared entirely domestic, after the healing of the wounds which brought them into captivity, and they have thus successfully mounted into the air and joined some passing party pursuing their way to the North.

A Mr. Platt, of Long Island, having wounded a female Wild Goose, succeeded in taming it, and left it at large with his other Common Geese. Its wound healed, and it soon became familiar and reconciled to its domestic condition; but in the following spring it joined a party of Canada Geese and disappeared until autumn; when at length, out of a passing flock, Mr. Platt observed three Geese detach themselves from their companions, and after wheeling round several times, alight in the barn-yard, when, to his astonishment, he recognized in one

VOL. II. - I9 
of the three his long-lost fugitive, who had now returned, accompanied by her offspring, to share the hospitality of her former acquaintance. However incredible this story may appear, I have heard two or three relations of the same kind, as well authenticated as any other facts in ndtural history. One of these happened to a planter near Okrocock inlet, in North Carolina, in which, as in the present instance, the female, after being absent the summer, returned recruited with her brood in autumn; but the greedy farmer, less humane than Mr. Platt, having probably heard of the old adage that "a bird in the hand is worth two in the bush," made sure of his prizes by killing them without delay. It appears from the relations of travellers, and particularly a Dr. Sanchez, that in the Cossack villages on the Don (in the autumn of I 736), he remarked, as he travelled along, a great number of Geese in the air, which alighted and dispersed through the hamlets. On inquiry he learned that these birds came from the remote northern lakes, and that every year, on the breaking up of the ice, six or seven pairs of Geese leave each hut of the village and return not until the beginning of winter; that then these flocks arrive, increased by their progeny, and each little party, separating from the rest, seek out the houses where they lived the preceding winter.

The Canada Goose breeds sparingly in the northern portions of the New England States and in New Brunswick. It is still a common bird, and in some localities is found in great numbers while migrating.

\section{HUTCHINS GOOSE.}

\section{SOUTHERN GOOSE.}

BRANTA CANADENSIS hUTCHINSII.

Char. Similar to Canada Goose in plumage, but of smaller size. Length about 30 inches.

Nest. Usually on a sandy beach, - a mere depression in the sand lined with grass and feathers. Like the Canada Goose, this variety sometimes builds in a tree, generally in the deserted nest of a Hawk or Crow, and often builds on the ground a large nest of twigs and grass.

Eggs. 5-8; pale creamy or whitish; 3.20 $\times 2.10$. 
On Captain Parry's second voyage several flocks of Geese were seen on Melville Peninsula which were thought to be the Barnacle, but which the Esquimaux said were the males of the Brant that during the breeding-season separated themselves from the females. A number of specimens were obtained, all of which proved to be males, and Dr. Richardson described the species as a variety of the Brant; but from information afterwards obtained, he considered these specimens as belong. ing to a different species, hitherto confounded with the 4 . canadensis. In Hudson Bay these birds are well known by the Cree name of Apistiskeesh, and are generally thought by the residents to be merely a small kind of the Canada Goose, as they have the white, kidney-shaped patch on the throat, which is deemed peculiar to that species. Their habits, however, are dissimilar, the Canada Geese frequenting the freshwater lakes and rivers of the interior, and feeding chiefly on herbage; while the present species are always found on the sea-coast, feeding on marine plants, and the mollusca which adhere to them, whence their flesh acquires a strong fishy taste.

In form, size, and general colors of the plumage, the new species more nearly resembles the Brant than the Canada Goose. It differs, however, from the former in having the white, reniform patch on the throat and cheeks, in wanting the spotted white mark on the side of the neck, in the black color terminating four inches higher, instead of including the swell of the upper parts of the back and breast, and in the white of the vent being more extended. It is totally unlike $A$. leucopsis in plumage, and has a larger bill.

This species of Barnacle, named in honor of Mr. Hutchins, from whom Pennant and Latham derived most of their information respecting the birds of Hudson Bay, - breeds in considerable numbers on the shores and islands of the Arctic Sea, being seldom seen in the interior, and keep near the seacoast in their migrations. They feed on marine plants and mollusca, as well as on grass and berries, in common with the A. bernicla. 
Hutchins Gonse is now considered a variety of canadensis, though in habits it is quite distinct.

The present race breeds in the Arctic region and winters in the Southern States; but on the Atlantic coast is now rather rare north of Cape Hatteras, though formerly it was quite common. On the prairies and west of the Rockies these birds are still abundant.

Note. - The Cackling Goose (B. canadensis minima), a smaller race, - length about $2+4$ inches, - which breeds in Alaska and winters in California, is occasionally represented in the Mississippi valley by a few individuals.

Another occasional visitor from the West to this faunal province is the BLACK Brant (B. nigricans). A few examples of this species have been taken on the Atlantic coast.

Still another visitor of this group is the BARNACLE Goose (B. leucopsis), a European bird. This species is said to be a regular visitor to South Greenland, and Reinhardt thought it nested in the interior of that country. It has been seen also on Hudson Bay. 


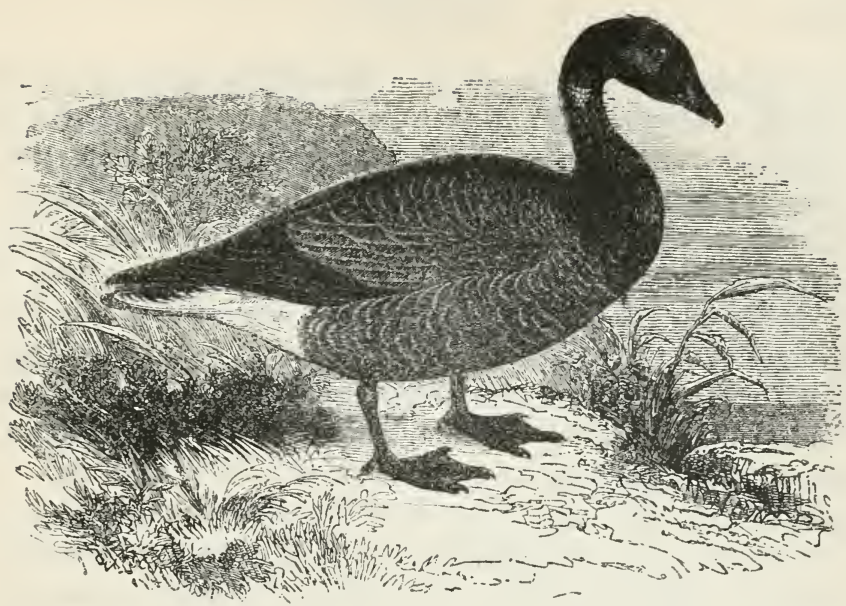

BRANT.

BLACK BRANT. BRANT GOOSE.

Branta BERNicla.

Char. Mantle blackish brown, the feathers paler on the edges; head and neck black, with patch of white on sides of the throat; quills and tail black; tail-coverts white; under parts grayish brown, the feathers tipped with white, lower belly white; bill and legs black. In the winter the mantle has a rufous tinge. Length about 25 inches.

Nest. On a cliff or sandy beach; made of grass, moss, and weed-stems thickly lined with down.

Eggs. 4-6 (usually 4); dull white or creamy; average size about 2.85 $\times$ I.90.

The Brant is another of the hardy aquatic birds common to the hyperboreal regions of both continents. It breeds in great numbers on the coasts and islands of Hudson Bay and the Arctic Sea, and is rarely seen in the interior. In Europe these birds proceed to the most northern isles of Greenland and to the dreary shores of Spitzbergen. In winter they are very abundant in Holland and in Ireland, as well as in Shetland, where they remain until spring. In America, though they visit in the course of their migrations most of the Northern and Middle States, they proceed still farther south to spend 
the winter, being seen on the Mississippi nearly to New Orleans. They retire from their natal regions in the North in September, and early in October are seen to arrive in great numbers about Ipswich, Cape Ann, and Cape Cod, in Massachusetts, continuing to come till the month of November, and generally appearing in greater numbers after the occurrence of an eastwardly storm. In hazy weather they also fly low, and diverge into the bays and inlets. Many of these wandering flocks pass on to the South almost without any delay, usually in marshalled and angular lines, but sometimes in a confused gang, loudly gabbling as they proceed. Their stay here is commonly so short that it is necessary to ambuscade in huts on their route in order to obtain them. The course of their passage is remarkably uniform, and instead of winding round the bays, they cross over the narrow necks and peninsulas of land which lie in their southern route, as if in haste to arrive at some particular destination, or dissatisfied with the prospect of fare. They continue almost without interruption their inflexible course until, seduced by the mildness of the climate or the abundance of their food, they seem inclined to take up their permanent winter residence in the inlets of Long Island and the sheltered bays of New Jersey, arriving, according to Wilson, in Egg Harbor sometimes as early as the 20 th of September, or almost without the intermission of any interval, but for necessary food and repose, from the time of their leaving the shores of Hudson Bay. The first flights, still adventurous and roving, generally remain here only a few days, and then pass on still farther to the South. Flocks continue, however, to arrive from the North, and many individuals remain in the waters of New Jersey until the severe weather of December urges them to seek out milder regions. On recommencing their journey they assemble in one great flight, making an extensive spiral sweep some miles in circuit, to reconnoitre their route; when, rising at length high in the air, they steer to the ocean, and continue their course along the bays, or even out at sea for several leagues, till they arrive again at some new destination. 
The Brant feeds usually on the bars at low water, and now and then also in the marshes; its common fare is the laver and other tender marine plants, and it now and then also eats small shell-fish. In the spring the old birds are generally lean and ill-flavored; but in winter they are justly esteemed as a delicacy, and sell at a high price. Brant never dive, but wade about in quest of their food at the recess of the tide. At the time of high water they swim out at their ease in the bay, ranged in long lines, particularly during the continuance of calm weather.

The voice of the Brant is hoarse and honking, and when gabbling in company, almost equals the yell of a pack of hounds. When pursued, or nearly approached in a state of confinement, these birds hiss like Common Geese. They are often quarrelsome amongst each other and with the Ducks in their vicinity, driving the latter off their feeding-ground. They never dive in quest of food, yet, when its wing is broken, the Brant will go a hundred yards or more at a stretch under the water ; and it is then very difficult to obtain. About the middle of May it reappears on its way to the North, but at this time rarely stops long, unless driven in by stormy weather.

Brant have been found breeding very far north,- - beyond latitude $82^{\circ}$, - and Hagerup reports them as migrants only along the southern shores of Greenland; but numbers also breed probably on the lakes near Cumberland Bay, and some doubtless go no farther than the interior of Labrador. Large numbers linger on the northern shore of Nova Scotia until about the Ist of June, and then sail away northward, gathering in one immense flock and rising in the air to a great height.

Brant are generally written down "marine birds ;" but Thompson says they occur regularly in Manitoba, though not common, and Coues saw them in vast numbers on the banks and mud-bars of the Missouri River. 


\section{WHISTLING SWAN.}

\section{Olor COLUMbianus.}

CHAR. Plumage white; bill black, with a yellow spot between the eyes and nostrils; legs black. Length about 55 inches.

Nest. On the margin of a lake or on an ocean island, sometimes in a marsh on a river bank, - a large structure of coarse herbage lined with fine grass or moss.

Eggs. 2-7; dull white, sometimes washed with a greenish or buffish tint; the surface is rough; average size about $4.25 \times 2.70$.

The Whistling Swan retires into the Arctic regions to pass in more security the period of reproduction during the short but brilliant summers which there prevail. In autumn it migrates over both continents, and in winter is sometimes numerous in the Bay of Chesapeake. Flocks are seen and heard to pass also through various parts of the interior of America, and they are nowhere more abundant at that season than in Missouri, Arkansas, and Louisiana, to which countries, by the great valley of the Mississippi, they are seen to repair in lofty and numerous flights to the very close of winter, protracting their stay sometimes until driven to move by the severest frosts. In the winter of I8 8 I I saw two of these graceful birds in a state of domestication near St. Louis (Missouri), which were obtained with several others at the same time, in consequence of the extreme cold. The thermometer falling to $15^{\circ}$ below zero, they were unable to bear the cutting severity of the weather, and fell disabled, accompanied by several Wild Ducks, into an adjoining field, where a few survived and became tame.

Whistling Swans arrive in Hudson Bay about the end of May in small flocks, accompanied by Geese, and propagate in great numbers along the shores, islands, and inland lakes. These birds, distinguished by their note and inferior size from the following species, are called Hoopers, and mostly frequent the sea-coast. The Cygnets are esteemed a delicate dish, and the full-grown young are also excellent food. The aborigines 
of the interior make much use of the down of the Swan as a matter of decoration, in which taste they have also been very successfully followed by civilized nations. Among the Icelanders, Swans are an object of chase in the moulting season, which takes place in August, after rearing their young; they are pursued by dogs and on horseback, the animals being purposely trained to pass nimbly over bogs and marshes. The eggs in the spring, as well as the flesh in autumn, are in Iceland much used as food, and the feathers form an article of trade. In Kamtschatka, where Swans likewise abound and breed, they are taken and used in the same manner; their food consists of aquatic plants and insects.

The Whistling Swan, though commonly tamed and domesticated in Russia, has not the grace and elegance of the Mute species, as instead of the beautiful curve of the neck it swims with it erect. Its vocal organs are also remarkably assisted by the elaborate structure of the trachea, which, instead of passing on direct to the lungs, as in the Mute Swan, forms two circumvolutions within the chest, like a trumpet, before terminating in the respiratory organ; and it is thus enabled to utter a powerful and sonorous note. The common Tame Swan, on the contrary, is the most silent of birds, being unable to utter any louder noise than a hiss. This deficiency of voice is, however, amply made up by beauty of form and insinuating grace. Its pure, spotless, and splendid attire; its stately attitude; the ease and elegance with which, like a bark, it sits and moves majestically on the water, as if proud and conscious of its beauty; aiding its pompous progress by gently raising its snow-white wings to catch the sportive breeze, wherein it wantons with luxuriant ease, queen of its native element, - in short, all conspires to shroud the Swan, however mute, with its long acknowledged and classic perfection. And as if aware of its high and ancient pretensions, it still, as in former ages, frequents the now neglected streams of the Meander and the Strymon; with an air of affected languor it is yet seen silently sailing by the groves of Paphos, though no longer cherished by its beauteous queen. 
The Hooper emits its notes only when flying, or calling on its mate or companions; the sound is something like 'whoogh, 'whoogh, very loud and shrill, but by no means disagreeable when heard high in the air and modulated by the winds. The natives of Iceland indeed compare it, very flatteringly, to the notes of a violin. Allowance must be made, however, for this predilection when it is remembered that they hear this cheerful clarion at the close of a long and gloomy winter, and when, in the return of the Swan, they listen to the harbinger of approaching summer; every note must be, therefore, melodious which presages the speedy thaw and the return of life and verdure to their gelid coast.

It is to this species alone that the ancients could attribute the power of melody, - the singular faculty of tuning its dying dirge from among the reedy marshes of its final retreat. In a low, plaintive, and stridulous voice, in the moment of death, it murmured forth its last prophetic sigh. These doleful strains were heard at the dawn of day or when the winds and waves were still, and, like the syrinx of Pan, were in all probability nothing more than the murmurs and sighs of the wind through the marshes and forests graced and frequented by these elegant aquatic birds.

Nuttall confounded the American bird with the Hooper, or Whooper, of Europe, also sometimes called the Whistling Swan, though they are quite distinct.

Our bird winters on the Atlantic shore of the Southern States and breeds in the fur countries, but does not migrate either way along the Atlantic coast, where it is rarely seen north of Chesapeake Bay. Within the last few years a few examples have been seen in New England, and I examined in the flesh one that was shot in New Brunswick. I think that in former years it must have occurred more frequently in this vicinity, for the Indians of Maine and the Provinces know the bird well, and have a distinctive name for it. The Indians say the Swan is always found in the wake of a flock of Geese; though a small flock that were seen on the Charles River in I89I were apparently travelling without a guide.

Mr. McIlwraith reports that in March, I890, a flock of twenty Swans appeared on Lake Ontario, near Hamilton. 


\section{TRUMPETER SWAN.}

\section{OLOR BUCCINATOR.}

Char. Plumage white; bill and legs black. Length 60 to 65 inches.

Nest. Usually on dry upland, hid amid scrubby bushes; made of grass and twigs lined with feathers and down.

Eggs. 2-6; white with a rough chalk-like surface; average size 4.40 $\times 2.60$.

According to Richardson, this is the most common Swan in the interior of the fur countries, which it frequents to breed as far south as the 6 Ist parallel, but principally within the Arctic Circle. In its migrations it is generally seen to precede the Geese by a few days. It is to the Trumpeter that the bulk of the Swan-skins imported by the Hudson Bay Company belong. Lawson remarks that these birds arrive in great flocks in Carolina in autumn, and frequent the rivers and fresh waters, retiring thence to breed in the North as early as February. This species, remarkable for its loud clarion, descends the valley of the Mississippi in great flights at the approach of winter. Hearne, who also observed this Trumpeter, remarks : "I have heard them, in serene evenings, after sunset, make a noise not very unlike that of a French horn, but entirely divested of every note that constituted melody, and have often been sorry that it did not forebode their death." The trachea is well supplied with the means of producing this hollow clang, a fold of it entering a protuberance on the dorsal or interior aspect of the sternum at its upper part, which is wanting both in Cygnus ferus and C. bewickii; in other respects the windpipe is distributed through the sternum nearly as in the latter of these species.

The Trumpeter is a bird of the interior, and is seen but occasionally to the eastward of the Mississippi, and is rare on the Atlantic coast. A few examples have been seen on Lake Ontario. It breeds from Iowa and Dakota northward.

Note. - The Whooping Swan (Olor cygnus), a European bird, occurs occasionally in Greenland. 


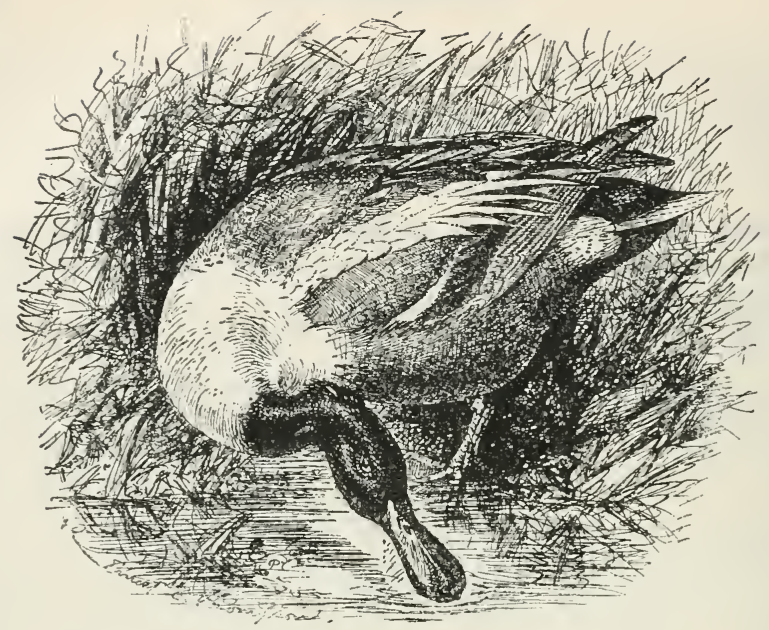

SHOVELLER.

SPOONBILL. BROADBIILL.

Spatula Clypeata.

CHAR. Back brown, the feathers paler on the edges; shoulders blue; wing-coverts white; secondaries brown with a green patch; primaries black; rump and tail black; head and neck green; lower neck and breast white; belly rich chestnut; vent white; under tail-coverts black; bill widened at the end and of dark leaden blue; legs reddish. Female darker and duller; head and neck mottled with two shades of brown; under parts pale brown or buff. Length 20 inches.

Nest. On marshy margins of a lake or stream; made of grass lined with down, which the female plucks from her body after she begins to sit.

Eggs. 6-I 4 ; pale greenish buff, sometimes tinged with blue; $2.05 \times$ I. 45 .

The Shoveller, remarkable by the broadness of its bill, is an inhabitant of the northern parts of both continents; according to Richardson it frequents chiefly the clear lakes of the hyperboreal districts, selecting for a breeding-place the Barren Grounds, where it remains to pass the summer, appearing in numbers in the more southern and woody country only in the spring and autumn when migrating. Early in October these 
birds visit the small fresh-water lakes and marshes near the sea in Massachusetts, and in the course of the winter continue south to the extremity of the Union, penetrating into Mexico and along the coast of the Gulf to Vera Cruz, and perhaps still farther, in quest of subsistence and shelter from the cold. Soon after March, according to Baillon, they disperse through the fens in France to breed, and select the same places with the Summer Teal, choosing, with them, large tufts of rushes, making a nest of withered grass in the most boggy and difficult places of access, near waters. The young, in consequence of the great disproportion of the bill, at that period, have a most uncouth and awkward appearance, seeming to be oppressed by its weight, and perpetually inclined to rest it upon the breast. They run about and swim, however, as soon as hatched, and are carefully attended by the parent, who incessantly guards them from the surprise of ravenous birds. On these occasions, when the danger becomes unavoidable, the young are seen to squat silently among the grass, while the old birds run off and dive. The cry of this species has been compared to that of a rattle turned by small jerks in the hand.

The Shoveller is considered one of the most tender and delicate-flavored Ducks, growing very fat in winter. Its usual food is said to be small fish and insects, - rarely vegetables and seeds. In a pair of the young which I examined, that were killed in Fresh Pond, in this vicinity, the stomach contained many fragments of a very delicate divaricated small green Fucus, minute Scirpi plucked up by the roots, also fragments of some Chara, with minute Natica and Anomia shells quite comminuted, and a portion of gravel. We see, therefore, that the remarkable structure of the bill in this species is no way generally indicative of any peculiar habit of feeding. The labyrinth in the trachea of the male is small, and its voice probably proportionately feeble.

This beautiful bird, with its strangely shaped bill, is but rarely seen along the Atlantic coast north of Connecticut, though, like others of our water-fowl, it is well-known to gunners and sportsmen in more southern shooting resorts. 
These birds migrate across the country to the Western plains, where they nest, from North Dakota and Manitoba northward, ranging as far as Alaska.

\section{LABRADOR DUCK.}

PIED DUCK.

\section{CAMPTOLAIMUS LABRADORIUS.}

CHAR. Male: head, neck, breast, and most of wings white; crown, collar or neck, back, primary wing-feathers, tail, and under parts black; bill orange at the base, the terminal half black; legs and feet lead blue. Female: brownish gray, the wings darker, - primaries dusky. Length I8 to 20 inches.

Nest and Eggs. Unknown.

Nuttall made but slight mention of this species, supposing it to be a straggler from the Pacific. He reported it as visiting the Middle States in winter, and stated that the gunners of New Jersey and Pennsylvania called it the Sand-shoal Duck. The flesh, he adds, is dry and unsavory.

The majority of the ornithologists of the present day believe that the species has become extinct, though some forty years ago it occurred regularly all along the coast from Labrador to Delaware, and nested in the lower fur countries.

The last example known to have been taken was shot on Long Island in 1875. Previous to that date one had been taken at Grand Menan in $187 \mathrm{I}$.

As the bird was shy and difficult to approach, a strong swimmer and of rapid flight, its extinction is a curious phenomenon, and unaccountable. There are only thirty-three specimens known to be preserved in the museums of America. 


\section{MA L LA R D.}

\section{WILD DUCK.}

\section{ANaS BOSCHaS.}

CHAR. Male: head and neck glossy green, with some purple reflections, and followed by a narrow ring of white; back brown, shading to gray on the wings and to black on the rump; wing-bar purple, bordered by black and white; upper tail-coverts black; the longest feathers curling upwards at the tips, rest of tail gray; lower neck and breast rich chestnut; belly dull white, and marked with fine waved lines of gray; bill greenish yellow; feet orange. Female : general plumage dark brown, varied with buff; wings similar to the male. Length about 24 inches.

Nest. Usually on the ground, amid tall grass or under a bush, upon a dry knoll near a pond or stream, sometimes in a tree, - a loose, bulky structure of grass and leaves, lined with down.

Eggs. 6-I2, sometimes I6; greenish buff of various shades; average size $2.30 \times$ ז.60.

The Mallard, or original of our Domestic Duck, like so many other species is common to most parts of the northern hemisphere. As a bird of passage, in spring and autumn it is seen in every part of the United States, and indeed inhabits more or less the whole continent, from the Gulf of Mexico to the 68th parallel, in the fur countries of the Canadian wilderness. In Europe it is met with everywhere, and many pass the greater part of the winter in the dreary climate of Greenland. Avoiding the sea-coast, it is but rarely that the Mallard visits this vicinity, retiring south by an interior route.

These birds breed in the inland woody districts of the fur countries, and more or less through all the intermediate space as far south as Pennsylvania. They nest commonly on the borders of rivers and lakes, sometimes at a considerable distance from water, amongst reeds, grass, or in fields and copses, according to the convenience of the locality, and occasionally even upon trees impending over waters. For its nest it scrapes together a small quantity of such dry weeds as happen to be contiguous. At the time of incubation the female plucks the down from her breast to line the nest, and frequently covers the eggs when she leaves them. 
Although it is most natural for all those birds whose young run as soon as they are hatched, to deposit their eggs on the ground, in the Mallard we have some curious exceptions. It is asserted by a person of veracity in England that a half-domesticated Duck was known to nest in a tower, where she hatched her young, and brought them down in safety to a piece of water at a considerable distance. Mr. Tunstall mentions one at Etchingham, in Sussex, which was found sitting upon nine eggs, on an oak twenty-five feet from the ground; and in another instance one was known to take possession of the nest of a Hawk in a large oak. Though believed to be monogamous, the fact is doubtful, as during the season of incubation the Mallards are seen to congregate apart from the Ducks as among other polygamous birds. Indeed, so little is the male interested in the fate of the brood he has procreated that the female, as incubation advances, is assiduous to hide herself from the company of her indifferent mate; she steals to her nest with caution, and sits on her eggs with the greatest pertinacy and instinctive affection. When the young are hatched in situations remote from water, the parent is seen to transport them to it by carrying them gently in her bill. In the evening the mother retires into the reeds, and broods her young under her wings for the night. Almost from the moment of hatching, the Ducklings swim and dive with the greatest address, employing themselves often in catching gnats and other insects on which they at first principally feed; but though so alert and well provided for their aquatic life, their aërial progress is slow, as the growth of their wings is very tardy, these continuing short and misshapen for near six weeks, and the bird can scarcely attempt to fly in less than three months. This protracted infancy necessarily indicates the necessity of pairing early in the season; and in the milder parts of Europe the males, jealous and quarrelsome with each other, begin towards the close of February already to address their mates.

Wild Ducks at all times show more activity in the night than in the day. They feed, migrate, arrive, and depart chiefly in the evening and in the night. In the dusk the 
rustling of their wings often alone marks their progress. Their flight is generally in the form of a wedge, or two converging lines $(>)$; and being very cautious, they never alight until they have wheeled several times round the spot, as if to survey any lurking danger that may possibly threaten. They often also swim out at a distance from the shore, and one or more of the party, experienced as leaders, usually watch for the common safety, and give instant alarm whenever there is occasion. During the day they thus roam at large on the lakes, secluded pools, or broad rivers remote from the shores, resting or sleeping till the approach of twilight. In a domestic state, though their habits are so much changed, they are very noisy and watchful in the evening and at dawn, responding their quack and cackle to the early crowing of the cock. It is at this time that the fowler, secreted in his hut or in any other way, lies in wait for their approach to the lure of his female decoys, and pours among them his destructive fire.

It would far exceed our limits to detail the various arts employed in order to obtain this wily and highly esteemed game. Decoys of wood, carefully painted to imitate these and other species, are sometimes very successful lures in the morning twilight. The imitation of floating objects, as a boat painted white amongst moving ice, has also sometimes been attended with complete success. In India and China the natives, wading into the water and concealing the head in a calabash, steal upon the Ducks imperceptibly, and drawing them down severally by the legs, fasten them to a girdle, till it becomes loaded with its unsuspicious game.

In the fens of Lincolnshire extensive and ingenious decoys are made for this purpose in the form of a winding canal passing out of the lake where the Ducks resort, and which is screened on one side by a high reed-fence. At the bottom of this artificial and converging sluice, inarched with willows, a tunnel net is laid, into which the birds are driven by a dog trained for the purpose and sent out to the Ducks at the entrance of the inlet; they are thus, with suitable precaution,

VOL. II. -20 
at length urged into the net, sometimes in such quantities that five or six dozen have been taken out at one drift.

The food of the Wild Duck is small fish, fry, snails, aquatic insects and plants, as well as seeds and most sorts of grain. In the severity of winter, if the standing waters become frozen, these birds remove to running rivers and resort to the edge of woods in quest of acorns or other suitable food; but if the frost continues for eight or ten days they disappear, and do not return till the early thaws of the spring.

The Mallard is a rare bird in New England and the Provinces, but it is quite common in western Ontario and Manitoba, and elsewhere throughout North America, breeding from Indiana and Iowa northward. On the Atlantic coast it is not known to breed south of Labrador.

Nuttall's statement that many of these birds pass the greater part of the winter in Greenland has been questioned, though European naturalists have been aware that the Mallards were influenced to migrate more by the absence of open water than by change of temperature. Mr. Hagerup has confirmed Nuttall's statement lately by reporting that in south Greenland the Mallards "are common the whole year round, but most numerous in winter, when they keep in small flocks along the shore." 


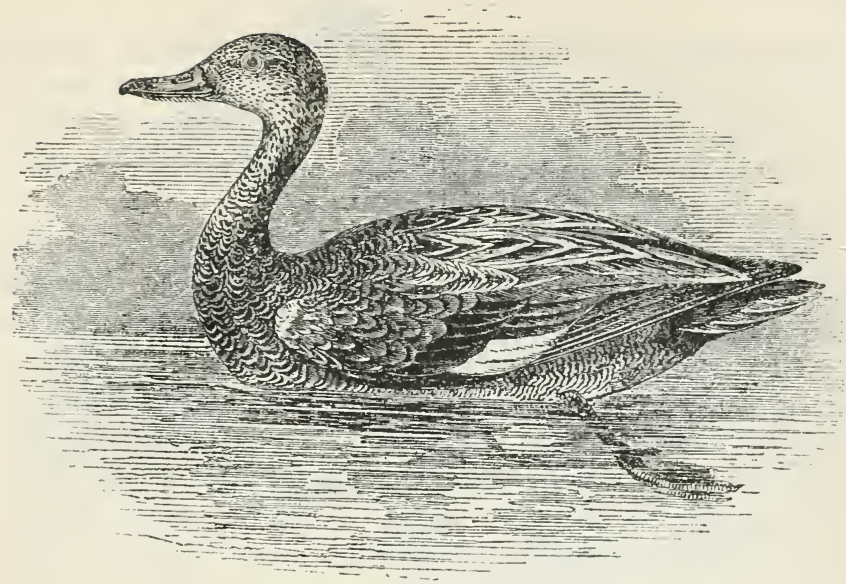

\section{GADIVALL.}

GRAY DUCK.

\section{ANAS STREPERA.}

CHAR. Upper parts brown, barred and vermiculated with white, giving a general appearance of brownish gray; head and neck light brown, mottled with darker; wings brown and black, wing-patch white; rump black; tail-feathers brown, edged with paler; lower neck and breast dark gray; belly white, with fine wavy lines of gray; bill lead blue; legs dull orange. The female is darker in color, the dark-brown tints prevailing above, the white below. Length about $2 \mathrm{I}$ inches.

Nest. Usually near the water, though often some distance away, placed under a bush or amid a tussock of rank herbage; made of grass and lined with feathers, - sometimes a mere depression in the soil, lined with feathers.

Eggs. 8-I3; pale buff, tinged with green when fresh; 2.10 $\times$ I.50.

The Gadwall inhabits the northern regions of both continents, but does not in America, according to Richardson, proceed farther than the 68th parallel, and in Europe it seems not to advance higher than Sweden. In the Russian Empire it extends over most of the latitudes of the European and Siberian part, except the east of the latter and Kamtschatka. In migrations it passes chiefly into the warmer parts of Europe, being very rare in England, but common on the coasts of 
France, Italy, and Sardinia. In the United States it appears to be generally rare. A few of the young birds are seen in this vicinity, and Wilson met with it in the interior on Seneca Lake in October, and in February at Louisville on the Ohio, and near the Big Bone Lick, in Kentucky.

The Gadwall breeds in the woody districts of the remote northern fur countries of Canada. In the North of Europe it inhabits the vast rushy marshes, and in Holland, where it is common, associates in the same places with the Wild Duck, or Mallard. These birds are very much esteemed as game, are very alert at diving and swimming, and plunging at the flash of the gun, are obtained with difficulty. They are very timorous, lurking in the marshes by day, feeding only in the twilight of the morning and evening, and often till some time after nightfall; they are then heard flying in company with the Whistlers, and, like these, obey the call of the Decoy Ducks. Their cry much resembles that of the common Wild Duck; nor is it more raucous or louder, though Gesner seems to have meant to characterize its note by applying the epithet strepera, which has been adopted by succeeding ornithologists. The food of this bird consists of small fish, shelly mollusca, insects, and aquatic plants.

The Gadwall breeds from the Middle States to the lower fur countries. It is rather rare to the eastward of the Mississippi valley, but in that region it is abundant north to the Saskatchewan.

This is a freshwater Duck, and its favorite resort is the marshy margin of a retired lake or stream, where it dozes through the hours of the day, and at night feeds among the tangled rushes. It is a shy bird and wary, but sociable with its kind, and may be found in company with other wild fowl. It swims light and buoyantly, but never dives unless wounded, and its flight is strong and swift. 


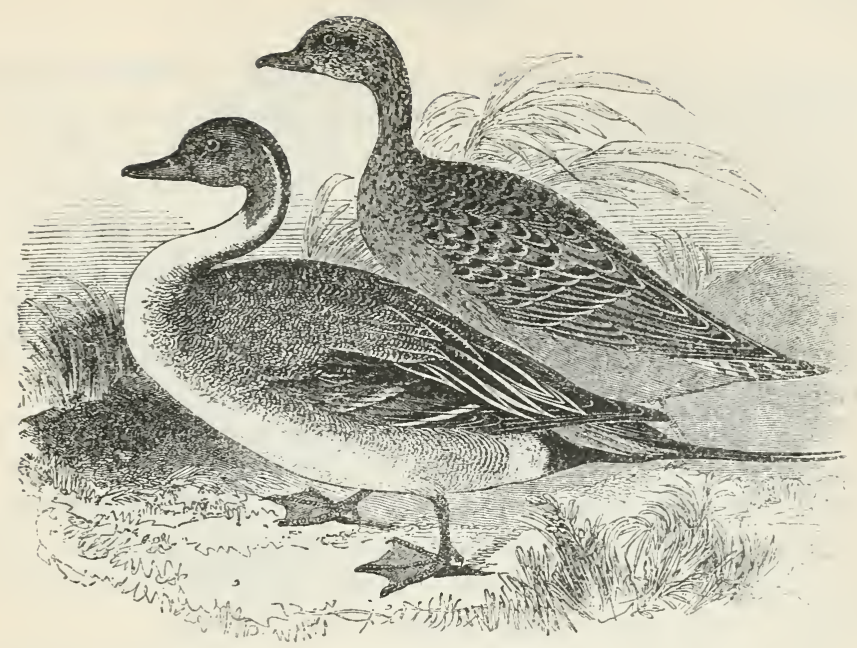

PINTAIL.

GRAY DUCK. SPRIGTAIL.

DAFILA ACUTA.

CHAR. Male: back and flanks mottled gray; head and neck brown, shading to black on the nape; wing-coverts buff; wing-patch, or "speculum," green, margined with black and white; tail black, the two central feathers much elongated; under parts white, - a line from the breast extending up the sides of the neck; bill and legs slate gray. Length 26 to 30 inches. Female: upper parts mottled gray and brown, and lower parts gray and white; wing as in male, but of duller tints; tail with oblique bars. Length 21 to 23 inches.

Nest. Usually at considerable distance from the water, but often very near; always amid a tuft of tall grass, in a dry spot, - a deep, bowl-like structure of sedges, and lined with grass and down.

Eggs. 7-10; pale buffish green; average size about $2.10 \times 1.50$.

This elegant species is an inhabitant of the northern parts of both continents, leaving its remote natal regions as the winter advances, when it is seen pretty frequently in the markets of the United States, and is a game much esteemed for the excellence of its flavor. According to Richardson, these birds frequent chiefly the clear lakes, and breed in the Barren Grounds, 
appearing in the more southern and wooded districts when about to migrate, at which period they proceed even beyond the limits of the United States, being noticed by Hernandez in Mexico. In Europe they are said to retire to the marshes of the White Sea to breed. In Missouri and some of the other Western States they are abundant early in March, and frequent the small pools and ponds in the prairies; at the same time they are likewise seen on their way north on the shores of the Delaware.

The Pintail is shy and cautious, feeding on the mud-flats and shallow freshwater marshes, but rarely taking to the seacoast. It seldom dives, is very noisy and chattering, uttering a quack like the Common Duck, and plunges and hides with great dexterity when wounded. It is also troublesomely vigilant in giving alarm on the approach of the gunner.

The food and nest of this species are very similar to those of the preceding. I have found the stomach in one instance nearly filled with the seeds of the Zostera. A female Pintail bred in confinement, when paired with a Widgeon in Lord Stanley's menagerie in Knowsley, sat so closely upon her eggs towards the close of the period of incubation as to allow herself to be taken off the nest by hand without forsaking her hatching, and a brood of these hybrids was successfully reared.

The Pintail is abundant in the interior, breeding along the northern border of the United States and in Manitoba, and thence to the Arctic Circle. It is rather rare on the Atlantic coast, where it appears in autumn and winter north of Chesapeake Bay. 


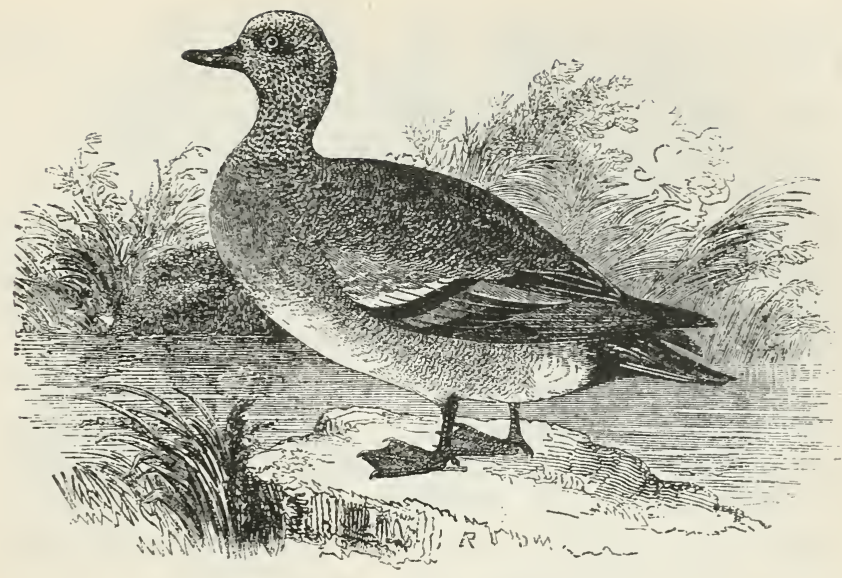

BALDPATE.

WIDGEON.

\section{ANAS AMERICANA.}

CHAR. Mantle brownish gray, varied with fine waved lines of black; head and neck grayish white, with dark spots, - the crown with few or no spots; a green patch on the sides of the head behind the eyes; wingpatch green, bordered with black; tail grayish brown; breast mottled reddish brown; belly white; bill and legs grayish blue. Length 19 inches. The female has a dark-brown back; head and neck yellowish white, spotted with black.

Nest. Under a bush on upland, or on a dry knoll in a marsh; made of weed-stenis, grass, and leaves, - sometimes a mere depression amid dead leaves, - lined with down.

Eggs. 7-I2; ivory white; average size $2.20 \times 1.50$.

This species, so nearly allied to the European Widgeon, has not been found in the old continent; yet it retires north to breed, inhabiting in summer the woody districts of the remote fur countries near the Saskatchewan and the coasts of Hudson Bay as far as the 68th degree of northern latitude. In autumn and winter these birds are common in nearly all parts of the Union, many wintering in North and South Carolina in the 
open rivers and bays, sometimes considerably inland. Indeed, I have never seen them anywhere so numerous as in the Neuse River, round Newbern, forty miles from the ocean, where, in company with the Canvas-back and Buffle-head, they are seen constantly in February and March. They are also numerous in Chesapeake Bay, and in the course of the winter extend their migrations as far as St. Domingo and other of the West India Islands, as well as into Cayenne in the tropical parts of the continent.

The Widgeon, or Baldpate, is a frequent attendant on the Canvas-back, and often profits by this association. The former, not being commonly in the habit of diving for subsistence, or merely from caprice, watches the motions of its industrious neighbor, and as soon as the Canvas-back rises with the favorite root on which they both greedily feed, the Baldpate snatches the morsel and makes off with his booty. These birds are always very alert and lively, feeding and swimming out into the ponds and rivers at all hours of the day, but are extremely watchful, sheltering in coves and behind the land, and on the slightest attempt to steal upon them, immediately row out into the stream beyond gunshot, and then only take to wing when much disturbed. In Carolina and the West Indies they frequent the rice-fields in flocks, and in Martinico are said to do considerable damage to the crops. When thus feeding in company they have a sort of sentinel on the watch. At times they keep in covert until twilight, and are then traced by their low, guttural, and peculiar whistle, or 'whew, 'whew, as well as other calls; and their whistle is frequently imitated with success to entice them within gunshot. They feed much in the winter upon aquatic vegetables, cropping the pond-weed as well as other kinds of freshwater plants and seeds, and sometimes dive and collect the roots and leaves of the sea-wrack.

Although generally distributed throughout North America, the Baldpate rarely appears on the Atlantic coast excepting in winter, when it is found on the shores of the Southern States. It is a "tolerably common summer resident" of Manitoba, writes Ernest Thompson, and the bird is well known in Ontario. 


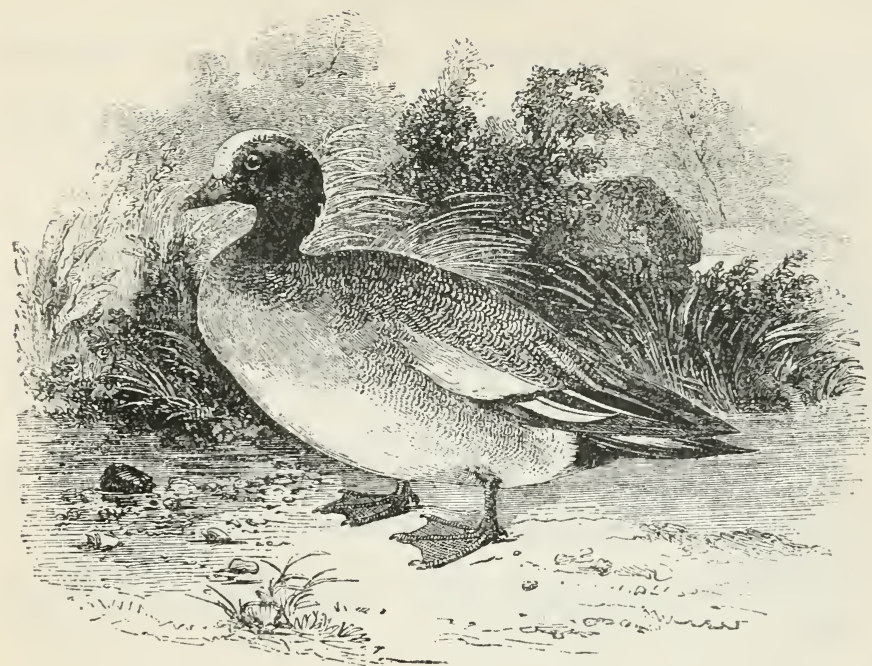

\section{WIDGEON.}

\section{ANAS PENELOPE.}

ChAR. Adult male: mantle white, marked with fine lines of dark gray; shoulders white, followed by bar of black; wing-patch green; longer wing-feathers and tail dark brown; head and neck chestnut, shading to buff on the forehead and to black on the throat; breast gray, tinged with rufous and shading to white below, which extends across the belly; sides marked with fine lines of dark gray; under tail-coverts black; bill slate blue, tipped with black; legs and feet dusky lead color. Soon after the mating season the male assumes plumage similar to the female. Female : upper parts grayish brown, - the feathers with paler margins; under parts white, the breast buffish brown; under tail-coverts barred with brown; wing-patch grayish brown. Length $\mathrm{r} 8$ inches.

Nest. Concealed amid rank herbage or under a bush, on the margin of a lake; a deep bowl made of sedges and lined with grass and down.

Eggs. 7-I 2 (usually about 10); rich cream color or buff; average size $2.20 \times 1.50$.

Though generally set down in the books as a bird of the Old World, the Widgeon has been known to occur on this western shore of the Atlantic much too often to be omitted from the present connection. The bird breeds on Iceland, and probably occurs regularly in Greenland, though in small numbers; and every year 
more or less examples are seen along our coast from Nova Scotia to Virginia.

The nest has not been found within our borders, and it is not probable that any nests have been built here. The breeding area lies north of the Arctic Circle.

The Widgeon is one of the most abundant and best-known of the Ducks that migrate through the British Islands, where it appears in flocks of enormous size, covering like a cloud the mudflats of the sea-shore when the tide is out, or settling upon any large sheet of inland water adjacent to the sea; for these birds feed on the buds and seeds of aquatic plants as well as on marine insects and mollusks.

The call of the male Widgeon is a shrill-whistled whee-you, or mee-yu, - the first note loud and prolonged. The female utters a low, purring note, like kir-r-r. When flushed, both male and female rise in silence.

The Widgeon is not easily shot. It is extremely shy and difficult to approach, and its flight is rapid. 


\section{BLACK DUCK.}

DUSKY DUCK. DUSKY MALLARD.

ANAS OBSCURA.

CHAR. General plumage blackish brown, paler on under parts; head and neck lighter; wing-patch greenish purple, bordered with black ; lining of wings white; bill greenish yellow; legs red. Length about 23 inches.

Nest. On the ground in a wet meadow or marshy border of lake or stream, - sometimes under a bush or amid rushes; a large but well-made structure of grass and weed-stems lined with feathers.

Eggs. 6-12 (usually about 8) ; pale buff or buffish green; $2.40 \times 1.70$.

This species seems to be an exclusive inhabitant of America, being met with from Labrador to Florida, but is not found in the higher boreal regions of the continent. It is generally known by the improper name of the "Black Duck," though it is merely dusky, and both sexes, nearly alike in plumage, have a great resemblance to the female of the Common Mallard. It is a numerous and common species in the salt-marshes, as well as freshwater rivers and lakes. It is only partially migratory, many birds often wintering in the Middle and Southern States, where they also pass the summer and breed from the Carolinas to Labrador in retired places in the freshwater marshes, or in the sea islands, making a nest of rank weeds.

Many of these birds migrate north as well as into the interior at the approach of spring. Their principal food in autumn and winter appears to consist of minute shell-fish, particularly those univalves which are so abundant in the salt-marshes. They also at times in great numbers visit the sandy beach in quest of small bivalves and other shelly mollusca, and occasionally feed on seeds of aquatic and bog plants, such as those of the Scheutzeria ; and, as usual, swallow gravel with the rest of their fare. They roost in the shallow ponds and islands, where many are caught by the minx and fox, and are extremely shy during the day, being at that time very seldom seen, except when surprised in their retreats or alarmed by the report of the gun, when they often rise from the marsh in great numbers and 
disperse confusedly in every direction. In calm weather they fly high; but when the wind blows hard they proceed within gunshot over the salt meadows, and may then be brought down in great numbers by the concealed gunner as they proceed over their usual track. Their voice or quack resembles that of the common Wild Duck, and their flesh when well fed, notwithstanding the nature of their food, is scarcely inferior to that of any other species.

The Black Duck is found throughout this Eastern Province, north to Labrador and the Hudson Bay region, breeding south to "Illinois and New Jersey" (Chapman).

Note. - The Florida Duck (Anas fulvigula) is a Southern race of the Black Duck, though it has been given specific rank within recent years. The plumage is similar to that of obscura, though fulvigula is varied somewhat with buff; the cheeks and throat plain buff; wing-patch greenish purple. It ranges through the Gulf States and west to Kansas. 


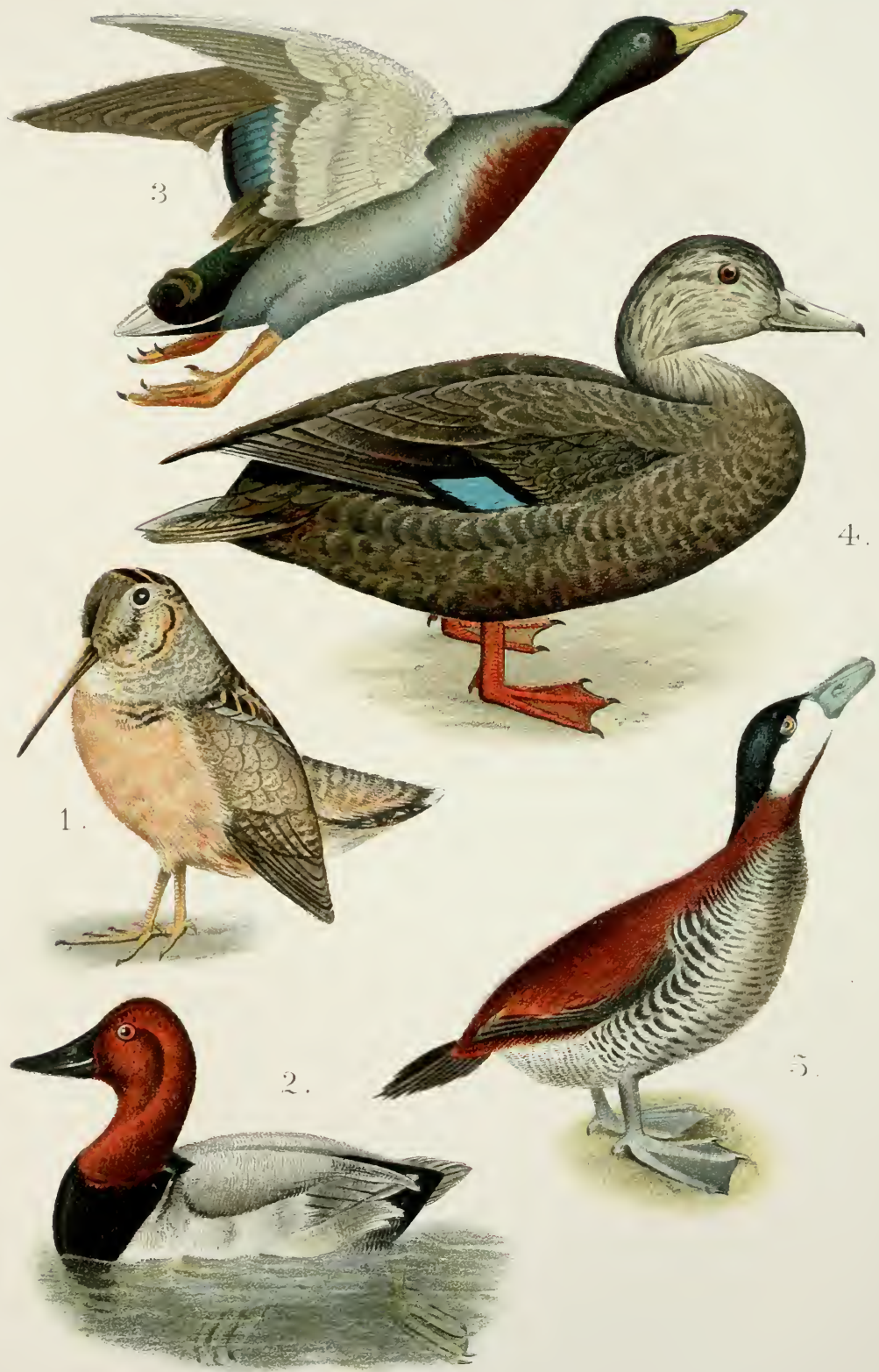

1. Woodcock.

4. Black Duck.

3 Mallard Duck

2. Canvas-Back Duck.

5. Ruddy Dack . 



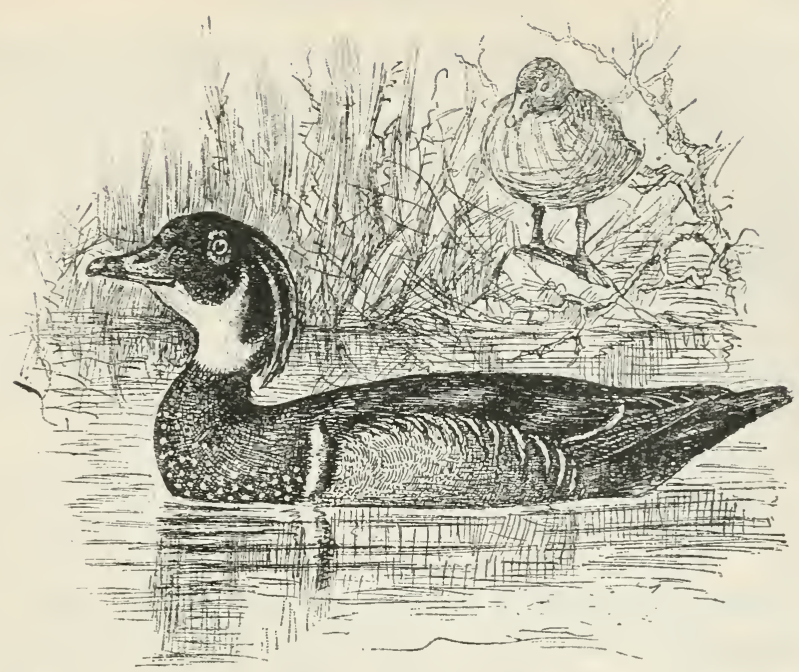

WO O D D UCK.

SUMMER DUCK.

\section{AIX SPONSA.}

CHAR. Upper parts dark brown, varied with black; head and crest metallic green and purple; lines of white above and behind the eyes; throat white; breast chestnut, with spots of white; under parts white, flanks with fine waved lines of black; black and white crescents in front of shoulder ; wings glossed with purple and green, and tipped with white; bill red, black, and white; legs yellow. Female mostly grayish brown, and duller than the male; throat and patch around the eye white. Length I7 to 9 inches.

Nest. In a hollow tree; made of twigs and grass lined with down.

Eggs. 8-I4; pale buff or creamy; average size 2.10 $\times$ I.6o.

This most beautiful of Ducks seems to be dressed in a studied attire, to which the addition of a flowing crest adds a finish of peculiar elegance; and hence Linnæus has dignified the species with the title of sponsa, or the bride. This splendid bird is peculiar to America, but extends its residence from the cold regions of Hudson Bay, in the 54th parallel, to Mexico 
and the Antilles. Throughout a great part of this vast space, or at least as far south as Florida and the Mississippi Territory, the Summer Duck is known to breed. In the interior it is also found in the State of Missouri and along the woody borders and still streams which flow into most of the Great Northwestern Lakes of the St. Lawrence. The Summer Duck so called from its constant residence in the United States - has indeed but little predilection for the sea-coast, its favorite haunts being the solitary, deep, and still waters, ponds, woody lakes, and the mill-dams in the interior, making its nest often in decayed and hollow trees impending over the water.

Though many migrate probably to the shores of the Mexican Gulf, numbers pass the winter in the States south of Virginia. Early in February they are seen associated by pairs on the inundated banks of the Alabama, and are frequent at the same season in the waters of West Florida. In Pennsylvania they usually nest late in April or early in May, choosing the hollow of some broken or decayed tree, and sometimes even constructing a rude nest of sticks in the forks of branches. The eggs are yellowish white, rather less than those of the Domestic Hen, and they are usually covered with down, probably plucked from the breast of the parent. The same tree is sometimes occupied by the same pair for several successive years in the breeding-season. The young, when hatched, are carried down in the bill of the female, and afterwards conducted by her to the nearest water. To these places, when once selected, if not disturbed, they sometimes show a strong predilection, and are not easily induced to forsake the premises, however invaded by noise and bustle. While the female is sitting, the male is usually perched on some adjoining limb of the same tree, keeping watch for their common safety. The species is scarcely ever gregarious; the birds are only seen in pairs or by families. The common note of the Drake is peet, peet; but when at his post as sentinel, on espying danger, he makes a sort of crowing noise, like 'hoo eek, 'hoo eek.

The food of the Wood Duck consists principally of acorns, the seeds of aquatic plants, such as those of the wild oat, etc., 
and insects which dwell in or near waters; and I have seen a fine male whose stomach was wholly filled with a mass of the small coleoptera, called Donatias, which are seen so nimbly flying over or resting on the leaves of the pond-lily. These birds are therefore very alert in quest of their prey, or they never could capture these wary insects. They are not uncommon in the markets of the Eastern and Middle States, and are justly esteemed as food.

Wood Ducks have sometimes been tamed, and soon become familiar. They have even been so far domesticated as to run about at large in the barn-yard like ordinary fowls. In France they have also been acclimated and tamed, and have bred in this condition.

The Wood Duck breeds from Florida to the lower fur countries, - latitude $60^{\circ}$ being the probable limit of its northern range, - and winters in the Southern States and southward. It is common in New England, and rare in Manitoba.

\section{BLUE-WINGED TEAL.}

\section{ANAS DISCORS.}

CHAR. Back mottled reddish brown, black, and buff; forehead, crown, and throat dark lead color; cheeks with tinge of lavender and a white, crescentic patch between the eyes and bill; shoulders sky blue; wingpatch green, bordered with white; under parts pale reddish buff, more or less spotted with dusky; bill black; legs yellowish. The female is mottled dull brown and buff, and has an indistinct patch on the cheeks. Length about $15 \mathrm{I} / 2$ inches.

Nest. Amid a tuft of rank grass, usually in a wet meadow on the marshy margin of a pond ; made of grass and weed-stems and lined with feathers.

Eggs. 6-12 ; pale buff or ivory white, sometimes with a tinge of green when fresh; average size $1.85 \times 1.30$.

The Blue-winged Teal, according to the season, inhabits every part of the American continent, from the plains of the Saskatchewan and the $5^{8 \text { th }}$ parallel to Guiana and the West Indies. The breeding-place of these birds is, however, to the 
north and west; they are particularly abundant as early as August in the Territory of Michigan, and Mr. Say observed them there on the $7^{\text {th }}$ of June, so that they probably breed in the vicinity of the Great Lakes of the St. Lawrence as well as in the remote interior of the Canadian fur countries.

These Teal arrive in this vicinity and other parts of Massachusetts near to the sea-coast early in September, and according to Wilson are seen soon after on the muddy shores of the Delaware, where they are often observed basking or hiding in crowded companies close to the edge of the water, where they can only be approached under cover. They fly out with rapidity, and when they alight, drop down suddenly among the reeds in the manner of the Snipe or Woodcock. As the first frosts come on, they proceed to the south, and then abound in the inundated rice-fields of the Southern States, where great numbers are taken in traps placed on the small dry eminences that here and there rise above the water, to which they are decoyed with rice; and by the common contrivance called a Figure 4, they are taken alive in box-traps. In the month of April they pass through Pennsylvania on their way to the North, but make little stay at that season; they are seen also in the spring in the State of Missouri, and spread themselves widely to breed throughout a great extent of the western and northern wilderness.

Though often contiguous to the sea, these birds have no predilection for visiting the shores, feeding chiefly on vegetables and insects, and particularly on the wild rice which abounds in the Northwestern lakes and sluggish streams. They are much esteemed as game, and commonly become very fat. Their note, which is somewhat like a diminutive quack, is uttered low and rather rapidly.

The Blue-winged Teal is uncommon in New England and the Provinces, and we must go to the region bordering the Mississippi valley to find it in abundance. It breeds from the northern tier of States northward, and winters in the Southern States, the West Indies, and Central America. 


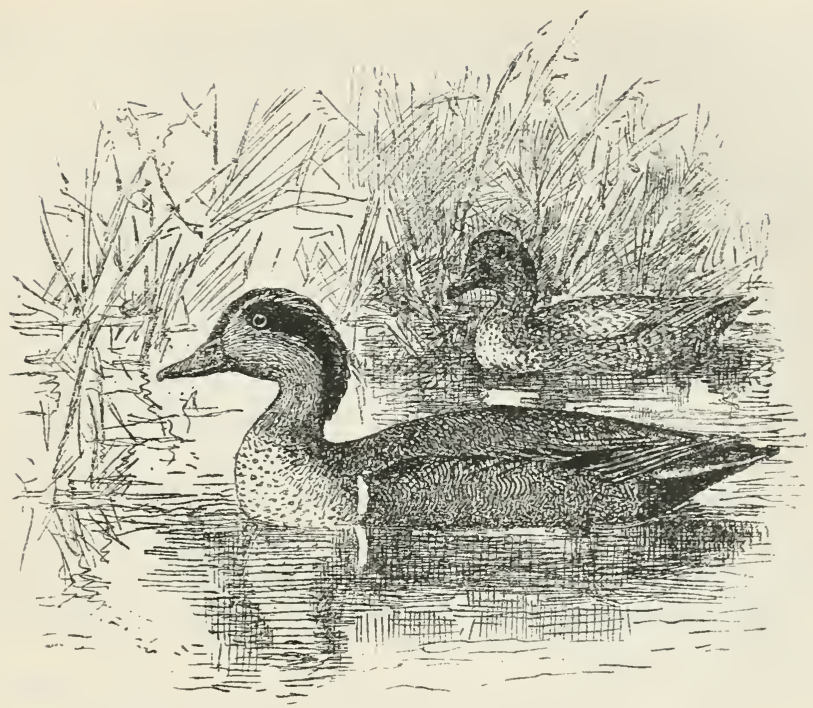

\section{GREEN-WINGED TEAL.}

\section{ANAS CAROLINENSIS.}

ChAR. Upper parts and flanks dark gray and white in fine waved lines; head and neck chestnut, with a broad green band on the sides; wing-patch rich green and black, bordered with buff and white; a white crescentic patch in front of the shoulder; under parts white, the breast spotted; bill black; legs leaden gray. The female is duller in general color, and has fewer and less conspicuous markings. Length about 14 inches.

Nest. Amid a tuft of grass, - made of grass and weed-stems and lined with feathers.

Egrs. 6-12; pale buff or ivory white, tinged with green when fresh; $1.80 \times 1.30$.

The Green-winged Teal, as a species, is common to the northern and temperate parts of both continents. The American bird appears to be a permanent and distinct variety. There is, according to Dr. Richardson, however, in the Hudson Bay Museum a specimen from the fur countries agreeing

VOL. II. - $2 \mathrm{I}$ 
in all respects with the European species. Our variety is abundant to the extremity of the continent, both in the woody and barren districts of the remote fur countries of Hudson Bay. It is also plentiful about Severn River, in the woods and plains near fresh waters, where it breeds, the young being about six or seven at a hatch. It feeds much upon freshwater insects, seeds, and aquatic plants, and when fat is delicate food. In the autumn and winter it is very common throughout the waters of the United States, both in the interior and contiguous to the sea-coast. In the course of the winter it retires as far south as Jamaica, and is probably common also along the coasts of the Mexican Gulf. It frequents ponds, marshes, the reedy shores of creeks and rivers, and in winter is very abundant in the rice-plantations of the South. The birds usually fly in small parties, feeding mostly by night, associating with the Mallard, and are commonly decoyed by its call.

The Teal is found in the North of Europe as far as Greenland and Iceland, and it also inhabits the borders of the Caspian to the south. In France and England it is said to breed. It is commonly seen on the pools, in close companies of ten or twelve together, frequenting the rivers and unfrozen springs in winter, where it subsists on aquatic plants. It flies very swiftly, and utters a sort of whistling cry. It breeds in the fens, continuing in the temperate parts of Europe the whole year. It conceals its nest among the bulrushes, constructing it of their stalks and lining it with feathers; it rests also sometimes on the surface of the water, so as to rise and fall with the flood. The female takes the whole management of incubation; the males at this time seeming to leave them and associate by themselves in companies. The American Teals in the autumn, which visit this quarter, are also for the most part young birds and females, the males pursuing a different route apart from the rest, and are rarely seen here until their return in the spring.

The Green-winged Teal is abundant in Manitoba and the surrounding region during the migrations, and numbers nest as far 
south as Lake Winnipeg. It is numerous also westward to the Pacific slope, breeding in the mountain region of Oregon, and northward to Alaska. In the East it is quite common during the migrations, though perhaps more numerous in the interior than on the lakes and streams adjacent to the coast, and breeding chiefly in the Hudson Bay region north of latitude 50 degrees. Being a strictly freshwater bird, it is rarely found along the sea-shore, though I have met with stragglers occasionally near the mouths of streams which empty into the Bay of Fundy.

I cannot indorse Nuttall's statement that the males are rarely seen in the autumn in this region, though they do usually appear in small flocks, and separated from the females.

This species ranges in winter from "Kansas and Virginia southward to the West Indies and Central America" (Chapman).

Note. - A few examples of the Cinnamon Teal (Anas cyanoptera) have wandered from the Pacific slope to the valley of the Mississippi and to Manitoba. Another straggler of this group the European Teal (Anas crecca) - has been taken on the Atlantic coast. 


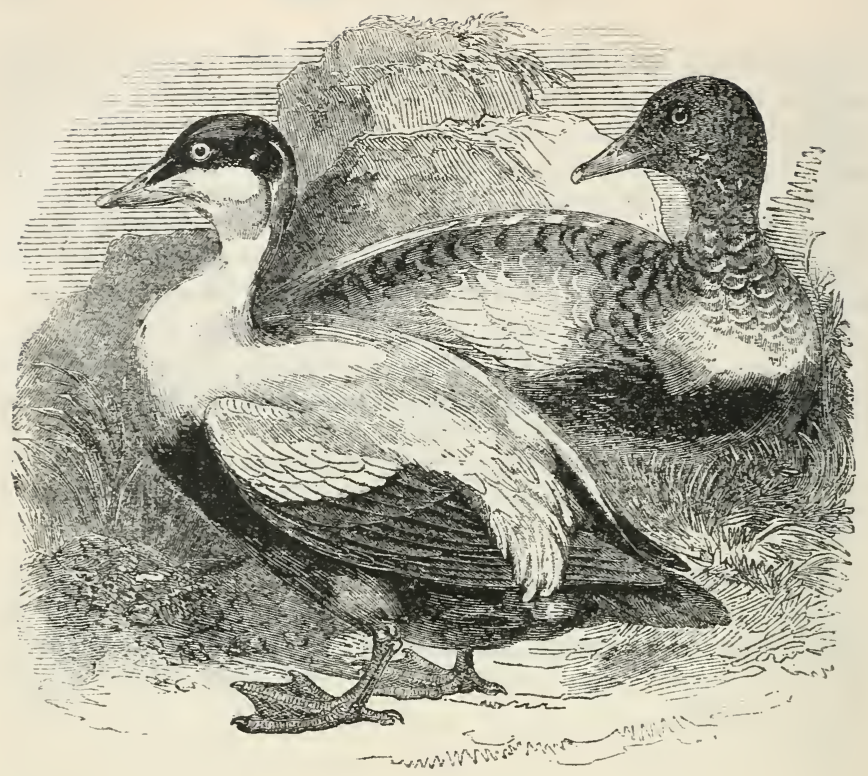

\section{AMERICAN EIDER.}

\section{COMMON EIDER. SEA DUCK.}

\section{SOMATERIA DRESSERI.}

CHAR. Back, cheeks, and wing-coverts white; top of head, wings, tail, and belly black; patch of sea-green on sides of neck; breast rosy buff; bill of greenish color, and with long wedges of feathers extending from the forehead and cheeks towards the nostrils; legs dull green. The female is nearly uniform dull brown, mottled with paler on the breast; belly dull white. Length about 25 inches.

Nest. Generally on a flat and grassy ocean island, often on a bluff on the coast, - sometimes on a heath-covered moorland; a substantial structure of coarse marine herbage thickly lined with down.

Eggs. 4-IO; color varies from pale olive buff to bluish gray; $2.95 \times$ 2.00.

The Eider Duck, remarkable for the softness of its valuable down, seems thus purposely provided by Nature with a clothing suited to the inclement regions in which it generally dwells. Living mostly out at sea, it is thus enabled to endure the sever- 
ity of the glacial regions, for which it has such a predilection. The older birds are indeed only partially migratory, moving no farther southward in winter than to permanent open water. The presence of these birds, with a few others of like habits and hardihood, contributes to give an air of animation to the bleak and dreary coasts of Greenland and Spitzbergen. They are found throughout Arctic America, and in severe winters sometimes wander as far south to sea as the capes of the Delaware. In the depth of winter, or from November to the middle of February, the old birds are also usually seen in small numbers towards the extremities of Massachusetts Bay and along the coast of Maine. A few pairs even have been known to breed on some rocky islands beyond Portland. Mr. Audubon found several nesting on the isle of Grand Menan, in the Bay of Fundy; but on the bleak and wintry coast of Labrador they were seen by him in abundance, nesting and laying from April to the last of May. The nest was usually placed under the shelter of a low prostrate branched and dwarf fir (probably Pinus Banksiana), and sometimes several are made under the same bush within a foot or two of each other. The groundwork of the nest, as usual, was sea-weeds and moss, but the down of the female parent is only added when all the eggs are laid. The Duck, now acquiring an attachment for her eggs, was at this time easily approached, her flight being even and rather slow. As soon as the task of incubation has commenced, the males leave the land, and associate together in large flocks out at sea, in July begin to moult, and in August become so bare as to be scarcely able to rise out of the water.

As soon as the young are hatched they are led to the water by their attentive parent, and there remain, excepting in the night and in tempestuous weather. Their greatest enemy, besides man, is the Saddle-back Gull (Larus marinus) ; they, however, elude his pursuit by diving, at which both old and young are very expert. The down, though so valuable, is neglected in Labrador. It is so light and elastic that two or three pounds of it, pressed into a ball that may be held in the hand, will swell out to such an extent as to fill and distend the 
foot-covering of a large bed. The best kind, termed live down, is that which the Eider plucks to line the nest; the down taken from the dead bird is greatly inferior, and it is rare that so valuable a bird is now killed for the purpose. To augment the quantity of down from the same bird, the eggs, which are very palatable, are taken, and the female again strips herself to cover the second and smaller hatch. If the nest be a second time plundered, as the female can furnish no additional lining, the male now lends his aid and strips the coveted down from his breast, which is well known by its paler color. The last laying, of only two or three eggs, is always left, to kindle the parents' hopes of progeny ; for if this be taken they will abandon the place, but thus indulged, they continue to return the following year, accompanied by their young. The most southern breeding-place of this species in Europe is the Ferne Isles, on the coast of Northumberland; and voyagers who have ventured to the dreary extremity of Arctic Europe, hear, in summer, from the caverns and rocks of the final cape, the deep moan of the complaining Eider. In Norway and Iceland the Eider districts are considered as valuable property, carefully preserved, and transmitted by inheritance. There are spots that contain many hundreds of these nests; and the Icelanders are at the utmost pains to invite the Eiders each into his own estate; and when they perceive that they begin to frequent some of the islets which maintain herds, they soon remove the cattle and dogs to the mainland, to procure the Eiders an undisturbed retreat; and to accommodate them, sometimes cut out holes in rows on the smooth, sloping banks, of which, to save themselves trouble, they willingly take possession and form their nests. These people have even made many small islands for this purpose by disjoining promontories from the continent. It is in these retreats of peace and solitude that the Eiders love to settle; though they are not averse to nestle near habitations if they experience no molestation. "A person," says Horrebow, "as I myself have witnessed, may walk among these birds while they are sitting, and not scare them; he may even take the eggs, and yet they will 
renew their laying as often as three times." According to the relation of Sir George Mackenzie, on the 8th of June, at Vidöe, the Eider Ducks, at all other times of the year perfectly wild, had now assembled in great numbers to nestle. The boat by which the party approached the shore passed through multitudes of these beautiful fowls, which scarcely gave themselves. the trouble to go out of the way. "Between the landing-place and the governor's house the ground was strewed with them, and it required some caution to avoid treading on the nests. The drakes were walking about uttering a sound very like the cooing of Doves, and were even more familiar than the common Domestic Ducks. All round the house, on the garden wall, on the roofs, and even in the inside of the houses and in the chapel were numbers of Ducks sitting on their nests. Such as had not been long on the nest generally left it on being approached; but those that had more than one or two eggs sat perfectly quiet, suffering us to touch them, and sometimes making a gentle use of their bills to remove our hands. When a drake happens to be near his mate, he is extremely agitated when any one approaches her. He passes and repasses between her and the object of his suspicion, raising his head and cooing."

One female, during the whole time of laying, generally gives half a pound of neat down, and double that quantity before cleansing. According to Troil, in the year $175^{\circ}$ the Iceland Company sold as much of this article as amounted to $£ 85^{\circ}$ sterling, besides deducting what was sent directly to Gluckstad.

At the time of pairing, according to Brunnich and Skioldebrand, the male is heard continually calling out with a raucous and moaning voice 'ha ho, 'ha ho; but the cry of the female resembles that of the Common Duck. At this exciting period the males, more numerous than their mates, have sharp contests with each other, and the vanquished and superannuated are afterwards seen wandering about at sea in much milder climates than the rest of their fraternity. Both birds labor in concert while forming the nest, and though the male gives no assistance in hatching, during the period of laying he keeps 
strict watch in the vicinity, giving notice of any danger as soon as it appears. The Ravens, it seems, no less than the Gulls, are the enemies of this valuable bird, often sucking the eggs and killing the young; the female therefore hastens to convey her brood to the sea, sometimes even carrying them on her back to the element in which they are thenceforth destined to live. The male now also leaves her, and neither of them returns more that season permanently to the land. Several hatches associate together at sea and form flocks of twenty or thirty, attended by the females, who lead them, and are seen continually splashing the water, to raise with the mud and sediment, the insects and small shell-fish for such of the young as are too weak to dive for themselves.

The Eider dives deep after fry, and feeds upon small shell-fish, mussels, and univalves, and sometimes on the seaurchin (Echinus) and various kinds of marine insects and seaweeds, and in summer mostly on the soft mollusca so abundant in the Arctic and hyperboreal seas. Its flesh is dark and fishy, though sufficiently tender, and that of the young and the female may be considered good. It is commonly eaten by the Greenlanders, and its skin is esteemed as an excellent inner garment. Prepared with the feathers left on, it also forms an article of commerce with the North, and particularly with the Chinese. Fitted purposely for inhabiting the coldest climates and the sea, the Eider does not long survive in temperate regions, and all attempts to domesticate it have consequently failed.

In the breeding-season, in Norway, some of the male Eiders are seen roaming about unpaired, either superannuated or unable to keep possession of the females. Mr. Audubon remarks that the Sea Ducks (Eiders, Surf Duck, Velvet, and Scoter) moult in July, and by the Ioth of August are so naked of feathers, and even destitute of quills, as to be unable to rise either from the water or the ground. At this juncture, in the Bay of Fundy, the Indians in large companies assemble in their canoes at the entrances of the bays frequented by these birds, and dividing themselves on either side of the headland, 
fire blank charges and hooting and yelling as loud as possible, drive the terrified birds into the cove at high-tide, where the natives remain until the ebb. The Ducks are then left grounded on the naked coast, and are thus easily despatched with clubs.

This Eider formerly nested on the islands in the Bay of Fundy, but in recent years has not been known to breed to the southward of the St. Lawrence, though it does not range north of Labrador During the winter months it is found in the Gulf of St. Lawrence and along the Atlantic coast as far as Delaware. Examples are seen occasionally on the Great Lakes.

Mr. Thomas A. Jaggar, who visited Labrador in I890, told me that he found a number of the nests of this species, and that they invariably contained four eggs.

\section{NORTHERN EIDER.}

\section{SOMATERIA MOLLISSIMA BOREALIS.}

ChAR. - Almost similar in coloration to $S$. dresseri, but differing in the shape of the wedge-like characters of the bill.

Nest and Eggs. Similar to dresseri.

The birds found breeding in Greenland were formerly supposed to be of the European race, - typical mollissima; but within a few years it has been discovered that there was sufficient difference to warrant a separation, there being a slight distinction in the coloration and in the shape of the bill.

In habits these Greenland birds do not differ from their more southern allies. Mr. Hagerup states that large numbers winter near the open water in South Greenland, arriving there chiefly from the northward. They winter south to Massachusetts.

\section{KING EIDER.}

\section{SOMATERIA SPECTABILIS.}

CHAR. Top of head pearl gray, shading to deeper on the nape; a black line bordering the base of the bill, which is formed like a shield; cheeks white, with patches of green; neck, upper back, and shoulders white ; lower back black; wings and tail dark brown; two lines of black from the chin form a chevron on the throat; breast white, tinged with 
buff; bill and legs orange. The female has the entire plumage of two shades of brown, the centre of the feathers dark brown, and the edges rufous. Length 24 inches.

$N^{\prime}$ est. On an ocean island or sea-side cliff, sometimes on a dry hillside, - usually a depression in the soil thickly lined with down; often a high structure of twigs and moss.

Eggs. 6-10 (usually 6); green of various shades, with more or less tinge of buff; $2.60 \times 1.90$.

This species is an inhabitant of the glacial regions, living generally out at sea, and feeding, independently of the land, chiefly upon the mollusca which abound in the Arctic Sea. It is never seen in fresh waters, and only resorts to land for the indispensable purposes of reproduction. Being well provided with a thick and downy robe, it is little inclined to change its situation, however rigorous the climate; and as the frost invades its resorts, it continually recedes farther out to sea, and dwells securely amidst eternal barriers of ice and all the horrors of an Arctic winter. The King Duck, still more sedentary than the Eider, is seldom seen beyond the 59 th parallel, except in the depth of winter, when, according to Audubon, it is observed off the coast of Halifax in Nova Scotia, Newfoundland, etc., and a few have been obtained off Boston, and at Eastport in Maine. These birds abound in Greenland and Spitzbergen, and visit and sometimes breed in the Orkneys and other of the remote Scottish isles. A few are also occasionally seen on the coasts of the Baltic and in Denmark. They breed sometimes in the crevices of rocks impending over the sea, making a nest of sticks and moss, lined with down from the breast.

The flesh is said to be palatable, the gibbous part of the bill being accounted a delicacy; and the down collected by the Greenlanders is esteemed of equal value with that of the Common Eiders.

The King Eider breeds in high latitudes, - north of latitude $73^{\circ}$, - but a few pairs nest on the Labrador coast, and Mr. Boardman says that nests have been found in the Bay of Fundy.

In winter these birds are found in South Greenland and along the coast of New Jersey (sparingly), and occasionally on the Great Lakes. 


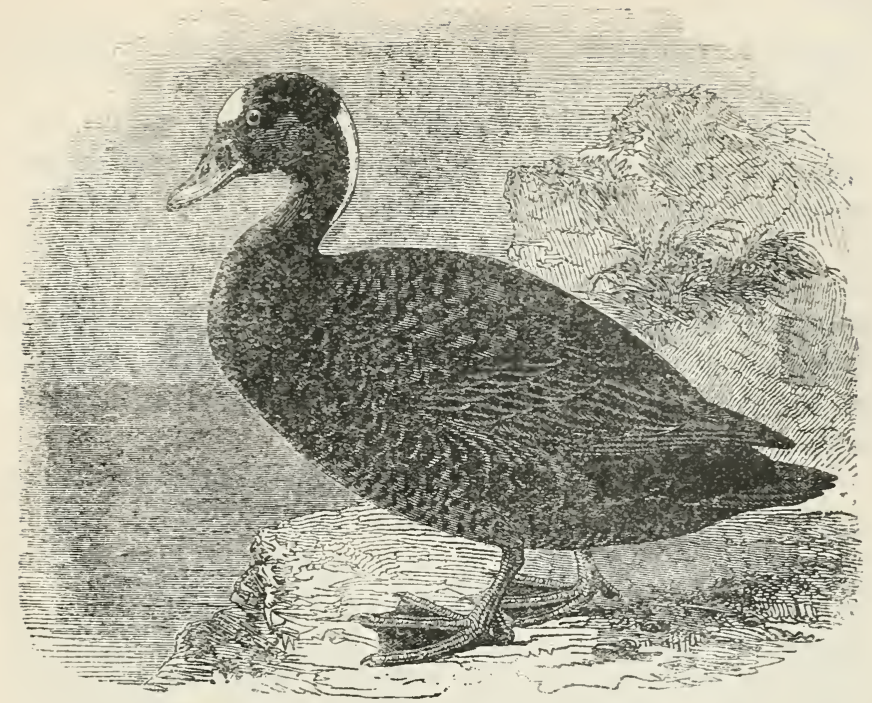

SURF SCOTER.

SURF DUCK. PATCH-HEAD. HORSE-HEAD COOT. SKUNK-HEAD.

OIDEMIA PERSPICILLATA.

ChAR. Male : general color deep black above, paler below; a white patch on the forehead and on the nape; bill mostly orange red, with a patch of black near the base of the upper mandible, bordered by orange and pale blue; lower mandible pinkish; legs and toes orange, webs dull green, claws black. Female : upper parts dusky or sooty brown; under parts grayish; bill dusky; legs and feet dull buff. Length about I9 inches.

Nest. On the margin of a lake or sluggish stream, concealed amid a tussock of rank herbage or beneath a low branch, - made of coarse weedstems and lined with down.

Eggs. $5-8$; pale buff or ivory white ; $2.40 \times 1.65$.

This species of Sea Duck, with other dark kinds here commonly called Coots, may be properly considered as an American species, its visits in the Orkneys and European seas being merely accidental. It breeds on the Arctic coasts, and 
extends its residence to the opposite side of the continent, having been seen at Nootka Sound by Captain Cook.

During summer these Ducks feed principally in the sea; they also commonly frequent shallow bars and surf-lashed shores and bays in quest of various kinds of small shell-fish, for which while on our coast they are almost perpetually diving. They begin to migrate southward from their northern resorts in company with the Long-Tailed Ducks, at which period the flocks halt both on the shores of Hudson Bay and on the lakes of the interior as long as they remain open, feeding on tender shelly mollusca.

The Surf Duck, or Sea Coot, breeds also along the shores of Hudson Bay and in Labrador, and is said to make a nest of grass, lining it with down or feathers, and lays from four to six white eggs, which are hatched in the month of July. It selects the borders of freshwater ponds for its eyries, on which the young are fed, and protected until they are nearly ready to fly. Although these birds extend their migrations to the coast of Florida, they often continue along all the shores and open bays of the Union throughout the winter ; or at least parties go and come during the greater part of the period. Early in May, or the close of April, they are again seen bending their course towards the North. They are shy birds to approach, but can be decoyed by imitative wooden ducks of the same general appearance. Their flesh, however, remarkably red and dark when cooked, is very fishy, and has but little to recommend it; the young birds are somewhat superior in flavor, but the whole are of little consequence as game, though often eaten by the inhabitants of the neighboring coasts.

The Surf Scoter breeds reguiarly throughout Labrador and in the Hudson Bay and Great Slave Lake regions. It is common on the Atlantic coast and in Manitoba while migrating, and winters from Massachusetts to the Carolinas and the lower valley of the Ohio. 


\section{AMERICAN SCOTER.}

\section{BLACK SCOTER. BUTTER-BILLED COOT. BLACK COOT. SEA COOT.}

\section{OIDEMIA AMERICANA.}

CHAR. Male: general plumage black, the under parts somewhat brownish; bill black, with large patch of orange or yellow on upper mandible; legs and feet black. Length about 20 inches. Female: smaller than the male; plumage dusky brown, more or less mixed with white on under parts.

Nest. On a sea-side cliff or moorland bluff near a lake, - made of coarse herbage and lined with down.

Eggs. 6-IO; buff of various shades; $2.55 \times 1.80$.

This species, probably confounded with the Common Scoter, is said to inhabit the shores of Hudson Bay, breeding between the 5 oth and 6oth parallels, but does not appear to frequent the interior. It lives and feeds principally at sea, and its flesh is rank and oily. The American Scoters visit the coasts and bays of Massachusetts and New York in considerable numbers, associating with the Surf, Velvet, Eider, and other Sea Ducks, and are brought occasionally to Boston market about the first week in November. While here they appear to feed principally on shell-fish, particularly mussels, and the flesh of the young is tolerably palatable.

The American Scoter is not so strictly a sea-bird as Nuttall supposed, for though common on the coast it is found also on all the larger inland waters. In the A. O. U. "Check List" this bird's distribution is given as follows: "Coasts and larger inland waters of northern North America; breeds in Labrador and the northern interior; south in winter to New Jersey, the Great Lakes, Colorado, and California."

In October, I878, I shot a male near the head waters of the Restigouche river, in the center of New Brunswick.

In habits this species does not differ materially from its allies. 


\section{WHITE-WINGED SCOTER.}

WHITE-WINGED COOT. SEA COOT. VELVE'T SCOTER.

\section{OIDEMIA DEGLANDI.}

ChAR. Male : black, with a broad band of white on the wings, and a small patch of white under the eyes; knob on bill black, rest of bill and legs orange. Female: sooty brown, paler below; head more or less varied with white; wing-patch white; bill and legs blackish. Length 20 to 23 inches.

Nest. On the bank of a lake or sluggish stream, concealed at the foot of a low tree or bush, - made of coarse herbage and moss, lined with feathers; sometimes lined with down.

Eggs. 6-9 (usually 6) ; pale dull buff, varying to delicate cream color; $2.70 \times 1.85$.

The White-winged Scoter might be characterized as a Sea Duck that retires inland to breed. It occurs in summer, and builds from about latitude $50^{\circ}$ to the fur countries, and winters on the Massachusetts coast and south to Chesapeake Bay. Some few individuals are found in winter on the Great Lakes.

The habits of these birds do not differ from others of the group. Their principal food is mollusks, which they obtain by diving, generally in deep water; and they are most active at night, floating on the water asleep during a great part of the day. Their note is a harsh ker-ker.

Note. - The European Velvet Duck (Oidemia fusca) wanders oceasionally to the coasts of Greenland.

\section{RUDDY DUCK.}

SPINE-TAILED DUCK. BROAD-BILL DUCK. DIPPER DUCK.

\section{ERISMATURA RUBIDA.}

Char. Bill long and very wide at the end and deep at the base; tailfeathers stiff and pointed. Male in summer: upper parts rich chestnut; crown and nape black; cheeks and chin white; rump and wing-coverts grayish brown; wings and tail dusky; under parts silvery white, shaded with dusky; bill and feet bluish. Male in winter, young male, and female: upper parts dull grayish brown, varied with dull buff, top of head darker; cheeks and chin dull white; neck brownish gray; lower parts grayish white; bill and feet dusky. Length about 15 inches. 
Nest. In the marshy margin of a pond or sluggish stream, amid the rank herbage close by the water's edge, - a loosely made, bulky structure of reeds and coarse grass, lined with grass.

Eggs. ? sometimes 20 ; pale buff or dirty white, with a rough surface; $2.40 \times 1.80$.

This species, an exclusive inhabitant of America, retires to the North to breed, frequenting the small lakes in the interior of the fur countries up to the $5^{8 \text { th }}$ parallel. On the $5^{\text {th }}$ of August it was also observed by Mr. Say at Pembino, in the latitude of $49^{\circ}$, where, no doubt, it also passes the period of reproduction. These birds are very unwilling to take wing, though they fly pretty well when once started. They dive with the greatest facility, and particularly at the flash of the gun, or even the report of the percussion-cap. When swimming they have a habit of carrying the tail so erect that it appears of the same height with the head and neck. Small flocks, consisting of the female and young, are often seen in Fresh Pond, in this vicinity; but scarcely ever the adult males, who seem to migrate usually apart at this season. They visit us early in October, and in the course of the winter proceed south to the extremity of the Union. On their first arrival they are tame and unsuspicious; but the old males are extremely shy and difficult of approach. Their food appears to be principally marine and fluviatile vegetables, and seeds, for which they dive. Besides gravel, I have found in the stomach seeds and husks of the Ruppia maritima. They rarely, if ever, visit the sea, but are found towards the head of tide-waters in estuaries and small ponds at no great distance from the ocean. They are common in the markets of Boston, where they are sold under the name of Dun-birds, and their flesh is good and much esteemed.

The Ruddy Duck is said to be generally distributed over North America and to breed throughout its range; but in the New England States it occurs principally as a fall and spring migrant, and a few individuals have been seen during the winter months. I think they breed on the Grand Lake Meadows in New Brunswick, for I have seen very young birds there.

The males are rarely seen in full plumage, in which they make a 
strikingly beautiful appearance, and the bird is familiar only in the duller colors, worn at all seasons by the young male and female; and in this inconspicuous dress these birds are enabled to avoid observation by hiding in the rank herbage so common at their resorts, and thus have gained a reputation for being rare, while they are fairly common. They are known to be common by the gunners of Chesapeake Bay, who take them to market, - their food being chiefly marine plants, which they obtain by diving; their flesh is tender, and of pleasant flavor.

\section{CANVAS-BACK}

\section{AyTHYa VALLISNERIA.}

CHAR. Mantle and sides silvery white, daintily marked with waved lines of dusky; head and neck brownish red; lower neck and breast and rump brownish black; wings and tail gray; under parts white; bill black; legs leaden gray. In the female the head, neck, and breast are dull brown; upper parts grayish brown; belly white. Length about 22 inches.

Nest. In marshy margin of stream or lake, concealed amid rank herbage, - made usually of grass and weed stems and lined with feathers.

Eggs. 6-10; grayish olive, - sometimes tinged with drab; $2.40 \times 1.75$.

The Canvas-back, so well known as a delicacy of the table, is a species peculiar to the continent of America. It breeds, according to Richardson, in all parts of the remote fur countries, from the 5 oth parallel to their most northern limits, and at this period associates much on the water with the ordinary tribe of Ducks. After the close of the period of reproduction, accumulating in flocks, and driven to the open waters of the South for their favorite means of subsistence, these birds arrive about the middle of October seawards on the coast of the United States. A few at this time visit the Hudson and the Delaware, but the great body of emigrants take up their quarters in the Bay of Chesapeake and in the numerous estuaries and principal rivers which empty into it, particularly the Susquehanna, the Patapsco, Potomac, and James rivers. They also frequent the sounds and bays of North Carolina, and are abundant in the river Neuse, in the vicinity of Newbern, and probably in most of the other Southern waters to the coast of 
the Gulf of Mexico, being seen in winter in the mild climate of New Orleans. In these different sections of the Union they are known by the various names of Canvas-backs, Whitebacks, and Sheldrakes. In the depth of winter a few pairs, probably driven from the interior by cold, arrive in Massachusetts Bay, in the vicinity of Cohasset and near Martha's Vineyard; these, as in the waters of New York, are commonly associated with the Red-head, or Pochard, to which they have so near an affinity. Their principal food, instead of the freshwater plant Valisneria, which is confined to so small a space; is in fact the different kinds of sea-wrack, known here by the name of eel-grass, from its prodigious length. These vegetables are found in nearly every part of the Atlantic, growing like submerged fields over all the muddy flats, shallow bays, estuaries, and inlets, subject to the access of salt or brackish waters. They are the marine pastures in which most of the Sea Ducks, no less than the present, find at all times, except in severe frosts, an ample supply of food.

The Canvas-backs on their first arrival are generally lean; but by the beginning of November they become in good order for the table. They are excellent divers, and swim with speed and agility. They sometimes assemble by thousands in a flock, and rising suddenly on wing, produce a noise like thunder. During the day they are commonly dispersed about in quest of food, but towards evening collect together, and coming into the creeks and river inlets, ride as it were at anchor, with their heads under their wings asleep; sentinels, however, appear awake and ready to raise an alarm on the least appearance of danger. At other times they are seen swimming about the shoals and diving after the sea-wrack, which they commonly pluck up, and select only the tenderest portion towards the root. Though thus laboriously engaged, they are still extremely shy, and can rarely be approached but by stratagem; for even while feeding, several remain unemployed, and vigilant against any surprise. When wounded in the wing, they dive to prodigious distances, and with such rapidity and perseverance as almost to render the pursuit hopeless. The great demand

VOL. II. -22 
and high estimation in which these Ducks are held, spurs the ingenuity of the gunner to practise every expedient which may promise success in their capture. They are sometimes decoyed to shore or within gunshot by means of a dog trained for the purpose, which, playing backwards and forwards along the shore, attracts the vacant curiosity of the birds, and as they approach within a suitable distance, the concealed fowler rakes them first on the water, and afterwards as they rise. Sometimes by moonlight the sportsman directs his skiff towards a flock, whose position he has previously ascertained, and keeping within the projecting shadow of some wood, bank, or headland, he paddles silently along to within fifteen or twenty yards of a flock of many thousands, among whom he consequently makes great destruction.

As the severity of the winter augments, and the rivers become extensively frozen, the Canvas-backs retreat towards the ocean, and are then seen in the shallow bays which still remain open, occasionally also frequenting the air-holes in the ice, and openings which are sometimes made for the purpose, immediately over the beds of sea-grass, to entice them within gunshot of the hut or bush fixed at a convenient distance for commanding the hungry flocks. So urgent sometimes are the Ducks for food in winter that at one of these artificial openings in the ice, in James River, a Mr. Hill, according to Wilson, accompanied by a second person, picked up from one of these decoys, at three rounds each, no less than eighty-eight Canvasbacks. The Ducks crowded to the place so that the whole open space was not only covered with them, but vast numbers, waiting their turn, stood inactive on the ice around it.

The Canvas-back will also eat seeds and grain as well as marine grass, and seems especially fond of wheat, by which it may be decoyed to particular places, after continuing the bait for several days in succession. The loss of a vessel loaded with this grain, near the entrance of Great Egg Harbor, in New Jersey, attracted vast flocks of these Ducks to the spot, so that not less than two hundred and forty were killed in one day by the neighboring gunners, who assembled to the spot in quest 
of these strange birds, which were afterwards sold among the neighbors at the low rate of twelve and a half cents apiece, without the feathers. These Sea Ducks, as the gunners then called them, - from the direction, probably, in which they arrived, - were no other than the famous Canvas-backs, which commonly sold in the Philadelphia market at from a dollar tc a dollar and a half per pair, - and indeed sometimes much higher prices are given, when they are scarce, and considered indispensable.

The Canvas-back is rare in New England and the Maritime Provinces, and occurs in that portion of the country as a migrant only; but it is abundant in winter on Chesapeake Bay, and breeds in the fur countries, appearing in numbers, while migrating, in the region of the Great Lakes. A few pairs breed in Nanitoba, but the bulk of the flocks go farther north, - as far even as Alaska and the lower valley of the Mackenzie River. The breeding area may extend farther to the southward than Manitoba, for Dr. Newberry reported finding very young broods on the lakes and streams amid the Cascade Mountains in Upper California, in which region Canvas-backs are said to be very numerous, - more numerous than any other water-fowl. 


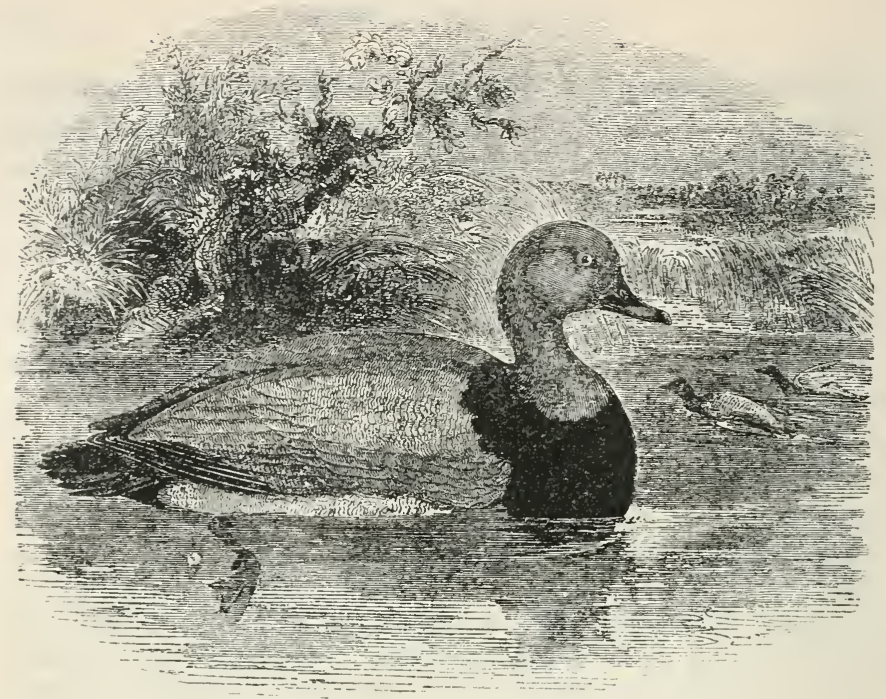

\section{REDHEAD.}

\section{POCHARD.}

\section{AYTHYA AMERICANA.}

CHAR. Mantle and sides silvery white, varied with fine waved lines of dusky; belly white; head and neck rich chestnut; lower neck, breast, and rump black; wings and tail slate gray; bill dull bluish black, tipped with gray; legs and feet leaden gray. In the female the head, neck, and breast are grayish brown, and the markings on the back less distinct and of a browner tint. Length 17 to 21 inches.

Nest. Amid the rank herbage in marshy margin of stream or lake, sometimes resting upon the water; made of grass and sedges and lined with feathers.

Eggs. 7-I 4 (usually about I0); pale buff or creamy, tinged more or less with olive; $2.40 \times 1.75$.

The Pochard, so nearly related to the Canvas-back, with which it generally associates, is common to the north of both continents. It is abundant in Russia in rivers and lakes in all latitudes, as well as in Denmark, the north of Germany, and as a bird of passage is seen in England, Holland, France, Italy, and in the course of the winter proceeds as far south as Egypt. In the present continent these birds are found to 
breed in all parts of the fur countries, from the 5oth parallel to their utmost boreal limits, and, dwelling in fresh waters, are seen to associate generally with the ANATrNÆ, or proper Ducks, taking to the sea in autumn with their broods, and appearing within the limits of the United States towards the close of October; they afterwards spread themselves over the bays, rivers, and freshwater lakes at no great distance from the sea. In the Bay of Chesapeake and its tributary streams they are now seen in flocks with the Canvas-backs, and feed much on the same kind of submarine grass, or wrack-weed, on which they become very fat, and are in flavor and size but little inferior to their companions, - being often, in fact, both sold and eaten for the same, without the aid of any very sensible imposition. In the months of February and March they are common in the fresh waters of North and South Carolina, where many pass the greater part of the winter; they are also seen at this season in the lower part of the Mississippi, around Natchez, and probably accompany the flocks of the preceding species near New Orleans. Brisson's Mexican Pochard, described by Fernandez, is also in all probability the same bird.

The Pochards dive and swim with great agility. They are in England sometimes taken in the decoy pools in the usual manner of driving, but are by no means welcome visitors; for by their continual diving they disturb the rest of the fowls on the water, and thus prevent their being enticed into the tunnel nets; nor are they willingly decoyed with the other Ducks. They are said to walk awkwardly and with difficulty. It is also added that their cry more resembles the hollow hiss of a serpent than the voice of a bird. Their flight is more rapid than that of the common Wild Duck, and the noise of their wings very different. The troop forms a close body in the air ; but they do not proceed in angular lines or obey any particular leader, nor have they any call sufficient for the purpose. On their first arrival they are restless and watchful, alighting on the water, and then again wheeling and reconnoitring in the air for some time, uncertain in tne choice of their move- 
ments. The only time when they can be approached within gunshot, like so many other of the species, is about daybreak, from an ambush or the shelter of some concealment.

In the London markets these Ducks are sold under the name of Dun Birds, and are very deservedly esteemed as a delicate and well-flavored game.

Although it has been said that this species will not live in confinement, Mr. Rennie states that no bird appears sooner reconciled to the menagerie; and one in his possession which had been badly wounded in tire wing took immediately to feeding on oats, and after three years confinement appeared very tame, and remained in good health.

The Redhead is generally distributed throughout North America, but is uncommon or rare in New England and the adjacent Provinces, while common to abundant on the Great Lakes and westward. It breeds from Maine northward, and winters in Chesapeake Bay, and south to the shores of the Gulf of Mexico.

While in general appearance this bird is so like the Canvas-back that purchasers are readily deceived as to the species the marketman is offering them, yet the difference is so pronounced that but little care is required to select the more delicately flavored of these cousins. In the Canvas-back the head is dark brown, - almost blackish brown, - in contrast to the rich chestnut of the Redhead, and the bill of the former displays more black color. The shape of the head is different also, that of the Canvas-back being longer and narrower. 


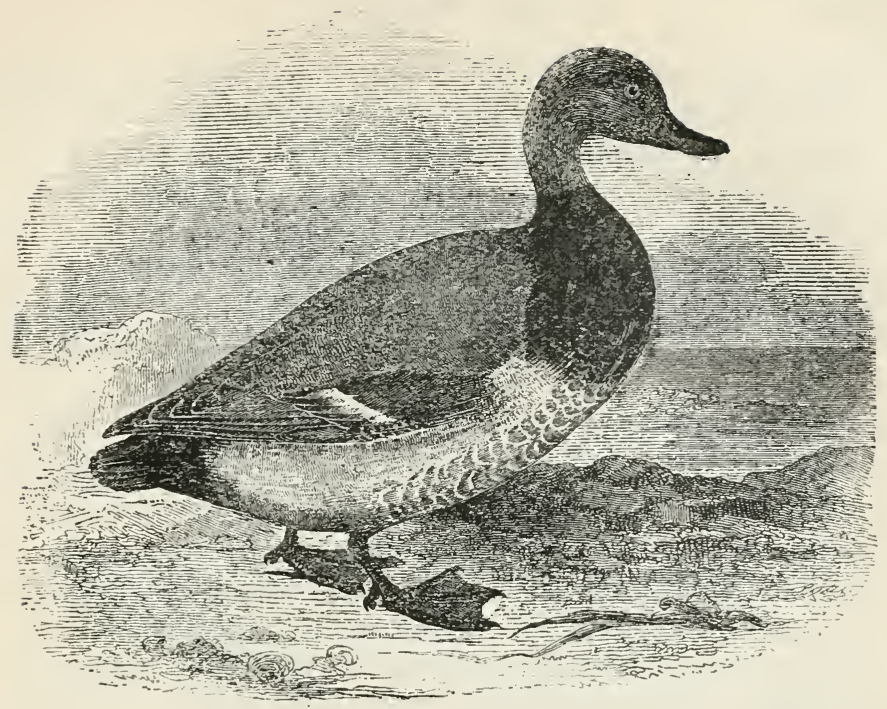

\title{
AMERICAN SCAUP DUCK.
}

\author{
BIG BLACKHEAD. BLUEBILL.
}

\section{AYTHYA MARILA NEARCTICA.}

CHAR. Male: head, neck, and breast black, with green reflections; back and sides white, marked with fine waved lines of black; rump, wings, and tail brownish black; wing-patch white; belly white, pencilled with black; vent and under tail-coverts black; bill leaden blue, with a black "nail" at the tip; legs gray, feet blackish. Female: general plumage of upper parts dull brown; band of white at base of bill; wing-patch and belly white. Length about 18 inches.

Nest. Amid rank herbage near a lake or stream; a rude structure of loosely laid grass and sedges, lined with feathers.

Eggs. 6-10; pale buff tinged with olive, - sometimes tinged with drab; $2.55 \times 1.70$.

This species, better known in America by the name of the Bluebili, is another general inhabitant of the whole northern hemisphere, passing the period of reproduction in the remote and desolate hyperboreal regions, whence at the approach of winter it issues over the temperate parts of Europe as far as 
France and Switzerland, and in the United States is observed to winter in the Delaware, and probably proceeds as far as the waters of the Southern States, having been seen in the lower part of Missouri by Mr. Say in the spring. It is abundant also in winter in the Mississippi around and below St. Louis. The breeding-places of this bird, according to the intelligent and indefatigable Richardson, are in the remote fur countries, from the most southern point of Hudson Bay to their utmost northern limits.

The Scaup Duck is said to derive its name from feeding on scaup, or broken shell-fish, for which and other articles of subsistence, such as marine insects, fry, and marine vegetables, it is often seen diving with great alertness. It is a common species here both in fresh waters and bays, particularly frequenting such places as abound in its usual fare, and like most of its tribe it takes advantage of the accommodation of moonlight. These birds leave the Middle States in April or early in Nay.

Both male and female of the Scaup make a similar grunting noise, and have the same singular toss of the head, with an opening of the bill when sporting on the water in the spring. While here they are heard occasionally to utter a guttural quanck, very different from that of Common Ducks. In a state of domestication during the summer months, when the larvæ of various insects are to be found in the mud at the bottom of the pond these birds frequent, they are observed to be almost continually diving. They feed, however, contentedly on barley, and become so tame as to come to the edge of the water for a morsel of bread. Mr. Rennie adds, of all the aquatic birds we have had, taken from their native wilds, none have appeared so familiar as the Scaup. The flesh of this species is but little esteemed, though the young are more tender and palatable.

The Bluebill is well known to the gunners on the Atlantic, though more common to the southward than on the New England shores, and abundant in the Western interior. It breeds from about latitude $50^{\circ}$ northward, and winters south to Central America. 


\section{LESSER SCAUP DUCK.}

\section{LITTLE BLACKHEAD. LITTLE BLUEBILL,}

\section{AYTHYA AFFINIS.}

CHAR. Similar in coloration to marila nearctica, but in the present species the gloss of the head is purple instead of green, and the flanks are pencilled with dusky instead of being unmarked. Size smaller, length about 16 inches.

Nest. Sometimes on an island, but usually in the marshy margin of a stream or pond, hid amid the ranker herbage close to the water; made of grass and weed-stems and lined with down.

Eggs. 6-9; pale dull buff tinged with olive; $2.25 \times 1.60$.

The slight difference between this bird and its larger ally has caused such confusion of the two that the distinctive distribution and habits of the present species has not been determined. Both are classed with the Sea Ducks, yet both build their nests by inland waters usually, and not on the sea-coast. The nests are generally by an inland stream, but Dr. Bell reports finding several on Nottingham Island, in Hudson Bay.

Of the two birds the present is less frequently found on salt water even in winter. During the migrations it is uncommon along the shores of northern New England and the Provinces, though Mr. Brewster considers it common on the Massachusetts coast in the fall, while rare in the spring. It winters farther south than does the larger bird, and is more plentiful on the streams and creeks running into Chesapeake Bay than at any locality to the northward. It is very abundant along the lower valley of the Mississippi, and Dr. Coues reported finding it abundant on the upper Missouri. Thompson reports it " an abundant summer resident" of Manitoba.

Audubon considered this species could be approached easily, while feeding; but the examples I have met with have been rather wary, and though they rose from the water with difficulty, and therefore rarely took wing, they generally managed to swim out of the range of my gun.

Authors differ as to the origin of the name given to these birds, some referring it to their fondness for mollusks, while others think the cry is responsible for the name, which sounds like the word scaup, delivered by a harsh voice in a screaming tone. The cry is exceedingly discordant. 


\title{
RING-NECKED DUCK.
}

\author{
RING-BILLED BLACKHEAD. RING-NECKED BLACKHEAD. \\ MARSH BLUEBILL.
}

\section{AYTHYA COLLARIS.}

CHAR. Upper parts and breast black, deepest on the head; an orangebrown collar on the neck; wings slate gray, wing-patch bluish; under parts white, flanks marked with fine waved lines; bill leaden blue, tipped with black, and with subterminal and basal bands of pale blue.

The female lacks the collar and the waved lines on flanks; band of grayish white around base of b:ll shading to pure white on the chin; general tints brownish. Length 16 to 18 inches.

Nest. Concealed amid rank herbage in reedy margins of a stream or pond; made of grass and lined with feathers.

Eggs. 6-12; grayish buff tinged with olive; $2.25 \times 1.60$.

The Ring-necked Duck is found throughout North America, breeding from about latitude $45^{\circ}$ northward, and wintering from Chesapeake Bay and the lower Ohio to the IVest Indies. It does not appear to be an abundant bird anywhere, but is more common along the valley of the Mississippi than near the Atlantic, where it is so uncommon as to be considered rare by many local ornithologists. Mr. Boardman writes to me that the bird breeds regularly on the St. Croix River, and is not uncommon about the mouth of the Bay of Fundy. I had met with it elsewhere in New Brunswick, but considered it rather rare.

The habits of this species are similar to those of others of the group. Its food consists chiefly of aquatic insects and seeds, varied with such small marine animals as come within reach of its bill. It swims and dives with ease, and its flight is strong and rapid; and as it rises from the water with more ease, it more frequently attempts to escape from a pursuer by flight than does either of its congeners. 


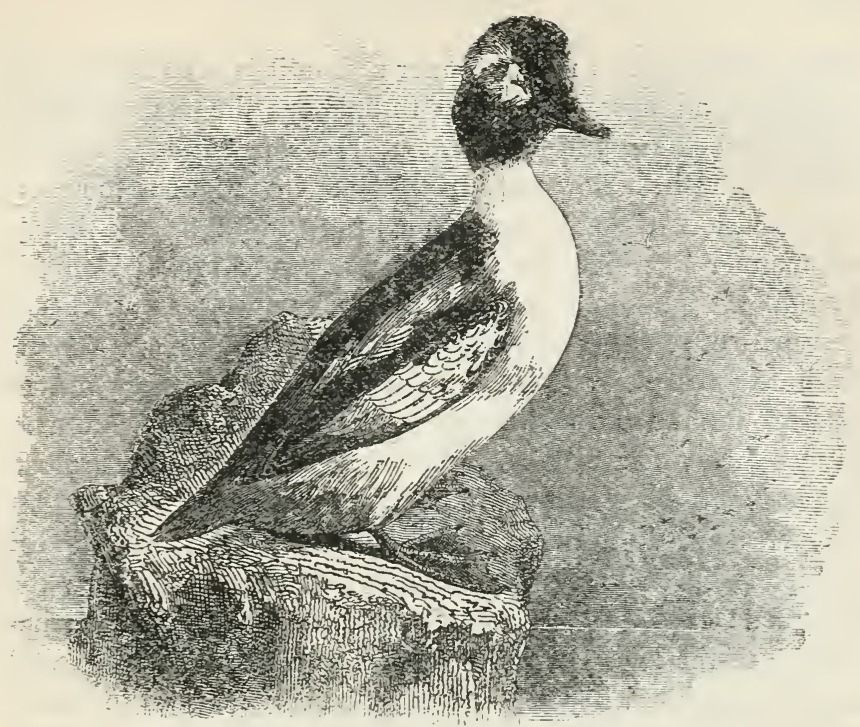

BUFFLE-HEAD.

\section{DIPPER. BUTTER-BALL. SPIRIT DUCK.}

\section{Charitonetta albeola.}

CHAR. Back, rump, and part of wings black, remainder of wing white, varied somewhat with black; head black, with green and purple reflections; a triangular patch of white from the eyes to the nape; lower neck and under parts white; tail slate gray; bill leaden blue; legs yellowish pink. Length 15 inches. The female is smaller, with a general color of grayish brown and a white patch on the cheeks and wings. Young birds resemble the female.

Nest. In a hollow of a tree or stump near a pond or stream, - a thick cushion of down on a platform of decayed wood.

Eggs. 6-I4 (usually about 10); ivory white or pale buff, sometimes with a tinge of olive; average size $2.00 \times 1.45$.

This very elegant little Duck, so remarkable for its expertness in diving and disappearing from the sight, is another of those species, like the Golden-eye, to which the aborigines have given the name of Spirit, or Conjurer, from the impunity with which it usually escapes at the flash of the gun or the 
twang of the bow. In the summer season it is seen abundantly on rivers and freshwater lakes throughout the fur countries, where it breeds in June, and about Hudson Bay it is said to make its nest in hollow trees in the woods contiguous to water, - a provision of some importance, probably, from the impotent manner in which the birds of this group proceed on the ground. In autumn and winter these birds are seen almost in every part of the Union, sometimes frequenting the sea-shores, but more particularly rivers and lakes. They are observed in Missouri, and on the Mississippi round Natchez. In February they were very abundant on the river Neuse in North Carolina, in the vicinity of Newbern, and used to dive very dexterously and perseveringly in quest of their food, which at that time is principally fluviatile and submerged vegetables, particularly the sea-wrack; they also sometimes visit the bays and salt-marshes in quest of the laver, or Ulva lactuca, as well as crustacea and small shell-fish. They are often exceedingly fat, and in Pennsylvania and New Jersey are commonly known by the ridiculous name of Butter-Box, or Butter-Ball. Their flesh, however, like that of the preceding species, is not in very high request for the table; but the females and young, which are almost the only kinds that visit this part of Massachusetts in winter, are very tender and well flavored.

In February, the males are already engaged in jealous contests for the selection of their mates, and the birds are then seen assembled in small flocks of both sexes. The drake is now heard to quak, and seen repeatedly to move his head backward and forward in the frolicksome humor of our domestic Ducks; and by about the middle of April or early in May every single individual will have disappeared on its way to the natal regions of the species in the North.

From their great propensity to diving, these birds are commonly known in the Carolinas by the name of Dippers; when wounded or hit with a shot, they will often dive or conceal themselves with such art that they seem to have buried themselves in the water, and probably often remain wholly submerged to the bill, or disappear in the jaws of a pike. 
The Buffle-head ranges over this entire continent, breeding from about latitude $45^{\circ}$ northward, and wintering from Massachusetts and the Great Lakes southward; it is more abundant in the West than near the Atlantic. Thompson reports it a common summer resident of Manitoba.

\section{AMERICAN GOLDEN-EYE.}

\section{WHISTLER.}

\section{Glaucionetta Clangula americana.}

CHAR. Male : upper parts black, the head with green reflections; a round patch between the bill and eyes; wings varied with white; lower neck and under parts white; bill black; legs and feet orange, with dusky webs. Length 19 to 23 inches. Female: upper parts brown, back, breast, and sides varied with gray; belly dull white; wing-patch white; bill, legs, and feet dull orange, webs dusky. Smaller than the male, - length about 17 inches. Young birds resemble the female.

Nest. In a hollow tree or stump, made of leaves and moss, and lined with down. .

Eggs. 6-12; bright green when fresh, but fading to a dull ashy green ; $2.40 \times 1.70$.

The Golden-eye is a common inhabitant of the boreal regions of both continents, from whence it migrates in small flocks at the approach of winter, accompanying the Velvet, Surf Duck, and Scoter in their desultory route in quest of subsistence. On their way, soon after the commencement of their adventurous voyage, these birds visit the shores of Hudson Bay and congenial lakes in the interior, on which they linger, feeding on tender and small shell-fish until debarred by the invasion of frost. They breed in all parts of the desolate and remote fur countries in great numbers, frequenting the rivers and freshwater lakes, on whose borders they pass the period of reproduction, making a rude nest of grass, and protecting the necessary warmth of their eggs by a layer of feathers or down plucked from the breast.

Although furnished with a remarkably complicated trachea in the male, whence the name of Clangula, we cannot learn that they ever possess any audible voice. When flusned they rise 
in silence, and we then only hear, instead of a cry or a quack, the very perceptible and noisy whistling of their short and laboring wings, for which reason they are here sometimes called by our gunners the Brass-eyed Whistlers. In their native haunts they are by no means shy, allowing the sportsman to make a near approach, as if conscious at the same time of their impunity from ordinary peril, for no sooner do they perceive the flash of the gun or hear the twang of the bow, than they dive with a dexterity which sets the sportsman at defiance, and they continue it so long and with such remarkable success that the aboriginal natives have nicknamed them as conjuring of "Spirit Ducks."

The food of the Golden-eye, for which it is often seen diving, consists of shell-fish, fry, small reptiles, insects, small crustacea, and tender marine plants. In and near fresh waters it feeds on fluviatile vegetables, such as the roots of Equisetum and the seeds of some species of Polygonum. Its flesh, particularly that of the young, is generally well flavored, though inferior to that of several other kinds of Ducks.

In Europe these birds descend in their migrations to the South along the coasts of the ocean as far as Italy, where they are known by the name of Quattr' Occhi, or "Four Eyes," from the two round and white spots placed near the corners of the bill, which at a distance give almost the appearance of two additional eyes. They likewise pass into the central parts of the Continent, and visit the great lakes of Switzerland. They are equally common, at the same season, in most parts of the United States, as far probably as the extremity of the Union, and early in spring they are again seen in Missouri and on the wide bosom of the Mississippi, preparing to depart for their natal regions in the North. Though they fly with vigor, from the shortness of their legs and the ampleness of the webs "of their feet, the Clangulas walk badly and with pain; they advance only by jerks, and strike the ground so strongly with their broad feet that each step produces a noise like the slapping of the hands; the wings are also extended to retain an equilibrium, and if hurried, the awkward bird falls on its breast 

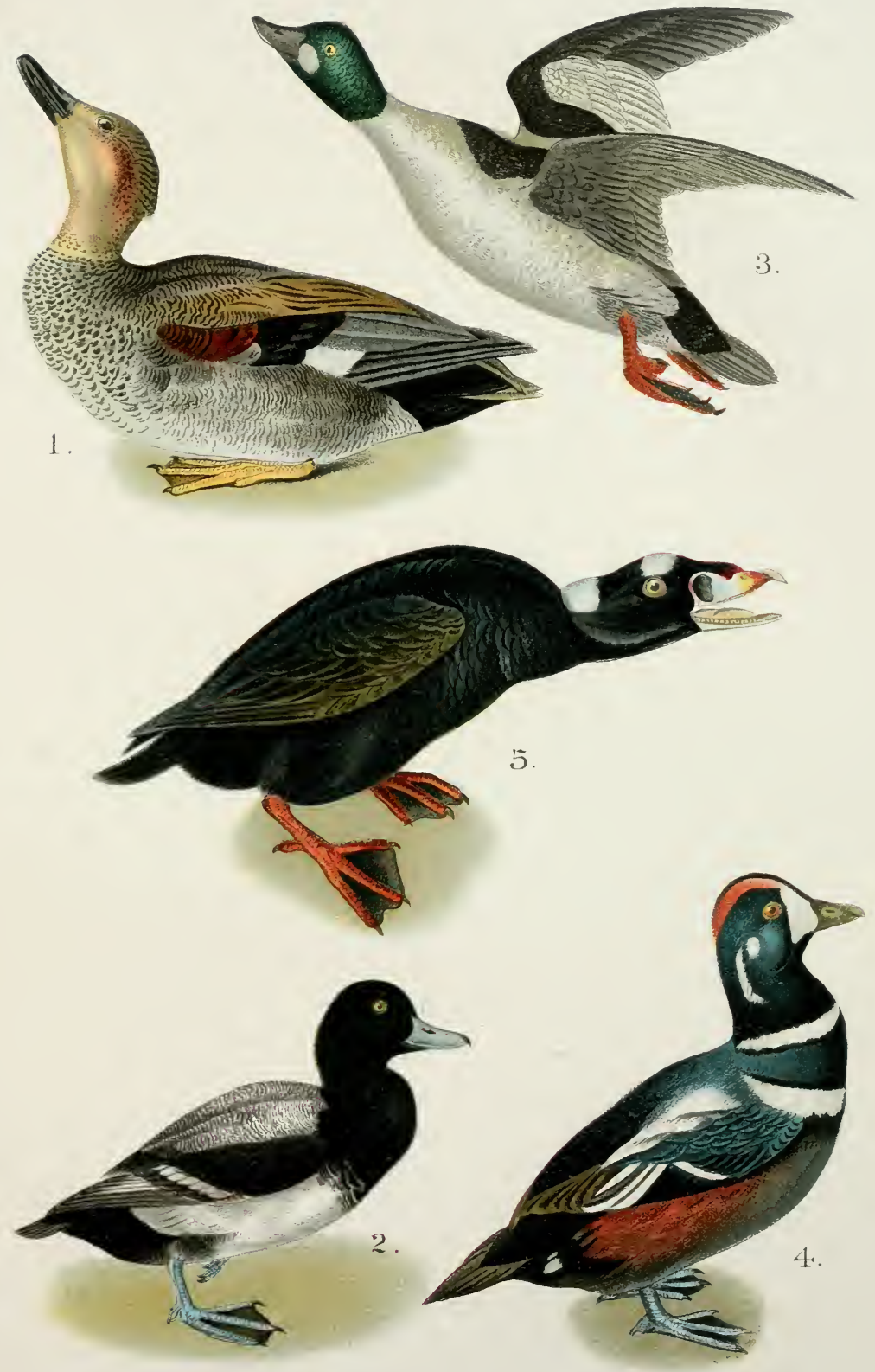

1. Gadwail Duck.

3. American Golden-Eve.

5. Surf Duck.
2. Scaup Duck.
4. Harlequin Duck. 

and stretches its feet out behind. Born only for the water, the Golden-eye, except in the season of propagation, seldom quits it but to dry itself awhile in the air, and immediately after returns to its natural element.

The Whistlers are common throughout the country, breeding from Maine and Manitoba to the lower fur countries, and wintering from the Bay of Fundy to Cuba.

\section{BARROW'S GOLDEN-EYE.}

\section{ROCKY MOUNTAIN GOLDEN-EYE. WHISTLER.}

\section{GlaUcionetTa ISLANDiCA.}

CHAR. Similar to the Common Golden-eye, but the white patch on the cheek oblong or pear-shaped, instead of round.

Nest. In a hollow tree, made of twigs and moss lined with down.

Eggs. 6-10; bright green when fresh, but fading to a dull grayish tint; $2.45 \times 1.75$.

Barrow's Golden-eye Duck is so much like the more common Whistler that few but experts can separate them, the shape of the white patch on the cheeks of the male being the only distinguishing characteristic.

In habits the two species do not differ, but the present one is found farther north, breeding from the Gulf of St. Lawrence to northern Greenland, and wintering to the Bay of Fundy, northern New York, Illinois, and Utah. On the Atlantic coast it is rarely seen so far south as Massachusetts.

I am inclined to question the statement made in "The Water Birds of North America," that these birds "undoubtedly breed" along the St. Croix River. An occasional unfertile or unhealthy example may linger in the Bay of Fundy and adjacent waters during the summer months, but no evidence has been obtained of an evidently mated pair having been seen there. Neither IVilson nor Audubon knew this bird, and Nuttall writes: "It has hitherto been found only in the valleys of the Rocky Mountains." 


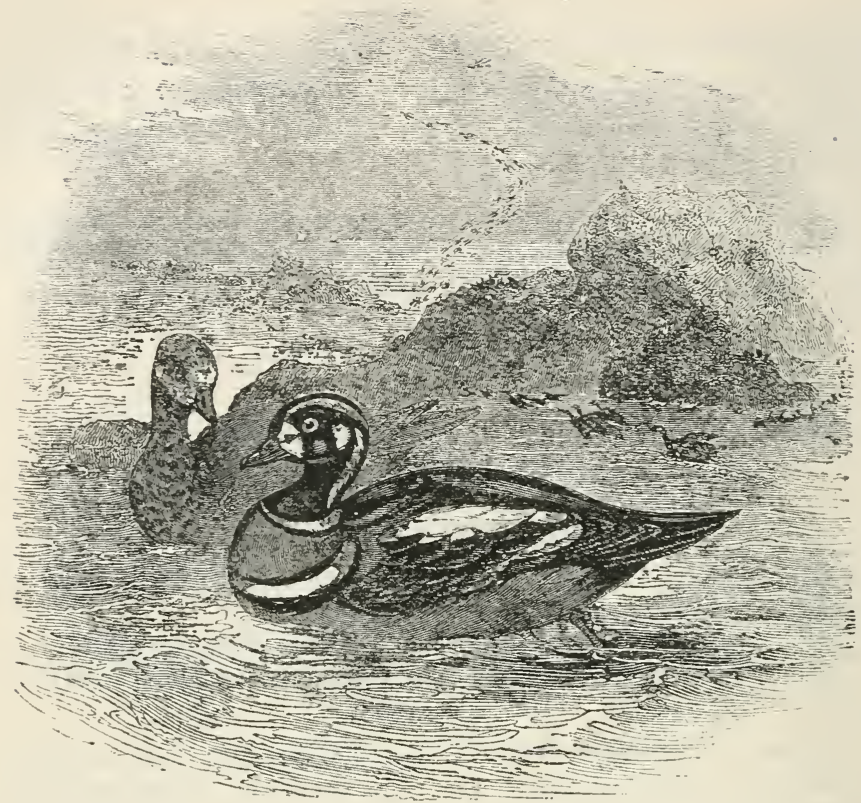

\section{HARLEQUIN DUCK.}

\section{LORD AND LADY.}

\section{HISTRIONICUS HISTRIONICUS.}

CHAR. Male : upper parts chiefly bluish black, the wings varied with white; wing-patch purple; stripes of white on head, neck, and breast; stripes of chestnut on sides of crown; breast and belly grayish brown, sides chestnut; bill bluish black; legs and feet leaden blue. Length about 17 inches. The female smaller and of a general grayish brown color above ; band of white around base of bill; belly dull white.

Nest. Usually on the ground close to a stream, - sometimes in a hollow tree; made of grass and sedges and lined with feathers.

Eggs. 6-10; warm cream color, often tinged with olive; $2.30 \times 1.70$.

This singularly marked and beautiful species is almost a constant resident of the hyperboreal regions of the northern hemisphere, from which it migrates but short distances towards more temperate latitudes, and is, as in Europe, a rare 
and almost accidental visitor as far as the Middle States of the Union. It is, however, more frequent in Eastern Europe up to Greenland, and common from Lake Baikal to Kamtschatka. Now and then it is killed in Scotland and the Orkneys. Dr. Richardson found it to be a rare bird in the fur countries, haunting eddies under cascades and rapid streams, where it dwells and breeds apart from all other Ducks. In Kamtschatka it affects the same retired and remarkable romantic situations. Like the Alpine Cinclus, it prefers the most rocky and agitated torrents; in such situations it has been seen in the rivulets of Hudson Bay at as great a distance as ninety miles inland from the sea. Here it seeks out its appropriate fare of spawn, shell-fish, and the larvæ of aquatic or fluviatile insects. On the low bushy and shady banks of these streams it constructs its nest, and on the margins of freshwater ponds in Labrador Mr. Audubon also observed this species; and he remarks that, instead of rearing its young in the same situations chosen for breeding, as with the Velvet and Surf Duck, it conducts its brood to the sea as soon as they are hatched. Its flight is high and swift, and it swims and dives with the utmost dexterity. So great is its confidence in the security of its most natural element that on the report of a gun over the water it instantly quits its flight and dives at once with the celerity of thought. It is said to be clamorous, and that its voice is a sort of whistle; the anatomy of the trachea is, however, unknown, and we cannot tell whether this sibilation be really produced from the throat or the wings, as in the case of the Common Clangula, or Golden-eye.

Driven from their solitary resorts in the interior by the invasion of frost, these birds are now seen out at sea engaged in obtaining a different mode of subsistence. Amidst these icy barriers they still continue to endure the rigors of winter, continually receding farther out to sea, or making limited and almost accidental visits to milder regions. When discovered, they display the utmost vigilance, and instantly take to wing.

This bird is considered to be game superior in flavor to the Common Wild Duck. From the singular and beautiful crescentVOL. II. -23 
shaped lines and marks which ornament its neck and breast, it has probably come by the dignified appellation of Lord among the fishers of Newfoundland. It is here too rare to have acquired any particular name.

The Harlequin breeds from Newfoundland to high Arctic regions, and winters south to the Middle Atlantic States and the Ohio valley. It is common during the winter months in the Bay of Fundy, and rare in Massachusetts and the Great Lake region. In the Rocky Mountains it has been known to breed in latitude $49^{\circ}$.

The favorite resort in summer of these birds is on the swift currents of a rapid and secluded stream, or the surging pool at the base of a fall. In winter they are found in the bays and estuaries on the sea-coast. They swim buoyantly, and dive with ease. Their flight is swift and powerful, and being shy and vigilant, they are not easily shot.

I have met with these handsome waterfowl in winter only, and in but one locality, - Mace's Bay, on the western shore of the Bay of Fundy. The Harlequins gathered there did not appear to be the solitary and unsociable birds that many writers have represented them. I frequently saw flocks of ten or more, and usually found these in company with Old Squaws, - their rivals in warjness and rapid flight. When approaching the bar at Mace's Bay, on which during the gunning season there is generally a dangerous array of firearms, these mixed flocks slacken their pace for two or three hundred yards, and when within range increase their speed, and go over the bar so swiftly that but few shot hit them. 


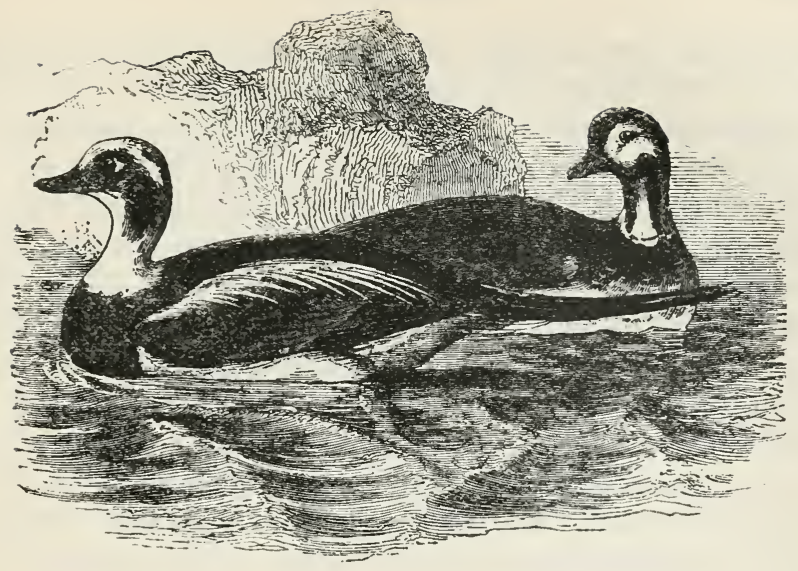

\section{OLD SQUAW.}

LONG-TAILED DUCK. SOU-SOUTHERLY. COCKAWEE.

Clangula hyemalis.

Char. Male : back, rump, and tail black, the central tail-feathers very long; crown and neck white; cheeks brownish gray, and below the gray a patch of brown ; breast and wings black, the wings varied with white; belly white; bill pale pink, nail and base black; legs and feet leaden blue, the webs darker. Length 20 to 23 inches; middle tail-feathers 8 to 9 inches. The female has the crown and upper parts dark brown; a dark stripe behind the eyes; under parts white; tail without long feathers.

Nest. Concealed under a bush, sometimes amid a tussock of rank herbage, - made of a few weed-stems and some grass, and thickly lined with down.

Eggs. 5-7; pale grayish green, sometimes greenish buff; $2.10 \times 1.50$.

This elegant and noisy Duck, known so generally in the Southern States by the nickname of "South-Southerly," from its note, and in most other parts by the appellation of "Old Squaws," or "Old IVives," is an Arctic inhabitant of both continents, and abounds in the glacial seas of America, where it is seen commonly associated with the Eider, Surf, Black, and other Ducks of congenial habits, who invariably prefer the frail but, to them, productive dominion of the sea to the land or its more peaceful waters. So strong is the predilection of 
this species for its frigid natal climes and their icy barriers that it is seen to linger in the north as long as the existence of any open. water can be ascertained. When the critical moment of departure at length approaches, common wants and general feeling begin so far to prevail as to unite the scattered families into numerous flocks. They now proceed towards the South, and making a halt on the shores and inland lakes round Hudson Bay, remain until again reluctantly driven towards milder climes. They are the last birds of passage that take leave of the fur countries. Familiar with cold, and only driven to migrate for food in the latter end of August, when already a thin crust of ice is seen forming in the night over the still surface of the Arctic Sea, the female Harelda is observed ingeniously breaking a way with her wings for the egress of her young brood.

According to the state of the weather we consequently observe the variable arrival of these birds. In October they generally pay us a visit, the old already clad in the more dazzling garb of winter. The young sometimes seek out the shelter of the freshwater ponds, but the old keep out at sea. No place in the Union so abounds with these gabblers as the Bay of Chesapeake. They are lively, restless, and gregarious in all their movements, and fly, dive, and swim with unrivalled dexterity, and subsist chiefly upon small shell-fish and marine plants, particularly the Zostera, or grass-wrack. Late in the evening or early in the morning, towards spring more particularly, vast flocks are seen in the bays and sheltered inlets, and in calm and foggy weather we hear the loud and blended nasal call reiterated for hours from the motley multitude. There is something in the sound like the honk of the Goose, and as far as words can express a subject so uncouth, it resembles the guttural syllables 'ogh ough egh, and then 'ogh ogh ogh ough egh, given in a ludicrous drawling tone; but still, with all the accompaniments of scene and season, this humble harbinger of spring, obeying the feelings of nature and pouring forth his final ditty before his departure to the distant North, conspires, together with the novelty of his call, to please rather 
than disgust those happy few who may be willing "to find good in everything." His peculiar cry is well known to the aboriginal sons of the forest, and among the Crees the species is called 'Hah-ha-way, — so much like the syllables I have given above that many might imagine my additions no more than a version of the same. But I may perhaps be allowed to say that the notes I had taken on the subject were made two years previous to the publication of Dr. Richardson's "Zoology," whence I learn this coincidence of the name and sound as given by the aborigines of the North. This Duck is no less known to the Canadian voyagers, who have celebrated it in their simple effusions by the name of the "Cackàwee."

In the course of the winter the Long-tailed Ducks wander out into the bays and inlets nearly if not quite to the extremity of the United States coasts; and in the spring, voyaging along the unruffled bosom of the great Mississippi with the many thousands of other water-fowl which penetrate by this route into the interior, we find among the crowding throng some small flocks of the present species, who proceed as far as the banks of the Missouri. In Spitzbergen, Iceland, and along the grassy shores of Hudson Bay, they make their nests about the middle of June, lining the interior with the down from their breasts, which is equally soft and elastic with that produced by the Eider.

These birds abound in Greenland, Lapland, Russia, and Kamtschatka, are seen about St. Petersburg, and from October to April many flocks pass the winter in the Orkneys. They are only accidental visitors on the Great Lakes in Germany and along the borders of the Baltic, and are often seen, but never in flocks, upon the maritime coasts of Holland. The flesh of the old birds is but little esteemed, yet that of the young is pretty good food.

The Old Squaw breeds at extremely high latitudes, being more Arctic in its distribution than any other species of Duck. It winters in numbers along the coast of south Greenland, and is common all along the Atlantic to the Southern States. 


\section{AMERICAN MERGANSER.}

\section{GOOSANDER, BUFF-BREASTED SHELLDRAKE. SAW-BILL.}

\section{Merganser americanus.}

CHAR. Head and neck black, with green reflections; back and scapulars black; rump slate gray; wings brown, varied with white; a black bar across the white wing-coverts; under parts white, tinged with delicate salmon pink, which soon fades after death; bill bright red; legs and feet orange. Length about 26 inches. The female is smaller, the head and neck are chestnut, and the feathers of the neck are elongated to a conspicuous crest.

Nest. Usually in a hollow tree, - often in a wooden box set for its use by egg-hunters; sometimes in a hole in a cliff or under a rock, or even in an abandoned nest in a tree; made of grass, leaves, and moss, and thickly lined with down.

Egos. 6-12 (usually about 8) ; creamy white ; size very variable, average about $2.65 \times$ i.So.

The Goosander inhabits the remote northern regions of both continents, being seen during summer on the borders of grassy lakes and streams throughout the whole of the fur countries, and is among the latest of its tribe in autumn to seek an asylum in milder climates. It is said to breed in every latitude in the Russian empire, but mostly in the north. It is common also in Kamtschatka, and extends through northern Europe to the wintry shores of Iceland and Greenland. Many of these birds, however, pass the breeding-season in the Orkneys, and these scarcely ever find any necessity to migrate. They are seen in small families or companies of six or eight in the United States in winter, and frequent the sea-shores, lakes, and rivers, continually diving in quest of their food, which consists principally of fish and shelly mollusca. They are also very gluttonous and voracious, like the Albatross, sometimes swallowing a fish too large to enter whole into the stomach, which therefore lodges in the œesophagus till the lower part is digested, before the remainder can follow. The roughness of the tongue, covered with incurved projections, and the form of the bent serratures which edge the bill, appear all purposely contrived with reference to its piscatory habits. In the course 
of the season these birds migrate probably to the extremity of the Union, being seen in winter on the Mississippi and Missouri, from whence at the approach of spring they migrate north or into the interior to breed.

The Goosander is seen to frequent the coast only in the depth of winter; and in its remote resorts in the North it fears the cold much less than the ice, as when that appears, its supply of food is necessarily cut off. The extent of the breedingrange of this species, as of that of many other retiring birds, is yet far from being sufficiently ascertained. Early in the month of May (1832), while descending the Susquehanna near to Dunnstown, a few miles below the gorge of the Alleghanies, through which that river meanders, near the foot of the Bald Eagle Mountain, G. Lyman, Esq., and myself observed near the head of a little bushy island a wild Duck, as we thought, with her brood making off round a point which closed the view. On rowing to the spot the wily parent had still continued her retreat, and we gave chase to the party, which with all the exertions that could be made in rowing still kept at a respectable distance before us. We now perceived that these diminutive possessors of their natal island were a female Goosander, or Dun-Diver, with a small but active little brood of eight young ones. On pushing the chase for near half an hour, the young, becoming somewhat fatigued, drew around their natural protector, who now and then bore them along crowding on her back. At length, stealing nearly from our sight as the chase relaxed, the mother landed at a distance on the gravelly shore, which, being nearly of her own gray color and that of her family, served for some time as a complete concealment. When we approached again, however, mother and brood took to the water, and after a second attempt, in which the young strove to escape by repeated divings, we succeeded in cutting off the retreat of one of the family, which was at length taken from behind a flat boat under which it had finally retreated to hide. We now examined the little stranger, and found it to be a young Merganser of this species not bigger than the egg of a Goose, and yet already a most elegant 
epitome of its female parent, generally gray, with the rufous head and neck and the rudiments of a growing crest. After suffering itself to be examined with great calmness and without any apparent fear, we restored it to its more natural element, and at the first effort this little diminutive of its species flew under the water like an arrow, and coming out to the surface only at considerable distances, we soon lost sight of it, making good its aquatic retreat in quest of the parent. On inquiry we learned from the tavern-keeper that for several years past a nest or brood of these birds had annually been seen near this solitary and secluded island. In such situations, probably, escaping the observation of man, many of these birds spread through the country and breed from Pennsylvania to the remotest parts of the Canadian fur countries. .

This bird is not found in abundance in any part of our temperate regions, but it breeds (sparingly) about latitude $45^{\circ}$, and thence to the fur countries, - probably to the limit of forests. It winters from New Brunswick and Illinois to the Southern States.

\section{RED-BREASTED MERGANSER.}

SHELLDRAKE.

\section{MERGANSER SERRATOR.}

CHAR. Head black, with green reflections, the feathers of the nape elongated to a conspicuous crest; white collar on the neck; back black; wings mostly white, the outer feathers black; in front of the wings a tuft of white feathers broadly edged with black; breast pale chestnut, streaked with black; belly white; bill red; legs and toes reddish orange. Length 20 to 25 inches.

The female is smaller, and has the head and neck reddish brown, almost similar in coloration to the female americanus.

Nest. Generally on an inland island or the bank of a secluded stream, placed under cover of a bush or rock, or concealed amid rank herbage; usually made of grass, heather, or leaves, and lined with down. Sometimes the first eggs are laid on the bare ground, and down gradually tucked about them.

Eggs. 6-12 (usually about 9); olive gray or pale drab, tinged with green; $2.60 \times 1.70$. 
This Merganser is again another general inhabitant of the whole northern hemisphere, spreading itself in the summer season throughout the remote fur countries and western interior, from whence, at the approach and during the continuance of winter, it migrates towards the sea-coast in quest of open water and the necessary means of subsistence. The Redbreasted Mergansers, equally common in Europe as in North America, are seen as far as Iceland, breed in Greenland, and inhabit most parts of the Russian dominions, particularly the great rivers of Siberia and the waters of Lake Baikal. They arrive about Hudson Bay in June as soon as the ice breaks up, and make their nests immediately after, of withered grass, and a lining of down or feathers from their breasts. The young are at first of a dirty brown, like young goslings.

The breeding-range of these birds is no less extensive than the preceding. According to Audubon they nest in rank weeds on the borders of lakes in Maine and other parts of the Union, and Mr. Say observed them on Lake Michigan in $42^{\circ}$, on the $7^{\text {th }}$ of June, assembled there, no doubt, to pass the summer.

This species, like the rest of the family, dives well, and dexterously eludes the sportsman when wounded, moving about often in the greatest silence, with its bill only elevated above the water for respiration. In the winter, while here, these birds frequent the bays and estuaries as well as fresh waters, and feed as usual on fry and shell-fish.

The Shelldrake breeds from about latitude $42^{\circ}$ in the West, and from about latitude $45^{\circ}$ in the East, to the Arctic Circle, and sparingly north of that line. It winters on the coast from south Greenland to the Southern States.

It breeds in abundance on the Miramichi River in New Brunswick.

The female bears all the burden of hatching the eggs and rearing the young, for she is deserted by her mate soon after she begins to sit. She is, however, equal to the task, and makes a most dutiful mother. She sits patiently and very closely on the nest, never rising from it until an intruder is almost within arm's reach, and then strives to decoy him from the spot. Soon after they are hatched, the young are led to the water, and at an early age they 
swim rapidly and dive with great expertness, as I have learned by experience. I paddled after a brood one hot summer's day, and though several times they were almost within reach of my landing-net, they eluded every effort to capture them. Throughout the chase the mother kept close to the young birds, and several times swam across the bow of the canoe in her efforts to draw my attention from the brood and to offer herself as a sacrifice for their escape. 


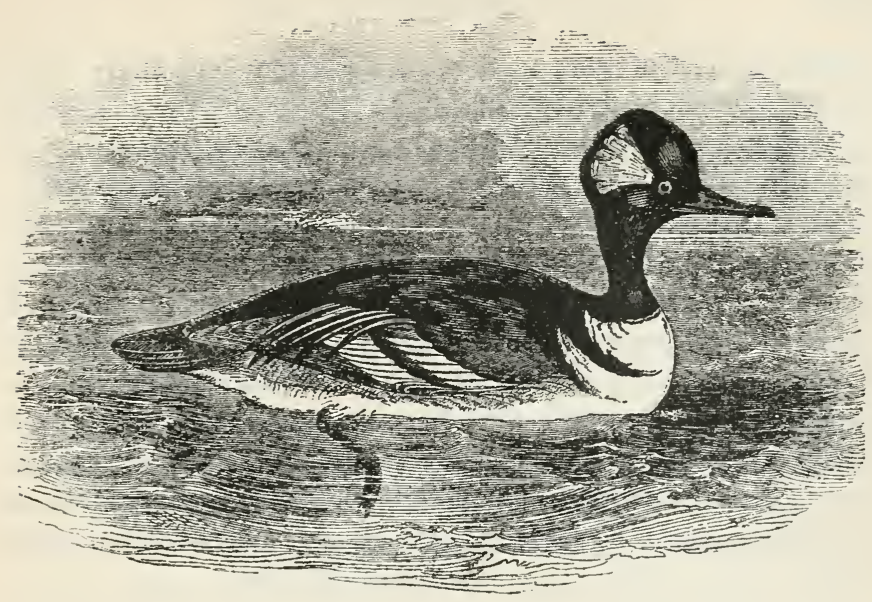

\section{HOODED MERGANSER.}

\section{HOODED SHELLDRAKE.}

\section{LOPHODYTES CUCULLATUS.}

CHAR. Male: upper parts black; wings and tail with a brownish tinge; a triangular patch of white on the nape; under parts white, the breast with two crescentic stripes of black, and sides varied with lines of yellowish brown; bill leaden blue, with a white nail; legs dull red. Length about 19 inches. Female is rather smaller; upper parts dark brown; crest reddish brown; under parts white ; breast pale brown.

Nest. In a hole in tree, or stump, or fallen log, lined with grass and leaves covered with down.

Eggs. 5-18 (usually about 8); ivory white; $2.10 \times 1.75$.

This elegant species is peculiar to North America, and inhabits the interior and northern parts of the fur countries to their utmost limits. It is also among the latest of the ANATIDE to quit those cold and desolate regions. It makes a nest of withered grass and feathers in retired and unfrequented places, by the grassy borders of rivers and lakes. According to Audubon, it also breeds around the lagoons of the Ohio, and on the Great Northwestern Lakes of the interior. On the River St. Peters, in the $45^{\text {th }}$ parallel, Mr. Say observed examples on the 18 th of July, - no doubt in the same place where they had 
passed the rest of the summer. At Hudson Bay, where these birds arrive about the end of May, they are said to nest close to the borders of lakes. 'The young are at first yellowish, and begin to fly in July. The Hairy Head, as this species is sometimes called, is rarely seen but in fresh waters and lakes, approaching the sea only in winter, when its favorite haunts are blocked up with ice. It delights in the woody interior, and traces its way up still creeks, and sometimes visits the millponds, perpetually diving for small fish and insects in the manner of the Red-breasted Merganser. In the course of the winter it migrates as far south as Mexico, is very common throughout the whole winter in the Mississipi, and is rendered very conspicuous by the high circular and party-colored crest which so gracefully crowns the top of the head.

The Hooded Merganser ranges throughout North America, breeding from about latitude $45^{\circ}$ to the vicinity of the Arctic Circle, and wintering from Massachusetts (sparingly) to the Southern States. It is rather common as a spring and fall migrant in New England and adjacent provinces, but breeds in numbers in the northern portions of Ontario and in Manitoba.

Note. - The Rufous-Crested Duck (Netta rufina), from Europe, has been taken near New York. One example of STELleR's Duck (Eniconetta stelleri), a North Pacific species, has also wandered from its usual habitat and been captured in Greenland.

The MaSked Duck (Nomonyx dominicus), a tropical bird, occurs occasionally on the lakes of the interior, but cannot be regarded as more than a straggler.

\section{AMERICAN WHITE PELICAN.}

\section{Plecanus erythrorhynchos.}

CHAR. General color white, the breast and nape washed with pale yellow; wings mostly. black; bill long, the lower mandible connected with a larger gular sac; bill and sac reddish in life, but fading to yellowish after death; legs and feet orange. Length about 5 feet.

Nest. Usually on the beach of an island in a large lake, - a loosely built structure of twigs on the top of a mound of gravel and sand.

Eggs. I-4 (usually 2); white, with a rough chalk-like surface; $3.35 \times$ 2.20 . 
The Pelican, the largest of web-footed water-fowl, known from the earliest times, has long held a fabulous celebrity for a maternal tenderness that went so far as to give nourishment to its brood at the expense of its own blood. Its industry and success as a fisher allows of a more natural and grateful aliment for its young; and pressing the well-stored pouch to its breast, it regurgitates the contents before them, without staining its immaculate robe with a wound.

If, indeed, authors do not include more than a single species in the $P$. onocrotalus, no bird wanders so widely or inhabits such a diversity of climates as the Common Pelican. In the cooler parts of Europe it is, however, seldom seen, being observed in France, England, and Switzerland only as a very rare straggler. It is likewise uncommon in the north of Germany, though great numbers occur on the banks of the Danube. This resort and that of the Strymon, also famous for its Swans, are noticed by Aristotle. The Pelican is found in Red Russia, Lithuania, Volhinia, Podolia, and Pokutia, but is unknown in the northern parts of the Muscovian empire, being seldom met with as far as the Siberian lakes, yet it is observed about Lake Baikal. The lakes of Judæa and of Egypt, the banks of the Nile in winter, and those of the Strymon in summer, seen from the heights, appear whitened by flocks of Pelicans. They are likewise common in Africa, on the Senegal and the Gambia, as well as at Loanga, and on the coasts of Angola, Sierra Leone, and Guinea. They occur at Madagascar, at Siam, in China, on the isle of Sunda, and at the Philippines, especially in the fisheries of the great lake of Manilla. They are sometimes met with at sea, and have been seen in the remote islands of the Indian Ocean. Captain Cook observed them likewise in New Holland.

In America Pelicans are found in the North Pacific, on the coast of California and New Albion, and from the Antilles and Terra Firma, the isthmus of Panama and the bay of Campeachy, as far as Louisiana and Missouri. They are very rarely seen along the coast of the Atlantic, but stragglers have been killed in the Delaware, and the $y$ are known to breed in Florida. In all the fur countries they are met with up to the 
6ist parallel of northern latitude. Indeed, in these remote and desolate regions they are numerous, but seem to have no predilection for the sea-coast, seldom coming within two hundree miles of Hudson Bay. They there, according to Richardson, deposit their eggs usually on small rocky islands, on the banks of cascades where they can scarcely be approached, but still are by no means shy. They live together generally in flocks of from six to fourteen, and fly low and heavily, sometimes abreast, at others in an oblique line; and they are often seen to pass close over a building, or within a few yards of a party of men, without exhibiting any signs of fear. For the purpose of surprising their prey they haunt eddies near water-falls, and devour great quantities of carp and other fish. They can only swallow, apparently, when opening the mouth sideways and somewhat upwards, like the shark. When gorged with food, they doze on the water or on some sand-shoal projecting into or surrounded by it, where they remain a great part of their time in gluttonous inactivity, digesting their overgorged meal. At such times they may be easily captured, as they have then great difficulty in starting to flight, particularly when the pouch is loaded with fish. Though they can probably perch on trees, which I have never seen them attempt, they are generally on the wing, on the ground, or in their favorite element.

In the old continent the Pelican is said to nest on the ground in an excavation near to the water, laying two or three, and rarely four eggs, which are pure white, and of nearly equal thickness at both ends. The report that it nests in deserts remote from water, and the story of the parents bringing water for their young in the pouch in such quantities as to afford drink for camels and wild beasts, appears only one of those extravagant fictions or tales of travellers invented to gratify the love of the marvellous. Yet so general is the belief in the truth of this improbable relation that the Egyptians styled it the camel of the river, and the Persians, Tacab, or the water-carrier. The pouch of the Pelican is, however, very capacious, and besides drowning all attempts at distinct voice, it gives a most 
uncouth, unwieldy, and grotesque figure to the bird with which it is associated. The French very justly nickname these birds Grand-gosiers, or Great-throats; and as this monstrous enlargement of the gullet is capable of holding a dozen quarts of water, an idea may be formed of the quantity of fish they can scoop when let loose among a shoal of pilchards or other fish, which they pursue in the course of their migrations.

The Pelican appears to attain to a great age. According to Culmann, in Gesner, a tame one in possession of the Emperor Maximilian, which is said to have followed him with the army, lived to the age of fourscore.

It is remarkable that while the Pelican of the Atlantic and the Pacific habitually frequents the ocean, that which so generally inhabits North America is rarely seen on the sea-coast, and then only as a straggler, seeking, even at such times, the protection of bays and rivers. Its habits are also essentially different. It never boldly soars aloft, nor seeks its prey at sea. The oceanic species is likewise seen in troops, sometimes following a retreating shoal of fish and circumventing their escape by enclosing them as in a ring; at other times soaring over their prey, these birds drop like a plummet, and plunging headlong, cause the water to fly up eight to ten feet. These and other actions foreign to our bird would seem to indicate an original difference of race. Yet again we find them on the old continent, principally upon large rivers and lakes.

The White Pelican does not occur regularly to the eastward of the Mississippi valley, though numbers have at sundry times wandered to the Atlantic, appearing all along the coast from Florida to the Bay of Fundy, and I have examined one specimen that was captured on the Gulf of St. Lawrence.

It occurs regularly in the Mississippi Valley, and is common in Manitoba. Small flocks are seen occasionally on the Great Lakes. It winters on the Gulf coast. 


\section{BROIVN PELICAN.}

\section{Pelecanus fuscus.}

CHAR. Upper parts ashy gray; head white ; neck rich chestnut; wingcoverts and rump brown; under parts brownish gray; bill brownish; sac dusky; legs black. Length about 4 feet. In winter the head and neck are white.

Nest. On an island along the coast, usually on the ground, sometimes in a tree; made of twigs and sedges, and lined with grass.

Eggs. 2-5 (usually 3); white, with a chalk-like surface; $3.00 \times 1.95$.

The Brown Pelican inhabits exclusively the sea-coast of the warmer parts of America, being abundant in the West Indies, particularly in Jamaica, Barbadoes, etc. These birds are likewise common in the Southern States, abounding in the bay of Charleston, where they are seen actively engaged in pursuit of their prey. They likewise breed and inhabit in the peninsula of East Florida, and occasionally wander up the Mississippi as far as the river Missouri. They are, like the preceding species, very gluttonous and voracious. After gorging themselves, they retire to the rocks or islets, and during the process of digesting their enormous meal remain dozing and inactive for hours together, with the bill resting on the breast, at which times, in South America, it is no uncommon thing for the natives to steal upon them unawares and seize them by the neck, without their making any defence or resistance. Yet, like some other gregarious birds, they are said to show a great affection for the wounded of their own species, to which they will carry a supply of food. Father Raymond relates that he had seen one of these Pelicans so well tamed and taught among the aborigines that it would go off in the morning, and return before night to its master with its pouch distended with fish, a great part of which the savages made it disgorge, leaving it in possession of the remainder as a reward for its service.

The Brown Pelican is common on the coast of the Gulf States, and on the Atlantic to North Carolina. A few examples have wandered as far north as Massachusetts and Illinois. 


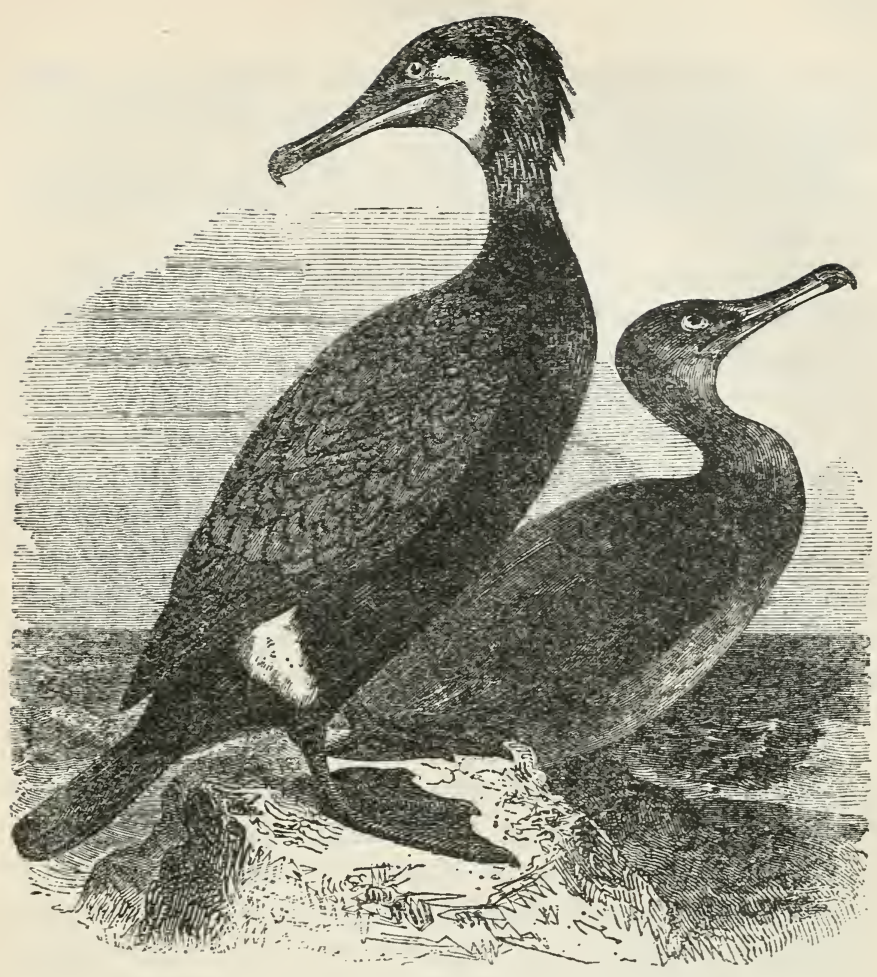

\section{CORMORANT.}

SHAG.

\section{Phalacrocorax Carbo.}

CHAR. Prevailing color black, with metallic reflections of green and purple, the mantle glossed with bronzy brown; the gular pouch bare, and yellow in color, and at its base is a white band extending from beneath the eyes across the throat. During the spring the feathers of the nape are elongated and form a mane-like crest, and white hair-like feathers appear on the head; also a patch of white is worn on the flanks. Bill black, shading to yellow at the base; legs black. Length about 36 inches.

Nest. In a crevice of a sea-washed cliff, or on the flat beach of a lake, or in trees by river, - made of large twigs, sometimes mixed with sea-

VOL. II. -24 
weed and lined with grass or leaves. Usually the nest is the accumulation of years, and becomes a heap of twigs, rotten at the base and surmounted by a layer of fresh herbage.

Eggs. 2-6 (usually 3); white, with a rough, chalk-like surface, the inside of the shell sea-green or pale blue; size variable, average about $2.60 \times 1.60$.

The Cormorant, Phalacrocorax, or Bald Raven, of the Greeks, like the Pelican, to which it is nearly related, is also a general inhabitant of nearly every maritime part of the world, and even extends its residence into the inclement regions of Greenland, where, by following the openings of the great icy barriers of that dreary region, it finds means to subsist and to fish throughout the year. To the natives of this frigid climate it also proves of singular service: its tough skin is used by them as garments, the pouch is employed as a bladder to float their fishing-tackle, and the flesh, though coarse, is still acceptable to those who can regale upon seal's and whale's blubber.

These uncouth and gluttonous birds are plentiful on the rocky shores of Great Britain, Holland, France, and Germany. On the shores of the Caspian they are sometimes seen in vast flocks, and are frequent on Lake Baikal. They inhabit China and the coast of the Cape of Good Hope, and are common in the Philippine Islands, New Holland, New Zealand, and other neighboring regions. At Nootka Sound and in Kamtschatka they have been observed by various navigators, and are found in North America from Hudson Bay and Labrador to the coasts of Carolina and Georgia. They are not, however, common in the central parts of the United States, though they penetrate into the interior as far as the Missouri River. They breed and are seen in the vicinity of Boston on bare and rocky islands nearly throughout the year, and in all places appear shy, retiring, and sedentary, enduring the most severe weather with impunity, and only removing seaward or south in the depth of winter for the purpose of acquiring food. Mr. Audubon found them breeding on the ledges of almost inaccessible rocks at Grand Menan isle, in the Bay of Fundy. They appear very wary and shy, and feed their young with great assiduity, whose voice at this time resembles the hissing of snakes. 
The Cormorant is a very dexterous and voracious fisher, committing great havoc when it visits pools and lakes; but it almost constantly resides or the sea-shores, and is seldom seen inland. Swimming beneath the water with the velocity of a dart in the air, and remaining a long time submerged, its prey scarcely ever escapes, and it almost always rises with a fish in its bill, to swallow which it employs the expedient of tossing it into the air, and dexterously catches the head in its descent, so that the fins lie flat, and thus favor the passage down the throat ; the small pouch at the same time stretches so as to admit the whole body of the fish, which is often very large in proportion to the neck, and it there remains, undergoing a preparatory digestion previous to its passage into the lower part of the stomach.

In some countries, as in China, and formerly in England, the dexterity of the Cormorant in fishing was turned to profit; for by buckling a ring about the lower part of the neck, to prevent deglutition, and accustoming it to return with its acquisitions in the bill to its master, it was made a useful and domestic fisher. On the rivers of China, Cormorants thus fixed are perched on the prows of boats, and at a signal made by striking the water with an oar, they instantly plunge, and soon emerge with a fish, which is taken from them. And this toil continues till its master is satisfied ; he looses the collar, and finishes the task by allowing it to fish for itself. But it is only hunger which gives activity to the Cormorant; when glutted with its meal, which is soon acquired, it relaxes into its native indolence, and dozes away the greatest part of its time in gluttonous inebriety, perched in solitude on naked and insulated or inaccessible rocks, to which it prudently retires for greater safety from the intrusion of enemies.

In Europe, where these birds are alike sedentary and averse to migration, they are known to breed from the coasts of Holland to the shores of Greenland, and they are equally residents in America nearly to the extremity of the Union. The nest is usually made with sticks, sea-weeds, grass, and other coarse materials, commonly upon rocks, but sometimes upon trees on the banks of rivers, where they are occasionally seen perched. 
According to Lawson, they are observed in great flocks in Carolina in March and April, when the herrings ascend the creeks, at which time they are seen on fallen logs in the water waiting and watching the approach of their prey.

This species of Cormorant was formerly considered a common winter visitor to New England, and nested sparingly along the coast from Nahant to the Bay of Fundy; but during recent years it has been rarely seen south of the Gulf of St. Lawrence, though in winter a few examples wander as far south as the New Jersey shore. Mr. Hagerup reports the bird a resident of Greenland, being most numerous in the northern section.

Nuttall was mistaken in giving this bird a more southern range; Mr. Lawson, whom he quotes, probably confused the present species with its Double-crested cousin, - a pardonable error in one to whom the southern bird was not familiar when in its winter plumage, for at that season the two species are somewhat similar in appearance.

\section{DOUBLE-CRESTED CORMORANT.}

SHAG.

\section{PhalaCrocorax dilOPHUS.}

CHAR. Prevailing color black, with green reflections, the back and wings varied with grayish brown; gular sac orange; bill bluish; legs and feet black. During the mating season the male wears crests of long, thin plumes on the sides of the crown, extending from above the eyes to the nape. In eastern or sea-coast birds these plumes are black, but birds taken in the interior have white mingled with the black, and in Pacific-coast specimens the plumes are entirely white. Length about 32 inches.

Nest. In a crevice of a sea-washed cliff, or on the beach of a lake or on a tree by a river bank; made of twigs and grass, - sometimes entirely of marine herbage.

Eggs. 2-5; chalky white and rough on the surface, with inner shell of blue or green tint; average size $2.40 \times 1.40$.

The range of this species extends from the Gulf States to Labrador and the Saskatchewan valley, and its breeding area from about latitude $45^{\circ}$ northward. It winters north to the Bay of Fundy (sparingly).

The Double-crested Cormorant is the common Shag of our saltwater fishermen, and is numerous in Manitoba also, though rather rare on the Great Lakes. 


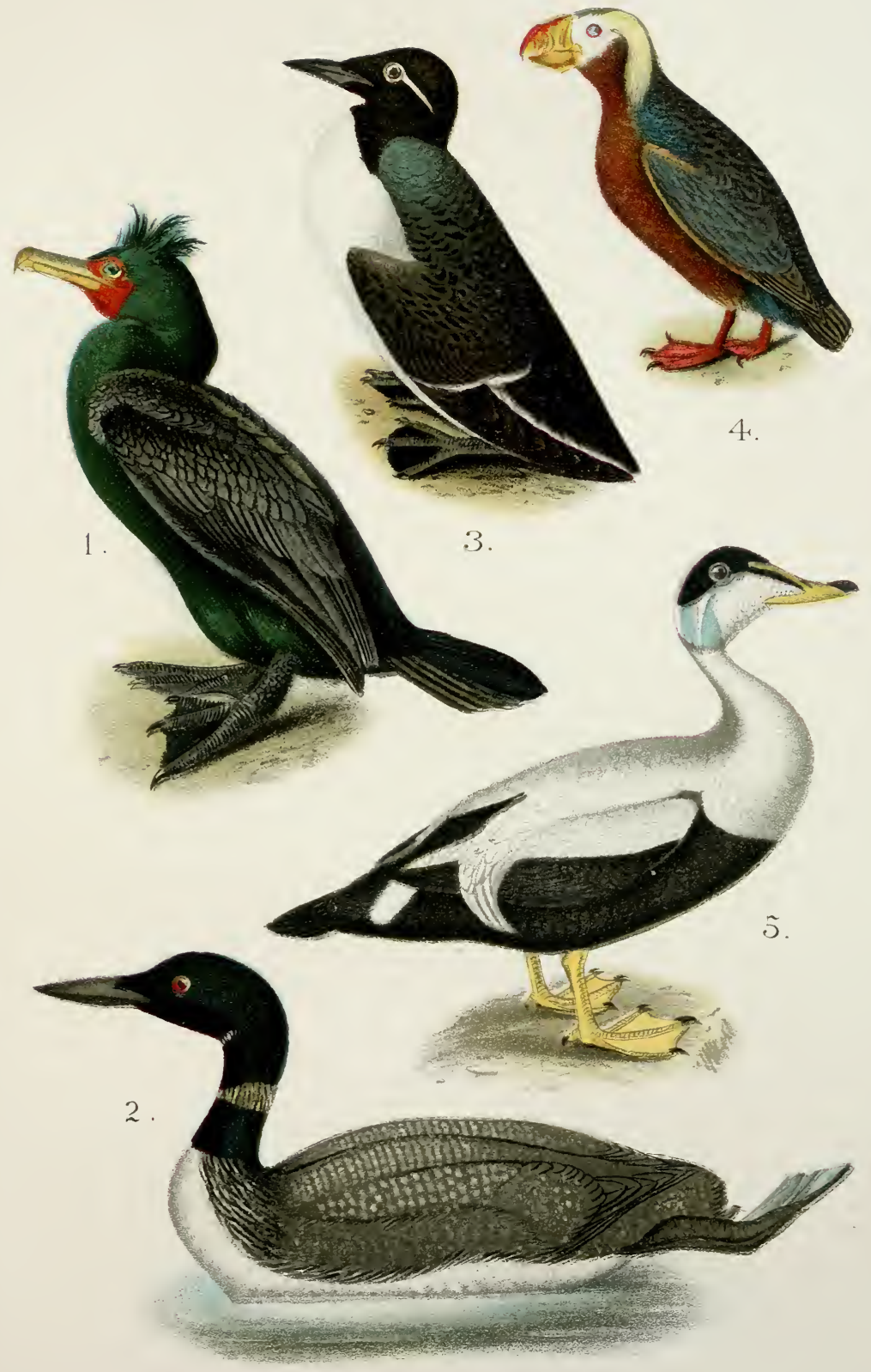

1. Double-Crested Cormorant.

4. Puffin .

3. Brünnich's Murre. 

In habits this species does not differ from others of the group. It feeds principally on fish, which it obtains by diving from the surface of the water. It is an expert diver, and strong, fast swimmer, and can remain under water for a very long period, coming to the surface out of gunshot of a pursuer.

Note. - The Florida Cormorant ( $P$. dilophus floridanus) is a smaller variety of the Double-crested species, differing from the type in size only. Length about 25 inches. It is restricted chiefly to the Gulf States, though occurring occasionally on the Atlantic shores of the more southern States, and along the Mississippi valley to southern Illinois.

Another species, the Mexican Cormorant ( $P$. mexicanus), occurs occasionally on the shores of the Gulf States, and has been taken in southern Illinois.

\section{MAN-OF-IVAR BIRD.}

\section{FRIGATE BIRD. FRIGATE PELICAN.}

Fregata aQUila.

CHAR. Prevailing color black, with reflections of green and purple. Length about 40 inches.

Nest. On mangrove-trees near the shore, loosely made of twigs.

Eggs. Usually I ; white ; $2.70 \times 1.85$.

The Frigate Pelican, or Man-of-War Bird, is chiefly seen on the tropical seas, and generally on the wing. These birds are abundant in the island of Ascension, India, Ceylon, and China. In the South Sea they are seen about the Marquesas, Easter Isles, and New Caledonia ; also at Otaheite. Dampier saw them in great plenty in the island of Aves, in the West Indies; and they are common off the coast of East Florida, particularly around the reefs or keys, often assembled in flocks of from fifty to a thousand. They are also not uncommon, during summer, along the coasts of the Union as far as South Carolina, and breed in various places, retiring to warmer latitudes on the approach of cool weather.

The Frigate Bird is often seen smoothly gliding through the air, with the motions of a Kite, from one to two hundred 
leagues from the land, sustaining these vast flights with the greatest apparent ease, sometimes soaring so high as to be scarcely visible, at others approaching the surface of the sea, where, hovering at some distance, it at length espies a fish, and darts upon it with the utmost rapidity, and generally with success, flying upwards again as quickly as it descended. In the same manner it also attacks the Boobies and other marine birds, which it obliges to relinquish their prey.

These birds breed abundantly in the Bahamas, and are said to make their nests on trees, if near; at other times they lay on the rocks. The eggs, one or two, are of a flesh color, marked with crimson spots. The young birds, covered with a grayish-white down, are assiduously attended by the parents, who are then tame and easily approached. When alarmed, like Gulls, they as readily cast up the contents of their pouch as those birds do of the stomach.

The Frigate Bird occurs regularly off the coast of Florida, and examples have been seen as far north as Nova Scotia, Ohio, and Wisconsin ; but outside of subtropical regions it must be considered an accidental straggler. 


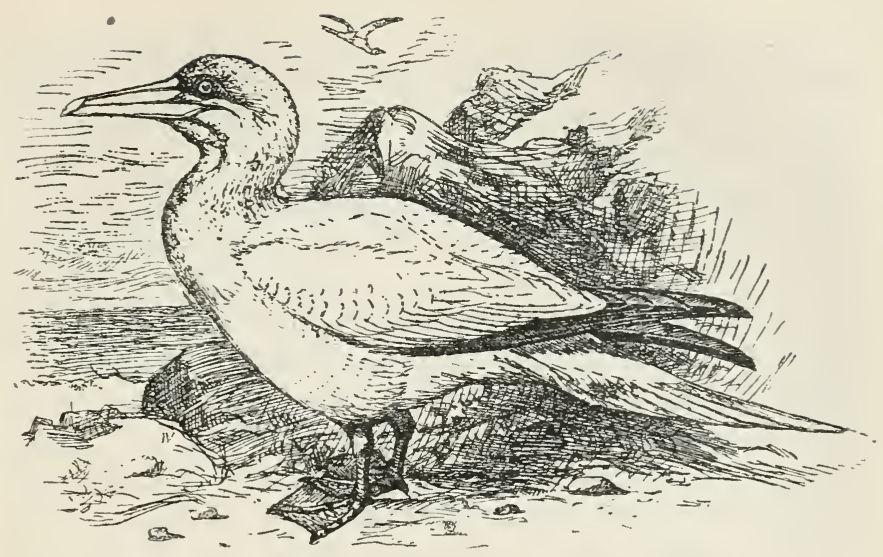

GANNET.

\section{SOLAN GOOSE.}

\section{Sula Bassana.}

CHAR. Prevailing color white; head and neck washed with buff; outer wing-feathers (primaries) black. Length about 34 or 36 inches.

The young birds are dusky brown, spotted all over with white.

Nest. On a cliff of an ocean island, - made of sea-weed and grass.

Eigg. I ; chalky white, inner shell pale blue; average size 3.10 $\times$ I.90.

The Gannet is another of the many marine birds common to both sides of the Atlantic Ocean. In the summer season these birds are extremely abundant on some rocky isles in the Bay of the St. Lawrence, and not uncommon on the coasts of the United States, especially to the south of Cape Hatteras. On the south side of Long Island and the neighboring coast they are seen in numbers in the month of October associating with the Velvet and Scoter Ducks. In the summer they also penetrate into the Arctic regions of both continents, are seen on the coast of Newfoundland, and occasionally in Greenland. In Iceland they breed and are seen in great flocks. They are also equally common to the northwest coast of America. 
These birds abound in Norway and the Hebrides, particularly on some of the least accessible of the islands. According to Dr. Harvey, Bass Island, near Edinburgh, not more than a mile in circumference, has in the months of May and June its surface almost wholly covered with nests, eggs, and young birds, so that it is scarcely possible to walk without treading on them; and the flocks of birds are so prodigious as, when in flight, to darken the air like clouds, and their noise is so stunning that it is scarcely possible to hear your next neighbor. Looking down towards the sea from the top of the precipice, you see it on all sides covered with multitudes of birds, swimming and chasing their prey; and if in sailing round the island you survey the hanging cliffs, you may see on every crag or fissure of the rocks numberless birds of various sorts and sizes; and seen in the distance, the crowding flocks passing continually to and from the island can only be compared to a vast swarm of bees.

The rocks of St. Kilda are no less frequented by the Gannets, and Martin assures us that the inhabitants of that small island consume annually no less than twenty-two thousand young birds of this species, besides a vast quantity of their eggs, these being, in fact, their principal support. This supply, though spontaneous from nature, is not obtained without imminent hazard of life to those who engage in procuring these birds and their eggs; as besides climbing difficult and almost inaccessible paths among the rocks beetling over the sea, they sometimes lower each other down from above, by ropes in baskets, to collect their game from the shelvings and fissures of the rocks chosen by these sagacious birds. The young are a favorite dish with the North Britons in general, and during the season they are constantly brought from the Bass Isle to Edinburgh.

As might be supposed, the Gannets are in these islands birds of passage, making their first appearance in the month of March, continuing there till August or September, according as the inhabitants take or leave their first egg; but in general, the time of breeding and departing appears to coincide with the arrival of the herring and its migration out of those 
seas. It is probable that these birds attend the herring and the pilchard during their whole circuit round the British Islands, the appearance of the first being always esteemed by the fishermen as a sure pressage of the approach of the last. Gannets migrate in quest of food as far south as the mouth of the Tagus, being frequently seen off Lisbon in December, plunging for sardines.

In the month of August, Dr. Harvey observed in Caithness their northern migrations; they were passing the whole day in flocks, from five to fifteen in each. In calm weather they fly high; in storms they proceed lower and near the shore, but never cross over the land, even when a bay with its promontories intervenes, but follow at an equal distance the course of the bay, and regularly double every cape. Many of the moving parties would make a sort of halt for the sake of fishing ; for this purpose they soar to a great height, then, darting headlong into the sea, make the water foam and swell with the violence of the concussion, after which they pursue their route. With the arrival of the shoals of pilchards in the latter end of summer, they are seen on the coast of Cornwall, and in November, when the pilchards retire, the Gannets mostly disappear, though a few linger on the coast throughout the winter. An individual killed near Mount's Bay made, as is common with this bird, a long struggle with a water-spaniel, assisted by a boatman, showing himself both strong and pugnacious, and sufficiently redeeming on his part the Gannet family from the ill-supported charge of cowardice and stupidity.

Many years ago a Gannet, flying over Penzance, and seeing some pilchards lying on a fir-plank in a cellar used for curing fish, darted down with such violence that it struck its bill through the board and broke its neck.

These birds appear to have a strong predilection for particular spots. On the Gannet Rock, in the Gulf of St. Lawrence, they are seen in amazing multitudes. This rock (according to Audubon, from whom we derive the interesting information) is four hundred feet in height, and several acres in extent on the summit. At that time, the 8 th of June, it was covered with 
innumerable birds upon their nests, so crowded or closely arranged as to give the appearance of a huge mass of snow, while the hovering crowds seen around this inaccessible marine mountain forcibly presented at a distance the actual appearance of a snow-storm. While thus engaged, the report of a musket did not seem in the least to alarm them; and defenceless while obeying this powerful instinct, they allow themselves to be approached and despatched without using any means for escape, appearing riveted to the spot, while engaged in the affections and cares of reproduction.

The nest of the Gannet is composed chiefly of sea-weed, and generally placed upon the most inaccessible parts of the highest rocks. The egg (only one being laid before hatching) is white, and very like that of the Cormorant, but not nearly so large as the egg of the Goose, weighing about three and a quarter ounces.

The Gannet seems incapable of diving, - at least, no alarm can force it to immerse. Upon the water it swims as buoyantly as a Gull. When offered fish it will accept, but will never go into a pond after food; and from every appearance of its actions on water, to which it will go only from compulsion, it cannot procure fish beyond the extent of its neck. At times these birds rise from the water with so much difficulty that they are easily run down by a boat; but when thus surprised they defend themselves with much vigor.

Within a few years this species has deserted Gannet Rock, near Grand Menan, though a large number still gather on the Magdalen Islands, in the Gulf of St. Lawrence. They continue to breed further northward, and in winter range south to the Gulf of Mexico.

Mr. William Brewster reports that in I88I he found some fifty thousand birds nesting on one of those islands, and describes the number as astonishing and impressive, but insignificant when compared with the legions seen there by Dr. Bryant some twenty years before.

The food of this species consists entirely of fish, which it procures by diving from the wing, plunging into the water from a great height, - sometimes a hundred yards or more. When pursued or wounded, it rarely or never dives, trusting to its flight, which is strong and rapid. 


\section{BOOBY.}

\section{SUlA SUlA.}

Char. Upper parts and breast sooty brown, more or less varied with gray; under parts white. Length $3 \mathrm{r}$ inches.

Nest. On an ocean island, sometimes on the ground, but usually placed on a bush or low tree; rudely made of twigs and sea-weed.

Eggs. I-2; chalky white; size very variable, average about $2.35 \times$ I. 55 .

The Booby is found to be an inhabitant of islands and desolate sea-coasts throughout all the warm and temperate parts of the globe, and has acquired its degrading name from its silly aspect and peculiar stupidity, suffering itself to be taken, not only at sea on the ship's yards, but also on land, where these birds may be despatched merely with clubs and sticks in great numbers one after the other, without seeming to take any general alarm, or using any efficient effort for escape. The only cause that can be assigned for this want of conservative instinct, so general and prompt among most of the feathered tribes, is probably the fact of the difficulty and almost impossibility of setting their long wings into motion when they happen to be surprised on level ground, or fatigued with undue exertion.

The Boobies, however, have a domestic enemy more steady, though less bloodthirsty, in his persecutions than man; this is the Frigate Pelican, or Man-of-War Bird, who with a keen eye descrying his humble vassal at a distance, pursues him without intermission, and obliges him by blows with the wings and bill to surrender his finny prey, which the pirate instantly seizes and swallows.

The Boobies, however, notwithstanding this tribute to their marine monarch, contrive to obtain an ample supply of provision. They commonly hover above the surface of the waves, at times scarcely moving their wings, and drop on a fish the instant it emerges or approaches in view. Their flight, though rapid and long-sustained, is greatly inferior to that of the Frigate Bird; accordingly, they do not roam so far, and their 
appearance is generally hailed by mariners as an indication of the approach of land. Yet numbers are not wanting around the remotest and most sequestered islands in the midst of the wide ocean. There they live in companies, associated with Gulls, Tropic Birds, and their tyrannical persecutor, the Frigate, who, appreciating their assistance as providers, dwells and rests in the same retreats.

Among the Frigates, some (probably the males after incubation) live in societies apart from the rest, dispersed to situations most suitable for obtaining pillage.

Boobies utter a loud cry, something in sound betwixt that of the Raven and the Goose ; and this quailing is heard more particularly when they are pursued by the Frigate, or when, assembled together, they happen to be seized by any sudden panic. As they can only begin the motion of their wings by starting from some lofty station, they usually perch like Cormorants, and in flying stretch out the neck and display the tail.

According to Dampier, in the Isle of Aves these birds breed on trees, though in other places they nestle on the ground, and always associate in numbers in the same place. They lay one or two eggs, and the young continue for a long time covered for the most part with a very soft and white down. The flesh is black and unsavory, yet sailors frequently make a meal of it. In summer they are not uncommon on the coasts of the Southern States.

The Booby is chiefly restricted to the tropical or sub-tropical seas, but an occasional example wanders as far north as off the coast of Georgia.

Note. - The Blue-Faced Booby (Sula cyanops) and the RedFOOTED BOoBy (Sula piscator) occasionally straggle north to the Florida waters ; and the ANHINGA (Anhinga anhinga), also a tropical bird, has been taken off North Carolina and on the Mississippi River. 


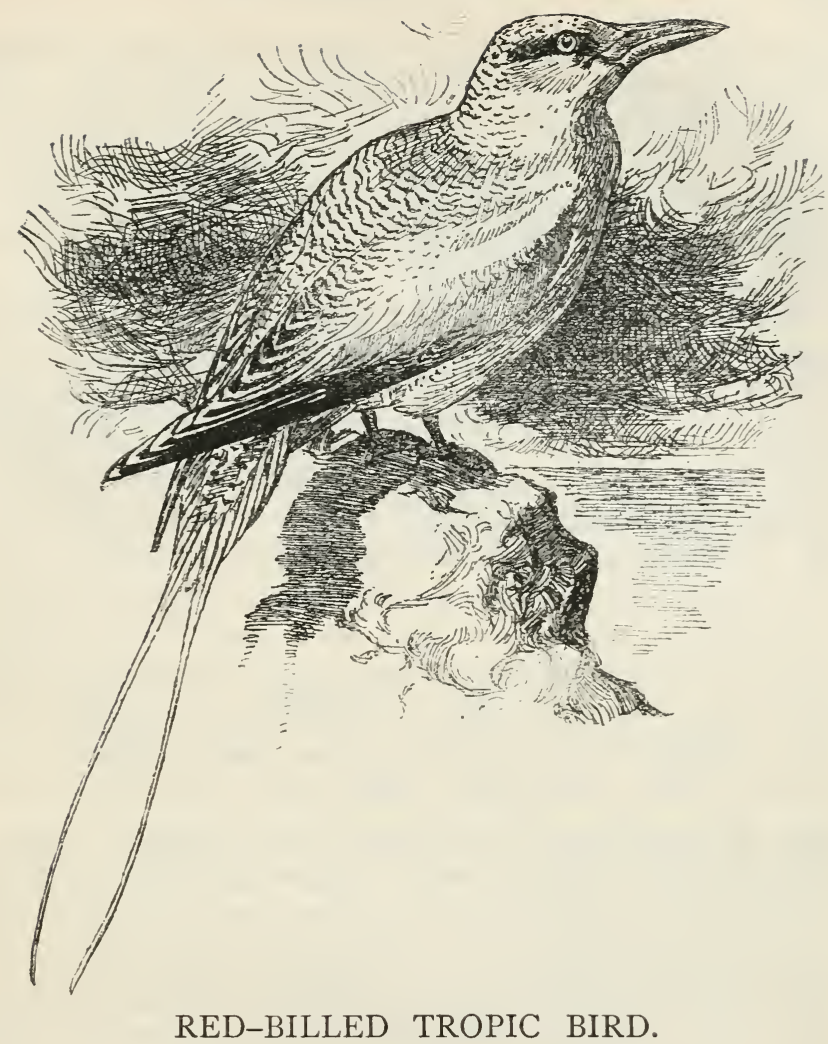

PHAËTHON eTHEREUS.

CHAR. Prevailing color white; the upper parts varied with blackish; a stripe on the sides of the head, and the outer wing-feathers deep black; bill deep red; legs yellow, toes black. Length, including elongated tailfeathers, about 33 inches; the tail-feathers measure about 20 inches.

Nest. In a hole or crevice of a sea-washed cliff, - sometimes slightly lined with twigs and coarse herbage.

Egg. I ; purplish white or creamy white, with a delicate purple tinge, and marked with fine spots of rich brown; $2.26 \times$ r.6o.

The Tropic Bird, soaring perpetually over the tepid seas, where it dwells without materially straying beyond the verge of the ecliptic, seems to attend the car of the sun under the 
mild zone of the tropics, and advertises the mariner with unerring certainty of his entrance within the torrid climes. Yet though generally confined to these more favored solar realms, which it widely explores to their utmost bounds, it sometimes strays beyond the favorite limit, and hence we have given it a place among the oceanic birds which stray in summer to the coasts of the warmer States.

The flight of the Tropic Bird is often conducted to a prodigious height, at which in every season it can obtain a temperature of the most delightful kind. At other times, affected by the ordinary wants of nature, it descends from its lofty station, and accompanied by an ignoble throng of Frigates, Pelicans, and Boobies, it attends the appearance of the flyingfish as they emerge from the water, pursued by their enemies of the deep. These birds are sometimes observed to rest on the surface of the sea, and have been seen in calm weather upon the backs of the drowsy tortoises supinely floating, so that they have been easily taken by allowing the approach of a boat. On shore they will perch on trees, and are said to breed on the ground beneath the shade of the adjoining woods. They are met with on the islands of St. Helena, Ascension, Mauritius, New Holland, and in various parts of the South Seas, but in no place are they so numerous as at Palmerston Island, where, along with the Frigates, they have been seen in such plenty that the trees were absolutely loaded with them, and so tame or listless that they suffered themselves to be taken from the boughs by hand. In the Sandwich and Friendly Islands, where they also abound, the natives set a high value on the long tail-feathers, made use of by way of ornament, and in Otaheite they form a conspicuous part of the ostentatious garment worn by mourners. The flesh, though often eaten by mariners, cannot be accounted good.

This cannot be considered more than an accidental straggler to Northern waters, though examples have been taken as far north as the Gulf of St. Lawrence.

Note. - The Yellow-Billed Tropic Bird (P. favirostris) has been taken in Western New York. 


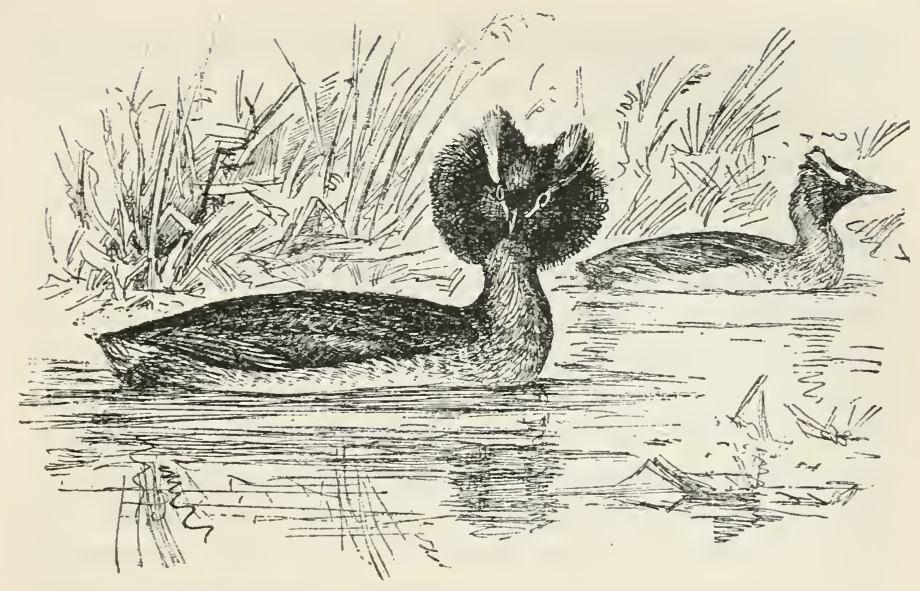

HORNED GREBE.

SPIRIT DUCK. HELL DIVER. DUSKY GREBE.

Colymbus auritus.

CHAR. Upper parts dull brown, the feathers paler on the edges; head darker; breast rufous; wings varied with white; lower parts silvery white. Length about $\mathrm{I}_{4}$ inches. In the mating season the sides of the head are adorned with crests (horns) of short feathers of black color.

Nest. Amid the rank herbage on reedy margin of a lake, - usually fastened to rushes and floating on the surface of shallow water; a mass of dried stems of rushes and coarse sedges.

Eggs. 2-7 (usually 4); bluish white, stained with brown; 1.80 $\times$ I.20.

The Horned Grebe is an inhabitant of the northern regions of both continents, being very common in the summer season throughout the Hudson Bay fur countries, frequenting almost every lake with grassy borders, in which seclusion, about the month of June, it constructs its nest of coarse herbage, which, left afloat, is sometimes moored to the surrounding reeds and rushes. The eggs are white, spotted, and, as it were, soiled with brown; in order to hide them from its enemies, it has the habit of covering them while abroad. In the autumn these birds retire to the South, appearing in Massachusetts, some- 
times, in the small freshwater lakes near the ocean. At a later period they retire still farther, being very common in the Middle and Southern States, where they are known, with other species, by the name of Dippers and Water Witches. The Indians of Hudson Bay give the Horned Grebe the name of Seekeep. While here, they keep generally in the salt water, swimming and diving with great agility and elegance, and these are almost universally young birds, the old ones keeping probably more inland in their migrations towards the South. In most of the individuals which have fallen under my notice, the stomach, like a pouch in form, has been generally swelled out with its own feathers, apparently bent and masticated before swallowing; the birds had been feeding on minute eels and coleopterous insects, and had, besides the matted feathers plucked from the breast, a quantity of sand and gravel. The appetite of this Grebe is, indeed, keen and little scrupulous, - for which, sometimes it pays a dear forfeit, as happened to an individual seen by Mr. N. Wyeth, which had its bill clasped in the shell of a clam in such a manner as to disable it both from flying and diving.

This expert diver is a common bird throughout this eastern country, breeding from about latitude $45^{\circ}$ to the higher fur countries, and wintering from the Bay of Fundy to the Southern States.

\section{HOLBCELL'S GREBE.}

RED-NECKED GREBE.

\section{Colymbus holbellit.}

CHAR. Upper parts dusky; head and nape black; cheeks ashy; neck rich chestnut; wings varied with white; under parts silvery white, varied with gray. Length about I9 inches.

Nest. On the border of a reedy pond or sluggish stream, fastened to the rank herbage, - made of reeds and sedges.

Eggs. 2-7; dull white, sometimes tinged with green, washed with brown; average size $2.25 \times 1.35$.

The Red-necked Grebe, like most of the other species, retires to the hyperboreal regions of both continents to pass 
the breeding-season, delighting in the seclusion of the desolate wilderness, penetrating in the present continent as far as the remote inland shores of Great Slave Lake, where individuals were observed by Captain Franklin's adventurous party in the month of May. In the course of the winter these birds proceed to the South, probably as far as Florida, but are rarely seen in the United States. At this season they frequent lakes and the estuaries or rivers in the vicinity of the sea, but at other times are seen more abundantly on fresh waters. They are common in the eastern parts of Europe, and frequently visit Great Britain, Germany, and Switzerland. Their food, as usual, is small fish, fry, reptiles, coleopterous insects, and vegetables. The nest is similar to that of the preceding species; the eggs number three or four, of a whitish green, and appearing as if soiled with yellowish or brown.

The Red-necked Grebe breeds from about latitude $45^{\circ}$ to the higher fur countries, but is rather uncommon in New England and the adjacent provinces, where it occurs chiefly as a winter visitor. It is quite abundant in Manitoba.

In common with others of the family, this Grebe is an expert diver. Often it will sink into the water without any apparent effort, though more generally it jumps forward, throwing the head into the water, and the body into the air. It is an expert and rapid swimmer also, and all its movements on the water are extremely graceful. When pursued, these birds invariably endeavor to escape by diving, though when on the wing they fly rapidly, their necks and feet stretched at full length.

It is said that the female takes the newly hatched young upon her back, and swims with them in that position, feeding them, while eating her own meal, on portions of the fish and vegetable matter which she gathers.

VOL. II. -25 


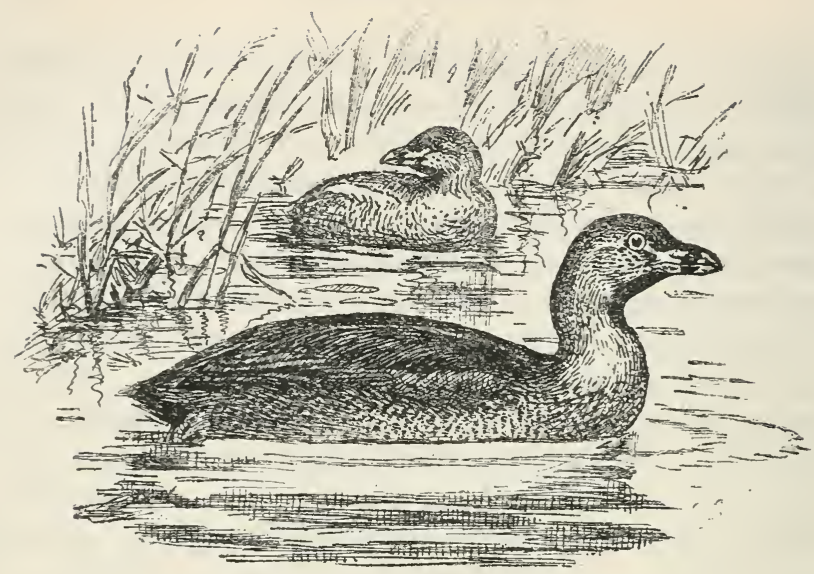

PIED-BILLED GREBE.

LITTLE GREBE. DABCHICK. CAROLINA GREBE.

PodilyMbUS PODICEPS.

CHAR. Upper parts dusky, wings varied with ashy and white; under parts silvery white, mottled with dusky; breast washed with rufous; chin and throat black; bill short and thick, of a bluish white color, with a black band across the centre. Length about $\mathrm{I}_{4}$ inches.

Nest. Anid the rushes at the edge of a pond or sluggish stream, made of coarse herbage lined with grass; sometimes floating on the water, fastened to reeds.

Eggs. 4-10 (usually 5); white stained with pale brown; $2.00 \times$ I.70.

The Pied-billed Dabchick is an exclusive inhabitant of the North American continent, proceeding north to breed as far as the remote fur countries of Upper Canada, a specimen having been killed on Great Slave Lake by the exploring party of Captain Franklin. It arrives in the Northern and Middle States about the close of August, and is then seen residing in our small freshwater lakes until the approach of winter, when it retires probably as far south as the lagoons of the Mississippi and the tidewater streams and bays of the Mexican Gulf. It is the most common species in the Union, and is met with in all the States as far as Florida, leaving those coun- 
tries, however, for the North in the month of April. Most of the birds seen in this vicinity are young or unadult; they feed principally on fish and aquatic insects such as large Nepas and other kinds. They often swim about without appearing to take any alarm from the peaceful spectator, but in the next moment dive and swim under water for such a length of time as to appear for several minutes entirely invisible; and at such times these Water Witches, as they are deservedly called, are often moving about entirely submerged to the bill, which is the only part elevated above the water; and in the covert of the surrounding aquatic herbage this small projecting point is not only easily overlooked, but with difficulty discovered. Like Ducks, they are also somewhat nocturnal in their habits, and may be perceived after sunset in the dusky twilight actively engaged, and swimming about the ponds with great activity. While here they are not heard to utter any note, and their breeding-places are wholly unknown. The young are often eaten, and are generally tender and well flavored.

The Dabchick is more abundant near the Atlantic than any other of this group. It breeds in the Hudson Bay district and southward, - its breeding area being laid down in the A. O. U. "Check List" as "nearly throughout its range," which extends to Chili and the Argentine Republic. It winters as far north as New Jersey.

Since Nuttall's day we have learned something more of the breeding habits of this species, and modern observers are apt to express surprise that the bird should have escaped the notice of earlier naturalists. In habits the Dabchick does not differ materially from other Grebes. 


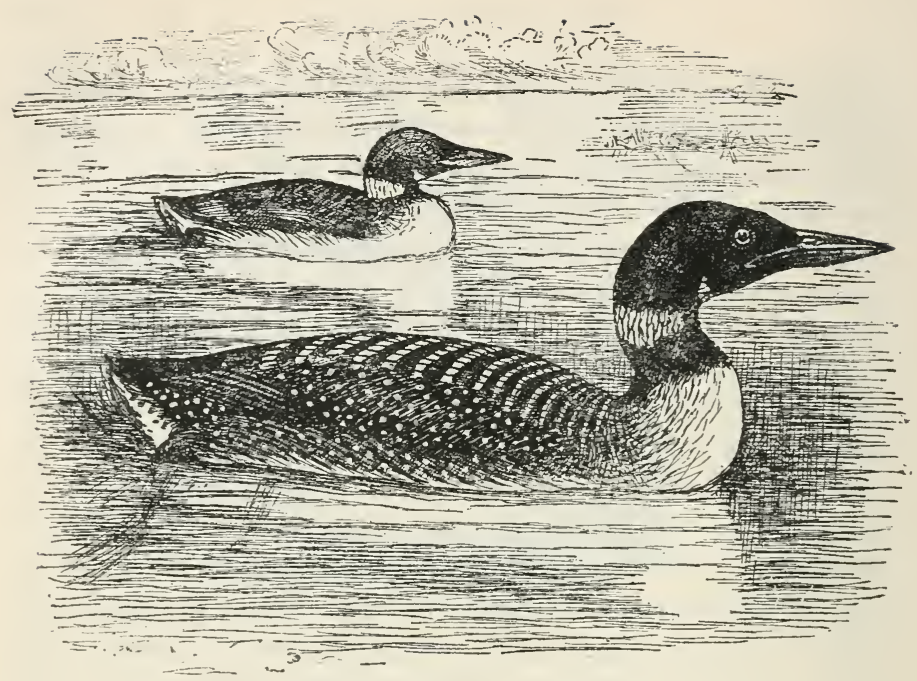

\section{LOON.}

GREAT NORTHERN DIVER.

\section{URINATOR IMBER.}

¿HAR. Mantle black, spotted with white; head and neck black, with green and purple reflections; throat with two bands of white stripes; znder parts white. Length very variable, ranging from 28 to 33 inches, though specimens measuring about the extremes of this variation are more common than those of intermediate length.

Nest. Amid rank herbage near the water, on the margin of a lake or river, often on an island, sometimes on the sea-shore.

Eggs. 2-3 (usually 2); olive brown with a few darker spots; average size about $3.50 \times 2.25$.

The Loon, the most common of its tribe in the United States, is a general inhabitant of cold and temperate climates throughout the whole northern hemisphere. It is found in the north of Europe, and spreads along the Arctic coasts as far as Kamtschatka, Nootka Sound, and the mouth of the Ob. It dwells on the dreary coast of Spitzbergen, Greenland, Iceland, and Hudson Bay. These birds abound in all the lakes of the fur countries, where, as well as in the interior of the most 
northern of the States, and probably in the inland seas of the St. Lawrence, along the whole Canadian line, they pass the period of reproduction. They have been known to breed as far south as the Farne Isles, on the coast of Northumberland, along with the Eider Ducks, with which they also associate on the shores of Labrador. In the Hebrides they are common in the summer season, as well as in Norway, Sweden, and Russia, from all which countries they seldom migrate to any considerable distance, being only accidental passengers on the coasts of the ocean; the young only are seen, and rarely, on the lakes of Germany, France, and Switzerland, but in those regions the old are unknown. In the United States, from the superior severity of the winters, the young, and even occasionally the old, are seen to migrate nearly, if not quite, to the estuary of the Mississippi.

The Loon, cautious, vigilant, and fond of the security attending upon solitude, generally selects, with his mate, some lonely islet, or the borders of a retired lake far from the haunts of men; here, on the ground, contiguous to the water, they construct their rude and grassy nest. About the i Ith of June, through the kindness of Dr. T. W. Harris, I received three eggs which had been taken from the nest of a Loon, made in a hummock, or elevated grassy hillock, at Sebago Pond, in New Hampshire. These were about the size of the eggs of a Goose, of a dark, smoky olive, coarsely blotched nearly all over with umber-brown spots. The males, after the period of incubation, secede from their mates, and associate by themselves in the bays and estuaries near to the sea. They soon after moult, and become so bare of feathers as to be unable to rise from the water. The young, after being duly attended by the female parent, disperse with her towards the sea. Instinctively warned of the approach of frost, they avoid its consequences by slow but efficient migrations. As soon as the fish begin to fail, the young, unable or unwilling to fly, are sometimes seen waddling from one pond to another, and in this situation are easily captured, as they refuse, or are incapacitated, to rise from the ground. When approached, they 
utter a long-drawn, melancholy scream, like $\dot{o} \bar{o} \bar{o} h$, with a shrill, loud, sighing, and rising note. Now and then, as if a call upon the parent, the tone is broken almost in the manner of running the finger across the mouth while uttering a sound. A young bird of this kind which I obtained in the salt-marsh at Chelsea Beach, and transferred to a fish-pond, made a good deal of plaint, and would sometimes wander out of its more natural element, and hide and bask in the grass. On these occasions it lay very still until nearly approached, and then slid into the pond and uttered its usual plaint. When out at any distance, it made the same cautious efforts to hide, and would commonly defend itself in great anger, by darting at the intruder and striking powerfully with its dagger-like bill. This bird, with a pink-colored iris, like albinos, appeared to suffer from the glare of broad daylight, and was inclined to hide from its effects, but became very active towards the dusk of evening. The pupil of the eye in this individual, like that of nocturnal animals, appeared indeed dilatable; and the one in question often put down its head and eyes into the water to observe the situation of its prey. This bird was a most expert and indefatigable diver, and would remain down sometimes for several minutes, often swimming under water, and as it were flying with the velocity of an arrow in the air. Though at length inclined to be docile, and showing no alarm when visited, it constantly betrayed its wandering habit, and every night was found to have waddled to some hidding-place, where it seemed to prefer hunger to the loss of liberty, and never could be restrained from exercising its instinct to move onwards to some secure or more suitable asylum.

Far out at sea in winter, and in the Great Western Iakes, particularly Huron and Michigan, in summer, I have often heard on a fine calm morning the sad and wolfish call of the solitary Loon, which like a dismal echo seems slowly to invade the ear, and rising as it proceeds, dies away in the air. This boding sound to mariners, supposed to be indicative of a storm, may be heard sometimes for two or three miles, when the bird itself is invisible, or reduced almost to a speck in the distance. 
The aborigines, nearly as superstitious as sailors, dislike to hear the cry of the Loon, considering the bird, from its shy and extraordinary habits, as a sort of supernatural being. By the Norwegians its long-drawn howl is, with more appearance of reason, supposed to portend rain. Judging, however, from the young bird already mentioned, this expression, like that of other fowls, indicated nothing beyond the humble wants or social communication of the species.

The flesh of the Loon is dark, tough, and unpalatable; yet the young birds are frequently seen in the markets of New York and Boston, and are therefore no doubt sometimes eaten. Some of the Russian Tartars on the $\mathrm{Ob}$ and the Irtisch tan the breasts of this and other water-fowl, preserving the down upon them, and sewing them together, sell them for garments and caps. The Greenlanders, as well as the aborigines round Hudson Bay and on the banks of the Columbia River, employ their skins as articles of dress or of decoration; and the Indians of the Missouri and Mississippi also often ornament the sacred calumet with the brilliant neck-feathers of this and other species.

The Loon is found throughout this Eastern Province, breeding from the northern tier of States to the Arctic Ocean. It winters from the Middle States south to the Gulf of Mexico.

\section{BLACK-THROATED LOON.}

URINATOR ARCTICUS.

CHAR. Prevailing color above black, varied with white; head grayish brown; chin and throat black, with a patch of short white streaks; streaks of white on side of neck; under parts white. Length about 26 inches.

Nest. On the bank of an island lake, - a hollow stamped in the moss, sparingly lined with grass, or sometimes a floating mass of coarse herbage covered with moss and sedge.

Eggs. Usually 2 ; brown of an olive or russet tint, and marked with dark brown; average size $3.25 \times 2.10$.

This species, common to the hyperboreal parts of both continents, is much more rare in the United States than the 
preceding, and though frequent near the shores of Hudson Bay, is seldom seen in the interior of the fur countries. It abounds in the northern parts of Europe, Norway, Sweden, and Denmark, and in the inland lakes of Siberia, especially those of the Arctic regions; it is also seen in Iceland, Greenland, and the Faröe Isles. It is held in superstitious regard by the Norwegians, who believe its cry to portend rain. The skins of this and other species, being tough and impervious to wet, are used by the Indians and Esquimaux, as well as by the Norwegians, for articles of dress.

The Arctic Diver is an autumnal and winter bird of passage in England, Germany, and Holland, more rare upon the interior lakes of France, but common upon those of Switzerland. It lives on fish, frogs, insects, and aquatic plants, and nests in the reeds and herbage upon the borders of lakes and in marshes, preferring those which are much intersected by waters: it is said to lay two eggs, which are brown, marked with scattered black spots.

The Black-throated Loon is somewhat uncommon everywhere within its range, but is especially rare on this eastern side of the Atlantic. It breeds in the Far North, and in winter has been found as far south as the Bay of Fundy, and casually to Ohio and Long Island.

This is a rather solitary bird, though occasionally two or three pairs breed on the same lake, but rarely associate. In the migration small flocks are sometimes met with. 


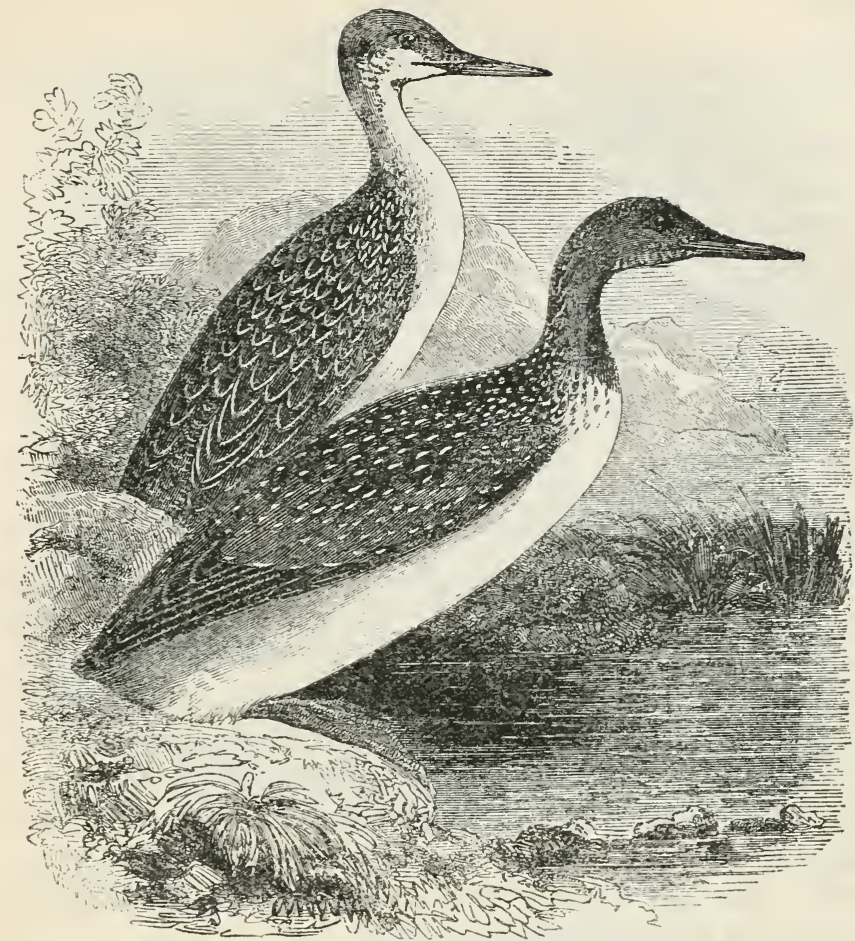

\section{RED-THROATED LOON.}

\section{URINATOR LUMME.}

Char. Prevailing color brownish black, varied by paler and a few spots of white; head and neck light slate gray, the throat with a patch of bright chestnut ; under parts silky white. Length about 25 inches.

Nest. On the margin of a retired pond, - a depression in the sand, close to the water's edge; sometimes lined with a few bits of grass.

Eggs. Usually 2; pale brown, often tinged with olive, and spotted: with dark brown; average size about $2.75 \times$ 1.80.

This species is again a general inhabitant of the northern regions of both continents, from whence few migrate to any great distance, - except the young, and these are seen not uncommonly along the coasts of the United States in the course 
of the winter. According to Richardson, these birds frequent the shores of Hudson Bay up to the extremity of Melville Peninsula, and are also abundant on the interior lakes, where they breed. Mr. Audubon found them nesting on the coast of Labrador near small freshwater lakes. Their food is similar to that of the preceding species. Fleming says that they breed in Zetland and the Orkneys. In Greenland and Iceland they also lay among the herbage on the shores contiguous to water, and make a nest of moss and grass, lining it with down. The young of this species, called the Cobble, is frequently seen in England in the winter in bays and inlets, and sometimes in freshwater rivers and lakes. In the river Thames this bird attends the arrival of the sprats, on which it feeds, and is hence known to the fishermen by the name of the Sprat Loon. From its diving habits it is frequently taken in the fishing-nets, to which it is attracted by their contents. It flies well, and dives and swims with remarkable dexterity, and while proceeding in the air is said to be sometimes very noisy. At Hudson Bay the young fly before the end of August, and the whole commence their migrations in the course of September. These birds are common also to the Baltic and the White Sea, and are found in the inclement regions of eastern Asia, as in Kamtschatka and Siberia.

This species breeds from the lower fur countries to the Arctic, and in winter migrates south to the Middle States, and casually to North Carolina. 


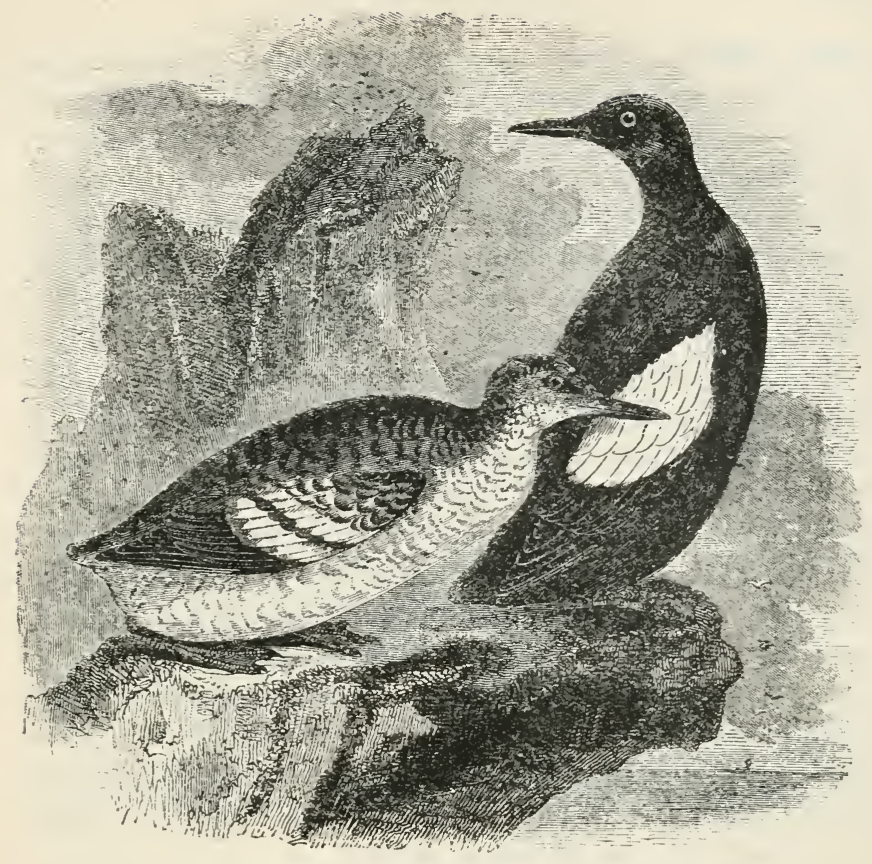

BLACK GUILLEMOT.

\section{SEA PIGEON.}

\section{Cepphus Grylle.}

CHAR. Prevailing color black; large patch on the wings white, with a black bar, sometimes wholly or partially concealed; bill black; legs and feet bright red. Length about 13 inches. In winter the upper parts are varied with white, and the lower parts mostly white; feet pinkish.

Nest. On a rock-bound coast, placed on the ledge of a cliff, or under loose bowlders on the top of a bluff; sometimes amid the shingle of a beach; no attempt is made at nest-building; the eggs are deposited on the bare rocks.

Eggs. 2-3 (usually 2); ivory white, sometimes tinged with bluish green, marked with rich brown and gray; $2.30 \times 1.60$.

The Black Guillemot is a general inhabitant of the whole Arctic seas of both continents. It has even been called the Dove of Greenland, being common in that country, as well as 
on the still more dreary coasts of Spitzbergen. In the hyperboreal seas and straits of America it also abounds, from the inclement shores of Melville Island down to Hudson Bay and Labrador. According to Mr. Audubon it also breeds on the isle of Grand Menan, in the Bay of Fundy. Like the other Guillemots, these birds are entirely marine, never going inland, and rarely seek the coast but for the indispensable purpose of reproduction. In the cold and desolate regions of the North, abandoned by nearly every other animal, the Guillemots, though in diminished numbers, find means to pass the winter; frequenting at such times the pools of open water, which occur even in these high latitudes amongst the floes of ice. Others, but in small numbers, and those probably bred in lower latitudes, venture in the winter along the coasts of the United States. In Europe they are also seen at this season along the borders of the Atlantic. They are alike indigenous to the western side of the American continent, and occur in Kamtschatka. At St. Kilda, on the Bass Isle, in the Firth of Forth, in the Farne Islands, off the coast of Northumberland, and on some parts of the coast of Wales, particularly near Tenby, they are known to breed.

They fly commonly in pairs with considerable rapidity, almost grazing the surface of the sea, but at other times they proceed in a more elevated course. Their note, according to Audubon, is a contracted whistle. They nestle sometimes under ground, but more commonly in the deep and rocky fissures of inaccessible cliffs and bold headlands projecting into the sea. To avoid the access of water to the eggs, they commonly pile together a nest of pebbles, beneath which the rain-water or melting snow passes off without any injury or inconvenience. To escape becoming the prey of the foxes which incessantly watch for them, the young, when pushed to the necessity, throw themselves without difficulty from their impending eyries into the sea. These birds dive with great facility, and feed upon small fish, but particularly on shrimps, small crabs, and other crustacea, and marine insects. They show considerable vigilance on being approached, and are 
much more shy and wary than the other Guillemots. The eggs (called improperly those of the Noddy) are brought sometimes in small coasting-vessels to Boston market.

There are two races of the Sea Pigeon in our fauna,- for Mandt's Guillemot is only a Northern race or variety of the present species, - and of these the Black Guillemot is the more southern in distribution, breeding from the Bay of Fundy to southern Labrador. In winter it is rather common on the New England shores, and a few examples wander as far south as New Jersey.

I did not find these birds as shy as Nuttall's statement led me to anticipate. They were somewhat wary and alert, but allowed me to paddle within easy shooting distance without displaying much alarm. When they finally concluded that I was an unsafe neighbor, they lost no time in getting out of my sight, diving with surprising suddenness. They usually swam a long distance under water with great rapidity, using their wings as well as feet, and coming to the surface far beyond gunshot range.

The Sea Pigeons are met usually in small flocks of half a dozen or more, and generally feed in the open sea at the base of bold cliffs. When on the wing they proceed rapidly and in a straight line, and rarely more than a few feet from the surface of the water. On approching their nesting-site they rise rather abruptly, and fly directly to their nests.

Note. - MaNdT'S Guillemot (C. mandtii) is a northern variety of the Sea Pigeon, differing from grylle in lacking the black bar on the wing-patch, and having a somewhat stouter bill. It breeds from high Arctic regions to the coast of Labrador and Hudson Bay, and in winter may be found off the Atlantic shores from south Greenland to New Jersey, though it is not at all common along the southern portion of its range.

The Black-winged Guillemot ( $C$. motzfeld $i$ ) is said to occur on the shores of Cumberland Bay and in Greenland, though it has been put in the Hypothetical List of "The A. O. U. Check List" with the note: "Its specific validity not satisfactorily established." 


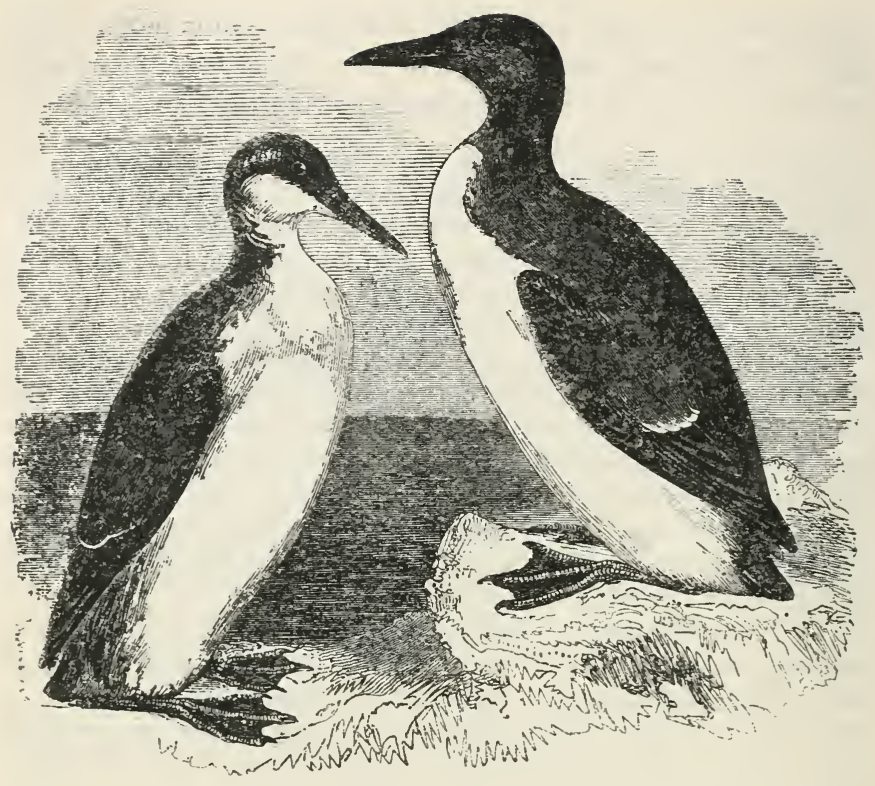

MURRE.

FOOLISH GUILLEMOT. COMMON GUILLEMOT. PENGUIN.

URIA TROILE.

CHAR. Upper parts rich velvet brown, variable in tint; under parts white; wings with a small white patch; bill long and slender and of black color; legs blackish, webs olive. Length about is inches (female rather smaller). In winter the chin, throat, and sides of neck become white, more or less mottled with black.

Nest. On a ledge of an ocean cliff; no attempt is made to construct a receptacle for the egg, - it is laid upon the bare rock.

Egg. I ; variable in color, the prevailing tints being ivory white, yellowish green, dark green, pale blue, and reddish brown, with numerous intermediate tints ; markings irregular, and of browns and grays in various shades; size variable, average about $3.25 \times 1.90$.

The Foolish Guillemot, so called for its fatuity in the breeding-season, in allowing itself sometimes to be seized by the hand or killed on the spot without flying from its 
favorite cliffs, is another singular and common inhabitant of the high northern latitudes of both continents. In Europe these birds extend their swarming colonies as far as the ever wintry coast of Spitzbergen; they are also seen in Lapmarck, and along the White and Icy Sea as far as Kamtschatka. Along the whole coast of Hudson Bay, Labrador, and Newfoundland, they congregate in swarms. They also breed in the Orkneys and in more temperate climates, when the local situation happens to suit their particular habits and instinct; thus, they are extremely numerous in the desert Isle of Priestholm, contiguous to the Island of Anglesey, on the Godreve rocks, not far from St. Ives, in Cornwall, the Farne Isles, off the coast of Northumberland, and the cliffs of the Isle of Wight, and of Scarborough in Yorkshire. Occasionally the young are seen along the coasts of the United States; but the great body of the species in America, according to Audubon, winter in the Bay of Fundy, where they find an open sea, congenial rocks, and a cool temperature.

These birds begin to assemble on their customary cliffs in England early in May, and crowd together in such numbers that it is not uncommon to see hundreds sitting upon their eggs on the ledge of a rock, all in a line, and nearly touching each other. They lay but a single egg, on the flat and bare rock, without any precaution to protect it or the progeny arising from it by any shelter or convenience at all like a nest. It is of a palish green, blotched and marked with black and deep umber brown. They rarely quit their eggs unless disturbed, and are fed during the time, chiefly with small fish or other marine productions, by the male. In inaccessible places, or where seldom disturbed, it is with difficulty that they are roused to flight, and may then sometimes be taken by the hand; others flutter into the water below the cliffs on which they nestle, and seem, in fact, to try every expedient but that of flight. They are at all times extremely expert in diving, using their pinions as oars instead of the feet, thus flying as it were in the water, as well as in the air. After the young are hatched and capable of migrating, by the close of August, they all dis- 
appear from the shores of Britain, and are seen in winter on the coasts of the Baltic, Holland, France, along the borders of the Atlantic, and as far southward as Italy. Many of the young, as well as old birds of this species, also, bred in colder latitudes, migrate in winter along the coasts of Norway, Holland, and England, seeming as it were to fill up the place of those which have left their native shores for still milder climates.

The inhabitants of Kamtschatka kill the Murres in great numbers for the sake of their flesh, though it is said to be tough and ill tasting, but more especially for their skins, of which, as of other fowls, they make garments; but the eggs are everywhere accounted as a delicacy. This bird is called by the Welsh Guillem, and in the southern parts of England Willock.

During very recent years it has been discovered that the "Common "Guillemot is a decidedly uncommon bird on our shores, if not quite rare; it has been confused with Brünnich's, which it very closely resembles. The present species is credited with breeding from the Bay of Fundy to the Frozen Ocean; but Mr. Hagerup considers it rare in south Greenland, while Kumlien reported finding Guillemots " breeding by thousands" on the Greenland coast.

A few of these birds are found off the New England shores in winter. 


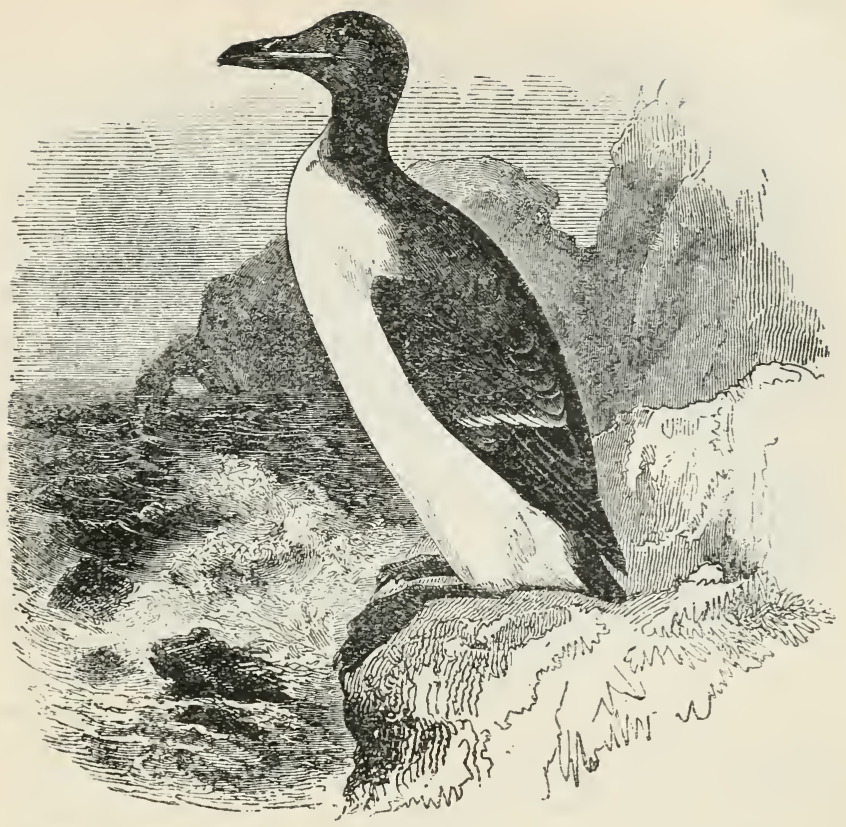

BRÜNNICH'S MURRE.

THICK-BILLED GUILLEMOT. FOOLISH GUILLEMOT. PENGUIN.

\section{URIA LOMVIA.}

CHAR. Upper parts sooty black, deeper on head and nape; sides of head and neck, chin, and throat brown; wing with small patch of white; bill short and thick, and of black color. Length about I 8 inches; female somewhat smaller. In winter the throat becomes white. Young birds are similar to the adult in winter plumage.

Nest. On the bare rocks of an ocean cliff.

Egg. I ; very variable in color, markings, and size; average about 3.1 $5 \times 2.05$.

This is the Common Guillemot of our shores, and is rather abundant in some localities, breeding from the Gulf of St. Lawrence to the Frozen Ocean, and wintering from south Greenland to New Jersey. Some European naturalists consider this bird a variety of $U$. troile, and not entitled to specific rank; but the "American

VOL. II. -26 
School " of ornithologists are nothing if not "separatists," and by separating forms which appear to them to have gained the right to distinct and separate recognition, the A. O. U. are proving their right to the title of "pioneers of modern ornithological science," given them by an illustrious European savant.

Whether the path which these "pioneers" are blazing - with its unbending adherence to a fixed line, over whatever difficulty it may lead - will be followed strictly by future systematists, is a debatable question; but followed strictly or but partially, the present generation of American ornithologists have established themselves among the leaders of the science, and the influence of their determinations is acknowledged wherever birds are studied or described.

I will not pretend to be in full sympathy with all of the separating that has been attempted, nor of all that has been accepted. There will be, doubtless, a revision of the present system, - nay, many revisions; ornithology is in its infancy yet. I follow the American school because an amateur writer must follow somebody, - we have had too many unskilled hands tinkering with systematic work. I follow the Americans also because I am doing American work for American readers, and the use of the A. O. U. system of classification and nomenclature will avoid confusion. I follow this system for another reason: I consider it the best that has as yet been issued; and so I give to Brünnich's Murre specific instead of varietal rank.

This bird does not differ in habits from its congeners. During the winter it lives on the open sea, and in the breeding-season assembles in large flocks on bold cliffs and rocky headlands. It is an expert diver, using wings and feet to get under water and to swim through it. 


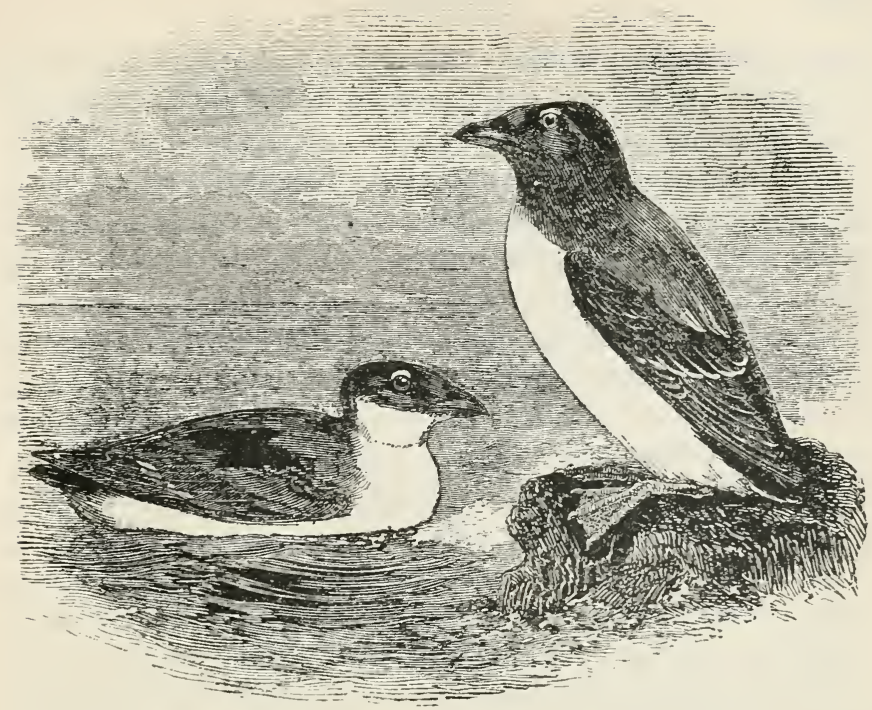

\section{DOVEKIE.}

SEA DOVE. LITTLE AUK.

Alle ALLE.

CHAR. Head, neck, and upper parts black; wings with small patch of white, sometimes divided by a black bar ; under parts white ; bill black; legs red. Length about $81 / 2$ inches.

In winter the chin and throat are white, and in spring and fall the white is more or less varied with black.

Nest. On a ledge of an ocean cliff, or any high elevation adjacent to the sea. There is no receptacle for the egg, which is laid on the bare rock or amid loose stones.

Egg. I; pale greenish blue, sometimes streaked with buff; average size $1.85 \times 1.30$.

This neat and singular little bird, with a quaint resemblance to the Columbine tribe, is known to mariners by the name of the Greenland Dove; and in this vicinity it is also called the Pigeon Diver. It inhabits, however, a region where the gentle cooing of the Dove is never heard. It dwells far within the Arctic Circle, approaching the very Pole, having been obtained 
by Dr. Richardson from the dreary coast of Melville Island, in the latitude of $75^{\circ}$ and $76^{\circ}$, in August, where these birds were seen by thousands. This is probably almost the last bird observed within the desolate and glacial boundaries of the earth. In Greenland and Spitzbergen Dovekies congregate in great flocks, and in the depth of winter, watching the motion of the ice in the offing when it is broken up by storms, they crowd by thousands into every opening fissure or flaw, in order to snatch up the marine productions on which they subsist. Mr. Audubon found a few individuals breeding on the coast of Labrador. In Newfoundland this species is called the Ice Bird, being the sure harbinger of severe weather, as it seldom proceeds far from its inclement natal regions, except when accidentally driven to shore by storms. In the United States its appearance is always solitary, being a mere wanderer, as it is also along the milder coasts of Europe. The uniform predilection of these birds is for the hyperboreal regions of their nativity, and they even fatten in storms when not overwhelmed by their fury, as at these times the small crustacea and marine insects on which they feed are cast up and brought to the surface in greater abundance. At times they appear to fly well, as appears by their extensive accidental migrations, they having sometimes been met with considerably inland. The water, however, is their more natural element; they dive with great facility, and are often observed dipping their bills into the water, as if drinking.

Those individuals which have been obtained in this vicinity, usually in the depth of winter, have sometimes been found in Fresh Pond, so lean and exhausted, by buffeting weather and fatigue, as to allow themselves to be quietly taken up by the hand.

Like other species of the genus, and the family generally, associated with the Razor-bills, they seek out for their breeding-places the most inaccessible impending cliffs which project into the ocean, and in their clefts, without any artificial nest, deposit their single egg, which is of a pale bluish-green, commonly without spots, but sometimes scattered with a few small 
touches of blackish. At this time, probably, they are heard to utter their uncouth and monotonous call of rottet, by which as a name they are known to the Dutch navigators who have penetrated to their dreary and remote haunts.

Captain Ross's party met with these birds in great numbers on the west coast of Greenland, where they were shot daily, and supplied to the ship's company, who found them very palatable, and free from any fishy taste, though their food consists chiefly of a small species of crab (Cancer), with which the Arctic seas abound.

This interesting little wanderer, that comes to our shores only during the winter months, and gains our sympathy by its graceful form and apparent helplessness, is a much more sturdy and selfreliant bird than it gives any evidence of as we pick it up exhausted from battling with the strong north wind that has thrown it in our way, faint from hunger and wearied from the protracted struggle. Its wings are small, but they are moved almost as rapidly as a Humming Bird's, and propel the bird through the air with great rapidity. This bird is an expert diver too, and though awkward on the land, swims with easy grace; and when wearied, it tucks its head beneath its little wing, and rocked in the cradle of the deep, sleeps as calmly and serenely as do human children upon their mother's breast. When hungry, these little children of the sea draw their food from the ocean's bosom.

The Little Auk nests only north of the Arctic Circle, and there assembles in vast communities, and fills the air with its wild note, which bears some resemblance to the syllables al-le.

These birds are seen on our shores only in winter, and then straggle as far south as New Jersey. Occasionally an example is blown inland by a gale, one having been found as far away from the sea as the Detroit River. 


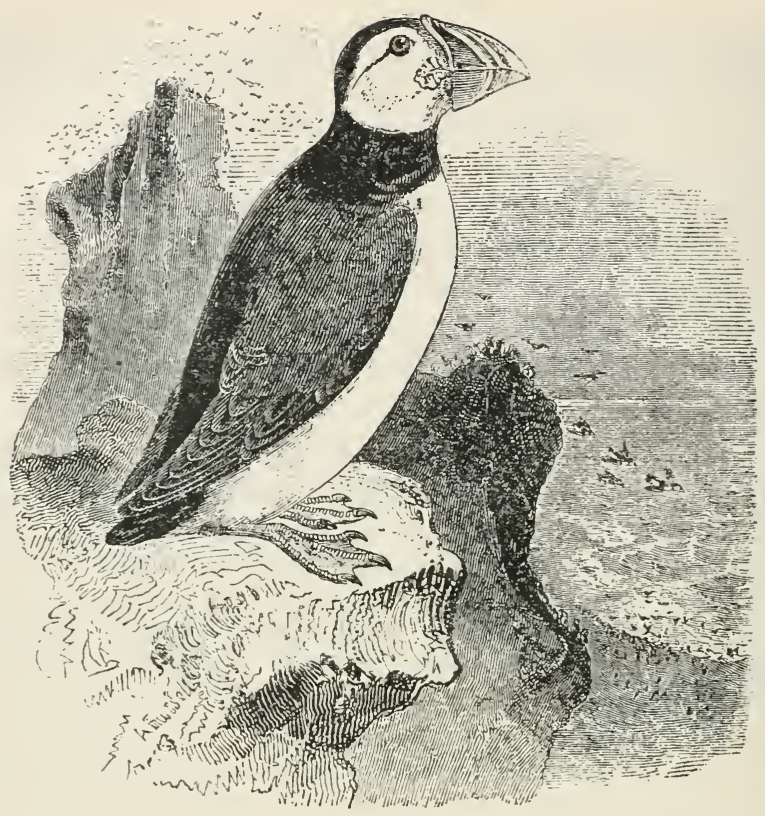

\section{PUFFIN.}

SEA PARROT.

FRATERCULA ARCTICA.

CHAR. Upper parts black or dusky, a band of same across the neck; cheeks and under parts white. Length about $\mathrm{I} 2$ inches.

Nest. In a crevice of a cliff or in a burrow.

Egg. I ; dull white, marked with pale brown and lilac; average size $2.40 \times 1.70$.

The Puffin is a general inhabitant of the cold and inclement regions of the whole northern hemisphere. On the coasts of northern Europe it is met with to the Icy Sea. It is found in Iceland, Greenland, Spitzbergen, and the Faröe Isles; on the coast of Kamtschatka and the Kuriles it is also common. In the temperate climates of Great Britain, as well as in the Shetland and Orkney Isles, it likewise breeds in large communities, as at the Farne Isles, off the coast of 
Northumberland, Priestholm Isle, near Anglesea, the small islands off St. David's in Wales, the Isle of Wight, the cliffs of Beachy Head, Dover, Scarborough, and in the vicinity of Holyhead. These birds were also found by Audubon on the sterile and dreary coast of Labrador, but not beyond Brador; they also probably inhabit the coasts of Newfoundland, and in the winter are seen in great numbers in the Bay of Fundy. They are little more than stragglers on the coast of New England, but according to Catesby proceed in the course of the season as far south as Carolina. In Europe they are also seen on the coasts of Andalusia in Spain.

In England, at Priestholm Isle, they are seen in flocks innumerable. They assemble and begin to visit the island early in April, but do not commence their incubation until the first week in May. They make no proper nest, but burrow deep holes in the loose earth, in the labor of which both male and female unite, forming excavations three or four feet in depth. As this labor is very considerable, they sometimes content themselves with the deserted burrow of the rabbit, and probably at times dislodge the owners for this coveted convenience. They lay a single whitish-colored egg on the bare mould of their den. The young are hatched by the beginning of July, and are attentively fed by the assiduous parents, who are now seen busily engaged fishing for them, and bringing their prey in the bill, until they are so far grown as to feed and defend themselves. About the close of August they all go off in a body, to a single bird; and indeed so completely that they desert the young ones which are hatched late, leaving them a prey to the Falcon and other rapacious birds who watch for them at the mouths of their holes. Yet notwithstanding this apparent neglect of their young at this time, when every other instinct is merged in the desire and necessity of migration, probably after food, no bird is more attentive to them in general, since they will suffer themselves to be taken by the hand, and use every endeavor to save and screen their young, biting not only their antagonist, but, when laid hold of by the wings, inflicting bites on themselves, as if actuated by the agonies of despair; 
and when released, instead of flying away, they hurry again into the burrow to their cherished young.

The Puffin, essentially aquatic in its nature and habits, makes no great progress in the air, taking wing with difficulty; and it walks on the whole length of the leg and foot with a wriggling, awkward gait. In tempestuous weather these birds seek shelter in caverns, the holes of the nearest rocks, in their burrows, or in the rabbit-holes on the beach, in which they doze till the return of calmer weather. Though accustomed to the severest cold, they are unable to brave the storm, and when overtaken by it are often drowned and cast dead on the shore. Their food consists of various kinds of small fish, particularly sprats, the smaller kinds of crabs, shrimps, and sea-weeds ; and it is not improbable but that their sudden migrations are regulated by the presence or absence of certain kinds of fish on which they delight to feed. They are exceedingly rank in flavor; yet the young, preserved with spices and pickled, are by some people much admired. They are even potted at St. Kilda and elsewhere, and sent to London as rarities.

Though pertinacious in attachment to their favorite breeding-places, they have sometimes been known to desert them in a very unaccountable manner. At the great Isle of Arran, Galway Bay, in Ireland, the stupendous cliffs to the southwest of the island, which from time immemorial had been the place of resort, or rather the natural habitation, of such numbers of Puffins as is almost incredible, was at once deserted on the $24^{\text {th }}$ of June by the entire species, who thus abandoned their eggs and young and went off to sea. The like incident is said to have happened forty years previous, and no reason could be assigned for this extraordinary dereliction.

Among the enemies of the Coulternebs is sometimes the piratical Raven, who makes bold to offer battle; but as soon as he approaches, the defender of the premises catches him under the throat with her beak, and sticks her claws into his breast till he screams out with pain and tries to get away. But the Coulterneb retains her hold, and tumbles him about, till both frequently fall into the sea, where the aggressor is 
drowned, and the Puffin returns in triumph to her nest. But should the Raven at the first onset get hold of the Coulterneb's neck, he generally comes off victorious, killing the mother and feasting on her eggs or young. The fishermen sometimes draw these birds out of their burrows by introducing the hand into the hole, which is seized by the bird, which suffers itself to be pulled out rather than lose its hold. Its bite is, however, very severe, and it can when irritated take out a piece of flesh from a man's hand without any extraordinary effort. When reared and domesticated, these birds become quite tame, and in the end familiar.

The Puffin breeds on the islands at the mouth of the Bay of Fundy, and north to Greenland, and in winter is more or less common, from Nova Scotia to New Jersey.

Note. - The Large-Billed Puffin ( $F$. arctica glacialis) is said to breed farther north than true arctica. It is similar to the common Puffin, but larger.

The Tufted Puffin (Lunda cirrhata), a North Pacific bird, is entitled to notice here through Audubon's report that he captured an example at the mouth of the Kennebec River, Maine. 


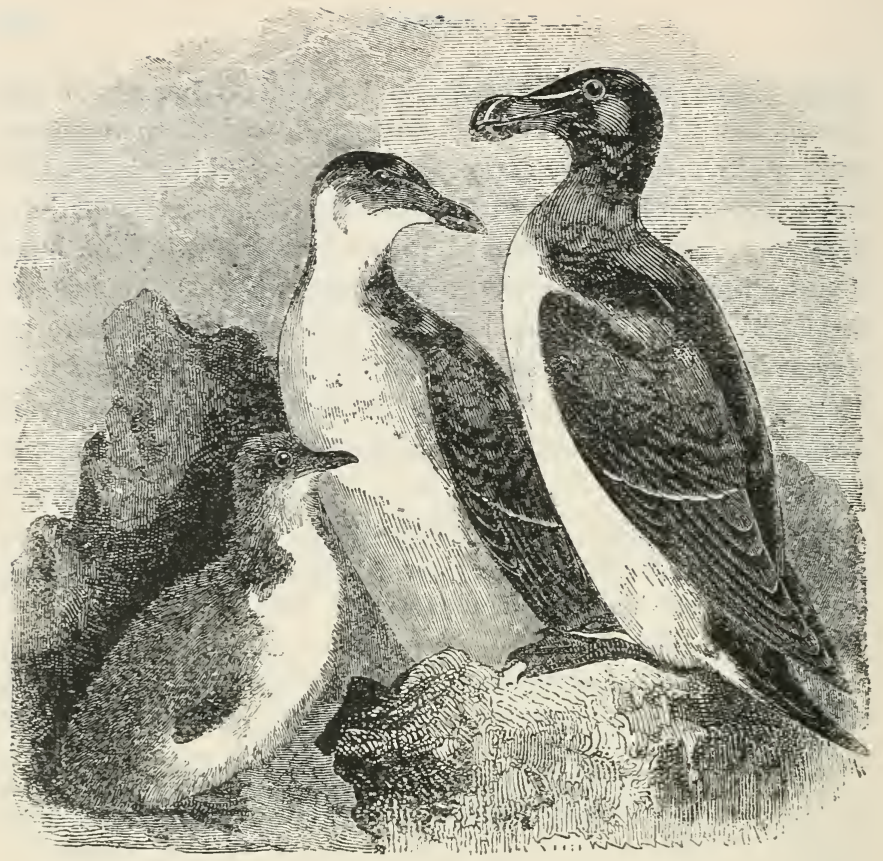

\section{RAZOR-BILLED AUK.}

TINKER.

\section{ALCA TORDA.}

CHAR. Upper parts black, with green reflections; throat deep brown; a line of white in front of the eyes; a narrow bar of white on the wings; under parts white; bill horn-brown with a bar of white. Length about 17 inches.

In winter the throat becomes white, the bill loses the horny shield at the tip and the white bar, and appears smaller and sharper, and the line from the eyes is indistinct.

Nest. On an ocean cliff, - usually near the summit; the egg is laid on the bare rock, generally in a crevice or amid loose stones.

Egg. I ; ground color shaded from ivory white or pale buff to dark buff or reddish brown; marked with dark brown and gray; size variable, average about $2.90 \times$ I.80.

The Razor-bill is another of those gregarious marine birds which dwell amidst the wildest scenes of Nature, and penetrate 
into the most dreary hyperboreal climates throughout the whole of the northern hemisphere. They abound in the north of Europe as far as Iceland and Greenland, and in America swarm on the bleak and barren coasts of Labrador. Small groups of from ten to twelve proceed along the coasts of the United States as far as New York, in severe winters remaining in deep water; but they are by no means common, and scarcely ever seen in Massachusetts Bay.

Like most of the birds of this family, they have a steady predilection for their ancient eyry. From time immemorial they resort to the same rocks and coasts, and there are but few places sufficiently desert, rocky, and inaccessible suited to their furtive habits and marine food. One of their great resorts in England is on and about the Needle-rocks and other precipitous cliffs, so dangerous to the shipwrecked mariner, which flank the romantic Isle of Wight. As curious and striking works of Nature and instinct, these, and the birds which frequent them, afford an interesting spectacle in May and June. The Razor-bills are here in such numbers that a boatful might be killed in a day; and the eggs being esteemed a delicacy, particularly for salads, the fishermen and other indigent and adventurous inhabitants traverse the precipices in search of the pickle samphire and the eggs of the Murre. Some of these stupendous cliffs are six hundred feet above the yawning deep, which lashes and frets them into gloomy caverns. Seaward they present rugged and deeply indented cliffs, on whose rude shelvings and ledges the birds arrange themselves by thousands, and without further preparation lay their eggs, which lie as it were strewed without precaution by hundreds in a row, in no way attached to or defended by the rocks, so that in a gale of wind whole ranks of them are swept into the sea. To these otherwise inaccessible deposits the dauntless fowlers ascend, and passing intrepidly from rock to rock, collect the eggs and descend with the same indifference. In most places, however, the attempt is made from above. The adventurer is let down from the slope contiguous to the brink of the cliff by a rope sustained by a single assistant, who, lowering his companion, depends on his per- 
sonal strength alone to support him; which if failing, the fowler is dashed to pieces or drowned in the sea which roars and heaves below.

In order to study the habits of these marine birds, the celebrated Edwards spent several days among these terrific and romantic rocks. If a cannon was fired, the air was darkened with a black cloud of the cliff birds, which issued by thousands from every hole and cranny, as if summoned into sudden existence by the work of enchantment. They fly about in silence near to the surface of the sea, perform a few circuits, and on the removal of the cause of alarm return soon to their eyry, or, alighting on the waves, dive out of the way of harm until well assured that no enemy is near.

These Auks lay but one egg except when robbed of the first, and if this is taken they will sometimes give a third. Mr. Audubon found them breeding in great numbers on the coast of Labrador, generally taking possession of the most rugged and precipitous isles, in the deep indentations and fissures of which they crowded, and deposited their eggs as near together as distinct proprietorship would admit, - commonly upon a nest of pebbles, artificially collected together, under and between which the dripping waters and melting ice thus passed without ever coming in contact with the eggs. The Murre sits on her nest in an upright posture, and with her head facing the wind. The young are fed by regurgitated food until they attain a considerable size, after which the small fish, on which old and young principally feed, are merely laid before them. They leave their rock or nest when about half grown, and then immediately commence fishing for themselves. Thousands of these birds are here seen breeding on the same rock.

The flight of the Razor-bill is rapid, and according to Mr. Audubon sometimes even greatly protracted, but low above the surface of the water, and sustained by a constant stiff and short flapping of the wings. It dives to great depths and swims under the surface with considerable velocity, using its wings as flattened fins, and in this manner, like the Divers, it may be seen pursuing and seizing its prey. 
Bésides breeding in Labrador, Mr. Audubon found that the Razor-bill occasionally nested in the Island of Grand Menan, the Seal Islands, and others situated at the entrance of the Bay of Fundy.

Though it walks and runs awkwardly, this bird moves swiftly, and can easily escape from place to place. The bite of the old bird, like that of the Puffin, is very severe. The fishermen of this region call this species the Hawk-billed Murre. Its flesh is quite palatable, although very dark, and much eaten by the Greenlanders, according to Crantz, forming their chief subsistence during the months of February and March. These birds are killed with missiles, chased and driven ashore in canoes, or taken in nets made of split whalebone. Their skins are also used for clothing. The eggs are everywhere accounted a delicacy, and the feathers of the breast are extremely fine, warm, and elastic. For the sake of this handful of feathers, according to Audubon, thousands of these birds are killed in Labrador, and their bodies strewed on the shore.

The islands between the small port of Little Macatine and Brador abound with these and other allied marine birds, whose eggs are collected by the inhabitants of Nova Scotia. For this purpose they commence by trampling on all they find laid, and the following day begin to collect those which are newly dropped; and such is the abundance of the eggs that Mr. Audubon fell in with a party of three men who, in the course of six weeks, had collected thirty thousand dozen, of the estimated value of four hundred pounds sterling. Beyond Brador the Murres and Puffins were no longer found.

The Razor-bill breeds on the Atlantic coast from the Bay of Fundy to the northern part of Labrador, though very few examples are found in summer south of the Gulf of St. Lawrence. In winter these birds wander along the coast of New England and the adjacent Provinces and southward casually to North Carolina. 


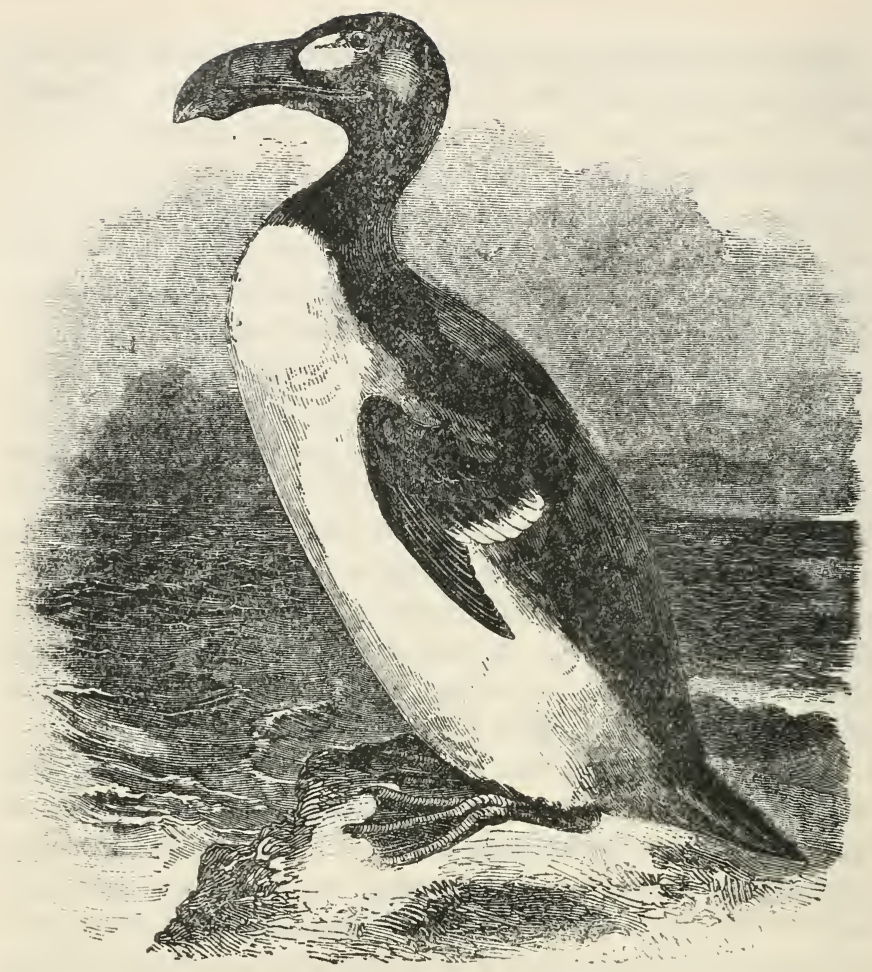

\section{GREAT AUK.}

GREAT PENGUIN. GARE FOWL.

\section{Plautus impenNis.}

CHAR. Upper parts black, a white patch in front of the eyes; under parts white; sides of the throat dark buff; wings little more than rudimentary. Length about 30 inches.

Nest. Among the shingle on a sea-washed beach, sometimes at a considerable distance from the water. The birds probably make no nest.

Eggs. Probably I ; creamy white or buff, sometimes tinged with green, marked with dark brown and gray; average size $4.80 \times 2.90$.

The Great Auk, or Northern Penguin, inhabits the highest latitudes of the globe, dwelling by choice and instinct amidst 
the horrors of a region covered with eternal ice. Here it is commonly found upon the floating masses of the gelid ocean, far from land, to which alone it resorts in the season of procreation.

Deprived of the use of wings, degraded as it were from the feathered ranks, and almost numbered with the amphibious monsters of the deep, the Auk seems condemned to dwell alone in those desolate and forsaken regions of the earth; yet aided by all-bountiful Nature, it finds means to subsist, and triumphs over all the physical ills of its condition. As a diver it remains unrivalled, proceeding beneath the water, its most natural element, almost with the velocity of many birds in the air. It thus contrives to vary its situation with the season, migrating for short distances, like the finny prey on which it feeds. In the Faröe Isles, Iceland, Greenland, and Newfoundland these birds dwell and breed in great numbers. They nest among the steepest cliffs of islands, remote from the shore, in the vicinity of floating ice, taking possession of caverns, and the crannies and clefts of rocks; or they dig for themselves deep burrows in which they lay their only egg, about the size of that of the Swan, whitish yellow, marked with numerous lines and spots of black, which present to the imagination the idea of Chinese characters. They are so unprolific that if this egg be taken away they lay no other that season. Their time of breeding is June and July.

The Auk is known sometimes to breed in the Isle of St. Kilda, and in Papa Westra, according to Mr. Bullock, for several years past no more than a single pair had made their appearance. It feeds on large fish, and also on some marine plants, as well as on those which grow on the rocks contiguous to their holes or burrows. The young birds tear up the roots of the Rhodiola rosea. Many are said to breed on the desert coasts of Newfoundland, where they have been seen by navigators, though not recently. According to Pennant, the Esquimaux, who frequented this island, made clothing of the skins of these birds. The older ones are very shy, and but rarely venture to the shore, on which they walk badly, though 
the young are not unfrequently met with. When fed in confinement, the Auk expresses its anxiety by raising and shaking the head and neck and uttering a gurgling noise, but appears to be on the whole essentially dumb, as well as deprived of flight.

Since Nuttall wrote, the Great Penguin of the North Atlantic has become extinct. There is no mystery surrounding the extinction of these birds; they simply yielded to the inevitable law of the survival of the fittest. Through disuse the wings became unfit for service, and the parents could not reach a place of safety for their eggs ; and though expert divers, and strong, swift swimmers, their legs were almost useless when upon land, and the birds were continually surprised by hunters and captured in large numbers, until the last one perished.

Not many years ago they were abundant in the vicinity of Newfoundland, and they no doubt occurred as far south as the shores of Massachusetts. The year 1842 is given as that in which the last of these Auks were seen. Now a few stuffed specimens is all that can be found of former legions. 


\section{N D E X.}

Acanthis brewsterii, i. 359.

hornemannii, i. 359 .

hornemnanii exilipes, i. 358 .

linaria, i. 355 .

linaria holballii, i. 357 .

linaria rostrata, i. 357 .

Accipiter atricapillus, i. $3 \mathrm{I}$. cooperi, i. 34 .

velox, i. 35 .

Actitis macularia, ii. I60.

Agialitis hiaticula, ii. 66.

meloda, ii. 59.

meloda circumcincta, ii. 60.

montana, ii. 67.

semipalmata, ii. 64 .

vocifera, ii. 62.

wilsonia, ii. 6r.

Estrelata gularis, ii. 268.

hasitata, ii. 268.

Agelaius phoeniceus, i. 96. phoniceus bryanti, i. Ior.

Aix sponsa, ii. 317.

Ajaja ajaja, ii. 108.

Alauda arvensis, i. 297.

Albatross, Wandering, ii. 278.

Yellow-nosed, ii. 277.

Alca torda, ii. 4 Io.

Alle alle, ii. 403 .

Ammodramus caudacutus, i. 344 . caudacutus nelsoni, i. 346. caudacutus subvirgatus, i. 345 .

henslowii, i. 330 .

leconteii, i. $33 \mathrm{r}$.

maritimus, i. 346.

maritimus peninsula, i. 347 .

nigrescens, i. 347 .

princeps, i. 326.

sandwichensis savanna, i. 325 . savannarum passerinus, i. 329 .
Ampelis cedrorum, i. 154 . garrulus, i. 152 .

Anas americana, ii. $3 \mathbf{I r}$. boschas, ii. 303 .

carolinensis, ii. $32 \mathbf{I}$.

crecca, ii. 323 .

cyanoptera, ii. 323 .

discors, ii. 319 .

fulvigula, ii. $3 \mathbf{1} 6$.

obscura, ii. 315 .

penelope, ii. 313.

strepera, ii. 307.

Anhinga anhinga, ii. 380 .

Ani, i. 438.

Anous stolidus, ii. 232.

Anser albifrons gambeli, ii. 284 .

Anthus pensylvanicus, i. 292. pratensis, i. 293.

Antrostomus carolinensis, i. 465 .

vociferus, i. 467.

Aphelocoma floridana, i. 137.

Aquila chrysaëtos, i. I5.

Aramus giganteus, ii. 102.

Archibuteo lagopus sancti-johannis,

i. 41 .

Ardea candidissima, ii.86. cinerea, ii. 8I.

corulea, ii. 94 .

egretta, ii. 84 .

herodias, ii. 78 .

occidentalis, ii. 82.

rufa, ii. 88 .

tricolor ruficollis, ii. 96.

virescens, ii. 97.

wardi, ii. 82.

Arenaria interpres, ii. $7 \mathbf{1}$.

Asio accipitrinus, i. 68. wilsonianus, i. 66.

Auk, Great, ii. 414.

VoL. II. - 27 
Auk, Little, ii. 403. razor-billed, ii. 4 Io.

Avocet, ii. 106.

Aythya affinis, ii. 345 . americana, ii. 340 . collaris, ii. 346 . marila nearctica, ii. 343 . vallisneria, ii. 336 .

Baldpate, ii. $3 \mathbf{I}$.

Bartramia longicauda, ii. 164.

Beach-bird, ii. 49.

Beetlehead, ii. 68.

Bittern, ii. 99.

Cory's Least, ii. I02.

Least, ii. 101.

Blackbird, Bahama red-winged, i. ror.

Cow, i. 104.

Crow, i. 115 .

Red-winged, i. 96.

Rusty, i. I 19 .

Skunk, i. rog.

Yellow-headed, i. ro2.

Blackbreast, ii. I 26.

Blackhead, Big, ii. 343 .

Little, ii. 345 .

Ring-billed, ii. 346.

Ring-necked, ii. 346 .

Blackheart, ii. 126.

Bluebill, ii. 343 .

Little, ii. 345 .

Marsh, ii. 346.

Bluebird, i. 285.

Bobolink, i. 109.

Bob-white, ii. 23.

Cuban, ii. 30 .

Florida, ii. 30 .

Bogsucker, ii. 176.

Bonasa umbellus, ii. 30 . umbellus torgata, ii. 34 .

Booby, ii. 379. Blue-faced, ii. 380 . Red-footed, ii. 380 .

Botaurus exilis, ii. 101. lentiginosus, ii. 99. neoxena, ii. 102.

Brant, ii. 293. Black, ii. 292, 293. White, ii. $28 \mathrm{r}$.

Branta bernicla, ii. 293. canadensis, ii. 285 . canadensis hutchinsii, ii. 290.
Branta canadensis minima, ii. 292. leucopsis, ii. 292.

nigricans, ii. 292.

Brant-bird, ii. $7 \mathbf{r}$.

Broadbill, ii. 300 .

Brownback, ii. 169.

Bubo virginianus, i. 6 1.

virginianus saturatus, i. 64 . virginianus subarcticus, i. 64 .

Bufflehead, ii. 347 .

Bull-bat, i. 470 .

Bullhead, ii. 68 .

Bulweria bulweri, ii. 268.

Bunting, Bay-winged, i. 320.

Black-throated, i. 298.

Henslow's, i. 330.

Indigo, i. 310.

Lark, i. 299.

Le Conte's, i. 33 r.

Painted, i. 314.

Snow, i. 300.

Townsend's, i. 299.

Varied, i. 313 .

Yellow-winged, i. 329 .

Burgomaster, ii. 248.

Butcher-bird, i. 159.

Buteo borealis, i. 46.

borealis harlani, i. 48.

brachyurus, i. 50.

latissimus, i. 49.

lineatus, i. 43 .

lineatus alleni, i. 45 .

swainsoni, i. 48 .

Butterball, ii. 347 .

Buzzard, King, i. 6.

Turkey, i. $\mathbf{I}$.

Calamospiza melanocorys, i. 299.

Calcarius lapponicus, i. 304.

ornatus, i. 305.

pictus, i. 305 .

Calichelidon cyaneovirides, i. 403.

Calidris arenaria, ii. 49.

Campephilus principalis, i. 441.

Camptolaimus labradorius, i. 302.

Canary, Wild, i. 348.

Caracara. Audubon's, i. 6.

Cardinal, i. 362.

Cardinalis cardinalis, i. 362 .

Carduelis carduelis, i. 353 .

Carpodacus purpureus, i. 372.

Catbird, i. 195. 
Catharista atrata, i. 4 .

Cathartes aura, i. I.

Cedar-bird, i. 154 .

Ceophloeus pileatus, i. 444 .

Cepphus grylle, ii. 395 .

mandtii, ii. 397 .

motzfeldi, ii. 397 .

Certhia familiaris americana, i. 387 .

Certhiola bahamensis, i. $3^{88 .}$

Ceryle alcyon, i. $46 \mathrm{I}$.

Chatura pelagica, i. 463 .

Charadrius apricarius, ii. 58 . dominicus, ii. 57 . squatarola, ii. 68.

Charitoneta albeola, ii. 347.

Chat, Yellow-breasted, i. I72.

Chebec, i. 42 I.

Chelidon erythrogaster, i. 394 .

Chen carulescens, ii. 283 . hyperborea, ii. 283 . nivalis, ii. $28 \mathbf{I}$.

Cherry-bird, i. 154 .

Chewink, i. 359.

Chickadee, i. 146.

Carolina, i. 150.

Hudsonian, i. 15 1.

Chippy, i. 333.

Chondestes grammacus, i. 317.

Chordeiles virginianus, i. 470. virginianus chapmani, i. 473.

Chuck-will's-widow, i. 465 .

Circus hudsonius, i. 5 t.

Cistothorus mariance, i. 280. palustris, i. 279. stellaris, i. 277.

Clangula hyemalis, ii. 335 .

Clivicola riparia, i. 401 .

Cobb, ii. $25^{2}$.

Coccothraustes vespertina, i. 367.

Coccyzus americanus, i. 432. erythrophthalmus, i. $43^{6}$. minor, i. 437. minor maynardi, i. 438 .

Cockawee, ii. 355 .

Colaptes auratus, i. 438 .

Colinus virginianus, ii. 23 . virginianus cubanensis, ii. 30 . virginianus floridanus, ii. 30 .

Columb a leucocephala, ii. 7 .

Columbigalina passerina, ii. 13 .

Colymbus auritus, ii. $3^{83}$. holbelii, ii. $3{ }^{8}$.
Compsothlypis americana, i. 244 .

Contopus borealis, i. 410. virens, i. 419.

Conurus carolinensis, i. $42 \mathrm{~S}$.

Coot, ii. 197.

Black, ii. 333.

Butter-billed, ii. 333 .

European, ii. 201.

Horse-head, ii. 33 I.

Sea, ii. 333,334 .

White-winged, ii. 334 .

Cormorant, ii. 469 .

Double-crested, ii. 372.

Florida, ii. 373 .

Mexican, ii. 373 .

Corvus americanus, i. 126.

americanus floridanus, i. I31.

caurinus, i. 132.

corax principalis, i. 120.

ossifragus, i. $\mathbf{1} 3 \mathbf{1}$.

Coturnix coturnix, ii. 30 .

Courlan, ii. 102.

Cowbird, i. ror.

Crake, ii. 194.

Carolina, ii. I89.

Corn, ii. 196.

Spotted, ii. 196.

Crane, Blue, ii. 78.

Brown, ii. 77.

Great White, ii. 73 .

Little Brown, ii. 76 .

Sandhill, ii. 77.

Whooping, ii. 73 .

Creeper, Bahama Honey, i. 388.

Black and White, i. 3 So.

Brown, i. $3^{8} 7$.

Crex crex, ii. 196.

Crossbill, American, i. 378 .

Common, i. 378 .

Red, i. 378.

White winged, i. $3^{81}$.

Crow, i. 126.

Carrion, i. 4 .

Fish, i. 13I.

Florida, i. 13r.

Rain, i. $432,436$.

Crow Duck, ii. 197.

Crymophilus fulicarius, ii. 205.

Cuckoo, Black-billed, i. 436.

Mangrove, i. 437.

Maynard's, i. 438.

Yellow-billed, i. 432 . 
Curlew, Eskimo, ii. I22. Hudsonian, ii. 120. Jack, ii. 120.

Long-billed, ii. II 8. Short-billed, ii. 122.

Cyanocitta cristata, i. 133 . cristata florincola, i. 136. Cymodroma grallaria, ii. 268.

Dabchick, ii. $3^{86 .}$

Dafila acuta, ii. 309 .

Dendragapus canadensis, ii. $4 \mathbf{I}$.

Dendroica astiva, i. 220. auduboni, i. 220.

blackburnice, i. 232.

carulea, i. 247.

crrulescens, i. 245 .

carbonata, i. 265.

castanea, i. 237 .

coronata, i. 217 .

discolor, i. 242.

dominica, i. 228 .

dominica albilora, i. 229.

kirtlandi, i. 26j.

maculosa, i. 224.

montana, i. 265.

palmarum, i. 220.

palmarum hypochrysea, i. 219.

pensylvanica, i. 235.

striata, i. $23 \mathrm{~S}$.

tigrina, i. 226.

townsendi, i. 265.

vigorsii, i. 239.

virens, i. 230.

Dickcissel, i. 298.

Diomedea exulans, ii. 278 .

Dipper, ii. 347.

Diver, Great Northern, ii. $3^{88 .}$

Dolichonyx oryzivorus, i. 109 .

Doughbird, ii. 122.

Dove, Carolina, ii. 11.

Ground, ii. 13.

Key West, ii. 9.

Mourning, ii. I r.

Sea, ii. 403.

Turtle, ii. II.

Zenaida, ii. 10.

Dovekie, ii. 403 .

Dowitcher, ii. 169.

Long-billed, ii. $\mathbf{I} 7 \mathrm{r}$.

Dryobates borealis, i. 454 .

pubescens, i. $45^{2}$.
Dryobates villosus, i. 451 .

villosus audubonii, i. 452 .

villosus leucomelas, i. 452 .

Duck, Black, ii. 315 .

Broad-bill, ii. 334 .

Canvas-back, ii. 336 .

Crow, ii. 197 .

Dipper, ii. 334 .

Dusky, ii. 315.

Florida, ii. 316.

Gray, ii. 307, 309.

Harlequin, ii. $35^{2}$.

Labrador, ii. 302.

Lesser Scaup, ii. 345 .

Long-tailed, ii. 355 .

Masked, ii. 364.

Pied, ii. 302.

Ring-necked, ii. 346 .

Ruddy, ii. 334 .

Rufous-crested, ii. 364 .

Scaup, ii. 343 .

Sea, ii. 324 .

Spine-tailed, ii. 334 .

Spirit, ii. 347,383 .

Steller's, ii. 364 .

Summer, ii. 317.

Surf, ii. 33I.

Velvet, ii. 334 .

IVild, ii. 303 .

Wood, ii. 317 .

Dunlin, ii. 1 26, 128.

Eagle, Bald, i. 19.

Caracara, i. 6.

Golden, i. 15.

Gray Sea, i. 26.

Washington, i. 19.

White-tailed, i. 26.

Ectopistes migratorius, ii. I.

Egret, ii. 84.

Blue, ii. 94 .

Little White, ii. 86.

Peale's, ii. $\delta 8$.

Reddish, ii. 88.

Eider, ii. 324 .

Common, ii. 324 .

Greenland, ii. 329 .

King, ii. 329.

Elanoides forficatus, i. 39.

Elanus leucurus, i. $3^{8}$.

Empidonax acadicus, i. 425 .

flaviventris, i. 426. 
Empidonax minimus, i. $42 \mathrm{I}$. pusillus traillii, i. 424 .

Eniconetta stelleri, ii. 364 .

Ereunetes pusillus, ii. 143 . occidentalis, ii. I44.

Erismatura rubida, ii. 334 .

Euetheia bicolor, i. 315.

canora, i. 315.

Falco columbarius, i. II. islandus, i. 7 .

mexicanus, i. 9.

peregrinus anatum, i. 9. regulus, i. 12.

rusticolus, i. 7 .

rusticolus gyrfalco, i. 8 . rusticolus obsoletus, i. 8. sparverioides, i. I4. sparverius, i. 13 . tinnunculus, i. 14.

Falcon, Peregrine, i. 9. Prairie, i. 9

Finch, Grass, i. 320.

Lark, i. 317.

Lincoln's, i. 328.

Pine, i. 351 .

Purple, i. 372.

Seaside, i. 346.

Shore, i. 344 .

Summer, i. 327.

Thistle, i. 348 .

Fire-bird, i. 83 .

Flamingo, ii. 104.

Flicker, i. 438.

Flycatcher, Acadian, i. 425.

Crested, i. 4I3.

Fork-tailed, i. 427 .

Least, i. 421.

Olive-sided, i. 4 10.

Scissor-tailed, i. 427.

Small-headed, i. 168.

Traill's, i. 424 .

Yellow-billed, i. 426.

Fratercula arctica, ii. 406. arctica glacialis, ii. 409 .

Frigate Bird, ii. 373 .

Fregata aquila, ii. 373 .

Fulica americana, ii. 197 atra, ii. 201.

Fulmar, ii. 269.

Lesser, ii. 271.

Fulmaris glacialis, ii. 269.
Fulmaris glacialis minor, ii. 271 .

Gadwall, ii. 307 .

Galeoscoptes carolinensis, i. 195.

Gallinago delicata, ii. 172.

gallinago, ii. 176.

Gallinula galeata, ii. 203.

Gallinule, Common, ii. 203.

Florida, ii. 203.

Purple, ii. 20I.

Gannet, ii. 375 .

Gare Fowl, i. 4 I4.

Gavia alba, ii. 244.

Gelochelidon nilotica, ii. 218.

Geothlypis agilis, i. 253.

formosa, i. 246 .

philadelphia, i. 25 I.

trichas, i. 247 .

trichas occidentalis, i. $25 \mathrm{I}$.

trichas ignota, i. $25 \mathrm{I}$.

Geotrygon martinica, ii. 9. montana, ii. 10.

Glaucionetta clangula americana, ii. 349.

islandica, ii. $35 \mathrm{I}$.

Gnatcatcher, Blue-gray, i. 170.

Goatsucker, i. 470.

Godwit, Black-tailed, ii. 169.

Hudsonian, ii. 168.

Marbled, ii. 166.

Golden-eye, ii. 349.

Barrow's, ii. $35 \mathbf{r}$.

Rocky Mountain, ii. 351 .

Goldfinch, i. 353 .

American, 348.

Black-headed, i. 350.

Goosander, ii. 358 .

Goose, Barnacle, ii. 292.

Blue, ii. 283.

Brant, ii. 293.

Cackling, ii. 292.

Canada, ii. 285.

Greater Snow, ii. 28I.

Hutchins's, ii. 290.

Laughing, ii. 284 .

Lesser Snow, ii. 283 .

Solan, ii. 375 .

Southern, ii. 290.

White-fronted, ii. 284.

Wild, ii. 285 .

Goshawk, i. 31 .

Grackle, Boat-tailed, i. 114 . 
Grackle, Bronze, i. I I8.

Florida, i. I 8 .

Purple, i. II5.

Grassquit, i. 315 .

Melodious, i. 315.

Green-shank, ii. I 59.

Grebe, Carolina, ii. 386.

Dusky, ii. $3^{\delta_{3}}$.

Holbœll's, ii. $3^{8} 4$.

Horned, ii. ${ }_{3} \delta_{3}$.

Little, ii. 386 .

Pied-billed, ii. $3^{86}$.

Red-necked, ii. 384 .

Grosbeak, Blue, i. 37 r.

Evening, i. 367 .

Pine, i. 375 .

Rose-breasted, i. 369 .

Grotophaga ani, i. 438 .

Grouse, Canada, ii. 41.

Canadian Ruffed, ii. 34 .

Pinnated, ii. 35 .

Prairie Sharp-tailed, ii. $4 \mathbf{I}$.

Ruffed, ii. 30 .

Sharp-tailed, ii. 39 .

Spotted, ii. 4 I.

IVhite, ii. 43 .

Grus americana, ii. 73.

canadensis, ii. 76 .

mexicana, ii. 77 .

Guara alba, ii. 112.

rubra, ii. II 2.

Guillemot, Black, ii. 395 .

Black-winged, ii. 397 .

Common, ii. 398 .

Foolish, ii. 398, 4 or.

Mandt's, ii. 397.

Thick-billed, ii. 40r.

Guiraca carulea, i. 371.

Gull, Black-headed, ii. 236.

Bonaparte's, ii. 238.

Common, ii. 243.

Forked-tailed, ii. 234.

Franklin's, ii. 238.

Glaucous, ii. $24^{8}$.

Great Black-backed, ii. 252.

Herring, ii. $246,247$.

Iceland, ii. 250.

Ivory, ii. 244.

Kumlien's, ii. 25 r.

Laughing, ii. 236.

Little, ii. 235.

Mackerel, ii. 213.
Gull, Parasitic, ii. 255.

Ring-billed, ii. 243.

Ross's, ii. 239.

Sabine's, ii. 234.

Siberian, ii. 25 I.

Summer, ii. 213.

Wedge-tailed, ii. 239.

White-winged, ii. 250.

Gyrfalcon, i. 7 .

Habia ludoviciana, i. 369.

Hamatopus ostralegus, ii. 56 . palliatus, ii. 54 .

Hagdon, ii. 272.

Black, ii. 275.

White, ii. 269, 27 I.

Hairbird, i. 333.

Haliaetus albicilla, i. 26.

leucocephalus, i. $\mathbf{1 9}$.

Hang-nest, i. $\delta_{3}$.

Harporhyncus rufus, i. 192.

Hawk, Black, i. 4 I.

Blue, i. 5 r.

Blue Hen, i. 3 I.

Broad-winged, i. 49.

Cooper's, i. 34 .

Cuban Sparrow, i. I4.

Duck, i. 9.

Fish, i. 27.

Florida Red-shouldered, i. 45.

Great-footed, i. 9.

Harlan's, i. $4^{8}$.

Harris's, i. 46.

Marsh, i. 5 I.

Pigeon, i. I I .

Red-shouldered, i. 43 .

Red-tailed, i. 46 .

Rough-legged, i. 4 I.

Sharp-shinned, i. 35 .

Short-tailed, i. 50 .

Snail, i. 40.

Sparrow, i. 13.

Swainson's, i. 48 .

Winter, i. 43.

Heath Hen, ii. $3 \delta$.

Helinaia swainsonii, i. 256.

Hell-diver, ii. $3^{8} 3$.

Helminthophila bachmani, i. 26r.

celata, i. 264.

chrysoptera, i. 260.

cincinnatiensis, i. 265.

lawrencei, i. 265. 
Helminthophila leucobronchialis, i.265. peregrina, i. 261.

pinus, i. 258.

ruficapilla, i. 263.

Helmitherus vermivorus, i. 255.

Hen, Heath, ii. 38 .

Hen, Prairie, i. 35.

Heron, Black-crowned Night, ii. 9I.

Blue, ii. $\delta$ r.

Florida, ii. 82 .

Great Blue, ii. 78 .

Great White, ii. 82 .

Green, ii. 97.

Little Blue, ii. 94.

Louisiana, ii. 96.

Small White, ii. 86.

Snowy, ii. 86.

Ward's, ii. 82.

Wurdeman's, ii. 82.

Yellow-crowned Night, ii. 90.

Hesperocichla navia, i. 202.

- High-holder, i. 438.

Himantopus mexicanus, ii. 52 .

Histrionicus histrionicus, ii. $35^{2}$.

Humming-bird, i. 457.

Hydrochelidon leucoptera, ii. 23 I. nigra surinamensis, ii. 230.

Ibis, Glossy, ii. I14.

Scarlet, ii. I1 2.

White, ii. II2.

Wood, ii. I 10.

Icteria virens, i. 172.

Icterus bullocki, i. 93 .

galbula, i. 83 .

icterus, i. 82.

spurius, i. 93.

Ictina mississippiensis, i. 37 .

Ionornis martinica, ii. 201.

Jackdaw, i. I I 4 .

Jaeger, Arctic, ii. 258 .

Long-tailed, ii. 259.

Parasitic, ii. 258 .

Pomarine, ii. 257.

Richardson's, ii. 258 .

Jay, Blue, i. 133.

Canada, i. 138 .

Florida, i. 137.

Florida Blue, i. 136.

Labrador, i. I4I.

Funco carolinensis, i. $34 \mathrm{I}$.
Funco hyemalis, i. 339.

hyemalis oregonus, i. $34^{\text {I. }}$.

Oregon, i. 34 I.

Slate-colored, i. 339 .

Kestrel, i. 14.

Killdeer, ii. 62.

Kingbird, i. 404.

Arkansas, i. 409.

Gray, i. 4I4.

Kingfisher, i. 46 I.

Kinglet, Cuvier's, i. 282.

Golden-crowned, i. 283.

Ruby-crowned, i. 281.

Kite, Black, i. 40.

Black-shouldered, i. 38 .

Blue, i. 37.

Everglade, i. 40.

Fork-tailed, i. 39 .

Hook-billed, i. 40.

Mississippi, i. 37 .

Swallow-tailed, i. 39 .

White-tailed, i. 38 .

Kittiwake, ii. 24 I.

Knot, ii. 140.

Krieker, ii. I 30 .

Lagopus lagopus, ii. 43 .

lagopus alleni, ii. 47 .

rupestris, ii. 47 .

rupestris reinhardti, ii. 48 .

welchi, ii. 48 .

Lanius borealis, i. 159 .

ludovicianus, i. 162.

ludovicianus excubitorides, i. 163.

Lapwing, ii. 70.

Lark, Field, i. 79.

Horned, i. 294.

Meadow, i. 79 .

Mexican Meadow, i. 82.

Prairie Horned, i. 296.

Shore, i. 294.

Western Meadow, i. 82 .

Larus affinis, ii. $25 \mathrm{I}$.

argentatus, ii. 247.

argentatus smithsonianus, ii. 246 .

atricilla, ii. 236.

canus, ii. 243.

delawarensis, ii. 243.

franklinii, ii. 238 .

glaucus, ii. 248.

kumlieni, ii. $25 \mathbf{r}$. 
Larus leucopterus, ii. 250. marinus, ii. 252. minutus, ii. 135 . philadelphia, ii. 238.

Limosa fedoa, ii. 166. hamastica, ii. 168. limosa, ii. 169.

Limpkin, ii. 102.

Linnet, i. 372.

Brewster's, i. 359.

Pine, i. 351.

Redpoll, i. 355 .

Log-cock, i. 444 .

Longspur, Chestnut-collared, i. 305. Lapland, i. 304 . Smith's, i. 305.

Loon, ii. 388. Black-throated, ii. 391. Red-throated, ii. 393.

Lophodytes cucullatus, i. 363 .

Lord-and-Lady, ii. 352 .

Loxia curvirostra minor, i. 378 . leucoptera, i. $3^{81}$.

Macrorhampus griseus, ii. 169. scolopaceus, ii. 17 I.

Magpie, i. 132.

Mallard, ii. 303. Dusky, ii. 315 .

Man-of-War, ii. 258.

Man-of-War Bird, ii. 373 .

Marsh Harrier, i. 51 .

Marsh Hen, ii. 197.

Marsh Hen, Freshwater, ii. 188.

Marlin, ii. 166. Ring-tailed, ii. 168.

Martin, Bee, i. 404. Purple, i. 391. Sand, i. 401.

Maryland Yellow-throat, i. 249.

Meadow Hen, ii. 197. Saltwater, ii. 183.

Meadow-wink, i. 109.

Megalestris skua, ii. 255.

Megascops asio, i. 57. asio floridanus, i. 60.

Melanerpes carolinus, i. 448 . erythrocephalus, i. 447.

Meleagris gallopavo, ii. 15 .

Melospiza fasciata, i. 322 . georgiana, i. 342 . lincolni, i. 328 .
Merganser americanus, ii. 358 . serrator, ii. 360.

Merganser, ii. 358 . Hooded, ii. 363 .

Red-breasted, ii. 360 .

Merlin, i. 12.

Merula migratoria, i. 198.

Micropalama himantopus, ii. 145 .

Milvulus forficatus, i. 427 . tyrannus, i. 427 .

Mimus polyglottus, i. 187.

Mniotilta varia, i. 389 .

Mocking-bird, i. 187.

Molothrus ater, i. I04.

Moor Hen, ii. 197.

Moose-bird, i. 138.

Motacilla alba, i. 293.

Mother Carey's Chicken, ii. 267.

Mud Hen, ii. 183 , 197. Red-billed, ii. 203.

Murre, ii. 398.

Brünnich's, ii. 401.

Myiarchus crinitus, i. 413.

Netta rufina, ii. 364 .

Night Hawk, i. 470.

Florida, i. 473.

Noddy, ii. 232, 269, 271.

Nomonyx dominicus, ii. 364 .

Nonpareil, i. $3^{1} 4$.

Numenius borealis, ii. 122.

hudsonicus, ii. 120.

longirostris, ii. 118 .

Nuthatch, Brown-headed, i. 386.

Red-breasted, i. 385.

White-breasted, i. $3^{83}$.

Nyctala acadica, i. 72 .

tengmalmi richardsoni, i. 73 .

Nyctea nyctea, i. 55 .

Nycticorax nycticorax navius, ii. 9r. violaceus, ii. 90.

Oceanites oceanicus, ii. 264.

Oceanodroma leucorhoa, ii. 263.

Oidemia americana, ii. 333 .

deglandi, ii. 334 .

fusca, ii. 334.

perspicillata, ii. 33 r.

Old-squaw, ii. 355 .

Old-Tom-Peabody, i. 318 .

Olor buccinator, ii. 299. columbianus, ii. 296. 
Olor cygnus, ii. 299.

Oriole, Baltimore, i. 83 .

Bullock's, i. 93 .

Orchard, i. 93 .

Osprey, i. 27.

Otocoris alpestris, i. 294. alpestris praticola, i. 296.

Oven-bird, i. 215.

Owl, Acadian, i. 72.

Barn, i. 75 .

Barred, i. 70.

Burrowing, i. 78 .

Cat, i. 6r.

Dusky Horned, i. 64 .

Florida Barred, i. 7 I.

Florida Screech, i. 60.

Great Gray, i. 64 .

Great Horned, i. 6I.

Hawk, i. 53.

Hoot, i. 70 .

Long-eared, i. 66.

Mottled, i. 57.

Red, i. 57.

Richardson's, i. 73.

Saw-whet, i. 72.

Screech, i. 57.

Short-eared, i. 68.

Snowy, i. 55.

Sparrow, i. 73 .

Western Horned, i. 64.

Oyster-catcher, ii. 54 .

European, ii. 56.

Pale-belly, ii. 57 .

Pandion haliaëtus carolinensis, i. 27,

Parabuteo unicinctus harrisi, i. 46.

Parakeet, i. 428.

Paroquet, Carolina, i. 428 .

Parrot, Carolina, i. 428 .

Sea, ii. 406.

Partridge, ii. 23, 30 .

Birch, ii. 30.

Spruce, ii. 4 I.

Passer domesticus, i. 354 .

Passerella iliaca, i. 338 .

Passerina ciris, i. 314 .

cyanea, i. 3 ro.

versicolor, i. 313 .

Parus atricapillus, i. 146.

bicolor, i. 142.

carolinensis, i. 150.

hudsonicus, i. 151 .
Patch-head, ii. 331 .

Pavoncella pugnax, ii. 150.

Peabody-bird, i. 318.

Pediocetes phasianellus, ii. 39 . phasianellus campestris, ii. 41.

Peep, ii. 136.

Peet-weet, ii. 160.

Pelagodroma marina, ii. 268.

Pelecanus erythrorhynchos, ii. 364 . fuscus, ii. 368.

Pelican, Brown, ii. 368 .

Frigate, ii. 373 .

White, ii. 364 .

Penguin, ii. 398,40 r.

Great, ii. 414.

Perisoreus canadensis, i. 138 . canadensis nigricapillus, i. $14 \mathrm{I}$.

Petrel, Black-capped, ii. 268.

Bulwer's, ii. 268.

Fork-tailed, ii. 263.

Leach's, ii. 263.

Peale's, ii. 268.

Stormy, ii. 267.

White-bellied, ii. 268.

White-faced, ii. 268.

Wilson's, ii. 264.

Petrochelidon fulva, i. 403 . lunifrons, i. 396.

Peucaa astivalis, i. 328. astivalis bachmanii, i. 327 .

Pewee, i. 415. Wood, i. 4 I9.

Pewit, i. 415.

Phaëthon athereus, ii. $38 \mathrm{I}$.

flavirostris, ii. 382.

Phalacrocorax carbo, ii. 369 .

dilophus, ii. 372.

dilophus floridanus, ii. 373 .

mexicanus, ii. 373 .

Phalarope, Gray, ii. 205.

Northern, ii. 207.

Red, ii. 205.

Red-necked, ii. 207.

Wilson's, ii. 2 II.

Phalaropus lobatus, ii. 207. tricolor, ii. 211.

Phasianus colchicus, ii. 22.

Pheasant, ii. 30 .

English, ii. 22.

Philohela minor, ii. 176.

Phœbe, i. 415.

Say's, i. 418. 
Phonicopterus ruber, ii. 104.

Pica pica hudsonica, i. $1^{2}$.

Picoiles americanus, i. 456 . arcticus, i. 455.

Pigeon, Partridge, ii. 9. Passenger, ii. $\mathbf{I}$.

White-crowned, ii. 7 .

Wild, ii. $\mathbf{x}$.

Pinicola enucleator, i. 375.

Pintail, ii. 309.

Pipilo erythrophthalmus, ii. 359 . erythrophthalmus alleni, i. $36 \mathbf{r}$.

Pipit, i. 292. Meadow, i. 293.

Piranga erythromelas, i. 306. ludoviciana, i. 310 . rubra, i. 309.

Plautus impennis, ii. 4I4.

Plectrophenax nivalis, i. 300.

Plegadis autumnalis, ii. 114.

Plover, Belted-piping, ii. 60.

Black-bellied, ii. 68 .

Chicken, ii. 7 I.

Common, ii. 57.

European Golden, ii. $5^{8 .}$

Field, ii. 164.

Golden, ii. 57.

Green, ii. 57.

Mountain, ii. 67.

Piping, ii. 59.

Red-legged, ii. $7 \mathbf{r}$.

Ringed, ii. 66.

Ruddy, ii. 49.

Semi-palmated, ii. 64 .

Swiss, ii. 68.

Upland, ii. I64.

Whistling, ii. 57.

Wilson's, ii. 6I.

Pochard, ii. 340.

Podilymbus podiceps, ii. $3^{\text {S6. }}$

Polioptila carulea, i. 170.

Polyborus cheriway, i. 6.

Poocates gramineus, i. 320.

Porzana carolina, ii. 189 . jamaicensi, ii. 196. noveboracensis, ii. 194. porzana, ii 196.

Prairie Chicken, ii. 35, 39, 41.

Procellaria pelagica, ii. 267.

Progne subis, i. 391 .

Protonotaria citrea, i. 257.

Ptarmigan, Allen's, 1i. 47.
Ptarmigan, Reinhardt's, ii. 48 .

Rock, ii. 47.

Welch's, ii. 48 .

Willow, ii. 43 .

Puffin, ii. 406.

Large-billed, ii. 409.

Puffinus auduboni, ii. 275 .

borealis, ii. 274 .

kuhlii, ii. 273, 274 .

major, ii. 272.

Puffinus puffinus, ii. 276 . stricklandi, ii. 275 .

Qua Bird, ii. 91 .

Quail, 1i. 23.

Messina, ii. 30 .

Quail-dove, Blue-headed, ii. I4. Ruddy, ii. 10.

Quiscalus major, i. 114. quiscula, i. 115.

quiscula ancus, i. 118.

quiscula agleus, i. 118.

Rail, Big, ii. $\delta_{3}$.

Black, ii. 196.

Carolina, ii. I89.

Clapper, ii. $\mathbf{1} \delta_{3}$.

Common, ii. I 89 .

Florida Clapper, ii. 187.

King, ii. $\mathbf{I} 88$.

Land, ii. 196.

Lesser Clapper, ii. I 80.

Louisiana Clapper, ii. 187.

Red-breasted, ii. 180,188 .

- Scott's, ii. I 87 .

Virginia, ii. I So.

Yellow, ii. I94.

Rallus elegans, ii. I88.

longirostris crepitans, ii. I83.

longirostris saturatus, ii. 187 .

longirostris scottii, ii. 187 .

virginianus, ii. 180 .

Raven, i. I20.

Razor-bill, ii. 260.

Recurvirosta americana, ii. 106.

- Redbird, i. 362.

Redhead, ii. $34^{\circ}$.

Redpoll, i. 355 .

Greater, i. 357.

Greenland, i. 359 .

Hoary, i. 358.

Holbœll's, i. 357. 
Redpoll, Lesser, i. 355 . Mealy, i. 358 .

Redstart, i. 164 .

Regulus calendula, i. 281 . cuvieri, i. 282. satrapa, i. 283.

Rhodostethia rosea, ii. 239.

Rice-bird, i. Iog.

Rissa tridactyla, ii. $24 \mathrm{I}$.

Robin, i. 198.

Golden, i. 83.

Ground, i. 359 .

Swamp, i. 205.

Rostrhanius sociabilis, i. 40.

Ruff, ii. 150.

Rynchops nigra, ii. 260.

Saddleback, ii. $25^{2}$.

Sanderling, ii. 49.

Sandpiper, Baird's, ii. 142.

Bartramian, ii. I64.

Biack-bellied, ii. $\mathbf{2} 26$.

Bonaparte's, ii. I29.

Buff-breasted, ii. $\mathbf{3}^{2}$.

Curlew, ii. 125 .

Green, ii. 157 .

Least, ii. 136.

Pectoral, ii. 130.

Purple, ii. I 34 .

Red-backed, ii. 126.

Semi-palmated, ii. 143 .

Solitary, ii. 157.

Spotted, ii. 160.

Stilt, ii. 145 .

Western, ii. 144 .

White-rumped, ii. 129.

Sapsucker, Yellow-bellied, i. 450.

Saw-bill, ii. 358 .

Saxicola cenanthe, i. 290.

Sayornis phobe, i. 415.

saya, i. 418.

Scolecophagus carolinus, i. 119.

Scolopax rusticola, ii. 179 .

Scoter, American, ii. 333 .

Black, ii. 333 .

Surf, ii. 33I.

Velvet, ii. 334 .

White-winged, ii. 334 .

Sea-goose, ii. 205, 207, 21 I.

Seamew, ii. 243.

Sea-pigeon, ii. 395 .

Sea-swallow, ii. 213.
Seiurus aurocapillus, i. 215. motacilla, i. 214.

noveboracensis, i. $2 \mathbf{I} 2$.

Setophaga ruticilla, i. 164 .

Shad-bird, ii. 172.

Shag, ii. 369,372 .

Shearwater, Audubon's, ii. 275.

Cory's, ii. 274.

Greater, ii. 272.

Manx, ii. 276.

Sooty, ii. 275 .

Shelldrake, ii. 360 .

Buff-breasted, ii. 358 .

Hooded, ii. 363 .

Shoveller, ii. 300.

Shrike, Loggerhead, i. 162.

Northern, i. 159.

White-rumped, i. 163.

Sialia sialis, i. 285.

Sickle-bill, ii. 118.

Siskin, Pine, i. 35 I.

Sitta canadensis, i. $3{ }^{8} 5$. carolinensis, i. $3^{8} 3$. pusilla, i. $3^{86 .}$

Skimmer, Black, ii. 260.

Skua, ii. 255.

Buffon's, ii. 259.

Skunk-head, ii. 33I.

Skylark, i. 297.

Snipe, Common, ii. $\mathbf{1} 72$.

English, ii. 172.

European, ii. I 76 .

Grass, ii. 130.

Gray, ii. 169 .

Jack, ii. 130, I 72 .

Red-breasted, ii. 140, 169 .

Robin, ii. 140, 169.

Rock, ii. 134 .

Stone, ii. I 52 .

Wilson's, ii. 172.

Winter, ii. 126,134 .

Snow-bird, i. 339.

White, i. 300.

Snowflake, i. 300.

Somateria dresseri, ii. $3^{24}$.

mollissima borealis, ii. 329 .

spectabilis, ii. 329 .

Sora, ii. 189.

Sou-southerly, ii. 355 .

Sparrow, Acadian Sharp-tailed, i. 345.

Bachman's, i. 327.

Brewer's, i. 335 . 
Sparrow, Clipping, i. 333.

Clay-colored, i. 337.

Dusky Seaside, i. 347.

English, i. 354 .

Field, i. 336.

Fox, i. 338 .

Ground, i. 325 .

Grasshopper, i. 329 .

Henslow's, i. $33^{\circ}$.

House, i. 354 .

Ipswich, i. 326.

Lark, i. 317 .

Le Conte's, i. 331.

Lincoln's, i. 328 .

Nelson's, i. 346.

Pine Woods, i. 328.

Savanna, i. 325.

Scott's Seaside, i. 347 .

Seaside, i. 346.

Sharp-tailed, i. 344.

Song, i. 322 .

Swamp, i. $34^{2}$.

Tree, i. 332.

Vesper, i. $3^{20}$.

White-crowned, i. 315 .

White-throated, i. 3 r8.

Yellow-winged, i. 329 .

Spatula clypeata, ii. 300.

Speotyto cunicularia floridana, i. 78 .

cunicularia hypogaa, i. 78 .

Sphyrapicus varius, i. 450 .

Spinus notatus, i. 350.

pinus, i. 351 .

tristis, i. $34^{8}$.

Spiza americana, i. 298.

townsendi, i. 299.

Spizella breweri, i. 335 .

monticola, i. 332 .

pallida, i. 337 .

pusilla, i. 336 .

socialis, i. 333 .

Spoonbill, ii. 300 .

Roseate, ii. 108.

Sprigtail, i. 309.

Squawk, ii. 91.

Stake Driver, ii. 99.

Starling, i. 82.

Starnoenas cyanocephala, ii. I4.

Stelgidopteryx serripennis, i. 403 .

Stercorarius longicaudus, ii. 259. parasiticus, ii. 258 .
Stercorarius pomarinus, ii. 257 .

Sterna ancthetus, ii. 228. antillarum, ii. 225. dougalli, ii. 223 .

forsteri, ii. 216 . fuliginosa, ii. 228 . hirusudo, ii. 213. maximn, ii. 217. paradiscea, ii. 220. sandvicensis acuflavida, ii. 222 trudeaui, ii. 228. tschegrava, ii. 227.

Stilt, Black-necked, ii. 52.

Stork, Wood, ii. I ro.

Striker, Gannet, ii. 217, 227.

Little, ii. 225.

Strix pratincola, i. 75 .

Sturnella magna, i. 79 . magna mexicana, i. 82. magna neglecta, i. 82 .

Sturnus vulgaris, i. 82 .

Sula bassana, ii. 375 . cyanops, ii. 380 . sula, ii. 379 . piscator, ii. $3^{80}$.

Summer Red-bird, i. 309. Yellow-bird, i. 220.

Surnia ulula caparoch, i. 53.

Swallow, Bahama, i. 403 .

Bank, i. 401 .

Barn, i. 394.

Chimney, i. 463 .

Cliff, i. 396 .

Cuban Cliff, i. 403.

Eave, i. 396.

Rough-winged, i. 403.

Singing, i. 399.

Tree, i. 399.

White-bellied, i. 399.

Swan, Trumpeter, ii. 299.

Whistling, ii. 296.

Whooping, ii. 299.

Swift, Chimney, i. 463 .

Sylvania canadensis, i. 227. microcephala, i. 265. mitrata, i. 16\%. pusila, i. 168.

Sylvia minuta, i. 168.

Symphemia semipalmata, ii. 146 . semipalmata inornata, ii. 149.

Syrnizm nebulosum, i. 70. nebulosum alleni, i. $7 \mathbf{1}$. 
Tachycineta bicolor, i. 399.

Tanager, Louisiana, i. $3 \mathbf{1 0}$.

Scarlet, i. 306.

Summer, i. 309.

Tantalus loculator, ii. I10.

Tattler, ii. $\mathbf{1}^{2}$.

Teal, Blue-winged, ii. 319.

Cinnamon, ii. 323 .

European, ii. 323 .

Green-winged, ii. 321 .

Teeter-tail, ii. 160 .

Tell-tale, ii. 152 .

Tern, Arctic, ii. 220.

Black, ii. 230.

Bridled, ii. 228.

Cabot's, ii. 222.

Caspian, ii. 227.

Cayenne, ii. 217.

Common, ii. 213.

Forster's, ii. 216.

Gull-billed, ii, 2 r 8.

Least, ii. 225.

Marsh, ii. 218 .

Roseate, ii. 223.

Royal, ii. 217.

Sandwich, ii. 222.

Short-tailed, ii. 230.

Silvery, ii. 225 .

Sooty, ii. 228 .

Trudea's, ii. 228.

White-winged Black, ii. 23I.

Wilson's, ii. 313 .

Thalassogeron culminatus, i. 277.

Thistle-bird, i. 348 .

Thrasher, Brown, i. 192.

Thrush, Alice's, i. 211.

Bicknell's, i. 212.

Brown, i. 192.

Golden-crowned, i. 215.

Gray-cheeked, i. 211.

Hermit, i. 205.

Louisiana Water, i. 2I 4 .

Olive-backed, i. 2 I 1 .

Red-winged, i. 202.

Tawny, i. 207.

Varied, i. 202.

Water, i. 212.

Wilson's, i. 207.

Wood, i. 202.

Thryothorus bewickii, i. 276.

ludovicianus, i. 272, 275 .

Tinker, ii. 410.
Tip-up, ii. 160.

Titlark, i. 292.

Titmouse, Tufted, i. 142.

Totanus flavipes, ii. 154 . melanoleucus, ii. 152 . nebularius, ii. 159 . ochropus, ii. 159. solitarius, ii. 157.

Towhee, i. 359 . White-yed, i. 36r.

Tringa alpina, ii. 128 . alpina pacifica, ii. 126. bairdii, ii. 142. canutus, ii. 140 . ferruginea, ii. 125. fuscicollis, ii. 129.

Tringa maritima, ii. 134 . maculata, ii. 130. minutilla, ii. 136 .

Trochilus colubris, i. 457 .

Troglodytes aëdon, i. 266. aëdon parkmanii, i. 270. americanus, i. 270. hiemalis, i. 270.

Tropic-bird, Red-billed, ii. 381 . Yellow-billed, ii. $3^{82}$.

Troupial, i. 82.

Tryngitis subruficollis, ii. 132.

Turdus alicice, i. 211 . alicia bicknelli, i. 212. aonalaschka pallasii, i. 205. fuscescens, i. 207. iliacus, i. 202. mustelinus, i. 202. ustulatus swainsonii, i. 21 I.

Turkey, IVild, ii. 15 .

Turnstone, ii. $7 \mathbf{I}$.

Tympanuchus americanus, ii. 35 . cupido, ii. $3^{\delta}$.

Tyrannus dominicensis, i. 414 . tyrannus, i. 404. verticalis, i. 409.

Ulula cinerea, i. 64 .

Uria lomvia, ii. 401 . troile, ii. 398.

Urinator arcticus, ii. 391 . imber, ii. 388 . lunme, ii. 393 .

Vanellus vanellus, ii. 70. Veery, i. 207. 
Vireo bellii, i. I 80.

favifrons, i. 174.

flavoviridis, i. I\$6.

gilvus, i. I8o.

noveboracensis, i. 178 .

noveboracensis maynardi, i. I8o.

olivaceus, i. 182 .

philadelphicus, i. 186.

solitarius, i. 176 .

solitarius alticola, i. 177.

Vireo, Bell's, i. Iso.

Blue-headed, i. 176.

Key IVest, i. I8o.

Mountain Solitary, i. 177.

Philadelphia, i. 186.

Red-eyed, i. 182 .

Solitary, i. 176.

Warbling, i. I 80.

White-eyed, i. 178.

Yellow-green, i. 186.

Yellow-throated, i. I74.

Vulture, Black, i. 4 .

Turkey, i. I.

Wagtail, White, i. 293.

Warbler, Andubon's, i. 220.

Bachman's, i. 26r.

Bay-breasted, i. 237.

Black and White, i. 389 .

Black and Yellow, i. 224.

Blackburnian, i. 232.

Black-poll, i. 238 .

Black-throated Blue, i. 245.

Black-throated Green, i. 230.

Blue, i. 247.

Blue Mountain, i. 265.

Blue-winged, i. 258.

Blue Yellow-backed, i. 244.

Brewster's, i. 265.

Canadian, i. 227.

Cape May, i. 226.

Carbonated, i. 265.

Cerulean, i. 247.

Chestnut-sided. i. 235 .

Cincinnati, i. 265.

Connecticut, i. 253.

Golden-winged, i. 260.

Gray-headed, i. 253.

Hemlock, i. 233 .

Hooded, i. 167.

Kentucky, i. 246.

Kirtland's, i. 265.
Warbler, Lawrence's, i. 265.

Magnolia, i. 224.

Mourning, i. 251.

Myrtle, i. 2 I 7.

Nashville, i. 263.

Orange-crowned, i. 264.

Palm, i. 220.

Parula, i. 244.

Pine, i. 239.

Prairie, i. 242.

Prothonotary, i. 257.

Small-headed, i. 265.

Summer, i. 220.

Swainson's, i. 256 .

Sycamore, i. 229

Tennessee, i. 26r.

Townsend's, i. 263.

Wilson's, i. 168.

Worm-eating, i. 255.

Yellow, i. 220.

Yellow-crowned, i. 217.

Yellow-palm, i. 2 I9.

Yellow Red-poll, i. 219。

Yellow-rumped, i. 217 .

Yellow-throated, i. 228.

Water Hen, ii. 203.

Water Wagtail, i. 21 2.

Wavey, ii. $28 \mathrm{r}$.

Blue, ii. $2 S_{3}$.

Waxwing, Bohemian, i. 152.

Cedar, i. 154 .

Whale-bird, ii. 205.

Wheatear, i. 290.

Whip-poor-will, i. 467 .

Whiskey Jack, i. ${ }_{1}{ }^{8}$.

Whistler, ii. 349, 35 I.

Widgeon, ii. $3^{\mathrm{I}} \mathrm{I}-3^{\mathrm{I}} 3$.

Willet, ii. 146 .

Western, ii. 149.

Wilsonia minuta, i. 168.

IVilson's Blackcap, i. 168.

Woodcock, ii. 176 .

Black, i. 444.

European, ii. I 79 .

Woodpecker, American three-toed, i. 456.

Arctic three-toed, i. 455 .

Banded-backed, i. 456 .

Black-backed, i. 455 .

Downy, i. 452 .

Golden-winged, i. $43^{8}$.

Hairy, i. $4 j^{1}$. 
Woodpecker, Ivory-billed, i. 44I. Pigeon, i. $43^{8}$.

Pileated, i. 444.

Red-bellied, i. 448 .

Red-cockaded, i. 454.

Red-headed, i. 446 .

Wren, Bewick's, i. 276.

Carolina, i. 272.

Florida, i. 275.

House, i. 266.

Long-billed Marsh, i. 279.

Long-tailed House, i. 276.

Marian's Marsh, i. 28 o.

Mocking, i. 272.

Parkman's, i. 270.

Short-billed Marsh, i. 277.

Winter, i. 270.

Wood, i. 266, 270.
Xanthocephaius xanthocephalus, i. 102.

Xema sabinii, ii. 234.

Yellow-bird, i. 348.

Yellow-legs, ii. I54.

Greater, ii. 152.

Lesser, ii. 154 .

Summer, ii. 154 .

Winter, ii. 152 .

Yellow-throat, Florida, i. 251.

Maryland, i. 249.

Western, i. $25 \mathrm{I}$.

Zenaida zenaida, ii. 10.

Zenaidura macroura, ii. II.

Zonotrichia leucophrys, i. 315.

albicollis, i. 318 . 



o 



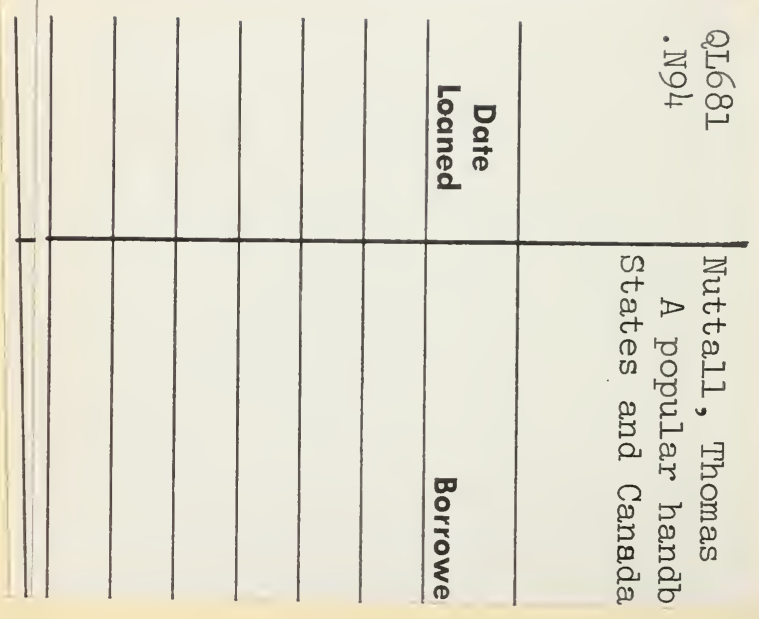


AMNH LIBRARY

|| ||||||||||||||||||||||||||||||||||||||||

||||||||||||||||||||||||||||||| 100104194 